\title{
CARACTERIZACIÓN ARQUEOMÉTRICA DE LA PRODUCCIÓN CERÁMICA NUMANTINA
}

\author{
Tesis Doctoral presentada \\ por \\ MANUEL GARCÍA HERAS
}

Directores: Dr. Gonzalo Ruiz Zapatero y Dr. Alfredo Jimeno Martínez

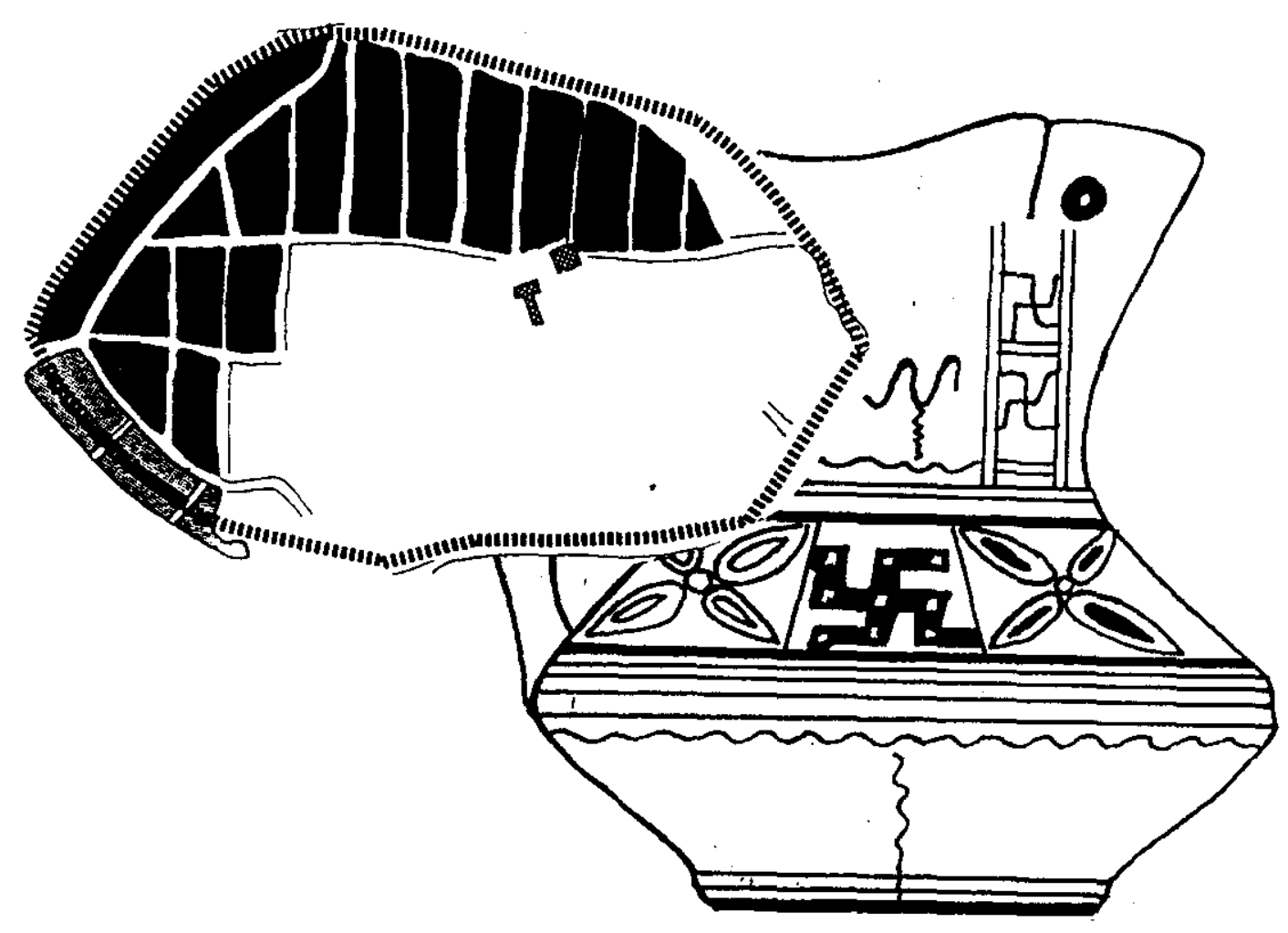

Departamento de Prehistoria

Facultad de Geografia e Historia

Universidad Complutense de Madrid 


\title{
CARACTERIZACIÓN ARQUEOMÉTRICA DE LA PRODUCCIÓN CERÁMICA NUMANTINA
}

\author{
Tesis Doctotal presentada \\ por \\ MANUEL GARCÍA HERAS
}

Directores: Dr. Gonzalo Ruiz Zapatero y Dr. Alfredo Jimeno Martínez

Departamento de Prehistoria

Facultad de Geografía e Historia

Universidad Complutense de Madrid

Abril 1997 
" Damos comúnmente a nuestras ideas de lo desconocido el color de nuestras nociones de lo conocido. "

Fernando Pessoa Libro del Desasosiego 


\section{ÍNDICE}

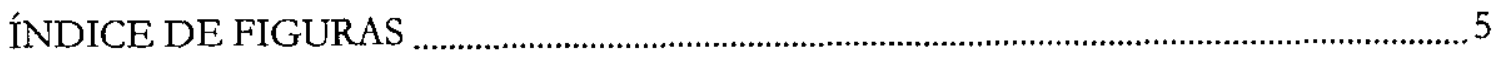

ÍNDICE DE TABLAS ...........................................................................................................

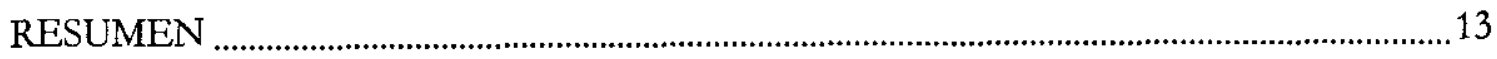

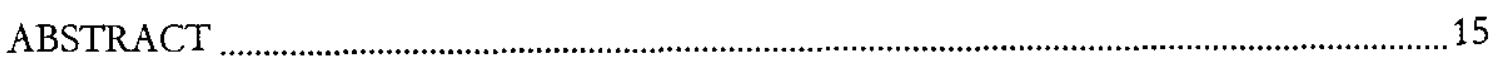

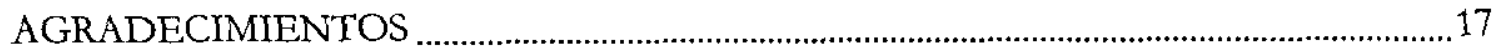

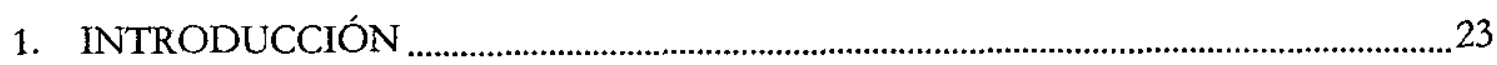

2. MARCO TEÓRICO Y OBJETTVOS DE LA INVESTIGACIÓN ...............................33

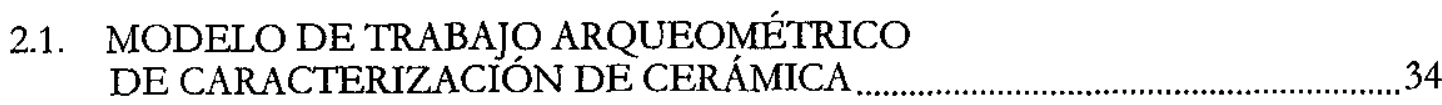

2.1.1. Probabilidades a priori ................................................................................

2.1.2. Selección de muestras ................................................................................36

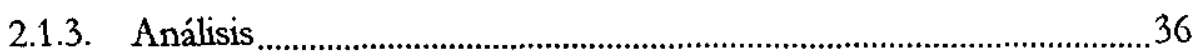

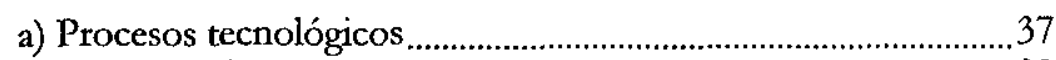

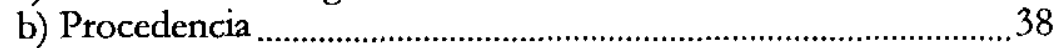

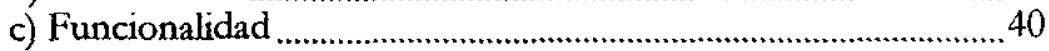

d) Alteraciones y contaminaciones ..................................................4

2.1.4. Integración de los datos $y$ síntesis........................................................ 41

2.2. OBJETIVOS DE LA INVESTIGACIÓN ………….................................................4

3. ÁREA DE ESTUDIO: MARCO GEOGRÁFICO Y YACIMIENTOS ..........................45

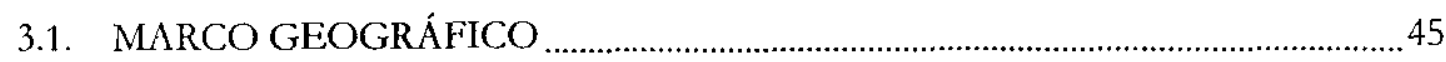

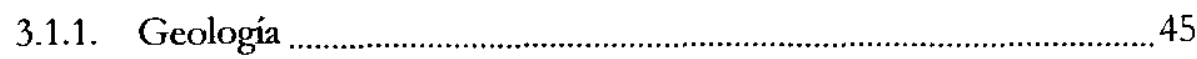

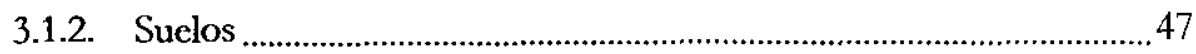




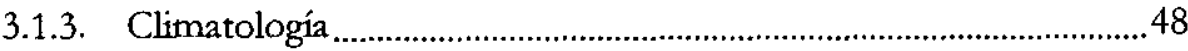

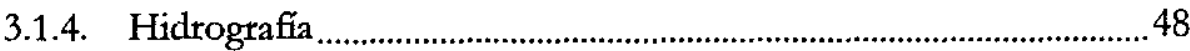

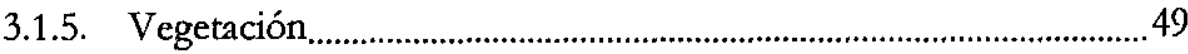

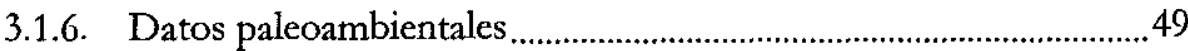

3.2. PANORAMA ARQUEOLÓGICO DEL SIGLO I A. C.

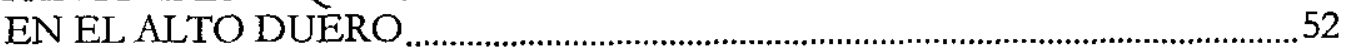

3.3. SELECCIÓN DE LOS YACIMIENTOS ARQUEOLÓGICOS ............................54

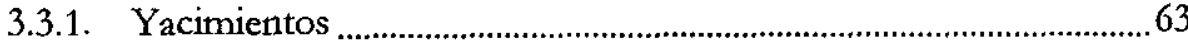

1.- NUMANCLA (Garray, Soria) ..................................................63

2.- CASTILTERREYO (Izana, Soria) ..........................................69

3.- IAS QUINTANAS y CUESTA DEL MORO (Langa de Duero, Soria)...........................................................70

4.- Necrópolis de EL PRADILLO

(Pinilla Trasmonte, Burgos) ....................................................70

5.- EL PALOMAR (Aragoncillo, Guadalajara) …............................. 71

4. SELECCIÓN DE MUESTRAS Y TÉCNICAS DE ANÁLISIS .....................................73

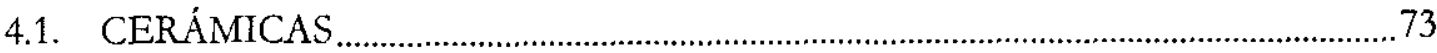

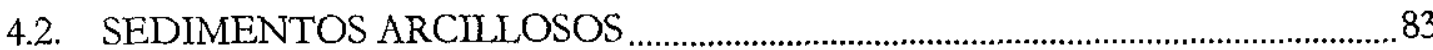

4.2.1. Tratamiento de los sedimentos arcillosos ...........................................8

4.3. TÉCNICAS DE ANÁLISIS

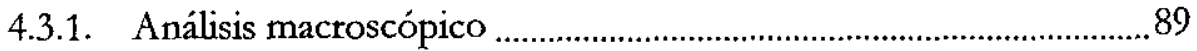

4.3.2. Análisis textural de los sedimentos arcillosos:

Pipeta de Robinson .......................................................................... 90

4.3.3. Análisis pettográfico mediante lámina delgada ..............................91

- Análisis textural ............................................................................91

- Test de tepresentatividad .............................................................92

4.3.4. Difracción de tayos $\mathrm{x}$ (XRD) ….....................................................93

4.3.5. Fluorescencia de rayos $\mathrm{x}$ por reflexión total (TXRF) ......................93

- Toma de muestras ............................................................................. 94

4.3.6. Microscopía electrónica de batrido (SEM) $\mathrm{y}$ análisis mediante Energia dispersiva de rayos $\mathrm{x}(\mathrm{EDX})$..............96

- Preparación de muestras embutidas...............................................96

4.3.7. Microscopía óptica de luz reflejada ................................................97

4.3.8. Espectroscopia de fotocorrelación: Quasy-Elastic Light Scattering (QELS) ........................................ 97

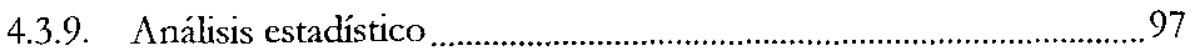


4.4. PROCESO DE CONTRASTACIÓN DE LA POTENCIALIDAD

DE LA FLUORESCENCIA DE RAYOS X

POR REFLEXIÓN TOTAL (TXRF) EN EL ANÁLISIS

DE CERÁMICAS ARQUEOLÓGICAS 100

4.4.1. La técnica de TXRF 103

4.4.2. Investigación previa 104

4.4.3. Preparación preliminat de muestras 105

4.4.4. Obtención de datos 105

4.4.5. Resultados preliminares 106

4.4.6. Método definitivo de análisis 107

4.4.7. Preparación definitiva de muestras 108

4.4.8. Resultados definitivos 110

4.5. DETERMINACIÓN DE LOS ÍNDICES DE ERROR DE LA TXRF EN LOS ANÁLISIS DE RUTTNA MASIVOS

4.6. COMPROBACIÓN DE LA REPRESENTATIVIDAD

DE LAS MUESTRAS CERÁMICAS

4.7. COMPROBACIÓN DE LAS VARIACIONES COMPOSICIONALES EN SEDIMENTOS ARCILLOSOS COCIDOS A DISTINTAS TEMPERATURAS

5. RESULTADOS

5.1. ANÁLISIS MACROSCÓPICO

5.2. ANÁLISIS TEXTURAL DE LOS SEDIMENTOS ARCILIOSOS 136

5.2.1. Colores 140

5.3. ANÁLISIS PETROGRÁFICO MEDLANTE LÁMINA DELGADA 140

5.3.1. Cerámicas 141

5.3.2. Sedimentos arcillosos 151

5.3.3. Análisis textural 152

5.4. DIFRACCIÓN DE RAYOS X (XRD) 155

5.4.1. Cerámicas 156

5.4.2. Pruebas de recocción 161

5.4.3. Sedimentos arcillosos 165

5.4.4. Temperaturas de cocción 170 
5.5. FLUORESCENCIA DE RAYOS X POR REFLEXIÓN TOTAL (TXRF) ........174

5.5.1. Análisis estadístiço 174

5.6. MICROSCOPIA ELECTRÓNICA DE BARRIDO (SEM) Y ANÁLISIS MEDLANTE ENERGIAA DISPERSIVA DE RAYOS X (EDX)

5.6.1. Pigmentos decorativos 202

5.6.2. Microestructuras 209

6. DISCUSIÓN 213

6.1. TECNOLOGÍA DE LA PRODUCCIÓN CERÁMICA NUMANTINA 213

6.1.1. Selección y recogida de materias primas 216

6.1.2. Preparación y acondicionamiento de las materias primas 217

6.1.3. Modelado 220

6.1.4. Secado 225

6.1.5. Cocción 226

6.2. MODOS DE PRODUCCIÓN 231

6.3. PROCEDENCIA DE LA CERÁMICA NUMANTINA. 233

6.4. FUNCIONALIDAD 240

6.5. ALTERACIONES Y CONTAMINACIONES 243

6.6. INTEGRACIÓN DE DATOS Y SINTTESIS HISTÓRICA. 246

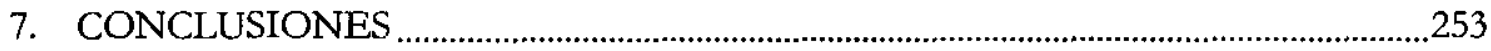

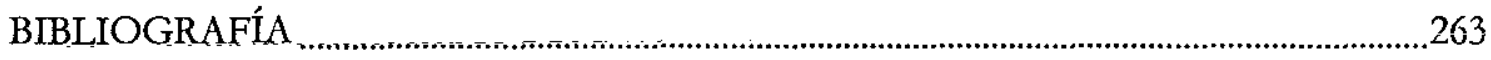

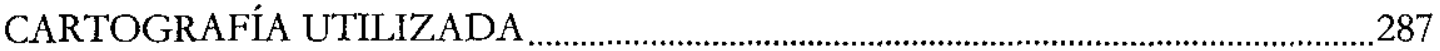

TABLAS

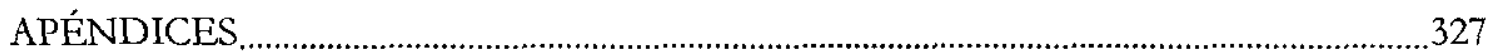

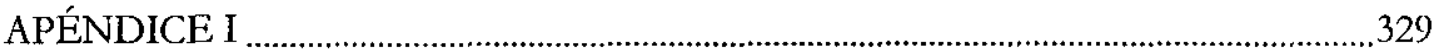

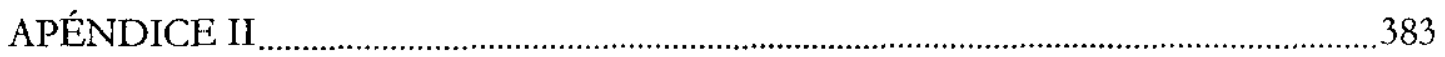

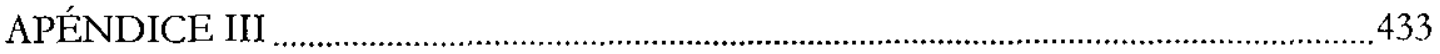




\section{ÍNDICE DE FIGURAS}

Figura 2.1.- Modelo de trabajo arqueométrico para la caracterización de cerámica............ 35

Figura 2.2.- Zona de Incertidumbre y Zonas de Conjunción ........................................................ 40

Figura 3.1.- Asentamientos de los siglos II y I a. C. en la zona del Alto Duero. 53

Figura 3.2.- Asentamientos fortificados de los siglos II y I a. C. en relación con las vías romanas.

Figuta 3.3.- Yacimientos que presentan cerámicas polícromas y cerámicas con motivos decorativos numantinos .57

Figura 3.4.- Cerámicas con motivos decotativos numantinos, procedentes de la necrópolis de El Pradillo (Pinilla Trasmonte, Burgos)

Figura 3.5.- Situación de los yacimientos seleccionados para la tealización de los análisis de caracterización 64

Figura 3.6.- Limites de Numancia en el siglo I a. C. 66

Figura 4.1.- Dibujos de algunas de las muestras procedentes de Numancia. $74-75$

Figura 4.2.- Dibujos de algunas de las muestras procedentes de Numancia $76-77$

Figura 4.3.- Dibujos de algunas de las muestras procedentes de Numancia 78-79

Figura 4.4.- Dibujos de las muestras procedentes de El Palomar (Aragoncillo, Guadalajara) $80-81$ 
Figura 4.5.- Situación de los puntos en los cuales se han tomado los sedimentos arcillosos procedentes de las inmediaciones de Numancia, según el mapa geológico escala 1: 50.000 del I.G.M.E (Hoja 318 Almarza y 350 Soria) .84

Figura 4.6.- Taladto utilizado en la toma de muestras para el análisis mediante Fluorescencia de tayos $\mathrm{x}$ por teflexión total (TXRF) .95

Figura 4.7.- Geometria de reflexión total en la técnica de TXRF 102

Figura 4.8.- Espectros de fotocorrelación (QELS) de las distribuciones de tamaño de partícula presentes en el Set-1, Set-2 y Set-3 103

Figura 4.9.- Espectro característico de TXRF obtenido a partir del patrón "Ohio Red Clay-2" 104

Figura 4.10.- Espectro de fotocorrelación (QELS) de la distribución del tamaño de partícula presente en el Set-4 .108

Figura 4.11.- Proceso definitivo de preparación de muestras .109

Figura 4.12.- Microfotografias obtenidas mediante Microscopía electrónica de barrido (SEM), de deposiciones realizadas con diferentes agentes suspendentes

Figura 4.13.- Comparación de las concentraciones elementales del Set-4, en relación a los resultados obtenidos mediante Activación de neutrones (NAA)

Figura 4.14.- Lineas de transición características del Ni, Sr y Zn, en un espectro de TXRF obtenido a partir del patrón "Ohio Red Clay-2" 114

Figura 4.15.- Situación de los puntos en los que se ha obtenido muestra, en el análisis de un recipiente completo procedente del yacimiento de El Palomar (Aragoncillo, Guadalajara) 118

Figura 4.16.- Concentraciones de los elementos As, $\mathrm{Cr}, \mathrm{Hf}, \mathrm{Ni}, \mathrm{Rb}, \mathrm{Sr}, \mathrm{Zn}, \mathrm{Al}$, $\mathrm{Ba}, \mathrm{Ca}, \mathrm{K}, \mathrm{Mn}, \mathrm{Ti}, \mathrm{V}, \mathrm{Cu}, \mathrm{Ga}$ e Y, en las muestras obtenidas en el perfil del recipiente completo EP-25, procedente del yacimiento de El Palomar (Aragoncillo, Guadalajara). 120-121 
Figura 5.1.- Porcentajes de las diferentes formas tipológicas presentes en el conjunto cerámico de Numancia.

Figura 5.2.- Número de ejemplates atribuidos a cada fábrica macroscópica, según su tipologia,

Figura 5.3.- Porcentaje de las diferentes formas tipológicas ptesentes en el conjunto cerámico de Izana

Figura 5.4.- Porcentajes de las diferentes fäbricas macroscópicas y de las cerámicas decoradas, presentes en el conjunto cetámico de Numancia 131

Figura 5.5.- Diagrama ternario de la clasificación textural de los sedimentos arcillosos, según el límite norteamericano de diámetro de las partículas de la arcilla, situado en $2 \mu \mathrm{m}$ 137

Figura 5.6.- Curvas granulométricas y porcentajes de la fracción arena de los sedimentos arcillosos

Figura 5.7.- Medias de los porcentajes del tamaño de las inclusiones, en las agrupaciones establecidas en el Análisis petrográfico, a partir de los resultados del Análisis textural

Figura 5.8.- Evolución, por efecto de la temperatura, de las fases mineralógicas cristalinas, en los experimentos de recocción de 4 muestras cerámicas 163

Figura 5.9.- Evolución, por efecto de la temperatura, de las fases minetalógicas cristalinas detectadas en el análisis de los sedimentos arcillosos calcáreos cocidos a distintas tempetaturas $167-168$

Figura 5.10.- Evolución, por efecto de la temperatura, de las fases mineralógicas cristalinas detectadas en el análisis de los sedimentos arcillosos no calcáreos (N-4 y N-7) y de la muestra de caolín (N-8), cocidos a distintas temperaturas 169

Figura 5.11.- Dendrograma resultante del Análisis cluster a partir de la transformación logarítmica de las concentraciones elementales de 135 muestras, utilizando el método del centroide y matriz de distancias euclídeas al cuadrado 
Figura 5.12.- Análisis de componentes principales a partir de la transformación logaritmica de las concentraciones elementales de 135 muestras. Representación del peso de las variables (16 elementos), en los dos primeros componentes 176

Figura 5.13.- Análisis de componentes principales a partir de la transformación logatitmica de las concentraciones elementales de 135 muestras. Representación de las muestras y sus agrupaciones, según la puntuación en los dos primeros componentes

Figura 5.14.- Análisis de componentes principales a partir de la transformación logaritmica de las concentraciones elementales de 135 muestras. Representación del peso de las variables (16 elementos), en el primer y tercer componentes 178

Figura 5.15.- Análisis de componentes principales a partir de la transformación logatítmica de las concentraciones elementales de 135 muestras. Representación de las muestras y sus agrupaciones, según la puntuación en el primer y tercer componentes 178

Figura 5.16.- Gráfico bivariante $\mathrm{Ca}$ versus $\mathrm{Cr}$ de las concentraciones elementales de 135 muestras, según las agrupaciones establecidas en el Análisis de componentes principales 183

Figura 5.17.- Gráfico bivariante Ca versus $\mathrm{Sr}$ de las concentraciones elementales de 135 muestras, según las agrupaciones establecidas en el Análisis de componentes principales 183

Figura 5.18.- Gráfico bivariante $\mathrm{K}$ versus $\mathrm{Rb}$ de las concentraciones elementales de 135 muestras, según las agrupaciones establecidas en el Análisis de componentes principales 184

Figura 5.19.- Gráfico bivariante Ti versus $\mathrm{Rb}$ de las concentraciones elementales de 135 muestras, según las agnupaciones establecidas en el Análisis de componentes principales 184 
Figura 5.20.- Análisis discriminante a partir de la transformación logarítmica de las concentraciones elementales de 135 muestras y de las agrupaciones establecidas en el Análisis de componentes principales. Representación de las muestras según la puntuación en las dos primeras variables canónicas 188

Figura 5.21.- Análisis de componentes principales a partir de la transformación logaritmica de las concentraciones elementales de 29 muestras procedentes de El Palomar. Representación del peso de las variables ( 16 elementos), en los dos primeros componentes 191

Figura 5.22.- Análisis de componentes principales a partir de la transformación logarítmica de las concentraciones elementales de 29 muestras procedentes de El Palomar. Representación de las muestras y sus agrupaciones, según la puntuación en los dos primeros componentes 191

Figura 5.23.- Gráfico bivariante $\mathrm{Rb}$ versus $\mathrm{Ti}$ de las concentraciones elementales de 29 muestras procedentes de El Palomar, según las agrupaciones establecidas en el Análisis de componentes principales

Figuta 5.24.- Gráfico bivariante Ga versus Al de las concentraciones elementales de 29 muestras procedentes de El Palomar, según las agrupaciones establecidas en el Análisis de componentes principales

Figura 5.25.- Dendrograma resultante del Análisis cluster a partir de la transformación logarítmica de las concentraciones elementales (exchuyendo el Ca) de 135 muestras, utilizando el método del centroide y matriz de distancias euclídeas al cuadrado 195

Figura 5.26.- Análisis de componentes ptincipales a partir de la transformación logarítmica de las concentraciones elementales de 135 muestras. Representación del peso de las variables (excluyendo el $\mathrm{Ca}$ ), en los dos primeros componentes 196

Figura 5.27.- Análisis de componentes principales a partir de la transformación logarítmica de las concentraciones elementales (excluyendo el $\mathrm{Ca}$ ) de 135 muestras. 
Representación de las muestras y sus agrupaciones, según

la puntuación en los dos primeros componentes 196

Figura 5.28.- Difractograma del pigmento negro, obtenido por raspado, de la muestra NP-74

Figura 5.29.- Espectros y resultados promedio del microanálisis mediante Energía dispersiva de rayos $\mathrm{x}(\mathrm{EDX})$, efectuado sobre partículas obtenidas por raspado, de los pigmentos negro, rojo y blanco, de la muestra NP-79

Figuta 5.30.- Espectros y resultados promedio del microanálisis mediante Energía dispersiva de rayos $\mathrm{x}$ (EDX), efectuado en la matriz y el pigmento blanco de la muestra NP-77

Figura 6.1.- Secuencia de Ptoducción básica de la cerámica numantina

Figura 6.2.- Representación ideal del posible proceso de levigado llevado a cabo en la preparación de la arcilla

Figura 6.3.- Gráficos bivariantes (diámetro de boca versus altura) de las formas tipológicas 2 (vasos carenados), 9 (vasijas globulates) y 14 (morteros), en las Fábricas 1, 2 y negra

Figura 6.4.- Punzón de asta de venado, procedente de las excavaciones de Numancia, utilizado para realizar la decoración estampada 225

Figura 6.5.- Posibilidades teóticas de producción de la cerámica numantina. 237

Figura 6.6.- Posible funcionalidad de la producción cerámica numantina. 241

Figura 7.1.- Esquema de razonamiento del trabajo arqueométrico 254

Figura 7.2.- Conclusiones principales de la Tesis Doctoral 255 


\section{ÍNDICE DE TABLAS}

Tabla 4.1.- Caracteristicas de los sedimentos arcillosos analizados. 86

Tabla 4.2.- Colores Munsell de los sedimentos arcillosos cocidos a distintas temperaturas. 88

Tabla 4.3.- Concentraciones elementales del patrón "Ohio Red Clay-2" analizado mediante Activación de neutrones (NAA) en el Missouri University Research Reactor (MURR) de Columbia (USA). 101

Tabla 4.4.- Resultados comparativos de las concentraciones elementales del Set-1, Set-2 y Set-3 obtenidas mediante TXRF.

Tabla 4.5.- Resultados comparativos de las concentraciones elementales del Set-4 obtenidas mediante TXRF 112

Tabla 4.6.- Resultados comparativos de las concentraciones elementales de los controles efectuados en los análisis de rutina mediante TXRF.

Tabla 5.1.- Número de ejemplares que presentan decoración polícroma atribuidos a cada fábrica macroscópica según su tipología.

Tabla 5.2.- Número de ejemplares que presentan decoración estampada atribuidos a cada fábrica macroscópica según su tipología.

Tabla 5.3.- Número de ejemplares que presentan grafitos atribuidos a cada fábrica macroscópica según su tipología. 132 
Tabla 5.4.- Número de ejemplares típificados como "juguetes" atribuidos a cada fábrica macroscópica según su tipología

Tabla 5.5.- Porcentajes de las fracciones arena, limo y arcilla en las muestras de los sedimentos arcillosos

Tabla 5.6.- Características de los grupos determinados en el Análisis petrográfico mediante lámina delgada

Tabla 5.7.- Características de los gnupos determinados en el análisis mediante Difracción de rayos $\mathrm{x}(\mathrm{XRD})$.

Tabla 5.8.- Matriz de correlación obtenida a partir de la transformación logarítmica de las concentraciones elementales de 135 muestras.

Tabla 5.9.- Grupos determinados en el Análisis de componentes principales 181

Tabla 5.10.- Matriz de correlación obtenida a partir de la transformación logaritmica de las concentraciones elementales de 29 muestras procedentes del yacimiento de El Palomar

Tabla 5.11.- Matriz de correlación obtenida a partir de la transformación logarítmica de las concentraciones elementales de 135 muestras excluyendo el $\mathrm{Ca}$ 194

Tabla 5.12.- Muestras analizadas mediante Mictoscopía electrónica de barrido (SEM) y Energía dispersiva de rayos $\mathrm{x}(\mathrm{EDX})$

Tabla 6.1.- Secuencias de Producción de la cerámica de Numancia e Izana 214 


\section{RESUMEN}

Esta Tesis Doctoral, presenta los resultados obtenidos en la caracterización arqueométrica de la producción cerámica numantina del siglo I a. C. A través de un modelo de trabajo arqueométrico, generado desde planteamientos arqueológicos, se ha pretendido dat respuesta a los principales interrogantes que planteaba la investigación actual en el estudio de estas producciones, como eran, entre otros, la determinación de sus centros de manufactura, sus áreas de distribución o los procesos tecnológicos que tenían lugar en su fabricación.

Conocidas, básicamente, a partir de los abundantes materiales proporcionados por las excavaciones de principios de siglo efectuadas en la ciudad de Numancia (Garray, Soria) y en otros asentamientos del Alto Duero, su presencia fuera de este área, definida siempre sobre la base de semejanzas decorativas, se venía interpretando como fruto de un incipiente comercio o intercambio de cerámica.

Para llevar a cabo esta investigación, se han utilizado las siguientes técnicas de caracterización: lupa binocular, análisis mecánico mediante Pipeta de Robinson, lámina delgada, Difracción de rayos $\mathrm{x}(\mathrm{XRD})$, Fluorescencia de rayos $\mathrm{x}$ por reflexión total (TXRF), Microscopía electrónica de barrido (SEM), microanálisis de Energía dispersiva de rayos $x$ (EDX), Microscopía óptica de luz reflejada y Espectroscopía de fotocorrelación, Quasi-Elastic Light Scattering (QELS). Se han analizado un total de 121 muestras cerámicas, procedentes de 5 yacimientos arqueológicos: 83 de la ciudad de Numancia (Garray, Soria), 17 de Castilterreño (Izana, Soria), 5 de Las Quintanas y Cuesta del Moro (Langa de Duero, Soria), 11 de la necrópolis de El Pradillo (Pinilla Trasmonte, Burgos) y 5 de El Palomar (Aragoncillo, Guadalajara). Además, también se han analizado, de forma comparativa, 9 sedimentos arcillosos recogidos en las inmediaciones de los yacimientos de Numancia e Izana. Asimismo, para conocer la variabilidad composicional del conjunto cerámico estudiado, como posible indicador de las distintas unidades de producción representadas, se han aplicado tres técnicas estadísticas exploratorias de análisis multivariante: Análisis cluster, Análisis de componentes principales y 
Análisis discriminante.

La técnica de Fluorescencia de rayos x por reflexión total (TXRF), se ha utilizado, por primera vez a escala internacional, en el análisis de cerámicas atqueológicas. Se trata de una técnica muy precisa para la determinación simultánea de elementos químicos con un númeto atómico inferiot a 12. Por ello, en esta investigación, se ha realizado una contrastación de la potencialidad que presentaba en el análisis de estos materiales, por medio de la comparación de los resultados obtenidos en un material arcilloso de referencia analizado mediante Activación de neutrones (NAA). Esta contrastación, ha permitido comprobat que la Fluorescencia de rayos $\mathrm{x}$ por reflexión total (TXRF), produce determinaciones semi-cuantitativas muy precisas, con un método de preparación de muestras muy sencillo, siendo una técnica viable para la caracterización composicional de cerámicas arqueológicas.

Los resultados generales de esta investigación, permiten inferir que los principales tipos de manufactura de la cerámica numantina, se han elaborado a partir de cuatro Secuencias de producción distintas, que indican un modo de producción altamente especializado y estandarizado. El desarrollo de unas estructuras productivas de estas características a lo largo del siglo I a. C., se ha relacionado con el avance del proceso de romanización en la zona del Alto Duero. Por otro lado, y aunque, por ahora, no se conocen evidencias relacionadas con talleres alfareros en la ciudad de Numancia, a partir de los datos aportados por el análisis estadístico, se establece el carácter local de estas producciones.

Estos resultados, obligan, además, a realizar un replanteamiento de la interpretación tradicional, debido a que las cerámicas no procedentes del área del Alto Duero, son incompatibles, desde un punto de vista composicional, con las halladas en los yacimientos de Numancia o Izana. Finalmente, y dadas las similitudes que presentan las cerámicas de estos dos yacimientos, la procedencia de estos conjuntos cerámicos se ha inscrito en dos Zonas de Conjunción, es decir, zonas que presentan características composicionales similares, pero en las que no es posible tealizar una atribución de otigen exacta pata ninguna de ellas. 


\section{ABSTRACT}

This $\mathrm{Ph} . \mathrm{D}$. Dissertation presents the results from the archaeometric characterization of the first century bc Numantian pottery production. The main issues posed by current research have been archaeologically approached through an archaeometric study. These questions rely on determining their production centers, areas of distribution, and technological processes that took place in their manufacture.

Numantian pottery was unearthed in several excavation sites since the beginnings of the twentieth century in the town of Numancia (Soria, Spain) and other locales from the Upper Duero area. Whenever such pottery was found outside this region, conventional wisdom took for granted (based on decoration patterns) that this was the outcome on an incipient trade or exchange.

To carry out this research, the following characterzation techniques were used: binocular glass, mechanical analysis for textural classification of clay sediment samples, thin section, X-ray Diffraction (XRD), Total Reflection X-ray Fluorescence (TXRF), Scanning Electron Microscopy (SEM), Energy Dispersive X-ray microanalysis (EDX), Reflected Light Optical Microscopy, and Photocorrelation Spectroscopy, Quasi-Elastic Light Scattering (QELS).

A total amount of 121 pottery samples from 5 archaeological sites were analyzed: 83 from the town of Numancia (Gatray, Soria), 17 from Castilterreño (Izana, Soria), 5 from Las Quintanas and Cuesta del Moro (Langa de Duero, Soria), 11 from El Pradillo burial site (Pinilla Trasmonte, Burgos), and 5 from El Palomar (Aragoncillo, Guadalajara). In addition, 9 clay sediment samples from Numancia's and Izana's surroundings were analyzed as well. Three exploratory multivariate statistical techniques were used (Cluster Analysis, Principal Components Analysis, and Discriminant Analysis) to approach the compositional variability of this assemblage, as its variation could suggest different units of production.

This study introduces Total Reflection X-ray Fluorescence (TXRF) for the analysis of archaeological ceramics, a method now employed for the first time in the international arena for 
the investigation of solid samples such as pottery. TXRF is a valuable technique for a simultaneous determination of chemical elements with atomic number less than 12 . For that reason, the technique has been compared with clay reference material analyzed by Neutron Activation (NAA) as a way to assess its sensitivity and accuracy for determining the elemental composition of such materials. TXRF produces precise semi-quantitative results after a simple sample preparation process, for which it might turn out to be a suitable technique for the multielemental characterization of archaeological ceramics.

Generally speaking, the results from this study allow the recognition of four different production sequences in the main fabrics of Numantian pottery. Such sequences are part of a highly specialized and standardized mode of production. The development of this kind of productive structures during the first century bc has been linked to the romanization of the Upper Duero. Although workshops are not known either in Numancia nor in its surroundings, this study assumes that Numantian productions should be interpreted as local ptoducts.

This doctoral dissertation challenges commonly held asumptions regarding ceramic production from the Upper Duero region in that compositional spectra of samples from outside and inside this area are not alike. Lastly, provenance of both ceramic assemblages from Numancia and Izana is arranged in two Conjunction Zones, even though it is not possible to state their origins from the compositional evidence found to date in either of them. 


\section{AGRADECIMIENTOS}

La investigación desarrollada en esta Tesis Doctoral es, en gran medida, fruto del concurso, apoyo, ayuda, amistad y una buena dosis de paciencia recibidas por parte de un numeroso grupo de personas. Personas sin las cuales este trabajo no hubiera podido llevarse a cabo y a las que el autor, desde estas páginas, desea expresarles su más sincero y profundo agradecimiento.

En primer lugar, a los doctores del Departamento de Prehistoria de la Universidad Complutense de Madrid, Gonzalo Ruiz Zapatero y Alfredo Jimeno Martínez, co-directores de esta Tesis Doctoral. Al primero, por el apoyo y la ayuda prestadas en todo momento en la solución de un sinfin de inconvenientes surgidos a lo largo del trabajo. Al segundo, por su extraordinatia entrega y predisposición a que una investigación de estas características pudiera finalmente concluirse, a pesar de los dificiles problemas de financiación que, en muchas ocasiones, se han planteado. Y finalmente a ambos, además de haberme brindado su amistad y el enorme calor de su calidad humana, por haber aceptado la dirección de este trabajo.

Asimismo, Ramon Fernández Ruiz, técnico de los laboratorios del Servicio Interdepartamental de Investigación de la Universidad Autónoma de Madrid, ha sido un estímulo constante en la realización del mismo. Las interminables discusiones que con él se han mantenido, así como su contínuo aporte de nuevas y buenas ideas, han entiquecido de manera notable los resultados alcanzados en esta investigación y han hecho que el arduo trabajo rutinario de laboratorio siempre fuera muy grato. Su especial sensibilidad hacia los problemas que plantea la caracterización físico-química de cerámicas arqueológicas, permite decir que se ha ganado un técnico excelente para la futura investigación arqueométrica de nuestro país. Por otro lado, se agradecen al Dr. Jesús Tornero, responsable de la Sección de Rayos X de los laboratorios mencionados, las facilidades dadas para la realización de los diferentes análisis. Igualmente, al Dr. Miguel Angel Dominguez Reboiras, por su experto asesoramiento en los análisis mediante QELS (Quasi-Elastic Light Scattering) y a Patricia Ruano Puché y Gema 
Barroso García, becarias del Servicio Interdepartamental de Investigación, por su esfuerzo y dedicación en la preparación de un buen númeto de muestras.

El autor también desea expresar su más profundo agradecimiento a los doctores Hector Neff y Michael D. Glascock del Laboratorio de Arqueometría de la Universidad de Missouri (Columbia, USA), por habetle permitido utilizar el patrón "Ohio Red Clay-2" y los datos de sus mediciones mediante Análisis de activación de neutrones (NAA).

El Dr. Manuel González Rodríguez, perteneciente al Departamento de Química Inorgánica de la Universidad de Sevilla, ha sido de gran ayuda en la realización de los análisis mediante Difracción de rayos x. Gracias a su desinteresada colaboración, este trabajo pudo contar con un número de difracciones superior al estimado en un principio.

Los agradecimientos también deben hacerse extensivos a algunos de los miembros del Departamento de Geografia Fisica y Análisis Regional de la propia Universidad Complutense de Madrid. En primer lugar, a su director, Dr. Juan Sanz Donaire, por cedernos las instalaciones de su laboratorio. En ellas se llevaron a cabo la mayoría de las observaciones petrográficas a través de lámina delgada, así como el análisis textural de las muestras de sedimentos arcillosos. También a Almudena Sánchez, responsable de dicho laboratorio, por las molestias que contínuamente le fueron causadas y a la Dra. Pilar Gatcía, por el interés mostrado en la consecución de este trabajo.

Un sincero agradecimiento debe dirigirse a la Dra. M Concepción López de Azcona, del Instituto de Geología Económica del C.S.I.C. en Madrid, por la ayuda prestada en la realización de las microfotografias sobre lámina delgada y por haber permitido el acceso al microscopio petrográfico con el que se llevaron a cabo.

De igual forma, el autor también desea expresar su más profundo agradecimiento a Emilio Criado, investigador científico del Instituto de Cerámica y Vidrio del C.S.I.C. en Arganda del Rey (Madrid), por su apoyo y ayuda constantes en los análisis mediante Microscopía electrónica de barrido, realizados en este instituto. Agradecimientos que deben extenderse a su director, Dr. Angel Caballero, y a una parte importante del personal de estas instalaciones que hicieron que la estancia en el Instituto fuera realmente agradable.

También se agradece el apoyo y amistad brindada por el Dr. Jesús María Rincón del Instituto "Eduardo Torroja" de Ciencias de la Construcción del C.S.I.C. en Madrid. A él se debe la introducción del autor en el mundo de la Microscopía electrónica. Una larga serie de conversaciones y discusiones con el Dr. Rincón, han enriquecido de manera importante algunos aspectos de esta Tesis. 
De forma especial hay que agtadecer la ayuda prestada al Dr. José G. Arribas, quien siempre estuvo dispuesto a ofrecernos todo su apoyo a lo largo de estos últimos años. También a Evelio Amanz, alfarero de Quintana Redonda (Soria), por su sincera amistad, por su agradable y cálida conversación y por haber familiarizado al autor con los procesos de elaboración de cerámicas tradicionales. Juntos fueron de gran ayuda en la selección y preparación de las muestras de sedimentos arcillosos procedentes del área de estudio.

Carmen Bravo Llatas, perteneciente al Área de Apoyo a la Investigación del Centro de Proceso de Datos de la Universidad Complutense de Madrid, colaboró en el tratamiento estadístico de los datos obtenidos mediante Fluorescencia de rayos x por reflexión total (TXRF) $\mathrm{El}$ autor agradece el trabajo realizado.

Asimismo, deben darse las gracias al personal ligado a los museos en donde se, hallan depositadas las colecciones cerámicas manejadas en esta investigación, por las facilidades dadas a la hora de acceder a las mismas, así como por las tramitaciones necesarias realizadas para obtener muestras de los distintos materiales cerámicos. En primer lugar, al Dr. José Luis Argente, director del Museo Numantino de Soria, y a todo el personal de este museo que se volcó para hacer lo más agradable posible un trabajo que resultó muy duto. Especialmente, a Octavio y a M Luisa Revilla. Con M Angeles Arlegui, conservadora del museo, se mantuvieron largas e interesantes discusiones de gran utilidad para la concepción general de este trabajo. El acceso a un ejemplar de su tesina se agradece de forma singular. Una mención especial debe hacerse a dos buenos amigos: Inmaculada Sebastián y Óscar Almajano, por su paciencia y por la inestimable ayuda prestada en la ordenación y clasificación de los materiales de Numancia en los fondos del Museo Numantino. Una experiencia ciertamente "numantina". Por último, también se agradecen las facilidades dadas para el acceso a los materiales depositados en el Museo Arqueológico Nacional de Madrid, a Magdalena Barril, conservadora de este museo.

En estos agradecimientos no puede olvidarse la importante colaboración de dos personas: Jaime Nuño González y Jesús A. Arenas Esteban. Ambos dieron todo tipo de facilidades en la obtención de muestras pertenecientes a fragmentos cerámicos procedentes de las excavaciones arqueológicas dirigidas por ellos. El primero, en el caso de la necrópolis de $\mathrm{El}$ Pradillo (Pinilla Trasmonte, Burgos), cuyos agradecimientos también deben extenderse al resto de los responsables de esta excavación; y el segundo, en el caso de las muestras procedentes del yacimiento de El Palomar (Aragoncillo, Guadalajara). Gracias también a ellos por la comprensión experimentada hacia este trabajo. 
Igualmente importante ha sido la ayuda recibida por parte de Ana Carmen Pascual, atqueóloga territorial de la Junta de Castilla y León en Burgos, al permitir la rápida consulta de los informes inéditos sobre las excavaciones efectuadas en el yacimiento de Pinilla Trasmonte, depositados en el Servicio Territorial de Cultura y Turismo de esta ciudad.

Vaya también, desde estas líneas, un sincero agradecimiento a Jesús Sánchez Corral, del Departamento de Geodinámica de la Universidad Complutense, por su competencia en la confección de las láminas delgadas realizadas para este trabajo, así como a Antonio Crespo, del Programa de Asistencia Técnica a la Investigación de esta misma universidad, por su asesoramiento en la elaboración de los diferentes tipos de portas y soportes de aluminio que han ido siendo necesarios en el desarrollo de la investigación.

Por otro lado, Gonzalo J. Trancho, del Departamento de Biologia Animal I de la Universidad Complutense, fue de gran ayuda en la discusión de datos relacionados con suelos y sedimentos arcillosos. Además, siempre se mostró muy interesado en la consecución de este trabajo. El autor agradece muy especialmente las atenciones recibidas por parte de este investigador.

Tampoco puede olvidarse a Carlos Olaetxea, de la Sociedad de Ciencias Aranzadi de San Sebastián, ni a la Dra. Virginia Galván, con quienes se comparte una grata y cálida amistad. Con ellos se ha venido colabotando desde hace ya algún tiempo, produciéndose un tico intercambio de ideas a lo largo de todo el trabajo.

Las discusiones mantenidas con el Dr. Jaume Buxeda i Garrigós y con Miguel Angel Cau i Ontiveros, durante una breve estancia en Barcelona, han tenido un valor importante en algunos aspectos de la concepción teórica de este trabajo. Se agtadece, por ello, el interés ptestado, así como la entrega de un ejemplar de la Tesis Doctoral por parte del primero.

Por último, sólo queda mencionar también la ayuda en la sombra de buenos amigos como Guillermo Mirecki, Julio Mercader, Luis T. Sanz Castro, Raquel Martí y Carmen Zomeño, a quienes se agradece la luz en aquellos momentos de mayor oscuridad y obcecación.

La investigación se ha realizado dentro de los trabajos de caracterización físico-química de los materiales cerámicos del Plan Director del yacimiento de Numancia (Soria), dirigido por el Dr. Alfredo Jimeno Mattínez y patrocinado por la Dirección General de Patrimonio y Promoción Cultural de la Junta de Castilla y León. La inclusión de estos trabajos en dicho Plan Director se debe, en gran medida, al propio Dr. Alfredo Jimeno Martínez, al que se agradece, de modo especial, su constante esfuerzo e interés en proveer los fondos económicos necesarios para realizar esta investigación. No obstante, ésta no hubiera podido ponerse en práctica sin la 
concesión de una beca pre-doctoral del Servicio de Investigación y Relaciones Internacionales de la Universidad Complutense de Madrid, durante los años 1.993 a 1.996.

Finalmente y con el ánimo de no olvidar a ninguna de las personas que de una u otra forma han prestado su colaboración durante el desarrollo de esta Tesis Doctoral, el autor desea expresar su más grato y cordial agradecimiento a Ana Cristina López Corral, no sólo por su enorme paciencia en la corrección de estilo de un borrador de este volumen, sino también, y sobre todo, por el tremendo amor que ha puesto en esta ingrata tarea.

En definitiva, vaya a todos ellos una vez más, desde aquí, el reconocimiento y la gratitud del autor, sin olvidar que, en última instancia, las ideas expuestas en este trabajo son responsabilidad exclusiva del que suscribe estas líneas. 



\section{INTRODUCCIÓN}

El trabajo de investigación que finalmente ha quedado plasmado en esta Tesis Doctoral, es el fruto de más de seis años de formación en la aplicación de técnicas de caracterización en el estudio de la cerámica arqueológica. Una formación que ha debido adquiritse, en su mayor parte, fuera de los cauces tradicionales de investigación en el campo arqueológico y cuya dinámica se ha desarrollado a partir de una reflexión un tanto pendular, como se explica a continuación.

En primer lugar, la reflexión partió de las nuevas necesidades que planteaba la moderna investigación arqueológica en lo referente al estudio de materiales cerámicos, en donde la aproximación crono-tipológica tradicional se veía incapaz de solucionar todos aquellos problemas relacionados con la producción, tecnología y procedencia de estos materiales, al carecer de resolución suficiente en la recuperación de la mayoria de los niveles de información que contiene un material cerámico. Esto es, desde un nivel estético y formal hasta un nivel estrictamente nuclear (Kingery, 1982; García Heras, 1994 a).

Para la recuperación de información en estos niveles, necesaria para solucionar problemas tecnológicos y de procedencia de materiales y que no puede extraerse con ningún otro medio arqueológico, se había recurrido, desde hacía ya varias décadas, a técnicas de caracterización fisico-química, importadas de la llamada Ciencia de los Materiales. La utilización de esta metodología desde planteamientos teóricos puramente arqueológicos, se inscribía, de esta forma, en una nueva disciplina conocida como Arqueometría (1). Una especie de híbrido, o si se quiere, de puente entre la Arqueología y las Ciencias Experimentales.

Teniendo en cuenta que la investigación que se pretendía iniciar, estaba orientada a la resolución de problemas de este tipo en conjuntos cerámicos conocidos como numantinos de la zona geográfica del Alto Duero, el siguiente paso en la reflexión aludida al principio exigía que el péndulo oscilase hacia el otro extremo. En otras palabras, era necesario conocer y aprender el manejo de las distintas técnicas de caracterización empleadas habitualmente por la moderna Ciencia de Materiales y adaptarlas a los requerimientos de una investigación dirigida al estudio de

(1) I a Arqucometría cubre básicamente los siguientes campos de investigación: geo-cronología, análisis de artefactos y materias biológicas, rcconstrucción medioambiental y prospección gcofisica. 
materiales cerámicos manufacturados con técnicas tradicionales.

Esta reflexión reclamaba, por tanto, una implicación definitiva en el uso de técnicas de caracterización, ante el convencimiento de que alguien entrenado a la vez en Arqueología y Ciencia Apticada es más capaz de resolver problemas relevantes a la propia Arqueología, que un científico experimental aficionado a ésta (Bintliff, 1979; Harbottle, 1982; Vila y Estévez, 1989). Una reflexión de estas características exigia, además, un replanteamiento en la formación adquirida en una licenciatura de Arqueología en España, puesto que, hasta el momento, este tipo de especialización no se contempla en ningún plan de estudios.

El desarrollo de esta idea ha topado, no obstante, con un buen número de dificultades, ya que este entrenamiento ha debido realizarse en un medio académico todavía poco apto y escasamente concienciado. La profesionalización en este tipo de investigación sigue siendo, lamentablemente, lo más parecido a una maratón. Requiere un periodo de entrenamiento largo, gran resistencia y el concurso de muchos y variados conocimientos procedentes de diversas disciplinas. Este aspecto hace que la investigación arqueométrica se mueva en lo que Vidale ha llamado un mundo cubista, ya que los problemas se resuelven desde muchos y vatiados puntos de vista (Vidale, 1993, 146). Otra dificultad añadida, es el riesgo de convertirse, en muchos casos debido a barreras psicológicas dificilmente comprensibles, en un verdadero "outsider" para los demás colegas, no sólo de la propia disciplina arqueológica, sino también para aquellos investigadores del campo de la Ciencia Aplicada que ven como una intrusión incómoda la llegada de arqueólogos empleando estas técnicas (Cuomo di Caprio, 1986, 46; Maggetti, 1994; 20).

Una vez consumido el periodo de formación y conocimiento de las técnicas mencionadas, el péndulo debia volver a su posición inicial para abordar el problema de la caracterización de las producciones cerámicas numantinas del Alto Duero, en donde las exigencias de la investigación actual requerian nuevas aproximaciones, como ya habían puesto de manifiesto algunos autores para la totalidad de las producciones cerámicas celtibéricas de la Segunda Edad del Hietro, en donde se incluyen las numantinas. Entre ellas, la necesidad de conocer sus procesos productivos y sus implicaciones socio-económicas, así como la determinación de sus centros de producción y sus áteas de distribución (Rometo Carniceto, 1988, 197; Romero Carnicero y Ruiz Zapatero, 1992, 118; Romero Carnicero, 1992, 733-734).

La constatación de necesidades similares en la bibliografía especializada, en contextos de la Edad del Hierro de distintas zonas del continente europeo y los resultados alcanzados por medio de aproximaciones de estas características, albergaba buenas expectativas en su aplicación al caso concreto que plantea esta Tesis Doctoral. Entre los trabajos emprendidos, destaca el llevado a cabo por Gosden, por medto de métodos petrográficos, para las producciones estampadas del periodo de La Tène $\mathrm{A}$ del $\mathrm{NO}$ de Bohemia, en cuyas conclusiones expone que la cerámica se produce en pequeños talleres locales que surten a áreas reducidas de territorio (Gosden, 1987). 'También destaca el realizado a través de técnicas mineralógicas de lámina 
delgada y Difracción de rayos $\mathrm{x}(\mathrm{XRD})$ (2)sobre cerámicas bícromas, igualmente de La Tène, procedentes de la región francesa de Champagne, cuyos tesultados indican que son producto de un único taller (Riby et al., 1989). Asimismo, los estudios emprendidos hace ya algún tiempo por Peacock (1969) mediante técnicas petrográficas, sobre las producciones de tipo Glastonbury, que definen la cerámica decorada de La Tène del SO del Reino Unido, cuyo modo de producción orientado a la comercialización de estas piezas expuesto por este autor, es rebatido en el reciente trabajo de Cagle (1992), a partir de los resultados obtenidos con Espectroscopía de plasma de acoplamiento inductivo (ICPS). También el trabajo llevado a cabo mediante XRD, Fluorescencia de rayos $\mathrm{x}$ (XRF) y Análisis térmico diferencial (DTA) sobre producciones de La Tène $\mathrm{B}$ del $\mathrm{O}$ de Hungría procedentes del taller de Sopron-Ktautacker, en donde se llega a la conclusión de que se trata de una producción en masa totalmente industrializada (Katdos et al., 1985). Los trabajos efectuados por medio de técnicas mineralógicas y geoquímicas de lámina delgada, XRD y XRF en el estudio de las producciones negras de los períodos de Hallstatt D2 y D3 procedentes de los "oppida" de Heuneburg y Châtillon-sûr-Glâne, estimando que se trata de producciones locales en ambos casos (Maggetti y Galletti, 1980; Maggetti y Schwab, 1982). O también el estudio realizado mediante métodos petrográficos y $\mathrm{XRD}$, sobre producciones de fines de Hallstatt $\mathrm{D}$ y comienzos de La Tène $\mathrm{A}$ en la Hunsrück-Eifel-Kultur centroeuropea, cuyos resultados indican que la cerámica de este periodo se manufacturaba de forma especializada en toda una serie de centros de producción (Nicholson, 1989).

Por el contratio, como se mencionaba anteriormente, apenas se habian iniciado aproximaciones de este tipo al estudio de producciones cerámicas de la Edad del Hierro peninsular, en consonancia con el escaso desarrollo que, de forma general, presentan éstas en el conjunto de la investigación arqueológica española. En un reciente estudio bibliométrico que abarca el periodo comprendido entre los años 1.972 a 1.995 (García Heras, En prensa a) se constata que la mayoría de trabajos emprendidos sobre cerámicas de la Edad del Hierro, se han efectuado sobre materiales ibéricos y que son pocos los llevados a cabo, por ejemplo, sobre producciones celtibéricas. A todo ello habría que añadir que la mayor parte de éstos, presentan los resultados obtenidos a partir de un corto número de análisis y en los cuales no es frecuente integrar los resultados en una interpretación de carácter general. En este sentido, los estudios de caracterización publicados sobre cerámica celtibética han servido de poca ayuda en el desarrollo de esta investigación. Además, se centran básicamente en producciones procedentes de yacimientos situados en zonas geográficas que no pertenecen estrictamente a los territorios considerados como celtibéricos. El primer trabajo que presenta datos de caracterización, se

(2) lara hacer referencia a las distintas técnicas de caracterización, sc ha preferido utilizar las siglas en inglés de cada una de cllas, ya que, de csta forma, es como son más conocidas en la bitliografta especializada. Por otro lado, algunas no tienen cquivalente en español, como el Análisis de activación de neutrones, conocido por las siglas NAA o el análisis mediante Espectroscopia de plasma de acoplamiento inductivo, conocido por las siglas ICPS. 
incluye en la tipología publicada por E. Wattenberg $(1978,74)$ y en él se muestran los resultados obtenidos en el análisis químico de 4 muestras procedentes de los yacimientos de Simancas y Soto de Medinilla de Valladolid. No obstante, estos resultados tienen un valor bastante limitado ya que ni siquiera se especifica cuál ha sido la técnica utilizada en los análisis. Otro estudio se centra en la caracterización mediante XRD y Microscopía electrónica de barrido (SEM) de 13 fragmentos procedentes del yacimiento de Fuente el Saz del Jarama (Madrid), entre los cuales se hallan especies a mano, estampadas y grises, junto a un fragmento de cerámica ática y dos de engobe rojo. Excepto estas últimas, a todas se les atribuye un origen local (Galván y Galván Martínez, 1985). Después, el estudio llevado a cabo a través de XRD, Microscopía electrónica de transmisión (TEM) y Espectroscopía infrarroja (IS) sobre cerámicas y sedimentos arcillosos procedentes del yacimiento perteneciente a la Cultura Castreña del NO de La Corona y El Castro de Corporales (León), en donde sólo se analiza un fragmento de cerámica celtibérica al que se le atribuye un origen local (Galván y Galván Martínez, 1988). También se analizan producciones celtibéricas en el trabajo realizado mediante XRF sobre un conjunto cerámico procedente del yacimiento de El Castrelín de San Juan de Paluezas (León), perteneciente al igual que el anterior a la Cultura Castreña del NO. En este caso, se presentan los resultados del análisis de 30 fragmentos cerámicos y de 4 sedimentos arcillosos. Entre los 30 fragmentos, sólo 6 son cerámicas celtibéricas, cuya producción se estima que no es local (Galván Martínez et al., 1993). Por último, hay otro trabajo en donde se analiza, también mediante XRD, un solo fragmento de cerámica celtibérica procedente del yacimiento de Castillejo (Garray, Soria) cuyos resultados son, evidentemente, poco representativos (Morales y Sanz, 1994).

Volviendo al tema concreto de las producciones numantinas del Alto Duero, las exigencias de la investigación eran, en cierto modo, muy similares a las apuntadas más arriba para el estudio de ciertas producciones de la Edad del Hierro europea. En las primetas excavaciones arqueológicas llevadas a cabo a principios de siglo en el yacimiento de Numancia y en otros yacimientos del entomo geogtáfico del Alto Duero, se definieron, sobre la base de criterios crono-tipológicos $\mathrm{y}$ estéticos, toda una serie de producciones cerámicas tardías conocidas como numantinas. Dichas producciones aparecían entre otros, además de en el propio yacimiento de Numancia, en Castilterreño (Izana), Los Castejones (Calatañazor), El Castillo (Ocenilla) o Las Quintanas y Cuesta del Moro en Langa de Duero, todos ellos en la provincia de Soria. Sin embargo, y aparte de ciertos estudios emprendidos a lo largo de los años (Taracena, 1924; Wattenberg, 1963; Romero Carnicero, 1976; Arlegui, 1986), todavia hoy no se conocía de forma clara y exhaustiva cómo se articulaban estas producciones en el territorio mencionado, cuáles eran sus centros de manufactura, sus áreas de distribución, qué procesos tecnológicos tenian lugar en su elaboración o cómo podía valorarse su producción en el contexto socio-cconómico del siglo I a. C. Tampoco se conocía si ciertas cerámicas similares a partir de criterios formales y decorativos y aparecidas en yacimientos no incluidos en este territorio, procedían efectivamente del mismo o si, por el contrario, se trataba de imitaciones manufacturadas en otros contextos. La contrastación de esta hipótesis era importante también 
porque la presencia de cerámicas importadas podía ser un indicador de comercio de otros materiales o prueba de otras formas de intercambio.

De esta forma, la utilización de técnicas de caracterización para la resolución de los interrogantes anteriores, quedaba plenamente justificada. Por lo tanto, el paso siguiente debía consistir en el diseño de un proyecto de investigación encaminado a estos fines.

El proyecto se inició con la realización de un estudio preliminar sobre la producción cerámica del yacimiento de Castilterteño en Izana (Soria) que constituyó la Memoria de Licenciatura del autor de esta Tesis (García Heras, 1993 a) y cuyos resultados se publicaron en varios trabajos (García Heras, 1993 b; 1994 b; 1994 c; 1995). Este asentamiento se eligió al considerar que podría tratarse de un centro secundario de producción de cerámicas numantinas, que habria articulado todo el territorio dependiente de Numancia en la margen derecha del Alto Duero. Por este motivo, también se estudiaron los conjuntos cerámicos de otros 13 asentamientos contemporáneos de esta misma margen (3), con el propósito de determinar el átea de distribución de las producciones de Izana.

Sin embargo, esta primera experiencia, que en líneas generales se valoró como positiva, puesto que ratificaba la viabilidad de una aproximación de estas características en el estudio de estas producciones, lejos de solucionar los principales interrogantes planteados, añadió nuevas expectativas a la investigación y puso de manifiesto la necesidad de reorientar la mayoría de los presupuestos iniciales del proyecto. También exigió una importante crítica interna a posteriori, ya que los resultados podian considerarse, en general, como poco representativos y en consecuencia, las conclusiones extraidas de los mismos, como ciertamente abusivas. Ahora bien, es preciso resaltar que esta primera experiencia se llevó a cabo con un buen número de limitaciones, entre las que cabe destacar las de carácter económico.

El trabajo partió del análisis de una muestra de 37 fragmentos cerámicos y 4 sedimentos arcillosos. De las 37 cerámicas, 16 procedían del yacimiento de Izana, 4 de Los Castejones, 4 del Altillo de las Viñas y 3 de El Molino, mientras que las restantes se correspondían con una muestra de cada uno de los yacimientos mencionados en la nota 3. Por otro lado, los sedimentos arcillosos procedían uno de Izana, otro de Altillo de las Viñas y dos de Quintana Redonda. Un total de 33 muestras fueton analizadas mediante lámina delgada, 25 mediante XRD (de las que sólo 19 pertenecían a cerámicas) y 30 mediante Fluorescencia de rayos x por reflexión total (TXRF) de las cuales 4 pertenecian a sedimentos arcillosos.

A pesar de que, a través de los resultados obtenidos, podía reconstruirse de modo satisfactorio la secuencia de producción y, por tanto, la tecnología de estas producciones, no

(3) Fstos 13 ascotamientos fucron los siguientes: El Gamonar (Camparañón), los Quemados il (Navalcaballo), Ia Garcimona (los I.I amosos), Royo Albar (Quintana Redonda), Los Castejones (Calatañazor), Li Molino (Calatañazor), Ios Castillejos (Muriel de la Fuente), Nltillo de las Viñas (Ventosa de Fuentepinilla), El Chorrón (Ventosa de l'ucntepinilla), Fl Malacate (Osonilla), lil Pico (Cabrcjas del Pinar), El Castillo (Ocenilla) y Castillejo (Golmayo). 
ocurria lo mismo para el caso de la procedencia de las mismas. Dentro de la homogeneidad que presentaban, únicamente se distinguían dos agrupaciones, cerámicas calcáreas y cerámicas no calcáreas, que, ante la ausencia de evidencias arqueológicas relacionadas con procesos de manufactura, dificilmente podían adscribirse a centros concretos de producción, aunque no se descartaba la posibilidad de que procedieran de un único centro que podría situarse en el propio asentamiento de Izana.

En cualquier caso, este trabajo evidenció grandes y graves carencias en la investigación y sirvió para reorientat los presupuestos iniciales, tal y como se indicaba anteriormente. Estas carencias se relacionaban con dos tipos de problemas. Por un lado, con problemas de carácter arqueológico y por otro, con problemas de carácter metodológico.

En lo referente a los problemas arqueológicos, el número de muestras analizado era, a todas luces, insuficiente, tanto para determinar la variabilidad tecnológica y composicional de los conjuntos cerámicos entre asentamientos como dentro de cada uno de ellos. En gran parte de los mismos, sólo se había podido analizar una muestra. Asimismo, la mayoria de los materiales, exceptuando los procedentes de Izana, Los Castejones de Calatañazor y El Castillo de Ocenilla, provenían de prospecciones superficiales (Pascual, 1991), con lo que esto implica para el establecimiento de relaciones sincrónicas y para el conocimiento de la totalidad de los conjuntos cerámicos.

Por lo que respecta a los problemas de carácter metodológico, mediante la utilización de una técnica de análisis como la Fluorescencia de rayos $\mathrm{x}$ por reflexión total (TXRF), que se empleaba por primera vez a escala internacional en el análisis de sólidos $\mathrm{y}$, más concretamente, en el análisis composicional de cerámicas arqueológicas, se obtenían unos perfiles composicionales semi-cuantitativos compuestos por 22 elementos químicos, pero se desconocía el grado de exactitud y precisión (4) con el que eran obtenidos.

Todos estos aspectos ponían de manifiesto dos hechos extremadamente importantes. En primer lugar, que la escala de análisis no era la adecuada. Mientras no se contase con un tegistro arqueológico más detallado de la región, en donde se pudieran manejar una mayor abundancia de datos procedentes de excavaciones sistemáticas, no se podían iniciar trabajos de caracterización a la escala deseada, puesto que no era posible contar con datos que permitieran conocer la totalidad de los conjuntos cerámicos de cada yacimiento $\mathrm{y}$, pot consiguiente, su variabilidad tecnológica y composicional. En segundo lugar, se hacía necesario realizar un estudio previo en el cual se llevara a cabo un seguimiento de la exactitud y precisión que presentaba la Fluorescencia de rayos x por teflexión total (TXRF) en el análisis de este tipo de

(4) Iil término "precisión" hace referencia a la capacidad que téne la técnica de análisis para reproducir los resultados de la medición de cada elemento químico que detecta. Ell término "exactitud" hace referencia a la aproximación entre los datos experimentales y los datos ya contrastados, quue lleva a cabo la técnica en la medición de los distintos clementos químicos que detecta. 
materiales, con el fin de lograr una correcta estandarización, normalización y reproducibilidad de sus determinaciones elementales, que permitiera valorar cuál en la calidad de los datos obtenidos. Este aspecto era de suma importancia ya que cuanto menor fuera el grado de resolución de la técnica, más se reduciría la urilidad infetencial de estos datos.

El enfrentamiento con estos dos hechos ha sido básicamente lo que ha motivado la realización de esta Tesis Doctoral Con respecto al primero, se decidió ampliar la escala de análisis y contar sólo con materiales procedentes de yacimientos excavados. Si se pretendian caracterizar las producciones cerámicas numantinas del siglo I a. C., el primer paso había que darlo en el propio yacimiento de Numancia que, en definitiva, era en donde habian sido definidas en su totalidad. Esto exigia el estudio pormenorizado de todo el conjunto cerámico aportado por las excavaciones llevadas a cabo en este yacimiento, con el propósito de conocer tanto su variabilidad tecnológica como composicional Ello, además, permititia hacer posible cualquier tipo de comparación con producciones similares halladas en otros asentamientos.

Tras conocer las características de estas producciones en el yacimiento principal, se decidió compararlas con las aportadas por otros yacimientos a partir de dos escalas de análisis diferentes. Una que cubriera el territorio inmediatamente circundante a Numancia y otra que representase a las producciones halladas fuera de éste. Para el primer caso, se eligió el yacimiento de Izana, en el que ya se contaba con un conocimiento pormenorizado de su conjunto cerámico a través del trabajo realizado en la Memoria de Licenciatum. Para el segundo, se eligieron tres yacimientos que presentaban cerámicas con características numantinas, situados en las provincias de Soria (Langa de Duero), Burgos (Pinilla Trasmonte) y Guadalajara (Aragoncillo). De esta forma, podría comprobarse si las producciones del área de influencia de Numancia eman homogéneas o procedian de distintos centros de manufactura, así como determinar si las producciones halladas fuera de este entomo procedian efectivamente de él o podian considemarse como imitaciones locales.

Con respecto al segundo de los hechos, el relacionado con las potencialidades de la Fluorescencia de rayos $\mathrm{x}$ por reflexión total (TXRF), deben comentarse, primeramente, algunas cuestiones. Hay que tener en cuenta que la elección de esta técnica esturo condicionada desde un principio y en gran medida, por razones ajenas a la investigación. Como ya se ha señalado, los problemas que se pretendían solucionar coincidian con uno de los retos actuales más importantes a los que se enfrenta la investigación arqueométrica sobre cerámicas, como es el poder llegar a determinar centros de producción a escala intra-regional. En este sentido, el método que más ventajas ofrecia para la tesolución de estos interrogantes, era el Análisis de activación de neutrones (NAA). Sin embargo, su utilización en esta investigación eta totalmente inviable, debido a su elevado coste económico y a la imposibilidad de 
acceder a un reactor nuclear debidamente equipado para tareas de investigación en territorio español. $\mathrm{Si}$ bien se han utilizado como altemativa para la resolución de cuestiones de índole similar ottas técnicas más accesibles y menos costosas (XRF, ICPS, etc.), el acceso a las mismas constituía también un inconveniente importante en el desartollo de este trabajo. El proyecto se ponía en práctica desde un departamento universitario sin ningún equipamiento para la realización de este tipo de análisis y la Universidad Complutense no contaba con servicios de apoyo a la investigación, como los existentes en otras universidades españolas, en los cuales realizar los análisis por medio de estas técnicas. Ante esta situación, se contactó con técnicos del Servicio Interdepartamental de Investigación (S.I.d.I.) de la Universidad Autónoma de Madrid, con quienes es preciso resaltar que hubo un fructífero entendimiento y un tico intercambio de ideas desde el comienzo, con el propósito de llevar a cabo en estas instalaciones los análisis composicionales. En esos momentos, estos laboratorios ponian en práctica una técnica relativamente nueva, la Fhorescencia de rayos x por reflexión total (TXRF), que demostraba tener mayor potencialidad que algunas de las técnicas habituales más utilizadas, al menos en el análisis de muestras líquidas (Prange, 1989; Tölg y Klockenk-mper, 1993).

Tras sucesivas entrevistas, se llegó a un acuerdo para iniciar un programa de investigación encaminado, en un principio, a conocer la potencialidad de esta nueva técnica en el análisis de muestras sólidas, como era el caso de las cerámicas arqueológicas, para después desarrollar su aplicación a gran escala en la caracterización composicional de un nutrido número de muestras de cerámica numantina, por otro lado, muy superior al realizado en la Memoria de Licenciatura.

Una vez planteados los motivos que han guiado el desarrollo de este trabajo, bueno es reconocer también cuáles son sus principales limitaciones. Entre ellas, podrian destacarse tres, en función de su mayor impacto en los resultados aportados por esta investigación. La primera es una limitación inherente a cualquier trabajo de caracterización fisico-química de cerámicas y está relacionada con las dificultades de financiación, que a su vez se relacionan con dificultades en la realización de los análisis por medio de las diferentes técnicas y que repercuten directamente en el muestreo y selección del númeto de fragmentos cerámicos a analizar. Este aspecto es el punto crítico de una investigación de este tipo, puesto que, en última instancia, los resultados globales se sustentan sobre la base del muestreo efectuado.

La segunda de las limitaciones se relaciona con los datos arqueológicos manejados, ya que la mayor parte de los mismos procede de excavaciones antiguas realizadas a principios de siglo. Este inconveniente plantea la dificil, por no decir imposible, contextualización tigurosa de gran parte de los materiales cerámicos, además de serias dudas, en algunos casos, sobre su asignación cronológica.

La última de estas limitaciones se halla intimamente relacionada con la anterior. A los problemas de contextualización se unen las dificultades a las que debe enfrentarse el investigador para revisar y 
ordenar los conjuntos cerámicos depositados en los distintos museos, en los que no siempre existen buenas catalogaciones actualizadas. En este caso, la mayoria de los materiales estaban depositados en el Museo Numantino de Soria y en el Museo Arqueológico Nacional de Madrid. Mientras que en el primero de ellos su consulta fue extremadamente dificultosa -ya Romero Carnicero en un trabajo publicado en 1.984 planteaba la necesidad urgente de una revisión y catalogación de los fondos del Museo Numantino pertenecientes a yacimientos celtibéricos (Romero Camicero, 1984, 87-89)- en el segundo, esta labor se llevó a cabo sin demasiados problemas, gracias a la buena ordenación que presentaban los materiales celtibéricos y a la existencia de un reciente trabajo que recopilaba todos los materiales procedentes del yacimiento de Numancia depositados en este museo (Barrio Onrubia, 1991).

Por último, y antes de finalizar esta introducción, sería conveniente reconocer el desequilibrio que va asociado a todo trabajo de investigación científica, entre los propósitos iniciales y los objetivos finales que se alcanzan. Obviamente, estos últimos a menudo no superarian el 30 ó $40 \%$ si se expresasen en términos cuantitativos, aunque para ello el investigador cuenta con la ventaja de que siempre escribe los resultados a posteriori, esto es, una vez que el proceso experimental ha concluido.

Tampoco estaria de más hacer mención a otros aspectos no relacionados de una manera tan directa con la investigación desatrollada en esta Tesis Doctoral, pero a la que sin duda van intrinsecamente unidos, complementándola unas veces, restándole esfuetzos otras, en una relación dialéctica de dificil equilibrio. Mencionar las largas horas de trabajo, esos pequeños y grandes problemas que han ido surgiendo encadenados de manera continua y que, muchas veces, han estado a punto de afectar seriamente a la consecución de este trabajo, dudas constantes al hacer o no hacer alguna afirmación, la tensión acumulada a la hora de cumplir los plazos de tiempo estipulados, y tantas y tantas cosas de dificil enumeración. En definitiva, toda una parte de vida invertida a lo latgo de este trabajo en un esfuetzo que, sin embargo, ha metecido largamente la pena. No sólo por el enriquecimiento intelectual que ha representado, sino también, y especialmente, por el entiquecimiento personal que ha supuesto el contacto con un gran número de personas de gran valia, tanto profesional como humana, así como el reto constante de actuar siempre con el máximo rigor y honestidad. 



\section{MARCO TEÓRICO Y OBJETIVOS DE LA INVESTIGACIÓN}

A lo largo de las últimas décadas, han sido numerosos los trabajos que han insistido en que la naturaleza de los datos arqueológicos no siempre es puramente histórica, a pesar de que el método arqueológico se haya empeñado en aproximarse a ellos de esta forma, debido, sobre todo, a la formación histórico-humanística que tradicionalmente han tenido los arqueólogos. Sin embargo, sería preciso empezar a aceptar que la Arqueología debe sobrepasar los límites de las Ciencias Humanas, puesto que habitualmente se enfrenta con datos de muy distinta naturaleza.

En efecto, esto es especialmente cierto en lo que concierne a los estudios sobre cerámica arqueológica, en los cuales hasta hace poco tiempo ha primado una aproximación cronotipológica, centrada en el análisis y clasificación de formas y decotaciones en detrimento de otros aspectos de igual o mayor interés. Empero, el estudio de la cerámica también debe sobrepasar estos límites, en tanto en cuanto el investigador se enfrenta con un objeto de manufactura compleja cuya fabticación conlleva, en mayor o menor medida, conocimientos técnicos más que estéticos o artísticos (Aliaga et al., 1991; Kingery, 1988). Es precisamente de esta forma como puede lograrse una aproximación más realista a su significado dentro de un contexto atqueológico determinado.

Para el estudio de la cerámica bajo esta perspectiva tecnológica, se ha recurrido, como ya se apuntaba en la introducción, a métodos de caracterización importados de una de las ramas de la Ciencia de Materiales conocida como Ingeniería Cerámica, en donde estos métodos suelen emplearse para describir cualitativa y cuantitativamente la composición y estructura de un material cerámico, con el fin de evaluar sus propiedades y sus posibles usos (Rice, 1987, 309). De todos modos, mientras que en la moderna producción cerátnica industrial su utilización se centra en el control de calidad, en la investigación de nuevos materiales y en la reproducibilidad de los mismos, la Atqueología actual plantea otro tipo de preguntas al material cerámico antiguo, como, por ejemplo, cuáles han sido los procesos tecnológicos empleados en su manufactura o 
de dónde proceden las materias primas con las que fue elaborada.

La importación de esta metodología lleva consigo la obtención de unos datos que no tendrían relevancia arqueológica directa, si no fuera por los hechos, producidos por un sistema humano de conducta, que pueden inferitse a partit de dichos datos y que, en última instancia, son los que realmente interesan a la investigación (Mommsen et al., 1991, 57). Este aspecto pone de manifiesto que los estudios de caracterización no son un fin en sí mismos, sino que exigen el desarrollo de un marco teórico que sea generado desde la propta disciplina arqueológica, que los dote de significado y que integre tanto la información composicional como cultural en la interpretación (Bishop et al., 1982).

Los primeros trabajos de caracterización fueron emprendidos mayoritariamente por especialistas procedentes de las Ciencias Experimentales. Es por ello por lo que la preocupación por el desarrollo de un marco teónico específico ha tardado en producirse, aunque todavía no constituye una preocupación común a todos los trabajos de caracterización que se realizan.

\subsection{MODELO DE TRABAJO ARQUEOMÉtrico PARA LA CARACTERIZACIÓN DE CERÁMICA}

En el estudio preliminar que se llevó a cabo en la Memoria de Licenciatura, el trabajo arqueométrico se estructuró a partir de un modelo de producción local de cetámica (Gatcía Heras, 1993 a, 16; 1994 c, 136). Dicho modelo contaba con tres niveles de generación de información y cuatro niveles de inferencia. Los niveles de generación de información estaban compuestos por: datos de caracterización, datos etnográficos y datos procedentes de la experimentación realizada con muestras de sedimentos arcillosos pertenecientes a la zona de estudio; mientras que los niveles de inferencia estaban compuestos por: procesos tecnológicos, modos de producción, procedencia de las cerámicas y distribución. La integración de ambos elementos hacía posible la interpretación final.

Como ya se apuntaba en la introducción, una profunda crítica interna, realizada después de haber finalizado el trabajo, hacía ver que el modelo propuesto no respondía a todas las expectativas planteadas inicialmente, debido a que resultaba muy confuso, era excesivamente particularista, los diferentes niveles mezclaban información y no reflejaba de modo satisfactorio todo el proceso seguido en un trabajo de naturaleza arqueométrica. Por estos motivos, se ha. 


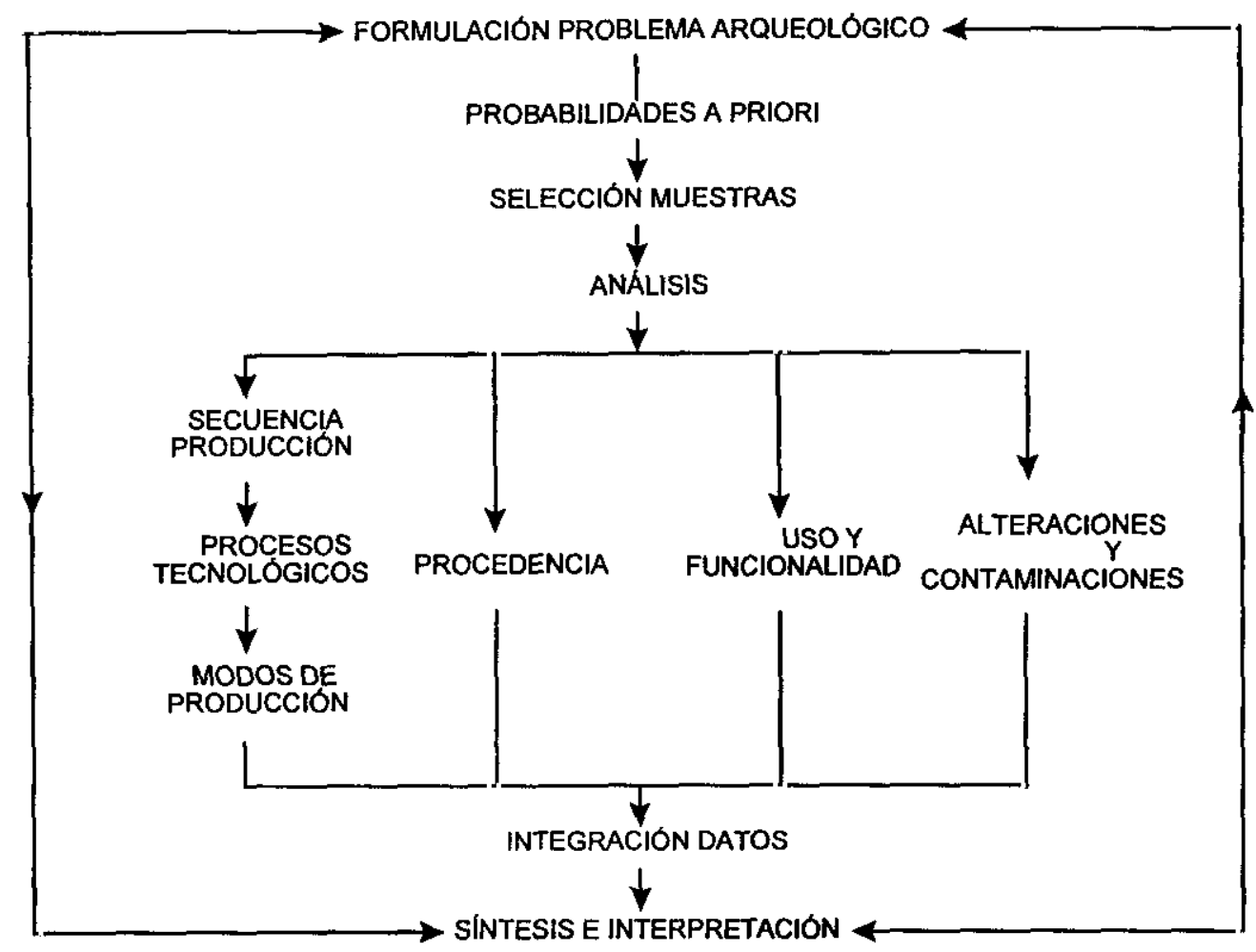

Figura 2.1: Modelo de trabajo arqueométrico para la caracterización de cerámica.

decidido plantear un nuevo modelo para el desarrollo de esta investigación, en un intento de superar los errores cometidos con anterioridad y de ganar un mayor grado de generalidad

Este modelo se muestra en el diagrama de la Figura 2.1 y parte de la concepción del trabajo arqueométrico de caracterización de cerámicas, como una investigación dinámica e interrelacionada entre los diferentes niveles, cuyo fin último es la integración de todos los datos en una interpretación con significado arqueológico.

\subsubsection{Probabilidades a priori}

El estudio comienza con la formulación de un problema susceptible de ser abordado por medio de una aproximación de estas catacterísticas. En la formulación de este problema deben definirse lo que algunos autores han llamado Probabilidades a priori, para referirse a aquellos argumentos que ofrecen soluciones más factibles que otras en la situación de un lugar de 
fabricación de cerámicas cuyo origen es desconocido. Estos argumentos pueden consistir en razones históricas, etnográficas, geológicas, etc. y son los que, en definitiva, hacen viable la realización de un trabajo de este tipo (Bishop y Neff, 1989, 59; Picon, 1995, 231).

\subsubsection{Selección de muestras}

Una vez definidas las Probabilidades a priori, se realiza la selección de las muestras a analizar. Quizás sea éste el paso más importante en cualquier estudio de caracterización, ya que este muestreo condicionará todos los resultados obtenidos (Hughes et al., 1991, 32). Para realizar un muestreo lo suficientemente representativo, resulta indispensable conocer, de manera exhaustiva, todo el conjunto cerámico estudiado. En esta investigación se ha optado por efectuar la cuantificación de todos los fragmentos (1) procedentes del yacimiento de Numancia (Apéndice I) y mediante un análisis macroscópico con lupa binocular, identificar sus fábricas (2)o tipos de manufactura. Ha sido a partir de esta identificación como se han seleccionado las muestras finalmente analizadas. La imposibilidad de realizar análisis masivos, hace necesario extraer la mayor cantidad de información a través de las características macroscópicas del material.

\subsubsection{Análisis}

A continuación, se inicia el proceso de análisis. Para la comprensión del material cerámico en todas sus dimensiones, se hace indispensable el concurso de varias técnicas de caracterización, ya que la utilización de una técnica aislada sólo ofrecería información parcial. Hay que tener en cuenta que el análisis de una cerámica va a activar la historia total del artefacto, o lo que es lo mismo, su composición en el presente, que es resuttado de la acción de muchos y variados procesos: desde su producción y uso posterior, pasando por las alteraciones postdeposicionales, en las que también se incluyen los procesos de limpieza, reconstrucción, consolidación, restauración, conservación e, incluso, la preparación para estos análisis (Buxeda, $1994,77)$.

(1) Cuando una picza sstaba compuesta por varios fragmentos, se ha contabilizado solamente como uno. Asimismo, cuando no cxistia seguridad sobre la pertenencia de varios fragmentos a una misma picza, estos han sido contabilizados por scparado. 
De esta forma, la información que se genera a través de estas técnicas puede descomponerse en cuatro líneas de indagación: a) procesos tecnológicos empleados en su manufactura, b) procedencia de sus materias primas, c) funcionalidad de los recipientes y d) alteración y contaminación sufrida por sus componentes, tanto durante su uso como en su posterior deposición en el medio que las ha conservado. Debe señalarse que no es posible hacer una distinción entre caracterización y tecnología como mantenía Renfrew (1977), puesto que ambas líneas de indagación son complementarias. Expresado en otras palabras, esto significa que no se puede aprehender la información sobre procedencia sin antes conocer la información tecnológica (Buxeda, 1994, 313). En cualquier caso, la determinación del origen de un conjunto cerámico nunca se realiza sólo y exclusivamente con argumentos de composición, sino que también influyen datos geológicos, mineralógicos, tecnológicos, tipológicos, etc., como se verá después (Picon, 1989, 246).

\section{a) Procesos tecnológicos}

En lo referente a la primera línea de indagación, se va a manejar el concepto de Secuencia de Producción propuesto por Rye (1988, 1-5). La manufactura de cerámicas, como cualquier otra actividad industrial, requiere una secuencia sucesiva de acciones para llevarse a cabo. Esta secuencia está compuesta por cinco acciones básicas:

1.- Selección y recogida de materias primas.

2.- Preparación y acondicionamiento de las mismas.

3.- Modelado.

4.- Secado.

5.- Cocción.

Con la utilización de dicha secuencia como base pragmática pata identificar los procesos tecnológicos, se asume que es posible, a través de los datos físico-químicos, teconstruir la conducta de los alfateros del pasado, ya que ésta ha quedado plasmada en la pasta cerámica a lo largo de las acciones mencionadas (Bishop et al., 1982, 276).

A partir de la secuencia o secuencias de producción determinadas, puede llegar a estimarse cuál es el carácter de la producción cerámica estudiada. Para ello se emplea el concepto

(2) Se entiende por fábrica la distribución, tamaño, forma, frecuencia y composición de los componentes de un material cerámico (Whitbread, 1989, 127). E] término "leabrica" hace referencia a esté material una vez cocido, micntras que con el término "Pasta" se hace referencia a la materia prima en crudo. 
de Modos de Producción (3), que introdujo Peacock (1982) en su trabajo etnogxáfico desarrollado para el estudio de la producción y el mercado de la cerámica romana. Este concepto es de gran utilidad para la aproximación a los aspectos sociales y económicos relacionados con la manufactura de cerämicas.

Peacock distingue ocho modos de producción en la cerámica romana. No obstante, y según los objetivos que persigue esta investigación, aqui solamente se va a incidir en tres de ellos, debido a que no es probable que la producción numantina se ajuste al resto de las situaciones. Estos modos de producción son los que tipifica como Industria Doméstica, Tallenes Industriales e Industria a Gran Escala.

La Industria Doméstica supone el primer paso hacia la especialización, aunque la manufactura de cerámicas todavía es una actividad a tiempo parcial. El consumo no excede los límites de la comunidad y no se requieren grandes inversiones en tecnología. Los Talleres Industriales pueden ser individuales o estar agrupados por necesidades de mercado, materias primas, etc. La producción está orientada, generalmente, a la obtención de un beneficio, tratándose de una actividad especializada a tiempo completo. Requiere importantes inversiones en tecnología como medio de incrementar la producción. En este caso, los alfareros dependen directamente de la demanda. Por último, la Industria a Gran Escala, está orientada a conseguir el máximo beneficio con el mínimo coste, pero requiere una distribución extensiva del producto. Con el fin de asegurar ha demanda, la cerámica trasciende su carácter utilitatio para ser un objeto con usos sociales o ideológicos. Igualmente, es una actividad especializada a tiempo completo.

Es importante destacar que estos conceptos pueden tener un gxado de variabilidad considerable y, por tanto, que las distintas situaciones pueden no llegar a delimitarse con claridad. De todas formas, no deben contemplarse como estadios de un sistema evolutivo lineal, ya que distintos modos de producción pueden estar operando a la vez dentro del mismo contexto socio-económico.

\section{b) Procedencia}

La determinación del onigen de los materiales analizados, se basa en el llamado Postalado de Proxdencia, el cual asume que las difetencias entre distintas fuentes de materia prima pueden ser reconocidas analiticamente y que las variaciones composicionales son más amplias entre distintas fuentes que dentro de la misma fuente (Weigand et al., 1977). De hecho, un estudio composicional de cerámica arqueológica es siempre un estudio sobre la variabilidad de las fuentes de materia prima (Neff $e t$ al., 1992, 59).

(3) I a utilización de este concepto, tomado de la teoria marxista de análisis cconómico, no implica que esta investigación esté orientada bajo esta perspectiva tcórica 
Es preciso difetenciar entre los términos origen y fuente. Con el término fuente se hace referencia al punto último donde se ha recogido la materia prima, mientras que origen se tefiere a una zona geográfica amplia de procedencia. Como fuente puede, además, entenderse un bartero único, un solo estrato arcilloso, todas las arcillas de una cuenca, una comunidad de alfaretos o un grupo de comunidades de alfareros que explotan la misma materia prima (Arnold et al., 1991, 70).

El estudio composicional tiene como principal objetivo la identificación de subgrupos en el conjunto general de datos. Estos subgrupos se identifican por medio de la utilización de técnicas estadísticas multivariantes, que determinan su mayor o menor similaridad, a partir de sus distancias en un espacio n-dimensional. Se trata, por tanto, de asociar un cierto número de atributos, en este caso los elementos químicos del perfil composicional de las cerámicas, por medio de varios métodos matemáticos de tratamiento de datos (Picon, 1984, 429). Así, un subgrupo se caracteriza por tener un rango de concentraciones elementales interrelacionadas con un único centro de masa, llamado Centroide, y un patrón particular de decrecimiento de densidad en diferentes direcciones, que determinan su forma, y que se estima por la matriz de varianza-covarianza (Neff et al., 1994, 337).

Estos subgrupos suelen ser conocidos en la bibliografia especializada con el nombre de Grupos de Referencia, cuando están constituidos por cerámicas y/o sedimentos arcillosos con un origen común reconocido, y como Unidades de Referencia Composicional, cuando no se conoce el origen (Picon, 1993, 13; Buxeda, 1994, 77). En este trabajo, estas denominaciones no van a ser utilizadas, ya que la técnica de análisis empleada, la Fluorescencia de rayos x por reflexión total (TXRF), proporciona sólo, por el momento, resultados semi-cuantitativos y estos términos, sólo se aplican con determinaciones cuantitativas.

El perfil composicional que se obtiene en una cerámica, es resultado, como ya se apuntaba anteriormente, tanto de factores naturales como culturales (Bishop y Neff, 1989, 69). Por ello, no siempre es posible asociar un subgrupo con una fuente determinada, ya que su composición puede haber sido alterada por los procesos tecnológicos de producción, por el uso posterior o por su interrelación con el medio en el que ha permanecido enterrada. De esta manera, habría que señalar que las determinaciones de procedencia son siempre de carácter probabilístico y que se basan, generalmente, en tres categorías de argumentos: Probabilidades a priori, Criterios de Evaluación y Criterios de Validación (Picon, 1989, 246; 1995, 231).

Los primeros ya fueron explicados más arriba. Los Criterios de Evaluación se basan en las diferencias o similaridades de composición para establecer el origen de las cerámicas. Por el 
contrario, los Criterios de Validación comprenden todos aquellos argumentos no composicionales, como son los datos mineralógicos, los datos tipológicos, el color, etc., que se emplean para apoyar una determinación de procedencia.

Es importante también indicar el significado de dos conceptos que se manejan en esta investigación, en relación a la estimación de la procedencia del conjunto cerámico estudiado. El primero de ellos es la llamada Zona de Incertidumbre o Espacio de no resolución, para hacer referencia a una zona en la que no es posible realizar ninguna distinción de origen a partir de criterios de composición. En otros términos, se trata de una incertidumbre teórica sobre la localización exacta del origen de las cerámicas. El segundo es conocido como Zonas de Conjunción. Las Zonas de Conjunción son Zonas de Incertidumbre que presentan características composicionales similares, lo cual significa que no es posible realizar una atribución de origen exacta para ninguna de ellas (Picon, 1984, 431; 1993, 10) (Figura 2.2).

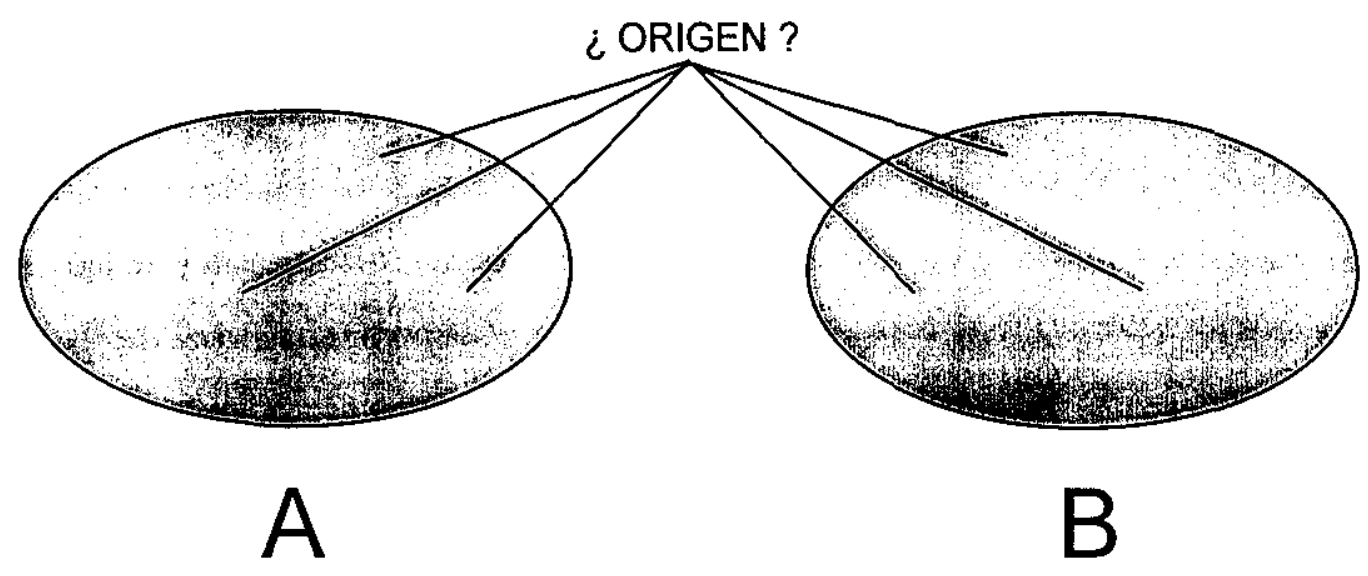

Figura 2.2: Zona de Incertidumbre y Zonas de Conjwnión. Los gráficos A y B muestran Zonas de Incertidumbre. Si ambas zonas presentasen características composicionales similares, serian consideradas Zonar de Conjunción.

\section{c) Funcionalidad}

Esta linea de indagación tiene una relación directa con los procesos tecnológicos y con los procesos de alteración y contaminación. En lo referente a los primeros, porque cualquier proceso tecnológico se desarrolla en función del uso al que vayan destinados los recipientes. En cuanto a los segundos, porque ciertas alteraciones y contaminaciones pueden ser atribuidas, precisamente, al uso dado a estos recipientes. En cualquier caso, este segundo aspecto no va a ser tratado en este trabajo, ya que requiere de toda una serie de técnicas de análisis concretas. 


\section{d) Alteraciones y contaminaciones}

Finalmente, para la cortecta realización de la caracterización de un conjunto cerámico, se hace necesario determinar cuáles han podido ser los procesos de alteración y contaminación que han sufrido las cerámicas analizadas. Este aspecto es de extraordinatia importancia porque la influencia de cualquiera de estos procesos puede oscurecer la asociación de un sub-conjunto con una fuente $y$, en consecuencia, las determinaciones de procedencia que se realicen.

Existen diferencias entre alteración y contaminación, aunque ambas conllevan modificaciones en la composición de un material cerámico. La alteración implica la transformación de alguna de las fases presentes en dicho material, con la posibilidad de pérdidas o enriquecimientos. Por otro lado, la contaminación supone un enriquecimiento con materiales externos, debido a procesos de absorción, difusión y precipitación (Buxeda, 1994, 76).

\subsubsection{Integración de los datos y síntesis}

Una vez llevados a cabo los distintos análisis, el modelo de trabajo arqueométrico concluye con la integración y valoración de los datos ptocedentes de las cuatro líneas de indagación, con el propósito de efectuar su síntesis y llegar a la interpretación global de los resultados.

Una de las diferencias principales que presenta el modelo planteado con respecto al modelo anterior desarrollado en la Memoria de Licenciatura, está relacionada con el uso de datos etnogtáficos. En aquella ocasión, estos datos se utilizaban, con carácter comparativo, en el estudio de las producciones cerámicas del yacimiento de Izana. Esta comparación se realizaba por medio de argumentos de analogía o de convergencia, consistentes en generalizaciones basadas en caracteres isomotfos, pero no estrictamente idénticos, existentes en dos producciones cerámicas distintas, desarrolladas bajo las mismas condiciones ecológicas y culturales. Es decir, conectando fenómenos actuales conocidos con fenómenos no conocidos del pasado (Neff et al., 1988 a, 346; Sinopoli, 1991, 71).

Aunque el uso de este tipo de argumentos es defendido por algunos autores (p. e. Arnold, 1985; Rice, 1996), sobre todo a la hora de establecer correlaciones conducta/material, referidas a las propiedades fisicas y tecnológicas de las materias primas o a procesos de manufactura, la verdad es que su utilización resulta muy problemática cuando está relacionada con el significado cultural de la producción cerámica. Debido a estas razones, en esta 
investigación se ha prescindido del empleo de datos etnogtáficos con criterios comparativos, procedentes de la zona de estudio o de áreas limítrofes, a pesar de contar con un grado de conocimiento importante de los mismos (4). Se ha decidido no utilizarlos ante el convencimiento de que las analogias no etan posibles, puesto que no se contaba con datos que permitieran saber si las condiciones ecológicas y culturales podían ser consideradas como equiparables. En todo caso, la falta de trabajos etnográficos y etnohistóricos que conecten y estudien los diferentes contextos de producción cerámica a lo latgo de los distintos períodos históricos, con el fin de valorar cuáles han sido las aportaciones tecnológicas, o de cualquier otro tipo, en cada uno de ellos, ha sido otro factor que ha influido, de manera importante, en tal decisión. Por ejemplo, en el área de los yacimientos de Numancia e Izana, no se tiene constancia de la existencia de centros de producción en ningún período histórico. Únicamente, son conocidos centros en Quintana Redonda, a unos $20 \mathrm{~km}$ de Soria capital, para época romana (Arlegui et al., 1993-94) y desde época moderna hasta la actualidad. En este lugar, el catastro del Marqués de la Ensenada de 1.752, registra la existencia de cuatto alfares (Martínez, 1983). También son conocidos alfares en la localidad de Tajueco, a unos $45 \mathrm{~km}$ de la capital, donde igualmente ha habido producción cerámica desde época modema hasta la actualidad. Dicho catastro registra aqui 13 alfareros (Fernández et al., 1981). Asimismo, se conoce la existencia de alfarerias tradicionales, hoy desaparecidas, en otros lugares de la provincia de Soria, como Almazán, Deza, la propia ciuđad de Soria o la localidad de Ágreda (Martínez, 1983).

Sin embargo, como se comentaba anteriormente, estos datos son dificilmente comparables, sin el apoyo de otros argumentos de conexión, con la producción cerámica de tipo numantino, ya que ambos contextos de producción han sido, con toda probabilidad, muy diferentes.

(4) Entre los trabajos etnográficos documentados, pucden citarse, para la provincia de Soria, los realizados por lernández ct al. (1981) y Martínez (1983), mientras que para cl resto del árca geográfica de la Meseta, destacan los trabajos de Abertos ct al. (1978) para la alfarcria popular conquense, de Castellote (1979) para la alfarcría popular de la provincia de Guadalajara, de Caurcel y Segura (1977), para la alfarería populat de la provincia de Madrid, los trabajos sobre la alfareria popular salmantina y de la provincia de Zamora de CortĆs Vázqué (1953; 1954; 1958), de Álvato Zamora (1980) sobre la alfarcría popular aragonesa, o cl trabajo de Burilo (1983 a) sobre el centro alfarero de Huesa del Común, en la provincia de I'encl. 


\subsection{OBJETIVOS DE LA INVESTIGACIÓN}

Por tanto, según los planteamientos expuestos en el capítulo anterior de introducción y en concordancia con el matco teórico descrito, los principales objetivos que se persiguen con esta investigación son los siguientes:

1.- Conocer la totalidad del conjunto cerámico perteneciente al yacimiento de Numancia, con el fin de determinar su variabilidad tecnológica y composicional.

2.- Reconstruir la secuencia de producción de las distintas fábricas o tipos de manufactura presentes en el conjunto cerámico de Numancia, de manera que pueda realizarse una estimación del modo de producción de la cerámica numantina.

3.- Comparar los conjuntos cerámicos de Numancia e Izana y determinat la procedencia de sus cerámicas.

4.- Determinar la procedencia de las cerámicas de los yacimientos de Langa de Duero, Pinilla Trasmonte y Aragoncillo.

5.- Estimar las posibilidades y viabilidad de la técnica de Fluorescencia de rayos x por reflexión total (TXRF) en el estudio de la cerámica numantina.

6.- Valoración de los resultados e integración de los datos en una interpretación con significado arqueológico. 



\section{3. ÁREA DE ESTUDIO: MARCO GEOGRÁFICO Y YACIMIENTOS}

En este capítulo se van a describir, en primex lugar, las caracteristicas geográficas de la zona del Alto Duero, en la que se ubican los yacimientos de Numancia e Izana. A continuación, se realizará una breve introducción al panorama arqueológico que presenta la zona de estudio para el período cronológico del siglo I a. C., en el cual se encuadran las producciones cerámicas numantinas; para finalizar con una revisión pormenorizada de los cinco yacimientos en los que se han seleccionado las distintas muestras para llevar a cabo este trabajo de caracterización, así como de las razones que han motivado la elección de estos yacimientos para la selección de dichas muestras.

\subsection{MARCO GEOGRÁFICO}

La zona del Alto Duero es un área geográfica perteneciente a la Meseta Oriental que se circunscribe, casi exclusivamente, a los límites de la actual provincia de Soria. En lineas generales, puede ser considerada una zona natural, diferenciada geográficamente tanto del área castellano-leonesa, en la que se incluye por razones históticas, como de la cuenca del Ebro (Jimeno, 1984, 13).

\subsubsection{Geología}

La configuración física de esta zona es producto de dos grandes plegamientos: el plegamiento Herciniano y el plegamiento Alpino. EI primero de ellos, tiene lugar durante el 
Paleozoico y es el que forma el llamado Macizo Hespérico, que se extendía desde Galicia hasta la parte oriental de la provincia de Soria, estando separado del Macizo del Ebro por una cuenca marina. Los procesos erosivos lo convierten, más tarde, en una penillanura formada, sobre todo, por materiales siliceos. Por otro lado, el plegamiento Alpino, es el que configura el Sistema Ibérico, fallando y plegando los materiales depositados durante el Secundario. En realidad, no es una cordillera propiamente dicha, sino un conjunto de vatios macizos montañosos y fosas tectónicas (Bachiller y Sancho, 1990, 7-8).

Como resultado de la evolución geológica, en el Alto Duero pueden distinguirse tres grandes unidades estructurales: el Ramal Septentrional y el Ramal Meridional del Sistema Ibérico y la Depresión Central del Dueto.

1.- Ramal Septentrional del Sistema Ibérico. Es un reborde montañoso de constitución pétrea y plegada en el que la erosión ha producido un fuerte arrasamiento de sus cumbres, con el posterior relleno de las cubetas. Este ramal está formado por tres unidades: línea de altas cumbres ibéricas, corredor intraibérico y sierras preibéricas u orla ibérica interior.

- Línea de altas cumbres ibéricas. Bordea la provincia de Soria desde el NO hasta el E, siendo el tramo más elevado de ésta. La linea de altas cumbres ibéricas divide las cuencas hidrográficas del Duero y del Ebro.

- Corredor intraibérico. Se trata de un conjunto de depresiones y cubetas de relleno que se sitúa entre estas dos unidades.

- Sierras preibéricas. Es un cordón contínuo que discurre paralelo al Ramal Septentrional. Está formado por pequeñas sierras de calizas matinas del Mesozoico, sobre todo cretácicas, cuya vertiente $\mathrm{N}$ suele ser abrupta, con frecuentes escarpes coronados por acantilados, mientras que la vertiente meridional se compone de supetficies arrasadas de suaves pendientes.

2. Ramal Meridional del Sistema Ibérico. Es un reborde montañoso, también de constitución pétrea, pero menos plegado que el septentrional. A ttavés de la Sierra de Pela se une ya con el Sistema Central.

3.- Depresión Central del Duero. Se encuentra situada entre los dos ramales del Sistema Ibérico, constituyendo un pasillo sedimentario cuyo eje es el Duero. Se trata de una gran cuenca terciaria, de rellenos arcillosos blandos, mayoritariamente miocénicos, dispuestos en capas 
horizontales (Bachiller y Sancho, 1990, 8-10; Sáenz García, 1951).

Los materiales más antiguos que se encuentran en esta zona, pertenecen a pequeñas extensiones del Jurásico Inferior (Lías), situadas en el $\mathrm{N}$, siempre bajo facies calizas o calizomargosas marinas. Después, aparecen materiales del Jurásico Medio (Dogger), que comienza con facies margosas que van haciéndose más calcáteas hacia el techo. En los estadios siguientes, Jurásico Superior y Cretácico Inferior continentales, se halla la facies llamada Purbeck-Weáldica, que se caracteriza por la alternancia de calizas, areniscas y arcillas cuarzoarenosas en potentes series de sedimentos. Junto a ésta aparece también la facies Utrillas, de areniscas poco consolidadas y arcillas grises con costras ferruginosas. El Cretácico Superior, que se distingue en la zona por formar sierras de altitud media, está constituido por calizas y calizas margosas de facies Cenomaniense, que aparecen en una capa cortada por gtandes fallas.

Seguidamente, se manifiestan ya los sedimentos terciarios. El Terciario es, prácticamente en toda la zona, concordante con el Cretácico, excepto en el área de Cabrejas del Pinar. Durante el Eoceno y el Oligoceno, la deposición es de carácter continental, encontrándose materiales como calizas, conglomerados, areniscas, margas y arcillas. El Mioceno ocupa una extensa región en esta zona, presentando características muy similares en diferentes puntos. Sus materiales más representativos son, en general, de tipo detrítico (conglomerados), aunque también aparecen margas $y$ arcillas.

Por último, el basculamiento progtesivo de la Meseta y los movimientos epirogénicos de los bloques colindantes, han dado lugar, durante el Cuaternario, al encajamiento del cauce de los ríos, originándose depósitos de terraza a varios niveles, compuestos por sedimentos aluviales, tañas y derrubios de ladera (1).

\subsubsection{Suelos}

Acorde con la diversidad topográfica que presenta la zona del Alto Duero, los suelos que se encuentran en la misma también presentan mucha variedad. Dentro del área serrana septentrional, aparecen los suelos de tipo ranker poco desarrollados, con horizontes superficiales ricos en materia orgánica, así como pequeñas extensiones de luvisoles, generalmente muy

(1) La información utilizada en la elaboración de este apartado, ha sido tomada de la cartografia geológica que aparece citada en la bibliografia del final de esta T'esis Doctoral. 
arcillosos, junto a los tíos Duero y Tera. Por el contrario, en la cuenca del Duero se hallan, entre los que ocupan mayor extensión, rendsinas y cambisoles. Suelos pardo-calizos desarrollados sobre sedimentos margosos terciarios, que se caracterizan por la presencia de carbonato cálcico libre en el perfil, por tener un $\mathrm{pH}$ neutro y ser ligeramente alcalinos (Palomar y Hernando, 1984; Morales, 1995, 11).

\subsubsection{Climatología}

El clima actual de esta zona se encuadra dentro de un tégimen térmico de tipo continental. Estas caracteristicas vienen condicionadas, por un lado, por factores exógenos y, por otro, por factores endógenos. Entre los factores exógenos, se encuentran las perturbaciones del Frente Polar y los anticiclones continental europeo y de Azores, mientras que, como factores endógenos, influyen la marcada altitud media de estos territorios, así como el cinturón montañoso ibérico, que frena la penetración de borrascas, produciendo así escasez de lluvias.

Existe una acusada oscilación térmica entre inviemo y verano, con una temperatura media anual de $9^{\circ} \mathrm{C}$. Los inviemos son largos y frios y los veranos cortos y calurosos. El mayor número de precipitaciones anuales se registra en el sector montañoso del $\mathrm{N}$, decreciendo en circulos concéntricos a medida que se desciende hacia el S. De esta forma, la mayor parte de la zona se sitúa entre los 400 y $600 \mathrm{~mm}$ anuales, aunque los valores aumentan o disminuyen según la altitud.

La distribución anual de precipitaciones presenta un mínimo en verano. Este mínimo estival, es mayor en las zonas próximas a la deptesión del Duero, en donde se acentúa el índice de aridez. Los máximos en las precipitaciones se constatan en los meses de primavera (mayo y junio) y otoño (principalmente noviembre). La media anual de días de lluvia se sitúa entre 90 y 100 (Bachiller y Sancho, 1990, 11-12).

\subsubsection{Hidrografia}

La hidrografia de esta zona es, en general, de régimen pluvionival. La red hidrográfica está constituida, básicamente, por el cauce del Duero, que recoge las aguas de la mayoría de los ríos y arroyos que discurren por la comarca. El Duero realiza encajado la mayor parte de su recorrido por la zona y sólo comienza a ensancharse al final de la misma, a partir de San Esteban 
de Gormaz, después de haber recibido ya el aporte de los numerosos afluentes que provienen de la región montañosa septentrional, como son los ríos Revinuesa, Ebrillos, Tera, Rituerto, Izana o Ucero. Estos afluentes son mucho más caudalosos que los de la margen izquierda, que descienden de las sierras meridionales próximas al Sistema Central. Entre estos últimos, pueden mencionarse los ríos Escalote, Talegones, Caracena y Pedro (Jimeno, 1984, 16; Morales, 1995, 13).

\subsubsection{Vegetación}

La vegetación más característica de esta zona ha sido, hasta hace relativamente poco tiempo, el bosque de tipo mediterráneo, dominado por la encina (Quercus ilex). No obstante, este tipo de vegetación ha ido reduciéndose progresivamente, ocupando sólo en la actualidad ciertas áreas de páramo. La degradación del encinar, ha dado paso a especies como el pino o el roble, que forman las masas boscosas más importantes. La variedad de Pinus sylvestris se distribuye por la zona montañosa del $\mathrm{N}$, mientras que la variedad Pinus pinaster lo hace en las comarcas centrales del Duero en su margen detecha. Asimismo, el roble ocupa una parte importante de esta zona, en sus variedades de quejigo (Quercus lusitanica) y roble común (Querus sessiliflora). Por otro lado, alineados en las márgenes de los ríos, pueden encontrarse fresnos (Fraxinus excelsior), olmos (Ulmus campestris) y también chopos (Populus alba).

El monte bajo está ampliamente repartido por toda esta zona del Alto Duero y en él se encuentran especies como el brezo (Erica arborea), aliagas (Genista anglica), jaras (Cistus ladaniferus) o tomillo (Tbymus vulgaris) Jimeno, 1984, 16-17; Morales, 1995, 13-14).

\subsubsection{Datos paleoambientales}

En los apartados anteriores, la descripción del marco geogtáfico del Alto Duero se ha realizado, fundamentalmente, a partir de datos actuales. Sin embargo, la investigación llevada a cabo en este trabajo, tiene por objeto, como ya se ha mencionado en los capítulos precedentes, la caracterización de las producciones cerámicas numantinas, desarrolladas a lo largo del siglo I a. C. Por este motivo, y teniendo en cuenta los cambios medioambientales que, sin duda, han acaecido en la zona desde entonces, se ha considerado de interés consultar los resultados obtenidos en aquellos trabajos en los que se han realizado estudios paleoambientales dentro de 
dicha zona geográfica, con el propósito de conttastarlos con la situación actual, sirviendo, además, como base, para intentar una aproximación a las características medioambientales existentes en la época en la que fueron elaboradas estas cerámicas.

En cualquier caso, este propósito ha contado con algunos inconvenientes, debido a que, en general, no son muchos los trabajos en los que se han realizado este tipo de estudios en la zona del Alto Duero. Asimismo, aquellos que se han puesto en práctica, suelen ser poco reptesentativos para la etapa del siglo I a. $C$, ya que abarcan períodos cronológicos más amplios. Por lo demás, tampoco se podía contar con datos de estas características procedentes de los trabajos arqueológicos efectuados en los yacimientos de Numancia o Izana, puesto que estas excavaciones se habian llevado a cabo a principios de siglo, en una época en la que todavía no se habían desarrollado esta clase de metodologías.

Por todo ello, aparte de los trabajos realizados en el área del Alto Duero, también se han consultado otras publicaciones, que ofrecen este tipo de datos para zonas geográficas adyacentes, con el fin de contar con una imagen lo más representativa posible, a partir de los datos disponibles.

En el Alto Duero, sólo tres trabajos ofrecen datos paleoambientales. En todos ellos, se han obtenido a través de análisis palinológicos efectuados en columnas estratigráficas. Los datos procedentes de la excavación de La Cueva del Asno, situada en el término de Los Rábanos, a unos $5 \mathrm{~km}$ al S de Soria y ocupada, primero, durante la Edad del Bronce y, después, durante época romana y visigoda, ofrecen información medioambiental para el período Subboreal, en tomo al 2.000 a. C. Estos datos se corresponden con una etapa templada y húmeda, caracterizada por la existencia de una abundante vegetación, constituida principalmente por un bosque mixto de pino, abedul, aliso y tilo, junto a herbáceas como el junco o el cardo (Eiroa, 1979, 53-56). Igualmente, los datos procedentes de la excavación del asentamiento de Los Tolmos de Caracena, situado a unos $70 \mathrm{~km}$ al SE de Soria y ocupado durante el Bronce Medio y, más tarde, en época tardorromana, ofrecen una información similar para el mismo periodo, aunque, en este caso, abundan las hetbáceas sobre un bosque abierto de pino, encina y roble (2) (Jimeno, 1984, 335-338; Jimeno et al., 1993, 11-12). Por último, los datos procedentes de las excavaciones efectuadas en el asentamiento celtibérico de Castilmontán en Somaén, situado a unos $10 \mathrm{Km}$ al $O$ de la localidad de Medinaceli y ocupado entre los siglos III y I a. C., están más

(2) El pino y el roble han sido documentados, igualmentc, entrc las maderas carbonizadas utilizadas en las construcciones del yacimiento de Numancia (jimeno et al., 1993, 12). 
próximos al periodo cronológico en el que se manufactutaron las producciones numantinas. Estos datos revelan una vegetación muy similar a la actual, en la que el porcentaje arbóreo representado por pinos, encinas y sabinas, sobrepasa el $50 \%$ de la muestra (Atlegui, 1990, 54; 1992 a).

Los resultados, sin embargo, que más interés podrían ofrecer para esta investigación, proceden de uno de los yacimientos en los que se han tomado muestras de cerámica para realizar los distintos análisis. Este yacimiento es el de El Palomar, que se encuentra situado en el término de Aragoncillo (Guadalajara) y que fue ocupado en diferentes períodos de la Edad del Hierro, como se verá en uno de los apartados siguientes. Los resultados del análisis polínico realizado, reflejan aquí un clima algo más húmedo que el actual, con la presencia de impottantes masas boscosas (Arenas, 1991-92).

Finalmente, quizás los datos más importantes, como se apuntaba al principio de este apartado, sean los aportados por un ambicioso proyecto realizado recientemente en distintos yacimientos del valle medio del Dueto, en el que se ha intentado cubrit la evolución paleoambiental durante todo el Primer Milenio a. C. en esta zona, por medio de diferentes tipos de análisis (palinológicos, antracológicos, carpológicos, etc.). Los yacimientos muestreados se localizan todos en la provincia de Valladolid y han sido los siguientes: Soto de Medinilla, Montealegre, Cerro de la Mota de Medina del Campo, La Era Alta de Melgar de Abajo y Carralaceña en Pesquera de Duero (Mariscal, 1995; Ruiz Zapata, 1995; Yll, 1995; Uzquiano, 1995).

Los resultados alcanzados a través de este estudio, caracterizan un medio menos árido y seco que el actual, con un clima más riguroso y húmedo, en el que los niveles freáticos eran menos profundos. El nivel de aguas estaba, por ello, más alto, lo que permitía la existencia de más humedales y de mayores disponibilidades hídricas en superficie. Estos factores hacían que el Duero discurriese, al menos, entre 5 y 10 metros por encima del nivel actual (Calonge, 1995, 530-532; Escudero, 1994, 12). Por otro lado, la vegetación estaba formada, mayoritariamente, por bosques mixtos de encinas y quejigos de piso bioclimático meditertáneo, junto a pinares y olmedas que ocupaban zonas de vega. De esta forma, en lineas generales, el paisaje estaba constituido por cuatro medios distintos: 1) zonas boscosas frondosas, 2) humedales, junto a rios y arroyos, 3) zonas antropizadas, relacionadas con la agricultura y 4) zonas deforestadas (Mariscal et al., 1995, 424-427).

En definitiva, teniendo en cuenta los datos que se han comentado y admitiéndolos con las debidas reservas, a causa, por un lado, de la mayor o menor distancia a la zona de estudio y, 
por otro, de la diferencia de altitud de los yacimientos en los que se han obtenido, resulta razonable suponer que el clima de fines del Primer Milenio a. C. en la región del Alto Duero, podria haber sido más húmedo que el actual, lo cual posibilitaría la existencia de mayores masas boscosas y la presencia de importantes cursos de agua y humedales. En este sentido, la información que proporcionan las fuentes clásicas, ratificaría, igualmente, el predominio de un clima de estas características, ya que mencionan que la ciudad de Numancia estaba rodeada de bosques muy densos (APIANO, Iber., 76), con una laguna cenagosa que la circundaba en su mayor parte (APLANO, Iber., 89-90), así como que el curso del Duero era navegable por esta zona (APIANO, Iber., 91).

\subsection{PANORAMA ARQUEOLÓGICO DEL SIGLO I A. C. EN EL ALTO DUERO}

A diferencia de otras regiones de la Meseta, el conocimiento de las bases arqueológicas de la zona del Alto Duero es, en la actualidad, bastante extenso. Esto es así, gracias a los trabajos emprendidos a lo largo de los últimos años, con objeto de la revisión y actualización de la Carta Arqueológica de la provincia de Sotia, que en su día publicara Blas Taracena (Taracena, 1941). La Carta Arqueológica, entendida como el estudio globalizado de una comarca, proporciona datos de sumo interés, en primer lugar, sobre cada uno de los yacimientos existentes y, en segundo lugar, sobre las relaciones de éstos con su entomo, sin olvidar los aspectos sincrónicos y diacrónicos de las distintas etapas culturales. De esta forma, es posible obtener una imagen representativa de cada una de estas etapas por separado, así como la evolución y conexión entre ellas.

Los distintos trabajos publicados hasta el momento, pertenecientes a dicha Carta Arqueológica, cubren las comarcas del Campo de Gómara (Borobio, 1985), Tierra de Almazán (Revilla, 1985), Zona Centro (Pascual, 1991; 1992) y Altiplanicie Soriana (Morales, 1995). En todos ellos, se señala que durante los siglos II y I a. C. se produce un desarrollo del poblamiento celtibérico, que se traduce en un aumento del número de asentamientos, cuyo emplazamiento, 


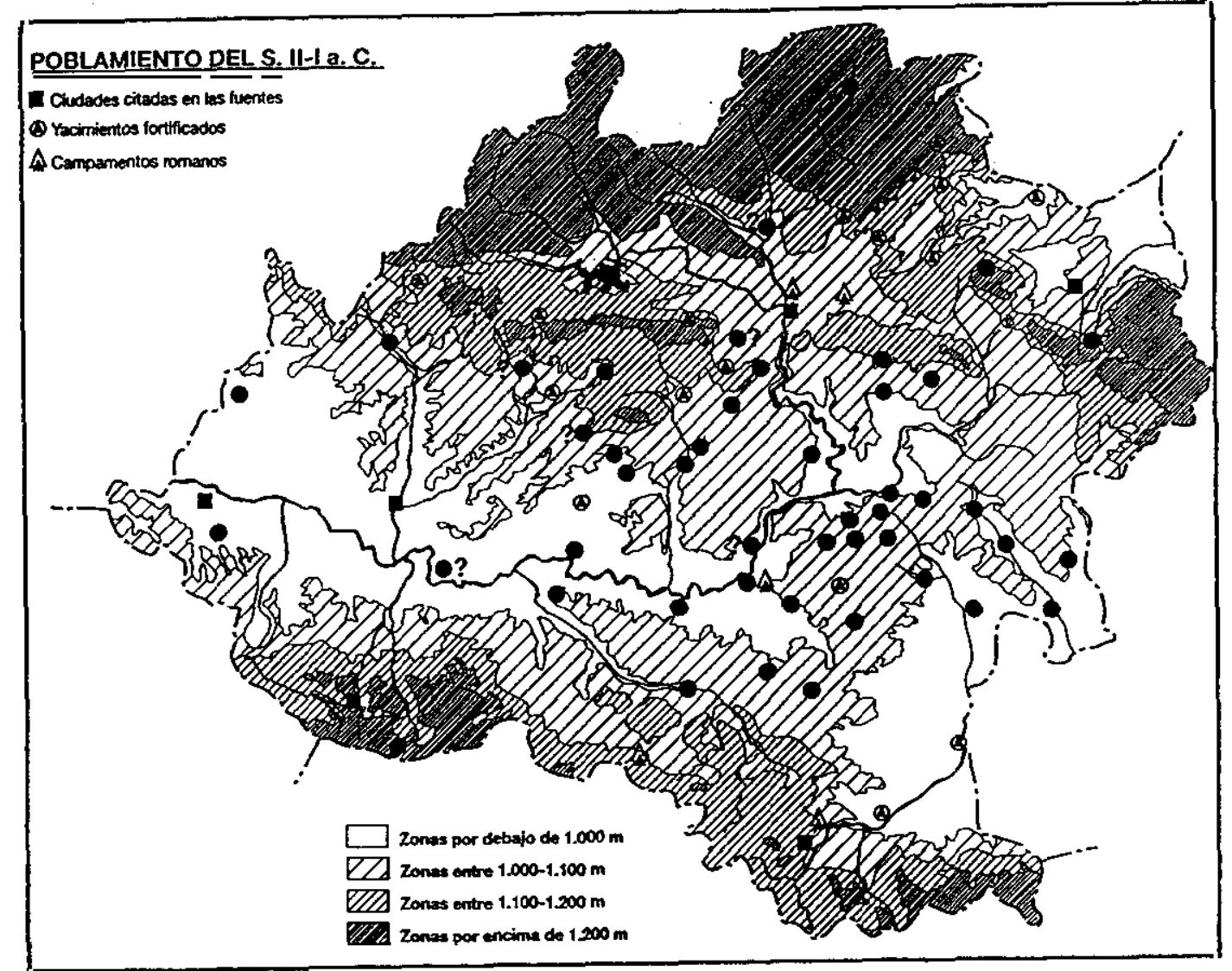

Figura 3.1: Asentamientos de los siglos II y I a. C. en la zona del Alto Duero (según Jimeno y Arlegui, 1995).

presenta diferencias con respecto a los asentamientos de cronología más antigua. Es el momento de una importante ocupación del territorio, que se pone en telación con el establecimiento de una nueva organización económica impuesta por Roma, en la cual prima el aprovechamiento agrícola del terreno. Por ello, los nuevos asentamientos se sitúan, mayoritariamente, en zonas bajas próximas a la vega de los ríos. La caída de Numancia en el 133 a. C., significa el comienzo de la romanización en esta zona, que empieza a ser efectiva, sobre todo, a lo largo del siglo I a. C.

La Figura 3.1, muestra un mapa de la provincia de Soria, con la ubicación de los yacimientos conocidos hasta el momento para los sigios II y I a. C. En esta Figura, el 73,3\% de los mismos son asentamientos de nueva planta, en relación a los siglos antetiores, en tanto que el 74,6 \% ocupan zonas de claro aprovechamiento agricola del terreno (Jimeno y Arlegui, 1995, 109). 
Dentro de la zona, se distinguen cuatro tipos de asentamientos en esta época, en lo que puede considerarse una organización jerárquica del territorio: ciudades, grandes aldeas ó poblados de mediano tamaño, pequeños asentamientos de carácter agricola y lugares defensivos óde vigilancia. Las ciudades se desarrollan en un momento tardío y sólo ligeramente anterior a la conquista romana. En este sentido, la fundación de la ciudad de Numancia, se sitúa a comienzos del siglo II o, como mucho, a finales del siglo III a. C. Generalmente, ocupan altozanos de lomo redondeado y escasa altura. Suelen estar rodeadas pot una línea de muralla y su interior presenta un ordenamiento en calles, sin la presencia de lugares abiertos o plazas. Ocupan superficies comprendidas entre las 10 y las 20 hectáreas. Las grandes aldeas se caracterizan, por el contrario, por presentar una menor superficie de ocupación (entre 3 y 6 hectáreas) aunque, a diferencia de los castros de siglos anteriores, cuentan con una destacada urbanización. Normalmente, se ubican en pequeñas elevaciones del terreno. No obstante, también se conocen ejemplos en cerros y lugares elevados, así como en zonas completamente llanas. Por otro lado, no todos presentan murallas. El yacimiento de Izana se situaría dentro de esta categoría de grandes aldeas. Dependientes de estos núcleos de población, se conocen toda una serie de pequeños asentamientos de menos de una hectárea de extensión, relacionados con explotaciones agrarias. Por último, los lugares defensivos, también conocidos en la bibliografia como castillos, se sitúan en cumbres y altozanos de fácil defensa natural, dominando gtandes extensiones de terteno y pasos natuales que debieton constituir vias de comunicación en esta época. Suelen tener una fuerte linea de muralla, con escasas edificaciones en su interior (Jimeno y Arlegui, 1995, 112).

Finalmente, la Figura 3.2 muestra el recorrido de las vías romanas, en relación a los asentamientos fortificados de las distintas categorias descritas en el párrafo anterior. La vía principal que atravesaba esta zona, era la que discurria entre Asturica y Caesaraugusta.

\subsection{SELECCIÓN DE LOS YACIMIENTOS ARQUEOLÓGICOS}

Como ya se comentó en el capítulo de introducción, se escogió el yacimiento de Numancia como punto de partida para iniciar la caracterización de las producciones cerámicas numantinas, al ser éste el ptincipal asentamiento en el que fueron definidas las características de estas producciones a principios de siglo. Por otro lado, la elección del yacimiento de Izana, vino condicionada, aparte de que ya se contaba con un conocimiento pormenorizado de su conjunto 
cerámico a través del trabajo realizado en la Memoria de Licenciatura, por ser un asentamiento que representaba una categoría distinta dentro de la zona del Alto Duero. De esta forma, el muestreo de la cerámica a analizar, contaría con cerámicas procedentes de una ciudad Äla propia Numanciä̈ y de un yacimiento categorizado como gran aldea o poblado de mediano tamaño, según se ha visto en el apartado anterior. Este aspecto, además, permitía cumplit con el tercero de los objetivos de la investigación (la comparación de los conjuntos cerámicos de Numancia e Izana) y comprobar si sólo se producian cerámicas en Numancia, si se producian también en centros secundarios o si, por el contrario, eran éstos los que abastecian a la ciudad.

Para la elección de los tres yacimientos restantes, es decir, aquellos que contaban con cerámicas de tipo numantino, pero no comprendidos en este territorio, se hacia necesario conocer, en primer lugar, qué yacimientos presentaban cerámicas de estas características, dónde

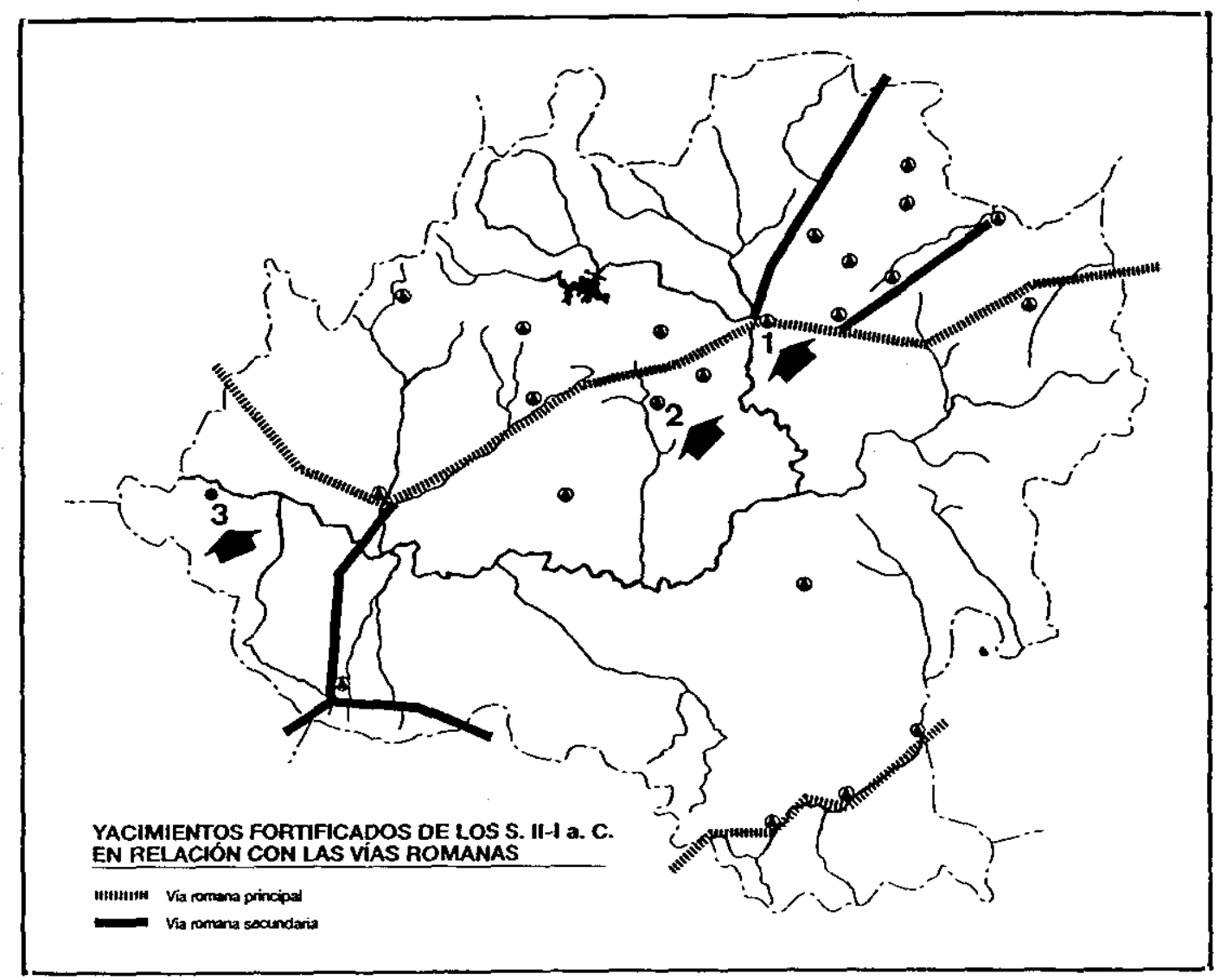

Figura 3.2: $\Lambda$ sentamicntos fortificados de los siglos lI y l a. C. en relación con las vias romanas (según Jimeno y Arlcgui, 1995). Las flechas y los números, indican los yacimientos cu los que se han tomado muestras para los distintos análisis. 1 Numancia (Garray). 2 Casulterreño (Izana). 3 Cuesta del Moro y I as Quintanas (Langa de Duero). A Asentamicnto 
se ubicaban, qué atribución cronológica tenían y qué posibilidades había para obtener muestras de los mismos. Por estos motivos, se iniçó un seguimiento bibliográfico de los diferentes yacimientos, que permitiera responder a todas estas cuestiones. Es importante resaltar que este seguimiento no ha pretendido ser exhaustivo, ya que el objetivo prioritario que se planteaba, era obtener muestras lo suficientemente representativas de estas producciones, dentro de los contextos arqueológicos que mejores condiciones ofrecieran para llevar a cabo esta labor, en detrimento de una localización pormenorizada de todos y cada uno de los fragmentos cerámicos de estas características, hallados en yacimientos de la Meseta y valle del Ebro.

Los resultados de este seguimiento se han cartografiado en la Figura 3.3, en un mapa que muestra aquellos yacimientos en los que han aparecido, tanto cerámicas con motivos decorativos conocidos como numantinos, como cerámicas polícromas. Se ha decidido también incluir estas últimas, por ser una de las producciones más genuinamente numantinas. No puede olvidarse que es, precisamente, en Numancia, en donde han aparecido en mayor número, dentro de contextos del siglo I a. C. No obstante, la presencia de cerámicas polícromas no implica, en todos los casos, que sus motivos decorativos sean similares. Su inclusión en este mapa, responde, básicamente, a criterios tecnológicos, ya que se entiende que su manufactura podría haber sido realizada a través de Secuencias de Producción semejantes.

En cualquier caso, la evidencia arqueológica para esta clase de producciones, es bastante desigual, como se va a tener oportunidad de ver a continuación. Comenzando con las cerámicas policromas, la mayoria de los yacimientos presentan un número escaso de fragmentos. Estos yacimientos, lejos de concentrarse en las proximidades de Numancia, se ubican, sobre todo, en el valle medio del Duero, mientras que en el valle del Ebro y Alto Jalón, sólo se documentan en dos de ellos. Según las distintas zonas, los yacimientos, expuestos con su cronologia y con las características de sus cerámicas polícromas, son los siguientes:

\section{Alto Duero}

1.- El Amortajado (Soria) (Figura 3.3, $\mathrm{n}^{\circ} 1$ ).

Cetámica: un fragmento con pigmentos negro y blanco.

Cronología: mediados del siglo I a. C.

Bibliografia: Barrio Ontubia et al., 1993; Morales, 1995, 251. 


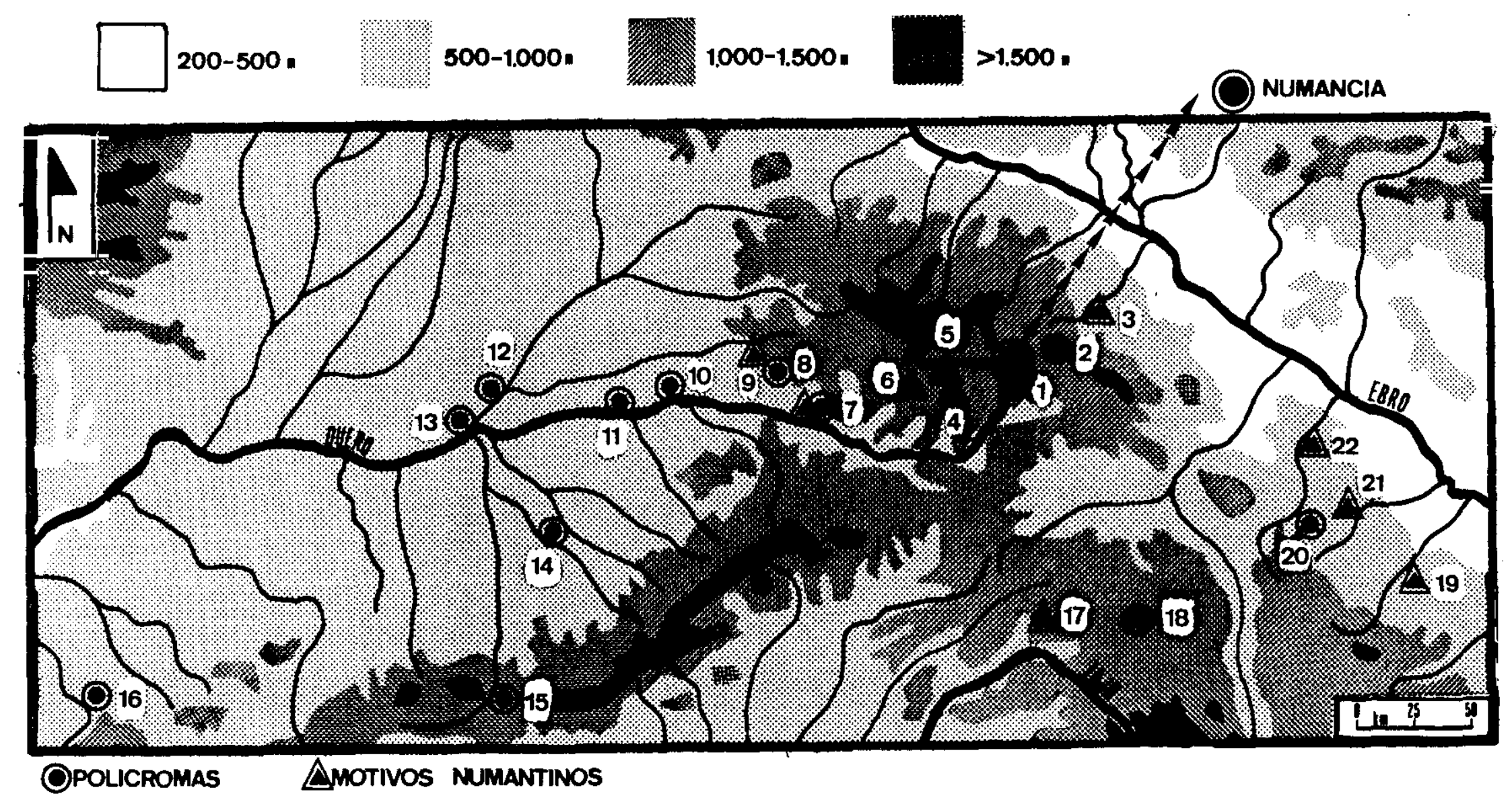

Figura 33: Yacimientos que presentan cerámicas policromas y cerámicas con motivos decorativos numantinos. 1 El Amortajado (Soria). 2 El Castillejo (Fuensaúco, Soria). 3 Contrebia Leucade (Agutlar del Río Alhama, Ia Rioja). 4 Castitemeño (Zzana, Soria). 5 El Castilo (Ocenilea, Soria). 6 Los Castejones (Calatañazor, Soria). 7 Las Quintanas y Cuesta del Moro (Langa de Duero, Soria). 8 Clunia (Peñalba de Castro, Burgos). 9 Necrópolis de El Pradillo (Pinilla Trasmonte, Burgos). 10 Rauda (Roa, Burgos). 11 Carralaceña (Pesquera de Duero, Valladolid). 12 Castro de Gorria (Valladolid). 13 Los Cenizales de Simancas (Valladiolid). 14 Coca (Segovia). 15 Ávila 16 Cudad Rodrigo (Salamanca). 17 El Palomar (Aragonollo, Guadahjara). 18 Necrópolis de La Yunta (Guadalajara). 19 El Castelillo (Alloza, Tenuel). 20 Los Castellares (Herrera de los Navarros, Zaragoza). 21 Piquete de la Atalaya (Azuara, Zaragoza). 22 Contrebia Belaisca (Botorita, Zaragoza). 
2.- El Castillejo (Fuensaúco, Soria) (Figura 3.3, $\mathrm{n}^{\circ}$ 2).

Cerámica: un fragmento con pigmentos negro y rojo, recogido en superficie.

Cronología: mediados siglo II a. C.

Bibliografia: Romero Carnicero, 1976, 187; 1991, 400-402.

3.- Las Quintanas y Cuesta del Moro (Langa de Duero, Soria) (Figura 3.3, $n^{\circ} 7$ ).

Cerámica: cinco fragmentos con pigmentos negro, blanco y rojo.

Cronología: siglo I a. C.

Bibliografia: Taracena, 1929, 38-40; 1932, 54; 1941, 89-90; Rometo Cannicero, 1976, 187.

\section{Duero medio}

1.- Clunia (Peñalba de Castro, Burgos) (Figura 3.3, $\mathrm{n}^{\circ} 8$ ).

Cerámica: dos fragmentos.

Características: expuestos en el Museo Provincial de Burgos y procedentes de las excavaciones de principios de siglo efectuadas por B. Taracena.

Cronología: desconocida.

Bibliografia: no se han encontrado referencias.

2.- Rauda (Roa, Burgos) (Figura 3.3, $\mathbf{n}^{\circ}$ 10).

Cetámica: seis fragmentos. Tres con pigmentos negro y rojo de contextos del siglo III a.

C. y tres con pigmentos negro y blanco de contextos de fines del siglo I a. C.

Cronología: siglo III a. C. y fines del siglo I a. C.

Bibliografia: Sacristán, 1986, 194 y 243.

3.- Carralaceña (Pesquera de Duero, Valladolid) (Figura 3.3, $\mathrm{n}^{\circ} 11$ ).

Cerámica: varios fragmentos con pigmentos negto y rojo.

Características: Proceden de un complejo alfarero en donde presentan una proporción muy reducida con respecto al conjunto total de cerámica.

Cronología: mediados siglo I a. C.

Bibliografia: Escudero y Sanz Mínguez, 1993, 487; Sanz Mínguez y Escudero, 1995, 297. 
4.- Castro de Gorrita (Valladolid) (Figura 3.3, $\mathrm{n}^{\circ} 12$ ).

Cerámica: un fragmento con pigmentos negro, blanco y rojo.

Cronología: mediados del siglo I a. C.

Bibliografia: Wattenberg, 1959, 210-211.

5.- Los Cenizales de Simancas (Valladolid) (Figura 3.3, $\mathrm{n}^{\circ} 13$ ).

Cerámica: trece fragmentos con pigmentos negro, blanco y rojo.

Cronologia: mediados del siglo I a. C.

Bibliografia: Wattenberg, 1959, 210-211; 1978.

\section{Otras zonas de la Meseta}

1.- Coca (Segovia) (Figura 3.3, $\mathrm{n}^{\circ} 14$ )

Cerámica: cuatro fragmentos con pigmentos negro, blanco y rojo.

Cronología: siglo I a. C.

Bibliografia: Wattenberg, 1959, 176; 1960, 173; Martín Valls, 1976, 383; Romero Carnicero, 1976, 187.

2.- Avila (Figura 3.3, $\mathrm{n}^{\circ}$ 15).

Cerámica: un vaso con pigmentos negro y rojo.

Cronologia: segunda mitad del siglo I a. C.

Bibliografia: Martín Valls, 1976, 383-384; Romero Carnicero, $1976,187$.

3.- Ciudad Rodrigo (Salamanca) (Figuta 3.3, $\mathrm{n}^{\circ} 16$ ).

Cerámica: dos vasos con pigmentos negto y rojo.

Cronología: segunda mitad del siglo I a. C.

Bibliografia: Martín Valls, 1976, 384; Romero Carnicero, 1976, 187. 


\section{Valle del Ebro}

1.- Los Castellares (Herrera de los Navarros, Zaragoza) (Figura 3.3, $\mathrm{n}^{\circ} 20$ ).

Cerámica: dos fragmentos con pigmentos negro y blanco.

Cronologia: Tránsito entre el siglo III y el siglo II a. C.

Bibliografia: Burillo, $1983 \mathrm{~b}$.

\section{Alto Jalón}

1.- Necrópolis de La Yunta (Guadalajara) (Figura 3.3, $\mathrm{n}^{\circ} 18$ ).

Cerámica: tres vasos con pigmentos negro y rojo.

Cronologia: sigio III a. C.

Bibliografia: García Huerta, 1988, 98.

Con respecto a los yacimientos que presentan cerámicas con motivos decorativos numantinos, la sttuación es bastante distinta. La mayotía de los mismos se concentra en las proximidades de Numancia, mientras que en las zonas adyacentes no son muy numerosos, exceptuando el valle del Ebro, que cuenta con cuatro yacimientos. En el valle medio del Dueto y Alto Jalón, sólo se documentan en dos lugares, uno en cada una de las zonas. Por otro lado, estas cerámicas no suelen aparecer en los mismos sitios que las polícromas. Únicamente, se conocen asociadas en Las Quintanas y Cuesta del Moro de Langa de Duero (Soria) (Figura $\left.3.3, \mathrm{n}^{\circ} 7\right)$.

La exposición de los materiales cerámicos con motivos numantinos hallados en estos yacimientos, resulta más problemática que para el caso de las cerámicas policromas, ya que en las publicaciones consultadas no siempre se hace una referencia completa a todas las cerámicas de estas características. Por este motivo, la relación de lugares no se expone en la forma en que se ha hecho para los materiales polícromos.

Comenzando por los yacimientos del Alto Duero, la presencia de motivos numantinos, en contextos del siglo I a. C., es general en los conjuntos cerámicos de Izana (Taracena, 1927, 3 21; 1941, 87-88; Pascual, 1991, 106-116; García Heras, 1993 a) (Figura 3.3, no 4), Los Castejones de Calatañazor (Taracena, 1926, 15-23; 1941, 46-47; Pascual, 1991, 32-54) (Figura 3.3, no 6), El Castillo de Ocenilla (Taracena, 1932, 37-52; 1941, 122-124) (Figura 3.3, $\mathrm{n}^{\circ}$ 5) y, en cierto modo, aunque no tan numerosos, en Las Quintanas y Cuesta del Moro de Langa de 
Duero (Taracena, 1929, 31-52; 1932, 52-61; 1941, 89-90) (Figura 3.3, $\mathrm{n}^{\circ}$ 7). Precisamente, como se apuntaba en el capítulo de introducción, fue en Numancia y en todos estos yacimientos, donde se definieron las producciones numantinas a principios de siglo.

Sin embargo, su presencia en otros yacimientos no es, ni mucho menos tan numerosa, exceptuando el conjunto de cerámicas hallado en la necrópolis de El Pradillo (Pinilla Trasmonte, Burgos) (Figura 3.3, $\mathrm{n}^{\circ}$ 9), en un sector fechado en el siglo I a. C. (Nuño, 1989; Moreda y Nuño, 1988; 1990). Así, en el valle del Ebro, en el asentamiento de E1 Piquete de la Atalaya (Azuara, Zaragoza) (Figura 3.3, $\mathrm{n}^{\circ} 21$ ), ocupado durante la primera mitad del siglo I a. C., se documenta un fragmento que, por su esquema decorativo, es adscrito por sus excavadores al repertorio de la cerámica numantina (Paz y Aguilera, 1984, 184). Asimismo, en El Castelillo de Alloza (Teruel) (Figua 3.3, n 19 ), yacimiento ocupado durante los siglos III y II a. C., se hallan cuatro piezas que, tanto por su tipología, como por sus motivos decorativos, se ponen también en relación con las producciones numantinas (Atrian, 1959, 259; 1966, 176; Romero Camicero, 1976, 164). Del mismo modo, cerámicas de estas características son conocidas en dos importantes ciudades de la época. Por un lado, en la ciudad de Contrebia Leucade, situada en la localidad de Aguilar del Rio Alhama (La Rioja) (Figura 3.3, n ${ }^{\circ}$ ) y, por otro, en Contrebia Belaisca, localizada en Botorrita (Zaragoza) (Figura 3.3, $\mathrm{n}^{\circ}$ 22). En la primera de ellas, los fragmentos dibujados con los números $125,128,133$ y 135 de la memoria de Hemández Vera (1982), podrian adscribirse perfectamente a producciones numantinas, así como algunas piezas de la segunda, presentadas en las publicaciones de Beltrán (1982) y Díaz Sanz (1987). En todo caso, un estudio más pormenorizado en la zona del valle del Ebro, sin duda proporcionaría un mayor número de yacimientos con materiales cerámicos presuntamente numantinos, ya que en esta zona, como señala Beltrán $(1987,31)$, se considera un rasgo celtibérico el empleo de pigmento negro en las decoraciones.

Por último, en la zona del Alto Jalón, el yacimiento de El Palomar, situado en Aragoncillo (Guadalajara) (Figura 3.3, $\mathrm{n}^{\circ} 17$ ) y con dos momentos de ocupación, en el que la etapa celtibérica se fecha en los siglos If y I a. C., también cuenta con varios fragmentos de cerámica con motivos numantinos (Arenas, Com. Pers.).

Los resultados de este seguimiento bibliográfico demostraban, pues, que aquellas cerámicas que eran definidas en las publicaciones como numantinas, siempre a partir de criterios de similitud formal y decorativa, no eran tan abundantes como podían hacer creer las constantes alusiones a las mismas en todo tipo de trabajos. Por ello, se decidió, solamente, seleccionar tres yacimientos: Langa de Duero (Soria), Pinilla Trasmonte (Burgos) y Aragoncillo (Guadalajara), 


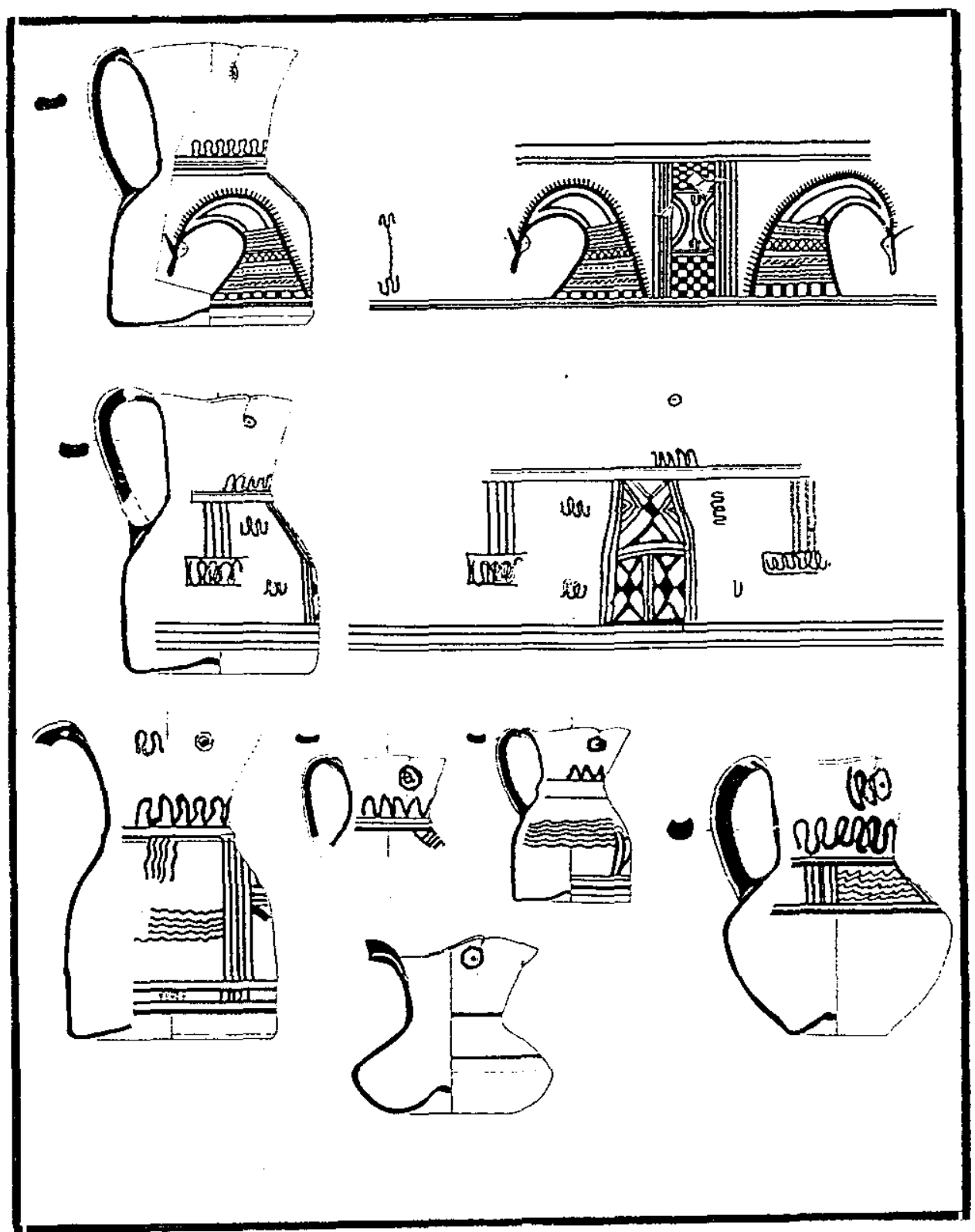

Figura 3.4: Cerámicas con motivos decorativos numantinos, procedentes de la nectópolis de El Pradillo, Pinilla Trasmonte, Burgos (scgún Moreda y Nuño, 1990). Sin escala en cl original.

con los que abordar el problema de la posible imitación local o, por el contrario, de la posible distribución de estas producciones, fuera de los límites del área de influencia de Numancia.

Estos tres yacimientos se han seleccionado por las razones siguientes. En el caso de Langa de Duero, para comparar sus cerámicas polícromas con las de Numancia. De este modo, se podrá establecer si ambas producciones comparten la misma tecnología y si tienen un origen 
común. De todas formas, la elección de este asentamiento, también ha estado condícionada por las pocas similitudes, tanto formales como estilísticas, que presentaban las cerámicas polícromas del resto de los yacimientos, con las aparecidas en la propia ciudad de Numancia. Este aspecto, pone de manifiesto las dificultades a las que debe enfrentarse el investigador, cuando sólo tiene acceso a los dibujos de los distintos materiales. Por otro lado, el yacimiento de Pinilla Trasmonte se eligió, aparte de por las facilidades dadas por sus excavadores para intervenir en el material, como consecuencia del extraordinario conjunto de jarras de boca trilobulada, decoradas en el más claro estilo numantino (Figura 3.4), que deparó uno de los sectores de la excavación de la necrópolis de El Pradillo. Finalmente, el asentamiento de Aragoncillo fue seleccionado por razones de índole metodológica, ya que en él se había iniciado con anterioridad la caracterización de sus producciones cerámicas (García Heras et al., En prensa a) y esto ayudaba, enormemente, a clarificar la procedencia de los fragmentos con motivos decorativos numantinos. Estos dos últimos yacimientos permitirian, por tanto, conocer si, efectivamente, aquellas cerámicas aparecidas en lugares no incluidos en el territotio de Numancia, podían ser consideradas como imitaciones locales.

En el apartado siguiente, se ofrece información adicional sobre cada uno de los cinco yacimientos seleccionados para la realización de esta investigación.

\subsection{Yacimientos}

La Figura 3.5 muestra la situación de los cinco yacimientos en los que se han tomado muestras para llevar a cabo los distintos análisis. En ella, se ba señalado la posible área de influencia teórica de la ciudad de Numancia, con círculos que representan distancias de 5 y 30 $\mathrm{km}$ respectivamente Dentro del átea de $30 \mathrm{~km}$, se halla el yacimiento de Izana. Este último círculo no se ha cerrado por el $\mathrm{N}$, debido a la existencia de otras dos ciudades que, con toda probabilidad, ya estuvieran ocupadas a fines del siglo I a. C. y que podrían distorsionar la apreciación del área de influencia de Numancia por esta parte. Estas dos ciudades se sitúan en Villar del Río y Muro de Ágreda (Morales, 1995, 305).

1.- NUMANCIA (Garray, Soria) (Figura 3.5, $\mathrm{n}^{\circ}$ 1). El yacimiento de Numancia se encuentra situado en la Muela de Garray, un cerro elevado unos 70 metros del entorno y próximo a la localidad de este mismo nombre, en la confluencia de los ríos Duero, Merdancho y Tera Oimeno 


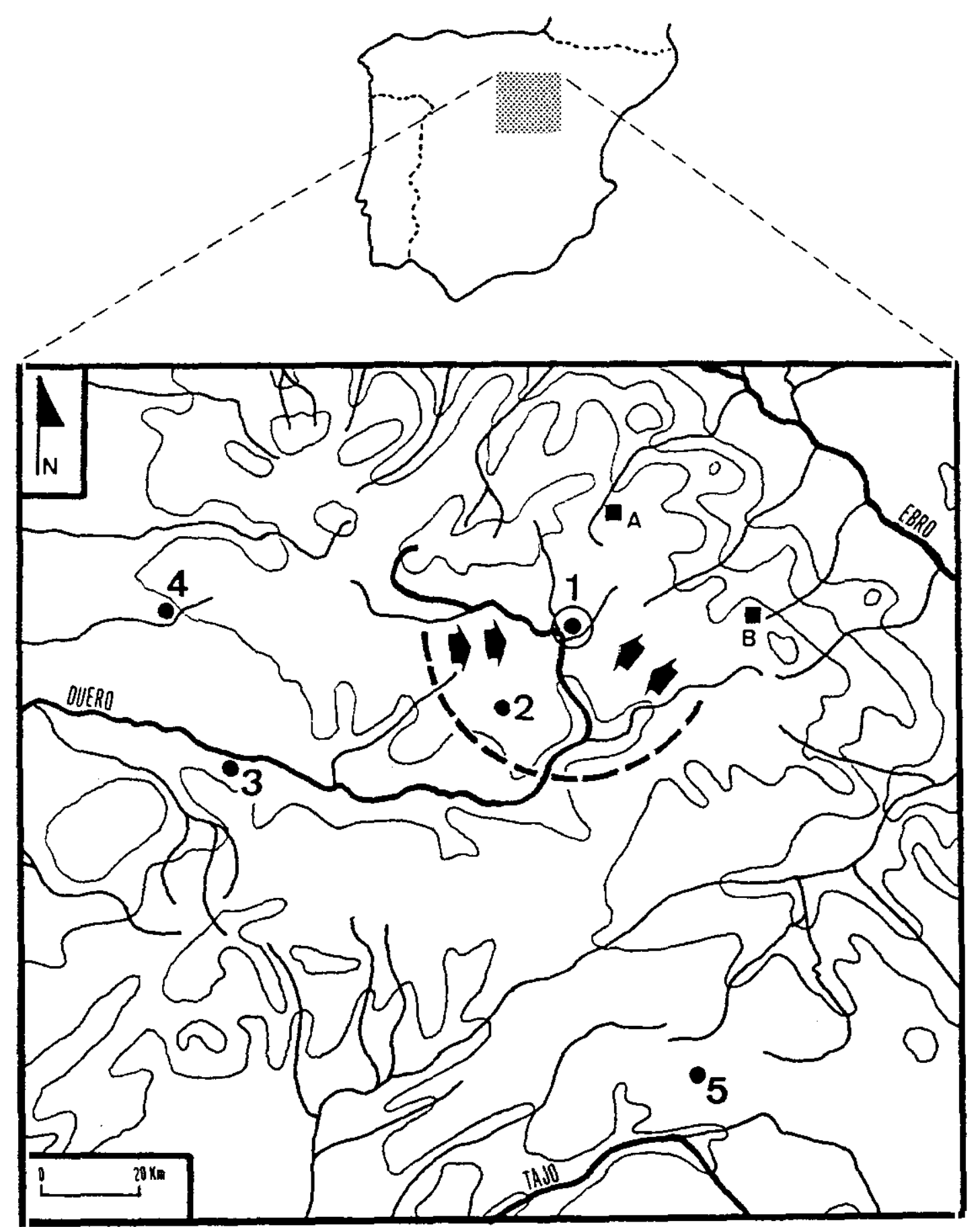

Figura 3.5: Situación de los yacimientos seleccionados para la realización de los análisis de caracterización. 1 Numancia (Garray, Soria). 2 Castilterreño (Izana, Soria). 3 Las Quintanas y Cuesta del Moro (langa de Ducro, Soria). 4 Necrópolis de El Praủillo (Pinilla Trasmonte, Burgos). 5 El Palomar (Aragoncillo, Guadalajara). A Villar del Róo (Soria). B Muro de Agreda (Soria). El circulo con línea contínua, indica el área teórica de influencia de Numancia situada a $5 \mathrm{Km}$. El semicirculo con linea discontínua y las flechas, indican estc mismo área de influencia a $30 \mathrm{Km}$. Este scmicirculo no se ha cerrado para indicar la posible distorsión de este área, motivada por la presencia de las ciudades A y $B$. 
et al., 1993, 11). La ubicación de la ciudad, todavia era conocida con exactitud en el siglo VII, aunque entre los siglos $\mathrm{X}$ al XV se sitúa en tierras de Zamora. No sexá, sin embargo, hasta mediados del siglo pasado, cuando E. Saavedra realice su identificación, mediante criterios científicos, en la Muela de Garray. Desde ese momento, los trabajos arqueológicos se suceden en el yacimiento. Las primeras campañas oficiales, se llevaron a cabo entre los años 1860 y 1866 y fueton patrocinadas por la Real Academia de la Historia, bajo la dirección del propio $\mathrm{E}$. Saavedra. Más tarde, será un equipo alemán, dirigido por A. Schulten, el que efectuará excavaciones en el año 1905. A partir de 1906 y hasta 1923, los trabajos van a estar a cargo de una Comisión Oficial de Excavaciones, dirigida, primero, por E. Saavedra y, después, por R. Mélida, en la que también jugará un papel destacado B. Taracena. Estos últimos trabajos, son los que ponen al descubierto casi la mitad de la ciudad (unas 6 hectáreas). Con posterioridad se emprenden otros trabajos, que ya no afectarán de manera importante a la superficie excavada, como los cortes estratigráficos practicados por Wattenberg en 1963 o las campañas de 1970 y 1971 de J. Zozaya, para documentar aspectos de la ocupación medieval (Jimeno, 1994 a, 29-31; Jimeno y Atlegui, 1995, 96; Jimeno y Tabernero, 1996; Romero Carnicero, 1991, 404). Finalmente, tras un largo periodo de inactividad y, por qué no decirlo, de abandono del yacimiento, A. Jimeno y F. Yusta redactan en 1990 un Plan Director, cuyo objetivo general es elaborar un programa encaminado a coordinar actuaciones sobre conservación, restauración, investigación y difusión, que hagan de Numancia un yacimiento "vivo", tanto para la investigación, como para el resto de la sociedad. Es en este marco, en el que se encuadra el trabajo desarrollado en esta Tesis Doctoral. Por otro lado, el descubrimiento en 1993 de la necrópolis celtibérica de esta ciudad, ha motivado, desde entonces, la realización de excavaciones arqueológicas en la misma que, sin duda, aportarán una visión renovada de Numancia en la investigación futura más inmediata (imeno y Morales, 1993; Jimeno, 1996).

La gran cantidad de trabajos arqueológicos llevados a cabo a lo latgo de los años por distintos equipos, hace que la información disponible en la actualidad sobre el yacimiento, esté, en gran medida, dispersa y desarticulada. Las estructuras urbanas y los materiales a ellas asociadas, se conocen de forma independiente. Además, no existen registros estratigráficos concisos que puedan restituir, al menos en parte, algunas de estas asociaciones. A estos inconvenientes, se une el problema de la superposición de varias ciudades, aunque, gracias a las recientes investigaciones, este hecho empieza a clarificarse. De esta forma, comienza a admitirse, en la actualidad, la existencia de tres ciudades. Una primera, fundada a fines del siglo III o principios del siglo II a. C., que será la que se destruya con el cerco de Escipión en el 133 a. C. 


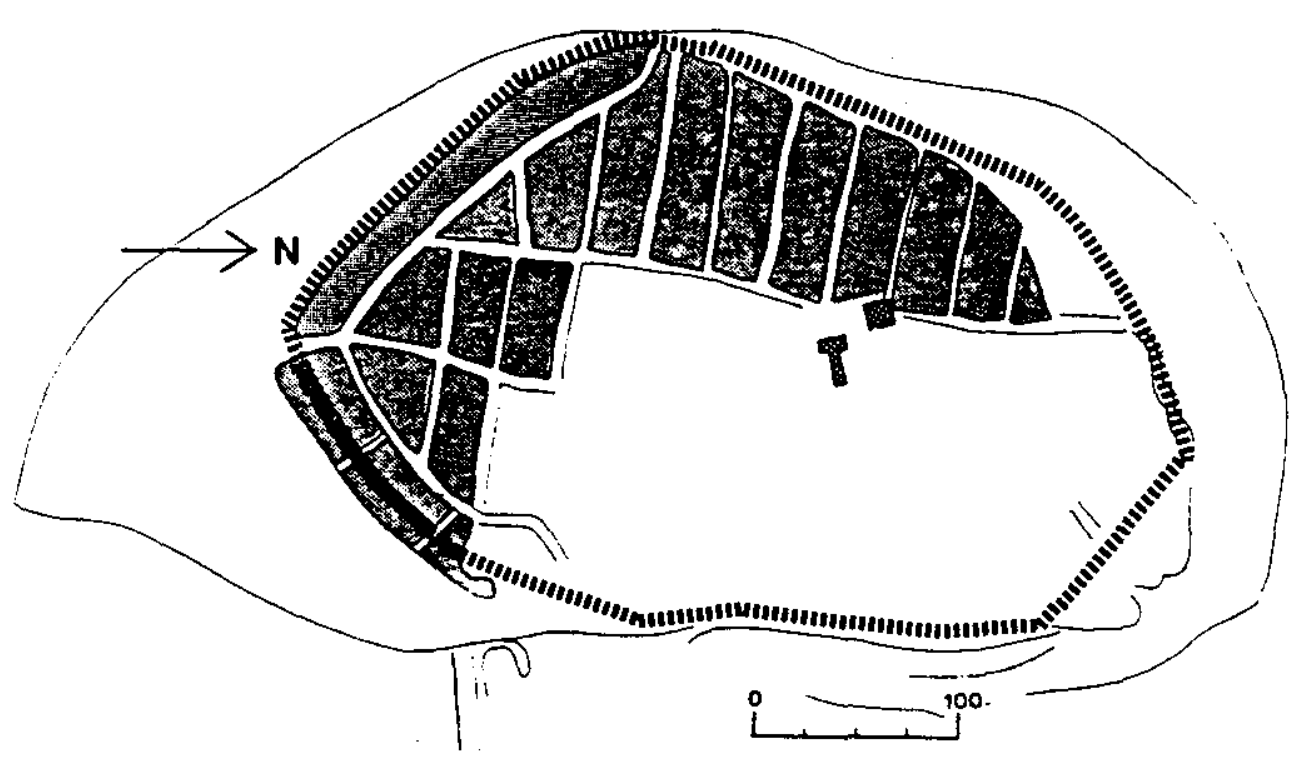

Figura 3.6: Limites de Numancia en el siglo I a. C. (según Jimeno y 'Tabernero, 1996).

Otra, de fundación posterior, con una cronologia que abarca desde fines del siglo II hasta fines del siglo I a. C., que se relaciona con las producciones cetámicas numantinas estudiadas en este trabajo y, por último, una tercera, de época imperial, cuyo desarrollo se establece a partir del cambio de era, que es la que puede observarse hoy si se visita el yacimiento (Jimeno, 1994 b, 123; Jimeno y Arlegui, 1995, 96).

$\mathrm{El}$ asentamiento imperial tiene una superficie total cercana a las 11 hectáreas. La zona excavada representa unas 6 hectáreas, en donde se delimitan 20 manzanas y algo más de 19 calles, en el interior de un recinto amurallado. La ciudad se estructura en retícula en torno a dos calles paralelas de dirección NO-SO, cruzadas por otras once de dirección E-O y sin espacio libre central. Dentro de estas manzanas es en donde se localizan las viviendas. Por otra parte, la extensión de la ciudad, cuya ocupación se desarrolla desde fines del siglo II $y$, fundamentalmente, a lo largo del siglo I a. C., no superaría las 9 hectáreas, según las últimas investigaciones (Jimeno y Tabernero, 1996, 431) (Figura 3.6). En esta última, las viviendas presentan planta rectangular y bodega.

En relación a las producciones cerámicas de este momento, los inconvenientes señalados, en general, para la contextualización de los materiales, deben hacerse extensivos para 
la cerámica. No obstante, no son los únicos, como se apuntaba en las limitaciones generales que tenía esta investigación en un capítulo anterior. También debe mencionarse la selección efectuada en los materiales recuperados, ya que sólo se recogían los mejor conservados o aquellos con unas caracteristicas estéticas excepcionales, como comenta Wattenberg (1963, 30), o su ordenamiento posterior en lotes, sin atender a criterios cronológicos o estratigxáficos (Arlegui, 1986, 1).

Por estos motivos, el conjunto cerámico de la ciudad del siglo I a. C conservado en la actualidad, está constituido por diferentes lotes de cerámica que, por otro lado, no constituyen, sin ningún género de dudas, el conjunto completo aportado por las excavaciones de la Comisión. Estos lotes se conforman a partir de algún rasgo estético o tecnológico concreto. Así, el conjunto cerámico del siglo I a. C. está formado por cerámicas grises; cerámicas monócromas de cocción oxidante, haciendo alusión al color del pigmento utilizado en su decoración; cerámicas polícromas de cocción oxidante, que se diferencian de las anteriores sólo por la utilización de dos o más pigmentos en dicha decoración; cerámicas lisas de cocción oxidante, es decir, piezas sin decorar o cuya decoración se ha perdido; cerámicas negras y cerámicas romanas, entre las que destaca, para esta época, la campaniense.

Los últimos trabajos realizados sobre estos materiales, se han basado, precisamente, en dichos lotes, alejándose de la visión de conjunto que mostraban el trabajo pionero de Taracena (1924) o el posteriot de Wattenberg (1963). Este hecho ha supuesto que se hayan estudiado, sin ninguna relación entre ellos, el lote de cerámicas polícromas (Romero Camicero, 1976; 1992), las cerámicas monócromas (Arlegui, 1986; 1992 b) o el lote de cerámicas romanas (Romero Carnicero, 1985).

Teniendo en cuenta que el estudio por lotes podía proporcionar sólo una visión parcial del conjunto cerámico de Numancia, en esta investigación se ha optado por manejar el conjunto completo de las producciones cerámicas del siglo I a. C., tanto de piezas completas como de fragmentos, de las excavaciones realizadas hasta 1923, exceptuando, por razones metodológicas (3), el lote de cerámicas campanienses que, obviamente, es de esta misma cronología. En cualquier caso, siendo su número bastante reducido (Taracena, 1924, 40), su exclusión dificilmente puede afectar, de manera importante, a los porcentajes finales que se ofrecen en el capitulo 5 .

(3) Como la cerámica campaniense se considera, en Numancia, un producto importado, su inclusión cn un trabajo que pretende caracterizar las producciones numantinas, sólo aportaria datos redundantes, a no ser que cl objetivo fucra conocer la procedencia concreta de este tipo de cerámica. 
Para comprender en todas sus dimensiones la ubicación cronológica que se acepta actualmente para las producciones cerámicas numantinas, es preciso contemplar cuál ha sido la visión de los diferentes investigadores que las han estudiado. Las excavaciones de Numancia estuvieron condicionadas, desde el primer momento, por la información de la ciudad que transmitian las fuentes clásicas. De esta forma, se asumió que los restos exhumados correspondían únicamente a dos ciudades. Una celtibérica, destruída por Escipión en el 133 a. C. y, otra romana, de época augústea, superpuesta a la anterior. Por este motivo, la primera sistematización crono-tipológica de la cerámica numantina realizada por Taracena, se adapta a este esquema, considerando que todas las producciones cerámicas celtibéricas debian ser, por tanto, anteriores a la fecha del 133 a. C. De este modo, Taracena fija su evolución cronotipológica en tres estilos: antiguo, geométrico y esquemático. El estilo antiguo, lo vincula a las cerámicas blancoamarillentas que presentan motivos pintados polícromos de carácter naturalista, situándolas a finales del siglo IV y principios del siglo III a. C. Por otro lado, el estilo geométrico, lo asocia a aquellas cerámicas rojas con motivos pintados bícromos de temas fantásticos, que fecha a lo largo del siglo III a. C. Por último, el estilo esquemático, cuyo desarrollo lo fija desde fines del siglo III al 133 a. C., lo hace coincidir con las cerámicas rojas que presentan motivos decorativos geométricos pintados exclusivamente en negro y correspondientes al último momento de los que se pensaba que era la Numancia indígena (Taracena, 1924, 72-78).

Sin embargo, el trabajo llevado a cabo por Wattenberg en los años 60 , basado en una revisión pormenorizada de las estratigrafias del yacimiento, va a proponer una nueva ordenación crono-tipológica de estas cerámicas, ya que para este investigador, las dos ciudades superpuestas asumidas por Taracena y por los trabajos de principios de siglo de la Comisión Oficial de Excavaciones, serian posteriores al 133 a. C., identificando, por tanto, una ciudad anterior y reivindicando la existencia de hasta tres momentos sucesivos de ocupación. Estos momentos de ocupación, los halla reflejados en el registro estratigráfico en tres niveles de incendio distintos que, a su vez, relaciona con otros tantos momentos históricos en los que Numancia se vio involucrada, según las fuentes clásicas, en conflictos bélicos. Entre ellos, el más potente lo relaciona con la destrucción del 133 a. C., mientras que el intermdio lo sitúa entre el 133 y el 75 a. C. y el tercero entre el 75 y el 29 a. C., haciéndolo coincidir con el inicio de las campañas contra cántabros y astures (Wattenberg, 1963, 20-22). Por ello, las cerámicas se ordenan en un esquema opuesto al planteado por Taracena, que se compone por una secuencia sucesiva de cinco momentos distintos: 
1) 320-220 a. C. Esta etapa se caracteriza por la presencia de cerámica a mano con decoración incisa.

2) 220-179 a. C. Etapa caracterizada por la introducción del torno en la manufactura de cerámicas.

3) 179-133 a. C. Es el momento en el que comienza la utilización del torno a gran escala y en el que se realizan las formas más típicas de la cerámica celtibérica.

4) 133-75 a. C. Es un perído caracterizado por la manufactura de cerámicas que imitan las formas de la campaniense A y B y que se decoran con motivos pintados simples.

5) 75-29 a. C. En esta etapa es cuando se generaliza la decoración pintada, apareciendo al final del proceso la policromía (Wattenberg, 1963, 33-36).

Es a partir de este trabajo cuando comienzan a admitirse unas fechas más recientes para la mayoria del conjunto cerámico numantino que, en líneas generales, se sitúan a lo largo del siglo I a. C., en conexión con el desarrollo de la ciudad que se funda después de la destruída en el 133 a. C. Así lo corroboran los trabajos posteriores emprendidos sobre algunos de los lotes a los que se aludía anteriormente, como el llevado a cabo por Atlegui (1986) para el lote de cerámicas monócromas, en el que la mayor parte de las mismas se fecha en este mismo siglo $I$ a. $C$., o el realizado por Romero Carnicero (1976) sobre las producciones polícromas en el que, a partir de las relaciones establecidas entre ciertos motivos iconógraficos de estas cerámicas, como la introducción de la figura humana, y los motivos que presentan algunas acuñaciones monetarias indigenas, se establece una cronología de fines del siglo I a. C. o, incluso, de inicios del Imperio. Es por ello por lo que las producciones polícromas se estiman, actualmente, más próximas al cambio de era que el resto de las producciones monócromas.

2.- CASTILTERREÑO (Izana, Soria) (Figura 3.5, $\mathrm{n}^{\mathbf{0}}$ 2). El yacimiento de Castilterreño está situado junto al pueblo de Izana, en un cerro amesetado sólo accesible por el lado $O$, que se eleva unos 70 metros de su entorno. En 1924 fue excavado por B. Taracena, cuyos trabajos se centraron en delimitar el perimetro de su muralla y en sacar a la luz una pequeña parte del 
poblado en su ángulo SE. En estos trabajos, Taracena señala la aparición de una torre, de una calle empedrada y de viviendas rectangulares también con bodega. La superficie total que ocupa, se estima en unos $22.000 \mathrm{~m}^{2}$. El conjunto cerámico que deparaton estas excavaciones es muy similar al hallado en Numancia, aunque aquí no aparecen cetámicas polícromas. Para Wattenberg $(1963,27-30)$, este conjunto se correspondería con las cerámicas pertenecientes a la última etapa del esquema crono-tipológico elaborado para la cerámica de Numancia, es decir, aquella que fechaba entre los años 75 y 29 a. C. Por otro lado, la cronologia que fija Taracena para el abandono de este yacimiento, se corresponde con la primera mitad del siglo I a. C. Este investigador piensa que el poblado de Castiltetreño podía haber sido un gran centro productor de cerámica, debido a los abundantes fallos de alfat que aparecieton durante la excavación. No obstante, ni en la memoria publicada ni en sucesivas visitas al mismo, se han podido constatar evidencias relacionadas con la producción de cerámica (Taracena, 1927, 3-21; 1941, 87-88; García Heras, 1993 a; 1993 b; 1994 b; 1994 c; 1995).

\section{3.- LAS QUINTANAS y CUESTA DEL MORO (Langa de Duero, Soria) (Figura 3.5, $\mathrm{n}^{\circ}$} 3). Son dos yacimientos muxy próximos entre sí, situados a unos $2 \mathrm{~km}$ de la localidad de Langa de Duero. Las campañas de excavación efectuadas también por $\mathrm{B}$. Taracena a finales de los años 20 , confirmaron que se trataba de distintas partes de un mismo yacimiento, que se correspondía con una ciudad abierta, sin muralla, en la que habia espacios sin edificar y, cuya fecha de ocupación, se establecía a fines del siglo I a. C. Esta ciudad, como los yacimientos anteriores, también contaba con viviendas de planta rectangular y bodega. Por lo demás, su conjunto cerámico era, en líneas generales, bastante similar al de Numancia o Izana, aunque las cerámicas polícromas eran mucho menos abundantes (Taracena, 1929; 1932; 1941, 89-90).

4.- Necrópolis de EL PRADILLO (Pinilla Trasmonte, Burgos) (Figura 3.5, $\mathrm{n}^{\circ}$ 4). La necrópolis de EI Pradillo se localiza en una terraza fluvial del río Esgueva, situada $1 \mathrm{~km}$ al $O$ del castro del Alto de San Pedro, que se encuentra ubicado en el término de Pinilla Trasmonte. Este asentamiento ocupa un espigón con una superficie superior a las 17 hectáreas y estuvo habitado desde la Primera Edad del Hietro hasta el siglo I a. C. La realización de varias campañas de excavación en la necrópolis, han puesto de manifiesto la existencia de diferentes sectores en la misma, compuestos por distintos tipos de tumbas y ajuares, que se han interpretado como pertenecientes a dos etapas cronológicas diferenciadas. Una relacionada con enterramientos de la Primera Edad del Hierro, cuyos ajuares se componen, mayoritariamente, de recipientes 
cerámicos hechos a mano, y otra celtibérica, en la que los ajuares están compuestos, casi exclusivamente, por cerámica elabotada a torno. Esta cerámica es, en concreto, la que presenta motivos decorativos y formas típicamente numantinas, como los que se muestran en la Figura 3.4. Por el contratio, se trata de una necrópolis en la cual son escasos los elementos metálicos en general y, en particular, las armas. Tan sólo se han recuperado algunas pinzas de depilar de bronce y varias navajas de afeitar con hoja de hierro (Nuño, 1989; Moreda y Nuño, 1988; 1990; Sacristán y Ruiz Vélez, 1985).

5.- EL PALOMAR (Aragoncillo, Guadalajara) (Figura 3.5, $\mathrm{n}^{\circ}$ 5). El yacimiento de El Palomar se encuentra ubicado en la localidad de Aragoncillo, dentro de las denominadas Parameras de Molina, unidad perteneciente a la rama castellana del Sistema Ibérico. Este área queda comprendida en la cuenca hidrográfica del Tajo, en el tramo alto del río Arandilla. El yacimiento se enmarca en una red regional de asentamientos, de diferente extensión, fortificados en altura, que está siendo estudiada en la actualidad por J. Arenas en lo que constituitá su Tesis Doctoral. Varias campañas de excavación, dirigidas por este investigador, han constatado, en su recinto interno, la existencia de viviendas de planta rectangular construídas con zócalos de piedra y muros de adobe. El yacimiento se ha fechado en el siglo II a. C., aunque se ha detectado una ocupación anterior perteneciente a la Primera Edad del Hierro, en niveles estratigráficos desplazados (Arenas, 1990). El conjunto cerámico que ha ofrecido este asentamiento, está constituido, principalmente, por cerámicas oxidantes decoradas con pigmentos negtos, así como por cerámicas grises y negras, todas ellas con distintas tipologias. Los fragmentos que presentan motivos decorativos numantinos, se asocian con las especies oxidantes. Los resultados aportados por un reciente estudio de caracterización llevado a cabo mediante técnicas petrográficas, Difracción de rayos $\mathrm{x}$ (XRD), Microscopía electrónica de barrido (SEM) y Fluorescencia de rayos $\mathrm{x}$ por reflexión total (TXRF), sobre una muestra de 24 fragmentos cerámicos, indican que la mayoria de estas cerámicas podrían haberse producido dentro de la zona geográfica que ocupa el yacimiento (García Heras et al., En prensa a). 
. 


\section{SELECCIÓN DE MUESTRAS Y TÉCNICAS DE ANÁLISIS}

Esta investigación se ha realizado a partir de un muestreo aleatorio de 121 fragmentos de cerámica, así como de 9 muestras de sedimentos arcillosos. Las cerámicas pertenecientes a los yacimientos de Numancia e Izana, se seleccionaton después de haber llevado a cabo un análisis macroscópico en la totalidad de sus conjuntos cerámicos, que permitió su clasificación en fábricas o tipos de manufactura. En el caso de Izana, como se indicaba en los capítulos anteriores, este trabajo ya había sido realizado en la Memoria de Licenciatura. Aunque los resultados de este análisis macroscópico se van a ofrecer en el capítulo siguiente, por razones de organización en la exposición de los resultados, en este capítulo se hará referencia a las fábricas en las que quedó clasificado el material, con el fin de mostrar cómo se distribuyen los fragmentos analizados en función de las mismas.

Las muestras pertenecientes a los yacimientos de Numancia, Izana y Langa de Duero, que se hallaban depositadas en los fondos del Museo Numantino de Soria, se han obtenido a partir de la concesión de un permiso del Ministerio de Cultura, previa redacción de un informe técnico solicitado por la Dirección General de Bellas Artes y Conservación y Restauración de Bienes Culturales (referencia resolución DEPO. 46/95).

\subsection{CERÁMICAS}

La Tabla 1, que se ofrece en un apartado situado al final de este trabajo, recoge las características más importantes de las muestras seleccionadas para realizar los distintos análisis. Por otra parte, en las Figuras 4.1, 4.2, 4.3 y 4.4, se ofrecen los dibujos de algunas de las piezas 
Figura 4.1: (Página siguiente). Dibujos de algunas de las muestras procedentes de Numancia, reproducidos a partir del trabajo de Wattenberg (1963). El priner número indica el número de inventario del Musco Numantino de Soria, mientras que el número precedido de $W$ indica el de la pieza en dicho trabajo.

N-11.- 1.071 W487. Diámetro boca: $160 \mathrm{~mm}$. Diảmetro base: $140 \mathrm{~mm}$. Altura: $35 \mathrm{~mm}$.

N-12.- 1.101 W244. Diámetro boca: $220 \mathrm{~mm}$. Altura conservada: $240 \mathrm{~mm}$.

N-13.- 1.123 W/313. Anchura: $80 \mathrm{~mm}$. Altura: $40 \mathrm{~mm}$.

N-14.- 1.282 W241. Diámetro boca: $160 \mathrm{~mm}$. Diámetro base: $90 \mathrm{~mm}$. Alnura: $155 \mathrm{~mm}$. N-15.- $1.456 \mathrm{~W} 113$. Diámetro boca: $220 \mathrm{~mm}$. Diámetro base: $125 \mathrm{~mm}$. Altura: $255 \mathrm{~mm}$. N-17.- 11.708 W667. Diámetro boca: $310 \mathrm{~mm}$. Diámetro base: $130 \mathrm{~mm}$. Alrura: $160 \mathrm{~mm}$. N-18- 11.886 W261. Diámetro boca: $220 \mathrm{~mm}$. Diämetro base: $145 \mathrm{~mm}$. Altura: $270 \mathrm{~mm}$. N-21.- 13.805 W179. Diámetro boca: $170 \mathrm{~mm}$. Diámetro base: $120 \mathrm{~mm}$. Altura: $190 \mathrm{~mm}$. N-24.- 1.695 W924. Diámetro boca: $175 \mathrm{~mm}$. Diámetro base: $88 \mathrm{~mm}$. Altura: $53 \mathrm{~mm}$. N-30.- 11.771 W752. Diámetro boca: $260 \mathrm{~mm}$. Diámetro base: $140 \mathrm{~mm}$. Alrura: $176 \mathrm{~mm}$. N-31.- 11.787 W756. Diámetro boca: $168 \mathrm{~mm}$. Dímetro base: $90 \mathrm{~mm}$. Altura: $95 \mathrm{~mm}$. N-33.- 1.479 W958. Diämetro boca: $95 \mathrm{~mm}$. Diämetro base: $45 \mathrm{~mm}$. Altura: $55 \mathrm{~mm}$. N-34.- 1.377 W517. Diámetro boca: $88 \mathrm{~mm}$. Diămetro base: $50 \mathrm{~mm}$. Altura: $50 \mathrm{~mm}$. N-35.- 1.477 W472. Diámetro boca: $156 \mathrm{~mm}$. Diámetro base:48 $\mathrm{mm}$. Altura: $60 \mathrm{~mm}$. N-36.- 1.483 W1.009. Diámetro boca: $72 \mathrm{~mm}$. Diámetro base: $92 \mathrm{~mm}$. Altura: $116 \mathrm{~mm}$. N-37.- 1.536 W1.085. Diámetro boca: $100 \mathrm{~mm}$. Diämetro base: $72 \mathrm{~mm}$. Altura: $190 \mathrm{~mm}$. N-38.- 1.538 W1.091. Diámetro boca: $108 \mathrm{~mm}$. Diảmetro base: $85 \mathrm{~mm}$. Altura: $190 \mathrm{~mm}$. N-39.- 1.737 W825. Diámetro base: $155 \mathrm{~mm}$. Altura: $75 \mathrm{~mm}$.

N-46.- 3.385 W891. Diámetro boca: $154 \mathrm{~mm}$. Diämetro base: $82 \mathrm{~mm}$. Altura: $106 \mathrm{~mm}$. N-49.- 8.222 W417. Diámetro boca: $110 \mathrm{~mm}$. Altura conservada: $240 \mathrm{~mm}$.

N-57.- 1.111 W125. Anchura: $50 \mathrm{~mm}$. Altura: $55 \mathrm{~mm}$.

N-61.- 1.376 W515. Diámetro boca: $84 \mathrm{~mm}$. Diámetro base: $45 \mathrm{~mm}$. Altura: $50 \mathrm{~mm}$. 

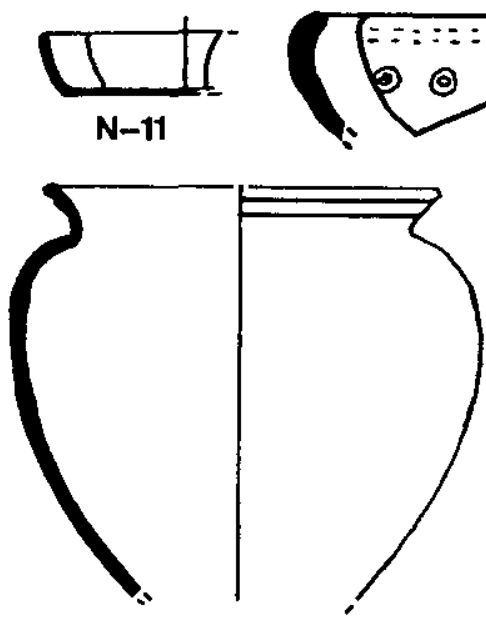

$\mathrm{N}-12$
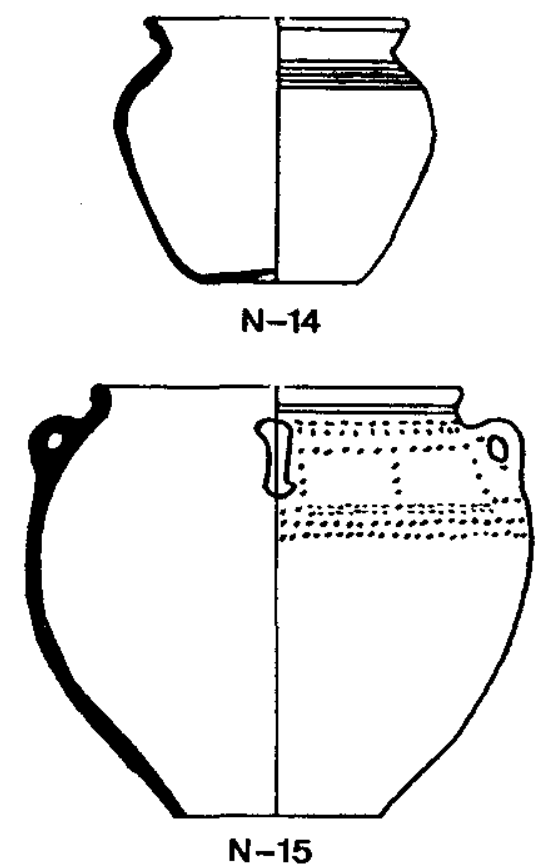

$\mathrm{N}-15$
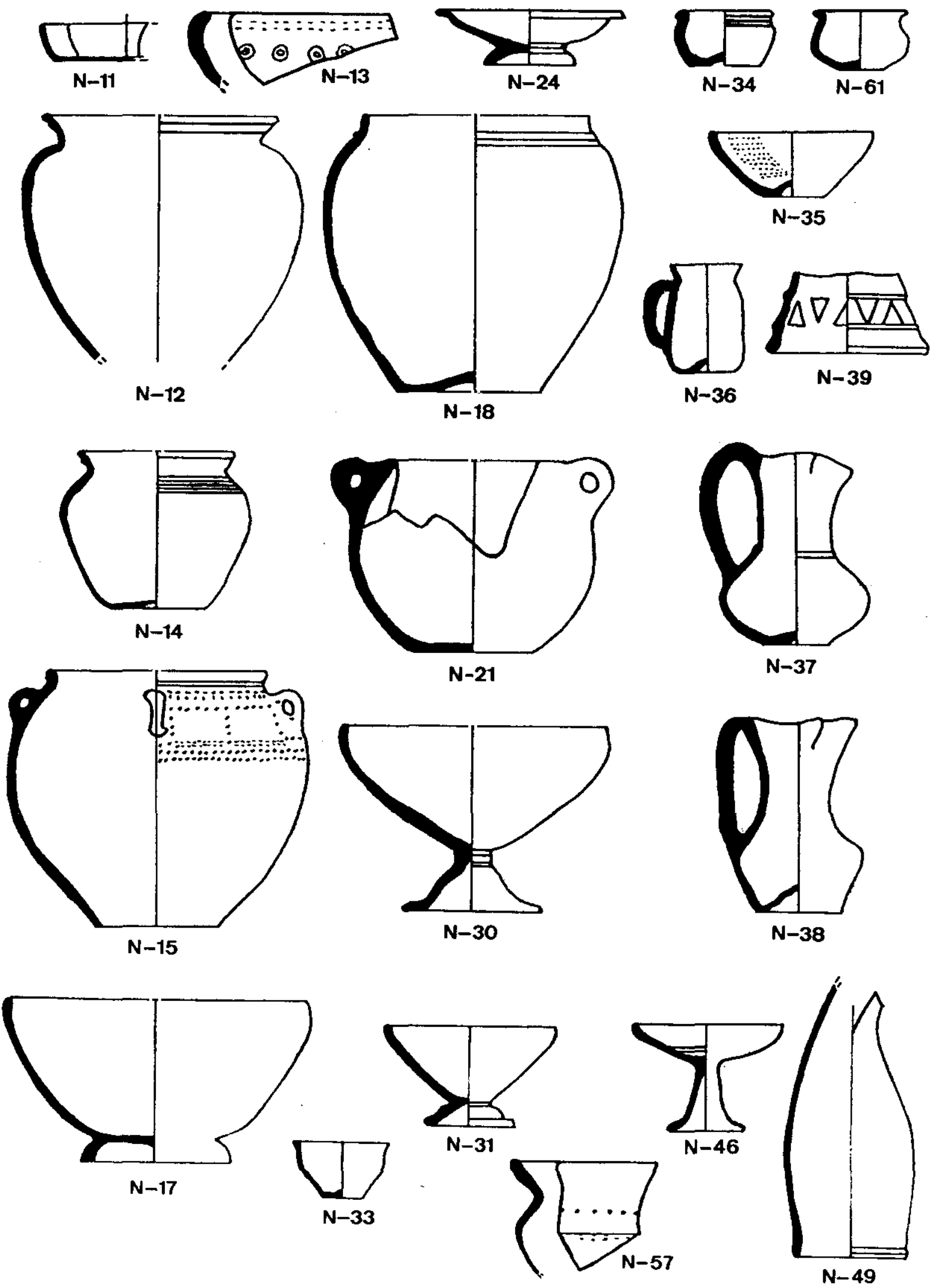


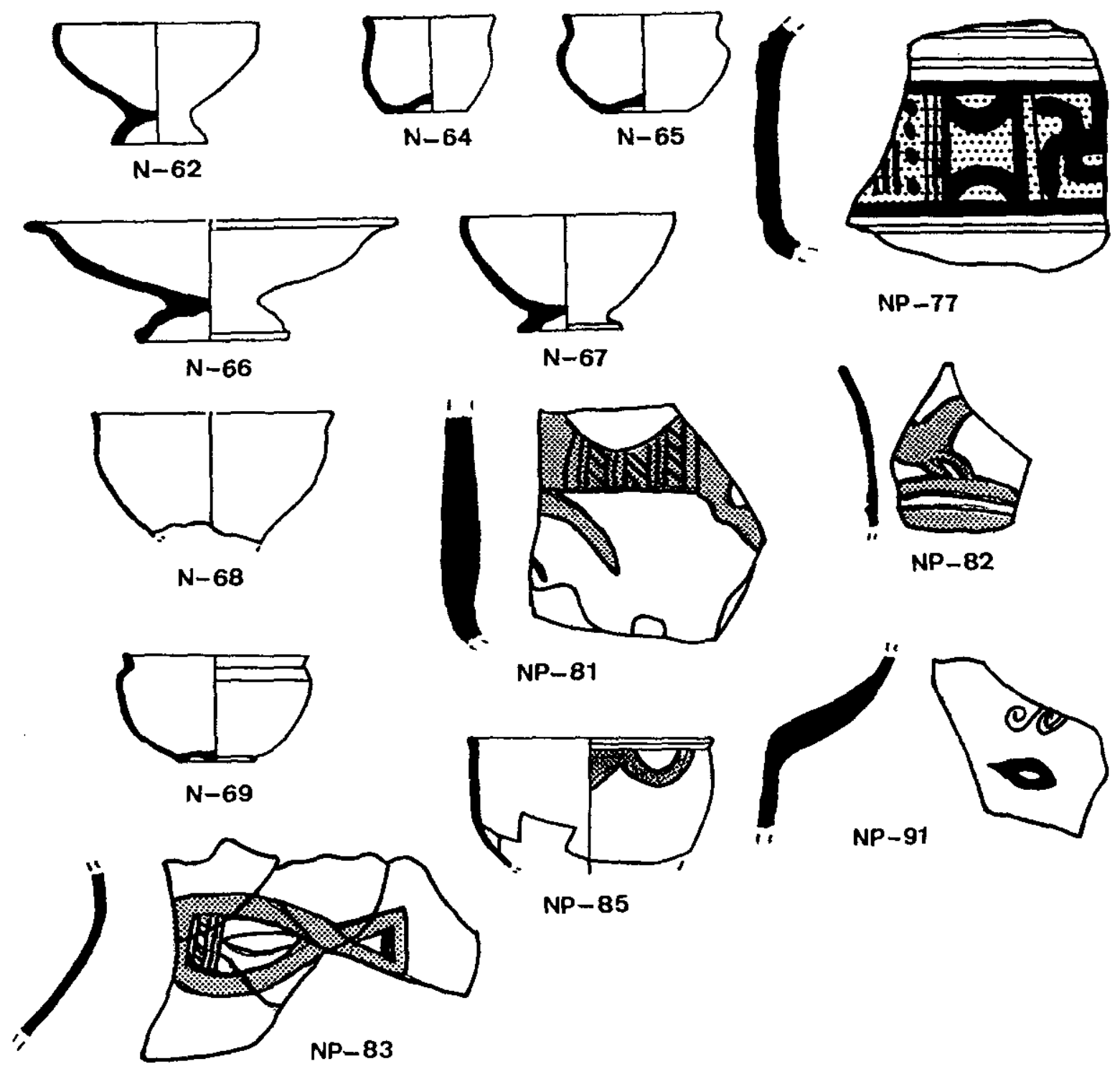


Figura 4.2: (Página antcrior). Dibujos de algunas de las muestras procedentes de Numancia, reproducidos a partir de los trabajos de Wattenberg (1963) y Romero Cannicero (1976). El primer número indica el número de inventario del Museo Numantino de Soria, el número precedido de W indica el de la pieza en el trabajo de Wattenberg y el número precedido de $\mathrm{R}$ el de la pieza en el trabajo de Romero Carnicero. El punteado indica pigmento blanco, mientras que el punteado más denso indica pigmento rojo.

N-62.- 1.326 W758. Diámetro boca: $165 \mathrm{~mm}$. Diámetro base: $74 \mathrm{~mm}$. Altura: $95 \mathrm{~mm}$. N-64.- 1.368 W561. Diámetro boca: $108 \mathrm{~mm}$. Diámetro base: $70 \mathrm{~mm}$. Altura: $73 \mathrm{~mm}$. N-65.- 1.374 W557. Diámetro boca: $135 \mathrm{~mm}$. Diámetro base: $60 \mathrm{~mm}$. Altura: $75 \mathrm{~mm}$. N-66.- 1.461 W918. Diámetro boca: $144 \mathrm{~mm}$. Diámetro base: $60 \mathrm{~mm}$. Altura: $46 \mathrm{~mm}$. N-67.- 1.547 W727. Diámetro boca: $178 \mathrm{~mm}$. Diảmetro base: $85 \mathrm{~mm}$. Altura: $96 \mathrm{~mm}$ N-68.- 1.724 W956. Diámetro boca: $196 \mathrm{~mm}$. Altura conservada: $100 \mathrm{~mm}$.

N-69.- 11.716 W204. Diámetro boca: $145 \mathrm{~mm}$. Altura: $83 \mathrm{~mm}$.

NP-77.- 12.698 W1.226 R246. Anchura: $65 \mathrm{~mm}$. Altura: $62 \mathrm{~mm}$.

NP-81,- 2.115 W1.137 R5. Anchura: $47 \mathrm{~mm}$. Altura: $49 \mathrm{~mm}$.

NP-82.- 2.124 R4. Anchura: $61 \mathrm{~mm}$. Altura: $62 \mathrm{~mm}$.

NP-83.- 2.239 W1.275 R37. Anchura: $142 \mathrm{~mm}$. Altura: $94 \mathrm{~mm}$.

NP-85.- 3.084 W944 R90. Dtámetro boca: $205 \mathrm{~mm}$. Altura conservada: $130 \mathrm{~mm}$.

NP-91.- 3.071 R77. Anchura: $60 \mathrm{~mm}$. Altura: $50 \mathrm{~mm}$. 
Figura 4.3: (†ágina siguiente). Dibujos de algunas de las muestras procedentes de Numancia, reproducidos a partir del trabajo de $A r l$ egui (1986). El primer número indica el número de inventario del Museo Numantino de Soria, mientras que el número precedido de $A$ indica el de la pieza en dicho trabajo.

N-29.- 8.903 A132. Diámetro boca: $130 \mathrm{~mm}$. Diámetro base: $81 \mathrm{~mm}$. Altura: $110 \mathrm{~mm}$.

N-40.- 2.777 A327. Diámetro boca: $150 \mathrm{~mm}$. Altura: $210 \mathrm{~mm}$.

N-42.- 2.805 A206. Diämetro boca: $90 \mathrm{~mm}$. Altura conservada: $110 \mathrm{~mm}$.

N-47. 3.616 A218. Diảmetro base: $70 \mathrm{~mm}$. Altura conservada: $200 \mathrm{~mm}$. 


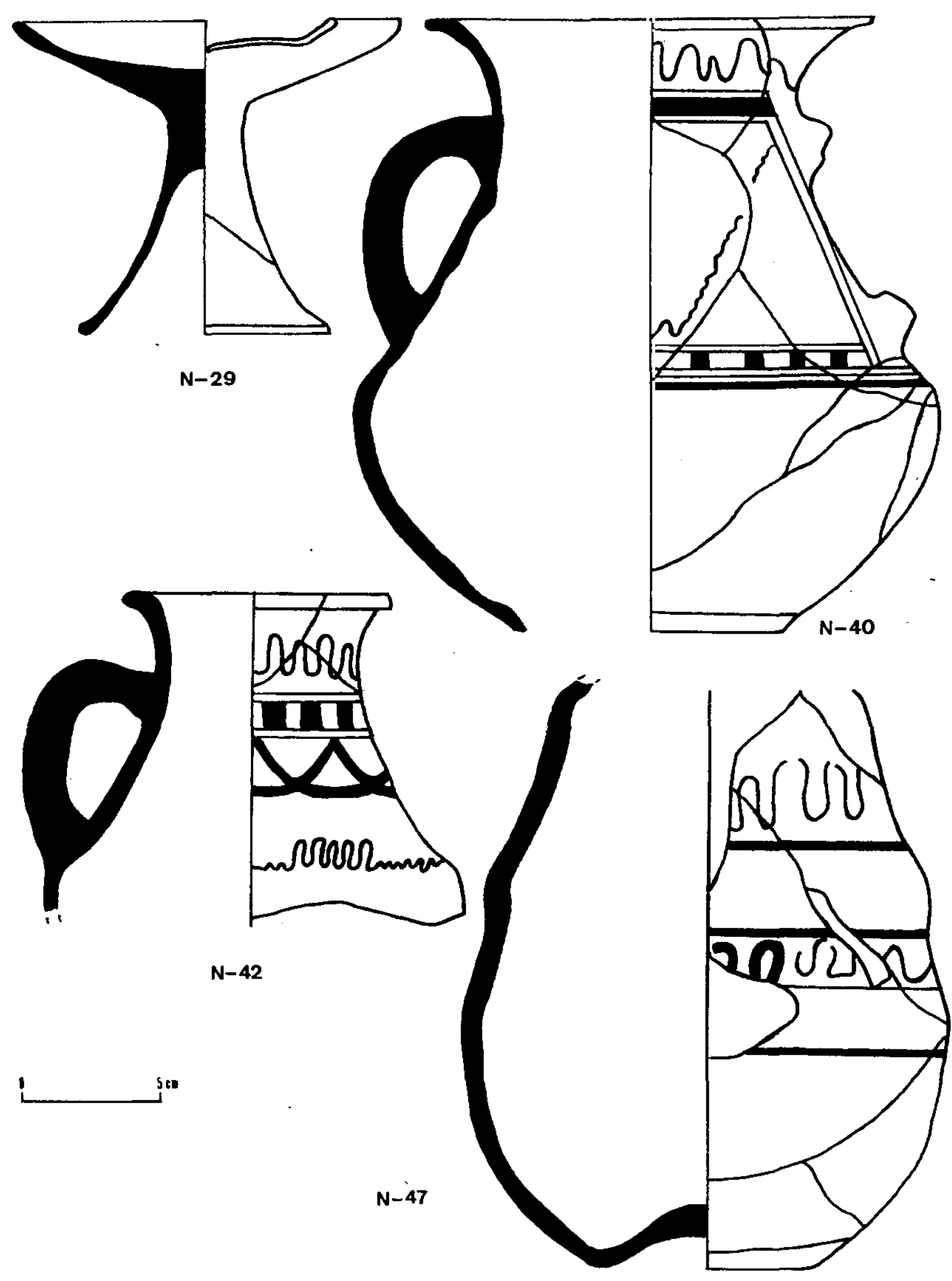



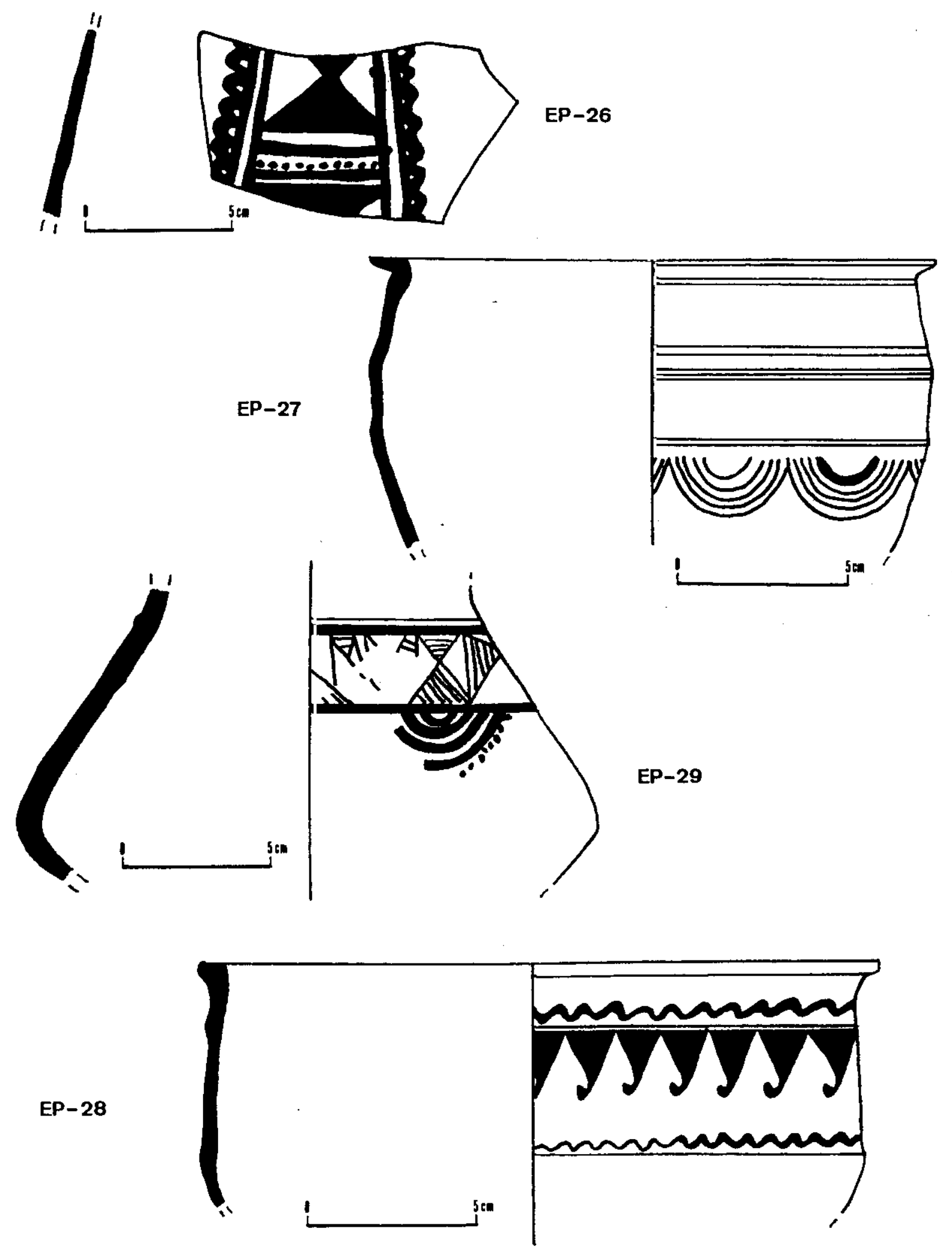
Figura 4.4: (lágina anterior). Dibujos de las muestras procedentes de El Palomar (Aragoncillo, Guadalajara), reproducidos a partir de los realizados por Jesús Arenas.

EP-26.- Anchura: $100 \mathrm{~mm}$. Altura: $60 \mathrm{~mm}$.

EP-27.- Diámetro de boca: $160 \mathrm{~mm}$. Altura conservada: $80 \mathrm{~mm}$.

EP-28.- Diámetro de boca: $200 \mathrm{~mm}$. Altura conservada: $80 \mathrm{~mm}$.

EP-29.- Diámetro máximo: $190 \mathrm{~mm}$. 
más representativas en las que se ha obtenido muestra. A este respecto, debe señalarse que se ha optado por no presentar los dibujos de todas las muestras, debido, por un lado, a que la mayor parte está ya publicada en los diferentes trabajos que se han centrado en la cerámica numantina y cuyas referencias aparecen en la Tabla $1 \mathrm{y}$, por otro, porque el dibujo de ciertos fragmentos, seleccionados, precisamente, por su escasa representatividad morfológica, no hubiera tenido demasiado interés.

En el yacimiento de Numancia, se seleccionaron un total de 83 muestras, de las cuales 21 se correspondían con cerámicas que presentaban decoración polícroma. Dichas muestras representan a las cuatro fábricas determinadas en el análisis macroscópico, distribuyéndose seguin los porcentajes de cada una de ellas. De esta manera, la fábrica 1 cuenta con 32 muestras, la fábrica 1-b con 21, la fábrica 2 con 17 y la fábrica que se relaciona con la cerámica negra, 13 . Las muestras se han identificado con una $N$, primera letra del nombre del yacimiento de Numancia, seguidas de un guión y un número correlativo que comienza en 10 , ya que los números del 1 al 9 se reservaron para las muestras de los sedimentos arcillosos. En las muestras de cerámicas con decoración polícroma, se ha añadido una $\mathrm{P}$ después de la $\mathrm{N}$, con el propósito de poder ser identificadas con facilidad.

En el yacimiento de Izana, se han seleccionado 17 muestras, 7 de las cuales han vuelto a ser analizadas, a través de las distintas técnicas, con respecto al trabajo realizado en la Memoria de-Licenciatura De ellas, 9 pertenecen a la fábrica 1, 2 a la fábrica $1-b, 2$ a la fábrica 2 y 4 a la fábrica de cerámica negra. Estas muestras se han identificado con las tres primeras letras del nombre del lugar donde se sitúa el yacimiento (IZA), seguidas, igualmente, de un guión y un númeto correlativo desde el 1 . Obsérvese que faltan los números 12 y 13 , que se corresponden con muestras no analizadas en este trabajo.

En Langa de Duero y El Palomar, se han tomado 5 muestras en cada uno de ellos. Las muestras de Langa de Duero se han identificado con las letras LD y sus números son correlativos con las pertenecientes a Numancia. Las muestras de El Palomar, se identifican con las letras EP y sus números son correlativos a las 24 muestras ya analizadas en un trabajo anterior (García Heras et al., En prensa a). Sólo 4 de las 5 muestras de El Palomar se corresponden con cerámicas que presentan motivos decorativos numantinos. La muestra restante, perteneciente a una vasija completa, se utilizó en una prueba realizada para comprobar si una sola muestra podía ser considerada representativa de toda la pieza. Esta prueba puede seguirse en el apartado 4.6 de este mismo capítulo.

Por último, en el yacimiento de Pinilla Trasmonte, se han seleccionado 11 muestras que se identifican con las letras PT y un número correlativo desde el 1 al 11. 


\subsection{SEDIMENTOS ARCILLOSOS}

Con el fin de contar con un apoyo complementatio a la caracterización de las cerámicas arqueológicas, se ha realizado un muestreo aleatorio de sedimentos arcillosos en el entorno geográfico del yacimiento de Numancia. En una investigación de estas características, lo ideal sería realizar un muestreo sistemático de todas las fuentes potencialmente utilizables de la zona para la elaboración de cerámica (Bronitsky, 1986; Neff et al., 1992). Sin embargo, un trabajo como éste excedia ampliamente los límites de esta investigación.

El muestreo se efectuó contemplando la información contenida en el mapa geológico de la zona, para procurar que las muestras abarcasen diferentes ambientes geológicos, contando con la ayuda de un geólogo, el Dr. José G. Arribas, y del alfarero Evelio Arnanz. También se contempló la hipótesis, expresada por B. Taracena en el trabajo que realizara sobre la cerámica numantina, que mantenía que ciertas especies cerámicas, las llamadas por él blancoamarillentas, habían sido elaboradas con caolín recogido en la llanura de Chavaler. Una localidad situada, según este autor, a $2 \mathrm{~km}$ al $\mathrm{N}$ de Numancia (Taracena, 1924, 3) (1). De este modo, el caolín de Chavaler también fue muestreado, aunque su localización no coincidía exactamente con la apuntada por Taracena, con el propósito de comprobar si esta hipótesis podía o no mantenerse.

Un total de 8 muestras se han tomado en las inmediaciones del yacimiento de Numancia, cuya situación aparece reflejada en el mapa de la Figura 4.5. Asimismo, también se ha tomado un sedimento atcilloso procedente del entorno del yacimiento de Izana. Esta muestra, que ha sido reanalizada en este trabajo, ya estaba incluida en la Memoria de Licenciatura. Las muestras se tomaron siempte a profundidades superiores a $l o s 50 \mathrm{~cm}$. Para el caso de Numancia, se han identificado, al igual que las cerámicas, con la letra $\mathrm{N}$, seguida de un guión y un número correlativo del 1 al 8 , mientras que la muestra de Izana se identifica sólo con las letras IZA.

La localización y características de estas muestras, son las siguientes:

N-1. Se toma en la ladera E de la Muela de Garray, a 1,25 km aproximadamente de Numancia, en terrenos secundarios del Jurásico Inferior, dentro de la formación Cortes de Tajuña/Imón, según el mapa geológico del I.G.M.E (Hoja 350 Soria).

$\mathrm{N}-2$. Esta muestra se recoge en la misma ladeta, al $\mathrm{N}$ de la toma anterior y a $1,4 \mathrm{~km}$ de Nurnancia. Sus características geológicas son similares.

(1) Tista opinion ha sifo recogida, después, en los trabajos de Romero Cannicero (1976), quien también la cita en otro de sus trabajos (Romero Carnicero, 1982), y de $\Lambda$ regui (1986) 


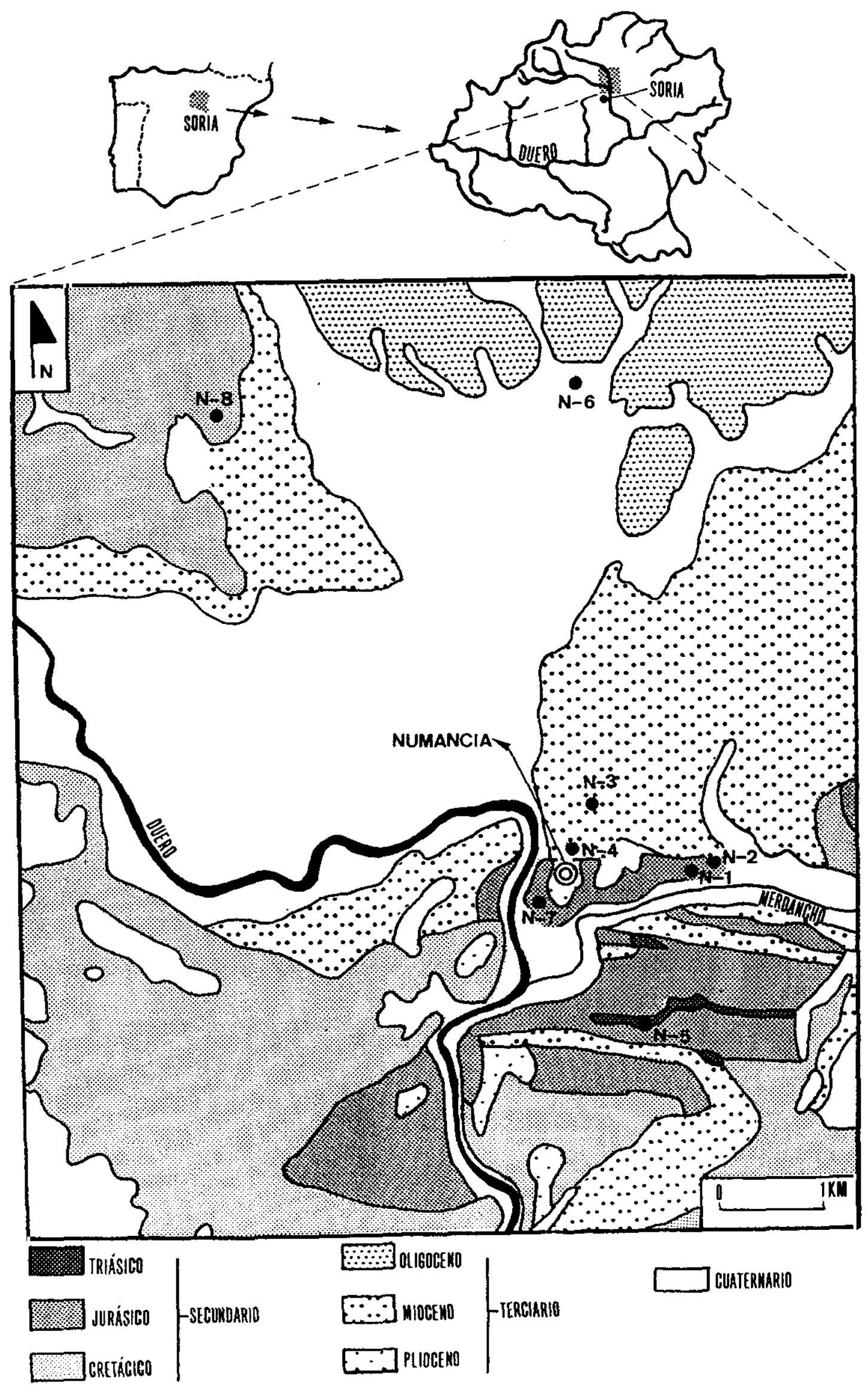


Figura 4.5: (Página anterior). Situación de los puntos en los cuales se han tomado los sedimentos arcillosos procedentes de las inmediaciones de Numancia, según el mapa geológico escala 1: 50.000 del 1.G.M.E. (Hojas 318 Almarza y 350 Soria).

$\mathrm{N}$-2. Esta muestra se recoge en la misma ladera, al $\mathrm{N}$ de la toma anterior y a $1,4 \mathrm{~km}$ de Numancia. Sus características geológicas son similares.

N-3. Se toma en la ladera $\mathrm{N}$ de la Muela de Garray, a $0,5 \mathrm{~km}$ de Numancia. Según la misma hoja del mapa geológico mencionado, se trata de terrenos terciarios del Mioceno, encuadrados dentro de la formación Tartajo. Esta formación presenta facies conglomeráticas cuyos clastos, que se hallan en una matriz arenosa fuertemente cementada por carbonatos, están compuestos por caliza mesozoica, arenisca, cuarzo y cuarcita.

N-4. Este sedimento arcilloso se toma también en la ladera $\mathrm{N}$ de la Muela de Gatray, junto a la carretera que sube a Numancia, 15 metros antes de llegar a la puerta de acceso al recinto que protege el yacimiento. Se sitúa aproximadamente a $0,15 \mathrm{~km}$ del asentamiento, hallándose en terrenos terciarios del Plioceno, dentro de la formación Numancia, compuestos por una cobertera detrítica que abarca, desde bloques de cuarcitas y areniscas, hasta fracciones de limo y arcilla.

N-5. Esta muestra se recoge junto al campamento romano de Peña Redonda, situado al otro lado del Merdancho, y se sitúa a $1,8 \mathrm{~km}$ de Numancia, en terrenos secundarios del Triásico. La muestra está constituida por arcillas rojas del Keuper.

N-6. Se toma junto a la carretera que conecta Fuentecantos con la N-111 Soria/Logroño, en una cantera actual de explotación de áridos (2), a 4,45 km de Numancia. Se encuentra situada en terrenos cuaternarios y está compuesta por arcillas de la llanura de inundación del Duero, según la Hoja 318 (Almarza) del mapa geológico del I.G.M.E.

N-7. Esta muestra se recoge en la ladera $S$ de la Muela de Garray, a unos $0,45 \mathrm{~km}$ de Numancia. Pertenece a sedimentos procedentes de la campaña de excavaciones arqueológicas de 1994

(2) Lista cantera aparce en el Mapa de Rocas Industriales (I Ioja 31, Soria) con el número 62. 
TABLA 4.1. CARACTERÍSTICAS DE LOS SEDIMENTOS ARCILLOSOS
ANALIZADOS

\begin{tabular}{|c|c|c|c|c|c|c|c|}
\hline $\mathrm{N}^{\mathrm{o}}$ & MUESTRA & $\begin{array}{l}\text { ALTTTUD (m) } \\
\text { (s.n.m.) }\end{array}$ & ERA & PERIODO & MATERIAIES & FORMACION & $\begin{array}{c}\text { DISTANCIA } \\
(\mathrm{km})\end{array}$ \\
\hline 1 & $N-1$ & 1.030 & Secundario & $\begin{array}{l}\text { Jurásico } \\
\text { Inferior }\end{array}$ & $\begin{array}{l}\text { Carniolas } \\
\text { y dolomías } \\
\text { tableadas }\end{array}$ & $\begin{array}{c}\text { Cortes } \\
\text { de } \\
\text { Tajuña/Imón }\end{array}$ & 1.25 \\
\hline 2 & $\mathrm{~N}-2$ & 1.030 & Secundario & $\begin{array}{l}\text { Jurásico } \\
\text { Inferior }\end{array}$ & $\begin{array}{l}\text { Camiolas } \\
\text { y dolomias } \\
\text { tableadas }\end{array}$ & $\begin{array}{c}\text { Cortes } \\
\text { de } \\
\text { Tajuña/Imón }\end{array}$ & 1.40 \\
\hline 3 & $\mathrm{~N}-3$ & 1.050 & Terciario & Mioceno & $\begin{array}{l}\text { Conglomerados, } \\
\text { arenas limos } \\
\text { y calizas }\end{array}$ & Tartajo & 0.50 \\
\hline 4 & $N-4$ & 1.060 & 'Terciario & Plioceno & $\begin{array}{c}\text { Cuarcitas } \\
y \text { areniscas }\end{array}$ & Numancia & 0.15 \\
\hline 5 & $N-5$ & 1.040 & Secundario & Triäsico & Arcillas y yesos & Keupex & 1.80 \\
\hline 6 & $N-6$ & 1.040 & Cuaternario & Indiferencjado & $\begin{array}{c}\text { I imos y arenas } \\
\text { fluviales }\end{array}$ & $\ldots$ & 4.45 \\
\hline 7 & $N-7$ & 1.050 & Secundario & $\begin{array}{l}\text { Jurásico } \\
\text { Inferior }\end{array}$ & $\begin{array}{l}\text { Carriolas } \\
\text { y dolomias } \\
\text { tableadas }\end{array}$ & $\begin{array}{c}\text { Cortes } \\
\text { de } \\
\text { Tajuña/Imón }\end{array}$ & 0.45 \\
\hline 8 & $N-8$ & 1.080 & Secundario & Jurásico Malm & $\begin{array}{c}\text { Calizas } \\
y \text { limolitas }\end{array}$ & Oncala & 5.30 \\
\hline 9 & $I Z A$ & 1.100 & Terciario & $\begin{array}{l}\text { Eoceno/ } \\
\text { Oligoceno }\end{array}$ & $\begin{array}{l}\text { Conglomerados } \\
\text { y margas rojas }\end{array}$ & $\cdots$ & 0.10 \\
\hline
\end{tabular}

Las distancias se han medido sobre el mapa geológico desde el vértice geodésico situado en la Muela de Garray a 1.074 metros s.n.m.

efectuada en la necrópolis. También se encuentra situada en terrenos secundarios del Jurásico Inferior, dentro de la formación Cortes de Tajuña/Imón.

N-8. Se trata de una muestra de caolín tomada en la mitad de la ladera de la Sierra de Carcaña, en un lugar llamado La Mina. Este lugar es un yacimiento de caolín conocido y explotado por los vecinos de la zona, aunque no está señalado en ningún mapa, ni siquiera en el de Rocas Industriales, sin duda, por su escasa potencialidad de explotación. El punto de extracción se sitúa a 5,3 $\mathrm{Km}$ de Numancia, distancia que, obviamente, no coincide con la expuesta por Taracena $(1924,3)$. Según el trapa geológico del I.G.M.E. (Hoja 318, Almarza), estos terrenos secundarios 
del Jurásico se encuadran en la formación Oncala.

IZA. Se toma al pie del cerro del yacimiento de Izana, en su ladera NE, a una distancia de 0,10 $\mathrm{km}$ aproximadamente del asentamiento. La muestra se sitúa en terrenos terciarios del Eoceno/Oligoceno, según el mapa geológico del I.G.M.E. (Hoja 349, Cabrejas del Pinar).

La Tabla 4.1 recoge, de manera esquemática, las características de todas estas muestras.

\subsubsection{Tratamiento de los sedimentos arcillosos}

En primer lugar, y con el fin de conocer las características granulométricas de estos sedimentos, se realizó un Análisis Textural, por medio de Pipeta de Robinson, que es un procedimiento utlizado habitualmente por edafólogos, de una parte de las muestras en bruto N-1 a N-7. En la N-8 e IZA, no se llevó a cabo este análisis. En la primera, porque el tamaño de grano era muy reducido y uniforme y, en la segunda, porque no se disponia de suficiente cantidad de muestra. Hay que tener en cuenta que, cuando se tomó para el trabajo desarrollado en la Memoria de Licenciatura, esta técnica no pensaba utilizarse.

La otra parte de todas las muestras, se acondicionó para ser calcinada a distintas temperaturas. Como ya era conocido, por el trabajo anterior, que los tamaños de partícula de las cerámicas de Izana rara vez superaban los $0,5 \mathrm{~mm}$ y, considerando que es más factible comparar arcillas y cerámicas que hayan sufrido los mismos procesos de selección de partícula (Kilikoglou et al., 1988, 45), las muestras fueron preparadas por el alfarero Evelio Arnanz, según el siguiente proceso.

Primero, las muestras se dejan en remojo tres dias para ablandarlas, transcurridos los cuales se procede a su tamizado con una criba de latón de 120 mallas. Más tarde, se modelan en planchas, de las que posteriormente se obtendrán las probetas, para después dejarlas secar durante otros tres días a temperatura ambiente. Una vez finalizado este proceso, las probetas se trasladan al laboratorio, en donde se dejan secar diez días más, igualmente a temparatura ambiente, con el propósito de lograr su completa deshidratación.

Seguidamente, se realizó su cocción en atmósfera oxidante a $700,800,900$ y $1.000^{\circ} \mathrm{C}$, por ser éstos los rangos de temperatura más probables en los que se cocieton las cerámicas arqueológicas. En la nomenclatura de las muestras, se ha anadido una $A$, para hacer referencia a la probeta analizada a temperatura ambiente, una $\mathrm{B}$, que expresa la temperatura de $700^{\circ} \mathrm{C}$, una $\mathrm{C}$ para los $800^{\circ} \mathrm{C}$, una $\mathrm{D}$ para 
TABLA 4.2. COLORES MUNSELL DE LOS SEDIMENTOS ARCILLOSOS COCIDOS A DISTINTAS TEMPERATURAS

\begin{tabular}{|c|c|c|}
\hline MUESTRA & $\begin{array}{l}\text { TEMPERATURA } \\
\text { COCCION }{ }^{\circ} \mathrm{C} \\
\end{array}$ & $\begin{array}{r}\text { COLOR } \\
\text { MUNSELL } \\
\end{array}$ \\
\hline$N-1 A$ & $T . A$. & 5 YR $5 / 6$ \\
\hline$N-1 B$ & 700 & 2.5 YR $6 / 6$ \\
\hline$N-1 C$ & 800 & $5 Y R 7 / 6$ \\
\hline$N-1 D$ & 900 & 2.5 YR $6 / 6$ \\
\hline $\mathrm{N}-1 \mathrm{E}$ & 1.000 & $2.5 \mathrm{YR} 7 / 6$ \\
\hline$N-2 A$ & T:A. & 7.5 YR $6 / 3$ \\
\hline $\mathrm{N}-2 \mathrm{~B}$ & 700 & 5 YR $7 / 6$ \\
\hline $\mathrm{N}-2 \mathrm{C}$ & 800 & 5 YR $6 / 8$ \\
\hline $\mathrm{N}-2 \mathrm{D}$ & 900 & 5 YR $6 / 6$ \\
\hline $\mathrm{N}-2 \mathrm{E}$ & 1.000 & $2.5 \mathrm{YK} 6 / 6$ \\
\hline$N-3 A$ & T.A. & 7.5 YR $6 / 4$ \\
\hline$N-3 B$ & 700 & $5 \operatorname{YR~} 6 / 6$ \\
\hline$N-3 C$ & 800 & $5 \mathrm{YR} 6 / 8$ \\
\hline$N-3 D$ & 900 & 5 YR $6 / 8$ \\
\hline $\mathrm{N}-3 \mathrm{E}$ & 1.000 & $2.5 \mathrm{YR} 5 / 6$ \\
\hline$N-4 A$ & T.A. & $2.5 \mathrm{YR} 4 / 6$ \\
\hline$N-4 B$ & 700 & 2.5 YR $5 / 8$ \\
\hline $\mathrm{N}-4 \mathrm{C}$ & 800 & 2.5 YR $5 / 8$ \\
\hline$N-4 D$ & 900 & $2.5 \mathrm{YR} 6 / 8$ \\
\hline N-4I; & 1.000 & $2.5 \mathrm{YR} 5 / 6$ \\
\hline$N-5 A$ & T.A. & $2.5 \mathrm{YR} 4 / 4$ \\
\hline $\mathrm{N}-5 \mathrm{~B}$ & 700 & 25 YR $6 / 6$ \\
\hline $\mathrm{N}-5 \mathrm{C}$ & 800 & 2.5 YR $5 / 8$ \\
\hline $\mathrm{N}-5 \mathrm{D}$ & 900 & 2.5 YR $5 / 8$ \\
\hline N.5E & 1.000 & 2.5 YR $6 / 6$ \\
\hline$N-6 A$ & T.A. & $5 \mathrm{YR} 6 / 3$ \\
\hline$N-6 B$ & 700 & 25 YR $6 / 6$ \\
\hline $\mathrm{N}-6 \mathrm{C}$ & 800 & 2.5 YR $6 / 6$ \\
\hline$N-6 D$ & 900 & 5 YR $6 / 8$ \\
\hline $\mathrm{N}-6 \mathrm{E}$ & 1.000 & 2.5 YR $6 / 6$ \\
\hline$N-7 A$ & $I^{*} A$ & $25 \mathrm{YR} 4 / 4$ \\
\hline $\mathrm{N}-7 \mathrm{~B}$ & 700 & 2.5 YR $5 / 8$ \\
\hline$N-7 C$ & 800 & $2.5 \mathrm{YR} 5 / 8$ \\
\hline N.71 & 900 & 2.5 YR $5 / 8$ \\
\hline N-7E: & 1.000 & $2.5 \mathrm{YR} 4 / 6$ \\
\hline $1 / \lambda+0$ & 'T. $\Lambda$ & 5 YRR $7 / 3$ \\
\hline$[\angle A-700$ & 700 & 5 YR $6 / 6$ \\
\hline$[\% \wedge .800$ & 800 & 5 YR $6 / 6$ \\
\hline $1 \% \times 900$ & 900 & $5 Y R 7 / 6$ \\
\hline $1 \% A-1000$ & 1.000 & $5 \mathrm{YRR} 7 / 6$ \\
\hline
\end{tabular}

la muestra N-8 no sc ha incluido en esta tabla, porque el color blanco que presenta a temperatura ambiente no varia en los rangos de fimperatura supcriores. Además, este color no ticne cquivalcncia cn la tabla Munsell.

'I.A. temperatura ambiente 
los $900^{\circ} \mathrm{C}$ y una $\mathrm{E}$ para los $1.000^{\circ} \mathrm{C}$. Las probetas se han cocido en un homo eléctrico HEROTEC (actualmente HOBERSAL) Modelo HE-22. La cocción se ha realizado con un temple de dos horas y media, en el que la temperatura se eleva $50^{\circ} \mathrm{C}$ cada 30 minutos, hasta alcanzar los $300^{\circ} \mathrm{C}$. Después, los rangos varían, elevándose $100^{\circ} \mathrm{C}$ cada 10 minutos, hasta lograr la temperatura establecida. La máxima temperatura sólo se mantiene, en cada caso, 15 minutos. La Tabla 4.2 muestra los colores Munsell de las probetas cocidas a las temperaturas mencionadas.

\subsection{TÉCNICAS DE ANÁLISIS}

Algo más de 500 análisis han sido realizados en esta investigación, a través de las distintas técnicas utilizadas. En los apartados siguientes, se exponen las características de estas técnicas, las condiciones de trabajo de cada uno de los equipos, así como los procedimientos experimentales seguidos en cada caso.

\subsubsection{Análisis macroscópico}

Este análisis se ha llevado a cabo por medio de una lupa binocular NIKON, equipada con un objetivo de hasta 80 aumentos. Las observaciones se intentaron realizat siempre sobre fractura fresca. No obstante, y dado que se manejaron materiales depositados en los fondos de dos museos, esta práctica no se pudo realizar en un elevado porcentaje de cerámicas, ya que esto hubiera supuesto fragmentar una parte muy importante de las mismas, con el consiguiente deterioro que habría ocasionado a las colecciones.

Para realizar el análisis macroscópico que, como ya se adelantaba en el capítulo anterior, se efectuó en la totalidad del conjunto cerámico de Numancia, se confeccionaron dos tipos de tablas que codificaban, en distintos niveles, los atributos a tegistrat. Una de las tablas estaba ideada para la generalidad del conjunto cerámico, mientras que la otra se adaptó para registrar los atributos del lote de cerámicas negras, ya que éstas presentaban diferencias con respecto al resto. En la primera de estas tablas, los atributos se han codificado en ocho niveles distintos. Un primer nivel, recoge los números de inventario de ambos museos y su correlación con los números de catálago de los diferentes trabajos que han estudiado la cerámica numantina. El segundo, registra los colores Munsell de las superficies y el corte. Estos colores se midieron siempre bajo las mismas condiciones lumínicas para todas las cerámicas. A continuación, el tercer nivel, contempla los tratamientos superficiales. El cuarto, registra el tamaño, la cantidad y 
la distribución de las inclusiones (3) presentes en la matriz cerámica. Para determinar el porcentaje de inclusiones con respecto a la matriz, se utilizaron las cartas de estimación visual de Matthew et al. (1991). El quinto nivel registra la macroporosidad y el sexto las mediciones formales. La tipología se registra en el séptimo nivel. Para la clasificación tipológica, se ha seguido la establecida por Arlegui en su trabajo sobre el lote de cerámicas de cocción oxidante con decoración monócroma (Arlegui, 1986), a pesar de que algunos tipos presentes en el conjunto de la cerámica numantina, no estaban contemplados en el mismo (ver Apéndice I). Por último, en el octavo, se registran las características y el color de las decoraciones. En las tablas adaptadas para la cerámica negra, se modificaron los códigos referentes al tratamiento de las superficies y a la decoración.

Se han observado un total de 11.408 individuos, de los cuales 9.529 son fragmentos y 1.879 piezas completas o fragmentos cuya tipología es reconocible. Debe señalarse que, aunque todo el conjunto ha sido observado con lupa binocular, sólo se ha realizado una observación pormenorizada, registrando los atributos en tablas, en los 1.879 individuos mencionados. Estas tablas, se ha decidido no incluirlas en este trabajo, ya que lo hubieran extendido de una manera considerable. En todo caso, están a disposición de cualquier persona interesada en su consulta. Un modelo de las mismas, se ofrece en las Tablas 2 y 3 , del final de este trabajo.

\subsubsection{Análisis textural de los sedimentos arcillosos: Pipeta de Robinson}

Este análisis comienza con el secado de la muestra cuarteada a temperatura ambiente. Una vez seca, se tamiza con una criba de $2 \mathrm{~mm}$ de luz. A continuación, se agregan a la muestra $200 \mathrm{~cm}^{3}$ de agua oxigenada $\left(\mathrm{H}_{2} \mathrm{O}_{2}\right)$ al $40 \%$ en dos etapas: una en frío y otra en caliente al baño Maria. De esta forma, se calcina la materia orgánica presente. Realizado este proceso, la muestra se deseca en estufa a $110^{\circ} \mathrm{C}$, tras lo cual se pesa y se introduce en una botella de boca ancha a la que se agregan $10 \mathrm{~cm}^{3}$ de dispersante, compuesto por $35,7 \mathrm{gr}$ de hexametafosfato sódico (Na Po3)6 y 7,94 gr de carbonato sódico, diluídos en un litro de agua desionizada. Después, la mezcla se agita durante un período de ocho horas, por medio de un agitador rotatorio. La muestra se tamiza entonces con una criba de $0,05 \mathrm{~mm}$ de luz, para obtener, una vez seca, la cantidad de arena gruesa. Más tarde, se introduce en una botella enrasada a un litro, en la que se hallan las fracciones arena muy fina, limo y arcilla. La cantidad de la fracción arena fina, se conoce extrayendo la diferencia con respecto a los demás valores. Para extraer el conjunto de la fracción limo y arcilla, la muestra se agita con una varilla durante unos momentos. Cuando han

(3) Ln este trabajo se ba prescindido de la utilización del término "desgrasante", por entender cute su uso establece uma infercncia de conducta, a partir de una observación analítica (Rice, 1987, 412). lín su jugat, se ha utilizado siempre el término "inclusión", que hace referencia a cualquier particula mayor de $30 \mathrm{~mm}$ presente cu la matriz arcillosa de una cerámica, sea su presencia natural o aĩadida intencionadamente 
transcurrido 4 minutos y 47 segundos (4), se toman $20 \mathrm{~cm}^{3}$, mediante Pipeta de Robinson, a una profundidad de $10 \mathrm{~cm}$, medidos desde la superficie del líquido. Estos $20 \mathrm{~cm}^{3}$, se depositan en una cápsula de porcelana previamente pesada. La Pipeta de Robinson se lava entonces con agua desionizada, con el fin de arrastrar las partículas que hayan podido quedar en su interior. Este agua también se introduce en la cápsula que luego se deseca al baño Maria. Tras secar la muestra en una estufa a $110^{\circ} \mathrm{C}$, se vuelve a pesar. La diferencia en peso, establece el contenido en limo y arcilla. Para extraer esta última fracción, se vuelve a agitar con una varilla el contenido de la botella. En este segundo caso, deben transcurrir 7 horas y 57 minutos, antes de proceder a una extracción similar a la anteriot. A continuación, la muestra se trata del mismo modo que para la toma limo y arcilla. Por diferencia entre ambas fracciones, se obtiene la cantidad de limo. Finalmente, las cantidades se expresan en porcentajes.

\subsubsection{Análisis petrográfico mediante lámina delgada}

Para llevar a cabo este análisis, se utilizó un microscopio petrográfico OLYMPUS Modelo C011. Las microfotografias fueron obtenidas con un microscopio ZEISS Modelo 62354. Las muestras se prepararon a partir de un corte realizado en el fragmento cerámico con un disco de diamante. Este corte se realizó siempre perpendicular al borde del fragmento, cuando éste lo conservaba, o perpendicular a las líneas del torno, cuando se trataba de galbos. Las láminas delgadas se han teñido hasta la mitad con rojo de alizarina, con el fin de distinguir los carbonatos. Para la estimación del porcentaje de inclusiones con respecto a la matriz, se utilizaron también las tablas de estimación visual de Matthew et al. (1991). El Análisis petrográfico cubrió todas las muestras cerámicas, excepto 6 , procedentes de Izana, en las que no pudo realizarse, debido a la escasa cantidad de muestra disponible. Asimismo, también se tealizó en 4 muestras de sedimentos arcillosos cocidos a $700^{\circ}$ y $900^{\circ} \mathrm{C}: \mathrm{N}-1 \mathrm{~B}, \mathrm{~N}-1 \mathrm{D}, \mathrm{N}-4 \mathrm{~B}$ y N-4D.

Análisis textural. El Análisis textural de las láminas delgadas, que se realiza para conocer la distribución del tamaño de las inclusiones, se llevó a cabo por el método de conteo de puntos o análisis modal (Darvill y Timby, 1982; Middleton et al., 1985), con la ayuda de un micrómetro

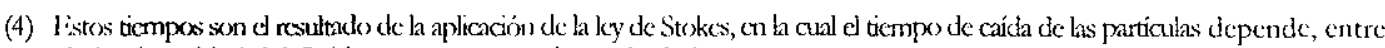
otros factores, de la viscosidad del fluido que, a su ve\%, depende de la temperatura. 
incorporado al microscopio. El tamaño de las inclusiones se estimó siempre en su eje mayor. Los conteos se han realizado siguiendo líneas imaginarias de $10 \mathrm{~mm}$ de longitud, separadas cada 0,4 o $0,8 \mathrm{~mm}$, según el tamaño de particula de la muestra y paralelas, en la medida de lo posible, a la superficie de las cerámicas. Las inclusiones que tocan estas lineas, son las que, finalmente, se contabilizan. Por último, los tesultados se expresan en porcentajes que abarcan fracciones de $0,10 \mathrm{~mm}$.

Test de representatividad. Para estimar cuál era el número de inclusiones más representativo en las muestras analizadas, se lievó a cabo un test de representatividad en 6 de ellas. Con anterioridad a su realización, se consultó la bibliografia especializada, con el propósito de conocer el número de inclusiones que se habían contabilizado en trabajos similares. El primer investigador que utilizó esta técnica fue Peacock, en el análisis de cerámicas grises de Fishboume, en el que media un total de 50 inclusiones (Peacock, 1971). Otros trabajos posteriores, aumentan este número, aunque mantienen que no existen diferencias significativas en los resultados, entre contabilizar 50, 100, 150 o 200 inclusiones (Wandibba, 1982). En todo caso, y a pesar de que no puede hablarse de consenso, ya que mientras algunos autores contabilizan sólo 100 inclusiones (Darvill y Timby, 1982), otros 150 (Whitbread, 1989) y, a veces, hasta 200 (Little, 1990), hay trabajos en los que se recomienda la cifra de 150 inclusiones, como la más adecuada para cubrir la distribución de todas ellas (Streeten, 1982).

De esta forma, en el test de representatividad llevado a cabo en esta investigación, se optó por realizar 4 conteos distintos, cada uno de los cuales, en una parte diferente de la lámina delgada, elegida al azar. En cada conteo, se contabilizaron 150, 200 y 300 inclusiones, de manera que, se realizaron, un total de 12 conteos por muestra. Las 6 muestras seleccionadas se eligieron aleatoriamente, representando las distintas fábricas en las que había quedado clasificado el conjunto cerámico de Numancia, mediante el Anảisis macroscópico.

Los resultados, expuestos gráficamente al final del Apéndice II, demuestran que no existen diferencias significativas entre los conteos representados por 150, 200 o 300 inclusiones, en cualquiera de las muestras. Asimismo, tampoco existen diferencias en los conteos realizados en una u otra parte de la lámina delgada. Por tanto, y a partir de estos datos, se decidió efectuar el Análisis textural de todas las láminas delgadas, a través de un solo conteo por muestra constituido por 150 inclusiones. 


\subsubsection{Difracción de rayos $\times(X R D)$}

Para llevar a cabo este análisis, las muestras se molieron con mortero y mazo de ágata, hasta conseguir un tamaño de grano próximo a los $30 \mathrm{~mm}$. El equipo utilizado ha sido un PHLIPS Modelo 1.710, usando la radiación $\mathrm{K} \alpha$ del $\mathrm{Cu}(1,54051)$ y bajo condiciones de trabajo de $40 \mathrm{kV}$ y $20 \mathrm{~mA}$. La mayoría de las muestras se han barrido con una velocidad angular de $2^{\circ}$ minuto, en la región comprendida entre $2^{\circ}$ y $64^{\circ} 2 \theta$. No obstante, 27 de ellas (5) fueron barridas en la región comprendida entre $3^{\circ}$ y $64^{\circ} 2 \theta$. En la evaluación cualitativa de los difractogramas, se ha utilizado el paquete informático DIFFRAC/AT, que incluye el banco de datos del Joint Committee of Pouder Diffraction Standards (J.C.P.D.S.).

Se han difractado todas las muestras cerámicas, los sedimentos arcillosos a temperatura ambiente y cocidos a las temperaturas especificadas en un apartado anterior, así como las recocciones de 4 muestras cerámicas a temperaturas de $700^{\circ}, 800^{\circ}, 900^{\circ}$ y $1.000^{\circ} \mathrm{C}$. Para la recocción de estas piezas, se siguió el mismo proceso que para la cocción de los sedimentos arcillosos. Estas muestras se han identificado añadiendo una barra y el primer número del rango de temperatura a la que han sido recocidas, mientras que para diferenciarlas del fragmento cerámico del que proceden, se ha añadido a la difracción las iniciales ECSR, que significan Estado Como Se Reciben, es decir, la muestra tal y como llega al laboratorio. En el caso de las muestras de Izana, 6 de ellas han sido reanalizadas en relación al trabajo efectuado en la Memoria de Licenciatura.

\subsubsection{Fluorescencia de rayos x por reflexión total (TXRF)}

El equipo utilizado ha sido un espectrómetro SEIFERT Modelo EXTRA-II (Rich. Seifert \& Co., Ahrensburg, Alemania), equipado con dos tubos de foco fino de Mo y W operando a $50 \mathrm{kV}$ y $30 \mathrm{~mA}$ y un detector de $\mathrm{Si}(\mathrm{Li})$ de $80 \mathrm{~mm}^{2}$ con una resolución de $157 \mathrm{eV} \mathrm{a}$ $5,9 \mathrm{keV}$. La electrónica periférica y el paquete informático de deconvolución de perfiles, ha sido suministrado por Link Systems Ldd. (AN-10.000), actualmente Oxford Instruments. Por medio de esta técnica, se han analizado un total de 163 muestras que se corresponden con 121 fragmentos cerámicos, 8 sedimentos arcillosos distribuidos en 15 muestras, 7 controles y 20 análisis de las

(5) Lstas 27 muestras son las siguientes: $[Z / A-16, I Z A-17,1 Z \Lambda-700, I Z A-800, I Z A-900, I 7, A-1000, N-8 \Lambda, N-8 B, N-$ $8 \mathrm{C}, \mathrm{N}-8 \mathrm{D}, \mathrm{N}-8 \mathrm{E}: \mathrm{N}-54 / 7, \mathrm{~N}-54 / 8, \mathrm{~N}-54 / 9, \mathrm{~N}-54 / 1, \mathrm{~N}-20 / 7, \mathrm{~N}-20 / 8, \mathrm{~N}-20 / 9, \mathrm{~N}-20 / 1, \mathrm{~N}-25 / 7, \mathrm{~N}-25 / 8, \mathrm{~N}-25 / 9, \mathrm{~N}-25 / 1$, PT-11/7, PI'-11/8, PT-11/9 y Pl'-11/1. 
diferentes preparaciones del patrón "Ohio Red Clay-2".

Toma de muestras. En la mayor parte de los estudios composicionales de cerámica que emplean técnicas geoquímicas, se suelen utilizar taladros, generalmente de zafiro o diamante, para tomar las muesttas, con el propósito de no contaminarlas (Gilmore, 1991, 2-3). También, para intentar dañar el objeto lo menos posible, ya que no puede tomarse muestra nada más que una vez. En cualquier caso, es importante utilizar un solo tipo de taladro a lo largo de un proyecto, para asegurat al máximo la uniformidad en el muestreo (Hughes, 1992, 897; Hughes et al., 1991, 34).

En esta investigación, se ha empleado un taladro diseñado especialmente para este proyecto (Figura 4.6). Se trata de un taladro de acero, en el que se ha realizado una deposición electrolitica de diamante en el corte. Distintas pruebas realizadas en el laboratorio, han constatado que este tipo de taladro no produce inducciones que pudieran distorsionar las determinaciones analíticas de algún elemento.

La toma de muestras con este utensilio, se inicia con la limpieza de las superficies del fragmento cerámico con el borde del taladro, para eliminar la suciedad y las posibles incrustaciones. Esta limpieza afecta, aproximadamente, a $1 \mathrm{~mm}$ de profundidad en cada superficie del fragmento. A continuación, se obtiene un pequeño cilindro de la cerámica que luego se introduce, junto con el taladro, en un baño de ultrasonidos con agua supraputa (Millipore-Q-Plus, 18,2 M 2 ), para eliminar la suciedad producida durante el corte. Más tarde, la muestra se seca en estufa a $110^{\circ} \mathrm{C}$, iniciándose entonces el proceso de preparación para el análisis mediante esta técnica, que se explicará en uno de los apartados siguientes.

En otro orden de cosas, conviene recordar que las muestras IZA-1BIS, IZA-2BIS e IZA-15, procedentes del yacimiento de Izana, se obtuvieron de otro modo. Como ya se comentaba en la Memoria de Licenciatura (García Heras, 1993 a, 100), los problemas surgidos para tomar muestras en cerámicas depositadas en los fondos del Museo Arqueológico Nacional de Madrid, obligaron a extrer éstas por raspado, mediante un útil de acero. Este aspecto es importante que se tenga en cuenta a la hora de evaluar los perfiles composicionales obtenidos en estas muestras. Por otro lado, es muy probable que algunos de los fragmentos de cerámica polícroma de Numancia, hayan sido tratados químicamente en el proceso de restauración. Sin embargo, este extremo no ha podido ser confirmado en los registros del Museo Numantino de Soria. Además, tampoco ha sido posible intervenir en otros fragmentos que con seguridad no hubieran sido tratados, ya que no han podido localizatse en los fondos de dicho museo. 
Evidentemente, en esta investigación no deberían haberse analizado materiales restaurados, pero si esto no se hubiera hecho, no se habría podido manejar un número significativo de cerámicas polícromas. Es obvio, por tanto, que los trabajos de caracterización deberian estar asociados con los de conservación y restauración. De esta forma, los fenómenos de alteración y contaminación ligados a estas actividades, dejarían de estar comprendidos en el modelo teórico expuesto en el capitulo 2. De cualquier modo, este hecho no hace sino poner de manifiesto que, en la mayoría de los museos españoles, se cuenta con una información mínima de la pieza cerámica cuando ésta se va a consolidar o restaurar. En este sentido, cuando este proceso se lleva a cabo, siempre priman más los criterios estéticos que los tecnológicos (Grabriel, 1981, 32).

Figura 4.6: 'Taladro utilizado en la toma de muestras para el análisis mediante Fluorescencia de rayos x por reflexión total (TXRF). En negro, se muestra la situación de la deposición clectrolíica de diamante.

DIAMANTE

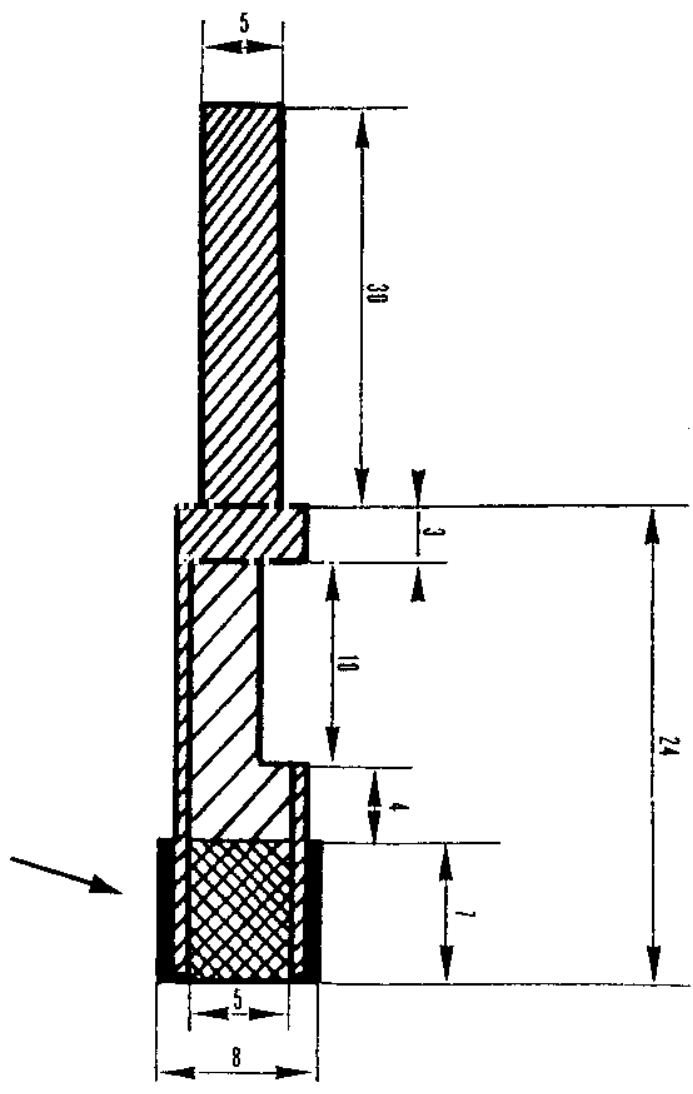




\subsubsection{Microscopía electrónica de barrido (SEM) y análisis mediante Energía dispersiva de $\operatorname{rayos} \times(E D X)$}

En esta investigación se han utilizado dos equipos distintos. Para el análisis de las cerámicas y sus pigmentos decorativos, se empleó un microscopio electrónico de barrido ZEISS Modelo DSM-950, equipado con un sistema de microanálisis de Energia dispersiva de rayos x (EDX) TRACOR NORTHERN Z-II con detector de Si (Li). Los análisis semi-cuantitativos con patrón teórico interno, se han obtenido utilizando el método de corrección ZAF, de la firma Tracor Co. (McCarthy y Schamber, 1979). Por otra parte, en el estudio realizado para conocer la potencialidad de la Fluorescencia de rayos $\mathrm{x}$ por reflexión total (TXRF) en el análisis de muestras sólidas, se ha utilizado un microscopio electrónico de barrido PHILIPS Modelo XL-30, para examinat el tamaño y la morfología de las partículas en las deposiciones que, finalmente, analiza el equipo de TXRF.

Con esta técnica de análisis, se han observado sólo 9 muestras cerámicas, debido, ptincipalmente, a problemas de acceso a los microscopios, así como los elevados costes a los que ha habido que enfrentarse para su utilización. La microscopía electrónica se ha empleado, en este caso, para examinar dos zonas distintas de los fragmentos cerámicos. Por un lado, la microestructura, que se ha realizado sobre fractura fresca y, por otro, la composición de los diferentes pigmentos decotativos, que se ha efectuado con muestras embutidas en pastillas de resina, preparadas tal y como se especifica más abajo. Tras la realización de varias pruebas y la consulta de algunos trabajos que habían analizado pigmentos de cerámicas de La Tène con esta técnica (Andrews, 1991 a; 1991 b; 1996), se eligió, finalmente, este proceso de preparación de mụestra, al ser el que mejor garantizaba el análisis del pigmento, sin interferencias provocadas por el resto del cuerpo cerámico.

Preparación de muestras embutidas. En primer lugar, se corta una sección del fragmento cerámico con un disco de diamante. Esta sección se deja secar durante dos horas en una estufa a una temperatura de $110^{\circ} \mathrm{C}$. Más tarde, se embute a doble vacio en resina Epofix mezclada con un endurecedor. El procedimiento de doble vacio, se empleó por la importante porosidad que presentaban las muestras. Una vez embutidas, se dejan nuevamente secar a temperatura ambiente durante un período de dos días. Después, se inicia su pulido, que se realiza en dos fases. La primera, se lleva a cabo a mano mediante papeles de carburo de Si de "grit" 120,320 y $600 \mathrm{y}$, la segunda, se hace de forma automática en Vibromet, con papeles de diamante de $6,3 \mathrm{y}$ 
1, utilizando un paño de nylon como lubricante. A continuación, se deposita en la superficie de la pastilla un recubrimiento conductor, compuesto por una fina capa de Au evaporado mediante la técnica de "sputtering", quedando, asî, la muestra lista para el análisis. La aplicación de esta capa, facilita la observación de la microestructura con imagen de electrones secundarios, pero puede afectar al análisis químico mediante Energia dispersiva de rayos $\mathrm{x}$ (EDX), debido a la absorción que experimenta la capa de Au sobre la emisión de elementos detectados por el espectrómetro (García Heras y Rincón, 1996, 333; Woldseth, 1973).

\subsubsection{Microscopía óptica de luz reflejada}

Esta técnica se utilizó para seleccionar los campos de observación y las áreas de interfase matriz/pigmento, en las muestras embutidas que iban a ser examinadas mediante Microscopía electrónica de barrido (SEM). Para ello, se empleó un microscopio ZEISS Modelo 67371, con el que también se realizaton las microfotografias correspondientes.

\subsubsection{Espectroscopía de fotocorrelación: Quasi-Elastic Light Scattering (QELS)}

La Espectroscopía de fotocorrelación se empleó para determinar el tamaño de partícula de un total de 20 muestras, preparadas siguiendo distintos procedimientos, del patrón "Ohio Red Clay-2", en el estudio realizado para conocer la potencialidad de la Fluorescencia de rayos $\mathrm{x}$ por reflexión total (TXRF) en el análisis de muestras sólidas. El espectrómetro utilizado ha sido un AutoSizer Modelo IIc, de Malvern Instruments Ltd., equipado con un láser de He-Ne de $5 \mathrm{~mW}$, un fotomultiplicador y un sistema electrónico de procesado y correlación, controlado por el paquete informático Malvern AutoSizer.

\subsubsection{Análisis estadístico}

Para la interpretación de los datos composicionales obtenidos mediante Fluorescencia de rayos $\mathrm{x}$ por reflexión total (TXRF), se han utilizado tres técnicas exploratorias de análisis multivariante: Análisis cluster, Análisis de componentes principales y Análisis discriminante. Estos análisis 
se han llevado a cabo a partir de la transformación logarítmica de las concentraciones elementales, con el fin de compensar las diferencias de magnitud entre los valores de los elementos mayores y trazas (6), en el cálculo de los coeficientes de similaridad (Bishop y Neff, $1989,63)$.

El Analisis cluster se ha realizado con el programa SPSS/PC v. 3.0 (SPSS reference guide). Se trata de un método para representar las distancias euclídeas en dos dimensiones. La distancia euclídea puede entenderse como una generalización n-dimensional de la distancia en una línea recta y se calcula midiendo los cuadrados de las diferencias de los valores de cada elemento, según

$$
d_{i k}^{2}=\sum_{j=1}^{\mathrm{n}}\left(Y_{i j}-Y_{k j}\right)^{2}
$$

donde i y $\mathrm{k}$ son los valores de cada muestra para un elemento determinado (Attas et al., 1977, 38; Glascock, 1992: 17). Por otro lado, para la agrupación de muestras, se ha empleado el Método del centrmide, que calcula las distancias a partir de los centroides de las agrupaciones surgidas en el proceso de fusión (Buxeda, 1994, 113). El Análisis cluster se ha utilizado como primer acercamiento a la estructura general de los datos obtenidos.

El Análisis de componentes principales se ha realizado con el programa SPAD.N v. 2.5. Este análisis determina la dirección y magnitud de la varianza máxima de los datos (Glascock, 1992, 17) y en él, la proximidad viene expresada en términos de distancia angular (Shennan, 1992, 251). Su aplicación se ha llevado a cabo a partir de una matriz de correlación XX'. El coeficiente de cortelación entre dos vartables se define como:

$$
r=\frac{C_{x y}}{s d_{x} s d_{y}}
$$

donde $C_{x y}$ es la covarianza de las dos variables, mientras que $s_{x}$ y sdy representan la desviación estándar de cada una de ellas (Baxter, 1994, 33). Los componentes constituyen un nuevo grupo

(6) Los dementos mayores son agucllos cuya concentración se presenta en cantidades mayores a un $1 \%$; Ios clementos menores aquehos que presentan una concentración comprendida entre 0,1 y $1 \%$ y, les trazas, aquellos que se presentan en concentraciones inferiores al $0,1 \% \mathrm{o}$, lo quc es lo mismo, $1.000 \mathrm{ppm}$ (partes por millón). 
de ejes de referencia que son combinaciones lineales de los datos originales, de la forma:

$$
P=a_{1} Y_{1}+a_{2} Y_{2}+\ldots a_{p} Y_{p}
$$

donde $\mathrm{Y}$ son los datos de la matriz de correlación (Baxter, 1994, 49; Bishop y Neff, 1989, 64). El Análisis de componentes principales, se ha empleado como técnica exploratoria de contrastación, de los resultados preliminares obtenidos mediante el Análisis cluster.

Por último, el Análisis discriminante, llevado a cabo con el progtama estadístico BMDP (Jennrich y Sampson, 1990), se ha utilizado para evaluar las agrupaciones obtenidas en el análisis anterior. Esta técnica enfatiza las diferencias existentes entre dos o más grupos, evaluando las distancias entre los puntos individuales y los diferentes centroides, definidos por las concentraciones elementales (Glascock, 1992, 18; Bishop y Neff, 1989, 67-68). El Análisis discriminante resulta en una función de la forma siguiente para cada fila de la matriz de datos:

$$
F=a_{0}+a_{1} Y_{1}+a_{2} Y_{2}+\ldots a_{p} Y_{p}
$$

donde $\mathrm{Y}$ son los datos de la matriz (Baxter, 1994, 188-189). Para evaluar las distancias entre los puntos individuales y los centroides de las distintas agrupaciones, se ha empleado la Distancia de Mabalanobis o Distancia Generalizada. La Distancia de Mahalanobis del individuo k al centroide del grupo A, se define como:

$$
d_{k A}^{2}=\sum_{i=1}^{\mathrm{n}} \sum_{j=1}^{\mathrm{n}}\left(Y_{i k}-\bar{A}_{i}\right) S_{i j}^{j}\left(Y_{j k}-\overline{A_{j}}\right)
$$

donde $\bar{A}_{i}$ y $\bar{A}_{i}$ son la media de los elementos i, j en el grupo y $S_{i j}{ }^{-1}$ es la inversa de la matriz de varianza-covarianza (Glascock, 1992, 18). Esta distancia, no sólo consideta la proximidad, en términos euclideos, de un punto a su centroide, sino el rango en el cual la densidad de puntos decrece en todas las n-dimensiones desde el centroide a los puntos de interés (Neff et al., 1994, 338). 


\subsection{PROCESO DE CONTRASTACIÓN DE LA POTENCIALIDAD DE LA FLUORESCENCIA DE RAYOS X (TXRF) EN EL ANÁLISIS DE CERÁMICAS ARQUEOLÓGICAS}

Como se apuntaba en la introducción de esta Tesis Doctoral, la utilización de una técnica, que se empleaba por vez primera a escala internacional en el análisis de sólidos y, más concretamente, en el análisis de cerámicas arqueológicas, exigía la realización de un estudio previo, en el cual se llevara a cabo un seguimiento de su exactitud y precisión en el análisis de este tipo de materiales, con el fin de lograr una correcta normalización y reproducibilidad en las determinaciones elementales. Es preciso resaltar, que lo importante de cualquier técnica geoquímica, es que tenga, precisamente, una buena reproducibilidad. En otras palabras, esto significa que no es primordial que los análisis sean exactos, sino que los errores en las determinaciones estén controlados y sean reptoducibles (Picon, 1993, 5; Bishop et al., 1990, 541543). En cualquier caso, este es un aspecto que afecta, o deberia afectar, de modo directo, a los arqueólogos, puesto que, en última instancia, la precisión de los datos obtenidos, es la que dicta el nivel inferencial que se establezca en la interpretación final (De Atley y Bishop, 1991, 372).

$\mathrm{El}$ análisis mediante Fluorescencia de rayos $\mathrm{x}$ por reflexión total (TXRF) (7), es una técnica, relativamente nueva, con la que se han obtenido datos muy precisos en el análisis de muestras líquidas (Prange, 1989; Tölg y Klockenkämper, 1993). Sin embargo, la idea de aplicar la TXRF al análisis de sólidos, surgió a partir de la consulta del estudio publicado por Schneider (1989) sobre el análisis de trazas metálicas atmosféricas. Este investigador planteaba la posibilidad de extrapolar la deposición de partículas coloidales atmosféricas, a la deposición de un sólido genérico -mediante una suspensión previa- siempre que ésta cumpliese tres requerimientos básicos: homogeneidad química, tamaños de partícula promedio inferiores a 10 $\mu \mathrm{m}$ y distribución estadística de las particulas depositadas (Kregsamer, 1991; Aiginger, 1991).

De esta forma, se inició un programa de investigación encaminado a comprobar cuáles eran las prestaciones que ofrecía la TXRF en el análisis de materiales cerámicos. Para llevar a cabo esta comprobación, se eligió un material arcilloso de referencia analizado mediante Activación de neutrones (NAA), por ser ésta una técnica ampliamente aceptada, por su exactitud y precisión en determinaciones multielementales. Con este fin, se contactó con los doctores $\mathrm{H}$. Neff y M. D. Glascock, de la Universidad de Missouri (Columbia, USA), quienes suministraron

(7) A partir de ahora, tas referencias a esta técnica se van a hacer sicmpre mediante las iniciales ' lXRl' 
TABLA 4.3. CONCENTRACIONES ELEMENTALES DEL PATRÓN "OHIO RED CLAY-2" ANALIZADO MEDIANTE ACTTVACIÓN DE NEUTRONES (NAA) EN EL MISSOURI UNIVERSITY RESEARCH REACTOR (MURR) DE COLUMBIA (USA)

\begin{tabular}{|c|c|c|}
\hline Elemento & Concentración (ppm) & Desviación estándar $(n=20)$ \\
\hline As & 14,295 & 6.5 \\
\hline $\mathrm{La}$ & 50,781 & 4.5 \\
\hline $\mathrm{Lu}$ & 0,595 & 4.2 \\
\hline $\mathrm{Nd}$ & 45,228 & 9.1 \\
\hline $\mathrm{Sm}$ & 9,711 & 6.7 \\
\hline $\mathrm{U}$ & 3,111 & 15.8 \\
\hline $\mathrm{Yb}$ & 4,337 & 5.8 \\
\hline $\mathrm{Ce}$ & 113,754 & 2.8 \\
\hline Co & 23,110 & 3.5 \\
\hline $\mathrm{Cr}$ & 91,683 & 3.3 \\
\hline $\mathrm{Cs}$ & 10,304 & 3.6 \\
\hline Eu & 1,755 & 4.0 \\
\hline $\mathrm{Fe}$ & $51.465,000$ & 3.5 \\
\hline Hf & 7,509 & 3.6 \\
\hline $\mathrm{Ni}$ & 72,000 & 24.8 \\
\hline $\mathrm{Rb}$ & 185,094 & 3.9 \\
\hline $\mathrm{Sb}$ & 1,119 & 6.9 \\
\hline $\mathrm{Sc}$ & 18,754 & 3.8 \\
\hline Sr & 27,000 & 106.4 \\
\hline $\mathrm{Ta}$ & 1,515 & 3.1 \\
\hline $\mathrm{Tb}$ & 1,279 & 17.3 \\
\hline Th & 15,106 & 3.9 \\
\hline $\mathrm{Zn}$ & 92,957 & 7.0 \\
\hline$\angle \mathbf{r}$ & 179,400 & 13.7 \\
\hline $\mathrm{Al}$ & $95.292,000$ & 2.2 \\
\hline $\mathrm{Ba}$ & 588,000 & 23.4 \\
\hline $\mathrm{Ca}$ & $1.548,000$ & 13.1 \\
\hline Dy & 7,040 & 2.4 \\
\hline K & $32.870,000$ & 23.3 \\
\hline $\mathrm{Mn}$ & 264,900 & 2.3 \\
\hline $\mathrm{Na}$ & $1.412,000$ & 2.1 \\
\hline li & $6.165,000$ & 5.2 \\
\hline V & 201,500 & 2.8 \\
\hline
\end{tabular}




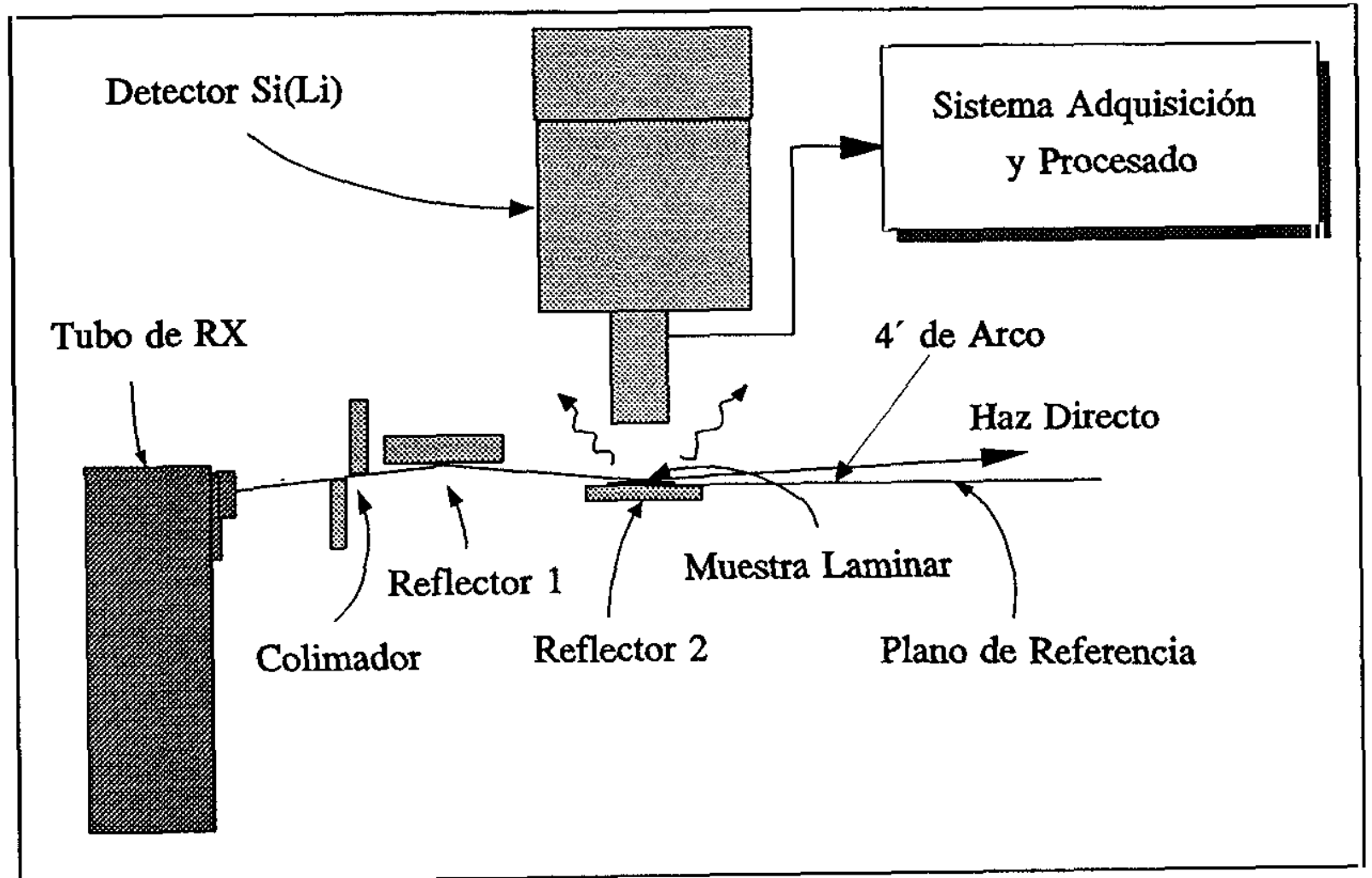

Figura 4.7: Geometria de reflexión total en la técnica de TXRF.

el patrón arcilloso "Ohio Redart Clay" de Resco Products Inc. (Oak Hill, Ohio, USA), conocido en la bibliografia especializada como "Ohio Red Clay-2". Esta muestra es constantemente verificada por este equipo (Cogswell et al., 1996) y sus concentraciones elementales se ofrecen en la Tabla 4.3. No obstante, una muestra similar, conocida como "Ohio Red Clay-1", se suele utilizar como patrón de normalización entre el Brokbaven National Laboratory (BNL) de Nueva York, el National Institute of Science and Technology (NIST) de Massachussetts y el Missouri University Research Reactor (MURR) de Columbia (Glascock, 1992, 14-15). Aunque ambas muestras son, composicionalmente, muy similares, no son exactamente idénticas.

A continuación, se ofrecen los tesultados obtenidos en la comparación de estas dos técnicas: TXRF y Análisis de activación de neutrones (NAA). Dicha comparación, se ha tealizado utilizando dos métodos diferentes en la preparación de las muestras, con el fin de determinar con cuál de los dos se obtenían los mejores resultados. 


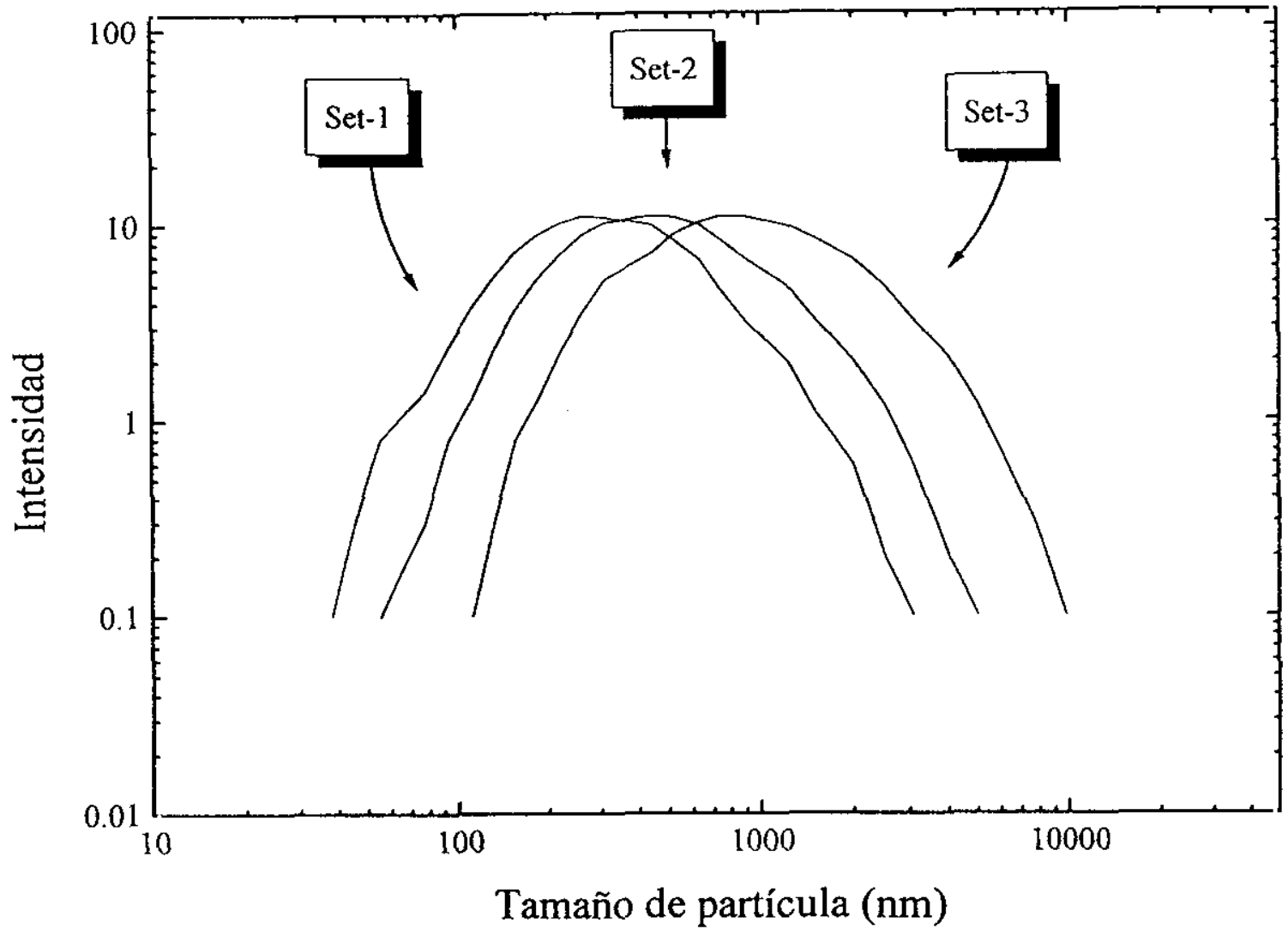

Figura 4.8: Espectros de fotocorrelación (QELS) de las distribuciones de tamaño de partícula presentes en el Set-1, Set-2 y Set-3.

\subsubsection{La técnica de TXRF}

En los equipos corrvencionales de Fluorescencia de rayos $\mathrm{x}$ (XRF), el ángulo de incidencia del haz de rayos $\mathrm{x}$ puimario, es del orden de $45^{\circ}$. Por el contratio, el ángub de incidencia en un equipo de TXRF, es de 4 minutos de arco. Este hecho, produce un incremento sustancial de a relación señal/fondo. Sin embango, ba muestra debe tener una geometrí de kámina delgacá. Fsta condición se obtiene evaporando el solvente en el pottamuestras, pata el caso de musstras liquidas, las cuales presentan una ausencia de conrecciones debidas a la absorción de la matriz (Prange, 1989, 438). La Fìgua 4.7 ofrece un esquema de la goometria de rayos $\mathrm{x}$ por reflexión total 


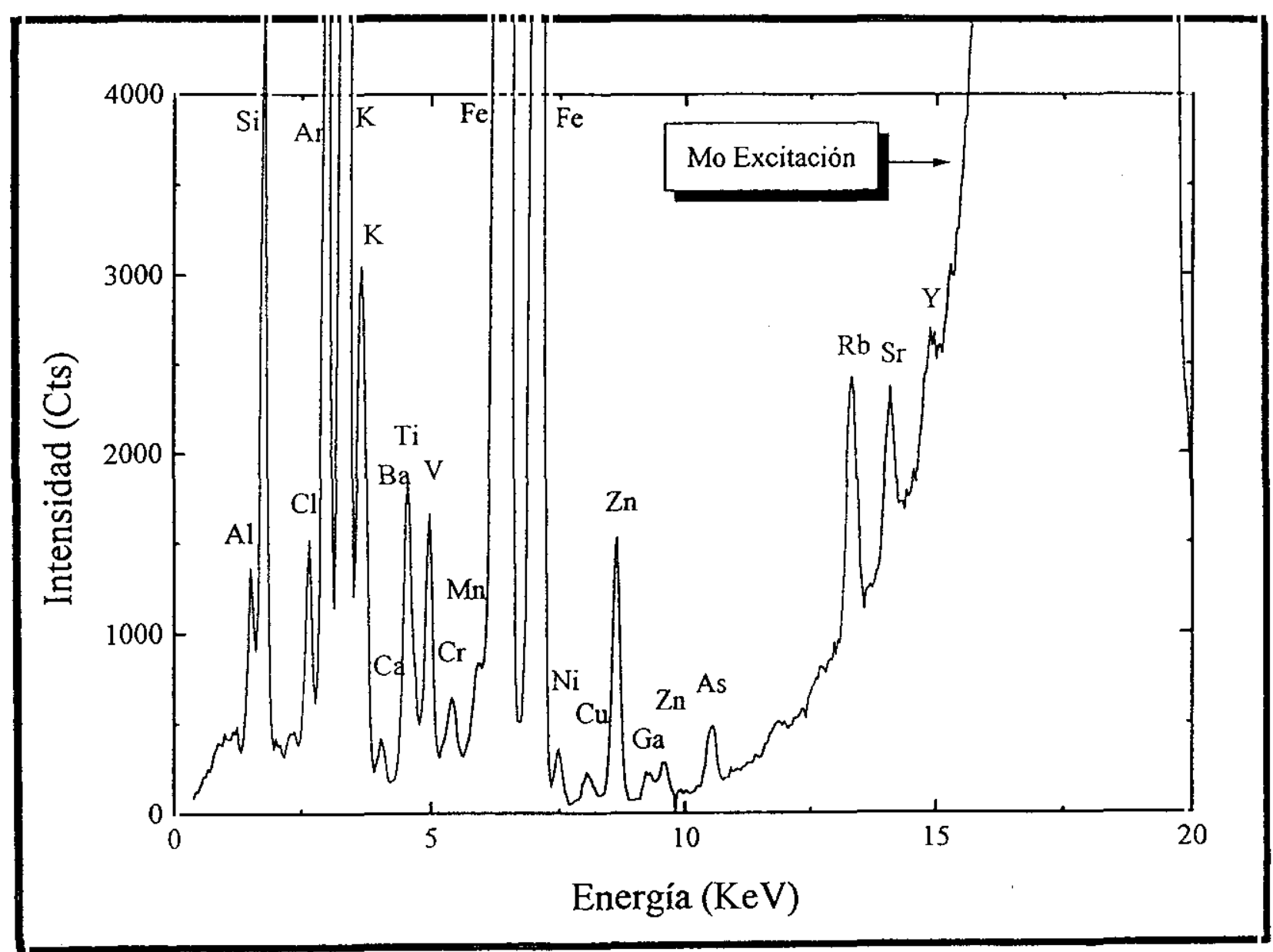

Figura 4.9: Espectro característico de TXRF obtenido a partir del patrón "Ohio Red Clay-2".

\subsubsection{Investigación previa}

Como se ha mencionado anteriormente, para obtener una geometría de lámina delgada, era necesario cumplir con tres requerimientos fundamentales:

1.- Homogeneidad química, para evitar que se produzcan sedimentaciones selectivas de micropartículas en función de su densidad.

2.- 'Tamaños de partícula promedio inferiores a $10 \mu \mathrm{m}$, para reducir al mínimo el efecto matriz.

3.- Distribución estadística de las partículas depositadas en forma de capa monopartícula. 


\subsubsection{Preparación preliminar de muestras}

Si se considera a la arcilla compuesta por micropartículas de diferentes tamaños, pero químicamente homogéneas, es factible obtener distintas fracciones de tamaño, utilizando el método de decantación. Por consiguiente, y aceptando esta consideración, se prepararon tres series de muestras (Set-1 a Set-3), de 5 muestras por serie, del patrón "Ohio Red Clay-2", según el siguiente procedimiento. Primero, la muestra se molió durante 3 horas con un mortero de ágata, tras lo cual se tomaton $100 \mathrm{mg}$ que se introdujeron en un tubo de ensayo, al que se le añadió agua suprapura (Millipore-Q-Plus, 18,2 M 2 ) hasta $10 \mathrm{ml}$. Después, el tubo de ensayo se emplazó, durante una hora, en un baño de ultrasonidos, con el propósito de disgregar y homogeneizar la muestra. Una vez concluido este proceso, ésta se dejó decantar durante un periodo de 12 horas. Finalmente, se tomaron alícuotas de $1 \mathrm{ml}$ a tres alturas diferentes, medidas desde la base: $15 \mathrm{~cm}$ para el Set-1, $10 \mathrm{~cm}$ para el Set-2 y $5 \mathrm{~cm}$ para el Set3, con el fin de obtener una distribución promedio de los diferentes tamaños de partícula, evidentemente, siempre inferiores a $10 \mu \mathrm{m}$, tal y como planteaba el segundo de los requerimientos. De esta forma, se obtuvieron tres series de muestras, con los siguientes tamaños de partícula: Set-1, inferior a $1 \mu \mathrm{m}$; Set-2, entre 0,05 y $2 \mu \mathrm{m}$ y Set-3, entre 0,1 y $5 \mu \mathrm{m}$. La Figura 4.8 recoge estos resultados, verificados mediante Espectroscopía de fotocorrelación (QELS).

\subsubsection{Obtención de datos}

Los datos se obtuvieron del siguiente modo. En primer lugar, se utilizó el paquete informático AN-10.000, para deconvolucionar el espectro. Esta deconvolución proporciona las áreas integradas de cada elemento. Después de obtener estas áreas, se convierten en unidades de masa relativa, según la ecuación:

$$
M_{x}=\left(\frac{P_{x} R_{\text {lie }}}{P_{\text {lic }} R_{x}}\right) M_{\text {ree }}
$$

donde $\mathrm{M}$ es la masa relativa o concentración de un elemento dado, $\mathrm{P}$ es el área del pico, $\mathrm{R}$ es la intensidad relativa de fluorescencia, el indice $x$ define cada elemento analizado y Fe el 
elemento escogido como referencia. Los valores de $\mathrm{R}$ son constantes del sistema, mientras que el resto de los parámetros son experimentales. Un valor de 100 se asocia, entonces, a la concentración de $\mathrm{Fe}\left(\mathrm{M}_{\mathrm{Fe}}\right)$, obteniéndose, de esta forma, valores $\left(\mathrm{M}_{\mathrm{x}}\right)$ expresados como \% versus Fe. Este elemento, se escogió debido a que se encuentra siempre presente en arcillas y cerámicas de interés arqueológico, mostrando un perfil claramente diferenciado en los espectros de TXRF (Figura 4.9).

Las concentraciones elementales del patrón "Ohio Red Clay-2", venian expresadas en $\mathrm{Ppm}$, por lo que fueron normalizadas respecto al $\mathrm{Fe}$, con el fin de que los resultados obtenidos mediante TXRF fuesen comparativos. Asi, realizar una sencilla proporción directa, es el único procedimiento necesario para transformar datos cuantitativos (ppm) en resultados semi-cuantitativos (\% versus. Fe).

\subsubsection{Resultados preliminares}

Se determinaron los siguientes 25 elementos: As, La, Nd, U, Co, Cr, Cs, Hf, Ni, Rb, Sc, Sr, Zn, Al, Ba, Ca, K, Mn, Ti, V, Si, Cu, Ga, Y y Fe. De estos 25, un total de 19 se escogieton para los análisis de rutina. El Si fue desechado, debido a que el portamuestras es de cuarzo, lo cual supone un incremento aleatorio dificil de cuantificar. El Co también se desechó, porque se camufla, en este caso, con las líneas de emisión del Fe. Este hecho se manifiesta cuando el rango dinámico entre el Fe y el Co es superior a 104. Por otro lado, el La, $\mathrm{U}$, Cs y Sc se descartaron, igualmente, por encontrarse en los límites de detección que la TXRF presenta para estos elementos.

Los resultados semi-cuantitativos obtenidos, mostraron que se producian enriquecimientos (p. e. Zn, Ti o Cu) o empobrecimientos (p. e. As, V, o Sr), con respecto a las concentraciones obtenidas mediante Activación de neutrones (NAA). Esto eta fácilmente explicable, ya que las arcillas están compuestas por varios minerales, lo que significa que puede haber diferencias, tanto químicas como mineralógicas, entre las partículas de diferentes tamaños. Por tanto, este hecho entraba en contradicción con el primero de los requerimientos expresados más arriba, poniendo de manifiesto que el método de sedimentación no era adecuado para el análisis mediante TXRF de este tipo de materiales, como muestra la Tabla 4.4 . 
TABLA 4.4. RESULTADOS COMPARATIVOS DE LAS CONCENTRACIONES ELEMENTALES DEL SET-1, SET-2 Y SET-3 OBTENIDAS MEDIANTE TXRF

\begin{tabular}{ccccc}
\hline $\begin{array}{c}\text { Elemento } \\
(\% v s . \mathrm{Fe})\end{array}$ & $\begin{array}{c}\text { Set-1 S.D. } \\
(\mathrm{n}=5)\end{array}$ & $\begin{array}{c}\text { Set-2 S.D. } \\
(\mathrm{n}=5)\end{array}$ & $\begin{array}{c}\text { Set-3 S.D. } \\
(\mathrm{n}=5)\end{array}$ & $\begin{array}{c}\text { NAA S.D. } \\
(\mathrm{n}=20)\end{array}$ \\
\hline $\mathrm{As}$ & $0.17 \pm 0.07$ & $0.12 \pm 0.04$ & $0.054 \pm 0.002$ & $0.028 \pm 0.002$ \\
$\mathrm{Nd}$ & $0.03 \pm 0.04$ & $0.06 \pm 0.05$ & $0.06 \pm 0.03$ & $0.09 \pm 0.01$ \\
$\mathrm{Cr}$ & $0.14 \pm 0.02$ & $0.19 \pm 0.04$ & $0.17 \pm 0.03$ & $0.18 \pm 0.01$ \\
$\mathrm{Hf}$ & $0.09 \pm 0.01$ & $0.01 \pm 0.005$ & $0.008 \pm 0.005$ & $0.015 \pm 0.001$ \\
$\mathrm{Ni}$ & $0.16 \pm 0.01$ & $0.19 \pm 0.05$ & $0.15 \pm 0.02$ & $0.14 \pm 0.03$ \\
$\mathrm{Rb}$ & $0.34 \pm 0.02$ & $0.33 \pm 0.02$ & $0.24 \pm 0.05$ & $0.36 \pm 0.02$ \\
$\mathrm{Sr}$ & $0.25 \pm 0.04$ & $0.19 \pm 0.03$ & $0.118 \pm 0.004$ & $0.05 \pm 0.06$ \\
$\mathrm{Zn}$ & $0.34 \pm 0.07$ & $0.8 \pm 0.2$ & $0.5 \pm 0.1$ & $0.18 \pm 0.02$ \\
$\mathrm{Al}$ & $168 \pm 35$ & $163 \pm 33$ & $147 \pm 28$ & $185 \pm 6$ \\
$\mathrm{Ba}$ & $0.8 \pm 0.3$ & $0.8 \pm 0.2$ & $0.9 \pm 0.2$ & $1.2 \pm 0.3$ \\
$\mathrm{Ca}$ & $5.2 \pm 0.8$ & $6 \pm 2$ & $3 \pm 0.2$ & $3 \pm 0.4$ \\
$\mathrm{~K}$ & $94 \pm 10$ & $85 \pm 11$ & $53 \pm 2$ & $64 \pm 16$ \\
$\mathrm{Mn}$ & $0.25 \pm 0.04$ & $0.27 \pm 0.02$ & $0.26 \pm 0.02$ & $0.51 \pm 0.01$ \\
$\mathrm{Ti}$ & $3.3 \pm 0.7$ & $3.40 \pm 0.06$ & $6.4 \pm 0.5$ & $11.9 \pm 0.6$ \\
$\mathrm{~V}$ & $2 \pm 1$ & $2 \pm 1$ & $0.43 \pm 0.03$ & $0.39 \pm 0.01$ \\
$\mathrm{Cu}$ & $0.06 \pm 0.01$ & $0.12 \pm 0.04$ & $0.05 \pm 0.03$ & ---- \\
$\mathrm{Ga}$ & $0.049 \pm 0.007$ & $0.046 \pm 0.005$ & $0.042 \pm 0.006$ & $-\cdots$ \\
$\mathrm{Y}$ & $0.06 \pm 0.01$ & $0.06 \pm 0.01$ & $0.05 \pm 0.01$ & ---- \\
\hline \hline
\end{tabular}

S.D. Desviación estándar.

\subsubsection{Método definitivo de análisis}

Con el fin de resolver el fenómeno de segregación producido por el método de sedimentación y cumplir con el primer requerimiento expuesto al principio de este apartado, se decidió preparar un nueva serie de 5 muestras (Set-4) del patrón "Ohio Red Clay-2", que fuera químicamentc homogénea. 


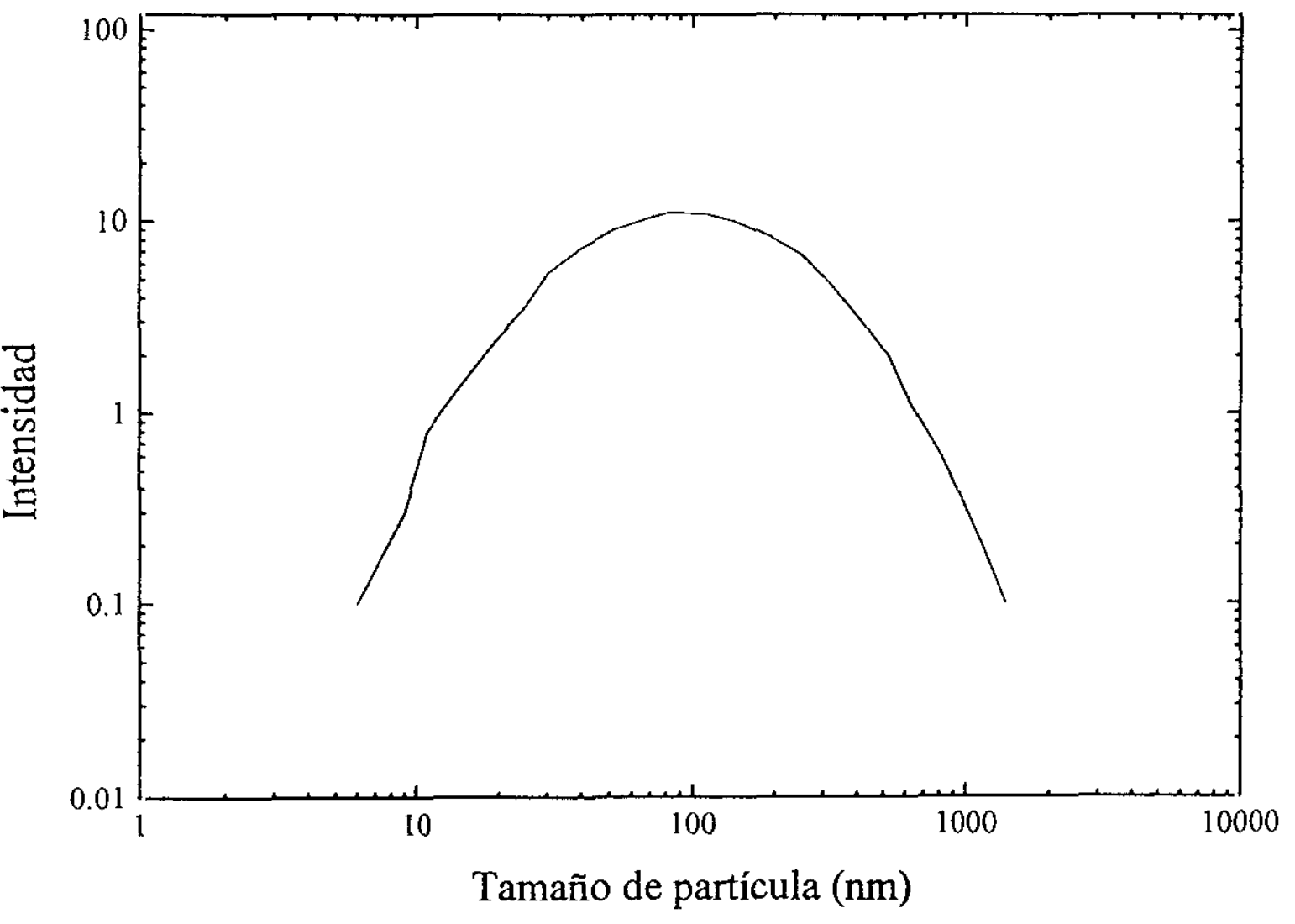

Figura 4.10: Espectro de fotocorrelación (QELS) de la distribución del tamaño de particula presente en el Set-4.

\subsubsection{Preparación definitiva de muestras}

En el Set-4, las muestras se prepararon del siguiente modo. En primer lugar, cada muestra se molió con mortero de ágata hasta conseguir un tamaño de partícula próximo a los $30 \mu \mathrm{m}$. Más tarde, se sometió, durante una hora, a una segunda molienda en un micropulverizador Fritzch con bola y base también de ágata. Después de finalizar este proceso, se añadió a la muestra $1 \mathrm{ml}$ de agua suprapura y se emplazó en un tubo de ensayo, al que se le añadió agua de estas mismas características, hasta $10 \mathrm{ml}$. A continuación, la muestra se homogeneizó, durante un período de media hora, en baño de ultrasonidos, con el fin de disgregar las posibles aglomeraciones de partículas. Finalmente, se comprueba la distribución del tamaño de partículas en suspensión, mediante Espectroscopia de fotocorrelación (QELS), hasta conseguir la distribución requerida, es decir, tamaños de partícula inferiores a $10 \mu \mathrm{mi}$ (Figura 4.10). Cuando la muestra tiene esta distribución, se homogeniza de nuevo, se toman 5 


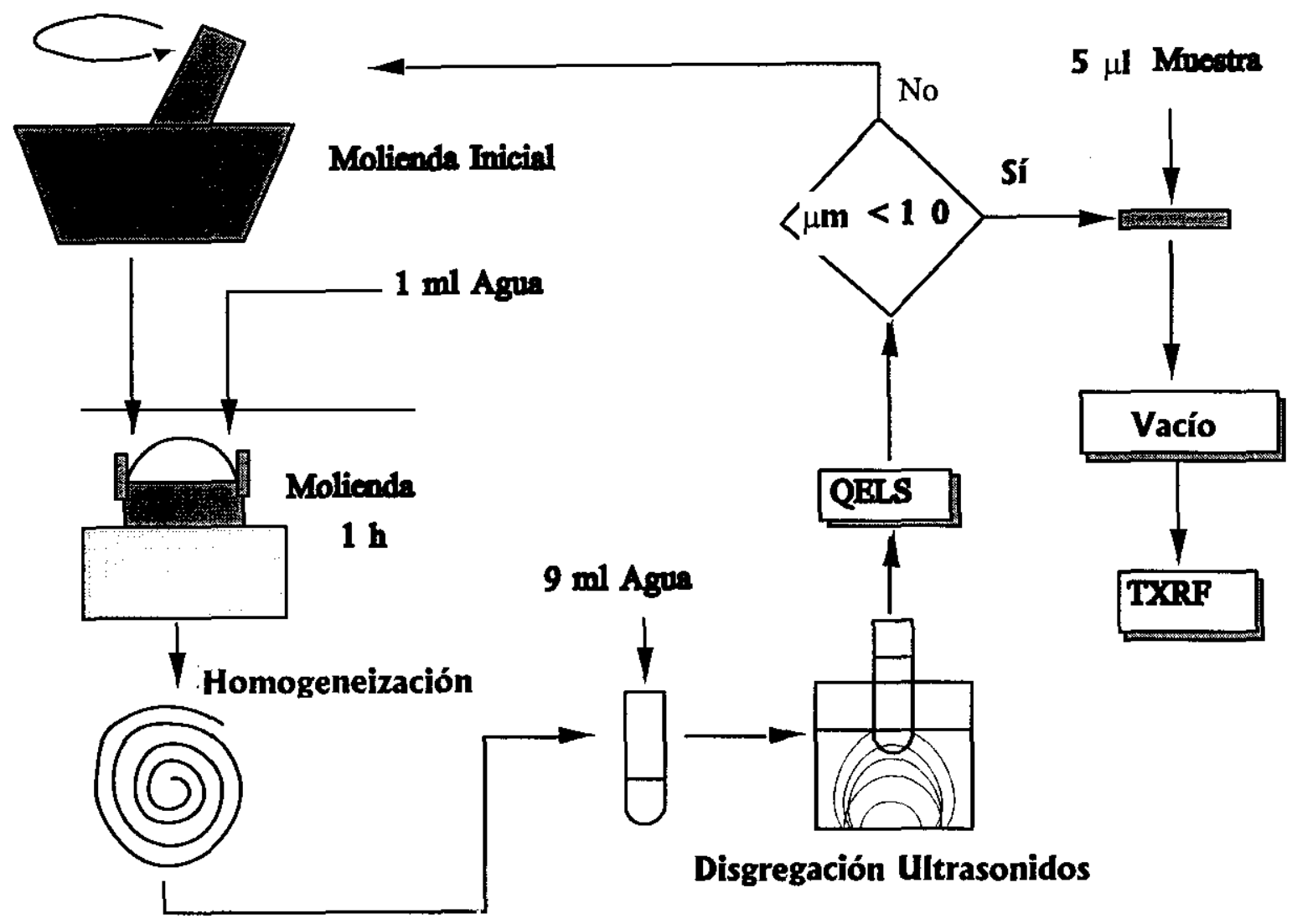

Figura 4.11: Proceso definitivo de preparación de muestras.

$5 \mu$ de la suspensión y se depositan sobre el portamuestras, en donde el agua se evapora a vacio. Este proceso se ilustra en la Figura 4.11.

Con el propósito de verificar el tercer requerimiento, se observaton, mediante Microscopía electrónica de barrido (SEM), diferentes tipos de deposiciones en el Set-4. La primeta se suspendió en agua, presentando una distribución de anillos concéntricos, probablemente asociados al efecto de borde en la interfase líquido/sólido, durante el proceso de evaporación del agua. Este hecho, entraba en contradicción con el tercer requerimiento (Figura 4.12 a y b). Por este motivo, y con el fin de obtener una distribución de partículas aislada y homogénea, se experimentaron distintos medios suspendentes con diferentes tensiones superficiales (metanol, etanol, acetona, tolueno, etc.). Por último, se comprobó que era el tolueno el que ofrecía la mejor distribución (Figura 4.12 c y d). No obstante, este medio desvirtuaba seriamente las determinaciones elementales, por lo que se optó, finalmente, por agua suprapura, aunque no cumpliese, estrictamente, el tercero de los requerimientos. De hecho, el agua era el agente que ofrecia los mejores resultados analíticos. 
Como el principal objetivo de esta contrastación era el análisis de materiales cerámicos, también se observó el aspecto de varias muestras de cerámica arqueológica, utilizando agua suprapura como agente para la suspensión, mediante Microscopía electrónica de barrido (SEM). La Figura 4.12 e y 4.12 f, recoge el aspecto de una de estas muestras, en donde puede observarse una distribución homogénea.

\subsubsection{Resultados definitivos}

La Tabla 4.5 y la Figura 4.13, muestran los resultados obtenidos en el análisis del Set-4, para los 19 elementos seleccionados. En este caso, la exactitud para el $\mathrm{Nd}, \mathrm{Cr}, \mathrm{Rb}, \mathrm{Hf}, \mathrm{Al}, \mathrm{Ba}$, $\mathrm{Ca}, \mathrm{K}, \mathrm{Mn}, \mathrm{Fe}$ y Tí con respecto a los valores del análisis mediante Activación de Neutrones (NAA), fue excelente, como puede observarse en la Tabla 4.5. Por ejemplo, entre otros, pueden destacarse los siguientes valores: $\operatorname{Cr}(0,18 \pm 0,01$ de la TXRF, frente a $0,18 \pm 0,01$ de la activación), $\mathrm{Rb}(0,354 \pm 0,004$ de la TXRF, frente a $0,36 \pm 0,02$ de la activación) o $\mathrm{Mn}(0,50$ $\pm 0,01$ de la TXRF, frente a $0,51 \pm 0,01$ de la activación). No obstante, hay que destacar la discrepancia que existe en las concentraciones de los elementos As, V, Ni, Sr y $\mathrm{Zn}$, para los que la TXRF presenta una elevada sensibilidad, siendo detectados en el espectro asociado a la muestra de manera inequívoca (Figura 4.14). Por lo demás, mediante TXRF, se han podido también reconocer y semi-cuantificar, tres elementos químicos no analizados por Activación de neutrones (NAA), en el patrón "Ohio Red Clay-2": Cu, Ga e Y.

La precisión obtenida en las mediciones realizadas mediante TXRF, varía desde un $1 \%$ de error relativo para el $\mathrm{Rb}$, hasta un $54 \%$ para el $\mathrm{Hf}$, mientras que en los análisis mediante Activación de neutrones (NAA), la precisión varía desde un $2 \%$ para el $\mathrm{Al}$, hasta un $106 \%$ para el Sr. Estos factores, no implican que la TXRF sea una técnica más poderosa que la activación, sino, más bien, que la TXRF puede ofrecer una exactitud y una precisión comparables a la activación para 15 elementos. En todo caso, debe tenerse en cuenta que el Missouri University Research Reactor (MURR) de Columbia (USA), analiza de forma rutinaria, mediante activación, un total de 33 elementos químicos.

En resumen, la técnica de TXRF proporciona, en el análisis de muestras cerámicas, determinaciones simultáneas de un buen número de elementos químicos, en concentraciones mayores, menores y trazas. El método requiere, como ha podido verse, una mínima cantidad de muestra (10 mg son suficientes) y presenta la ventaja de reducir al mínimo el efecto matriz, 

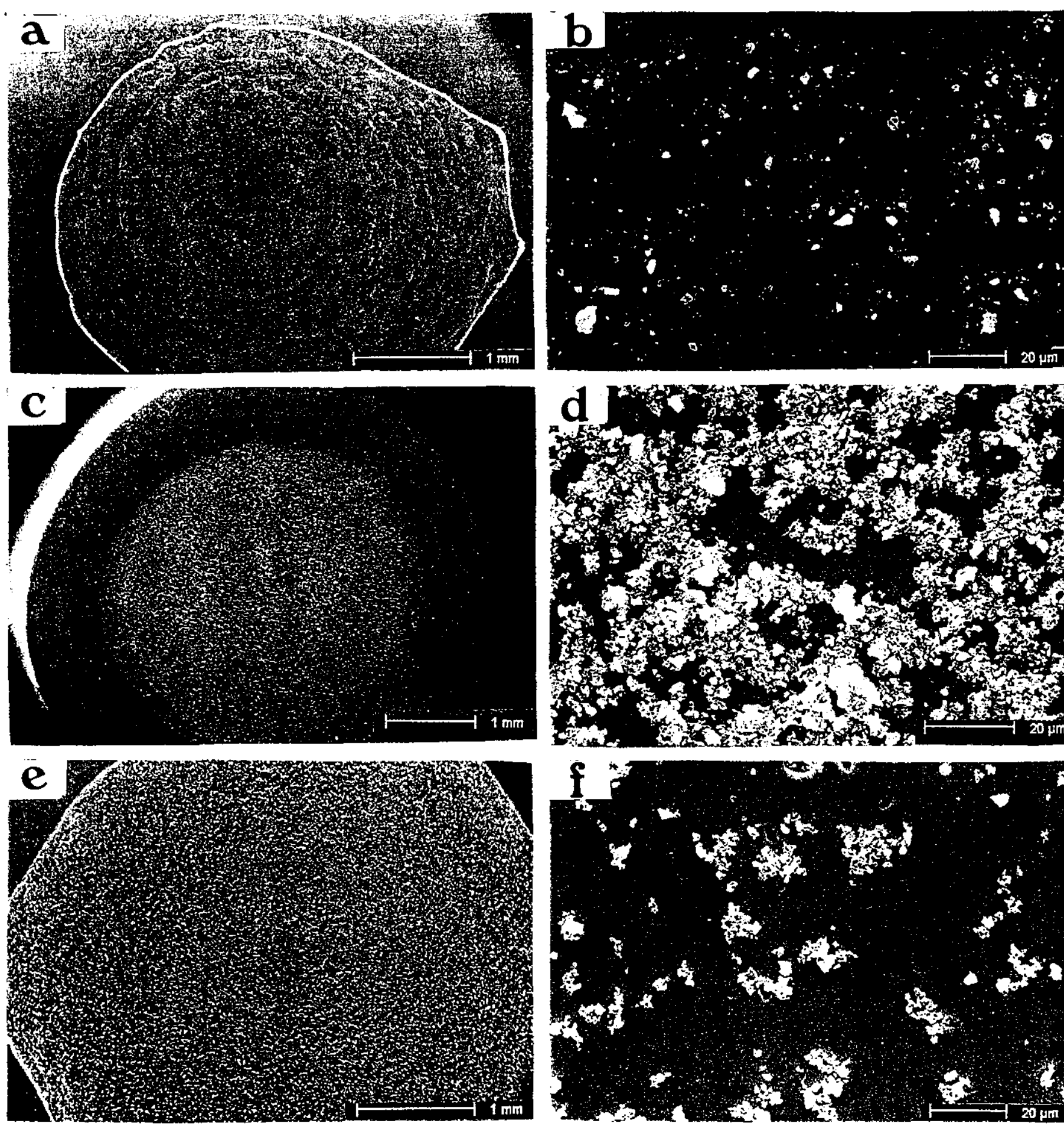

Figura 4.12: Microfotografias obtenidas mediante Microscopia electrónica de barrido ( $(\mathrm{M} M)$, de deposiciones realizadas con diferentes agentes suspendentes. a-b "Ohio Red Clay-2" en agua suprapura. c-d "Ohio Red Chay-2" en tolueno. e-f muestra de 


\section{TABLA 4.5. RESULTADOS COMPARATIVOS DE LAS CONCENTRACIONES ELEMENTALES DEL SET-4 OBTENIDAS MEDIANTE TXRF}

\begin{tabular}{|c|c|c|}
\hline Elemento (\% vs. Fe) & NAA $(\mathrm{N}=20)$ Media \pm S.D. & TXRF $(\mathbb{N}=5)$ Set-4 Media \pm S.D. \\
\hline As & $0.028 \pm 0.002$ & $0.041 \pm 0.002$ \\
\hline $\mathrm{Nd}$ & $0.09 \pm 0.01$ & $0.06 \pm 0.02$ \\
\hline $\mathrm{Cr}$ & $0.18 \pm 0.01$ & $0.18 \pm 0.01$ \\
\hline Hf & $0.015 \pm 0.001$ & $0.013 \pm 0.007$ \\
\hline $\mathrm{Ni}$ & $0.14 \pm 0.03$ & $0.44 \pm 0.01$ \\
\hline $\mathrm{Rb}$ & $0.36 \pm 0.02$ & $0.354 \pm 0.004$ \\
\hline Sr & $0.05 \pm 0.06$ & $0.131 \pm 0.004$ \\
\hline $\mathrm{Zn}$ & $0.18 \pm 0.02$ & $0.28 \pm 0.03$ \\
\hline $\mathrm{Al}$ & $185 \pm 6$ & $151 \pm 30$ \\
\hline $\mathrm{Ba}$ & $1.2 \pm 0.3$ & $1.34 \pm 0.07$ \\
\hline $\mathrm{Ca}$ & $3.0 \pm 0.4$ & $2.81 \pm 0.04$ \\
\hline $\mathrm{K}$ & $64 \pm 16$ & $69 \pm 1$ \\
\hline$M \mathbf{n}$ & $0.51 \pm 0.01$ & $0.50 \pm 0.01$ \\
\hline $\mathrm{Ti}$ & $11.9 \pm 0.6$ & $12.3 \pm 0.2$ \\
\hline $\mathrm{V}$ & $0.39 \pm 0.01$ & $0.49 \pm 0.02$ \\
\hline $\mathrm{Cu}$ & --- & $0.04 \pm 0.01$ \\
\hline Ga & $\cdots$ & $0.050 \pm 0.002$ \\
\hline Y & ---- & $0.08 \pm 0.01$ \\
\hline $\mathrm{Fe}$ & 100-Referencia & 100-Referencia \\
\hline
\end{tabular}

S.D. Desviación estándar.

con respecto a la Fluorescencia de rayos $\mathrm{x}$ (XRF) tradicional. No obstante, para la aplicación de la TXRF, es necesario desarrollar un complejo proceso en la preparación de las muestras. Un proceso que implica que la muestra sea químicamente homogénea, que contenga tamaños de partícula promedio inferiores a $10 \mu \mathrm{m}$ y que presente una distribución estadística de sus partículas. Para obtener una muestra de estas características, el método más apropiado ha resultado ser una molienda severa suspendida en agua suprapura, con una disgregación ultrasónica que se deposita en el portamuestras, cuyo tiempo de realización se ha estimado en unas dos horas aproximadamente, incluyendo la adquisición de datos por el espectrómetro.

Quizás, uno de los aspectos más importantes que conviene destacar, sea el que la muestra se analiza sin ningún tipo de manipulación química, en contraste con otros métodos geoquímicos. 


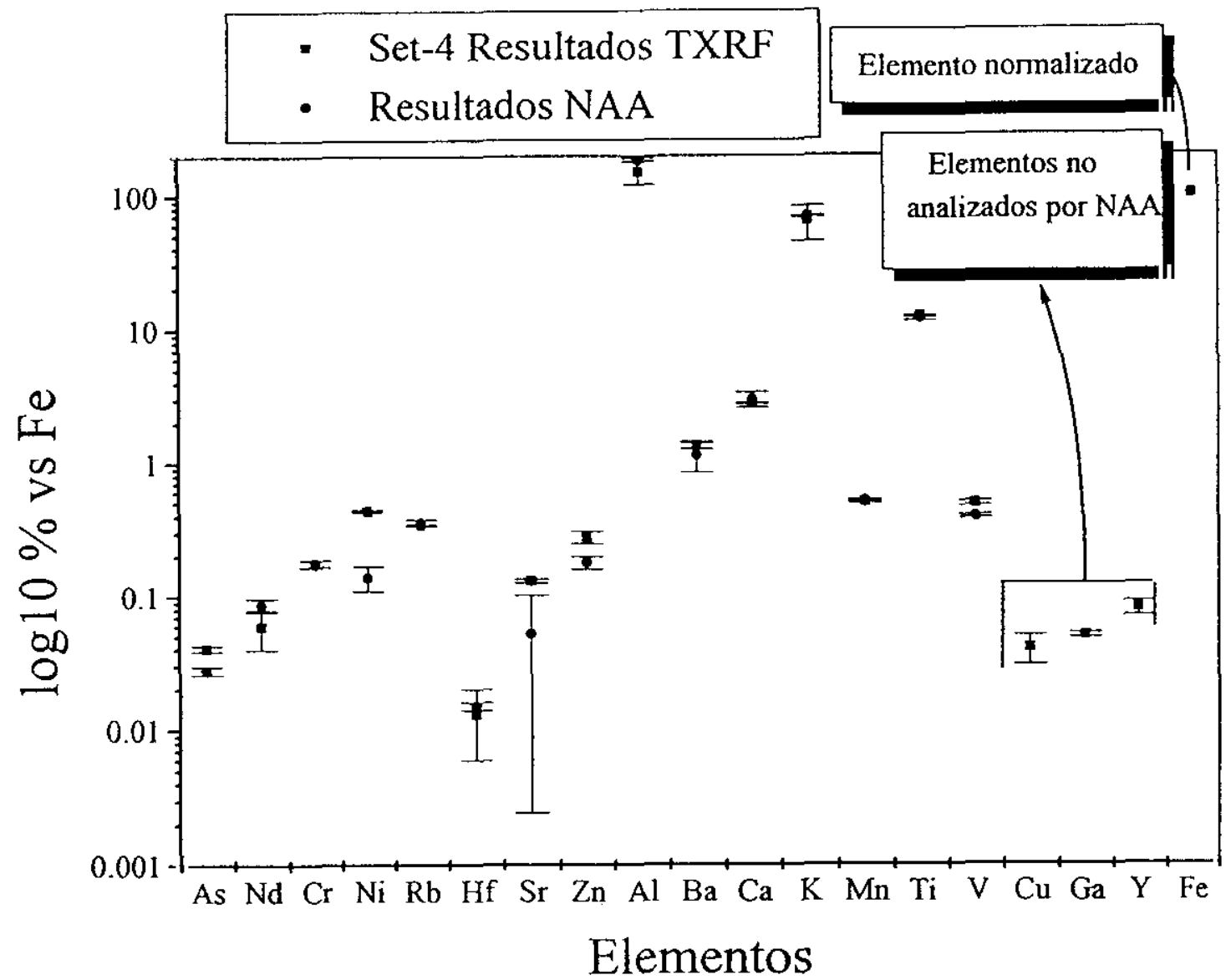

Figura 4.13: Comparación de las concentraciones elementales del Set-4, en relación a los resultados obtenidos mediante Activación de Ncutrones (NAA).

En concordancia con estos resultados, los análisis de rutina se van a realizar para los siguientes 19 elementos: $\mathrm{Al}, \mathrm{Ca}, \mathrm{K}, \mathrm{Ti}, \mathrm{Fe}$ (mayores); $\mathrm{Mn}, \mathrm{Zn}, \mathrm{Sr}, \mathrm{Rb}, \mathrm{Cr}$ (menores) y As, $\mathrm{Nd}$, $\mathrm{Hf}, \mathrm{Ni}, \mathrm{Ba}, \mathrm{V}, \mathrm{Cu}, \mathrm{Ga}$ e Y (trazas). La determinación de los elementos $\mathrm{Nd}$, Cr, Rb, Hf, Al, Ba, $\mathrm{Ca}, \mathrm{K}, \mathrm{Mn}$, Fe y $\mathrm{Ti}$, se realiza con un alto grado de exactitud, mientras que para el As, $\mathrm{V}, \mathrm{Ni}$, Sr y Zn, los resultados de la contrastación llevada a cabo con el patrón "Ohio Red Clay-2" analizado mediante Activación de neutrones (NAA), muestran ciertas discrepancias, que están siendo investigadas en la actualidad y que, por tanto, aún no pueden ser discutidas en esta Tesis Doctoral. 


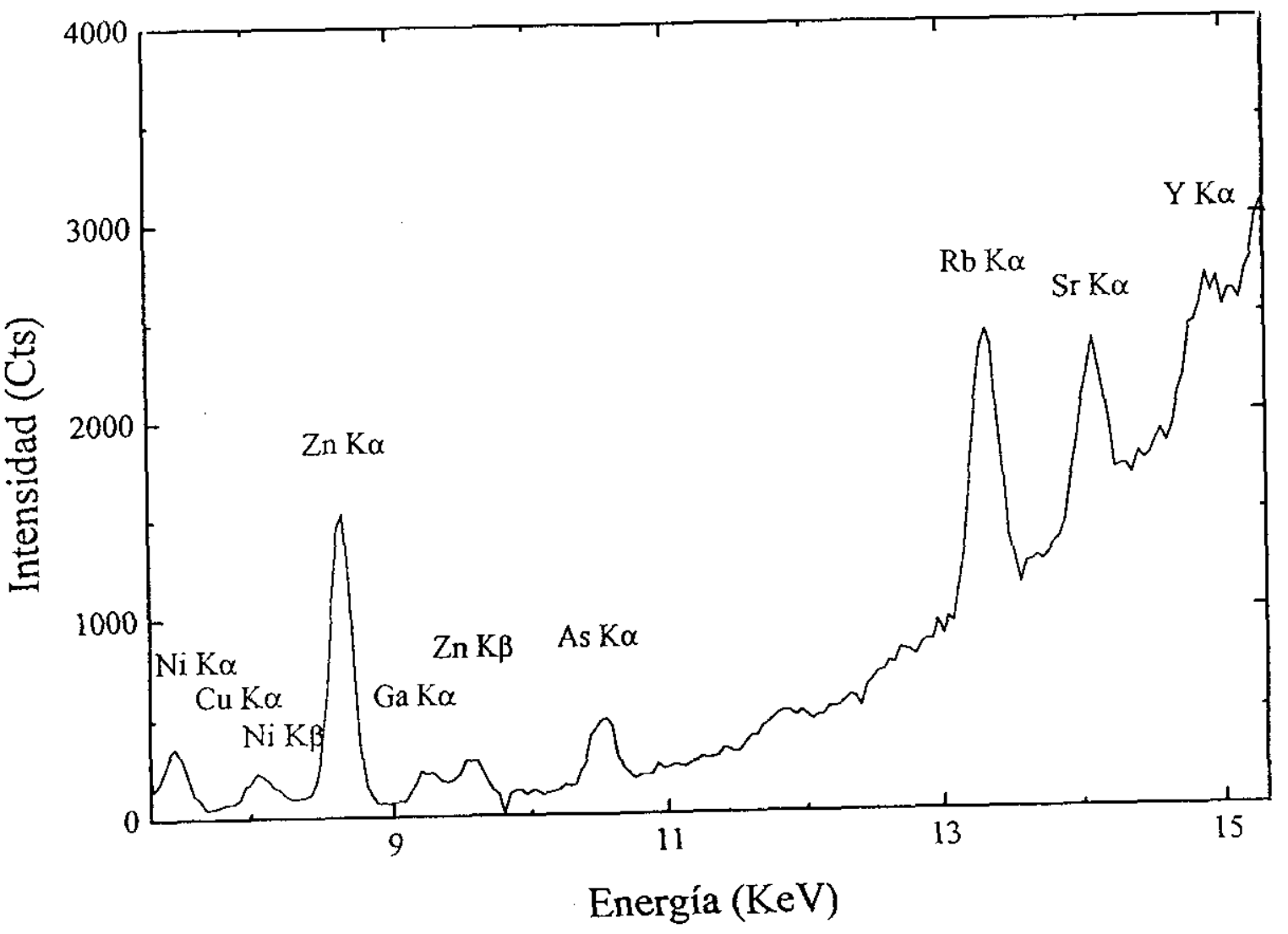

Figura 4.14: Líneas de transición caracteristicas del Ni, Sr y Zn, en un espectro de TXRF obtenido a partir del patrón "Ohio Red Clay-2".

Otro aspecto que merece ser destacado, es que la TXRF, en el estado actual de la investigación, sólo proporciona determinaciones semi-cuantitativas, lo cual no representa un serio obstáculo para la comparación con datos cuantitativos obtenidos con otras técnicas, como se ha tenido oportunidad de comprobar. Por otro lado, lo novedoso de los resultados aportados por esta contrastación, aconsejaton datlos a conocer en diferentes publicaciones, antes de la defensa de esta Tesis Doctoral (García Heras et al., En prensa b; En prensa c).

En otro orden de cosas, y con el objetivo de contar siempre con el mayor control de los errores producidos durante los procesos de muestreo y análisis, se han realizado también otras pruebas experimentales a través de la TXRF. Estas pruebas, se han centrado en tres aspectos distintos: 
1.- Determinar cuáles son los índices de error de la técnica de TXRF en los análisis de rutina masivos.

2.- Comprobar si una sola muestra puede ser representativa de todo un recipiente cerámico.

3.- Comprobar si se producen variaciones significativas, en las concentraciones elementales, de las muestras de sedimentos arcillosos cocidos a distintas temperaturas.

En los siguientes apartados, se exponen los resultados y discusión de estas pruebas.

\subsection{DETERMINACIÓN DE LOS ÍNDICES DE ERROR DE LA TXRF EN LOS ANÁLISIS DE RUTINA MASIVOS}

Para determinar estos indices de error, se analizaton un total de 7 muestras del patrón "Ohio Red Clay-2", a lo largo del proceso de análisis efectuado sobre las 121 muestras de cerámica arqueológica y las 15 procedentes de sedimentos arcillosos, de manera que se analizara el patrón cada 15 o 20 muestras aproximadamente. De esta forma, podría conocerse el compottamiento de la técnica en los análisis de rutina, en los que no se lleva a cabo un control estricto, mediante Espectroscopía de fotocorrelación (QELS), de los tamaños de partícula, en la preparación de las muestras, ya que esta labor encarecería, de forma notable, el conjunto de los análisis.

Los resultados de esta prueba, que aparecen recogidos en la Tabla 4.6, junto a los aportados por el Análisis de activación de neutrones (NAA) y del Set-4 mencionado en el apartado anterior, muestran que no se producen variaciones importantes en 13 de los 19 elementos determinados. Incluso, en los elementos $\mathrm{Al}, \mathrm{Cu}, \mathrm{Ga}$ e $\mathrm{Y}$, se reduce el error relativo al determinar su concentración. Sin embargo, en los elementos $\mathrm{Nd}, \mathrm{Hf}, \mathrm{Ni}, \mathrm{Zn}, \mathrm{Ba}$ y $\mathrm{Mn}$, se producen discrepancias, con respecto a los resultados de la contrastación. En todos ellos, se obtienen concentraciones inferiores, que deben ponerse en relación con el mayor tamaño de partícula, como se veía anteriormente en los resultados obtenidos en el Set-1, Set-2 y Set-3. No obstante, mientras que en el Ba y el Mn es en los que peor se replican las concentraciones, en los casos del Ni y el Zn, sus valores se aproximan más, incluso que en el Set-4, a los obtenidos mediante Activación de neutrones (NAA). Por otro lado, la inducción producida, 


\section{TABLA 4.6. RESULTADOS COMPARATIVOS DE LAS CONCENTRACIONES ELEMENTALES DE LOS CONTROLES EFECTUADOS EN LOS ANÁLISIS DE RUTINA MEDIANTE TXRF}

\begin{tabular}{|c|c|c|c|}
\hline \multirow[t]{2}{*}{ Elemento (\%vs. Fe) } & $\mathrm{NAA}(\mathrm{N}=20)$ & Set-4 TXRF (N=5) & Rutina TXRF $(\mathrm{N}=7)$ \\
\hline & Media \pm S.D. (\% error) & Media \pm S.D. (\% error) & Media \pm S.D. $(\%$ exror $)$ \\
\hline As & $0.028 \pm 0.002(7.1 \%)$ & $0.041 \pm 0.002(4.9 \%)$ & $0.044 \pm 0.002(4.5 \%)$ \\
\hline $\mathrm{Nd}$ & $0.09 \pm 0.01(11.1 \%)$ & $0.06 \pm 0.02(33.3 \%)$ & ---- \\
\hline $\mathrm{Cr}$ & $0.18 \pm 0.01(5.5 \%)$ & $0.18 \pm 0.01(5.5 \%)$ & $0.18 \pm 0.01(5.5 \%)$ \\
\hline $\mathrm{Hf}$ & $0.015 \pm 0.001(6.6 \%)$ & $0.013 \pm 0.007(53.8 \%)$ & $0.009 \pm 0.002(22.2 \%)$ \\
\hline $\mathrm{Ni}$ & $0.14 \pm 0.03(21.4 \%)$ & $0.44 \pm 0.01(2.3 \%)$ & $0.15 \pm 0.003(2 \%)$ \\
\hline $\mathrm{Rb}$ & $0.36 \pm 0.02(5.5 \%)$ & $0.354 \pm 0.004(1.1 \%)$ & $0.37 \pm 0.01(2.7 \%)$ \\
\hline $\mathrm{Sr}$ & $0.05 \pm 0.06(120 \%)$ & $0.131 \pm 0.004(3 \%)$ & $0.14 \pm 0.005(3.6 \%)$ \\
\hline $\mathrm{Zn}$ & $0.18 \pm 0.02(11.1 \%)$ & $0.28 \pm 0.03(10.7 \%)$ & $0.20 \pm 0.01(5 \%)$ \\
\hline Al & $185 \pm 6(3.2 \%)$ & $151 \pm 30(19.9 \%)$ & $152 \pm 5(3.3 \%)$ \\
\hline $\mathrm{Ba}$ & $1.2 \pm 0.3(25 \%)$ & $1.34 \pm 0.07(5.2 \%)$ & $0.73 \pm 0.2(27.4 \%)$ \\
\hline $\mathrm{Ca}$ & $3.0 \pm 0.4(13.3 \%)$ & $2.81 \pm 0.04(1.4 \%)$ & $3.5 \pm 0.3(8.6 \%)$ \\
\hline $\mathrm{K}$ & $64 \pm 16(25 \%)$ & $69 \pm 1(1.4 \%)$ & $70 \pm 2(2.8 \%)$ \\
\hline $\mathrm{Mn}$ & $0.51 \pm 0.01(2 \%)$ & $0.50 \pm 0.01(2 \%)$ & $0.40 \pm 0.01(25 \%)$ \\
\hline $\mathrm{Ti}$ & $11.9 \pm 0.6(5 \%)$ & $12.3 \pm 0.2(1.6 \%)$ & $11.6 \pm 0.2(1.7 \%)$ \\
\hline V & $0.39 \pm 0.01(2.5 \%)$ & $0.49 \pm 0.02(4.1 \%)$ & $0.38 \pm 0.02(5.1 \%)$ \\
\hline $\mathrm{Cu}$ & --- & $0.04 \pm 0.01(25 \%)$ & $0.03 \pm 0.004(13.3 \%)$ \\
\hline $\mathrm{Ga}$ & --- & $0.050 \pm 0.002(4 \%)$ & $0.051 \pm 0.001(2 \%)$ \\
\hline $\mathrm{Y}$ & $+\cdots$ & $0.08 \pm 0.01(12.5 \%)$ & $0.08 \pm 0.007(8.7 \%)$ \\
\hline $\mathrm{Fe}$ & t00-Referencia & 100-Referencia & 100-Referencia \\
\hline
\end{tabular}

S.D. Desviación estándar.

durante el proceso de molienda, en la preparación de las muestras, influye en la determinación del Nd y el Hf que, cuando se detectan, se determinan siempre con más de un $2 \%$ de error relativo.

De cualquier modo, estos resultados confirman las tendencias que ya se observaban en la contrastación de la técnica, lo cual permite comprobar que los datos semi-cuantitativos obtenidos en las muestras analizadas, cuentan, en general, con un alto grado de fiabilidad. 


\subsection{COMPROBACIÓN DE LA REPRESENTATIVIDAD DE LAS MUESTRAS CERÁMICAS}

Para comprobar si una sola muestra puede ser representativa de la composición global de todo un recipiente cerámico, se seleccionó una vasija completa procedente del yacimiento de EI Palomar (Aragoncillo, Guadalajara). La vasija se escogió en este yacimiento, debido a que no fue posible obtener permiso para intervenir en un recipiente completo de Numancia. Sus características macroscópicas, pueden considerarse como representativas de la mayor parte del conjunto cerámico de Numancia, a excepción de la cerámica negra que, como ya se hacía referencia con anterioridad, presentaba características distintivas. Evidentemente, también hubiera sido de interés intervenir en un recipiente completo de cerámica negra, pero tampoco se consiguió permiso para obtenerlo.

Dicha vasija se identifica con la etiqueta EP-25, cuyas características pueden ser consultadas en la Tabla 1, del final de este trabajo. La muestra presenta una cocción oxidante y la temperatura estimada, a partir de los datos mineralógicos, se sitúa entre los $850^{\circ}$ y $900^{\circ} \mathrm{C}$.

En este recipiente, se han tomado un total de 9 muestras a lo largo de su perfil: 3 en la base, 3 en el galbo y 3 en el borde, identificadas con una letra mayúscula desde la $\mathrm{A}$ a la $\mathrm{I}$. La situación de las mismas, se ilustra en la Figura 4.15.

A pesar de que son muchos los autores que recomiendan esta clase de pruebas experimentales (Schneider, 1995, 25), en la bibliografía especializada, no son abundantes los trabajos que muestran experiencias de este tipo. En este sentido, sólo se hallan pruebas similares en los trabajos de Dufournier (1972) y de Henrickson y Blackman (1992). El primer investigador analiza, mediante XRF, 6 recipientes de cerámica medieval francesa, en los que toma 5 muestras en cada uno, a lo largo de su perfil. En estos análisis determina 10 elementos químicos: $\mathrm{Si}, \mathrm{Al}, \mathrm{Ca}, \mathrm{Mg}, \mathrm{Fe}, \mathrm{Ti}, \mathrm{Na}, \mathrm{K}, \mathrm{Mn}$ y P. Dufournier sólo encuentra variaciones significativas en la concentración de $\mathrm{Ca}$, que suele presentarse en mayores cantidades en las bases de los mismos. Este enriquecimiento, lo conecta con el posible contenido que habrían albergado estos recipientes. Asimismo, Henrickson y Blackman, analizan 2 vasijas completas de almacenamiento, mediante NAA, de cerámica de tradición Godin III del $\mathrm{O}$ de Irán, fechada entre el 2.600 y el 1.400 a. C. Esta cerámica, presenta una buena cocción oxidante, con una temperatura estimada entre $\operatorname{los} 800^{\circ}$ y los $1.000^{\circ} \mathrm{C}$.

Los autores toman entre 8 y 12 muestras en el perfil de cada vasija y llegan a la conclusión de que no existen vatiaciones significativas en ninguno de los 25 elementos determinados. Este hecho, les lleva a plantear que la producción de esta cerámica se realiza de 


\section{EP-25}

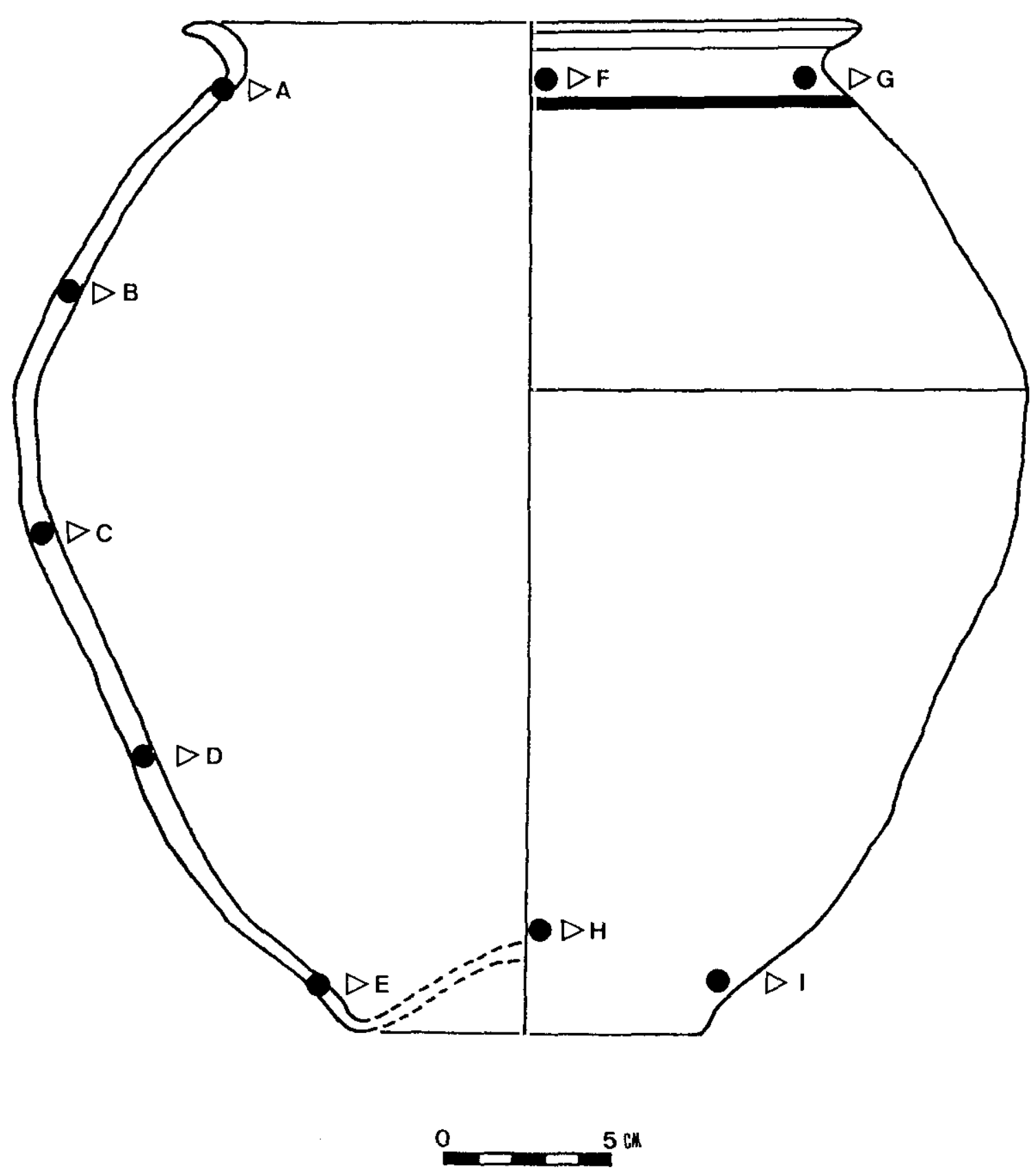

Figura 4.15: Situación de los puntos en los que se ha obtenido muestra, en el análisis de un recipiente completo procedente del yacimicnto de fi Palomar (Nragoncillo, Guadalajara) (Dibujo: J. Arenas, modificado por M. García I leras). 
forma especializada y que los alfareros preparan grandes cantidades de pasta a la hora de elaborarla.

Los resultados del experimento llevado a cabo en esta investigación, se ofrecen en la Tabla 4 del final de este trabajo y, de una manera más gráfica, en la Figura 4.16. En líneas generales, no se producen variaciones significativas en ninguno de los elementos determinados, al igual que en el trabajo de Hentickson y Blackman (1992). Las concentraciones no siguen ningún patrón, en función de la parte del recipiente de la que proceden. No obstante, deben comentarse algunos hechos de interés. El Nd sólo se ha detectado en una de las tomas, con una concentración relativa respecto al $\mathrm{Fe}$, casi despreciable. Por ello, no se ha representado en la Figura 4.11. Por otra parte, destaca el valor anómalo del $\mathrm{Ca}$ en la toma EP-25H. Este valor, excesivamente elevado con respecto al resto, puede ponerse en relación con la heterogeneidad de la propia muestra, según se ha comprobado en el análisis petrográfico de la misma, que se expondrá en el capítulo siguiente. La detección de pequeñas inclusiones de calcita podría influir en este valor, ya que la muestra puede haberse tomado, precisamente, en una de ellas. En cualquier caso, no se observa un fenómeno semejante al que exponía el trabajo de Dufournier (1972). Por lo demás, los elementos As, Mn y V, muestran una variabilidad no sistemática, relacionable, sin duda, con las características que la TXRF presenta en la detección de estos elementos, tal y como se vió en el apartado 4.4.

En definitiva, y a partit de estos resultados, la toma de una sola muestra por fragmento, se consideró como representativa del mismo, para la totalidad del muestreo realizado en esta Tesis Doctoral. De todas formas, esta decisión debe exchuir a la cerámica negra, puesto que no se pudo realizar un experimento similar con ella. Finalmente, hay que señalar que la toma EP-25A fue la que se escogió para representar la muestra EP-25, en los análisis estadísticos realizados posteriormente. 

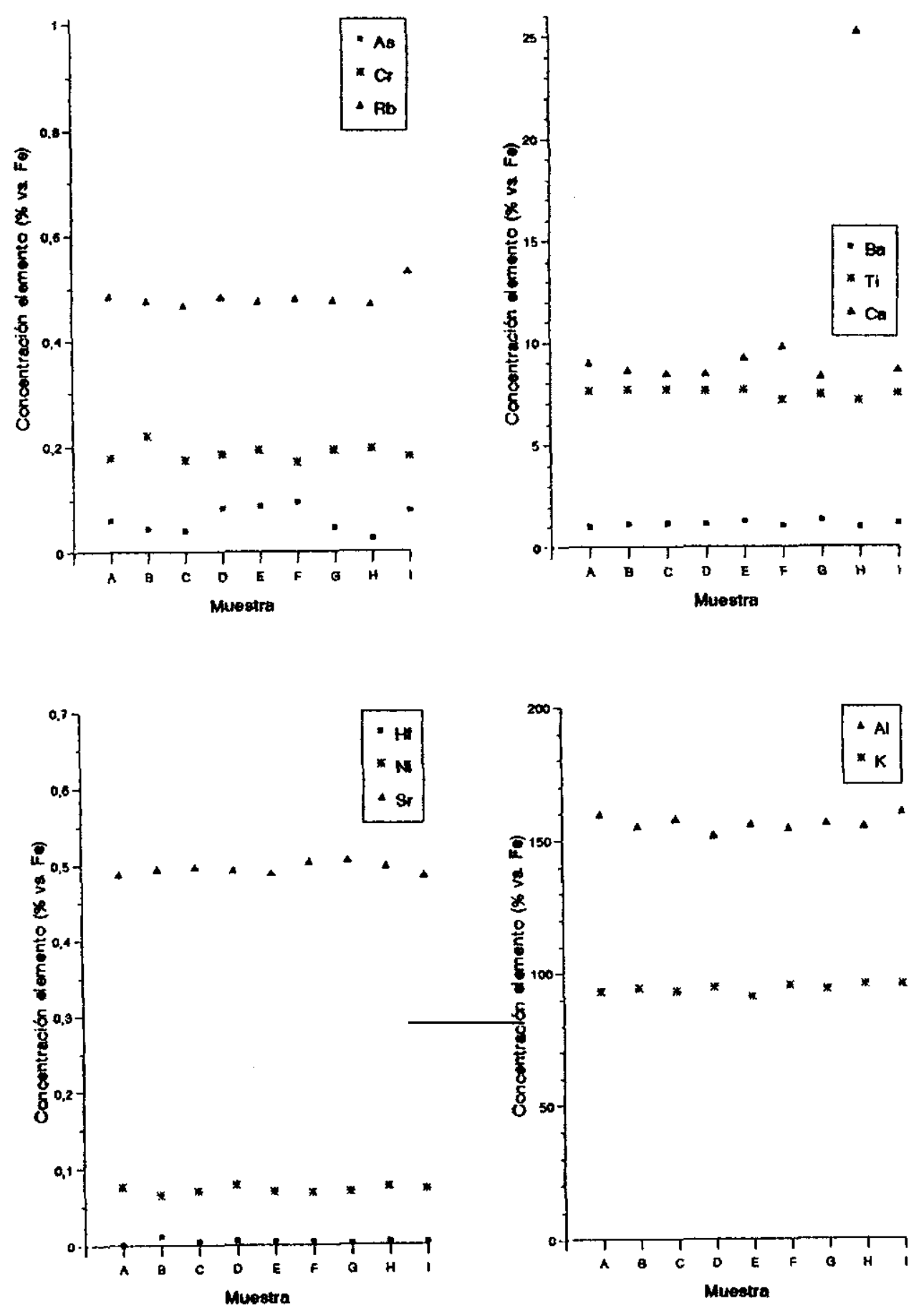

Figura 4.16: Concentraciones de los elementos As, Cr, Hf, Ni, Rb, Sr, Zn, Al, Ba, Ca, K, Mn, 'li, V, Cu, Ga c Y, en las muestras obtenidas en el perfil del recipiente completo $\mathrm{VP}-25$, procedente del yacimiento de Bl Palomar

(Aragoncillo, Guadalajara). 

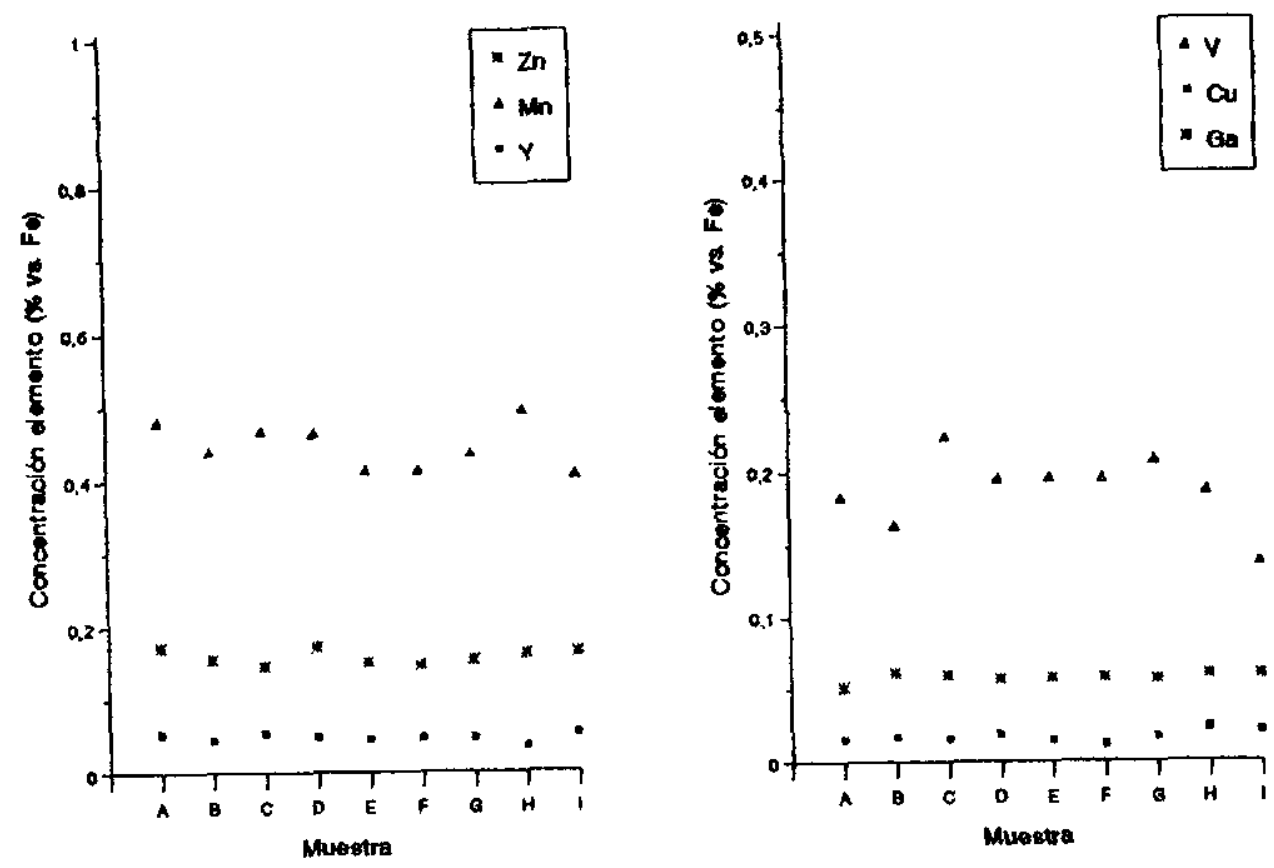

Figura 4.16: Continuación.

\subsection{COMPROBACIÓN DE LAS VARIACIONES COMPOSICIONALES EN SEDIMENTOS ARCILLOSOS COCIDOS A DISTINTAS TEMPERATURAS}

Con el fin de comprobar si se producían variaciones significativas en la concentración de alguno de los elementos determinados, en las muestras de los sedimentos arcillosos cocidos a distintas temperaturas, se seleccionaron dos probetas de cada muestra, las identificadas con las letras $A$ y $D$, que se correspondían con el sedimento a temperatura ambiente y cocido a $900^{\circ} \mathrm{C}$. Este último tango de temperatura, se eligió al ser considerado como el más probable al que se cocieron la mayoría de las cerámicas numantinas, según el conocimiento previo que se tenía de este tipo de cerámica, a partir de los datos obtenidos en la Memoria de Licenciatura. Por otro lado, la constatación de este aspecto resultaba, asimismo, importante, puesto que se pretendía seleccionar solamente una probeta, en los posteriores análisis estadísticos. En 
cualquier caso, debe señalarse que, para realizar una comprobación de estas características, lo ideal hubiera sido analizar toda la serie de cocciones de cada una de las probetas, incluso, con diferentes fracciones de tamaño de partícula. Sin embargo, las limitaciones económicas han jugado un papel decisivo en el diseño final de este experimento.

La prueba se llevó a cabo con 6 muestras de Numancia y 1 de Izana, realizándose un total de 15 análisis. La muestra N-5 no se analizó en ninguno de los dos rangos de temperatura, ya que a los pocos días de su cocción empezó a fracturarse, como consecuencia de la reacción del abundante $\mathrm{CaO}$ generado durante la cocción, con el vapor de agua presente en el aire. Ante este hecho, se pensó que con este tipo de arcilla dificilmente se podría elaborar cerámica, siendo desechada, en consecuencia, para el resto de los análisis. En el caso de la muestra de caolín N-8, sólo se analizó la probeta en crudo, debido a que presentaba un perfil composicional muy distinto al resto de las cerámicas y sedimentos arcillosos analizados en este trabajo. Por lo tanto, el objetivo principal, que consistía en corroborar si esta muestra podia asociarse a alguna de las clases de cerámica analizadas, quedaba cubierto con un solo análisis.

Adelantando algunos de los resultados que serán expuestos en el capítulo siguiente, los análisis efectuados muestran un grupo de arcillas calcáreas, compuesto por las probetas $\mathrm{N}-1$, N-2, N-3, N-6 e IZA, y otro grupo de arcillas no calcáreas, representado por las muestras N-4 y N-7, quedando suelta la muestra de caolín N-8. Estos resultados aparecen reflejados en la Tabla 5 del final de este trabajo.

En general, la mayoria de los elementos determinados mantienen sus valores con la cocción, no produciéndose la volatilización de ninguno de ellos. No obstante, se detectan pérdidas, nunca significativas, en los elementos $\mathrm{Al}, \mathrm{Ba}, \mathrm{Ca}$ y $\mathrm{Ti}$, tanto en las arcillas calcáreas, como en las no calcáteas. Por otra parte, los incrementos en las concentraciones de Ba y Mn en la muestra N-4 y de Zn en la N-3, pueden ponerse en relación con la variabilidad que la TXRF presenta en la detección de estos elementos, tal y como ya se ha comentado en varios de los apartados anteriores.

Con el propósito de intentar explicar a qué pueden ser debidas estas pérdidas, se han consultado varios trabajos que realizan pruebas similares. Empero, debe advertirse que sus resultados no serán directamente comparables, puesto que las determinaciones elementales se han llevado a cabo con técnicas cuantitativas. Además, no siempre los elementos determinados, coinciden con los aquí analizados. De todos modos, hay que adelantar que en ninguno de ellos se ha encontrado explicación a este fenómeno. Por el contrario, los 
resultados que ofrecen son bastante divergentes, aunque también es importante tener en cuenta que los tipos de arcilla manejados tienen características muy distintas.

En el trabajo, ya clásico, que realizaran Perlman y Asato (1969) para evaluar la precisión de la técnica de Activación de neutrones (NAA), se señala la completa volatilización del $\mathrm{Br}$ en arcillas cocidas a $705^{\circ} \mathrm{C}$. Por otro lado, Poole y Finch (1972), mencionan el S y el Sr como elementos que más varían en la cocción, mientras que la experimentación realizada por Attas et al. (1977) con 7 arcillas, sometidas a distintos tratamientos, indica que no es la temperatura el factor que más afecta a las concentraciones elementales, sino el tamaño de partícula del propio material. Asimismo, el trabajo de Rye y Duerden (1982) llevado a cabo sobre dos sedimentos arcillosos, señala la existencia de pérdidas progresivas de $\mathrm{Br}$ a partir de $700^{\circ} \mathrm{C}$, de $\mathrm{Cl}$ por encima de los $800^{\circ} \mathrm{C}$ y de $\mathrm{S}$ entre $700^{\circ}$ y $800^{\circ} \mathrm{C}$. El estudio realizado por Kilikoglou et al. (1988), a partir de 6 arcillas procedentes de la isla de Creta, ofrece también datos interesantes. En este trabajo detectan que la cocción incrementa las concentraciones elementales en las fracciones finas, mientras que éstas decrecen en las fracciones gruesas. Sin embargo, el equipo del Missouri University Research Reactor (MURR) de Columbia (USA), entre los 33 elementos químicos determinados en el patrón "Ohio Red Clay-2", sólo detecta pérdidas importantes de $\mathrm{Br}$ en la cocción de esta arcilla (Cogswell et al., 1996). Por último, Storey (1988), apunta un inexplicable descenso de $\mathrm{Y}$ en las cocciones de arcillas procedentes del E del Reino Unido, en su trabajo sobre la cexámica romana de esta zona.

Por lo tanto, los decrecimientos de $\mathrm{Al}, \mathrm{Ba}, \mathrm{Ca}$ y $\mathrm{Ti}$, resultan difíciles de interpretar, al menos, a partir de los trabajos que se ha tenido oportunidad de consultar. De cualquier modo, y ante estos resultados, se optó, finalmente, por incluir ambas probetas, la que se corresponde con la temperatura ambiente y la cocida a $900^{\circ} \mathrm{C}$, en los análisis estadísticos, con el fin de comprobar cómo se comportaban en cada caso, dentro de las agrupaciones establecidas. Por otro lado, este experimento aconsejaba, para la realización de estudios posteriores, utilizar sedimentos cocidos a temperaturas próximas a las estimadas para la cerámica arqueológica y acondicionados siguiendo los mismos patrones granulométricos que los observados en ésta, en la comparación de los perfiles composicionales de arcillas y materiales cerámicos. 



\section{RESULTADOS}

\subsection{ANÁLISIS MACROSCÓPICO}

Los resultados del Análisis macroscópico, se exponen en el Apéndice 1. Por varias razones, entre las que se encuentran la deficiente ordenación de las colecciones cerámicas de Numancia en el Museo Numantino de Soria o la pérdida de números de inventario, no se han podido reconocer todas las piezas y fragmentos, al menos que conservaran este número, recogidos en los diferentes trabajos que han estudiado la cerámica numantina. Así, de las 1.268 piezas que presenta Wattenberg (1963), sólo se han reconocido 980 o, lo que es lo mismo, un $77,3 \%$ de las mismas. De igual modo, de las 380 piezas o fragmentos polícromos con número de inventatio, que presenta Romero Carnicero (1976), solamente se han localizado 353 (un $93 \%$ y de las 217 recogidas en el trabajo de Arlegui (1986), tan sólo 181, un 83,4\%, han sido reconocidas. Esta situación, contrasta con los materiales depositados en el Museo Arqueológico Nacional de Madrid (Barrio Onrubia, 1991), los cuales han podido ser localizados en su mayoría.

Por otro lado, en la medición de los colores, también se han presentado ciertos problemas, debido a que un $39 \%$ de las piezas consideradas completas, es decir, aquellas en las que es posible reconstruir totalmente la forma tipológica, han sido restauradas. El proceso de restauración varía los colores que, originalmente, presentaban. Por tanto, dichas piezas no se han contemplado en los registros de color que aparecen al final del Apéndice I.

En otro orden de cosas, debe advertirse que no se ha coincidido, en todos los casos, con la tipologia atribuida por estos investigadores a muchas de las piezas, ya que en algunas ocasiones se trataba de stmples fragmentos que podrían incluirse en más de un tipo. Cuando ha habido que enfrentarse a esta situación, la pieza ha sido contabilizada como un fragmento más. En este sentido, por ejemplo, no se ha conseguido atribuir ningún individuo a la variante $15 e$ de copas de pie alto, a la $20 \mathrm{~h}$ de jarras troncocónicas, ni a la $22 \mathrm{~d}$ de vasijas con asa de cesta, de la tipología desarrollada por Atlegui (1986). Asimismo, se han añadido cinco tipos que no 


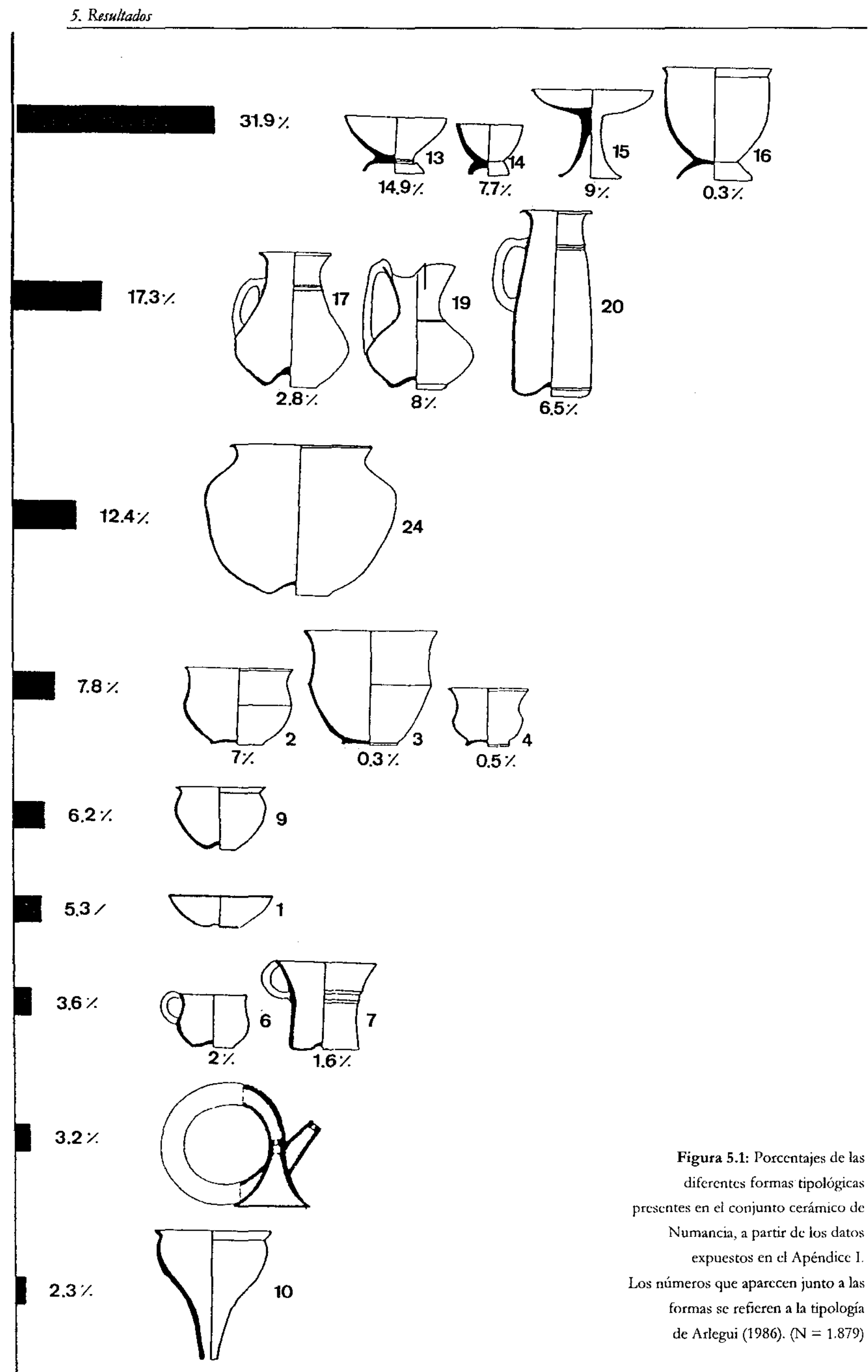




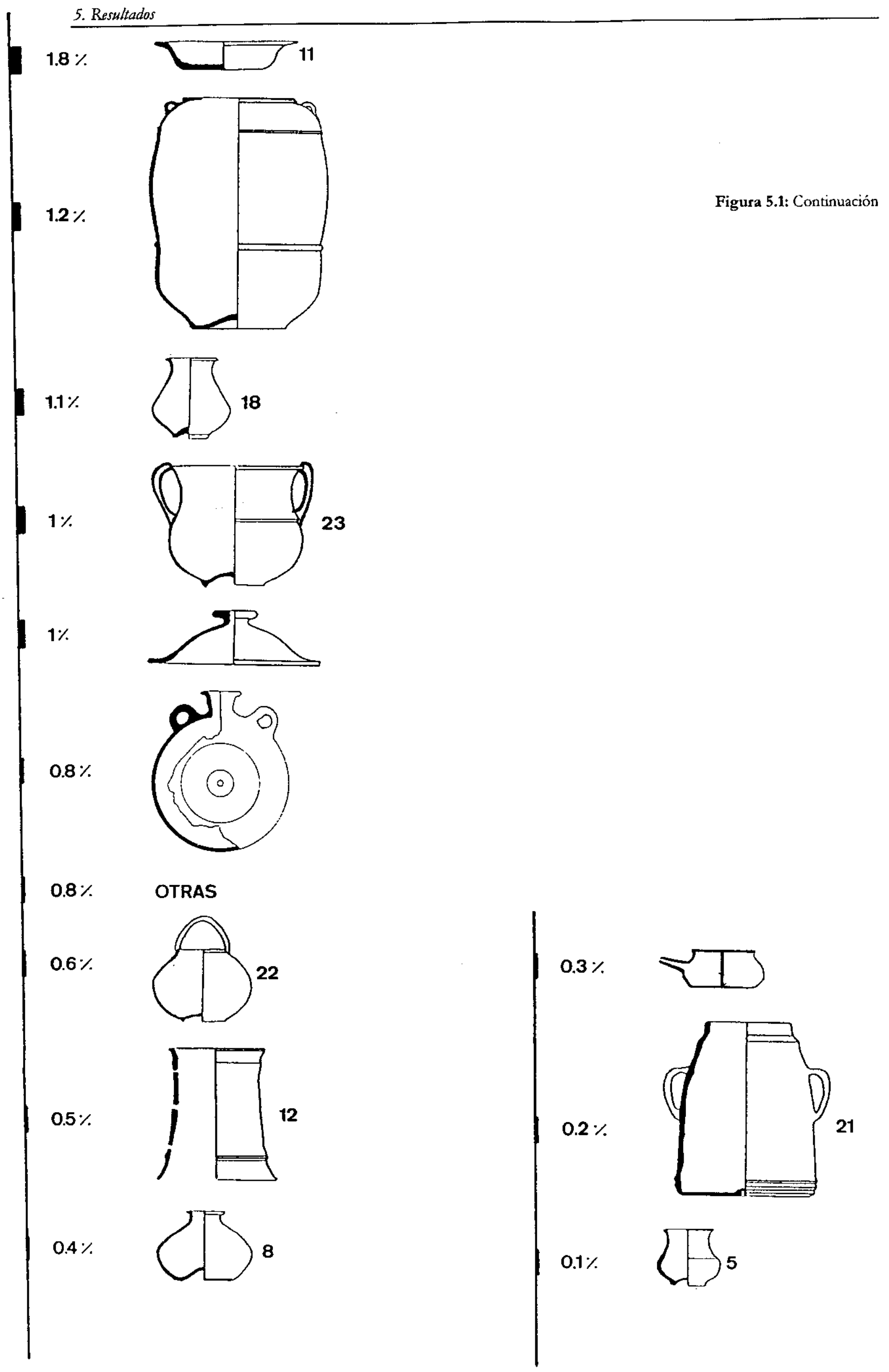



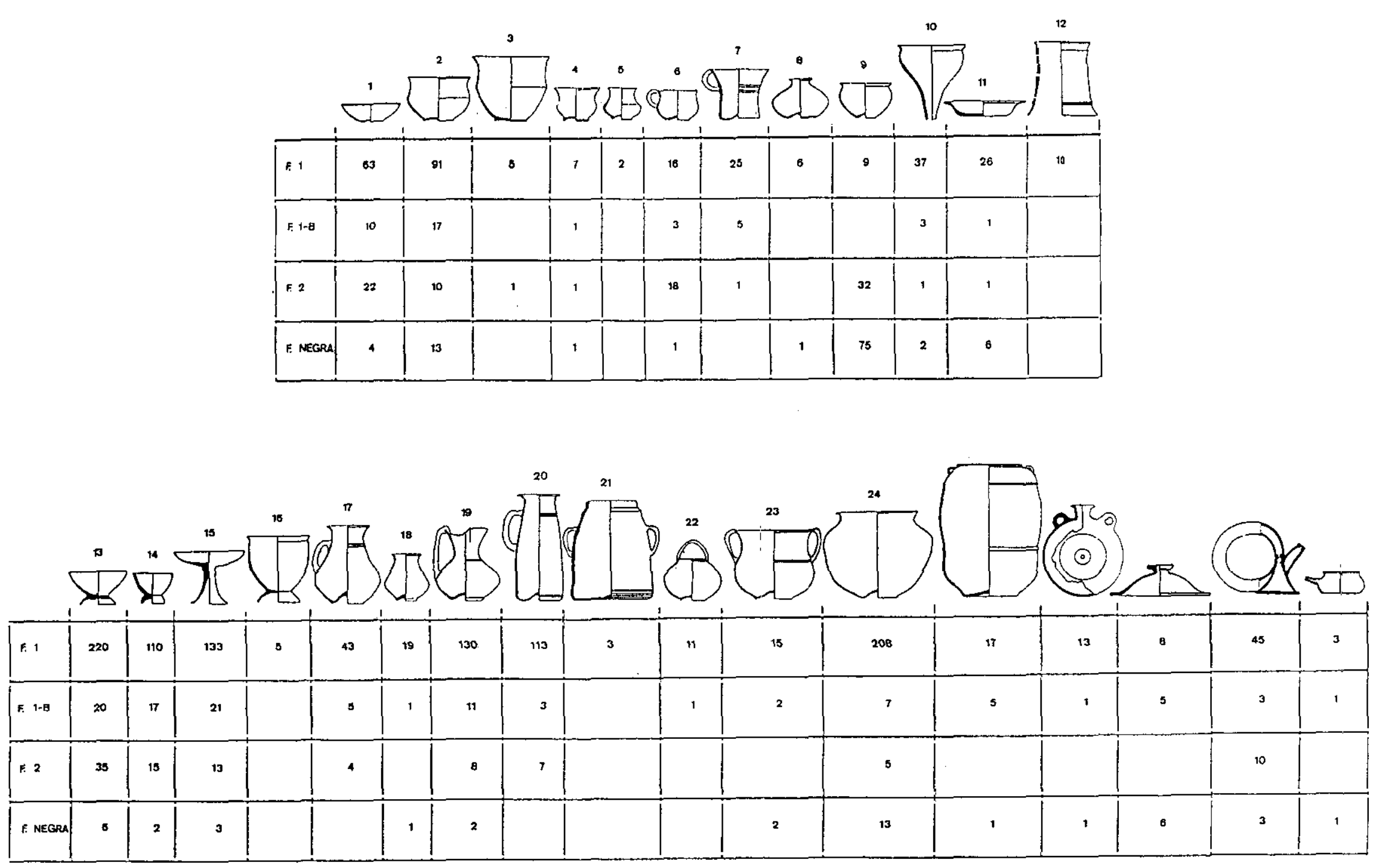

Figura 5 2: Número de ejemplares atribuidos a cada fábrica macroscópica, según su tipologia Los números que aparecen encima de las formas se refieren a la tipología de Arlegui (1986) $(\mathrm{N}=1.879)$ 


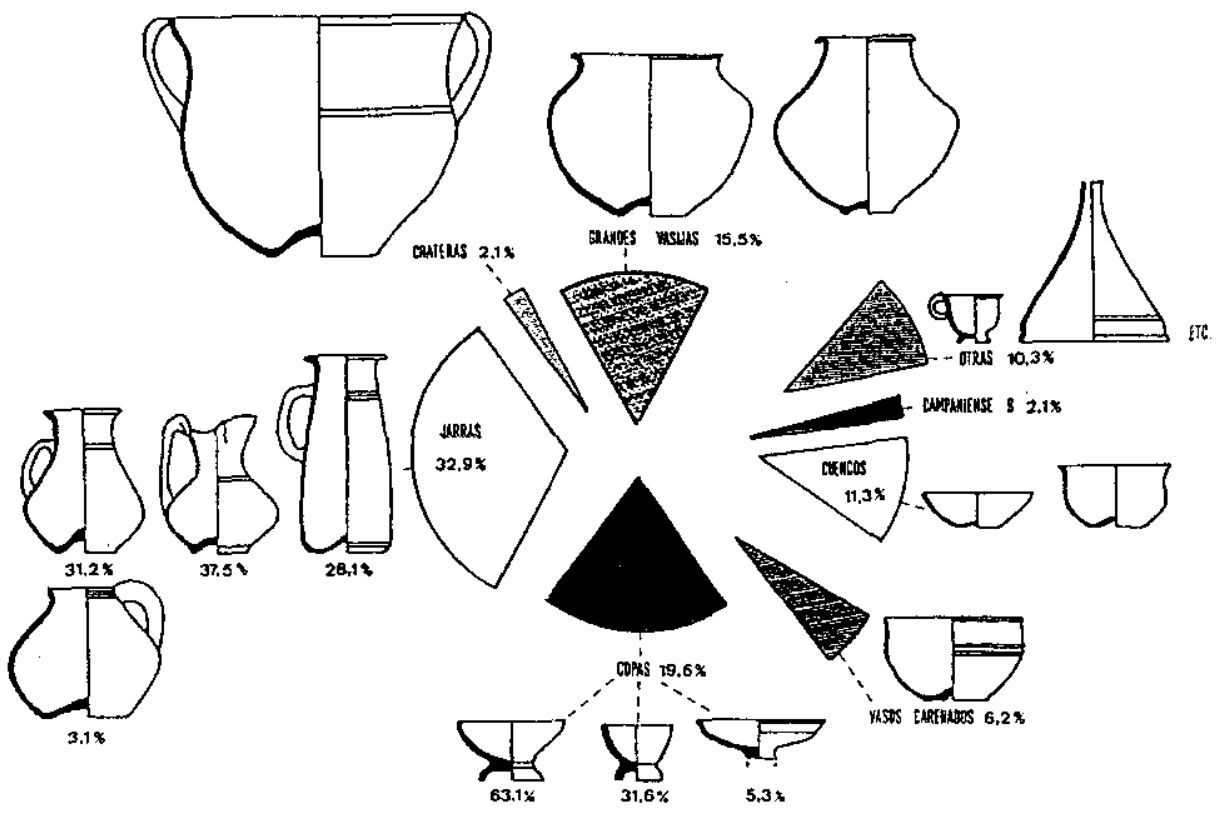

Figura 5.3: Porcentaje de las diferentes formas ajpológicas presentes en el conjunto cerámico de Izana. $(\mathrm{N}=97)$ (según Garcia Heras, 1993 a; 1994 d).

aparecían en esta tipología. Estos tipos son: trompas, tapaderas, grandes tinajas, cantimploras y biberones.

Tipológicamente, en el conjunto cerámico de Numancia, predominan tres grandes grupos de formas, como puede observarse en la Figura 5.1. Copas, con un 31,9\% de ejemplares; jarras, con un 17,3\% y grandes vasijas, con un porcentaje del 12,4\%. A continuación, se sitúan los vasos carenados $(7,8 \%)$, las vasijas globulares $(6,2 \%)$ y los cuencos $(5,3 \%)$, entre los más representativos. En comparación con el conjunto cerámico del yacimiento de Izana, estudiado en la Memoria de Licenciatura (Figura 5.3), los tres grandes grupos de formas coinciden, aunque en distinta proporción. No obstante, alli también se incluian las piezas de Campaniense B en los porcentajes totales. De csta forma, en Numancia, en términos relativos, hay más copas y menos jarras y grandes vasijas. Sin embargo, los cuencos son más numerosos en Izana.

Atendiendo a los atributos registrados en el Análisis macroscópico, el material cerámico de Numancia se ha clasificado en 4 fábricas o tipos de manufactura. En este trabajo, y con el fin de evitar confusiones, se ha procurado mantener la nomenclatura de las fábricas determinadas en la Memoria de Licenciatura, a pesar de que, según los casos, se han observado algunas variaciones que serán oportunamente señaladas. 
El tipo de manufactura mayoritario es la Fábrica 1 , mientras que las tres restantes presentan porcentajes muy similates, tanto en piezas completas, como en fragmentos (Figura 5.4 A y B). La tipología de las piezas asignadas a cada fábrica, puede observarse en la Figura 5.2. Todas ellas han sido elaboradas a torno, incluidas las cerámicas que se han tipificado como Fábrica negra. A continuación, se exponen las características principales de estas 4 fábricas:

Fábrica 1. Se trata de una fábrica muy homogénea que presenta cocción oxidante, con frecuentes cambios de coloración. Muestra una gama de colores que se concentra en los códigos Munsell 2.5 YR, 5 YR y 7.5 YR, correspondientes a naranjas, naranjas-rojizos y marrones-rojizos (Apéndice 1). Cuando se han podido observar, sus inclusiones se distribuyen unimodalmente en cantidades bajas $(<15 \%$ ). Las cerámicas de esta fábrica, suelen tener las superficies internas alisadas y las externas pulidas. En estas últimas, se observan las trazas del facetado dejadas por el útil empleado en el pulido. En general, no presenta una macropotosidad importante, no observándose huellas de posibles engobes.

La Fábrica 1 representa el $74,6 \%$ de las piezas completas y el $79 \%$ de los fragmentos (Figura 5.4 A y B). Un $61,2 \%$ de piezas completas están decoradas, mientras que los fragmentos representan un 57,8\%. La decotación está constituida, mayotitariamente, por pigmentos que se aplican en el exterior, salvo en las copas, en las cuales también se aplican en el interior. El porcentaje de cerámicas polícromas en esta fábrica, se sitúa en un $8,8 \%$ para las piezas completas, que se concentran en las formas 13 (copas de pie bajo) y 15 (copas de pie alto), según puede verse en la Tabla 5.1, y en un 4,3\% para los fragmentos. Por el contrario, también aparece la decoración estampada, que muestra los mismos motivos que en la Fábrica 2 o en la Fábrica negra, aunque ésta sólo está presente en 8 piezas completas y en 22 fragmentos (ver Tabla 5.2). Por lo demás, 20 piezas completas presentan gtafitos en sus superficies, que se concentran en las copas de pie bajo (forma 13) (ver Tabla 5.3), así como un total de 45 fragmentos.

Es la única fábrica en la que se realiza todo el repertorio de formas tipológicas. Incluso, hay formas, como la 12, 16 y 21, que sólo aparecen en esta fábrica (Figura 5.2). En el conjunto cerámico de Numancia, se han detectado piezas de muy pequeño tamaño, que se han tipificado como "juguetes", pero que se realizan en las mismas tipologias que las piezas de tamaño normal. En la Fábrica 1, se han contabilizado 19 "juguetes" que se presentan en las formas 1 (cuencos) y 13 (copas de pie bajo) (ver Tabla 5.4). 
A

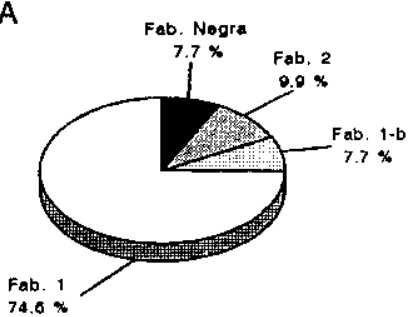

$74.6 \%$

PIEZAS COMPLETAS

( $n=1.879$ )

C

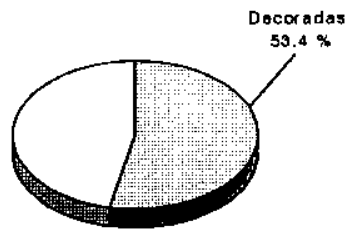

B Fab. Nogra

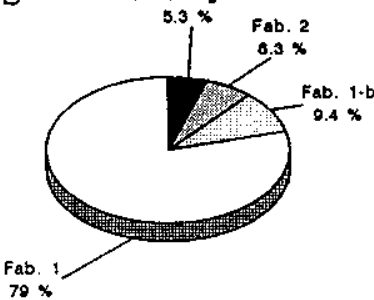

FRAGMENTOS

( $n=9.529$ )

D

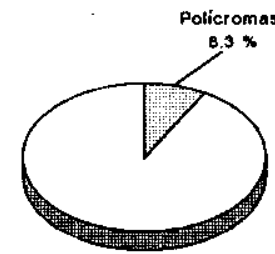

PIEZAS COMPLETAS

$(\mathrm{n}=1.879)$

$E$

F
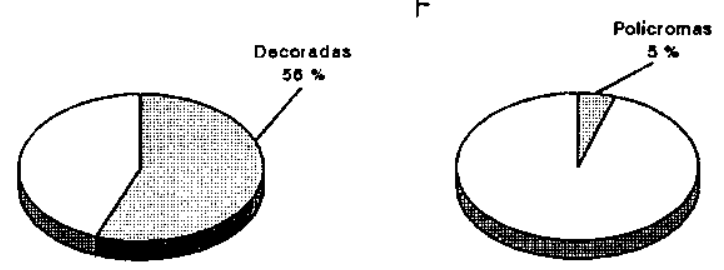

FRAGMENTOS

(n $=9.529$ )

Figura 5.4: Porcentajes de las diferentes fábricas macroscópicas y de las cerámicas decoradas, presentes en el conjunto cerímico de Numancia. lín los gráfiços D y F, sc muestra el porcentaje total de cerámicas que presentan decoración polícroma. 
TABLA 5.1. NÚMERO DE EJEMPLARES QUE PRESENTAN DECORACIÓN POLÍCROMA ATRIBUIDOS A CADA FÁBRICA MACROSCÓPICA SEGÚN SU TIPOLOGÍA

\begin{tabular}{|c|c|c|c|c|c|c|c|c|c|c|c|c|c|c|c|c|c|c|c|c|c|c|}
\hline & $\sqrt{1}$ & 2 & 4 & 6 & 7 & $\overline{8}$ & 9 & 12 & $\overline{13}$ & 15 & 16 & 17 & 18 & 19 & 20 & 22 & $\overline{23}$ & 24 & $\bar{c}$ & $\bar{B}$ & 0 & $\overline{\text { Total }}$ \\
\hline F. 1 & 7 & 6 & 1 & 1 & 1 & $\overline{1}$ & 1 & 1 & 46 & 28 & 1 & 5 & & 5 & 8 & 1 & $\overline{1}$ & 5 & 1 & $\sqrt{1}$ & 1 & 123 \\
\hline F. 1-b & $\overline{2}$ & 5 & 1 & & 1 & & & & $\overline{4}$ & 7 & & 2 & 1 & 6 & & & $\sqrt{1}$ & & & & 1 & 31 \\
\hline F.2 & 1 & & & & . & & & & & & & 1 & & 1 & & & & & 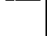 & & & 3 \\
\hline Total & $\overline{10}$ & $\overline{11}$ & 2 & 1 & $\overline{2}$ & 1 & 1 & 1 & 50 & 35 & 1 & 8 & 1 & 13 & 8 & 1 & 2 & 5 & 1 & $\overline{1}$ & $\overline{2}$ & 157 \\
\hline
\end{tabular}

Los números se refieren a la tipologia de Arlegui (1986). Las letras a las formas siguientes: $C$ cantimploras. $B$ biberones. $O$ otras.

TABLA 5.2. NÚMERO DE EJEMPLARES QUE PRESENTAN DECORACIÓN ESTAMPADAATRIBUIDOS A CADA FÁBRICA MACROSCÓPICA SEGÚN SU TIPOLOGÍA

\begin{tabular}{|c|c|c|c|c|c|c|c|c|c|c|c|c|c|c|c|c|}
\hline & 1 & 2 & 6 & 9 & 11 & 13 & 15 & 17 & 18 & 23 & 24 & c & $\mathrm{T}$ & B & 0 & Total \\
\hline F. 1 & 1 & 1 & & & & 4 & & 1 & & & & & 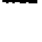 & 1 & & 8 \\
\hline F. 2 & 1 & 2 & 1 & 10 & & 4 & 2 & 1 & & & & & 3 & & 1 & 25 \\
\hline F. Negra & 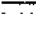 & - & $\bar{i}$ & 14 & $\overline{2}$ & $i$ & . & 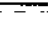 & $i$ & 1 & $=\frac{7}{3}$ & $\overline{\overline{1}}$ & 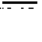 & 1 & 1 & 26 \\
\hline Total & 2 & 3 & 2 & 24 & 2 & 9 & 2 & 2 & 1 & 1 & 3 & $\overline{1}$ & $\sqrt{3}$ & 2 & $\overline{2}$ & 59 \\
\hline
\end{tabular}

Los números se refieren a la tipologia de Arlegui (1986). Las letras a las formas siguientes: $C$ cantimploras. $T$ trompas. $B$ biberones. $O$ otras.

TABLA 5.3. NÚMERO DE EJEMPLARES QUE PRESENTAN GRAFITOS ATRIBUIDOS A CADA FÁBRICA MACROSCÓPICA SEGÚN SU TIPOLOGÍA

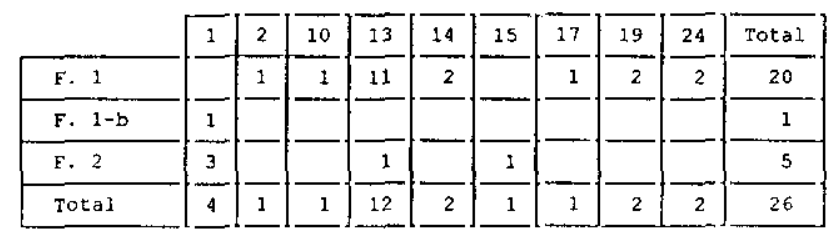

I.os números se refieren a la tipología de Arlegui (1986).

TABLA 5.4. NÚMERO DE EJEMPLARES TIPIFICADOS COMO "JUGUETES" ATRIBUUIDOS A CADA FÁBRICA MACROSCÓPICA SEGÚN SU TIPOLOGĹA

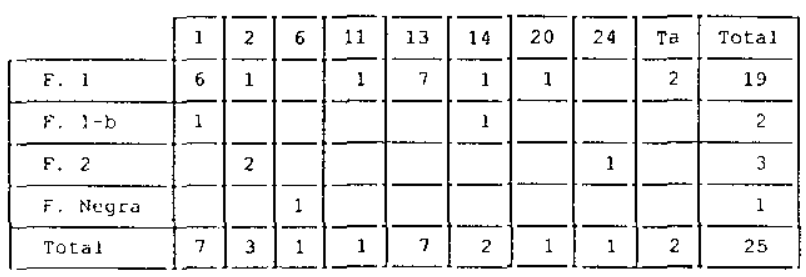

L.os números se sefieren a la tipología de Arlcgui (1980). Ta tapadcras. 
En Izana, esta fábrica representaba el 81,2 \% del conjunto cerámico (García Heras, 1993 a, 46-48).

Fábrica 1-b. En un principio, en la Memoria de Licenciatura, se consideró una Fábrica 1-a para agrupar aquellas cerámicas de la Fábrica 1 que mostraban pulidas las superficies externas. Sin embargo, cuando se finalizó el Análisis macroscópico, se vió que este rasgo no era suficiente para definir, por sí mismo, una fábrica. Por este motivo, se optó por agrupar todas las cerámicas en la Fábrica 1, existiendo, por ello, una Fábrica 1-b, que coincide con las características que se exponen seguidamente.

Esta fábrica, también muestra cocción oxidante y sus colores se concentran en los códigos Munsell 2.5 YR y, sobre todo, 5 YR y 7.5 YR, que se corresponden con tonalidades naranjas, naranjas pálidos y naranjas amarillentos claros (Apéndice I). No siempre resulta fácil distinguirla de la fábrica anterior, a pesar de que, generalmente, cuenta con una macroporosidad más acusada. Es también bastante homogénea, sus inclusiones se distribuyen unimodalmente, en cantidades bajas $(<15 \%$ ) y sus superficies aparecen alisadas. En las cerámicas de esta fábrica, tampoco se observa la existencia de posibles engobes.

Representa el 7,7\% de piezas completas y el 9,4\% de los fragmentos (Figura 5.4 A y B) y la decoración está presente en un 50,3\% de las piezas completas y en un 64,3\% de los fragmentos. Sólo está decorada con pigmentos, situados de la misma forma que en la fábrica anterior. La decoración estampada, no aparece en esta fábrica. El porcentaje de decoración polícroma, se sitúa en un $21,4 \%$ para las piezas completas y en $15,8 \%$ para los fragmentos. En las piezas completas, se concentra en las formas 13 y 15 (copas), en las jartas de boca trilobulada (forma 19) y en los vasos catenados (forma 2), como se muestra en la Tabla 5.1. Por tanto, en términos comparativos, la Fábrica 1-b se decora más con policromía que la Fábrica 1.

Como puede observarse en la Figura 5.2, son los cuencos (forma 1), los vasos carenados (forma 2), las copas (formas 13 y 15) y las jarras de boca trilobulada (forma 19), los tipos que más se elaboran en esta fábrica. No obstante, hay formas, como la 3, 8, 9, 12, 16 y 21 que no aparecen en la misma. Por otra parte, sólo un cuenco presenta un grafito (ver Tabla 5.3) y nada más que dos piezas, se han tipificado como "juguetes" (ver Tabla 5.4).

En Izana, esta fábrica representaba el 4,7\% del conjunto cerámico de este yacimiento (García Heras, 1993 a, 46 y 53).

Fábrica 2. Se trata de un tipo de manufactura homogénea, en todo semejante a la Fábrica 1 , excepto en la cocción, que es reductora. Sus colores, por tanto, son diferentes, concentrándose en los códigos Munsell 2.5 YR, 5 YR y 7.5 YR, que se corresponden con grises-rojizos y marrones-grisáceos y, en menor medida, con colores cercanos al negro (Apéndice I).

La Fábrica 2 representa el $9,9 \%$ de las piezas completas y el $6,3 \%$ de los fragmentos (Figura 5.4 A y B). Un 25,7\% de las piezas completas están decoradas, mientras que los 
fragmentos representan un 38,9\%. En las primeras, la decoración mayoritaria es el estampado, que aparece en un 13,4\% de los ejemplares, concentrándose en vasijas globulares (forma 9) (ver Tabla 5.2) y, en los segundos, la decoración más abundante se realiza con pigmentos aplicados en las superficies extemas. La policromía sólo aparece en 3 piezas completas (ver Tabla 5.1) y en 11 fragmentos. Por consiguiente, en términos comparativos, la Fábrica 2 se decora muy poco con pigmentos polícromos y, de forma más abundante que en las Fábricas 1 y 1-b, con motivos estampados.

Esta fábrica, al igual que la 1-b, tampoco cubre todas las formas tipológicas, según puede observarse en la Figura 5.2. Principalmente, se elaboran con ella vasijas globulares (forma 9), cuencos (forma 1), vasos carenados (forma 2), tazas pequeñas (forma 6) y copas (formas $13 \mathrm{y}$ 15), en este orden. Las formas $5,8,12,16,21,22,23$, grandes tinajas, cantimplotas, tapaderas y biberones, no se fabrican. Los grafitos están presentes en 5 piezas completas (ver Tabla 5.3) y en 7 fragmentos, mientras que sólo 3 piezas se han tipificado como "juguetes" (ver Tabla 5.4).

En Izana, esta fábrica representaba el 6,2\% del conjunto cerámico (García Heras, 1993 a, 46 y 53$)$.

Fábrica negra. En esta fábrica, se han agrupado conjuntamente, las definidas en la Memoria de Licenciatura como 3-a y 4, ambas negras. Según los datos petrográficos, una de ellas, la Fábrica 3-a, presentaba inclusiones de calcita machacada añadida intencionadamente a la pasta, mientras que la otra, la Fábrica 4, contenía inclusiones en un rango de tamaños mayor que el resto de las fábricas descritas anteriormente, pero sin adición de calcita. Sin embargo, desde un punto de vista macroscópico, ambas fábricas resultan dificiles de distinguir, cuando no se tiene acceso a una fractura fresca, como ha ocurrido en múltiples ocasiones en este trabajo, dada la ubicación de los materiales analizados. Por este motivo, se ha decidido tratarlas en conjunto, a pesar de que, en términos generales, son dos fábricas distintas. Este aspecto, por tanto, no permite hacer comparaciones con los porcentajes que arrojó el análisis del conjunto cerámico del yacimiento de Izana.

Las cerámicas pertenecientes a este tipo de manufactura, presentan una cocción reductora en negro. En la mayoría de los casos, puede observarse una abundante macroporosidad, con poros y fisuras de morfologías alargadas. Normalmente, las superficies suelen estar alisadas, aunque también son abundantes las superficies pulidas, tanto externas como internas. Cuando se han podido observar, las inclusiones se distribuyen multimodalmente en cantidades medias $(15-25 \%$ ) y altas ( $>25 \%$ ), con tamaños máximos, medidos en su eje mayor, de 1,5 mm. Los colores se concentran en los códigos Munsell $2.5 \mathrm{YR}$ y, sobte todo, $5 \mathrm{YR}$ y $7.5 \mathrm{YR}$, que se corresponden con tonalidades negras, marrones, marrones-rojizas, etc. (Apéndice $\mathrm{I}$ ). Eñ general, la coloración es muy heterogénea, observándose abundantes cambios de coloración, incluso en la misma pieza. Al igual que en las fábricas anteriores, no se han detectado posibles engobes. 
Esta fábrica representa el 7,7\% de las piezas completas y el $5,3 \%$ de los fragmentos (Figura 5.4 A y B). Un $17,8 \%$ de las piezas completas y un $34,7 \%$ de los fragmentos presentan decoración. Esta decoración es siempre estampada y se concentra, básicamente, en vasijas globulares de la forma 9 (ver Tabla 5.2). Por otra parte, tampoco se presenta en todas las formas tipológicas. Las formas que más se realizan en esta fábrica son vasijas globulares (forma 9), vasos carenados (forma 2) y grandes vasijas (forma 24), respectivamente, no apareciendo las formas 3 , $7,12,16,17,20,21$ y 22 (Figura 5.2). En sus superficies no se han encontrado grafitos y, solamente una pieza, se ha tipificado como "juguete" (ver Tabla 5.4).

A modo de resumen, pueden indicarse algunas generalidades que presenta el conjunto cerámico, conservado en la actualidad, procedente de las excavaciones efectuadas a principios de siglo en la ciudad de Numancia. En este sentido, las cerámicas con decoración polícroma, representan el 8,3\% de las piezas completas y el $5 \%$ de los fragmentos (Figura 5.4 C-F). Sobre todo, se decoran así los ejemplares pertenecientes a la Fábricas 1-b y 1, en las formas 13 y 15 (copas), en las formas 17, 19 y 20 (jarras), así como en la forma 2, perteneciente a los vasos carenados, mientras que en la Fábrica 2, apenas se decoran piezas con policromía. En la Fábrica Negra, no hay cerámicas polícromas.

Los colores que presentan los pigmentos que conforman este tipo de decoración, son bastante homogéneos, como puede observarse al final del Apéndice I. No obstante, hay que tener en cuenta que, el número de fragmentos en los que se ha podido medir el color, no es muy extenso, con lo cual estos datos podrían ser poco representativos. En cualquier caso, el trabajo de Romero Carnicero (1976), mostraba los colores de 440 piezas y fragmentos, tomados por medio de las tablas de Llanos y Vegas (1974). Sin embargo, este investigador no menciona si estos colores se tomaron antes o después de que las piezas fuetan restauradas. Por ello, y ante este inconveniente, dichos datos no se han contemplado en esta investigación.

La decoración polícroma combina pigmentos negtos, blancos y rojos. En general, no es frecuente que aparezcan los tres a la vez en una misma pieza, siendo las combinaciones de negto y blanco y, en menor medida, de negro y rojo, las más abundantes. El negro, se concentra en los códigos Munsell 2.5 YR, 5 YR y 7.5 YR, que se corresponden con marrones-rojizos oscuros y marrones oscuros. El pigmento blanco, lo hace en los códigos $5 \mathrm{YR}$ y $7.5 \mathrm{YR}$, en tonalidades grises claras y muy claras, mientras que el rojo se agrupa en torno a colores marrones-rojizos de los códigos Munsell 2.5 YR, 5 YR y 7.5 YR (ver Apéndice I). 
En lineas generales, los colores que muestran las superficies de las piezas cerámicas, suelen ser diferentes a los que muestran las secciones de las mismas (ver Tabla 1 del final de este trabajo). Este aspecto, pone de manifiesto que los colores externos e internos, no son buenos indicadores del color de la pasta.

Por otro lado, los grafitos predominan dentro de la Fábrica 1 y sólo aparecen en ciertas formas, entre las que destacan las copas de pie bajo (forma 13), no apareciendo ninguno de ellos en la Fábrica Negra (ver Tabla 5.3). Las piezas tipificadas como "juguetes", se corresponden con las formas mayoritarias de la tipología general, mostrándose en todas las fábricas.

Por último, se han localizado lañas de plomo, asi como agujeros de lañado, en piezas y fragmentos, principalmente, de la Fábrica 1. Estas huellas de teparación en piezas cerámicas, no se concentran en ninguna forma específica ni en ningún tipo de decoración determinado.

\subsection{ANÁLISIS TEXTURAL DE LOS SEDIMENTOS ARCILLOSOS}

Los resultados del análisis textural se ofrecen en la Tabla 5.5. La Figura 5.5 muestra su clasificación textural y la Figura 5.6 la caracterización de la fracción arena, siguiendo los métodos de representación gráfica consultados en los trabajos de Grimshaw (1971) y Köster (1966). Sólo dos sedimentos se clasifican como arcillas: las muestras $\mathrm{N}-3$ y N-7. El resto, son todos diferentes entre sí, siendo el más arenoso el N-5. En esta clasificación, el término inglés "loam"

TABLA 5.5. PORCENTAJES DE LAS FRACCIONES ARENA, LIMO Y ARCILLA EN LAS MUESTRAS DE LOS SEDIMENTOS ARCILLOSOS

\begin{tabular}{|c|c|c|c|c|}
\hline MUESIRA & $\%$ ARINA (SAND) & $\%$ LIMO (SII'I) & $\% A R C I I L A(C L A Y)$ & CLASIFICACION \\
\hline $\mathrm{N}-1$ & 34.64 & 32.68 & 32.68 & $\begin{array}{l}\text { Arcilla margosa } \\
\text { (Clay Loam) }\end{array}$ \\
\hline $\mathrm{N}-2$ & 43.37 & 31.14 & 25.48 & Marga (Loam) \\
\hline $\mathrm{N}-3$ & 23.12 & 30.20 & 46.68 & Arcilla (Clay) \\
\hline$N-4$ & 44.94 & 7.86 & 47.19 & $\begin{array}{l}\text { Arcilla arcnosa } \\
\text { (Sandy clay) }\end{array}$ \\
\hline$N-5$ & 52.43 & 16.79 & 30.78 & $\begin{array}{l}\text { Arcilla margosa arcoosa } \\
\text { (Sandy clay loam) }\end{array}$ \\
\hline$N-6$ & 39.96 & 57.17 & 2.86 & $\begin{array}{l}\text { I imo margoso } \\
\text { (Silt lcam) }\end{array}$ \\
\hline N-7 & 39.38 & 7.91 & 52.71 & Arcilla (Clay) \\
\hline
\end{tabular}



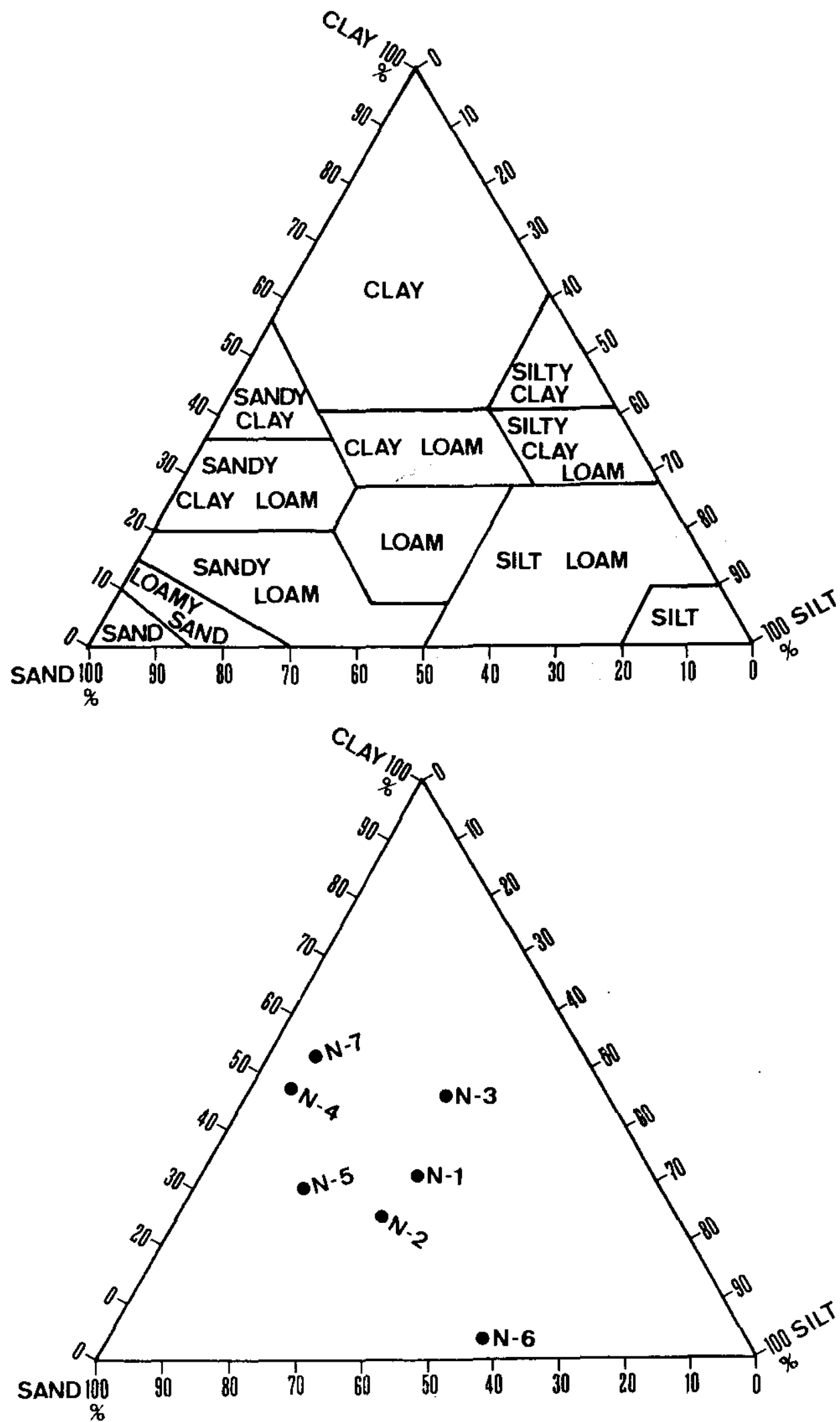

Figura 5.5: Diagrama ternario de la clasificicion textural de los scedmentes arcillosos, scgún cl limite tortcamericams de dímétro de las particulas ofe la arcillh, situado en 2 mm. N-1 arcilla margosa, N-2 marga, N-3 arcilla, N-4 arcilla arenosa, N-5 arcilla margosa arcnosa, $N-6$ limo margoso, $N-7$ arcilla. 


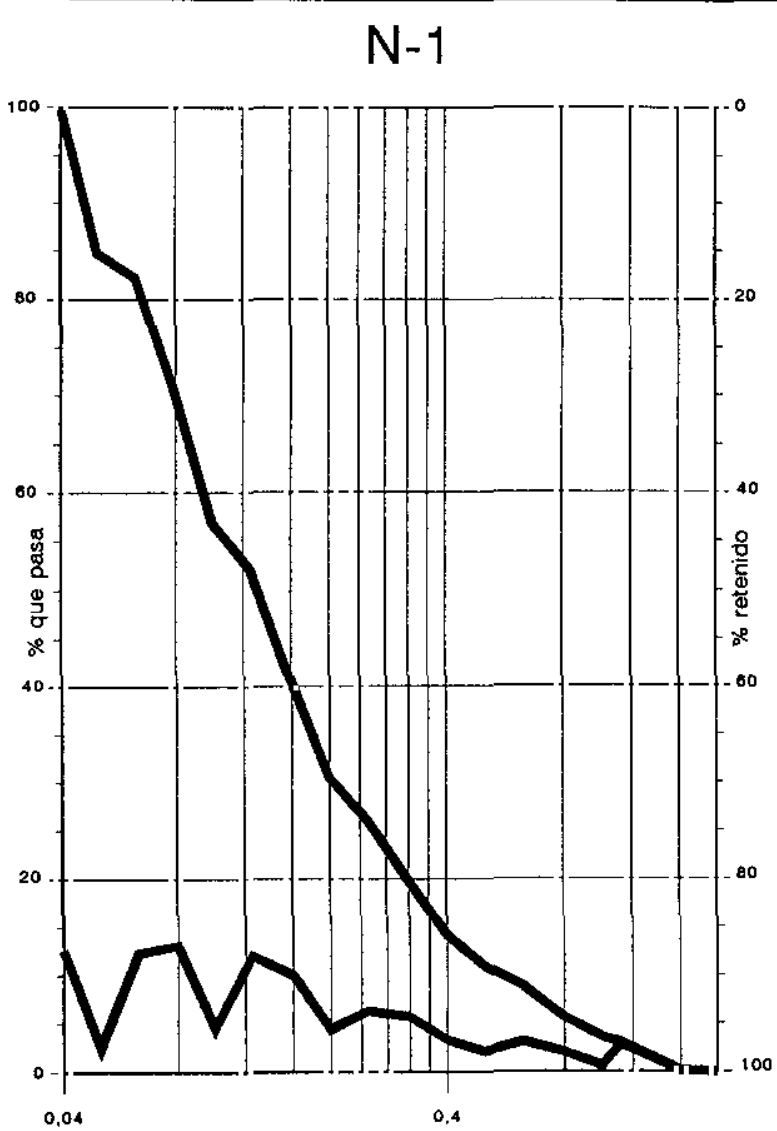

Tamaño particules $\mathrm{mm}$

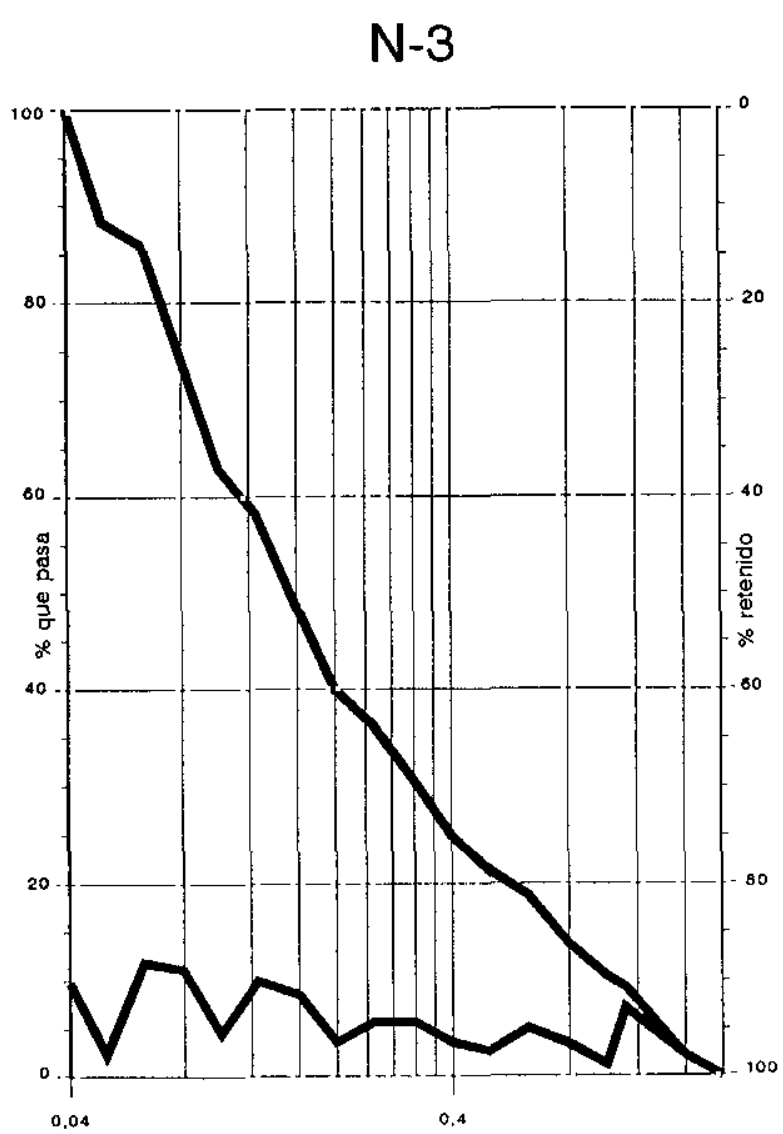

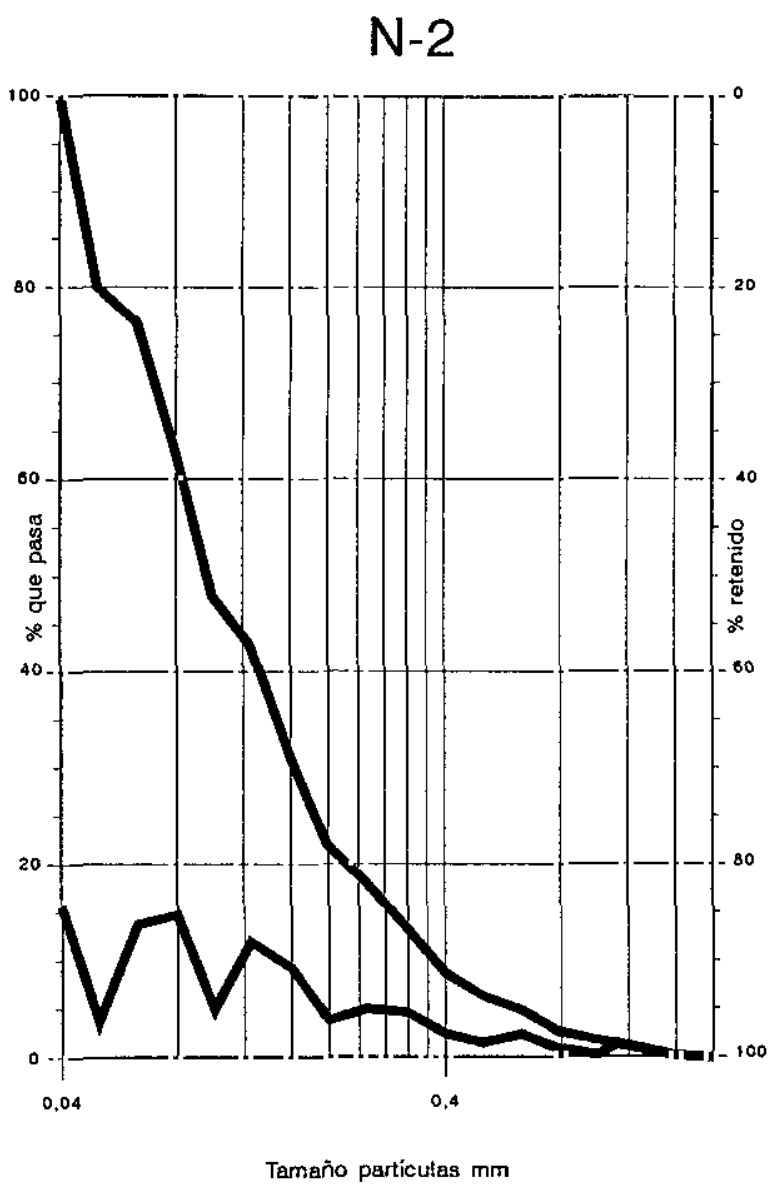

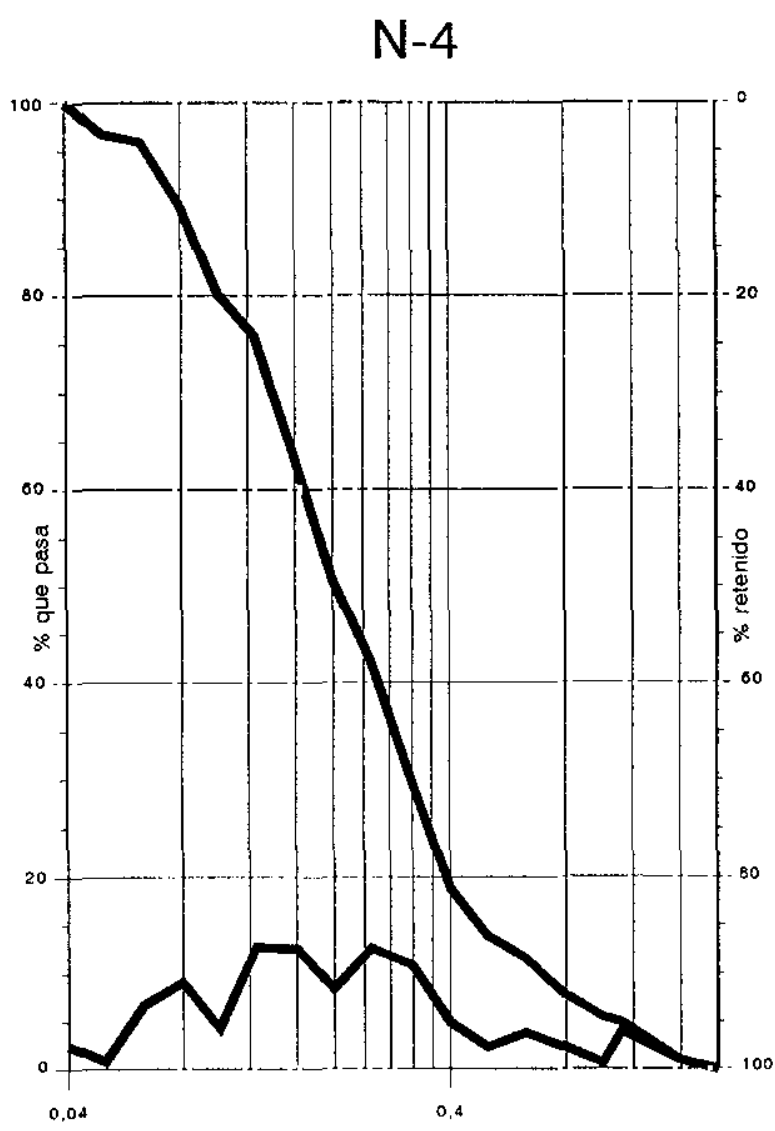

Figurañ 5.8 rúculas mm 
$\mathrm{N}-5$

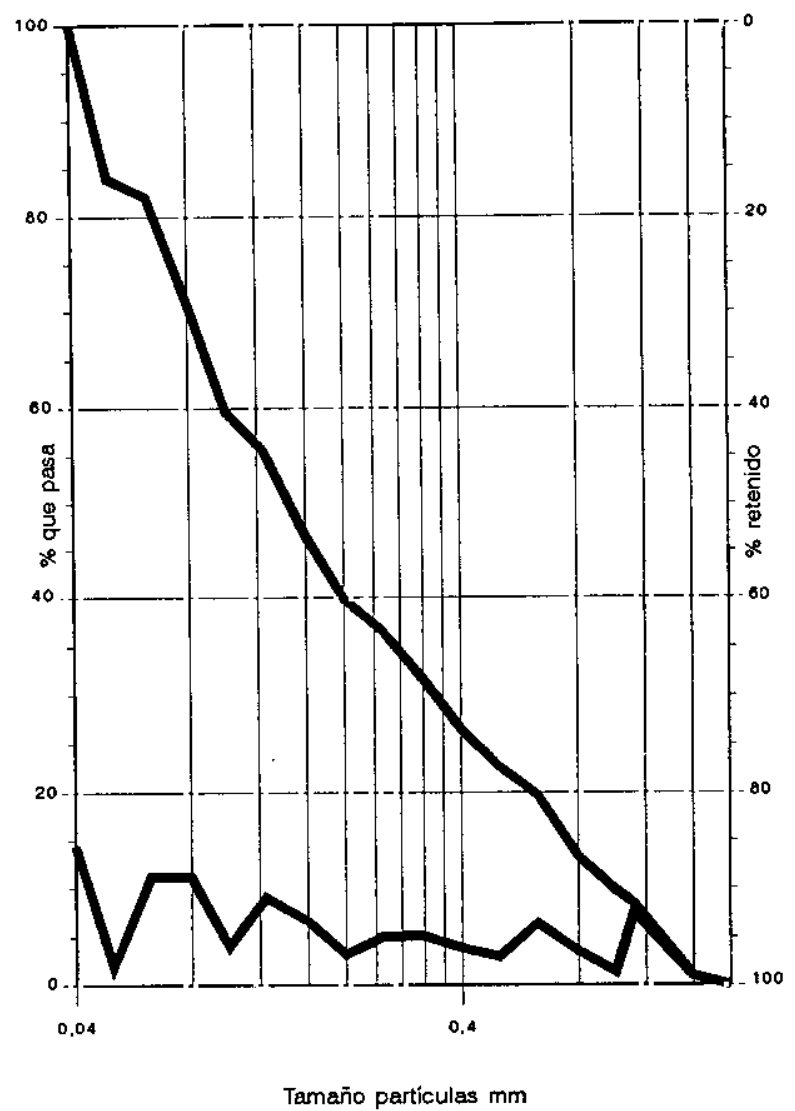

N-6

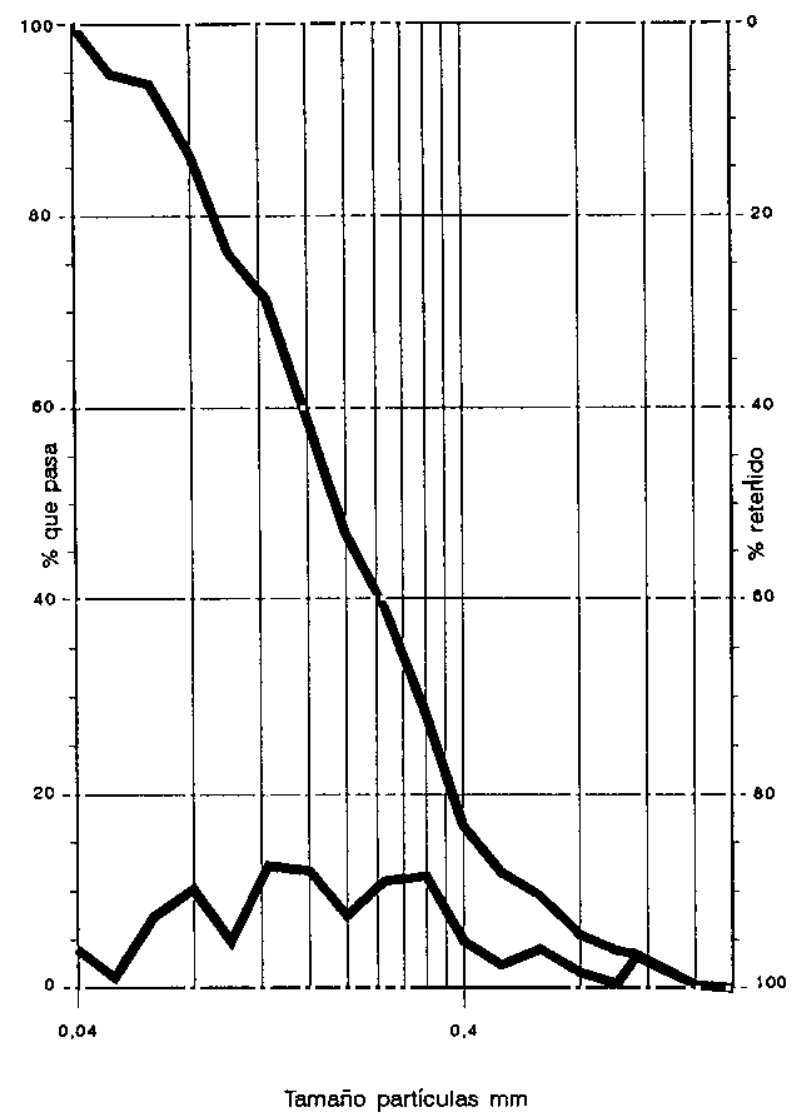

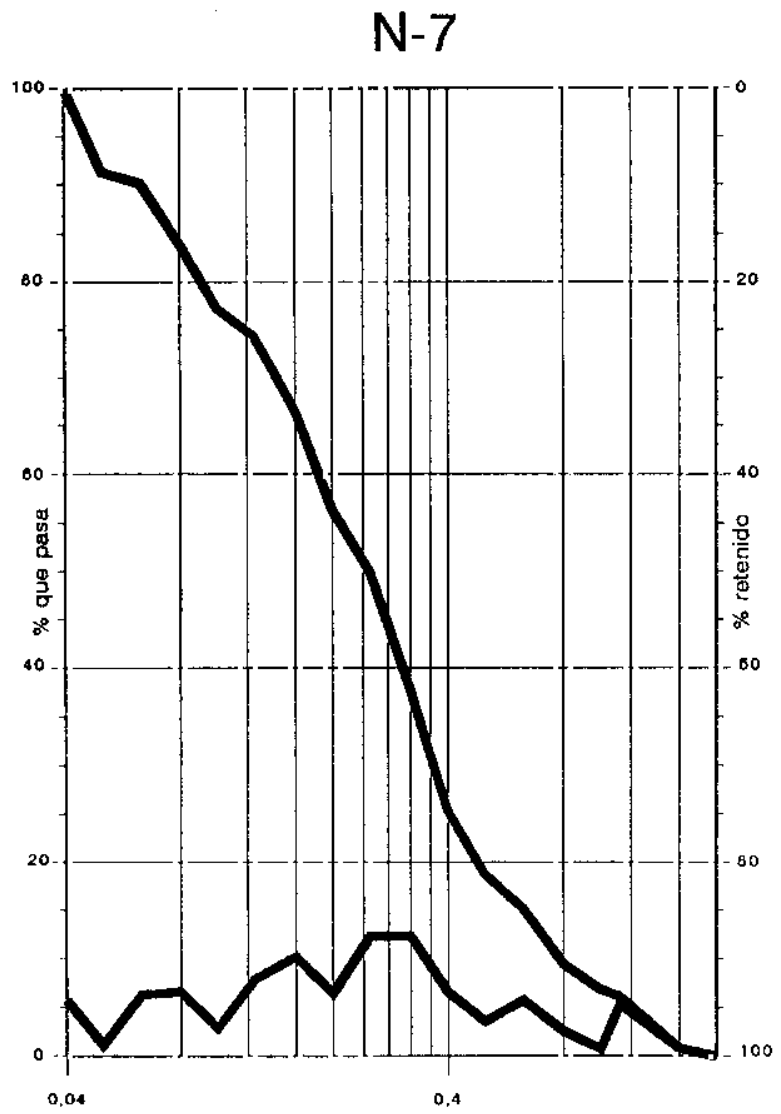

Figura 5.6: Conticulas mm 
se ha traducido como marga. No obstante, debe tenerse en cuenta que este término se emplea, en general, para referirse a mezclas de arena y arcilla, en un sentido textural (Grinshaw, 1971, 415).

\subsubsection{Colores}

Los colores Munsell que presentan las muestras, una vez cocidas a las temperaturas especificadas, se han expuesto en la Tabla 4.2 del capítulo anterior. Esta Tabla, ofrecía sólo un color, ya que no había diferencias entre los códigos Munsell que tenían las probetas en su parte extema y en el interior de la pasta. Como podía observarse, el color de las muestras en crudo es distinto para cada una de ellas. De manera general, con el aumento de la temperatura los colores se van aclarando, no habiendo diferencias importantes entre $700^{\circ}$ y $800^{\circ} \mathrm{C}$ y entre $900^{\circ}$ y $1.000^{\circ} \mathrm{C}$ respectivamente. Asimismo, si se comparan los datos de las Tablas 1 y 4.2 , la mayor parte de las secciones de las muestras cerámicas analizadas de los yacimientos de Numancia e Izana, no comparte los colores que presentan las probetas a las distintas temperaturas. De todas formas, los colores de las superficies de las cerámicas, no se han comparado con estas probetas, ya que, como se apuntaba en el apartado del Análisis macroscópico, dichos colores no son buenos indicadores del que presenta la pasta.

Finalmente, la muestra de caolín blanca N-8, no tiene equivalencia en los registros Munsell. Por ello, no se incluyó en la Tabla 4.2, aunque el color que presentaba a temperatura ambiente no variaba en rangos superiores.

\subsection{ANÁLISIS PETROGRÁFICO MEDIANTE LÁMINA DELGADA}

Los tesultados del análisis petrográfico, se ofrecen en la Tabla 6 del final de este trabajo. Se ha optado por presentarlos de manera semi-cuantitativa, ya que a partir de los conteos efectuados en el Análisis textural, se tenía oportunidad de conocer los porcentajes de cada una de las fases presentes en las láminas delgadas. No obstante, es importante incidir en la naturaleza semi-cuantitativa de estos datos, debido a los problemas que plantea el reducido tamaño de algunas inclusiones, con lo que ello representa para identificatlas correctamente y para 
contabilizarlas en su totalidad, en los campos seleccionados al realizar los conteos.

\subsubsection{Cerámicas}

En lineas generales, la mayoría de las muestras analizadas presenta una mineralogía muy homogénea. Es por ello, por ejemplo, por lo que las muestras pertenecientes a los yacimientos de Numancia e Izana, no pueden distinguirse entre sí. En cualquier caso, y a pesar de esta homogeneidad, pueden establecerse 4 agrupaciones, en función de las distintas características observadas. Antes de pasar a su descripción, debe señalarse que no ha sido posible diferenciar por separado las fases de cuarzo y feldespato, dado el reducido tamaño que, en genetal, presentan estas inclusiones. Por este motivo, en la Tabla 17, la semi-cuantificación de estas fases se muestra conjuntamente. Estas 4 agrupaciones, definidas a partir del tasgo más sobresaliente que las caracteriza, son las siguientes:

Grupo con calcita añadida. Este grupo está compuesto por 10 muestras (ver Tabla 5.6 para su identificación). En él se observan abundantes inclusiones, de diferentes tamaños, compuestas por calcita criptocristalina con caras limpias y claros ángulos de exfoliación que, a veces, forman romboedros (Fotos 1 y 2). Estos ángulos de exfoliación, podrían indicar que esta calcita se ha añadido intencionadamente a la pasta. También se observan inclusiones de calcita micrítica, de menor tamaño, distinta a la anterior y mucho menos abundantes. Las muestras de este grupo, presentan matrices isótropas sin indicios de vitrificación y con abundantes cambios de coloración entre el rojo y el marrón. Se trata, generalmente, de matrices oxidantes con superficies reducidas. Asimismo, se identifican también inclusiones redondeadas de pequeño tamaño de cuarzo y feldespato, algunas laminillas de mica y óxidos de Fe. La macroporosidad de estas muestras es importante, observándose gran cantidad de poros alargados paralelos a las superficies de la cerámica. La media del porcentaje de inclusiones con respecto a la matriz, se sitúa en el 34,5\%. Se han medido tamaños de grano de hasta $1,10 \mathrm{~mm}$, aunque en el caso de la calcita criptocristalina, se concentra en las fracciones comprendidas entre 0,10 y $0,40 \mathrm{~mm}$. $\mathrm{La}$ muestra $\mathrm{N}-17$, tiene, no obstante, un tamaño de grano menor que el resto. En la muestra $\mathrm{N}-21$, se han identificado dos inclusiones de chamota de gran tamaño (Foto 3). Esta chamota presenta unos bordes bien delimitados y tiene una textura distinta, con inclusiones de mucho menor tamaño, que el resto de la matriz. Las características que exhibe, podrían coincidir, como se verá 
FOTO 1.- N-18. X 10. Matriz con inclusiones de calcita añadida. Nícoles cruzados.

FOTO 2.- 1ZA-11, X 10. Matriz con inclusiones de calcita añadida. Nícoles cruzados. FOTO 3.- N-21. X 10. Detalle de inclusión de chamota. Nicoles crazados. FOTO 4.- N-11. X 10. Nícoles cruzados.

FOTO 5.- N-24. X 12,5. Nícoles cruzados.

FOTO 6.- N-45. X 10. Nícoles cruzados. 


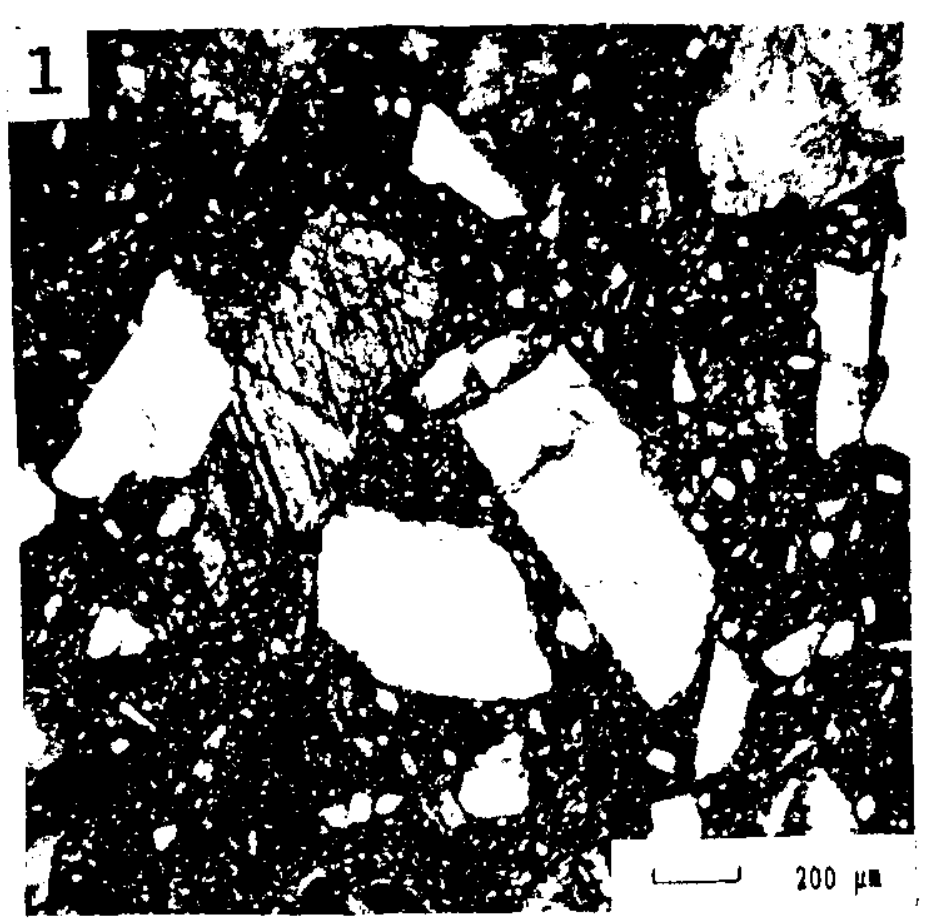

$3 \% 48 \%$

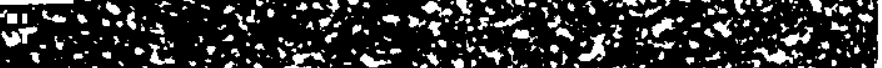

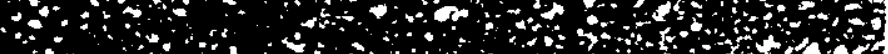

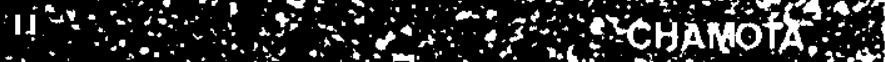

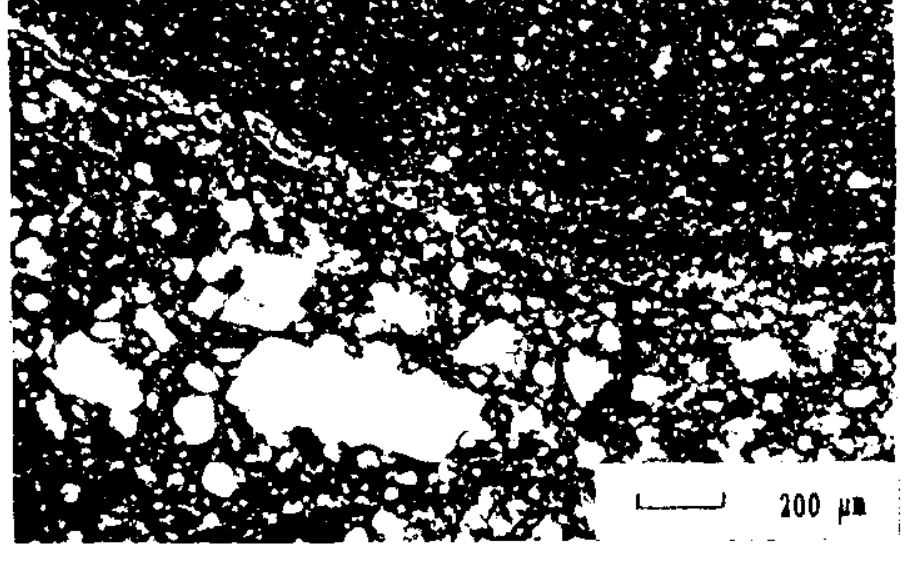

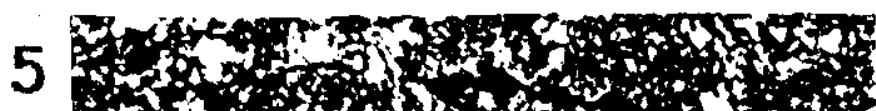

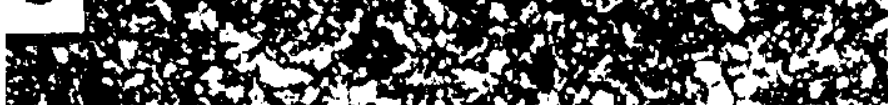

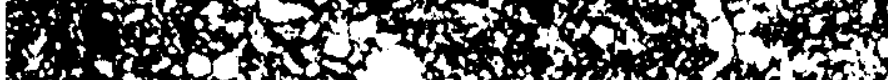

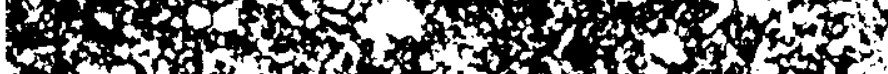

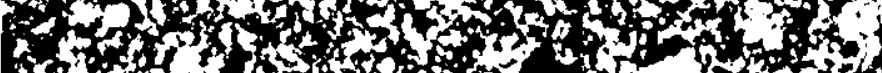

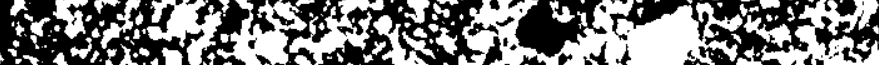

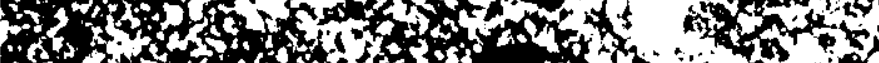

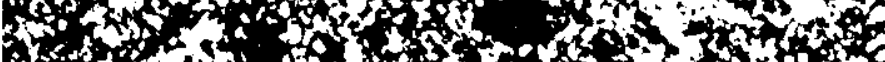

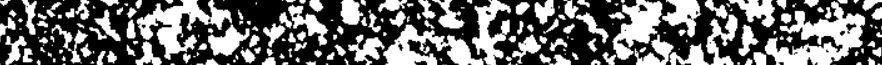

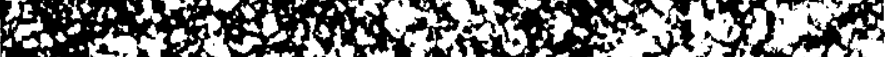

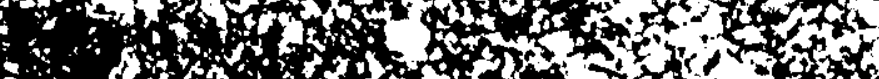

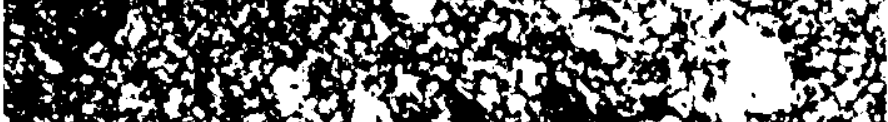

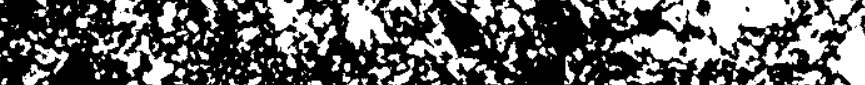

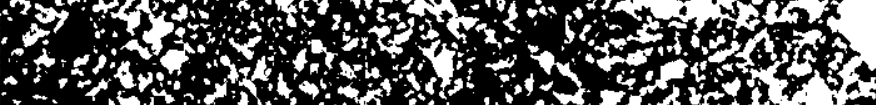

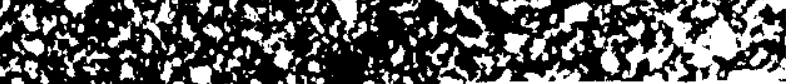

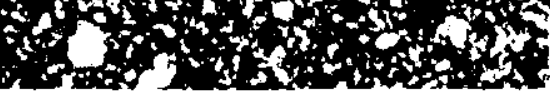

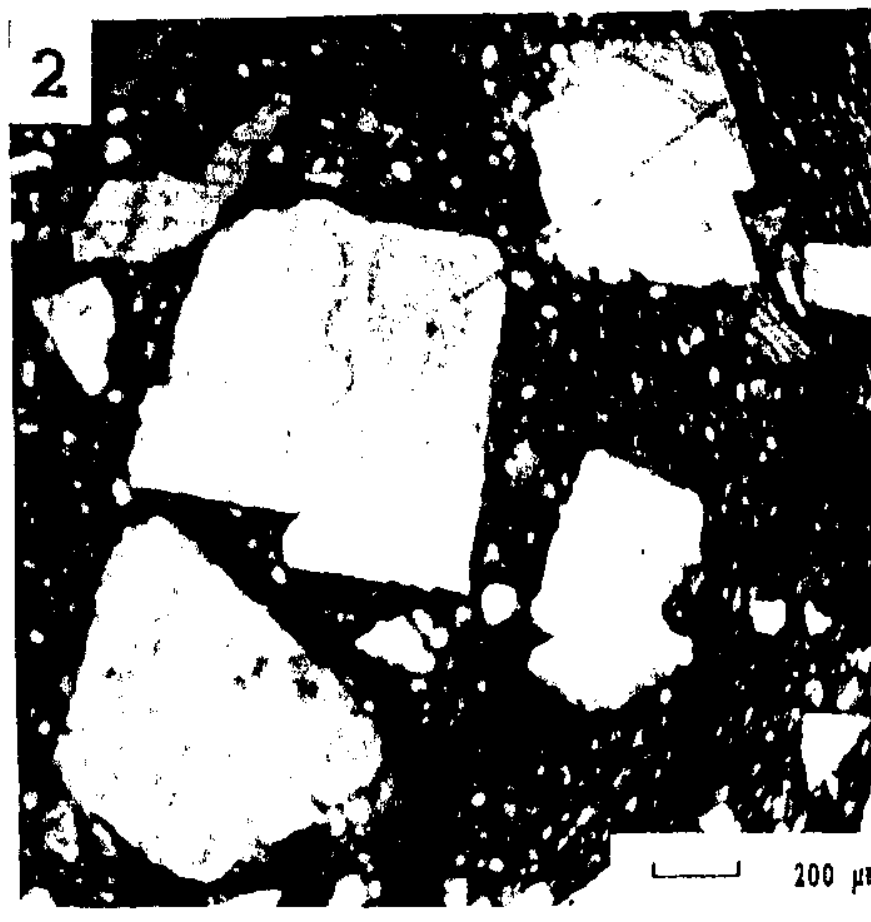

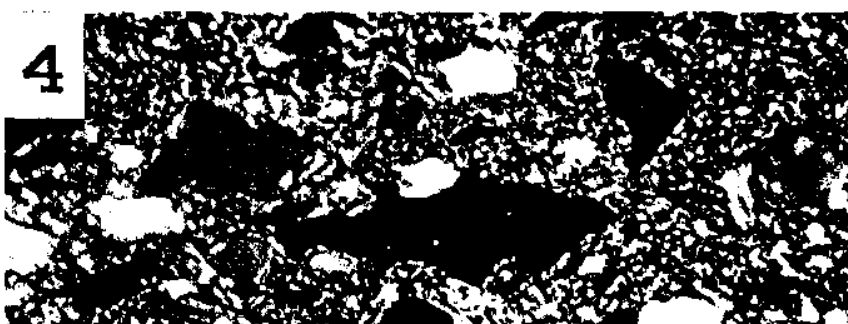

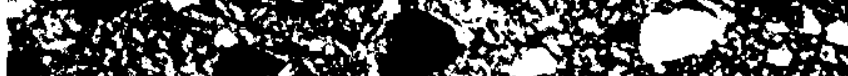

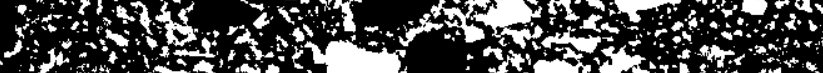

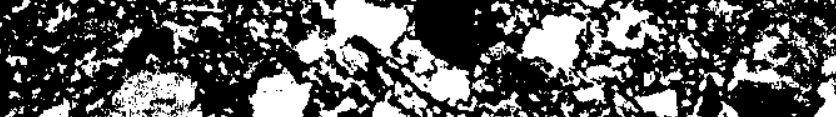

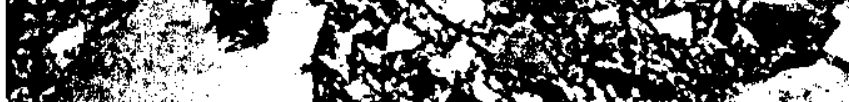

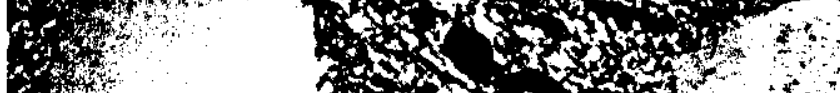

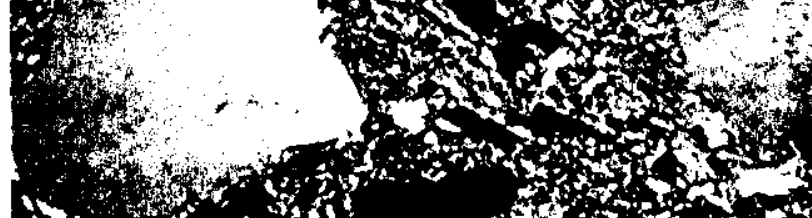
(b)

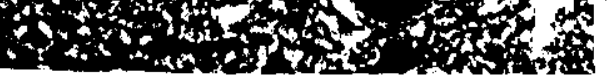

$200 \mathrm{k}$

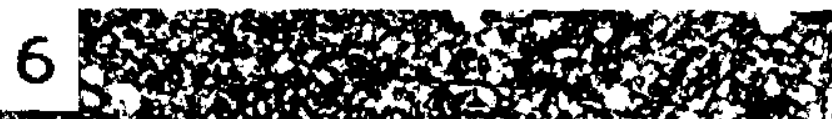

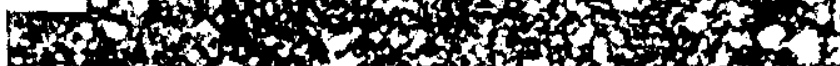

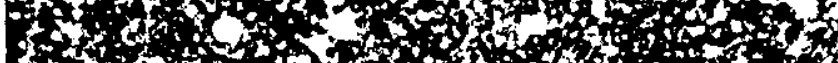

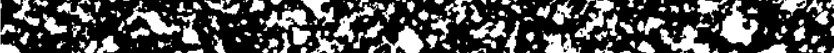

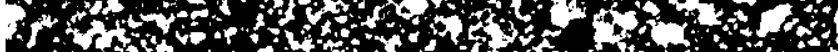

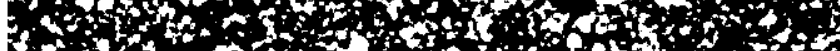

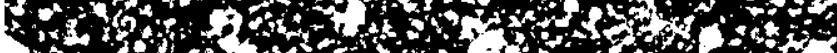

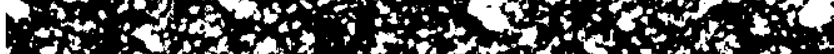

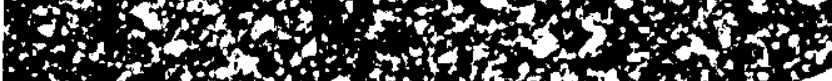

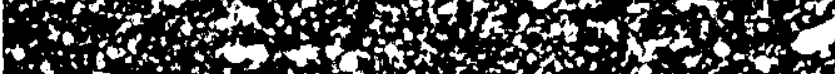

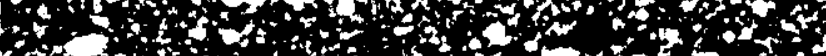

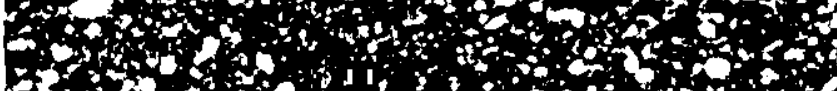

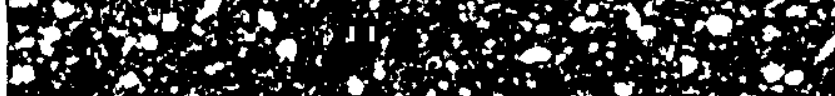

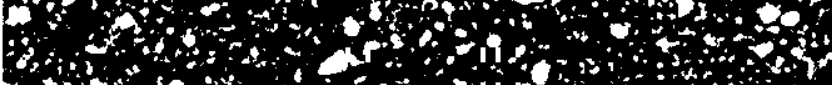

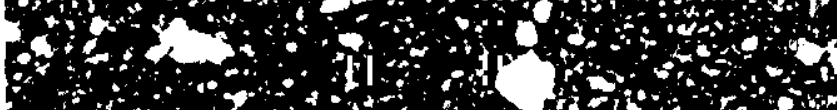

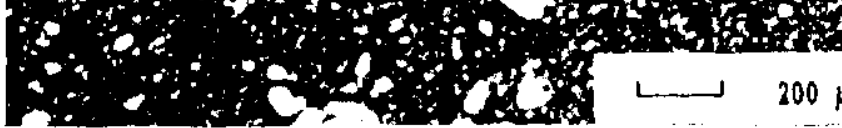


FOTO 7.- IZA-5. X 10. Nícoles cruzados.

FOTO 8. $\mathrm{N}-60 . \times 10$. Detalle de la superficie externa reducida. Nicoles cruzados. FO'TO 9.- NP-97. X 10. Nícoles cruzados.

FOTO 10.- NP-97. X 63. Detalle de los minerales arcillosos de la matriz. Nicoles cruzados. FOTO 11.- N-27. X 10. Nícoles cruzados.

FOTO 12.- LD-94. X 10. Nicoles cruzados. 


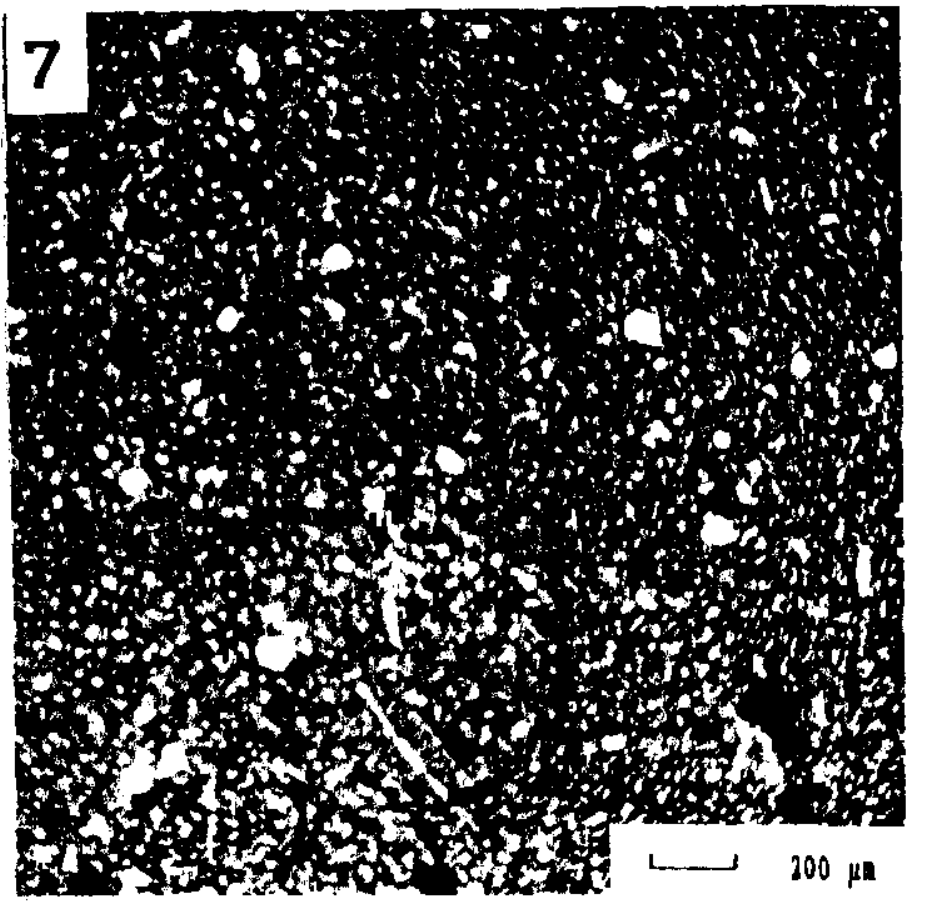

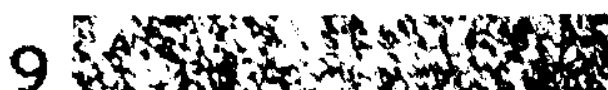

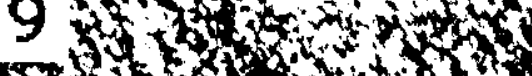

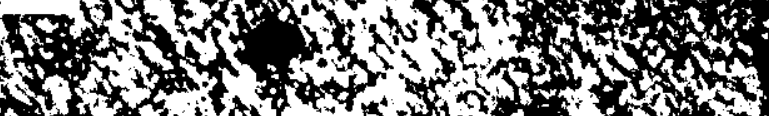

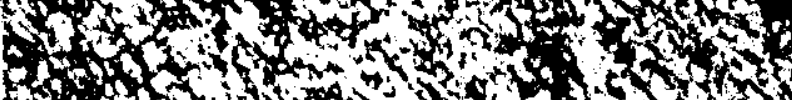

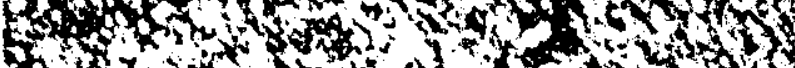

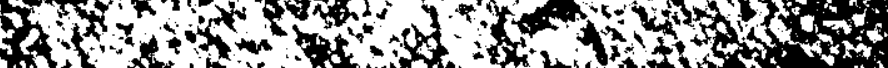

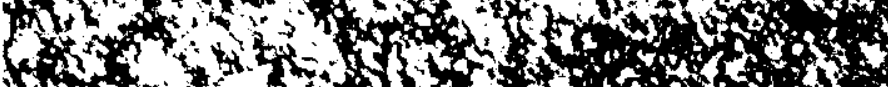

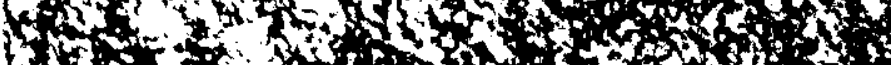

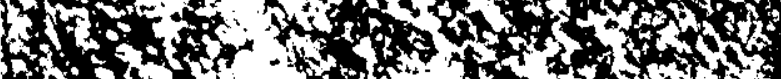

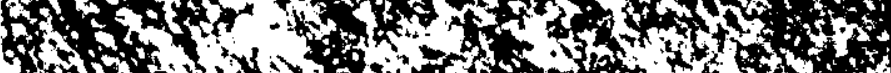

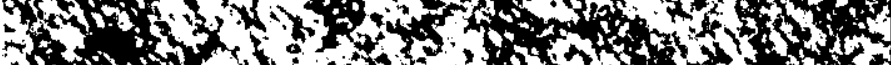

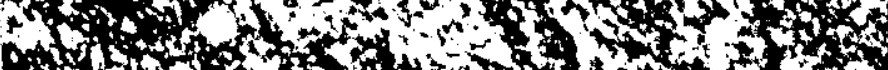

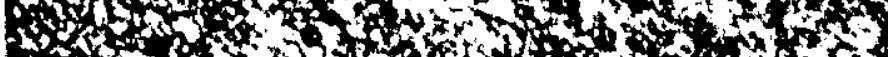

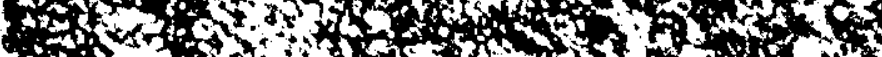

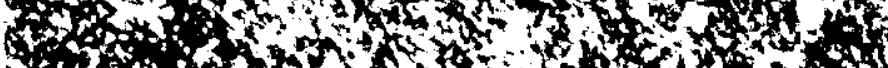

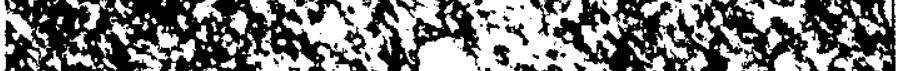

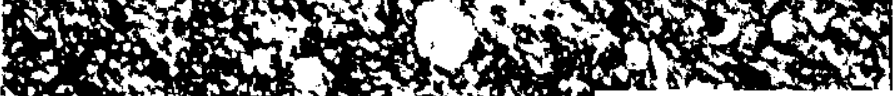

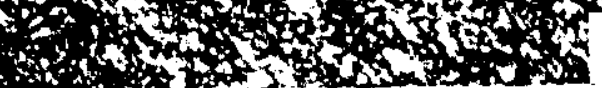

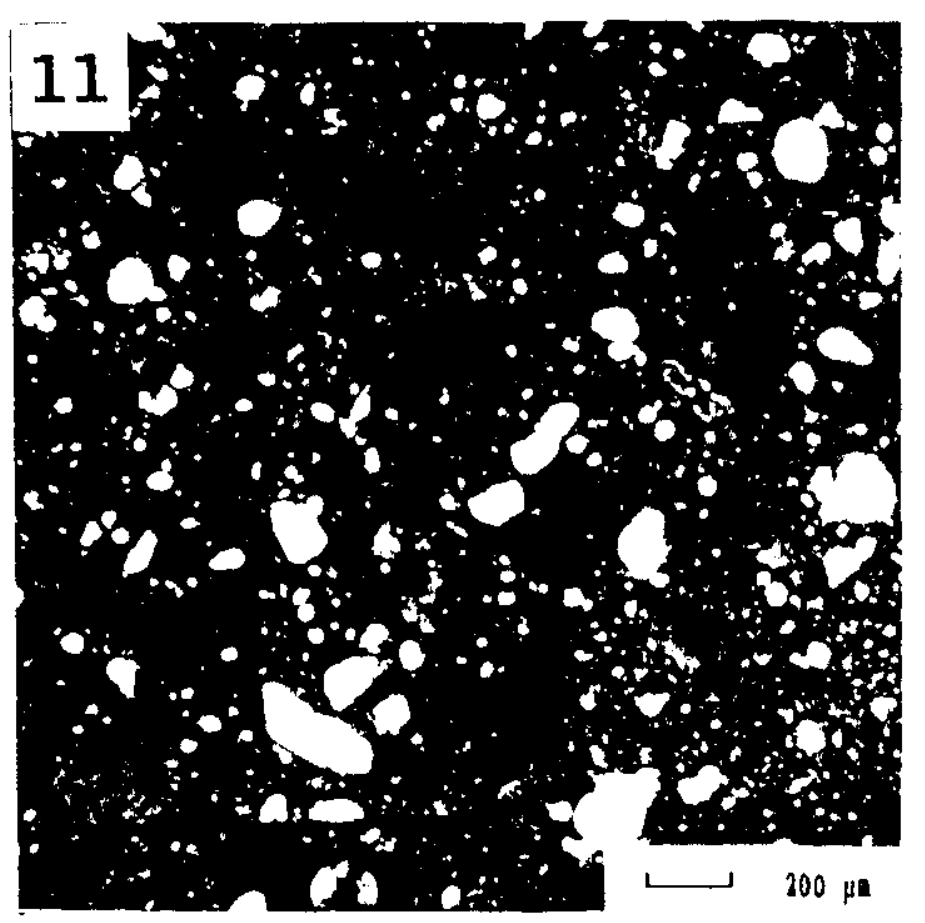

8

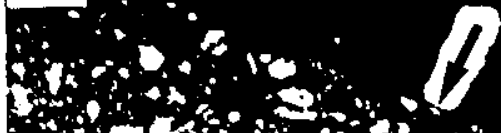

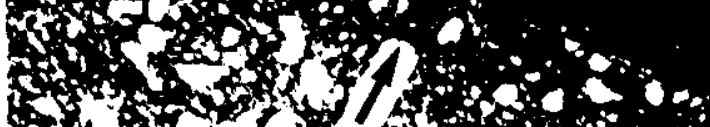

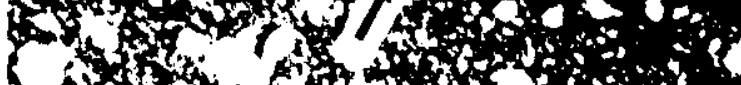

Hol

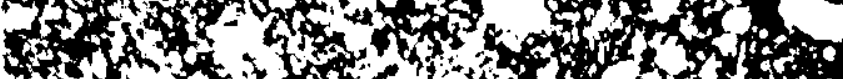

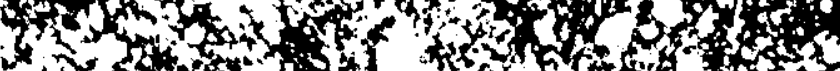

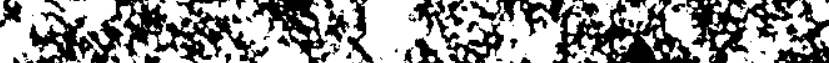

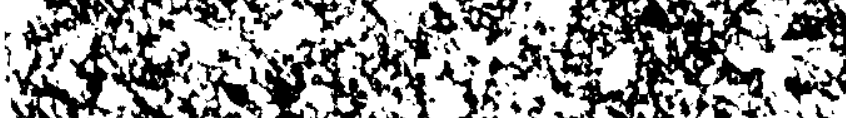

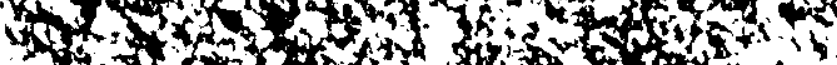

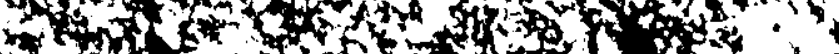

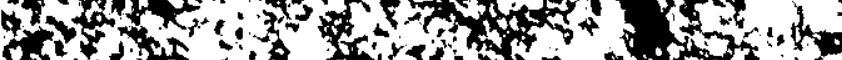

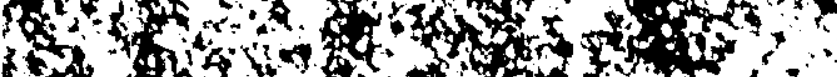

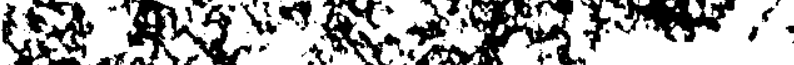

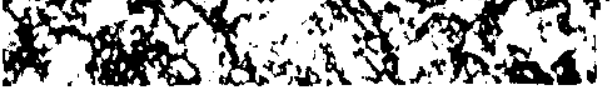

$200 \%$

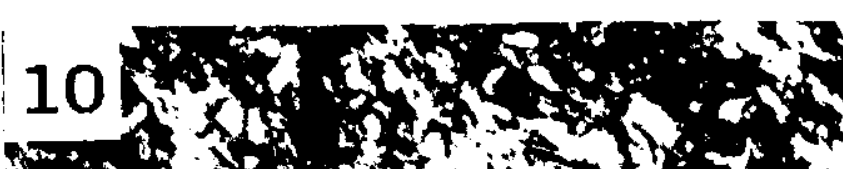

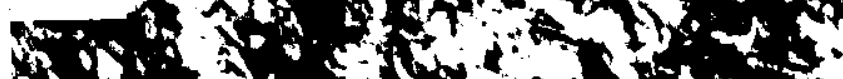

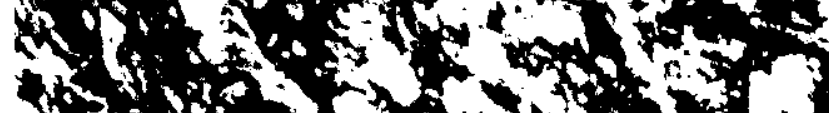

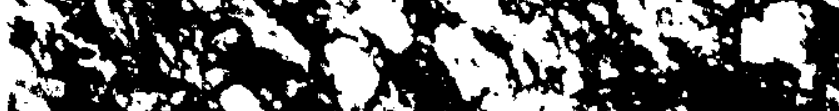

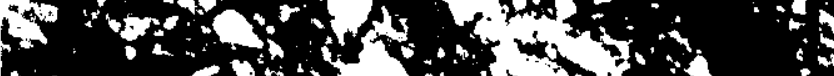

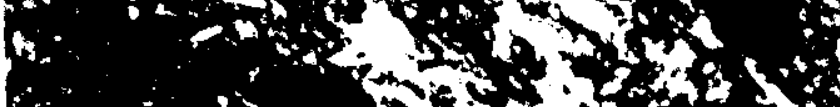

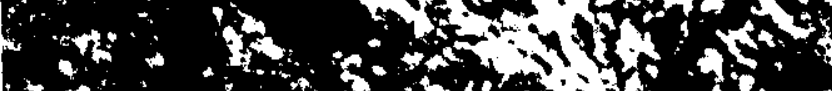

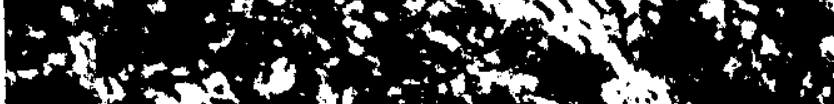

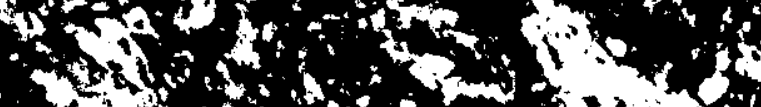

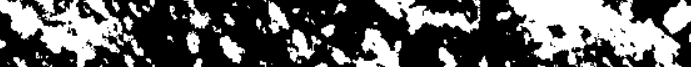

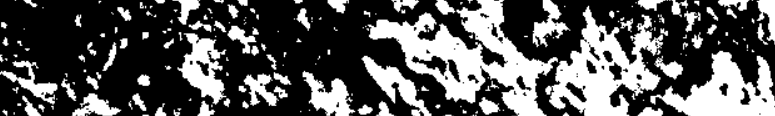

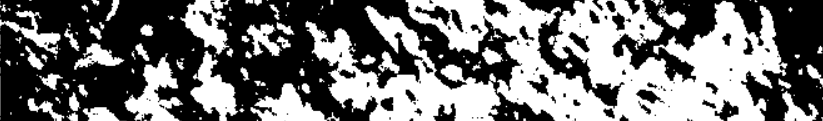

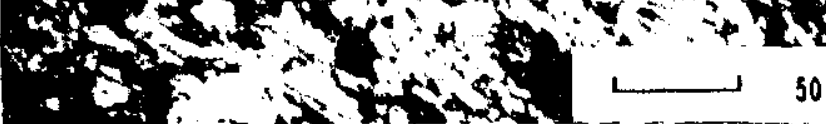

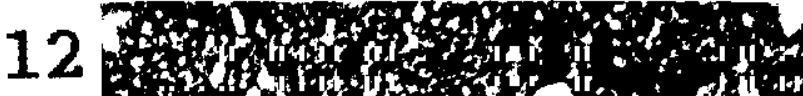

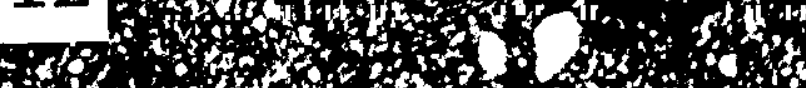

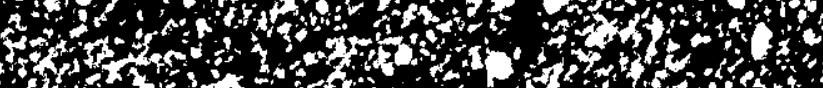

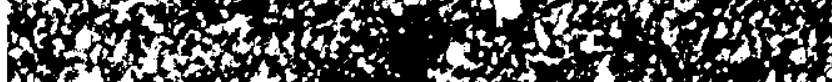

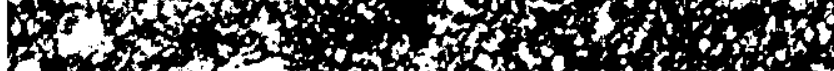

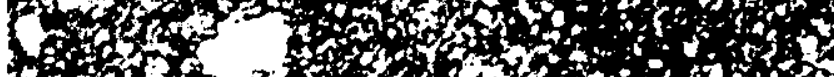
2030 a

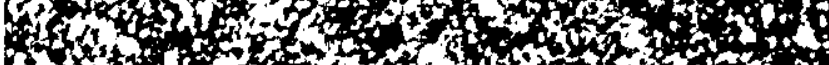

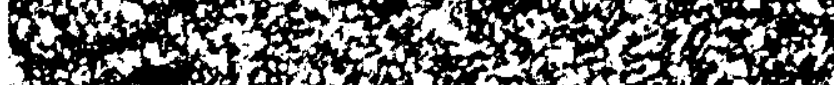

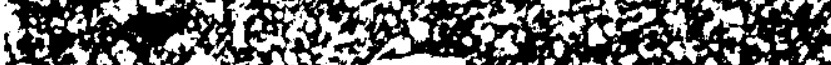

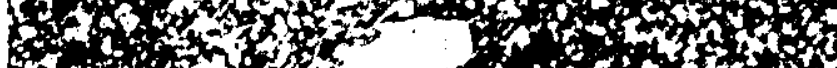

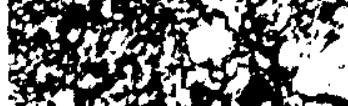

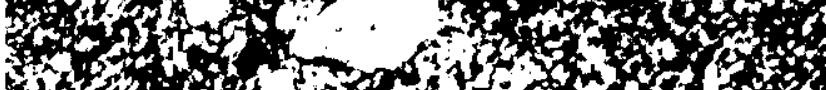

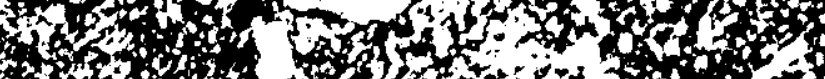

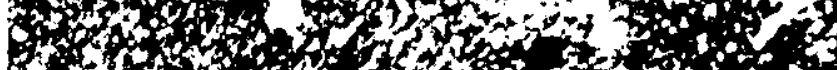

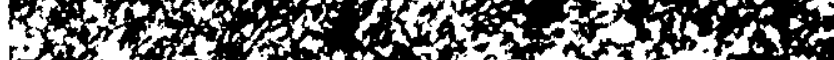

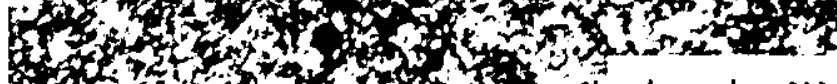

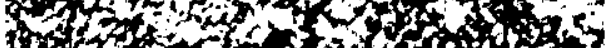


TABLA 5.6. CARACTERÍSTICAS DE LOS GRUPOS DETERMINADOS EN EL ANÁLISIS PETROGRÁFICO MEDIANTE LÁMINA DELGADA

\begin{tabular}{|c|c|c|c|c|c|c|c|c|c|}
\hline \multirow{2}{*}{\multicolumn{2}{|c|}{$\begin{array}{c}\text { GRUPOS Y } \\
\text { CARACTERISTICAS } \\
\text { Calcita añadida }\end{array}$}} & \multirow{2}{*}{$\frac{\begin{array}{c}\mathrm{N}^{\circ} \\
\text { MUESTRAS }\end{array}}{10}$} & \multicolumn{7}{|c|}{ MUESTRAS } \\
\hline & & & $\begin{array}{l}N-10 \\
N-12\end{array}$ & $\begin{array}{l}N-15 \\
N-17\end{array}$ & $\begin{array}{l}N-18 \\
N-19\end{array}$ & $\begin{array}{l}\mathrm{N}-20 \\
\mathrm{~N}-21\end{array}$ & $\begin{array}{l}\mathrm{N}-23 \\
\mathrm{IZA}-11\end{array}$ & & \\
\hline \multicolumn{2}{|c|}{ Calcárea } & 1 & N-27 & & & & & & \\
\hline \multirow[t]{2}{*}{ Principal } & Matriz roja & 51 & $\begin{array}{l}N-24 \\
N-28 \\
N-31 \\
N-34 \\
N-35 \\
N-36 \\
N-37 \\
N-38\end{array}$ & $\begin{array}{l}\text { N-39 } \\
\text { N-40 } \\
\text { N-41 } \\
\text { N-43 } \\
\text { N-45 } \\
\text { N-46 } \\
\text { N-47 } \\
\text { N-48 }\end{array}$ & $\begin{array}{l}\text { N-49 } \\
\text { N-50 } \\
\text { N-52 } \\
\text { N-53 } \\
\text { N-54 } \\
\text { N-55 } \\
\text { N-56 } \\
\text { N-57 }\end{array}$ & $\begin{array}{l}\text { N-58 } \\
\text { N-59 } \\
\text { N-64 } \\
\text { N-65 } \\
\text { N-67 } \\
\text { N-68 } \\
\text { N-69 } \\
\text { NP-72 }\end{array}$ & $\begin{array}{c}\text { NP-74 } \\
\text { NP-75 } \\
\text { NP-76 } \\
\text { NP-77 } \\
\text { NP-78 } \\
\text { NP-79 } \\
\text { NP-82 } \\
\text { NP-88 }\end{array}$ & $\begin{array}{c}\text { NP-89 } \\
\text { NP-90 } \\
\text { IZA-1 } \\
\text { IZA-2 } \\
\text { IZA-3 } \\
\text { IZA-4 } \\
\text { IZA-5 } \\
\text { IZA-6 }\end{array}$ & $\begin{array}{l}\text { IZA-7 } \\
\text { IZA-9 } \\
\text { IZA-11 }\end{array}$ \\
\hline & $\begin{array}{l}\text { Matriz } \\
\text { blanco- } \\
\text { amarillenta }\end{array}$ & 25 & $\begin{array}{l}\mathrm{N}-25 \\
\mathrm{~N}-26 \\
\mathrm{~N}-29 \\
\mathrm{~N}-30\end{array}$ & $\begin{array}{l}\mathrm{N}-32 \\
\mathrm{~N}-33 \\
\mathrm{~N}-42 \\
\mathrm{~N}-44\end{array}$ & $\begin{array}{l}N-51 \\
N-60 \\
N-61 \\
N-62\end{array}$ & $\begin{array}{l}\text { N-63 } \\
\text { N-66 } \\
\text { N-70 } \\
\text { NP-73 }\end{array}$ & $\begin{array}{c}\text { NP-80 } \\
\text { NP-81 } \\
\text { NP-83 } \\
\text { NP-84 }\end{array}$ & $\begin{array}{c}\text { NP-85 } \\
\text { NP-86 } \\
\text { NP-87 } \\
\text { NP-91 }\end{array}$ & NP-97 \\
\hline \multicolumn{2}{|c|}{$\begin{array}{l}\text { Menor selección } \\
\text { tamaño de grano }\end{array}$} & 7 & N-11 & N-13 & N-14 & $\mathrm{N}-16$ & $\mathrm{~N}-22$ & N-71 & IZA-8 \\
\hline
\end{tabular}

más adelante, con las cerámicas de matriz roja del grupo principal. Todas las muestras de esta agrupación, pertenecen a la Fábrica Negra.

Grupo principal. Este grupo está compuesto por 76 muestras, que representan todas las cerámicas analizadas de las Fábricas 1, 1-b y 2 (ver Tabla 5.6). Principalmente, estas muestras contienen inclusiones redondeadas y subrredondeadas de cuarzo y feldespato, abundantes laminillas de mica, óxidos de Fe y opacos y, en menor medida, alguna inclusión de cuarcita, de pequeño tamaño, fragmentos de roca con estructura planar y calcita micrítica (Fotos 5, 6, 7, 8 y 9). Estos últimos tres tipos de inclusiones, no se detectan en todas las láminas. Su macropotosidad es escasa y los tamaños de grano se sitúan, mayoritariamente, entre $0,10 \mathrm{y}$ $0,30 \mathrm{~mm}$, siendo pocas las muestras en las que se alcanzan los $0,4 \mathrm{~mm}$. No obstante, en la muestra NP-79, algunas inclusiones llegan a los $0,5 \mathrm{~mm}$. La media del porcentaje de inclusiones 
con respecto a la matriz, se sitúa en un $19 \%$, lo que indica que el sedimento utilizado como materia prima, ha sido muy seleccionado.

En función de las características de la matriz, siempre sin indicios de vitrificación, excepto en pequeñas partes de las muestras N-28, N-53 y N-62, pueden distinguirse dos subgrupos: uno con matrices rojizas y anaranjadas (Fotos 5,6 y 7) y, otro, con matrices blancoamarillentas, en general, más birrefringentes (Foto 9), en las cuales todavía se observa, a gran aumento, la estructura de los minerales arcillosos (Foto 10).

En las cerámicas grises de la Fábrica 2, presentes en ambos subgrupos, sólo se observan pequeñas superficies reducidas (Foto 8), que no afectan a la totalidad de la matriz. Tan sólo la muestra N-65, es casi toda ella gris claro. Este aspecto, podría indicar que solamente se ha producido un pequeño ciclo reductor al final del proceso de cocción.

Grupo con menor selección de tamaño de grano. Las 7 muestras pertenecientes a este grupo, todas ellas de la Fábrica negra (ver Tabla 5.6), presentan matrices isótropas sin vitrificar, con frecuentes cambios de coloración. En general, tienen un color marrón, aunque en la muestra N-13, la matriz es roja. Al igual que en el grupo anterior, sólo las superficies presentan áreas reducidas. En estas cerámicas, el sedimento utilizado como materia prima, tiene una menor selección del tamaño de grano que en las pertenecientes al grupo principal. En este sentido, se han medido tamaños de hasta $1,10 \mathrm{~mm}$ en la muestra $\mathrm{N}-16$. No obstante, las muestras N-14 y $\mathrm{N}-71$, con un tamaño de grano menor, se parecen más a las de matriz roja del grupo anterior. Debido a que muestran una mineralogia muy similar, podría tratarse del mismo tipo de pasta, aunque con una menor selección.

En las láminas, se observan abundantes inclusiones de cuarzo y feldespato, de distintos tamaños (Foto 4), óxidos de Fe y opacos y algún pequeño fragmento de roca con estructura planar. Las laminillas de mica son muy escasas, excepto en la muestra N-16. Por otra parte, las muestras $\mathrm{N}-13, \mathrm{~N}-16, \mathrm{~N}-22$ y N-71, presentan, además, pequeñas inclusiones de calcita micrítica, más abundantes en la N-22. Hay también cuarcita de varios tamaños en las muestras $\mathrm{N}-13, \mathrm{~N}-16$ e IZA-8. En una de ellas, en la N-16, se distinguen también algunas plagioclasas.

En general, presentan una importante mactoporosidad, con poros alargados paralelos a las superficies. La media del porcentaje de inclusiones con respecto a la matriz, es más elevada que en el grupo anterior, situándose en un $30,8 \%$. 
FOTO 13.- LD-95. X 10. Nicoles cruzados.

FOTO 14.- EP-27. X 10. Nícoles cruzados.

FOTO 15,- PT-8. X 10. Nicoles cruzados.

FOTO 16.- N-48. X 10. Superficie interna con calcita secundaria depositada. Nícoles cruzados. FOTO 17.- N-1D. X 10. Sedimento arcilloso cocido en atmósfera oxidante a $900^{\circ} \mathrm{C}$ Nícoles cruzados. FOTO 18.- N-4D. X 10. Sedimento arcilloso cocido en atmósfera oxidante a $900^{\circ} \mathrm{C}$. Nícoles cruzados. 

13 a

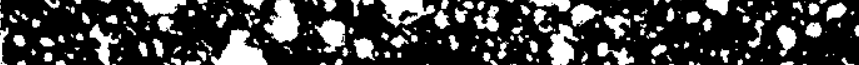

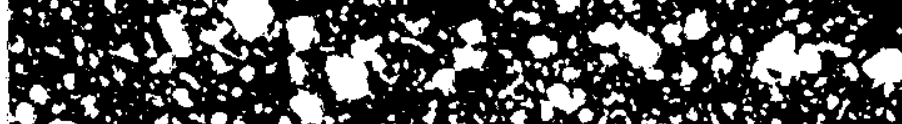

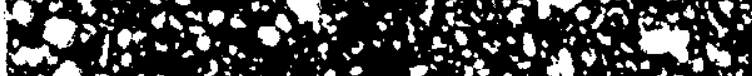

3 s.

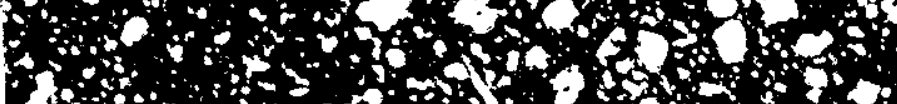
(4)

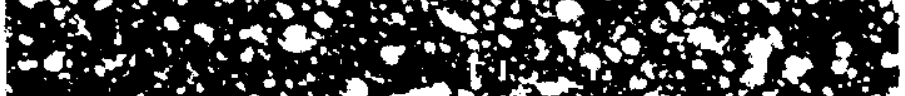

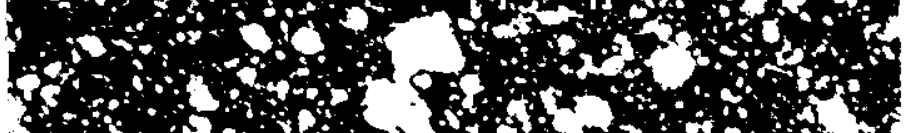

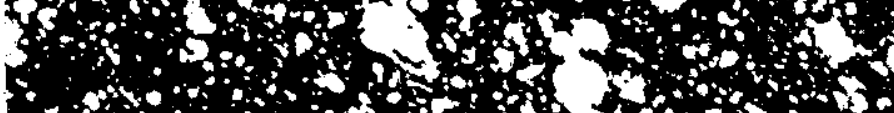

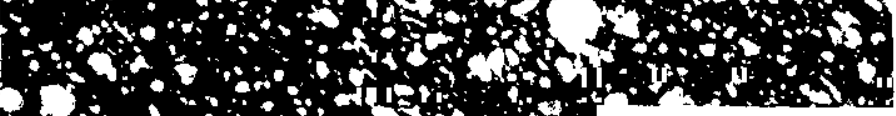
$\therefore-200 \mu$

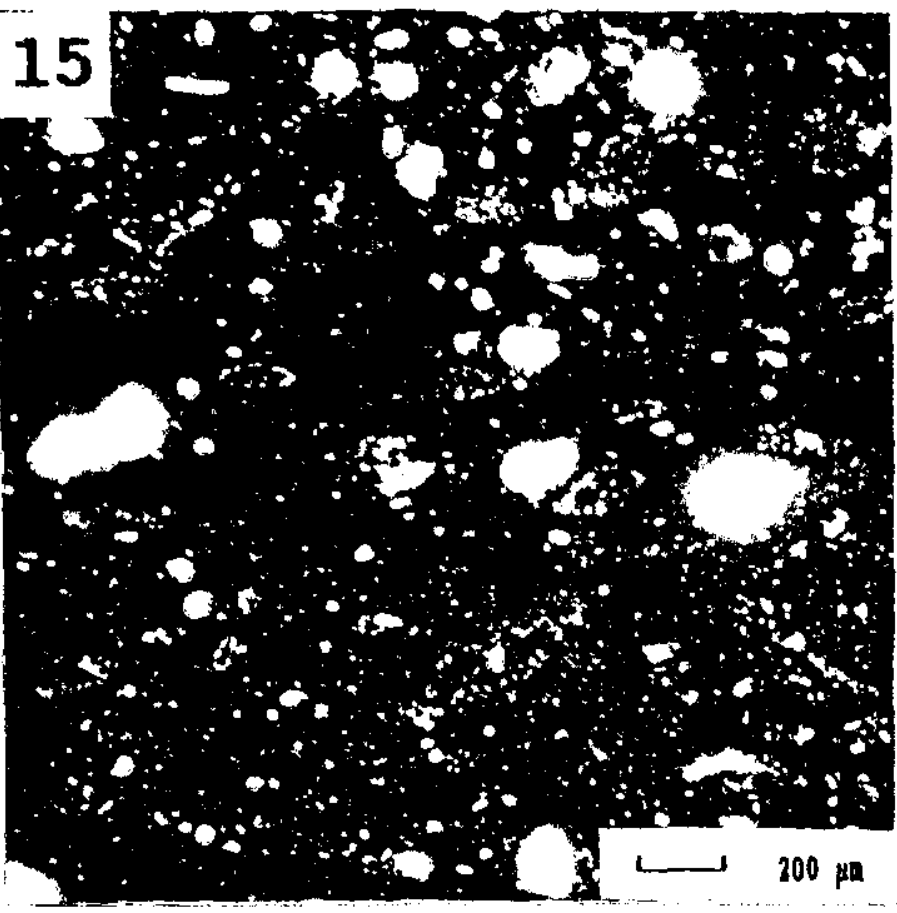

$17 \times$ ars

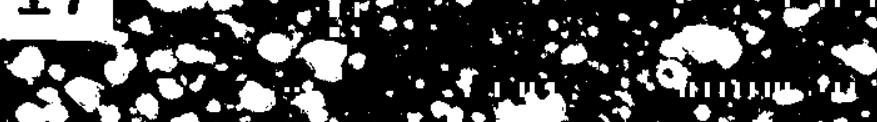
4.8. 0

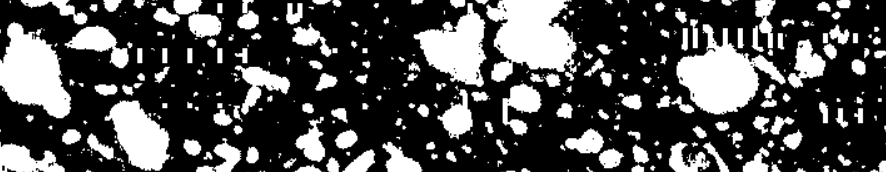

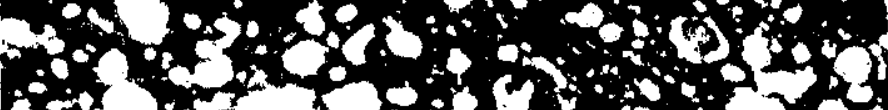
Ler. x. $x^{2}$. C. $0.15 x$ . 50.0

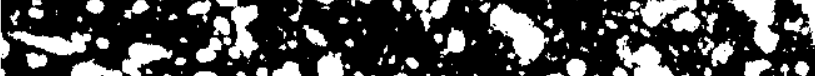

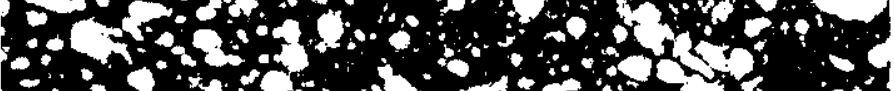
1. $18+4,0$ 1.1 .40

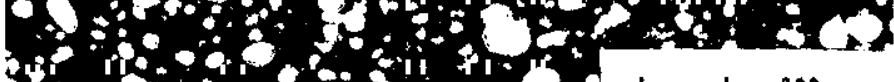

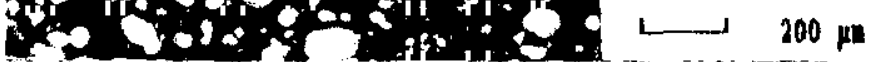

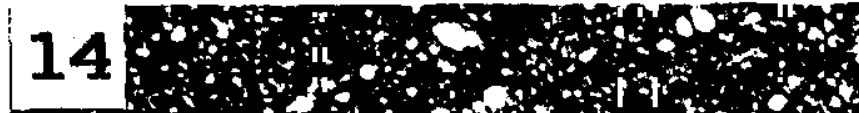

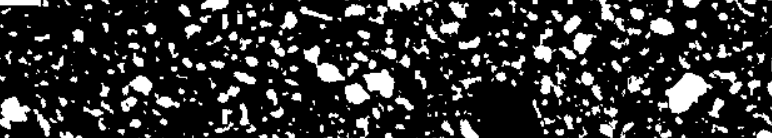
$\operatorname{tin}+4,4$

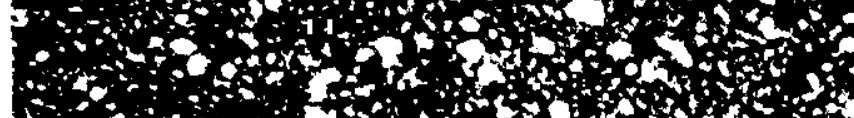

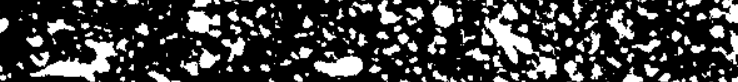

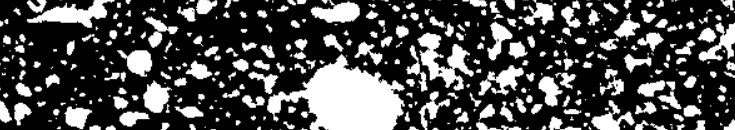

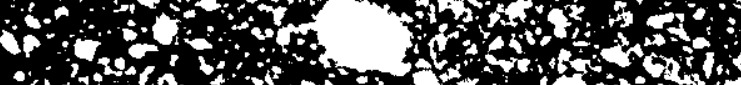

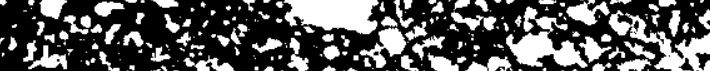

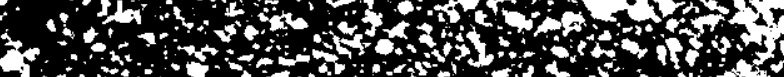

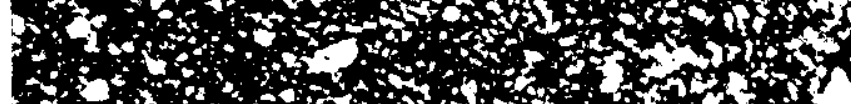

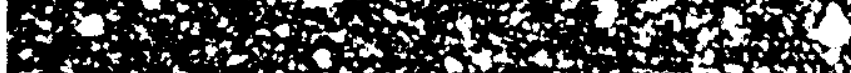

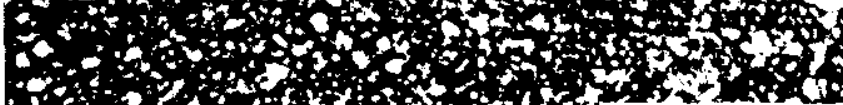

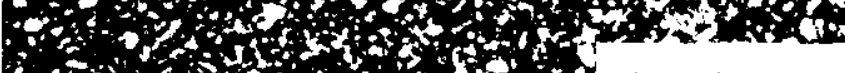

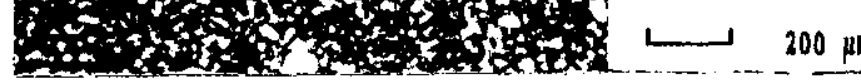

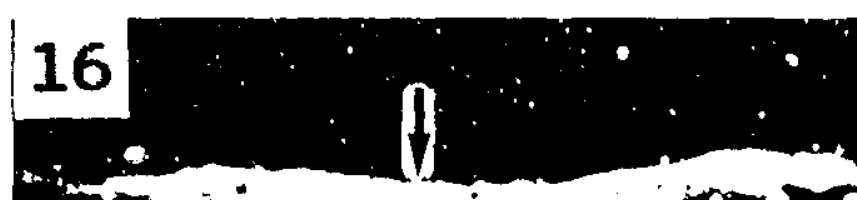

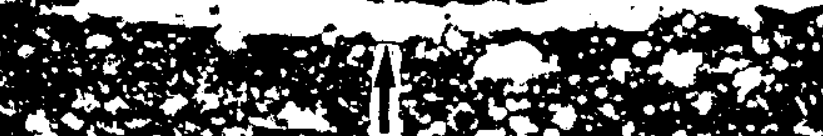

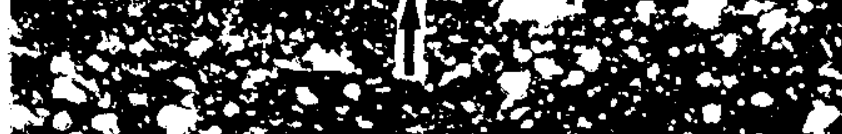

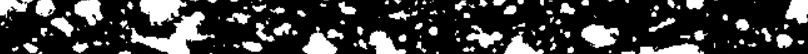

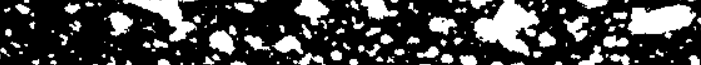

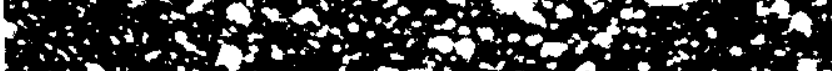

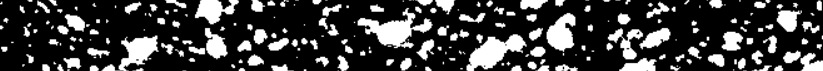

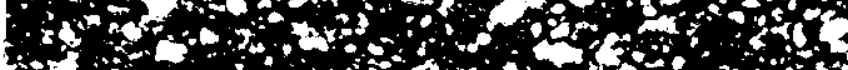

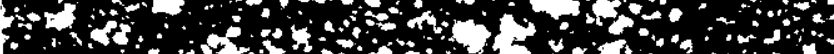

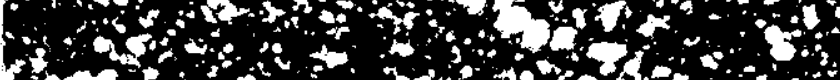

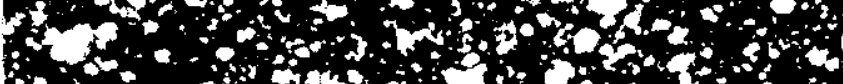

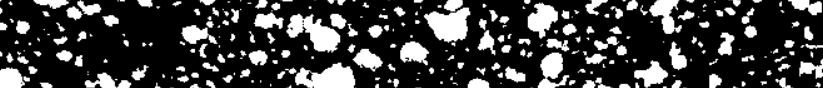
For

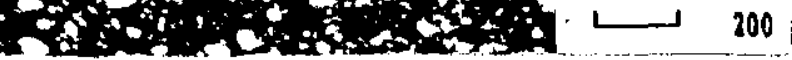

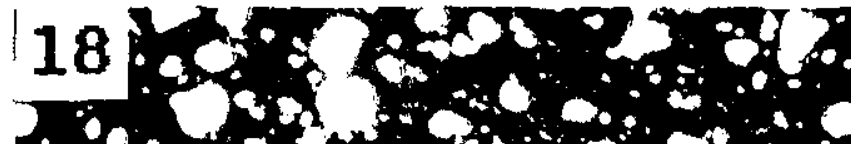

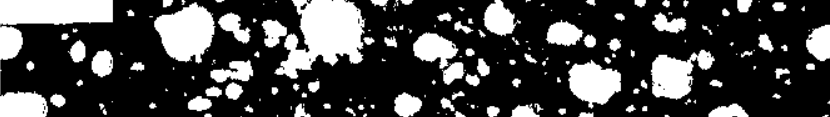

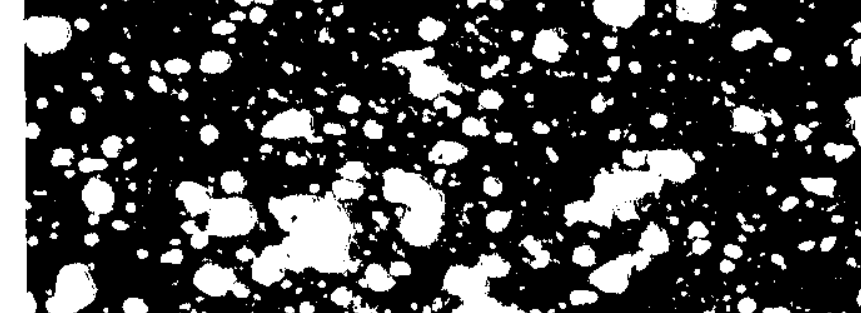

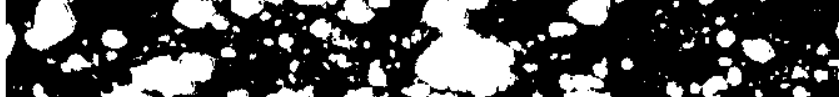

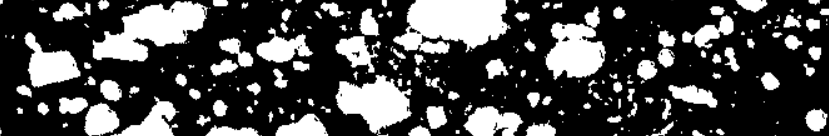
- $1250 \%$ 50,

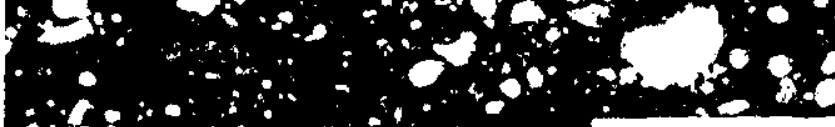
$140-20=$ - 
Grupo de cerámica calcárea. Esta agrupación está compuesta, solamente, por la muestra N-27 (Tabla 5.6). Desde un punto de vista mineralógico, es muy similar a las muestras de matriz roja del grupo principal, aunque ésta presenta abundantes inclusiones de calcita micrítica, de pequeño tamaño. De igual forma, sus patrones de tamaño de grano y de porcentaje de inclusiones con respecto a la matriz, son muy semejantes. La matriz, sin embargo, muestra bastantes áreas con inicios de vitrificación (Foto 11), que podrian indicar una mayor temperatura de cocción.

En estas agrupaciones, según puede verse en la Tabla 5.6, se han incluido también las muestras procedentes del yacimiento de Izana, ya que, como se mencionaba anteriormente, no es posible hacer distinciones entre éstas y las procedentes de Numancia. Con respecto a las muestras de los tres yacimientos restantes, las pertenecientes a la necrópolis de El Pradillo de Pinilla Trasmonte (Burgos), son las que más diferencias ofrecen, en relación a dichas agrupaciones. Por otro lado, y aunque se van a describir por separado en los párrafos siguientes, las muestras de Langa de Duero y de El Palomar, presentan características mineralógicas y texturales muy similares a las del grupo principal, especialmente, las procedentes del segundo de ellos.

A pesar de las similaridades mineralógicas, en las 5 muestras de Langa de Duero, se observan unas matrices más heterogéneas y menos cohesionadas, con abundantes cambios de coloración, que pueden ponetse en conexión con un proceso de cocción más irregular. En función de las características de la matriz, también se distinguen dos grupos: uno con matrices rojas, compuesto por la muestra LD-95 (Foto 13), en la cual se observan áreas con inicios de vitrificación y, otro, con matrices blancoamarillentas (Foto 12), integrado por las cuatro muestras restantes.

Las muestras procedentes de El Palomar, se asemejan, en todas sus características, a las muestras de matriz roja del grupo principal (Foto 14). Únicamente, en la matriz de la EP-29, se han detectado áreas con inicios de vitrificación.

En general, las muestras del yacimiento de Pinilla Trasmonte, son bastante más calcáreas. Este aspecto, es el que más las diferencia de los grupos establecidos con las muestras de Numancia e Izana, ya que, en estos yacimientos, apenas se elaboran cerámicas calcáreas, si se exceptúa la muestra $\mathrm{N}-27$. Sus matrices son muy heterogéneas, mostrando cambios de coloración desde el marrón oscuro al rojo. Salvo tres muestras (PT-1, PT-5 y PT-6), todas presentan inicios de vitrificación (Foto 15). Aparte de las abundantes inclusiones de calcita micrítica diseminadas por toda la matriz, también se observan cantidades considerables de 
cuarzo y feldespato de varios tamaños, que se presenta en inclusiones redondeadas, subrredondeadas y, en ocasiones, angulates. Igualmente, se detectan inclusiones de óxido de Fe y opacos, mientras que son escasas las laminillas de mica observadas. Por otra parte, el tamaño de grano suele ser mayor que en el resto de las muestras analizadas. De esta forma, todas contienen inclusiones de hasta $0,4 \mathrm{~mm}$ e, incluso, dos de ellas, alcanzan los $0,5 \mathrm{~mm}$. La media del porcentaje de inclusiones con respecto a la matriz, se sitúa en un $15,9 \%$, siendo, asimismo, su macroporosidad muy escasa.

Por último, se han detectado deposiciones de calcita secundatia de aporte externo, en las superficies interiores y exteriores (Foto 16) y en poros y grietas interiores, en todas las muestras del grupo con calcita añadida, en 31 pertenecientes al grupo principal, en 2 del grupo con menor selección de tamaño de grano, en la muestra calcárea N-27, en una muestra de Langa de Duero y otra de El Palomar, así como en 3 de las 11 muestras procedentes del yacimiento de Pinilla Trasmonte.

\subsubsection{Sedimentos arcillosos}

Como ya se hacia referencia en el capítulo anterior, se seccionaron un total de 4 probetas, pertenecientes a dos sedimentos arcillosos, uno calcáreo (N-1) y otro no calcáreo (N-4), cocidos a $700^{\circ}$ y $900^{\circ} \mathrm{C}$, con el fin de comprobar, petrográficamente, cuáles eran los cambios sufridos por efecto de la temperatura.

La observación de estas muestras, permitió determinar que sus características mineralógicas, eran muy similares a las que presentaban las muestras con matriz roja del grupo principal de cerámicas arqueológicas, aunque, obviamente, el contenido en calcita micrítica, era muy superior en la muestra $\mathrm{N}-1$.

Las matrices de los sedimentos cocidos a $700^{\circ} \mathrm{C}$, son isótropas y en ellas, tadavia no se observan áreas con inicios de vitrificación. La muestra N-1 presenta, a esta temperatura, un color rojo, mientras que en la N-4, este rojo es mucho más intenso. Por otro lado, a $900^{\circ} \mathrm{C}$, la muestra $\mathrm{N}-1$ presenta una fase de vitrificación mucho más extensa (Foto 17) que la N-4 (Foto 18). A esta temperatura, la muestra calcárea $N-1$ se vuelve marrón y la N-4, mucho más roja. En la muestra $\mathrm{N}-1$, las inclusiones de calcita micrítica se hacen más borrosas y empiezan a adquirir un color más oscuro, lo que podría indicar que se han transformado en portlandita o hidróxido de $\mathrm{Ca}$, $\mathrm{Ca}(\mathrm{OH})_{2} \dot{O}$, quizás, que la calcita ya se ha rehidratado y, por tanto, se trate de inclusiones de 
calcita de origen secundario. En cualquier caso, en estas láminas no se han detectado fases de alta tempetatura.

\subsubsection{Análisis textural}

Los resultados de este análisis, se ofrecen, de forma gráfica y ordenados por yacimientos, en el Apéndice II. En general, las muestras analizadas tienen un tamaño de grano no superior a los $0,4 \mathrm{~mm}$, salvo en el caso de las muestras pertenecientes a la Fábrica negra.

En el grupo principal, el tamaño de gtano nunca es superior a los $0,4 \mathrm{~mm}$ (Figura 5.7). La media para la fracción $<0,10 \mathrm{~mm}$, se sitúa próxima al $95 \%$, lo que indica fracciones de arena muy fina $(0,063-0,125 \mathrm{~mm})$ e inferiores (limos y arcillas). La media para la fracción 0,11 $0,20 \mathrm{~mm}$, se encuentra en torno al $5 \%$ y para la comprendida entre $0,21-0,30 \mathrm{~mm}$, cercana al 1 $\%$, lo cual supone una escasa representación de la fracción arena muy fina $(0,160-0,250 \mathrm{~mm})$. Estos datos, indican que se trata de un sedimento muy seleccionado, no observándose diferencias entre el subgrupo que muestra matrices rojas y el subgrupo de matrices blancoamarillentas.

En el grupo con menor selección de tamaño de grano (Figura 5.7), la fracción $<0,10 \mathrm{~mm}$ tiene una media del $75,7 \%$, que indica una menor proporción de arena muy fina, así como de fracciones inferiores (limos y arcillas). Sin embargo, las fracciones superiores están mejor representadas, con un porcentaje del $14,3 \%$, para la fracción comprendida entre 0,11 $0,20 \mathrm{~mm}$ y un 4,6\% para la comprendida entre $0,21-0,30 \mathrm{~mm}$, que podrían ponerse en relación con una mayor presencia de arena fina. Del mismo modo, la arena media $(0,320-0,50 \mathrm{~mm})$, también estaría representada, aunque en proporciones más bajas, según muestran los porcentajes del 1,9\%, para la fracción comprendida entre $0,31-0,40 \mathrm{~mm}$ y del $1 \%$, para la que se encuentra entre $0,41-0,50 \mathrm{~mm}$. Por otra parte, la presencia de arena gruesa $(0,630-2 \mathrm{~mm})$, es poco importante.

En el grupo compuesto por aquellas muestras en las que se detecta la adición de calcita (Figura 5.7), se observa una menor presencia de la fracción $<0,10 \mathrm{~mm}$, con un porcentaje medio del $55,2 \%$, sin duda oscurecida por la adición de calcita machacada. Sin embargo, esta calcita rara vez supera $1 \mathrm{~mm}$, lo cual podría indicar una selección del tamaño de grano añadido. En la mayoría de las muestras, las fracciones superiores a $0,31 \mathrm{~mm}$, están compuestas, casi exclusivamente, por calcita criptocristalina, de tal forma que, si se elimina ésta de los conteos, el 

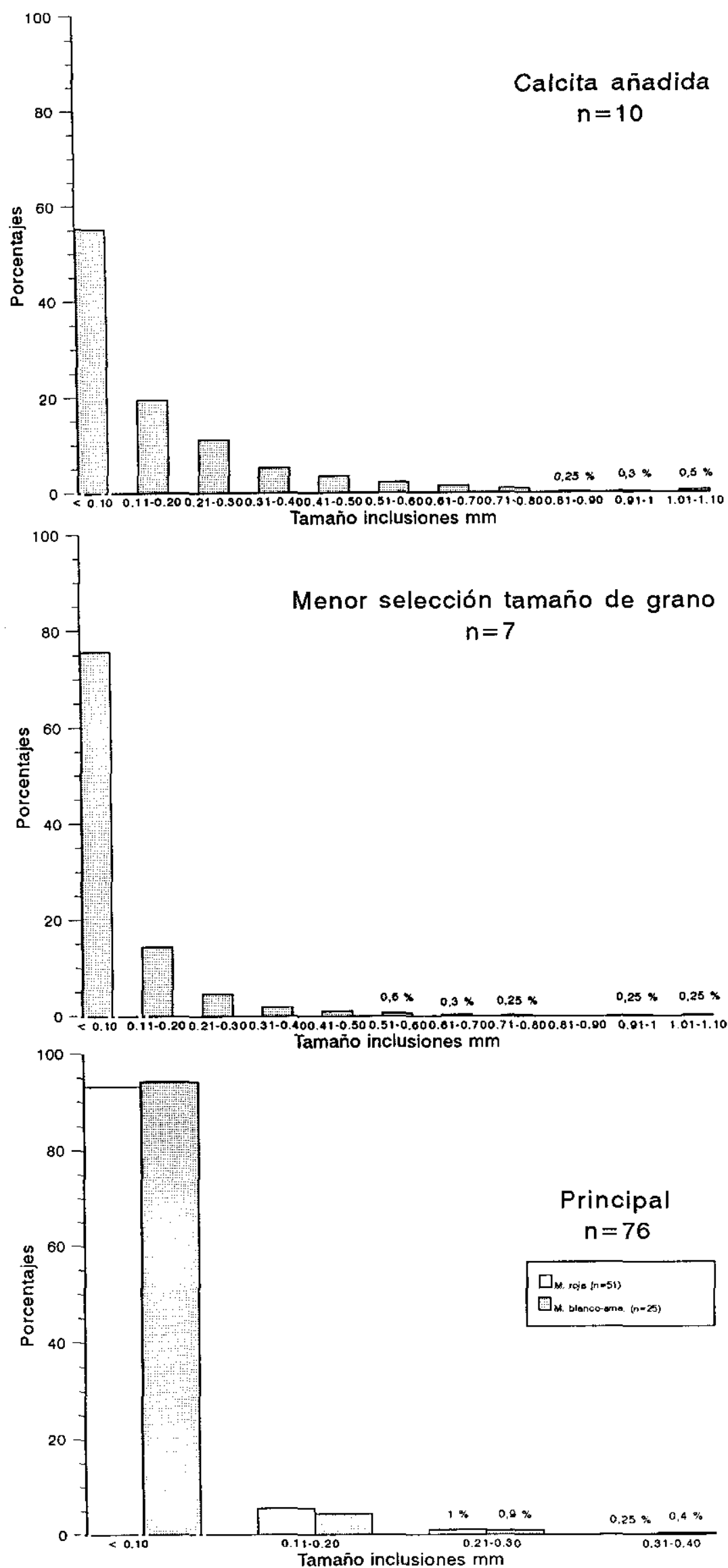

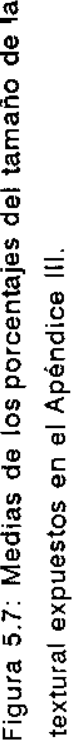




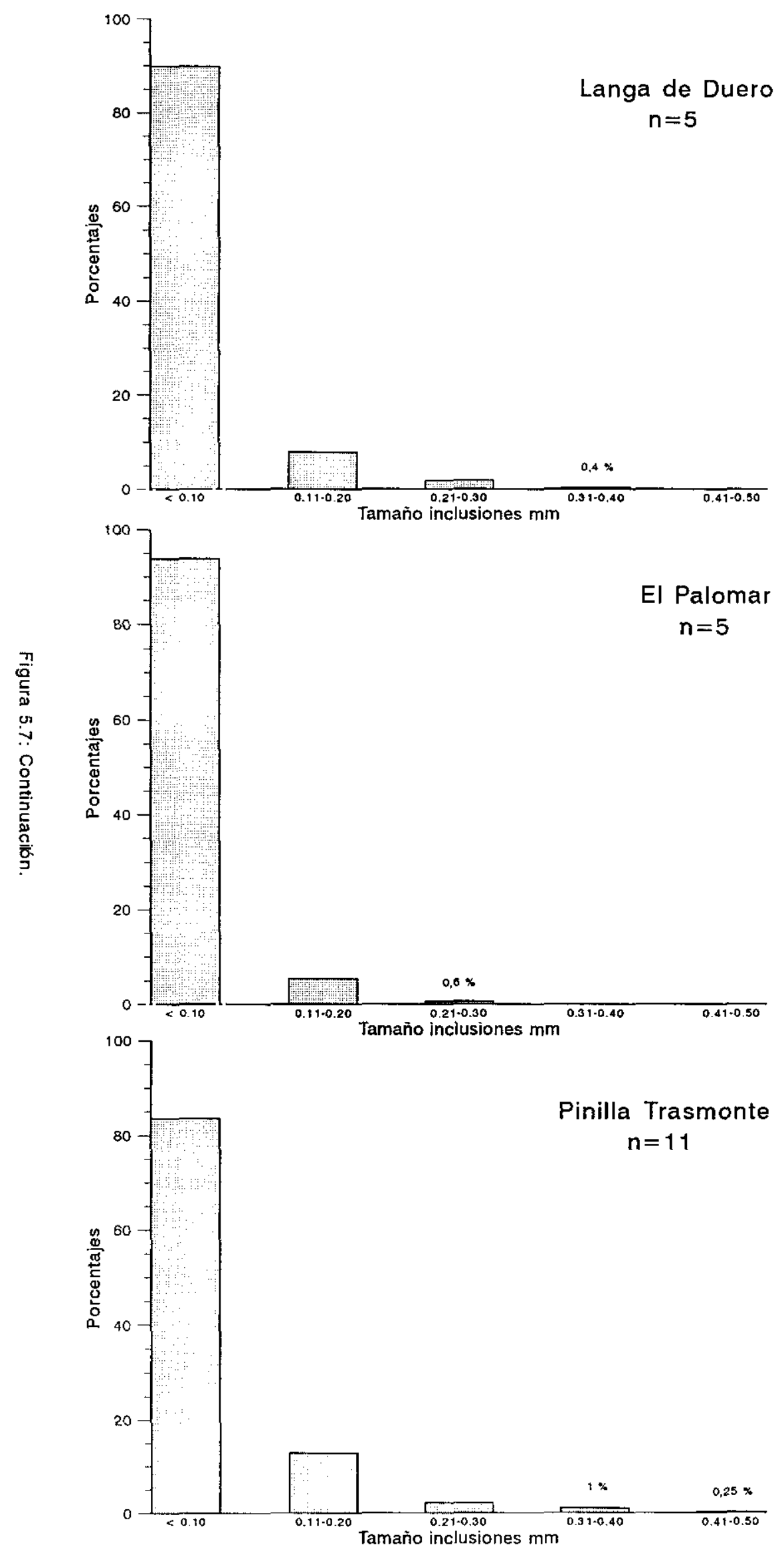


sedimento resultante es, prácticamente similar, al que presentan las muestras del grupo principal.

Los resultados obtenidos en el análisis de las muestras procedentes de los yacimientos de Langa de Duero y El Palomar (Figura 5.7), muestran porcentajes similates a los descritos para las muestras del grupo principal. Este aspecto, podría indicar que los procesos seguidos en la selección del sedimento, han sido muy semejantes.

Las muestras de Pinilla Trasmonte, proceden, en general, de un sedimento menos seleccionado (Figura 5.7). Estas muestras, contienen un mayor porcentaje de arena fina, con medias del $12,9 \%$ para la fracción comprendida entre 0,11 - 0,20 mm y del 2,2\% para la situada entre $0,21-0,30 \mathrm{~mm}$, así como una menor proporción de arena muy funa y fracciones inferiores (limos y arcillas), como indica el porcentaje del intervalo $<0,10 \mathrm{~mm}$, que se sitúa en el $83,5 \%$. Aunque en una proporción muy baja, la media es del $0,1 \%$, los tamaños comprendidos entre $0,41-0,50 \mathrm{~mm}$, también están representados.

Finalmente, los conteos efectuados en las muestras de los sedimentos arcillosos $\mathrm{N}-1$ y

N-4 (ver Apéndice ID), preparados según el procedimiento explicitado en el apartado 4.2.1, muestran porcentajes similares a los que presentan las muestras cerámicas del grupo principal. A pesar de que las técnicas de análisis no son comparables, puesto que el Análisis textural de los sedimentos arcillosos en bruto se llevó a cabo mediante Pipeta de Robinson, puede observarse que, para conseguir el tamaño de grano que presentan estas muestras, nunca superior a $0,2 \mathrm{~mm}$, a través del método de conteo de puntos realizado sobre lámina delgada, debe desecharse, al menos, un $30 \%$ del sedimento en bruto, para el caso de la muestra N-1 (una arcilla margosa) y cerca de un 50\% para la muestra N-4 (una arcilla arenosa). Si se admite que, los sedimentos utilizados como materia prima para eleborar las cerámicas del grupo principal, pudieron haber sido muy parecidos a los analizados en esta investigación, la inversión de trabajo necesaria en la selección de los sedimentos arcillosos, durante el proceso de preparación de la pasta cerámica, pudo ser bastante importante.

\subsection{DIFRACCIÓN DE RAYOS X (XRD)}

Los difractogramas obtenidos en la realización de este análisis, aparecen agrupados en el Apéndice III del final de este trabajo. Los pertenecientes a las muestras de cerámica, se ofrecen ordenados por yacimientos, mientras que aquellos pertenecientes a los sedimentos arcillosos 
cocidos a distintas temperaturas y los relacionados con la recocción de 4 cerámicas, se exponen, primero, en columna, con el fin de poder apreciar la evolución de las distintas fases mineralógicas en función de la temperatura $y$, después, individualmente para facilitar una observación pormenorizada.

\subsubsection{Cerámicas}

Los resultados cualitativos de este análisis, se muestran en la Tabla 7 del final de este trabajo. Al igual que ocurtía en el Análisis petrográfico, no se pueden realizar distinciones entre las muestras procedentes de Numancia y de Izana, dada la homogeneidad mineralógica que presentan. En líneas generales, se ha identificado cuarzo, ilita y filosilicatos y feldespato potásico, como fases principales y calcita, hematites, diópsido, gehlenita y anortita, como fases secundarias. De todos modos, en función de la mayot o menor concurrencia de estas fases, se han distinguido 7 agrupaciones. Las muestras que componen cada una de estas agrupaciones, se ofrecen en la Tabla 5.7, en la que también se señala el gtupo composicional al que se asocian, ttas la aplicación del análisis estadístico, cuyos resultados se expondrán en el próximo apartado de este mismo capítulo. Aunque la referencia del grupo composicional al que se asocian, supone avanzar unos datos que todavía no han sido tratados en esta Tesis Doctoral, se ha decidido incluirlos en esta Tabla, con el propósito de hacer más dinámica la comparación de los datos obtenidos mediante Difracción de rayos x (XRD) y Fluorescencia de rayos $\mathrm{x}$ por reflexión total (TXRF).

Las 7 agrupaciones a las que se ha aludido, son las siguientes:

Grupo con calcita como fase predominante (C). Esta agrupación está compuesta por 13 muestras (Tabla 5.7) y, básicamente, coincide con el grupo composicional G-1 y con la agrupación petrográfica que presentaba calcita añadida. No obstante, en este caso, se agrupan tres muestras más. Dos procedentes de Izana (IZA-16 e IZA-17), con las que no pudo realizarse una lámina delgada por falta de muestra y, otra (N-22), que se asociaba al grupo con menor selección de tamaño de grano. En cualquier caso, todas las muestras pertenecen a la Fábrica negra. Este grupo se caracteriza por la presencia de calcita, como fase predominante; de cuarzo, como segunda fase, de ilita y filosilicatos $y$, finalmente, como fases secundarias apenas detectadas, feldespato potásico y anortita, aunque en 5 muestras (N-22, N-23, IZA-11, IZA-16 e 
TABLA 5.7. CARACTERÍSTICAS DE LOS GRUPOS DETERMINADOS EN EL ANÁLISIS MEDIANTE DIFRACCIÓN DE RAYOS X (XRD)

\begin{tabular}{|c|c|c|c|c|c|}
\hline GRUPOS & $N^{\circ}$ & \multicolumn{4}{|c|}{ MUESTRAS } \\
\hline $\mathrm{C}$ & 13 & $\begin{array}{l}\text { N-10 (G-1) } \\
N-12(G-1) \\
N-15(G-1) \\
N-17(G-2 A)\end{array}$ & $\begin{array}{l}\mathrm{N}-18(G-1) \\
\mathrm{N}-19(\mathrm{G}-1) \\
\mathrm{N}-20(G-1) \\
\mathrm{N}-21(\mathrm{G}-5)\end{array}$ & $\begin{array}{l}\text { N-22 (G-1) } \\
\text { N-23 (G-1) } \\
\text { IZA-11 (G-1) } \\
\text { IZA-16 (G-1) }\end{array}$ & IZA-17 (G-1) \\
\hline $\mathrm{MC}$ & 1 & N-27 (Outlier) & & & \\
\hline $\mathrm{P}$ & 29 & $\begin{array}{l}\text { N-13 (G-3) } \\
\text { N-24 (G-4A) } \\
\text { N-25 (G-6) } \\
\text { N-35 (G-3) } \\
\text { N-36 (G-4A) } \\
\text { N-37 (G-3) } \\
\text { N-38 (G-4A) } \\
\text { N-39 (G-3) }\end{array}$ & $\begin{array}{l}\text { N-40 (G-4A) } \\
\text { N-41 (G-5) } \\
\text { N-42 (G-5) } \\
\text { N-43 (G-3) } \\
\text { N-44 (G-4A) } \\
\text { N-46 (G-4A) } \\
\text { N-48 (G-4A) } \\
\text { N-49 (G-7) }\end{array}$ & $\begin{array}{l}\text { N-50 (G-3) } \\
\text { N-54 (G-4A) } \\
\text { N-55 (G-4A) } \\
\text { N-59 (G-3) } \\
\text { N-64 (G-5) } \\
\text { NP-74 (G-5) } \\
\text { NP-76 (G-4A) } \\
\text { NP-77 (G-4A) }\end{array}$ & $\begin{array}{l}\text { NP-87 (Outlier) } \\
\text { IZA-1 (G-3) } \\
\text { IZA-3 (G-4A) } \\
\text { IZA-4 (G-4A) } \\
\text { IZA-9 (G-3) }\end{array}$ \\
\hline PSH & 13 & $\begin{array}{l}\text { N-34 (G-4A) } \\
N-56(G-5) \\
N-58(G-3) \\
N-60(G-5)\end{array}$ & $\begin{array}{l}\text { N-61 (G-5) } \\
\text { N-63 (G-5) } \\
\text { N-66 (G-5) } \\
\text { N-67 (G-5) }\end{array}$ & $\begin{array}{l}\text { N-68 (G-5) } \\
\text { NP-86 (G-6) } \\
\text { IZA-8 (G-2B) } \\
\text { IZA-14 (G-3) }\end{array}$ & IZA-15 (G-3) \\
\hline FK & 18 & $\begin{array}{l}\text { N-14 }(G-3) \\
\text { N-16 }(G-3) \\
\text { N-26 }(G-6) \\
\text { N-28 }(G-3) \\
\text { N-45 (G-3) }\end{array}$ & $\begin{array}{l}\text { N-52 (G-4A) } \\
\text { N-53 (G-3) } \\
\text { N-65 (G-5) } \\
\text { NP-72 (Outlier) } \\
\text { NP-73 (G-5) }\end{array}$ & $\begin{array}{l}\text { NP-75 (G-3) } \\
\text { NP-78 (G-5) } \\
\text { NP-79 (G-4A) } \\
\text { NP-80 (G-5) } \\
\text { NP-81 (G-6) }\end{array}$ & $\begin{array}{l}\text { NP-82 (G-6) } \\
\text { NP-89 (G-6) } \\
\text { IZA-10 (G-4A) }\end{array}$ \\
\hline FKSH & 23 & $\begin{array}{l}\text { N-11 (G-3) } \\
\text { N-29 (G-6) } \\
\text { N-30 (G-5) } \\
\text { N-31 (G-5) } \\
\text { N-32 (G-5) } \\
N-33(G-5)\end{array}$ & $\begin{array}{l}\text { N-51 (G-5) } \\
\text { N-57 (G-3) } \\
\text { N-62 (G-6) } \\
\text { N-69 (Outlier) } \\
\text { N-70 (G-5) } \\
\text { N-71 (G-3) }\end{array}$ & $\begin{array}{l}\text { NP-83 (G-6) } \\
\text { NP-84 (G-6) } \\
\text { NP-85 (G-6) } \\
\text { NP-88 (G-5) } \\
\text { NP-90 (G-6) } \\
\text { NP-91 (G-6) }\end{array}$ & $\begin{array}{l}\text { NP-97 (G-6) } \\
\text { IZA-1BIS }(G-3) \\
\text { IZA-5 (G-7) } \\
\text { IZA-6 (G-4A) } \\
\text { IZA-7 (G-3) }\end{array}$ \\
\hline $\mathrm{AT}$ & 3 & $\mathrm{~N}-47(\mathrm{G}-5)$ & IZA-2 (Outlier) & IZA-2BIS OOu & \\
\hline
\end{tabular}

Junto al nombre de la mucstra se señala, entre paréntesis, ct grupo composicional al que pertenece, tras la aplicación del análisis estadistico que se ofrece en el apartado siguicnte. Las que muestran el término "outlier", no pertenecen a ningúin grupo composicional. C grupo con calcita como fast predorninantc. MC grupo con menos calcita. P grupo principal. PSII grupo prineipal sin hematites. FK grupo con feldespato potásico. [FKSH grupo con feldespato potásico sin hematites. $\left.\Lambda^{\prime}\right]^{\prime}$ grupo con fases de alta temperatura. 
IZA-17), esta última fase no se detecta. Por otra parte, en las muestras N-17 y N-23, la fase predominante es el cuarzo, a pesar de que las reflexiones de calcita están, en su mayoría, presentes en el difractograma.

Grupo con menos calcita (MC). Está representado solamente por la muestra $\mathrm{N}-27$, que se correspondía con la única cerámica calcárea observada a través de lámina delgada. La característica más sobresaliente que ofrece su difractograma, es la presencia de calcita como segunda fase más importante. No obstante, también se detecta cuarzo, como fase principal, ilita y filosilicatos y, como fases secundarias, feldespato potásico, hematites, diópsido, gehlenita y anortita. Esta muestra no pertenece a ninguna de las agrupaciones establecidas a partir del análisis estadístico.

Grupo principal (P). Este grupo está compuesto por un total de 29 muestras (Tabla 5.7) en su mayoría pertenecientes a la Fábrica 1. Se caracteriza por la presencia de cuarzo, como fase predominante, de ilita y filosilicatos $\mathrm{y}$, como fases secundarias, feldespato potásico, calcita, hematites, diópsido, gehlenita y anortita. De todas formas, existen diferencias entre las distintas muestras. Así, las hay con una mayor presencia de hematites (p. e. N-36, N-48 o N-54), con una menor proporción en las reflexiones de los minerales arcillosos (p. e. N-50, NP-77 o NP-87) e, incluso, una cantidad importante de muestras que no han desartollado diópsido. Si se consulta la Tabla 1 del final de este trabajo, puede comprobarse que son los colores naranjas los predominantes en las muestras asociadas a este grupo. Por otro lado, ha mayoría de las mismas, pertenecen al grupo principal de matriz roja definido a través del Análisis petrográfico. No obstante, 4 muestras de este grupo (N-25, N-42, N-44 y NP-87), tenían matrices blancoamarillentas y una (N-13), se agrupaba al conjunto con menor selección de tamaño de grano. Asimismo, dos muestras de la Fábrica 2, a pesar de ser grises, han desarrollado hematites (N-59 y N-64), por lo que han sido asociadas a este grupo. En él están presentes 5 de las 7 agrupaciones composicionales, establecidas en el análisis estadístico.

Grupo principal sin hematites (PSH). Esta agrupación presenta las mismas características que la anterior, aunque las 13 muestras que la componen no han desarrollado hematites (Tabla 5.7), por eso pertenecen en su mayoría a la Fábrica 2, aunque también hay muestras de las Fábricas 1, 1-b y negra. Consultando la Tabla 1 del final de este trabajo, puede apreciarse que predominan los colores grises claros en las mismas. Sin embargo, hay tres muestras (N-56, IZA-14 e IZA-15) 
que presentan colores naranjas y no han desarrollado hematites. En el grupo, están presentes 4 de las 7 agrupaciones composicionales, establecidas en el análisis estadístico. En general, se corresponden con el grupo principal del Análisis petrogtáfico, estando presentes, tanto muestras con matrices rojas, como con matrices blancoamarillentas.

Grupo con feldespato potásico (FK). Este conjunto de 18 muestras (Tabla 5.7) se caracteriza por la presencia de feldespato potásico como segunda fase más importante. Además, se detecta cuarzo, como fase predominante, ilita y filosilicatos y, como fases secundarias, calcita, hematites, diópsido, gehlenita y anortita. En cualquiet caso, hay muestras que no contienen diópsido (p. e. N-26, NP-78 y NP-89) ni anortita (p. e. N-65). En este grupo, la mayoría de las muestras pertenecen a las Fábricas 1 y 1-b, aunque dos pertenecen a la Fábrica negra y una a la Fábrica 2. Si se consulta la Tabla 1 del final de este trabajo, puede comprobarse que son los colores naranjas pálidos los predominantes en las muestras asociadas a este grupo. Por otro lado, casi todas ellas pertenecen al grupo principal de matriz roja definido a través del Análisis petrográfico. Empero, 4 muestras de este grupo (N-26, NP-73, NP-80 y NP-81), tenían matrices blancoamarillentas y $2(\mathrm{~N}-14$ y N-16), se agrupaban al conjunto con menor selección de tamaño de grano. En esta agrupación, están presentes 4 de los 7 gtupos composicionales, establecidos en el análisis estadístico.

Grupo con feldespato potásico sin hematites (FKSH). Este grupo, compuesto por 23 muestras (Tabla 5.7), presenta las mismas características mineralógicas que el anterior, aunque, al igual que en el grupo principal, éstas no han desartollado hematites. La mayoría pertenecen a las Fábricas 1-b y 2 . No obstante, también hay 2 muestras de la Fábrica negra y 4 de la Fábrica 1. En la Tabla 1 del final de este trabajo, se aprecia que son los colores grises claros los que predominan en las mismas. Por el contrario, la N-31 y la IZA-5, presentan colores naranjas, no habiendo desarrollado hematites. En este grupo, están presentes 5 de las 7 agrupaciones composicionales, establecidas en el análisis estadístico. Por otra parte, las muestras se corresponden, mayoritariamente, con el grupo principal del Análisis petrográfico que presentaba matrices blancoamarillentas, aunque hay 8 muestras con matriz toja y 2 pertenecen al grupo con menor selección de tamaño de grano.

Grupo con fases de alta temperatura (AT). Este grupo de 3 muestras (Tabla 5.7) se caracteriza, principalmente, por la presencia de mullita y alfa-alúmina o corindón, ambas fases de 
alta temperatura, y la ausencia de reflexiones relacionadas con los minerales arcillosos. No obstante, también presentan cuarzo, como fase predominante, feldespato potásico, hematites, diópsido (ausente en la muestra IZA-2BIS) y anortita. Sólo en la muestra IZA-2 se detecta gehlenita. Las muestras de esta agrupación, pertenecen al grupo principal de matriz roja del Análisis petrográfico. Por otro lado, sólo la muestra N-47, se asocia a uno de los grupos composicionales establecidos en el análisis estadístico.

Las muestras procedentes de Langa de Duero, aunque mineralógicamente son muy similares a las de Numancia o Izana, presentan diferencias con respecto a éstas. Entre las 5 muestras analizadas, un grupo de 3 (LD-92, LD-93 y LD-94) se sitúa ptóximo a las características definidas para la agrupación principal sin hematites. En estas tres muestras, se detecta cuarzo, como fase predominante, ilita y filosilicatos y, como fases secundatias, feldespato potásico, calcita, diópsido (no detectado en la muestra LD-93), gehlenita y anortita. La sección de las muestras LD-92 y LD-93, presenta unos colores grises, cuyos códigos Munsell sólo se registran en estos dos ejemplares (ver Tabla 1 del final de este trabajo). Por ello, en ellas no se detecta hematites. Sin embargo, la muestra LD-94, en la que sí aparece esta fase, tiene un color marrón-grisáceo. Por otro lado, todas ellas pertenecen al mismo grupo establecido en el anátisis estadístico. Un grupo que se separa claramente, como se verá en el apartado siguiente, de las muestras procedentes de Numancia e Izana, a pesar de que también presentaban matrices blancoamarillentas en el Análisis petrogtáfico.

Las otras dos muestras, deben comentarse por separado. La LD-95 no presenta apenas reflexiones de ilita y filosilicatos, aunque las pertenecientes a la calcita y a la anortita, se hallan muy pronunciadas. Por lo demás, el resto de las fases son similares a las descritas para el grupo principal de cerámicas de Numancia e Izana. Estas características, unidas al desarrollo de una fase vítrea observada, en su matriz roja, por medio del Análisis petrográfico, hacen pensar que esta muestra pertenece a esta agrupación, aunque su temperatura de cocción fue más elevada. De hecho, se trata de una muestra perteneciente a la Fábrica 1. Por otta parte, la muestra LD-96, también de matriz blancoamarillenta, como las 3 muestras comentadas anteriotmente, apenas presenta reflexiones relacionadas con los minerales arcillosos. Este factor, unido, igualmente, a la observación de áreas con inicio de vitrificación, a través de la lámina delgada, ponen de manifiesto que se trata de una muestra similar, pero cocida a mayor temperatura.

La presencia de dolomita en las 5 muestras procedentes del yacimiento de El Palomar, las diferencia claramente del resto de las muestras analizadas. No obstante, y con excepción del 
diópsido, las demás fases detectadas coinciden con las descritas para el grupo principal de cerámicas de Numancia e Izana. Cuarzo como fase predominante, ilita y filosilicatos y, como fases secundarias, feldespato potásico, calcita, hematites, gehlenita y anortita. Estas 5 muestras, forman un grupo composicional homogéneo y diferenciado en el análisis estadístico. Asimismo, las fases detectadas coinciden con las determinadas en otros cuatro ejemplares de la misma fábrica, analizados en un trabajo anterior, al que ya se ha hecho referencia en otros capítulos (Garcia Heras et al., En prensa a).

Finalmente, las muestras procedentes de Pinilla Trasmonte, como ya ocurría en el Análisis petrográfico, son las que muestran una mayor presencia de calcita, en relación al conjunto total de muestras analizadas, exceptuando la N-27. Por este motivo, estas muestras desarrollan más aluminosilicatos de Ca del tipo gehlenita (p. e. PT-2, PT-3, PT-8 o PT-9) o del tpo anortita (PT-9) y menos hematites (en las muestras PT-5 y PT-6 ni siquiera se detecta), ya que en entomos ricos en $\mathrm{Ca}$, bajo condiciones oxidantes, se produce una inhibición del crecimiento de óxidos de Fe (Maniatis et al, 1981, 267; 1983, 781; Genis et al., 1991, 344; Vendrell Saz et al., 1992, 4). Asimismo, la mayoría de las muestras presentan colores ocres en sus superficies (ver Tabla 1 del final de este trabajo), como consecuencia de la incorporación del Fe en la estructura de los aluminosilicatos de Ca (Molera et al., 1996, 71). En el análisis estadístico, estas muestras forman una agrupación homogénea y diferenciada del resto de las cerámicas analizadas.

\subsubsection{Pruebas de recocción}

En este experimento, se han recocido en el laboratorio un total de 4 muestras cerámicas, siguiendo el mismo proceso que el llevado a cabo en la cocción de los sedimentos arcillosos y utilizando el mismo rango de temperaturas, es decit, $700^{\circ}, 800^{\circ}, 900^{\circ}$ y $1.000^{\circ} \mathrm{C}$ (ver apartado 4.2.1). Estas 4 muestras, se han seleccionado teniendo en cuenta el tamaño que presentaba el fragmento, ya que de cada uno de ellos se han extraído cuatto pequeñas porciones, así como los grupos mineralógicos a los que pertenecían. De esta forma, se seleccionó una muestra que representaba al grupo petrográfico con calcita añadida (N-20), otras dos que representaban al grupo principal, en sus variantes de matriz roja (N-54) y matriz blancoamarillenta (N-25) y, por último, una muestra más, perteneciente a la agrupación calcárea formada por las cerámicas procedentes del yacimiento de Pinilla Trasmonte (PT-11). Evidentemente, hubiera resultado de 
sumo interés, poder realizar este tipo de experimentos, al menos, en una muestra de los diferentes grupos establecidos en el análisis mediante Difracción de rayos $\mathrm{x}$ (XRD). Sin embargo, como ya se ha hecho referencia en más ocasiones, las limitaciones presupuestarias han influido de forma importante en esta selección.

Las pruebas de recocción, se han realizado con el fin de determinar las temperaturas en las cuales se producen cambios mineralógicos relevantes en las cerámicas analizadas. Estas determinaciones resultan muy útiles para la estimación de las temperaturas de cocción, como se verá en el apartado 5.4.4.

Los resultados cualitativos de esta experimentación, se ofrecen en la Tabla 8 del final de este trabajo. Asimismo, los colores Munsell que muestran las 4 cerámicas recocidas a las temperaturas mencionadas, se recogen en la Tabla 9. Por otro lado, un seguimiento de los cambios mineralógicos acaecidos en las distintas muestras, puede realizarse consultando la Figura 5.8 .

Comenzando por la muestra $\mathrm{N}-20$, representativa del grupo con calcita añadida, debe señalarse que a $700^{\circ} \mathrm{C}$, el difractograma resultante es similar a la muestra en el Estado Como se Recibe (ECSR) (1) (ver el final del Apéndice III). Sin embargo, a $800^{\circ} \mathrm{C}$ ha comenzado ya la disociación de calcita, formándose cantidades importantes de $\mathrm{CaO}$. La mayoria de este $\mathrm{CaO}$ no ha reaccionado con los filosilicatos, ya que sólo se ha formado una pequeña fase de anortita. Por el contratio, al enfriarse la muestra, parte de éste ha reaccionado con el vapot de agua de la atmósfera y ha formado una importante cantidad de portlandita o hidróxido de Ca (Rye, 1988, 107; Bronitsky, 1986, 218). Dado su mayor volumen, la muestra se fracturó a los pocos días de ser recocida. Por otro lado, a esta temperatura, la ilita y los filosilicatos, han desaparecido casi totalmente.

Al alcanzar los $900^{\circ} \mathrm{C}$, la disociación de calcita ha sido mayor. Solamente una pequeña parte del $\mathrm{CaO}$ ha formado gehlenita, mientras que la mayoría de éste, ha reaccionado, igualmente, con el vapor de agua de la atmósfera, generando una gran cantidad de portlandita, cuyo volumen fracturó también la muestra a los pocos días de la recocción. En este rango de temperatura, los filosilicatos han desaparecido completamente.

Finalmente, a $1.000^{\circ} \mathrm{C}$, apenas existe señal de $\mathrm{CaO}$, aunque han seguido formándose pequeñas cantidades de gehlenita y anortita. No obstante, y a pesar de esta débil señal, se formó

(1) La expresión "Lstado como sc recibe", que a partir de este momento va a scr abreviada con las iniciales LCSR, hace refercncia a las condiciones en las que llcga la mucstra al laboratorio. Esta expresión, se utiliza con al propósito de diferenciar dicha muestra de las resultantes, después de haber sido sometida a diferentes cxperimentaciones en el laboratorio (Maniatis y' I'ite, 1981). 


$$
\mathrm{N}-25
$$$$
N-54
$$
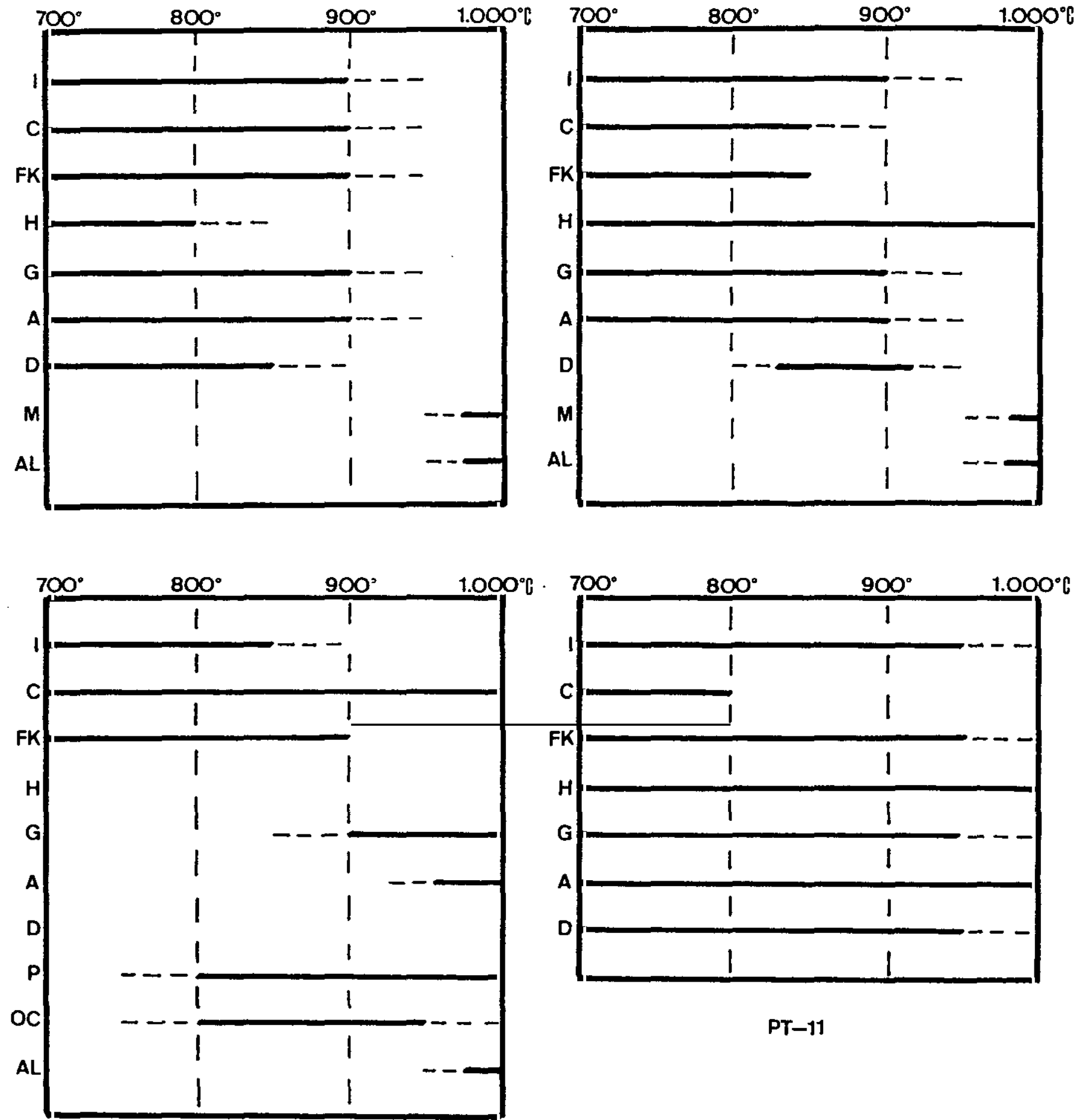

$$
\mathrm{N}-20
$$

Figura 5.8: Lvolución, por efecto de la temperatura, de las fases mineralógicas cristalinas, en los experimentos de recocción de 4 mucstras ccrámicas. I ilita y filosilicatos. C calcita. IK feldespato potásico. II hematites. G gehlenita. $\Lambda$ anortita $D$ diópsido. M mullita. $\mathrm{A} \mathrm{I}$, alfa-alúmina (corindón). 
también portlandita, fracturándose la muestra a los pocos días, al igual que en los casos anteriores. De todas formas, a esta temperatura, una parte considerable de esta portlandita debe de haberse alterado a calcita, de origen secundatio (Maggetti et al., 1984; Buxeda y Cau Ontiveros, 1995), ya que, en este rango, las reflexiones que muestra esta fase son mayores que a temperaturas inferiores. De otro modo, no podría explicarse su presencia, puesto que la calcita es incompatible con una temperatura de $1.000^{\circ} \mathrm{C}$. Por otra parte, también se ha formado cierta cantidad de alfa-alúmina o corindón.

Un aspecto que debe resaltarse en la recocción de este fragmento, es que las inclusiones de calcita criptocristalina, no han llegado a desaparecer por completo, reteniendo, incluso, su forma. En este sentido, conviene tener en cuenta que la descomposición de los carbonatos depende del tipo de cristalinidad, cuanto mayor sea ésta, más aumentará el tiempo de descomposición; del tamaño de sus partículas, las inclusiones mayores causan retraso en esta disociación (Heimann y Maggetti, 1981, 164; Echallier y Mery, 1991, 254); de la cantidad en que se hallen presentes, de la temperatura y duración de la cocción, así como de la permeabilidad que tenga la pieza cerámica (Dámaso, 1994, 595). De esta forma, la calcita policristalina se descompone siempre antes que la calcita monocristalina (Shoval et al., 1993, 270), como ha ocurrido en esta experimentación, en la que parte de la calcita, no ha llegado a descomponerse por completo.

El color de este fragmento varía en la recocción desde, un matrón-grisáceo inicial, a un naranja que se va aclarando con el aumento de la temperatura (ver Tabla 9 del final de este trabajo). Sin embargo, la importante presencia de $\mathrm{Ca}$, ha impedido la formación continuada de hematites (Maniatis et al., 1981, 267; 1983, 781; Genis et al, 1991, 344; Vendrell Saz et al., 1992, 4).

La muestra N-25, representativa del grupo petrográfico principal de matriz blancoamarillenta, presenta las mismas fases mineralógicas que el ejemplar ECSR, hasta los $800^{\circ} \mathrm{C}$. Por otro lado, los únicos cambios detectados a $900^{\circ} \mathrm{C}$, se corresponden con la menor presencia de ilita y filosilicatos y con el cese del crecimiento de hematites. Por último, cuando se alcanzan $\operatorname{los} 1.000^{\circ} \mathrm{C}$, comienza el desarrollo de mullita y corindón, desapareciendo, en el difractograma, el resto de las fases, a excepción del cuarzo. Esta muestra, como se verá en el apartado siguiente, resulta muy similar al sedimento arcilloso $\mathrm{N}-7$, aunque la materia prima de este ejemplar debió ser menos ferruginosa, en tanto en cuanto ha formado una menor cantidad de hematites, y más caolinítica, puesto que el crecimiento de mullita y alfa-alúmina, ha sido más importante. En la recocción, el color varía desde, un gris muy claro inicial, hasta un naranja 
amarillento claro (Tabla 9 del final de este trabajo).

Los únicos cambios que exhibe la muestra N-54, tepresentativa del grupo petrográfico principal de matriz roja, hasta los $900^{\circ} \mathrm{C}$, con respecto al ejemplar ECSR, son la formación de una pequeña cantidad de piroxenos del tipo diópsido, a partir de los $800^{\circ} \mathrm{C}$, y el incremento de la fase hematites. A $1.000^{\circ} \mathrm{C}$, desaparecen todas las fases, salvo la hematites, que continúa desarrollándose. Asimismo, también se forma una pequeña cantidad de mullita y de corindón. En general, se trata de una muestra mucho más ferruginosa que la $\mathrm{N}-25$, aunque también menos caolinítica, ya que desarrolla mayor cantidad de hematites y menor de mullita y alfa-alúmina. Con algunas diferencias, es el sedimento arcilloso $\mathrm{N}-4$, el que más similaridades presenta con esta muestra. Por otra parte, sus colores varian poco a lo largo de la recocción. Dada la cantidad de óxidos de Fe presentes, son las tonalidades naranjas las predominantes (Tabla 9).

Hasta los $800^{\circ} \mathrm{C}$, en la muestra PT-11, representativa de las cerámicas calcáreas procedentes del yacimiento de Pinilla Trasmonte, no hay diferencias importantes en referencia al ejemplar ECSR, salvo la disociación de la mayor parte de la calcita. A $900^{\circ} \mathrm{C}$ de temperatuta, continúa el desarrollo de las fases gehlenita y anortita, así como de hematites, mientras que decrece el desatrollo de diópsido. Finalmente, a $1.000^{\circ} \mathrm{C}$, desaparecen por completo los filosilicatos, continuando la formación de hematites y una cantidad considerable de anortita. Por otro lado, se observa un decrecimiento de las fases gehlenita y diópsido. A pesar de ser una muestra calcárea, es importante destacar la formación de una gran cantidad de hematites. Asimismo, los colores vatian desde, un marrón-grisáceo inicial, hasta un naranja, al final del proceso de recocción (Tabla 9).

\subsubsection{Sedimentos arcillosos}

Los resultados cualitativos del análisis de los sedimentos arcillosos cocidos a distintas temperaturas, se ofrecen en la Tabla 10 del final de este trabajo. En función de estos resultados, los sedimentos analizados pueden agruparse en tres categorías distintas: arcillas calcáreas, arcillas no calcáreas y caolín.

La agrupación constituida por las arcillas calcáreas, está compuesta por 6 muestras (N-1, N-2, N-3, N-5, N-6 e IZA), todas ellas muy similares entre sí. En los sedimentos analizados a temperatura ambiente, se detecta cuarzo, como fase predominante, calcita, como segunda fase más importante, ilita y filosilicatos, caolinita y feldespato potásico. En la muestra 
$\mathrm{N}-3$, se detecta, además, hematites. Hay, no obstante, pequeñas diferencias entre las distintas muestras. La N-1 y la N-5, por ejemplo, presentan muy poca caolinita. Asimismo, según se trate de un sedimento más o menos arenoso, la presencia de filosilicatos es distinta. Así, la muestra más arcillosa en términos texturales (N-3), es la que contiene mayor cantidad de filosilicatos, mientras que en la más arenosa ( $\mathrm{N}-5$ ), éstos son menos importantes.

A lo largo de la cocción a las temperaturas especificadas (ver Figura 5.9), el cuarzo permanece estable. La ilita y los filosilicatos se detectan hasta los $800^{\circ} \mathrm{C}$, desapareciendo a una temperatura próxima a los $900^{\circ} \mathrm{C}$. Por otro lado, la caolinita ha desaparecido en todas las muestras cocidas a $700^{\circ} \mathrm{C}$, ya que esta fase se descompone a $550^{\circ} \mathrm{C}$, formando metacaolin amorfo y liberando Si y gamma-alúmina (Maggetti, 1982, 127; Linares et al., 1983; Rice, 1987, 90). La calcita se ha disociado entre $700^{\circ}$ y $800^{\circ} \mathrm{C}$ en las muestras $\mathrm{N}-1, \mathrm{~N}-3$ y N-5, entre $800^{\circ}$ y $850^{\circ} \mathrm{C}$ en la $\mathrm{N}-2$ y, a una temperatura cercana a los $900^{\circ} \mathrm{C}$, en las muestras N-6 e IZA. Su descomposición depende, en gran medida, del tamaño de partícula y de la cantidad en que se halle presente (Dámaso, 1994, 595). Por ello, su disociación se ha producido a temperaturas distintas en cada una de las muestras. En la N-1 y, sobre todo, en las muestras N-2 y N-5, se ha formado $\mathrm{CaO}$ procedente de la decarbonatación de dicha calcita. Este $\mathrm{CaO}$ se ha hidratado después, tras reaccionar con el vapor de agua de la atmósfera, formando portlandita o hidróxido de Ca. De esta forma, y al igual que ocurría en la recocción de la muestra cerámica $\mathrm{N}-20$, las probetas se cuartearon a los pocos días de ser cocidas, en especial la N-5, que terminó por deshacerse completamente, debido al aumento de volumen que experimenta la pottlandita en relación al $\mathrm{CaO}$ (Rye, 1988, 107; Bronitsky, 1986, 218). Por lo demás, las reflexiones correspondientes al feldespato potásico están presentes hasta $\operatorname{los} 1.000^{\circ} \mathrm{C}$, aunque su intensidad disminuye a partir de $\operatorname{los} 900^{\circ} \mathrm{C}$. En todas las muestras, se detecta hematites a una temperatura de $700^{\circ} \mathrm{C}$, excepto en la $\mathrm{N}-3$, en la que ya estaba presente en el difractograma obtenido a temperatura ambiente. Es, precisamente, esta muestra la que más hematites desatrolla cuando se alcanzan los $1.000^{\circ} \mathrm{C}$, siendo, por ello, la más rojiza. En la deshidroxilación de los minerales arcillosos, la ruptura de su red cristalina libera Fe que luego formará óxidos de este elemento. El tamaño de las partículas de estos óxidos, principalmente la hematites, se incrementa de forma contínua, con el aumento de la temperatura, en arcillas no calcáreas y decrece en arcillas calcáreas, ya que la presencia de Ca inhibe el crecimiento de estos óxidos (Maniatis et al., 1981, 267; 1983, 781; Genis et al., 1991, 344; Vendrell Saz et al., 1992, 4). Por este motivo, las muestras pertenecientes a esta agrupación, no desarrollan gran cantidad de hematites. 
$N-2$
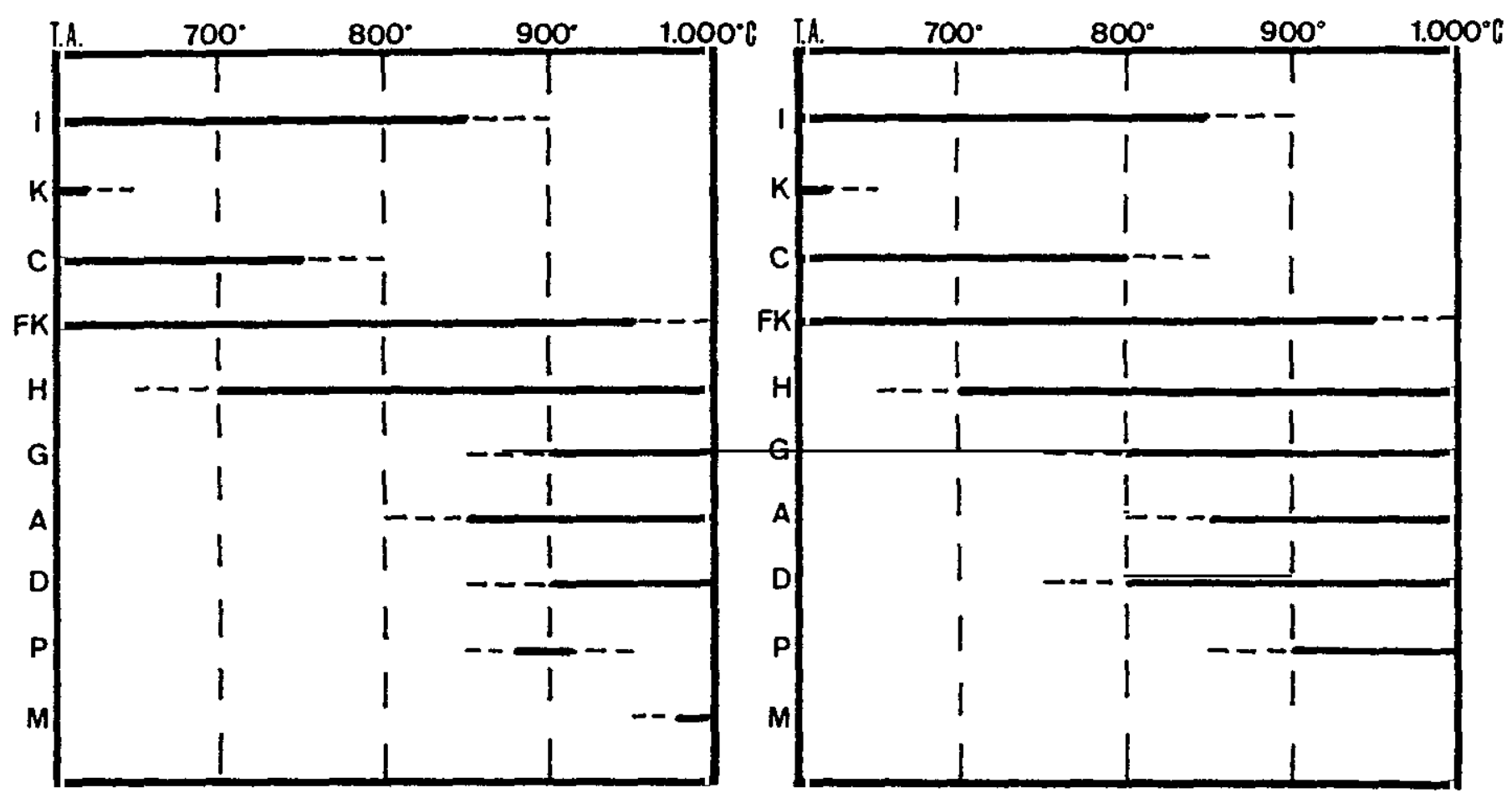

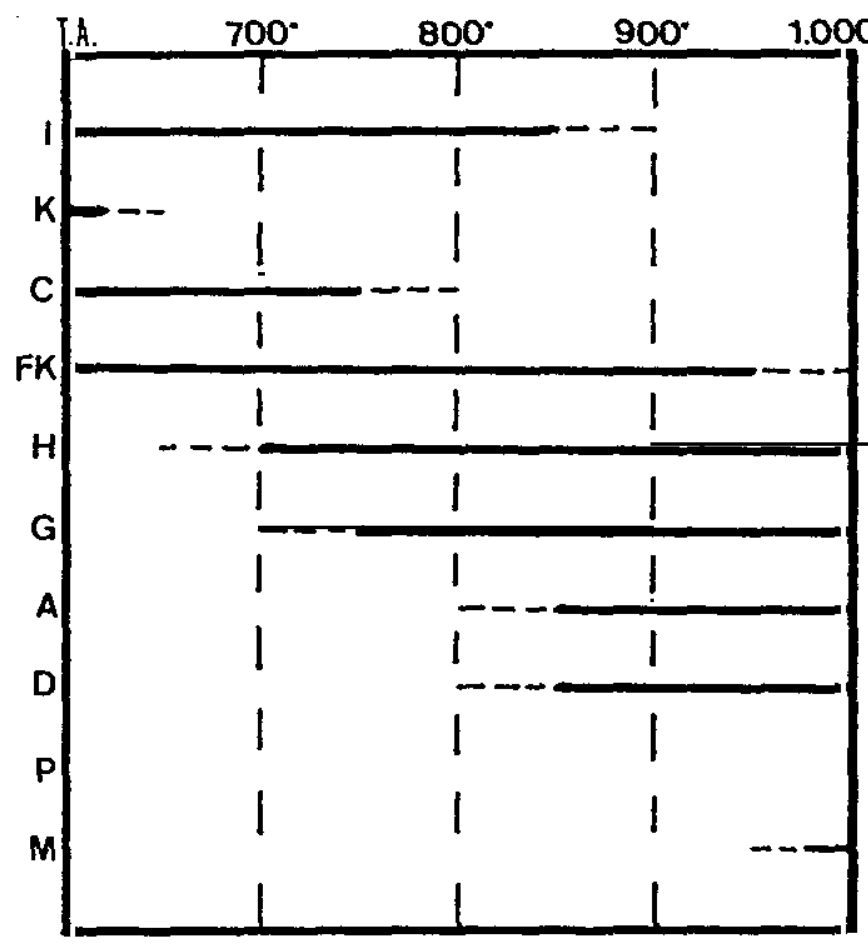

$\mathbf{N}-\mathbf{3}$

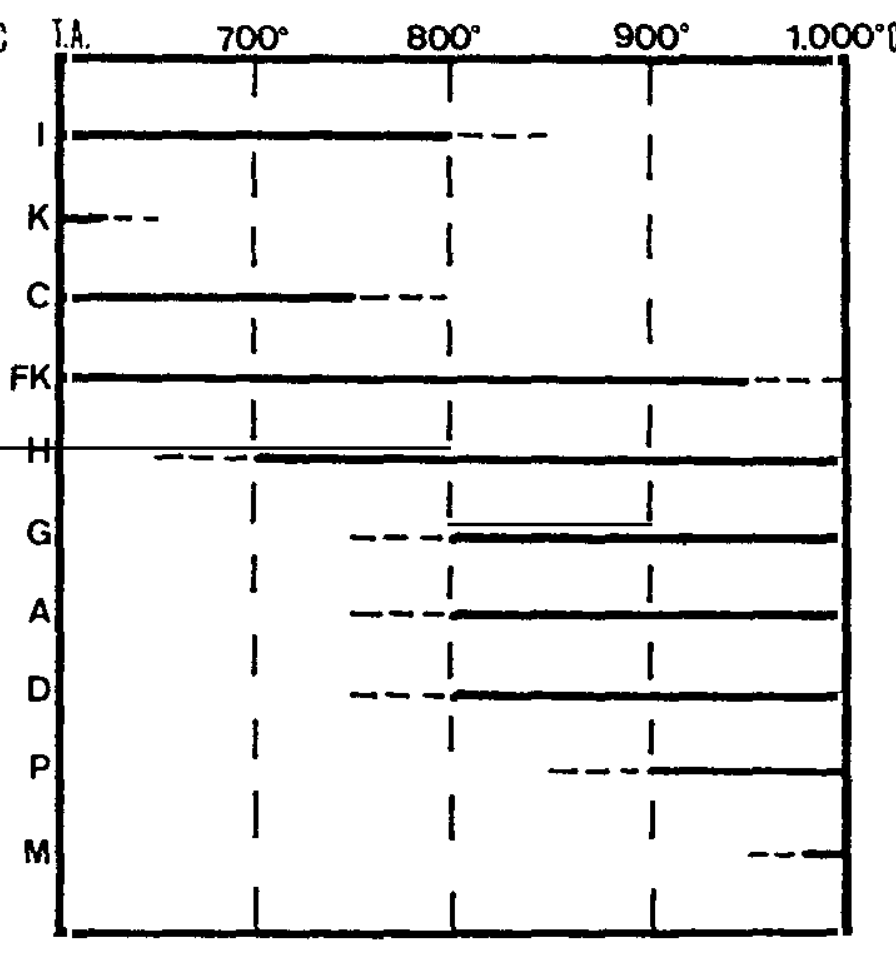

$\mathbf{N}-5$

Figura 5.9: Livolución, por efecto de la temperatura, de las fases mineralógicas cristalinas detectadas cn el análisis de los sedimentos arcillosos calcáreos cocidos a distintas temperaturas. I ilita y filosilicatos. $\mathrm{K}$ caolinita. $\mathrm{C}$ calcita.

liK feldespato potásico. H hematites. $G$ gethenita. A anortita. D diópsido. P portlandita. M mullita. 

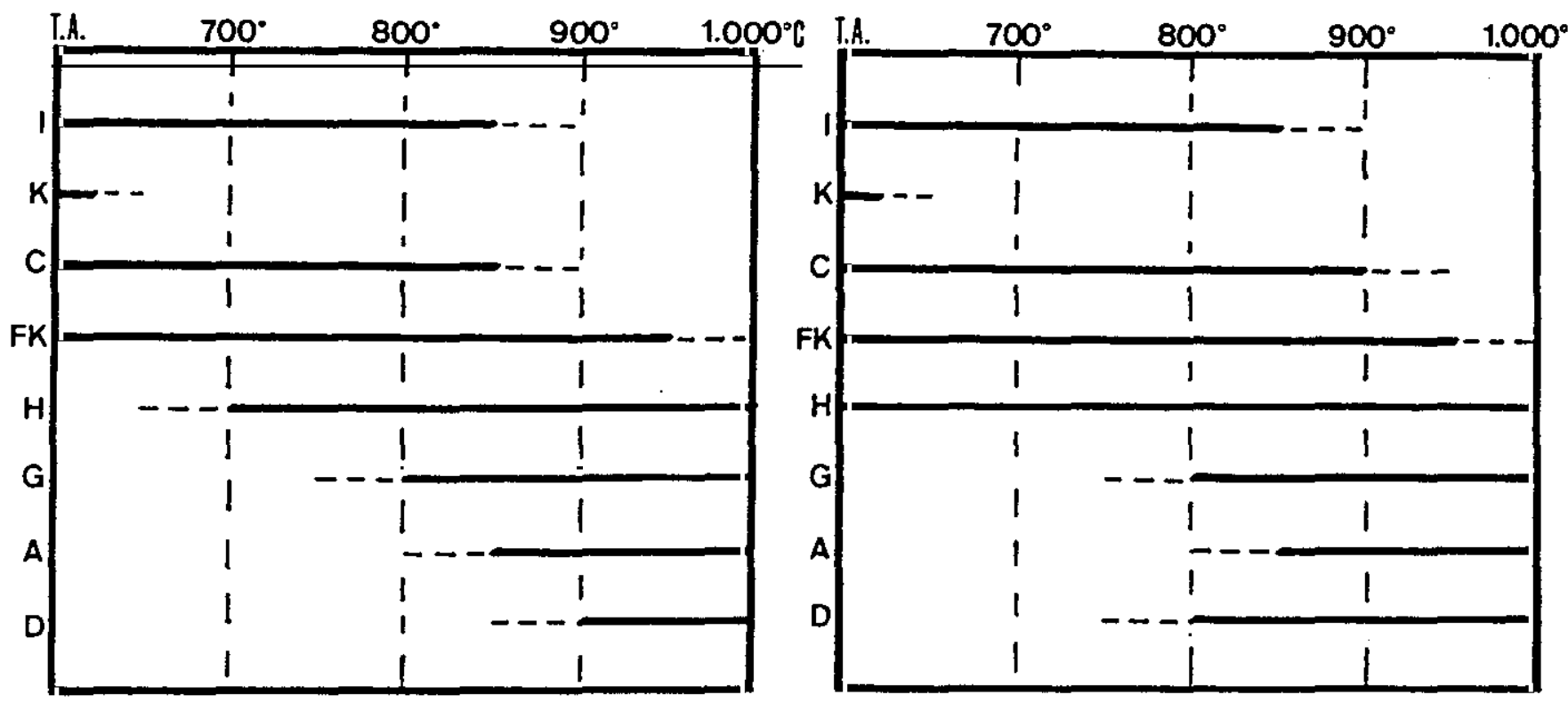

Figura 5.9: Continuación.

Por otra parte, en todas ellas se forman aluminosilicatos producidos por la reacción de los filosilicatos con el $\mathrm{CaO}$. Así, la anortita, aluminosilicato del grupo de las plagioclasas, se ha formado entre $\operatorname{los} 800^{\circ}$ y $850^{\circ} \mathrm{C}$ en todas las muestras, presentando las reflexiones de mayor intensidad en los difractogramas correspondientes a las temperaturas de $900^{\circ}$ y $1.000^{\circ} \mathrm{C}$. Asimismo, la gehlenita, se ha desarrollado a partir de $\operatorname{los} 800^{\circ} \mathrm{C}$, excepto en la muestra $\mathrm{N}-1$, en la que su formación se ha retardado hasta los $850^{\circ} \mathrm{C}$. Del mismo modo, las reflexiones de mayor intensidad, se constatan en los rangos de temperatura correspondientes a los $900^{\circ}$ y $1.000^{\circ} \mathrm{C}$. El diópsido, se ha formado entre $\operatorname{los} 750^{\circ}$ y $800^{\circ} \mathrm{C}$. Siendo un silicato de $\mathrm{Ca} \mathrm{y} \mathrm{Mg}$, su desarrollo depende, aparte de la presencia de $\mathrm{Ca}$, de la cantidad de $\mathrm{Mg}$ que contenga la muestra. En este sentido, es en la probeta $\mathrm{N}-1$, en la que se detectan sus reflexiones de una forma más definida.

Por lo demás, en estas muestras, sólo se ha detectado una pequeña fase de alta temperatura, la mullita, en las probetas cocidas a $1.000^{\circ} \mathrm{C}$. De todas formas, su formación ha sido escasa, dada la pequeña cantidad inicial de caolinita que contienen estos sedimentos.

El grupo de arcillas no calcáreas, está constituido por las muestras N-4 y $\mathrm{N}-7$ y se caracteriza por la presencia, a temperatura ambiente, de cuarzo, como fase predominante, ilita y filosilicatos, caolinita, feldespato potásico y hematites. Asimismo, y a pesar de haberias agrupado como arcillas no calcáreas, también se detecta una pequeña cantidad de calcita, más importante en el sedimento $\mathrm{N}-7$. 


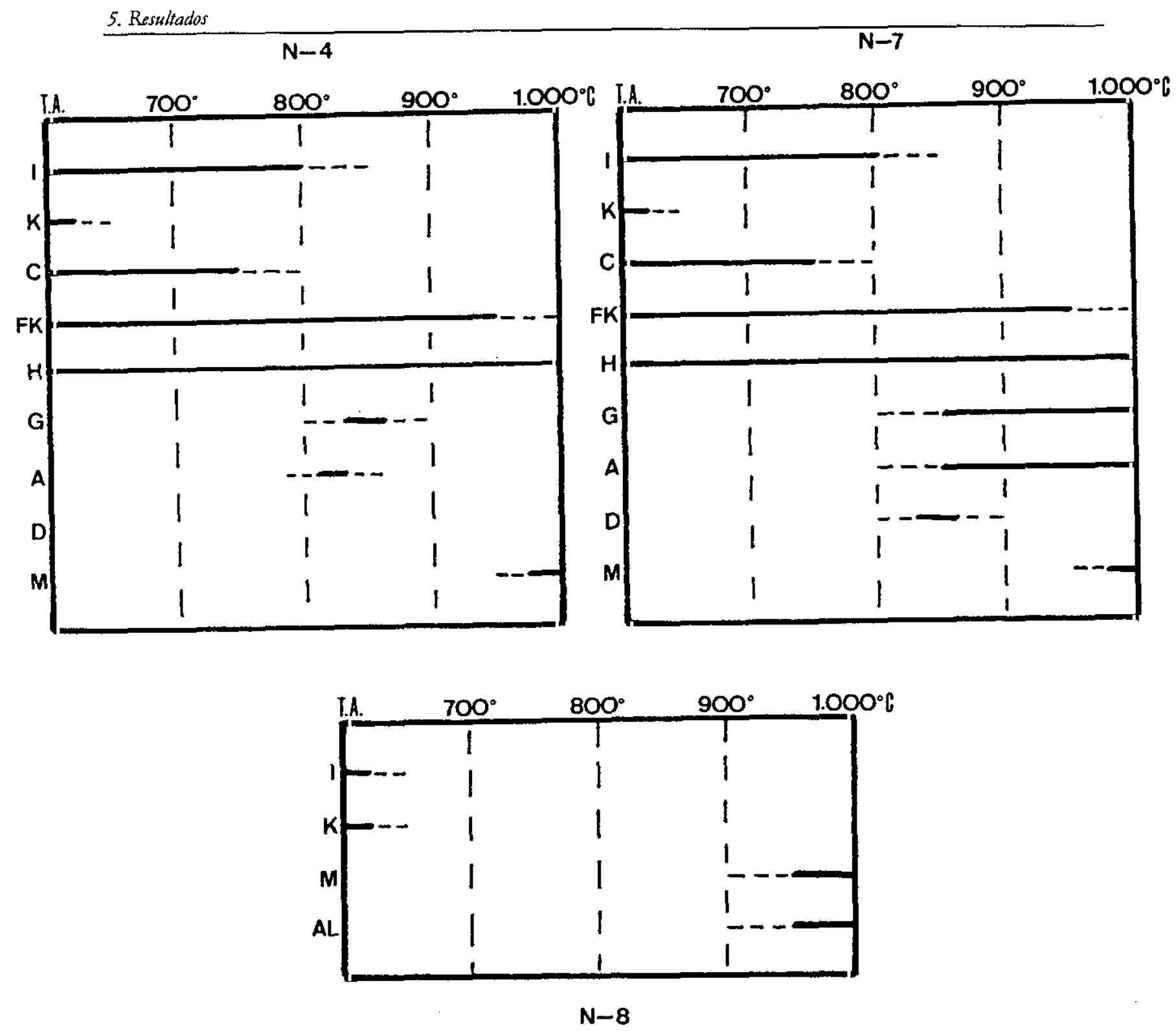

Figura 5.10: Evolución, por efecto de la temperatura, de las fases mineralógicas cristalinas detectadas en el análisis de los sedimentos arcillosos no calcáreos (N-4 y $\mathrm{N}-7)$ y de la muestra de caolín $(\mathrm{N}-8)$, cocidos a distintas temperaturas. I ilita y Ejlosilicatos. K caolinita. C calcita. FK feldespato potásico. H hematites. G gehlenita. A anortita. D diópsido. M mullita. $\mathrm{Al}$ alfáalúmina (corindón).

A lo largo de la cocción a las temperaturas especificadas (ver Figuta 5.10), el cuarzo permanece estable. La ilita y los filosilicatos desaparecen entre los $800^{\circ}$ y $850^{\circ} \mathrm{C}$, un poco antes que en las arcillas calcáreas. Para la caolinita y el feldespato potásico, se observa el mismo comportamiento. Es importante destacar el abundante crecimiento de hematites, debido a las razones expuestas anteriormente. Por otro lado, dada la escasa cantidad de calcita presente en ambas muestras, se han formado muy pocos aluminosilicatos de Ca. En la N-4, sólo aparecen reflexiones de pequeña intensidad, correspondientes a la gehlenita y a la anortita, entre $800^{\circ} \mathrm{y}$ 
$900^{\circ} \mathrm{C}$, mientras que en la muestra $\mathrm{N}-7$, estas reflexiones son algo más pronunciadas. Esta última, también presenta un poco de diópsido en el mismo rango de tempetaturas. Finalmente, las dos desarrollan mullita, en mayor cantidad que las arcillas calcáreas, a $1.000^{\circ} \mathrm{C}$.

La probeta $\mathrm{N}-8$, correspondiente a la muestra de caolín, se caracteriza por la presencia de caolinita, como fase predominante a temperatuta ambiente. En cualquier caso, esta muestra, al igual que la mayoría de los caolines, presenta ciertas impurezas que no han podido identificarse. Por ejemplo, dos de las reflexiones comprendidas en las regiones entre 15 y $16^{\circ} 2 \theta$ y entre 30 y $31^{\circ} 2 \theta$ (ver Apéndice III). Asimismo, tampoco existe segutidad en la identificación de una pequeña cantidad de ilita y filosilicatos.

Sin embargo, el comportamiento de esta muestra a lo largo de la cocción a las temperaturas especificadas, responde claramente al de un caolín típico. Esto es, destrucción de la estructura cristalina de la caolinita a $550^{\circ} \mathrm{C}$, liberando $\mathrm{Si}$ y gamma-alúmina y formando metacaolín amorfo y desarrollo, a temperaturas próximas a $\operatorname{los} 1.000^{\circ} \mathrm{C}$, de mullita y alfa-alúmina o corindón (Maggetti, 1982, 127; Linares et al., 1983; Rice, 1987, 90).

En tesumen, los datos obtenidos en el análisis de los sedimentos arcillosos, indican que se trata de atcillas ilítico-caoliníticas bastante ferruginosas, tanto calcáteas como no calcáreas. Por otro lado, el análisis de la muestra de caolín, indica que ambos tipos de sedimento son muy diferentes entre sí. De esta forma, puede observarse que la materia prima de la mayoría de las cerámicas, con excepción de las que presentan calcita añadida, es muy similar a los sedimentos no calcáreos. No obstante, muchas de estas cerámicas, contienen una mayor cantidad de filosilicatos, lo cual podría indicar que se elaboraron con sedimentos más arcillosos, en todo caso, no muestreados en esta investigación. Estos datos, también demuestran que las cerámicas numantinas no se realizaron con sedimentos calcáreos como los aquí analizados. Además, ninguna cerámica se realiza exclusivamente con caolín, al menos, con un caolín como el que se ha muestreado, ya que los difractogramas obtenidos en el análisis de estas cerámicas, nunca se asemejan a los de la muestra N-8.

\subsubsection{Temperaturas de cocción}

En términos arqueométricos, la determinación de la temperatura de cocción, no tiene un significado directo si no se analizan otros factores de la producción cerámica (Echallier, 1984). Su determinación exige el establecimiento de una relación entre, la propia temperatura de 
cocción y los cambios mineralógicos y microestructurales que sufre la materia prima con la que se ha elaborado la cerámica, por efecto de la temperatura. Estos cambios, dependen de la composición de esta materia prima, de la atmósfera y de la duración del proceso de cocción. Por tanto, la estimación directa de la temperatura de cocción de una cerámica arqueológica, nunca es posible, ya que se desconocen parámetros como la atmósfera y la duración de dicha cocción. Por este motivo, se recurre a dos tipos de aproximación indirecta, en los cuales se maneja el concepto de Temperatura de cocción equitalente (Rice, 1987, 435). Una de estas aproximaciones, se lleva a cabo a través de la recocción de muestras arqueológicas analizadas previamente, con el fin de determinar cuándo se producen los cambios mineralógicos y microestructurales y, la otra, por medio de la realización de piezas experimentales a partir de una materia prima, lo más parecida posible, a la utilizada en la elaboración de la cerámica arqueológica (Tite, 1995, 37-38). Ninguna de ellas pretende realizar determinaciones precisas de temperatura, puesto que, en última instancia, su variabilidad puede ser extremadamente amplia, sobre todo en cocciones tradicionales o, incluso, en partes distintas de un mismo recipiente cerámico (Rice, 1987, 158). En esta investigación, se ha optado, como ha quedado patente en los apartados anteriores, por abordar, ambas aproximaciones, conjuntamente.

De esta forma, a partit de los datos aportados por estos dos tipos de aproximación, se han estimado las siguientes temperaturas de cocción equivalente, para las cerámicas de los distintos grupos establecidos en este análisis:

Grupo con calcita como fase predominante (C). Para esta agxupación, se ha estimado una temperatura de cocción equivalente de unos $700^{\circ} \mathrm{C}$, por ser éste el rango de temperatura previo a la disociación de la calcita y por la presencia, tadavía importante, de filosilicatos. Como demostraba el experimento de recocción de la muestra N-20, si se soprepasa esta temperatura, comienzan los problemas asociados a la decatbonatación de la calcita y a la posterior rehidratación del $\mathrm{CaO}$ generado en la cocción que, en última instancia, puede llegar a fracturar los recipientes cerámicos (Rye, 1988, 107; Bronitsky, 1986, 218).

Grupo con menos calcita (MC). La muestra N-27, único ejemplar de esta agrupación, podría haber sido cocida en tomo a $900^{\circ} \mathrm{C}$, debido a la presencia de las fases gehlenita, diópsido y anortita. Esta temperatura vendría, asimismo, apoyada, por los datos que ofrecía la lámina delgada, en donde se observaban áreas con inicios de vitrificación (Foto 11). El inicio de esta fase vitrea, se constata, precisamente, en la muestra del sedimento arcilloso $\mathrm{N}-1 \mathrm{D}$, cocido a esta 
misma temperatura (Foto 17 ).

Grupos principal (P), principal sin hematites ( $\mathrm{PSH}$ ), con feldespato potásico (FK) y con feldespato potásico sin hematites (FKSH). Para la mayoria de las cerámicas pertenecientes a estos grupos, se ha fijado una temperatura de cocción equivalente situada entre los $800^{\circ}$ y $900^{\circ} \mathrm{C}$. Esta temperatura se ha estimado a partir de la presencia de filosilicatos, la formación de pequeñas cantidades de aluminisilicatos de Ca del tipo gehlenita y anortita, el desartollo de piroxenos del tipo diópsido, así como la detección de ciertas cantidades de calcita, todavía no disociada. También, a partir de la comparación de los datos aportados por la recocción experimental de las muestras N-25 y N-54 y de la cocción de los sedimentos arcillosos no calcáreos $\mathrm{N}-4$ y N-7, próximos a las características que presenta la materia prima de estas cerámicas.

En todo caso, hay muestras más cercanas a los $900^{\circ} \mathrm{C}$ (p. e. N-50 o NP-88), así como otras más próximas a los $800^{\circ} \mathrm{C}$ (p. e. NP-72 o NP-73), según demuestra la mayor o menor presencia de filosilicatos. Incluso, hay muestras que podrian no haber superado estos $800^{\circ} \mathrm{C}$ (p. e. N-32, N-63 o N-70) y ottas que se habrían cocido por encima de los $900^{\circ} \mathrm{C}$ (p. e. N-39, N-65, NP-77 o NP-87). En este sentido, conviene recordar que el proceso de deshidroxilación de los minerales arcillosos del tipo ilita, tiene lugar entre los $400 \mathrm{y} \operatorname{los} 650^{\circ} \mathrm{C}$. No obstante, este proceso no conlleva la pérdida total de su orden cristalino, sino una compactación de su estructura. Es sólo a partir de los $900^{\circ}-950^{\circ} \mathrm{C}$, cuando llegan a desaparecer por completo (Maggetti, 1982, 127; Linares et al., 1983; Buxeda, 1994, 141).

Grupo con fases de alta temperatura (AT). La presencia de las fases de alta temperatura mullita y alfa-aḱmina o corindón, hacen que para esta agrupación, se hayan estimado unas temperaturas de cocción equivalente situadas en torno a los $1.000^{\circ} \mathrm{C}$. Como se veía en la recocción de las muestras cerámicas N-25 y N-54 y en la cocción de los sedimentos arcillosos N4 y N-7, era, precisamente, a partir de esta temperatura, cuando comenzaba el crecimiento de estas fases.

La estimación de estas temperaturas de cocción, permite apreciar una serie de hechos de interés. Entre ellos, puede destacarse que las cerámicas grises de la Fábtica 2, se han cocido a la misma temperatura que el resto de las cerámicas analizadas. En cualquier caso, y a pesar de haber sido cocidas en condiciones reductoras, al menos, en algún momento del ciclo de cocción, 
no se ha detectado la formación de fases típicas de estos ambientes, como podria ser el caso de la magnetita. Este aspecto, podría indicar que el ciclo reductor al que se sometieron estas cerámicas durante el proceso de cocción, fue poco intenso. De hecho, en el Análisis petrográfico, se observaba sólo una pequeña extensión reducida, que se correspondía con las superficies de los recipientes, mientras que el resto de la matriz mostraba características oxidantes. Asimismo, en varios de los difractogramas pertenecientes a cerámicas grises, se detecta la presencia, a veces importante, de hematites, una fase incompatible con un ambiente reductor intenso.

Por otro lado, estos datos también indican que no existen diferencias de temperatura entre las cerámicas de las distintas fábricas, excepto en el caso de las cerámicas de la Fábrica negra, que contienen calcita añadida. Igualmente, tampoco existen este tipo de diferencias entre recipientes de distinta tipología, ni entre cerámicas con distintos tipos de decoración. Esto quiere decir, por ejemplo, que las cerámicas que presentan decoración polícroma, fueron cocidas a las mismas temperaturas que el resto de la cerámica numantina.

Para las muestras LD-92, LD-93 y LD-94, procedentes del yacimiento de Langa de Duero, se ha estimado también una temperatura de cocción equivalente situada entre los $800^{\circ} \mathrm{y}$ $900^{\circ} \mathrm{C}$, por los mismos motivos que los apuntados para el caso de las cerámicas de Numancia e Izana. Sin embargo, para las muestras LD-95 y LD-96, se ha estimado una temperatura superior a los $900^{\circ} \mathrm{C}$, debido a la mayor presencia de anortita, la ausencia de reflexiones correspondientes a los filosilicatos y a la observación de áreas con inicios de vitrificación, a través del Análisis petrográfico

Asimismo, este rango de temperaturas puede mantenerse para las muestras de El Palomar. No obstante, la muestra E.P-28 puede estar más cercana a los $800^{\circ} \mathrm{C}$, habida cuenta de la mayor presencia de filosilicatos, mientras que la EP-29, debido a su mayor concentración de gehlenita, diópsido y anortita, a la ausencia casi total de filosilicatos y a la observación de áteas con inicios de vitrificación a través de la lámina delgada, podria situarse próxima a los $900^{\circ} \mathrm{C}$.

Por último, para la mayoría de las cerámicas procedentes del yacimiento de Pinilla Trasmonte, se ha estimado una temperatura de cocción equivalente situada entre los $850^{\circ}$ y los $900^{\circ} \mathrm{C}$, a partir de los datos obtenidos en la recocción de la muestra PT-11, así como por la presencia de aluminosilicatos de los tipos gehlenita y anortita y la escasez de reflexiones correspondiantes a los minerales arcillosos. De todas formas, hay muestras (p. e. PT-2, PT-3 o PT-6) que conservan una mayor cantidad de filosilicatos y calcita y que han desartollado menos diópsido y anortita. Estas muestras, podrian haber sido cocidas en un rango inferior, que se 
situaría entre los $800^{\circ} \mathrm{y} \operatorname{los} 850^{\circ} \mathrm{C}$.

\subsection{FLUORESCENCIA DE RAYOS X POR REFLEXIÓN TOTAL (TXRF)}

Los resultados semi-cuantitativos obtenidos en el análisis mediante TXRF de las muestras cerámicas procedentes de Numancia, se ofrecen en la Tabla 11 del final de este trabajo. Asimismo, los resultados de las muestras de Izana, aparecen recogidos en la Tabla 12 , mientras que los obtenidos en el análisis de las muestras procedentes de Langa de Duero, El Palomar y Pinilla Trasmonte, se ofrecen en la Tabla 13. Estas tablas muestran las concentraciones semicuantitativas (\% peso versus $\mathrm{Fe}$ ) determinadas en un total de 121 muestras cerámicas, para los siguientes 18 elementos: As, Nd, Cr, Hf, Ni, Rb, Sr, Zn, Al, Ba, Ca, K, Mn, Ti, V, Cu, Ga e Y.

En estas concentraciones, algunos de los elementos de ciertas muestras, se han determinado con, al menos, un $2 \%$ de error relativo. Entre ellos, los que muestran de una manera más sistemática este tanto por ciento de error, son el $\mathrm{Nd}$ y el Hf. Ambos se han determinado, en la mayoría de las muestras, con más de un $2 \%$ de error relativo, incluso, cuando no han podido ser semi-cuantificados, hecho bastante habitual en casi todas ellas. Sólo en las muestras N-33 y LD-93, la concentración del Hf se ha estimado sin ningún tipo de error, mientras que para las concentraciones del $\mathrm{Nd}$, la única muestra determinada de esta forma, ha sido la N-8A. Sin duda, los errores obtenidos en la medición de estos elementos, deben ponerse en relación con el fenómeno de inducción que podría producirse, durante el proceso de molienda, en la preparación de las muestras (ver apartado 4.5). Por otro lado, el As presenta errores en las muestras NP-74, NP-80 e IZA-2; el Ba, en la N-4A, LD-93, LD-96, PT-4, PT-5, PT-6, PT-7 y PT-10 y el V, en la muestra NP-84. Estos factores, conviene tenerlos en cuenta a la hora de valorar los resultados del análisis estadístico.

\subsubsection{Análisis estadístico}

Como ya se hacia teferencia en el capítulo 4 , se han utilizado tres técnicas exploratorias de análisis multivariante (Análisis cluster, Análisis de componentes principales y Análisis 


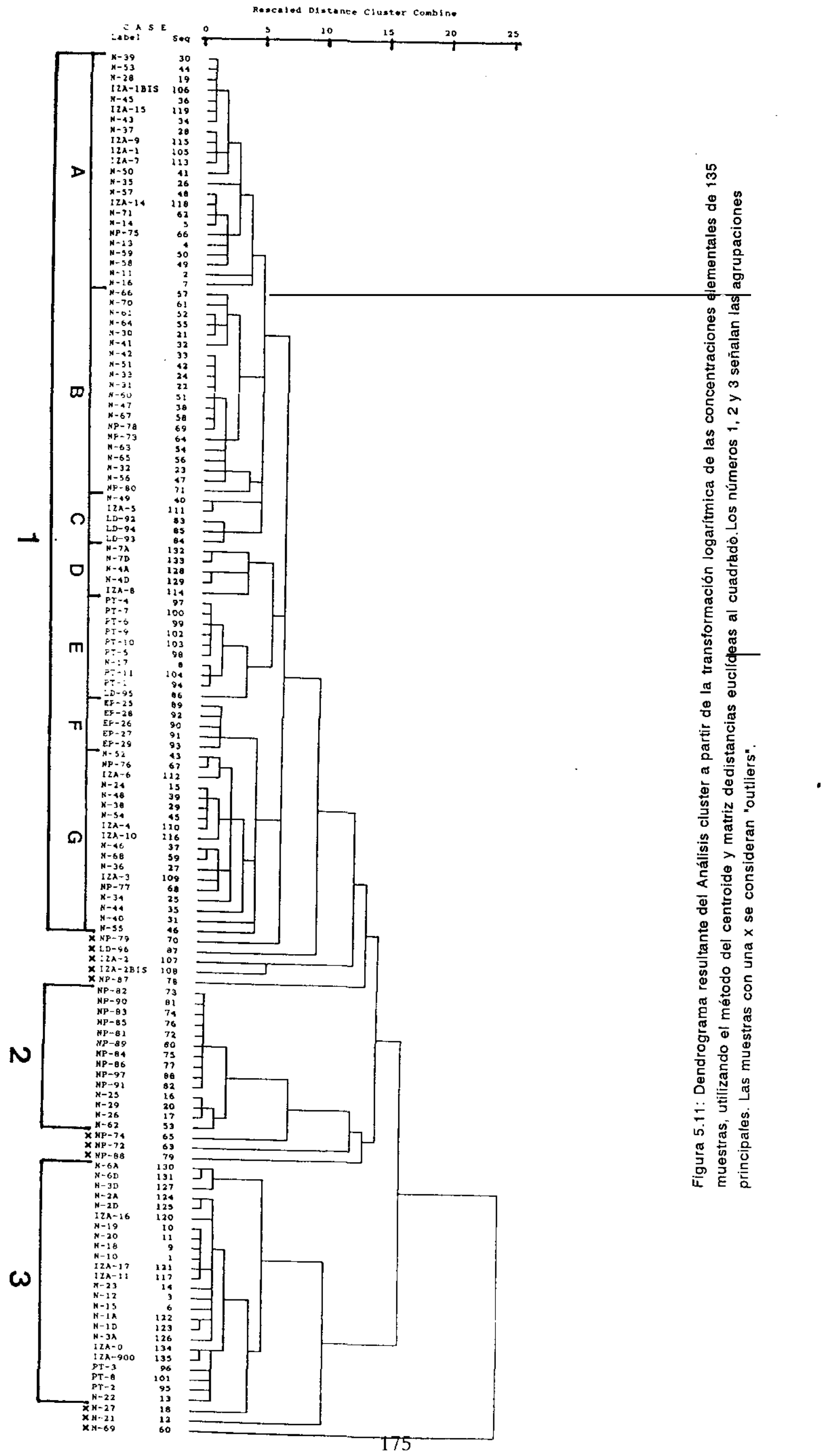




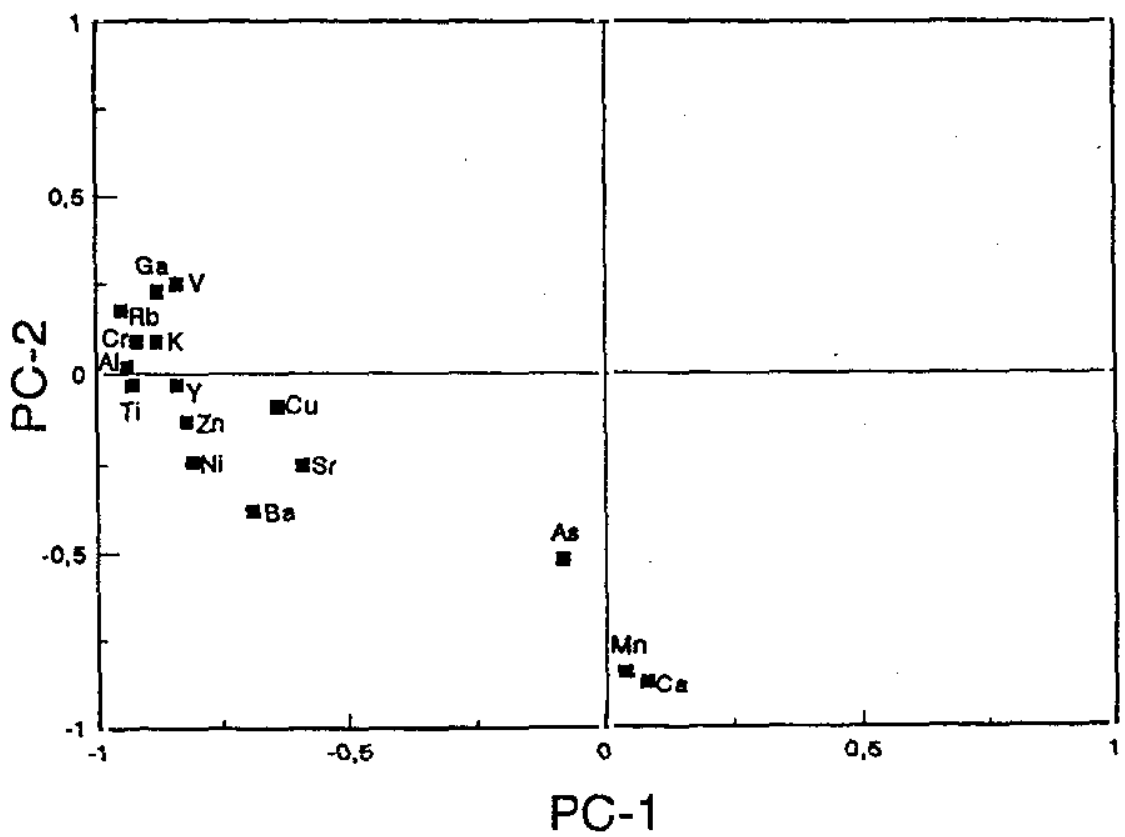

Figura 5.12: Análisis de componentes principales a partir de la transformación logarítmica de las concentraciones elementales de 135 muestras. Representación del peso de las variables ( 16 elementos), en los dos primeros componentes.

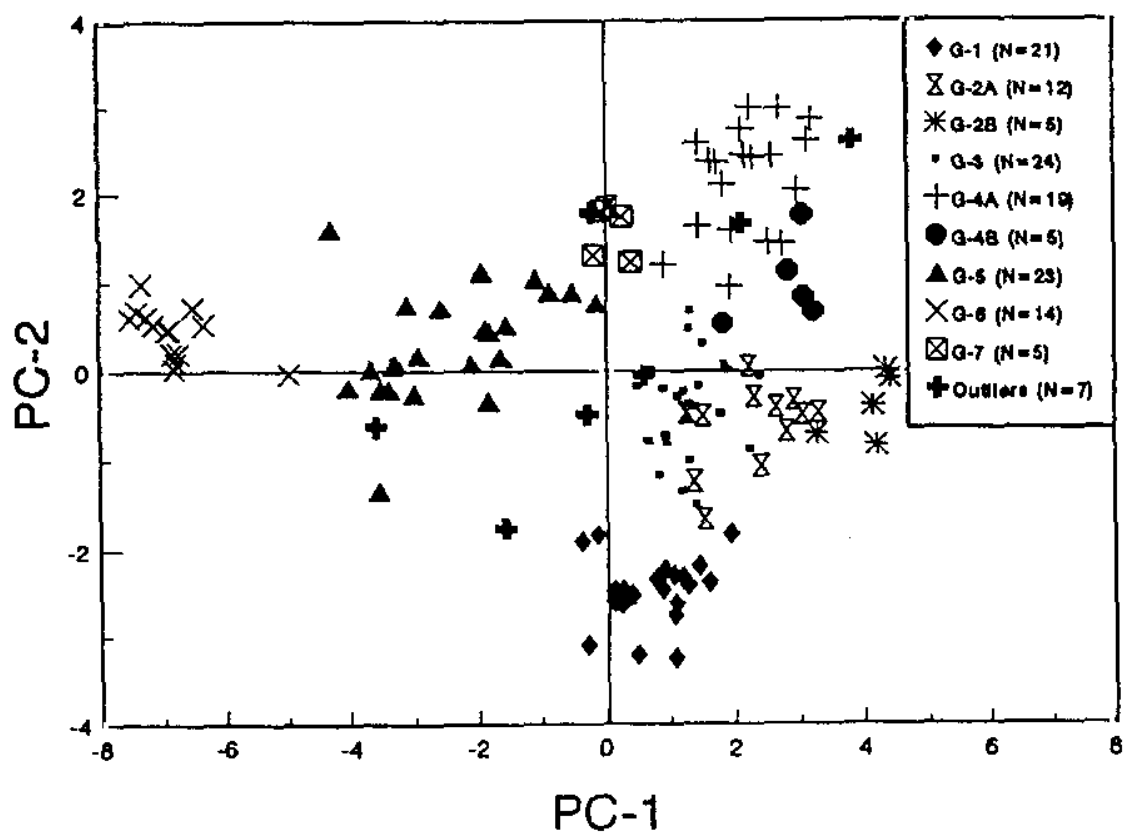

Figura 5.13: Análisis de componentes principalcs a partir de la transformación logaritmica de las concentraciones clementales de 135 muestras. Representación de las muestras y sus agrupaciones, según la puntuación en los dos primeros componentes. 
discriminante), en la evaluación de los datos composicionales obtenidos mediante TXRF. Estos análisis, como también se apuntaba allí, se han realizado a partir de la transformación logarítmica de las concentraciones elementales, con el fin de compensar las diferencias de magnitud, entre los valores de los distintos elementos.

El análisis estadístico, se ha llevado a cabo con un total de 136 individuos, que se corresponden con 121 muestras cerámicas y 15 muestras de sedimentos arcillosos (ver apartado 4.7). De los 18 elementos determinados por medio de la TXRF, sólo 16 se han incluido en estos análisis, habiéndose desechado el $\mathrm{Nd}$ y el Hf, por los problemas de determinación apuntados anteriormente. Cuando una variable ofrece muchos ceros, como en estos dos casos, es aconsejable eliminarla, con el fin de evitar que sus valores dominen el análisis a realizar (Baxter, $1994,41)$.

En primer lugar, se llevó a cabo un análisis explotatorio de todo el conjunto de datos, no ofrecido en esta Tesis Doctoral, mediante Análisis cluster y Análisis de Componentes principales, con el fin de realizar una primera aproximación a la estructura que presentaban estos datos. Con este paso, se comprobó que la muestra N-8A de caolín, podía considerarse un claro "outlier" (2) con respecto al conjunto analizado. Por ello, se decidió eliminarla y realizar un nuevo análisis con estas dos mismas técnicas, ante el convencimiento de que podría oscurecer la estructura general del resto de los datos (Baxter, 1994, 79).

Este nuevo Análisis cluster, realizado utilizando la distancia euclídea al cuadrado y el método de aglomeración del centroide, proporciona un dendrograma en el que puede apteciarse, en líneas generales, la existencia de tres grandes agrupaciones y de 11 individuos que pueden considerarse como "outliers" (Figura 5.11). No obstante, en una de estas agrupaciones, la situada a la izquierda del dendrograma, se distinguen 7 subgrupos más pequeños (Figura 5.11, $1 \mathrm{~A}$ a AG). Por lo tanto, el número total de agrupaciones es de 9 . Dentro de estos conjuntos, se aprecian algunos aspectos de interés. Por ejemplo, el grupo 1, está compuesto por todos los sedimentos arcillosos calcáreos y por gran parte de las cerámicas que presentaban calcita añadida en el Análisis petrogtáfico. Asimismo, en el grupo 1C, se asocian 3 de las 5 muestras procedentes de Langa de Duero; en el 1D, los scdimentos arcillosos no calcáreos; en el 1E, la mayoría de las muestras procedentes de Pinilla Trasmonte: mientras que en el grupo 1F, aparecen todas las muestras del yacimiento de El Palomar. Otro aspecto importante, que corrobora los resultados

(2) I:l término ingles "outlier", hace referencia a una muestra cuya composición elcmental dificre significativamente del resto de las muestras de un conjunto determinado. $\mathrm{Al}$ no haberse encontrado cn español ninguin término que reflejase exactamente el sentido que tienc en ingles, se ha preferido mantenerlo a lo largo de este trabajo, con e] propósito de evitar confusiones a aquellos investigadores familiarizades con los análisis cstadísticos. 


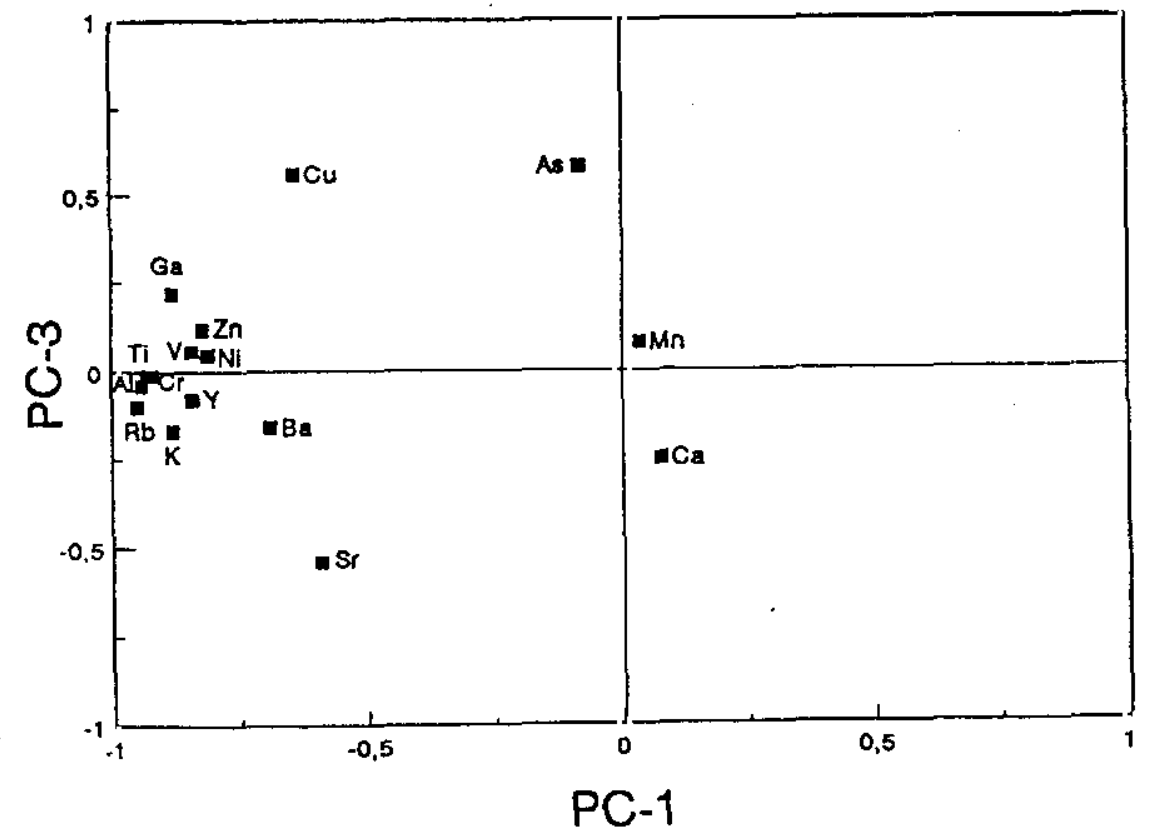

Figura 5.14: Análisis de componentes principales a partir de la transformación loganitmica de las concentraciones elementales de 135 muestras. Representación del peso de las variables (16 elementos), en el primer y tercer componente.

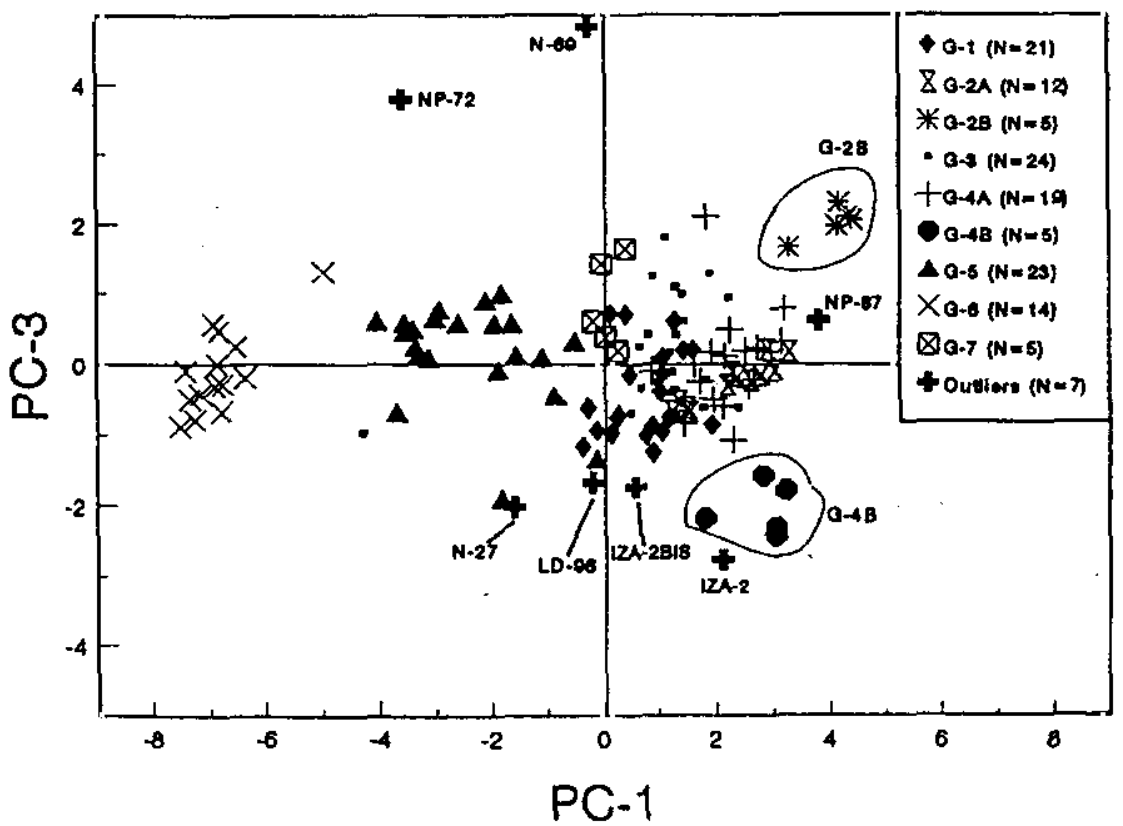

Figura 5.15: Análisis de componentes principales a partir de la transformación logarítrnica de las concentraciones clementales de 135 muestras. Representación de las muestras y sus agrupacioncs, scgún la puntuación en el primer y tercer componente. 
TABLA 5.8. MATRIZ DE CORRELACIÓN OBTENIDA A PARTIR DE LA TRANSFORMACIÓNLOGARÍTMICA DE LAS CONCENTRACIONES

ELEMENTALES DE 135 MUESTRAS

\begin{tabular}{|c|c|c|c|c|c|c|c|c|c|c|c|c|c|c|c|c|}
\hline & As & $\mathrm{Cr}$ & $\mathrm{Ni}$ & $\mathrm{Rb}$ & Sr & $\mathrm{Zn}$ & $\mathrm{Al}$ & $\mathrm{Ba}$ & $\mathrm{Ca}$ & $\mathrm{K}$ & $\mathrm{Mn}$ & $\mathrm{Ti}$ & V & $\mathrm{Cu}$ & $\mathrm{Ga}$ & $\mathrm{Y}$ \\
\hline As & 1.00 & & & & & & & & & & & & & & & \\
\hline $\mathrm{Cr}_{r}$ & 0.06 & 1.00 & & & & & & & & & & & & & & \\
\hline $\mathrm{Ni}$ & 0.16 & 0.73 & 1.00 & & & & & & & & & & & & & \\
\hline $\mathrm{Rb}$ & -0.04 & 0.87 & 0.75 & 1.00 & & & & & & & & & & & & \\
\hline $\mathrm{Sr}$ & 0.03 & 0.52 & 0.41 & 0.54 & 1.00 & & & & & & & & & & & \\
\hline $\mathrm{Zn}$ & 0.09 & 0.71 & 0.75 & 0.73 & 0.39 & 1.00 & & & & & & & & & & \\
\hline $\mathrm{Al}$ & 0.09 & 0.89 & 0.70 & 0.90 & 0.56 & 0.70 & 1.00 & & & & & & & & & \\
\hline $\mathrm{Ba}$ & 0.12 & 0.55 & 0.61 & 0.58 & 0.47 & 0.51 & 0.61 & 1.00 & & & & & & & & \\
\hline $\mathrm{Ca}$ & 0.30 & -0.09 & 0.07 & -0.21 & 0.29 & -0.02 & -0.01 & 0.26 & 1.00 & & & & & & & \\
\hline $\mathrm{K}$ & 0.03 & 0.77 & 0.68 & 0.90 & 0.60 & 0.63 & 0.81 & 0.68 & -0.17 & 1.00 & & & & & & \\
\hline $\mathrm{Mn}$ & 0.28 & -0.16 & 0.21 & -0.18 & 0.07 & 0.17 & -0.11 & 0.26 & 0.59 & -0.11 & 1.00 & & & & & \\
\hline $\mathrm{Ti}$ & 0.08 & 0.86 & 0.69 & 0.88 & 0.56 & 0.78 & 0.87 & 0.60 & -0.04 & 0.78 & 0.02 & 1.00 & & & & \\
\hline V & 0.04 & 0.79 & 0.61 & 0.81 & 0.38 & 0.66 & 0.75 & 0.47 & -0.27 & 0.68 & -0.19 & 0.76 & 1.00 & & & \\
\hline $\mathrm{Cu}$ & 0.25 & 0.53 & 0,49 & 0.48 & 0.16 & 0.54 & 0.56 & 0.43 & -0.05 & 0.48 & 0.10 & 0.56 & 0.51 & 1.00 & & \\
\hline $\mathrm{Ga}$ & 0.08 & 0.81 & 0.59 & 0.83 & 0.41 & 0.66 & 0.85 & 0.47 & -0.31 & 0.75 & -0.19 & 0.80 & 0.77 & 0.71 & 1.00 & \\
\hline $\mathrm{Y}$ & 0.03 & 0.75 & 0.70 & 0.78 & 0.45 & 0.69 & 0.78 & 0.58 & 0.01 & 0.66 & -0.03 & 0.79 & 0.69 & 0.44 & 0.66 & 1.00 \\
\hline
\end{tabular}

obtenidos con las otras técnicas, es que las muestras de Numancia e Izana se agrupan conjuntamente.

En la matriz de correlación, obtenida antes de la aplicación del Análisis de componentes principales (ver Tabla 5.8), se observa que los elementos que más han influido en la formación de estas agxupaciones, son aquellos que se hallan altamente correlacionados entre sí, esto es, el $\mathrm{Rb}, \mathrm{Al}, \mathrm{Ti}, \mathrm{Cr}, \mathrm{K}, \mathrm{Ga} \mathrm{y} \mathrm{V}$, en contraste con aquellos otros en los que la correlación es escasa o negativa, como ocurre con el Ca o el Mn, en relación a los elementos anteriores.

Esta situación, es la que refleja el Análisis de componentes principales realizado posteriormente, con el En de contrastar los resultados del Análisis cluster. En este análisis, los tres primeros componentes explican el 77,08\% de la variación total de los datos. Con respecto al primer componente, que explica un 56,17 \% de la variación, los elementos $\mathrm{Ca}$ y $\mathrm{Mn}$ se correlacionan positivamente con él, mientras que, de manera negativa, lo hacen el $\mathrm{Rb}, \mathrm{Al}, \mathrm{Ti}, \mathrm{Ct}$, $\mathrm{K}$ y Ga. En el segundo componente, con un 13,71\% de la variación de los datos, son el V, Ga y $\mathrm{Rb}$, los elementos que se correlacionan de forma positiva, mientras que en los casos del Ca y el $\mathrm{Mn}$, la correlación es negativa. Por último, en el tercer componente, que sólo explica un $7,2 \%$ de la variación, los elementos As, Cu y Ga, se correlacionan positivamente, en tanto el $\mathrm{Sr}$, Ca, Ba y $\mathrm{K}$, lo hacen de manera negativa (Figuras 5.12 y 5.14 ).

En general, este análisis corrobora los resultados obtenidos en el Análisis cluster, clasificando también las muestras en 9 agrupaciones composicionales distintas, aunque, en este caso, sólo se distinguen 7 "outliers" (Figura 5.13). Las características que presentan estas agrupaciones, se van a describir a continuación. En cualquier caso, la Tabla 5.9, recoge las muestras que componen cada agrupación, mientras que en la Tabla 14 del final de este trabajo, se exponen la media y la desviación estándard que presenta cada uno de estos grupos, para los 
18 elementos determinados. Por otro lado, en las Figuras 5.16, 5.17, 5.18 y 5.19, se muestran ejemplos bivariantes, tanto de variables escasamente correlacionadas, como de variables altamente correlacionadas, con el propósito de ilustrar la situación de estas agrupaciones, en función de las concentraciones determinadas para cada una de estas variables.

Grupo G-1. En este grupo, compuesto por 21 ejemplares (Tabla 5.9), se clasifican todas las muestras que presentaban calcita añadida en el Análisis petrográfico, excepto la N-17 y la N-21. La N-17, no se integra en la agrupación, porque las concentraciones de todos sus elementos son más bajas que la media de éstos en todo el grupo G-1. Sin embargo, la N-21 tiene concentraciones más altas que la media del grupo, en todos los elementos, salvo en el $\mathrm{Zn}, \mathrm{Al}$ y Mn. También se incluyen la totalidad de los sedimentos arcillosos calcáreos, así como la muestra N-22, que en el Análisis petrográfico se clasificaba en el grupo con menor selección de tamaño de grano. En general, la puntuación de estas muestras, está bien representada en el primer componente, debido a la correlación negativa del Ca y el Mn (Figuras 5.13 y 5.15). No en vano, es el grupo con la mayot concentración media de estos elementos. Por otra parte, la agrupación coincide con la número 3 del Análisis cluster, aunque allí también quedaban incluidas tres muestras (PT-2, PT-3 y PT-8) procedentes de Pinilla Trasmonte.

Grupo G-2A. En esta agrupación, compuesta por 12 muestras (Tabla 5.9), aparecen asociadas todas las cerámicas del yacimiento de Pinilla Trasmonte. No obstante, también se agrupa la muestra N-17, por sus menores contenidos en Ca. Esta cetámica, presentaba, en lámina delgada, una menor cantidad de calcita criptocristalina que el resto de las cerámicas con calcita añadida. Este es el segundo gxupo con las mayotes concentraciones medias en Ca. En líneas generales, coincide con la agrupación $1 \mathrm{E}$ del cluster, aunque, como se ha comentado anteriormente, tres de las muestras se clasificaban en el grupo número 3. Es importante resaltar la gran variabilidad que presentan las determinaciones de Ba. Empero, en cinco de las muestras de esta agrupación, sus mediciones se han realizado con más de un $2 \%$ de error relativo, como ya se advertía al comienzo de este apartado.

Grupo G-2B. Este pequeño grupo de 5 muestras (Tabla 5.9), está compuesto por los sedimentos arcillosos no calcáteos y por una muestra cerámica procedente de Izana que, en el Análisis petrográfico, se clasificaba como perteneciente al grupo con menor selección de tamaño de grano. En general, se trata de puntos bien representados en el primer componente (Figuras 
TABLA 5.9. GRUPOS DETERMINADOS EN EL ANÁLISIS DE COMPONENTES PRINCIPALES

\begin{tabular}{|c|c|c|c|c|c|c|c|c|}
\hline GRUPOS & $\mathrm{N}^{0}$ & \multicolumn{7}{|c|}{ MUESTRAS } \\
\hline G-1 & 21 & $\begin{array}{l}N-1 A \\
N-1 D \\
N-2 A\end{array}$ & $\begin{array}{l}N-2 D \\
N-3 A \\
N-3 D\end{array}$ & $\begin{array}{l}N-6 A \\
N-6 D \\
N-10\end{array}$ & $\begin{array}{l}\text { N-12 } \\
\text { N-15 } \\
\text { N-18 }\end{array}$ & $\begin{array}{l}\mathrm{N}-19 \\
\mathrm{~N}-20 \\
\mathrm{~N}-22\end{array}$ & $\begin{array}{l}\text { N-23 } \\
\text { IZA-11 } \\
I Z A-16\end{array}$ & $\begin{array}{l}\text { IZA-17 } \\
\text { IZA-0 } \\
\text { IZA-900 }\end{array}$ \\
\hline$G-2 A$ & 12 & $\begin{array}{l}\text { N-17 } \\
\text { PT-1 }\end{array}$ & $\begin{array}{l}\mathrm{PT}-2 \\
\mathrm{PT}-3\end{array}$ & $\begin{array}{l}\text { PT-4 } \\
\text { PT-5 }\end{array}$ & $\begin{array}{l}\text { PT-6 } \\
\text { PT-7 }\end{array}$ & $\begin{array}{l}\text { PT-8 } \\
\text { PT-9 }\end{array}$ & $\begin{array}{l}\text { PT-10 } \\
\text { PT-11 }\end{array}$ & \\
\hline G-2B & 5 & N-4A & $N-4 D$ & N-7A & N-7D & IZA-8 & & \\
\hline$G-3$ & 24 & $\begin{array}{l}N-11 \\
N-13 \\
N-14 \\
N-16\end{array}$ & $\begin{array}{l}N-28 \\
N-35 \\
N-37 \\
N-39\end{array}$ & $\begin{array}{l}\text { N-43 } \\
\text { N-45 } \\
\text { N-50 } \\
\text { N-53 }\end{array}$ & $\begin{array}{l}N-57 \\
N-58 \\
N-59 \\
N-71\end{array}$ & $\begin{array}{l}\text { NP-75 } \\
\text { IZA-1 } \\
\text { IZA-IBIS } \\
\text { IZA-7 }\end{array}$ & $\begin{array}{ll} & \text { IZA-9 } \\
& \text { IZA-14 } \\
\text { S } & \text { IZA-15 } \\
& \text { LD-95 }\end{array}$ & \\
\hline$G-4 A$ & 19 & $\begin{array}{l}N-24 \\
N-34 \\
N-36\end{array}$ & $\begin{array}{l}N-38 \\
N-40 \\
N-44\end{array}$ & $\begin{array}{l}\text { N-46 } \\
\text { N-48 } \\
\text { N-52 }\end{array}$ & $\begin{array}{l}N-54 \\
N-55 \\
N-68\end{array}$ & $\begin{array}{l}\text { NP-76 } \\
\text { NP-77 } \\
\text { NP-79 }\end{array}$ & $\begin{array}{l}\text { IZA-3 } \\
\text { IZA-4 } \\
\text { IZA-6 }\end{array}$ & IZA-10 \\
\hline$G-4 B$ & 5 & EP-25 & EP-26 & EP-27 & EP-28 & EP-29 & & \\
\hline G-5 & 23 & $\begin{array}{l}N-21 \\
N-30 \\
N-31 \\
N-32\end{array}$ & $\begin{array}{l}\mathrm{N}-33 \\
\mathrm{~N}-41 \\
\mathrm{~N}-42 \\
\mathrm{~N}-47\end{array}$ & $\begin{array}{l}N-51 \\
N-56 \\
N-60 \\
N-61\end{array}$ & $\begin{array}{l}N-63 \\
N-64 \\
N-65 \\
N-66\end{array}$ & $\begin{array}{l}\text { N-67 } \\
\text { N-70 } \\
\text { NP-73 } \\
\text { NP.74 }\end{array}$ & $\begin{array}{l}\text { NP-78 } \\
\text { NP-80 } \\
\text { NP-88 }\end{array}$ & \\
\hline G-6 & 14 & $\begin{array}{l}N-25 \\
N-26\end{array}$ & $\begin{array}{l}\mathrm{N}-29 \\
\mathrm{~N}-62\end{array}$ & $\begin{array}{l}\text { NP-81 } \\
\text { NP-82 }\end{array}$ & $\begin{array}{l}\text { NP-83 } \\
\text { NP-84 }\end{array}$ & $\begin{array}{l}\text { NP-85 } \\
\text { NP-86 }\end{array}$ & $\begin{array}{l}\text { NP-89 } \\
\text { NP-90 }\end{array}$ & $\begin{array}{l}\text { NP-91 } \\
\text { NP-97 }\end{array}$ \\
\hline $\mathrm{G}-7$ & 5 & $\mathrm{~N}-49$ & LD-92 & LD-93 & LD-94 & IZA-5 & & \\
\hline Outliers & 8 & $\begin{array}{l}N-8 A \\
N-27\end{array}$ & $\begin{array}{l}N-69 \\
N P-72\end{array}$ & $\begin{array}{l}\text { NP-87 } \\
\text { IZA-2 }\end{array}$ & $\begin{array}{l}\text { IZA-2B } \\
\text { LD-96 }\end{array}$ & & & \\
\hline
\end{tabular}

5.13 y 5.15), por la correlación negativa que se establece entre el Rb, Al y Ti. Por otro lado, estos sedimentos muestran una menor concentración de $\mathrm{Rb}$ y $\mathrm{Ti}$, en relación al resto de los sedimentos analizados. $A$ pesar de que la muestra IZ.A-8 se asocia a los sedimentos $\mathrm{N}-4$ y $\mathrm{N}-7$, se aprecian algunas diferencias en las concentraciones de los elementos $\mathrm{Rb}, \mathrm{Zn}, \mathrm{Ba}, \mathrm{Mn}$ y $\mathrm{Cu}$ (ver Tablas 4 y 12). Esta agrupación, coincide, plenamente, con la 1D del Análisis cluster. 
Grupo G-3. En el grupo G-3, compuesto pot 24 ejemplares, se asocian, tanto muestras de Numancia, como de Izana (Tabla 5.9). Asimismo, también se asocia una muestta (I.D-95) procedente de Langa de Duero, aunque sus contenidos en Ca son más altos que los de la media del grupo (ver Tabla 26). Esta agrupación coincide con la $1 \mathrm{~A}$ del Análisis cluster, excepto en dicha muestra de Langa de Duero, que se agrupaba, en esa ocasión, en el 1E. La mayoría de las muestras, pertenece a la Fábrica 1. No obstante, también hay muestras de la Fábrica 1-b, de la 2 y de la Fábrica negra. En el caso de la Fábrica 1-b, sólo aparecen aquí dos de ellas (N-28 e IZA15), que muestran los colores más naranjas de todas las muestras analizadas pertenecientes a esta fábrica (ver Tabla 1). Por otro lado, sólo una muestra con decoración polícroma (NP-75), se asocia a este grupo.

Grupo G-4A. Al igual que el grupo anterior, esta agrupación composicional compuesta por 19 ejemplates, también presenta, conjuntamente, muestras de Numancia e Izana (Tabla 5.9). En general, se trata de cerámicas pertenecientes a la Fábrica 1, aunque dos muestras pertenecen a la Fábrica 2 y una a la Fábrica 1-b. Los ejemplares asociados a este grupo, son puntos bien representados en el segundo componente (Figura 5.13). Por otra parte, sólo tres muestras con decoración polícroma, aparecen en este conjunto.

Grupo G-4B. El grupo G-4B, está compuesto, exclusivamente, por las 5 muestras procedentes del yacimiento de El Palomat (Tabla 5.9). Como puede apreciarse en la Figura 5.15, se trata de muestras bien representadas en el tercer componente. Fundamentaimente, se diferencia del grupo G-4A, por el mayor contenido medio en St (ver Tabla 14). Este elemento, es el que tiene, precisamente, una mayor correlación negativa con el tercero de los componentes principales. Por otro lado, este conjunto coincide, totalmente, con el grupo 1F del Análisis cluster.

Grupo G-5. La agrupación composicional G-5, compuesta por 23 ejemplares, sólo contiene muestras procedentes del yacimiento de Numancia (Tabla 5.9). Además, estas muestras pertenecen, mayoritariamente, a las Fábricas 1 y 2 . De hecho, casi todas las muestras analizadas de la Fábrica 2, aparecen en este conjunto. Por lo demás, 5 cerámicas con decoración polícroma, están prescntes en el mismo. En líneas generales, son muestras bien representadas en el primer componente (Figuras 5.13 y 5.15), por la correlación negativa de los elementos $\mathrm{Cr}, \mathrm{Rb}, \mathrm{Al}, \mathrm{K}$, $\mathrm{Ti}$ y Ga. En este sentido, es preciso resaltar que se trata del segundo grupo con mayores contenidos medios en estos elementos. Sin embargo, hay una muestra, la $\mathrm{N}-21$, perteneciente a las cerámicas 


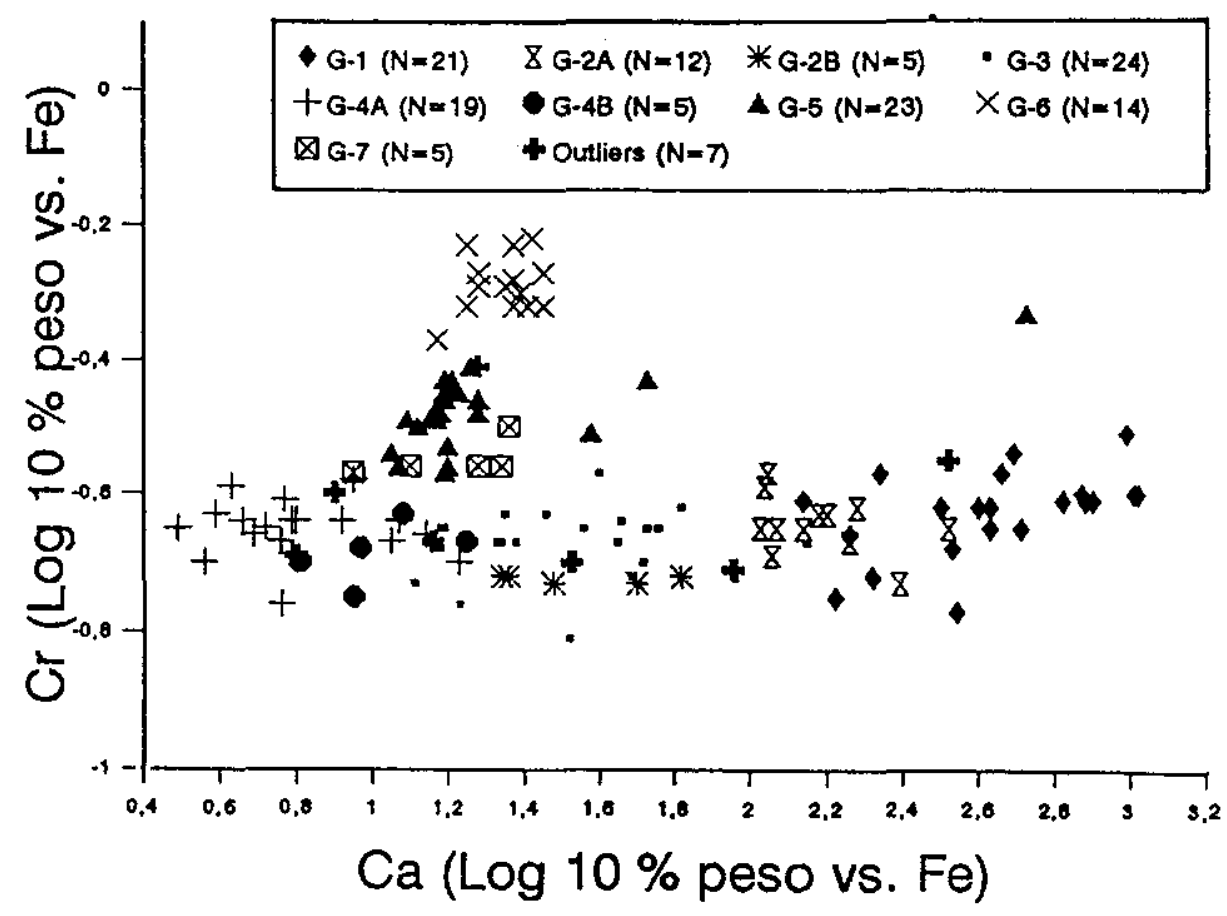

Figura 5.16: Gráfico bivariante $\mathrm{Ca}_{\text {a versus }} \mathrm{Cr}$ de las concentraciones elementales de 135 muestras, según las agrupaciones establecidas en el Análisis de componentes principales.

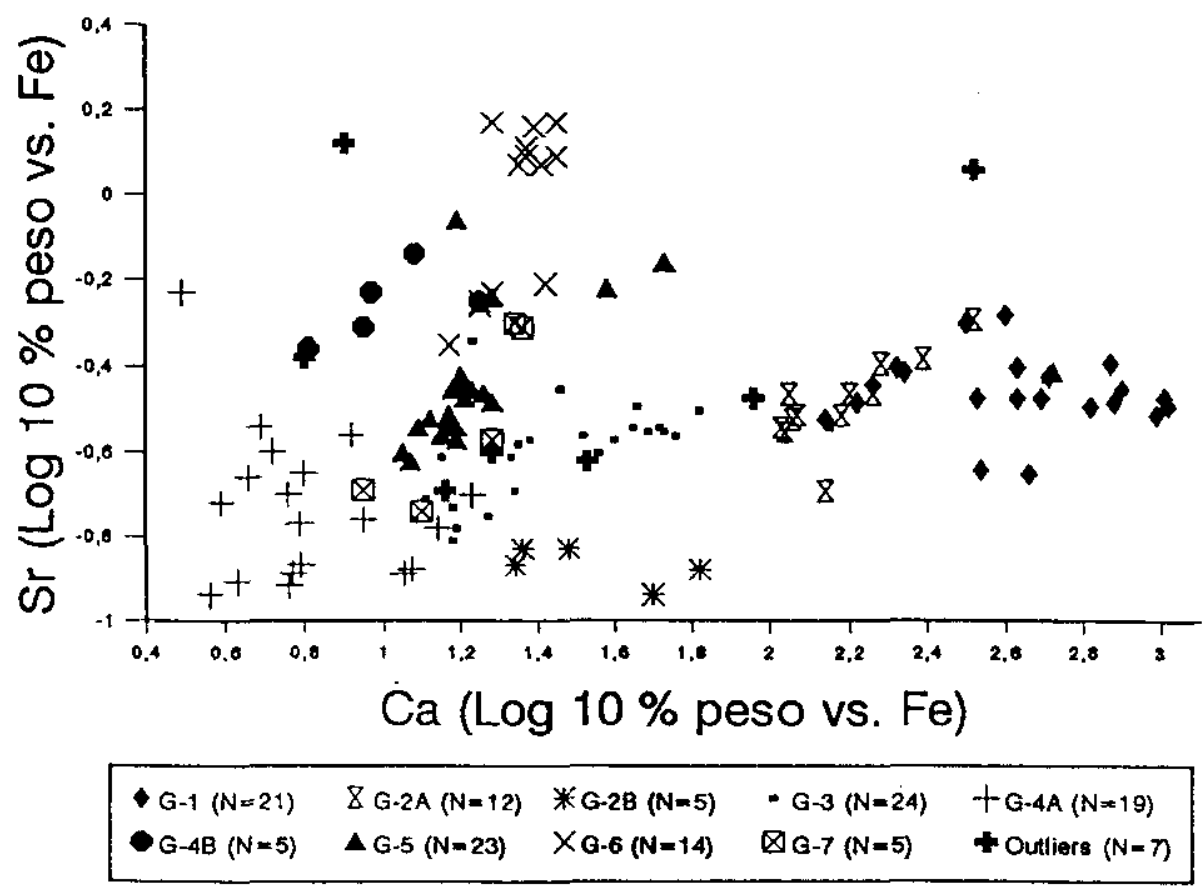

Figura 5.17: Gráfico bivariante Ca versus $\mathrm{S} r \mathrm{de}$ las concentraciones clementales de 135 muestras, scgún las agrupaciones establccidas en el Análisis de componentes principales. 


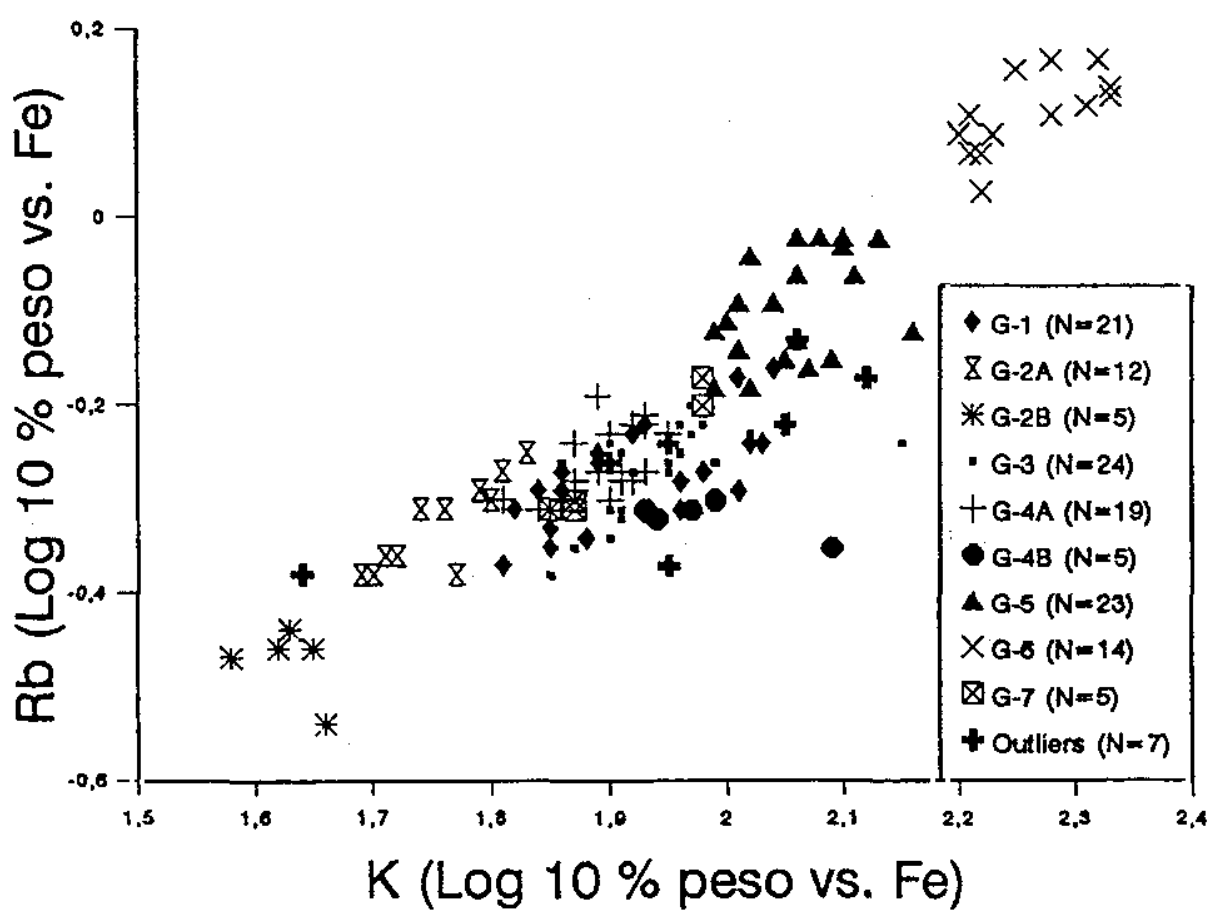

Figura 5.18: Gráfico bivariante $\mathrm{K}$ versus $\mathrm{Rb}$ de lass concentraciones elementales de 135 muestras, según las agrupaciones establecidas en el Análisis de componentes principales.

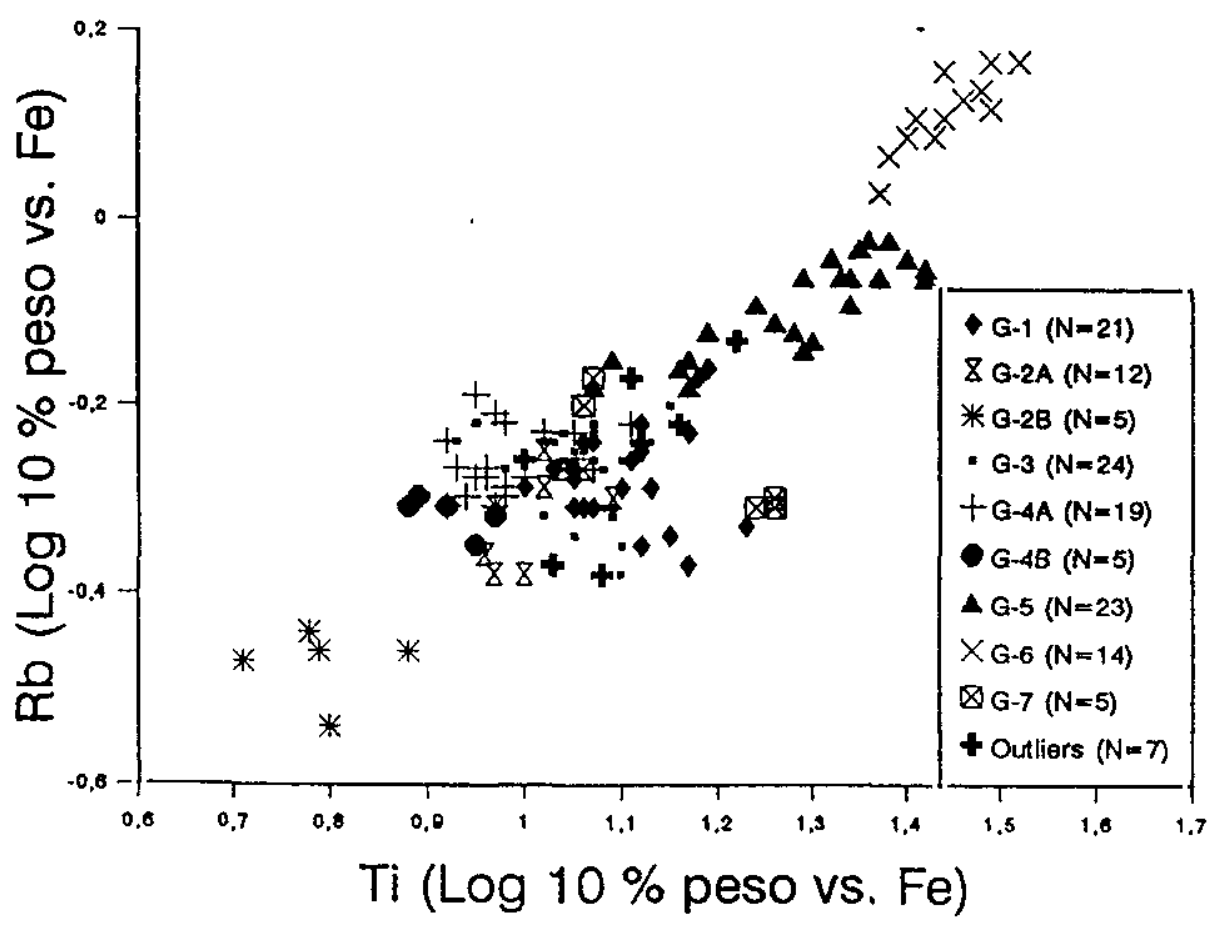

Figura 5.19: Gráfico bivariante Tï versus Rb de las concentraciones dementalcs de 135 mucstras, scgún las agrupacioncs establecidas en el Análisis de componentes principales. 
que presentaban calcita añadida en el Análisis petrográfico, que resulta extraña en esta agrupación. Sus concentraciones en $\mathrm{As}, \mathrm{C}, \mathrm{Ba}, \mathrm{K}, \mathrm{Cu}$ y, sobre todo, en $\mathrm{Ca}$, son más altas que la media de los mismos en el grupo. Es más, la inclusión del contenido en Ca de esta muestra, desvirtúa seriamente la media y la desviación estándar del elemento en la agrupación (Ver Tabla 14). Sin ella, se sitúa en $18,196 \pm 9,6 \mathrm{y}$, con ella, asciende hasta un $40,094 \pm 105,434$. En el Análisis cluster, las muestras de este conjunto aparecían asociadas al grupo 1B, aunque alli la muestra N-21 era un claro "outlier".

Grupo G-6. En esta agrupación, compuesta por 14 muestras, sólo se asocian, igualmente, ejemplares procedentes de Numancia (Tabla 5.9), siendo en su mayoría de la Fábrica 1-b, excepto en dos casos (N-62 y NP-91), que son muestras de la Fábrica 2. El grupo también está bien representado en el primer componente, por las mismas tazones que en el anterior (Figuras 5.13 y 5.15). De hecho, este es el grupo con mayor contenido medio en $\mathrm{Cr}, \mathrm{Rb}, \mathrm{Al}, \mathrm{K}$, Ti y Ga. Por otro lado, la mayor parte de cerámicas que presentan decoración polícroma, se sitúan en este conjunto. Coincide por entero, con la agrupación número 2 del Análisis cluster.

Grupo G-7. En este pequeño grupo, compuesto solamente por 5 muestras, se asocian 3 de los 5 ejemplares procedentes de Langa de Duero (Tabla 5.9). No obstante, también aparecen una muestra de Numancia y otra de Izana. Dado el tamaño tan reducido que tiene este grupo, es dificil dilucidar si puede ser tratado como una agrupación homogénea o, simplemente, como una serie de "outliers" próximos en el espacio n-dimensional. En cualquier caso, las muestras N-49 e IZA-5, presentan un mayor contenido en $\mathrm{Rb}, \mathrm{K}$ y Cu y una concentración menor en Al, Ca, Ti y Ga, en relación a las cerámicas de Langa de Duero. Con respecto a los resultados del Análisis cluster, esta agrupación es similar al grupo $1 \mathrm{C}$.

"Outliers". En el Análisis de componentes principales, se han definido 4 "outliets" menos que en el Análisis cluster. La muestra N-21 que, aunque con problemas, como se ha comentado anteriormente, se incluye en el grupo G-5; el ejemplar NP-74, que se asocia también al grupo G-5; la muestra NP-79, que se agrupa en el G-4A y, por último, la muestra NP-88, que, igualmente, se encuadra en el propio grupo G-5. El resto de los "outliers" son los mismos (Tabla $5.9)$.

La muestra $\mathrm{N}-27$, bien representada en el segundo y tercer componente (Figura 5.15), se separa del grupo G-1, del que puede ser considerada "outlier", porque tiene menores contenidos 
en $\mathrm{Ca}$. Este aspecto, ya quedaba patente en el Análisis petrográfico y en el análisis mediante Difracción de rayos $\mathrm{x}(\mathrm{XRD})$. En todo caso, se trataba de una cerámica calcárea procedente de Numancia, en donde no es común, como se ha visto hasta ahora, la elaboración de cerámicas con arcillas calcáreas. Además, sus concentraciones en $\mathrm{Sr}, \mathrm{Ba}, \mathrm{K}, \mathrm{V}$ e $\mathrm{Y}$, son mayores que las que presenta la media de estos elementos para todo el grupo (ver Tablas 11 y 14).

La muestra N-69, es un punto bien representado en el tercer componente (Figura 5.15), por sus concentraciones, extremadamente altas, en $\mathrm{Cu}$ y $\mathrm{Ga}$, elementos que se correlacionan positivamente con este tercet componente. En cualquier caso, y dada la tipología que presenta este ejemplar, por lo demás, muy común en el yacimiento de Numancia, habría que pensar que estas concentraciones tan altas, son producto de algún proceso de contaminación.

La muestra NP-72, bien representada en el tercer componente (Figura 5.15), puede ser considetada un "outlier" del grupo G-5, ya que presenta un mayor contenido de As y Cu, que la media de estos elementos para todo el grupo (Tablas 11 y 14). Por el contrario, la NP-87, puede ser considerada un "outlier" de la agrupación composicional G-4A, debido a que sus concentraciones son menores a la media de la mayotía de los elementos de este grupo (Figuta 5.15). Esta cerámica, no obstante, mostraba claros indicios de estar cocida a una mayor temperatura, en los análisis de difracción. Quizás sea por este motivo, por lo que se separe de la agrupación G-4A. Igual comentario merecen las tres muestras restantes, bien representadas en el tercer componente (Figura 5.15), que también presentaban indicios de sobrecocción. La IZA-2, "outlier" del grupo G-4A; la IZA-2BIS, del grupo G-3 y la muestra LD-96, "outlier" de la agrupación G-7, que contenia 3 de las 5 cerámicas analizadas, procedentes de Langa de Duero.

Con el fin de realizar una evaluación de los hipotéticos grupos composicionales definidos a través del Análisis de componentes principales, se ha llevado a cabo un Análisis discriminante, a partit de las mismas 135 muestras. Debe tenerse en cuenta que, este tipo de análisis, no se utiliza como técnica exploratoria, sino como técnica descriptiva, puesto que, en su aplicación, se presupone la existencia de una estructura en los datos. Esto es, las agrupaciones establecidas en el Análisis de componentes principales. En definitiva, lo que se pretende con esta técnica, es demostrat que, la separación entre los grupos definidos, es consistente (Baxter, 1994, 188).

Debido al escaso número de muestras que conforman las agrupaciones $G-2 B$ y $G-4 B$, se decidió unificarlas en los grupos G-2 y G-4, habida cuenta de su proximidad en el espacio ndimensional. Por lo tanto, dichas agrupaciones están compuestas, en este análisis, por 17 y 24 
muestras respectivamente, que representan los ejemplates de los grupos $G-2 A / G-2 B$ y $G$ $4 A / G-4 B$ unidos.

Tras realizar un análisis de la varianza, se comprobó que las variables con más poder discriminante eran 7: $\mathrm{Al}, \mathrm{Ca}, \mathrm{K}, \mathrm{Ni}$, $\mathrm{Ti}$, As y $\mathrm{Mn}$. De esta forma, se calcularon las variables canónicas, que ofrecen la mejor correlación entre las combinaciones lineales de las variables con más poder discriminante, con el fin de indicar la probabilidad de pertenencia a las agrupaciones establecidas. En este análisis, las dos primeras variables canóniças explican un $86,31 \%$ de la variación total de los datos. Las puntuaciones que presentan las muestras, con respecto a estas dos variables canónicas, se ofrecen en la Figura 5.20, en la que puede observarse una buena discriminación entre los gxupos definidos previamente. Por otro lado, en la Tabla 15 del final de este trabajo, se exponen las distancias de Mahalanobis de cada muestra, con respecto a los centroides de dichas agrupaciones.

Aunque, en general, los resultados del Análisis discriminante, se ajustan satisfactoriamente a los datos aportados por el Análisis de componentes principales, en algunos casos, se aprecian pequeñas discrepancias o nuevos condicionantes, que ayudan a clarificar la posición de ciertas muestras. Especialmente, en lo referente a los "outliers". Entre ellos, cabe destacar los siguientes:

En el grupo definido aquí como G-2, destaca la distancia, ciertamente alta (22.8) (Tabla 15), que presenta la muestra IZA 8 , al centroide del mismo. Este aspecto, podría indicar que esta muestra, en realidad, no se corresponde con los sedimentos arcillosos no calcáteos, tomados en las inmediaciones del yacimiento de Numancia.

En la agrupación $G-3$, las distancias mayores se corresponden con las muestras $N-11, N$ 13, N-16 y N-71 (Tabla 15), todas ellas pertenecientes al grupo con menor selección de tamaño de grano, que se estableció en el Análisis petrográfico. Por lo tanto, aunque la agrupación es bastante homogénea, desde un punto de vista composicional, la distinta selección de la materia prima con la que se han elaborado estas cerámicas, hace que puedan distinguirse en el interior de la misma, con relativa nitidez. De todos modos, este extremo confirma que se fabricaron con la misma materia prima, eso sí, menos seleccionada, que el resto de las cerámicas del grupo. Asimismo, la muestra LD-95, procedente de Langa de Duero, también presenta una gran distancia al centroide de esta agrupación. Este factor, podría indicar que, efectivamente, esta cerámica tiene diferencias composicionales importantes con aquellas procedentes de Numancia o Izana. 


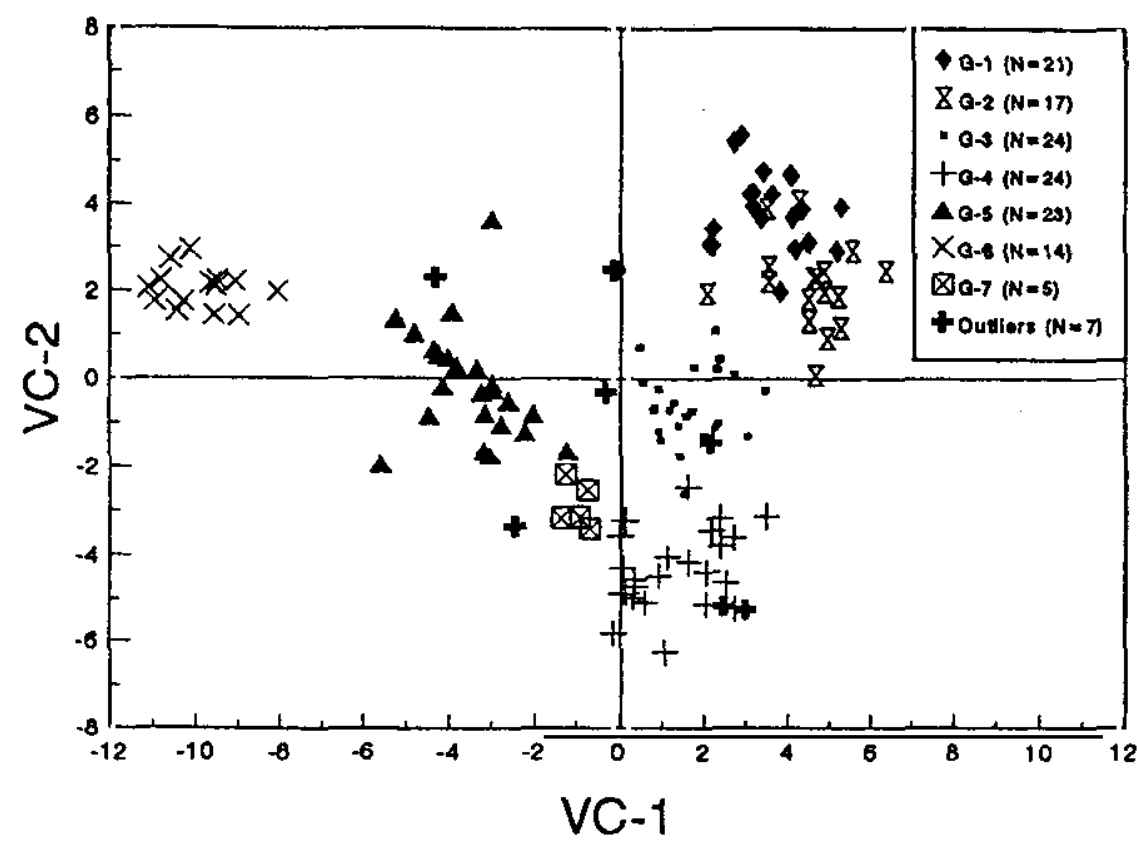

Figura 5.20: Anälisis discriminante a partir de la transformación logarítmica de las concentraciones elementales de 135 muestras y de las agrupaciones establecidas en el Análisis de componentes principales. Representación de las muestras según la puntuación en las dos primeras variables canónicas. Los grupos $G-2 A / G-2 B$ y $G-4 A / G-4 B$, se han unificado en un solo grupo G-2 y G-4, respectivamente.

En el caso de la muestra NP-79, que en el Análisis de componentes principales quedó asociada a la agrupación G-4A (Tabla 5.9), la distancia al centroide de este grupo (25.2), es mayor que la que tiene para el centroide del grupo G-7 (18.5) (Tabla 15). Estas discrepancias, pueden ser debidas a que sus concentraciones en $\mathrm{As}$ y $\mathrm{Cu}$, son mayores a la media de estos elementos en el grupo G-4A (ver Tablas 22 y 26). Los problemas en la clasificación de esta muestra, quizás indiquen, al igual que se comentaba anteriormente para las muestras N-69 o NP- 72, que, las concentraciones en As y Cu, están desvittuadas por algún proceso de contaminación.

En el grupo G-5, destaca la excesiva distancia (41.7) (Tabla 15) que presenta la muestra $\mathrm{N}-21$, con calcita añadida, al centroide de esta agrupación, lo cual corrobora su delicada pertenencia a la misma, como ya se comentaba en los resultados que ofrecían el Análisis cluster y el Anátisis de componentes principales.

Por lo demás, los ejemplares mal clasificados en este Análisis discriminante, continúan siendo los 7 "outliers" ya definidos anteriormente. No obstante, deben destacarse algunos datos de interés. En el caso de la muestra LD-96, perteneciente a Langa de Duero, la rutina 7M del 
programa BMDP utilizada en la realización de este análisis, la considera del grupo G-7, con un $100 \%$ de probabiliad de pertenencia a dicho grupo. Algo similar ocurre para las muestras IZA-2 e IZA-2BIS. La primera, la considera del grupo G-4, también con un $100 \%$ de probabilidad, mientras que, la segunda, la incluye en la agrupación G-3, con un $99 \%$ de probabilidad. Estos datos están en consonancia con los obtenidos a través del análisis de Difracción de rayos $\mathrm{x}$ (XRD), en los que se podía comprobar, que se trataba de muestras sobrecocidas. Es por ello, por lo que se separan de las agrupaciones con las que comparten mayores semejanzas composicionales. Por ejemplo, la inclusión de la muestra LD-96 en el grupo G-7, hace que se asocie al grupo en el cual aparecen el resto de las muestras de este yacimiento, excepto la LD-95, que se asocia a otra agrupación.

En otro orden de cosas, y aprovechando que ya se había analizado en un trabajo anterior, un conjunto de 24 muestras procedentes del yacimiento de El Palomar, con los mismos procedimientos experimentales que los explicitados en esta Tesis Doctoral, de modo que, los resultados pudieran ser comparables (García Heras et al., En prensa a), se procedió a comprobar cómo se clasificaban las 5 nuevas muestras analizadas en esta investigación y procedentes también de este yacimiento, con el fin de conocer si había diferencias composicionales entre ellas. De esta forma, se llevó a cabo un Análisis de componentes principales, con los mismos procedimientos que el anterior, es decir, sin tener en cuenta las concentraciones del $\mathrm{Nd}$ y el $\mathrm{Hf}$, con las 29 muestras mencionadas.

Debe apuntarse que, en el trabajo anterior, el Análisis de componentes principales realizado en aquella ocasión, se llevó a cabo con las concentraciones elementales de los 18 elementos determinados. Este análisis, daba como resultado, la clasificación de las muestras en dos agrupaciones claramente diferenciadas. Una compuesta por 4 ejemplates de lá fábrica de cocción oxidante mayoritaria en el conjunto cerámico del yacimiento $y$, otra, en la que se agrupaban el resto de las muestras analizadas.

Los resultados obtenidos en esta ocasión, proporcionan una clasificación de las muestras en cuatro agrupaciones distintas (Figura 5.22). Por un lado, el grupo anterior de 20 muestras, se ha subdividido en tres conjuntos diferentes (P-2, P-3 y P-4). Por otro, las 5 cerámicas analizadas aquí por primera vez, se han unido a la agrupación anterior, que se componia de 4 ejemplares de la fábrica mayoritaria de cocción oxidante, como tefleja el grupo P-1 de la Figura 5.22. Estos resultados, indican que la composición de los 5 fragmentos de cerámica con motivos decorativos numantinos procedentes de El Palomar, es similar a la que muestra el grupo cerámico mayoritario de este asenfamiento. 
TABLA 5.10. MATRIZ DE CORRELACIÓN OBTENIDA A PARTIR DE LA TRANSFORMACIÓ LOGARITTMICA DE LAS CONCENTRACIONES ELEMENTALES DE 29 MUESTRAS PROCEDENTES DEL YACIMIENTO DE EL PALOMAR

\begin{tabular}{|c|c|c|c|c|c|c|c|c|c|c|c|c|c|c|c|c|}
\hline & As & $\mathrm{Cr}$ & $\mathrm{Ni}$ & $\mathrm{Rb}$ & Sr & $\mathrm{Zn}$ & $\mathrm{Al}$ & $\mathrm{Ba}$ & $\mathrm{Ca}$ & $\mathrm{K}$ & $\mathrm{Mn}$ & Ti & $\mathrm{V}$ & $\mathrm{Cu}$ & $\mathrm{Ga}$ & $Y$ \\
\hline$A s$ & 1.00 & & & & & & & & & & & & & & & \\
\hline $\mathrm{Cr}$ & 0.17 & 1.00 & & & & & & & & & & & & & & \\
\hline $\mathrm{Ni}$ & 0.31 & 0.59 & 1.00 & & & & & & & & & & & & & \\
\hline $\mathrm{Rb}$ & -0.12 & -0.31 & -0.58 & 1.00 & & & & & & & & & & & & \\
\hline $\mathrm{S}_{\mathrm{I}}$ & -0.31 & -0.11 & -0.23 & 0.57 & 1.00 & & & & & & & & & & & \\
\hline $\mathrm{Zn}$ & 0.16 & 0.42 & 0.69 & 0.03 & 0.20 & 1.00 & & & & & & & & & & \\
\hline $\mathrm{Al}$ & 0.15 & 0.68 & 0.27 & -0.10 & -0.41 & 0.23 & 1.00 & & & & & & & & & \\
\hline $\mathrm{Ba}$ & 0.19 & 0.09 & 0.01 & -0.10 & 0.18 & 0.04 & -0.33 & 1.00 & & & & & & & & \\
\hline $\mathrm{Ca}$ & 0.41 & 0.32 & 0.59 & -0.51 & -0.19 & 0.47 & 0.09 & 0.25 & 1.00 & & & & & & & \\
\hline $\mathrm{K}$ & -0.25 & -0.28 & -0.42 & 0.87 & 0.79 & 0.11 & -0.32 & -0.01 & -0.40 & 1.00 & & & & & & \\
\hline $\mathrm{Mn}$ & 0.06 & 0.16 & 0.38 & -0.12 & 0.45 & 0.40 & -0.29 & 0.28 & 0.60 & 0.24 & 1.00 & & & & & \\
\hline $\mathrm{Ti}$ & 0.19 & 0.68 & 0.30 & -0.13 & -0.35 & 0.23 & 0.97 & -0.34 & 0.13 & -0.32 & -0.25 & 1.00 & & & & \\
\hline $\mathrm{V}$ & 0.06 & 0.28 & 0.09 & -0.06 & -0.27 & -0.08 & 0.25 & -0.19 & -0.33 & -0.12 & -0.26 & 0.27 & 1.00 & & & \\
\hline $\mathrm{Cu}$ & 0.49 & 0.51 & 0.72 & -0.59 & -0.53 & 0.30 & 0.47 & -0.03 & 0.64 & -0.59 & 0.20 & 0.47 & -0.02 & 1.00 & & \\
\hline $\mathrm{Ga}$ & -0.08 & 0.55 & 0.04 & 0.17 & -0.19 & 0.19 & 0.89 & -0.34 & -0.11 & -0.01 & -0.29 & 0.85 & 0.17 & 0.18 & 1.00 & \\
\hline $\mathrm{Y}$ & 0.34 & 0.60 & 0.56 & -0.42 & -0.29 & 0.25 & 0.71 & -0.25 & 0.32 & -0.44 & 0.00 & 0.78 & 0.06 & 0.63 & 0.53 & 1.00 \\
\hline
\end{tabular}

En la Tabla 5.10, se expone la matriz de correlación realizada antes de la aplicación de este análisis. En ella, puede observarse que son los elementos $\mathrm{Cr}, \mathrm{Ni}, \mathrm{Al}, \mathrm{K}, \mathrm{Ti}, \mathrm{Cu}, \mathrm{Ga}$ e Y, los que se encuentran más correlacionados entre sí, mientras que elementos como el Rb y el Ti, apenas se muestran correlacionados con los anteriores. Los gráficos bivariantes de las Figuras 5.23 y 5.24 , reflejan dos de estas situaciones.

En este análisis, los tres primeros componentes explican el 71,11\% de la variación total de los datos. Con respecto al primer componente, que explica un 36,06\% de la variación, los elementos $\mathrm{Y}, \mathrm{Cu}, \mathrm{Ti}, \mathrm{Al}, \mathrm{Cr}$ y $\mathrm{Ni}$ se correlacionan positivamente con él, mientras que, de manera negativa, lo hacen el K, Rb y Sr. En el segundo componente, con un $20,27 \%$ de la variación de los datos, son el Ga, Al, Ti y V, los elementos que se correlacionan de forma positiva, mientras que en los casos del $\mathrm{Mn}, \mathrm{Ca}, \mathrm{Ba}$ y $\mathrm{Ni}$, la correlación es negativa. Por último, en el tercer componente, que explica un $14,78 \%$ de la variación, los elementos $\mathrm{S}$, $\mathrm{K}$, Zn y Rb, se correlacionan positivamente, en tanto el V, Cu y As, lo hacen de manera negativa (Figura 5.21).

Pasando a otras cuestiones, la detección, en el Análisis petrográfico, de calcita criptocristalina añadida intencionadamente a la pasta, en algunas de las cerámicas analizadas pertenecientes a la Fábrica negra, hacia preveer que las concentraciones de Ca se verian seriamente afectadas en estas cerámicas, ya que la adición de materiales no plásticos produce 


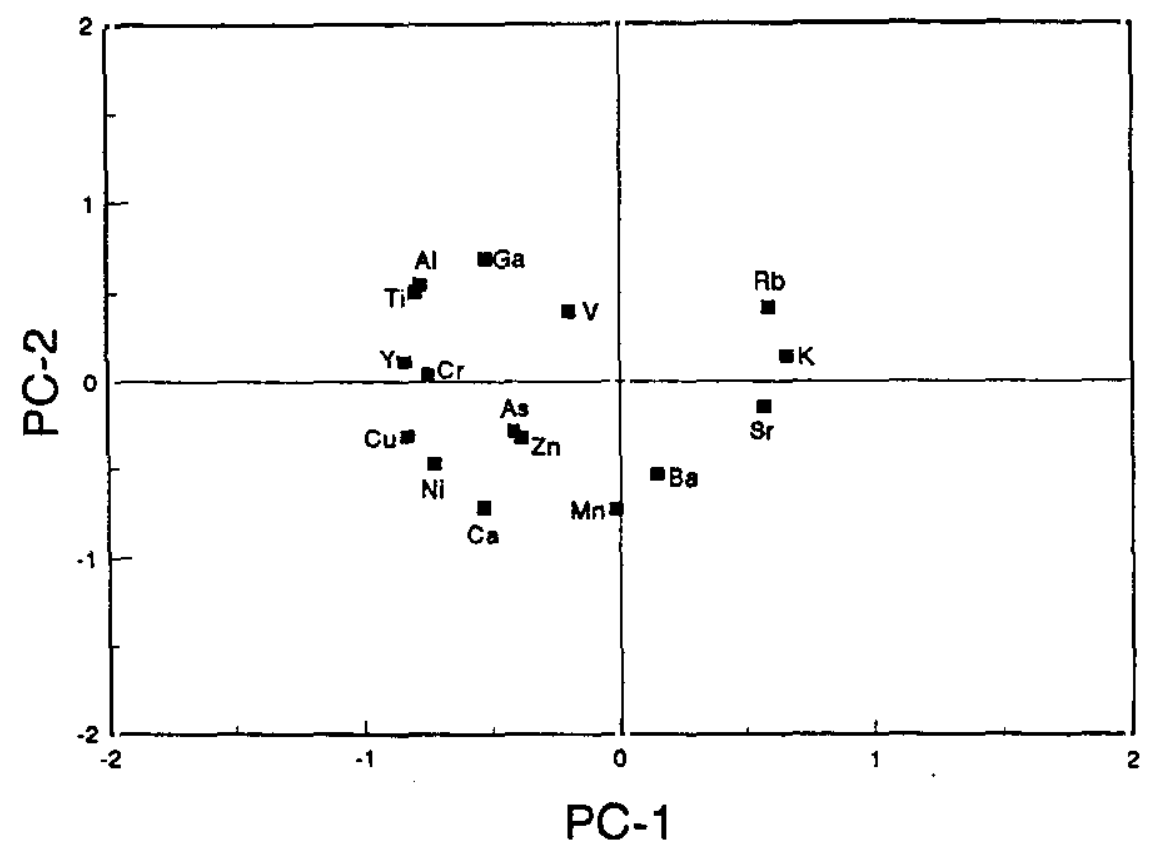

Figura 5.21: Análisis de componentes principales a partir de da transformación logaritmica de las concentraciones elementales de 29 muestras procedentes de El Palomar. Representación del peso de las variables (16 elementos), en los dos primeros componentes.

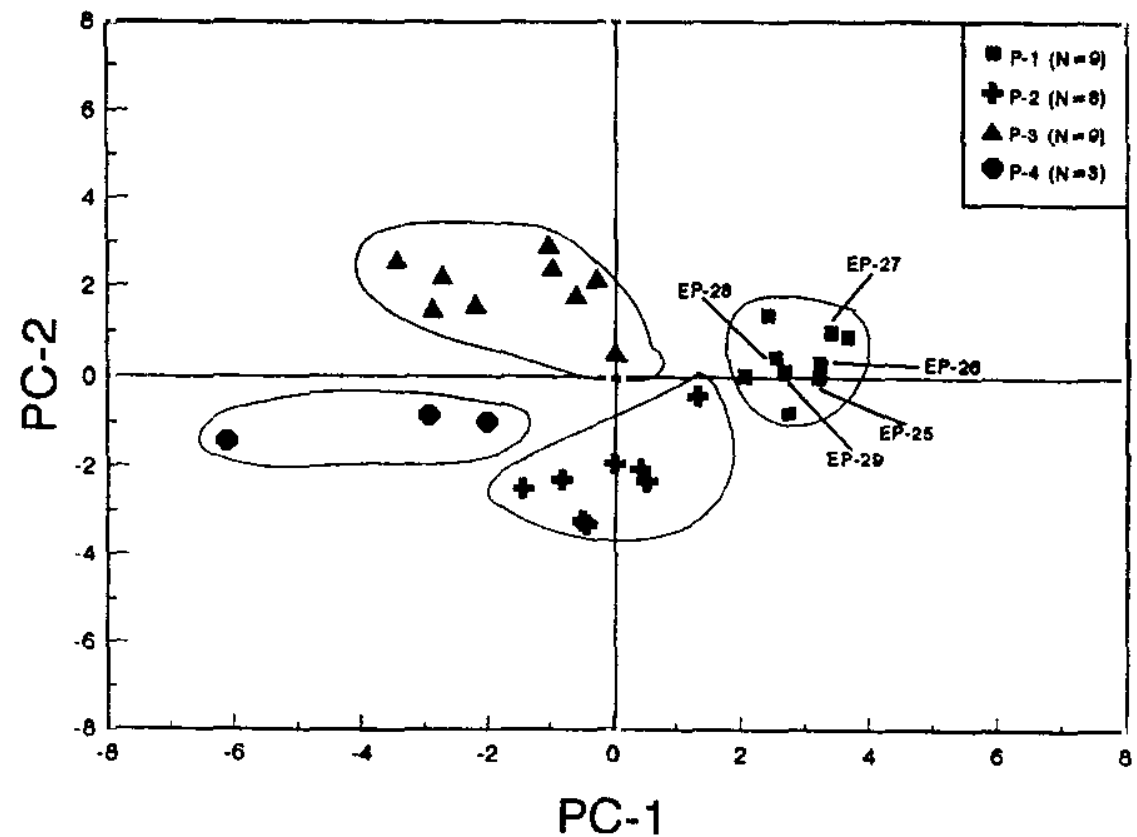

Figura 5.22: Análisis de componentes principales a partir de la transformación logaritnica de las concentraciones elementales lè 29 mucstras procedentes de Fil Patomar. Representación de las muestras y sus agrupaciones, según la puntuación en los dos primeros componentes. 


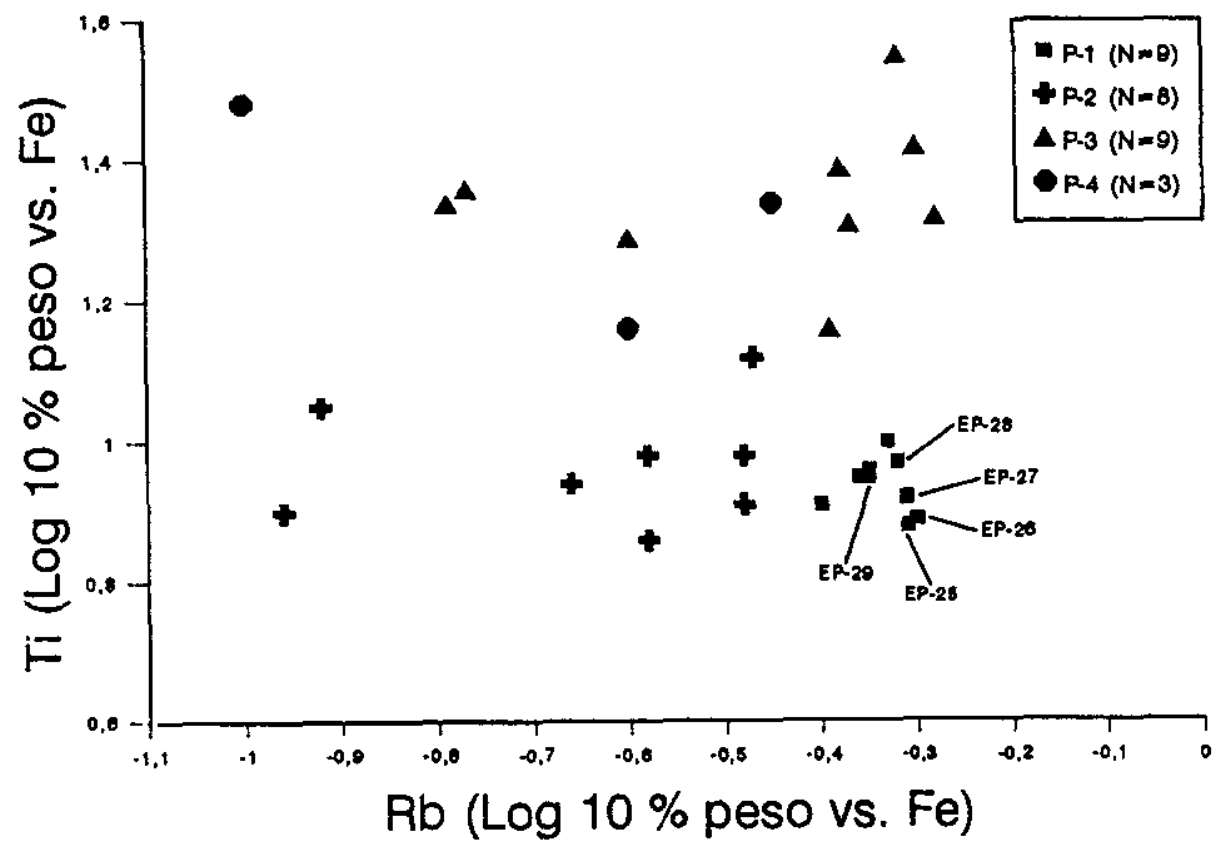

Figura 5.23: Gráfico bivariante Rb versus Ti de las concentraciones elementales de 29 muestras procedentes de El Palomar, según las agrupaciones establecidas cn el Análisis de componentes principales.

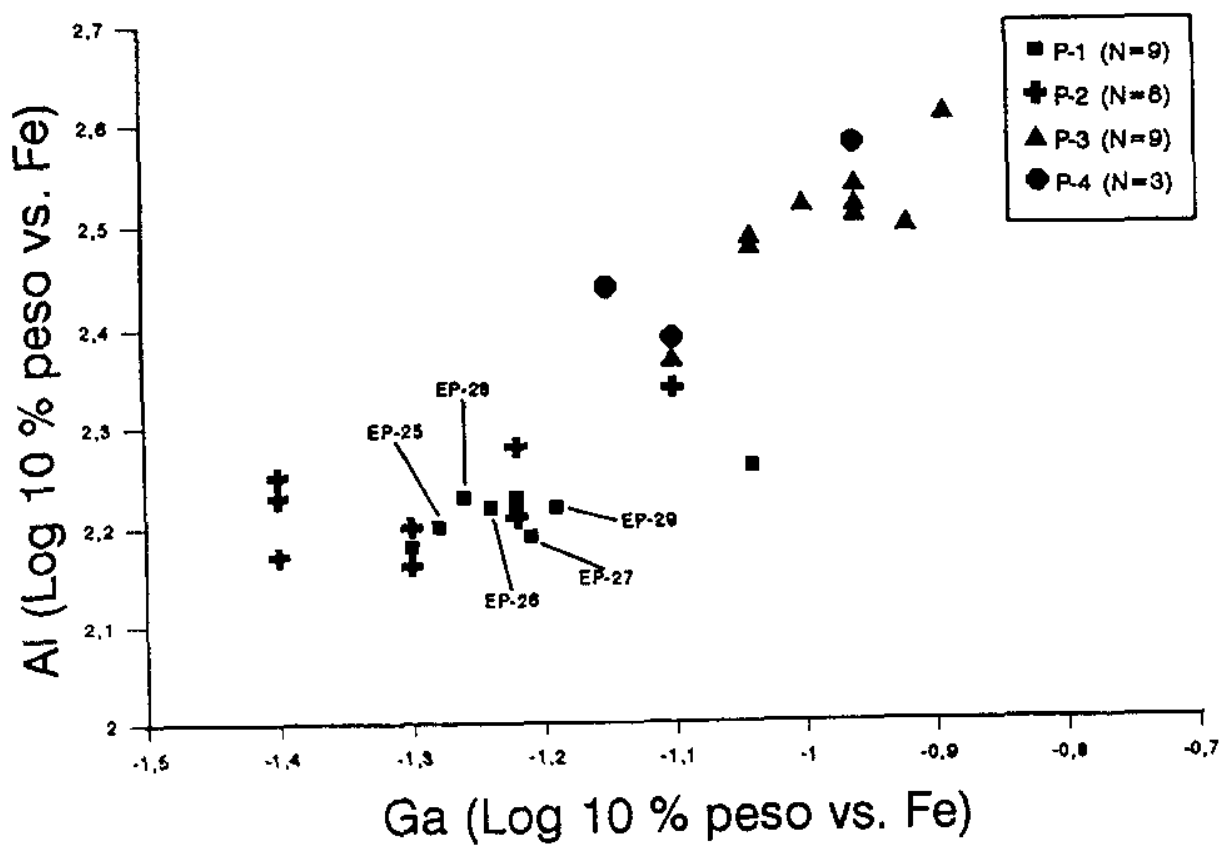

Figura 5.24: G Gáfico bivariante Ga versur $A$ de las concentraciones elementales de 29 muestras procedentes de lil Palomat, scgún las agrupaciones establecidas en d Análisis de componentes principales. 
efectos de dilución. Estos efectos, se traducen en un dectecimiento sistemático de las concentraciones de todos los elementos, debido a que, en general, los materiales no plásticos, como es la calcita en este caso, tienen unas concentraciones menores en los elementos traza (Taylor y Robinson, 1996, 246). De cualquier modo, no son comunes, en la bibliografia especializada, trabajos que hayan explorado este tipo de efectos de dilución. No obstante, en uno de los más importantes, llevado a cabo a partir de un modelo de simulación matemática, con datos procedentes de Análisis de activación de neutrones (NAA) de arcillas y desgrasantes de una región de Guatemala, se concluye que la adición de calcita causa enriquecimientos en Ca, así como efectos de dilución en la mayoría de los elementos químicos, dependiendo de las características de la calcita y de la cantidad añadida (Neff et al., 1988 b; 1989).

Con el propósito de comprobar cómo se agrupan las muestras que presentan calcita añadida y, en consecuencia, cómo se clasifican los sedimentos arcillosos calcáreos, se realizó un nuevo Análisis cluster y otro Análisis de componentes principales, con los mismos procedimientos que los anteriores, sin tener en cuenta las concentraciones de Ca. En este sentido, era importante contrastar si estas cerámicas se agnupaban entonces al resto de las muestras o si, por el contrario, presentaban características composicionales diferenciadas.

El dendrograma obtenido mediante el Análisis cluster, muestra ahora la existencia de sólo dos agrupaciones (Figura 5.25). Un gran conjunto de muestras, situado a la izquierda del gráfico, que fusiona los grupos anteriores 1 y 3 y, que a su vez, se subdivide en 8 agrupaciones más pequeñas, más otro, que coincide con la agrupación pretérita número 2 . Por lo tanto, en este nuevo análisis, las muestras también se clasifican en 9 agrupaciones, con la presencia de 11 "outliers". Dentro de los 8 subconjuntos del grupo 1-3, es donde se producen algunas variaciones, con respecto al dendrograma generado anteriormente. $E \mathrm{l}$ subconjunto $A$, se agranda de forma considerable, debido a la inclusión de muestras que antes se asociaban a otras agrupaciones. El B, pierde tres individuos, mientras que el $\mathrm{C}$, permanece igual. Asimismo, el subconjunto $\mathrm{D}$, se desprende de la muestra IZA-8, que ahora pasa a ser un "outlier". El E, pierde dos individuos; el $\mathrm{F}$, continúa igual y el G, pierde solamente uno de ellos. Por otra parte, aparece una agrupación nueva, la $\mathrm{H}$, que asocia muestras procedentes de varias de las agrupaciones anteriores. Con respecto a los "outliers", sólo se produce un cambio. La muestra $N-27$, pasa ahora a formar parte del nuevo subconjunto $H$, mientras que la IZA-8, como ya se ha mencionado, aparece, en esta ocasión, como otro "outlier" más.

En la matriz de correlación, obtenida, igualmente, antes de la aplicación del Análisis de componentes principales (Tabla 5.11), se observa que los elementos más correlacionados entre si, son el $\mathrm{Rb}, \mathrm{Al}, \mathrm{Ti}, \mathrm{Cr}, \mathrm{K}, \mathrm{V}$ y Ga, en contraste con el Mn y el As, que apenas se hallan correlacionados con éstos. 
TABLA 5.11. MATRIZ DE CORRELACIÓN OBTENIDA A PARTIR DE LA

TRANSFORMACIÓN LOGARÍTMICA DE LAS CONCENTRACIONES ELEMENTALES DE 135 MUESTRAS EXCLUYENDO EL Ca

\begin{tabular}{c|ccccccccccccccc} 
& $\mathrm{As}$ & $\mathrm{Cr}$ & $\mathrm{Ni}$ & $\mathrm{Rb}$ & $\mathrm{S}$ & $\mathrm{Zn}$ & $\mathrm{Al}$ & $\mathrm{Ba}$ & $\mathrm{K}$ & $\mathrm{Mn}$ & $\mathrm{Ti}$ & $\mathrm{V}$ & $\mathrm{Cu}$ & $\mathrm{Ga}$ & $\mathrm{Y}$ \\
\hline $\mathrm{As}$ & 1.00 & & & & & & & & & & & & & \\
$\mathrm{Cr}$ & 0.06 & 1.00 & & & & & & & & & & & & \\
$\mathrm{Ni}$ & 0.16 & 0.73 & 1.00 & & & & & & & & & & & \\
$\mathrm{Rb}$ & -0.04 & 0.87 & 0.75 & 1.00 & & & & & & & & & & \\
$\mathrm{Sr}$ & 0.03 & 0.52 & 0.41 & 0.54 & 1.00 & & & & & & & & & \\
$\mathrm{Zn}$ & 0.09 & 0.71 & 0.75 & 0.73 & 0.39 & 1.00 & & & & & & & & \\
$\mathrm{Al}$ & 0.09 & 0.89 & 0.70 & 0.90 & 0.56 & 0.70 & 1.00 & & & & & & & \\
$\mathrm{Ba}$ & 0.12 & 0.55 & 0.61 & 0.58 & 0.47 & 0.51 & 0.61 & 1.00 & & & & & & \\
$\mathrm{~K}$ & -0.03 & 0.77 & 0.68 & 0.90 & 0.60 & 0.63 & 0.81 & 0.68 & 1.00 & & & & & \\
$\mathrm{Mn}$ & 0.28 & -0.16 & 0.21 & 0.18 & 0.07 & 0.17 & -0.11 & 0.26 & -0.11 & 1.00 & & & & \\
$\mathrm{Ti}$ & 0.08 & 0.86 & 0.69 & 0.88 & 0.56 & 0.78 & 0.87 & 0.60 & 0.78 & 0.02 & 1.00 & & & \\
$\mathrm{~V}$ & -0.04 & 0.79 & 0.61 & 0.81 & 0.38 & 0.66 & 0.75 & 0.47 & 0.68 & 0.19 & 0.76 & 1.00 & & \\
$\mathrm{Cu}$ & 0.25 & 0.53 & 0.49 & 0.48 & 0.16 & 0.54 & 0.56 & 0.43 & 0.48 & 0.10 & 0.56 & 0.51 & 1.00 & \\
$\mathrm{Ga}$ & 0.08 & 0.81 & 0.59 & 0.83 & 0.41 & 0.66 & 0.85 & 0.47 & 0.75 & -0.19 & 0.80 & 0.77 & 0.71 & 1.00 \\
$\mathrm{Y}$ & 0.03 & 0.75 & 0.70 & 0.78 & 0.45 & 0.69 & 0.78 & 0.58 & 0.66 & -0.03 & 0.79 & 0.69 & 0.44 & 0.66 & 1.00
\end{tabular}

Del mismo modo, esta es la estructura que recoge el Análisis de componentes principales, en el que, los tres primetos componentes, explican el 77,62\% de la variación total de los datos. Con respecto al primer componente, que explica un 59,88\% de la variación, sólo ahora el Mn se correlaciona positivamente con él, mientras que, de manera negativa, lo hacen, básicamente, los mismos elementos que en el análisis antetior. Esto es, Rb, $\mathrm{Al}, \mathrm{Ti}, \mathrm{Cr}$ y $\mathrm{K} \mathrm{En} \mathrm{el}$ segundo componente, con un $10,71 \%$ de la variación de los datos, se observan más diferencias, ya que ahora, en algunos elementos, se han invertido las correlaciones. En esta ocasión, son el $\mathrm{Mn}, \mathrm{As}, \mathrm{Ba}$ y $\mathrm{Cu}$, los elementos que se correlacionan de forma positiva y el V, $\mathrm{Rb}$, Ga y $\mathrm{Cu}$, los que muestran una correlación negativa. Por último, el tercer componente, muy similar al anteriot, aunque ahora el Mn también interviene en la correlación negativa, explica sólo un 7,04 $\%$ de la variación. Los elementos $\mathrm{Cu}, \mathrm{As}, \mathrm{Ga}$ y $\mathrm{V}$, son los que se correlacionan positivamente, en tanto el Sr, Ba y Mn, son los que lo hacen de manera negativa (Figura 5.26).

El cambio principal que presentan los resultados de este nuevo análisis, en relación al anterior, es la fusión de los grupos G-1 y G-3. De esta forma, la totalidad de las muestras, se clasifican ahora sólo en 8 agrupaciones composicionales distintas, con la presencia de 7 "outliers". Los grupos G-2B, G-4B y G-7, no varían. Los restantes, sufren pequeñas modificaciones, al intercambiarse algunas muestras entre ellos. $\mathrm{El}$ grupo $\mathrm{G}-2 \mathrm{~A}$, pierde las muestras PT-1, PT-2 y PT-3 y gana la muestra N-50. Asimismo, al grupo G-4A, se le une la muestra NP-87 que, en el análisis anterior, era un "outlier". Por otro lado, los grupos G-5 y G-6, se intercambian la mucstra N-62. Las muestras consideradas como "outliers", siguen siendo las mismas, salvo en el caso de la NP-87, ahota en el gropo $G-4 A, y$ la $-\mathrm{N}-56$, que pasa a ser un nuevo "outlier". 

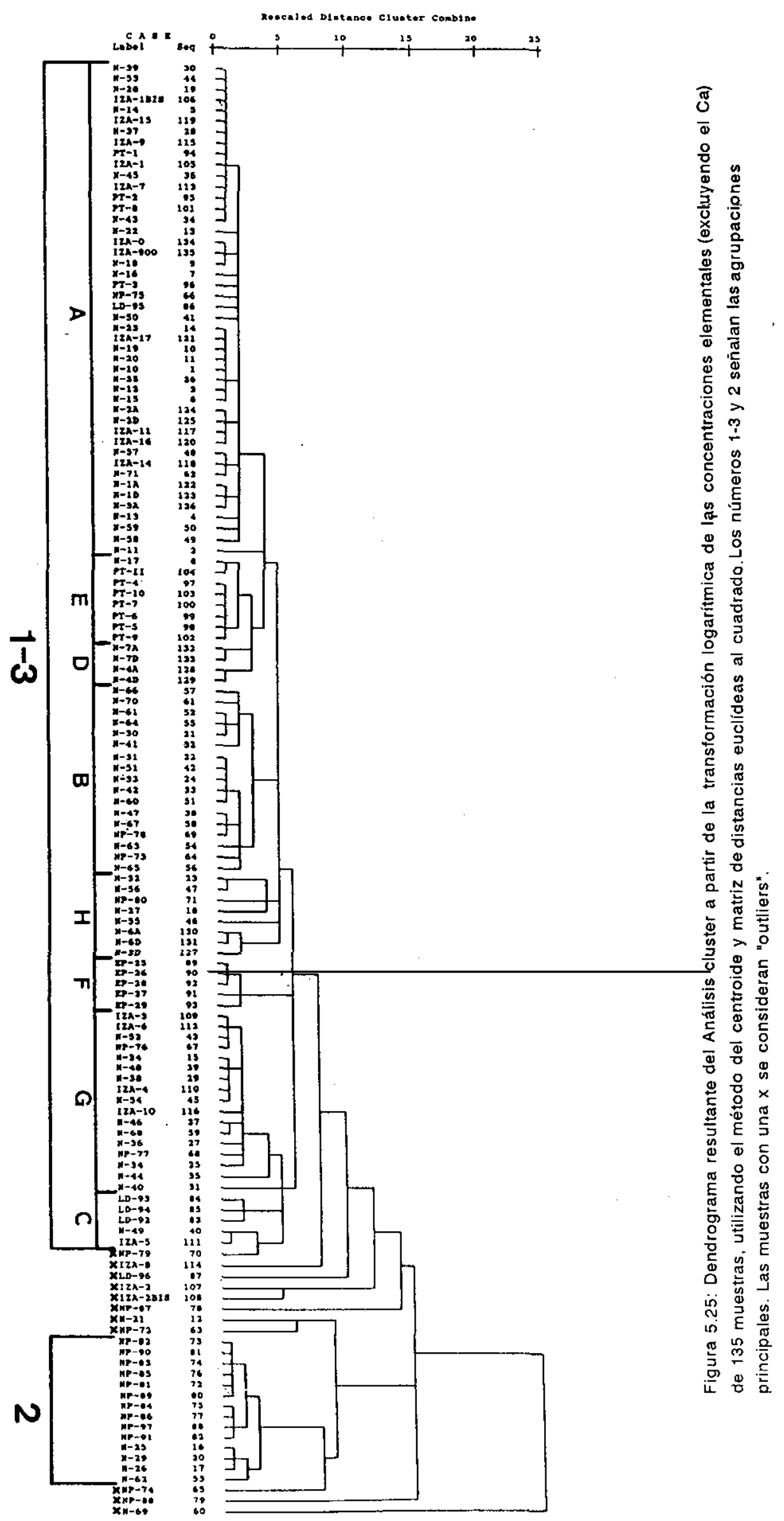


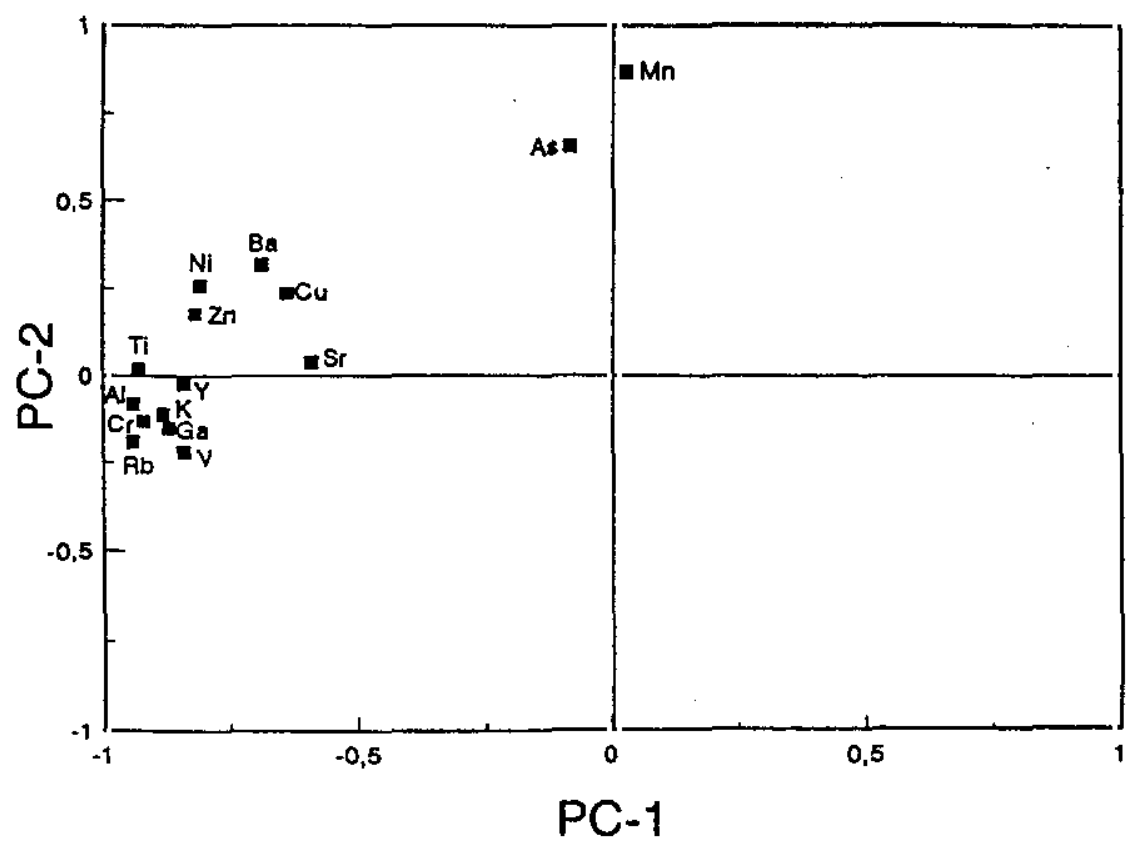

Figura 5.26: Análisis de componentes principales a partir de la transformación logarítmica de las concentraciones elementales de 135 muestras. Representación del peso de las variables (excluyendo el Ca), en los dos primeros componentes.

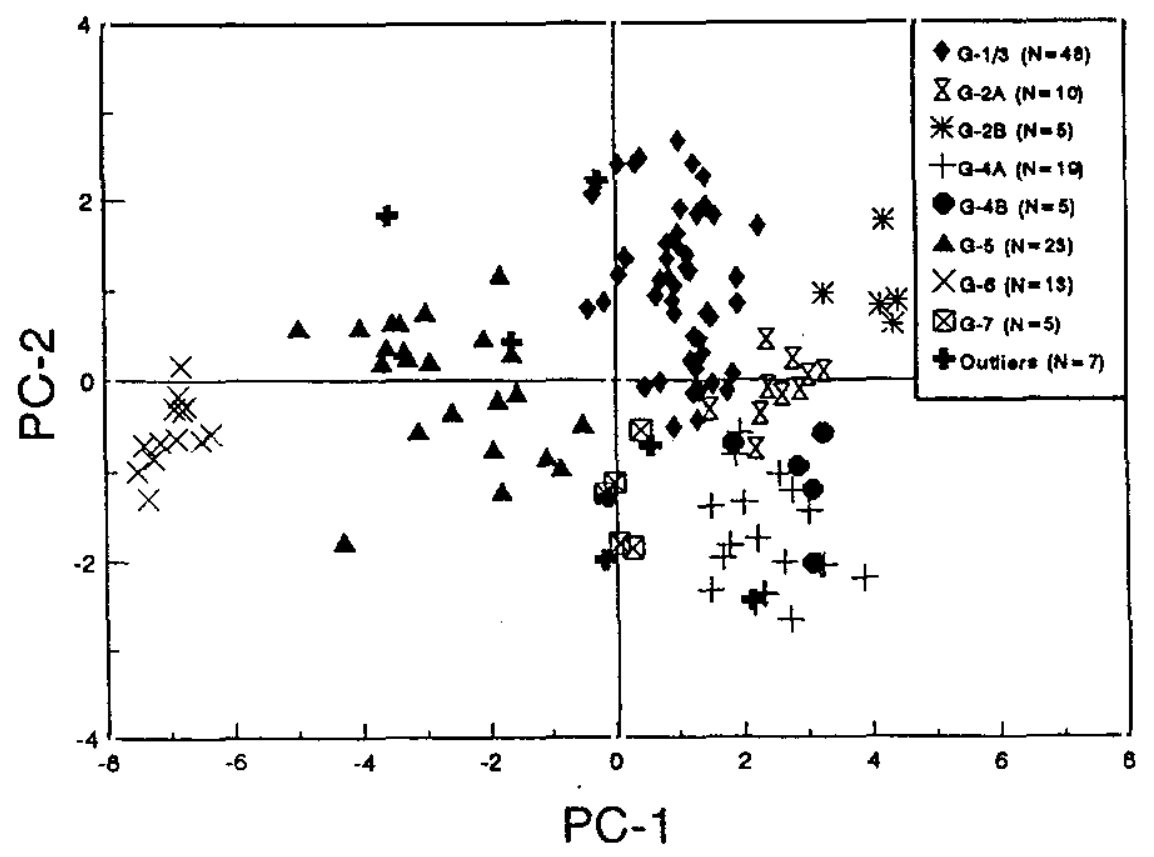

Figura 5.27: Análisis de componentes principales a partir de la transformación logaritmica de las concentraciones elementales (excluyendo d Ca) de 135 muestras. Representación de las muestras y sus agrupaciones, según la puntuación en los dos primeros componentes. 
La agrupación G-1/3 cambia de posición, como consecuencia de la correlación positiva del $\mathrm{Mn}$ con el primer componente, ya que éste es el grupo con una mayor concentración media en este elemento. No obstante, las muestras pertenecientes a esta agrupación, también son puntos bien representados en el segundo componente (Figura 5.27). Excepto en el caso de la muestra N-50, todo el grupo G-3 anterior, ha quedado fusionado al G-1. Esto significa, que las cerámicas que presentaban calcita añadida, se agrupan ahora al resto de las cerámicas de la Fábrica negra que, en el Análisis petrográfico, se clasificaban en el grupo con menor selección de tamaño de grano. Por lo tanto, sin tener en cuenta las concentraciones de $\mathrm{Ca}$, estas muestras presentan más semejanzas entre sí, lo que podría indicar que ambas se manufacturaron con materias primas muy similares. Por otro lado, en esta ocasión, un mayor número de ejemplares cerámicos de todas las fábricas, procedentes, tanto de Numancia, como de Izana, se agrupan junto a los sedimentos arcillosos calcáreos de ambos lugares. Por lo demás, 4 muestras de otras agrupaciones, se han agregado a ésta. La muestra $\mathrm{N}-55$, que anteriormente pertenecía al G-4A y las muestras PT-1, PT-2 y PT-3, pertenecientes al grupo G-2A.

Por último, teniendo en cuenta los resultados globales del análisis estadístico, y considerando que elementos como el $\mathrm{Al}$, el $\mathrm{K}$ y el $\mathrm{Ti}$, pueden ser buenos indicadores del contenido en filosilicatos o minerales arcillosos (Blackman, 1992, 118), entre los grupos G-3, G-4A, G-5 y G-6, puede establecerse una variación progresiva, de menor a mayor, en las concentraciones medias de estos elementos. Así, el grupo G-3, presenta una concentración media en $\mathrm{Al}$, expresada en $\%$ peso versus $\mathrm{Fe}$, de $206,081 \pm 20,275$; de $87,867 \pm 14,204$ de $\mathrm{K}$ y de $11,372 \pm 1,221$ de Ti. El G-4A, de 186,138 $\pm 11,752$ para el Al; de 78,456 $\pm 6,569$ para el $\mathrm{K}$ y de $9,633 \pm 1,234$ para el Ti. El gnupo G-5, de $289,581 \pm 39,255$ para el Al; de 116,161 $\pm 12,595$ para el $\mathrm{K}$ y de 19,769 \pm 4,285 para el Ti; mientras que en el grupo G-6, la concentración media

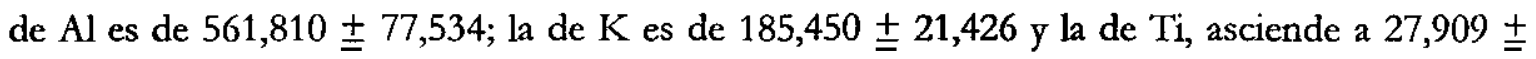
3,105. Asimismo, estos datos se correlacionan con el color que muestran las cetámicas pertenecientes a estas agrupaciones. En este sentido, cuanto menor es la concentración de Al, $K$ y Ti, las cerámicas son más rojizas. Por el contratio, cuanto mayor es la concentración de estos elementos, los ejemplares cerámicos son más ocres. Expresado en ottas palabras, esto significa que las cerámicas de estas agrupaciones, se han elabotado con una gama de materias primas no calcáreas que abarca desde, arcillas ilítico-caoliníticas muy ferruginosas (cerámicas naranjas y rojas), hasta sedimentos con una mayor concentración en minerales arcillosos, como expresan los contenidos de $\mathrm{Al}, \mathrm{K}$ y Ti, del tipo ilita $-\mathrm{K} \mathrm{Al} 4(\mathrm{Si}, \mathrm{Al})_{8} \mathrm{O}_{18} 2 \mathrm{H}_{2} \mathrm{O}-$ y caolinita $-\mathrm{Al}_{4} \mathrm{Si}_{4} \mathrm{O}_{10}$ $(\mathrm{OH})_{8}-$, pero con contenidos menores en Fe (ceramicas ocres). Esta situación, ya quedaba reflejada en el análisis mediante Difracción de rayos $\mathrm{x}$ (XRD), en el que, precisamente, gran parte de las cerámicas que conforman las agrupaciones G-5 y G-6, pertenecían al grupo con mayor presencia de feldespato potásico, relacionable con la variación progresiva en los contenidos de $\mathrm{Al}$ y $\mathrm{K}$. Es por ello, por lo que resulta dificil separar, desde un punto de vista macroscópico, las fábricas 1 y 1-b. Si bien es verdad, la Fábrica 1, tiende a concentrarse en los 
grupos G-3 y G-4A, que se relacionan con cerámicas elaboradas con arcillas más ferruginosas, mientras que, la Fábrica 1-b, tiende a concentrarse en los grupos G-5 y G-6, aquellos a los que se asocian las cerámicas elaboradas con arcillas de menor contenido en Fe.

Aunque, en general, las muestras procedentes de Numancia o Izana, no pueden discriminarse, ni por criterios mineralógicos, ni por criterios composicionales, es importante resaltar, que las muestras de Izana, se concentran sólo en los grupos G-1, G-3 y G-4A, no asociándose nunca al resto de las agrupaciones. Dicho de otro modo, esto refleja que en Izana, en el caso de que se produjese cerámica, ésta no se fabricó con materiales arcillosos de escaso contenido en Fe. Por el contrario, lo que sí queda patente es que las muestras procedentes de Langa de Duero, El Palomar y Pinilla Trasmonte, se discriminan claramente del resto de las cerámicas de Numancia y de Izana.

Otro aspecto que se desprende de estos resultados, es que las cerámicas grises de la Fábrica 2, ya sean de Numancia o Izana, se han elaborado con la misma materia prima que el resto de las cerámicas. De todos modos, en el caso de las procedentes de Numancia, éstas se concentran, mayoritariamente, en el grupo G-5.

Por lo que se refiere a los ejemplares que presentan decoración polícroma, éstos tienden a concentrarse en aquellas agrupaciones menos ferruginosas (grupos G-4A y, sobre todo, G-5 y G-6), en consonancia con los resultados del análisis macroscópico, en los que podía comprobarse que, era en la Fábrica 1-b, donde más predominaban. Por otro lado, en ninguna de las agrupaciones establecidas en el análisis estadístico, se distinguen formas tipológicas determinadas.

En los estudios composicionales de cerámica arqueológica, a veces surgen problemas de diversa índole, para establecer el grado de correspondencia entre los datos procedentes de distintas fuentes de materia prima y los aportados por el análisis de las cerámicas. De tal forma que, ya sea por los procesos de selección o purificación de la materia prima realizados por los alfareros del pasado, por la adición de materiales no plásticos o por las alteraciones sufridas durante el enterramiento, los datos composicionales de las cerámicas no coinciden con los obtenidos en el análisis de sedimentos arcillosos actuales (Bishop et al., 1982; Kilikoglou et al, 1988). Pues bien, este problema es el que presenta el conjunto cerámico procedente de Numancia e Izana, en relación a los sedimentos arcillosos muestreados en los altededores de ambos yacimientos, ya que, en general, ninguno de los grupos composicionales se asocia a estos sedimentos arcillosos. Esto no quiere decir que, en el caso de que se hubiera producido cerámica en Numancia, ésta no se hubiera elaborado con materias primas del entorno más inmediato del asentamiento, sino que se utilizaron sedimentos arcillosos menos calcáreos, aunque, ciertamente muy similares, a los aquí analizados. En última instancia, no puede olvidarse que, variaciones de hasta un $20 \%$, son comunes en el perfil de Ca de muchos depósitos arcillosos (Pradell et al., 1995, 24). 
TABLA 5.12. MUESTRAS ANALIZADAS MEDIANTE MICROSCOPÍA ELECTRÓNICA DE BARRIDO (SEM) Y ENERGĹA DISPERSIVA DE RAYOS X (EDX)

\begin{tabular}{|c|c|c|c|}
\hline MUESTRA & $\begin{array}{l}\text { AGRUPACION } \\
\text { LÁMINA } \\
\text { DELGADA } \\
\end{array}$ & $\begin{array}{c}\text { AGRUPACION } \\
\text { DRX }\end{array}$ & $\begin{array}{l}\text { AGRUPACION } \\
\text { TXRF }\end{array}$ \\
\hline $\mathrm{N}-27$ & Calcárea & MC & Outlier \\
\hline N-62 & $\begin{array}{l}\text { Principal matriz } \\
\text { blanco-amarillenta }\end{array}$ & FKSH & $G-6$ \\
\hline N-70 & $\begin{array}{l}\text { Principal matriz } \\
\text { blanco-amarillenta }\end{array}$ & FKSH & G-5 \\
\hline * NP-74 & Principal matriz roja & $\mathrm{P}$ & $G-5$ \\
\hline * NP-77 & Principal matriz roja & $\mathrm{P}$ & $G-4 A$ \\
\hline *NP.79 & Principal matriz roja & $\mathrm{FK}$ & $\mathrm{G}-4 \mathrm{~A}$ \\
\hline NP-81 & $\begin{array}{l}\text { Principal matriz } \\
\text { blanco-amarillenta }\end{array}$ & $\mathrm{FK}$ & G-6 \\
\hline * NP-84 & $\begin{array}{l}\text { Principal matriz } \\
\text { blanco-amarillenta }\end{array}$ & FKSH & $G-6$ \\
\hline NP-91 & $\begin{array}{l}\text { Principal matriz } \\
\text { blanco-amatillenta }\end{array}$ & FKSH & G-6 \\
\hline
\end{tabular}

En las muestras con un asterisco es en las que se ha realizado el estudio de los pigmentos decorativos.

\subsection{MICROSCOPÍA ELECTRÓNICA DE . BARRIDO (SEM) Y ANÁLISIS MEDIANTE ENERGÍA DISPERSTVA DE RAYOS $X$ (EDX)}

En la Tabla 5.12, se expone una relación de las muestras analizadas a través de esta técnica, tanto para la caracterización de los pigmentos decorativos, como para el examen de las microestructuras. 
FOTO 19.- NP.74. X 200. Detalle del pigmento negro en la superficie extema.

Luz reflejada. Las flechas y la $\mathrm{N}$ señalan la situación del pigmento.

FOTO 20.- NP-77. X 200. Detalle del pigmento blanco en la superficie externa. Luz reflejada.

Las flechas y la B señalan la situación del pigmento.

FO'TO 21.- NP-84. X 100. Detalle de la densificación de la matriz en la superficie externa. Luz reflejada.

FOTO 22.- NP-79. X 12,5. Detalle del pigmento rojo sobre blanco en la superficie extema Nícoles cruzados.

Las flechas, $R$ y $B$ señalan la situación de ambos pigmentos. 


\section{9}

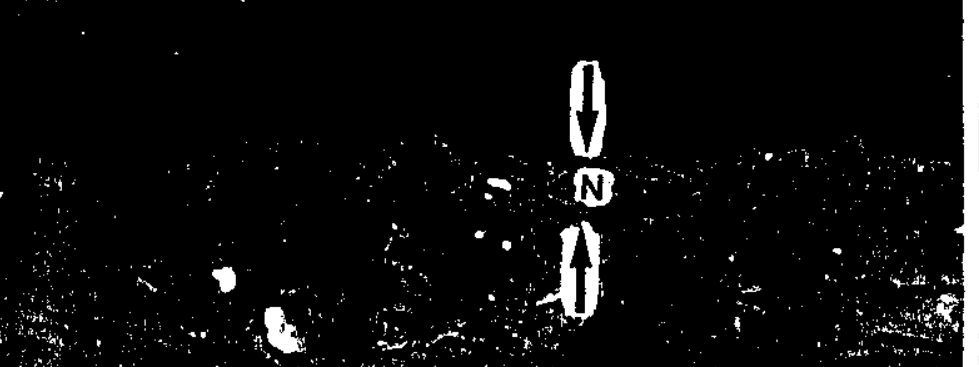

\section{0}
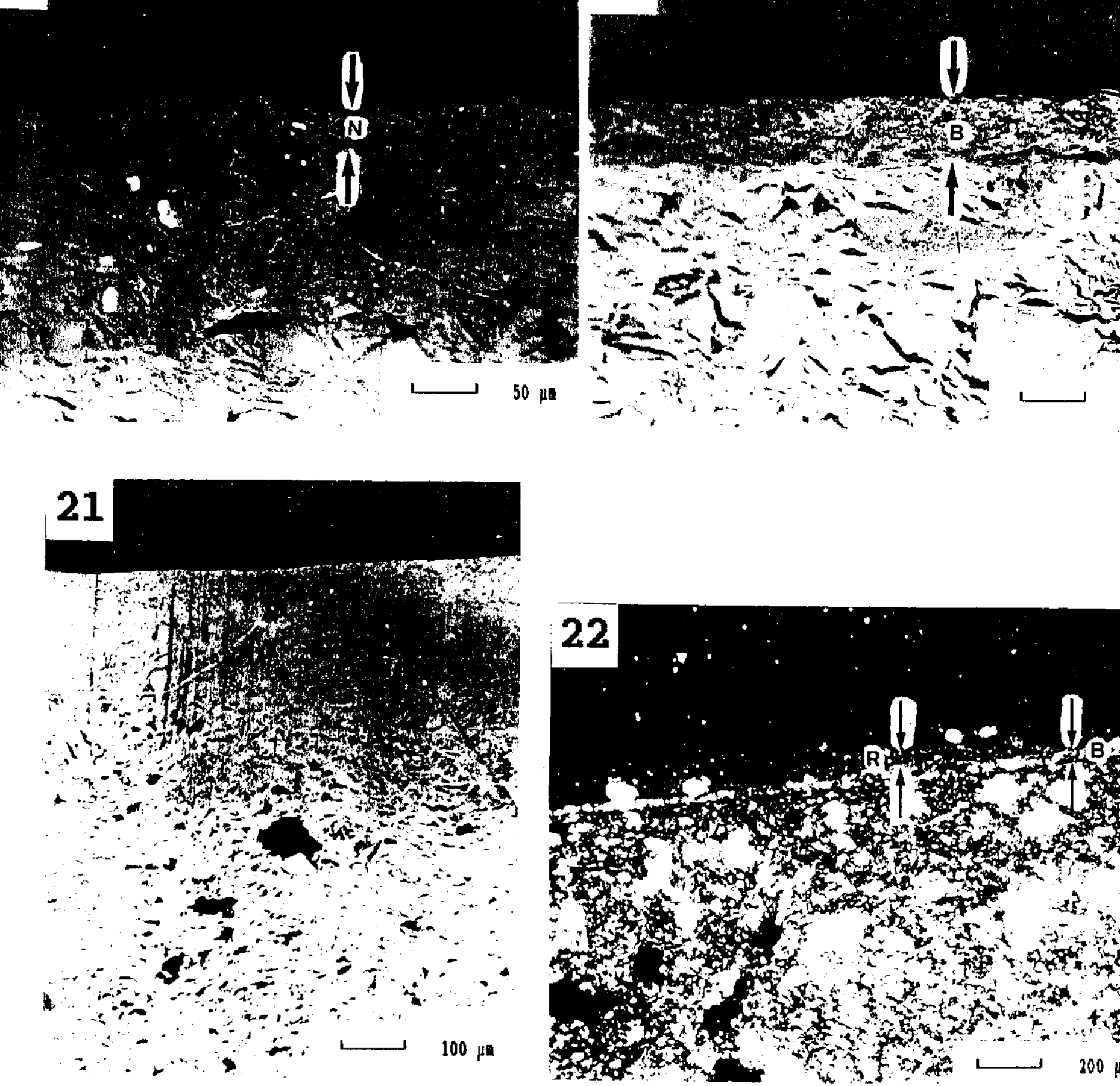

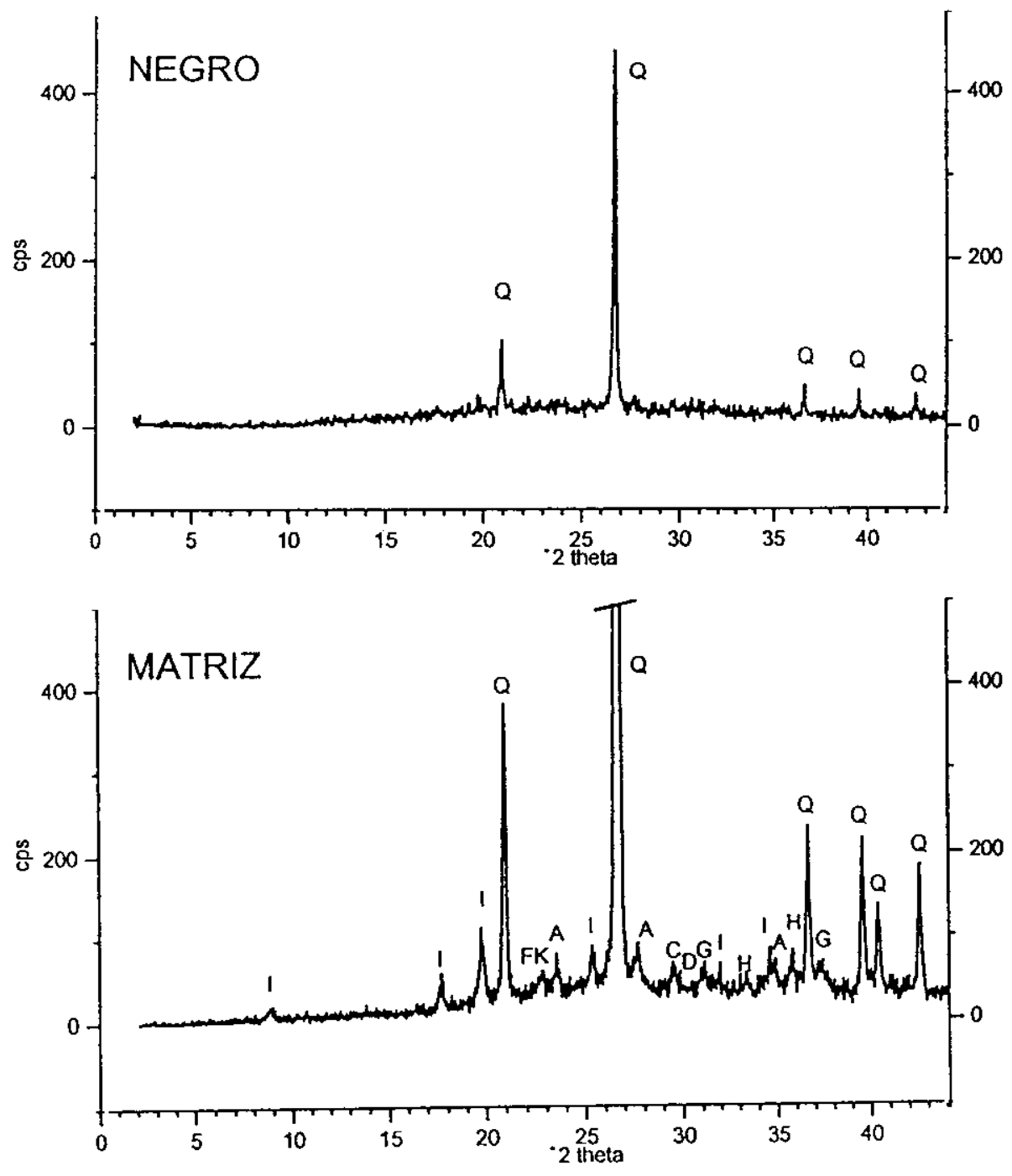

Figura 5.28: Difractograma del pigmento negro obtenido por raspado, de la muestra NP.74. En la parte de abajo, de forma comparativa, se ofrece el difractograma obtenido en el análisis de la matriz de esta misma muestra.

\subsubsection{Pigmentos decorativos}

En primer lugat, como se indicaba en el capítulo 4, se han seleccionado los campos de observación y las áreas de interfase matriz/pigmento, mediante Microscopía óptica de luz reflejada. De esta forma, se determinaron los grosores de los distintos pigmentos. A modo de ejemplo, la microfotografía número 19 , recoge un área del pigmento negro de la muestra NP-74, con un grosor de unos $60 \mathrm{~mm}$ y la número 20 , un área del pigmento blanco de la muestra NP-77, cuyo grosor se aproxima a los $100 \mathrm{~mm}$. En estas microfótografías, los poros se presentan en tonalidades oscuras, mientras que los puntos blancos son óxidos de $\mathrm{Fe}$ o de Ti. Por el 

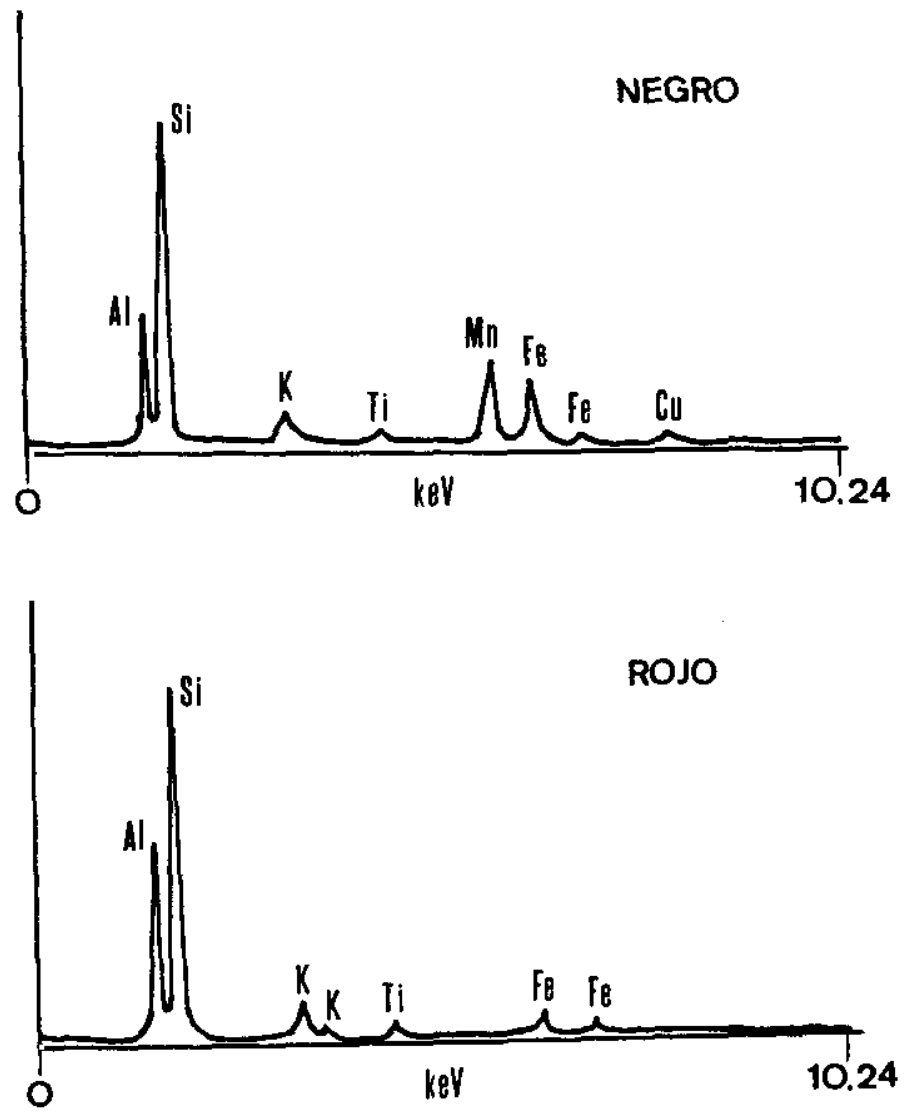

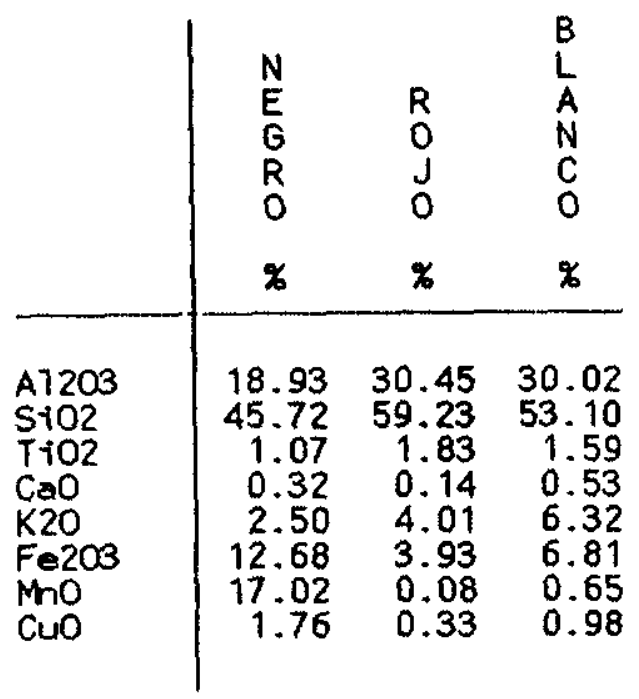

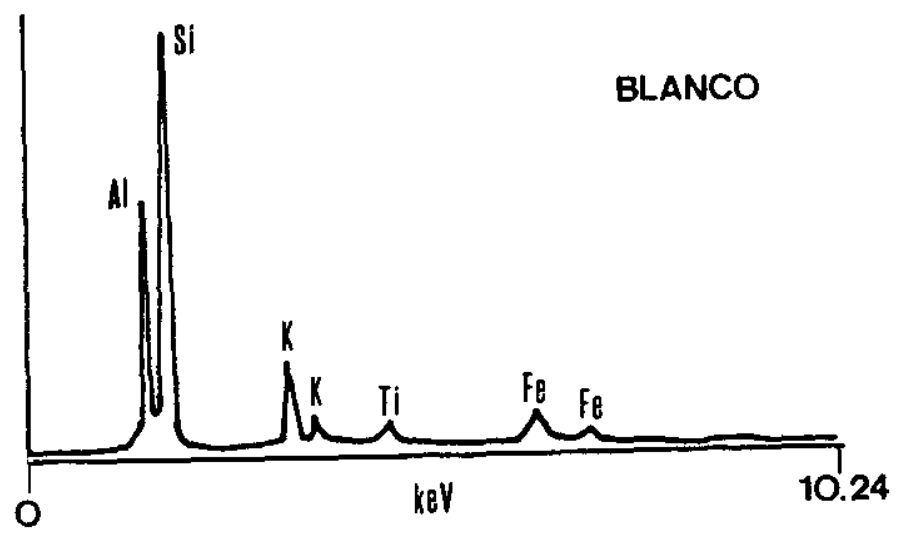

Figura 5.29: Lispectros y resultados promedio del microanálisis mediante Lncrgía dispersiva de rayos $\mathrm{x}$ (WDX), cfectuado sobre particulas obtenidas por raspado, de los pigmentos negro, rojo y blanco, de la muestra NP-79. 

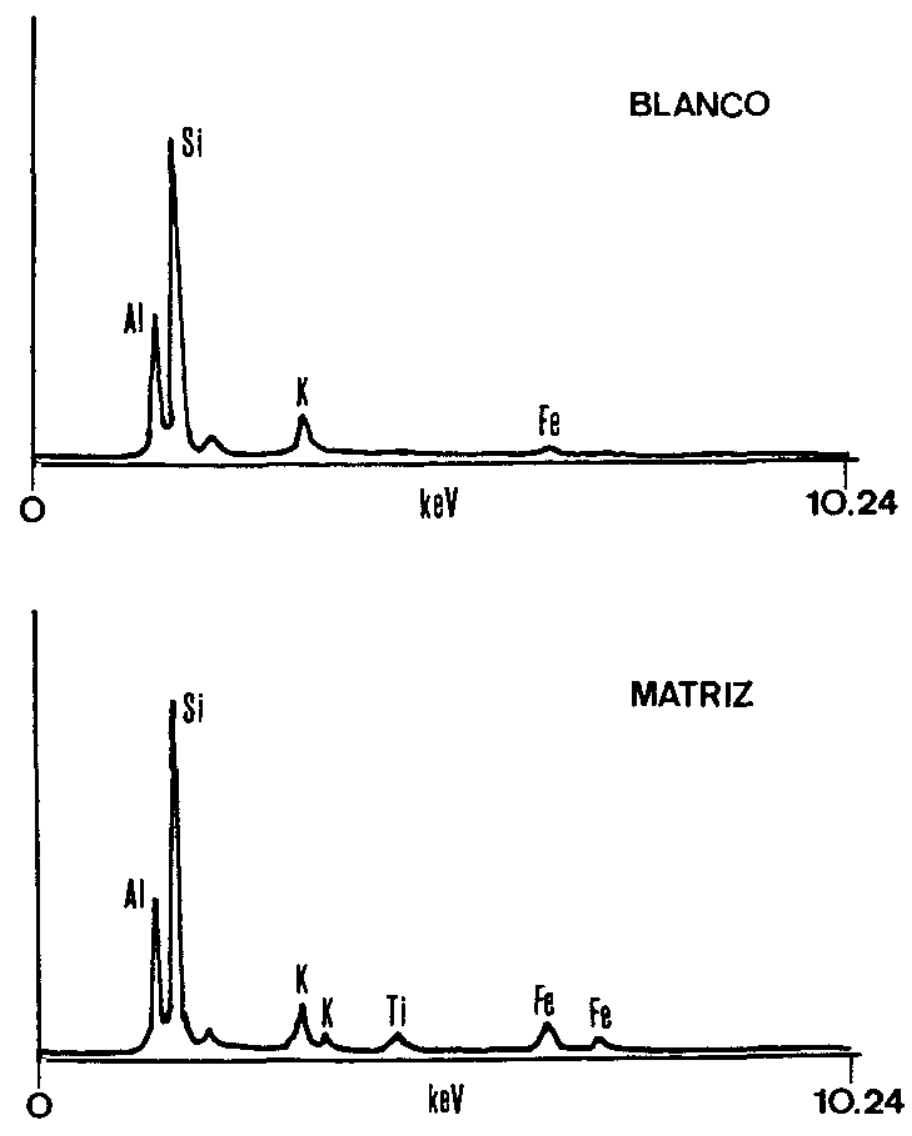

\begin{tabular}{|c|c|c|}
\hline & $\begin{array}{l}B \\
L \\
A \\
N \\
C \\
0\end{array}$ & $\begin{array}{l}M \\
A \\
T \\
R \\
I \\
Z\end{array}$ \\
\hline & $\mathbf{x}$ & $x$ \\
\hline $\begin{array}{l}\text { A } 1203 \\
\text { SiO2 } \\
\text { TiO2 } \\
\text { CaO } \\
\text { K2O } \\
\text { Fe203 }\end{array}$ & $\begin{array}{r}27.88 \\
63.57 \\
0.45 \\
5.26 \\
2.84\end{array}$ & $\begin{array}{r}23.77 \\
58.71 \\
3.22 \\
0.37 \\
4.26 \\
9.67\end{array}$ \\
\hline
\end{tabular}

Figura 5.30: Espectros y resultados promedio del microanálisis mediante Energía dispersiva de rayos $\mathrm{x}$ (EDX), efectuado en la matriz y el pigmento blanco de la muestra NP-77.

contrario, en los pigmentos rojos, no se puede llegar a medir con exactitud, debido al escaso grosor que presentan. Asimismo, en la muestra NP-84 (Foto 21), se observa una mayor densificación de la matriz en superficie, que puede ser originada por el alisado extemo al que se someten las piezas cerámicas, durante el proceso de modelado en el torno.

Antes de llevar a cabo el análisis mediante Microscopía electrónica, se realizó una identificación cualitativa de cada uno de los pigmentos, con el fin de averiguar qué elementos químicos debían buscarse, a través del espectrómetro de Energía dispersiva de rayos $\mathrm{x}$ (EDX), como característicos de cada uno de ellos. En un principio, y en función de los datos que aportaban el trabajo de Taracena (1924) y unas pruebas experimentales realizadas en la Memoria de Licenciatura (García Hetas, 1993 a), podía preveerse que, al menos, el pigmento negro, estaba constituido por algún tipo de óxido de Fe. El trabajo de Taracena, recogía los resultados de los análisis efectuados por vía seca y por via húmeda en este pigmento, los cuales indicaban que podía haberse obtenido empleando limonita $\left(\mathrm{Fe}_{2} \mathrm{HO}_{3}\right)$, un gel de $\mathrm{Fe}$ que se origina en condiciones oxidantes, por meteorización superficial, a partir de sulfuros de Fe como la pirita $\left(\mathrm{S}_{3}\right.$ $\mathrm{Fe}$ ). Estos datos, fueron verificados en la Memoria de Licenciatura, en la que se experimentó en 
el laboratorio con este tipo de materiales, sobre probetas elaboradas con el sedimento arcilloso procedente de Izana. En aquella ocasión, se pudo comprobar que, efectivamente, con la utilización de limonita, se obtenían pigmentos con coloraciones similates, al cocer las probetas por encima de $700^{\circ} \mathrm{C}$ (García Heras, 1993 a, 61-62).

La identificación cualitativa a la que se ha aludido, se llevó a cabo raspando los pigmentos directamente de los fragmentos cerámicos y analizándolos primero en polvo, mediante Difracción de rayos $\mathrm{x}$ (XRD) y después, montados en un portamuestras y recubiertos de capa conductora, mediante Energía dispersiva de rayos $\mathrm{x}(\mathrm{EDX})$.

A través de los difractogramas obtenidos, se comprobó que el análisis mediante Difracción, no era viable para realizar esta identificación, debido a que no se conseguía suficiente resolución. El raspado también desprendia partículas de la matriz, por lo que, finalmente, sólo se conseguían detectar las reflexiones características del cuarzo, fase predominante en este tipo de matrices, como se ha tenido oportunidad de comprobar en el apartado que recogíalos resultados de los análisis por medio de Difracción de tayos x (XRD).

Sin embargo, y a pesar de que el microanálisis con Energía dispersiva de rayos $\mathrm{x}$ (EDX), también reflejaba parte de los componentes de la matriz, en la muestra NP-79 (Figura 5.29), se observó que el pigmento negto tenía una importante cantidad de $\mathrm{MnO}(17,02 \%)$, que no podía proceder por entero de la matriz, puesto que en el análisis químico mediante TXRF, esta muestra ofrecía tan sólo un $0,159 \%$ en peso versus Fe de este elemento. No obstante, el pigmento negro, también presentaba una concentración notable de $\mathrm{Fe}_{2} \mathrm{O}_{3}$.

Por otro lado, los pigmentos rojo y blanco, eran más dificiles de identificar. En el caso del rojo (Figura 5.29), porque las concentraciones de $\mathrm{Al}_{2} \mathrm{O}_{3}, \mathrm{SiO}_{2}, \mathrm{TiO}_{2}, \mathrm{~K}_{2} \mathrm{O}$ y $\mathrm{Fe}_{2} \mathrm{O}_{3}$, podían considerarse como caracteristicas de la matriz, por lo que era complicado determinar en qué grado formaban parte del pigmento, aunque, dada esta composición, podría tratarse de un material obtenido a partir de la fracción más fina de una arcilla ferruginosa. El pigmento blanco, ptesentaba contenidos similares al rojo en $\mathrm{Al}_{2} \mathrm{O}_{3}$ y $\mathrm{SiO}_{2}$, pero mayores en $\mathrm{K}_{2} \mathrm{O}$, lo cual parecía indicar que se había utilizado un material rico en minerales arcillosos, quizás, de naturaleza caolinítica. De todas formas, la separación de ambos pigmentos por raspado, resultó ptoblemática, ya que el rojo suele aparecer superpuesto al blanco, como puede observarse en la microfotografia 22 del final de este trabajo. Este aspecto, ya lo ponía de manifiesto Romero Carnicero en su estudio estilistico de las cerámicas polícromas numantinas, en el que planteaba que el pigmento rojo se aplicaba muy diluido sobre fondos realizados con pigmentos blancos, sirviendo así para trazar siluetas y motivos geométricos sobre dichos fondos (Romero Carnicero, $1976,168)$.

Finalmente, a la vista de estos resultados, los análisis del pigmento negro se centraron en la localización de $\mathrm{MnO}$, los del pigmento tojo en la localización de $\mathrm{Fe}_{2} \mathrm{O}_{3}$, mientras que, para el pigmento blanco, se optó por buscar altas concentraciones de $\mathrm{Al}_{2} \mathrm{O}_{3}, \mathrm{SiO}_{2}$ y $\mathrm{K}_{2} \mathrm{O}$. En estos análisis, se trabajó, fundamentalmente, con líneas o perfiles de EDX centrados en estos óxidos, 
FOTO 23-- NP-84. X 5.000. Perfil EDX de Mn sobre pigmento negro en la superficie externa. SEM. Las flechas y la $N$ señalan la situación del pigmento.

FOTO 24.- NP-77. X 500. "Mapping" de Mn sobre pigmento negro de la zona de la Foto 25. SEM. FOTO 25.- NP-77. X 500. Detalle del pigmento negro sobre el blanco en la superficie externa SEM. Las flechas, asi como la $N$ y la $B$ señalan la situación de ambos pigmentos.

FOTO 26.- NP-84. X 5.000. Perfil EDX de Fe sobre pigmento rojo de la superficie externa. SEM. Las flechas y la R señalan la situación del pigmento.

FOTO 27,- NP-84. X 2.000. Perfil EDX de Fe sobre pigmento rojo de la superficie en otra zona distinta a la de la Foto 26. SEM. Las flechas y la $\mathrm{R}$ señalan la situación del pigmento 


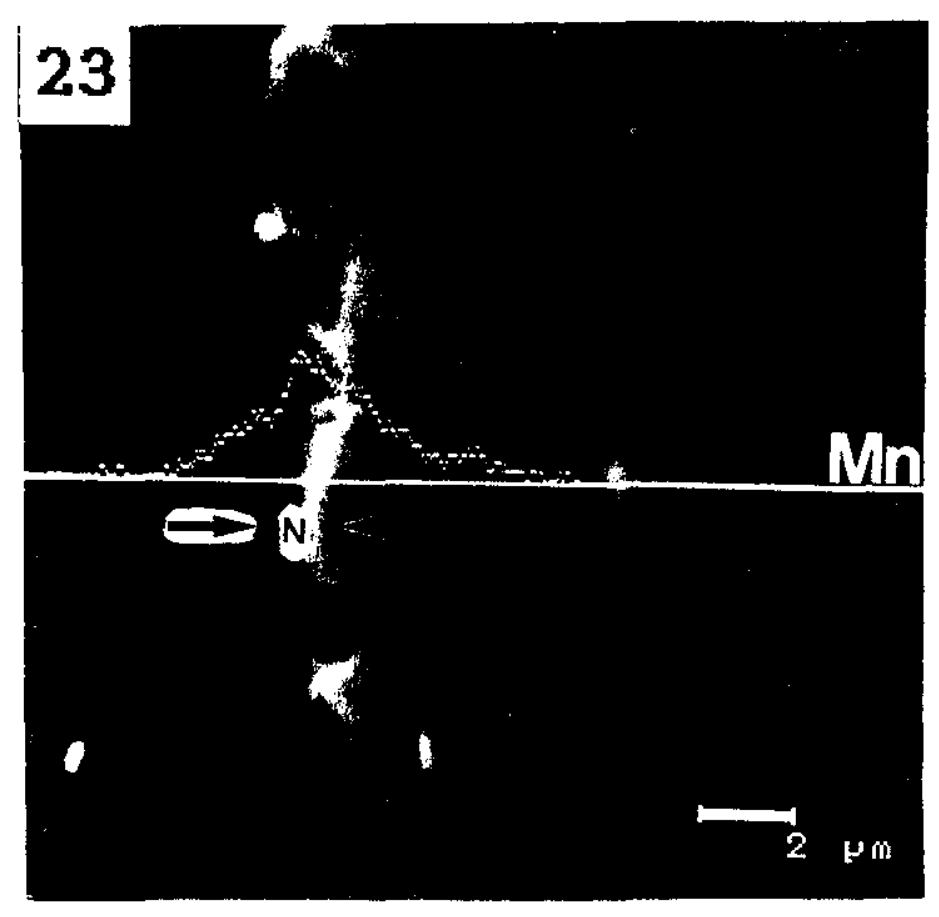

\section{4}

Mn

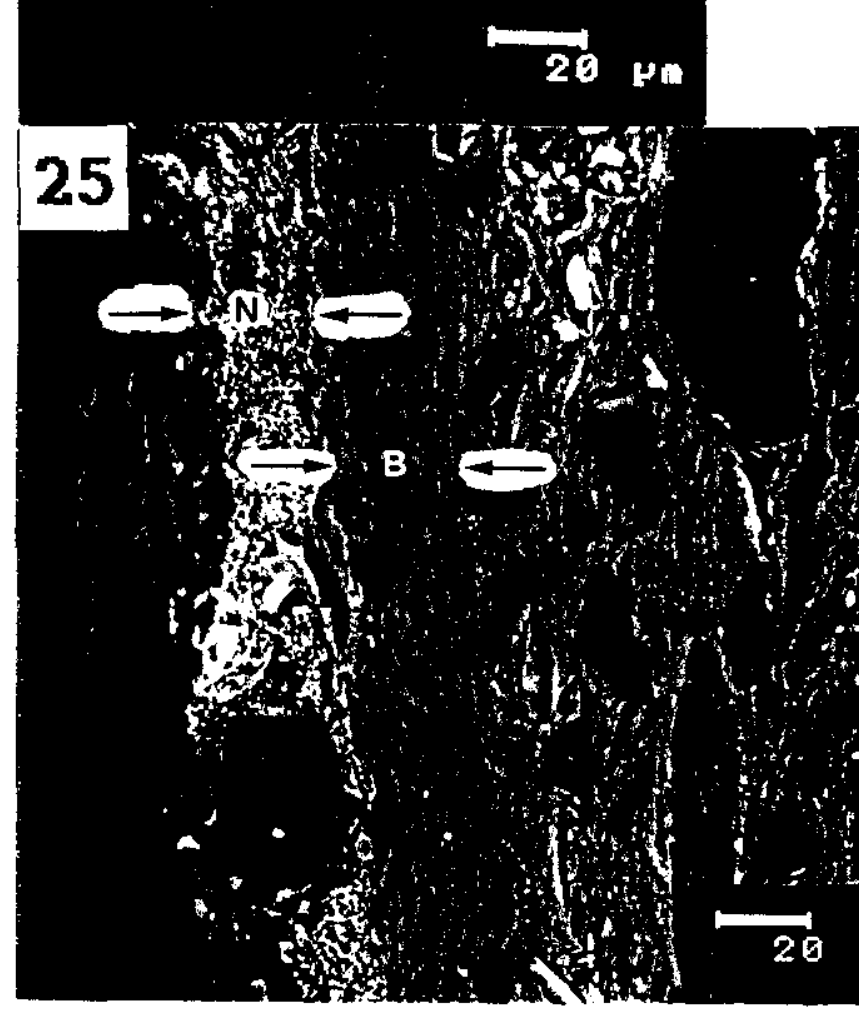

\section{6}

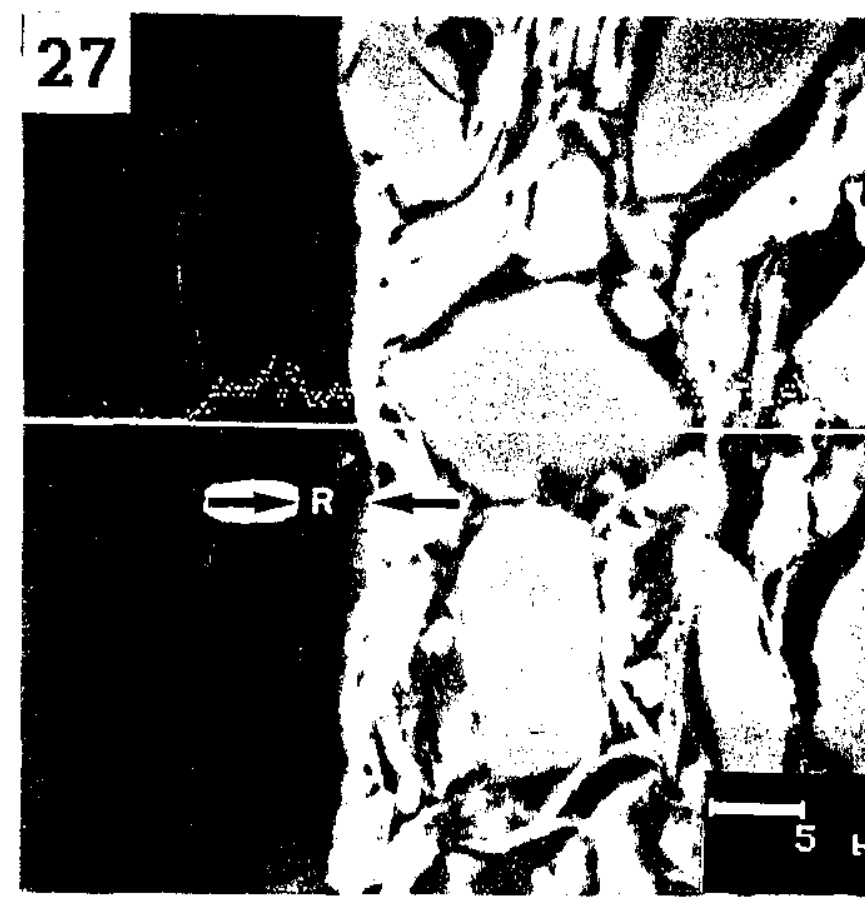


así como con la técnica de "mapping", en las zonas previamente seleccionadas a través de Microscopia óptica de luz reflejada. En total, se seleccionaron 10 zonas pertenecientes a 4 muestras distintas (ver Tabla 5.12): 4 de pigmento negro, 3 de pigmento rojo y otras 3 de pigmento blanco.

En general, en las zonas de pigmento negro, el contacto de la interfase matriz/pigmento, no está claramente limitado, ya que ha habido difusión del pigmento en la matriz, como puede observarse por el decrecimiento que presenta el perfil de Mn en la microfotografia 23. No obstante, la concentración de $\mathrm{Mn}$ que aparece después, ya en la matriz, es prácticamente insignificante. En esta microfotografia, la zona oscura que aparece a la izquierda del pigmento, es el relieve producido en el embutido de la muestra.

El pigmento blanco, siempre se detecta por debajo del negro o del rojo (Fotos 22 y 25). En la microfotografia 25, se observa una buena delimitación de las fases de pigmento negro, blanco y de la matriz, aspecto que también puede seguirse en la microfotografia del "mapping" de $\mathrm{Mn}$ (Foto 24), para esta misma zona. Cada una de las fases, muestra una macroporosidad y una microestructura distintas. En los espectros adquiridos en la matriz y el pigmento blanco de este área (Figura 5.30), se aprecia, por un lado, una mayor concentración de $\mathrm{Al}_{2} \mathrm{O}_{3}, \mathrm{SiO}_{2}$ y $\mathrm{K}_{2} \mathrm{O}$ y, por otro, una menor proporción de $\mathrm{Fe}_{2} \mathrm{O}_{3}$, en la segunda de estas fases.

Las microfotografias 26 y 27 , recogen distintas zonas de pigmento rojo. En ellas, puede observarse que este pigmento presenta una microestructura más vitrificada $y$, por tanto, con menor microporosidad, que la matriz. Al igual que en la microfotografia 23 , las zonas más oscuras situadas a la izquierda del pigmento, también se corresponden con el relieve producido en el embutido de las muestras. En estos casos, los perfiles de Fe, tienen una menor definición que los obtenidos para el $\mathrm{Mn}$, debido a la presencia de $\mathrm{Fe}_{2} \mathrm{O}_{3}$ también en la matriz. En cualquier caso, nunca se ha identificado $\mathrm{MnO}$ en los pigmentos rojos. Por el contratio, en los de color negro, siempre se identifica una pequeña cantidad de $\mathrm{Fe}_{2} \mathrm{O}_{3}$.

En resumen, y a pesar del corto número de muestras que se han analizado, puede concluirse que, los pigmentos negros, están compuestos mayoritariamente por $\mathrm{MnO}$, no presentando, en ninguno de los casos analizados, cantidades importantes de $\mathrm{Fe}_{2} \mathrm{O}_{3}$. Por tanto, estos resultados entran en contradicción con los mencionados en el trabajo de Taracena (1924), en el que se argumentaba que estaban constituidos por óxidos de Fe, procedentes de la utilización de limonita en șu preparación. Asimismo, los pigmentos blancos, debido a las altas concentraciones de $\mathrm{Al}_{2} \mathrm{O}_{3}, \mathrm{SiO}_{2}$ y $\mathrm{K}_{2} \mathrm{O}$ que presentan, pueden ponerse en relación con la utilización de una arcilla, probablemente caolinitica, ya que la presencia de $\mathrm{Fe}_{2} \mathrm{O}_{3}$, nunca es importante. Por otro lado, los pigmentos rojos, que, en general, aparecen vitrificados, podrian proceder de la fracción más fina de una arcilla rica en $\mathrm{Fe}_{2} \mathrm{O}_{3}$. En todo caso, todos se aplican antes de la cocción (pigmentos postcocción apenas son conocidos en la prehistoria europea), aunque se desconoce si, en esta aplicación, se utilizó algún vehículo adherente de carácter orgánico. La presencia, no obstante, de fenómenos de difusión en los pigmentos negros, hace 
pensar que éstos pudieron aplicarse diluidos en un mayot o menor grado. A veces, incluso, este mayor o menor grado de dilución, produce efectos de bicromía, al jugar con la distinta intensidad del color que ofrece el pigmento. Es por ello, por lo que, en algunas ocasiones es posible, mediante lupa binocular, observar los trazos dejados por el útil empleado en su aplicación.

\subsubsection{Microestructuras}

La microestructura de cualquier material cerámico, está determinada por la selección y el procesado de las materias primas utilizadas en su manufactura, asi como por las condiciones y temperaturas de la cocción (Kingery, 1987, 99; Kingery et al., 1976, 516). De esta forma, algunos de los procesos que tienen lugar a lo largo de la secuencia de producción, pueden inferirse a partir del estudio de las microestructuras.

Como ya se mencionaba en el capítulo 4, en esta investigación sólo se han observado 9 muestras cerámicas (Tabla 5.12) debido, tanto a problemas de acceso a los microscopios, como al elevado coste al que ha habido que enfrentarse para su utilización. En este sentido, hubiera sido interesante también, observar los cambios microestructurales acaecidos en la recocción experimental de las 4 muestras cerámicas que se exponen en el apartado 5.4 .4 de este mismo capítulo, ya que estos datos hubieran servido de apoyo al establecimiento de las temperaturas de cocción equivalente, que allí se tealizaba.

En las muestras N-62, N-70, NP-74, NP-79, NP-81, NP-84 y NP-91 (Tabla 5.12), se observa una microestructura laminat que puede relacionarse con un alto contenido en minerales micáceos del grupo de la ilita (Fotos 28,31 y 33). No obstante, en distintas partes de las muestras NP-74 y NP-91, también se identifican paquetes de caolín que todavía conservan su estructura cristalina (Fotos 29 y 30). Estas muestras, pertenecen a las agtupaciones composicionales G-5 y G-6, agrupaciones que presentaban el mayor contenido en minetales arcillosos de todas las establecidas en el análisis estadístico. Estos minerales arcillosos, todavía no han sido destruidos, lo cual confirma los datos obtenidos, a través de la Difracción de rayos $\mathrm{x}$ (XRD), respecto a su temperatura de cocción equivalente, que se establecía entre $800^{\circ}$ y $900^{\circ} \mathrm{C}$, en concordancia con un estado de sinterizado de no vitrificación. Por este motivo, las reflexiones de la ilita y los filosilicatos aún están presentes en los difractogramas, puesto que la estructura de la ilita se mantiene por encima de $\operatorname{los} 850^{\circ} \mathrm{C}$ (Maggetti, 1982, 127; Linares et al., 1983). Sin embargo, se detectan paquetes de caolín a esta temperatura, a pesar de que éste sufre una transformación estructural a $550^{\circ} \mathrm{C}$, para convertirse en la fase amorfa metacaolín. Aunque no se detecta caolinita en los difractogramas de estas muestras, su presencia puede deberse a una elevación rápida de la temperatura, que no haya permitido la completa desestructuración de toda la caolinita presente en las muestras. Por otro lado, en las muestras grises N-62 y N-70 de la 
FOTO 28.- NP-79. X 500. Microestructura laminar. SEM.

FOTO 29.- NP-91. X 10.000. Detalle de un paquete de caolin. SEM

FOTO 30.- NP-74. X 6.104. Detalle de un paquete de caolin. SEM.

FOTO 31. NP-79. X 5.000. Microestruchura laminar. Detalle de minerales del grupo de la ilita. SEM. FOTO 32.- NP.77. X 10.000. Microestructura de fase de vitrificación inicial. SEM.

FOTO 33. N-70. X 5.000. Microestructura laminar. SEM. 

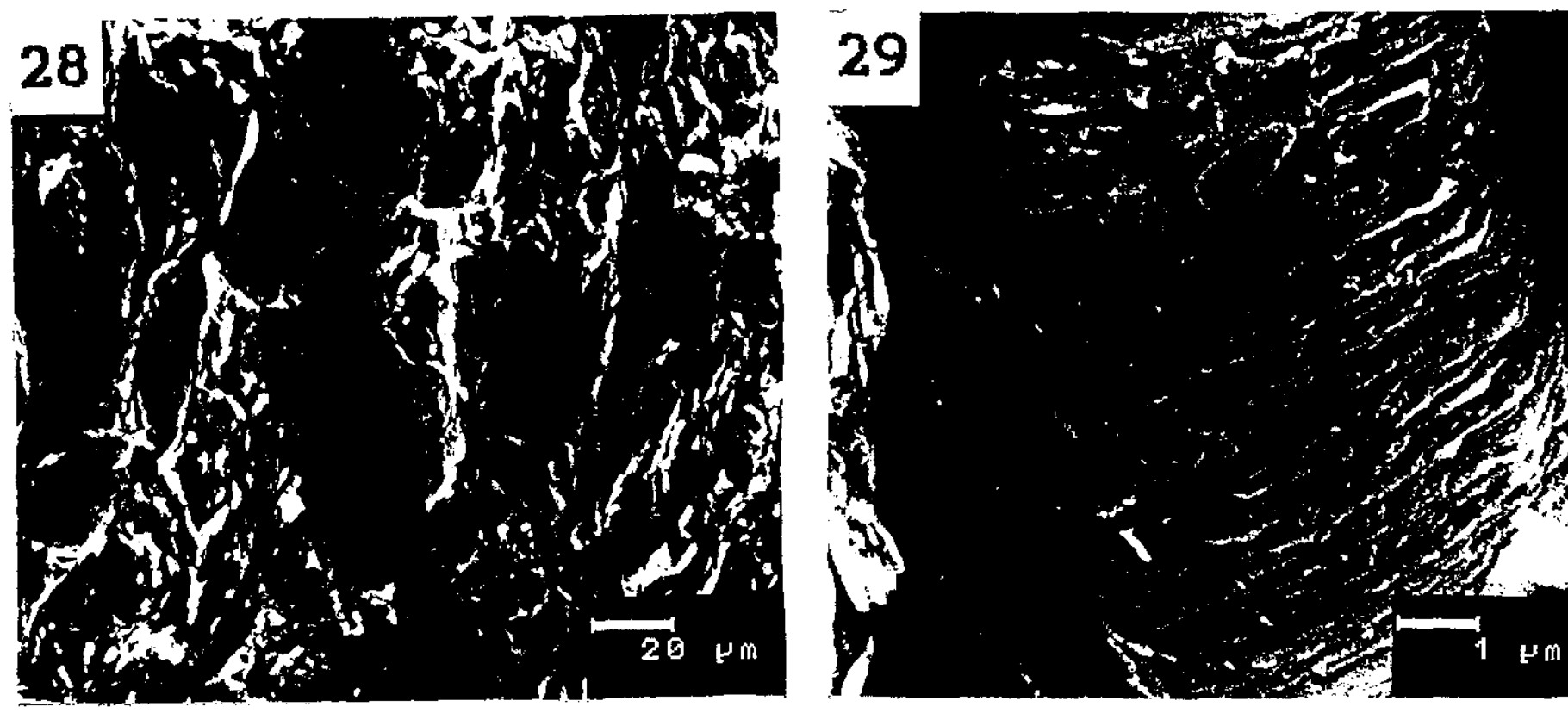

30 箦

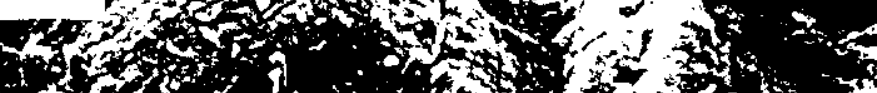
403 r tosis

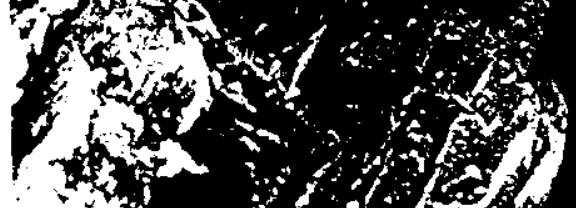

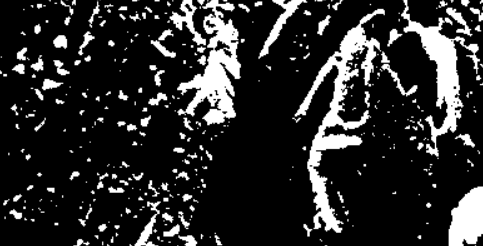

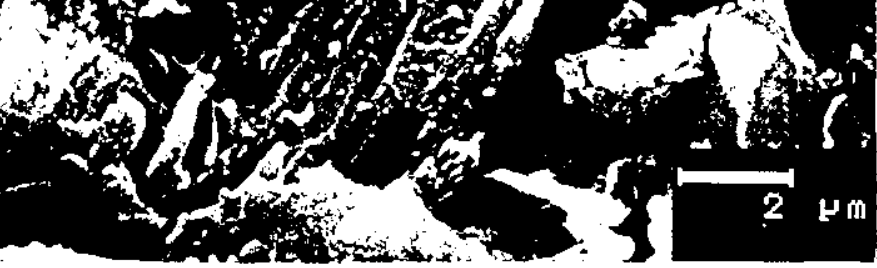

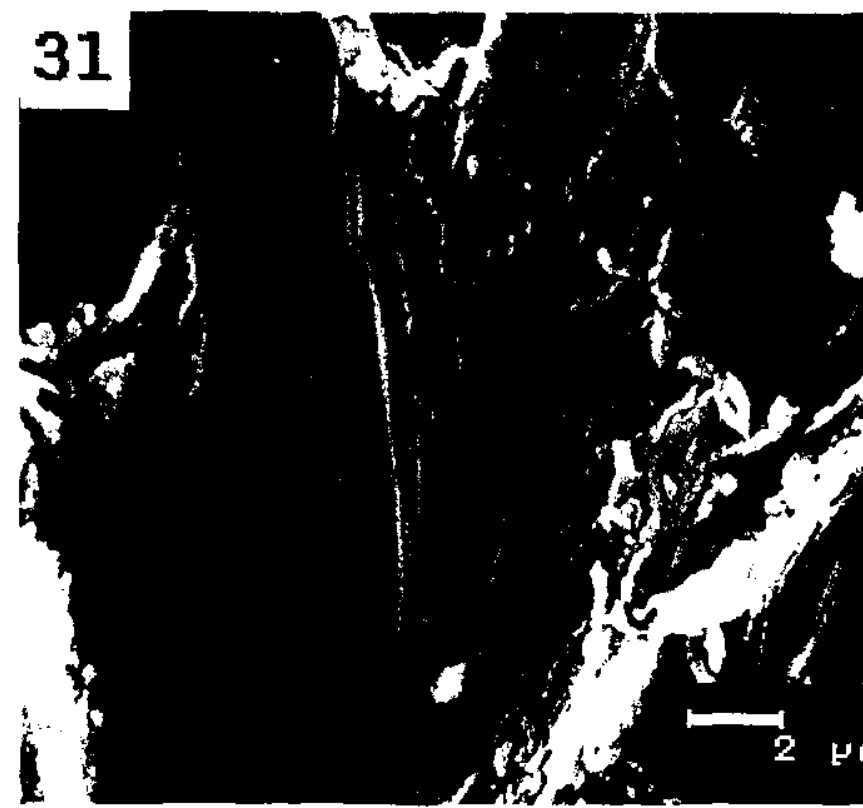

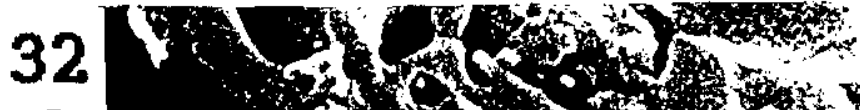
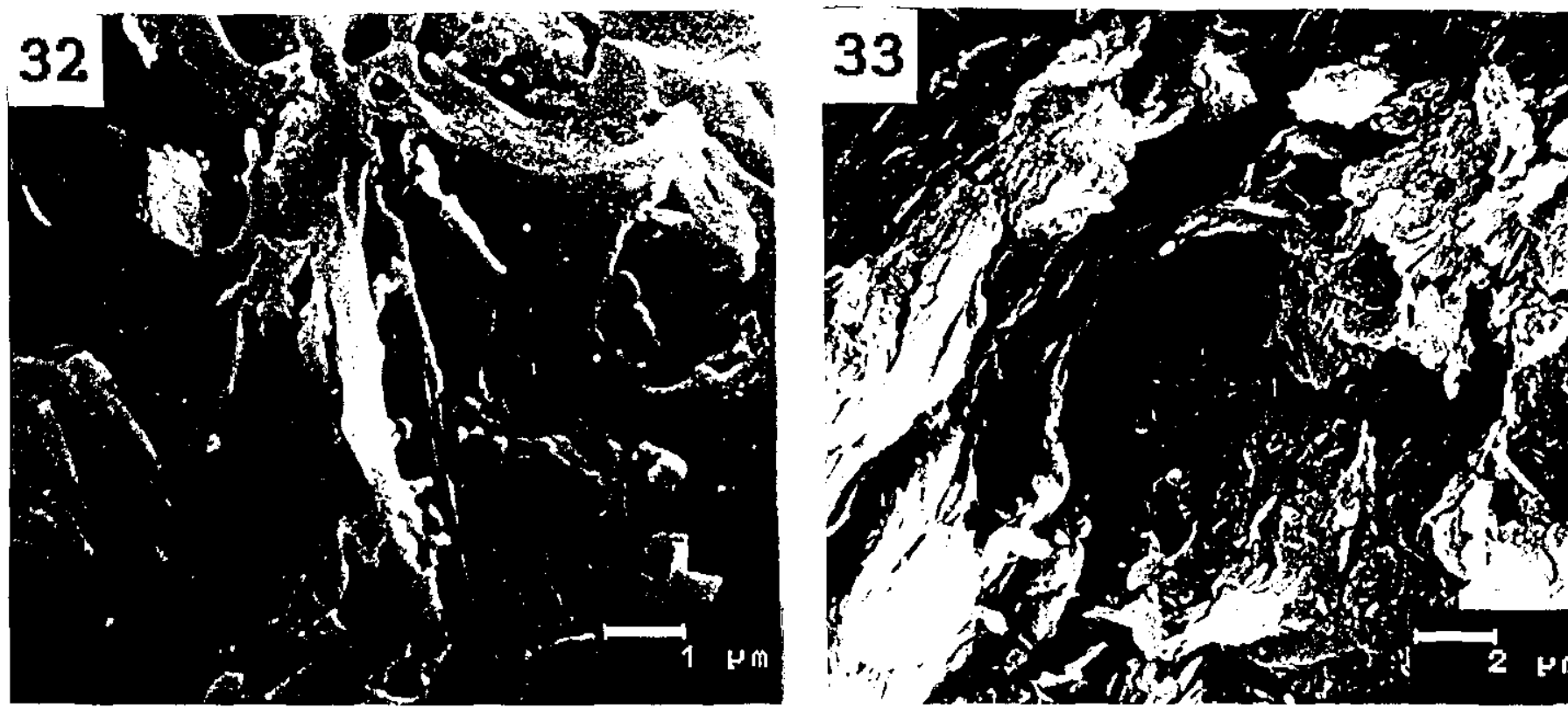
Fábrica 2, se observa la misma microestructura, relacionada con un estado de sinterizado de no vitrificación, lo cual indica que, el ciclo reductor, ha sido un proceso corto, que no ha dado lugat al desarrollo de las microestructuras típicas de cocciones reductoras.

El ejemplar NP-77, perteneciente a la agrupación composicional G-4A (Tabla 5.12), muestra una microestructura relacionada con un estado de sinterizado de inicio de vitrificación (Foto 32), en la que aparece una menor microporosidad, por el sellado de las laminillas de arcilla. Este hecho, se correlaciona con los datos obtenidos a través de Difracción, en donde la escasez de reflexiones correspondientes a la ilita y los filosilicatos, se ponía en relación con una temperatura de cocción equivalente superior a $\operatorname{los} 900^{\circ} \mathrm{C}$.

La muestra calcárea $\mathrm{N}-27$, no recogida en las microfotografías, es la única que presenta la típica microestructura de vitrificación celular, con poros pequeños interconectados, producto de la expulsión del $\mathrm{CO}_{2}$ procedente de la disociación de la calcita. Esta microestructura, se correlaciona con los datos petrográficos, ya que, a través de la lámina delgada, también se observaba un estado de sinterizado de inicio de vitrificación, así como con los datos obtenidos mediante Difracción, con los que se fijaba una temperatura de cocción equivalente situada por encima de $\operatorname{los} 900^{\circ} \mathrm{C}$.

Por último, debe mencionarse que los datos obtenidos en las muestras que presentan microestructura laminar y estado de sinterizado de no vitrificación, se hallan en concordancia con los obtenidos en un trabajo anterior, en el que se examinaron, entre otras muestras de la zona de estudio que cubría la Memoria de Licenciatura, los ejemplates IZA-1, IZA-3, IZA-6, IZA-8 e IZA-11, procedentes del yacimiento de Izana (García Heras y Rincón, 1996). No obstante, en aquella ocasión, las muestras no procedían de una fractura fresca, sino de una sección obtenida mediante un disco de diamante. 


\section{DISCUSIÓN}

En este capítulo, que se redacta con el propósito de cubrir uno de los principales objetivos de esta investigación, como era la integración de los datos en una interpretación con significado arqueológico, se van a discutir los resultados obtenidos siguiendo el modelo de trabajo arqueométrico esbozado en el capítulo referente al marco teórico, para llegar, de esta forma, a una síntesis histótica, que se aproxime al contexto en el que se desarrolló la producción cerámica numantina.

\subsection{TECNOLOGÍA DE LA PRODUCCIÓN CERÁMICA NUMANTINA}

A partir de los datos obtenidos, se ha podido inferir la existencia de cuatro Sectuencias de Producción diferenciadas en el conjunto de la cerámica numantina. No obstante, estas cuatro secuencias, no se corresponden con las cuatro fábricas macroscópicas descritas en el apartado 5.1. Así, la cerámica de cocción oxidante, que engloba las Fábricas 1 y 1-b, se encuadra en una de estas secuencias; la Fábrica 2, de cerámicas grises, en otra, mientras que, en la Fábrica negra, se distinguen dos secuencias distintas. En cualquier caso, las diferencias observadas en cada una de ellas, se corresponden con la modificación de alguna de las cinco acciones básicas que comprenden una Secuencia de Producción. En la discusión de estas cinco acciones, que se va a realizar a continuación, se especificarán las diferencias que presenta cada una de estas secuencias. Es preciso resaltar que estos datos hacen referencia, fundamentalmente, a los conjuntos cerámicos procedentes de Numancia e lzana, ya que ha sido, en estos yacimientos, en los que se ha estudiado la totalidad de dichos conjuntos. Por otra parte, hay que decir que, en sentido estricto, se habrian identificado dos secuencias más, aunque, en ambos casos, esta identificación se ha realizado a partit de una sola muestra. La N-27, que se elabora con materias primas calcáreas y, la muestra $\mathrm{N}-21$, en la que se detecta la utilización de chamota. Estas cuatro 
TABLA 6.1. SECUENCIAS DE PRODUCCIÓN DE LA CERÁMICA DE NUMANCIA E IZANA

\begin{tabular}{|c|c|c|c|c|}
\hline $\begin{array}{l}\text { Secuencias de } \\
\text { productón }\end{array}$ & $I$ & 2 & 3 & 4 \\
\hline Fabricas & 1 y 1-b & 2 & Negra & $\begin{array}{l}\text { Cerámicas con } \\
\text { calcita anadida } \\
\text { de Fabrica negra }\end{array}$ \\
\hline $\begin{array}{l}\text { 1. Seleceión } \\
\text { materias primas }\end{array}$ & $\begin{array}{l}\text { Variacion progresiva } \\
\text { entre arcillas illtico- } \\
\text { caoliniticas ferruginosas } \\
\text { y arcillas más caoliniticas } \\
\text { con menof contenido en Fe }\end{array}$ & $\begin{array}{l}\text { Arcillas ilitico- } \\
\text { calinlticas con } \\
\text { contenidas medios } \\
\text { en Fe }\end{array}$ & $\begin{array}{l}\text { Arcillas ilitico- } \\
\text { caolinticas } \\
\text { ferruginosas }\end{array}$ & $\begin{array}{l}\text { Arcillas ilitico- } \\
\text { caoliniticas } \\
\text { ferruginosas }\end{array}$ \\
\hline $\begin{array}{l}\text { 2. Preparación } \\
\text { materias primas }\end{array}$ & Levig̣ado & Levigado & $\begin{array}{l}\text { Menor selecclon } \\
\text { tamaño de grano }\end{array}$ & $\begin{array}{l}\text { Adición calcita } \\
\text { monocristalina } \\
\text { machacada }\end{array}$ \\
\hline 3. Madelado & Torno & Torno & Torno & Tokno \\
\hline Decoración & $\begin{array}{l}\text { Pintada } \\
\text { Estampada }\end{array}$ & $\begin{array}{l}\text { Estampada } \\
\text { Pintada }\end{array}$ & Estampada & Estampada \\
\hline 4. Secado & $?$ & $?$ & $?$ & $?$ \\
\hline 5. Coccion & $\begin{array}{l}\text { MODO A (Ox / Rd! } \\
\text { Horno doble cárnara }\end{array}$ & $\begin{array}{l}\text { MODO B (Rd / Rd) } \\
\text { Horno doble camara }\end{array}$ & $\begin{array}{l}\text { MODO B (Rd / Rd) } \\
\text { Horno doble cátara }\end{array}$ & $\begin{array}{l}\text { Mobos A Y B } \\
\text { Horno doble cámara }\end{array}$ \\
\hline & $800^{\circ}-900^{\circ} \mathrm{C}$ & $800^{\circ}-900^{\circ} \mathrm{C}$ & $800^{\circ}-900^{\circ} \mathrm{C}$ & $700^{\circ} \mathrm{C}$ \\
\hline
\end{tabular}

El estadio de secado se ha indicado con un signo de interrogación, debido a las dificultades que entraña la realización de inferencias sobre este estadio, a partir de datos de caracterización. Ox oxidante. Rd reductora.

\footnotetext{
Figura 6.1: (Página siguiente). Secuencia de Producción básica de la cerámica numantina. Fintre las acciones 2 y 3 , la línca discontínua recoge el paso de la adición de calcita machacada para algunas de las ccrámicas de la leábrica negra 1) Obtención de la arcilla 2) Preparación de la arcilla mediante levigado. 3) Modelado en un torno de doble rueda y representación de los dos tipos de decoración más habituales. 4) Secado. 5) Cocción en un horno de doble cámara.
} 


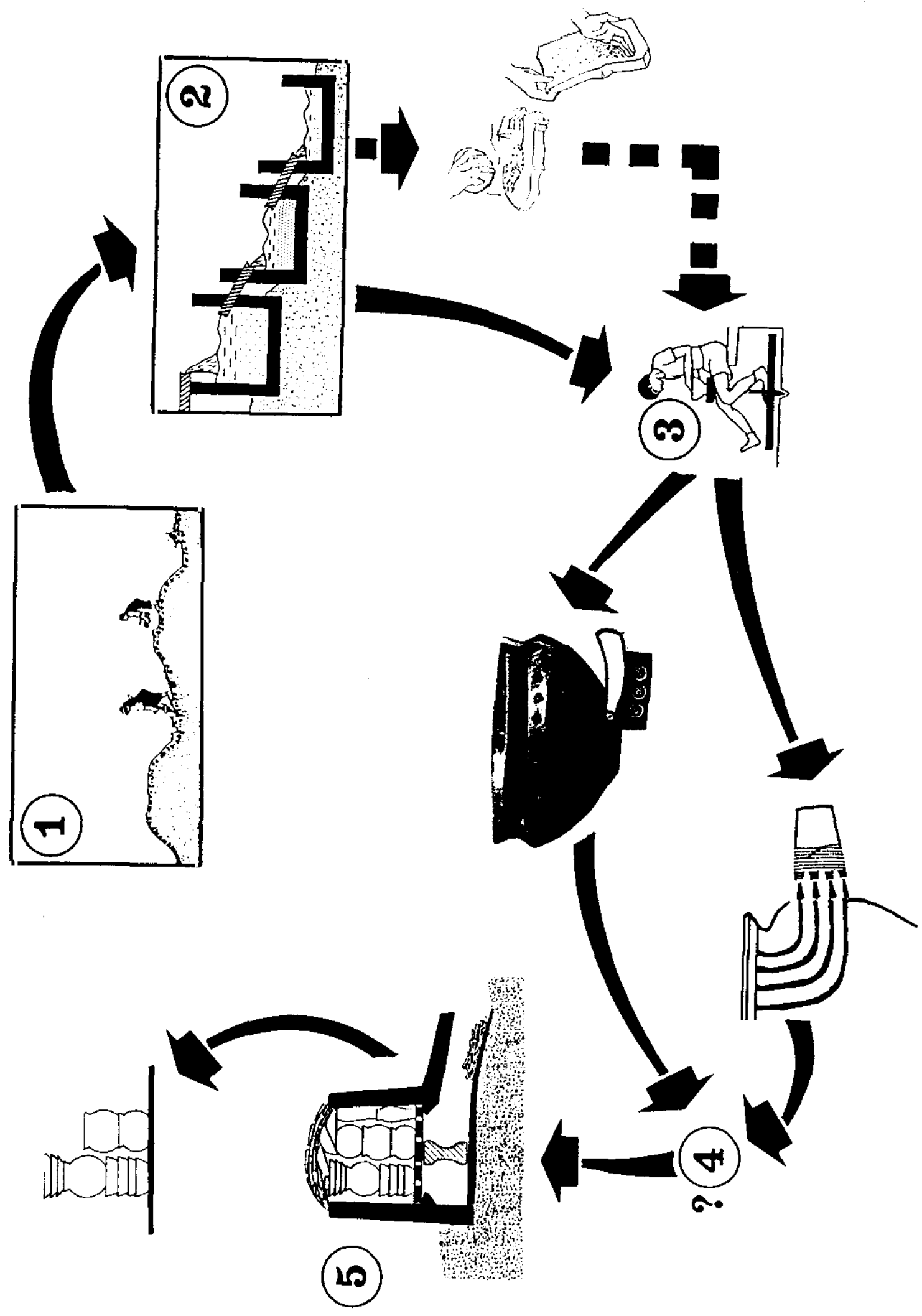


Secuencias de Producción, se exponen, de manera pormenorizada, en la Tabla $6.1 \mathrm{y}$, de forma gráfica, en la Figura 6.1.

\subsubsection{Selección y recogida de materias primas}

En general, la mayor parte de la producción cerámica numantina, se ha realizado a partir de materiales arcillosos no calcáreos. Sólo en un caso, representado por la muestra $\mathrm{N}-27$, como se comentaba más arriba, se ha detectado la utilización de arcillas calcáreas. Para la elaboración de las cerámicas de cocción oxidante de las Fábricas 1 y 1-b, se seleccionó toda una gama de sedimentos arcillosos ilítico-caoliníticos, cuya variación progresiva se establece a partir de su contenido en $\mathrm{Fe}$. No obstante, aunque las cerámicas pertenecientes a la Fábrica 1-b, tienden a concentrarse en los grupos elaborados con arcillas menos ferruginosas, la separación entre ambas resulta complicada. De todos modos, es factible pensar, a partir de los datos petrográficos (matrices blancoamarillentas), mineralógicos (ausencia de hematites), composicionales (altas concentraciones relativas de Al) y microestructurales (presencia de paquetes de caolín), que las cerámicas más ocres, se realizaron con sedimentos más caoliníticos, habida cuenta de que este mineral arcilloso, dada la estructura fija de sus dos niveles de $\mathrm{Si}$ y Al, es menos propenso a captar cationes de otros elementos, que otros minerales arcillosos como la ilita (Kingery et al, 1976; Rice, 1987, 45). Es por ello, por lo que estos matertales contienen una menor cantidad de Fe.

Por otro lado, las cerámicas grises de la Fábrica 2, se elaboraron con el mismo tipo de sedimento arcilloso que el empleado en las Fábricas 1 y 1-b. Especialmente, con un sedimento de contenidos medios en Fe, en relación a la variación progtesiva señalada anteriormente. En este sentido, las cerámicas pertenecientes a esta fábrica, tienden a concentrarse en la agrupación composicional G-5. La utilización de pastas similares en la manufactura de tipos cerámicos distintos, es decir, cerámicas grises versus cerámicas de cocción oxidante, parece ser un hecho habitual en las producciones cerámicas de fines de la Segunda Edad del Hierro en la Peninsula. Así lo corroboran algunos de los trabajos de caracterización llevados a cabo hasta el momento, como por ejemplo, el realizado por Gancedo et al. (1985) con las producciones cetámicas ibéricas de Lora del Río (Sevilla); el estudio de la cerámica ibérica de los yacimientos levantinos de La Bastida de les Alcuses (Mogente), la Serreta de Alcoy y Plaza de la Reina (Valencia) (Antón, 1973; Aranegui y Antón, 1973; Antón et al., 1972) o el llevado a cabo por Galván y Galván Martinez (1985), sobre una muestra de 13 fragmentos procedentes del yacimiento de Fuente el Saz del Jarama (Madrid). En todos estos trabajos, se detecta la utilización de las mismas materias primas en la manufactura, tanto de cerámicas grises, como de cerámicas de cocción oxidante. 
Las cerámicas pertenecientes a la Fábrica negra, también se manufacturaron con el mismo tipo de materia prima. Así parecen indicarlo los resultados obtenidos en el Análisis textural de aquellas cerámicas que presentan calcita añadida, en las que, si se eliminan las inclusiones de calcita monocristalina, el sedimento resultante es muy similar al de las fábricas anteriores. De hecho, cuando se ha eliminado el Ca en el análisis estadístico, estas muestras se han asociado al grupo G-3. Pot el contrario, para el resto de las cerámicas de esta fábrica, se detecta un sedimento con una menor selección de tamaño de grano, pero con características semejantes al del resto de las fábricas. En el análisis estadístico, estas cerámicaś se concentran, igualmente, en la agrupación G-3. Por lo tanto, la totalidad del conjunto de cerámicas de la Fábrica negra, se elaboró con los materiales arcillosos más ferruginosos, no habiendo constancia de que se urilizaran en su manufactura, aquellos sedimentos considerados más caoliníticos.

\subsubsection{Preparación y acondicionamiento de las materias primas}

Tal y como se exponía en los resultados del Análisis textural, la materia prima utilizada en las cerámicas de las Fábricas 1, 1-b y 2, mostraba unos tamaños de grano que rara vez superaban los $0,4 \mathrm{~mm}$, concentrándose en las fracciones arena muy fina e inferiores (limos y arcillas). Este factor, hacía suponer que se trataba de un sedimento muy seleccionado que, muy probablemente, se hubiera obtenido mediante algún proceso gravitacional simple, como pudiera ser el levigado. Un proceso en el que, a través de sucesivos lavados del sedimento, se consiguen seleccionar las fracciones más finas del mismo (Blackman, 1992, 115) (Figura 6.2). La comparación de los datos obtenidos en dos de las muestras de los sedimentos arcillosos analizados, permitáa comprobar, de modo preliminar, que para logtar una materia prima con estas características granulométricas, era necesario desechar entre un 30 y un $50 \%$ del sedimento en bruto. Naturalmente, estos datos son sólo aproximativos, ya que hay que tener en cuenta que no necesariamente se habrían utilizado sedimentos como los muestreados. Tal vez, estos tamaños de grano, ya etan seleccionados directamente del depósito arcilloso. En cualquier caso, los resultados se aproximan a los expuestos por Echallier y Montagu en un trabajo experimental, realizado en un taller alfarero actual, en el que reproducen distintas cerámicas romanas, cuya materia prima resulta próxima, desde un punto de vista granulométrico, a las aquí analizadas. En este trabajo, concluyen que el levigado elimina cerca de un $50 \%$ del sedimento inicial, de modo que, para preparar un kilogramo de pasta, son necesarios 10 litros de agua y 2 kilos de sedimento 


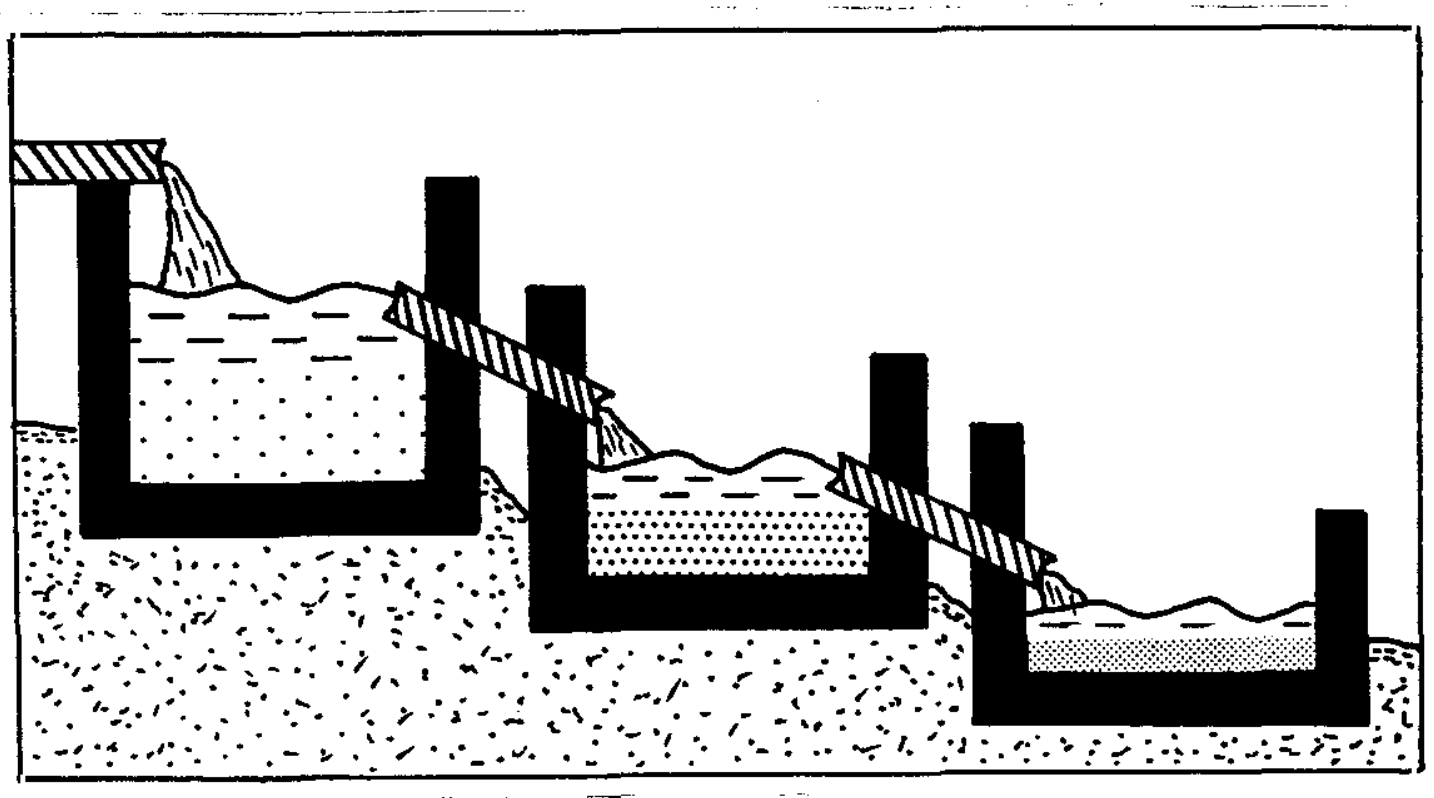

Figura 6.2: Representación ideal del posible proceso de levigado llevado a cabo en la preparación de la arcilla

(Echallier y Montagu, 1985).

Para la elaboración de las cerámicas pertenecientes a la Fábrica negra, el sedimento habría sido más o menos el mismo, aunque la selección del tamaño de grano fue menor. Un hecho que, sin duda, y como se verá más adelante, tiene implicaciones funcionales. La asociación de las muestras de esta fábrica al grupo composicional G-3, parece descartar la posibilidad de que se hubieran mezclado distintos batros o de que se hubiera añadido un sedimento más arenoso, ya que este comportamiento habria alterado, de manera importante, la composición de las mismas y su asociación a las cerámicas de las fábricas restantes.

Pot otro lado, la presencia de calcita criptocristalina, con claros ángulos de exfoliación y tamaños determinados, en un grupo de muestras de la Fábrica negra, hace pensar en que su adición ha sido fruto de un comportamiento intencionado. Un comportamiento, por lo demás, ampliamente documentado, tanto en el registro etnográfico, como en el arqueológico. En el registro etnogtáfico, se documentan cerámicas con calcita añadida entre los indıos de norteamerica o entre ciertos alfareros de Melanesia (Rye, 1976). Los alfateros de Ticul (Yucatán, México), por ejemplo, utilizan calcita cristalina pura para elaborar vasijas de cocina (Shoval et al.; 1993, 263). Asimismo, en el registro arqueológico, se conocen multitud de producciones cerámicas de diferentes periodos, en las que se detecta la adición de este tipo de calcita. En la 
Peninsula Ibérica, se documenta en cerámicas neolíticas valencianas (Gallatt, 1980 a; 1980 b); en cerámicas campaniformes (Batrios et al, 1991); en cerámicas del Bronce Antiguo (De Andrés y Balcázar, 1989); en cerámicas de la Edad del Hierro (Olaetxea, 1993); en las producciones de cocina de algunos poblados ibéricos (Mata et al., 1990, 616; Soria y Córdoba, 1994, 24); así como en ciertas cerámicas comunes tardorromanas (Rodriguez y Marín, 1987-88). Por otra parte, en el continente europeo, son conocidas cerámicas con este material, entre otros períodos, en el Neolítico Medio y Final francés (Arnal et al., 1987; Echallier y Jallot, 1992; Echallier y Courtin, 1994); en el Bronce Final británico, en donde, por ejemplo, en el yacimiento de Devil's Hill (Yorkshire, Reino Unido), se halló un hoyo con 5 kilos de calcita y un martillo o mazo de piedra, para producir cerámicas con estas características (Wardle, 1987, 30); o en cerámicas de la Edad del Hierro centroeuropea, procedentes del conocido yacimiento de Heuneburg (Maggetti y Schwab, 1982, 31). Por último, y ya fuera del continente europeo, también se documentan en el Próximo Oriente, tanto en asentamientos de la Edad del Bronce (Lazzarini y Colombo, 1995), como en asentamientos de la Edad del Hierro (Shoval et al., 1993, 269).

De todos modos, la adición de este material no plástico, se ha realizado sobre un sedimento de base que presenta las mismas características que el utilizado para elaborar gran parte del resto de las cerámicas. En el análisis estadísitico, una vez desechado el $\mathrm{Ca}$, las cerámicas que contienen calcita machacada añadida, se asocian al grupo G-3. Asimismo, en el Análisis textural, cuando se eliminan las inclusiones de calcita monocristalina, el sedimento resultante es muy similar, desde un punto de vista granulométrico, al que presentan las cerámicas de las Fábricas 1, 1-b o 2. Estas inclusiones, por otro lado, se han añadido seleccionando un rango de tamaños que rara vez supera el milímetro, sin duda porque, con partículas superiores a este tamaño, es difícil modelar a torno (Rye, 1988, 61).

Sólo en una de las muestras que, además, presenta calcita añadida (N-21), se han identificado inclusiones de chamota. Estas inclusiones pueden pertenecer, como ya se señalaba en el capítulo anterior, a un fragmento de cerámica de cocción oxidante. En todo caso, al haberse identificado solamente en una de las muestras analizadas, no puede afirmarse que su utilización haya sido un hecho generalizado en la producción cerámica numantina. En este sentido, quizás sería conveniente apuntar que su presencia puede deberse a un hecho fortuito en la preparación de la pasta de este recipiente. No obstante, en la Memoria de Licenciatura, también se identificó chamota en una muestra de Izana, no reanalizada en esta investigación, así como en dos muestras procedentes de los yacimientos de El Molino (Calatañazor, Soria) y del Altillo de las Viñas (Ventosa de Fuentepinilla, Soria), respectivamente (García Heras, 1993 a, 71 - 
72).

Por lo demás, en la mayonía de las muestras e, independientemente de la Secuencia de Producción seguida, se observa una buena homogeneización de la materia prima utilizada. Homogeneización que ha debido llevarse a cabo mediante un buen proceso de amasado, que contribuye a uniformizar la pasta, dispersando las burbujas de aire, haciendo el barto más trabajable y reduciendo el riesgo de fracturas durante la fase de secado. Este factor, ha podido comprobarse, de manera comparativa, a través del análisis de varias muestras obtenidas en el perfil de un recipiente cerámico de cocción oxidante, procedente del yacimiento de El Palomar, en el que las determinaciones composicionales mostraban una gran uniformidad a lo largo de todo el perfil.

\subsubsection{Modelado}

La totalidad de la producción cetámica numantina se ha realizado a tomo, incluyendo las cerámicas de la Fábrica negra. Se hace especial hincapié en estas últimas, porque en el trabajo anterior realizado en la Memoria de Licenciatura, los problemas derivados de su ubicación cronológica, planteaban dudas sobre su manufactura a tomo (García Heras, 1993 a). En la memoria de excavación del asentamiento de Izana, se señalaba que estas cerámicas no eran contemporáneas al resto de las producciones, sino que procedian de una ocupación anterior, que podía situarse a comienzos de la Segunda Edad del Hierro (Tatacena, 1927). Sin embargo, en el caso de Numancia, los resultados aportados por esta investigación, demuestran que las producciones negras son contemporáneas al resto de las cetámicas numantinas, no sólo porque presentan los mismos motivos decorativos estampados, presentes, por lo demás, en todas las fábricas, excepto en la 1-b, sino también porque, en general, aparecen en las mismas tipologías (ver Figura 5.2).

Para la elaboración de la cerámica numantina, debe inferirse el empleo de un totno con rotación contínua, ya que las paredes de los recipientes presentan un grosor uniforme. De todas formas, resulta difícil la aproximación al tipo de tomo utilizado, aunque, con toda probabilidad, fuera un torno de pie o doble rueda (ver Figura 6.1). Dejando a un lado los recipientes de mayor tamaño, las piezas se fabricarian a partir de una sola pella de arcilla, que se iría levantando en el torno, dejando un mayor espesor en la base para poder soportar el peso de la misma. Por ello, es fácil encontrar, entre los distintos fragmentos, bases intactas. De cualquict modo, todas las 
piezas no se fabricatian con una misma técnica. En muchas ocasiones, se emplea más de una en la manufactura de un solo recipiente, como en el caso de las copas (formas 13 y 15), que se elaboran a partir de dos pellas de arcilla. Una que constituye el pie torneado, que es hueco y, otra, que forma la parte superior y que se realiza igual que los cuencos hemiesféricos (forma 1). Por este motivo, es fácil hallar pies sueltos en los que pueden observarse las huellas de la unión con la parte superior. Algo parecido ocurre con las grandes vasijas (forma 24), en las que el borde se añade una vez finalizada la confección del resto de la pieza. Por ello, los bordes suelen fracturarse por la parte por donde se han añadido a la pated del recipiente. Igual comentario debe hacerse para los embudos (forma 10), fabricados a partir de dos piezas elaboradas por separado, o para las cantimploras, que se elaboran mediante la unión de dos cuencos hemiesféricos. En los recipientes en los que se añadieron asas y molduras de refuerzo (principalmente jarras de las formas 17, 19 y 20), estos elementos fueron unidos una vez que la pieza estaba en estado de "piel dura" (1). Por otro lado, otras formas tipológicas, como las trompas, se realizan a partir de vatias planchas elaboradas por separado y sin la utilización del torno (Taracena, 1924, 70-71; Pastor Ejxarch, 1987).

El acabado final de los recipientes, se debió realizat utilizando algún tipo de alisador. Es por ello, por lo que a través de la lupa binocular, se han observado las trazas del facetado, orientadas siempre en una sola dirección, dejadas por el útil empleado en el alisado de las superficies externas. Por el contrario, no se ha detectado la aplicación de engobes en ninguna de las fábricas. Este aspecto, contrasta con las ideas mantenidas pot Atlegui, para la cerámica de cocción oxidante con decoración monócroma, o por Romero Carnicero, para las cerámicas con decoración polícroma, ya que ambos investigadores apuntan la existencia de engobes externos con colores iguales o muy similares al que presentan los recipientes, en la mayoría de las piezas que estudiaron (Arlegui, 1986, 35-36; Romero Carnicero, 1982, 36).

En cuanto al repertorio formal, los datos del Análisis mactoscópico, reflejan que no en todas las fábricas se manufacturan las mismas formas tipológicas. Así, mientras que, en la Fábrica 1, aparecen todos los tapos del catálogo general; en la Fábrica 1-b, están ausentes seis de ellos; en la Fábrica 2, no se elaboran once de estas formas y, en la Fábrica negra, ocho están también ausentes. Este aspecto, se manifiesta, igualmente, en el conjunto cerámico de Izana, en donde además debe señalarse que, ocho de las formas del repertorio general definido para la cerámica de Numancia, no están presentes en ninguna de las fábricas identificadas en estc

(1) Traducción de la cxpresión inglesa "leather hard", que hace referencia a un cstado en el que las piças cerámicas se han sccado ya adquiriendo durera, pero en el que todavia no han perdiclo roda su humedad. 


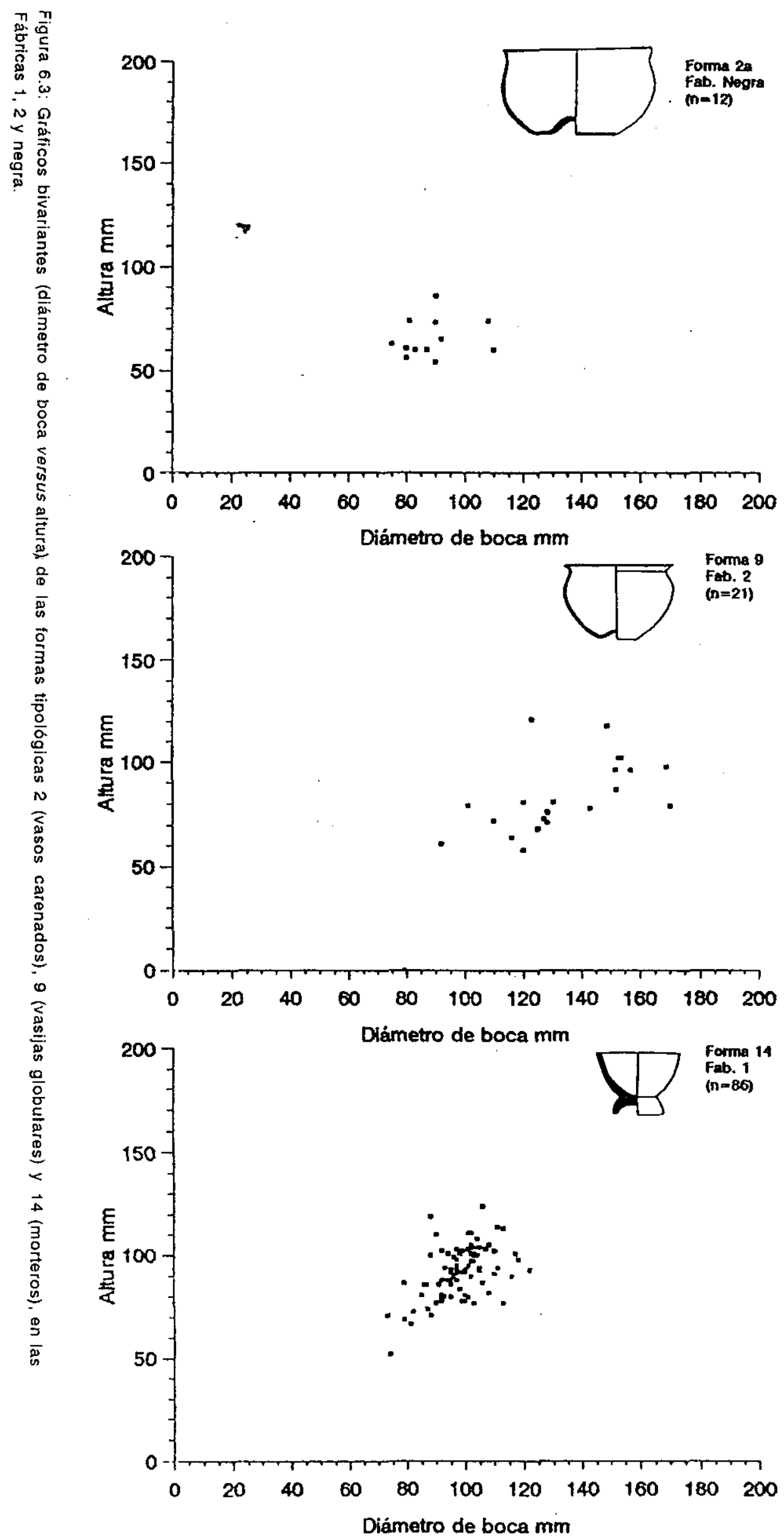


yacimiento (García Heras, 1993 a, 39). Asimismo, en cada fábrica predominan unas formas determinadas. En la Fábrica 1, el mayor número de ejemplares está representado por grandes vasijas (forma 24), jarras (formas 17,19 y 20), copas (formas 13 y 15) y morteros (forma 14). En la Fábrica 1-b, las formas que más se realizan se corresponden con cuencos (forma 1), vasos carenados (forma 2), copas (formas 13 y 15) y jarras de boca trilobulada (forma 19). En la Fábrica 2, se elaboran, principalmente, vasijas globulares (forma 9), cuencos (forma 1) y vasos carenados (forma 2); mientras que, en la Fábrica negra, las formas más comunes son también las vasijas globulares (forma 9), los vasos carenados (forma 2), así como las grandes vasijas (forma 24).

En otro orden de cosas, resulta importante destacar la estandarización que presentan algunas de estas formas tipológicas. A modo de ejemplo, en la Figura 6.3, se muestran tres gráficos bivariantes (diámetro de boca versus altura), que ilustran esta estandarización, para tres de las formas más características presentes en las Fábricas 1, 2 y negra. Esto es, los morteros (forma 14), en la Fábrica 1; las vasijas globulares (forma 9), en la Fábrica 2 y, los vasos carenados (forma 2), en la Fábrica negra.

La decoración de los recipientes, no se consideta, en esta investigación, como un estadio específico de la Secuencia de Producción, ya que se realiza inmediatamente después del modelado (Tabla 6.1 y Figura 6.1). Por otro lado, y aunque el estudio de los motivos decorativos, desde un punto de vista estético y formal, no se ha contemplado en este trabajo, sí conviene, si cabe, recordar, algunas de las conclusiones que exponen los investigadores que han estudiado estas decoraciones, al menos, en lo referente a las cerámicas con decoración polícroma y monócroma. En este sentido, es importante resaltar que el repertorio iconográfico numantino es bastante escaso, abundando los convencionalismos. Los motivos se repiten de fotma monótona, con las mismas sintaxis compositivas, de modo que, aunque nunca hay dos motivos iguales, parece ser que algunos se dibujaron en serie (Romero Carnicero, 1976, 160; 1982, 43; Arlegui, $1992 \mathrm{~b}, 9)$. De todas formas, la decoración siempre se estructura en función de la forma del recipiente. Por ello, en cada una de ellas, se desarrollan motivos característicos en zonas concretas. Estos motivos, suelen disponerse en conjuntos simétricos (Rometo Carnicero, 1976, 145 y 172; Arlegui, 1986, 98). Además, no todas las formas presentan decoración. En líneas generales, ésta se centra, sobre todo, en copas, jarras, vasos carenados y grandes vasijas.

La gran mayoria de los recipientes se decoran en el exterior, salvo en el caso de las copas, en las que la decoración también se añade en su interior. Los pigmentos se aplican una vez que la pieza ha alcanzado el estado de "piel dura". Pot este motivo, por ejemplo, en los circulos 
pintados en la parte superior de las grandes vasijas (forma 24), que se realizan con un compás, se observan los puntos centrales dejados por el extremo de este instrumento, que demuestran que la pieza aún no habia perdido toda su humedad. Por otra parte, estos pigmentos se aplicarian con algún tipo de pincel, ya que, a través de la lupa binocular, se observan trazos en una sola dirección (vet Figura 6.1). Esto reflejaria también que, las líneas horizontales, se realizaban aplicando el pincel a la pared del vaso, mientras se hacía girar el tomo.

Todos estos aspectos indican que, en cierto modo, los motivos decorativos se han adaptado a una producción en serie. Sobre todo, si se tiene en cuenta que, con la excepción de algunas vasijas, por lo demás, muy conocidas en la bibliogtafía especializada, como pueden ser el "vaso de los guerreros", "el vaso de los danzantes", el "vaso de los toros", etc., la mayor parte de los motivos son de carácter geométrico. Los datos de las cerámicas polícromas, son muy indicativos a este respecto, ya que un $80,5 \%$ de las mismas, presentan sólo motivos de este tipo (Romero Camicero, 1976; 1982, 37-38). Una decoración conceptual y abstracta, sin duda, se adapta mejor a una producción en serie.

Desde un punto de vista tecnológico, los pigmentos se preparan, como se ha visto en el capítulo anterior, a partir de distintos materiales. Así, el pigmento rojo, proviene de la fracción más fina de una arcilla ilítica tica en compuestos de Fe. Por ello, las cerámicas polícromas en las que se ha utilizado este pigmento, pertenecen mayoritariamente a la Fábrica 1-b, ya que el color ocre de sus superficies, contrasta mejor con el color rojo del mismo. Aplicándose sobre cerámicas rojas, el pigmento se vería con mayot dificultad. Por otro lado, el pigmento blanco, procede de una arcilla caolinítica muy similar a la de los grupos composicionales G-5 y G-6, mientras que el negro, se elaboratía a partir de un material rico en $\mathrm{MnO}$.

Un repaso a los trabajos que han caracterizado los pigmentos rojos utilizados en la decoración de la cerámica ibérica del SE peninsular, permite comprobar que, los pigmentos aquí analizados, están compuestos por materiales muy similares. Es decir, la fracción más fina de una arcilla ilítica, con agentes de pigmentación ricos en óxidos de Fe. Estas conclusiones son las que se alcanzan en el análisis de los pigmentos de la cerámica ibérica de los yacimientos levantinos de La Bastida de les Alcuses (Mogente), la Serreta de Alcoy y Plaza de la Reina (Valencia) (Antón, 1973; Aranegui y Antón, 1973; Antón et al, 1972); de la cerámica ibérica de Cerro Macareno (Sevilla) (González Vílchez et al, 1988); en los análisis efectuados sobre distintos fragmentos procedentes de varios yacimientos de la provincia de Córdoba (Barrios et al., 1992; 1994); de la cerámica de Torreló del Boverot (Almazora, Castellón) (Boix et al., 1995); así como en un fragmento de cetámica romana de tradición indígena procedente del cerro de la Virgen de la 


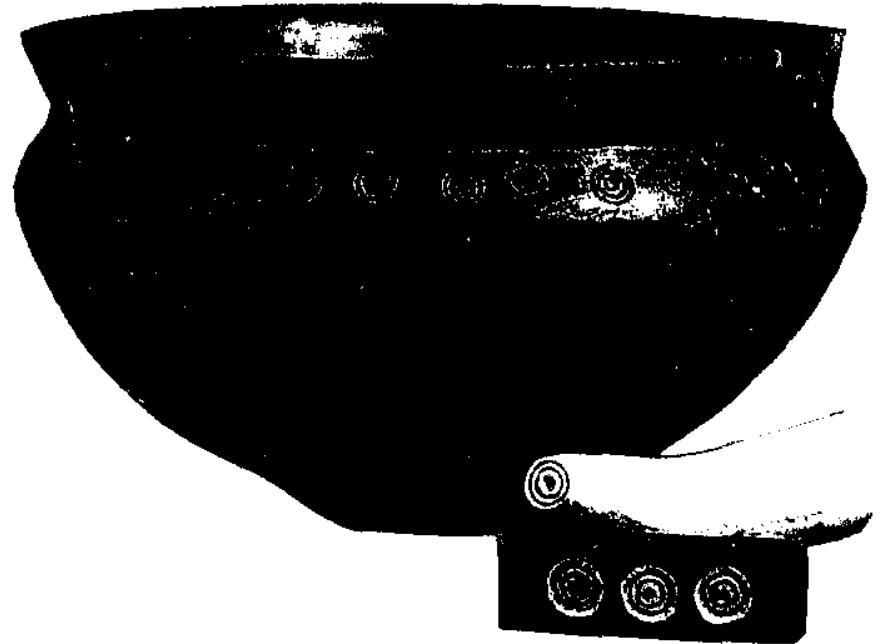

Figura 6.4: Punzón de asta de venado, procedente de las excavaciones de Numancia, utilizado para realizar la decoración estampada, en un recipiente de la Fábrica 2 perteneciente a la forma 9.

Muela (Driebes, Guadalajara) (Rincón, 1986). Por otro lado, en el continente europeo, los análisis realizados sobre cerámicas bícromas de La Tène, principalmente francesas, también identifican materiales ilíticos ricos en hematites para los pigmentos rojos, mientras que, en los blancos, se detecta la utilización de arcillas caoliníticas (Andrews, 1991 a; 1991 b; 1996; Guichard y Guineau, 1991).

Por último, la decoración estampada, predominante en las cerámicas pertenecientes a la Fábrica negra, se realiza utilizando punzones de hueso, confeccionados a partit de fragmentos pulimentados de asta de venado. Un buen número de estos punzones, se ha hallado en varios puntos de la ciudad de Numancia (Taracena, 1924, 2-3; Fernández Moreno, 1992, 6). En la Figura 6.4, se muestra un ejemplo de esta decoración, junto a uno de estos punzones.

\subsubsection{Secado}

El secado de las piezas cerámicas, es uno de los estadios más importantes de la Secuencia de Producción, puesto que, si los recipientes se cuecen con humedad, pueden producirse roturas de fatales consecuencias durante el proceso de cocción. Sin embargo, también es un estadio en el que resulta muy difícil realizar inferencias a partir de datos de caracterización, 
debido a las escasas huellas directas que deja en los materiales. En cualquier caso, debe suponerse que el secado, dadas las proporciones de la producción cerámica numantina, debió de ser un proceso controlado, aunque se desconozcan parámetros como el porcentaje de piezas que finalmente resultaban defectuosas, por efecto de un mal secado.

Los resultados del análisis mineralógico, no obstante, muestran la utilización de una materia prima compuesta por arcillas ilítico-caoliniticas. Entre las ventajas que presentan este tipo de arcillas, especialmente las caoliníticas, se encuantra la rapidez de secado, como consecuencia del tamaño y distribución de sus partículas minerales (Rye, 1988, 21 y 30). Hay que tener en cuenta que la duración de esta fase, no es la misma para todas las piezas, ya que, como es fácil suponer, las de mayores dimensiones tardarían más tiempo en secarse. Sin embargo, el proceso de secado está influido, de una manera determinante, por los factores climáticos. La ausencia de humedad y bajas temperaturas, son indispensables para que el secado se produzca en un periodo de tiempo razonable. En el caso del Alto Duero, según los datos expuestos en el capítulo 3 dedicado al marco geográfico, las condiciones climáticas actuales son extremadamente duras durante el invierno. Si a ello se une el que a fines del Primer Milenio a. C., el clima podría haber sido más húmedo que el actual, la época en la cual la producción cerámica se podría llevar a cabo con mayores gatantías, se situaría en los meses cálidos en los que, además, se producirían menos lluvias. En este sentido, los datos etnográficos pueden arrojar alguna luz sobre este tema. Sempere $(1992,190)$ señala que, en algunas alfarerías tradicionales de la provincia de Soria, las producciones se secaban en el interior de las viviendas, preferentemente en la cocina por la proximidad al hogar, durante los meses frios del invierno. Si se acepta una producción continuada a lo largo de todo el año para la cerámica numantina, este aspecto podtía formar parte de la Secuencia de Producción.

\subsubsection{Cocción}

En un estudio sobre los aspectos tecnológicos de las sigillatas de Lezoux, Picon definió su proceso de cocción de acuerdo a tres modos: 1) Modo $A$, en el que la cocción dominante es reductora con un enfriamiento oxidante, entendiendo por ambiente reductor la alternancia de fases oxidantes y reductoras. 2) Modo B, en el que el ciclo de cocción es reductor, siendo el enfriamiento también reductor. Y 3) Modo $C$, en el que la cocción dominante es oxidante, al igual que el enfriamiento. En los dos primeros, la cocción puede llevarse a cabo en homos de doble 
cámara, en los cuales la cerámica entra en contacto con las llamas de la cámara de combustión. Sin embargo, en el Modo $C$, la cerámica se cuece por convección en hornos de mufla, en los que la cámara de combustión se halla separada de la cámara de cocción, no estando la cerámica, por tanto, en contacto directo con las llamas (Picon, 1973, 62-63; Cuomo di Caprio, 1994, 153-154).

Siguiendo este razonamiento, las cerámicas de las Fábricas 1 y 1-b, podrian haberse cocido en $M o d o A$, es decir, a través de un ciclo reductor dominante, con un enfriamiento de carácter oxidante. Por ello, en el Análisis macroscópico, se observaban abundantes cambios de coloración en sus superficies, así como una importante cantidad de corazones negros, en aquellos fragmentos en los que se pudo acceder a su sección. Igualmente, en el Análisis petrográfico, se observaban matrices con coloraciones rojizas y blancoamarillentas, mientras que en las difracciones, se detectaba la formación de hematites, en función del contenido en compuestos de Fe que presentara la pasta.

Por el contrario, las cerámicas grises pertenecientes a la Fábrica 2, podrían haberse cocido en $\operatorname{Modo} B$, aunque el enfriamiento reductor debía tener escasa duración, ya que, según se observaba en la mayoría de las matrices, sólo conseguía oscurecer las superficies de los recipientes. Además, en los difractogramas de varias de estas muestras, se detectaba hematites, fase incompatible con un ambiente reductor continuado, no identificándose el desartollo de fases típicas de atmósferas reductoras, como la magnetita o, a mayores temperaturas, la hercinita.

Finalmente, los datos que ofrecen las cerámicas pertenecientes a la Fábrica negra, indican, asimismo, que también pudieron cocerse en Modo $B$, quizás con un periodo de enfriamiento reductor mayor. De todos modos, estas cerámicas presentan una gtan heterogeneidad, no sólo en los colores que muestran sus superficies, sino también en los que se han observado en sus matrices, de tal forma que, incluso en algunos casos, las cerámicas son totalmente rojizas (p. e., la muestra N-16), detectándose, por consiguiente, el crecimiento de hematites. En estas cerámicas, tampoco se han llegado a determinar, mediante Difracción de rayos $\mathrm{x}(\mathrm{XRD})$, fases típicas de ambientes reductores. Por lo tanto, no debe descartarse la posibilidad de que algunas de ellas se cocieran también siguiendo un Modo A (Tabla 6.1).

Las temperaturas de cocción equivalente estimadas en el capitulo anterior, se situaban entre los $800^{\circ}$ y los $900^{\circ} \mathrm{C}$, para la gran mayoría de las cerámicas analizadas. No obstante, había muestras que se habrían cocido a temperaturas próximas a los $1.000^{\circ} \mathrm{C}$, debido a que presentaban el desarrollo de fases de alta temperatura, como la mullita o el corindón. Por otro lado, las cerámicas de la Fábrica negra que contienen calcita añadida, se cocieron en tomo a unos $700^{\circ} \mathrm{C}$. 
En líneas generales, estas temperaturas se aproximan a las indicadas por otros investigadores que han analizado cerámica ibética. Un tipo de cerámica tecnológicamente muy similar a la numantina en casi todos sus tipos de manufactura, aunque, normalmente, se fabrica a partir de materias primas calcáreas. Así, un rango de temperaturas situado entre los $780^{\circ} \mathrm{y}$ los $820^{\circ} \mathrm{C}$, se estima para una serie de platos ibéricos aparecidos en varias motillas de La Mancha (Capel, 1986). Igualmente, en el análisis de dos cerámicas procedentes de la nectópolis de Castellones de Ceal (Jaén), se señala una temperatura de cocción comprendida entre los $850^{\circ}$ y los $900^{\circ} \mathrm{C}$ (Castelo y Rincón, 1986), rango, por otro lado, similar, al que se estima para varias cerámicas ilergetas de la provincia de Lleida (Junyent y Alastuey, 1991), para cerámicas de Cástulo (Jaén) (Rincón, 1985), para fragmentos procedentes de varios yacimientos de la provincia de Alicante (Echallier y Jullien, 1985), o para cerámicas procedentes del yacimiento de El Castellón en Albacete (Soria y Córdoba, 1994). Otros trabajos, sin embargo, señalan temperaturas de cocción inferiores a $950^{\circ} \mathrm{C}$, como los realizados con la cerámica ibérica proveniente de Torreló del Boverot (Almazora, Castellón) (Boix et al, 1995) o de Illa d'en Reixac y Puig de Sant Andreu de Ullastret (Girona) (Ptadell et al., 1995). Por otra parte, también se han estimado temperaturas próximas a $\operatorname{los} 700^{\circ} \mathrm{C}$, para el caso de la cerámica que presenta calcita añadida (Mata et al., 1990; Soria y Córdoba, 1994).

Dadas las características que muestra el conjunto de las cerámicas analizadas, en cualquiera de las cuatro Secuencias de Producción, ha sido necesario el uso de un homo con el que poder ejercer el control, tanto de las temperaturas, como de las atmósferas de cocción. Sin embargo, y aunque la ausencia de evidencia no puede considetarse, por ahora, evidencia de ausencia, ni en las inmediaciones del yacimiento de Numancia, ni en los alrededores del yacimiento de. Izana, se han localizado restos claros que pudieran relacionatse con homos u otras estructuras ligadas a la producción cerámica. Pese a estos inconvenientes, Taracena (1924, 2) señalaba que, de todos modos, si en Numancia hubieran existido alfares, éstos se situarian, por las necesidades de agua que requiere este tipo de producción, cerca de alguno de los dos ríos que discurren a los pies de la ciudad. No obstante, también señala que, en diversos lugates de la excavación, se hallaton masas hemiesféticas de barro sin cocer con huellas de dedos, que pudieran corresponderse con pellas de pasta para hacer piezas cerámicas (Taracena, 1924, 3). Asimismo, y aunque estos datos aún no se han confirmado, Jimeno (1994 a) reseña que, en los sondeos realizados en 1992 en la ladera E del cerro de La Muela, encaminados a la localización de la necrópolis de Numancia, se documentaron unas interesantes instalaciones artesanales que, quizás, estuvieran relacionadas con la producción de cerámica. 
En cualquier caso, si se quiere realizar una aproximación a los tipos de hornos utilizados en la cocción de la cerámica numantina, ésta debe llevarse a cabo por vía indirecta, a través de los ejemplos conocidos en otros ámbitos, tanto del territotio celtibérico, como del ibérico. Territorios en los que, por otro lado, y debido a la influencia meditertánea, el desarrollo de hornos permanentes es mucho más temprano que en otras partes del continente europeo, en donde no son conocidos hasta el período final de La Tène, en torno al cambio de era (Peacock, 1982; Rigby et al., 1989, 8; Vicente et al., 1983-84, 367). Estos hornos, suelen ser siempre de tiro vertical o de llama libre, es decir, que no presentan canalizaciones para la extracción de humos entre la cámara de combustión y la cámara de cocción $\mathrm{y}$, generalmente, de planta cuadrangular, aunque también hay documentados hornos de planta circular. Por lo tanto, las cocciones, según la terminología de Picon $(1973,62-63)$, se realizan en $M o d o ~ A$ y en $M o d o B$.

En la Meseta, los mejores ejemplos, se encuentran situados en el área vaccea. Uno de los más importantes, se documenta en el conjunto arqueológico de Padilla/Pesquera de Duero (Valladolid), fechado a mediados del siglo I a. C., en el que se han hallado tres homos para cocción de cerámicas. La excavación de uno de ellos, ha proporcionado datos de gran interés sobre un horno de planta circular, con doble cámara, parrilla perforada y muro central que separa la cámara de combustión (Sanz Mínguez y Escudero, 1991; 1995; Escudero y Sanz Minguez, 1993). Asimismo, también son conocidos al menos cinco hornos, fechados a mediados del siglo III a. C., en el área de Los Azafranales de la ciudad vaccea de Cauca (Coca, Segovia) (Blanco García, 1990; 1992), así como restos de alfares, no excavados, en Roa (Burgos) (Sacristán, 1986). El ejemplo más cercano a la zona del Alto Duero, es el horno de planta circular documentado en el yacimiento del Alto del Arenal (San Leonardo de Yagüe, Soria), perteneciente a la Cultura Castreña Soriana y fechado entre el siglo IV y fines del siglo II a. C. (Carnicero et al., 1991). Por otro lado, uno de los recintos de Las Cogotas (Cardeñosa, Avila), ofrece un horno de una sola cámara, utilizado en la producción de vasos estampillados negros del siglo III a. C. (Mariné y Ruiz Zapatero, 1988; Ruiz Zapatero y Álvarez Sanchís, 1995; Juan Tovar y Bermúdez, 1991).

En el área ibérica, hay catalogados algo más de 60 hornos, aunque sólo un tercio de los mismos está bien documentado (Escudero y Sanz Mínguez, 1993, 480). En general, son más abundantes los hornos de planta cuadrangular, como los excavados, por ejemplo, en el yacimiento de Los Vicarios (Teruel), en donde se documentan dos hornos de doble cámara y posible parrilla perforada (Vicente et al., 1983-84). 
Ante estas evidencias, debe, pues, suponerse que, con toda probabilidad, la cerámica numantina se coció en un horno de estas características, ya fuera de planta cuadrangular o circular, como el que se muestra en la Figura 6.1. Es dificil, empero, conjeturar sobre el tipo de cubierta que pudieran haber tenido estos homos, en el caso de que ésta fuera permanente. De todas formas, lo que sí es seguro es que, para cocer las cerámicas de las Fábricas 2 y negra, era necesario algún tipo de cubierta que permitiera cerrat el horno al final del proceso de cocción, para conseguir el ciclo reductor durante el periodo de enfriamiento.

Aunque en los procesos de cocción tradicional, las temperaturas y las atmósferas tienen una gran variabilidad, hasta el punto de que una misma pieza cerámica, sobre todo si es de gtandes dimensiones, puede estar sujeta, por la circulación de los gases en el interior de la cámara del horno, a diferentes condiciones a lo largo de toda la cocción (Rye, 1988, 110), las producciones numantinas, presentan, en general, un grado de cocción muy homogéneo. Este aspecto, queda patente en la uniformidad de los colores que muestran (Apéndice I), así como en los datos obtenidos en los análisis de Difracción de rayos $\mathrm{x}(\mathrm{XRD})$, pese a que algunas cerámicas presentan indicios de sobrecocción, quizás motivados, por la posición que ocuparon estos recipientes en la cámata del horno.

En otro orden de cosas, un aspecto que es importante comentar, es el combustible que pudo haberse utilizado en dichos hornos, para alcanzar las temperaturas mencionadas anteriormente. En este sentido, los datos que ofrecen las investigaciones realizadas en algunos de los hornos citados más arriba, pueden servir para llevar a cabo un acercamiento a este tema. Por ejemplo, los análisis efectuados en dos muestras de catbón de uno de los homos de Padilla/Pesquera de Duero (Valladolid), indican que en la combustión se utilizó Pynus sylvestris, cuya madera tiene un importante potencial calorifico (Mariscal et al., 1995, 444; Uzquiano, 1995, 413; Sanz Mínguez y Escudero, 1995, 299). Es factible, por tanto, pensar que un tipo de combustible similar pudo ser el empleado en la cocción de la cerámica numantina, sobre todo teniendo en cuenta que, según los datos paleoambientales expuestos en el capítulo 3, las masas boscosas de pinos eran abundantes en los alrededores del yacimiento de Numancia. No obstante, tampoco debe desecharse la posibilidad de la utilización de madera de encina, habida cuenta de que esta especie arbórea también se detecta en cantidades importantes, en alguno de los estudios señalados en dicho capítulo 3.

Otro aspecto de sumo interés, lo constituye el acercamiento a las cantidades necesarias de combustible para alcanzar temperaturas próximas a los $900^{\circ} \mathrm{C}$. En el trabajo experimental de Echallier y Montagu (1985), al que ya se ha hecho referencia con anterioridad, se estima que son 
necesarios unos 400 kilogramos de madera por $\mathrm{m}^{3}$ de horno, aunque hay que destacar que, evidentemente, todas las maderas no son iguales. Estos datos, les sirven también para calcular que, para cocer un kilogramo de cerámica, hacen falta unos cinco kilogramos de madera como media. Por otra parte, un dato importante, en esta misma línea, lo ofrece el trabajo de Peacock $(1982,25)$, quien menciona que en cocciones experimentales realizadas con réplicas de homos romano-británicos, se han llegado a emplear diez unidades de madera por cada unidad de pasta cerámica.

\subsection{MODOS DE PRODUCCIÓN}

Si el concepto de estandarización se entiende como una reducción de la variabilidad en todos los estadios de la Secuencia de Producción (Rice, 1987, 202), como se ha ido viendo en los apartados anteriores, las Secuencias de Producción inferidas para las distintas fábricas o tipos de manufactura, muestran, de esta forma, un modo de producción altamente especializado y estandarizado, en el que las cualidades del producto final están claramente predeterminadas desde el principio del proceso. En este sentido, las cerámicas numantinas se han fabricado con una completa homogeneidad tecnológica, en función de unos usos determinados, como se verá en uno de los apartados siguientes. Estos aspectos, pueden seguirse a lo largo de los distintos pasos de las Secuencias de Producción, en los que se comprueba que la materia prima se ha seleccionado y preparado en función de estos usos. Por ello, en cada fábrica, se han manufacturado formas concretas, que después se han cocido de una determinada manera, tal y como señalaban los resultados del Análisis macroscópico. Todos estos aspectos, suponen, en definitiva, un control exhaustivo de todo el proceso de producción.

Teniendo en cuenta el volumen de esta producción, con las necesidades de espacio que esto conlleva; la existencia de diferentes secuencias para tipos de manufactura distintas; la estandarización de las formas, que requiere el empleo de técnicas complejas de modelado, que conllevan una división de las acciones según las dimensiones y las partes de los recipientes que se realicen; las distintas técnicas de cocción, que requieren la utilización de hornos permanentes de doble cámara, con la inversión de trabajo necesaria, tanto para su mantenimiento, como para la obtención del combustible necesario pata su funcionamiento; debe inferirse un modo de producción relacionado con la existencia de talleres industriales, que sobrepasan el simple 
artesanado, siguiendo la terminología propuesta por Peacock (1982). Dichos talleres, estarían caracterizados por ser una producción especializada a tiempo completo, orientada a la obtención de un beneficio.

La falta de evidencias relacionadas con estructuras de producción cerámica, tanto en el yacimiento de Numancia, como en el de Izana, hace que, por el momento, no sea posible la aproximación a otros aspectos de la producción. De esta forma, no puede conocerse si habría más de un taller produciendo este tipo de cerámicas, si todos fabricarían las mismas o si, por el contratio, cada uno estatía especializado en la manufactura de tipos concretos.

No obstante, alguno de los rasgos tipificados por Peacock (1982) en la industria a gran escala, también estarían presentes en la producción numantina. Como, por ejemplo, el que la cerámica trascienda su carácter utilitario, para convertirse en un objeto con usos sociales o ideológicos (Amold, 1985, 157). Este aspecto, podría relacionatse con toda una gama de objetos cerámicos, en su mayoria no contemplados en esta investigación. No tanto para el caso de la abundante colección de pesas de telar y fusayolas, cuya funcionalidad parece bastante evidente (Arlegui y Ballano, 1995), sino por la existencia de una importante serie de exvotos, antropomotfos y zoomorfos, instrumentos musicales como trompas, bolas de barro y piezas cerámicas tipiftcadas, en este trabajo, como "juguetes" (Taracena, 1941, 76), que no son más que imitaciones, en pequeño tamaño, de algunas de las vasijas presentes en el catálogo general de la cerámica numantina.

La realización de grafitos, llevados a cabo, generalmente, sobre las superficies extemas de ciertos recipientes después de la cocción y, probablemente, cuando la pieza ya estaba en uso, podria también estar relacionada con algún hecho que trasciende el carácter utilitario de esta cerámica, aunque, por el momento, resulte extremadamente dificil adelantar alguna interpretación. Por lo demás, la presencia de grafitos es común en muchos conjuntos cerámicos celtibéricos. En Contrebia Belaisca (Botorrita, Zaragoza), incluso se sitúan sobre cerámicas campanienses (Beltrán, 1982). Asimismo, también son conocidos en cerámicas de la Edad del Hierro europea, entre otras, en cerámicas de Magdalensberg (Austria) o en cerámicas de Camulodunum (Colchester, Reino Unido) (Marco, 1990, 144).

De todos modos, en este tema habria que hacer algunas puntualizaciones, en relación a lo que se ha escrito sobre ellos en la bibliografia especializada, ya que, normalmente, se hace referencia a que en la cerámica de Numancia, es común la aparición de inscripciones pintadas aplicadas antes de la cocción. Estas inscripciones, compuestas por nombres en genitivo, se relacionan con la pertenencia de las piezas a grupos familiares concretos (Arlegui, $1992 \mathrm{~b}, 10$; 
1992 c, 486; De Hoz, 1988, 149; Jimeno et al, 1993, 27). Pues bien, en todo el conjunto cerámico de Numancia, sólo se ha detectado una inscripción con estas características (ver Apéndice I, ejemplar de la forma 19a de jarras de boca trilobulada, con número de inventario 11.874), lo cual indica que, de ninguna manera, puede considerarse un hecho generalizado. Lo normal, es que aparezcan signos sueltos, predominantes en cerámicas de la Fábrica 1, sobre todo, pertenecientes a copas de pie bajo (forma 13). Sin embargo, en el conjunto cerámico de Izana, sólo se ha detectado un grafito, realizado sobre un morteto (forma 14) (García Heras, 1993 a, 128).

\subsection{PROCEDENCIA DE LA CERÁMICA NUMANTINA}

Como ya se planteaba en los resultados del análisis estadístico, no se ha podido establecer un grado de correspondencia razonable, entre los datos composicionales aportados por el análisis de los sedimentos arcillosos y los aportados por el análisis de las cerámicas. Sólo cuando se han eliminado las concentraciones de $\mathrm{Ca}$, se ha conseguido asociar los sedimentos arcillosos calcáreos a una de las agrupaciones composicionales que presentaban las cerámicas, mientras que los sedimentos arcillosos no calcáreos y la muestra de caolín, presentaban composiciones muy diferenciadas, con respecto a dichas cerámicas. Esto significa, que el muestreo realizado en los alrededores de los yacimientos de Numancia e Izana, no ha sido suficiente para identificar las posibles fuentes de materia prima con las que se manufacturó la cerámica numantina. En cualquier caso, y dado que no es posible contar con evidencias directas que pudietan probar que, tanto en Numancia, como en Izana, pudo haberse producido cerámica, debe recurrirse, entonces, a criterios de validación, basados en argumentos no composicionales, que apoyen un origen local para estas producciones. En este sentido, no debe olvidarse que, en última instancia, como ya se adelantaba en el capítulo dedicado al marco teórico, las determinaciones de procedencia son siempre de carácter probabilístico y en muy contadas ocasiones se realizan, sólo y exclusivamente, con argumentos composicionales. De todos modos, el problema principal que presenta la producción cerámica numantina, se corresponde con uno de los retos fundamentales a los que se enfrenta el estudio arqueométrico de cerámicas arqueológicas, como es la determinación de centros de producción a escala intraregional, en los que las diferencias composicionales se establecen a una escala muy reducida, 
particularmente en aquellas regiones geográficas que presentan una geología muy homogénea.

El primeto de los criterios de validación utilizados, es el volumen de producción, ya que si estas cerámicas no procedieran de la zona, dificilmente se hubieran importado en estas cantidades. No obstante, el problema radica en conocer si toda la cerámica se producia en el centro principal, la ciudad de Numancia, o si, por el contrario, también se producía en centros secundarios como Izana, y parte de la cerámica hallada en Numancia procediera de centros como éste o viceversa. Un poco más adelante, se volvetá sobre la discusión de este punto.

El segundo de los criterios de validación, parte de la comparación de los datos obtenidos en esta investigación, con los datos consultados en el Mapa de Rocas Industriales (Hoja núm. 31 Soria) del I.G.M.E. Con la ayuda de este mapa, se han comparado los datos mineralógicos y geoquímicos de aquellas estaciones más próximas a los yacimientos de Numancia o Izana, dentro de los apartados de arcillas y arenas. De este modo, se ha podido comprobar que, las arenas caoliniferas de facies "utrillas", correspondientes al Cretácico Inferior, son las que más concordancias ofrecen con los grupos composicionales G-5 y G-6, establecidos en este trabajo. En general, se trata de arenas clatas, blancoamarillentas, pardas y rojizas, con frecuentes impurezas constituídas por hidróxidos de Fe. En la fracción gruesa predomina el Si, con la presencia de feldespato como mineral accesorio. Los datos de la estación 397, situada en el término municipal de Almazán, son bastante indicativos. Su composición mineralógica está constituida por cuarzo (59\%), caolinita (28\%), ilita (7\%) y calcita $(6 \%)$, mientras que su composición quimica, normalizada en \% en peso versus $\mathrm{Fe}$, para los elementos que coinciden con los analizados en esta investigación, presenta una concentración de 715,77 para el $\mathrm{Al}$, de 15,34 para el $\mathrm{Ca}$, de 22,96 para el $\mathrm{K}$ y de 2,83 para el Ti. Ambas series de datos resultan, en términos comparativos, muy similares a las obtenidas en los análisis de las cerámicas pertenecientes a las agrupaciones G-5 y G-6, aunque en éstas, los contenidos de $\mathrm{K}$, son siempre mayores. Por otro lado, las fases mineralógicas coinciden con las detectadas en estas cerámicas, aunque en ellas, también están presentes fases neoformadas constituidas por aluminosilicatos, que podrían proceder de una composición inicial similar, como resultado de la cocción. Por ello, a través de la lámina delgada se observan matrices rojizas y blancoamarillentas, mientras que en los difractogramas, se detecta un mayor o menor desarrollo de hematites, en función de la mayor o menor presencia de impurezas constituidas por hidróxidos de Fe.

Estos datos, podrían indicar que parte de las cerámicas numantinas, se han elaborado a partir de una fracción inferior a 0,3 o $0,4 \mathrm{~mm}$ (según los resultados del Análisis textural), seleccionada por levigado, de un sedimento constituido por arenas caoliníferas del Cretácico 
Inferior, mientras que el resto, en concordancia con el tratamiento estadístico una vez eliminado el Ca, podría haberse realizado con sedimentos arcillosos, fundamentalmente jurásicos, similares a los analizados, pero con menor contenido en carbonatos. El Mapa de Rocas Industriales, muestra composiciones mineralógicas muy parecidas a las detectadas en los sedimentos $\mathrm{N}-1, \mathrm{~N}$ 2 o $\mathrm{N}-7$, en estaciones situadas también en terrenos secundarios del Jurásico, aunque siempre con menores concentraciones en calcita.

De cualquier modo, y siguiendo los mapas geológicos del I.G.M.E (Hojas núm. 318 Almarza y 350 Soria), la única zona en la que afloran sedimentos de facies "utrillas", se sitúa en la Sierra de Carcaña, entre los términos de Chavaler y Canredondo de la Sierra, a unos $6 \mathrm{~km}$ aproximadamente del yacimiento de Numancia. Si efectivamente se utilizaton sedimentos de este tipo, con toda probabilidad, los talletes en los que se producía esta cerámica, se ubicarian más cerca de estos depósitos y, por tanto, más retirados de la ciudad de lo que siempre se ha supuesto. En todo caso, lo que sí es seguro, es que se situarian cerca de algún curso fluvial importante, quizás el Duero en este caso, no sólo por las necesidades de agua requeridas para esta producción, sino también porque se trata de un tipo de artesanado molesto y peligroso cerca de una ciudad, debido al fuego y al humo de las cocciones. Los talleres galo-romanos, por ejemplo, siempre se instalaron en la periferta de las ciudades (Dufay, 1994, 28). Asimismo, los ejemplos conocidos en otras partes del territorio celtribérico lo confirman igualmente (Sacristán, 1993, 497). Tanto las instalaciones alfareras de Padilla/Pesquera de Duero (Valladolid) (Sanz Mínguez y Escudero, 1991; 1995; Escudero y Sanz Mínguez, 1993), como las de Roa (Burgos) (Sacristán, 1986), se sitúan fuera del perímetro de la ciudad, al otro lado del río.

A este respecto, debe comentarse que, aunque las cerámicas no se han fabricado sólo y exclusivamente con caolín, al menos como el muestreado, precisamente, cerca de Chavaler, las opiniones expresadas en su día por Taracena (1924), parece que iban en la línea correcta, puesto que hay evidencias razonables como para suponer que se habrían fabricado con arenas caoliniferas procedentes de afloramientos próximos a esta localidad. Ahora bien, no parece coincidir la distancia de $2 \mathrm{~km}$ al $\mathrm{N}$ del yacimiento, señalada por este autor, ya que estos terrenos se sitúan en tomo a 5 o $6 \mathrm{~km}$, según los datos consultados en el mapa geológico del I.G.M.E.

Por otro lado, en lo referente al sedimento arcilloso muestreado en los alrededores de Izana, los datos más próximos que ofrece el Mapa de Rocas Industriales, se corresponden con estaciones de arcillas miocénicas rojas, intercaladas entre niveles de arenas y margas, situadas en las inmediaciones de Quintana Redonda, centro alfarero de época romana y moderna (Arlegui et al., 1993-94). En general, estas estaciones, identificadas con los númetos 306, 319 y 323, 
muestran una composición mineralógica muy similar a la que presenta el sedimento IZA, aunque, entre los minerales arcillosos, aparece a veces clorita, no detectada en ninguna de las muestras analizadas en este trabajo. Este dato, podría ser de interés para discriminar las materias primas de esta zona, a pesar de que la clotita es un mineral arcilloso muy común, aunque para confirmarlo, seria necesario recurrir a Análisis de difracción en agregados orientados, no realizados en esta investigación. En todo caso, los contenidos en calcita son muy elevados, tanto en los datos de las estaciones, como en los resultados de la muestra IZZA. Estos contenidos tan elevados, sin embargo, nunca están presentes en las cerámicas procedentes de Izana, lo cual podría indicar que, o bien existen sedimentos en la zona con una menor concentración de carbonatos, o bien que las cerámicas no se han manufacturado con las materias primas de esta zona, procediendo, quizás, de Numancia.

En cualquier caso, los resultados de esta comparación deben tomarse con cautela, ya que, ni las técnicas de análisis, ni los procedimientos experimentales, han sido, en ambos casos, los mismos. En este sentido, sería conveniente seguir experimentando con nuevos sedimentos procedentes de estas localizaciones, con el fin de asegurar al máximo estas aseveraciones.

En otro orden de cosas, la presencia de distintas sub-agrupaciones en las cerámicas analizadas procedentes de Numancia e Izana, podrían relacionarse con distintas unidades productivas, correspondientes a un solo taller o, a varios de ellos, aunque también podrían tener significado cronológico. En este sentido, por ejemplo, tesulta importante señalar que en los grupos G-5 y G-6 es en los que se concentran las cerámicas con decoración polícroma, cerámicas para las que se establecía, en general, una cronología más tardía (fines del siglo I a. C. 0 , incluso, inicios del Imperio) que para el resto de las producciones numantinas (Wattenberg, 1963, 36; Romero Camicero, 1976, 185-186). Fste aspecto, podria indicar que, o bien dichas producciones se realizaban en otros talleres, o bien que los talleres que habian venido produciendo cerámica numantina, cambiaran a lo largo de este siglo sus estrategias en la selección de la materia prima, obteniéndola de lugares distintos. En todo caso, lo que no parece probable es que, en el supuesto de que hubiera habido más de un taller, cada uno de ellos estuviera especializado en la producción de ciertos tipos, debido a que ninguna forma específica se concentra en una agrupación composicional determinada.

De esta manera, se pueden esbozar, de modo preliminar, tal y como se expone en la Figura 6.5, cuatro posibilidades distintas en la producción de la cerámica numantina, admitiendo que ésta se hubiera realizado en Numancia: 

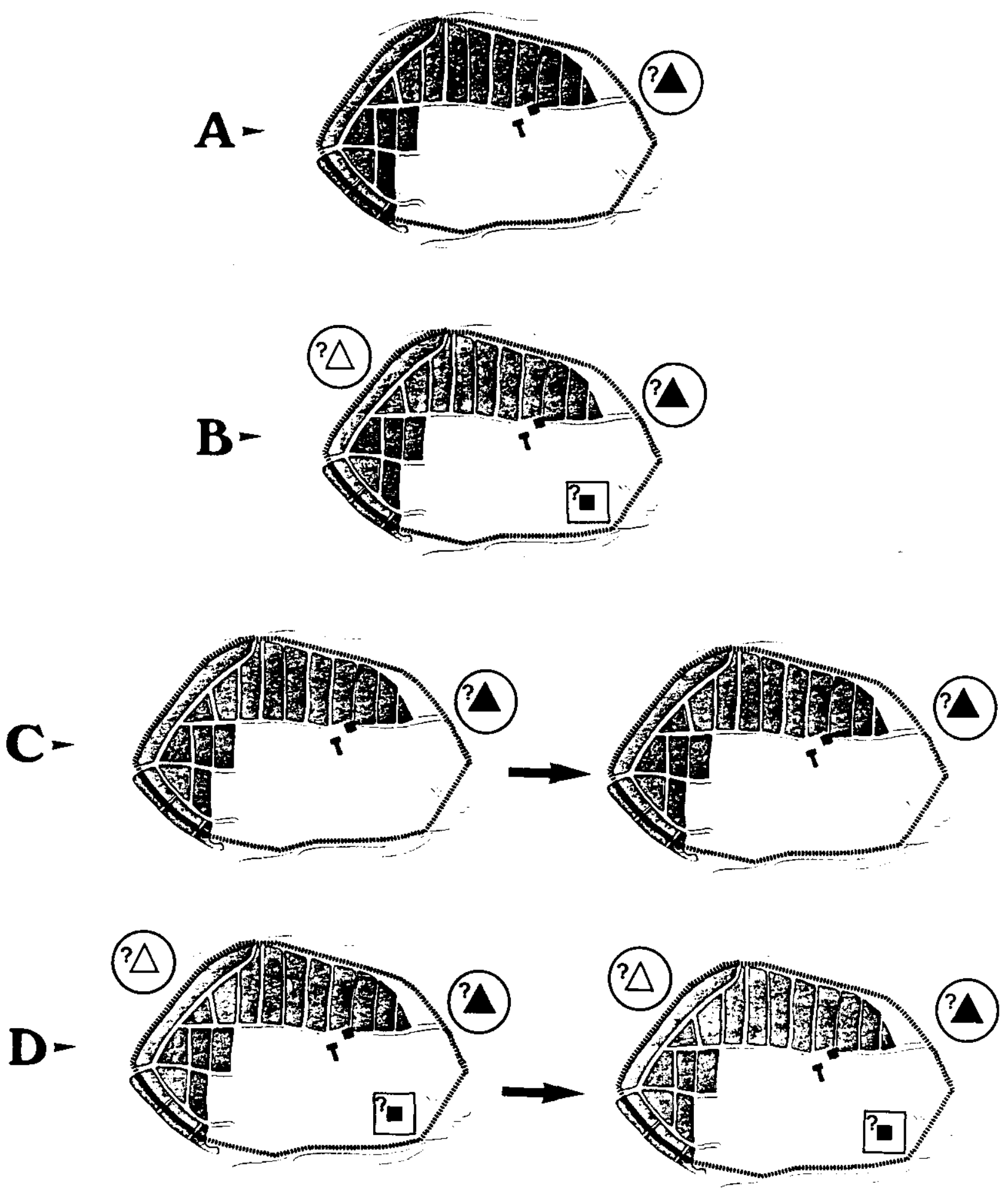

Figura 6.5: Posibilidades tcóricas de producción de la cerámica numantina. Los trángulos y los cuadrados represcntan los posibles talleres. Ii signo de interrogacion hace referencia a que su ubicación es desconocida. 
A) Que un solo taller realizara toda la producción a lo largo de todo el siglo I a. C.

B) Que varios talleres produjeran cerámica durante todo este siglo.

C) Que un solo taller tealizara toda la producción durante el siglo I a. C. y que cambiata sus estrategias de selección de materia prima a lo largo del tiempo o, por otro lado, que un taller primeto y, otro distinto después, utilizando una materia prima diferente, fueran los que hubieran producido cerámica en este periodo.

D) Que varios talleres realizaran toda la producción durante el siglo I a. C. y que cambiaran sus estrategias de selección de materia prima a lo largo del tiempo, o bien, que varios talleres primero y, otros distintos después, utilizando una materia prima diferente, fueran los que hubieran producido cerámica en este periodo.

De todas formas, lo que sí ha quedado patente, en los resultados expuestos en el capitulo anterior, es que no es posible diferenciar, ni por critetios mineralógicos, ni por criterios composicionales, las cerámicas del yacimiento de Numancia, de las provenientes del yacimiento de Izana. Únicamente se constata que, las cerámicas de Izana, nunca están presentes en las agrupaciones G-5 y G-6, agrupaciones en las que predomina la Fábrica 1-b y las decoraciones policromas, como se apuntaba anteriormente. Este aspecto, podría indicar que, al menos, las cerámicas de los grupos G-5 y G-6, se han manufacturado en talleres de Numancia y que, por distintas razones, no han alcanzado los yacimientos secundarios como Izana. No obstante, si se admite una cronologia distinta para estas producciones, la ocupación del yacimiento de Izana, podría no haber alcanzado el cambio de era.

La incertidumbre teórica que representa el no poder discriminar, por criterios composicionales, ambas ptoducciones, bace que, en tanto no se conozcan evidencias directas relacionadas con la manufactura de cerámicas, la procedencia de estos dos conjuntos cerámicos, se inscriba en dos Zonas de Conjunción, es decit, zonas que presentan características composicionales similares, en este caso, debido a la homogeneidad geológica del área de estudio, pero en las que no es posible realizar una atribución de origen exacta para ninguna de ellas (Picon, 1984, 431; 1993, 10). No obstante, en este aspecto, juega un papel determinante la técnica de análisis utilizada, puesto que cuanto mayor es el poder de resolución de una técnica, mayores son las posibilidades inferenciales de los datos obtenidos. Por esta razón, estas 
conclusiones serán válidas, en tanto en cuanto no se utilice un método de análisis con mayor resolución multielemental, que permita poder discriminar, si es posible, las producciones de Numancia e Izana. Es por ello, por lo que la investigación que actualmente se lleva a cabo con la Fluorescencia de rayos x por reflexión total (TXRF), está encaminada a explorar las posibilidades instrumentales de esta técnica, para determinaciones cuantitativas absolutas, en el estudio de materiales cerámicos arqueológicos.

Para el caso de los pigmentos utilizados en la decoración, la localización de la procedencia puede ser algo más complicada. No con respecto a los pigmentos rojo o blanco, los cuales pudieron haberse obtenido a partit de las fracciones más finas de los sedimentos utilizados en la fabricación de las cerámicas, sino en teferencia al pigmento negro, obtenido a partir de un material tico en $\mathrm{MnO}$, como ya se ha señalado anteriormente. En este sentido, la consulta del Mapa Metalogenético (Hoja 31 Sorta) del I.G.M.E., indica que, un material de estas características, puede obtenetse en la zona. En este mapa, hay tres estaciones próximas que presentan óxidos e hidróxidos de $\mathrm{Mn}$, de proceso genético sedimentario $\mathrm{y}$, por tanto, fáciles de explotar. Una de ellas, la número 16 , se localiza a unos $4,6 \mathrm{~km}$ del yacimiento de Numancia; la número 18 , a unos $5 \mathrm{~km}$; mientras que, la número 19 , se sitúa fuera ya del término municipal de Soria, a una distancia aproximada de $7,3 \mathrm{~km}$ de la ciudad de Numancia.

Por último, un punto importante en la discusión de la procedencia de la cerámica numantina, son los resultados obtenidos en el análisis de aquellas cerámicas provenientes de fuera del área del Alto Duero, que presentaban motivos y técnicas decorativas similares. Desde un punto de vista composicional, estas cerámicas se asocian siempre a grupos específicos, que indican una genética distinta para su materia prima, en relación a las cerámicas procedentes de Numancia o Izana.

Asi pues, las muestras procedentes de Langa de Duero, se asocian al grupo G-7. No obstante, una de ellas, la LD-95, se sitúa en la agrupación G-3, aunque, como se comprobaba en el Análisis discriminante, su elevada distancia de Mahalanobis con respecto al centroide de este grupo, la convertía en una muestra que presentaba diferencias importantes con esta agrupación. Por otra parte, tanto las muestras de El Palomar, como las de Pinilla Trasmonte, se asocian a grupos difetentes. Las primeras se sitúan en el grupo G-4B, mientras que, las segundas, lo hacen en el G-2A. Estas últimas, además, se han realizado con materias primas calcáreas, un rasgo que las diferencia netamente de las de Numancia, debido a que, en este asentamiento, apenas hay cerámicas manufacturadas con este tipo de materias primas. 
En definitiva, estos resultados demuestran que la cerámica numantina no traspasó los límites del Alto Duero. Por lo tanto, aquellas cerámicas que presentan decoraciones polícromas - motivos decorativos numantinos, deben ser producto de imitaciones locales. Eso sí, imitaciones locales elaboradas bajo la misma tradición cerámica, puesto que se han manufacturado a partir de Secuencias de Producción muy similares. En todo caso, es importante incidir en las limitaciones que tiene cualquier intento de generalización, sobre todo, a partir de un número de muestras tan reducido. Por ello, esta afirmación debe admitirse con un criterio abierto, ya que, el análisis de nuevos fragmentos cerámicos procedentes de otras áreas, podría hacet vatiar estas conclusiones.

\subsection{FUNCIONALIDAD}

Aunque la funcionalidad no forma parte, en sentido estricto, de la Secuencia de Producción, en buena medida condiciona toda esta secuencia, ya que, en última instancia, los recipientes cerámicos se fabrican para cumplir alguna función.

Tanto por su tipología, como por las características estructurales que presentan, la funcionalidad de las cerámicas pertenecientes a las Fábricas 1, 1-b y 2, debió estar relacionada, principalmente, con el consumo de alimentos y bebidas y con el almacenamiento de provisiones. Así parecen indicarlo la mayoría de las piezas, cuya tipología responde a formas habituales en una vajilla de mesa, esto es, cuencos, platos, tazas, copas o jarras, aunque también estarian presentes formas de grandes dimensiones, relacionadas con el almacenamiento, como las grandes vasijas o las tinajas. Una vajilla de mesa se utiliza, generalmente, para servir y para comer o beber alimentos y bebidas, unas actividades que suelen realizarse en compañía. Es por ello por lo que son precisamente estas formas, las que muestran una decoración más profusa y elaborada, aunque siempre bajo unos esquemas compositivos fijos. La Figura 6.6 expone, gráficamente, estos aspectos.

En líneas generales, al tratarse de materiales procedentes de excavaciones antiguas, no es posible contar con muchos datos contextuales que apoyen estas cuestiones. No obstante, en algunas de las memorias de estas excavaciones, se alude a que las grandes vasijas de provisiones, solían aparecer, en Numancia, alineadas a las paredes de las bodegas situadas debajo de las viviendas (Taracena, 1924, 20; 1941, 73; Arlegui, 1986, 71; Jimeno et al., 1993, 30). Incluso, en 


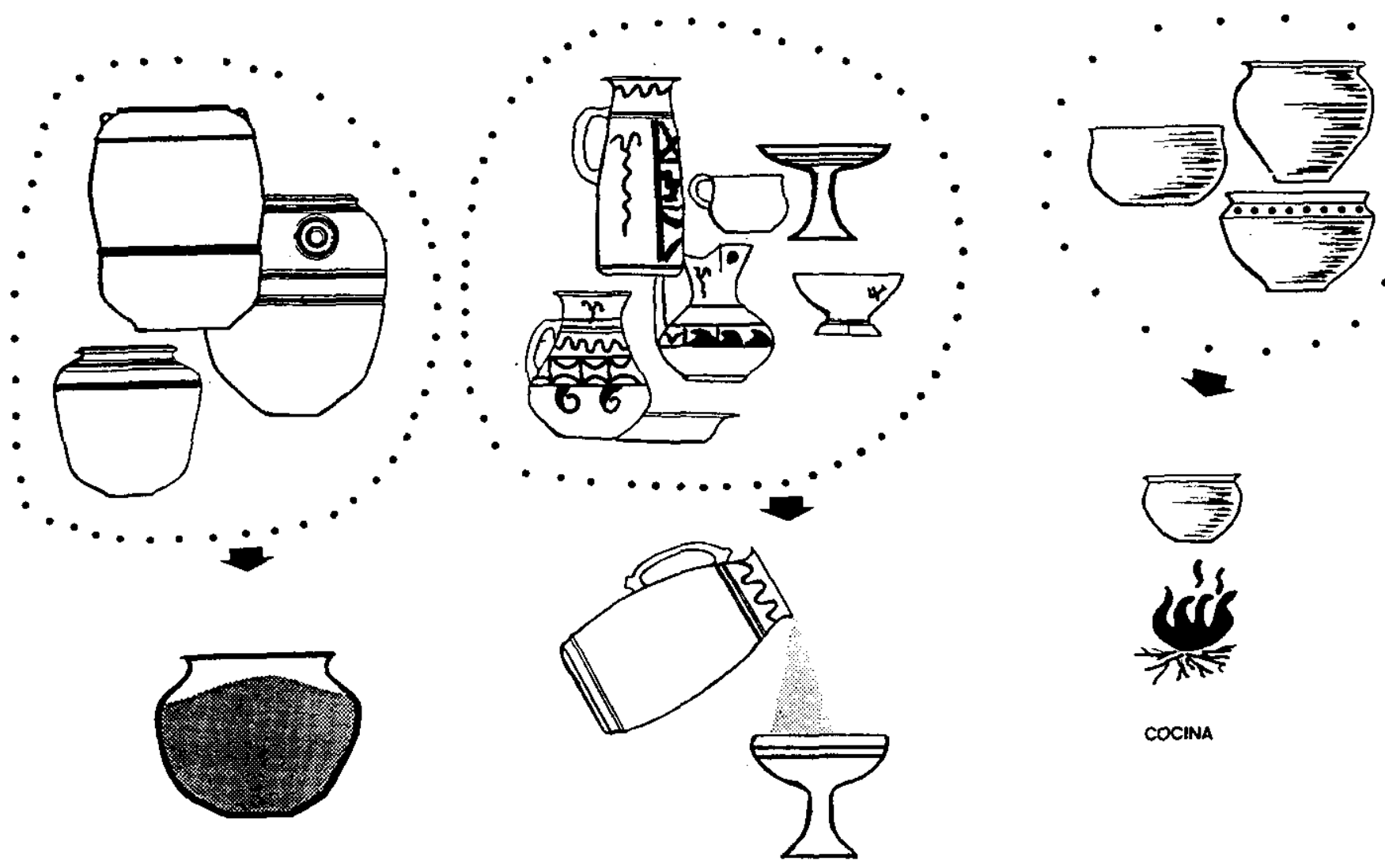

VAJILLA

Figura 6.6: Posible funcionalidad de la producción cerámica numantina. La función de almacenamiento y vajilla se ha inferido para las cerámicas pertenecientes a las Fábricas 1, 1-b y 2, mientras que las de la Fábrica negra se han considerado cerámicas de cocina que pueden ser expuestas al fuego.

una de las tinajas aparecidas en el asentamiento de Los Castejones de Calatañazor (Soria), se halló una buena cantidad de trigo en su interior (Taracena, 1926, 21). El almacenamiento de provisiones en contenedores de estas características, parece que era un hecho bastante común en los asentamientos de esta época, a tenor de lo que dice Plinio en su Historia Natural, en la que señala que las habas y legumbres metidas en tinajas llenas de aceite y cubiertas de paja, pueden conservarse durante largo tiempo (Plinio, Nat. Hist., XVIII, 73, 306).

La funcionalidad, sin embargo, de las cerámicas pertenecientes a la Fábrica negra, parece haber sido bastante distinta, ya que ésta debió ser la cerámica de cocina que se ponía directamente al fuego para preparar los alimentos (Figura 6.6). Por este motivo, las piezas de esta fábrica, suelen estar mucho menos decoradas. 
Como ya se ha apuntado en otras partes de esta Tesis Doctoral, hay que señalar que la selección a la que han sido sometidos los materiales cerámicos de Numancia, basada principalmente en criterios estéticos, puede haber incidido, de manera importante, en la conservación del conjunto constituido por las cerámicas negras, al ser consideradas éstas de una calidad inferior. Por tanto, es muy probable que su número, en términos comparativos, sea mucho menor al que realmente apareció en las excavaciones de principios de siglo. No debe olvidarse que, como señala Sacristán $(1986,198)$, los vasos de cocina elabotados a totno, son tal vez las especies más olvidadas en los estudios sobre la alfareria celtibérica.

A excepción de algunos ejemplares pertenecientes a otros tipos, la mayoría de las piezas de cerámica negra se concentran en la forma 9 de vasijas globulares, una forma que podría resistir satisfactoriamente los choques térmicos producidos por el contacto con el fuego, por sus contornos simples, por la uniformidad de sus paredes, por la ausencia de ángulos muy marcados o por presentar fondos redondeados con umbo (Bronitsky, 1986, 227). De todas formas, un aspecto que no encaja en la interpretación de la cerámica negra como cerámica exclusiva de cocina, es la presencia de piezas, entre otras, en las formas 13 y 15 de copas, en la forma 10 de embudos, en la forma 11 de platos, en la forma 19 de jarras de boca trilobulada o en ejemplares relacionados con trompas (ver Figura 5.2). Aunque el número de ejemplates con estas tipologías no es muy importante, quizás habría que pensar que estas formas sirvieran pata manipular o servir líquidos calientes. De cualquier modo, los datos contextuales que se conocen para este tipo de cerámica que pudieran apoyat esta funcionalidad, son bastante escasos. Únicamente, en la memoria de la excavación del yacimiento de Izana, Taracena señala la aparición de un lote de vasos de cerámica negra, junto a un hogar adosado al muro de una de las viviendas (Taracena, $1927,8)$.

Otro aspecto importante, lo constituye la presencia de calcita criptocristalina machacada, añadida intencionadamente a la pasta con un rango de tamaño de particula uniforme, en algunas de las cerámicas pertenecientes a esta fábrica. Este hecho, sin duda, puede estar relacionado con las propiedades térmicas que presenta este material, ya que la calcita monoctistalina previene la formación de fracturas que podrian producirse como consecuencia del choque térmico, cuando una pieza cerámica se somete a procesos de calentamiento o enfriamiento rápido, como los acaecidos al poner o retirar el recipiente del fuego (Shoval et al., 1993, 269). La calcita previene la formación de fracturas, debido a que tiene un coeficiente de expansión térmica muy similar al de las arcillas (Hoard et al., 1995, 825; Rye, 1988, 127; Rice, 1987, 229). 
Sin embargo, como ya se selañaba en los resultados del Análisis macroscópico, habia dificultades para identificar las cerámicas de esta fábrica que contenían calcita añadida, cuando no se tenía acceso a una fractura fresca. En cualquier caso, como también se ha tenido oportunidad de señalar, las cerámicas sin calcita, presentaban una menor selección del tamaño de grano, así como una gran macroporosidad constituida, básicamente, por poros de morfología alargada. Este aspecto, podría estar relacionado, igualmente, con la misma funcionalidad. Por un lado, porque un mayor tamaño de las inclusiones favorece el incremento de la porosidad y, por otro, porque un material con un volumen de poros importante tiene mayor tesistencia, ya que el choque térmico se distribuye regularmente (Bronitsky y Hamer, 1986, 97). La conductividad térmica está afectada directamente por la porosidad, por ello, el tamaño y la morfología de los poros resulta determinante para que el calor circule de forma adecuada a través de ellos (Rice, 1987, 368).

Es importante, por último, recordar que, ya Taracena, en su trabajo sobre la cerámica numantina publicado en 1924, adelantaba funcionalidades similares para los distintos tipos de manufactura en los que clasificaba el material procedente de Numancia, los cuales coinciden, casi en su mayoría, con las fábricas macroscópicas definidas en esta Tesis Doctoral. Así, este autor apuntaba que los vasos rojos (aquí la Fábrica 1) y las cerámicas que él tipificaba como amarillas o gris blancuzcas (la Fábrica 1-b), ambas cocidas en fuego oxidante según su terminologia, resultaban adecuadas para consumir alimentos y bebidas; mientras que la cerámica que consideraba carbonosa, por la adición de carbón pulverizado a la pasta y por estar cocida en fuego reductor (la Fábrica negra), podía ser utilizada como cerámica de cocina. Por otro lado, aquellas cerámicas que clasificaba como ahumadas (la Fábrica 2), también cocidas en fuego reductor, las consideraba como la vajilla doméstica de uso diario de los numantinos, quienes relegaban la utilización de los vasos tojos y blancoamarillentos para ocasiones especiales (Taracena, 1924, 8-14).

\subsection{ALTERACIONES Y CONTAMINACIONES}

Como ya se indicaba en el capítulo referente al marco teórico, la correcta caracterización de un conjunto cerámico exige el reconocimiento de los posibles procesos de alteración y contaminación sufridos por el material. En líneas generales, y al margen de los factores que 
pudieron influir durante el uso de la cerámica o, incluso, cuando ésta se recuperó en las labores de excavación, estos procesos están determinados por las características estructurales de la cerámica, así como por las características del medio que la ha conservado y en el que ha permanecido enterrada (Maggetti, 1982, 129).

Una de las contaminaciones detectadas a través del Análisis petrogxáfico, es la deposición de calcita secundaria de aporte externo en 49 de las muestras cerámicas analizadas. La deposición de calcita micrítica, procedente de soluciones carbonatadas, en las superficies y en los poros, es un hecho habitual en cerámicas que han permanecido enterradas en medios calcáreos, siendo muchos los trabajos en los que se menciona su aparición (p. e. Vendrell $\underline{\underline{\text { Saz et }}}$ al. 1992, 4). A pesar de que siempre se ha tetirado por medios mecánicos a la hora de obtener las muestras para los distintos análisis, su incidencia en el interior del fragmento resulta dificil de valorar. Entre otras causas, porque la mayoría de las muestras procede de excavaciones antiguas y no se conoce ningún dato sobre las características de los sedimentos en los que se encontraban enterradas.

A este respecto, y aunque de ninguna manera los resultados son comparables, debido a las distintas características de los materiales, puede resultar indicativo el que, en las pruebas realizadas para determinar si se han producido efectos diagenéticos en los restos óseos procedentes de la necrópolis de incineración de Numancia, por medio del análisis de elementos trazas mediante Espectroscopía de plasma de acoplamiento inductivo (ICP-AES), no se hallan detectado contaminaciones en Ca (Jimeno et al., 1993-94; Jimeno y Trancho, 1996). De hecho, las concentraciones de este elemento en las muestras de sedimento tomadas a 0,15 y $25 \mathrm{~cm}$ del hueso, son similares a las obtenidas en el análisis del sedimento arcilloso $\mathrm{N}-4$, de igual procedencia. La muestra N-4 pertenecía, además, al sedimento arcilloso menos calcáreo de todos los analizados. Este aspecto, unido a los datos que se poseen para la muestra N-7, tomada en el mismo cerro de La Muela donde se ubica el yacimiento, y también con bajas concentraciones de $\mathrm{Ca}$, hacen suponer que estas deposiciones de calcita, no han afectado, de forma importante, a los fragmentos cerámicos, si se asume que éstos podrían haber estado enterrados en un sedimento de similares características.

Dado que la calcita está presente en la mayoría de las muestras analizadas y que en casi todas ellas se han detectado fases neoformadas durante el proceso de cocción, resulta difícil, igualmente, determinat si parte de esta calcita es primaria o secundaria de recarbonatación, debido a la alteración de estas fases de cocción (Buxeda y Cau, 1995, 299). Un fenómeno de estas características sí parece haberse producido en las muestras N-27, IZA-2, IZA-2BIS y 
LD-95. Principalmente, porque la presencia de calcita primaria, seria incompatible con la temperatura de cocción equivalente estimada para estas muestras. En el caso de la N-27, la temperatura de cocción equivalente se situaba en torno a los $900^{\circ} \mathrm{C}$. En ese rango de temperatura, la cocción experimental de los sedimentos arcillosos calcáreos, nunca muestra reflexiones tan pronunciadas en esta fase. Bien es cierto que, posiblemente, esta calcita no tenga las mismas características en lo que se refiere al tamaño de partícula, al tipo de cristalinidad, etc., que podrian influir en un retardo de su disociación. Sin embargo, la presencia de aluminosilicatos de Ca como la anortita o la gehlenita, podrian haber contribuido a la formación de cierta cantidad de calcita secundaria. Este fenómeno, parece más evidente en las muestras IZA-2 e IZA-2BIS, cuya temperatura de cocción equivalente se situaba en torno a los $1.000^{\circ} \mathrm{C}$, por la presencia de fases de alta temperatura como la mullita o el corindón. La sobrecocción y la presencia de estas alteraciones, pueden ser las responsables de que, en el análisis estadístico, estas muestras fueran consideradas como "outliers". El mismo comentario es válido también para la muestra LD-95. Por ello, se asociaba a un grupo distinto al del resto de las muestras procedentes del yacimiento de Langa de Duero. Según puede observarse, y tal y como han ser̃alado algunos autores (p. e. Freestone y Rigby, 1988), este tipo de alteración se correlaciona con la presencia de cerámicas cocidas a alta temperatura.

Entre las fijaciones más habituales que presentan los materiales cerámicos, se encuentran las relacionadas con los elementos $\mathrm{Ba}, \mathrm{Sr}, \mathrm{Na}, \mathrm{P}, \mathrm{Fe}, \mathrm{Mn}$ o $\mathrm{Cu}$, aunque, como ya se ha adelantado anteriormente para la calcita secundaria, su determinación, en muchas ocasiones, resulta extremadamente complicada. En este caso, se han detectado fijaciones de $\mathrm{Cu}$ en la muestra N-69 y de Cu y As en las muestras NP-72 y NP-79. Por este motivo, al presentar discrepancias en estos elementos en relación al resto de las muestras analizadas, la N-69 y la NP-72 eran consideradas "outliers", mientras que la NP-79, mostraba una distancia de Mahalanobis excesivamente alta al centroide del grupo G-4A, que era la agrupación en la que quedaba incluida.

Según algunos investigadores, el Cu se fija a las cerámicas por la proximidad de afloramientos de este metal o por la proximidad a objetos de $\mathrm{Cu}$ durante el enterramiento (Picon, 1985; Walter y Besnus, 1989). En la zona de estudio, puede descartarse la primera de las posibilidades, puesto que no existen afloramientos de este metal en las cercanías del yacimiento de Numancia. Por lo tanto, estas fijaciones podrian haberse producido por el contacto de los fragmentos con algún objeto fabricado con $\mathrm{Cu}$. En el estudio de los testos óseos de la necrópolis aludido más arriba, también se descartan los efectos diagenéticos desde el suelo al hueso para el 
$\mathrm{Cu}$, indicándose que si los ha habido, se han producido por el contacto del hueso con objetos del ajuar elaborados con un metal como éste (Jimeno et al., 1993-94). En cualquier caso, parece seguro que las elevadas concentraciones de $\mathrm{Cu}$ que presentan estos ejemplares, exceden la variabilidad natural observada en el conjunto de las muestras analizadas. Por otro lado, un origen foráneo también puede ser descartado, puesto que la tipología que presenta la muestra N-69, única de las tres en la que ésta puede ser reconocida y que se corresponde con una vasija globular de la forma 9, es una de las más comunes en el asentamiento de Numancia.

Finalmente, tanto las contaminaciones de $\mathrm{As}$, como las de $\mathrm{Cu}$, de las muestras NP-72 o NP-79, podrian, quizás, ponerse en relación con alguno de los procesos de restauración al que fueron sometidos ciertos fragmentos con decoración polícroma (ver apartado 4.3.5) que, sin duda, han modificado las características composicionales originales de los mismos.

\subsection{INTEGRACIÓN DE DATOS Y SÍNTESIS HISTÓRICA}

Trabajar en un nivel de conjunción, que implica no poder realizar una atribución de origen exacta a partir de datos composicionales, puesto que no se manejan materiales procedentes de hornos o talleres cerámicos, conduce a contemplar los yacimientos de Numancia o Izana como centros de consumo de cerámica, independientemente de que ésta proceda de sus zonas de influencia más inmediata (Bennett et al, 1989). De esta forma, es preciso valorar cómo se interrelaciona la demanda de este material con el contexto socio-económico del siglo I a. C. Es importante entender que la tecnología cerámica evoluciona en función de la demanda social, de modo que, el desarrollo de esta tecnología, debe contemplarse siempre como una consecuencia del cambio social y nunca como su causa (Kingery, 1984, 171; Rye, 1988, 3).

En esta investigación, el desarrollo de la producción cerámica numantina, se contempla como una consecuencia de los cambios socio-económicos y culturales acaecidos en el Alto Duero a lo largo del siglo I a. C., debidos al inminente proceso de romanización de esta zona geográfica.

El siglo I a. C., plena etapa republicana, no es un momento cronológico excesivamente bien conocido desde el punto de vista histórico. En realidad, después de la caída de Numancia ễ el 133 a. C. tras el asedio de Escipión y su posterior repoblamiento, no se sabe a ciencia cierta qué es lo que pasa en esta parte del territorio celtibérico. A través de las fuentes clásicas, puede 
llegarse a la conclusión de que en torno a los años 75 y 74 a. C., las guerras sertorianas jugaton un papel importante en los asentamientos de esta zona, pero tampoco se conoce cómo influyeron en el ámbito general de esta comarca. Taracena, en las excavaciones que realizó a principios de siglo en muchos de los poblados de esta zona, situaba el fin de los mismos en torno a estas guerras, ante la falta de evidencias arqueológicas que pudieran sugerir un contexto ya romanizado. Sin embargo, esta visión comienza a superarse en la actualidad a raiz de los trabajos de prospección, que han constatado el surgimiento, durante toda esta etapa, de nuevos lugares de asentamiento que hay que relacionar con la irrupción de un nuevo sistema de explotación económica del territorio, orientada al aprovechamiento agrícola extensivo y, en consecuencia, con un nuevo orden socio-cultural, a pesat de que los diferentes sitios no ofrezcan una cultura material netamente diferenciada de la del periodo anterior, a excepción de la presencia de cerámicas campanienses (Borobio, 1985; Revilla, 1985; Pascual, 1991; Morales, 1995; Romero Carnicero, 1992). En este sentido, la cerámica numantina, al ser ya una producción de etapa romana, podría relacionarse mejor, desde un punto de vista tecnológico, con las cerámicas de tradición indigena, más que con las cerámicas propiamente celtibéricas.

De cualquier forma, tras las guerras sertorianas, la ciudad de Numancia vive un periodo de auge económico, motivado, entre otras causas, por su excelente localización geográfica, que la sitúa junto a una de las vías de comunicación más dinámicas de la época, como eta la vía que discurría entre Asturica (Astorga) y Caesaraugusta (Zaragoza) (Wattenberg, 1963, 30; Jimeno et al., 1993, 12). Aunque Numancia nunca realizó emisiones monetales (Burillo, 1995, 164), los hallazgos de monedas ibéricas autónomas e hispanorromanas, confirman este auge económico, poniendo de manifiesto la existencia de un amplio metcado que rebasa los límites locales e, incluso, regionales (jimeno y Martin, 1995, 187).

El inventario de estas monedas, puede reflejar la dirección que tenían algunos de estos contactos comerciales. En las excavaciones de la ciudad de Numancia, se halló un conjunto de unas 230 monedas que se clasifican del siguiente modo: una dracma ampuritana, 65 acuñaciones de tipo y leyenda ibérica, 143 de cecas hispanorromanas y 21 indeterminadas (Romero Carnicero y Martín Carbajo, 1992, 674). La mayoria de las monedas ibéricas, se fechan en la primera mitad del siglo I a. C. En general, son ases de bronce y denarios de plata, que indican relaciones comerciales, básicamente, con ciudades y territorios del valle del Ebro (Jimeno et al., 1993, 50). Así, se documentan 3 monedas con la leyenda de Arecoratas, 2 de Arsaos, 2 de Arse, 4 de Bascunes, una de Beligiom, 6 de Bilbilis, 16 de Bolskan, una de Caiscata, una de Castulo, 5 de Celse, una de Contrebia Carbica, 2 de Ilitirta, una de Kesse, una de Salduie, una de Salama, 7 de Sekaisa, 3 de Segia, 6 
de Segobirices, una de Segotias, 60 de Sesars, 2 de Seteiscen, 4 de Turiasu, 2 de Undicescen y una de Usamus. Por el contrario, las monedas hispanorromanas, las cuales se fechan en la segunda mitad del siglo I a. C. y en los primeros años de la era, son tnás numetosas, documentándose 21 con la leyenda de Bilbilis, 16 de Caesaraugusta, 23 de Calagurris, una de Carbula, 7 de Cascatum, 30 de Celsa, 5 de Clunia, una de Emerita, 2 de Ercavica, 2 de Gracumis, 4 de Osca, una de Saguntum y 31 de Turiasu. Estas últimas, también confirman las relaciones con el valle del Ebro (Romero Carnicero y Martín Carbajo, 1992, 678).

La dirección de estas relaciones comerciales, explicaría el hecho de que aparezcan cerámicas con motivos decorativos numantinos en yacimientos del valle del Ebro, tal y como se exponía en el capítulo 3. En este sentido, es muy significativo que en un asentamiento como el de El Castelillo de Alloza (Teruel), se haya documentado un ejemplar de trompa, como los hallados en la ciudad de Numancia (Atrián, 1959, 231). Por otro lado, en ese mismo capítulo, también se indicaba que, tanto estas cerámicas, como las que presentaban decoración polícroma, aparecian, del mismo modo, en un buen número de yacimientos del Duero medio. Sin embargo, la documentación de telaciones comerciales con esta zona geográfica a través de la numismática, resulta más problemática, debido a que en el territorio vacceo no hubo cecas (Burillo, 1995, 167).

De uno u otro modo, el auge económico de Numancia y sus contactos comerciales, tuvieron que influir en la difusión y el conocimiento de sus producciones cerámicas fuera de su territorio. Por ello, estas producciones se imitaron en otro lugares, como demuestra el estudio composicional realizado en esta investigación, hasta el punto de que en la necrópolis de El Pradillo (Pinilla Trasmonte, Burgos), un número importante de gente fue enterrada con ajuares compuestos por jartas de boca trilobulada, decoradas en el más puto estilo numantino. También resulta significativo que en el castro del Alto de San Pedro, un asentamiento con 17 hectáreas de extensión al que se asocia esta necrópolis y en el que, igualmente, se han documentado relaciones comerciales con el valle del Ebro a través de las monedas, principalmente con la leyenda de Sekobirikes, halladas en su excavación (Moreda y Nuño, 1990, 180; Sacristan y Ruiz Vélez, 1985, 208), pudiera habet artesanos capaces de ejecutar estas imitaciones.

El cambio producido por la irrupción de la política romana, el incremento del número de asentamientos y el crecimiento de los mismos, hacen surgir unas nuevas necesidades, no sólo físicas, sino también culturales, como puedan ser nuevos modos de vida o nuevas costumbres, que producen un incremento en la demanda de productos cerámicos. Estas nuevas necesidades, son las que hacen posible el desarrollo de una producción especializada de cerámica en torno a la ciudad de Numancia, realizada con la introducción de una tecnología romana, que se manifiesta 
en unas Secuencias de Producción totalmente estandarizadas, con las que se elaboran productos de mayor calidad.

En cualquier caso, esta situación tendráa su origen en la antetior, ya que, como acostumbraba a hacer Roma tras incorpotar un nuevo territorio, se servía, primero, de la herencia indígena que encontraba, transformándola después, según sus necesidades. No puede olvidarse que, es ya desde el siglo III a. C., cuando comienzan a desarrollarse las ciudades en los territorios celtibéricos, articulando áreas en torno a su zona de influencia, al menos, en lo que respecta a la Celtiberia Citerior (Fatás, 1987, 14). Este desarrollo, va a llevar implícito la disolución de su sistema tradicional de parentesco, que ahora se organiza en torno a familias restringidas, como demuestra la epigrafía (De Hoz, 1988). Los cambios ligados a esta nueva organización territorial, van a set los tesponsables de un nuevo sistema de acceso a la tierra y, por tanto, a la propiedad, que ya no está ligada a los vínculos de parentesco, sino que sólo va a ser accesible a los miembros de estas familias. Estos factores, son los que posibilitan que la tierra y la riqueza se concentre en unas pocas manos (Ruiz-Gálvez, 1990; 1991).

Pues bien, esta es la situación que se encuentran los romanos y que van a potenciar. Es importante resaltar que Roma siempre se decantó en favor de las élites dominantes locales en la anexión de nuevos territorios, lo cual sirvió para incrementar las desigualdades sociales ya existentes (Beltrán, 1988, 136). Estas élites, en posesión de los recursos y, por consiguiente, de la posibilidad de acceder a unos círculos comerciales, serían las responsables de un consumo masivo de cerámica, relacionado con la introducción de un nuevo modo de vida que, sin duda alguna, haria incrementar la demanda y la apreciación de este tipo de productos. Es por ello, por lo que la mayoria de los recipientes forman parte de las vajillas domésticas. Asimismo, dentro de este contexto, y asumiendo que las producciones numantinas no pueden ser consideradas una alfarería de lujo por su carácter eminentemente funcional, es en el que debe entenderse la presencia de cerámicas con un mayor valor estético, como podría ser el caso de las que se decoran con motivos polícromos, ya que su porcentaje sólo representa el $8,3 \%$ del conjunto cerámico del yacimiento, o la cerámica campaniense de procedencia foránea, que podría ser considerada un producto exótico y constituir un símbolo de "estatus" social.

Un aspecto que resulta importante comentar, está relacionado con la decoración que presentan la mayor parte de los recipientes. Según puso de manifiesto Romero Carnicero (1976, 1982), la mayoría de los motivos decorativos pintados, estarian conectados con una exaltación de la temática indígena. Si estos motivos se contemplan como un vehículo de expresión ideológica, con un valor simbólico que contribuiria a reforzar la identidad y la cohesión de la comunidad, 
amenazada por el avance de la romanización, sería difícil aceptat que ésta fuera la cerámica consumida por el conjunto de la sociedad. En este sentido, parece más lógico pensar que los motivos decorativos estén basados en la explotación, como moda, de una tradición común que conocía de sobra el pueblo arevaco. En todo caso, el carácter ampliamente especulativo de estas afirmaciones, hacen que esta cuestión deba dejarse abierta a nuevas hipótesis interpretativas.

Con toda probabilidad, el desatrollo de la producción cetámica numantina, estatía en conexión con otras producciones artesanales, puesto que en los yacimientos de Numancia o Izana, aparecen importantes conjuntos de objetos metálicos. Ante estos datos, aunque tampoco haya evidencias que lo prueben, seria factible aceptar que también existiese una producción metalúrgica a cierta escala. Hay que tener en cuenta que la cerámica, dada su ubicuidad por su buena predisposición a la conservación, puede estar ocultando la importancia de otras producciones artesanales, haciendo sobrevalorar este tipo de manufactura.

En otro orden de cosas, la definición de Zonas de Conjunción para las muestras analizadas procedentes de Numancia e Izana, no permite, por el momento, un acercamiento a las distintas escalas de distribución cerámica a nivel intra-regional. No obstante, y a partir de los datos del Análisis macroscópico, parece probado que en Izana, un centro secundario en el contexto del Alto Duero, no se consumen, o no se producen, las mismas formas tipológicas ni los mismos tipos de manufactura que en la ciudad de Numancia. En este asentamiento, no aparece todo el repertorio tipológico de Numancia, no hay cerámicas con decoración polícroma, mientras que las piezas de campaniense, están presentes en un número muy reducido. Ya en el capitulo 3, se señalaba que el poblamiento de esta época se jerarquizaba en función de cuatro tipos de asentamiento: ciudades, grandes aldeas como Izana, pequeños asentamientos de carácter agrícola y lugares defensivos. Por lo tanto, habría que asumir que no en todos los yacimientos se asentarian los mismos segmentos sociales y que cada uno de estos segmentos tendría diferentes demandas cerámicas y distintos grados de habilidad para conseguitlas (Rice, 1984, 47). En todo caso, lo que sí parece claro es que, al igual que ocurre en el área ibérica del SE peninsular, las instalaciones alfareras se ubicarian por todo el territorio, abasteciendo a las poblaciones de sus zonas de influencia más inmediata. Esta situación, puede encuadrarse en un modelo de distribución cerámica de carácter local o, a lo sumo, de carácter regional.

Por último, un aspecto que resulta difícil discutir, por la precariedad de los datos disponibles, está relacionado, tanto con los precedentes de la producción cerámica numantina del siglo I a. C., como con su evolución posteñor. En uno y otro caso, parece que la producción cerámica nunca tuvo un desarrollo semejantc. En el primero, porque los escasos fragmentos 
cerámicos procedentes de Numancia, acusan una tecnología diferenciada, con respecto a la cerámica analizada en este trabajo. No obstante, esta afirmación debe tomarse con cautela, no sólo porque la contextualización de gran parte de estas cerámicas esté todavia por realizar, sino también, porque debido a la ausencia de excavaciones arqueológicas, su valoración en referencia a otros yacimientos del Alto Duero, todavía no puede llevarse a cabo. Por otro lado, en el segundo caso, el desarrollo de la ciudad a lo largo de la época imperial, hizo que estas producciones fueran siendo sustituídas paulatinamente por otras, como las de tipo Clunia, también blancas, cuyo precedente más inmediato deben haber sido las cerámicas polícromas blancoamarillentas, analizadas en este trabajo. En cualquier caso, estos aspectos no hacen sino abundar en la necesidad de clarificar las secuencias estratigráficas de los yacimientos celtibéricos excavados a principios de siglo. 



\section{CONCLUSIONES}

Aunque la mayoria de las conclusiones a las que se ba llegado en esta investigación, se han ido ya exponiendo a lo largo de las páginas precedentes, resulta importante resaltar algunos puntos de especial interés, en concordancia con los objetivos fijados al comienzo de esta investigación. Por un lado, por su trascendencia teótico-metodológica $\mathrm{y}$, por otro, por su significación arqueológica. De forma esquemática, estos puntos pueden seguirse en la Figura 7.2.

Empezando con aquellas cuestiones de indole teórico-metodológica, una de las más relevantes para la investigación arqueométrica, como se ha tratado de demostrat en esta Tesis Doctoral, se relaciona con la necesidad de que los trabajos de caracterización se realicen a partir de unos planteamientos teóticos previos. Este aspecto pone de manifiesto que, en ningún caso, estos estudios deben ser considerados como un fin en sí mismos, sino como un medio para resolver los problemas que plantea la investigación de las producciones cerámicas del pasado. De este modo, un correcto planteamiento del trabajo arqueométrico, exige el desarrollo de un marco teórico que sea generado desde la propia disciplina arqueológica y que, en última instancia, sea capaz de integtar los datos tecnológicos, composicionales y culturales, en una interpretación histórica. Este razonamiento, como intenta plasmar la Figura 7.1, hace ver que la investigación arqueométrica surge con el fin de dar respuesta a preguntas formuladas por la Atqueologia y que dicha investigación sólo tiene sentido cuando los datos generados se reintegran en una interpretación con carácter arqueológico. En otras palabras, esto implica que si esta linea de razonamiento se quiebra, se corre el riesgo de que el trabajo arqueométrico pierda todo su significado y no cumpla con los objetivos que lo han motivado, realizándose entonces sólo desde aspectos relevantes al campo de las Ciencias Experimentales. Es por ello por lo que en esta Tesis se ha insistido, de manera especial, en la necesidad de que este trabajo se lleve a cabo por los propios arqueólogos, o por equipos integrados por varios especialistas, en los que figuren arqueólogos formados también en Ciencia Aplicada. La postura contraria, es decir, aquella que entiende la caracterización de cerámicas como el acceso a un servicio en el que el 


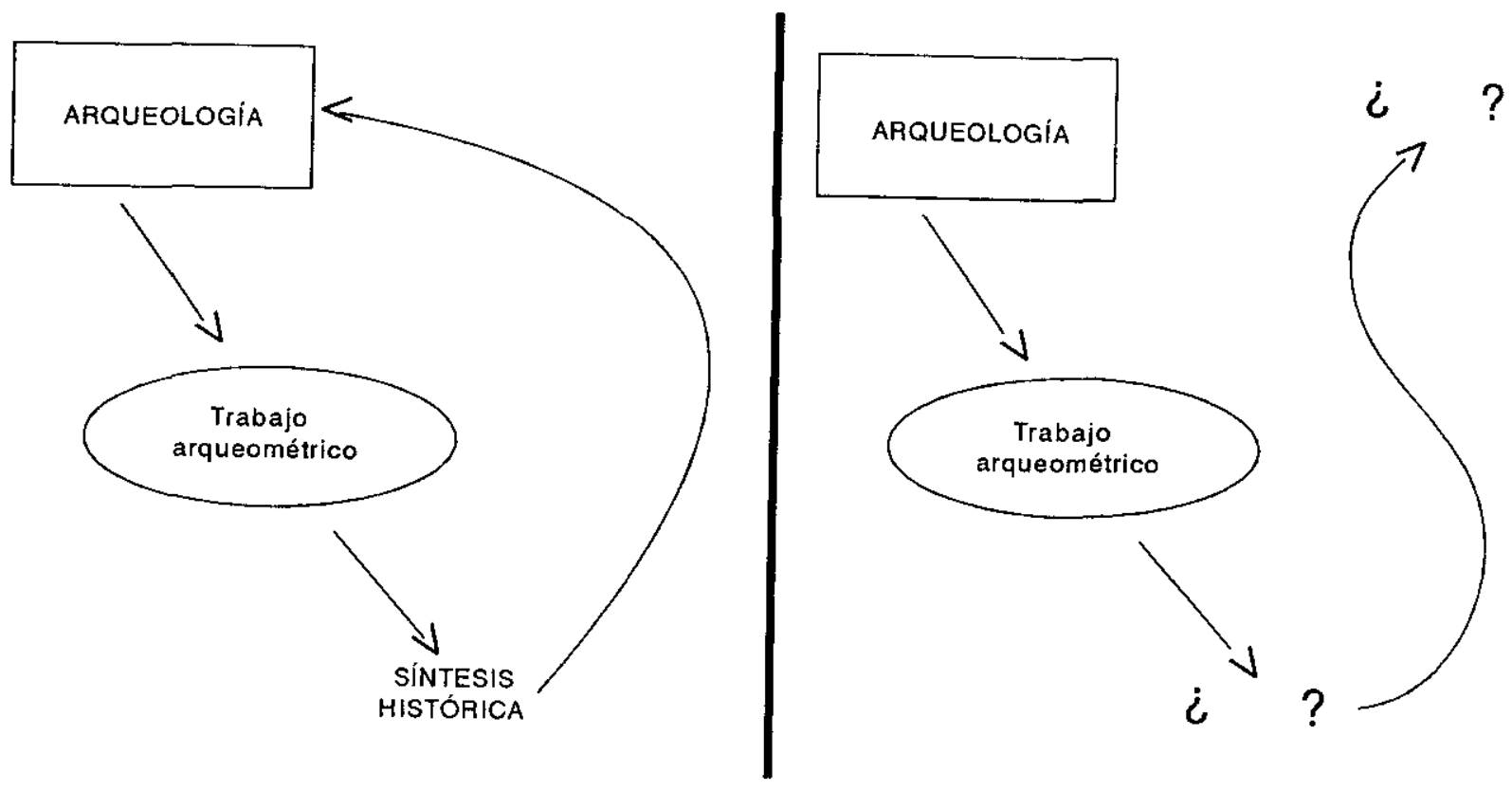

Figura 7.1: Esquema de razonamiento del trabajo axqueométrico.

especialista responde con complejas tablas de datos, no supone, en definitiva, un gran beneficio para la propia Arqueología, puesto que, en este caso, el arqueólogo desconoce el proceso analítico con el que se han obtenido (tan importante para conocer la calidad de los mismos), hipotecando seriamente, en consecuencia, su responsabilidad en la interpretación que finalmente realiza (De Atley y Bishop, 1991).

La constatación de que una aproximación crono-tipológica podía ofrecer ya pocas alternativas en la resolución de algunos de los principales interrogantes que tenía planteados la investigación actual de las producciones cerámicas numantinas del Alto Duero, producciones desarrolladas en un contexto de cambio cultural y socio-económico, originado por la irrupción de la política romana en el ordenamiento de estos territorios recién anexionados, de las que apenas se conocían sus procesos productivos, sus centros de producción o sus áteas de distribución más allá de las meras similaridades estéticas o formales, aparte de la peculiaridad de constituir unos conjuntos sin claros precedentes en la región, fueron algunas de las razones que motivaron el desarrollo de una aproximación arqueométrica en el estudio de estas producciones. Del mismo modo, las condiciones de descontextualización que presentaban estos materiales, al proceder en su mayoria de excavaciones arqueológicas llevadas a cabo a principios de siglo, permitia ratificar que, quizás, era ésta la única aproximación posible para el reintegro de estos materiales en las tareas de investigación. 
- Trabajo arqueométrico debe realizarse desde marco teójico generado por la Arqueología

- Análisis composicional requiere control estricio de todas las fuentes de variación [ Asegurar reproducibilidad de lios datos

TEÓRICO.

METODOLOGICAS

N

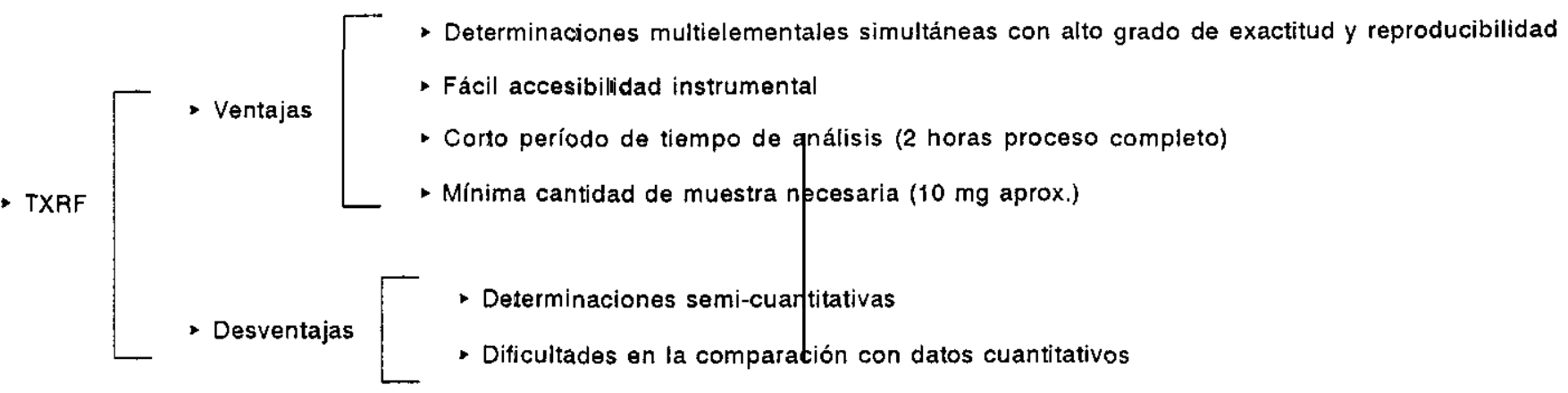

ARQUEOLGGICAS

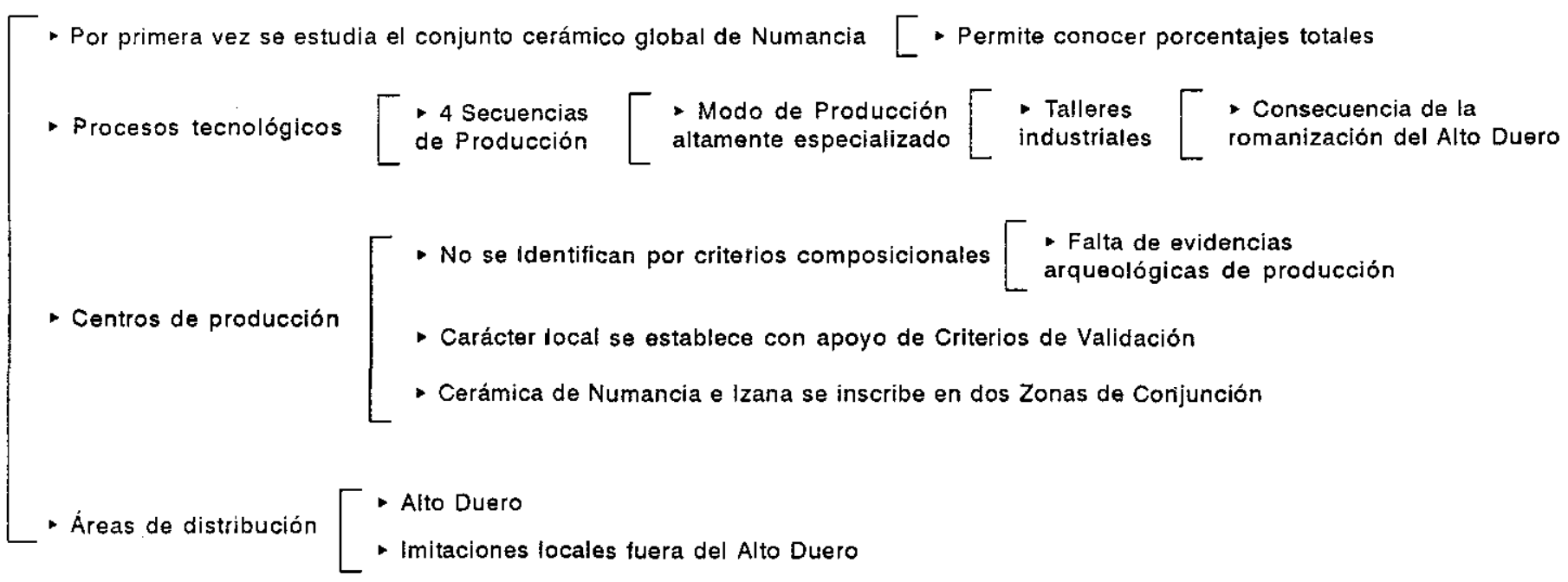

Figura 7.2: Conclusiones principales de la Tesis Doctoral 
Dado que uno de los principales objetivos de este trabajo era la discriminación de los posibles centros de producción de la cerámica numantina, se hacía necesario, por un lado, utilizar una técnica geoquímica en el estudio composicional de estas cerámicas, que contara con un nivel de resolución aceptable, en lo que a la determinación de elementos mayores, menores y trazas se refiere, así como, por otro, el llevar a cabo un estricto control de las posibles fuentes de vatiación en la determinación de estos elementos, en relación al análisis de una cerámica arqueológica, con el fin de asegurar la calidad y la reproducibilidad de los datos que se iban a obtener.

Con respecto al primero de estos requerimientos, y en función de los condicionantes a los que estaba sujeta la realización de una Tesis Doctoral de estas características, realizada desde un departamento universitario considerado no experimental, se optó por la utilización, en conjunción con otras técnicas de caracterización, de la Fluorescencia de rayos x por reflexión total (TXRF), como técnica para genetar los datos composicionales. Una técnica que había demostrado tener un mayor poder de resolución que la Fluorescencia de rayos $\mathrm{x}$ (XRF) tradicional en el análisis de muestras líquidas, pero que aún no se había utilizado en el análisis de muestras sólidas, como era el caso de la cerámica arqueológica.

En relación al segundo de los requerimientos, el control estricto de todas las posibles fuentes de vartación en el análisis composicional de una cerámica, se realizó siguiendo la ecuación propuesta por Bieber et alii $(1976,68-70)$, que resume estas fuentes de variación según:

$$
S_{r}^{2}=S_{N}^{2}+S_{S}^{2}+S_{A}^{2}
$$

donde $\mathrm{S}_{\mathrm{r}}^{2}$ es la variación total en las determinaciones de las concentraciones de un elemento particular en el análisis de una muestra dada; $\mathrm{S}_{\mathrm{N}}{ }^{2}$ es la variación natural que muestra la concentración de un elemento particular en un material cerámico; $\mathrm{S}_{\mathrm{S}}{ }^{2}$ es la variación de muestreo - los errores de estimación de la concentración de un elemento particular debidos a errores en el muestreo del individuo; $\mathrm{y}_{\Lambda}{ }^{2}$ es la variación analítica o los errores en la estimación de la concentración de un elemento particular, debidos a la técnica de analísis empleada, en donde se incluye la detección, la calibración, las interferencias y el procesado de los datos.

Comenzando por la última de estas fuentes, la variación analítica $\left(\mathrm{S}_{A}{ }^{2}\right)$, el empleo de una técnica que se utilizaba por primera vez a escala intemacional en el análisis de cerámicas, 
requería un seguimiento de su exactitud y precisión por medio de patrones cuya composición fueta conocida a través de otras técnicas. Para ello se recurrió a un material arcilloso de referencia (el "Ohio Red Clay-2") analizado por Activación de neutrones (NAA) en el Missour University Research Reactor (MURR) de Columbia (USA), al ser considerada ésta una técnica ampliamente aceptada, por su exactitud y precisión, en determinaciones multielementales. Este seguimiento, permitió comprobat que la TXRF podía realizar determinaciones semi-cuantitativas muy precisas de un buen número de elementos químicos, en concentraciones mayores, menores y trazas, siendo útil para distinguir grupos composicionalmente distintos. Esta técnica sólo requiere una pequeña cantidad de muestra (10 $\mathrm{mg}$ aproximadamente) y presenta la ventaja de teducir al mínimo el efecto matriz. Por el contrario, para su aplicación se hace necesario preparat una muestra que sea químicamente homogénea, que contenga tamaños de partícula promedio inferiores a $10 \mathrm{~mm}$ y que presente una distribución estadística de dichas partículas, a través de una molienda severa suspendida en agua suprapura, con una disgregación ultrasónica posterior. De esta forma, la muestra se analiza sin ningún tipo de manipulación química, en contraste con otros métodos.

La precisión obtenida en las mediciones realizadas mediante TXRF del patrón mencionado, vatía desde un $1 \%$ de error relativo para el $\mathrm{Rb}$, hasta un $54 \%$ para el $\mathrm{Hf}$, mientras que el análisis mediante Activación de neutrones (NAA), mostraba un rango de variación comprendido entre un $2 \%$ para el Al, hasta un $106 \%$ para el St. Estos resultados no implican que la TXRF sea una técnica más podetosa que la activación, sino que puede ofrecer una exactitud y una precisión comparables a esta última, al menos y por el momento, para 15 elementos.

A modo de resumen, entre las principales ventajas que presenta la TXRF con respecto a otras técnicas, pueden señalarse las siguientes: la realización de determinaciones multielementales simultáneas con un alto grado de exactitud y reproducibilidad; una fácil accesibilidad al instrumental; un corto periodo de tiempo en la ejecución del análisis, estimado en unas 2 horas para el proceso completo y la utilización de una mínima cantidad de muestra, que se sitúa en torno a los $10 \mathrm{mg}$. Por otro lado, también presenta desventajas, entre las que cabe señalar que, por el momento, sólo se han podido realizar determinaciones semi-cuantitativas, con la dificultad que ello ofrece para establecer posibles comparaciones con datos cuantitativos.

En cualquier caso, con el propósito de intentar superar estas desventajas, y teniendo en cuenta la potencialidad que, sin duda, la TXRF puede tener en el futuro en el análisis cuantitativo de estos materiales, actualmente ya se está llevando a cabo un programa de investigación 
encaminado a conocer cuál puede ser el potencial cuantitativo de la técnica, en el que las muestras se están preparando a través de distintos procesos de digestión por microondas y en el que se están analizando un mayor número de patrones certificados por otros organismos.

Retomando la ecuación a la que antes se hacía referencia, el seguimiento de la variación natural $\left(\mathrm{S}_{\mathrm{N}}{ }^{2}\right)$ en la concentración de los elementos determinados, ha sido útil para reconocer procesos de contaminación en algunas de las muestras analizadas. Asimismo, el análisis de varias muestras obtenidas en un mismo recipiente cerámico, ha permitido comprobar que los errores en el muestreo de los individuos $\left(\mathrm{S}_{\mathrm{S}}{ }^{2}\right)$, podían ser condiderados como despreciables y tener, por tanto, una escasa incidencia en los resultados globales de esta investigación.

En lo referente a los puntos de especial significación arqueológica, que se mencionaban al comienzo de este capítulo, cabe destacar, en primer lugar, que, en este trabajo se ha estudiado, de forma conjunta, la totalidad de los materiales cerámicos procedentes del yacimiento de Numancia, fechados en el siglo I a. C. y que, tradicionalmente, se habian venido estudiando por separado en lotes, definidos a partir de algún rasgo estético concreto, sin establecer ninguna conextón entre ellos. De esta forma, se han podido conocer, por primera vez, los porcentajes totales que presenta el conjunto cerámico de Numancia, tanto a nivel motfológico, como tecnológico, e identificar cuatro fábticas o tipos de manufactura distintos, por lo demás, también presentes en el asentamiento secundario de Izana, ubicado igualmente en el Alto Duero. No obstante, debido a la deficiente ordenación de las colecciones cerámicas de este yacimiento depositadas en el Museo Numantino de Soria, no se han podido llegar a reconocer todas las piezas y fragmentos recogidos en los diferentes trabajos que han estudiado la cerámica numantina anteriormente. Este hecho, ha puesto de manifiesto que, con el paso del tiempo, las colecciones cada vez se desordenan más, haciéndose necesaria una urgente reordenación del material, atendiendo tanto a criterios tecnológicos, como cronológicos.

Entre las principales cuestiones que motivaron el desarrollo de una aproximación arqueométrica en el estudio de las producciones cerámicas numantinas, se encontraban, como ya se ha mencionado con anterioridad, el conocimiento de los procesos tecnológicos que habían tenido lugar en su manufactura, la determinación de sus centros de producción, así como la delimitación de las posibles áreas de distribución de estos últimos. En este sentido, en cuanto a los procesos tecnológicos se refiere, puede concluirse que la cerámica numantina se ha elaborado a partir de cuatro Secuencias de Producción diferentes, que traducen un Modo de Producción altamente especializado y estandarizado, en el que las cualidades del producto final están claramente predeterminadas desde el principio del proceso. Este Modo de Producción, se ha 
puesto en relación con la posible existencia de talleres industriales, que podrian sobrepasar el simple artesanado. Por otro lado, el desarrollo de unas estructuras productivas de estas características durante el siglo I a. C., se ha estimado como una consecuencia del proceso de romanización acaecido en el Alto Duero a lo largo de este período, que permite a Numancia detentar una posición preminente, en la articulación de este territotio, a lo largo de esta etapa.

Por otro lado, en lo teferente a la determinación de los centros de producción de la cerámica numantina, la ausencia de evidencias arqueológicas relacionadas directamente con una producción alfarera, no ha permitido fijar una procedencia concreta para los distintos grupos composicionales identificados. Por este motivo, se ha recurrido a Criterios de Validación con los que, en conjunción con los argumentos composicionales, se ha establecido el carácter local de estas producciones. La identificación de estos grupos composicionales, ha servido para establecer, de modo preliminar, cuatro posibles modelos para la producción de estas cerámicas, que podrian relacionarse con la existencia de distintas unidades productivas correspondientes a un solo taller, o a varios de ellos operando en distintos períodos del siglo I a. C. Asimismo, también es importante resaltar que, mediante criterios composicionales, no han podido discriminarse las cerámicas analizadas procedentes de Numancia y del asentamiento secundario de Izana. Por ello, ambos conjuntos cerámicos se han inscrito en dos Zonas de Conjunción, es decir, zonas que presentan características composicionales distintas, pero en las que no es posible realizar una atribución de origen exacta para ninguna de ellas.

Por último, el análisis de varios fragmentos cerámicos que presentaban, por un lado, decoración polícroma y, por otro, motivos decorativos asociados tradicionalmente, por criterios estilísticos, al ámbito numantino y procedentes de los yacimientos de Las Quintanas y Cuesta del Moro (Langa de Duero, Soria), El Palomar (Aragoncillo, Guadalajara) y la necrópolis de El Pradillo (Pinilla Trasmonte, Burgos), ha permitido concluir que la cerámica numantina solamente se circunscribe al área del Alto Duero, en lo que puede tipificarse como un modelo de distribución local o, a lo sumo, regional. Por lo tanto, este aspecto lleva a considerar estas cerámicas como imitaciones locales, en un contexto socio-económico y cultural en el que las producciones numantinas gozaban de una especial aceptación, hasta el punto de ser ampliamente conocidas fuera de sus áreas de distribución.

Finalmente, el alcance de estas conclusiones, debe valorarse en función de las principales limitaciones que se señalaban al inicio de este trabajo, como eran, por un lado, las dificultades de financiación $y$, por otro, los problemas asociados a aquellos materiales carentes de un contexto arqueológico preciso, procedentes de excavaciones antiguas realizadas a principios de siglo. En 
el primer caso, estas dificultades han repercutido en el muestreo llevado a cabo, tanto en lo referente al número final de cerámicas y sedimentos arcillosos analizados, como en lo relacionado con la ampliación de la base experimental a través de la aplicación de las distintas técnicas de análisis. En este sentido, no debe olvidarse que, en última instancia, el muestreo realizado es el que ha influido, de un modo más directo, en las conclusiones alcanzadas por esta investigación. En el segundo caso, estos materiales han planteado, en muchas ocasiones, dificiles problemas de asignación cronológica, así como serios inconvenientes a la hora de realizar su ordenamiento y clasificación.

Asimismo, es preciso tener en cuenta que, aunque estas conclusiones han dado respuesta, como se ha ido exponiendo en estas páginas, a una parte importante de los interrogantes planteados en el estudio de las producciones cerámicas numantinas, la investigación no debe considerarse cerrada con la realización de este trabajo, puesto que, para uno de los objetivos que se planteaban, el relacionado con la determinación de la ptocedencia de las producciones de Numancia e Izana y, en consecuencia, el acercamiento a la posible circulación de cerámicas entre los dos yacimientos, no se ha alcanzado una respuesta positiva, debido a las dificultades para discriminar ambos conjuntos cetámicos. Este aspecto, además de restar "espectacularidad" a los resultados, pone de manifiesto algunas de las limitaciones que tienen las técnicas de caracterización, cuando se trata de discemir la procedencia de cerámicas provenientes de enclaves arqueológicos situados en zonas geográficas reducidas y con características geológicas muy homogéneas. En cualquier caso, la búsqueda de una solución para resolver este interrogante, va a seguir siendo abordada en la investigación post-doctoral.

A pesar de ello, estas conclusiones también abren toda una serie de nuevas expectativas en la aproximación a los patrones cerámicos del siglo I a. C. en la zona del Alto Duero. Expectativas que plantean, a su vez, nuevos requerimientos que habrán de ser abordados por la investigación futura, como el reordenamiento, con criterios actuales, de las colecciones cerámicas depositadas en los distintos museos; la realización de nuevas excavaciones que ayuden a clarificar las secuencias estratigráficas y permitan delimitar, de un modo más preciso, la evolución de estas producciones; así como la localización de estructuras productivas, como homos y talleres, que posibiliten la realización de nuevos trabajos de caracterización en un nivel de incertidumbre y no de conjunción, como se ha hecho en esta investigación.

En definitiva, un aspecto que queda patente con la realización de investigaciones de estas características, es que, si se pretende lograr un conocimiento más realista de las producciones cerámicas del pasado, se hace indispensable idear los procedimientos necesarios, 
que sean capaces de extraer todos los niveles de información que contiene un material cerámico. Dichos niveles de información, sólo resultan aprehensibles si se consigue una interrelación efectiva con el conocimiento que pueden aportar otras disciplinas. Ahora bien, este hecho es el reto que debe afrontat la investigación en los próximos años que, en buena medida, va a depender de la actitud que tome la propia comunidad arqueológica en la crítica interna de los resultados que ofrecen este tipo de aproximaciones. 



\section{BIBLIOGRAFÍA}

Aiginger, H. (1991): «Historical development and principles of total reflection $\mathrm{x}$-ray fluorescence analysis (TXRF)", Spectractimica Acta, 46B, 1.313-1.321.

Albertos, M M $^{2}$ D; A. Carretero y M. Fernández (1978): Estudio etnográfico de la alfanria conquense. Diputación Provincial de Cuenca, Cuenca.

Aliaga, S.; M. Garcia; S. Martínez; G. Mateu; J. Molera; T. Pradell y M. Vendrell-Saz (1991): "Tècniques experimentals per a l'estudi de la ceràmica», Limes, 1, 44-53.

Álvaro Zamora, M² I. (1980): Alfarria popular aragonesa. Pórtico Librerias, Colección estudios, 6, Zatagoza.

Andrews, K. (1991 a): “The technology of late La Tène 'painted pottery' decoration». En P. Budd, B. Chapman, C. Jackson, R. Janaway y B. Ottaway (eds.): Arcbaeological sciences 1989. Proceedings of a conference on the application of scientific techniques to archaeology (Bradford, 1989), Oxbow books, Monograph 9, Oxford, 1-7.

Andrews, K. (1991 b): «Slip decorated Iron Age ceramics from Central France». En E. Penikka y G. A. Wagner (eds.): Archaeometry 90. International symposium on archaeometry (Heidelberg, 1990), Birkhäuser verlag, Berlín, 229-236.

Andrews, K. (1996): "The technology of white 'ground' slip production on Iron Age finewares from Aulnat, France». En S. Demirci, A. M. Özer y G. D. Summers (eds.): Archaeometry 94. Praceedings of the 29th international symposium on archaeometry (Ankara, 1994), Tübitak, Ankara, 179-188.

Antón, G. (1973): Análisis por difraciön de rayos $x$ de cerámicas ibéricas valencianas. Diputación Provincial de Valencia, Servicio de Investigaciones Prehistónicas (SIP), 45, Valencia. 
Antón, G.; R. Vila; J. Vitoria y J. I. Fernández Alonso (1972): "Contribución al estudio y clasificación de cerámicas ibéricas valencianas», Boletín de la Saciedad Española de Cerámica y Vidrio, 11 (1), 47-55.

Aranegui, C. y G. Antón (1973): "Análisis por difracción de rayos x de cerámicas ibéricas. Cerámicas grises», XII congreso nacional de arqueologia (Jaén 1971), Zaragoza, 513-518.

Arenas, J. A. (1990): Análisis del poblamiento de la Segunda Edad del Hierro en la depresión de Tortuera-La Yunta, Guadalajara. Memoria de Licenciatura inédita, Universidad Complutense, Madrid.

Arenas, J. A. (1991-92): «El alfar celtibérico de 'La Rodriga' (Fuentelsaz, Guadalajara)», Kalathos, $11-12,205-232$

Atlegui, M. (1986): Las cerámicas monócromas de Numancia. Memoria de Licenciatura inédita, Universidad Complutense, Madrid.

Arlegui, M. (1990): «Introducción al estudio de los grupos celtibéticos del Alto Jalón», El Jalón. Via de comunicactón, Ciclo de conferencias del Museo Numantino, Junta de Castilla y León, Soria, 41-70.

Arlegui, M. (1992 a): «El yacimiento celtibérico de 'Castilmontán' Somaén (Soria): el sistema defensivon, $2^{\circ}$ symposium de arqueologia soriana (Soria, 1989), Vol. I, Diputación Provincial de Soria, Soria, 495-513.

Arlegui, M. (1992 b): «Las cerámicas con decoración monócroma». En A. Jimeno (ed.): Las cerámicas de Numancia, Arevacón, 17, Asociación de Amigos del Museo Numantino, Soria, $9-12$.

Arlegui, M. (1992 c): «Las cerámicas de Numancia con letrero tbérico», $2^{\circ}$ symposium de arqueologia soriana (Soria, 1989), Vol. I, Diputación Provincial de Soria, Soria, 473-494.

Arlegui, M. y M. Ballano (1995): «Algunas cuestiones acerca de las llamadas pesas de telar: los 'pondera' de Numancia, 'Cuesta del Moro' y 'Las Quintanas' (Langa de Duero) y 'Castilterteño' (Izana)», III Simposio sobre los celtiberos. Poblamiento celtibérico (Daroca, 1991), Institución Fernando El Católico, Zaragoza, 141-155.

Arlegui, M.; A. Sanz y $M^{2}$ J. Sanz Lucas (1993-94): «Dos instalaciones alfareras en la provincia de Soria: 'Royo Albar' en Quintana Redonda y 'La boca del Río Chico' en Ucero», Numantia, 6, 45-60. 
Arnal, G. B.; C. Gril y J. F. Lalanne (1987): «Caractérisation des céramiques préhistoriques par l'étude du dégraissants, Archéologie Expérimentale, 2, 69-79.

Arnold, D. E. (1985): Ceramic theory and cultural process. Cambridge University Press, New studies in archaeology, Cambridge.

Amold, D. E.; H. Neff y R. L. Bishop (1991): «Compositional analysis and 'sources' of pottery: and ethnoarchaeological approachy, American Anbropologist, 93 (1), 70-90.

Atrián, P. (1959): «Excavaciones en el poblado ibérico 'El Castelillo' (Alloza, Teruel). Segunda y tercera campañas", Teruel, 22, 225-260.

Atrián, P. (1966): «Excavaciones en el poblado ibérico 'El Castelillo' (Alloza, Tenuel). Cuarta y quinta campañass, Teruel, 36, 155-207.

Attas, M.; L. Yaffe y J. M. Fossey (1977): «Neutron activation analysis of early Bronze Age pottery from lake Vouliagméni, Perakhóra, Central Greeces. Archoeometry, 19 (1), 33-43.

Bachiller, J. Ma y $\mathrm{M}^{\mathrm{a}}$ C. Sancho (1990): «ntroducción al estudio del espacio geogtáfico soriano», Arevacón, 16, 5-26.

Barrio Onrubia, R. (1991): Numancia. Documentación de materiales depositados en el Museo Arqueológico Nacional. 2 Vols, Junta de Castilla y León, Valladolid.

Barrio Onrubia, R.; M. Lerin; O. L. Arellano; A. Ruiz De Marco; E. Heras y Mª J. Tarancón (1993): «'El Amortajado', un nuevo yacimiento celtibérico en la provincia de Soria», Numantia, 4, 149-157.

Barrios, J.; J. J. Navas; L. A. López Palomo y L. Montealegre (1991): «Características estructurales y mineralógicas de cerámicas campaniformes procedentes de Monturque (Córdoba)», Boletin de la Sociedad Española de Cerámica y Vidrio, 30 (3), 187-193.

Barrios, J.; I. A. López Palomo; L. Montealegre y J. J. Navas (1992): «Caracterización mineralógica y química de cerámicas ibéricas», XXXII congreso nacional de cerámica y vidrio (Almeria, 19921, Sociedad Española de Cerámica y Vidrio, Madrid, 177-178.

Barrios, J.; J. L. López Palomo y L. Montealegre (1994): «Caracterización mineralógica y petroestructural de cerámicas protohistóricas», Boletín de la Sociedad Española de Cerámica y Vidrio, 33 (1), 33-40. 
Baxter, M. J. (1994): Exploratory multivariate analysis in arbaeology. Edinburgh University Ptess, Edimburgo.

Beltrán, A. (1982): «Excavaciones arqueológicas en Contrebia Belaisca (Botorrita, Zaragoza), 1980), Noticiario Arqueológico Hispánico, 14, 319-364.

Beltrán, F. (1988): «Las guerras celtibéricas». En F. Burillo, J. A. Pérez y M². De Sus (eds.): Celtiberos, Diputación Provincial de Zaragoza, Zaragoza, 127-137.

Beltrán, M. (1987): «Problemas cronológicos de la celtiberia aragonesa», I symposium sobre los celtiberos (Daraca, 1986), Institución Fernando El Católico, Zaragoza, 19-42.

Bennett, W. J.; J. A. Blakely; R. Brinkmann y C. J. Vitaliano (1989): «The provenience postulate: thoughts on the use of physical and chemical data in the study of ceramic materials». En J. A. Blakely y W.J. Bennett (eds.): Analysis and publication of ceramics, B.A.R., International series, 551, Oxford, 31-44.

Bieber Jr., A. M.; D. W. Brooks; G. Harbottle y E. V. Sayre (1976): «Application of multivariate techniques to analytical data on Aegean ceramics», Archaeometry, 18 (1), 59-74

Bintliff, J. (1979): "Atchaeological science: science and archaeology or a science of archaeology?), Symposium on archaeological sciences (Bradford, 1978), University of Bradford, Bradford, 68-75.

Bishop, R. L. y H. Neff (1989): «Compositional data analysis in archaeology». En R. O. Allen (ed.): Archaeological chemistry $I V$, American Chemical Society, Advances in chemistry series, 220, Washington, 57-86.

Bishop, R. L.; R. L. Rands y G. R. Holley (1982): "Ceramic compositional analysis in archaeological perspective». En M. B. Schiffer (ed.): Advances in archaeological method and theory, Vol. V, Academic Press, Nueva York, 275-330.

Bishop, R. I.; V. Canouts; P. L. Crown y S. P. De Atley (1990): «Sensitivity, precision, and accuracy: their roles in ceramic compositional data basess, American Antiquity, 55 (3), 537 546.

Blackman, M. J. (1992): "The effect of human size sorting on the mineralogy and chemistry of ceramics claysm. En H. Neff (ed.): Chemical characterization of ceramic pastes in archaeology, Prehistory Press, Monographs in world archaeology, 7, Madison (Wisconsin), 113-124. 
Blanco García, J. F. (1990): «Un horno de cerámica vaccea en Coca", Revista de Arqueologia, 111, 63.

Blanco García, J. F. (1992): «El complejo alfarero vacceo de Coca (Segovia)", Revisia de Arqueologia, 130, 34-41.

Boix, A.; G. Clausell; M. M. Jordán y T. Sanfeliú (1995): «Estudio arqueométrico de fragmentos de cerámica antigua de Torrelló del Boverot de Almazora, Castellón (España)». En M. Vendrell Saz, T. Pradell, J. Molera y M. Gatcía (eds.): Studies on ancient ceramics. Proceedings of the Eumpean meeting on ancient ceramics (Barcelona, 1993), Generalitat de Catalunya, Barcelona, 73-76.

Borobio, Ma J. (1985): Carta Arqueológica de Soria. Campo de Gómara. Diputación Provincial de Soria, Soria.

Bronitsky, G. (1986): «The use of Materials-Science techniques in the study of pottery construction and usem. En M. B. Schiffer (ed.): Advances in archaeological metbod and theory, Academic Press, Nueva York, 209-276.

Bronitsky, G. y R. Hamer (1986): «Experiments in ceramic technology: the effects of various tempering materials on impact and thermal-shock resistance», American Antiquity, 51 (1), 89-101.

Burillo, F. (1983 a): La alfarria de Huesa del Común. Seminario de Arqueología y Etnología Turolense, Serie etnológica, 4, Teruel.

Burillo, F. (1983 b): El poblado de época ibérica y yacimiento medieval: 'Los Castellares' (Herrera de los Navarms, Zaragoza), I. Institución Fernando El Católico, Zaragoza.

Burillo, F. (1995): «Celtiberia: monedas, ciudades y territorios». En $\mathrm{M}^{2}$ P. García Bellido y R. M. Sobral (eds.): La moneda bispánica. Ciudad y temitorio. Actas del I encuentro peninsular de numismática antigua, C.S.I.C., Anejos de Archivo Español de Arqueología, 14, Madrid, 161-177.

Buxeda, J. (1994): La caracterització arqueomètrica de la ceràmica de Terra Sigillata Hispanica Avançada de la ciutat de Clunia i la seva conirastació amb la Terra Sigillata Hispanica d'un centre productor contemporani, el taller d'Abella. Tesis Doctoral inédita, Universidad de Barcelona, Barcelona.

Buxeda, J. y M. A. Cau Ontiveros (1995): «Identificación y significado de la calcita secundaria en cerámicas atqueológicas», Complutum, 6, 293-309. 
Cagle, C. G. (1992): "The use of compositional analysis in determining the production mode of Glastonbury warem. En H. Neff (ed.): Chemical characterization of ceramic pastes in archaeology, Prehistory Press, Monographs in world atchaeology, 7, Madison (Wisconsin), 269-285.

Calonge, G. (1995): «Interpretación de los resultados de las investigaciones medioambientales y arqueológicas y su relación con el pretérito espacio fisico vacceo del valle medio del Duerom. En G. Delibes, F. Romero Carnicero y A. Morales (eds.): Arquealogia y medio ambiente. El primer milenio a. C. en el Duero medio, Junta de Castilla y León, Valladolid, 529539.

Capel, J. (1986): «Estudio mineralógico y geoquímico de sedimentos y cerámicas arqueológicas de algunos yacimientos de La Manchan, Ortum, 2, 55-153.

Carnicero, J. M.; J. Enamorado y A. Sanz (1991): Informe de la excavación de urgencia en el yacimiento del 'Alto del Arnal', San Leonardo de Yagüe (Soria). Archivo del Servicio de Arqueología de la Consejería de Cultura y Turismo en Soria, Junta de Castilla y León, Soria.

Castellote, E. (1979): La alfarria popular en la provincia de Guadalajara. Institución Marqués de Santillana, Guadalajara.

Castelo, M. J. y J. M $\mathrm{M}^{2}$ Rincón (1986): «Arqueometría de dos cerámicas de una tumba ibérica de los Castellones de Ceal (Jaén)», Arqueología Espacial, 9, 382-385.

Caurcel, J. y C. Seguta (1977): La alfareria en la provincia de Madrid. Ediciones Castilla, Madrid.

Cogswell, J. W; H. Neff y M. D. Glascock (1996): «The effect of firing temperature on the elemental characterization of potteryn, Joumal of Arcbaeological Science, 23 (2), 283-287.

Cortés Vázquez, L. L. (1953): La alfareria popular salmantina. Centro de Estudios Salmantinos, Salamanca.

Cortés Vázquez, L. L. (1954): «La alfarería en Pereruela (Zamora)», Zepbyrus, 5, 141-163.

Cortés Vázquez, L. L. (1958): «Alfareria femenina en Moveros (Zamora)»,Zepbyrus, 9, 95-107.

Cuomo di Caprio, N. (1986): «Archaeology and Archaeometry: a difficult relationship». En G. Futlan (ed.): New paths in the use of nuclear techniques for ant and arbaeology, World scientific publishing, Singapur, 41-47. 
Cuomo di Caprio, N. (1994): «Tecniche di cottura». En G. Olcese (ed.): Ceramica romana $e$ archeometria: Lo stato degli studi, Edizioni all'insegna del giglio, Florencia, 153-156.

Dámaso, P. (1994): «Diferentes consideraciones sobre la cocción de productos cerámicos», Técnica Cerámica, 226, 590-600.

Darvill, T. y J. Timby (1982): «Textural analysis: a review of potentials and limitations». En I. C. Freestone, C. Johns y T. Potter (eds.): Cument researches in ceramics: thin-section studies, British Museum Occasional Paper, 32, Londres, 73-87.

De Andrés, A. Mª y J. L. Balcázar (1989): «Study of ceramic sherds of early Bronze Age sheiters (Peña Corva, Guadalajara, Spain)». En Y. Maniatis (ed.): Archaeometry. Proceedings of the 25th international symposium (Alenas, 19861, Elsevier Science Publishers, Amsterdam, 593601 .

De Atley, S. P. y R. L. Bishop (1991): «Toward an integrated interface for archaeology and archaeometrys, En R. L. Bishop y F. W. Lange (eds.): The ceramic legacy of Anna O. Shepard, University Press of Colorado, Niwot (Colorado), 358-380.

De Hoz, J. (1988): «La lengua y la escritura de los celtibetos». En F. Burillo, J. A. Pérez y $M^{a}$ L. De Sus (eds.): Celtiberos, Diputación Provincial de Zaragoza, Zaragoza, 145-153.

Díaz Sanz, Ma A. (1987): «Producciones cerámicas de tipo celtibérico procedentes de Contrebia Belaisca (Botorrita, Zaragoza)", I symposium sabre los celtiberos (Daroca, 1986), Institución Fernando El Católico, Zaragoza, 137-147.

Dufay, B. (1994): "Céramiques et potiers gallo-romains. 10 ans de recherche», Archeologia, 300, 26-33.

Dufournier, D. (1972): «Étude comparative de plusieurs tessons d'une même poterie. Interptetation et discussion', Arbéologie Médiévale, 2, 305-323.

Echallier, J. C. (1984): Eléments de technologie céramique et d'analyse des terres cuites archéologiques. Documents d'Archéologie Méridionale, Serie méthodes et techniques, 3, Lambesc.

Eichallier, J. C. y J. Courtin (1994): «Approche minéralogique de la poterie du Néolithique Ancien de La Baume Fontbrégoua à Salemes (Var)», Gallia Próbistoire, 36, 267-297. 
Echallier, J. C. y L. Jallot (1992): «Le matériel céramique de Moulin Villard (Caissargues, Gard). Remarques sur la formalisation et l'analyse de données provenant d'observations microscopiques et résultats», Revue d'Archéometrie, 16, 71-87.

Echallier, J. C. y J. Jullien (1985): «Remarques sur des poteries iberiques du $\Gamma^{\mathrm{im}}$ siècle av. J. C. de la province d'Alicante (Espagne)», Documents et travaux, 9, 113-117.

Echallier, J. C. y S. Mery (1991): «Evaluation du degree de cuisson de céramiques de l'Age du Bronze en Arabie par comparison avec des temoins de cuisson expérimentale», Archéologie expérimentale. Actes du colloque international expérimentation en archéologie: bilan et perspectives (Beaune, 1988), Editions Errance, Dijon, 250-257.

Echallier, J. C. y J. Montagu (1985): «Données quantitatives sur la préparation et la cuisson en four à bois de reconstitutions actuelles de poteries grecques et romaines», Documents d'Archéologie Méridionale, 8, 141-145.

Eiroa, J. J. (1979): La Cueva del Asno. Los Rábanos (Soria). Campañas 1976-1977. Excavaciones Arqueológicas en España, 107, Madrid.

Escudero, Z. (1994): «Medio ambiente en la Edad del Hierro. Un proyecto para su estudio en el valle medio del Dueron, Revista de Arqueologia, 163, 6-15.

Escudero, Z. y C. Sanz Mínguez (1993): «Un centro alfarero de época vaccea: el horno 2 de Carralaceña (Padilla/Pesquera de Duero, Valladolid)». En F. Romero Camicero, C. Sanz Minguez y Z. Escudero (eds.): Arqueologia vaccea. Estudios sobre el mundo prerromano en la comarca media del Duero, Junta de Castilla y León, Valladolid, 471-492.

Fatás, G. (1987): «Apuntes sobre organización política de los celtiberos», I symposium sobre los celtíberos (Daroca, 1986), Institución Fernando El Católico, Zaragoza, 9-18.

Fernández, M; A. Carretero y $\mathrm{M}^{\mathrm{a}} \mathrm{D}$. Albertos (1981): Museo Numantino. Alfarería popular en Tajueco, Ministerio de Cultura, Madrid.

Fernández Moreno, J. J. (1992): «Las cerámicas antiguas». En A. Jimeno (ed.): Las cerámicas de Numancia, Arevacón, 17, Asociación de Amigos del Museo Numantino, Soria, 4-7. 
Freestone, I. C. y V. Rigby (1988): «The introduction of Roman ceramic styles and techniques into Roman Britain: a case study from the King Harry Lane cemetery, St. Albans, Hertfordshire». En E. V. Sayre, P. B. Vandiver, J. Druzik y C. Stevenson (eds.): Materials issues in ant and arbaeology (Reno, 1988), Materials Research Society Symposium Proceedings, 123, Pittsburgh (Pennsylvania), 109-115.

Gabriel, R. (1981): «La ceràmica i l'arqueometria: una nova ciència interdisciplinària», Ciència, 12, 32-38.

Gallart, $\mathrm{M}^{2}$ D. (1980 a): «La tecnologia de la cerámica neolítica valenciana. Metodología y resultados del estudio ceramológico por medio de microscopía binocular, difractometría de rayos x y microscopía electrónica), Saguntum, 15, 57-91.

Gallart, $\mathrm{M}^{\mathrm{a}}$ D. (1980 b): «La tecnología cerámica». En B. Martí Oliver, V. Pascual Pérez, $\mathrm{M}^{2} \mathrm{D}$. Gallart, P. López Garcia, M. Pérez Ripoll, J. D. Acuña Hernández y F. Robles Cuenca: Cova de l'Or (Beniarrés, Alicantel, Diputación Provincial de Valencia, Servicio de Investigaciones Prehistóricas (SIP), 65, Valencia, 165-173.

Galván, J. y V. Galván Martínez (1985): «Estudio de trece fragmentos de cerámica procedentes del yacimiento celtibérico de Fuente el Saz (Madrid)». En $\mathrm{M}^{2} \mathrm{C}$. Blasco y $\mathrm{M}^{2}$ A. Alonso: Cerro Redondo: Fuente el Saz del Jarama, Madrid, Excavaciones Arqueológicas en España, 143, Madrid, 351-368.

Galván, J. y V. Galván Martínez (1988): «Estudio mineralógico de muestras de cerámica y arcilla procedentes de La Corona y el Castro de Corporales (León)». En $\mathrm{M}^{\mathrm{a}}$ D. FernándezPosse y F. J. Sánchez-Palencia: La Comna y el Castro de Corporales $I$, Excavaciones Atqueológicas en España, 153, Madrid, 249-250.

Galván Martínez, V; M $^{2}$ D. Fernández-Posse y F. J. Sánchez-Palencia (1993): «Tipos cerámicos y geoquímica: El Castrelín de San Juan de Paluezas (León)», Archivo Español de Arqueologia, 66, 248-257.

Gancedo, J. R; M. Gracia; A. Hemández Laguna; C. Ruiz García y J. Palomares (1985): aMössbauer spectroscopic, chemical and mineralogical characterization of Iberian pottery», Archaeometry, 27 (1), 75-82.

Garcia Heras, M. (1993 a): Castilterreño (1zana, Soria). Un modelo de productión cerámica de una comunidad cellibérica del Alto Duem en la Segunda Edad del Hierro. Memoria de Licenciatura inédita, Universidad Complutense, Madrid. 
Garcia Heras, M. (1993 b): «Celtiberian pottery production in the Spanish late Iton Age. A casestudy in the Central Meseta (Soria, Spain)». En P. Durán y J. F. Fernández (eds.): Proceedings of Third Eumpean Ceramic Society Conference (Madrid, 1993), Vol. 2, Sociedad Española de Cerámica y Vidrio y Faenza Editrice Ibérica S. L., Castellón, 953-958.

Garcia Heras, M. (1994 a): «Viaje al interior de una cerámica. El valor de la caracterización en el estudio de la cerámica arqueológicas, Revista de Arqueologia, 159, 26-35.

Garcia Heras, M. (1994 b): «Estudio arqueométrico de la cerámica de Izana (Soria) y de otros yacimientos celtibéricos del Alto Dueron, Boletin de la Sociedad Española de Cerámica y Vidrio, 33 (6), 315-325.

Garcia Heras, M. (1994 c): «El yacimiento celtibérico de Izana (Soria). Un modelo de producción cerámica), Zephyrus, 47, 133-155.

Garcia Heras, M. (1995): "Celtiberian potters: an archaeometric approach to pottery production in late Iron Age communities from the Spanish Central Meseta». En P. Vincenzini (ed.): The Ceramics Cultural Heritage. Procedings of the international symposium the ceramics beritage of the 8th CIMTEC-IWorld Ceramics Congress and Forum on New Materials (Florencia, 1994), Techna, Monogtaphs in materials and society, 2, Faenza, 457-464.

García Heras, M. (En prensa a): «Estudio bibliométrico de los trabajos de caracterización sobre materiales cerámicos arqueológicos en España: una valoración», Revista d"Arqueologia de Ponent, 7 .

Garcia Heras, M. y J. M ${ }^{2}$ Rincón (1996): vMicrostructural and microanalytical study (SEM/EDX) of celtiberian potsherds from the Spanish Central Mesetas, Geoarchaeology, $11(4), 329-344$.

García Heras, M.; J. A. Arenas; $\mathrm{M}^{2}$ C. González Vilchez y M. González Rodríguez (En prensa a): «La caracterización de los materiales cerámicos del yacimiento celtibérico de 'El Palomar' (Atagoncillo, Guadalajara): una producción especializada», Primer congreso nacional de arqueometria (Granada, 1995).

Garcia Heras, M.; R. Fernández Ruiz y J. D. Tomero (En prensa b): «Analysis of archaeological ceramics by TXRF and constrasted with NAA», Journal of Archaeological Science, 24.

Garcia Heras, M.; R. Fernández Ruiz y J. D. Tornero (En prensa c): «Análisis de cerámicas atqueológicas mediante Fluorescencia de rayos $\mathrm{x}$ por teflexión total (TXRF) y contrastación mediante análisis por Activación de neutrones (NAA)», Primter congreso nacional de arqueometria (Granada, 1995). 
García Huerta, R. (1988): «Necrópolis de La Yunta (Guadalajara)». En F. Burillo, J. A. Pérez y $\mathrm{M}^{2} \mathrm{~L}$. De Sus (eds.): Celtziberos, Diputación Provincial de Zaragoza, Zaragoza, 95-98.

Genis, $\mathrm{M}^{2}$ T.; T. Pradell y M. Vendrell Saz (1991): "Caracterización de la cerámica protocampaniense de Rhode (Alt Empordà. Catalunya)n, VII congreso de conservación de bienes culturales (Deusto 1988), Servicio central de publicaciones del gobierno vasco, Vitoria-Gasteiz, 338-353.

Gilmore, G. R. (1991): «Sources of uncertainty in the neutron activation analysis of pottery». En M. J. Hughes, M. R. Cowell y D. R. Hook (eds.): Neutron activation and plasma emission spectrometric analysis in anchaeology. Techniques and applications, British Museum Occasional Paper, 82, Londres, 1-28.

Glascock, M. D. (1992): «Characterization of archaeological ceramics at MURR by neutron activation analysis and multivariate statistics». En H. Neff (ed.): Chemical characterization of ceramic pastes in archaeology, Prehistory Press, Monographs in world archaeology, 7, Madison (Wisconsin), 11-26.

González Vîchez, Ma C.; F. González García; G. García Ramos y M. González Rodríguez (1988): «Estudio arqueométrico de pigmentos de algunas piezas cerámicas de Cerro Macareno (Sevilla)n, Boletín de la Sociedad Española de Cerámica y Vidrio, 27 (2), 73-80.

Gosden, C. H. (1987): «The production and exchange of La Tène A wheel-turned pottery in Bohemian, Archeologické Roz̧bledy, 39 (3), 290-316.

Grimshaw, R. W. (1971): The chemisty and physics of clays. Emest Benn Ltd., $4^{a}$ Ed., Londres.

Guichard, V. y B. Guineau (1991): «Quelques observations sur les pigments et la technique picturale de la céramique peinte celtique du Second Âge du Feb, La céramique peinte celtique dans son contexte eurpeen. Actes du symposium international d'Heutuillers (1987), Memoire de la Societé Archéologique Champanoise, 5, Reims, 315-320.

Harbottle, G. (1982): «Chemical characterization in archaeology». En J. E. Ericson y T. K. Earle (eds.): Context for prebistoric exchange, Academic Press, Nueva York, 13-51.

Heimann, R. B. y M. Maggetti (1981): «Experiments on simulated burial of calcareous Terra Sigillata (mineralogical change): preliminary results». En M. J. Hughes (ed.): Scientific studies in ancient ceramics, British Museum Occasional Paper, 19, Londres, 163-177. 
Henrickson, R. C. y M. J. Blackman (1992): «Scale and paste: investigating the production of Godin III painted buff wares. En H. Neff (ed.): Chemical characterization of ceramic pastes in arbaeology, Prehistory Press, Monogtaphs in wotld archaeology, 7, Madison (Wisconsin), 125-144.

Hernández Vera, J. A. (1982): Las ruinas de Inestrillas. Estudio argueológico. Aguilar del Río Albama, La Rioja. Instituto de Estudios Riojanos, Logroño.

Hoard, R. J.; M. J. O'Brien; M. Ghazavy y V. S. Gopalaratnam (1995): «A Materials-Science approach to understanding limestone-tempered pottery from the Midwestern United States», Joumal of Archacological Science, 22 (6), 823-832.

Hughes, M. J. (1992): «The past seen in the present: elemental analysis of museum objects», Chemistry and Industry, Diciembre de 1992, 897-901.

Hughes, M. J.; M. R. Cowell y D. R. Hook (1991): «Neutron activation analysis procedures at the British Museum Reseatch Laboratorym. En M. J. Hughes, M. R. Cowell y D. R. Hook (eds.): Neutron activation and plasma emission spectrometric analysis in archaeology. Techniques and applications, British Museum Occasional Paper, 82, Londres, 29-46.

Jenntich, R. y P. Sampson (1990): «Stepwise discriminant analysis». En W. J. Dixon (ed.): BMDP statistical software manual, Vol. 2, University of California Press, Berkeley (California), 339358.

Jimeno, A. (1984): Los Tolmos de Caracena (Soria). Campañas de 1977, 1978 y 1979. Nuevas bases para el estudio de la Edad del Bronce en la zona del Alto Duero, Excavaciones Arqueológicas en España, 134, Madrid.

Jimeno, A. (1994 a): «Investigación e historia de Numancia», El Museo Numantino. 75 años de la Historia de Soria, Junta de Castilla y León, Soria, 25-62.

Jimeno, A. (1994 b): «Numancia», Leyenda y arqueologia de las ciudades prerromanas de la Península Ibérica, Museo Arqueológico Nacional, Madrid, 119-134.

Jimeno, A. (1996): «Numancia: relación necrópolis-poblado», Arcbivo Español de Arqueología, 69, $57-76$.

Jimeno, A. y $\mathrm{M}^{\mathrm{a}}$ A. Arlegui (1995): «El poblamiento en el Alto Duero». En F. Burillo (Coord.): III Simposio sobre los celtiberos. Poblamiento celtibérico (Daroca, 1991), Institución Fernando El Católico, Zaragoza, 93-126. 
Jimeno, A. y A. M Martin (1995): «Estratigrafia y numismática: Numancia y los campamentos». En M $\mathrm{M}^{2}$ P. García Bellido y R. M. Sobral (eds.): La moneda bispánica. Ciudady ternitorio. Actas del I encuentro peninsular de numismática antigua, C.S.I.C., Anejos de Archivo Español de Arqueologia, 14, Madrid, 179-190.

Jimeno, A. y F. Morales (1993): «Localización y confirmación atqueológica de la necrópolis de Numanciay, Revista de Arqueologia, 148, 60-62.

Jimeno, A. y C. Tabernero (1996): "Origen de Numancia y su evolución urbana». En $\mathrm{M}^{\mathrm{a}} \mathrm{A}$. Querol y T. Chapa (eds.): Homenaje al profesor Manuel Femández-Miranda, Complutum Extra 6, Vol. I, Universidad Complutense, Madrid, 415-432.

Jimeno, A. y G. Trancho (1996): «Numancia», Investigación y ciencia, 232, 38-39.

Jimeno, A.; J. J. Fernández y $\mathrm{M}^{a}$ L. Revilla (1993): Numancia. Guia del yacimiento, Asociación de amigos del Museo Numantino, $2^{a}$ Ed., Soria.

Jimeno, A.; G. J. Trancho; F. Morales; B. Robledo e I. López-Bueis (1993-94): «Ritual y dieta alimenticia: la necrópolis celtibérica de Numancias, Numantia, 6, 31-44.

Juan Tovar, L. C. y A. Bermúdez (1991): «Talleres cerámicos en la Prehistoria y Protohistoria de la Península Ibérica: introducción a su estudion, Rivista di Archeologia, 15, 116-124.

Junyent, E. y A. Alastuey (1991): «La vaixella ilergeta de vernís roig», Revista d'Arqueologia de Ponent, 1, 9-50.

Kardos, J.; K. Zimmer; L. Kriston; O. Morozova; T. Träger y E. Jerem (1985): «Scientific investigations of the Sopron-Krautacker Iron Age pottery workshop', Arcbaeometry, 27 (1), 83-93.

Kilikoglou, V.; Y. Maniatis y A. P. Grimanis (1988): «The effect of purification and firing of clays on trace element provenance studies", Arcbaeometry, 30 (1), 37-46.

Kingery, W. D. (1982): «Plausible inferences from ceramic artifacts». En J. S. Olin y A. D. Franklin (eds.): Arbaeological ceramics, Smithsonian Institution Press, Washington, 37-45.

Kingery, W. D. (1984): «Interactions of ceramic technology with society». En P. M. Rice (ed.): Pots and potters: cument appraacbes in ceramic archaeology, University of California, Institute of Atchaeology, Monograph, 24, Los Angeles (California), 171-178. 
Kingery, W. D. (1987): «Mictostructure analysis as part of a holistic interpretation of ceramic art and archaeological artifacts", Archeomaterials, 1 (2), 91-99.

Kingery, W. D. (1988): «A role for ceramic materials science in art, history and atchaeology». En E. V. Sayre, P. B. Vandiver, J. Druzik y C. Stevenson (eds.): Materials issues in ant and archaeology (Reno, 1988), Materials Research Society Symposium Proceedings, 123, Pittsburgh (Pennsylvania), 159-168.

Kingery, W. D.; H. K. Bowen y D. R. Uhlmann (1976): Introduction to ceramics. John Wiley, $2^{\mathrm{a}}$ Ed., Nueva York.

Köster, E. (1966): Análisis mecánico de rocas y suelos. C.S.I.C., Monografias ecológicas y agrarias, 2, Madrid.

Kregsamer, P. (1991): «Fundamentals of total reflection x-ray fluorescence», Spectrocbimica Acta, $46 \mathrm{~B}, 1.333-1.340$.

Lazzarini, L. y C. Colombo (1995): «An atchaeometric study of Bronze Age pottery from Ebla (Syria)». En M. Vendrell Saz, T. Pradell, J. Molera y M. Garcia (eds.): Studies on ancient ceramics. Praceedings of the European meeting on ancient ceramics (Barcelona, 1993), Generalitat de Catalunya, Barcelona, 17-22.

Linares, J.; F. Huertas y J. Capel (1983): «La arcilla como material cerámico. Características y comportamientom, Cuadernos de Prehistoria de la Universidad de Granada, 8, 479-490.

Little, G. M. (1990): The technology of pottery production in Northwestern Portugal during the Iron Age. Universidade do Minho, Cadernos de arqueologia, Braga.

Llanos, A. y J. I. Vegas (1974): «Ensayo de un método para el estudio y clasificación tipológica de la cerámica», Estudios de arqueologia alavesa, 6, 265-313.

Maggetti, M. (1982): «Phase analysis and its significance for technology and otigin». En J. S. Olin y A. D. Franklin (eds.): Arcbaeological ceramics, Smithsonian Institution Press, Washington, $121-133$.

Maggetti, M. (1994): «Is there still a future for archaeometry at universities?». En G. Olcese (ed.): Ceramica romana e arcbeometria: lo stato degli studi, Edizioni all'insegna del giglio, Florencia, 15-22. 
Maggetti, M. y G. Galetti (1980): «Composition of Iton Age ceramics from Châtillons-Glâne (Kt. Fribourg, Switzerland) and the Heuneburg (Kr. Sigmaringen, West Germany)", Joumal of Archaeological Science, 7 (1), 87-91.

Maggetti, M. y H. Schwab (1982): «Iron Age fine pottery from Châtillon-s-Glâne and the Heuneburg), Archaeometry, 24 (1), 21-36.

Maggetti, M.; H. Westley y J. S. Olin (1984): «Provenance and technical studies of Mexican majolica using elemental and phase analysis». En J. B. Lambert (ed.): Archaeological chemistry III, American Chemical Society, Advances in chemistry series, 205, Washington, 151-191.

Maniatis, Y. y M. S. Tite (1981): «Technological examination of Neolithic-Bronze Age pottery from Central and Southeast Europe and from the Near Easo), Joumal of Archaeological Science, $8(1), 59-76$.

Maniatis, Y.; A. Simopoulos y A. Kostikas (1981): «Mössbauer study of the effect of calcium content on iron oxide transformations in fired claysm, Joumal of the American Ceramic Society, 64 (5), 263-269.

Maniatis, Y.; A. Simopoulos; A. Kostikas y V. Perdikatsis (1983): «Effect of reducing atmosphere on minerals and iron oxides developed in fired clays: the role of Can, Journal of the American Ceramic Society, 66 (11), 773-781.

Marco, F. (1990): Los celtas. Historia 16, 25, Madrid.

Mariné, M. y G. Ruiz Zapatero (1988): «Nuevas investigaciones en Las Cogotas. Una aplicación del $1 \%$ culturabs, Revista de Arqueología, 84, 46-53.

Mariscal, B. (1995): «Análisis polínico de los yacimientos de la Edad del Hietro de El Soto de Medinilla (campaña de 1989-1990) y El Cerro de la Mota en Medina del Campo, Valladolidy. En G. Delibes, F. Romero Carnicero y A. Morales (eds.): Arqueología y medio ambiente. El primer milenio a. C. en el Duer medio, Junta de Castilla y León, Valladolid, $337-$ 350 .

Mariscal, B.; C. Cubero y P. Uzquiano (1995): «Paisaje y recursos del valle del Duero durante el primer milenio antes de Cristo a través de la Paleoetnobotánica». En G. Delibes, F. Romero Carnicero y A. Morales (eds.): Arqueologia y medio ambiente. El primer milenio a. C. en el Duero medio, Junta de Castilla y León, Valladolid, 417-454. 
Marún Valls, R. (1976): «Nuevos hallazgos arqueológicos en Ciudad Rodrigo», Zepbyrus, 26-27, 373-388.

Martínez, J. M. (1983): «Alfatetía popular de la provincia de Soria», Arevacón, 8, 7-12.

Mata, C; $\mathrm{M}^{2}$ C. Millán; H. Bonet y J. Alonso (1990): «Análisis de cerámicas de poblados tbéricos valencianos». En P. Roig Picazo (ed.): Actes del VIII congrés de conservació de béns culturals (Valencia, 1990L, Generalitat Valenciana, Valencia, 611-619.

Matthew, A. J.; A. J. Woods y C. Oliver (1991): «Spots before the eyes: new comparison charts for visual percentage estimation in archaeological materiabs. En A. P. Middleton e I. C. Freestone (eds.): Recent developments in ceramic petrology, British Museum Occasional Paper, 81, Londres, 211-263.

McCarthy, J. J. y F. H. Schamber (1979): «Least-square fit with digital filter: a status reporb», Proceedings of workshop on EDX, National Bureau of Standards, Publication 604, Washington.

Middleton, A. P.; I. C. Freestone y M. N. Leese (1985): «Textural analysis of ceramic sections: evaluation of grain sampling procedures», Archaeometry, 27 (1), 64.74.

Molera, J.; M. García Vallés; T. Pradell y M. Vendrell Saz (1996): «Hispano-moresque pottery production of the fourteenth century workshop of Testar del Molí (Patema, Spain)», Archaeometry, 38 (1), 67-80.

Mommsen, H.; A. Kreuser; E. Lewandowski y J. Weber (1991): «Provenancing of pottery: a status report on neutron activation analysis and classifications. En M. J. Hughes, M. R. Cowell y D. R. Hook (eds.): Neuton activation and plasma emission spectrometric analysis in archaeology. Tecbniques and applications, British Museum Occasional Paper, 82, Londres, 5765 .

Morales, F. (1995): Carta Arqueológica de Soria. La Altiplanicie Soriana, Diputación Provincial de Soria, Soria.

Morales, F. y A. Sanz (1994): «Una copa-pebetero de cerámica a mano procedente de Castillejo (Garray, Soria)n, Celtiberia, 87-88, 253-264.

Moteda, J. y J. Nuño (1988): La necrópolis de la Edad del Hierro de 'El Pradillo'. Pinilla Trasmonte (Burgos). Informe de la campaña de 1988. Archivo del Servicio de Arqueología de la Consejería de Cultura y T'urismo en Burgos, Junta de Castilla y León, Burgos. 
Moreda, J. y J. Nuño (1990): «Avance al estudio de la necrópolis de la Edad del Hierro de 'El Pradillo', Pinilla Trasmonte (Burgos)m, II symposio sobre los celtiberos (Daroca, 1988), Institución Fernando El Católico, Zaragoza, 171-181.

Neff, H; R. L. Bishop y D. E. Arnold (1988 a): «Reconstructing ceramic production from ceramic compositional data: an example from Guatemalas, Joumal of Field Archaeology, 15 (3), 339-348.

Neff, H.; R. L. Bishop y E. V. Sayre (1988 b): «A simulation approach to the problem of tempering in compositional studies of archaeological ceramics», Journal of Archaeological Science, $15(2), 159-172$.

Neff, H.; R. L. Bishop y E. V. Sayre (1989): «More observations on the problem of tempering in compositional studies of archaeological ceramics», Joumal of Archaeological Science, 16 (1), $57-69$.

Neff, H.; F. J. Bove; B. L. Lou y M. F. Piechowski (1992): "Ceramic raw materials survey in Pacific coastal Guatemalar. En H. Neff (ed.): Chemical characterization of ceramic pastes in archaeology, Prehistory Press, Monographs in world archaeology, 7, Madison (Wisconsin), $59-84$.

Neff, H.; F. J. Bove; E. J. Robinson y B. Arroyo (1994): «A ceramic compositional perspective on the Formative to Classic transition in Southern Mesoamericas, Latin American Antiquity, 5 (4), 333-358.

Nicholson, P. T. (1989): Iron Age pottery production in the Hunsrück-Eifel-Kultur of Germany. B.A.R., International series, 501, Oxford.

Nuño, J. (1989): Excavaciones arqueologicas en la necrópolis de la Edad del Hierro de 'El Pradillo'. Pinilla Trasmonte (Burgos). Informe de la campaña de 1989. Archivo del Servicio de Arqueología de la Consejería de Cultura y Turismo en Burgos, Junta de Castilla y León, Burgos.

Olaetxea, C. (1993): La tecnología cerámica en la protobistoria de la provincia de Guipúzcoa. Memoria de Licenciatura inédita, Universidad Complutense, Madrid.

Palomar, M. L. y J. Hernando (1984): «Introducción al conocimiento de los suelos de Soria», Celtiberia, 68, 309-318.

Pascual, A. C. (1991): Carta Arqueologica de Soria. Zona Centm. Diputación Provincial de Soria, Soria. 
Pascual, A. C. (1992): «Notas sobre el poblamiento celtibérico de la zona de Quintana Redonda», $2^{\circ}$ symposium de arqueologia soriana (Soria, 1989), Vol. I, Diputación Provincial de Soria, Soria, 515-126.

Pastor Eixarch, J. M. (1987): «Las trompas de guerra celtibéricas», Celtiberia, 73, 7-19.

Paz, J. e I. Aguilera (1984): «Nuevos materiales procedentes del Piquete de la Atalaya (Azuara), en el Museo Provincial de Zaragozay, Juan Cabré Aguilo. Encuentro de bomenaje, Institución Fernando El Católico, Zaragoza, 183-198.

Peacock, D. P. S. (1969): «A contribution to the study of Glastonbury ware from South-Western Britain», Antiquaries Joumal, 49 (1), 41-61.

Peacock, D. P. S. (1971): «Petrography of certain coarse pottery». En B. Cunliffe (ed): Excavations at Fishboume, Report of the Research Committee of the Society of Antiquaries, 27 (2), Londres, 255-259.

Peacock, D. P. S. (1982): Pottery in the Roman world. An etbnoarchaeological approach. Longman, Londres.

Perlman, I. y F. Asaro (1969): «Pottery analysis by neutron activation», Ambaeometry, 11, 21-52.

Picon, M. (1973): Introduction à l'étude technique des céramiques sigillées de Leqoux. Centre de Recherches sur les Techniques Gréco-Romaines, 2, Université de Dijon, Dijon.

Picon, M. (1984): «Problèmes de détermination de l'origine des céramiques». En T. Hackens y M. Schvoeter (eds.): Datation-Caractérisation des céramiques anciennes (Bourdeaux-Talence, 1981), PACT 10, C.N.R.S., París, 425-433.

Picon, M. (1985): «Un example de pollution aux dimensions kilométriques: la fixation du baryum par les céramiques», Revue d'Archéometrie, 9, 27-29.

Picon, M. (1989): «Archéologie et laboratoire. Quel avenir pour la céramologie de laboratoire ?», Archéologie Médiévale, 19, 243-254.

Picon, M. (1993): "L'analyse chimique des céramiques: bilan et perspectives», Archeometria della ceramica. Problemi di metodo (Rimini, 19921, Ed. Int. Centro Ceramico, Bolonia, 3-26. 
Picon, M. (1995): «Compositions chimiques et détermination de l'origine des céramiques: réflexions sur la nature des preuves». En M. Vendrell-Saz, T. Pradell, J. Molera y M. García (eds.): Studies on ancient ceramics. Proceedings of the European meeting on ancient ceramics (Barcelona, 1993), Generalitat de Catalunya, Barcelona, 229-233.

Poole, A. B. y L. R. Finch (1972): «The utilization of trace chemical composition to correlate British Post-Medieval pottery with European kiln site materials», Arcbaeometry, 14 (1), 79 91.

Pradell, T.; M. A. Martín; M. García Vallés y M. Vendrell Saz (1995): «Attribution of 'painted Iberian' and 'monochrome grey Greek' ceramics of the 6th century B. C. to a local production of Ullastret (Catalonia)». En M. Vendrell Saz, T. Pradell, J. Molera y M. Garcia (eds.): Studies on ancient ceramics. Proceedings of the European meeting on ancient ceramics (Barcelona, 1993), Generalitat de Catalunya, Barcelona, 23-27.

Prange, A. (1989): «Total reflection x-ray spectrometry: method and applications», Spectrochimica Acta, 44B, 437-452.

Renfrew, C. (1977); «Introduction: production and exchange in early state societies. The evidence of potterym. En D. P. S. Peacock (ed.): Pottery and early commerce. Characterization and trade in Roman and later ceramics, Academic Press, Londres, 1-20.

Revilla, Mª L. (1985): Carta Arqueologica de Soria. Tierra de Almazán. Diputación Provincial de Soria, Soria.

Rice, P. M. (1984): «The archaeological study of specialized pottery production: some aspects of method and theorym. En P. M. Rice (ed.): Pots and potters: current approaches in ceramic archaealogy, University of California, Institute of Archaeology, Monograph, 24, Los Angeles (California), 45-54.

Rice, P. M. (1987): Pottery analysis: a sourcebook. Chicago University Press, Chicago (Tllinois).

Rice, P. M. (1996): «Recent ceramic analysis: 2. Composition, production, and theory», Joumal of Arbaeological Researh, 4 (3), 165-202.

Rigby, V.; A. P. Middleton e I. C. Freestone (1989): «The Prunay workshop: technical examination of La Tène bichrome painted pottery from Champagne», World Archaeology, $21(1), 1-16$. 
Rincón, J. $\mathrm{M}^{2}$ (1985): «Análisis mineralógico de piezas de cerámica común e ibérica de Cástulo». En J. M Blázquez, $M^{2}$ P. García-Gelabert y F. López Pardo: Cástulo $V$, Excavaciones Arqueológicas en Esapaña, 140, Madrid, 329-337.

Rincón, J. M (1986): «Caracterización arqueométrica de un fragmento de cerámica pintada procedente del cerro de la Virgen de la Muela (Driebes, Guadalajara)». En J. Abascal Palazón: La cerámica pintada romana de tradición indigena en la Peninsula Ibérica, Universidad de Alicante, Madrid, 305-312.

Rodríguez, J. y N. Marín (1987-88): «Estudio mineralógico de materiales cerámicos encontrados en la villa romana de Loma de Ceres. Establecimiento de sus temperaturas de coccióny, Cuadernos de Prebistoria de la Universidad de Granada, 12-13, 231-235.

Romero Carnicero, F. (1976): Las cenámicas policromas de Numancia. Centro de Estudios Sorianos, Soria.

Romero Carnicero, F. (1982): «Las cerámicas polícromas de Numancia», Revista de Arqueologia, $21,34-43$

Romero Carnicero, F. (1984): «La Edad del Hierro en la provincia de Soria. Estado de la cuestióny, I symposium de arqueología soriana (Soria, 1981), Diputación Provincial de Soria, Soria, 51-121.

Romero Camicero, F. (1988): «Una reflexión sobre la estética celtibérica a partir de las cerámicas de Numancian. En F. Burillo, J. A. Pérez y $\mathrm{M}^{\text {a }}$ L. De Sus (eds.): Celtiberos, Diputación Provincial de Zaragoza, Zaragoza, 197-199.

Romero Carnicero, F. (1991): Los castros de la Edad del Hierro en el norte de la provincia de Soria, Universidad de Valladolid, Studia Archaeologica, 80, Valladolid.

Rometo Carnicero, F. (1992): «Las cerámicas con decoración policroma». En A. Jimeno (ed.): Las cerámicas de Numaniza, Arevacón, 17, Asociación de Amigos del Museo Numantino, Soria, $13-20$.

Romero Carnicero, F. y M. A. Martín Carbajo (1992): «Hallazgos monetarios ibéricos e hispanorromanos en Numancias, $2^{\circ}$ symposium de arqueologia soriana (Soria, 1989), Vol I, Diputación Provincial de Soria, Soria, 671-681. 
Romero Carnicero, F. y G. Ruiz Zapatero (1992): «La Edad del Hierro. Problemas, tendencias y perspectivas", $2^{\circ}$ symposium de arqueología soriana (Soria, 1989), Vol I, Diputación Provincial de Soria, Soria, 103-120.

Romero Camicero, $M^{a}$ V. (1985): Numancia I. La Terra Sigillata. Excavaciones Arqueológicas en España, 146, Madrid.

Romero Carnicero, $\mathrm{M}^{\star}$ V. (1992): «La romanización en la provincia de Soria. Panorama y perspectivas", $2^{\circ}$ symposium de arqueología soriana (Soria, 1989), Vol I, Diputación Provincial de Soria, Soria, 699.744.

Ruiz Zapata, B. (1995): «Análisis polínico del yacimiento de 'Soto de Medinilla'. Campaña de 1986-87 en el poblado vacceo». En G. Delibes, F. Romero Camicero y A. Morales (eds.): Arqueologia y medio ambiente. El primer milenio a. C. en el Duero medio, Junta de Castilla y León, Valladolid, 351-356.

Ruiz Zapatero, G. y J. R. Álvarez Sanchís (1995): «Las Cogotas: oppida and the toots of urbanism in the Spanish Mesetar. En B. Cunliffe y S. Keay (eds.): Social complexity and the development of towns in Iberia. From the Copper Age to the Second Century AD, Oxford University Press, Proceedings of the British Academy, 86, Oxford, 209-235.

Ruiz-Gálvez, M² L. (1990): «Propuesta para el estudio e interpretación de las necrópolis sin armas", II symposio sobre los celtiberas (Darnca, 19881, Institución Fernando El Católico, Zaragoza, 343-347.

Ruiz-Gálvez, M² L. (1991): «La economía celtibérica». En M. Almagro Gorbea (ed.): Los celtas en la Península Ibérica, Númeto especial monográfico de Revista de Arqueología, Madrid, 72 75.

Rye, O. S. (1976): «Keeping your temper under control: materials and the manufacture of Papuan potteryn, Archaeology and Pbysical Anthropology in Oceania, 11 (2), 106-137.

Rye, O. S. (1988): Pottery technology: principles and reconstruction. Taraxacum Inc., Manuals on archaeology, 4, $2^{2}$ Ed., Washington.

Rye, O. S. y P. Duerden (1982): «Papuan pottery sourcing by PIXE: preliminary studics», Arbaeonetry, 24 (1), 59-64.

Sacristán, J. D. (1986): La Eidad del Hierm en el valle medio del Duem. Rauda (Roa, Buryos). Universidad de Valladolid y Junta de Castilla y León, Valladolid. 
Sacristán, J. D. (1993): «Aspectos industriales de la producción cerámica en época celtibérica. Los dermatoglifos». En F. Romero Camicero, C. Sanz Mínguez y Z. Escudero (eds.): Arqueología vaccea. Estudios sobre el mundo prerromano en la comarca media del Duero, Junta de Castilla y León, Valladolid, 493-506.

Sactistán, J. D. e I. Ruiz Vélez (1985): «La Edad del Hierro». En A. Montenegro (dir.): Historia de Burgos. I, Edad Antigua, Caja de Ahorros Municipal de Burgos, Burgos, 179-220.

Sáenz García, C. (1951): «Marco geográfico de la altimeseta soriana», Celtiberia, 1, 68-80.

Sanz Mínguez, C. y Z. Escudero (1991): «Pintia. Un bien de interés cultural por protegen, Revista de Arqueología, 126, 12-20.

Sanz Mínguez, C. y Z. Escudero (1995): «El conjunto arqueológico de Padilla/Pesquera de Duero (Valladolid). Evolución del asentamiento durante la etapa indígenas. En G. Delibes, F. Romero Carnicero y A. Morales (eds.): Arqueología y medio ambiente. El primer milenio a. C. en el Duero medio, Junta de Castilla y León, Valladolid, 271-305.

Schneider, B. (1989): «The determination of atmospheric trace metal concentration by collection of aerosol particles on sample holders for total reflection x-ray fluorescences, Spectrocbimica Acta, 44B, 519-523.

Schneider, G. (1995): «A short note on project planning and sampling for laboratory analysis of archaeological ceramics». En $A$. Lindahl y $O$. Stilborg (eds.): The aims of Laboratory analyses of ceramics in archaeology (Lund, 1995), Historie och Antikvitets Akademien, Konferenser 34, Estocolmo, 23-27.

Sempere, E. (1992): “Catalogación de los homos de España y Portugal», Tecnología de la coción cerámica desde la antigüedad a nuestros dias, Asociación de ceramologia de Agost, Alicante, 185-237.

Shennan, S. (1992): Arqueologia cuantitativa. Editorial Crítica, Barcelona.

Shoval, S.; M. Gaft; P. Beck e Y. Kitsh (1993): (Thermal behaviout of limestone and monocrystalline calcite tempers during firing and their use in ancient vessels", Joumal of Thermal Analysis, 40, 263-273.

Sinopoli, C. M. (1991): Appraaches to arbaeological ceramics. Plenum Press, Nueva York. 
Soria, L. y $\mathrm{M}^{2}$ A. Córdoba (1994): «Análisis mineralógicos de piezas cerámicas ibéricas procedentes de 'El Castellón' (Hellín, Albatana, Albacete)», Al-Basit, 35, 5-49.

SPAD.N (v. 2.5). Sistema compatible para el análisis de datos. Manual de referencia. CISLA, Madrid, (1994).

SPSS reference guide. SPSS Inc., Chicago (Illinois), (1990).

Storey, J. M. V. (1988): «A chemical study of clays and Roman pottery from the lower Nene Valley, Eastern England), Jourmal of Archaeological Science, 15 (1), 35-50.

Streeten, A. D. F. (1982): "Textural analysis: an approach to the characterisation of sandtempered ceramics). En I. C. Freestone, C. Johns y T. Potter (eds.): Carrent researches in ceramics: thin-section studies, British Museum Occasional Paper, 32, Londres, 123-134.

Taracena, B. (1924): La cerámica ibérica de Numancia. Samatán y Cía., Madrid.

Taracena, B. (1926): Excavaciones en diversos lugares de la provincia de Soria. Memorias de la Junta Superior de Excavaciones y Antigüedades, 75, Madrid.

Taracena, B. (1927): Excavaciones en las provincias de Soria y Logroño. Memorias de la Junta Superior de Excavaciones y Antigüedades, 86, Madrid.

Taracena, B. (1929): Excavaciones en las provincias de Soria y Logroño. Memorias de la Junta Superior de Excavaciones y Antigüedades, 103, Madrid.

Taracena, B. (1932): Excavaciones en la provincia de Soria. Memorias de la Junta Superior de Excavaciones y Antigüedades, 119, Madrid.

Taracena, B. (1941): Carta Arqueológica de España. Soria. C.S.I.C., Madrid.

Taylor, R. J. y V. J. Robinson (1996): «Provenance studies of Roman African red slip ware using neutron activation analysis», Archaeometry, 38 (2), 245-255.

Tite, M. S. (1995): «Firing temperature determinations - How and why ?). En A. Lindahl y O. Stilborg (eds.): The aims of laboratory analyses of ceramics in arbaeology (Lund, 1995), Historie och Antikvitets Akademien, Konferenser 34, Estocolmo, 37-42. 
Tölg, G. y R. Klockenkämper (1993): «The role of total-reflection x-tay fluorescence in atomic spectroscopyn, Spectrocbimica Acta, 48B, 111-127.

Uzquiano, P. (1995): aEl valle del Dueto en la Edad del Hierro: el aporte de la antracologías. En G. Delibes, F. Romero Carnicero y A. Morales (eds.): Arqueologia y medio ambiente. El primer milenio a. C. en el Duero medio, Junta de Castilla y León, Valladolid, 395-416.

Vendrell Saz, M.; J. Molera y M. García Vallés (1992): «La producción de ánforas romanas del taller de Can Feu (Batcelona): caracterización química y mineralógicas, Boletín de la Sociedad Española de Mineralogia, 15, 1-10.

Vicente, J. D.; A. I. Herce y C. Escriche (1983-84): «Dos hornos de cerámica de época ibética en 'Los Vicarios' (Valdecebro, Teruel)y, Kalatbos, 3-4, 311-372.

Vidale, M. (1993): «I giovani siberiani. Archeometria della ceramica antica e il problema delle nouve figure professionalin, Archeometria della ceramica. Problemi di metodo (Rimini, 1992), Ed. Int. Centro Ceramico, Bolonia, 131-150.

Vila, A. y J. Estévez (1989): “'Sola ante el peligro': la arqueología ante las ciencias auxiliares», Arcbivo Español de Arqueologia, 62, 272-278.

Walter, V. e Y. Besnus (1989): «Un example du pollution en phosphore et en manganèse de céramiques anciennes», Revue d'Archéometrie, 13, 55-64.

Wandibba, S. (1982): «Experiments in textural analysis», Archacometry, 24 (1), 71-75.

Wardle, P. (1987): «Peripatetic potters, pots or provision. The interptetation of pottery fabric datary. En C. F. Gaffney y V. L. Gaffney (eds.): Pragmatic archaeology. Theory in crisis?, B.A.R., British series, 167, Oxford, 27-34.

Wattenberg, E. (1978): Tipología de cerámica celtibérica en el valle inferior del Pisuerga (yacimientos de Tariego, Soto de Medinilla y Simancas). Museo Arqueológico de Valladolid, Monografias, 3, Valladolid.

Wattenberg, F. (1959): La región vaccea. Celiberismo y romanización en la cuenca media del Duero. Diputación Provincial de Valladolid, Valladolid.

Wattenberg, F. (1960): «Los problemas de la cultura celtibéricas, Primer simposium de prebistoria de la Peninsula lbérica (Barcelona, 1959), Diputación Foral de Navarra, Pamplona, 151-177. 
Wattenberg, F. (1963): Las cerámicas indígenas de Numancia. Biblioteca Praehistórica Hispana, IV, Madrid.

Wattenberg, F. (1978): Estratigrafia de Las Cenizales de Simancas (Valladolid). Museo Arqueológico de Valladolid, Monografias, 2, Valladolid.

Weigand, P. C.; G. Harbottle y E. V. Sayre (1977): «Turquoise sources and source analysis: Mesoamerica and the Southwestern U.S.A.n. En T. K. Earle y J. E. Ericson (eds.): Exchange systems in prebistory, Academic Press, Nueva York, 15-34.

Whitbread, I. K. (1989): «A proposal for the systematic description of thin sections towards the study of ancient ceramic technologys. En Y. Maniatis (ed.): Archaeometry. Proceedings of the 25th international symposizm (Atenas, 1986), Elsevier Science Publishers, Amsterdam, 127 138.

Woldseth, R. (1973): Quantitative analysis. X-ray spectrometry. Kevew Corporation, Burlingame (California).

Yl, R. (1995): «Análisis polínico de los yacimientos de la Edad del Hierto de Soto de Medinilla, La Era Alta y La Mota (Valladolid)». En G. Delibes, F. Romero Carnicero y A. Morales (eds.): Arqueologia y medio ambiente. El primer milenio a. C. en el Duero medio, Junta de Castilla y León, Valladolid, 357-370.

\section{CARTOGRAFÍA UTILIZADA}

- MAPA GEOLÓGICO DE ESPAÑA, Escala 1:200.000, Hoja núm. 31 "Soria". Instituto Geológico y Minero $19832^{\mathbf{a}}$ Ed.

Servicio de Publicaciones del Ministerio de Industria y Energia Madrid

\footnotetext{
- MAPA GEOLÓGICO DE ESPAÑA, Escala 1:50.000, Hoja núm. 23-13 (318) "Almarza" Instituto Geológico y Minero

1981

Servicio de Publicaciones del Ministerio de Industria y Energía Madrid
} 
- MAPA GEOLÓGICO DE ESPAÑA, Escala 1:50.000, Hoja núm. 22-14 (349) "Cabrejas del Pinar"

Instituto Geológico y Minero

1980

Servicio de publicaciones del Ministerio de Industria y Energia

Madrid

- MAPA GEOLÓGICO DE ESPAÑA, Escala 1:50.000, Hoja núm. 23-14 (350) "Soria" Instituto Tecnológico Geominero

1991

Servicio de Publicaciones del Ministerio de Industria, Comercio y Turismo

Madrid

- MAPA METALOGENÉTICO DE ESPAÑA, Escala 1:200.000, Hoja núm. 31 "Soria" Instituto Geológico y Minero

1973

Servicio de Publicaciones del Ministerio de Industria y Energía

Madrid

- MAPA DE ROCAS INDUSTRIALES, Escala 1:200.000, Hoja núm. 31 (6-4) "Soria" Instituto Geológico y Minero

1972

Servicio de Publicaciones del Ministerio de Industria y Energía

Madrid

MAPA TOPOGRÁFICO NACIONAL, Escala 1:50.000, Hoja núm. 23-13 (318) "Almarza" Servicio Geográfico del Ejército

$19923^{a} \mathrm{Ed}$.

Madrid

- MAPA TOPOGRÁFICO NACIONAL, Escala 1:200.000, Hoja núm. 23-14 (350) "Soria" Instituto Geográfico Nacional

$19812^{\mathbf{a}} \mathrm{Ed}$.

Madrid 
- MAPA TOPOGRÁFICO NACIONAL, Escala 1:50.000, Hoja núm. 22-14 (349) "Cabrejas del Pinar"

Servicio Geográfico del Ejército

$19904^{\mathrm{a}} \mathrm{Ed}$.

Madrid

- MAPA TOPOGRÁFICO NACIONAL, Escala 1:50.000, Hoja núm. 23-14 (350) "Soria" Servicio Geogxáfico del Ejército

1989

Madrid 



\section{TABLAS}




\section{TABLA 1. CARACTERÍSTICAS DE LAS MUESTRAS CERÁMICAS ANALIZADAS}

Los números de inventario se refieren todos al Museo Numantino de Soria, excepto las muestras pertenecientes a los yacimientos de El Palomar (Aragoncillo, Guadalajara) y El Pradillo (Pinilla Trasmonte, Burgos), junto a los precedidos por MAN, que indica números de inventario del Museo Arqueológico Nacional de Madrid. Los números situados entre paréntesis detrás de los tipos, hacen referencia a la tipología de Arlegui (1986). A número de catálogo del trabajo de Arlegui (1986). B pigmento blanco. M.P. pintura muy perdida como para poder medir su color. $\mathrm{N}$ pigmento negro. $\mathrm{R}$ número de catálogo del trabajo de Romero Carnicero (1976). RO pigmento rojo. $\mathrm{s} / \mathrm{n}$ sin número de inventario. W número de catálogo del trabajo de Wattenberg (1963). I Los colores se expresan en códigos Munsell.

\begin{tabular}{|c|c|c|c|c|c|c|c|c|c|c|}
\hline$\overline{\overline{N^{\circ}}}$ & MUESTRA & $\mathrm{N}^{\circ}$ IN & NVENTARIO & YACIMIENTO & TIPOLOGIA & DECORACION & EXTERNO & INTERNO & PASTA & FABRICA \\
\hline I & $N-10$ & & 226 & Numancia & Erag. Borde & Estarnpada & $\begin{array}{l}2.5 Y R \\
3 / 1\end{array}$ & $\begin{array}{l}5 \mathrm{YR} \\
6 / 2\end{array}$ & $\begin{array}{l}5 Y R \\
7 / 3\end{array}$ & 3-a \\
\hline 2 & $N-11$ & 1.071 & 1 (W 487 ) & Numancia & $\begin{array}{c}\text { Frag. Borde } \\
\text { Plato }\end{array}$ & & $\begin{array}{c}2.5 Y R \\
4 / 1\end{array}$ & $\begin{array}{c}2.5 \mathrm{YR} \\
4 / 1\end{array}$ & $\begin{array}{l}5 Y R \\
6 / 2\end{array}$ & 4 \\
\hline 3 & $N-12$ & 1.101 & I (W 244) & Numancia & $\begin{array}{c}\text { Frag. Borde } \\
\text { Vasija Globular } \\
(9)\end{array}$ & & $\begin{array}{l}7.5 \mathrm{YR} \\
5 / 1\end{array}$ & $\begin{array}{c}7.5 Y R \\
5 / 1\end{array}$ & $\begin{array}{l}7.5 Y R \\
6 / 1\end{array}$ & $3-a$ \\
\hline 4 & $\mathrm{~N}-13$ & 1.123 & 3 (w 313) & Nurancia & Frag. Borde & Estampada & $\begin{array}{l}7.5 Y R \\
6 / 2\end{array}$ & $\begin{array}{l}7.5 Y R \\
5 / 4\end{array}$ & $\begin{array}{l}5 Y R \\
7 / 4\end{array}$ & 4 \\
\hline 5 & $N-14$ & 1.282 & 2 ( 241$)$ & Numancia & $\begin{array}{c}\text { Erag. Galbo } \\
\text { Vasija Globular } \\
\text { (9) }\end{array}$ & & $\begin{array}{l}5 Y R \\
2 / 1\end{array}$ & $\begin{array}{l}5 \mathrm{YR} \\
4 / 1\end{array}$ & $\begin{array}{l}5 Y R \\
6 / 2\end{array}$ & 4 \\
\hline 6 & $N-15$ & 1.456 & 6 (W 113) & Numancia & $\begin{array}{c}\text { Frag. Borde } \\
\text { Gran Vasija }(24 d\}\end{array}$ & Estampada & $\begin{array}{l}7.5 Y R \\
4 / 1\end{array}$ & $\begin{array}{l}7.5 \mathrm{YR} \\
4 / 1\end{array}$ & $\begin{array}{l}5 Y R \\
5 / 4\end{array}$ & $3-a$ \\
\hline 7 & $8-16$ & 9.81 & $13-9.814$ & Numancia & $\begin{array}{l}\text { Prag. Borde } \\
\text { Gran Tinaja }\end{array}$ & & $\begin{array}{l}5 \times p \\
6 / 3\end{array}$ & $\begin{array}{l}5 Y R \\
7 / 3\end{array}$ & $\begin{array}{l}5 Y R \\
7 / 2\end{array}$ & 4 \\
\hline 8 & $\mathrm{~N}-17$ & 11.708 & 8 (W 667) & Numancia & $\begin{array}{l}\text { Frag. Borde Copa } \\
\text { Pie Bajo (13) }\end{array}$ & & $\begin{array}{l}5 Y R \\
5 / 2\end{array}$ & $\begin{array}{l}5 Y R \\
5 / 2\end{array}$ & $\begin{array}{l}5 Y R \\
6 / 3\end{array}$ & $3-a$ \\
\hline 9 & $N-18$ & 11.886 & $6\left(\begin{array}{ll}W & 261\end{array}\right)$ & Numancia & $\begin{array}{c}\text { Frag. Borde } \\
\text { Gran Vasija }(24 \mathrm{~h})\end{array}$ & & $\begin{array}{l}5 Y R \\
6 / 4\end{array}$ & $\begin{array}{l}5 Y R \\
6 / 4\end{array}$ & $\begin{array}{c}7.5 \mathrm{YR} \\
7 / 2\end{array}$ & $3-a$ \\
\hline 10 & $N-19$ & & 3.297 & Numaneia & $\begin{array}{l}\text { Frag. Borde } \\
\text { Crátera (23) }\end{array}$ & & $\begin{array}{l}5 Y R \\
5 / 1\end{array}$ & $\begin{array}{l}5 Y R \\
5 / 1\end{array}$ & $\begin{array}{l}5 Y R \\
6 / 1\end{array}$ & $3-a$ \\
\hline 11 & $\mathrm{~N}-20$ & & 3.299 & Numancia & $\begin{array}{l}\text { Frag. Borde Copa } \\
\text { Pie Bajo (13) }\end{array}$ & & $\begin{array}{l}5 Y R \\
5 / 2\end{array}$ & $\begin{array}{l}5 Y R \\
5 / 2\end{array}$ & $\begin{array}{l}7.5 Y R \\
7 / 2\end{array}$ & $3-a$ \\
\hline 12 & $N-21$ & 13.805 & 5 (พ 179) & Numancia & $\begin{array}{c}\text { Frag. Borde } \\
\text { Vasija Globular }\end{array}$ & & $\begin{array}{l}5 Y R \\
7 / 3\end{array}$ & $\begin{array}{l}5 \mathrm{YR} \\
7 / 3\end{array}$ & $\underset{4 / 1}{2.5 Y R}$ & $3-a$ \\
\hline 13 & $N-22$ & & $s / n$ & Numancia & Frag. Borde & & $\begin{array}{l}5 Y R \\
6 / 2\end{array}$ & $\begin{array}{l}5 \mathrm{YR} \\
6 / 2\end{array}$ & $\begin{array}{l}5 Y R \\
6 / 1\end{array}$ & 4 \\
\hline i4 & $\mathrm{N}-23$ & . & $s / n$ & Numancia & Frag. Borde & & $\begin{array}{l}5 Y R \\
5 / 1\end{array}$ & $\begin{array}{c}2.5 \mathrm{YR} \\
4 / 1\end{array}$ & $\begin{array}{l}5 Y R \\
5 / 1\end{array}$ & $3-a$ \\
\hline
\end{tabular}


TABLA 1. Continuación

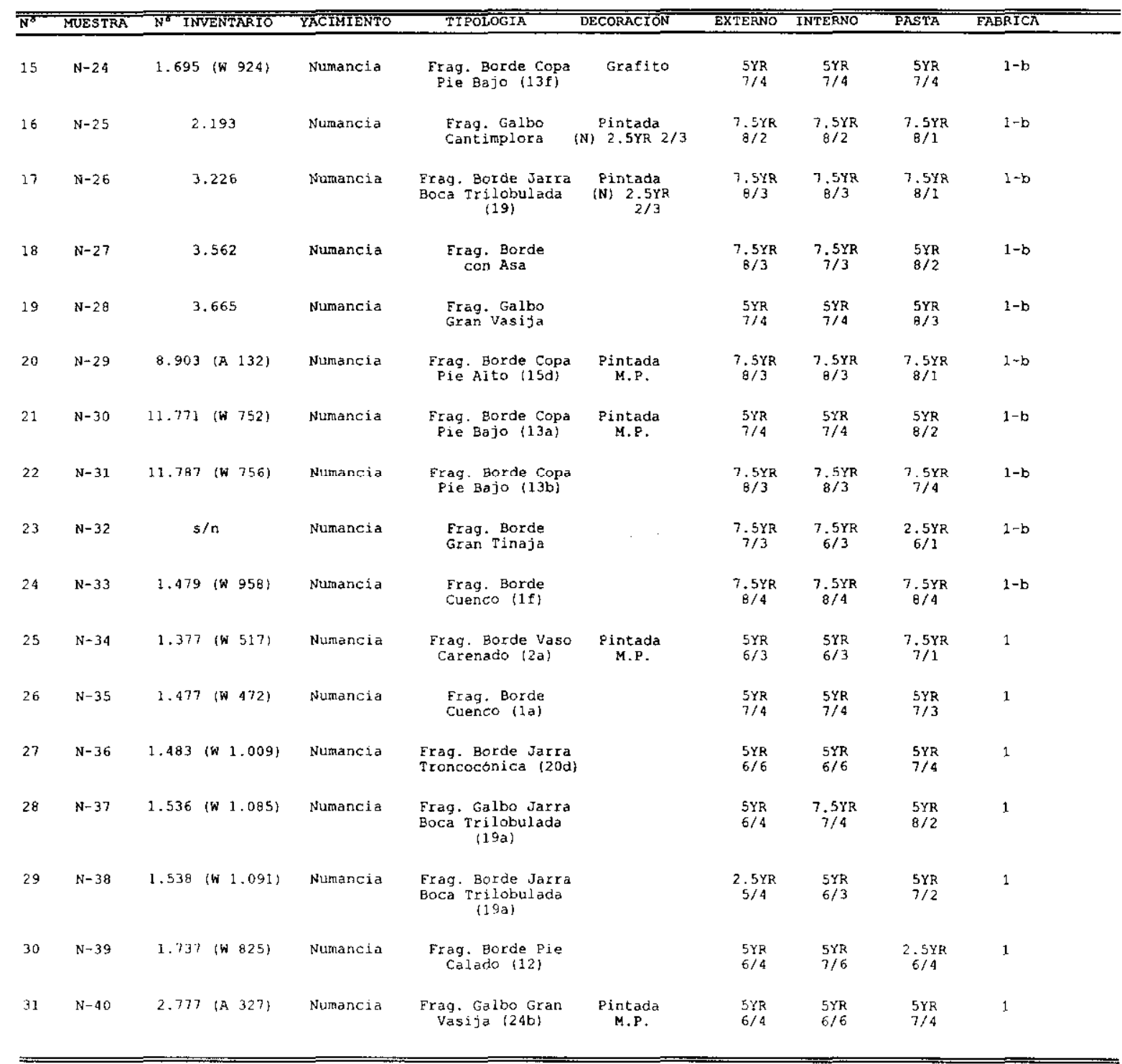


TABLA 1. Continuación

\begin{tabular}{|c|c|c|c|c|c|c|c|c|c|}
\hline $\mathrm{N}^{0}=$ & MUESTRA & $\mathrm{N}^{\circ}$ INVE NTARTO & YACIMIENTO & TIPOLOGIA & DECORACION & EXTERNO & INTERNO & PASTA & FABRICA \\
\hline 32 & $N-41$ & 2.794 & Numancia & $\begin{array}{l}\text { Frag. Borde Vaso } \\
\text { Carenado (2a) }\end{array}$ & $\begin{array}{c}\text { Pintada } \\
\text { (N) } 7.5 \mathrm{YR} \\
4 / 2\end{array}$ & $\begin{array}{l}5 Y R \\
7 / 4\end{array}$ & $\begin{array}{l}5 \mathrm{YR} \\
7 / 3\end{array}$ & $\begin{array}{l}5 Y R \\
7 / 2\end{array}$ & 1 \\
\hline 33 & $N-42$ & $2.805 \quad$ (A 206) & Numancia & $\begin{array}{l}\text { Frag. Borde Jarra } \\
\text { Boca Circular (17a) }\end{array}$ & $\begin{array}{l}\text { Pintada } \\
\text { M.P. }\end{array}$ & $\begin{array}{l}5 \mathrm{YR} \\
7 / 4\end{array}$ & $\begin{array}{l}5 Y R \\
7 / 3\end{array}$ & $\begin{array}{l}5 Y R \\
8 / 3\end{array}$ & 1 \\
\hline 34 & $N-43$ & 2.816 & Numancia & $\begin{array}{l}\text { Frag. Borde } \\
\text { Cuenco }\{1 \mathrm{~d}\}\end{array}$ & $\begin{array}{l}\text { Pintada } \\
\text { (N) } 5 Y R 2 / 3\end{array}$ & $\begin{array}{l}5 Y R \\
7 / 4\end{array}$ & $\begin{array}{l}5 Y R \\
6 / 4\end{array}$ & $\begin{array}{l}5 \mathrm{YR} \\
7 / 3\end{array}$ & 1 \\
\hline 35 & $N-44$ & 3.126 & Numancia & $\begin{array}{c}\text { Frag. Borde Jarra } \\
\text { Boca Trilobulada } \\
\text { (19) }\end{array}$ & $\begin{array}{l}\text { Qintada } \\
\text { (N) } 5 Y R 3 / 1\end{array}$ & $\begin{array}{l}5 Y R \\
6 / 6\end{array}$ & $\begin{array}{l}7.5 Y R \\
7 / 6\end{array}$ & $\begin{array}{l}7.5 \mathrm{YR} \\
7 / 6\end{array}$ & 1 \\
\hline 36 & $N-45$ & 3.224 & Numancia & $\begin{array}{c}\text { Frag. Borde Jarra } \\
\text { Boca Trilobulada } \\
(19)\end{array}$ & $\begin{array}{l}\text { Pintada } \\
\text { (N) } 2.5 \mathrm{YRR} \\
5 / 2\end{array}$ & $\begin{array}{l}2.5 Y R \\
7 / 6\end{array}$ & $\begin{array}{l}2.5 Y R \\
7 / 6\end{array}$ & $\begin{array}{l}\text { SYR } \\
8 / 4\end{array}$ & 1 \\
\hline 37 & $\mathrm{~N}-46$ & $3.385($ W 891) & Numancia & $\begin{array}{l}\text { Frag. Borde Copa } \\
\text { Pie Alto (15d) }\end{array}$ & $\begin{array}{l}\text { Pintada } \\
\text { M.P. }\end{array}$ & $2,5 Y R$ & 2. SYR & $2.5 Y R$ & 1 \\
\hline 38 & $N-47$ & 3.616 (A 218) & Numancia & Erag. Borde & $\begin{array}{l}\text { Pintada } \\
\text { M.P. }\end{array}$ & $\begin{array}{l}5 \mathrm{YR} \\
5 / 4\end{array}$ & $\begin{array}{l}5 Y R \\
5 / 4\end{array}$ & $\begin{array}{l}\mathrm{SYR} \\
7 / 3\end{array}$ & 1 \\
\hline 39 & $\mathrm{~N}-48$ & 3.659 & Numancia & $\begin{array}{l}\text { Frag. Borde } \\
\text { Cuenco (1) }\end{array}$ & & $\begin{array}{l}2.5 Y R \\
6 / 6\end{array}$ & $\begin{array}{l}2.5 Y R \\
6 / 6\end{array}$ & $\begin{array}{l}2.5 Y \mathrm{YR} \\
7 / 4\end{array}$ & 1 \\
\hline 40 & $\mathrm{~N}-49$ & $8.222(W 417)$ & Numancia & $\begin{array}{l}\text { Frag. Galbo } \\
\text { Trompa }\end{array}$ & & $\begin{array}{l}2.5 Y R \\
7 / 6\end{array}$ & $2,5 Y R$ & $\begin{array}{l}\text { SYR } \\
7 / 4\end{array}$ & 1 \\
\hline $4 I$ & $\mathrm{~N}-50$ & 12.515 & Numancia & $\begin{array}{l}\text { Frag. Borde Jarra } \\
\text { Troncocbnica (20b) }\end{array}$ & $\begin{array}{l}\text { Pintada } \\
\text { M.F. }\end{array}$ & $\begin{array}{l}5 Y R \\
6 / 4\end{array}$ & $\begin{array}{l}5 Y R \\
7 / 4\end{array}$ & $\begin{array}{l}5 \mathrm{YR} \\
7 / 3\end{array}$ & 1 \\
\hline 42 & $N-51$ & 12.542 & Numancia & $\begin{array}{l}\text { Frag. Borde Vaso } \\
\text { Carenado }(2 \mathrm{~b})\end{array}$ & $\begin{array}{l}\text { Pintada } \\
\text { (N) } 5 Y \text { YR } 2 / 1\end{array}$ & $\begin{array}{l}\text { SYR } \\
7 / 3\end{array}$ & $\begin{array}{l}5 \mathrm{YR} \\
7 / 3\end{array}$ & $\begin{array}{l}\text { SYR } \\
8 / 2\end{array}$ & 1 \\
\hline 43 & $N-52$ & 12.568 & Numancia & $\begin{array}{l}\text { Erag. Borde } \\
\text { Embudo (10a) }\end{array}$ & $\begin{array}{l}\text { Pintada } \\
\text { (N) } 5 Y R 3 / 3\end{array}$ & $2.5 \mathrm{YR}$ & $\begin{array}{l}5 Y R \\
7 / 6\end{array}$ & $\begin{array}{l}5 \mathrm{YR} \\
7 / 4\end{array}$ & I \\
\hline 44 & $N-53$ & 12.990 & Numancia & $\begin{array}{l}\text { Frag. Borde Gran } \\
\text { Vasija }(24 \mathrm{e})\end{array}$ & $\begin{array}{c}\text { Pintrada } \\
\text { (N) } \begin{array}{c}2.5 \mathrm{YR} \\
4 / 3\end{array}\end{array}$ & $\begin{array}{l}5 \mathrm{YR} \\
7 / 6\end{array}$ & $\begin{array}{c}7.5 Y R \\
6 / 8\end{array}$ & $\begin{array}{c}7.5 \mathrm{YR} \\
7 / 6\end{array}$ & 1 \\
\hline 45 & $N-54$ & $s / n$ & Numancia & $\begin{array}{l}\text { Frag. Borde Gran } \\
\text { Vasija }(24)\end{array}$ & $\begin{array}{l}\text { Pintada } \\
\text { (N) } 5 \mathrm{YR} 2 / 3\end{array}$ & $\begin{array}{l}5 Y R \\
6 / 4\end{array}$ & $2,5 Y R$ & $\begin{array}{l}2.5 Y R \\
2 / 6\end{array}$ & 1 \\
\hline 46 & $N-55$ & $s / n$ & Numancia & $\begin{array}{l}\text { Erag. Galbo } \\
\text { Embudo }(10)\end{array}$ & & $\begin{array}{l}5 \mathrm{YR} \\
7 / 4\end{array}$ & $\begin{array}{l}5 Y R \\
7 / 3\end{array}$ & $\begin{array}{l}5 Y R \\
7 / 2\end{array}$ & 1 \\
\hline 47 & $N-56$ & $s / n$ & Numancia & $\begin{array}{l}\text { Frag. Galbo } \\
\text { Gran Tinaja }\end{array}$ & & $\begin{array}{l}\text { bYR } \\
B / 3\end{array}$ & $\begin{array}{l}5 Y R \\
1 / 3\end{array}$ & $\begin{array}{l}5 Y R \\
7 / 4\end{array}$ & 1 \\
\hline 48 & $N-57$ & $1.111(\omega 125)$ & Numancia & $\begin{array}{c}\text { Erag, Borde Vasija } \\
\text { Globular }(9)\end{array}$ & Estampada & $\begin{array}{l}5 Y R \\
4 / 1\end{array}$ & $\begin{array}{l}5 \mathrm{YR} \\
4 / 1\end{array}$ & $\begin{array}{l}5 \mathrm{YR} \\
7 / 1\end{array}$ & 2 \\
\hline
\end{tabular}


TABLA 1. Continuación

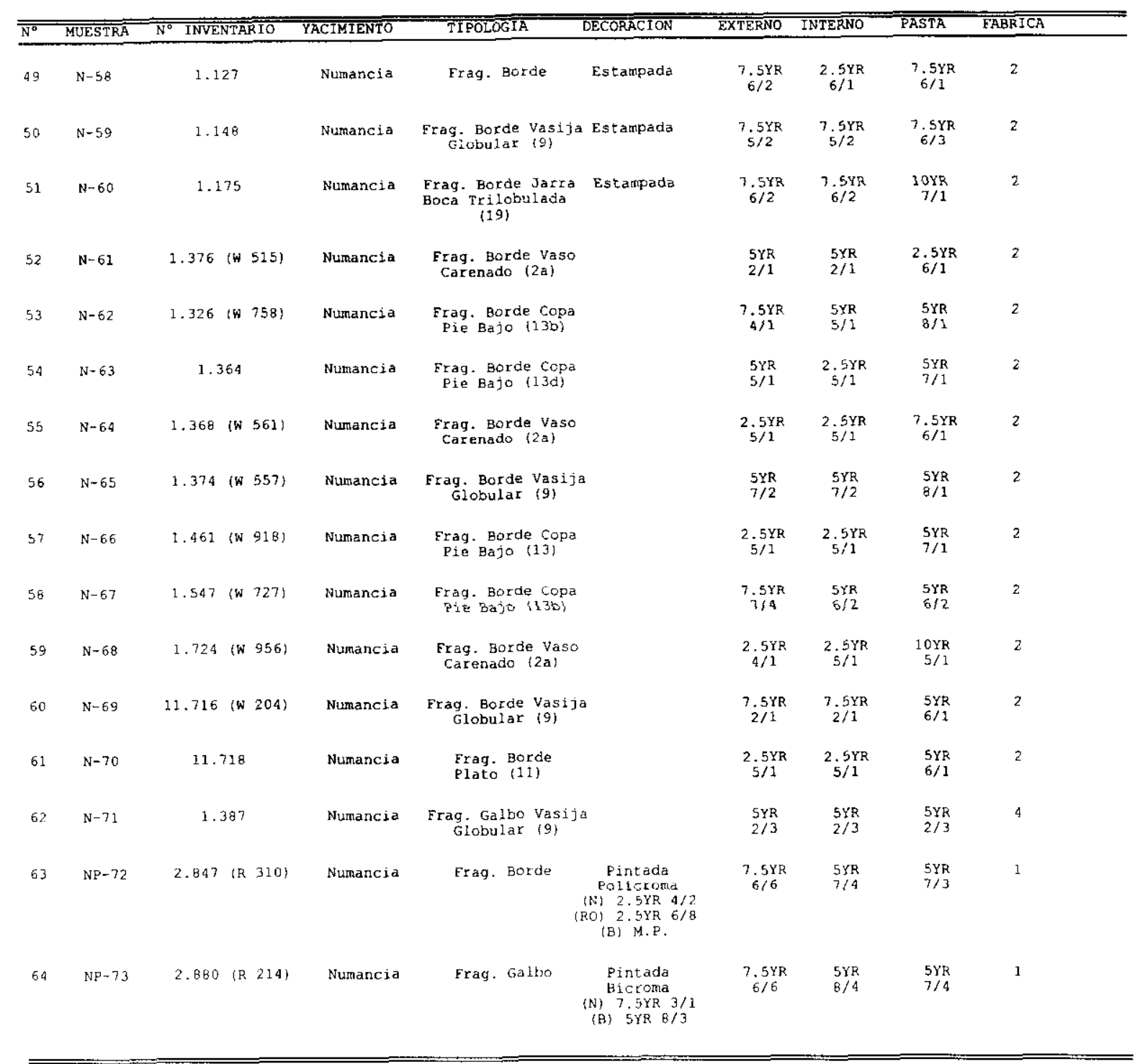


TABLA 1. Continuación

\begin{tabular}{|c|c|c|c|c|c|c|c|c|c|}
\hline$\overline{\mathrm{N}}^{\circ}$ & MUESTRA & N $\mathrm{N}^{\circ}$ INVENTARIO & YACIMIENTO & TIPOLOGIA & DECORACION & EXTERNO & INTERNO & PASTA & FABRICA \\
\hline 65 & NP-74 & $\begin{array}{l}2.918-2920 \\
(R 338)\end{array}$ & Numancia & Frag. Galbo & $\begin{array}{l}\text { Pintada } \\
\text { Bicroma } \\
\text { (N) } 2.5 \mathrm{YR} 4 / 2 \\
\text { (B) } 7.5 \mathrm{YR} 8 / 3\end{array}$ & $\begin{array}{c}2.5 \mathrm{YR} \\
7 / 6\end{array}$ & $\begin{array}{l}5 \mathrm{YR} \\
7 / 4\end{array}$ & $\begin{array}{l}5 Y R \\
8 / 2\end{array}$ & 1 \\
\hline 66 & $N P-75$ & 3.005 (R 239) & Numancia & Fraq. Borde & $\begin{array}{l}\text { pintada } \\
\text { Bicroma } \\
\text { (N) } 2.5 \mathrm{YR} 3 / 2 \\
\text { (B) } 5 \text { YR } 8 / 3\end{array}$ & $\frac{7.5 \mathrm{YR}}{6 / 6}$ & $\begin{array}{l}2.5 Y R \\
7 / 4\end{array}$ & $\begin{array}{l}5 \mathrm{YR} \\
6 / 4\end{array}$ & 1 \\
\hline 67 & NP-76 & 3.245 (R 14) & Numancia & Frag. Galbo & $\begin{array}{l}\text { Pintada } \\
\text { Blicroma } \\
\text { (N) } 7.5 Y R 4 / 2 \\
\text { (B) } 5 \text { YR } 8 / 2\end{array}$ & $\begin{array}{l}7.5 \mathrm{YR} \\
6 / 6\end{array}$ & $\begin{array}{l}5 Y R \\
7 / 3\end{array}$ & $\begin{array}{l}\text { SYR } \\
7 / 3\end{array}$ & 1 \\
\hline 68 & $N P-77$ & $\begin{array}{c}12.698(\mathrm{R} 246) \\
(\mathrm{W} I .226)^{2}\end{array}$ & Numancia & Frag. Galbo & $\begin{array}{l}\text { Pintada } \\
\text { Bicroma } \\
\text { (N) } 2.5 \mathrm{YR} \quad 3 / 3 \\
\text { (B) } 7.5 \mathrm{YR} 8 / 3\end{array}$ & $\begin{array}{c}2.5 Y R \\
6 / 6\end{array}$ & $\begin{array}{l}2.5 \mathrm{YR} \\
6 / 4\end{array}$ & $\begin{array}{l}5 Y R \\
7 / 4\end{array}$ & 1 \\
\hline 69 & NP-78 & $s / n$ & Numancia & Frag. Borde & $\begin{array}{l}\text { Pintada } \\
\text { Bicroma } \\
\text { (N) } 2.5 Y \mathrm{YR} 5 / 3 \\
\text { (B) } 7,5 \mathrm{YR} 8 / 3\end{array}$ & $\begin{array}{l}5 Y R \\
8 / 3\end{array}$ & $\begin{array}{l}5 Y R \\
6 / 3\end{array}$ & $\begin{array}{l}5 Y R \\
8 / 3\end{array}$ & 1 \\
\hline 70 & $N P-79$ & $s / n$ & Numancia & Frag. Borde & $\begin{array}{c}\text { Pintada } \\
\text { Polfcroma } \\
\text { (N) } 2.5 \mathrm{YR} \quad 3 / 3 \\
\text { (RO) } 2.5 \mathrm{YR} \quad 6 / 8 \\
\text { (B) } 7.5 \mathrm{YR} \quad 8 / 1\end{array}$ & $\begin{array}{c}2.5 \mathrm{YR} \\
7 / 6\end{array}$ & $2.5 \mathrm{YR}$ & $\begin{array}{l}5 Y R \\
8 / 4\end{array}$ & 1 \\
\hline 71 & NP- 80 & $s / n$ & Numancia & Frag. Galbo & $\begin{array}{l}\text { Qìntada } \\
\text { Bicroma } \\
\text { (N) M.P. } \\
\text { (RO) } 7.5 \mathrm{YR} \quad 6 / 6\end{array}$ & $\begin{array}{l}5 Y R \\
8 / 4\end{array}$ & $\begin{array}{l}5 Y R \\
8 / 4\end{array}$ & $\begin{array}{l}5 Y R \\
8 / 3\end{array}$ & 1 \\
\hline 72 & $N P-81$ & $\begin{array}{l}2.115 \text { (R } 5) \\
(W 1.137)\end{array}$ & Numancia & Frag. Galbo & $\begin{array}{l}\text { Pintada } \\
\text { Bicroma } \\
\text { (N) } 2.5 \mathrm{YR} 4 / 3 \\
\text { (RO) } 7.5 \mathrm{YR} 6 / 8\end{array}$ & $\begin{array}{l}7.5 Y R \\
8 / 2\end{array}$ & $\begin{array}{l}7.5 Y R \\
8 / 2\end{array}$ & $\begin{array}{c}7.5 Y R \\
8 / 2\end{array}$ & $1-b$ \\
\hline 73 & $N P-82$ & 2.124 (R 4) & Numancia & Erag. Borde & $\begin{array}{c}\text { Pintada } \\
\text { Bicroma } \\
\text { (N) } 7.5 Y R \quad 5 / 2 \\
\text { (RO) } 7.5 Y R \quad 6 / 8\end{array}$ & $\begin{array}{c}7.5 Y R \\
8 / 2\end{array}$ & $\begin{array}{c}7.5 \mathrm{YR} \\
8 / 2\end{array}$ & $\begin{array}{c}7.5 \mathrm{YR} \\
8 / 2\end{array}$ & $1-b$ \\
\hline 74 & $N P-83$ & $\begin{array}{c}2.239 \quad(R 37) \\
(W 1.275)\end{array}$ & Numancia & Frag. Galbo & $\begin{array}{c}\text { Pintada } \\
\text { Bicroma } \\
\text { (N) } 2.5 Y R \quad 4 / 2 \\
\text { (RO) } 2.5 Y R \quad 6 / 8\end{array}$ & $\begin{array}{c}7.5 \mathrm{YR} \\
\mathrm{B} / 2\end{array}$ & $\begin{array}{l}7.5 Y R \\
8 / 2\end{array}$ & $\begin{array}{l}7.5 Y R \\
8 / 2\end{array}$ & $1-b$ \\
\hline 75 & $\mathrm{NP}-84$ & $2.946\left(R_{1} \quad 112\right)$ & Numancia & Erag. Galbo & $\begin{array}{l}\text { Pintada } \\
\text { Bicroma } \\
\text { (N) } 7.5 Y R \quad 6 / 4 \\
\text { (RO) } 2.5 Y R \quad 6 / 6\end{array}$ & $\begin{array}{c}7.5 \mathrm{YR} \\
8 / 2\end{array}$ & $\begin{array}{c}7.5 Y R \\
8 / 3\end{array}$ & $\begin{array}{c}7.5 \mathrm{YR} \\
6 / 1\end{array}$ & $1-b$ \\
\hline
\end{tabular}


TABLA 1. Continuación

\begin{tabular}{|c|c|c|c|c|c|c|c|c|c|}
\hline$\overline{N^{5}}$ & MUES TRA & $\begin{array}{ll}\mathrm{N}^{\circ} & \text { INVENTARIO } \\
\end{array}$ & YACIMIENTO & TIPOLOGIA & DECORACION & EXTERNO & INTERNO & PASTA & FABRICA \\
\hline 76 & $N P-85$ & $\begin{array}{l}3.084 \text { (R } 90) \\
(W 944)\end{array}$ & Numancia & Frag. Borde & $\begin{array}{l}\text { Pintadia } \\
\text { Bicroma } \\
\text { (N) } 2,5 Y R \quad 4 / 2 \\
\text { (RO) } 5 Y R 6 / 6\end{array}$ & $\begin{array}{l}7.5 Y R \\
8 / 3\end{array}$ & $\begin{array}{l}7.5 Y R \\
8 / 2\end{array}$ & $\begin{array}{l}7.5 Y R \\
8 / 1\end{array}$ & $1-b$ \\
\hline 77 & $\mathrm{NP}-\mathrm{B} 6$ & 12.662 & Numancia & Frag. Galbo & (N) $\begin{array}{l}\text { Pintada } \\
2 . \text { SYR }_{4 / 2}\end{array}$ & $\begin{array}{l}7.5 Y R \\
8 / 2\end{array}$ & $\begin{array}{l}7.5 Y R \\
\theta / 2\end{array}$ & $\begin{array}{l}7.5 \mathrm{YR} \\
8 / 1\end{array}$ & $1-b$ \\
\hline 78 & $N P-87$ & $12.673(\mathrm{R} 118)$ & Nunancia & Frag. Galbo & $\begin{array}{c}\text { Pintada } \\
\text { Blcroma } \\
\text { (N) } 5 Y R \quad 3 / 2 \\
\text { (RO) } 2.5 Y R 6 / 6\end{array}$ & $\begin{array}{l}7.5 Y R \\
8 / 3\end{array}$ & $\begin{array}{l}7.5 Y R \\
8 / 3\end{array}$ & $\begin{array}{l}7.5 \mathrm{YR} \\
8 / 2\end{array}$ & $1-b$ \\
\hline 79 & NP- 88 & 16 & Numancia & $\begin{array}{l}\text { Erag. Borde } \\
\text { Copa pie Bajo } \\
\text { (13) }\end{array}$ & $\begin{array}{c}\text { Pintada } \\
\text { Bicroma } \\
\text { (N) } 5 \mathrm{YR} 8 / 4 \\
\text { (B) } 7.5 \mathrm{YR} 8 / 3\end{array}$ & $\begin{array}{l}5 Y R \\
7 / 4\end{array}$ & $\begin{array}{l}7.5 Y R \\
8 / 4\end{array}$ & $\begin{array}{l}7.5 \mathrm{YR} \\
\theta / 2\end{array}$ & $1-b$ \\
\hline 80 & NP- 89 & $s / n$ & Numancia & Erag. Borde & $\begin{array}{c}\text { Pintada } \\
\text { Bicroma } \\
\text { (N) } 5 \mathrm{YR} 4 / 3 \\
\text { (RO) } 7.5 \mathrm{YR} 7 / 3\end{array}$ & $\begin{array}{l}7.5 Y R \\
8 / 1\end{array}$ & $\begin{array}{l}7.5 Y R \\
8 / 1\end{array}$ & $\begin{array}{l}7.5 Y R \\
8 / 1\end{array}$ & $1-b$ \\
\hline 81 & $N P-90$ & $s / n$ & Numancia & Erag. Galbo & $\begin{array}{c}\text { Pintada } \\
\text { Bicroma } \\
\text { (N) } 2.5 \mathrm{YR} \quad 3 / 3 \\
\text { (RO) } 2.5 \mathrm{YR} \quad 6 / 6\end{array}$ & $\begin{array}{c}7.5 Y R \\
8 / 3\end{array}$ & $\begin{array}{c}7.5 Y R \\
8 / 3\end{array}$ & $\begin{array}{l}7.5 Y R \\
8 / 1\end{array}$ & $1-b$ \\
\hline 82 & NP- 91 & $3.071\{(R \quad 77\}$ & Numancia & Frag. Galbo & (N) $\begin{array}{l}\text { Pintada } \\
7.5 \mathrm{YR} \\
4 / 2\end{array}$ & $\begin{array}{l}7.5 \mathrm{YR} \\
8 / 1\end{array}$ & $\begin{array}{l}7.5 Y R \\
8 / I\end{array}$ & $\begin{array}{l}7.5 \mathrm{YR} \\
7 / 1\end{array}$ & 2 \\
\hline 83 & $N P-97$ & $3.246 \quad(8 \quad 16)$ & Numancia & Frag. Borde & $\begin{array}{c}\text { Pintada } \\
\text { Bicroma } \\
\text { (N) } 10 \mathrm{YR} 5 / 4 \\
\text { (RO) } 7.5 Y R \quad 8 / 2\end{array}$ & $\begin{array}{l}7.5 Y R \\
8 / 1\end{array}$ & $\begin{array}{l}7.5 \mathrm{YR} \\
8 / 1\end{array}$ & $\begin{array}{l}7.5 Y R \\
8 / 1\end{array}$ & $1-b$ \\
\hline 84 & $L D-92$ & $\begin{array}{c}1.713 \\
76 / 17 / 130\end{array}$ & $\begin{array}{l}\text { Cuesta del Moro } \\
\text { (Langa de Duero) }\end{array}$ & Frag. Galbo & $\begin{array}{l}\text { Pintada } \\
\text { Alcroma } \\
\text { (RO) } 2.5 \text { YR } 4 / 4 \\
\text { (B) } 7.5 \text { YR } 7 / 1\end{array}$ & --- & $\underset{7 / 3}{7.5 \mathrm{YR}}$ & $\begin{array}{r}5 Y \\
5 / 1\end{array}$ & $1-b$ \\
\hline 85 & LD -93 & $s / n$ & $\begin{array}{l}\text { Cuesta del Moro } \\
\text { (Langa de Duero) }\end{array}$ & Frag. Galbo & $\begin{array}{l}\text { Pintada } \\
\text { Bicroma } \\
\text { (N) } 7.5 \mathrm{YR} \quad 4 / 3 \\
\text { (B) } 7.5 \mathrm{YR} 7 / 1\end{array}$ & --- & $\begin{array}{l}7.5 \mathrm{YR} \\
7 / 2\end{array}$ & $\begin{array}{r}5 Y \\
5 / 1\end{array}$ & $1-b$ \\
\hline 86 & $L D-94$ & $s / n$ & $\begin{array}{l}\text { Cuesta del Moro } \\
\text { (Langa de Duerol }\end{array}$ & Frag. Galbo & $\begin{array}{c}\text { Pintada } \\
\text { Bicroma } \\
\text { (N) } 7 \text { FYR } 5 / 2 \\
\text { (B) } \text { iOYR } 8 / 1\end{array}$ & --- & $\begin{array}{c}7.5 Y \mathrm{YR} \\
7 / 2\end{array}$ & $\begin{array}{l}7.5 Y R \\
7 / 1\end{array}$ & $1-b$ \\
\hline
\end{tabular}


TABLA 1. Continuación

\begin{tabular}{|c|c|c|c|c|c|c|c|c|c|}
\hline$\overline{\overline{N^{\circ}}}$ & MUESTRA & "N ${ }^{\circ}$ INVENTARIO & YACIMIENTD & TIPOLŌGIA & DECORACION & EXTERNO & INTERNO & PASTA & $\overline{\text { FARRIC }}$ \\
\hline 87 & $L D-95$ & $\begin{array}{l}7.724 \\
76 / 1 / 8\end{array}$ & $\begin{array}{l}\text { Las Quintanas } \\
\text { (Langa de Duero) }\end{array}$ & $\begin{array}{c}\text { Frag. Galbo } \\
\text { Vaso Carenado }\end{array}$ & $\begin{array}{l}\text { Pintada } \\
\text { Bicroma } \\
\text { (RO) M.P. } \\
\text { (B) } 10 \mathrm{YR} 7 / 3\end{array}$ & -- & -- & $\begin{array}{l}5 Y R \\
7 / 4\end{array}$ & 1 \\
\hline 88 & LD -96 & $\begin{array}{c}1.712 \\
76 / 1 / 21\end{array}$ & $\begin{array}{l}\text { Las Quintanas } \\
\text { (Langa de Duero) }\end{array}$ & Frag. Borde & $\begin{array}{c}\text { Pintada } \\
\text { Blcroma } \\
\text { (N) SYR 4/4 } \\
\text { (RO) } 2.5 Y R \quad 4 / 4\end{array}$ & $\begin{array}{l}\text { SYR } \\
7 / 3\end{array}$ & $\begin{array}{l}5 Y R \\
7 / 3\end{array}$ & $\begin{array}{l}5 Y R \\
7 / 2\end{array}$ & $1-b$ \\
\hline
\end{tabular}

\begin{tabular}{|c|c|c|c|c|c|c|c|c|c|}
\hline 89 & $E P-25$ & $91 / X / I I I$ & $\begin{array}{c}\text { EI Palomar } \\
\text { (Guadalajara) }\end{array}$ & $\underset{(24 \mathrm{e})}{\operatorname{Gran} \text { Vasija }}$ & $\begin{array}{c}\text { Pintada } \\
\text { M.P. }\end{array}$ & $\begin{array}{l}\text { SYR } \\
6 / 6\end{array}$ & $\begin{array}{l}\text { SYR } \\
5 / 1\end{array}$ & $\begin{array}{l}5 Y R \\
6 / 6\end{array}$ & 1 \\
\hline 90 & $E P-26$ & $92 / I / I V$ & $\begin{array}{c}\text { El Palomar } \\
\text { (Guadalajara) }\end{array}$ & Erag. Galbo & $\begin{array}{l}\text { Pintada } \\
\text { (N) } 5 \text { YR } 2 / 2\end{array}$ & $\begin{array}{l}2.5 Y R \\
5 / 6\end{array}$ & $\underset{6 / 8}{2.5 \mathrm{YR}}$ & $\begin{array}{c}2.5 \mathrm{YR} \\
6 / 8\end{array}$ & 1 \\
\hline 92 & $E P-27$ & $94 / I / V I I-A$ & $\begin{array}{c}\text { El Palomar } \\
\text { (Guadalajara) }\end{array}$ & $\begin{array}{l}\text { Frag. Borde Vaso } \\
\text { Carenado (2b) }\end{array}$ & $\begin{array}{l}\text { Pintada } \\
\text { (N) } 2.5 Y R \\
2 / 2\end{array}$ & $\begin{array}{l}5 Y R \\
6 / 6\end{array}$ & $\begin{array}{l}5 Y R \\
6 / 6\end{array}$ & $\begin{array}{l}5 Y K \\
6 / 6\end{array}$ & 1 \\
\hline 92 & $E P-28$ & $94 /$ I $/$ III-A & $\begin{array}{c}\text { El Palomar } \\
\text { \{Guadalajara\} }\end{array}$ & $\begin{array}{l}\text { Erag. Borde Vaso } \\
\text { Carenado }(2 b)\end{array}$ & $\begin{array}{c}\text { Pintada } \\
\text { (N) } 2.5 \mathrm{YR} \\
3 / 2\end{array}$ & $\begin{array}{l}5 \mathrm{YR} \\
5 / 6\end{array}$ & $\begin{array}{l}5 Y R \\
5 / 6\end{array}$ & $\begin{array}{l}5 Y R \\
6 / 4\end{array}$ & 1 \\
\hline 93 & EP-29 & $92 / x / V-B$ & $\begin{array}{c}\text { El Palomar } \\
\text { (Guadalajara) }\end{array}$ & Frag. Galbo & $\begin{array}{l}\text { Pintada } \\
\text { M.P. }\end{array}$ & $\begin{array}{l}5 Y R \\
6 / 6\end{array}$ & $\begin{array}{l}5 Y R \\
6 / 6\end{array}$ & $\begin{array}{l}5 Y R \\
7 / 4\end{array}$ & 1 \\
\hline 94 & PT-1 & $8 \theta / 7 / 3 / 1 / 7 X$ & $\begin{array}{l}\text { El Pradillo } \\
\text { (Burgos) }\end{array}$ & $\begin{array}{c}\text { Frag. Borde } \\
\text { Jarra }\end{array}$ & & $\begin{array}{c}7.5 \mathrm{YR} \\
8 / 4\end{array}$ & $\begin{array}{l}7.5 \mathrm{YR} \\
8 / 4\end{array}$ & $\begin{array}{l}7.5 Y R \\
7 / 1\end{array}$ & $1-\mathrm{b}$ \\
\hline 95 & $\mathrm{PT}-2$ & $88 / 7 / 6 / 1$ & $\begin{array}{l}\text { El Pradillo } \\
\text { (Burgos) }\end{array}$ & $\begin{array}{c}\text { Frag, Borde Jarra } \\
\text { Boca Trilobulada } \\
\text { (19) }\end{array}$ & & $\begin{array}{l}7,5 Y R \\
7 / 4\end{array}$ & $\underset{7 / 4}{7.5 Y R}$ & $\begin{array}{l}\text { SYR } \\
7 / 6\end{array}$ & $1-b$ \\
\hline 96 & PT -3 & $88 / 7 / 3 / 1$ & $\begin{array}{l}\text { El Pradillo } \\
\text { (Burgos) }\end{array}$ & $\begin{array}{l}\text { Erag. Borde Jarra } \\
\text { Boca Tril lobulada } \\
\text { (19) }\end{array}$ & & $\underset{6 / 3}{7.5 Y R}$ & $\begin{array}{c}7.5 Y R \\
6 / 3\end{array}$ & $\begin{array}{c}10 Y R \\
7 / 1\end{array}$ & $1-b$ \\
\hline 97 & PT- 4 & $86 / 13 / I 1 / C$ & $\begin{array}{l}\text { El Pradillo } \\
\text { (Burgos) }\end{array}$ & $\begin{array}{c}\text { Erag. Galbo } \\
\text { Jarra }\end{array}$ & & $\begin{array}{l}7.5 \mathrm{YR} \\
7 / 8\end{array}$ & $\begin{array}{l}7.5 \mathrm{YR} \\
7 / 8\end{array}$ & $\begin{array}{l}7.5 Y R \\
5 / 2\end{array}$ & $1-b$ \\
\hline 98 & PT-5 & $86 / 13 / I I / A$ & $\begin{array}{c}\text { El Pradillo } \\
\text { (Burgos) }\end{array}$ & $\begin{array}{c}\text { Erag. Borde Jarra } \\
\text { Boca Trilobulada } \\
\text { (19) }\end{array}$ & & $\begin{array}{l}7.5 \mathrm{YR} \\
7 / 4\end{array}$ & $\begin{array}{l}7.5 Y R \\
7 / 4\end{array}$ & $\begin{array}{c}7.5 Y R \\
6 / 1\end{array}$ & $1-b$ \\
\hline 99 & $P T-6$ & $86 / 13 / 11 / A$ & $\begin{array}{l}\text { El Pradillo } \\
\text { (Burgos) }\end{array}$ & $\begin{array}{c}\text { Frag. Borde } \\
\text { Jarra }\end{array}$ & & $\begin{array}{l}7.5 Y R \\
7 / 6\end{array}$ & ${ }_{7 / 6}^{7.5 Y R}$ & $\begin{array}{l}7.5 \mathrm{YR} \\
7 / 1\end{array}$ & $1-b$ \\
\hline 100 & $\mathrm{PT}-7$ & $86 / 13 / 11 / C$ & $\begin{array}{l}\text { El Pradillo } \\
\text { (Burgos) }\end{array}$ & $\begin{array}{c}\text { Erag. Galbo } \\
\text { Jarra }\end{array}$ & & $\begin{array}{c}7.5 \times 8 \\
7 / 8\end{array}$ & $\begin{array}{c}7,5 Y R \\
7 / 8\end{array}$ & $\begin{array}{c}2.5 Y R \\
7 / 6\end{array}$ & $1-b$ \\
\hline
\end{tabular}


TABLA 1. Continuación

\begin{tabular}{|c|c|c|c|c|c|c|c|c|c|}
\hline$\overline{\overline{\mathrm{N}^{0}}}$ & MUESTRA & " $\mathrm{N}^{\circ}$ INVENTARIO & YACIMIENTO & TIPOLOGIA & ECORACION & EXTERNO & INTERNO & PASTA & EABRICA \\
\hline 101 & $\mathrm{PT}-8$ & $86 / 15 / 11 / \mathrm{H}$ & $\begin{array}{l}\text { El Fradillo } \\
\text { (Burgos) }\end{array}$ & $\begin{array}{c}\text { Frag. Borde Jarra } \\
\text { Boca Trilobulada } \\
\qquad 19\}\end{array}$ & $\begin{array}{l}\text { Pintada } \\
\text { (N) } 2.5 \mathrm{YR} \\
4 / 3\end{array}$ & ${ }_{7 / 6}^{7.5 Y R}$ & $\begin{array}{l}7.5 Y R \\
7 / 6\end{array}$ & $\underset{7 / 3}{7 / 5 \mathrm{YR}}$ & $1-b$ \\
\hline 102 & PT -9 & $88 / 7 / 1 / \mathrm{II} / \mathrm{V}$ & $\begin{array}{l}\text { El Pradillo } \\
\text { (Burgos) }\end{array}$ & Erag. Galbo & & $\begin{array}{l}7.5 \mathrm{YR} \\
7 / 6\end{array}$ & ${ }^{7} i / 6$ & $\begin{array}{l}7.5 Y R \\
6 / 1\end{array}$ & $1-b$ \\
\hline 103 & $P T-10$ & $86 / 13 / I I / B$ & $\begin{array}{l}\text { El Pradillo } \\
\text { (Burgos) }\end{array}$ & $\begin{array}{l}\text { Erag. Asa } \\
\text { Jarra }\end{array}$ & & ${ }^{7} ; 5 \mathrm{YR}$ & $\begin{array}{l}7.5 \mathrm{YR} \\
7 / 6\end{array}$ & $\begin{array}{l}7.5 \mathrm{YR} \\
5 / 2\end{array}$ & $1-b$ \\
\hline 104 & PT-11 & $86 / 13 / I I / B$ & $\begin{array}{c}\text { El Pradillo } \\
\text { (Burgos) }\end{array}$ & $\underset{\substack{\text { Frag. Galbo } \\
\text { Jarra }}}{ }$ & & $\begin{array}{l}\text { 5YR } \\
7 / 6\end{array}$ & $\begin{array}{l}5 \mathrm{YR} \\
7 / 6\end{array}$ & $\begin{array}{l}5 \mathrm{YR} \\
6 / 1\end{array}$ & $1-b$ \\
\hline 105 & $I Z A-1$ & 858 & Izana & $\begin{array}{l}\text { Frag. Galbo Gran } \\
\text { Vasija }(24 \mathrm{e})\end{array}$ & $\begin{array}{l}\text { Fintada } \\
\text { (N) } \operatorname{SYR~} 3 / 4\end{array}$ & $\begin{array}{l}\text { 5YR } \\
3 / 4\end{array}$ & $\begin{array}{l}2.5 \mathrm{YR} \\
7 / 4\end{array}$ & $\begin{array}{l}2.5 Y R \\
6 / 6\end{array}$ & 1 \\
\hline 106 & IZA-1BIS & MAN1 $927 / 25 / 10$ & Izana & Trosupa & & $\begin{array}{c}7.5 \mathrm{YR} \\
6 / 3\end{array}$ & $\begin{array}{l}7.5 Y R \\
6 / 3\end{array}$ & $\begin{array}{l}5 Y R \\
6 / 1\end{array}$ & 2 \\
\hline 107 & $I 2 A-2$ & $79 / 6 / 5$ & I zana & $\begin{array}{l}\text { Frag. Borde Gran } \\
\text { Vasija }(24)\end{array}$ & & $\begin{array}{l}5 Y R \\
6 / 4\end{array}$ & $\begin{array}{l}5 Y R \\
6 / 4\end{array}$ & $\begin{array}{l}5 \mathrm{YR} \\
6 / 1\end{array}$ & 2 \\
\hline 108 & $\mathrm{IZA}-2 \mathrm{BIS}$ & MAN $1926 / 45 / 5$ & Izana & $\underset{\{20 \mathrm{~h}\}}{\text { Jarra }}$ & & $\begin{array}{l}7.5 Y R \\
8 / 3\end{array}$ & $\underset{8 / 3}{7.5 \mathrm{YR}}$ & $\underset{8 / 3}{7.5 Y R}$ & $1-b$ \\
\hline 109 & $I 2 A-3$ & 778 & Izana & $\begin{array}{c}\text { Frag. Galbo Jarra } \\
\text { Boca Trilabulada } \\
\text { (I9a) }\end{array}$ & & $\begin{array}{l}2.5 Y R \\
5 / 4\end{array}$ & $\begin{array}{l}2.5 Y R \\
6 / 6\end{array}$ & $\begin{array}{l}5 Y R \\
5 / 6\end{array}$ & 1 \\
\hline 110 & $I 2 A-4$ & 779 & Izana & $\begin{array}{l}\text { Erag. Galbo Jarra } \\
\text { Boca Circular (17a) }\end{array}$ & & $\begin{array}{l}7.5 \mathrm{YR} \\
6 / 3\end{array}$ & $\begin{array}{l}5 \mathrm{YR} \\
6 / 4\end{array}$ & $\begin{array}{l}5 Y R \\
6 / 4\end{array}$ & 1 \\
\hline 111 & I $2 A-5$ & 748 & Izana & $\begin{array}{l}\text { Frag. Galbo } \\
\text { Mortero (14) }\end{array}$ & & $\begin{array}{l}7.5 \mathrm{YR} \\
6 / 4\end{array}$ & $\begin{array}{l}7.5 Y R \\
7 / 4\end{array}$ & $\begin{array}{l}5 Y R \\
6 / 3\end{array}$ & 1 \\
\hline 112 & I $Z A-6$ & 746 & Izana & $\begin{array}{l}\text { Frag. Borde Copa } \\
\text { Pie Bajo (13b) }\end{array}$ & & $2.5 Y R$ & $\begin{array}{l}5 \mathrm{YR} \\
5 / 2\end{array}$ & $\begin{array}{l}7.5 Y R \\
5 / 1\end{array}$ & 1 \\
\hline 113 & IZA-7 & 834 & Izana & $\begin{array}{l}\text { Frag. Borde Gran } \\
\text { Vasija }(24 \mathrm{c})\end{array}$ & $\begin{array}{l}\text { Pintada } \\
\text { M.P. }\end{array}$ & $\begin{array}{l}5 \mathrm{YR} \\
7 / 3\end{array}$ & $\begin{array}{l}5 Y_{R} \\
7 / 3\end{array}$ & $\begin{array}{l}5 Y R \\
6 / 4\end{array}$ & 1 \\
\hline 114 & $12 A-8$ & 777 & I zana & $\begin{array}{l}\text { Frag. Galbo Gran } \\
\text { Vasija }(24)\end{array}$ & & $\begin{array}{c}7.5 \mathrm{YR} \\
4 / 1\end{array}$ & $\begin{array}{l}7.5 Y R \\
\$ S / 2\end{array}$ & $\begin{array}{l}7.5 Y R \\
5 / 1\end{array}$ & 4 \\
\hline 115 & $: 2 A-9$ & 739 & Izana & $\begin{array}{l}\text { Frag, Galbo } \\
\text { Cuenco }(1 \mathrm{~g})\end{array}$ & $\begin{array}{l}\text { Pintada } \\
\text { (N) } 2.5 \mathrm{YR} \\
5 / 3\end{array}$ & $\begin{array}{l}2.5 \mathrm{YR} \\
6 / 6\end{array}$ & $\frac{2.5 Y R}{6 / 6}$ & $\begin{array}{l}5 Y R \\
6 / 6\end{array}$ & 1 \\
\hline 116 & $: 2 A-10$ & 772 & Izana & $\begin{array}{l}\text { Frag. Borde } \\
\text { Plato (11c) }\end{array}$ & $\begin{array}{c}\text { Pintada } \\
\text { (N) } 2.5 \mathrm{YR} \\
3 / 2\end{array}$ & $\begin{array}{l}2.5 Y R \\
3 / 2\end{array}$ & $\begin{array}{l}2.5 \mathrm{YR} \\
3 / 2\end{array}$ & $\begin{array}{l}5 Y R \\
5 / 4\end{array}$ & 1 \\
\hline 117 & $i Z A-11$ & 935 & Izana & $\begin{array}{c}\text { Frag. Borde } \\
\text { Vasija Gilobular }\end{array}$ & Estampada & $\begin{array}{l}5 \mathrm{YR} \\
4 / 1\end{array}$ & $\begin{array}{l}S Y R \\
4 / 3\end{array}$ & $\begin{array}{l}7.5 \mathrm{YR} \\
4 / 2\end{array}$ & $3-\bar{a}$ \\
\hline
\end{tabular}


TABLA 1. Continuación

\begin{tabular}{|c|c|c|c|c|c|c|c|c|c|}
\hline$\overline{\bar{N}^{6}}$ & $\overline{\text { MUESTRA }}$ & "N" INVENTARTO & YACIMIENTO & $\overline{\text { TIPOLOG }} \overline{\mathrm{IA}}$ & DECORACTON & EXTERNO & INTERNO & $\overline{\text { PASTA }}$ & $\overline{\text { FABRICA }}$ \\
\hline 118 & $I Z A-I A$ & 742 & Izana & Cuenco (1) & & $\begin{array}{l}7.5 \% \mathrm{R} \\
4 / 1\end{array}$ & $\underset{4 / 1}{7.5 \mathrm{YR}}$ & $\begin{array}{l}7.5 \mathrm{YR} \\
5 / 4\end{array}$ & 2 \\
\hline 119 & IZA-15 & $\operatorname{MAN} 1926 / 45 / 1$ & I zana & Crătera (23b) & $\begin{array}{l}\text { Pintada } \\
\text { M.P. }\end{array}$ & $\begin{array}{l}5 \mathrm{YR} \\
7 / 3\end{array}$ & $7,5 Y R$ & $\begin{array}{l}5 \mathrm{YR} \\
7 / 3\end{array}$ & $1-b$ \\
\hline 120 & $1 \mathrm{ZA}-1 \mathrm{G}$ & $79 / 36 / 5$ & Izanz & $\begin{array}{c}\text { Frag. Borde } \\
\text { vasija Globular }\end{array}$ & Estampada & $\begin{array}{l}5 Y 8 \\
4 / 1\end{array}$ & $\begin{array}{l}5 Y R \\
4 / 1\end{array}$ & $\begin{array}{l}5 Y R \\
4 / 1\end{array}$ & $3-a$ \\
\hline 121 & $12 A-27$ & 761 & I zana & $\begin{array}{l}\text { Frag. Borde } \\
\text { Cuenco (1) }\end{array}$ & & $\begin{array}{c}7.5 \% R \\
5 / 1\end{array}$ & $\begin{array}{l}7.5 Y R \\
5 / 1\end{array}$ & $\begin{array}{l}5 Y R \\
4 / 2\end{array}$ & $3-a$ \\
\hline
\end{tabular}


TABLA 2. TABLA UTILIZADA PARA EL REGISTRO DE LOS DIFERENTES ATRIBUTOS EN EL ANÁLISIS MACROSCÓPICO

\section{GENERAL}

HOJA $\mathrm{N}^{\circ}$ :

\begin{tabular}{|c|c|c|c|c|c|}
\hline \multirow{4}{*}{ SIGLAS } & Museo & & & & \\
\hline & Wattenberg & & & & \\
\hline & Romero & & & & \\
\hline & Arlegui & & & & \\
\hline \multicolumn{6}{|l|}{$\begin{array}{l}\text { PIEZA } \\
\text { COMPLETA }\end{array}$} \\
\hline \multicolumn{6}{|l|}{ FRAGMENTOS } \\
\hline \multirow{5}{*}{$\begin{array}{l}\text { COLOR } \\
\text { MUNSELL }\end{array}$} & Uniforme & & & & \\
\hline & No uniforme & & & & \\
\hline & Externo & & & & \\
\hline & Interno & & & & \\
\hline & Pasta & & & & \\
\hline \multirow{4}{*}{$\begin{array}{l}\text { TRATAMIENTO } \\
\text { SUPEREICIES }\end{array}$} & Porosa & & & & \\
\hline & Alisada & & & & \\
\hline & Pulida & & & & \\
\hline & Engobe & & & & \\
\hline \multirow{4}{*}{$\begin{array}{l}\text { Distribución } \\
\text { inclusiones }\end{array}$} & $\begin{array}{l}\text { No } \\
\text { observables }\end{array}$ & & & & \\
\hline & Unimodal & & & & \\
\hline & Bimodal & & & & \\
\hline & Multimodal & & & & \\
\hline \multirow{3}{*}{$\begin{array}{l}\text { Cantidad } \\
\text { inclusiones }\end{array}$} & $\mathrm{Baja}<15$ \% & & & & \\
\hline & Media $15-25$ 응 & & & & \\
\hline & Alta $>258$ & & & & \\
\hline \multirow{3}{*}{ POROSIDAD } & $\begin{array}{l}\text { No } \\
\text { observables }\end{array}$ & & & & \\
\hline & Poros & & & & \\
\hline & Fisuras & & & & \\
\hline \multicolumn{6}{|l|}{$\begin{array}{l}\text { GROSOR } \\
\text { PAREDES } \mathrm{mm} \\
\end{array}$} \\
\hline \multicolumn{2}{|l|}{$\begin{array}{ll}\text { DIÁMETRO } & \text { DE } \\
\text { BOCA mm } & \\
\end{array}$} & & & & \\
\hline \multicolumn{6}{|l|}{ ALTURA $\mathrm{mm}$} \\
\hline \multirow[t]{2}{*}{ TIPOLOGÍA } & Arlegui & & & & \\
\hline & Otras & & & & \\
\hline \multirow{9}{*}{ DECORACIÓN } & Exterior & & & & \\
\hline & Interior & & & & \\
\hline & Situación & & & & \\
\hline & Pintura & & & & \\
\hline & Moldura & & & & \\
\hline & Plástica & & & & \\
\hline & Estampada & & & & \\
\hline & Grafito & & & & \\
\hline & Otras & & & & \\
\hline \multirow{3}{*}{$\begin{array}{l}\text { COLOR } \\
\text { MUNSELL }\end{array}$} & Negro & & & & \\
\hline & Blanco & & & & \\
\hline & Rojo & & & & \\
\hline \multicolumn{2}{|l|}{ OBSERVACIONES } & & & & \\
\hline
\end{tabular}


TABLA 3. TABLA UTILIZADA PARA EL REGISTRO DE LOS DIFERENTES ATRIBUTOS EN EL ANÁLISIS MACROSCÓPICO

\section{CERÁMICA NEGRA}

HOJA $N^{\circ}$ :

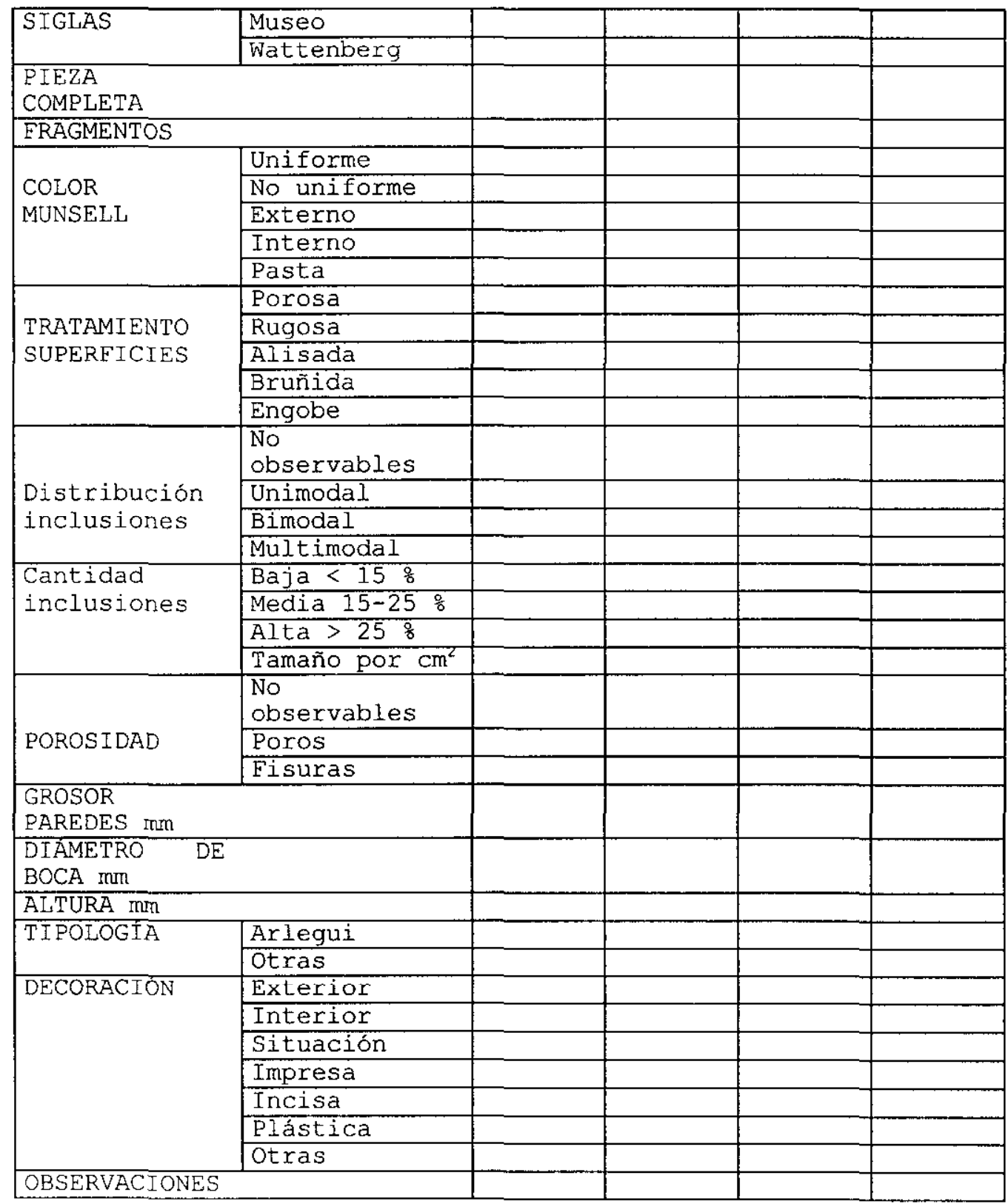


TABLA 4. RESULTADOS DE LOS ANÁLISIS MEDIANTE TXRF DE LAS MUESTRAS OBTENIDAS EN EL PERFIL DEL RECIPIENTE COMPLETO EP-25, PROCEDENTE DEL YACIMIENTO DE EL PALOMAR (ARAGONCILLO,

GUADALAJARA) (\% PESO VERSUS Fe)

\begin{tabular}{|c|c|c|c|c|c|c|c|c|c|c|c|c|c|c|c|c|c|c|}
\hline MUESTRA & As & Nd & $\mathrm{Cr}$ & $\mathrm{Hf}$ & $\mathrm{Ni}$ & $\mathrm{Ab}$ & $\mathrm{Sr}$ & $\mathrm{Zn}$ & Al & $\mathrm{Ba}$ & $\mathrm{Ca}$ & $K$ & $M n$ & $\mathrm{Ti}$ & v & $\mathrm{Cu}$ & $\mathrm{Ga}$ & $\mathrm{Y}$ \\
\hline EF-25A & 0.081 & 0.009 & 0.178 & 0.000 & 0.078 & 0.486 & 0,488 & 0,173 & 158,942 & 1.023 & 9.028 & 93,260 & 0,481 & 7,600 & 0,183 & 0.016 & 0.052 & 0.053 \\
\hline EP.258 & 0.045 & 0.000 & 0,220 & 0,011 & 0.086 & 0,477 & 0.495 & 0.156 & 155,281 & 1,145 & 8,612 & 94,192 & 0.440 & 7.653 & 0,163 & 0.017 & 0.061 & 0,045 \\
\hline EP. 25C & 0,041 & 0.000 & 0,175 & 0,005 & 0,071 & 0,468 & 0,498 & 0,146 & 157,996 & 1.169 & 8.479 & 92.998 & 0.468 & 7,677 & 0,224 & 0.016 & 0,060 & 0.053 \\
\hline EP.25D & 0.085 & 0.000 & 0,186 & 0.008 & 0.079 & 0.484 & 0,494 & 0,173 & 151,931 & 1.145 & 8.489 & 94,705 & 0.464 & 7,596 & 0,195 & 0,019 & 0,057 & 0.049 \\
\hline EP-25E & 0,088 & 0.000 & 0,193 & 0,005 & 0,070 & 0,475 & 0,489 & $0.15 t$ & 155,959 & 1,298 & 9,246 & 91,055 & 0.412 & 7,656 & 0,196 & 0,015 & 0.058 & 0.044 \\
\hline EP. $25 \mathrm{~F}$ & 0,096 & 0.000 & 0.171 & 0.004 & 0.088 & 0.484 & 0,504 & 0,147 & 154,548 & 1.043 & 9,780 & 95,337 & 0,413 & 7,178 & 0,195 & 0,012 & 0.058 & 0.046 \\
\hline EP.25G & 0.047 & 0.000 & 0.994 & 0.002 & 0.070 & 0,477 & 0,506 & 0,154 & 156,389 & 1,327 & 8,307 & 93,896 & 0.434 & 7,404 & 0,207 & 0,017 & 0,057 & 0,047 \\
\hline EP-25H & 0.026 & 0.000 & 0.195 & 0.005 & 0.077 & 0.470 & 0,497 & 0.161 & 155,226 & 1.014 & 25.262 & 95,887 & 0,493 & 7.112 & 0,186 & 0,023 & 0,060 & 0.035 \\
\hline EP.251 & 0,078 & 0.000 & 0,181 & 0.003 & 0.073 & 0,533 & 0,486 & 0,163 & 160,528 & 1.194 & 8,543 & 95,641 & 0.405 & 7,493 & 0,138 & 0,021 & 0,060 & 0,052 \\
\hline
\end{tabular}


TABLA 5. RESULTADOS DE LOS ANÁLISIS MEDIANTE TXRF DE LAS MUESTRAS DE LOS SEDIMENTOS ARCILLOSOS PROCEDENTES DE NUMANCIA E IZANA

(\% PESO VERSUS Fe)

\begin{tabular}{|c|c|c|c|c|c|c|c|c|c|c|c|c|c|c|c|c|c|c|}
\hline MUESTRA & As & $\mathrm{Nd}$ & $\mathrm{Cr}$ & $\mathrm{Hf}$ & $\mathrm{Ni}$ & $A b$ & st & $2 n$ & Al & Ba & $\mathrm{Ca}$ & $x$ & $\mathrm{Mn}$ & $T i$ & $v$ & $\mathrm{Cu}$ & $\mathrm{Ga}$ & $Y$ \\
\hline$N \cdot 1 A$ & 0,121 & 0,000 & 0,241 & 0.000 & 0,112 & 0.457 & 0.401 & 0,308 & 191,670 & 1,381 & 424,363 & 76.240 & 1.762 & 14,180 & 0,199 & 0,066 & 0.058 & 0.085 \\
\hline$N-10$ & 0,117 & 0.000 & 0.208 & 0,002 & 0,120 & 0,447 & 0,338 & 0,293 & 183,738 & 0,975 & 336.108 & 70,496 & 8.675 & 13,203 & 0,168 & 0,066 & 0,063 & 0.089 \\
\hline$N \cdot 2 A$ & 0,154 & 0.024 & 0,223 & 0,000 & 0,110 & 0,469 & 0.380 & 0,287 & 195,320 & 3,099 & 575.933 & 71,224 & 1,901 & 16,851 & 0,217 & 0,068 & 0.055 & 0,127 \\
\hline$N \cdot 20$ & 0,144 & 0.000 & 0.221 & 2.012 & 0.116 & 0.430 & 0.335 & 0.270 & 187.462 & 3,102 & 429,248 & 64,264 & 1,820 & 14.687 & 0.159 & 0,077 & 0.058 & 0.117 \\
\hline$N-3 A$ & 0.132 & 0,000 & 0.178 & 0,010 & 0,095 & 0,517 & 0,333 & 0.249 & 180.935 & 1,337 & 164,926 & 71,836 & 2,254 & 12.540 & 0.235 & 0.059 & 0.061 & 0.104 \\
\hline$N-3 D$ & 0.127 & 0.000 & 0.244 & 0.000 & 0,124 & 0.488 & 0,299 & 1.093 & 166,973 & 1,126 & 139,137 & 65,656 & 2,171 & 11.623 & 0.183 & 0,054 & 0.054 & 0,084 \\
\hline$N \cdot 4 A$ & 0,156 & 0.000 & 0.186 & 0.006 & 0.084 & 0.349 & 0.147 & 0,202 & 191,237 & 0.400 & 30.385 & 44,732 & 0,541 & 7,682 & 0,177 & 0,066 & 0,057 & 0,036 \\
\hline$N-40$ & 0.150 & 0.000 & 0.188 & 0.015 & 0,087 & 0.347 & 0.135 & 0,213 & 172.005 & 0.689 & 22,027 & 42,229 & 0.571 & 6.177 & 0,179 & 0,058 & 0,060 & 0,038 \\
\hline$N-6 A$ & 0,212 & 0.000 & 0.266 & 0.000 & 0,114 & 0,583 & 0,390 & 0,876 & 197.282 & 1,038 & 216,777 & 83,153 & 1,825 & 14.710 & 0.173 & 0.066 & 0.068 & 0,090 \\
\hline$N-80$ & 0,216 & 0,004 & 0,216 & 0,000 & 0,112 & 0.566 & 0.363 & 0,872 & 136,691 & 1,318 & 180,303 & 77.493 & 1.765 & 13,283 & 0,246 & 0,057 & 0.059 & 0,088 \\
\hline N-7A & 0.148 & 0,000 & 0.189 & 0,000 & 0,103 & 0.364 & 0.131 & 0,203 & 193,944 & 0,747 & 66,233 & 42,972 & 0,694 & 6,092 & 0,208 & 0,058 & 0,058 & 0,136 \\
\hline$N-7 D$ & 0,137 & 0,000 & 0.187 & 0,007 & 0.101 & 0,335 & 0.114 & 0,190 & 168,763 & 0,559 & 50,272 & 38,334 & 0.628 & 5,124 & 0.183 & 0.057 & 0.060 & 0.105 \\
\hline$N-8 A$ & 0.274 & 1.402 & 0.503 & 0,000 & 7,368 & 0,524 & 24,43 & 8,174 & 25262,83 & 22,769 & 195.317 & 3075,08 & 4.103 & 7,204 & 0,000 & 18,321 & 0.058 & 0.725 \\
\hline $1 Z A-O$ & 0,101 & 0.023 & 0.238 & 0.011 & 0.105 & 0,697 & 0,519 & 0,252 & 252,838 & 2,134 & 394,958 & 109,366 & 0,871 & 15,360 & 0,213 & 0,058 & 0,068 & 0,113 \\
\hline $12 \mathrm{~A}-900$ & 0,100 & 0.000 & 0.240 & 0.004 & 0,112 & 0.678 & 0,499 & 0,235 & 243,578 & 1.811 & 315.456 & 102,168 & 0,857 & 15,135 & 0,172 & 0.064 & 0.072 & 0,115 \\
\hline
\end{tabular}




\section{TABLA 6. RESULTADOS SEMI-CUANTITATIVOS DEL ANÁLISIS PETROGRÁFICO MEDIANTE LÁMINA DELGADA}

$\mathrm{H}$ matriz homogénea. He matriz heterogénea. * inicio vitrificación. + escasa $(<10 \%) .++$ media $(11-25 \%) .+++$ abundante $(26-75 \%)$. ++++ muy abundante $(>76 \%)$. ... trazas (sin cuantificar). Q/Fd cuarzo y feldespatos. Mi micas. CcC calcita criptocristalina. CcM calcita micrítica. CcP calcita secundaria depositada. $\mathrm{OH}$ óxidos de Fe y opacos. Qz cuarcita. FR fragmentos de roca. CHA chamota. Eil porcentaje que aparece junto a la muestra se refiere a la proporción de inclusiones con respecto a la matriz.

\begin{tabular}{|c|c|c|c|c|c|c|c|c|c|c|c|c|}
\hline MUESTRA & EABRICA & MATRI & & $\mathrm{Q} / \mathrm{Fd}$ & $\mathrm{Mi}$ & $\mathrm{CCC}$ & $\mathrm{CcM}$ & $\mathrm{CcP}$ & $\mathrm{OH}$ & $\mathrm{QZ}$ & FR & $\mathrm{CHA}$ \\
\hline$N-1 B\left(20^{\circ}\right)$ & $1-b$ & $\mathrm{H}$ & & +++ & + & & ++ & & + & & & \\
\hline$N-1 D(208)$ & $1-b$ & $\mathrm{H}$ & $\star$ & $++t$ & $t$ & & $t+$ & & + & & & \\
\hline$N-4 B(15 \%)$ & 1 & $\mathrm{H}$ & & ++++ & + & & + & & + & + & & \\
\hline$N-4 D(15 \%)$ & 1 & $\mathrm{H}$ & $\star$ & ++++ & + & & + & & + & $\cdots$ & & \\
\hline$N-10(258)$ & $3-a$ & $\mathrm{H}$ & & ++ & + & +++ & ++ & $\cdots$ & + & & & \\
\hline$N-11(358)$ & 4 & $\mathrm{H}$ & & ++++ & + & & & & & & $\ldots$ & \\
\hline$N-12(30 \%)$ & $3-a$ & $\mathrm{H}$ & & $+t+$ & $\cdots$ & +++ & $+t$ & $\cdots$ & ++ & & & \\
\hline $\mathrm{N}-13(20 \%)$ & 4 & $\mathrm{H}$ & & ++++ & + & & + & & + & + & $\cdots$ & \\
\hline $\mathrm{N}-14$ (25옹) & 4 & $\mathrm{H}$ & & ++++ & + & & & & + & & $\cdots$ & \\
\hline$N-15(25 \%)$ & $3-a$ & $\mathrm{H}$ & & ++ & + & +++ & ++ & $\ldots$ & ++ & & & \\
\hline $\mathrm{N}-16(30 \%)$ & 4 & $\mathrm{H}$ & & ++++ & + & & + & $\cdots$ & + & + & $\cdots$ & \\
\hline $\mathrm{N}-17(35 \%)$ & $3-a$ & $\mathrm{H}$ & & $++t$ & ++ & + & + & $\cdots$ & + & & & \\
\hline $\mathrm{N}-18\left(30^{\circ}\right)$ & $3-a$ & $\mathrm{H}$ & & + & + & $++t$ & ++ & $\cdots$ & ++ & & & \\
\hline$N-19\left(35 \frac{8}{0}\right)$ & $3-a$ & $\mathrm{H}$ & & + & + & +++ & ++ & & + & & & \\
\hline $\mathrm{N}-20(35 \%)$ & $3-a$ & $\mathrm{H}$ & & + & + & +++ & ++ & $\cdots$ & + & & & \\
\hline$N-21(45 \%)$ & $3-a$ & $\mathrm{H}$ & & + & + & +++ & ++ & $\ldots$ & $\cdots$ & & & + \\
\hline $\mathrm{N}-22(35 \%)$ & 4 & $\mathrm{H}$ & & ++++ & + & & $\cdots$ & $\cdots$ & & + & & \\
\hline $\mathrm{N}-23(35 \%)$ & $3-a$ & $\mathrm{H}$ & & + & $\cdots$ & +++ & ++ & $\cdots$ & + & & & \\
\hline $\mathrm{N}-24(15 \%)$ & $1-b$ & $\mathrm{H}$ & & +++ & + & & $\ldots$ & & $+t+$ & $\ldots$ & & \\
\hline $\mathrm{N}-25(25 \%)$ & $1-b$ & $\mathrm{H}$ & & $++t$ & ++ & & & $\cdots$ & $+t$ & & & \\
\hline $\mathrm{N}-26(20 \%)$ & $1-b$ & $\mathrm{H}$ & & $++t$ & $+t$ & & & & $t+$ & & & \\
\hline $\mathrm{N}-27(108)$ & $1-b$ & $\mathrm{He}$ & $\star$ & +++ & $\ldots$ & & ++ & $\cdots$ & + & & $\ldots$ & \\
\hline$N-28(15 \%)$ & $1-b$ & $\mathrm{He}$ & $\star$ & ++++ & ++ & & $\ldots$ & $\ldots$ & + & & $\ldots$ & \\
\hline $\mathrm{N}-29(15 \circ)$ & $1-b$ & $\mathrm{H}$ & & +++ & ++ & & & & + & & & \\
\hline $\mathrm{N}-30(20 \%)$ & $1-b$ & $\mathrm{H}$ & & $+t+$ & ++ & & & & + & & & \\
\hline $\mathrm{N}-31(25 \%)$ & $1-b$ & $\mathrm{H}$ & & ++++ & ++ & & & & + & & & \\
\hline $\mathrm{N}-32(10 \%)$ & $1-b$ & $\mathrm{H}$ & & $+t+$ & + & & & & $++t$ & & & \\
\hline$N-33(25 \%)$ & $1-b$ & $\mathrm{H}$ & & $t+t$ & $+t$ & & & & + & & & \\
\hline$N-34(25 \circ)$ & 1 & $\mathrm{H}$ & & $+++t$ & + & & & & + & & $\cdots$ & \\
\hline$N-35(20 \%)$ & 1 & $\mathrm{H}$ & & ++++ & + & & & & + & & & \\
\hline$N-36(20 \%)$ & 1 & $\mathrm{H}$ & & ++++ & + & & & & ++ & $\ldots$ & & \\
\hline$N-37(20 ㅇ)$ & 1 & $\mathrm{H}$ & & $+t+$ & +++ & & & & + & & & \\
\hline $\mathrm{N}-38(25 \%)$ & 1 & $\mathrm{H}$ & & $+t+t$ & + & & $\ldots$ & & + & & $\ldots$ & \\
\hline$N-39(25 \%)$ & 1 & $\mathrm{H}$ & & ++++ & + & & $\ldots$ & $\ldots$ & + & & & \\
\hline $\mathrm{N}-40(20$ 웅) & 1 & $\mathrm{H}$ & & ++++ & + & & & $\cdots$ & + & & & \\
\hline $\mathrm{N}-41\left(25 \frac{\mathrm{O}}{\mathrm{O}}\right)$ & 1 & $\mathrm{H}$ & & ++++ & $\cdots$ & & & & + & & & \\
\hline$N-42(30 \%)$ & 1 & $\mathrm{H}$ & & +++ & ++ & & & & + & & & \\
\hline$N-43(20 \%)$ & 1 & $\mathrm{H}$ & & ++++ & + & & $\cdots$ & $\cdots$ & + & & $\cdots$ & \\
\hline$N-44(20 \%)$ & 1 & $\mathrm{H}$ & & $t+t$ & + & & $\ldots$ & & ++ & & & \\
\hline$N-45(20 \%)$ & 1 & $\mathrm{H}$ & & ++++ & + & & + & $\cdots$ & + & & $\cdots$ & \\
\hline$N-46(20 \%)$ & 1 & $\mathrm{H}$ & & $+++t$ & + & & $\cdots$ & $\cdots$ & $+t$ & & $\ldots$ & \\
\hline $\mathrm{N}-47(30 \%)$ & 1 & $\mathrm{H}$ & & ++++ & + & & $\ldots$ & & + & & & \\
\hline$N-48(20 \%)$ & 1 & $\mathrm{H}$ & & ++++ & + & & $\ldots$ & $\cdots$ & + & & $\ldots$ & \\
\hline $\mathrm{N}-49(25 \%)$ & 1 & $\mathrm{H}$ & & $t+t t$ & $t+$ & & $\ldots$ & & + & & $\ldots$ & \\
\hline$N-50\left(30 \frac{\circ}{6}\right)$ & 1 & $\mathrm{H}$ & & ++++ & + & & $\ldots$ & & + & & & \\
\hline$N-51(30 \%)$ & 1 & $\mathrm{H}$ & & +++ & ++ & & & $\ldots$ & + & & & \\
\hline$N-52(20 \%)$ & 1 & $\mathrm{H}$ & & ++++ & ++ & & & & t & & & \\
\hline
\end{tabular}


TABLA 6. Continuación

\begin{tabular}{|c|c|c|c|c|c|c|c|c|c|c|c|c|}
\hline MUESTRA & FABRICA & MATRI & & Q/Ed & $\mathrm{Mi}$ & $\mathrm{CcC}$ & $\mathrm{CcM}$ & $\mathrm{CcP}$ & $\mathrm{OH}$ & $\overline{Q Z}$ & FR & $\mathrm{CHA}$ \\
\hline$N-53(20 \%)$ & 1 & $\mathrm{H}$ & * & ++++ & + & & $\ldots$ & $\ldots$ & + & & & \\
\hline$N-54(208)$ & 1 & $\mathrm{H}$ & & ++++ & + & & $\ldots$ & $\ldots$ & + & & & \\
\hline$N-55(208)$ & 1 & $\mathrm{H}$ & & ++++ & + & & & & ++ & & $\cdots$ & \\
\hline$N-56(58)$ & 1 & $\mathrm{H}$ & & +++ & + & & & $\ldots$ & $+t+$ & & & \\
\hline $\mathrm{N}-57(25 \%)$ & 2 & $\mathrm{H}$ & & ++++ & + & & + & $\ldots$ & + & & & \\
\hline$N-58(20 \%)$ & 2 & $\mathrm{H}$ & & ++++ & + & & $\ldots$ & & + & & $\cdots$ & \\
\hline $\mathrm{N}-59\left(20^{\circ}\right)$ & 2 & $\mathrm{H}$ & & ++++ & + & & $\ldots$ & $\cdots$ & ++ & & & \\
\hline$N-60(258)$ & 2 & $\mathrm{H}$ & & +++ & $+t$ & & $\ldots$ & $\ldots$ & + & & $\cdots$ & \\
\hline$N-61(10 \%)$ & 2 & $\mathrm{H}$ & & +++ & ++ & & & & + & & & \\
\hline$N-62(15 \%)$ & 2 & $\mathrm{H}$ & $*$ & $+++t$ & $+t$ & & $\ldots$ & $\ldots$ & + & & & \\
\hline$N-63\left\langle 10^{\circ}\right)$ & 2 & $\mathrm{H}$ & & +++ & $+t$ & & & & + & & & \\
\hline $\mathrm{N}-64(15 \%)$ & 2 & $\mathrm{H}$ & & ++++ & + & & & $\cdots$ & $+t$ & & & \\
\hline$N-65(30 \%)$ & 2 & $\mathrm{H}$ & & ++++ & + & & $\ldots$ & $\ldots$ & + & & & \\
\hline$N-66(15 \%)$ & 2 & $\mathrm{H}$ & & +++ & ++ & & & $\ldots$ & ++ & & & \\
\hline$N-67(20 \%)$ & 2 & $\mathrm{H}$ & & ++++ & ++ & & $\cdots$ & & + & & $\cdots$ & \\
\hline$N-68(20 \%)$ & 2 & $\mathrm{H}$ & & ++++ & + & & $\ldots$ & $\cdots$ & + & & & \\
\hline$N-69(20 \%)$ & 2 & $\mathrm{H}$ & & $+++t$ & + & & $\cdots$ & $\cdots$ & + & $\cdots$ & & \\
\hline$N-70(10 \%)$ & 2 & $\mathrm{H}$ & & $+t+$ & $t++$ & & & & $+t$ & & $\cdots$ & \\
\hline $\mathrm{N}-71\left(30^{\circ}\right)$ & 4 & $\mathrm{H}$ & & ++++ & + & & $\cdots$ & & + & & $\cdots$ & \\
\hline $\mathrm{NP}-72(15 \%)$ & 1 & $\mathrm{H}$ & & ++++ & + & & & $\cdots$ & ++ & & & \\
\hline$N P-73(15 ㅇ)$ & 1 & $\mathrm{H}$ & & ++++ & ++ & & & & + & & $\cdots$ & \\
\hline$N P-74(20 \%)$ & 1 & $\mathrm{H}$ & & $+++t$ & ++ & & & $\ldots$ & + & & & \\
\hline $\mathrm{NP}-75(15 \%)$ & 1 & $\mathrm{H}$ & & ++++ & + & & + & & + & & & \\
\hline$N P-76(20 \%)$ & 1 & $\mathrm{H}$ & & +++ & $+t$ & & $\cdots$ & & ++ & & $\cdots$ & \\
\hline$N P-77(208)$ & 1 & $\mathrm{H}$ & & ++++ & ++ & & $\cdots$ & $\cdots$ & + & $\cdots$ & $\ldots$ & \\
\hline$N P-78(25 \circ)$ & 1 & $\mathrm{H}$ & & $+t+t$ & + & & & $\cdots$ & + & & & \\
\hline $\mathrm{NP}-79(20 \%)$ & 1 & $\mathrm{H}$ & & $++t+$ & ++ & & $\ldots$ & & $+t$ & $\cdots$ & & \\
\hline$N P-80(10 \%)$ & 1 & $\mathrm{H}$ & & ++++ & + & & $\cdots$ & $\cdots$ & ++ & & & \\
\hline$N P-81(15 \circ)$ & $1-b$ & $\mathrm{H}$ & & ++++ & ++ & & & & + & & & \\
\hline$N P-82(15 \%)$ & $1-b$ & $\mathrm{H}$ & & ++++ & + & & $\ldots$ & & + & + & & \\
\hline$N P-83(15 \%)$ & $1-b$ & $\mathrm{H}$ & & +++ & +++ & & & & + & & & \\
\hline$N P-84(15 \%)$ & $1-b$ & $\mathrm{H}$ & & +++ & $+t$ & & & & + & & & \\
\hline $\mathrm{NP}-85\left(15 \frac{\mathrm{O}}{\mathrm{O}}\right)$ & $1-b$ & $\mathrm{H}$ & & $+++t$ & + & & & $\ldots$ & + & & & \\
\hline$N P-86(15 \circ)$ & $1-b$ & $\mathrm{H}$ & & +++ & ++ & & & $\cdots$ & + & & & \\
\hline$N P-87(20 \%)$ & $a-b$ & $\mathrm{H}$ & & +++ & + & & $\cdots$ & $\cdots$ & $++t$ & & & \\
\hline $\mathrm{NP}-88(208)$ & $1-b$ & $\mathrm{H}$ & & +++ & ++ & & & $\cdots$ & + & & & \\
\hline$N P-89(20 \circ)$ & $1-b$ & $\mathrm{H}$ & & +++ & ++ & & $\ldots$ & $\ldots$ & + & & & \\
\hline$N P-90(15 \circ)$ & $1-b$ & $\mathrm{H}$ & & ++++ & + & & $\cdots$ & & + & & & \\
\hline$N P-91$ (15\%) & 2 & $\mathrm{H}$ & & +++ & +++ & & $\ldots$ & & + & & & \\
\hline$N P-97(15 \%)$ & $1-b$ & $\mathrm{H}$ & & $++t$ & ++ & & & $\cdots$ & + & & & \\
\hline$L D-92(15 \%)$ & $1-b$ & $\mathrm{He}$ & $\star$ & ++++ & $\ldots$ & & + & $\cdots$ & + & & $\ldots$ & \\
\hline LD- $93(20 \circ)$ & $1-b$ & $\mathrm{He}$ & $\star$ & ++++ & $\ldots$ & & + & & $+t$ & & & \\
\hline$L D-94(158)$ & $1-\mathrm{b}$ & $\mathrm{He}$ & $\star$ & +++ & + & & $\ldots$ & & +++ & & & \\
\hline $\operatorname{LD}-95(20 \%)$ & 1 & $\mathrm{He}$ & $*$ & ++++ & ++ & & + & & + & & & \\
\hline LD-96(20용 & $I-b$ & $\mathrm{H}$ & & ++++ & + & & $\ldots$ & & + & & & \\
\hline$E P-25(15 \%)$ & 1 & $\mathrm{H}$ & & $+++t$ & + & & $\ldots$ & & + & & & \\
\hline$E P-26(208)$ & 1 & $\mathrm{H}$ & & ++++ & $+t$ & & + & & $\cdots$ & & & \\
\hline$E P-27$ (15웅 & 1 & $\mathrm{H}$ & & ++++ & + & & $\cdots$ & & + & & & \\
\hline $\mathrm{EP}-28(158)$ & 1 & $\mathrm{H}$ & & +++ & ++ & & + & & + & & & \\
\hline$E P-29\left(15 \frac{\circ}{5}\right)$ & 1 & $\mathrm{H}$ & $\star$ & ++++ & + & & + & $\cdots$ & + & & & \\
\hline $\mathrm{PT}-1(158)$ & $1-b$ & $\mathrm{H}$ & & $+++t$ & + & & + & & + & & & \\
\hline $\mathrm{PT}-2(15 \%)$ & $1-b$ & $\mathrm{He}$ & $\star$ & +++ & + & & $+t$ & & $\ldots$ & & & \\
\hline $\mathrm{PT}-3(20 \%)$ & $1-b$ & $\mathrm{H}$ & * & ++++ & + & & ++ & + & + & & & \\
\hline
\end{tabular}


TABLA 6. Continuación

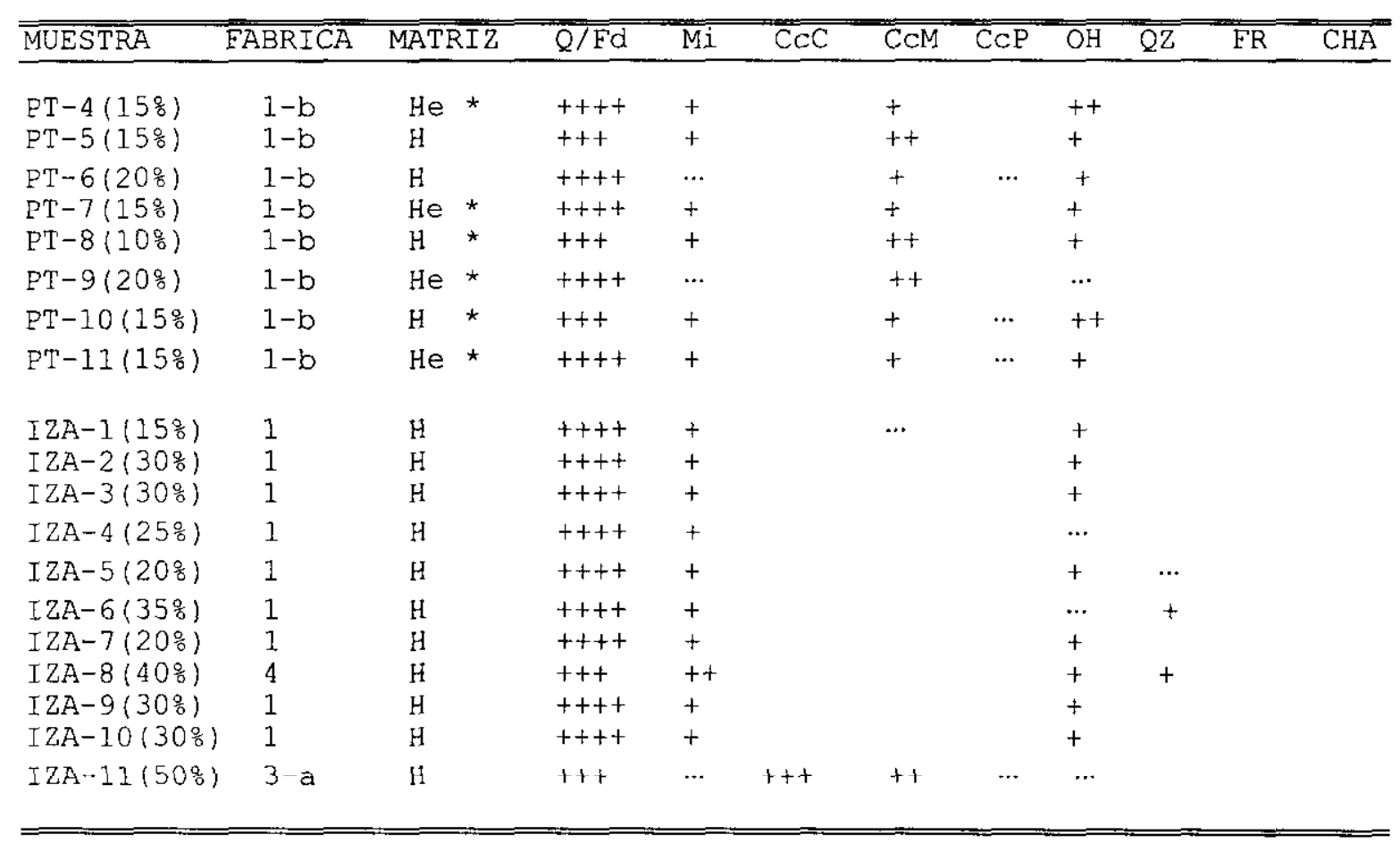


TABLA 7. FASES MINERALÓGICAS DETECTADAS EN EL ANÁLISIS MEDIANTE DIFRACCIÓN DE RAYOS X (XRD) DE LAS MUESTRAS CERÁMICAS

++ fase predominante. + presencia. ... trazas. Q cuarzo. Fd feldespatos. FK feldespato potásico. A anortita (plagioclasa). I ilita y filosilicatos. $C$ calcita. DO dolomita. $H$ hematites. $G$ gehlenita. D diópsido. M mullita. AL alfa-alúmina (corindón).

\begin{tabular}{|c|c|c|c|c|c|c|c|c|c|c|c|c|}
\hline \multirow[b]{2}{*}{ MUESTRA } & \multirow[b]{2}{*}{ FABRICA } & \multirow[b]{2}{*}{ Q } & \multicolumn{2}{|c|}{$\mathrm{Fd}$} & \multirow[b]{2}{*}{ I } & \multirow[b]{2}{*}{ C } & \multirow[b]{2}{*}{ DO } & \multirow[b]{2}{*}{$\mathrm{H}$} & \multirow[b]{2}{*}{ G } & \multirow[b]{2}{*}{$D$} & \multirow[b]{2}{*}{ M } & \multirow[b]{2}{*}{ AL } \\
\hline & & & EK & $\mathrm{A}$ & & & & & & & & \\
\hline $\begin{array}{l}\mathrm{N}-10 \\
\mathrm{~N}-11\end{array}$ & $\begin{array}{l}3-a \\
4\end{array}$ & $\begin{array}{l}+ \\
++\end{array}$ & $\begin{array}{l}+ \\
+\end{array}$ & $\begin{array}{l}\cdots \\
+\end{array}$ & $\begin{array}{l}+ \\
+\end{array}$ & $\begin{array}{l}++ \\
+\end{array}$ & & & & + & & \\
\hline $\begin{array}{l}\mathrm{N}-12 \\
\mathrm{~N}-13\end{array}$ & $\begin{array}{l}3-a \\
4\end{array}$ & $\begin{array}{l}+ \\
++\end{array}$ & $\begin{array}{l}+ \\
+\end{array}$ & $\begin{array}{l}\cdots \\
+\end{array}$ & $\begin{array}{l}+ \\
+\end{array}$ & $\begin{array}{l}++ \\
+\end{array}$ & & + & + & + & & \\
\hline$N-14$ & 4 & ++ & + & & + & + & & + & + & $\ldots$ & & \\
\hline $\mathrm{N}-15$ & $3-a$ & + & + & $\ldots$ & + & ++ & & & & & & \\
\hline$N-16$ & 4 & ++ & + & & + & + & & + & $\ldots$ & + & & \\
\hline $\mathrm{N}-17$ & $3-a$ & ++ & + & $\ldots$ & + & + & & & & & & \\
\hline $\mathrm{N}-18$ & $3-a$ & + & + & $\cdots$ & + & ++ & & & & & & \\
\hline $\mathrm{N}-19$ & $3-a$ & + & + & $\cdots$ & + & ++ & & & & & & \\
\hline $\mathrm{N}-20$ & $3-a$ & + & + & $\cdots$ & + & ++ & & & & & & \\
\hline $\begin{array}{l}N-21 \\
N-22\end{array}$ & $\begin{array}{l}3-a \\
4\end{array}$ & $\begin{array}{l}+ \\
++\end{array}$ & + & + & $\begin{array}{l}+ \\
+\end{array}$ & $\begin{array}{l}++ \\
+\end{array}$ & & & & & & \\
\hline $\mathrm{N}-23$ & $3-a$ & + & + & & + & ++ & & & & & & \\
\hline $\mathrm{N}-24$ & $1-b$ & ++ & + & + & + & + & & + & + & $\ldots$ & & \\
\hline$N-25$ & $1-b$ & ++ & + & + & t & t & & + & + & & & \\
\hline $\mathrm{N}-26$ & $1-b$ & ++ & + & + & + & + & & $\cdots$ & + & & & \\
\hline $\mathrm{N}-27$ & $1-b$ & ++ & + & + & + & + & & $\cdots$ & + & + & & \\
\hline $\mathrm{N}-28$ & $1-b$ & ++ & + & + & + & + & & $\cdots$ & + & + & & \\
\hline$N-29$ & $1-b$ & ++ & + & + & + & + & & & + & + & & \\
\hline $\mathrm{N}-30$ & $1-b$ & ++ & + & + & + & + & & & + & + & & \\
\hline$N-31$ & $1-b$ & ++ & + & + & + & + & & & + & & & \\
\hline$N-32$ & $1-b$ & $+t$ & + & + & + & + & & & + & $\cdots$ & & \\
\hline$N-33$ & $1-b$ & $+t$ & + & + & + & + & & & + & $\cdots$ & & \\
\hline$N-34$ & 1 & ++ & + & + & $\ldots$ & $\ldots$ & & & + & $\cdots$ & & \\
\hline $\mathrm{N}-35$ & 1 & $+t$ & + & + & + & + & & + & + & + & & \\
\hline $\mathrm{N}-36$ & 1 & ++ & + & + & + & + & & + & + & $\ldots$ & & \\
\hline$N-37$ & 1 & ++ & + & + & + & + & & + & + & & & \\
\hline $\mathrm{N}-38$ & 1 & ++ & + & + & + & + & & + & + & + & & \\
\hline $\mathrm{N}-39$ & 1 & ++ & + & + & $\ldots$ & $\ldots$ & & + & + & + & & \\
\hline $\mathrm{N}-40$ & 1 & ++ & + & + & + & + & & + & + & + & & \\
\hline $\mathrm{N}-41$ & 1 & ++ & + & + & + & + & & + & + & & & \\
\hline$N-42$ & 1 & ++ & + & + & + & + & & + & + & & & \\
\hline$N-43$ & 1 & ++ & + & + & + & + & & + & + & $\ldots$ & & \\
\hline$N-44$ & 1 & ++ & + & + & + & + & & + & + & + & & \\
\hline$N-45$ & 1 & ++ & + & + & + & + & & + & + & + & & \\
\hline$N-46$ & 1 & ++ & + & + & + & + & & + & + & & & \\
\hline$N-47$ & 1 & ++ & + & + & $\ldots$ & & & + & & & + & + \\
\hline$N-48$ & 1 & ++ & + & + & + & + & & + & + & & & \\
\hline$N-49$ & 1 & $+t$ & + & + & + & $t$ & & + & + & + & & \\
\hline $\mathrm{N}-50$ & 1 & $+t$ & + & + & $\ldots$ & + & & + & + & + & & \\
\hline $\mathrm{N}-51$ & 1 & ++ & + & + & + & + & & & + & + & & \\
\hline $\mathrm{N}-52$ & 1 & ++ & + & + & + & + & & + & + & + & & \\
\hline $\mathrm{N}-53$ & 1 & ++ & + & + & + & + & & + & + & + & & \\
\hline$N-54$ & 1 & ++ & + & + & + & + & & + & + & & & \\
\hline$N-55$ & 1 & ++ & + & + & + & + & & $\ldots$ & + & & & \\
\hline$N-56$ & 1 & ++ & + & + & + & + & & & + & + & & \\
\hline$N-57$ & 2 & ++ & + & + & + & + & & & + & & & \\
\hline
\end{tabular}


TABLA 7. Continuación

\begin{tabular}{|c|c|c|c|c|c|c|c|c|c|c|c|c|}
\hline \multirow[b]{2}{*}{ MUESTRA } & \multirow[b]{2}{*}{ EABRICA } & \multirow[b]{2}{*}{$Q$} & \multicolumn{2}{|c|}{$\overline{F d}$} & \multirow[b]{2}{*}{ I } & \multirow[b]{2}{*}{$\mathrm{C}$} & \multirow[b]{2}{*}{ DO } & \multirow[b]{2}{*}{$\mathrm{H}$} & \multirow[b]{2}{*}{ G } & \multirow[b]{2}{*}{$\mathrm{D}$} & \multirow[b]{2}{*}{$M$} & \multirow[b]{2}{*}{ AL } \\
\hline & & & $\mathrm{EK}$ & A & & & & & & & & \\
\hline$N-58$ & 2 & ++ & + & + & + & + & & & + & + & & \\
\hline$N-59$ & 2 & ++ & + & + & + & $\cdots$ & & + & + & & & \\
\hline$N-60$ & 2 & ++ & + & + & + & + & & & + & & & \\
\hline$N-61$ & 2 & ++ & + & + & + & + & & & + & + & & \\
\hline$N-62$ & 2 & ++ & + & + & + & + & & & + & + & & \\
\hline$N-63$ & 2 & ++ & + & + & + & + & & & + & + & & \\
\hline$N-64$ & 2 & ++ & + & + & + & + & & $\ldots$ & + & + & & \\
\hline$N-65$ & 2 & ++ & + & & + & + & & + & + & + & & \\
\hline$N-66$ & 2 & ++ & + & + & + & + & & & + & + & & \\
\hline$N-67$ & 2 & ++ & + & + & + & + & & & + & & & \\
\hline$N-68$ & 2 & $+t$ & + & + & + & $t$ & & & + & + & & \\
\hline$N-69$ & 2 & ++ & + & + & + & + & & & + & + & & \\
\hline$N-70$ & 2 & ++ & + & + & + & + & & & + & & & \\
\hline$N-71$ & 4 & ++ & + & + & + & + & & & + & & & \\
\hline $\mathrm{NP}-72$ & 1 & ++ & + & + & + & + & & + & + & + & & \\
\hline$N P-73$ & 1 & ++ & + & + & + & + & & + & + & + & & \\
\hline$N P-74$ & 1 & ++ & + & + & + & + & & + & + & + & & \\
\hline$N P-75$ & 1 & ++ & + & + & + & + & & + & + & + & & \\
\hline$N P-76$ & 1 & ++ & + & + & + & + & & + & + & & & \\
\hline $\mathrm{NP}-77$ & 1 & ++ & + & + & $\ldots$ & + & & + & + & + & & \\
\hline $\mathrm{NP}-78$ & 1 & ++ & + & + & + & + & & + & + & & & \\
\hline $\mathrm{NP}-79$ & 1 & ++ & + & + & + & + & & + & + & & & \\
\hline $\mathrm{NP}-80$ & 1 & $+t$ & + & + & + & + & & + & + & + & & \\
\hline$N P-81$ & $1-b$ & ++ & + & + & + & + & & + & + & + & & \\
\hline$N P-82$ & $1-b$ & +4 & + & + & + & + & & + & + & + & & \\
\hline $\mathrm{NP}-83$ & $1-b$ & ++ & + & + & + & + & & & + & + & & \\
\hline$N P-84$ & $1-b$ & $+t$ & + & + & + & + & & & + & & & \\
\hline$N P-85$ & $1-b$ & $t+$ & + & + & + & + & & & + & + & & \\
\hline $\mathrm{NP}-86$ & $1-b$ & ++ & + & + & + & + & & & + & & & \\
\hline$N P-87$ & $1-b$ & $+t$ & & & & & & & + & + & & \\
\hline$N P-88$ & $1-b$ & $+t$ & + & & + & & & & + & & & \\
\hline$N P-89$ & $1-b$ & ++ & + & & + & + & & + & + & & & \\
\hline NP-90 & $1-b$ & ++ & + & & + & + & & & + & & & \\
\hline$N P-91$ & 2 & $+t$ & + & + & + & + & & & + & & & \\
\hline$N P-97$ & $1-b$ & ++ & + & + & + & + & & & + & + & & \\
\hline LD- 92 & $1-b$ & ++ & + & + & + & + & & & + & $\ldots$ & & \\
\hline$L D-93$ & $1-b$ & ++ & + & + & + & + & & & + & & & \\
\hline$L D-94$ & $1-b$ & $+t$ & + & + & + & + & & + & + & + & & \\
\hline$L D-95$ & 1 & $+t$ & + & + & $\ldots$ & + & & + & + & + & & \\
\hline LD-96 & $1-b$ & ++ & + & + & & $\cdots$ & & + & + & + & & \\
\hline$E P-25$ & 1 & ++ & + & + & + & + & + & + & + & & & \\
\hline$E P-26$ & 1 & ++ & + & + & + & $\ldots$ & $\ldots$ & + & + & & & \\
\hline$E P-27$ & 1 & $+t$ & + & + & + & $\ldots$ & $\ldots$ & + & + & & & \\
\hline$E P-28$ & 1 & $+t$ & + & + & + & + & + & + & + & & & \\
\hline$E P-29$ & 1 & ++ & + & + & + & + & & + & + & + & & \\
\hline $\mathrm{PT}-1$ & $1-\mathrm{b}$ & ++ & + & + & + & + & & + & + & + & & \\
\hline $\mathrm{PT}-2$ & $1-b$ & ++ & + & + & + & + & & + & + & + & & \\
\hline $\mathrm{PT}-3$ & $1-b$ & ++ & + & + & + & + & & $\ldots$ & + & + & & \\
\hline $\mathrm{PT}-4$ & $1-b$ & ++ & + & + & + & + & & $\ldots$ & + & + & & \\
\hline $\mathrm{PT}-5$ & $1-b$ & ++ & + & + & + & + & & & + & + & & \\
\hline $\mathrm{PT}-6$ & $1-b$ & ++ & + & + & + & + & & & + & + & & \\
\hline
\end{tabular}


TABLA 7. Continuación

\begin{tabular}{|c|c|c|c|c|c|c|c|c|c|c|c|c|}
\hline \multirow[b]{2}{*}{ MUESTRA } & \multirow[b]{2}{*}{ FABRICA } & \multirow[b]{2}{*}{$Q$} & \multicolumn{2}{|c|}{$\mathrm{Fd}$} & \multirow[b]{2}{*}{$I$} & \multirow[b]{2}{*}{$\mathrm{C}$} & \multirow[b]{2}{*}{ DO } & \multirow[b]{2}{*}{$\mathrm{H}$} & \multirow[b]{2}{*}{ G } & \multirow[b]{2}{*}{$\mathrm{D}$} & \multirow[b]{2}{*}{$\mathrm{M}$} & \multirow[b]{2}{*}{$\mathrm{AL}$} \\
\hline & & & FK & $\mathrm{A}$ & & & & & & & & \\
\hline $\mathrm{PT}-7$ & $1-b$ & ++ & + & + & + & & & + & + & + & & \\
\hline $\mathrm{PT}-8$ & $1-b$ & ++ & + & + & + & + & & + & + & + & & \\
\hline $\mathrm{PT}-9$ & $1-b$ & ++ & + & + & + & + & & + & + & + & & \\
\hline $\mathrm{PT}-10$ & $1-\mathrm{b}$ & ++ & + & + & + & + & & + & + & + & & \\
\hline $\mathrm{PT}-11$ & $1-b$ & ++ & + & + & + & + & & + & + & + & & \\
\hline$I Z A-1$ & 1 & ++ & + & + & + & + & & + & + & & & \\
\hline IZA-1BIS & 2 & ++ & + & + & + & + & & & + & + & & \\
\hline$I Z A-2$ & 1 & ++ & + & + & & $\cdots$ & & + & + & + & $\cdots$ & $\cdots$ \\
\hline IZA-2BIS & $1-b$ & ++ & + & + & + & + & & & & & + & + \\
\hline$I Z A-3$ & 1 & ++ & + & + & + & & & + & + & & & \\
\hline$I Z A-4$ & 1 & ++ & + & + & + & + & & + & + & & & \\
\hline$I Z A-5$ & 1 & ++ & + & + & + & + & & & + & + & & \\
\hline IZA- 6 & 1 & ++ & + & & + & + & & & + & + & & \\
\hline$I Z A-7$ & 1 & ++ & + & $\cdots$ & + & + & & & + & + & & \\
\hline I ZA-8 & 4 & $+t$ & + & + & + & + & & & + & $\cdots$ & & \\
\hline$I Z A-9$ & 1 & ++ & + & + & + & + & & + & + & & & \\
\hline$I Z A-10$ & 1 & ++ & + & + & + & $\cdots$ & & + & + & + & & \\
\hline IZA-1] & $3-a$ & + & + & & + & $+t$ & & & & & & \\
\hline IZA-14 & 2 & ++ & + & + & + & + & & & + & & & \\
\hline IZA- 15 & 1 & ++ & + & + & + & + & & & + & + & & \\
\hline IZA-16 & $3-a$ & + & + & & + & ++ & & & & & & \\
\hline $1 Z A-17$ & $3-a$ & + & + & & + & $+t$ & & & & & & \\
\hline
\end{tabular}


TABLA 8. FASES MINERALÓGICAS DETECTADAS EN EL ANÁLISIS MEDIANTE DIFRACCIÓNDE RAYOS X (XRD) DE LA RECOCCIÓN EN LABORATORIO DE 4 MUESTRAS CERÁMICAS

++ fase predominante. + presencia. ... trazas. ECSR estado como se reciben. Q cuarzo. Fd feldespatos. FK feldespato potásico. A anortita. I ilita y filosilicatos. C calcita. H hematites. G gehlenita. D diópsido. $M$ mullita. AL alfa-alúmina (corindón). $\mathrm{OC}$ óxido de $\mathrm{Ca}(\mathrm{CaO})$. P portlandita (hidróxido de $\mathrm{Ca}$ ).

\begin{tabular}{|c|c|c|c|c|c|c|c|c|c|c|c|c|c|}
\hline \multirow[b]{2}{*}{ MUESTRA } & \multirow[b]{2}{*}{$\begin{array}{l}\text { TEMPERATURA } \\
\text { RECOCCION }{ }^{\circ} \mathrm{C}\end{array}$} & \multirow[b]{2}{*}{$Q$} & \multicolumn{2}{|c|}{$\overline{F d}$} & \multirow[b]{2}{*}{ I } & \multirow[b]{2}{*}{$\mathrm{C}$} & \multirow[b]{2}{*}{$\mathrm{H}$} & \multirow[b]{2}{*}{$G$} & \multirow[b]{2}{*}{$D$} & \multirow[b]{2}{*}{ M } & \multirow[b]{2}{*}{$\mathrm{AL}$} & \multirow[b]{2}{*}{ OC } & \multirow[b]{2}{*}{$\mathrm{P}$} \\
\hline & & & FK & A & & & & & & & & & \\
\hline $\mathrm{N}-20$ & ECSR & + & + & $\ldots$ & + & ++ & & & & & & & \\
\hline $\begin{array}{l}N-20 / 7 \\
N-20 / 8\end{array}$ & $\begin{array}{l}700 \\
800\end{array}$ & $\begin{array}{l}+ \\
++\end{array}$ & $\begin{array}{l}+ \\
+\end{array}$ & $\begin{array}{l}\cdots \\
+\end{array}$ & $\begin{array}{l}+ \\
+\end{array}$ & $\begin{array}{l}++ \\
+\end{array}$ & & & & & & + & + \\
\hline$N-20 / 9$ & 900 & ++ & & & $\cdots$ & + & & + & & & & + & + \\
\hline$N-20 / 1$ & 1.000 & + & $\cdots$ & + & & + & & + & & & ++ & + & + \\
\hline$N-25$ & ECSR & ++ & + & + & + & + & + & + & & & & & \\
\hline$N-25 / 7$ & 700 & ++ & + & + & + & + & + & + & + & & & & \\
\hline$N-25 / 8$ & 800 & $+t$ & + & + & + & + & + & + & + & & & & \\
\hline $\mathrm{N}-25 / 9$ & 900 & ++ & + & + & + & + & & + & + & & & & \\
\hline$N-25 / 1$ & 1.000 & ++ & & & & & & & & + & + & & \\
\hline$N-54$ & ECSR & ++ & + & + & + & + & + & + & & & & & \\
\hline$N-54 / 7$ & 700 & ++ & + & + & + & + & + & + & & & & & \\
\hline $\mathrm{N}-54 / 8$ & 800 & ++ & + & + & + & $\ldots$ & + & + & $\ldots$ & & & & \\
\hline$N-54 / 9$ & 900 & ++ & & + & + & $\ldots$ & + & + & $\ldots$ & & & & \\
\hline$N-54 / 1$ & 1.000 & ++ & & & & & + & & & + & + & & \\
\hline $\mathrm{PT}-11$ & ECSR & $+t$ & + & + & + & + & + & + & + & & & & \\
\hline $\mathrm{PT}-11 / 7$ & 700 & $+t$ & + & + & + & + & + & + & + & & & & \\
\hline $\mathrm{PT}-11 / 8$ & 800 & ++ & + & + & + & & + & + & + & & & & \\
\hline $\mathrm{PT}-11 / 9$ & 900 & ++ & + & + & + & & + & + & + & & & & \\
\hline $\mathrm{PT}-11 / 1$ & 1.000 & ++ & + & + & $\cdots$ & & & + & + & & & & \\
\hline
\end{tabular}


TABLA 9. COLORES MUNSELL DE LA RECOCCIÓN EN LABORATORIO DE 4 MUESTRAS CERÁMICAS

ECSR cstado como se reciben.

\begin{tabular}{|c|c|c|}
\hline MUESTRA & $\begin{array}{l}\text { TEMPERATURA } \\
\text { RECOCCION }{ }^{\circ} \mathrm{C}\end{array}$ & $\begin{array}{l}\text { COLOR } \\
\text { MUNSELL }\end{array}$ \\
\hline $\begin{array}{c}\mathrm{N}-20 \\
\mathrm{~N}-20 / 7 \\
\mathrm{~N}-20 / 8 \\
\mathrm{~N}-20 / 9 \\
\mathrm{~N}-20 / 1\end{array}$ & $\begin{array}{c}\text { ECSR } \\
700 \\
800 \\
900 \\
1.000\end{array}$ & $\begin{array}{ccc}7.5 & \text { YR } & 7 / 2 \\
5 & \text { YR } & 7 / 6 \\
2.5 & \text { YR } & 7 / 4 \\
2.5 & \text { YR } & 7 / 6 \\
2.5 & \text { YR } & 6 / 6\end{array}$ \\
\hline $\begin{array}{c}N-25 \\
N-25 / 7 \\
N-25 / 8 \\
N-25 / 9 \\
N-25 / 1\end{array}$ & $\begin{array}{c}\text { ECSR } \\
700 \\
800 \\
900 \\
1.000\end{array}$ & $\begin{array}{lll}7.5 & \text { YR } & 8 / 1 \\
7.5 & \text { YR } & 8 / 2 \\
7.5 & \text { YR } & 8 / 2 \\
7.5 & \text { YR } & 8 / 3 \\
7.5 & \text { YR } & 8 / 3\end{array}$ \\
\hline $\begin{array}{c}N-54 \\
N-54 / 7 \\
N-54 / 8 \\
N-54 / 9 \\
N-54 / 1\end{array}$ & $\begin{array}{c}\text { ECSR } \\
700 \\
800 \\
900 \\
1.000\end{array}$ & $\begin{array}{lll}2.5 & \text { YR } & 6 / 6 \\
2.5 & \text { YR } & 6 / 8 \\
2.5 & \text { YR } & 6 / 8 \\
2.5 & \text { YR } & 6 / 8 \\
2.5 & \text { YR } & 6 / 8\end{array}$ \\
\hline $\begin{array}{c}\mathrm{PT}-11 \\
\mathrm{PT}-11 / 7 \\
\mathrm{PT}-11 / 8 \\
\mathrm{PT}-11 / 9 \\
\mathrm{PT}-11 / 1\end{array}$ & $\begin{array}{c}\text { ECSR } \\
700 \\
800 \\
900 \\
1.000\end{array}$ & $\begin{array}{lll}5 & \text { YR } & 6 / 1 \\
5 & \text { YR } & 6 / 6 \\
5 & \text { YR } & 6 / 8 \\
5 & \text { YR } & 6 / 8 \\
5 & \text { YR } & 7 / 6\end{array}$ \\
\hline
\end{tabular}


TABLA 10. FASES MINERALÓGICAS DETECTADAS EN EL ANÁLISIS MEDLANTE DIFRACCIÓN DE RAYOS X (XRD) DE LOS SEDIMENTOS ARCILLOSOS COCIDOS A DISTINTAS TEMPERATURAS

++ fase predominante. + presencia. ... trazas. T.A. temperatura ambiente. Q cuarzo. Fd feldespatos. FK feldespato potásico. A anortita (plagioclasa). I ilita y filosilicatos. $\mathrm{K}$ caolinita. $\mathrm{C}$ calcita. $\mathrm{H}$ hematites. $\mathrm{G}$ gehlenita. D diópsido. M mullita. $A L$ : alfaalúmina (corindón). $\mathrm{P}$ portlandita (hidróxido de $\mathrm{Ca}$ ).

\begin{tabular}{|c|c|c|c|c|c|c|c|c|c|c|c|c|c|}
\hline \multirow[b]{2}{*}{ MUESTRA } & \multirow[b]{2}{*}{$\begin{array}{l}\text { TEMPERATURA } \\
\text { COCCION }{ }^{\circ} \mathrm{C}\end{array}$} & \multirow[b]{2}{*}{$Q$} & \multicolumn{2}{|c|}{$\overline{E d}$} & \multirow[b]{2}{*}{$I$} & \multirow[b]{2}{*}{$\mathrm{K}$} & \multirow[b]{2}{*}{$\mathrm{C}$} & \multirow[b]{2}{*}{$\mathrm{H}$} & \multirow[b]{2}{*}{ G } & \multirow[b]{2}{*}{$\mathrm{D}$} & \multirow[b]{2}{*}{ M } & \multirow[b]{2}{*}{$\mathrm{AL}$} & \multirow[b]{2}{*}{$\mathrm{P}$} \\
\hline & & & $F K$ & A & & & & & & & & & \\
\hline$N-1 A$ & T.A. & $+t$ & + & & + & + & + & & & & & & \\
\hline$N-1 B$ & 700 & ++ & + & & + & & + & + & & & & & \\
\hline$N-1 C$ & 800 & ++ & + & + & + & & + & + & + & + & & & \\
\hline$N-1 D$ & 900 & ++ & + & + & $\cdots$ & & & + & + & + & & & + \\
\hline$N-1 E$ & 1.000 & $+t$ & + & + & & & & + & + & + & + & & \\
\hline$N-2 A$ & T.A. & ++ & + & & + & + & + & & & & & & \\
\hline$N-2 B$ & 700 & ++ & + & & + & & + & + & & & & & \\
\hline$N-2 C$ & 800 & ++ & + & + & + & & + & + & + & + & & & \\
\hline$N-2 D$ & 900 & ++ & + & + & $\ldots$ & & & + & + & + & & & + \\
\hline$N-2 E$ & 1.000 & ++ & + & + & & & & + & + & + & & & + \\
\hline$N-3 A$ & T.A. & ++ & + & & + & + & + & + & & & & & \\
\hline$N-3 B$ & 700 & ++ & + & & + & & + & + & & & & & \\
\hline$N-3 C$ & 800 & ++ & + & + & + & & + & + & + & + & & & \\
\hline$N-3 D$ & 900 & ++ & + & + & + & & & + & + & + & & & \\
\hline$N-3 E$ & 1.000 & $+t$ & + & + & & & & + & + & + & + & & \\
\hline$N-4 A$ & T.A. & ++ & + & & + & + & + & + & & & & & \\
\hline$N-4 B$ & 700 & ++ & + & & + & & + & + & & & & & \\
\hline$N-4 C$ & 800 & ++ & + & + & + & & + & + & + & & & & \\
\hline$N-4 D$ & 900 & $+t$ & + & & & & & + & $\ldots$ & & & & \\
\hline$N-4 E$ & 1.000 & ++ & + & + & & & & + & & & + & & \\
\hline$N-5 A$ & T.A. & ++ & + & & + & $\ldots$ & + & & & & & & \\
\hline$N-5 B$ & 700 & ++ & + & & + & & + & + & & & & & \\
\hline$N-5 C$ & 800 & ++ & + & + & $\ldots$ & & + & + & + & + & & & \\
\hline$N-5 D$ & 900 & ++ & + & + & & & & & + & + & + & & + \\
\hline$N-5 E$ & 1.000 & ++ & + & + & & & & + & + & + & + & & + \\
\hline$N-6 A$ & T.A. & ++ & + & & + & + & + & + & & & & & \\
\hline$N-6 B$ & 700 & $+t$ & + & & + & & + & + & & & & & \\
\hline$N-6 C$ & 800 & $+t$ & + & + & + & & + & + & + & & & & \\
\hline$N-6 D$ & 900 & ++ & + & + & + & & + & + & + & + & & & \\
\hline$N-6 E$ & 1.000 & ++ & + & + & & & & + & + & + & & & \\
\hline$N-7 A$ & T.A. & ++ & + & & + & + & + & + & & & & & \\
\hline$N-7 B$ & 700 & ++ & + & & + & & + & + & & & & & \\
\hline$N-7 C$ & 800 & ++ & + & + & + & & + & + & + & $\ldots$ & & & \\
\hline$N-7 D$ & 900 & ++ & + & + & & & & + & + & $\ldots$ & & & \\
\hline$N-7 E$ & 1.000 & ++ & + & + & & & & + & + & & + & & \\
\hline $\begin{array}{l}N-8 A \\
N-8 B\end{array}$ & $\begin{array}{l}\text { T.A. } \\
700\end{array}$ & & & & $\ldots$ & ++ & & & & & & & \\
\hline$N-8 C$ & 800 & & & & & & & & & & & & \\
\hline$N-8 D$ & 900 & & & & & & & & & & $\ldots$ & $\ldots$ & \\
\hline$N-8 E$ & 1.000 & & & & & & & & & & + & + & \\
\hline$I Z A-0$ & T.A. & ++ & + & & + & + & + & & & & & & \\
\hline$I Z A-700$ & 700 & ++ & + & & + & & + & & & & & & \\
\hline$I Z A-800$ & 800 & $+t$ & + & + & + & & + & + & + & + & & & \\
\hline$I Z A-900$ & 900 & $+t$ & + & + & + & & + & + & + & + & & & \\
\hline$I Z A-1000$ & 1.000 & ++ & + & + & & & & + & + & + & & & \\
\hline
\end{tabular}


TABLA 11. RESULTADOS DE LOS ANÁLISIS MEDIANTE TXRF DE LAS MUESTRAS CERÁMICAS PROCEDENTES DE NUMANCIA (\% PESO VERSUS Fe)

\begin{tabular}{|c|c|c|c|c|c|c|c|c|c|c|c|c|c|c|c|c|c|c|}
\hline MUESTRA & As & $\mathrm{Nd}$ & $\mathrm{Cr}$ & $\mathrm{Hf}$ & $\mathrm{Ni}$ & $\mathrm{Rb}$ & $\mathrm{Sr}$ & $\mathrm{Zn}$ & $\mathrm{Al}$ & $\mathrm{Ba}$ & $\mathrm{Ca}$ & $\mathrm{K}$ & $\mathrm{Mn}$ & $\mathrm{Ti}$ & v & $\mathrm{Cu}$ & $\mathrm{Ga}$ & $Y$ \\
\hline$N \cdot 10$ & 0.101 & 0.000 & 0.249 & 0.000 & 0,109 & 0,572 & 0.323 & 0,278 & 265,955 & 3,853 & 1059.59 & 104,123 & 1,017 & $\$ 1,870$ & 0,283 & 0.049 & 0,054 & 0.072 \\
\hline $\mathrm{N}-11$ & 0.099 & 0.000 & 0.156 & 0.009 & 0,076 & 0,572 & 0,277 & 0.296 & 248,641 & 3,607 & 33,346 & 142,032 & 0,982 & 8,604 & 0,162 & 0.135 & 0,064 & 0,087 \\
\hline $\mathrm{N}-12$ & 0.089 & 0.000 & 0.266 & 0.000 & 0.106 & 0.511 & 0.221 & 0.217 & 223,513 & 2.949 & 461.736 & 69.991 & 1.561 & 13,609 & 0,193 & 0.031 & 0,058 & 0,095 \\
\hline$N-13$ & 0.131 & 0.022 & 0.214 & 0.003 & 0,122 & 0,485 & 0,204 & 0,281 & 188,470 & 1,510 & 21,939 & 80,982 & 3,347 & 11,950 & 0.254 & 0.047 & 0,064 & 0,062 \\
\hline $\mathrm{N}-14$ & 0,090 & 0,000 & 0.211 & 0.014 & 0,095 & 0,493 & 0.244 & 0,247 & 200,237 & 1.605 & 14,310 & 80,258 & 0,685 & 12,447 & 0,190 & 0,075 & 0,063 & 0.080 \\
\hline $\mathrm{N}-15$ & 0.104 & 0,000 & 0,170 & 0,000 & 0,097 & 0,516 & 0,230 & 0,247 & 234,677 & 3,759 & 344,225 & t02.747 & 1,439 & 10,080 & 0.209 & 0.047 & 0.066 & 0.107 \\
\hline $\mathrm{N}-16$ & 0,128 & 0,020 & 0.175 & 0,020 & 0,080 & 0,580 & 0,451 & 0,287 & 199,370 & 2,675 & 17,054 & 90,115 & 0,633 & 10,816 & 0,159 & 0,054 & 0.079 & 0,116 \\
\hline$N-17$ & 0,076 & 0.000 & 0.221 & 0.006 & 0,087 & 0,413 & 0,203 & 0,216 & 194,576 & 1,185 & 139,083 & 59,177 & 0.364 & 10,019 & 0.165 & 0,038 & 0,057 & 0.093 \\
\hline$N \cdot 18$ & 0.106 & 0.000 & 0.253 & 0.000 & 0,116 & 0,577 & 0,406 & 0.283 & 250.941 & 2,056 & 745,261 & 107,618 & 1,174 & 11,490 & 0,183 & 0,063 & 0,068 & 0.086 \\
\hline$N-19$ & 0.096 & 0,000 & 0.244 & 0,000 & 0,118 & 0,490 & 0,320 & 0.261 & 241,461 & 3.187 & 667,168 & 92,764 & 0,879 & 11,867 & 0,150 & $0.05 t$ & 0.059 & 0,085 \\
\hline$N-20$ & 0.105 & 0,000 & 0,247 & 0.000 & 0,104 & 0.533 & 0,330 & 0,254 & 259.186 & 2,879 & 754,770 & 94,668 & 0,814 & 10,828 & 0,203 & 0.050 & 0,046 & 0,096 \\
\hline $\mathrm{N}-21$ & 0,178 & 0,043 & 0.469 & 0.000 & 0,139 & 0,755 & 0,387 & 0,280 & 342,460 & 3,811 & 521,835 & 144,549 & 0,278 & 19.268 & 0,326 & 0,233 & 0,101 & 0,164 \\
\hline $\mathrm{N} \cdot 22$ & 0,102 & 0,000 & 0.188 & 0.000 & 0,089 & 0,528 & 0,398 & 0,242 & 212,928 & 2,132 & 207,619 & 91,974 & 0,798 & 11,331 & 0.129 & 0,045 & 0,060 & 0,055 \\
\hline $\mathrm{N}-23$ & 0.091 & 0,000 & 0.287 & 0.000 & 0.097 & 0.491 & 0.338 & 0.260 & 243,756 & 4,001 & 494,869 & 91,367 & 0,980 & 11,329 & 0.181 & 0,034 & 0,060 & 0,065 \\
\hline $\mathrm{N}-24$ & 0.060 & 0,000 & 0,234 & 0.007 & 0,085 & 0.600 & 0.191 & 0,236 & 192,326 & 0,816 & 3,927 & 85,755 & 0,159 & 9,642 & 0,246 & 0,033 & 0.065 & 0.045 \\
\hline$N-25$ & 0,201 & 0,040 & 0,531 & 0.017 & 0,210 & 1.376 & 0,588 & 0.557 & 616,928 & 3.941 & 19,045 & 215.932 & 0,354 & 30,275 & 0,379 & 0.140 & 0,191 & 0,184 \\
\hline$N \cdot 26$ & 0.131 & 0.000 & 0,478 & 0.019 & 0.208 & 1,353 & 0,558 & 0,544 & 638.077 & 2,025 & 17,837 & 216,088 & 0.310 & 29,187 & 0.416 & 0.126 & 0,200 & 0,203 \\
\hline $\mathrm{N}-27$ & 0.070 & 0,013 & 0,280 & 0.004 & 0,130 & 0.606 & $\$, 050$ & 0,245 & 237,748 & 3,688 & 328,538 & 112,426 & 0,614 & 14,469 & 0,363 & 0.079 & 0,063 & 0.135 \\
\hline$N-28$ & 0.108 & 0,000 & 0.223 & 0.008 & 0.093 & 0,592 & 0,277 & 0.233 & 223.174 & 1,787 & 57.763 & 104,171 & 0.821 & 11,018 & 0,199 & 0,057 & 0,070 & 0,074 \\
\hline $\mathrm{N}-29$ & 0.162 & 0.047 & 0.587 & 0.027 & 0,197 & 1,334 & 0,546 & 0,544 & 624,539 & 3,884 & 17,979 & 204,112 & 0,269 & 30.792 & 0.439 & 0,172 & 0.188 & 0.172 \\
\hline $\mathrm{N} \cdot 30$ & 0.095 & 0,000 & 0.292 & 0.018 & 0,150 & 0,942 & 0,382 & 0,751 & 328,105 & 1.734 & 15,984 & 121,023 & 0.274 & 22,905 & 0,352 & 0,067 & 0.106 & 0.141 \\
\hline$N-31$ & 0.123 & 0,096 & 0,387 & 0.028 & 0,169 & 0,990 & 0,347 & 0.587 & 346,076 & 2.255 & 18,324 & 135,625 & 0,841 & 26,507 & 0.393 & 0.088 & 0,118 & 0,161 \\
\hline $\mathrm{N} \cdot 32$ & 0.082 & 0.000 & 0.343 & 0.000 & 0,107 & 0.705 & 0,574 & 0.184 & 237,720 & 1,787 & 19,166 & 111,690 & 0.232 & 12,257 & 0.348 & 0,093 & 0,083 & 0,064 \\
\hline
\end{tabular}


TABLA 11. Continuación

\begin{tabular}{|c|c|c|c|c|c|c|c|c|c|c|c|c|c|c|c|c|c|c|}
\hline MUESTRA & As & $N d$ & $\mathrm{Or}$ & $\mathrm{Hf}$ & $\mathrm{Ni}$ & $\mathrm{Rb}$ & $\mathrm{Sr}$ & $\mathrm{Zn}$ & Al & $\mathrm{Ba}$ & $\mathrm{Ca}$ & $x$ & $M n$ & $\mathrm{TI}$ & $v$ & $\mathrm{Cu}$ & $\mathrm{Ga}$ & $Y$ \\
\hline $\mathrm{N}-33$ & 0,080 & 0.004 & 0.330 & 0,041 & 0.157 & 0,979 & 0,351 & 0,608 & 312,866 & 1,776 & 15,013 & 120,374 & 0,809 & 25.150 & 0,317 & 0.075 & 0.115 & 0,181 \\
\hline$N-34$ & 0.022 & 0,000 & 0.260 & 0.004 & 0,082 & 0,639 & 0,173 & 0,132 & 199,053 & 0.788 & 9,015 & 78,597 & 0,260 & 8,900 & 0,202 & 0.029 & 0.068 & 0,081 \\
\hline$N \cdot 35$ & 0.074 & 0,000 & 0.241 & 0.000 & 0,106 & 0,474 & 0,319 & 0.277 & 171,969 & 2,596 & 66,896 & 80,583 & 1,373 & 10,450 & 0.268 & 0,050 & 0,057 & 0,070 \\
\hline$N \cdot 36$ & 0.067 & 0,000 & 0,174 & 0.014 & 0.079 & 0.503 & 0,121 & 0.139 & 180,578 & 1,020 & 5.728 & 78,830 & 0,085 & 8,880 & 0,224 & 0,031 & 0,059 & 0,065 \\
\hline$N \cdot 37$ & 0.062 & 0,000 & 0.213 & 0.000 & 0.093 & 0,569 & 0,266 & 0.229 & 213,150 & 1,314 & 24,140 & 79,461 & 0,608 & 10,679 & 0.156 & 0,049 & 0.072 & 0.059 \\
\hline$N \cdot 38$ & 0,056 & 0,000 & 0.227 & 0.001 & 0.089 & 0.530 & 0.273 & 0.221 & 204,616 & 1,302 & 8,396 & 78,128 & 0.182 & 11,684 & 0.219 & 0,038 & 0,065 & 0,089 \\
\hline $\mathrm{N}-39$ & 0,044 & 0,000 & 0.224 & 0,004 & 0,085 & 0.590 & 0,282 & 0.231 & 205,943 & 1,486 & 53,466 & 94,461 & 1,021 & 11,900 & 0,188 & 0.055 & 0,067 & 0,080 \\
\hline$N-40$ & 0,022 & 0,000 & 0,212 & 0.020 & 0,110 & 0,497 & 0.128 & 0,216 & 170,029 & 1.052 & 11,312 & 71,842 & 0,380 & 8,657 & 0,216 & 0,041 & 0,058 & 0,191 \\
\hline$N \cdot 41$ & 0.091 & 0,000 & 0,328 & 0.011 & 0.177 & 0,864 & 0.334 & 0,573 & 315,058 & 2.162 & 18,088 & $\$ 14,387$ & 0,408 & 23,312 & 0,298 & 0.138 & 0,105 & 0.099 \\
\hline $\mathrm{N}-42$ & 0,090 & 0,053 & 0,347 & 0.027 & 0,151 & 0,869 & 0,362 & 0,690 & 312,031 & 1.907 & 15,583 & $\$ 15.711$ & 0,946 & 21,576 & 0,304 & 0.115 & 0,108 & 0.135 \\
\hline $\mathrm{N} \cdot 43$ & 0.058 & 0,000 & 0,229 & 0.011 & 0,088 & 0,596 & 0,320 & 0.248 & 229,909 & 2,386 & 45,746 & 95,164 & 0,595 & 11,856 & 0.255 & 0,055 & 0.073 & 0,080 \\
\hline $\mathrm{N} \cdot 44$ & 0,064 & 0.000 & 0.220 & $0.00 t$ & 0.071 & 0.518 & 0.287 & 0.216 & 177,151 & 1.019 & 4,911 & 73.592 & 0,048 & 9,151 & 0.199 & 0.033 & 0,063 & 0,108 \\
\hline $\mathrm{N} \cdot 45$ & 0.087 & 0,000 & 0.191 & 0.006 & 0,094 & 0,562 & 0,283 & 0,243 & 221,161 & 1,138 & 49,016 & 90,372 & 0,673 & 11,419 & 0,258 & 0,060 & 0.072 & 0,067 \\
\hline$N-46$ & 0.043 & 0,000 & 0.254 & 0.007 & 0,075 & 0,611 & 0.122 & 0,132 & 198,047 & 0,896 & 4,278 & 86,106 & 0,105 & 9,285 & 0.204 & 0,060 & 0,069 & 0.058 \\
\hline$N-47$ & 0.079 & 0.035 & 0.326 & 0.016 & 0,132 & 0.781 & 0.286 & 0,491 & 261,775 & 1,479 & 12.466 & 99,261 & 0,555 & 18,148 & 0,292 & 0.052 & 0,092 & 0,127 \\
\hline$N-48$ & 0,042 & 0,000 & 0,230 & 0,019 & 0,088 & 0,581 & 0.220 & 0,275 & 187,823 & 0,916 & 4,556 & 80,212 & 0,177 & 10,588 & 0.255 & 0,036 & 0.069 & 0,059 \\
\hline$N-49$ & 0.073 & 0,000 & 0.270 & 0.007 & 0,101 & 0,672 & 0.205 & 0,265 & 237,547 & 0.978 & 9,014 & 95.765 & 0.178 & 11,747 & 0,287 & 0.174 & 0,083 & 0,079 \\
\hline$N-50$ & 0,046 & 0,000 & 0.225 & 0.018 & 0,089 & 0.415 & 0.249 & 0,212 & 183,669 & 0.950 & 36,459 & 70.695 & 0.722 & 12.668 & 0,178 & 0,040 & 0,053 & 0,087 \\
\hline$N-5$ ! & 0,104 & 0,086 & 0,361 & 0,002 & 0,159 & 0,863 & 0.340 & 0,744 & 344,453 & 2.071 & 16,304 & 130,369 & 0.843 & 21,826 & 0.307 & 0.081 & 0,117 & 0,155 \\
\hline $\mathrm{N} \cdot 52$ & 0,046 & 0.000 & 0,217 & 0,005 & 0,103 & 0,532 & 0,165 & 0,216 & 194,688 & 1,240 & 13,901 & 87,316 & 0,457 & 8,500 & 0,224 & 0,052 & 0,065 & 0,073 \\
\hline $\mathrm{N} \cdot 53$ & 0.046 & 0.000 & 0,215 & 0,013 & 0.089 & 0,545 & 0.288 & 0.243 & 205,150 & 1,615 & 44,785 & 98.779 & 0.960 & 11,126 & 0,176 & 0,063 & 0.069 & 0,068 \\
\hline $\mathrm{N} .54$ & 0,045 & 0.000 & 0,229 & 0,005 & 0.080 & 0,518 & 0,221 & 0,200 & 200,428 & 1,111 & 6,338 & 83,612 & 0.121 & 9,987 & 0,264 & 0,065 & 0,064 & 0,073 \\
\hline N.55 & 0.034 & 0.004 & 0,215 & 0,000 & 0,134 & 0,542 & 0,200 & 0,681 & 186,032 & 8,687 & 5,789 & 84,531 & 0,356 & 9,192 & 0,251 & 0,050 & 0.059 & 0,082 \\
\hline
\end{tabular}


TABLA 11. Continuación

\begin{tabular}{|c|c|c|c|c|c|c|c|c|c|c|c|c|c|c|c|c|c|c|}
\hline MUESTRA & As & No & $\mathrm{Cr}$ & $\mathrm{Ht}$ & $\mathrm{Ni}$ & $\mathrm{Rb}$ & $\mathrm{Sr}_{r}$ & $\mathrm{Zn}$ & Al & Ba & $\mathrm{Ca}$ & $\mathrm{K}$ & $\mathrm{Mn}$ & $\mathrm{Ti}$ & $v$ & Cu & $\mathrm{Ga}$ & $Y$ \\
\hline $\mathrm{N}-56$ & 0,0144 & 0.000 & 0,311 & 0.001 & 0,108 & $0,662:$ & 0.607 & 0,184 & 221.466 & 1,537 & 38,188 & 105.749 & 0,260 & 11,902 & 0.285 & 0,070 & 0,077 & 0,065 \\
\hline $\mathrm{N}-57$ & 0.106 & 0,000 & 0.208 & 0,009 & 0,109 & 0.476 & 0,156 & 0.307 & 183.158 & 1.905 & 15,033 & 84.843 & 0,922 & 12,256 & 0,264 & 0,109 & 0,075 & 0,053 \\
\hline$N \cdot 58$ & 0,118 & 0.000 & 0.235 & 0.001 & 0.097 & 0.554 & 0,174 & 0,270 & 171,496 & 0.784 & 11,981 & 73,209 & 1.218 & 12.594 & 0,248 & 0,049 & 0.066 & 0,053 \\
\hline $\mathrm{N}-59$ & 0.091 & 0.000 & 0,221 & 0,021 & 0.107 & $0.455^{\prime}$ & 0.164 & 0,259 & 183,627 & 1,836 & $\$ 5,394$ & 80,121 & 1,760 & 11,288 & 0.166 & 0,056 & 0,062 & 0,044 \\
\hline $\mathrm{N}-60$ & 0.113 & 0.018 & 0.320 & 0,031 & 0.135 & 0.745 & 0,272 & 0,457 & 285,050 & 1.729 & 14,311 & 115,887 & 0.569 & 20,117 & 0.260 & 0,105 & 0,096 & 0,156 \\
\hline $\mathrm{N}-61$ & 0,094 & 0,034 & 0.315 & 0.023 & 0,146 & 0,811 & 0,303 & 0,586 & 276,577 & 1,397 & 13,153 & 109,707 & 0,193 & 17.469 & 0,296 & 0.083 & 0,097 & 0.105 \\
\hline $\mathrm{N}-62$ & 0,191 & 0.000 & 0,422 & 0,033 & 0,162 & $1,066:$ & 0.445 & 0,485 & 498,712 & 2,614 & 14,919 & 165,414 & 0.533 & 23,668 & 0,330 & 0.184 & 0,176 & 0.132 \\
\hline $\mathrm{N}-63$ & 0,120 & 0,036 & 0.285 & 0.007 & 0,150 & $0,699:$ & 0.249 & 0.482 & 265.878 & 2,895 & 11,191 & 122,031 & 1,036 & 14,700 & 0,350 & 0,087 & 0.091 & 0,097 \\
\hline $\mathrm{N}-64$ & 0.111 & 0.000 & 0,340 & 0.014 & 0,156 & 0,870 & 0,295 & 0,614 & 309,859 & 1,923 & 14,795 & 130,295 & 0,244 & 19,450 & 0,266 & 0,080 & 0,110 & 0.110 \\
\hline $\mathrm{N}-65$ & 0,095 & 0,052 & 0,350 & 0.005 & 0,179 & $0,936:$ & 0,358 & 0,988 & 328.208 & 1,229 & 16,978 & 126,506 & 1,366 & 22,476 & 0,405 & 0.064 & 0.114 & 0.148 \\
\hline $\mathrm{N}-66$ & 0.081 & 0,000 & 0,277 & 0,016 & 0,180 & 0,652 & 0,239 & 0,356 & 243.544 & 1,569 & 11.773 & 98,304 & 0,203 & 14,758 & 0,226 & 0.065 & 0,070 & 0,096 \\
\hline $\mathrm{N}-67$ & 0,098 & 0,000 & 0.369 & 0.011 & 0,146 & 0.727 & 0.287 & 0,481 & 251,986 & 1,457 & 15,470 & 101,529 & 0,608 & 19,444 & 0.292 & 0,075 & 0,082 & 0,103 \\
\hline $\mathrm{N}-68$ & 0,034 & 0,000 & 0,247 & 0.005 & 0,059 & $0,527 \mid$ & 0.128 & 0,136 & 187,705 & 1.059 & 5,900 & 82,317 & 0,115 & 8,962 & 0,233 & 0,037 & 0,064 & 0.071 \\
\hline $\mathrm{N} \cdot 69$ & 0,130 & 0,021 & 0,215 & 0,000 & 0,110 & 0,4231 & 0.206 & 0,293 & 178,831 & 1,626 & 14,442 & 88,539 & 1,197 & 10,746 & 0.200 & 1.919 & 0,264 & 0,041 \\
\hline $\mathrm{N} \cdot 70$ & 0.083 & 0,000 & 0,270 & 0,006 & 0,109 & $0,753:$ & 0.266 & 0.386 & 263,425 & 2,832 & 15,603 & 98,957 & 0.169 & 15,592 & 0,277 & 0.065 & 0.093 & 0,099 \\
\hline $\mathrm{N} \cdot 71$ & 0.106 & 0.000 & 0,224 & 0,010 & 0,123 & 0,4501 & 0,185 & 0,266 & 190,993 & 3.079 & 15,317 & 74,705 & 1,181 & 12.744 & 0.186 & 0,077 & 0,064 & 0,066 \\
\hline NP.72 & 0,606 & 0,068 & 0,392 & 0.022 & 0,176 & 0.735 & 0.252 & 0,704 & 276.273 & 2.063 & 19,308 & 114,464 & 0,364 & 16,641 & 0.409 & 0,404 & 0,118 & 0,146 \\
\hline NP.73 & 0.060 & 0,004 & 0.272 & 0,011 & 0.171 & $0,906:$ & 0,373 & 0,781 & 261,683 & 3.084 & 16,061 & 104,574 & 0,699 & 20,942 & 0,452 & 0,111 & 0.110 & 0,155 \\
\hline NP-74 & 0.0115 & 0.045 & 0,372 & 0,011 & 0.183 & $0,965:$ & 0,370 & 0.827 & 350,644 & 1.743 & 16,288 & 127,305 & 0,363 & 26,444 & 0,454 & 0,127 & 0.108 & 0,210 \\
\hline NP-75 & 0.0143 & 0,000 & 0.187 & 0,010 & 0,090 & $0.608:$ & 0,193 & 0,358 & 203,911 & 1,511 & 12,793 & 90,596 & 0,705 & 9,026 & 0.246 & 0,075 & 0.080 & 0,056 \\
\hline NP.76 & $0,0,38$ & 0.000 & 0,228 & 0,006 & 0,101 & 0,4931 & 0.133 & 0.284 & 166,904 & 0,971 & 11,769 & 69,935 & 0,309 & 9.415 & 0,202 & 0,039 & 0,062 & 0.065 \\
\hline NP-77 & 0.070 & 0.000 & 0.200 & 0,014 & 0,066 & 0,493 & 0.114 & 0.190 & 65,982 & 0.545 & 3,656 & 70,435 & 0,124 & 8,398 & 0,229 & 0,030 & 0,065 & 0.086 \\
\hline NP-78 & $0,0.46$ & 0.000 & 0,323 & 0.027 & 0.142 & $0,817 !$ & 0.308 & 0.516 & 270,705 & 1.276 & 14,964 & 103,162 & 0.711 & 22.056 & 0.264 & 0.083 & 0.087 & 0,137 \\
\hline
\end{tabular}


TABLA 11. Continuación

\begin{tabular}{|c|c|c|c|c|c|c|c|c|c|c|c|c|c|c|c|c|c|c|}
\hline MUESTAA & As & $\mathrm{Nd}$ & $\mathrm{Cr}_{\mathrm{r}}$ & $\mathrm{Hf}$ & $\mathrm{Ni}$ & $\mathrm{Rb}$ & Sr & $z_{n}$ & Al & $\mathrm{Ba}$ & $\mathrm{Ca}$ & $K$ & $M n$ & $\mathrm{Ti}$ & $v$ & $\mathrm{Cu}$ & $\mathrm{Ga}$ & Y \\
\hline NP.79 & 0,133 & 0,000 & 0.224 & 0,013 & 0,078 & 0.586 & 0.127 & 0.159 & 196,324 & 0.795 & 3,098 & 89.372 & 0.159 & 11,362 & 0,199 & 0,115 & 0,067 & 0,078 \\
\hline NP-80 & 0.025 & 0,000 & 0.367 & 0,006 & 0,132 & 0,684 & 0,691 & 0,431 & 246,477 & 2,608 & 54,133 & 118,463 & 0,268 & 14,426 & 0,291 & 0.092 & 0.076 & 0,095 \\
\hline NP-81 & 0.061 & 0,086 & 0.524 & 0,000 & 0,237 & 1.232 & 0,550 & 1.454 & 480,740 & 4,842 & 23,455 & 171,297 & 0,268 & 27,123 & 0.518 & 0.130 & 0,159 & 0,310 \\
\hline NP-82 & 0.060 & 0,077 & 0.507 & 0,036 & 0,210 & 1.166 & 0,504 & 1,006 & 488,375 & 3,668 & 22,295 & 161,688 & 0,390 & 24,269 & 0.494 & 0,133 & 0.166 & 0,221 \\
\hline NP-83 & 0.054 & 0,009 & 0.474 & 0.033 & 0.255 & 1,188 & 0,508 & 1,326 & 516,108 & 5,915 & 26,019 & 165,522 & 0,344 & 23,951 & 0.419 & 0,152 & 0,176 & 0.219 \\
\hline NP.84 & 0,081 & 0,000 & 0.498 & 0,066 & 0,220 & 1,459 & 0.594 & 0,674 & 629,584 & 4,094 & 24,700 & 178,391 & 0,355 & 27,738 & 0,422 & 0,116 & 0.221 & 0,198 \\
\hline NP-85 & 0,053 & 0.149 & 0,535 & 0,035 & 0,271 & 1,223 & 0.628 & 1,049 & 457.770 & 5,321 & 28,473 & 159,844 & 0,396 & 24,938 & 0,438 & 0,129 & 0,171 & 0,253 \\
\hline NP-86 & 0,057 & 0,000 & 0,483 & 0.016 & 0.230 & 1,481 & 0,742 & 0,649 & 672,604 & 5,013 & 28,314 & 207,875 & 0,291 & 31,085 & 0,477 & 0,148 & 0,209 & 0,225 \\
\hline NP.87 & 0,094 & 0.000 & 0,203 & 0,015 & 0,020 & 0,418 & 0.181 & 0,067 & 168,145 & 1,431 & 6,387 & 44,018 & 0,118 & 12,182 & 0,257 & 0,041 & 0,097 & 0,069 \\
\hline NP-88 & 0.017 & 0.152 & 0,358 & 0.036 & 0.168 & 0,948 & 0,359 & 0,871 & 284,312 & 2,501 & 15,397 & 116,247 & 0,346 & 23,974 & 0,471 & 0.111 & 0.117 & 0,145 \\
\hline NP-88 & 0,055 & 0,150 & 0,583 & 0,036 & 0,255 & 1,286 & 0,547 & 1.096 & 511,188 & 5.155 & 23.442 & 189.017 & 0.291 & 27.654 & 0.489 & 0.103 & 0.178 & 0.269 \\
\hline NP-90 & 0.066 & 0.000 & 0,477 & 0,020 & 0,249 & 1,278 & 0,508 & 1,182 & 477,978 & 4,578 & 23,744 & 164.079 & 0,435 & 25,790 & 0,490 & 0,155 & $0,18 t$ & 0,237 \\
\hline NP-81 & 0,087 & 0.116 & 0.515 & 0.000 & 0,208 & 1,487 & 0,628 & 0,709 & 597,169 & 3,003 & 18.959 & 189.070 & 0,491 & 30,857 & 0,616 & 0,181 & 0,201 & 0,236 \\
\hline NP.97 & 0,058 & 0.045 & 0.596 & 0.012 & 0,217 & 7.498 & 0,618 & 0,685 & 655,567 & 2,600 & 26,156 & 207,871 & 0,284 & 39,394 & 0,429 & 0,149 & 0,214 & 0,213 \\
\hline
\end{tabular}


TABLA 12. RESULTADOS DE LOS ANÁLISIS MEDIANTE TXRF DE LAS MUESTRAS CERÁMICAS PROCEDENTES: DE IZANA (\% PESO VERSUS Fe)

\begin{tabular}{|c|c|c|c|c|c|c|c|c|c|c|c|c|c|c|c|c|c|c|}
\hline MUESTRA & As & $\mathrm{Nd}$ & $\mathrm{Cr}$ & $\mathrm{Hf}$ & $\mathrm{Ni}$ & Ro & st & $\mathrm{Zn}$ & A: & Bat & $\mathrm{Ca}$ & $\mathrm{k}$ & $\mathrm{Mn}$ & $\pi i$ & $v$ & cu & $\mathrm{Ga}$ & Y \\
\hline IZA-1 & 0,000 & 0,000 & 0,233 & 0,008 & 0,088 & $0,57 \uparrow$ & 0,285 & 0,234 & 217,108 & 1,544 & 22,457 & 79,592 & 0,428 & 10,600 & $0,20 t$ & 0,045 & 0,074 & 0,083 \\
\hline$|Z A-1 B| S$ & 0,023 & 0,017 & 0,208 & 0.000 & 0,118 & 0,553 & 0,270 & 0,318 & 230,400 & 1,628 & 39,448 & 88,449 & 0,020 & $\$ 1,743$ & 0.187 & 0,062 & 0,070 & 0,076 \\
\hline $\mid Z A \cdot 2$ & 0,003 & 0,000 & 0,107 & 0.018 & 0,081 & 0,548 & 0,237 & 0.224 & 202,027 & 1,174 & 34,238 & 80,035 & 0,715 & 10.033 & 0,208 & 0,052 & 0,058 & 0,070 \\
\hline$|Z A-2 B| S$ & 0,011 & 0,000 & 0,193 & 0,000 & 0,100 & 0,578 & 0,336 & 0,371 & 233,094 & 1,392 & 21,108 & 89,151 & 0,885 & 13,185 & 0,192 & 0,000 & 0,062 & 0,112 \\
\hline IZA.3 & 0,040 & 0,000 & 0,204 & 0,008 & 0,077 & 0,514 & 0,160 & 0,234 & 184,705 & 0,584 & 0.114 & 73,020 & 0,285 & 0,508 & 0,173 & 0,043 & 0,080 & 0,050 \\
\hline IZA.4 & 0,035 & 0,000 & 0,223 & 0,004 & 0,084 & 0,500 & 0,252 & 0,217 & $1.92,023$ & 0,835 & 5,300 & 83,100 & 0,130 & 13,015 & 0,220 & 0,034 & 0,067 & 0,101 \\
\hline IZA-5 & 0,064 & 0,000 & 0,277 & 0,014 & 0,092 & 0,833 & 0,183 & 0,268 & $2 ; 19,304$ & 1,052 & 12,550 & 85,000 & 0,294 & 14,557 & 0,220 & 0,241 & 0,077 & 0,071 \\
\hline IZA.C & 0.054 & 0,000 & 0.187 & 0,007 & 0,059 & 0,500 & 0,197 & 0,238 & 1178,950 & 0,716 & 17,127 & 84,640 & 0,280 & 8.605 & 0,226 & 0,048 & 0,007 & 0,008 \\
\hline IZA.7 & 0,082 & 0,000 & 0,234 & 0,004 & 0,097 & 0,626 & 0,354 & 0,249 & $2,22,098$ & 1.187 & 28,818 & 84,477 & 0,540 & 14,021 & 0,200 & 0,054 & 0,008 & 0,070 \\
\hline IZA-8 & 0,135 & 0,000 & 0.190 & 0,011 & 0,079 & 0.288 & 0,149 & 0,131 & $1: 50,027$ & 1,094 & 22,849 & 46,243 & 1,193 & 6,283 & 0,188 & 0,127 & 0,057 & 0,053 \\
\hline IZA.9 & 0,069 & 0,000 & 0.212 & 0,001 & 0,100 & 0,550 & 0,243 & 0,265 & 2120,203 & 1,364 & 21,400 & 80,142 & 0,507 & 10,065 & 0.190 & 0,050 & 0,081 & 0,051 \\
\hline IZA-10 & 0,037 & 0,000 & 0.227 & 0,000 & 0,100 & 0,573 & 0,135 & 0.190 & $1 ; 72,765$ & 0,804 & 0,234 & 74,621 & 0.171 & 8,406 & 0,214 & 0,025 & 0,004 & 0,073 \\
\hline IZA-11 & 0,077 & 0,000 & 0,253 & 0,000 & 0,118 & 0,544 & 0,335 & 0,337 & $2,62,450$ & 2,504 & 1024,270 & 70,880 & 1,174 & $\$ 3,040$ & 0,214 & 0.075 & 0,049 & 0,175 \\
\hline $1 Z A-14$ & 0,082 & 0,000 & 0,215 & 0.001 & 0,116 & 0,507 & 0,170 & 0,285 & $2 \mid 19,807$ & 1.006 & 18,887 & 82,353 & 0,027 & 17,138 & 0,241 & 0,097 & 0,078 & 0,002 \\
\hline IZA-15 & 0,072 & 0,000 & 0,201 & 0,014 & 0,004 & 0,538 & 0,287 & 0,374 & 223,231 & 1,527 & 53,198 & 83,492 & 0,071 & 12,010 & 0,186 & 0,058 & 0,008 & 0,007 \\
\hline $\mid Z A \cdot 18$ & 0,002 & 0,000 & 0,243 & 0,000 & 0,130 & 0,507 & 0,356 & 0,322 & 259,830 & 3,803 & 791,943 & 85,496 & 1.828 & 13,256 & 0,189 & 0,074 & 0,072 & 0.132 \\
\hline $12 A-17$ & 101 & 0,042 & 0,308 & 0,000 & 0,115 & 0,535 & 0,311 & 0,270 & $27,73,034$ & 2,734 & 971,501 & 72,284 & 1,315 & $\$ 1,125$ & 0,179 & 0,037 & 0,050 & 0.001 \\
\hline
\end{tabular}


TABLA 13. RESULTADOS DE LOS ANÁLISIS MEDIANTE TXRF DE LAS MUESTRAS CERÁMICAS PROCEDENTES DE LANGA DE DUERO, EL PALOMAR Y PINILLA TRASMONTE

(\% PESO VERSUS Fe)

\begin{tabular}{|c|c|c|c|c|c|c|c|c|c|c|c|c|c|c|c|c|c|c|}
\hline MUESTRA & As & $\mathrm{Nd}$ & $\mathrm{cr}_{\mathrm{r}}$ & $\mathrm{Hit}$ & $\mathrm{Ni}$ & $\mathrm{Rb}$ & $\mathrm{sr}$ & $2 n$ & A) & $\mathrm{Ba}$ & $\mathrm{Ca}$ & $\mathrm{k}$ & $\mathrm{Mn}$ & $\pi i$ & v & $\mathrm{Cu}$ & $\mathrm{Ga}$ & Y \\
\hline LD. 92 & 0.053 & 0.000 & 0.276 & 0.025 & 0.040 & 0,498 & 0,288 & 0,233 & 323,750 & 0.984 & 22,170 & 75,015 & 0.236 & 18.356 & 0,324 & 0,085 & 0.102 & 0.095 \\
\hline LD. -93 & 0,050 & 0,000 & 0,316 & 0.059 & 0,045 & 0.493 & 0,308 & 0,872 & 314,929 & 0,804 & 22,909 & 70,305 & 0.255 & 17,530 & 209 & 0.109 & 0,111 & 0,094 \\
\hline LD. 94 & 0.038 & 0,000 & 0.273 & 0,009 & 0.042 & 0,487 & 0,268 & 0,501 & 304,571 & 1,120 & 18,137 & 73,787 & 0,247 & 18.236 & 0.340 & 0,100 & 0,112 & 0,062 \\
\hline LD-85 & 0,054 & 0,000 & 0.215 & 0,024 & 0.092 & 0.534 & 0.287 & 0,340 & 188,307 & 1,888 & 140,316 & 89.768 & 0,386 & 9,615 & 0,187 & 0,060 & 0.062 & 0.043 \\
\hline LD-96 & 0,081 & 0.052 & 0.252 & 0,012 & 0,070 & 0,671 & 1.333 & 0,223 & 274,370 & 0,545 & 7,987 & 132.625 & 0,132 & 12,922 & 0,196 & 0,048 & 0,102 & 0,099 \\
\hline EP-25 & 0.061 & 0.009 & 0.178 & 0,000 & 0.076 & 0,486 & 0,488 & 0.173 & 159,942 & 1.023 & 9,028 & 93,260 & 0,481 & 7,600 & 0.183 & 0,016 & 0,052 & 0,053 \\
\hline EP.26 & 0,050 & 0.000 & 0,214 & 0.008 & 0,071 & 0,496 & 0,557 & 0,141 & 165.368 & 0,0169 & 17,697 & 98,384 & 0.318 & 7,851 & 0,178 & 0.016 & 0,058 & 0.043 \\
\hline$E P \div 27$ & 0.027 & 0.000 & 0,210 & 0,006 & 0.061 & 0.487 & 0,590 & 0,139 & 155,197 & 0.848 & 9,325 & 84,701 & 0,300 & 8,259 & 0,227 & 0.019 & 0,081 & 0,048 \\
\hline$E P \cdot 28$ & 0,047 & 0,000 & 0.198 & 0,005 & 0,088 & 0.475 & 0,431 & 164 & 168,975 & 1.096 & 6.485 & 86,508 & 0,288 & 9.370 & 0,146 & 0,024 & 0.055 & 0.062 \\
\hline EP-29 & 0,042 & 0.026 & 0,236 & 0.003 & 0,081 & 0.448 & 0.717 & 0,162 & 168,142 & 1,780 & 12,143 & 123,901 & 0,461 & 8.924 & 0,201 & 0,030 & 0.085 & 0,052 \\
\hline Pr.1 & 0.068 & 0.028 & 0.268 & 0.004 & 0,107 & 0,538 & 0.345 & 0,229 & 212,206 & 1.453 & 111,876 & 64.195 & 0.467 & 10,872 & 0.202 & 0.044 & 0.073 & 0.076 \\
\hline$P Y-2$ & 0.098 & 0.000 & 0,223 & 0,000 & 0,101 & 0,534 & 0,517 & 0,202 & 233,757 & 1,256 & 328,773 & 64,525 & 0,842 & 11,571 & 0,158 & 0,063 & 0,065 & 0,069 \\
\hline PT-3 & 0.108 & 0.000 & 0,186 & 0,000 & 0.121 & 0,515 & 0.413 & 0,217 & 215,442 & 1,608 & 245,988 & 62.216 & 0,550 & 10,482 & 0,322 & 0,044 & 0.063 & 0,065 \\
\hline PT.4 & 0,102 & 0,000 & 0.222 & 0.003 & 0,085 & 0,415 & 0.308 & 0.242 & 203,554 & 0,478 & 117,913 & 48,932 & 0,477 & 9,247 & 0.213 & 0,042 & 0,061 & 0,059 \\
\hline PT-8 & 0.078 & 0,000 & 0.232 & 0,000 & 0,093 & 0,535 & 0,305 & 0.222 & 215,558 & 0.418 & 150,675 & 67,338 & 0.407 & 10,449 & 0,206 & 0,038 & 0,069 & 0,059 \\
\hline PT.6 & 0.005 & 0.000 & 0.208 & 0.000 & 0.090 & 0,487 & 0,298 & 0.230 & 206,562 & 0.427 & 114,154 & 58,098 & 0.603 & 9,372 & 0,203 & 0,043 & 0.061 & 0,075 \\
\hline PT.7 & 0.111 & 0.000 & 0,223 & 0,000 & 0,083 & 0,410 & 0,285 & 0.199 & 188,216 & 0.548 & 107,040 & 49,833 & 0.427 & 9,323 & 0,154 & 0,043 & 0.058 & 0.065 \\
\hline PT.8 & 0,088 & 0.000 & 0,212 & 0.012 & 0,078 & 0,431 & 0,343 & 0,215 & 192,780 & 1.275 & 181.118 & 52.469 & 0.638 & 9,080 & 0,224 & 0,056 & 0.060 & 0.074 \\
\hline PT-8 & 0.082 & 0.000 & 0,242 & 0,000 & 0,094 & 0,488 & 0.403 & 0,248 & 226,131 & 0,760 & 192,305 & 83,221 & 0,455 & 12,311 & 0,245 & 0.043 & 0,065 & 0,072 \\
\hline$P T-10$ & 0,090 & 0.000 & 0.235 & 0,000 & 0,089 & 0,490 & 0,342 & 0,210 & 198,499 & 0,563 & 160,263 & 55,606 & 0.459 & 9,307 & 0,261 & 0,047 & 0.062 & 0.068 \\
\hline$P T-11$ & 0,102 & 0.000 & 0,255 & 0,000 & 0,089 & 0.437 & 0,280 & 0,191 & 204,719 & 1,041 & $109,61 t$ & 51,052 & 0,464 & 9,214 & 0,165 & 0,038 & 0,056 & 0,063 \\
\hline
\end{tabular}


TABLA 14, MEDIAS Y DESVIACIÓN ESTÁNDARD DE LOS GRUPOS ESTABLECIDOS EN EL ANÁLISIS DE COMPONENTES PRINCIPALES

El asterisco de la media y la desviación estándard de Ca del grupoG.5, significaque no ha sido tenida en cuentala muestia N-21. Con olla, la media y la desviación estándardas de $40,004 \pm$ ios.434

\begin{tabular}{|c|c|c|c|c|c|c|c|c|c|}
\hline & $G-1 \quad(N=21)$ & $G-2 A \quad(N=12)$ & $G-2 B \quad(N=5)$ & $G-3 \quad(N=24)$ & $\mathrm{G} \cdot 4 \mathrm{~A}(\mathrm{~N}=19)$ & $G \cdot 4 B \quad(N=5)$ & $G-5 \quad(N=23)$ & $G-6(N=14)$ & G-7 $(N=5)$ \\
\hline As & $0.118=0.037$ & $0,091=0.013$ & $0.145 \div 0,009$ & $0.091 \pm 0.027$ & $0.048 \pm 0.024$ & $0.045=0.012$ & $0.084 \pm 0.037$ & $0,053=0.054$ & $0,058=0,013$ \\
\hline$c t$ & $0,237=0.033$ & $0.227 \pm 0.022$ & $0,188=0,001$ & $0.215 \div 0.022$ & $0.222=0,02$ & $0.207 \pm 0,021$ & $0,335=0,044$ & $0.515 \pm 0.049$ & $0.282=0.018$ \\
\hline $\mathrm{Ni}$ & $0,110=0.01$ & $0,093=0,012$ & $0.081 \pm 0.011$ & $0.087 \pm 0.013$ & $0,085=0,018$ & $0,075=0,01$ & $0.150=0.023$ & $0,223=0,028$ & $0.064=0,00$ \\
\hline Rb & $0.534 \pm 0.068$ & $0,478=0,052$ & $0,336=0,03$ & $0.540 \pm 0.058$ & $0.545 \pm 0.046$ & $0.478=0.018$ & $0.823=0.109$ & $1,315 \pm 0,132$ & $0.556 \pm 0.089$ \\
\hline $\mathrm{sr}$ & $0.354=0.07$ & $0,337=0,08$ & $0.135 \pm 0.014$ & $0.259=0.067$ & $0,177=0,054$ & $0,557 \pm 0,109$ & $0,363=0.113$ & $0,560 \pm 0,073$ & $0,250=0,054$ \\
\hline $2 n$ & $0.367=0,247$ & $0.218=0,017$ & $0.188=0.033$ & $0.273 \pm 0.042$ & $0,227=0,118$ & $0,155=0,015$ & $0.551=0.201$ & $0,854=0,322$ & $0.427=0.271$ \\
\hline N & $224,658=34,179$ & $208,499=13,039$ & $175,195=17,985$ & $206,081 \pm 20,275$ & $186,138=11,752$ & $163,525=5,844$ & $288,581 \pm 39,255$ & $561,810=77.534$ & $280,020=48,021$ \\
\hline $\mathrm{Ba}$ & $2,437=1$ & $0.917 \pm 0,433$ & $0.698=0.258$ & $1,779=0,666$ & $0,964=0,283$ & $1,183=0,354$ & $2.033 \pm 0.654$ & $4,047=1,186$ & $0,888=0,118$ \\
\hline $\mathrm{ca}$ & $506,677 \pm 298.683$ & $103,233=66,946$ & $38,353=19,289$ & $35,833=27,652$ & $7,229=3,704$ & $10,836 \pm 4,278$ & $18,196=8.6 *$ & $22,524 \pm 4,184$ & $17,157=6,116$ \\
\hline$k$ & $84,853=14,643$ & $58,063 \pm 6,371$ & $42,902 \pm 2,993$ & $87,887=14,204$ & $78,456=8.569$ & $97,351 \pm 15,814$ & $116,181 \pm 12,585$ & $185,450=21,426$ & $81,878=12,366$ \\
\hline $\mathrm{Mn}$ & $1.426 \pm 0.475$ & $0.498=0.091$ & $0,725=0,288$ & $0,941 \pm 0,603$ & $0.204=0.112$ & $0.370 \pm 0.093$ & $0,531=0,328$ & $0.358=0,083$ & $0,242=0.042$ \\
\hline$\pi$ & $12,924=1,758$ & $10.104 \pm 1.055$ & $5,272 \pm 0.915$ & $11.372 \pm 1.221$ & $9.633=1.234$ & $8.401 \pm 0.738$ & $19,789=4,285$ & $27,800 \div 3,105$ & $15,485 \pm 3,514$ \\
\hline$v$ & $0.193=0.035$ & $0.210=0.049$ & $0.187 \div 0.012$ & $0.207 \pm 0.097$ & $0.221 \pm 0.022$ & $0.197 \pm 0.03$ & $0,327=0,067$ & $0,453 \pm 0,088$ & $0.278=0.037$ \\
\hline $\mathrm{cu}$ & $0.057=0.013$ & $0.045=0.007$ & $0.073 \pm 0.03$ & $0.064 \pm 0.022$ & $0,044=0,02$ & $0,021=0,006$ & $0.094 \pm 0.037$ & $0,144 \pm 0,024$ & $0.142 \pm 0.085$ \\
\hline$G_{a}$ & $0.060=0.007$ & $0.062=0.005$ & $0.058=0.001$ & $0,069=0.007$ & $0,064 \pm 0,003$ & $0.058=0,005$ & $0,099 \pm 0,015$ & $0,180=0.01 \theta$ & $0,097=0,018$ \\
\hline$r$ & $0.093=0.022$ & $0.070=0,009$ & $0.074=0.045$ & $0.089 \pm 0.016$ & $0.080=0.031$ & $0.052 \pm 0.007$ & $0.128=0,036$ & $0.219=0.043$ & $0.080=0.014$ \\
\hline
\end{tabular}


TABLA 15. DISTANCIAS DE MAHALANOBIS DE 135 MUESTRAS A LOS CENTROIDES DE LAS AGRUPACIONES ESTABLECIDAS EN EL ANÁLISIS DE COMPONENTES PRINCIPALES

Grupo G-1 $(N=21)$

\begin{tabular}{cccccccc} 
& G-1 & G-2 & G-3 & G-4 & G-5 & G-6 & G-7 \\
\cline { 2 - 3 } N-10 & 7.6 & 51.2 & 39.4 & 89.5 & 77.4 & 195.4 & 104.9 \\
N-12 & 9.7 & 41.9 & 41.6 & 87.6 & 80.4 & 204.6 & 115.8 \\
N-15 & 22.8 & 64.4 & 41.9 & 90.9 & 106.1 & 239.8 & 127.0 \\
N-18 & 6.3 & 38.1 & 35.0 & 83.7 & 72.0 & 186.0 & 97.1 \\
N-19 & 3.5 & 37.8 & 31.4 & 76.5 & 67.5 & 186.2 & 97.5 \\
N-20 & 9.0 & 38.8 & 35.8 & 80.1 & 73.6 & 196.3 & 87.8 \\
N-22 & 7.1 & 32.6 & 16.6 & 52.0 & 64.6 & 200.1 & 73.9 \\
N-23 & 12.4 & 44.8 & 31.7 & 71.5 & 61.4 & 164.9 & 91.5 \\
& & & & & & & \\
N-1A & 5.4 & 35.4 & 36.6 & 85.4 & 77.7 & 224.6 & 99.2 \\
N-1D & 10.8 & 31.7 & 44.2 & 91.9 & 95.7 & 250.2 & 115.7 \\
N-2A & 12.5 & 59.3 & 49.8 & 108.8 & 87.9 & 234.2 & 122.5 \\
N-2D & 10.6 & 46.9 & 45.7 & 102.3 & 84.5 & 227.2 & 119.1 \\
N-3A & 9.8 & 34.6 & 29.4 & 77.1 & 88.4 & 245.1 & 99.1 \\
N-3D & 10.7 & 25.4 & 29.1 & 69.5 & 70.2 & 215.3 & 91.0 \\
N-6A & 10.6 & 41.0 & 36.1 & 85.0 & 66.8 & 199.2 & 92.7 \\
N-6D & 5.8 & 34.1 & 30.9 & 80.8 & 73.2 & 216.4 & 95.9 \\
& & & & & & & \\
IZA-11 & 10.8 & 33.0 & 46.3 & 97.6 & 79.0 & 199.7 & 97.0 \\
IZA-16 & 7.1 & 40.5 & 41.7 & 100.6 & 74.8 & 178.5 & 114.7 \\
IZA-17 & 19.7 & 34.8 & 60.0 & 111.2 & 88.6 & 188.0 & 116.9 \\
IZA-0 & 6.5 & 46.4 & 23.1 & 65.6 & 49.3 & 166.4 & 72.0 \\
IZA-900 & 5.6 & 37.4 & 21.0 & 62.1 & 45.7 & 159.6 & 69.1
\end{tabular}


TABLA 15. Continuación

Grupo G-2 (G-2A y G-2B) $(\mathrm{N}=17)$

\begin{tabular}{lccccccc} 
& G-1 & G-2 & G-3 & G-4 & G-5 & G-6 & G-7 \\
\cline { 2 - 5 } N-17 & 17.5 & 11.1 & 26.5 & 44.2 & 73.4 & 214.0 & 72.5 \\
N-4A & 56.8 & 9.2 & 56.6 & 76.0 & 113.1 & 254.3 & 83.1 \\
N-4D & 58.4 & 9.2 & 52.2 & 68.8 & 109.6 & 242.4 & 90.4 \\
N-7A & 60.2 & 12.1 & 74.8 & 103.8 & 136.7 & 264.6 & 125.3 \\
N-7D & 78.2 & 18.8 & 90.8 & 113.7 & 160.5 & 297.1 & 145.6 \\
& & & & & & & \\
IZA-8 & 54.0 & 22.8 & 37.5 & 59.8 & 95.6 & 240.4 & 70.2 \\
& & & & & & & \\
PT-1 & 23.5 & 13.2 & 26.0 & 45.8 & 48.0 & 150.3 & 64.6 \\
PT-2 & 19.2 & 10.0 & 43.4 & 82.1 & 77.3 & 192.2 & 85.0 \\
PT-3 & 24.5 & 17.4 & 52.0 & 91.0 & 95.7 & 217.7 & 117.0 \\
PT-4 & 40.8 & 3.2 & 56.7 & 78.8 & 103.2 & 234.4 & 89.4 \\
PT-5 & 32.4 & 13.2 & 45.7 & 63.6 & 90.2 & 223.3 & 82.6 \\
PT-6 & 34.6 & 5.5 & 47.0 & 69.1 & 99.4 & 241.4 & 81.8 \\
PT-7 & 33.8 & 2.3 & 46.9 & 67.3 & 93.1 & 230.8 & 78.3 \\
PT-8 & 21.8 & 4.4 & 35.2 & 63.3 & 84.9 & 220.0 & 77.5 \\
PT-9 & 20.3 & 6.6 & 35.9 & 61.3 & 68.7 & 190.2 & 68.7 \\
PT-10 & 32.0 & 2.9 & 47.5 & 69.0 & 91.4 & 223.2 & 81.5 \\
PT-11 & 30.8 & 4.8 & 40.4 & 61.5 & 74.9 & 192.4 & 73.8
\end{tabular}


TABLA 15. Continuación

Grupo G-3 $(\mathrm{N}=24)$

N-11

$\mathrm{N}-13$

N-14

$\mathrm{N}-16$

N-28

$\mathrm{N}-35$

N-37

N-39

$\mathrm{N}-43$

$\mathrm{N}-45$

N-50

N-53

N-57

N-58

N-59

N-71

NP-75

LD-95 22.6

IZA-1 39.4

IZA-1BIS 24.5

IZA-7 32.3

IZA-9 $\quad 33.7$

IZA-14 33.0

IZA-15 18.9
33.8

43.8

29.0

37.2

27.4

\begin{tabular}{c|c}
\hline $\mathbf{G}-\mathbf{3}$ & $\mathrm{G}-4$ \\
\hline 40.0 & 66.5
\end{tabular}

12.8

7.0

13.3

4.6

9.2

3.4

4.8

2.8

6.1

10.0

3.5

5.8

10.3

6.3

12.3

9.0

13.8

6.3

6.5

5.8

5.9

3.5

4.0
48.8

20.7

33.5

29.6

34.1

14.2

19.5

18.0

28.1

17.9

17.9

25.8

25.3

27.6

37.3

13.1

27.9

11.8

29.6

19.6

17.3

24.5

25.7
G-5

48.9

27.0

43.8

37.0

42.1

31.9

41.4

25.3

45.8

45.3

38.9

33.2

41.7

37.7

28.6

46.9

57.2

28.0

19.9

20.8

31.7

26.6

37.8
G-6

173.1

145.3

151.9

151.7

171.3

142.3

171.1

129.8

$172.2 \quad 42.9$

$191.1 \quad 37.5$

$165.4 \quad 35.1$

$159.8 \quad 42.7$

$178.9 \quad 43.9$

$162.9 \quad 47.8$

$138.1 \quad 51.2$

$162.1 \quad 34.3$

$197.6 \quad 58.6$

$129.0 \quad 27.2$

$114.7 \quad 35.2$

$132.9 \quad 22.2$

$135.1 \quad 36.2$

$130.3 \quad 33.4$

$158.7 \quad 37.5$ 
TABLA 15. Continuación

Grupo G-4 (G-4A y G-4B) $(\mathrm{N}=24)$

\begin{tabular}{ccccccccc} 
& G-1 & G-2 & G-3 & G-4 & G-5 & G-6 & G-7 \\
\cline { 2 - 3 } N-24 & 90.7 & 74.7 & 26.8 & 3.7 & 42.4 & 155.4 & 24.1 \\
N-34 & 93.2 & 70.1 & 34.0 & 8.6 & 57.1 & 168.2 & 35.7 \\
N-36 & 89.0 & 78.6 & 35.8 & 14.0 & 75.0 & 215.7 & 52.8 \\
N-38 & 71.1 & 60.2 & 20.4 & 7.9 & 29.1 & 136.2 & 21.7 \\
N-40 & 71.8 & 60.0 & 23.2 & 7.7 & 59.2 & 195.5 & 49.3 \\
N-44 & 108.3 & 81.5 & 45.0 & 13.0 & 58.0 & 174.6 & 33.9 \\
N-46 & 116.2 & 100.5 & 42.3 & 11.4 & 54.3 & 165.9 & 24.1 \\
N-48 & 87.9 & 71.6 & 25.0 & 2.5 & 39.3 & 152.5 & 25.8 \\
N-52 & 52.2 & 42.7 & 9.4 & 6.9 & 40.4 & 157.2 & 31.8 \\
N-54 & 97.2 & 80.3 & 31.1 & 8.3 & 42.1 & 154.8 & 14.8 \\
N-55 & 82.5 & 73.1 & 22.8 & 11.7 & 36.2 & 142.0 & 39.6 \\
N-68 & 116.5 & 105.0 & 45.3 & 11.4 & 71.7 & 199.8 & 35.4 \\
NP-76 & 61.3 & 51.8 & 19.9 & 7.6 & 52.6 & 188.1 & 47.2 \\
NP-77 & 95.7 & 73.3 & 36.8 & 9.6 & 78.1 & 221.7 & 44.3 \\
NP-79 & 105.4 & 102.4 & 38.4 & 25.2 & 51.0 & 175.6 & 18.5 \\
& & & & & & & \\
EP-25 & 73.1 & 66.8 & 24.6 & 15.9 & 69.7 & 207.1 & 55.4 \\
EP-26 & 71.4 & 67.2 & 26.7 & 14.0 & 64.0 & 192.1 & 52.8 \\
EP-27 & 99.2 & 82.2 & 37.8 & 12.5 & 73.8 & 208.2 & 47.2 \\
EP-28 & 79.7 & 68.9 & 22.9 & 7.6 & 46.3 & 169.8 & 35.8 \\
EP-29 & 96.9 & 108.4 & 34.6 & 22.6 & 53.1 & 166.5 & 49.5 \\
& & & & & & & \\
IZA-3 & 78.2 & 56.4 & 22.0 & 3.8 & 55.8 & 188.3 & 24.8 \\
IZA-4 & 96.0 & 87.1 & 33.1 & 7.3 & 44.1 & 165.5 & 28.7 \\
IZA-6 & 55.3 & 37.9 & 17.1 & 9.4 & 63.5 & 209.6 & 28.2 \\
IZA-10 & 86.8 & 66.9 & 33.6 & 9.1 & 61.7 & 183.8 & 54.5
\end{tabular}


TABLA 15. Continuación

Grupo G-5 (N = 23)

\begin{tabular}{ccccccccc} 
& & G-1 & G-2 & G-3 & G-4 & G-5 & G-6 & G-7 \\
\cline { 2 - 3 } N-21 & 67.9 & 117.7 & 75.4 & 116.0 & 41.7 & 91.5 & 84.7 \\
N-30 & 77.3 & 97.1 & 42.1 & 57.9 & 8.1 & 53.9 & 44.2 \\
N-31 & 89.3 & 127.3 & 56.6 & 86.1 & 9.4 & 37.0 & 61.7 \\
N-32 & 91.4 & 91.7 & 41.5 & 41.1 & 16.4 & 77.6 & 24.2 \\
N-33 & 75.7 & 106.1 & 39.7 & 62.2 & 5.5 & 52.6 & 48.9 \\
N-41 & 82.2 & 105.6 & 47.5 & 69.0 & 5.2 & 49.0 & 45.4 \\
N-42 & 78.9 & 100.7 & 40.1 & 64.8 & 4.4 & 46.3 & 38.5 \\
N-47 & 62.8 & 77.2 & 24.2 & 35.2 & 4.0 & 69.0 & 32.1 \\
N-51 & 83.0 & 109.5 & 46.8 & 72.9 & 7.5 & 34.9 & 51.1 \\
N-56 & 65.5 & 65.4 & 25.4 & 23.4 & 18.0 & 101.7 & 24.3 \\
N-60 & 68.6 & 94.4 & 29.1 & 47.6 & 2.8 & 65.4 & 28.7 \\
N-61 & 74.8 & 82.8 & 34.0 & 38.9 & 4.9 & 63.4 & 30.9 \\
N-63 & 67.2 & 96.2 & 24.9 & 48.8 & 9.8 & 68.3 & 45.5 \\
N-64 & 80.7 & 103.4 & 41.2 & 53.0 & 5.0 & 48.3 & 43.1 \\
N-65 & 74.5 & 97.6 & 45.6 & 74.4 & 13.1 & 50.2 & 58.4 \\
N-66 & 69.8 & 73.9 & 32.5 & 36.5 & 12.9 & 88.0 & 42.2 \\
N-67 & 70.1 & 91.4 & 34.9 & 49.1 & 5.2 & 73.9 & 36.2 \\
N-70 & 68.3 & 81.0 & 26.5 & 30.8 & 12.9 & 81.4 & 34.5 \\
NP-73 & 74.3 & 100.2 & 36.0 & 57.8 & 10.0 & 66.9 & 55.4 \\
NP-74 & 134.5 & 149.8 & 74.7 & 72.7 & 21.0 & 57.0 & 49.1 \\
NP-78 & 73.5 & 91.3 & 30.9 & 41.3 & 6.2 & 79.2 & 27.3 \\
NP-80 & 93.7 & 105.3 & 48.6 & 46.2 & 18.5 & 82.6 & 37.9 \\
NP-88 & 110.1 & 140.7 & 56.5 & 74.2 & 23.9 & 71.1 & 64.7
\end{tabular}


TABLA 15. Continuación

Grupo G-6 (N = 14)

$\mathrm{N}-25$

N-26

N-29

N-62

NP-81

NP-82

NP-83

NP-84

NP-85

NP-86

NP-89

NP-90

NP-91

NP-97

\begin{tabular}{ccc} 
G-1 & G-2 & \\
\hline 211.3 & 246.5 & 168
\end{tabular}

194.9

227.7

154.4

185.9

173.5

190.7

209.9

189.7

224.5

212.3

173.6

208.1

228.2
217.5

259.0

175.0

213.1

191.7

211.5

227.0

212.3

250.2

243.6

197.7

230.6

251.4

G-3

150.5

178.4

110.2

138.5

125.5

144.9

168.3

147.4

175.7

162.9

130.8

156.0

178.3
G-4

177.7

205.8

143.3

156.8

145.1

168.7

197.2

170.0

202.1

179.8

157.2

182.2

198.1

\begin{tabular}{|c|c|c|}
\hline G-5 & G-6 & G-7 \\
\hline 69.9 & 6.0 & 140.2 \\
\hline 62.8 & 8.2 & 121.0 \\
\hline 73.1 & 6.7 & 137.8 \\
\hline 41.3 & 11.5 & 86.7 \\
\hline 46.1 & 4.6 & 118.8 \\
\hline 42.8 & 2.4 & 103.7 \\
\hline 57.8 & 5.1 & 133.2 \\
\hline 77.2 & 5.5 & 150.0 \\
\hline 55.8 & 7.9 & 138.0 \\
\hline 77.3 & 5.1 & 147.4 \\
\hline 63.7 & 6.7 & 146.0 \\
\hline 46.7 & 3.7 & 121.9 \\
\hline 61.5 & 3.6 & 120.0 \\
\hline 74.1 & 5.4 & 137.4 \\
\hline
\end{tabular}

Grupo G-7 (N = 5)

\begin{tabular}{|c|c|c|c|c|c|c|c|}
\hline & G-1 & G-2 & G-3 & G-4 & G-5 & G-6 & G-7 \\
\hline N-49 & 90.3 & 79.8 & 32.2 & 25.3 & 26.6 & 116.5 & 8.8 \\
\hline LD-92 & 100.5 & 88.8 & 52.3 & 51.2 & 56.7 & 142.7 & 11.5 \\
\hline LD-93 & 104.9 & 84.0 & 57.2 & 55.4 & 53.8 & 129.3 & 11.9 \\
\hline LD-94 & 102.5 & 93.2 & 47.9 & 42.8 & 52.1 & 139.6 & 10.4 \\
\hline IZA-5 & 92.7 & 90.8 & 35.3 & 32.1 & 37.8 & 142.8 & 11.9 \\
\hline
\end{tabular}

“Outliers" (mal clasificados) $(\mathrm{N}=7$ )

\begin{tabular}{cccccccc} 
& G-1 & G-2 & G-3 & G-4 & G-5 & G-6 & G-7 \\
\cline { 2 - 8 } N-27 & 30.4 & 61.3 & 32.3 & 66.8 & 30.7 & 121.1 & 63.0 \\
N-69 & 128.9 & 131.9 & 84.4 & 115.6 & 103.3 & 190.2 & 108.0 \\
NP-72 & 95.4 & 116.7 & 72.3 & 109.1 & 28.2 & 65.8 & 69.3 \\
NP-87 & 139.2 & 122.2 & 81.0 & 60.7 & 128.4 & 275.9 & 69.9 \\
& & & & & & & \\
LD-96 & 131.5 & 109.5 & 67.2 & 53.9 & 54.1 & 117.1 & 30.6 \\
& & & & & & & \\
IZA-2 & 114.3 & 101.0 & 53.7 & 32.0 & 96.6 & 236.4 & 59.2 \\
IZA-2BIS & 52.8 & 57.7 & 24.3 & 33.6 & 56.4 & 185.7 & 43.2
\end{tabular}




\section{APÉNDICES}





\section{APÉNDICE I}

Este apéndice muestra el catálogo del conjunto cerámico global estudiado en el yacimiento de Numancia. En primer lugar, se reproduce la clasificación tipológica atribuida a las piezas completas y a los fragmentos con los que es posible reproducir la forma del recipiente y, en segundo lugar, se ofrece la clasificación del resto de los fragmentos. En ambos casos, se especifica la fábrica macroscópica asignada. Los números situados entre paréntesis detrás de los tipos, hacen referencia a la tipología de Arlegui (1986). Cuando no aparecen significa que el tipo no está presente en esta tipología. Los números de inventario se refieren siempre al Museo Numantino de Soria, salvo en los que se especifica la referencia MAN, pertenecientes al Museo Arqueológico Nacional de Madrid. Las columnas están ordenadas de izquierda a derecha y de menor a mayor número de inventario. Las piezas que se muestran en los tipos 1, 10, 11, 13, 15, $17,19,20,22,23$ y 24, son piezas incompletas que no han podido asignarse a ninguno de los subtipos. Los tipos $3,5,7,8,9,12,14,18$ y 21 no tienen subtipos en la tipología mencionada. Dos o más números unidos por un guión, indica que los fragmentos pertenecen a la misma pieza.

Al final de cste apéndice también se reproducen los colores Munsell de las superficies extemas e internas de las cerámicas, según las distintas fábricas macroscópicas, así como los colores de los pigmentos de la decoración. 


\section{CLAVES}

*: Indica que la pieza o el fragmento ha sido analizado en este trabajo

A: Número del catálogo del trabajo de Arlegui (1986)

B: Pigmento blanco

DE: Decoración estampada

DP: Decoración pintada

DPoli: Decoración polícroma

G: Grafito

GP: Grafito pintado

MAN: Museo Arqueológico Nacional de Madrid

$\mathrm{N}$ : Pigmento negro

R. Número del catálogo del trabajo de Romero Carnicero (1976)

RO: Pigmento rojo

$\mathrm{s} / \mathrm{n}$ : Sin númeto de inventario

W: Númeto del catálogo del trabajo de Wattenberg (1963) 


\section{PIEZAS COMPLETAS}

\section{CUENCOS (1)}

Fábrica 1

3.072 W937 R308 DPoli

$3.659 *$

9.017 DPoli N/B

$\mathrm{N} / \mathrm{B} / \mathrm{RO}$

Fábrica 1-b

2.048 W1.107 R28 DPoli

$\mathrm{N} / \mathrm{RO}$

Fábrica Negta

$236 \mathrm{~W} 135$

249W134

11.666 W354

$11.695 \mathrm{~W} 522$

\section{Subtipo 1a}

Fábrica 1

$1.477 \mathrm{~W} 472 *$

1.677 W539

11.719 W964

$1 \mathrm{~s} / \mathrm{n} \mathrm{DP}$

Fábrica 2

\begin{tabular}{lll}
$1.367 \mathrm{~W} 967$ & $1.372 \mathrm{~W} 966$ & $1.470 \mathrm{~W} 960$ \\
$11.715 \mathrm{~W} 968 \mathrm{G}$ & $11.720 \mathrm{~W} 969 \mathrm{G}$ & \\
\hline
\end{tabular}

\section{Subtipo 1b}

Fábrica 1

3.054 W973 R141 A2 DPoli $\mathrm{N} / \mathrm{B}$ 
Fábrica 1-b

12.430 W972 R187 DPoli

$\mathrm{N} / \mathrm{RO}$

Fábrica 2

$1.343 \mathrm{~W} 526 \quad 1.390 \mathrm{~W} 970 \mathrm{DE} \quad 1.471 \mathrm{~W} 962 \mathrm{G} 1 \mathrm{~s} / \mathrm{n}$

MAN 23.331BIS

\section{Subtipo 1c}

Fábrica 1

$\begin{array}{lll}1.304 & 1.473 \mathrm{~W} 497 & 1.609 \mathrm{DP} \\ 1.616 \mathrm{~W} 478 & 1.617 \mathrm{~W} 499 & 1.623 \mathrm{~W} 470 \\ 1.633 \mathrm{~W} 495 & 1.634 \mathrm{~W} 502 & 1.635 \mathrm{~W} 477 \\ 1.636 \mathrm{~W} 496 & 1.637 \mathrm{~W} 473 & 1.656 \mathrm{~W} 500 \\ 1.657 \mathrm{~W} 468 & 1.659 \mathrm{~W} 503 & 1.660 \mathrm{~W} 469 \mathrm{DE} \\ 1.661 \mathrm{~W} 467 & 1.693 \mathrm{~W} 471 & 1.706 \mathrm{~W} 704 \\ 1.711 \mathrm{~W} 528 & 1.714 \mathrm{~W} 529 & 1.721 \mathrm{~W} 533 \\ 1.747 \mathrm{~W} 541 & 2.061 & 3.082 \mathrm{~W} 953 \mathrm{R} 304 \mathrm{DPoli} \\ & & 11.806 \mathrm{~W} 530\end{array}$

Fábrica 1-b

1.679 W532G $1 \mathrm{~s} / \mathrm{n}$

Fábrica 2

$1.098 \mathrm{~W} 501 \quad 12.532 \mathrm{DP} \quad \mathrm{MAN} 1 \mathrm{~s} / \mathrm{n}$ 


\section{Subtipo 1d}

Fábrica 1

1.614 W714

$1.767 \mathrm{~W} 562$

1.859 W563

$2.816 \mathrm{DP}$ *

3.038 W974 A5 DP

3.619 R236 DPoli N/B

3.633 W947 A10 DP

12.426 R114 DPoli

12.539 A7 DP

12.555 A8 DP

$\mathrm{N} / \mathrm{RO}$

Fábrica 2

$1.856 \mathrm{~W} 568$

$3.106 \mathrm{DP}$

11.881 W1.110-1.292 A33

DPoli N/RO

\section{Subtipo 1e}

Fábrica 1

2.002 W1.166-1.295 R20

3.616 A18 DP

3.650 A17 DP

DPoli N/B

Fábrica 1-b

11.826

Subtipo If

Fábrica 1

1.768 W566

$3.614 \mathrm{DP}$

1.858 W 564

3.618 A15 DP

12.564

$1 \mathrm{~s} / \mathrm{n}$

1.867 W555 DP

$3.738 \mathrm{DP}$

Fábrica 1-b

1.479 W958 *

1.868 W546

1.869 W552

MAN 1920/37/18 DP 
Fábrica 2

\section{Subtipo $1 g$}

Fábrica 1

1.864 W548

2.796 DP 3.017

3.632 W957 A33 DP

12.551 W771

Fábrica 1-b

1.861 W553

Fábrica 2

Fábrica $1 \rightarrow 63$ (24 decorados) Total $=99(5.3 \%)$

Fábrica 1-b $\rightarrow 10$ (3 decorados)

Fábrica $2 \rightarrow 22$ (4 decorados)

Fábrica Negra $\rightarrow 4$ 


\section{VASOS CARENADOS (2)}

\section{Subtipo 2a}

Fábrica 1

\begin{tabular}{|c|c|c|}
\hline $1.377 \mathrm{~W} 517 \mathrm{DP} *$ & $1.480 \mathrm{~W} 506$ & 1.575 \\
\hline 1.613 W715 DP & $1.667 \mathrm{~W} 567 \mathrm{G}$ & 1.682 \\
\hline $1.710 \mathrm{~W} 545$ & $1.766 \mathrm{~W} 518$ & $1.857 \mathrm{~W} 219$ \\
\hline 1.862 W551 & 1.865 W325 & 1.866 W554 \\
\hline $\begin{array}{r}2.063 \text { W1.159 A93 DPoli } \\
\text { N/B }\end{array}$ & $2.095 \mathrm{~W} 1.298 \mathrm{DP}$ & $2.595 \mathrm{DP}$ \\
\hline 2.772 W950 A32 DP & $2.794 \mathrm{DP} *$ & 2.795 A30 DP \\
\hline 2.893 R150 DPoli N/B & $\begin{array}{r}2.894 \text { W556 R105 DPoli } \\
\text { N/B }\end{array}$ & $3.043 \mathrm{~A} 52 \mathrm{DP}$ \\
\hline $3.419 \mathrm{DP}$ & $3.420 \mathrm{~A} 28 \mathrm{DP}$ & $3.623 \mathrm{DP}$ \\
\hline 3.634 W946 A9 DP & $3.639 \mathrm{DP}$ & 3.649 A16 DP \\
\hline $3.652 \mathrm{~A} 12 \mathrm{DP}$ & $3.653 \mathrm{DP}$ & 3.657 A22 DP \\
\hline 3.734 & $3.735 \mathrm{DP}$ & $3.740 \mathrm{DP}$ \\
\hline $11.734 \mathrm{~W} 788 \mathrm{DE}$ & $\begin{array}{r}12.418 \text { W954 R226 DPoli } \\
\text { N/B }\end{array}$ & $\begin{array}{r}12.419 \text { W949 R210 DPoli } \\
\text { N/B }\end{array}$ \\
\hline 12.505 A19 DP & 12.541 & $12.545 \mathrm{DP}$ \\
\hline $12.546 \mathrm{DP}$ & $12.562 \mathrm{DP}$ & $13.797 \mathrm{DP}$ \\
\hline $3 \mathrm{~s} / \mathrm{n} \mathrm{DP}$ & MAN $1 \mathrm{~s} / \mathrm{n}$ DP & \\
\hline
\end{tabular}

Fábrica 1-b

$1.685 \mathrm{~W} 544$

$1.870 \mathrm{~W} 326$

2.046 W1.296 R29 DPoli $\mathrm{N} / \mathrm{RO}$

2.047 W1.167 R41 DPoli

$\mathrm{N} / \mathrm{RO}$

2.049 W942 R89 DPoli

$\mathrm{N} / \mathrm{RO}$

$3.731 \mathrm{DP}$

Fábrica 2

$1.368 \mathrm{~W} 561 *$

$1.463 \mathrm{~W} 327$

11.714 W516
$1.369 \mathrm{~W} 560$

1.724 W956*

$1 \mathrm{~s} / \mathrm{n} \mathrm{DE}$
$1.391 \mathrm{~W} 508 \mathrm{DE}$

11.704 W513 
Fábrica Negra

238

241

$1.090 \mathrm{~W} 512$

11.630

MAN $1 \mathrm{~s} / \mathrm{n}$
239 W543

1.086 W510

1.376 W515*

11.672 W509
240 W542

1.088 W511

$1.772 \mathrm{~W} 324$

11.691 W505

\section{Subtipo 2b}

Fábrica 1

2.780

2.818 A39 DP

3.083 DPoli N/B

$3.135 \mathrm{DP}$

$3.412 \mathrm{DP}$

$3.611 \mathrm{DP}$

$3.637 \mathrm{DP}$

$3.656 \mathrm{~A} 25 \mathrm{DP}$

12.501 DP

$12.534 \mathrm{DP}$

$5 \mathrm{~s} / \mathrm{n}$ DP
2.793 DP

$3.059 \mathrm{DP}$

$3.119 \mathrm{DP}$

$3.152 \mathrm{DP}$

$3.424 \mathrm{DP}$

$3.622 \mathrm{DP}$

$3.638 \mathrm{DP}$

12.444 W938 DP

$12.502 \mathrm{DP}$

12.540 A 40 DP

MAN 24.759
2.793 A26 DP

$3.062 \mathrm{DP}$

$3.134 \mathrm{DP}$

$3.279 \mathrm{DP}$

3.425 DP

$3.631 \mathrm{~A} 38 \mathrm{DP}$

3.654 DP

$12.452 \mathrm{DP} *$

$12.533 \mathrm{DP}$

13.303

MAN 1920/37/96 DP

Fábrica 1-b

\begin{tabular}{|c|c|c|}
\hline $2.812 \mathrm{DP}$ & $3.421 \mathrm{~A} 27 \mathrm{DP}$ & $\begin{array}{r}11.822 \text { W943 R88 DPoli } \\
\text { N/RO }\end{array}$ \\
\hline $\begin{array}{r}11.877 \text { W940 R87 DPoli } \\
\text { N/RO }\end{array}$ & $12.547 \mathrm{DP}$ & $1 \mathrm{~s} / \mathrm{n}$ \\
\hline
\end{tabular}

Fábrica 2

$3.423 \mathrm{DP}$

\section{Subtipo 2c}

Fábrica 1 


\section{Subtipo 2d}

Fábrica 1

$1.618 \mathrm{DP}$

1.769 W558

3.613 A43 DP

12.487 A37 DP

MAN $1 \mathrm{~s} / \mathrm{n}$ DP

Fábrica 1-b

2.774 A23 DP

$3.737 \mathrm{DP}$

$1 \mathrm{~s} / \mathrm{n}$

MAN 1920/37/78

Fábrica $1 \rightarrow 91$ (74 decorados)

Total $=131(7 \%)$

Fábrica 1-b $\rightarrow 17$ (13 decorados)

Fábrica $2 \rightarrow 10$ (3 decorados)

Fábrica Negra $\rightarrow 13$

VASOS CARENADOS GRANDES (3)

Fábrica 1

$2.781 \mathrm{~A} 41 \mathrm{DP}$

$3.185 \mathrm{DP}$

3.621 DP

3.640 A51 DP

12.565 A44 DP

Fábrica 2

2.784 DP

Fábrica $1 \rightarrow 5$ (5 decorados)

Total $=\rightarrow(0.3 \%)$

Fábrica $2 \rightarrow 1$ (1 decorado)

VASOS ACAMPANADOS (4)

Subtipo $4 a$

Fábrica 1

$1.594 \mathrm{DP}$

3.182 DP

$1 \mathrm{~s} / \mathrm{n} \mathrm{DP}$ 
Fábrica 1-b

3.063 W1.046 R86 DPoli

$\mathrm{N} / \mathrm{RO}$

Fábrica 2

$1.764 \mathrm{~W} 600$

Fábrica Negta

3.743

\section{Subtipo 4b}

Fábrica 1

1.616

$1.860 \mathrm{~W} 348 \mathrm{DP}$

2.105 W1.103 DP

3.065 W1.055 R262 DPoli

$\mathrm{N} / \mathrm{B}$

Fábrica $1 \rightarrow 7$ (6 decorados)

Total $=10(0.5 \%)$

Fábrica 1-b $\rightarrow 1$ (1 decorado)

Fábrica $2 \rightarrow 1$

Fábrica Negra $\rightarrow 1$

VASOS (5)

Fábrica 1

$1.760 \mathrm{~W} 140$

13.802 W1.034 DP

Fábrica $1 \rightarrow 2$ (1 decorado) Total $=2(0.1 \%)$ 


\section{TAZAS PEQUEÑAS (6)}

\section{Subtipo 6a}

Fábrica 1

1.504 W5 578

3.129 DP

$3 \mathrm{~s} / \mathrm{n}$

Fábrica 1-b

1.505

Fábrica 2

1.305 W594
1.308 W590
1.391
11700 W589

11.700 W589
$1.506 \mathrm{~W} 569$

$12.425 \mathrm{~W} 1.032 \mathrm{R} 286$

DPoli N/B
1.508 W572

12.499 W1.031 A78 DP

1.717 W591

1.307 W580

1.333

1.465 W596

11.709 W570

Fábrica Negra

$11.730 \mathrm{~W} 574 \mathrm{DE}$

\section{Subtipo 6b}

Fábrica 1

1.509 W581

1.510 W582

1.715 W586

2.584 W587 A77 DP

3.132 A75 DP

$1.331 \mathrm{~W} 571$

1.464 W597

11.701 W595

\subsection{W570}




\section{Subtipo 6c}

Fábrica 1

2.585 W948 A6 DP

2.587 W1.033 A79 DP

Fábrica 1-b

$11.808 \mathrm{~W} 138$

Fábrica 2

Fábrica $1 \rightarrow 16$ (7 decoradas)

Total $=38(2 \%)$

Fábrica 1-b $\rightarrow 3$

Fábrica $2 \rightarrow 18$ (1 decorada)

Fábrica Negra $\rightarrow 1$ (1 decorada)

\section{TAZAS GRANDES (7)}

Fábrica 1

$1.486 \mathrm{~W} 1.027$

$1.490 \mathrm{~W} 1.023$

$2.022 \mathrm{~W} 1.028 \mathrm{~A} 59 \mathrm{DP}$

$2.025 \mathrm{DP}$

2.097 W1.125 DP

3.197 A67 DP

3.610 A71 DP

12.472 A65 DP

MAN $1 \mathrm{~s} / \mathrm{n}$ DP
$1.487 \mathrm{~W} 1.026$

$1.491 \mathrm{~W} 1.024$

$2.023 \mathrm{~A} 63 \mathrm{DP}$

$2.026 \mathrm{~A} 62$

$2.364 \mathrm{DP}$

3.609 A73 DP

$3.741 \mathrm{DP}$

12.500 A61 DP
$1.488 \mathrm{~W} 363$

2.011 A68 DP

2.024 A69 DP

2.051 W1.039-1.289 R61

DPoli N/B

2.365 A64 DP

3.607 DP

12.461 A66 DP

$1 \mathrm{~s} / \mathrm{n}$

Fábrica 1-b

$$
\begin{array}{r}
2.012 \text { W1.030 R91 DPoli } \\
\text { N/RO }
\end{array}
$$

12.422 DP
2.013 A60 DP

MAN 1920/37/19 DP

$2.015 \mathrm{~W} 1.266$ 
Fábrica 2

3.145 DP

Fábrica $1 \rightarrow 25$ (18 decoradas)

Total $=31(1.6 \%)$

Fábrica $1-b \rightarrow 5$ (5 decoradas)

Fábrica $2 \rightarrow 1$ (1 decorada)

\section{VASOS CUELLO ESTRECHO (8)}

Fábrica 1

$1.360 \mathrm{~W} 775$

2.000 W1.114-1.236 R23

DPoli N/B
1.516 W782

3.732 DP

$1.687 \mathrm{~W} 376$

$1 \mathrm{~s} / \mathrm{n}$

Fábrica Negra

$1.091 \mathrm{~W} 375$

Fábrica $1 \rightarrow 6$ (3 decorados)

Total $=7(0.4 \%)$

Fábrica Negra $\rightarrow 1$

\section{VASIJAS GLOBULARES (9)}

Fábrica 1

$1.089 \mathrm{~W} 282$

2.111 W1.168 R348 A322

1.625 W520

1.854

DPoli N/B

3.118 A54 DP

3.612 DP

12.483 A58

12.519 A 53 DP

$12.556 \mathrm{DP}$ 
Fábrica 2

$1.111 \mathrm{~W} 125 \mathrm{DE} *$

$1.179 \mathrm{~W} 131 \mathrm{DE}$

$1.318 \mathrm{~W} 211$

1.321 W205

1.340

$1.344 \mathrm{~W} 209$

$1.371 \mathrm{~W} 126$

$1.460 \mathrm{~W} 212$

$11.705 \mathrm{~W} 217$

$5 \mathrm{~s} / \mathrm{n}(4 \mathrm{DE})$
$1.148 \mathrm{DE} *$

1.231-1.234 DE

1.319 W207

1.338 W210

1.341

$1.357 \mathrm{~W} 106$

$1.374 \mathrm{~W} 557$ *

$11.702 \mathrm{~W} 215$

11.716 W204*
1.157-1.168 W230-223 DE

$1.316 \mathrm{~W} 213$

$1.320 \mathrm{~W} 203$

1.339 W216

1.342 W218

$1.370 \mathrm{~W} 127$

$1.423 \mathrm{~W} 109 \mathrm{DE}$

11.703 W214

11.722 W119

Fábrica Negra

$1.070 \mathrm{~W} 273$

$1.087 \mathrm{~W} 284$

1.093 W283

$1.100 \mathrm{~W} 280$

$1.172 \mathrm{DE}$

$1.282 \mathrm{~W} 241$ *

1.286 W281

1.289 W237

$1.444 \mathrm{~W} 267 \mathrm{DE}$

1.452 W254 DE

$1.681 \mathrm{~W} 333$

$11.659 \mathrm{~W} 288$

11.688 W269

1.076 W270

1.092 W104

1.082 W239

$1.096 \mathrm{~W} 328$

1.093

$1.101 \mathrm{~W} 244$ *

1.099 W287

$1.280 \mathrm{~W} 248$

1.103 W87

1.284 W 236

1.281 W289

$1.285 \mathrm{~W} 246$

$1.287 \mathrm{~W} 255$

1.288 W274

$1.387 *$

1.447 W235 DE

1.392 W79 DE

$1.453 \mathrm{~W} 507 \mathrm{DE}$

$1.448 \mathrm{~W} 252 \mathrm{DE}$

1.762 W278

$1.646 \mathrm{~W} 277$

$11.663 \mathrm{~W} 89$

$1.855 \mathrm{~W} 220$

11.674 W247

11.689 W330

$11.690 \mathrm{~W} 136$

11.698

11.707 W272

11.721 W279

$11.768 \mathrm{~W} 250$

11.888 W258

$13.089 \mathrm{DE}$

$13.805 \mathrm{~W} 179$ *

$6 \mathrm{~s} / \mathrm{n}(3 \mathrm{DE})$

MAN 24.792

MAN 24.809

MAN 1920/37/1

MAN 1920/37/2

MAN 1920/37/3

MAN 1920/37/4

MAN 1920/37/13 DE

Fábrica $1 \rightarrow 9$ (5 decoradas)

Total $=116(6.2 \%)$

Fábrica $2 \rightarrow 32$ (10 decoradas)

Fábrica Negra $\rightarrow 75$ (14 decoradas) 
EMBUDOS (10)

Fábrica 1

3.761 DP

3.764 A92 DP

3.767 DP

$3.768 \mathrm{DP}$

$3.769 \mathrm{DP}$

$3.770 \mathrm{DP}$

$3.771 \mathrm{DP}$

$2 \mathrm{~s} / \mathrm{n}$

Fábrica 1-b

1.524 W814

3.773 A91 DP

\section{Subtipo 10a}

Fábrica 1

$\begin{array}{lll}1.517 \mathrm{~W} 818 & 1.518 \mathrm{~W} 816 & 1.518 \mathrm{~W} 824 \\ 1.521 \mathrm{~W} 827 & 1.523 \mathrm{~W} 817 & 3.751 \mathrm{DP} \\ 3.752 \mathrm{DP} & 3.754 \mathrm{DP} & 3.755 \mathrm{DP} \\ 3.756 \mathrm{DP} & 3.757 \mathrm{~A} 89 \mathrm{DP} & 3.758 \mathrm{~A} 90 \mathrm{DP} \\ 3.772 & 3.774 \mathrm{~A} 88 \mathrm{DP} & 12.568 \mathrm{DP} \\ 12.569 \mathrm{DP} & 1 \mathrm{~s} / \mathrm{n} & \text { MAN } 1920 / 37 / 79\end{array}$

Fábrica Negra

11.717 W821

$1 \mathrm{~s} / \mathrm{n}$

\section{Subtipo 10b}

Fábrica 1

$1.519 \mathrm{~W} 820$
$3.750 \mathrm{DP}$
$3.763 \mathrm{DP}$
$12.750 \mathrm{DP}$

1.522 W 822

3.749 DP

3.753 A86 DP

3.760 A107 DP

$3.765 \mathrm{DP}$

11.735 W819

Fábrica 1-b

3.762 
Fábrica 2

1.348 W 815

Fábrica $1 \rightarrow 37$ (24 decorados)

Total $=43(2.3 \%)$

Fábrica 1-b $\rightarrow 3$ (1 decorado)

Fábrica $2 \rightarrow 1$

Fábrica Negra $\rightarrow 2$

\section{PLATOS (11)}

Fábrica 1

1.615 W494

2.705-2.706-2.707-2.708

DP

$13.796 \mathrm{~W} 1.269$
1.621 W507

2.799 A 103 DP

$1 \mathrm{~s} / \mathrm{n}$
$1.713 \mathrm{~W} 540$

$3.288 \mathrm{DP}$

Fábrica 1-b

1.620 W536

Fábrica 2
11.718W675*
$1 \mathrm{~s} / \mathrm{n}$

Fábrica Negra

$1.071 \mathrm{~W} 487$ *

1.313 W146

6.991

$1 \mathrm{~s} / \mathrm{n}$

\section{Subtipo 11a}

Fábrica 1

$12.498 \mathrm{DP}$ 
Apéndice I

Fábrica Negra

203 DP

$11.626 \mathrm{DE}$

\section{Subtipo 11b}

Fábrica 1

3.746 A94

\section{Subtipo 11c}

Fábrica 1

\begin{tabular}{lll}
$2.060 \mathrm{~A} 104 \mathrm{DP}$ & $2.797 \mathrm{~W} 941 \mathrm{DP}$ & $2.808 \mathrm{DP}$ \\
$3.170 \mathrm{~A} 97 \mathrm{DP}$ & $12.518 \mathrm{~A} 98 \mathrm{DP}$ & \\
\hline
\end{tabular}

Subtipo 11d

Fábrica 1
1.665 W935
3.171 DP
3.172 A95 DP
3.173 A99 DP
$3.187 \mathrm{DP}$
$12.521 \mathrm{~A} 100 \mathrm{DP}$

12.724 DP

Subtipo 11e

Fábrica 1

$3.196 \wedge 101 \mathrm{DP}$

\section{Subtipo 11f}

Fábrica 1

$2.546 \mathrm{DP}$ 
Fábrica $1 \rightarrow 26$ (19 decorados)

Total $=34(1.8 \%)$

Fábrica 1 -b $\rightarrow 1$

Fábrica $2 \rightarrow 1$

Fábrica Negra $\rightarrow 6$ ( 2 decorados)

\section{PIES CALADOS (12)}

Fábrica 1

$\begin{array}{lll}1.737 \text { W825* } & 1.738 & 1.739 \mathrm{~W} 829 \\ 1.740 & 1.741 \mathrm{~W} 828 & 3.035 \text { A85 DP } \\ 3.036 \text { R186 DPoli N/B } & 3.040 \text { A158 DP } & 3.046\end{array}$

$11.804 \mathrm{~W} 831$

Fábrica $1 \rightarrow 10$ (3 decorados)

Total $=10(0.5 \%)$

\section{COPAS DE PIE BAJO (13)}

Fábrica 1

2 DPoli N/B

11 DPoli N/B

16 DPoli N/B

42 DPoli N/B G

$1.173 \mathrm{~W} 920 \mathrm{DE}$

$1.639 \mathrm{~W} 899$

1.674 W693

$1.736 \mathrm{~W} 928$

2.259 A123 DP

2.842 R436 DPoli N/B

2.898 R438 DPoli N/B

2.929 R121 DPoli N/B

2.944 R432 DPoli N/B

3.001 R437 DPoli N/B

$3.086 \mathrm{DP}$

$3.194 \mathrm{DE}$

3.350 R203 DPoli N/B

$3.354 \mathrm{DP}$

3.394 A118 DP

3.403 R217 DPoli N/B

3.719 DPoli N/B

$12.558 \mathrm{DP}$

$12.630 \mathrm{DP}$

MAN 1920/37/20 DPoli N/B
3 DPoli N/B

12 DPoli N/B

18 DPoli N/B

49 DPoli N/B

1.384 W909

$1.641 \mathrm{~W} 900$

$1.676 \mathrm{~W} 737 \mathrm{G}$

$1.753 \mathrm{~W} 598$

$2.260 \mathrm{DP}$

2.896 R174 DPoli N/B

2.901 R175 DPoli N/B

2.930 R219 DPoli N/B

2.999 W1.313 R433 DPoli

$$
\mathrm{N} / \mathrm{RO}
$$

3.051 R178 DPoli N/B

$3.100 \mathrm{DP}$

3.346 R202 DPoli N/B

3.351 R273 DPoli N/B

$3.355 \mathrm{DP}$

3.399 A $116 \mathrm{DP}$

$3.495 \mathrm{DP}$

11.303

12.597 R85 DPoli N/B

$7 \mathrm{~s} / \mathrm{n}(4 \mathrm{DP})$

MAN 2 s/n DPoli N/B
9 DPoli N/B

14 DPoli N/B

39 DPoli N/B

1.172 W141 DE

$1.413 \mathrm{~W} 293$

1.655 W908

1.729

2.212

$2.263 \mathrm{DP}$

2.897 R439 DPoli N/B

2.903 R111 DPoli N/B

2.931 R274 DPoli N/B

3.000 R282 DPoli N/B

3.056 R216 DPoli N/B

$3.110 \mathrm{DP}$

3.348 A121 DP

3.353 R272 DPoli N/B

3.356 R201 DPoli N/B

$3.400 \mathrm{DP}$

3.644

12.531 A122 DP

12.617 DP

MAN 23.337BIS 
Fábrica 1-b

35 DPoli N/B

2.907 R184 DPoli N/B
1.684 W188

3.089 DPoli N/RO
1.699 W736

12.429 R440 DPoli N/RO

Fábrica 2

371

1.366

$1.461 \mathrm{~W} 918$ *

$1 \mathrm{~s} / \mathrm{n}$
1.323 W668

$1.366 \mathrm{~W} 971$

1.936

1.386 W903

3.375

Fábrica Negra

$11.708 \mathrm{~W} 667 *$

13.292

$13.299 *$

\section{Subtipo 13a}

Fábrica 1

$1.564 \mathrm{~W} 316$

1.593 W713

11.771 W752 DP *

Fábrica 2

$11.833 \mathrm{DE}$

Fábrica Negra

$1.322 \mathrm{~W} 317$ 


\section{Subtipo 13b}

Fábrica 1

20/76

1.327 W697

1.468 W846

1.528 W729

1.548 W723

1.556 W721 G

1.568 W703

1.588 W744

1.591 W748

$1.609 \mathrm{~W} 690$

1.627 W746

1.631 W733

1.654 W719

1.678 W887

1.690 W754

1.698 W751

1.723 W750

1.726 W740

1.731 W759

1.752

1.943

1.978

$3.643 \mathrm{DPG}$

3.651 A108 DP

$3.720 \mathrm{DP}$

3.725 A125 DP

11.774 W673

11.786 W728

11.852

$12.509 \mathrm{DP}$

12.549

MAN 23.336
$26 \mathrm{DP}$

1.328 W677

1.525 W705

1.545 W708

1.549 W698

1.566 W711

1.569 W764

1.589 W716

1.592 W680

1.610 W722

1.628 W846

$1.632 \mathrm{~W} 761 \mathrm{G}$

$1.673 \mathrm{G}$

1.688 W741

1.691 W765

1.700 W767

1.725 W725

1.729 W707

1.732 W717

1.909 W659

1.957

3.093 W994 R237 DPoli

$\mathrm{N} / \mathrm{B}$

3.645 W951

$3.661 \mathrm{DP}$

$3.722 \mathrm{DP}$

11.769 W682

11.780 W679

11.845

11.860

12.527 W952 DP

13.801

MAN $1 \mathrm{~s} / \mathrm{n}$
$1.302 \mathrm{~W} 676$

1.462 W739

1.527 W706

1.547 W727 *

1.550 W699

1.567 W700

$1.570 \mathrm{~W} 695$

$1.590 \mathrm{~W} 692$

1.592 W694

1.611 W691 G

1.629 W686

1.652 W687

$1.675 \mathrm{~W} 720 \mathrm{G}$

1.689 W743

1.692 W769

1.720 W853

1.726

1.730 W737

1.749

1.925

1.959

3.404 DP

3.648 DP

$3.717 \mathrm{DP}$

3.724 DP

11.770 W712

11.785 W763

11.850

11.887 W674

12.548

$3 \mathrm{~s} / \mathrm{n}$

Fábrica 1-b

$8 / 76$
1.630 W 684
1.928
11.842 W 662
1.529 W710

1.608 W689

1.672 W766

1.697 W696

1.960

MAN 1920/37/76 
Fábrica 2

1.324 W755

1.329 W678

$1.352 W 702$

$11.781 \mathrm{~W} 475$
1.325 W683

$1.350 \mathrm{~W} 726$

1.354 W898

11.828 W603
$1.326 \mathrm{~W} 758$ *

$1.351 \mathrm{~W} 762$

$1.650 \mathrm{~W} 749$

Fábrica Negra

$1.565 \mathrm{~W} 315 \mathrm{DE}$

\section{Subtipo 13c}

Fábrica 1

\begin{tabular}{|c|c|c|}
\hline $1.476 \mathrm{~W} 981 \mathrm{G}$ & 1.530 W979 & $1.651 \mathrm{~W} 732$ \\
\hline 1.696 W983 & $1.709 \mathrm{~W} 672$ & 2.270 W988 G \\
\hline $2.698 \mathrm{DP}$ & $\begin{array}{r}3.057 \text { W986 R232 DPoli } \\
\text { N/B }\end{array}$ & 3.080 R198 DPoli N/B \\
\hline $3.151 \mathrm{DP}$ & $3.352 \mathrm{~A} 119 \mathrm{DP}$ & 3.368 W987 A112 DP \\
\hline 3.369 & $3.373 \mathrm{DP}$ & 3.374 W985 DP \\
\hline $3.380 \mathrm{~A} 114 \mathrm{DP} \mathrm{G}$ & 3.398 A110 DP & 11.737 W685 \\
\hline 11.782 W718 & 11.812 W1.248 A321 & $12.474 \mathrm{~A} 113 \mathrm{DP}$ \\
\hline
\end{tabular}

Fábrica 1-b

1.734 W768

3.378 DP

Fábrica 2

1.363 W980

$11.750 \mathrm{~W} 976 \mathrm{DE}$

\section{Subtipo 13d}

Fábrica 1

1.708 W896

$1.761 \mathrm{~W} 930$

3.078 R130 DPoli N/B/RO

12.424 R234 DPoli N/B/RO

$3 \mathrm{~s} / \mathrm{n}$ (1 DP, 1 DPoli N/B) 
Fábrica 2

$\begin{array}{lll}1.355 \mathrm{~W} 906 & 1.364^{*} & 1.395 \mathrm{~W} 907 \mathrm{DE} \\ 1.451 \mathrm{~W} 118 & 11.748 \mathrm{~W} 922 & \text { MAN } 1976 / 55 / 6\end{array}$

\section{Subtipo 13e}

Fábrica 1

$1 \mathrm{~s} / \mathrm{n} \mathrm{DP}$

Fábrica 1-b

1.735 W 982

\section{Subtipo 13f}

\section{Fábrica 1}

$\begin{array}{lll}1.532 \mathrm{~W} 932 & 1.640 \mathrm{~W} 897 & 1.653 \mathrm{~W} 901 \\ 1.695 \mathrm{~W} 924 \mathrm{G}^{*} & 1.701 \mathrm{~W} 927 & 2.586 \mathrm{DP} \\ 3.395 \mathrm{R} 171 \mathrm{DP} \text { oli N/B } & 3.402 \mathrm{DP} & 11.738 \mathrm{~W} 923\end{array}$

11.784 W730 G

Fábrica 2

\begin{tabular}{lll}
$1.353 \mathrm{~W} 905 \mathrm{DE}$ & $1.361 \mathrm{~W} 911 \mathrm{G}$ & $1.381 \mathrm{~W} 904$ \\
$1.383 \mathrm{~W} 931$ & $1.385 \mathrm{~W} 912$ & \\
\hline
\end{tabular}

Fábrica $1 \rightarrow 220$ (98 decoradas) Total $=281(14.9 \%)$

Fábrica $1-\mathrm{b} \rightarrow 20$ (5 decoradas)

Fábrica $2 \rightarrow 35$ (4 decoradas)

Fábrica Negra $\rightarrow 6$ (1 decorada) 


\section{MORTEROS (14)}

Fábrica 1

$1.180 \mathrm{~W} 102$

1.345 W658

1.347 W661

$1.467 \mathrm{~W} 845$

1.750 W534

1.873 W625

1.874 W631

1.877 W637 G

1.875 W648

1.876 W620

1.881 W639

1.878 W657

1.879 W644

1.882 W653

1.885 W628

1.886 W624

1.887 W642

1.888 W646

1.889 W640

1.890 W647

1.892 W618

1.893 W646

1.894 W626

1.895 W636

1.896 W627

1.897 W638

1.899 W607

1.901 W649

1.904 W613

1.905 W621

1.910 W606

1.911 W643

1.912

$1.912 \mathrm{BIS}$

1.915

1.916

1.917

1.918

1.919

1.921

1.922

1.924

1.926

1.927

1.930

1.931

1.932

1.933

1.938

1.939

1.940

1.941

1.944

1.945

1.946

1.947

1.948

1.949

1.951

1.952

1.956

1.961

1.962

1.963

1.967

1.970

1.971

1.973

1.974

1.975

1.979

1.981

1.982

1.983

1.986

1.987

11.827 W665

11.829 W651

3.721 A126 DP

11.831 W635

11.832 W655

$11.830 \mathrm{~W} 663$

11.833 W641

11.835 W650

11.838 W609

11.841 W608

11.843 W660

11.839 W604

11.846

11.847 *

11.853

11.856

11.849

11.858

11.859

11.862

11.863

11.866

11.868

MAN 1920/37/85

MAN 1920/37/86

MAN 1920/37/87 
Fábrica 1-b

1.884 W6 630

1.902

1.907 W611

1.966

11.840 W659

11.855

Fábrica 2

1.334 W616

1.337 W612

1.923

1.977

11.837 W619
1.898

1.902 W623

1.914

1.969

11.851

$1 \mathrm{~s} / \mathrm{n}$
$1.900 \mathrm{~W} 622$

1.903 W652

1.950

1.976

11.854
1.335 W617

1.891 W629

1.936

1.980

11.865
1.336 W615

1.913

1.968

1.985

$1 \mathrm{~s} / \mathrm{n}$

Fábrica Negra

1.965

1.984

Fábrica $1 \rightarrow 110$ (1 decorado)

Total $=144(7.7 \%)$

Fábrica 1-b $\rightarrow 17$

Fábrica $2 \rightarrow 15$

Fábrica Negra $\rightarrow 2$ 
COPAS DE PIE ALTO (15)

Fábrica 1

\begin{tabular}{|c|c|c|}
\hline 30/76 DPoli N/B & $28 \mathrm{DPoli}$ N/B & 29 DPoli N/B \\
\hline 1.577 DPoli N/B & 1.619 W731 & 1.642 W992 \\
\hline 1.663 W917 & 1.821 & $1.883 \mathrm{~W} 664$ \\
\hline $2.028 \mathrm{~W} 858$ & 2.100 W844-1.282 DP & 2.140 W870-1.280 DP \\
\hline 2.109 & $2.261 \mathrm{DP}$ & $2.264 \mathrm{DP}$ \\
\hline $2.307 \mathrm{~A} 139 \mathrm{DP}$ & 2.313 & $2.314 \mathrm{DP}$ \\
\hline 2.316 W893-1.279 R82 & 2.338 A161 DP & 2.343 W890-1.273 R83 \\
\hline DPoli N/RO & & DPoli N/RO \\
\hline $2.345 \mathrm{~A} 147 \mathrm{DP}$ & $2.437 \mathrm{DP}$ & $2.447 \mathrm{DP}$ \\
\hline 2.895 DPoli N/B & $\begin{array}{r}2.899 \text { W876 R316 DPoli } \\
\text { N/B/RO }\end{array}$ & 2.900 R209 DPoli N/B \\
\hline 2.904 R275 DPoli N/B & 2.905 R317 DPoli N/B/RO & 3.047 W883 A159 DP \\
\hline $3.053 \mathrm{DP}$ & $3.098 \mathrm{DP}$ & 3.099 R281 DPoli N/B \\
\hline 3.103 R208 DPoli N/B & $3.286 \mathrm{DP}$ & $3.347 \mathrm{DP}$ \\
\hline 3.359 R278 DPoli N/RO & 3.365 R280 DPoli N/RO & 3.366 \\
\hline $3.370 \mathrm{DP}$ & $3.371 \mathrm{DP}$ & 3.373 DPoli N/B \\
\hline 3.381 & 3.386 W881 & $3.387 \mathrm{DP}$ \\
\hline 3.389 DPoli N/B & 3.401 & $3.405 \mathrm{DP} 3.406 \mathrm{~A} 154 \mathrm{DP}$ \\
\hline $3.407 \mathrm{DP}$ & 3.723 & $8.896 \mathrm{DP}$ \\
\hline 11.779 & 11.783 W993 & 12.423 \\
\hline 12.428 W875 A152 DP & $12.443 \mathrm{~W} 1.283 \mathrm{DP}$ & $12.452 \mathrm{DP}$ \\
\hline 12.453 A155 DP & $12.481 \mathrm{~A} 150 \mathrm{DP}$ & 12.523 \\
\hline $12.530 \mathrm{DP}$ & $12.629 \mathrm{DP}$ & $13.776 \mathrm{DP}$ \\
\hline
\end{tabular}

Fábrica 1-b

1.644 W864

3.095 R200 DPoli N/B

3.382 W843
2.359 A136 DP

3.097 R199 DPoli N/B

3.384
3.076 R132 DPoli N/RO

3.363

12.526 R270 DPoli N/B

Fábrica 2

1.362 W963

$1.618 \mathrm{~W} 880$

$11.741 \mathrm{~W} 835$

$1 \mathrm{~s} / \mathrm{n}$
1.441 W666 DE

3.364

$11.779 \mathrm{~W} 362$
$1.442 \mathrm{~W} 859$

$11.725 \mathrm{~W} 862 \mathrm{DE}$

12.504 A157 DP 
Apéndice I

Fábrica Negra

1.062 W854

$11.661 \mathrm{~W} 850$

Subtipo 15a

Fábrica 1

1.555 W865

1.571 W849

1.595 W 832

$8.894 \mathrm{DP}$

11.878 W848 A137 DP

12.449 R128 DPoli N/B

$12.462 \mathrm{DP}$

$1 \mathrm{~s} / \mathrm{n}$

\section{Subtipo 15b}

Fábrica 1

$\begin{array}{lll}1.552 \mathrm{~W} 886 & 1.574 \text { W840 } & 1.594 \mathrm{~W} 884 \\ 1.596 \mathrm{~W} 885 & 1.872 & 1.874 \\ 2.361 \mathrm{~W} 882 \mathrm{~A} 141 \mathrm{DP} & 2.583 \mathrm{~A} 133 \mathrm{DP} & 3.102 \mathrm{R} 284 \mathrm{DPoli} \mathrm{N} / \mathrm{B} \\ 3.193 \mathrm{~A} 109 \mathrm{DP} & 3.360 \mathrm{~A} 134 \mathrm{DP} & 3.388 \mathrm{DP} \\ 3.718 & 11.767 \mathrm{~W} 888 & 12.537 \mathrm{~W} 856 \mathrm{DP}\end{array}$

Fábrica Negra

$11.658 \mathrm{~W} 851$

\section{Subtipo 15c}

Fábrica 1

3.099 R281 DPoli N/B

MAN 1920/37/95 DPoli N/B

Fábrica 1-b

$3.362 \mathrm{DP}$

11.968 W894 R79 DPoli

12.451 W869-1.288 DP

$\mathrm{N} / \mathrm{RO}$

MAN 1920/37/100 DP

MAN 1920/37/101 


\section{Subtipo 15d}

Fábrica 1

5 DPoli N/B

3.077 DPoli N/B

3.392 A127 DP

Fábrica 1-b

3.050 R277 DPoli N/B

$8.903 \mathrm{~A} 132 \mathrm{DP} *$
1.533 W857

3.361 A138 DP

$12.559 \mathrm{DP}$

$3.075 \mathrm{DP}$

$3 \mathrm{~s} / \mathrm{n}$ (1 DP, 1 DPoli N/B)
1.554 W889

3.385 W891 DP *

$1 \mathrm{~s} / \mathrm{n} \mathrm{DP}$

\section{Subtipo $15 f$}

Fábrica 1

1.478 W863

$1.531 \mathrm{~W} 871$

1.535 W836

1.553 W866

1.572 W868

1.573 W838

1.575 W839

1.597 W834

2.101 W874-1.277 DP

2.315 W877-1.284 R81

$2.342 \mathrm{DP}$

2.344 A142 DP

DPoli N/B/RO

2.347 A143 DP

2.790 A145 DP

2.545 A144 DP

2.547 R276 DPoli N/B

3.094 W878 DPoli N/B

3.367

3.396 R173 DPoli N/B

12.450 A140 DP

12.463

$12.528 \mathrm{~W} 879$

$1 \mathrm{~s} / \mathrm{n}$ DPoli N/B

Fábrica 2

\section{Subtipo 15g}

Fábrica 1 
Subtipo $15 h$

Fábrica 1

$1 \mathrm{~s} / \mathrm{n}$

Fábrica $1 \rightarrow 133$ (87 decoradas)

Total $=170(9 \%)$

Fábrica 1-b $\rightarrow 21$ (16 decoradas)

Fábrica $2 \rightarrow 13$ (4 decoradas)

Fábrica Negra $\rightarrow 13$ (4 decoradas)

COPAS ACAMPANADAS (16)

Subtipo 16a

Fábrica 1

3.109 W1.045 R266 DPoli

3.191 W842 A162 DP

$\mathrm{N} / \mathrm{B}$

\section{Subtipo 16b}

Fábrica 1

Fábrica $1 \rightarrow 5$ (4 decoradas)

Total $=5(0.3 \%)$

JARRAS DE BOCA CIRCULAR (17)

Fábrica 1

$2.550 \mathrm{~A} 178 \mathrm{DP} \quad 2.778 \mathrm{~A} 183 \mathrm{DP}$

Fábrica 2 


\section{Subtipo 17a}

Fábrica 1

$1.346 \mathrm{~W} 925 \mathrm{DE}$

$2.303 \mathrm{~W} 1.160-1.219 \mathrm{R} 67$

DPoli N/B

$2.588 \mathrm{DP}$

2.783 A 189 DP

$3.085 \mathrm{DP}$

3.149 A192 DP

3.415 A175 DP

$9.025 \mathrm{DP}$

12.488BIS DP
1.496 W792 G

2.309 A199 DP

2.589 A117 DP

$2.805 \mathrm{~A} 206 \mathrm{DP} *$

3.128 A182 DP

$3.188 \mathrm{DP}$

$3.416 \mathrm{DP}$

11.873 W1.257 R65 DPoli

$\mathrm{N} / \mathrm{B}$

$3 \mathrm{~s} / \mathrm{n}$ DP
2.302 W1.13 R68 DPoli N/B 2.542 A181 DP

2.782 A196 DP

$2.806 \mathrm{DP}$

3.130 A210 DP

3.414 A194 DP

3.647 A176 DPoli N/R

12.448 A186 DP

Fábrica 1-b

3.153 A197 DP

12.477 R321 DPoli N/B

$1 \mathrm{~s} / \mathrm{n} \mathrm{DP}$

Fábrica 2

\section{Subtipo 17b}

Fábrica 1

\begin{tabular}{lll}
$1.493 \mathrm{~W} 787$ & $2.766 \mathrm{~A} 205 \mathrm{DP}$ & 2.816 A188 DP \\
$3.150 \mathrm{~A} 209 \mathrm{DP}$ & $3.417 \mathrm{DP}$ & $8.987-8.988-8.989 \mathrm{DP}$ \\
$11.792 \mathrm{~W} 1.004$ & $12.442 \mathrm{~A} 211 \mathrm{DP}$ & $12.482 \mathrm{~A} 204 \mathrm{DP}$ \\
$12.510 \mathrm{~A} 212 \mathrm{DP}$ & $1 \mathrm{~s} / \mathrm{n} \mathrm{DP}$ & \\
\hline
\end{tabular}

Fábrica 1-b

12.402 W1.041-1.290 R56 DPoli N/R 
Fábrica 2

$3.184 \mathrm{DP}$

Subtipo 17c

Fábrica 1-b

3.121 A180 DP

Subtipo 17d

Fábrica 1

2.582 W1.008 A173 DP

3.011 R320 DPoli

$\mathrm{N} / \mathrm{B} / \mathrm{RO}$

Fábrica $1 \rightarrow 43$ (36 deocradas)

Total $=52(2.8 \%)$

Fábrica 1-b $\rightarrow 5$ (5 decoradas)

Fábrica $2 \rightarrow 4$ (4 decoradas)

VASIJAS DE PERFIL EN S (18)

Fábrica 1

$232 \mathrm{~W} 116$

1.485 W770

1.494 W780

1.612 W724 DP

2.813 W1.162 A174 DP

3.183 W779 A334 DP

$3.726 \mathrm{DP}$

$3.727 \mathrm{DP}$

$3.728 \mathrm{DP}$

$3.730 \mathrm{DP}$

$3.733 \mathrm{DP}$

$11.790 \mathrm{~W} 772$

11.791 W776

11.793 W774

12.458 A46 DP

12.550 W777 DP

$12.560 \mathrm{~A} 171$

12.563 A $170 \mathrm{DP}$

13.799 W773

Fab 1-b

3.073 W781 R92 DPoli N/R 
Fábrica Negra

$1 \mathrm{~s} / \mathrm{n} \mathrm{DE}$

Fábrica $1 \rightarrow 19$ (11 decorados)

Total $=21(1.1 \%)$

Fábrica 1-b $\rightarrow 1$ (1 decorado)

Fábrica Negra $\rightarrow 1$ (1 decorado)

\section{JARRAS DE BOCA TRILOBULADA (19)}

Fábrica 1

$1.585 \mathrm{~W} 1.146$

$2.262 \mathrm{~W} 1.148 \mathrm{DP}$

$2.337 \mathrm{DP}$

$3.199 \mathrm{DP}$

$3.219 \mathrm{DP}$

$3.244 \mathrm{DP}$

12.489 DPoli N/B
2.099 W1.108-1.287 A223

$2.273 \mathrm{DP}$

$2.598 \mathrm{DP}$

3.217 DP

$3.224 \mathrm{DP} *$

$11.807 \mathrm{~W} 1.143$

$7 \mathrm{~s} / \mathrm{n}(3 \mathrm{DP}, 1 \mathrm{DPoli}$ N/B)
2.242 DP

$2.337 \mathrm{DP}$

$3.126 \mathrm{DP} *$

$3.218 \mathrm{DP}$

$3.225 \mathrm{DP}$

12.464 A234 DP

Fábrica 1-b

$3.226 \mathrm{DP} *$

Fábrica 2

$1.409 \mathrm{~W} 1.140$

$2.432 \mathrm{DP}$

3.255 DP

13.803

Fábrica Negra 


\section{Subtipo 19a}

Fábrica 1

1.474 W1.061

$1.538 \mathrm{~W} 1.091 *$

$1.541 \mathrm{~W} 1.058$

$1.600 \mathrm{~W} 1.078$

$1.603 \mathrm{~W} 1.079$

2.108 A221 DP

2.319 A222 DP

$2.341 \mathrm{DP}$

$2.571 \mathrm{DP}$

2.789 W 1.088 A224 DP

$2.804 \mathrm{DP}$

$3.167 \mathrm{DP}$

$3.180 \mathrm{DP}$

3.608 DP

$11.615 \mathrm{DP}$

$11.773 \mathrm{~W} 1.093$

12.467 W1.099 A232 DP

$12.485 \mathrm{DP}$

12.508 A227 DP
$1.536 \mathrm{~W} 1.085$ *

$1.539 \mathrm{~W} 1.057$

1.583

$1.601 \mathrm{~W} 1.086$

$1.604 \mathrm{~W} 1.087$

2.113 W1.102 DP

$2.320 \mathrm{DP}$

$2.565 \mathrm{DP}$

$2.590 \mathrm{DP}$

$2.801 \mathrm{DP}$

3.162 A231 DP

$3.168 \mathrm{DP}$

$3.411 \mathrm{DP}$

$3.646 \mathrm{DP}$

$11.740 \mathrm{~W} 1.080 \mathrm{DP}$

11.874 W1.100 DP GP

$12.469 \mathrm{DP}$

$12.495 \mathrm{DP}$

$3 \mathrm{~s} / \mathrm{n}$ DP

2.018 W1.112-1.323 R2

DPoli N/RO

\author{
12.493 A230 DP
}

$1.537 \mathrm{~W} 1.081$

$1.540 \mathrm{~W} 1.060$

$1.599 \mathrm{~W} 1.090$

$1.602 \mathrm{~W} 1.094$

2.107 W1.092 A220 DP

$2.304 \mathrm{DP}$

$2.339 \mathrm{DP}$

$2.567 \mathrm{DP}$

$2.591 \mathrm{DP} G$

2.802

3.165 W1.084 A228 DP

$3.169 \mathrm{DP}$

$3.413 \mathrm{DP}$

8.982 A235 DP

11.772 W1.059

$12.447 \mathrm{DP}$

$12.480 \mathrm{DP}$

12.496 W1.082 A225 DP

Fábrica 1-b

2.003 W1.111-1.322 R1

DPoli N/RO

12.491 DP
12.394 W1.109 R25 DPoli

$\mathrm{N} / \mathrm{RO}$

Fábrica 2 


\section{Subtipo 19b}

Fábrica 1

1.475 W 1.074

$1.560 \mathrm{~W} 1.069$

$1.563 \mathrm{~W} 1.067$

$1.579 \mathrm{~W} 1.068$

$1.770 \mathrm{DP}$

2.305 A244 DP

$2.562 \mathrm{DP}$

$2.786 \mathrm{DP}$

$2.791 \mathrm{DP}$

2.809 A239 DP

3.088 W1.098 R148 DPoli

$\mathrm{N} / \mathrm{B}$

3.157 A229 DP

$12.476 \mathrm{DP}$

12.497 DP
$1.557 \mathrm{~W} 1.064$

$1.561 \mathrm{~W} 1.065$

$1.576 \mathrm{~W} 1.075$

$1.580 \mathrm{~W} 1.072$

2.053 W1.097 R71 DPoli

$\mathrm{N} / \mathrm{B}$

$2.543 \mathrm{DP}$

2.566 W1.018 DP

$2.787 \mathrm{DP}$

2.803 A240 DP

3.070 W1.105 A291 DP

3.105 DPoli N/B

$11.969 \mathrm{~W} 1.101 \mathrm{R} 319$

DPoli N/B/RO

$12.486 \mathrm{DP}$

$12.553 \mathrm{DP}$

2.052 R324 DPoli N/R

MAN 1920/37/21 DPoli

$\mathrm{N} / \mathrm{RO}$
1.559 W1.063

$1.562 \mathrm{~W} 1.066$

$1.578 \mathrm{~W} 1.077$

$1.582 \mathrm{~W} 1.076$

$2.065 \mathrm{DP}$

2.544 DP

$2.773 \mathrm{DP}$

2.788 DP

2.807 A242 DP

$3.087 \mathrm{DP}$

$3.136 \mathrm{DP}$

12.473 DP

12.495 DP

$2 \mathrm{~s} / \mathrm{n}(1 \mathrm{DP})$

2.073 W1.259 R66 DPoli

$\mathrm{N} / \mathrm{RO}$

$3.090 \mathrm{DP}$

Fábrica 2

2.075 W1.207 DP

Subtipo 19c

Fábrica 1

2.340 W1.096-1.199 A238 DP 


\section{Subtipo 19d}

Fábrica 1

Fábrica $1 \rightarrow 130$ (94 decoradas)

Total $=151(8 \%)$

Fábrica 1-b $\rightarrow 11$ (10 decoradas)

Fábrica $2 \rightarrow 8$ ( 4 decoradas)

Fábrica Negra $\rightarrow 2$

JARRAS TRONCOCÓNICAS (20)

Fábrica 1

\begin{tabular}{|c|c|c|}
\hline $1.499 \mathrm{~W} 1.011$ & $1.680 \mathrm{~W} 1.019$ & $\begin{array}{r}2.031 \text { W1.014-1.254 R78 } \\
\text { DPoli N/B }\end{array}$ \\
\hline $2.032 \mathrm{DP}$ & $2.060 \mathrm{DP}$ & 2.069 W1.119-1.196 DP \\
\hline $2.070 \mathrm{~W} 1.202 \mathrm{DP}$ & $2.074 \mathrm{DP}$ & $2.087 \mathrm{DP}$ \\
\hline $2.103 \mathrm{DP}$ & $2.110 \mathrm{DP}$ & $2.112 \mathrm{DP}$ \\
\hline 2.327 A256 DP & $2.329 \mathrm{~W} 1.267 \mathrm{~A} 251 \mathrm{DP}$ & $2.353 \mathrm{DP}$ \\
\hline \multirow{3}{*}{$\begin{array}{l}2.357 \text { W1.022 R327 DPoli } \\
\text { N/B } \\
2.377 \mathrm{DP}\end{array}$} & $2.356 \mathrm{DP}$ & $2.373 \mathrm{DP}$ \\
\hline & & \\
\hline & $2.540 \mathrm{DP}$ & $2.551 \mathrm{DP}$ \\
\hline $2.559 \mathrm{DP}$ & 2.560 A $300 \mathrm{DP}$ & $2.568 \mathrm{DP}$ \\
\hline $2.572 \mathrm{DP}$ & $2.580 \mathrm{~W} 1.021 \mathrm{DP}$ & $2.581 \mathrm{DP}$ \\
\hline \multirow[t]{2}{*}{$2.785 \mathrm{DP}$} & $3.066 \mathrm{~W} 1.006 \mathrm{R} 224$ & 3.067 R325 DPoli N/B \\
\hline & DPoli N/B & \\
\hline $3.111 \mathrm{DP}$ & $3.112 \mathrm{DP}$ & 3.117 A304 DP \\
\hline $3.124 \mathrm{DP}$ & $3.127 \mathrm{DP}$ & $3.143 \mathrm{DP}$ \\
\hline $3.144 \mathrm{DP}$ & $3.146 \mathrm{DP}$ & $3.147 \mathrm{DP}$ \\
\hline $3.156 \mathrm{DP}$ & 3.194 & 3.408 A257 DP \\
\hline $3.409 \mathrm{DP}$ & $3.625 \mathrm{DP}$ & $3.626 \mathrm{DP}$ \\
\hline $3.629 \mathrm{DP}$ & $3.630 \mathrm{DP}$ & 12.456 A29 DP \\
\hline $12.470 \mathrm{DP}$ & $12.471 \mathrm{DP}$ & $12.478 \mathrm{DP}$ \\
\hline \multirow{2}{*}{$\begin{array}{l}12.494 \mathrm{DP} \\
\mathrm{MAN} 23331 \mathrm{DP}\end{array}$} & $12.506 \mathrm{DP}$ & $1 \mathrm{~s} / \mathrm{n}$ \\
\hline & MAN 23.334 DP & \\
\hline
\end{tabular}

Fábrica 1-b

$3.039 \mathrm{DP}$ 
Fábrica 2

$1.732 \mathrm{DP}$

$2.064 \mathrm{DP}$

2.093 A302 DP

$2.570 \mathrm{DP}$

Subtipo 20a

Fábrica 1

3.069 W1.015 R326 DPoli N/B

Fábrica 2

3.034

\section{Subtipo 20b}

Fábrica 1

2.029 W1.203 DP

2.076 W1.201 R329 DPoli

$\mathrm{N} / \mathrm{B}$

2.354 DP

$2.541 \mathrm{DP}$

$2.577 \mathrm{DP}$

2.768 A255

$3.067 \mathrm{DP}$

$3.176 \mathrm{DP}$

11.967 W1.216 DP

$12.490 \mathrm{DP}$

$12.586 \mathrm{DP}$
2.055 DP

$2.330 \mathrm{DP}$

$2.356 \mathrm{DP}$

$2.554 \mathrm{DP}$

$2.578 \mathrm{DP}$

$2.769 \mathrm{DP}$

$3.113 \mathrm{DP}$

$3.535 \mathrm{DP}$

$12.457 \mathrm{DP}$

12.507 A254 DP

$4 \mathrm{~s} / \mathrm{n}$ DP
2.068 W1.120-1.195 DP

$2.331 \mathrm{DP}$

$2.539 \mathrm{DP}$

2.558 A252 DP

$2.579 \mathrm{DP}$

2.774 DP

3.125 A248 DP

$3.628 \mathrm{DP}$

$12.484 \mathrm{DP}$

12.513-12.515 DP

Subtipo 20c

Fábrica 1

MAN $1 \mathrm{~s} / \mathrm{n}$ 


\section{Subtipo 20d}

Fábrica 1

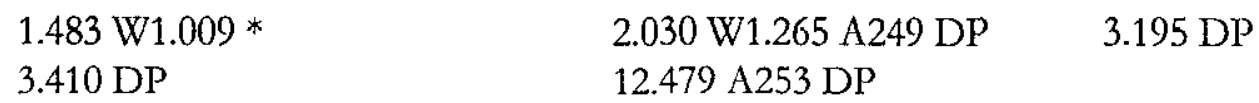

\section{Subtipo 20e}

Fábrica 1

$2.066 \mathrm{DP}$

$2.575 \mathrm{DP}$

2.067 W1.197 DP

2.538 A203 DP

12.475 DP 12.544

2.765 W1.020 DP

$3.142 \mathrm{DP}$

MAN 1920/37/93 DP

Fábrica 1-b

$2.356 \mathrm{DP}$

MAN 1920/37/99 DP

Fábrica 2

$1.469 \mathrm{~W} 1.016$

$2.350 \mathrm{DP}$

Subtipo $20 \mathrm{f}$

Fábrica 1

3.177 A295 DP

3.179 W1.013 A297 DP

Subtipo $20 \mathrm{~g}$

Fábrica 1

1.497 W1.010

2.306 W1.012-1.293 R331

2.355 R328 DPoli N/B

DPoli N/B

$3.133 \mathrm{DP}$ 
Fábrica $1 \rightarrow 113$ (106 decoradas)

Fábrica 1-b $\rightarrow 3$ (3 decoradas)

Fábrica $2 \rightarrow 7$ ( 5 decoradas)

\section{VASIJAS TRONCOCÓNICAS CON 2 ASAS (21)}

Fábrica 1

\section{VASIJAS CON ASA DE CESTA (22)}

Fábrica 1

2.308 W999-1.297 R22

12.466 W998 A303 DP $\quad 1 \mathrm{~s} / \mathrm{n} \mathrm{DP}$

DPoli N/RO

Fábrica 1-b

Subtipo 22a

Fábrica 1

$1.482 \mathrm{~W} 1.000$

$1 \mathrm{~s} / \mathrm{n}$

Fábrica 1-b

3.115 DP 
Subtipo 22b

Fábrica 1

3.161 A305

Subtipo 22c

Fábrica 1

$1.501 \mathrm{~W} 1.002$

Subtipo 22e

Fábrica 1

$3.120 \mathrm{DP}$

$2 \mathrm{~s} / \mathrm{n}$

Subtipo 22f

Fábrica 1

2.363 W1.038-1.194 A301 DP

Fábrica $1 \rightarrow 11$ (5 decoradas)

Total $=12(0.6 \%)$

Fábrica 1-b $\rightarrow 1$ (1 decorada)

CRATERAS (23)

Fábrica 1

3.190

$3.642 \mathrm{DP}$

9.815

Fábrica Negra

13.297 * 


\section{Subtipo 23a}

Fábrica 1

$2.814 \mathrm{DP}$

DPoli N/B

$12.468 \mathrm{~W} 1.036 \mathrm{~A} 80 \mathrm{DP}$

Fábrica 1-b

3.104 R244 DPoli N/B

\section{Subtipo 23b}

Fábrica 1

$1.602 \mathrm{DP}$

2.352 DP

2.572 DP

$2.594 \mathrm{DP}$

$3.061 \mathrm{~W} 1.037$ A81 DP

$3.174 \mathrm{DP}$

12.492 DP

MAN 1920/37/97 DP

Fábrica 1-b

3.641 W1.035 DP

Fábrica Negra

$11.728 \mathrm{~W} 100 \mathrm{DE}$

Fábrica $1 \rightarrow 15$ (13 decoradas)

Total $=19(1 \%)$

Fábrica 1-b $\rightarrow 2$ (2 decoradas)

Fábrica Negra $\rightarrow 2$ (1 decorada) 
GRANDES VASIJAS (24)

Fábrica 1

$1.763 \mathrm{~W} 259$

2.020-2.021 W1.150-1.294

R21 DPoli N/B/RO

$2.301 \mathrm{~W} 806 \mathrm{DP}$

$2.427 \mathrm{DP}$

2.596-2.597 DP

$3.081 \mathrm{DP}$

$3.203 \mathrm{DP}$

$3.277 \mathrm{DP}$

$3.776 \mathrm{DP}$

3.782 A169 DP

$11.809 \mathrm{DP}$ G

$2.005 \mathrm{DP}$

2.019 DP

$2.062 \mathrm{DP}$

$2.236 \mathrm{DP}$

2.321 DP

2.348 A216 DP

$2.428 \mathrm{DP}$

$2.485 \mathrm{DP}$

$2.762 \mathrm{DP}$

$3.033 \mathrm{DP}$

$3.158 \mathrm{DP}$

3.201 DP

3.204 A328 DP

3.207 W804 DP

$3.624 \mathrm{DP}$

$3.747 \mathrm{DP}$

$3.776 \mathrm{DP}$

3.780 W808 DP

3.783

9.817

$11.810 \mathrm{DPG}$

12.454 DP

12.989 W800 A310 DP

12.455 DP

$12.993 \mathrm{DP}$

12.420 W1.044 R54

DPoli N/B

$12.986 \mathrm{DP}$

12.996

$12.999 \mathrm{DP}$

$12.994 \mathrm{DP}$

$13.000 \mathrm{DP}$

$13.003 \mathrm{DP}$

$13.004 \mathrm{DP}$

$13.006 \mathrm{DP}$

$13.008 \mathrm{DP}$

$13.011 \mathrm{DP}$

$13.009 \mathrm{DP}$

$13.010 \mathrm{DP}$

$26 \mathrm{~s} / \mathrm{n}(23 \mathrm{DP})$

13.014 W810 A318 DP

MAN 24.651 DP

MAN 24.652 DP

MAN 24.654 DP

MAN 24.655 DP

MAN 24.658 DP

MAN 24.660 DP

MAN 24.663 DP

MAN 24.659 DP

MAN 24.661 DP

MAN 24.664 DP

MAN 24.668 DP

MAN 24.669 DP

MAN 24.671 DP

MAN 24.672 DP

MAN 24.674 DP

MAN 24.677 DP

MAN 24.675 DP

MAN 24.678 DP

MAN 24.680 DP

MAN 24.681 DP

MAN 24.684 DP

MAN 24.685 DP

MAN 24.688 DP

MAN 24.694 DP

MAN 24.690 DP

MAN 24.695 DP

MAN 24.699 DP

MAN 24.700 DP

MAN 24.743

MAN 24.744

MAN 24.747

MAN 24.748

MAN 24.751

MAN 24.752

MAN 24.763

MAN 24.757

MAN 24.767

$10 \mathrm{~s} / \mathrm{n}(9 \mathrm{DP})$ 
Fábrica 1-b

9.811

9.831

$3 \mathrm{~s} / \mathrm{n} \mathrm{DP}$

Fábrica 2

$3.775 \mathrm{DP}$

$1 \mathrm{~s} / \mathrm{n} \mathrm{DP}$

MAN $2 \mathrm{~s} / \mathrm{n}$

Fábrica Negra

$1.077 \mathrm{~W} 243$

1.295-1.296 W268

$1.405 \mathrm{~W} 98 \mathrm{DE}$

$1.605 \mathrm{~W} 263$

1.694 W519

11.697

$4 \mathrm{~s} / \mathrm{n}$

MAN 24.758

\section{Subtipo 24a}

Fábrica 1

2.569 DP

2.593 A331 DP

3.138 W1.043 DP

3.206 A335 DP

Fábrica 2

11.694 W352

\section{Subtipo 24b}

Fábrica 1

1.512 W786
2.083 DP
2.552 W1.051 A326 DP
2.800 A208
3.658
$1 \mathrm{~s} / \mathrm{n}$ DPoli N/B

$2.057 \mathrm{DP}$

$2.080 \mathrm{DP}$

$2.325 \mathrm{DP}$

2.549 DP

2.553 A177 DP

2.777 A327 DP *

3.114 A179 DP

3.198 DP

$12.440 \mathrm{DP}$

12.446 A333

MAN 1920/37/94 DP 


\section{Subtipo 24c}

Fábrica 1

$2.088 \mathrm{DP}$
$2.324 \mathrm{DP}$
2.573 A298 DP
$3.154 \mathrm{DP}$
$3.748 \mathrm{DP}$

$12.503 \mathrm{DP}$

$12.567 \mathrm{DP}$

$13.012 \mathrm{DP}$
$2.091 \mathrm{~A} 323 \mathrm{DP}$

$2.326 \mathrm{DP}$

$2.704 \mathrm{DP}$

$3.276 \mathrm{DP}$

11.970 W1.164 R24 DPoli N/B

$12.522 \mathrm{DP}$

12.988 W805 DP

$2 \mathrm{~s} / \mathrm{n}$ DP
2.323 DP

2.369 A $324 \mathrm{DP}$

$3.032 \mathrm{~W} 1.163 \mathrm{DP}$

3.345 W809 A313 DP

11.975 W1.324 A139 DP

12.566 DP

$12.995 \mathrm{DP}$

Fábrica 1-b

3.123

\section{Subtipo 24d}

Fábrica 1

9.761

$2.609 \mathrm{DP}$

2.953 W802 DP

Fábrica Negra

$1.456 \mathrm{~W} 113 \mathrm{DE} *$

\section{Subtipo $24 \mathrm{e}$}

Fábrica 1

\begin{tabular}{lll}
$2.610 \mathrm{DP}$ & $2.763 \mathrm{~W} 799 \mathrm{~A} 311 \mathrm{DP}$ & $3.781 \mathrm{DP}$ \\
$12.987 \mathrm{DP}$ & $12.990 \mathrm{DP}^{*}$ & $12.997 \mathrm{DP}$ \\
$12.993 \mathrm{DP}$ & $19.991 \mathrm{DP}$ & $19.992 \mathrm{DP}$ \\
$1 \mathrm{~s} / \mathrm{n} \mathrm{DP}$ & & \\
\hline
\end{tabular}


Subtipo $24 \mathrm{f}$

Fábrica 1

$1 \mathrm{~s} / \mathrm{n}$

Subtipo $24 g$

Fábrica 1

$\begin{array}{lll}2.869 \mathrm{~W} 1.049 \mathrm{~A} 316 \mathrm{DP} & 3.184 \mathrm{DP} & 3.205 \mathrm{DP}\end{array}$

$1 \mathrm{~s} / \mathrm{n}$ DPoli N/B

Fábrica Negra

$1.446 \mathrm{~W} 132 \mathrm{DE}$

\section{Subtipo $24 h$}

Fábrica 1-b

$11.886 \mathrm{~W} 261$ *

Fábrica $1 \rightarrow 208$ (179 decoradas)

Total $=233(12.4 \%)$

Fábrica 1-b $\rightarrow 7$ (3 decoradas)

Fábrica $2 \rightarrow 5$ (2 decoradas)

Fábrica Negra $\rightarrow 13$ (3 decoradas)

\section{GRANDES TINAJAS}

Fábrica 1

9.823

12.998 W934 A93
9.824-9.825-9.826

13.007 DP
11.759

$8 \mathrm{~s} / \mathrm{n}(5 \mathrm{DP})$ 
Fábrica 1-b

9.812

9.819

9.821

$2 \mathrm{~s} / \mathrm{n}$

Fábrica Negra

9.813-9.814*

Fábrica $1 \rightarrow 17$ (6 decoradas)

Total $=23(1.2 \%)$

Fábrica 1-b $\rightarrow 5$

Fábrica Negra $\rightarrow 1$

\section{CANTIMPLORAS}

Fábrica 1

$\begin{array}{lll}1.365 \mathrm{~W} 396 & 1.668 \mathrm{~W} 378 & 1.704 \mathrm{~W} 384 \\ 2.798 \mathrm{DP} & 3.141 \mathrm{DP} & 11.788 \mathrm{~W} 390 \\ 11.796 \mathrm{~W} 395 & 11.876 \mathrm{~W} 385 \mathrm{DP} & 12.441 \mathrm{~W} 1.157 \mathrm{R} 332 \\ & & \text { DPoli N/B } \\ 3 \mathrm{~s} / \mathrm{n} \mathrm{DP} & \text { MAN } 1920 / 37 / 91 \mathrm{DP} & \end{array}$

Fábrica 1-b

$1 \mathrm{~s} / \mathrm{n} \mathrm{DP}$

Fábrica Negra

$1 \mathrm{~s} / \mathrm{n} \mathrm{DE}$

Fábrica $1 \rightarrow 13$ (8 decoradas)

Total $=15(0.8 \%)$

Fábrica 1-b $\rightarrow 1$ (1 decorada)

Fábrica Negra $\rightarrow 1$ (1 decorada) 


\section{TAPADERAS}

Fábrica 1

$\begin{array}{lll}1.622 \mathrm{~W} 189 & 1.748 \mathrm{~W} 172 & 1.751 \mathrm{~W} 177 \\ 1.754 \mathrm{~W} 173 & 3.044 & 11.760 \\ 11.762 & 12.762 & \end{array}$

Fábrica 1-b

$1.745 \mathrm{~W} 176$

1.755 W178

11.802 W192

11.805 W174

$1 \mathrm{~s} / \mathrm{n}$

Fábrica Negra

1.437 W194

1.662 W914

11.693 W915

$3 \mathrm{~s} / \mathrm{n}$

Fábrica $1 \rightarrow 8$

Total $=19(1 \%)$

Fábrica $1-b \rightarrow 5$

Fábrica Negra $\rightarrow 6$

\section{TROMPAS}

Fábrica 1

$\begin{array}{lll}8.222 \mathrm{~W} 417 * & 8.224 \mathrm{~W} 412 \mathrm{DP} & 8.225 \mathrm{~W} 429-1.190 \mathrm{DP} \\ 8.227 \mathrm{~W} 416 & 8.229 \mathrm{~W} 415 \mathrm{DP} & 8.230 \mathrm{~W} 387 \\ 8.231 \mathrm{~W} 428 & 8.233 \mathrm{~W} 388 & 8.234 \mathrm{~W} 414 \\ 8.235 \mathrm{~W} 401-1.191 \mathrm{DP} & 8.242 \mathrm{~W} 419 & 8.243 \mathrm{~W} 402 \\ 8.245 \mathrm{~W} 446 & 8.246 \mathrm{~W} 440 & 8.247 \mathrm{~W} 409 \mathrm{DP} \\ 8.248 \mathrm{~W} 447 & 8.250 \mathrm{~W} 410 \mathrm{DP} & 8.251 \mathrm{~W} 405 \\ 8.252 \mathrm{~W} 418 & 8.253 \mathrm{~W} 426 & 8.254 \mathrm{~W} 432 \\ 8.255 \mathrm{~W} 431 & 8.257 \mathrm{~W} 422 & 8.260 \mathrm{~W} 424 \\ 11.904 \mathrm{~W} 389 & 11.905 \mathrm{~W} 398 & 16 \mathrm{~s} / \mathrm{n}(3 \mathrm{DP}) \\ \text { MAN } 1920 / 37 / 80 & \text { MAN } 1920 / 37 / 81 & \text { MAN } 1920 / 37 / 82 \mathrm{DP}\end{array}$


Fábrica 1-b

8.244 W436

$8.256 \mathrm{~W} 406$

12.687 DP

Fábrica 2

8.228 W448 DP

$8.239 \mathrm{~W} 404 \mathrm{DE}$

11.899 W393

Fábrica Negra

11.897 W394

Fábrica $1 \rightarrow 45$ (11 decoradas)

$8.229 \mathrm{~W} 411$

$8.240 \mathrm{~W} 434$

$11.901 \mathrm{~W} 400$
8.238 W441 DE

$11.880 \mathrm{~W} 392$

$2 \mathrm{~s} / \mathrm{n}$

Fábrica 1-b $\rightarrow 3$ (1 decorada)

Total $=61(3.2 \%)$

Fábrica $2 \rightarrow 10$ (4 decoradas)

Fábrica Negra $\rightarrow 3$

\section{BIBERONES}

Fábrica 1

$3.041 \mathrm{~W} 169$

3.092 R231 DPoli N/B

13.791 DE

Fábrica 1-b

11.713 W167

Fábrica Negra

$243 \mathrm{~W} 44 \mathrm{DE}$

Fábrica $1 \rightarrow 3$ (3 decorados)

Total $=5(0.3 \%)$

Fábrica $1-b \rightarrow 1$

Fábrica Negra $\rightarrow 1$ (1 decorado) 


\section{OTRAS}

Fábrica 1

$1.484 \mathrm{~W} 486$

3.048 W1.149 DP

$13.800 \mathrm{~W} 163$

Fábrica 1-b

3.052 R125 DPoli N/RO

6.107

Fábrica 2

$1.291 \mathrm{~W} 342$

1.457 W199 DE

$1.472 \mathrm{~W} 345$
$1.542 \mathrm{~W} 22$

3.064 R257 DPoli N/B

$1 \mathrm{~s} / \mathrm{n}$
2.067

$3.616 \mathrm{~A} 218 \mathrm{DP} *$

Fábrica Negra

$250 \mathrm{~W} 180$

$1.450 \mathrm{~W} 292 \mathrm{DE}$

Fábrica $1 \rightarrow 8$ ( 3 decoradas)

Total $=15(0.8 \%)$

Fábrica 1-b $\rightarrow 2$ (1 decorada)

Fábrica $2 \rightarrow 3$ (1 decorada)

Fábrica Negra $\rightarrow 2$ (1 decorada)

\section{PORCENTAJES TO'TALES}

Fábrica $1 \rightarrow 1.401(74.6 \%)$

Total $=1.879$

Fábrica $1-b \rightarrow 145(7.7 \%)$

733 restaurados (39\%)

Fábrica $2 \rightarrow 187(9.9 \%)$

Fábrica Negra $\rightarrow 146(7.7 \%)$ 


\section{FRAGMENTOS}

\section{Fábrica 1}

$7.526(79 \%)$.

4.354 decorados (4.009 DP, 323 DPoli, $22 \mathrm{DE}$ ).

$45 \mathrm{G}$.

1.393 con $\mathrm{n} 1$ de inventario.

Fábrica 1-b

$900(9.4 \%)$.

579 decorados (436 DP, 143 DPoli).

232 con $n 1$ de inventario.

Fábrica 2

$599(6.3 \%)$.

233 decorados (222 DP, 11 DPoli).

$7 \mathrm{G}$.

118 con $n 1$ de inventario.

Fábrica Negra

$504(5.3 \%)$

175 decorados DE.

188 con $\mathrm{n} 1$ de inventario.

Total $=9.529$

1.931 con $\mathrm{n} 1$ de inventario.

380 restaurados $(4 \%)$. 
FABRICA 1

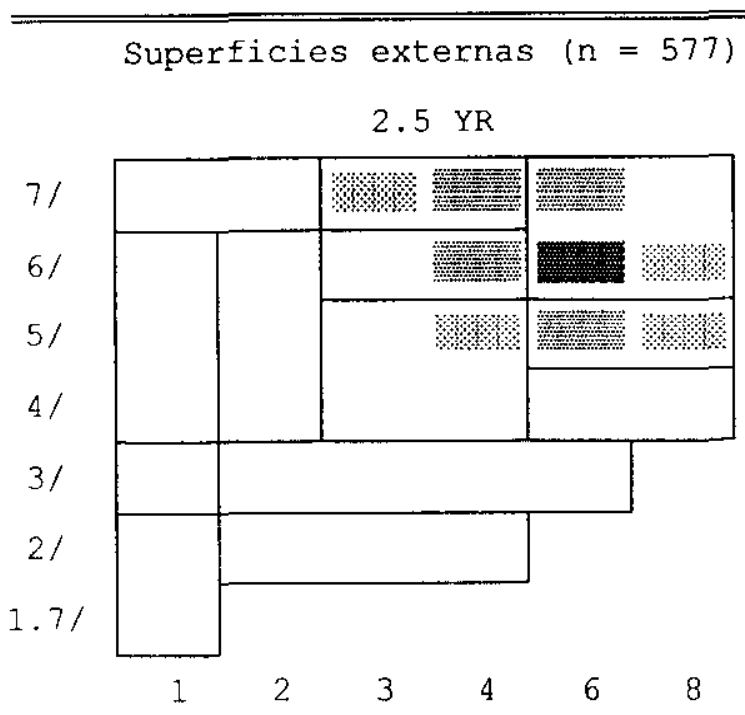

$5 \mathrm{YR}$

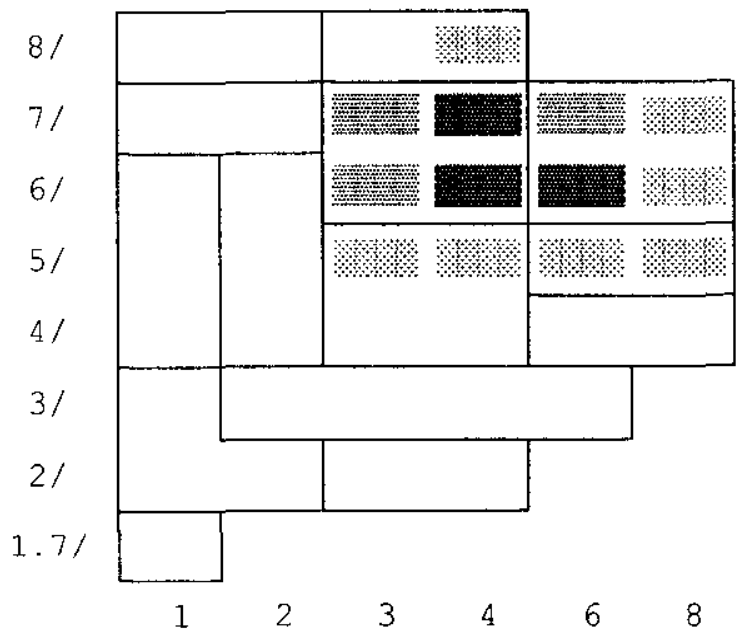

$7.5 \mathrm{YR}$

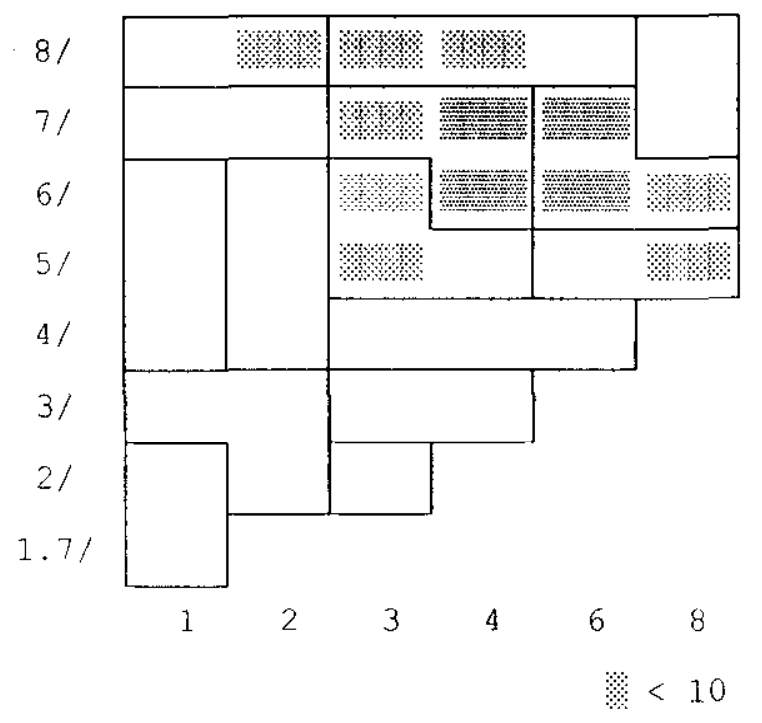

Superficies internas $(n=277)$

$2.5 \mathrm{YR}$

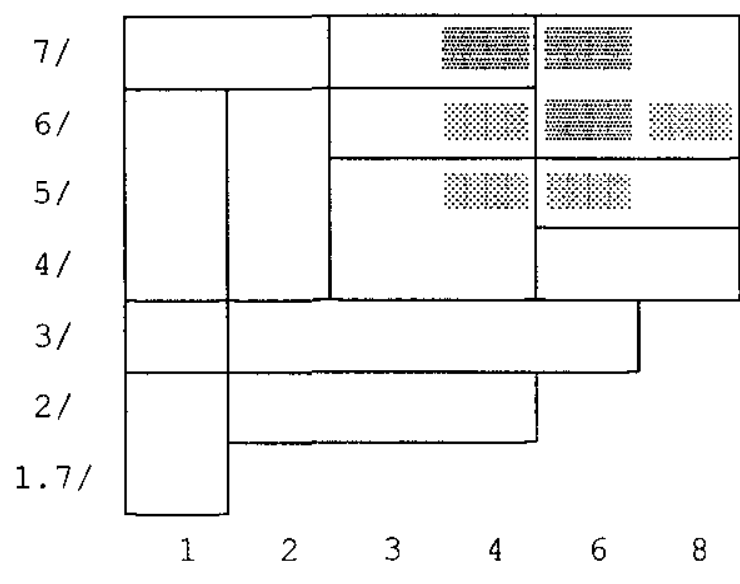

5 YR

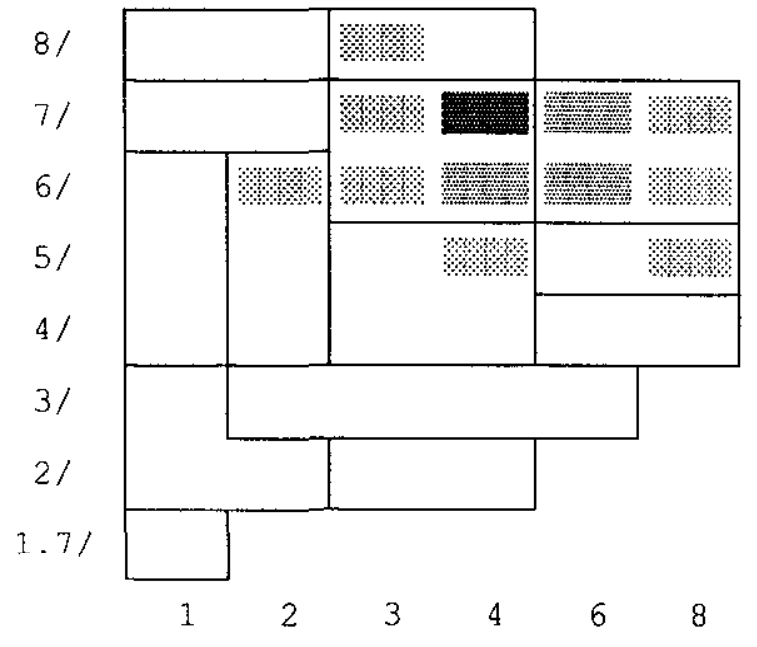

$7.5 \mathrm{YR}$

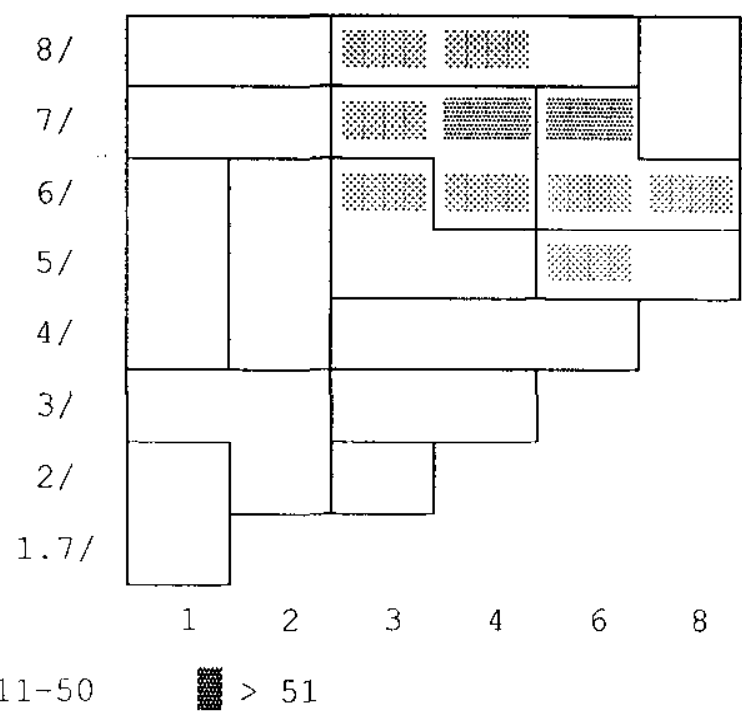


FABRICA $1-b$

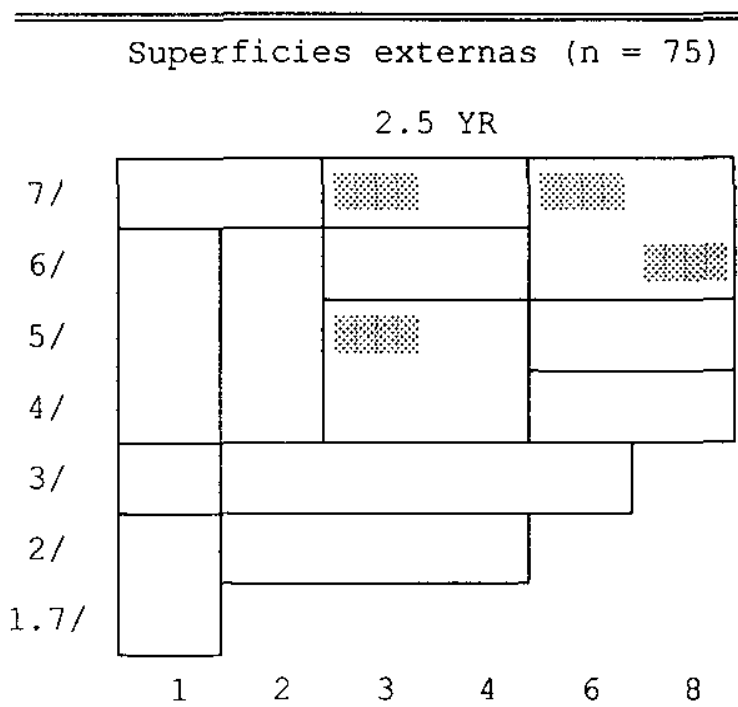

Superficies internas $(n=43)$

2. $5 \mathrm{YR}$

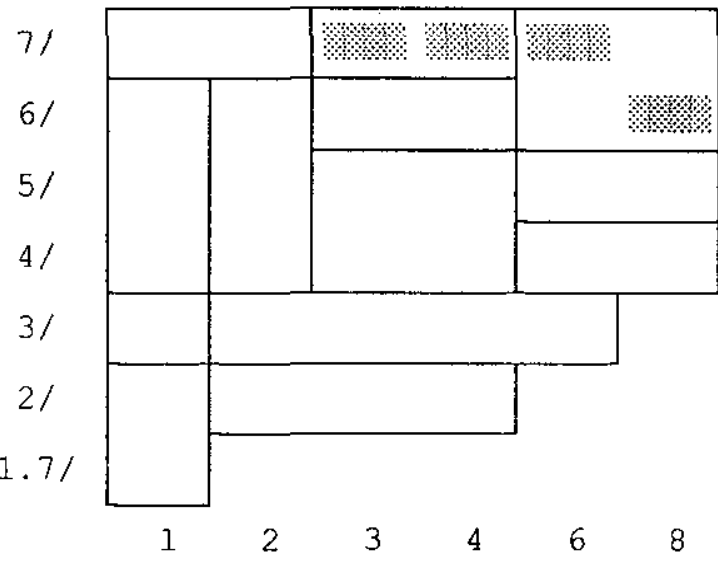

5 YR

5 YR
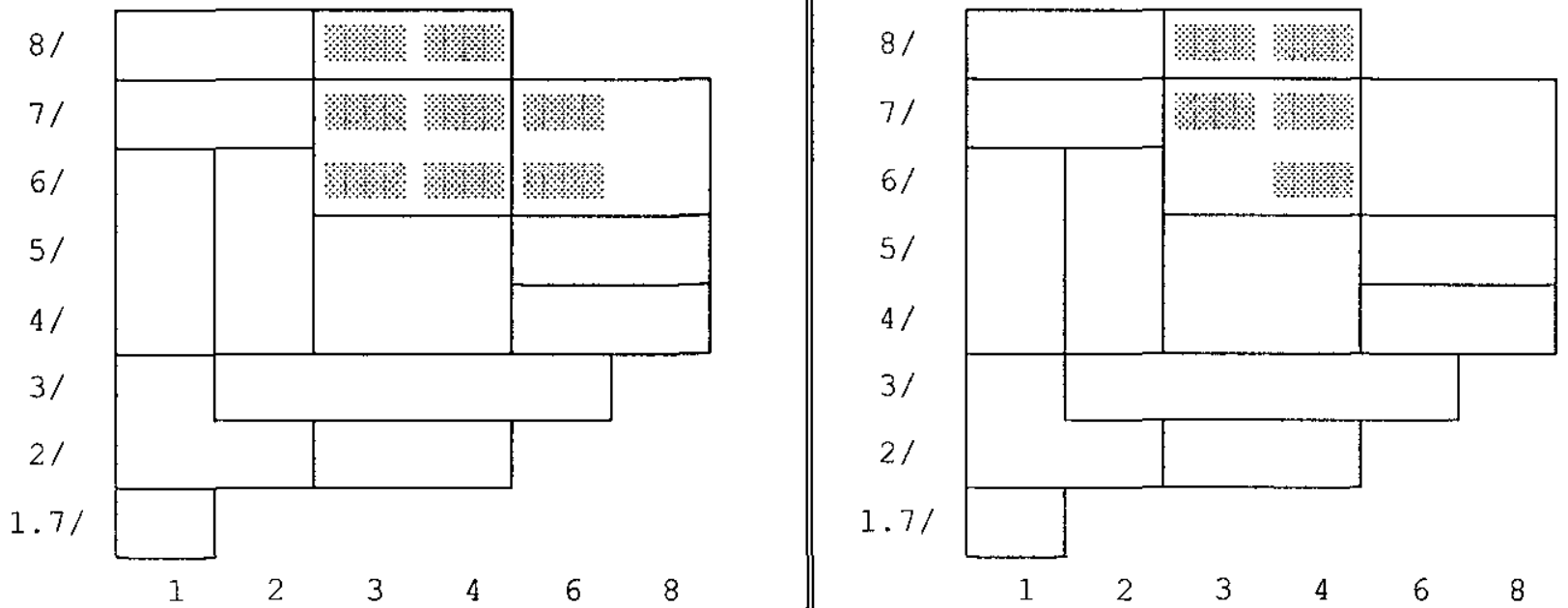

$7.5 \mathrm{YR}$

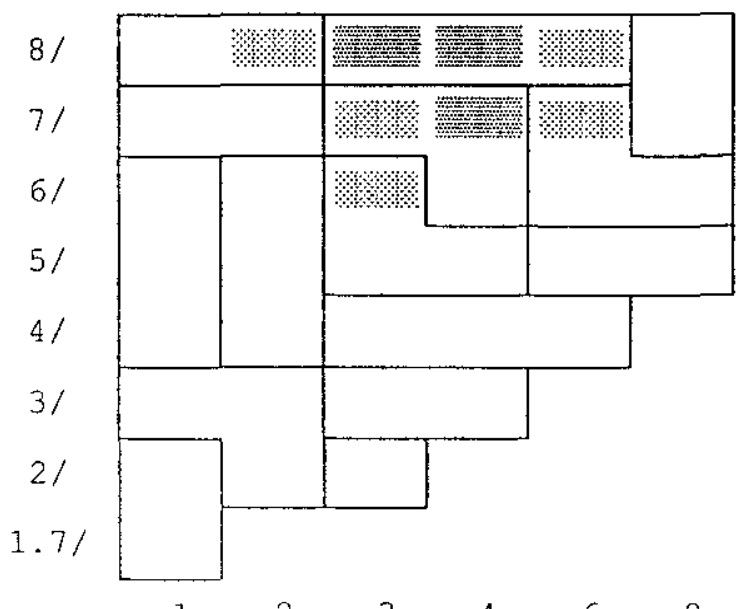

$7.5 \mathrm{YR}$

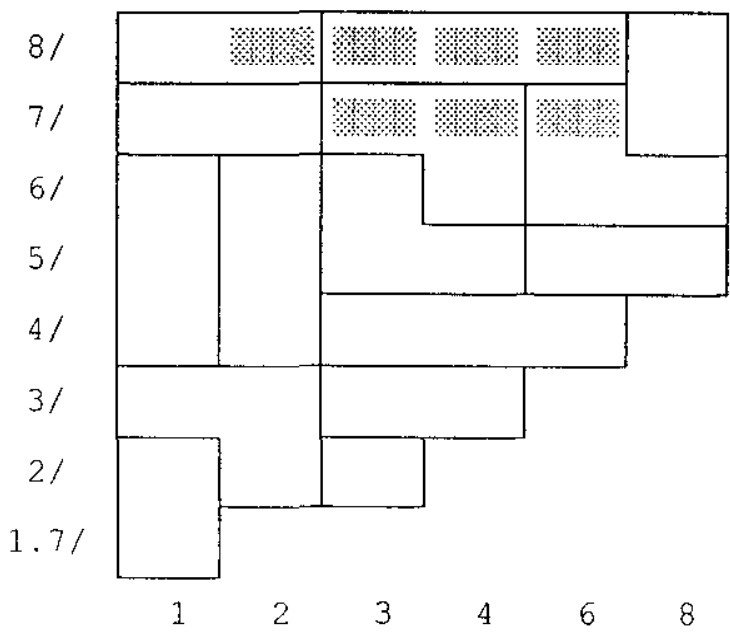

30
10 
FABRICA 2

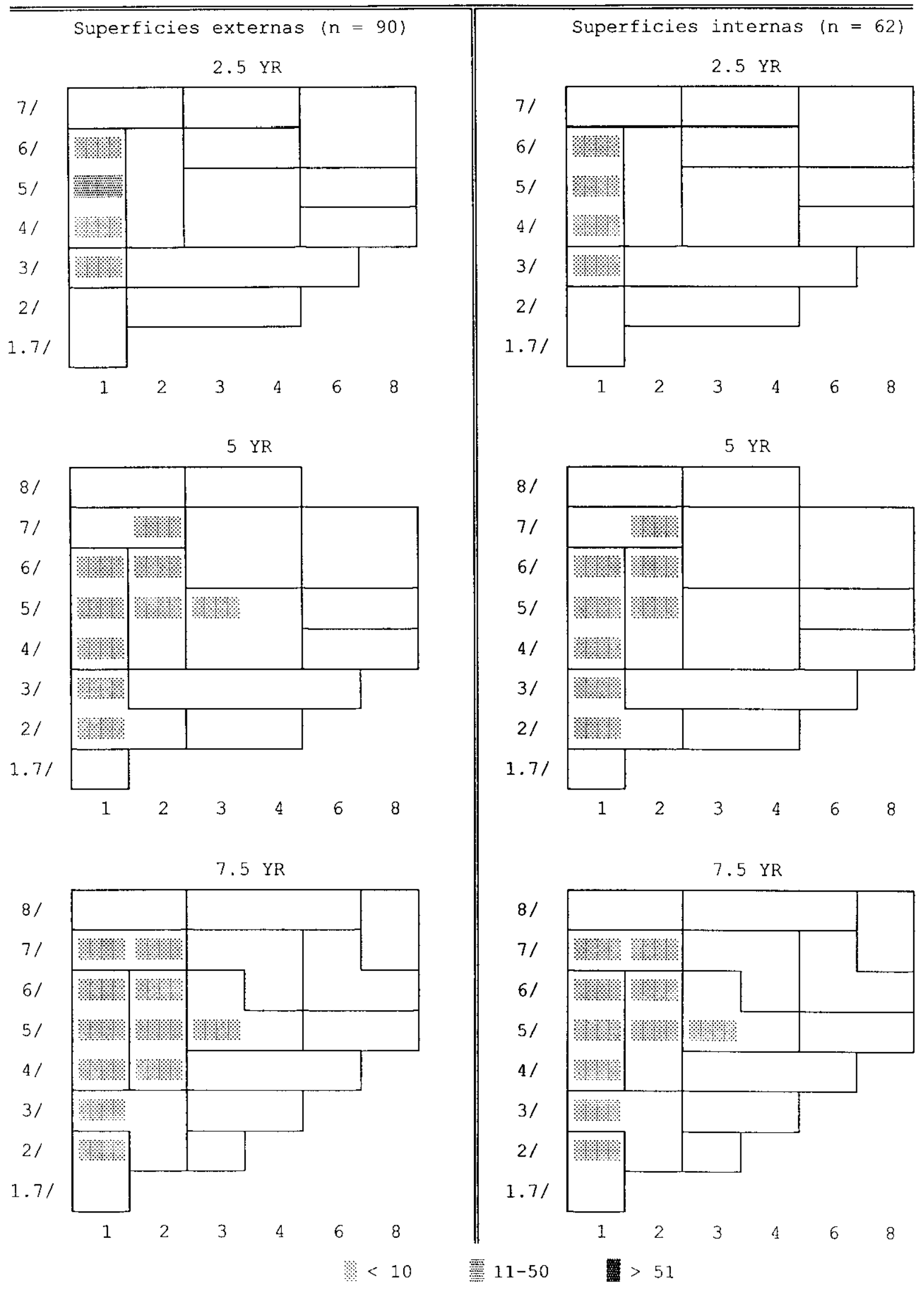


EABRICA NEGRA

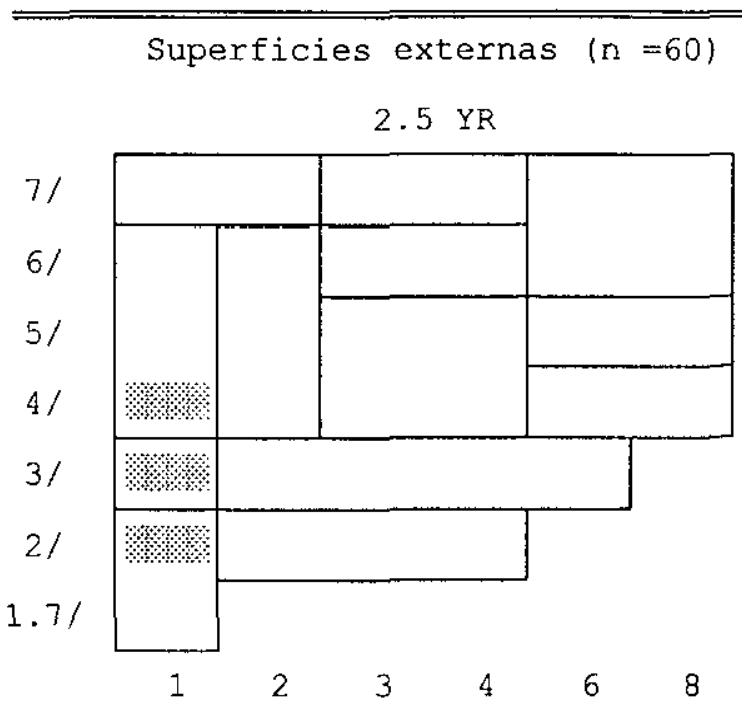

5 YR

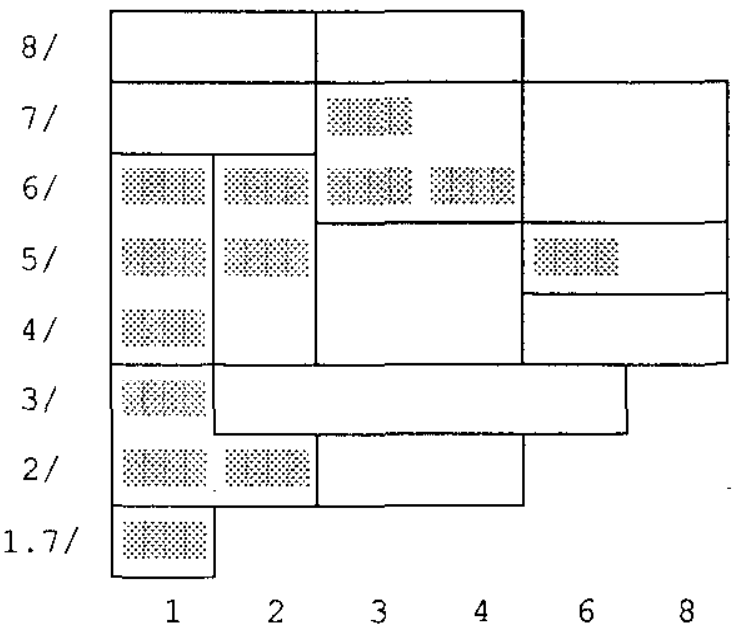

$7.5 \mathrm{YR}$

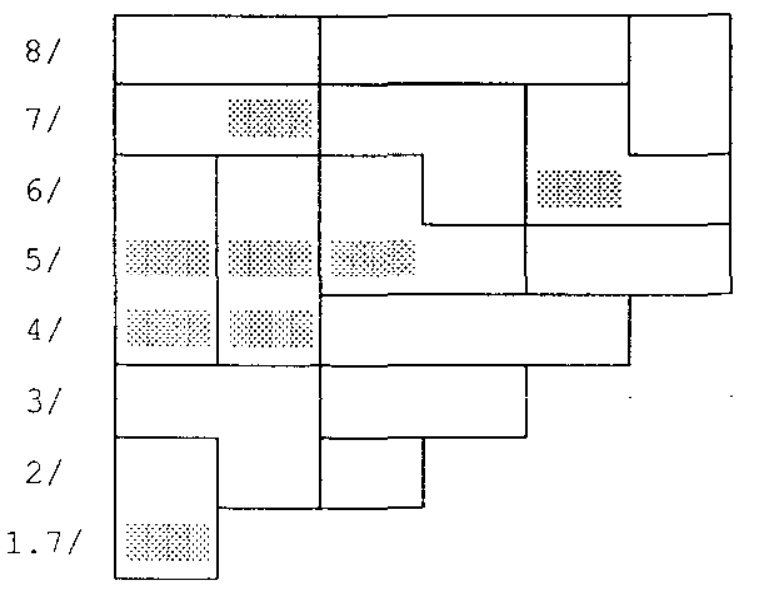

$\begin{array}{llllll}1 & 2 & 3 & 4 & 6 & 8\end{array}$

\% $<10$

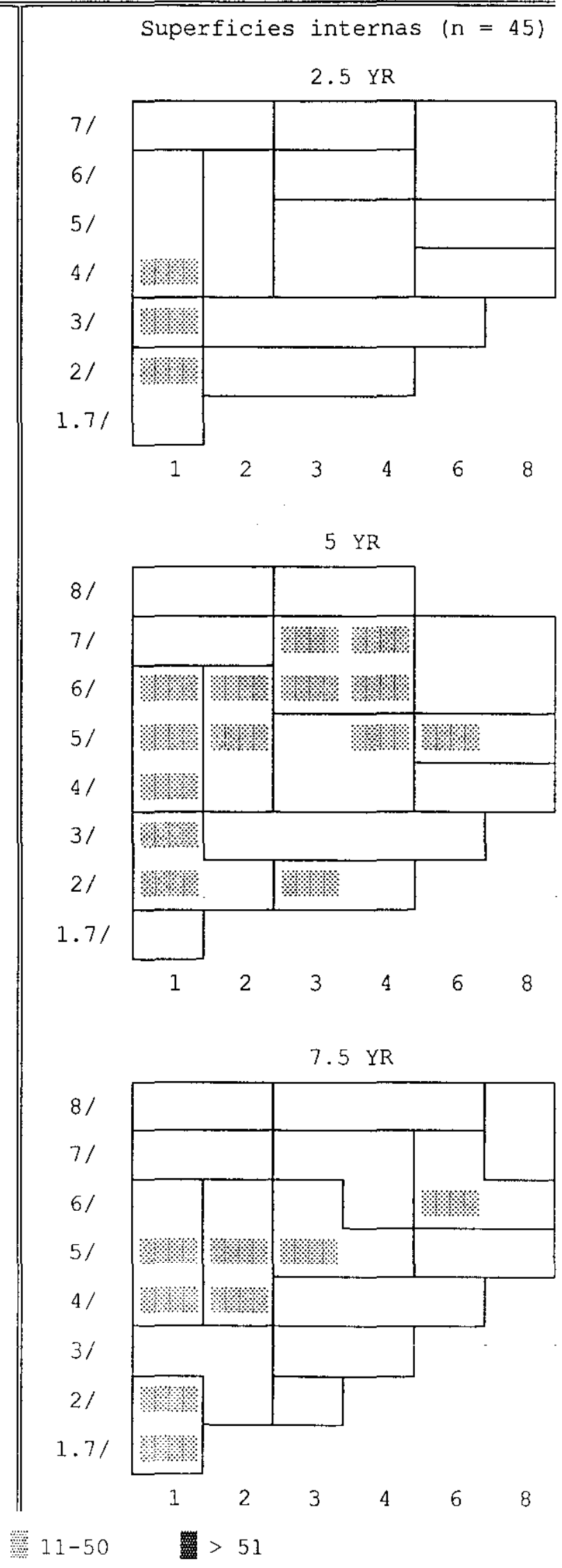



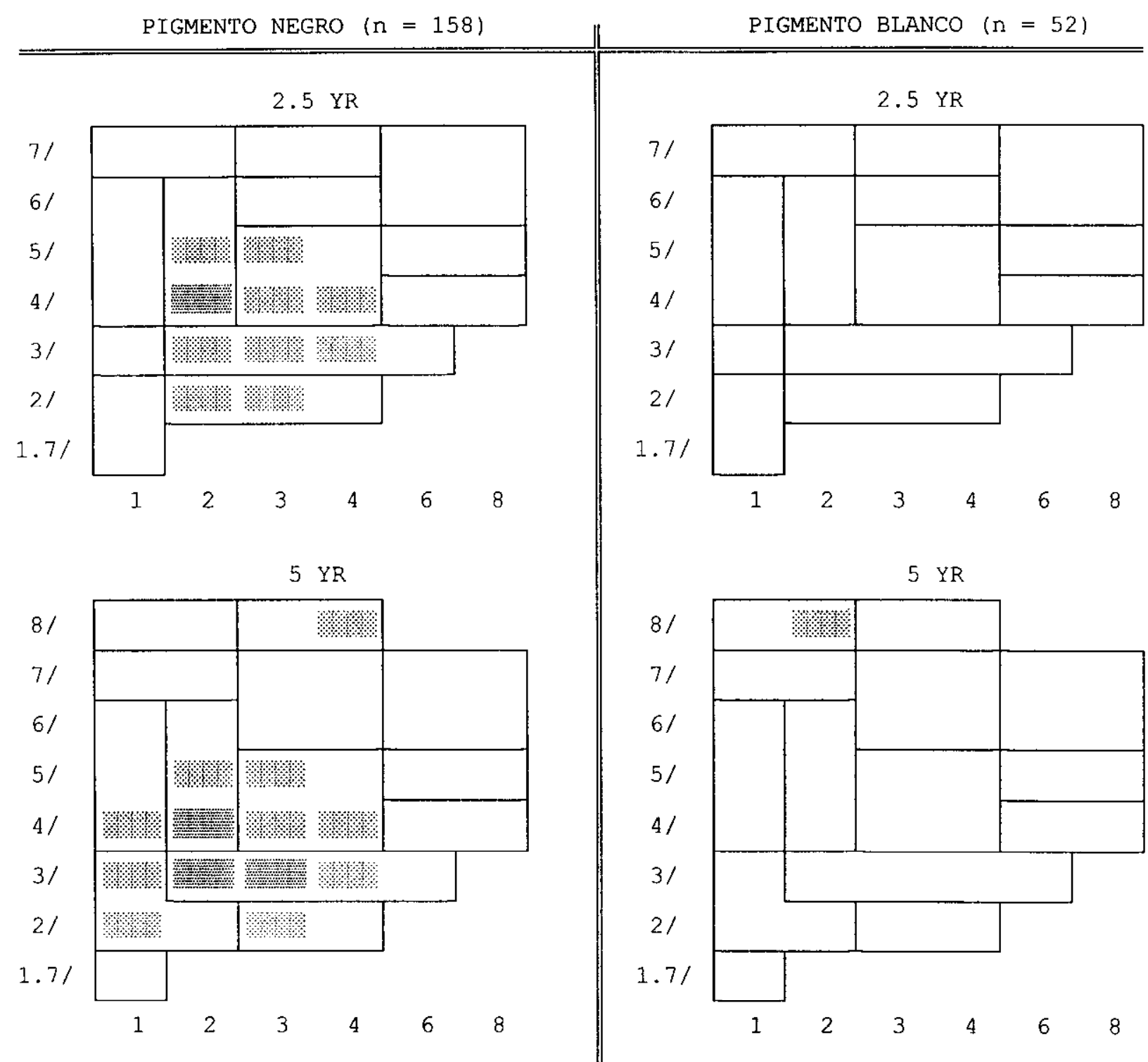

$7.5 \mathrm{YR}$
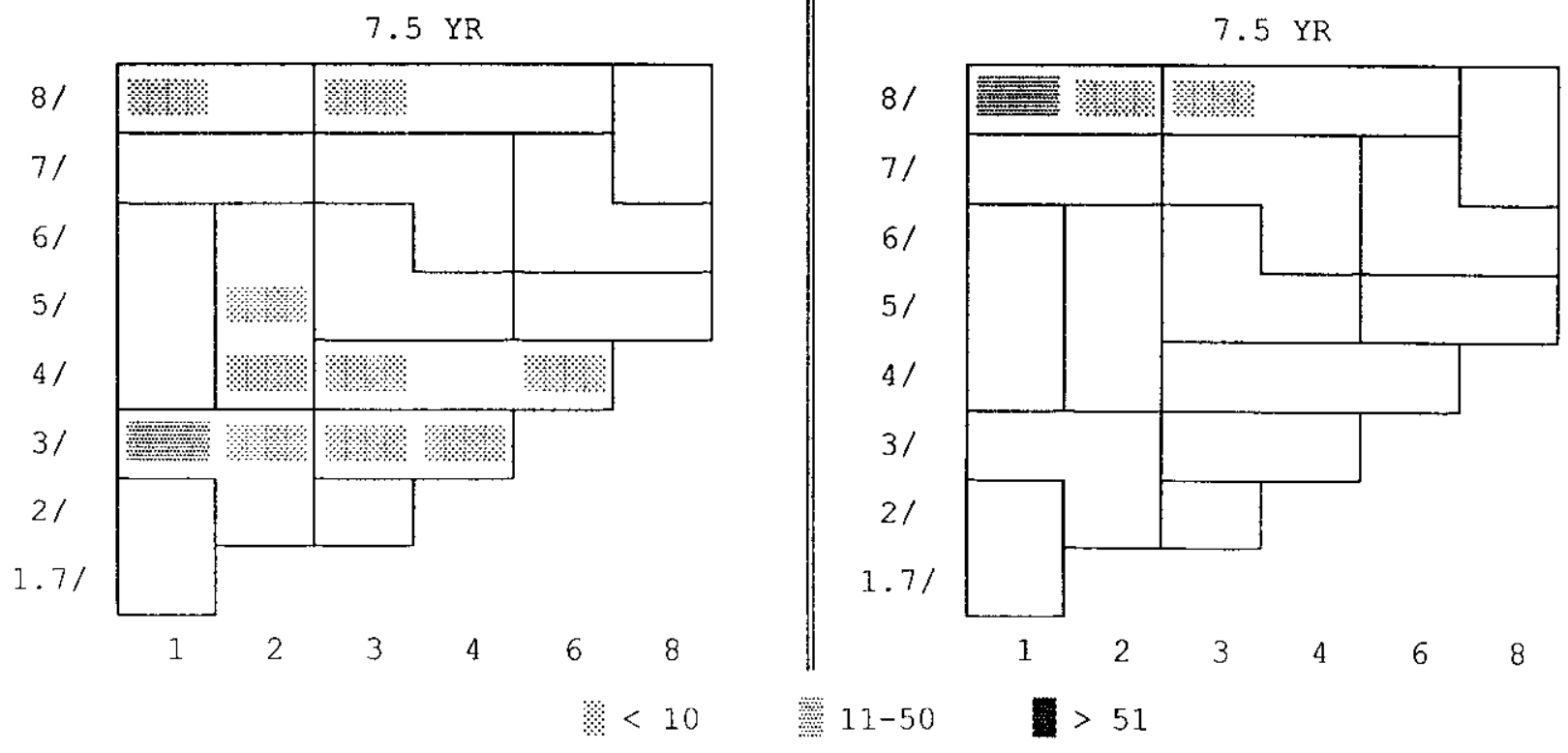
PIGMENTO ROJO ( $\mathrm{n}=11)$

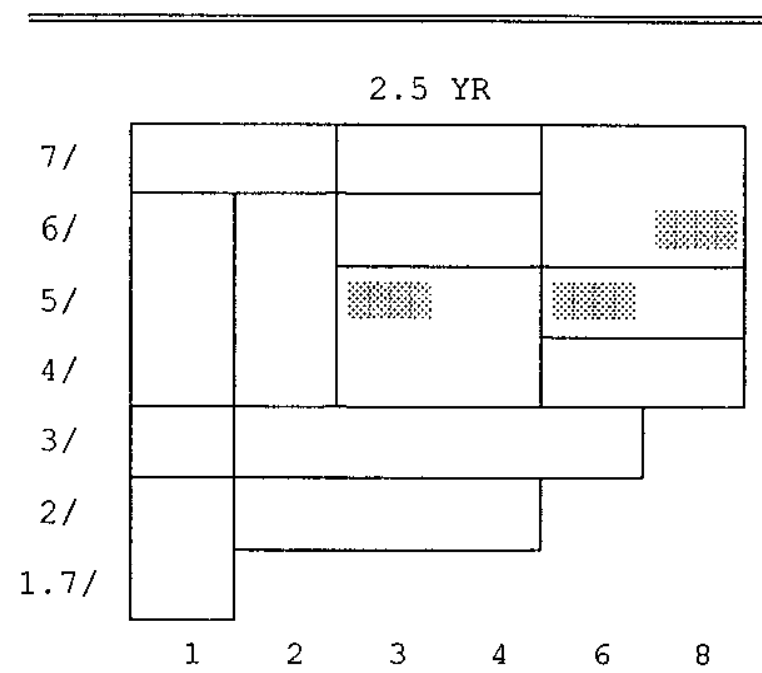

$5 Y R$

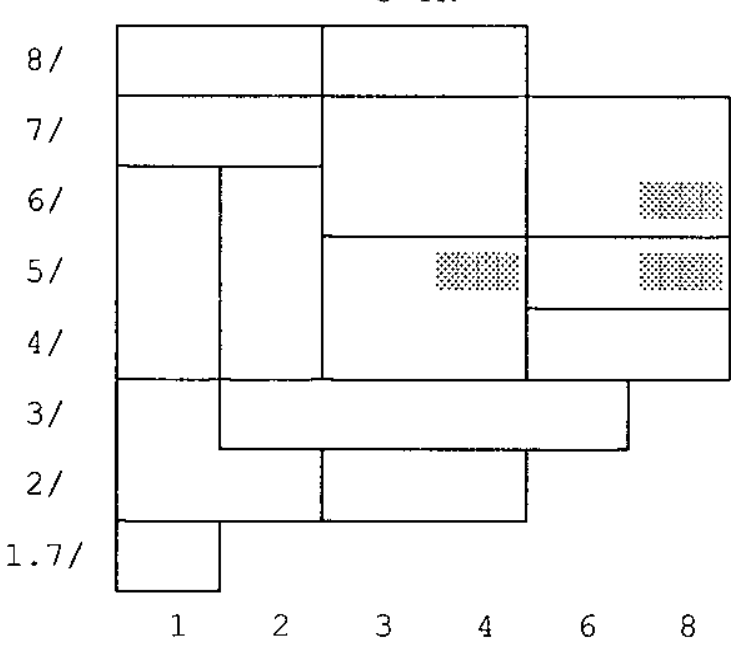

$7.5 \mathrm{YR}$

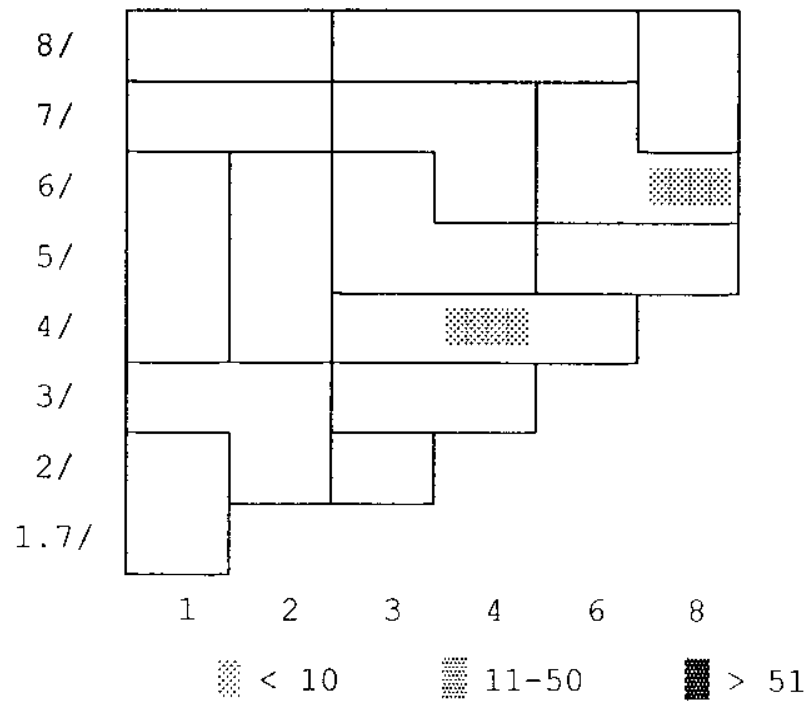




\section{APÉNDICE II}

En este apéndice se reproducen los gráficos del Análisis textural realizado en 115 cerámicas (83 de Numancia, 5 de Langa de Duero, 5 de El Palomar, 11 de Pinilla Trasmonte y 11 de Izana); de los sedimentos arcillosos cocidos a $700^{\circ} \mathrm{C}\left(\mathrm{N}-1 \mathrm{~B}\right.$ y N-4B) y a $900^{\circ} \mathrm{C}(\mathrm{N}-1 \mathrm{D}$ y $\mathrm{N}-4$ D) y del test de representatividad realizado en las muestras $\mathrm{N}-10, \mathrm{~N}-22, \mathrm{~N}-48, \mathrm{~N}-53, \mathrm{~N}-54$ y N-62. En los gráficos también se representa el porcentaje de las diferentes fases mineralógicas detectadas en cada fracción. En el test de representatividad las letras A, B, C y D indican los distintos lugares de la lámina delgada en los que se realizaron los conteos. En aquellos gráficos en los que el reducido tamaño de la columna impide ver con claridad la trama de la fase mineralógica correspondiente, se ha añadido la clave al lado, con el fin de facilitar su observación. 


\section{CLAVES}

Q/Fd: Cuarzo y Feldespatos

Mi: Mica

OH: Óxidos de Fe y Opacos

CcM: Calcita micrítica

CcC: Calcita criptocristalina

Qz: Cuarcita

FR. Fragmentos de roca 

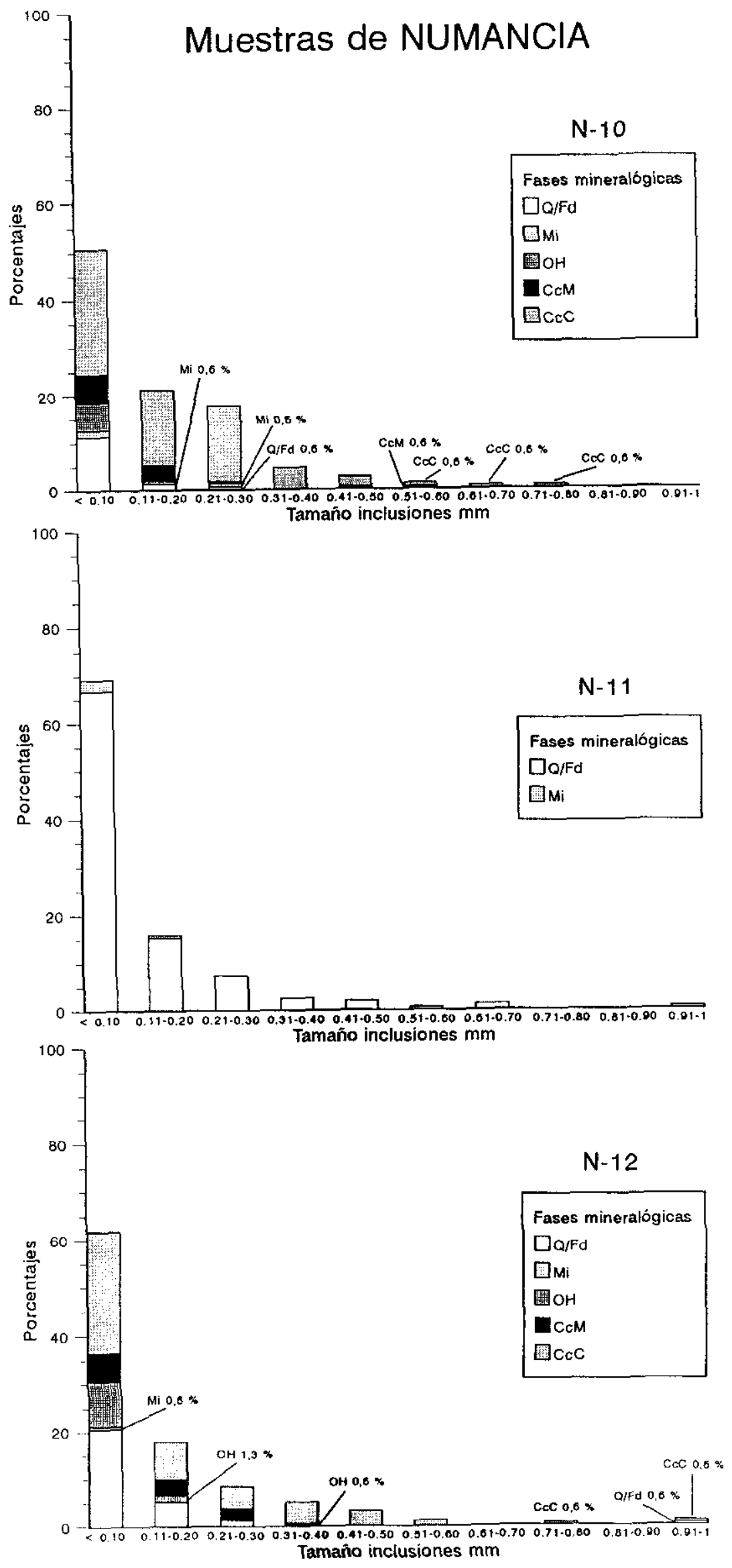

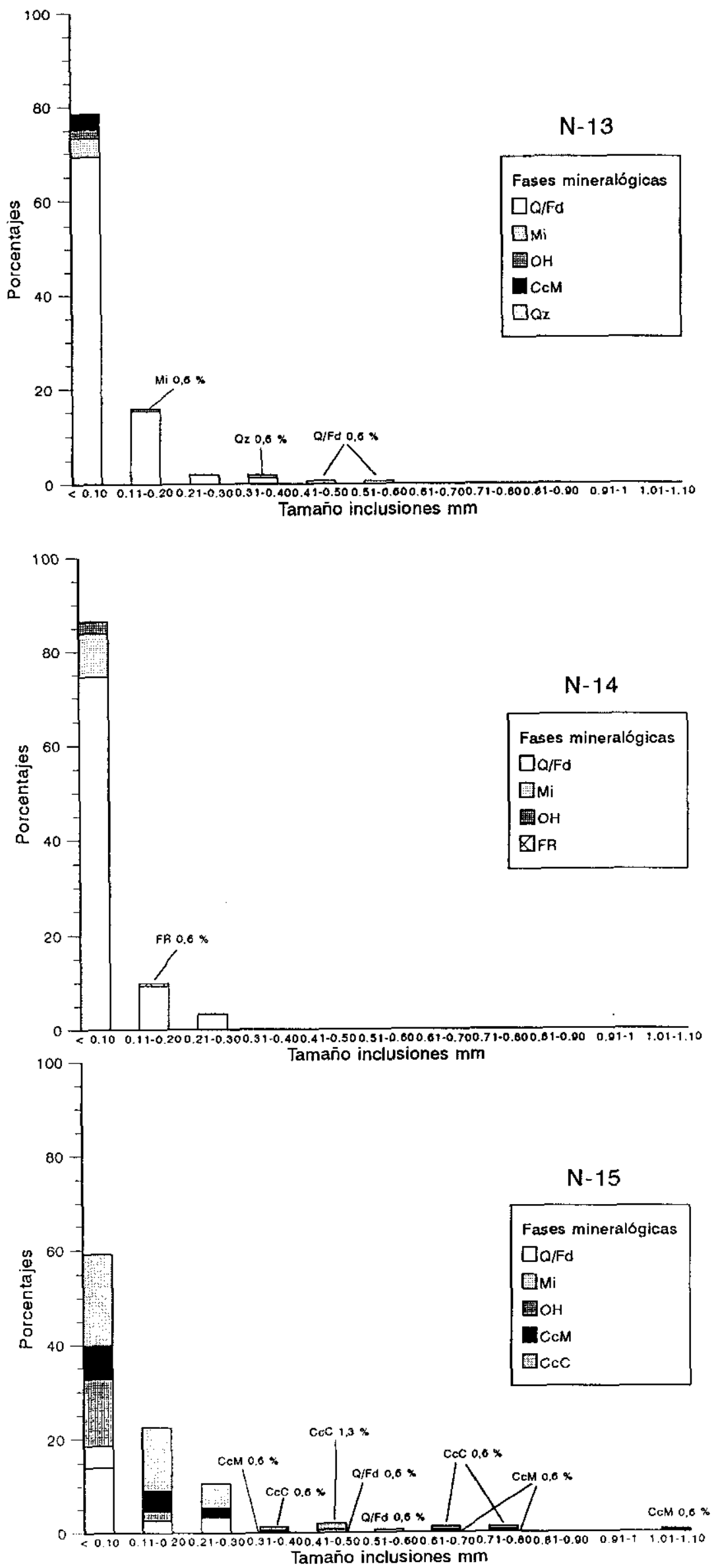

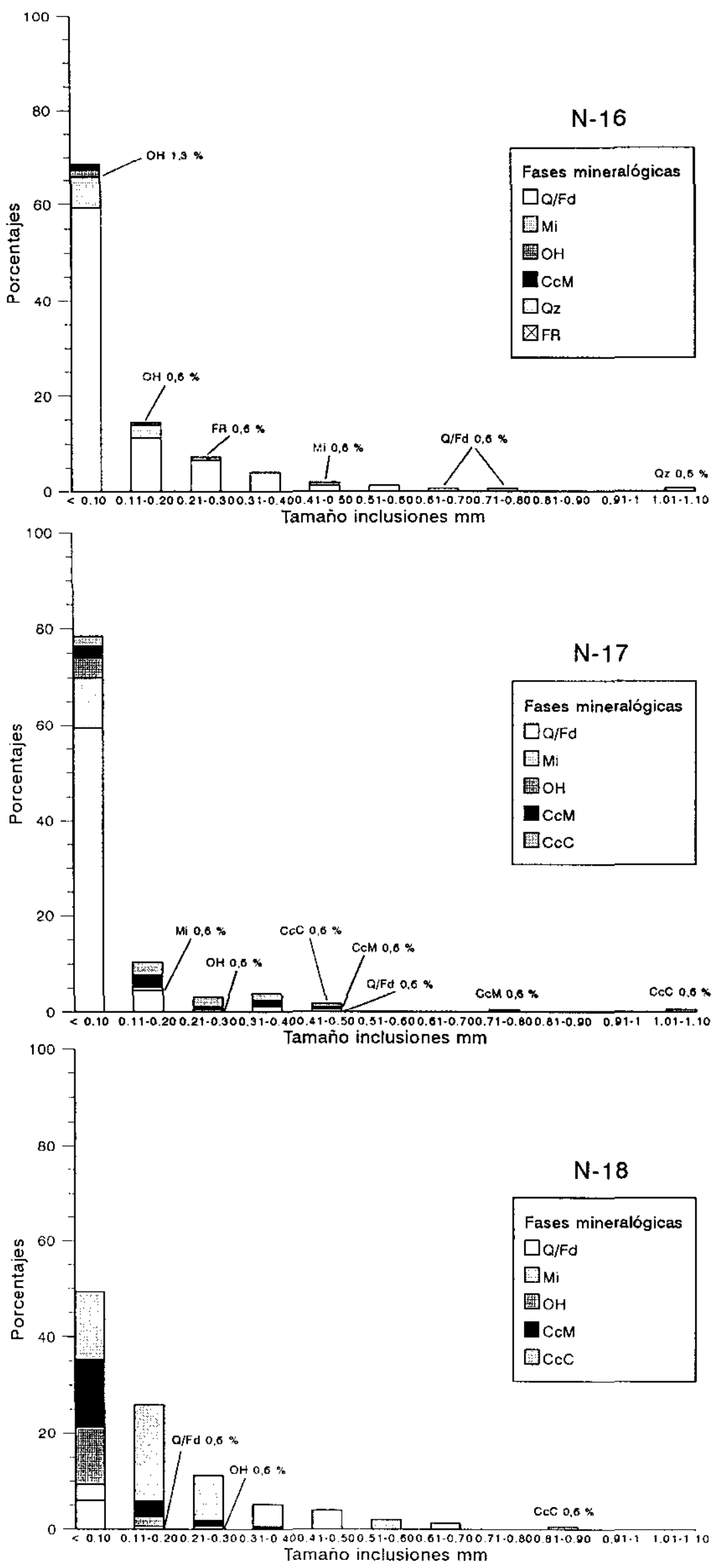

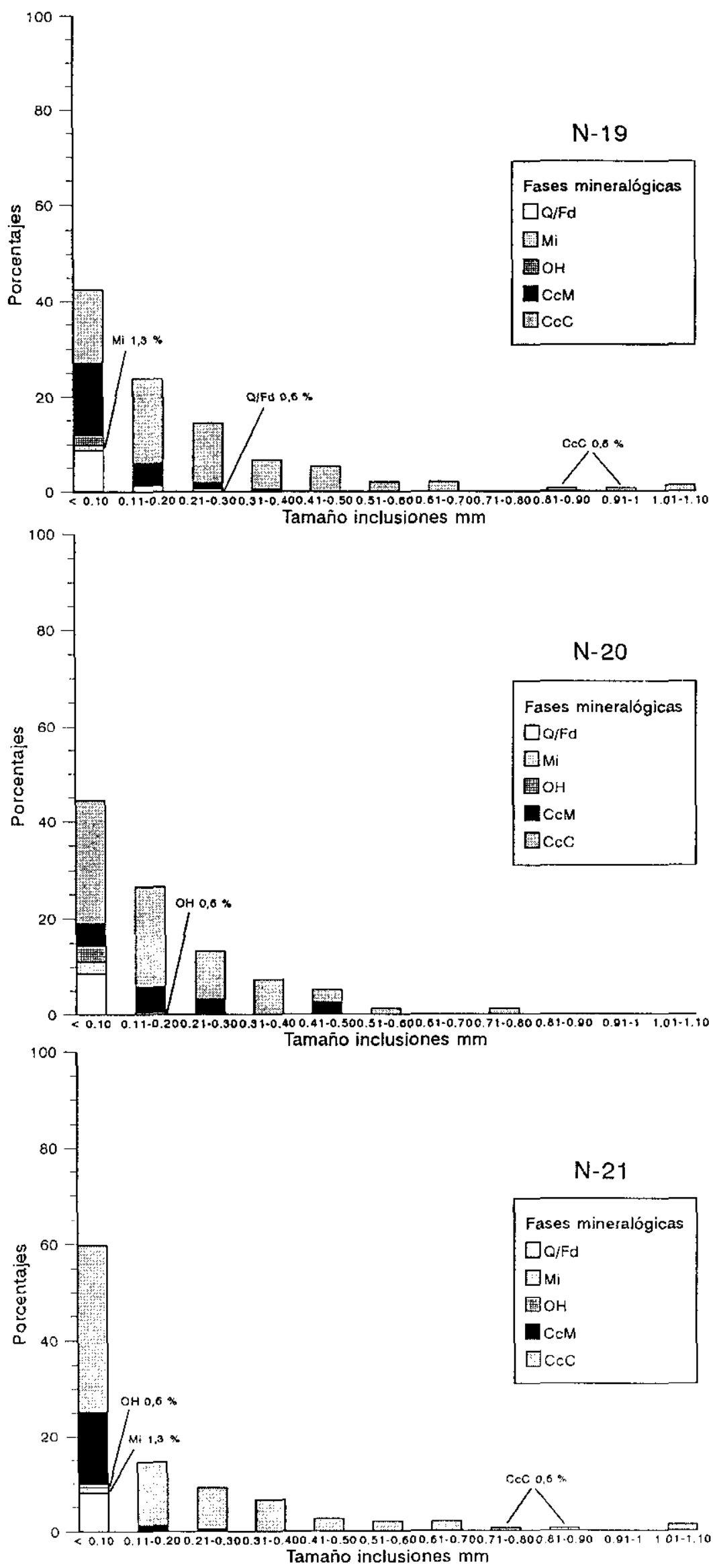

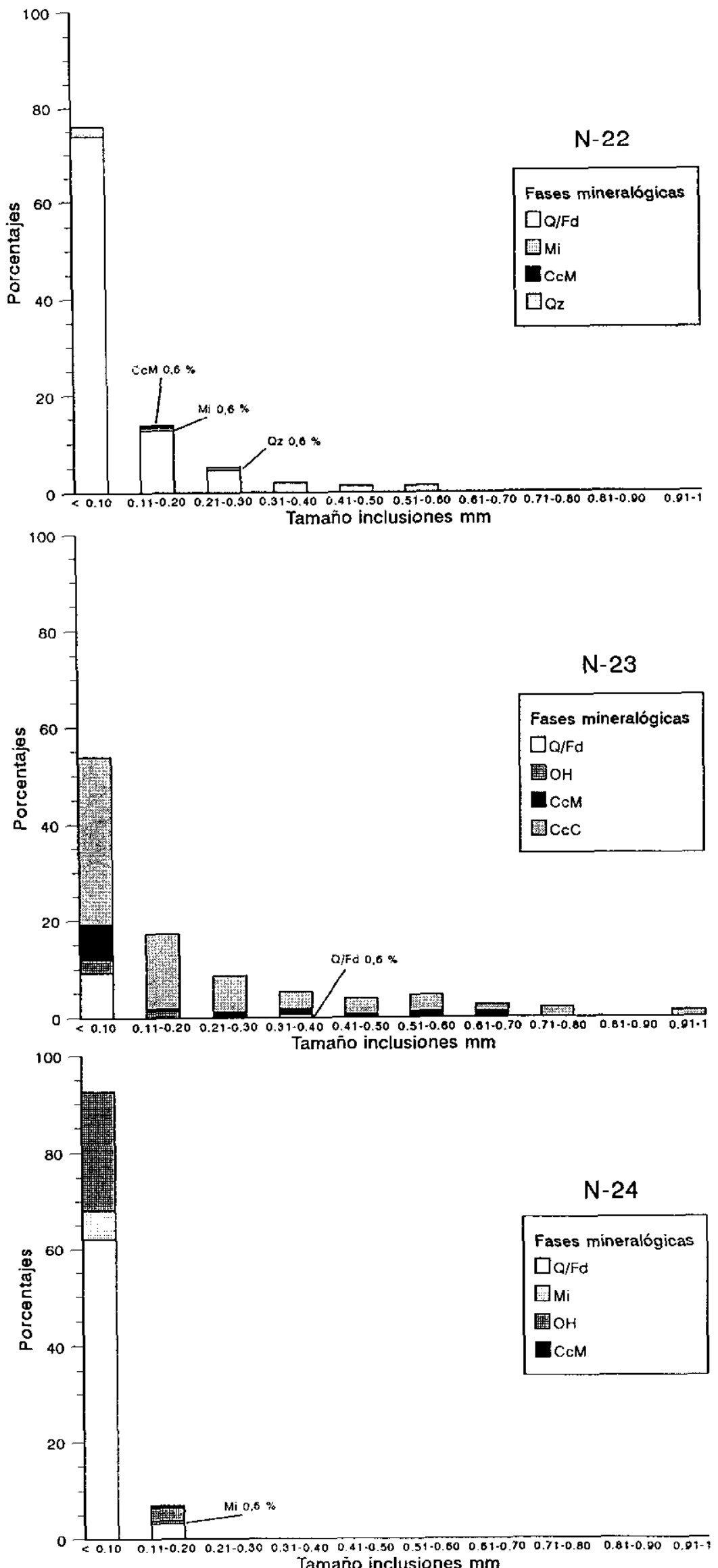

Tamaño inclusiones $\mathrm{mm}$ 

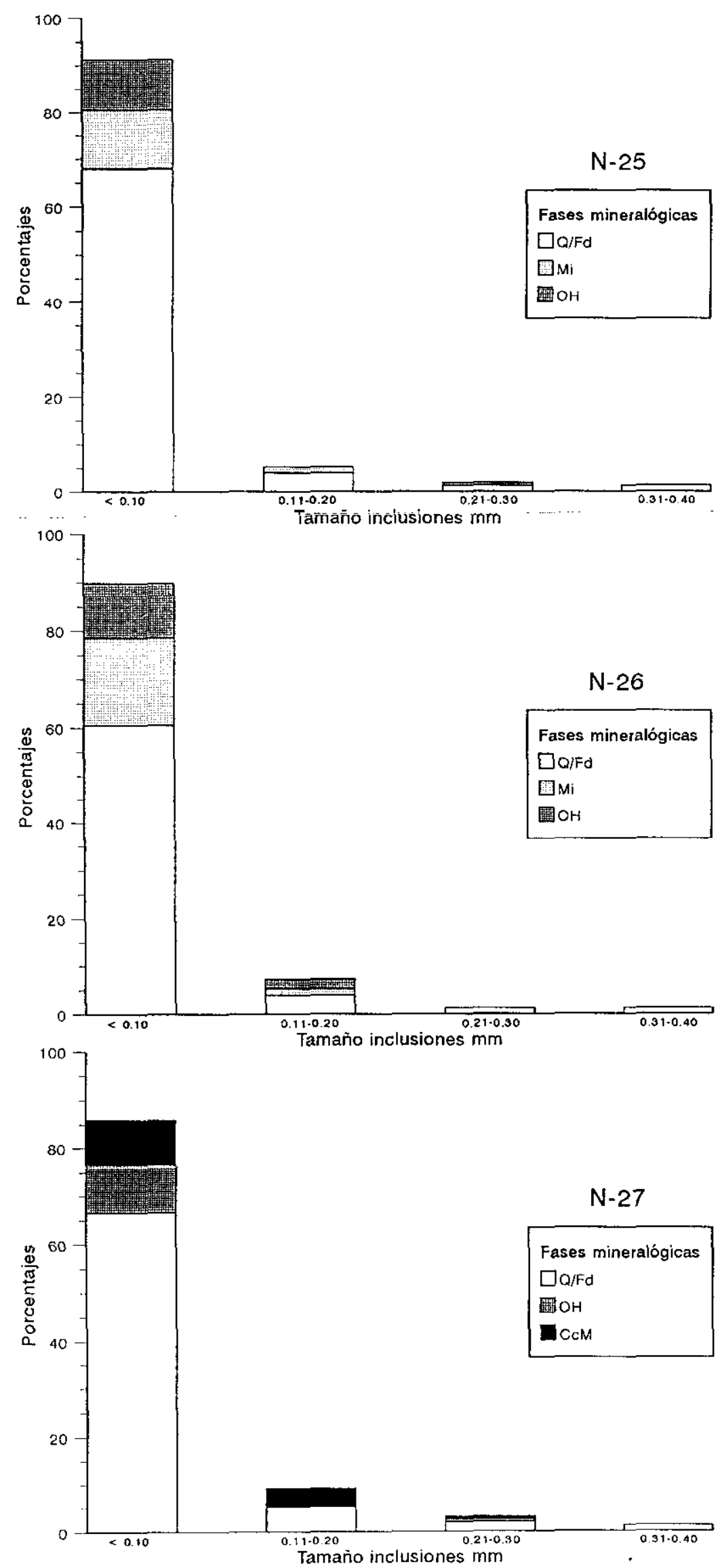

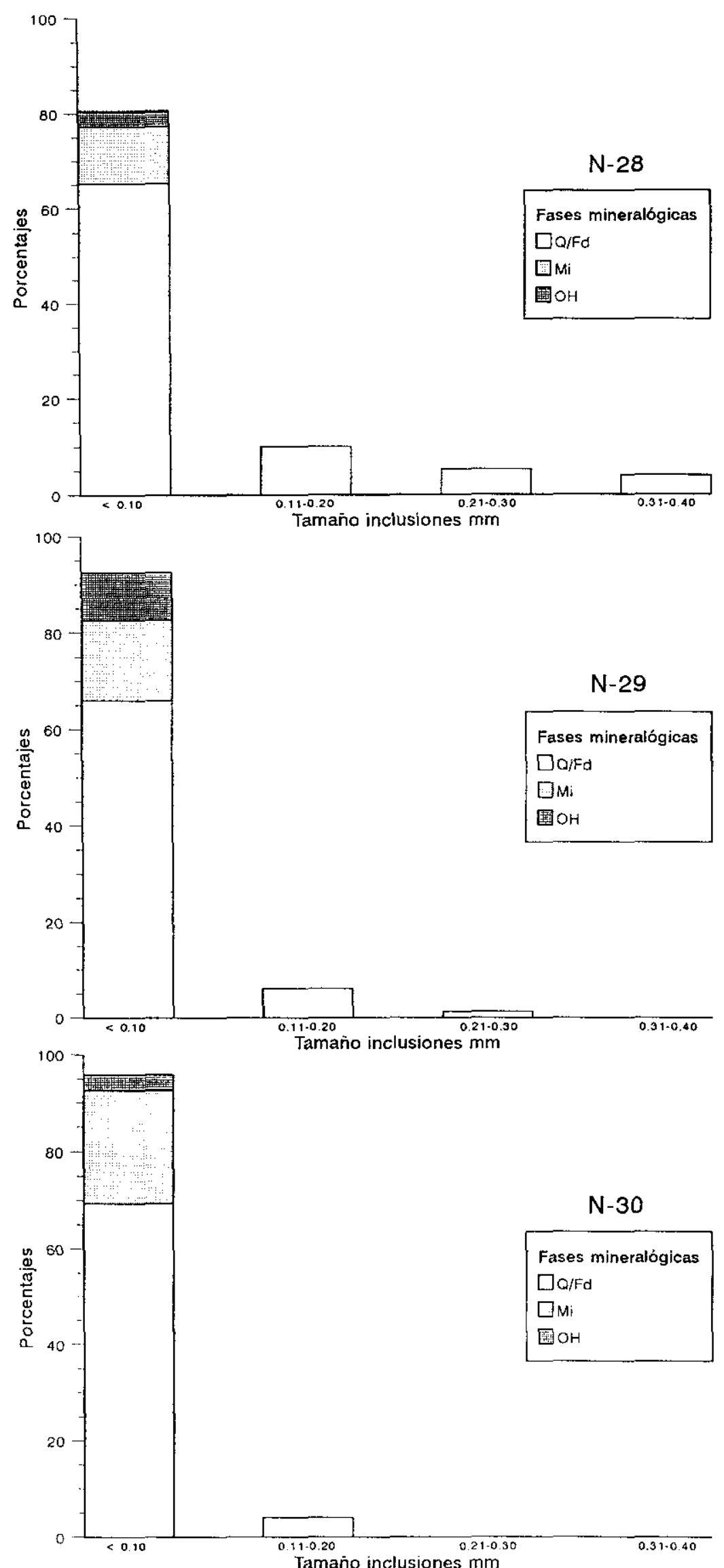

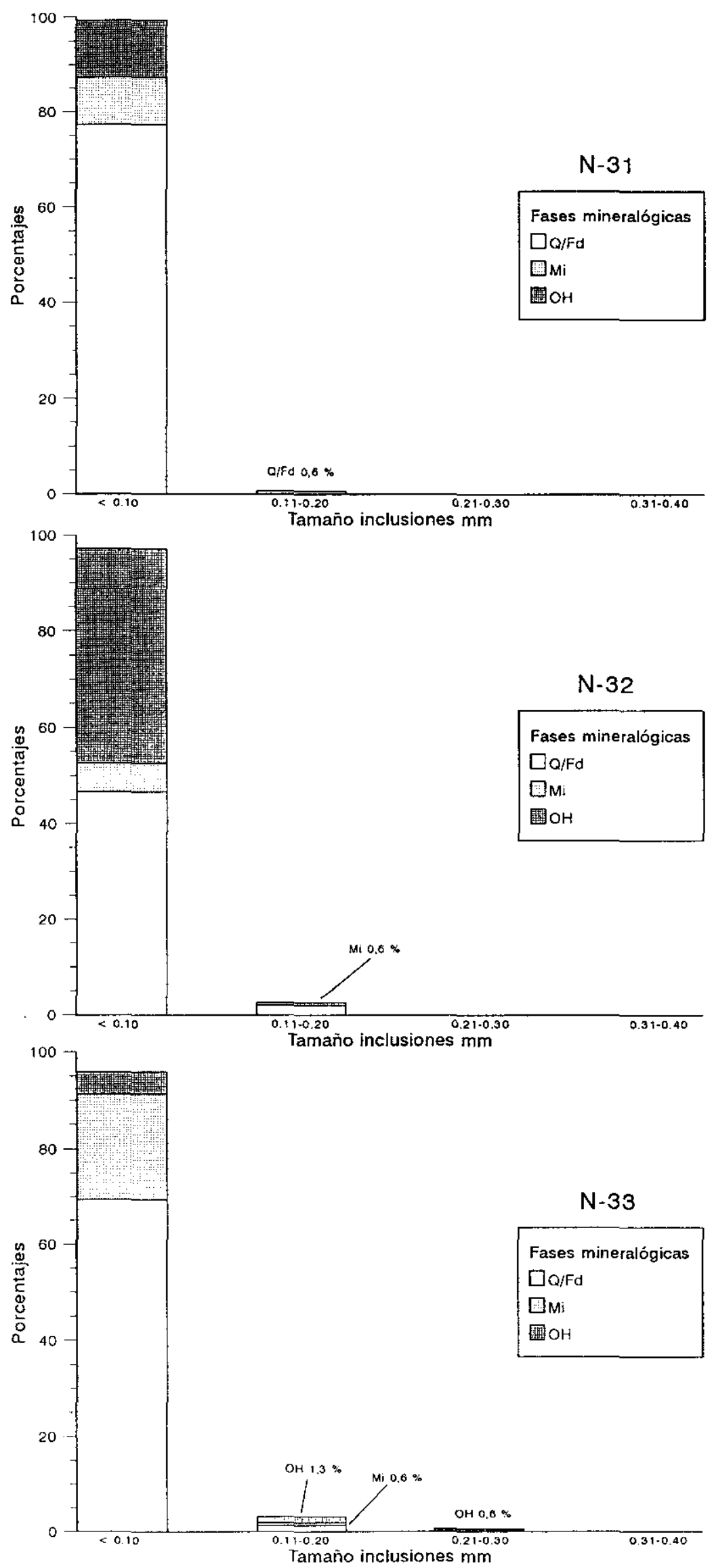

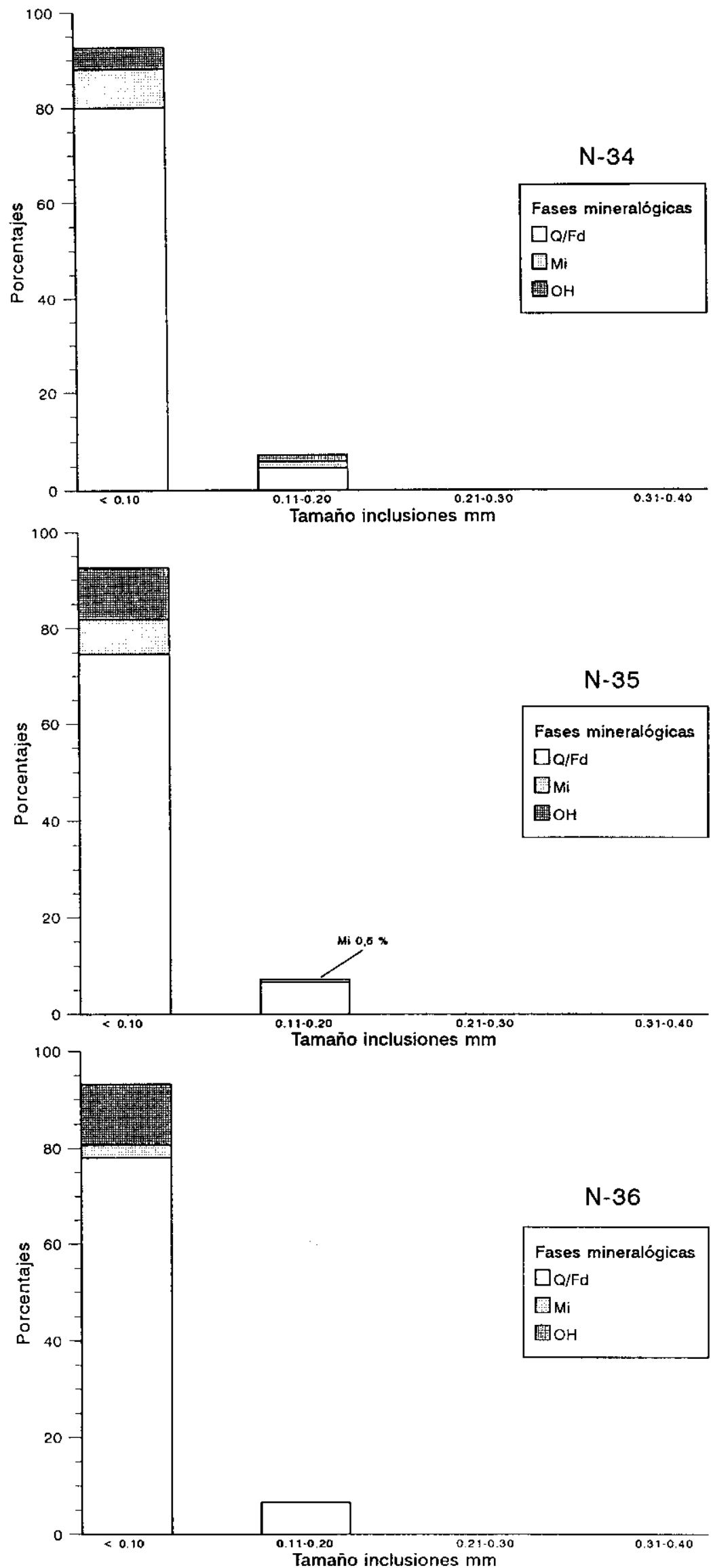

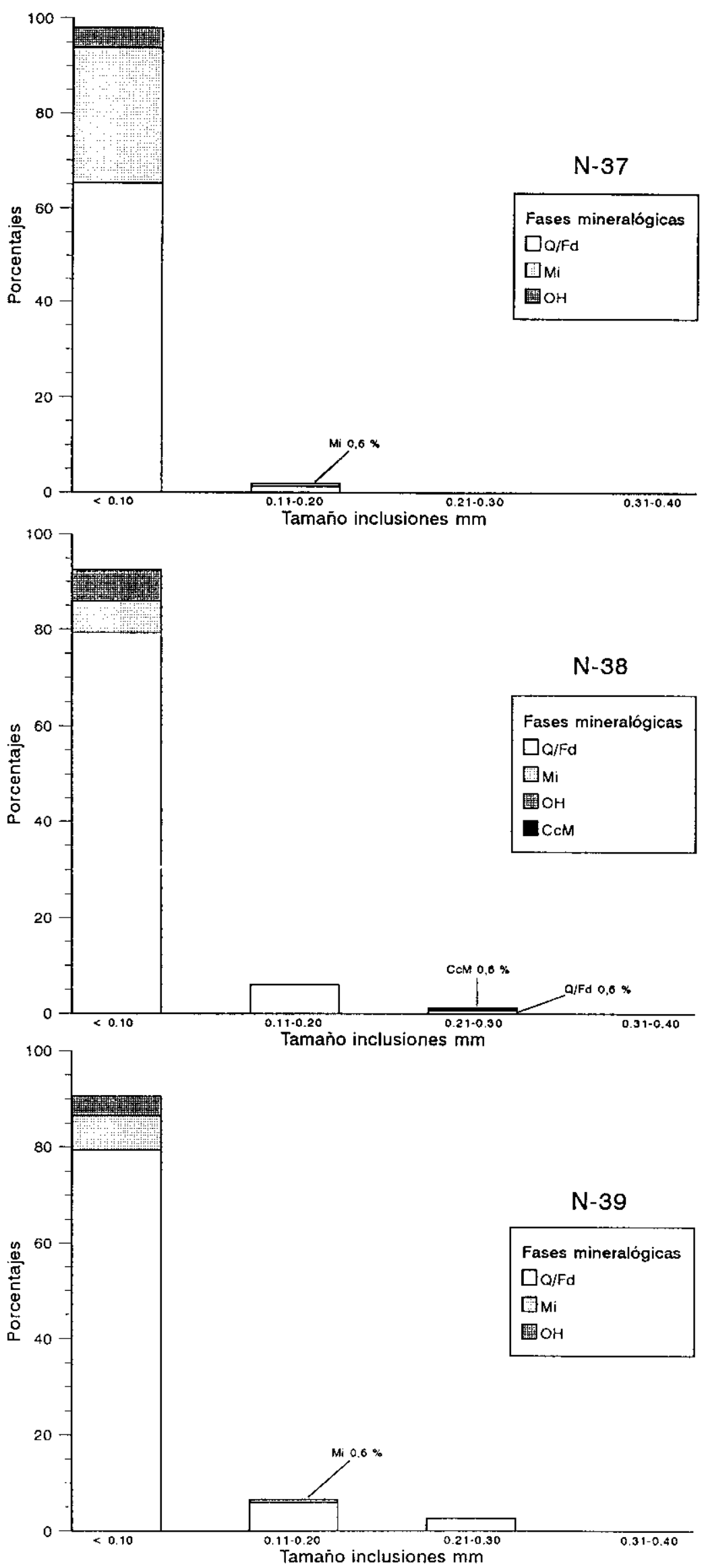

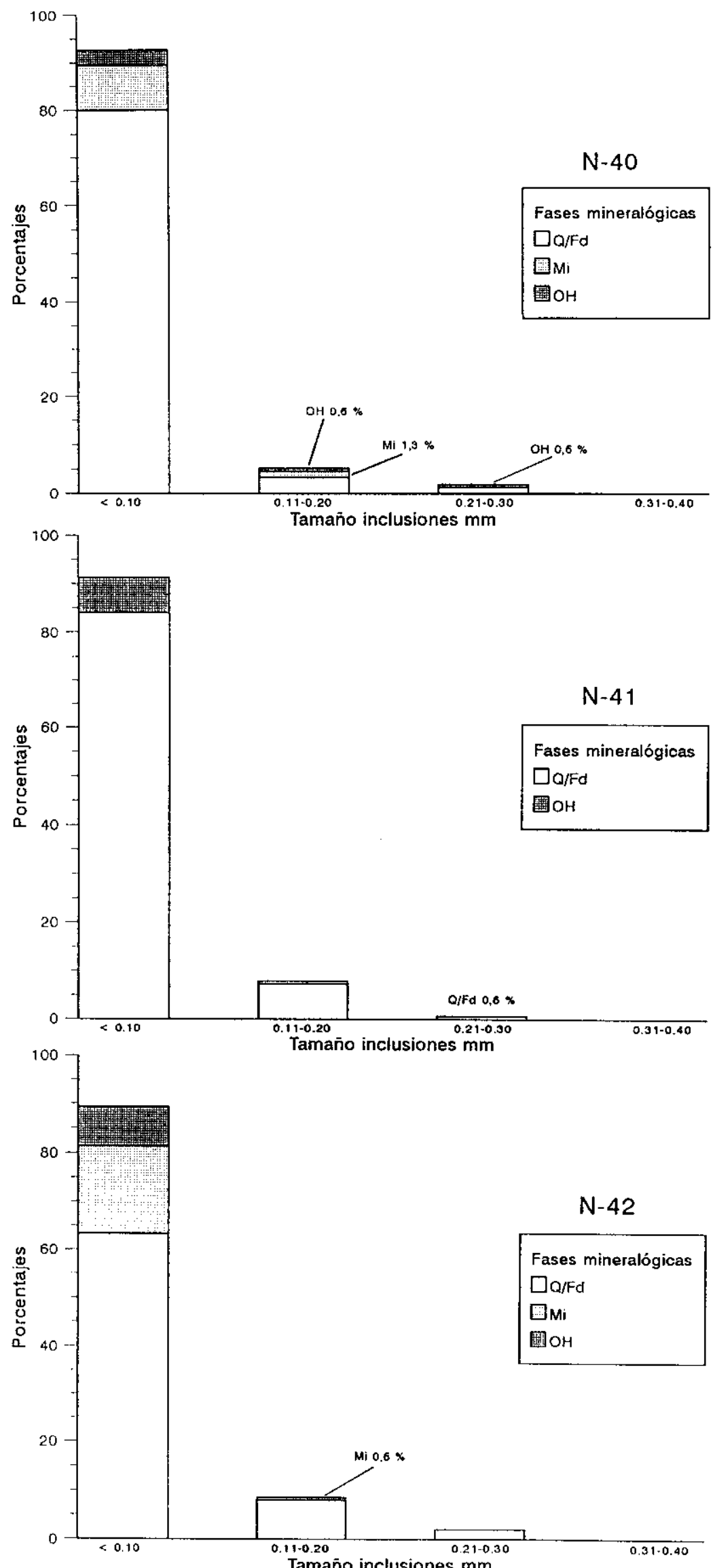

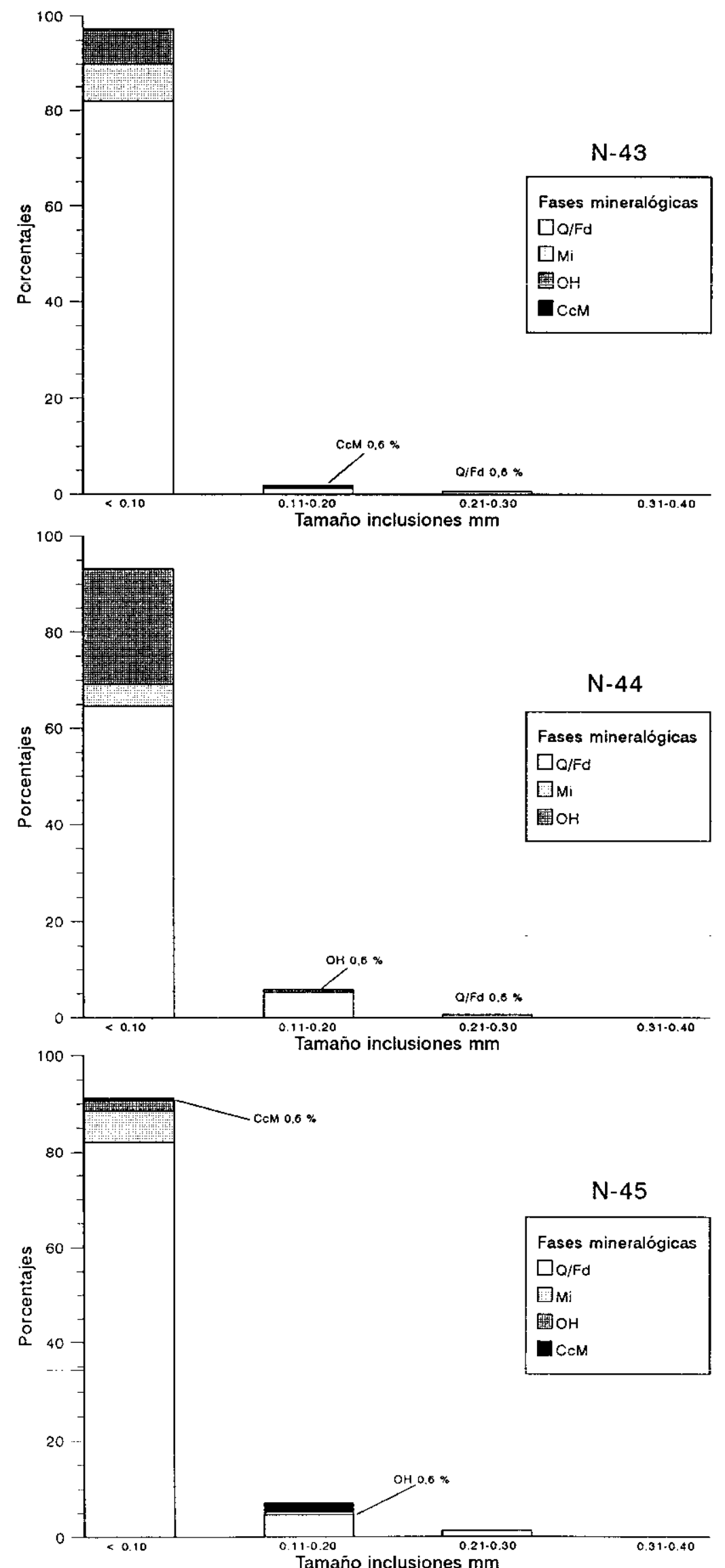

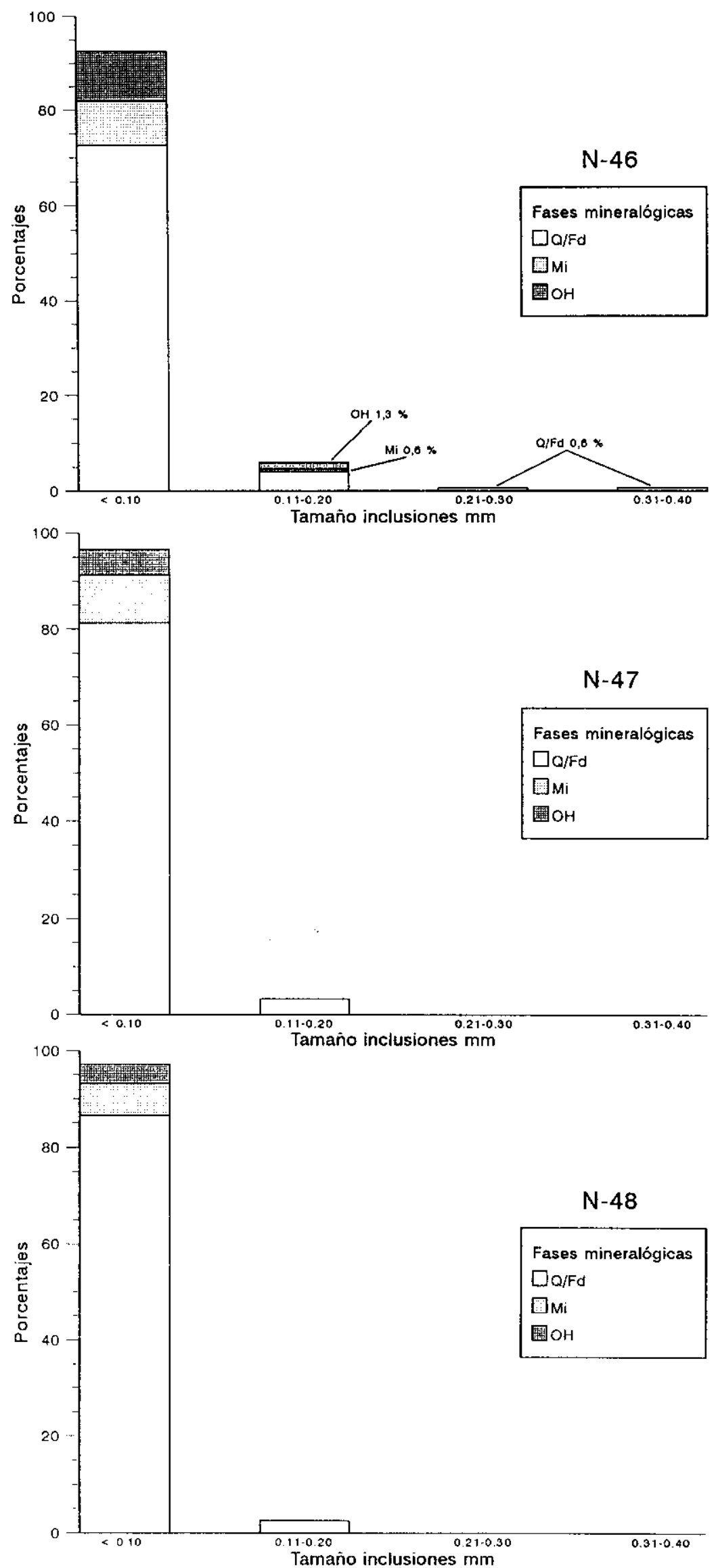

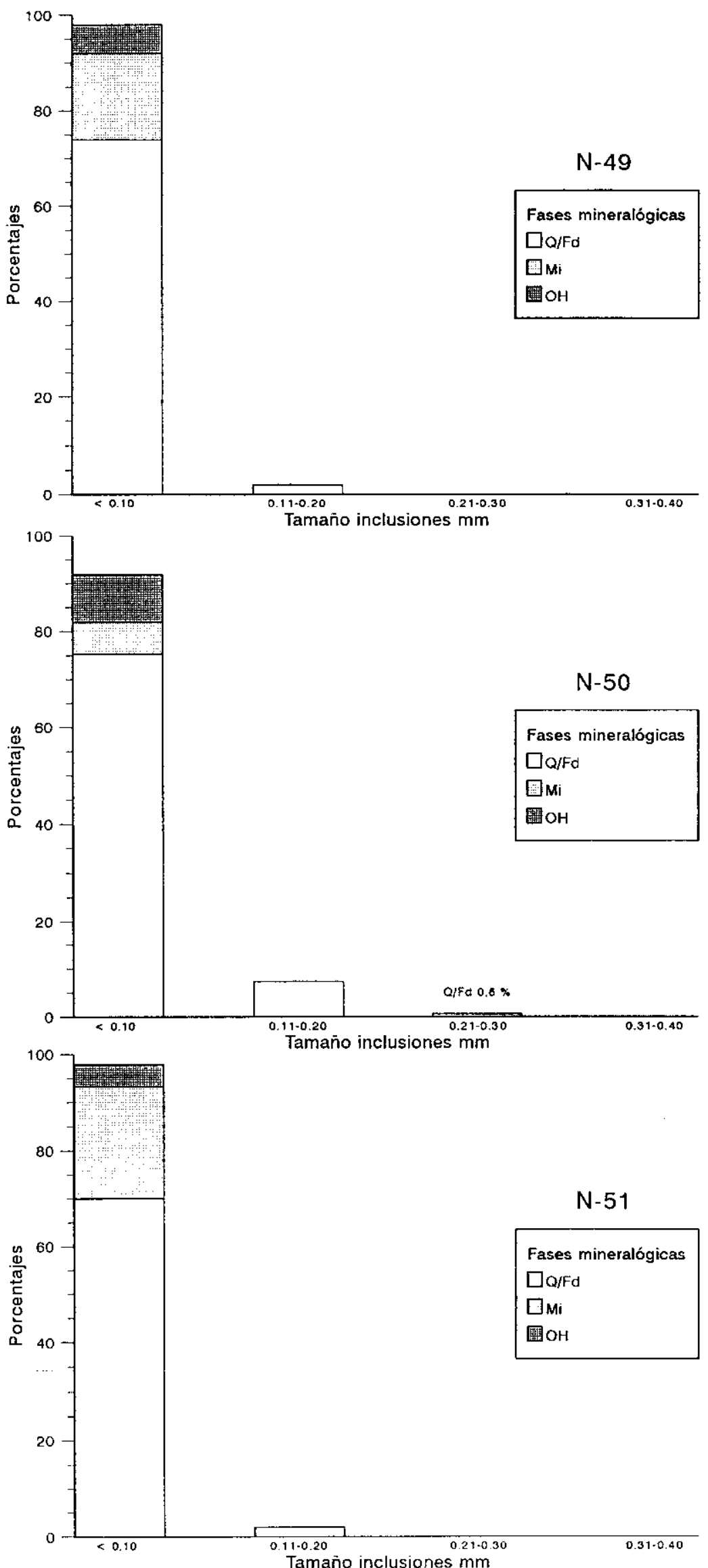

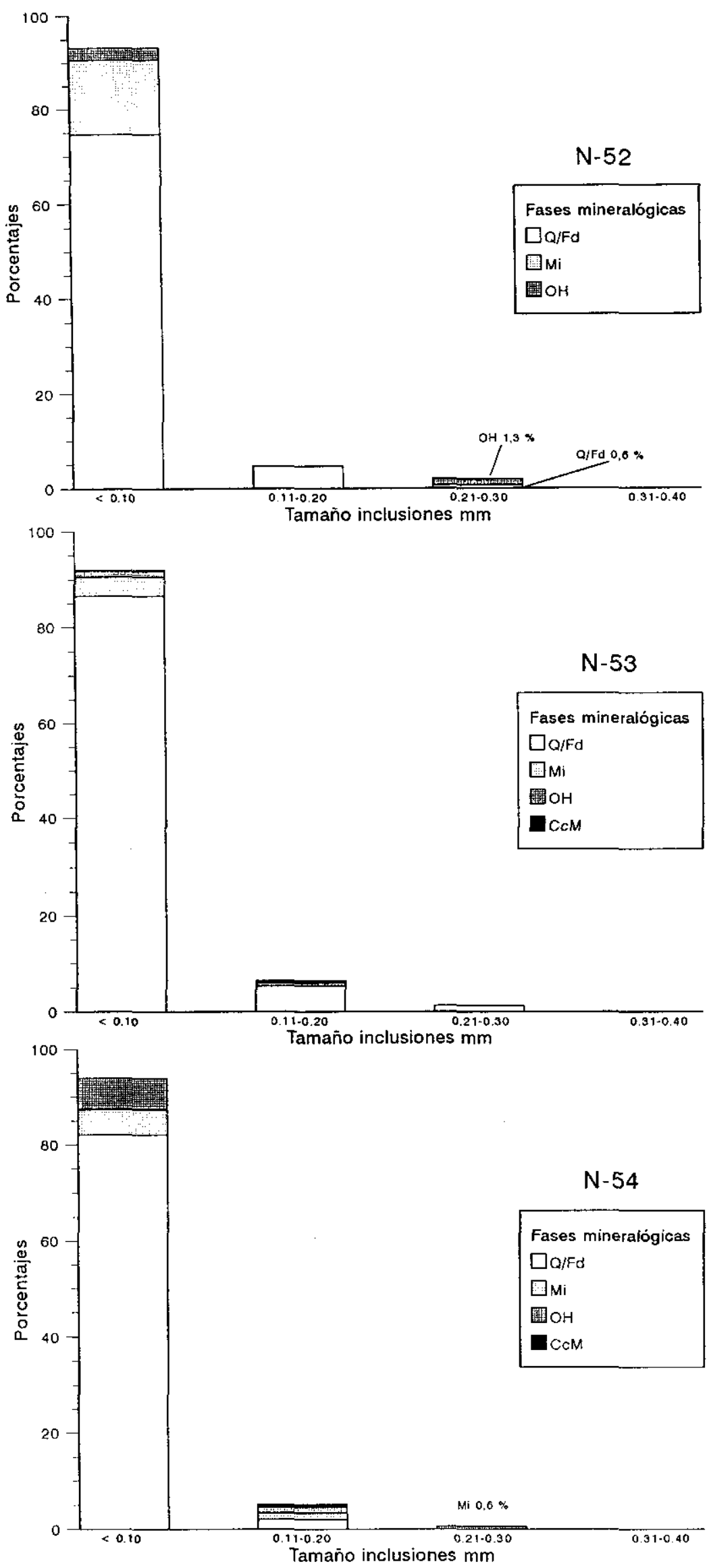

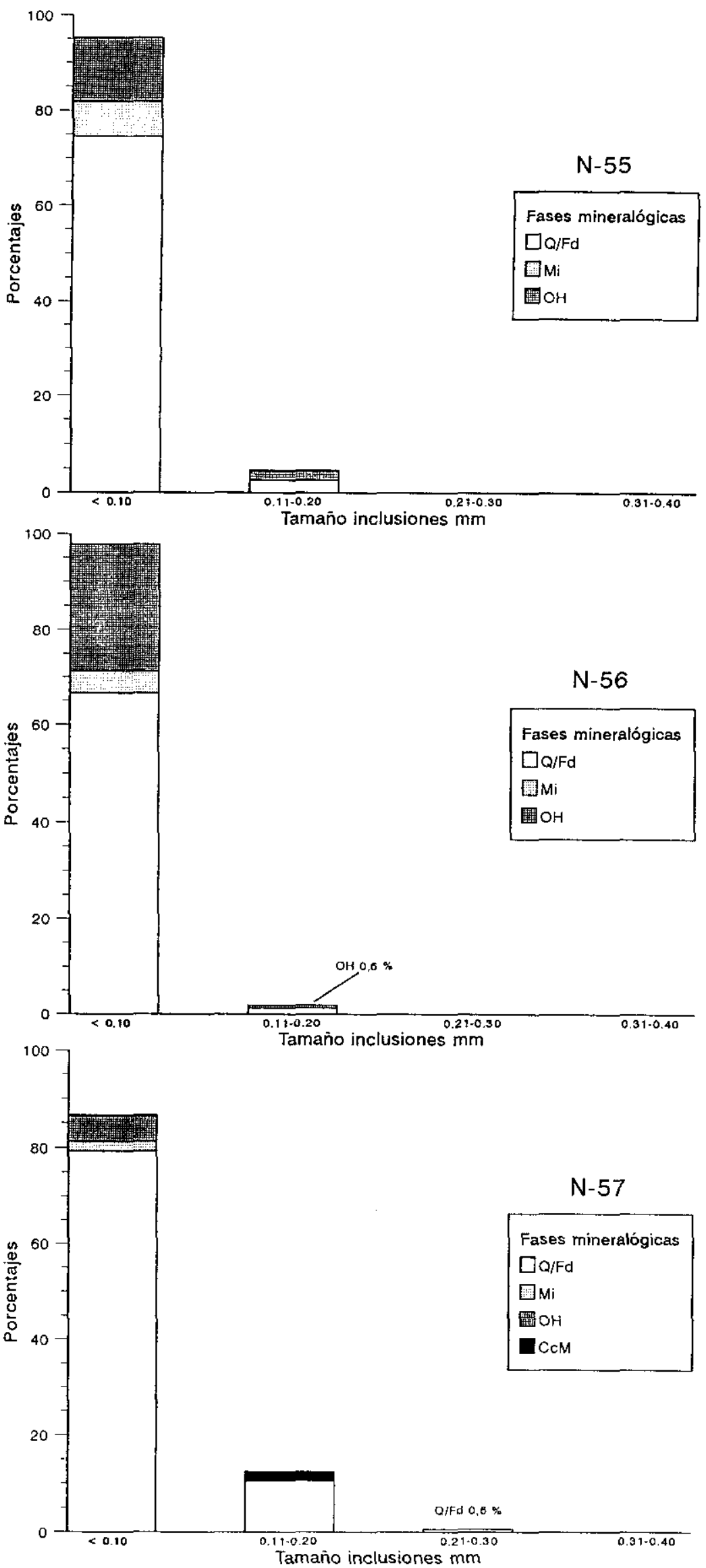

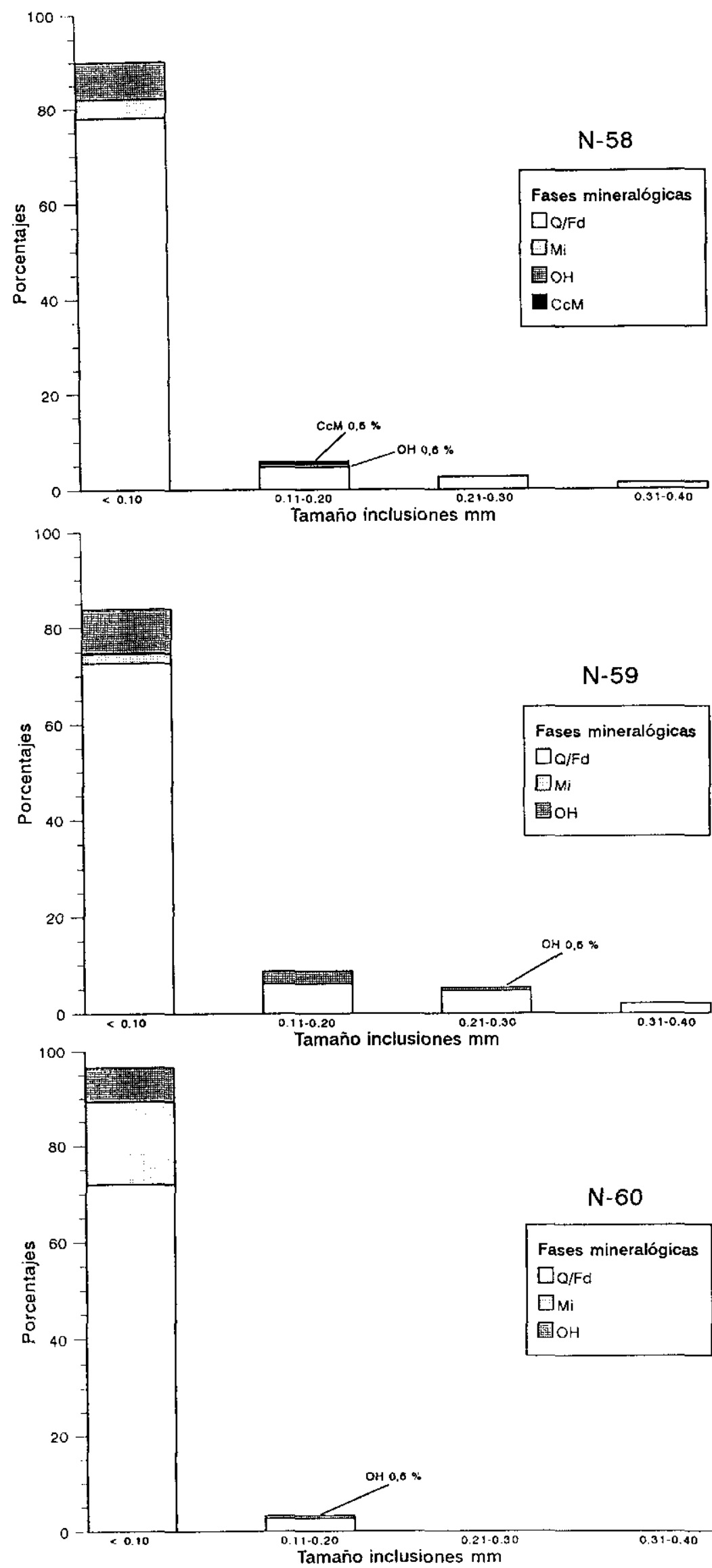

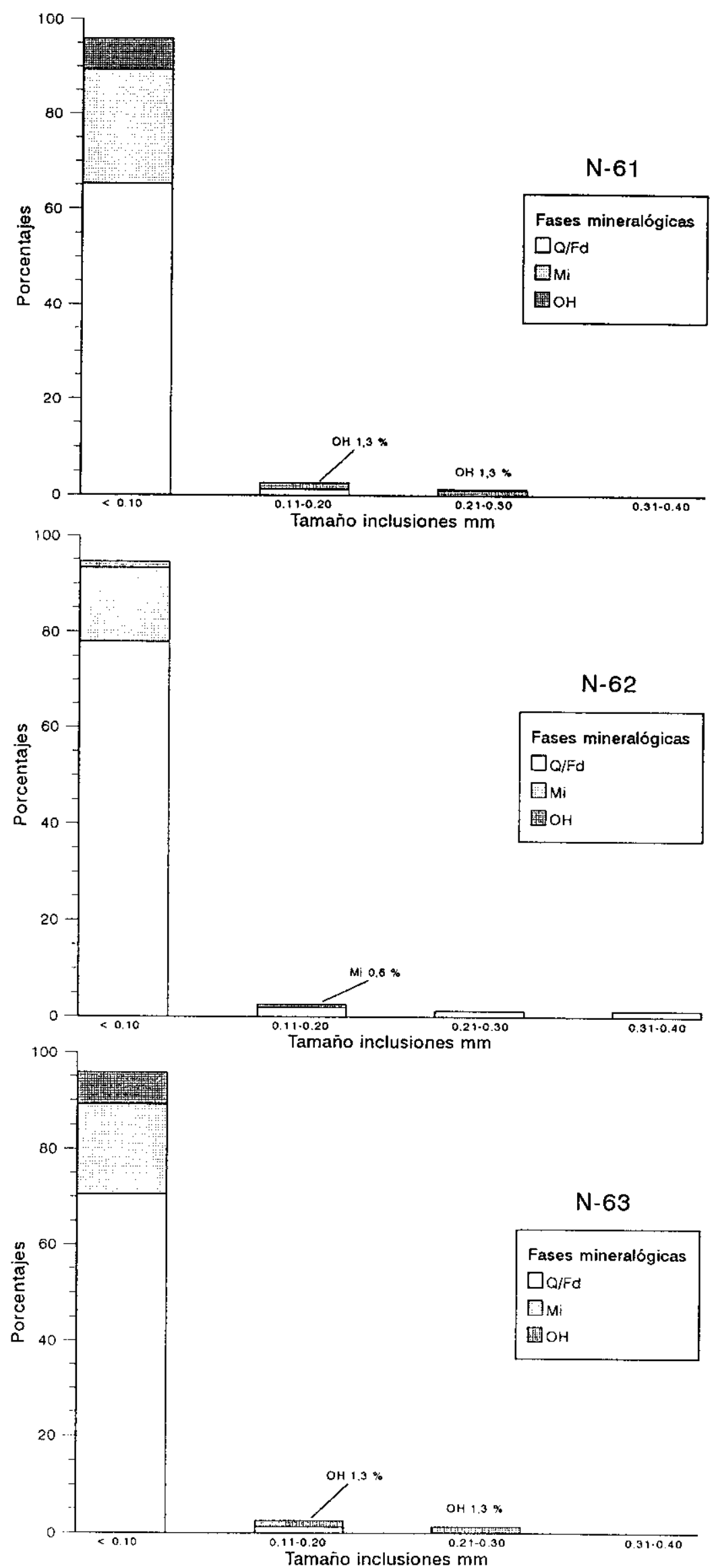

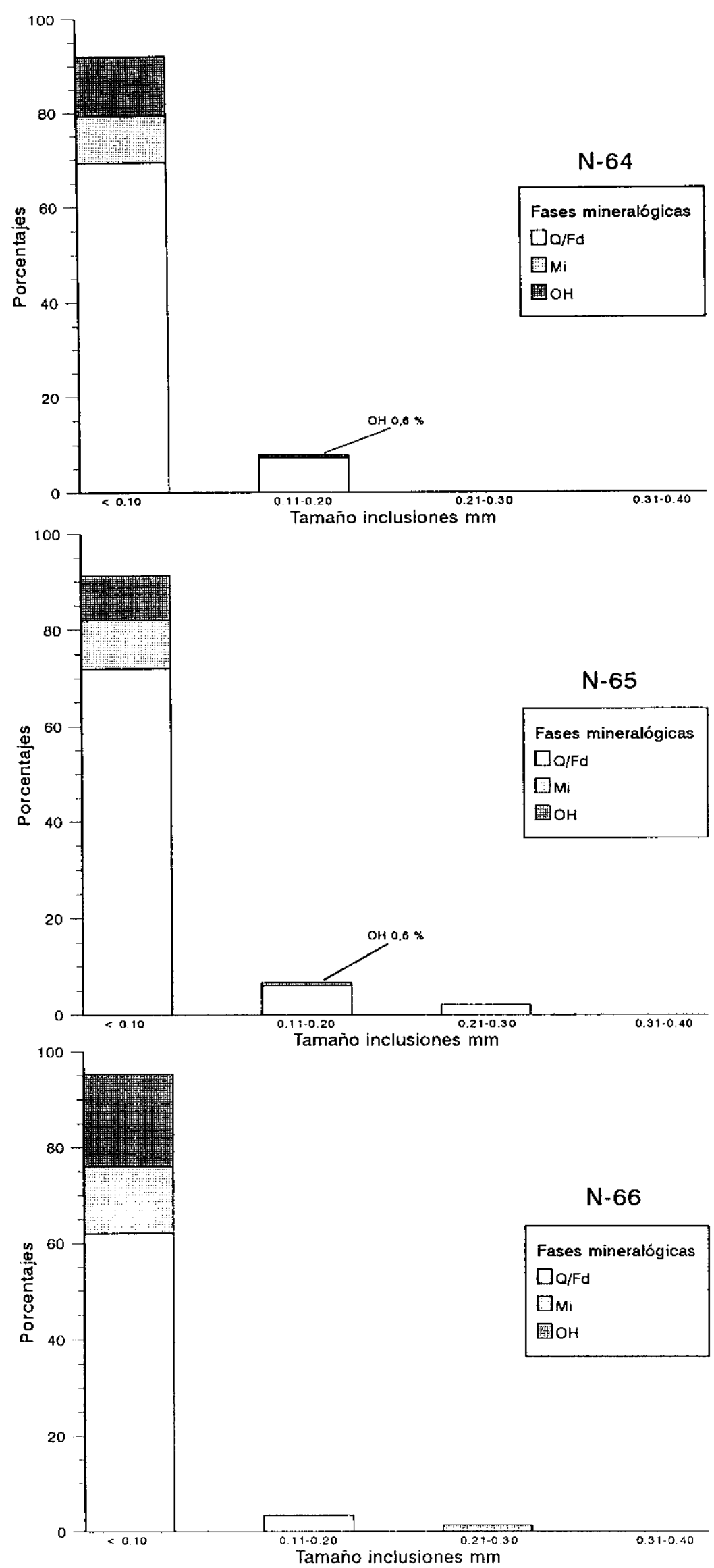

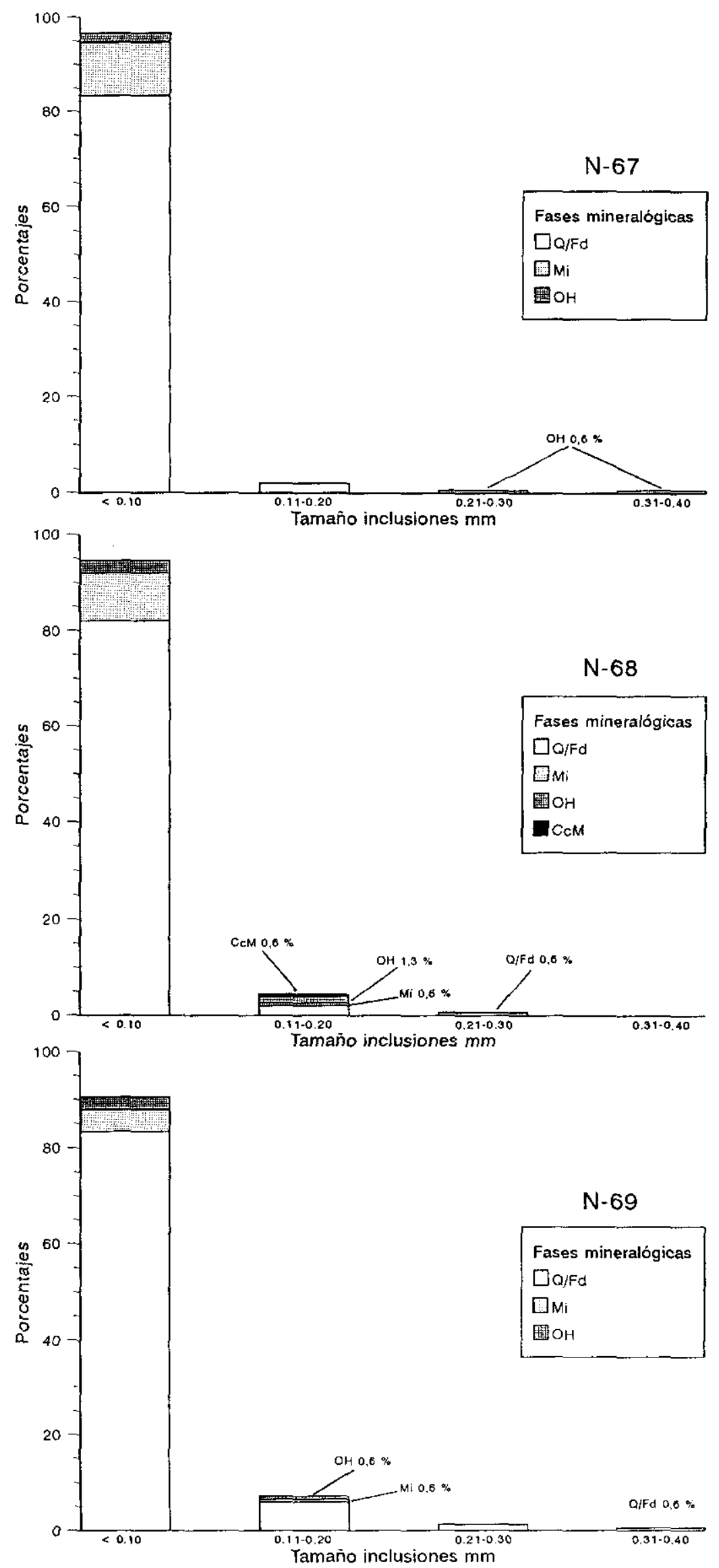

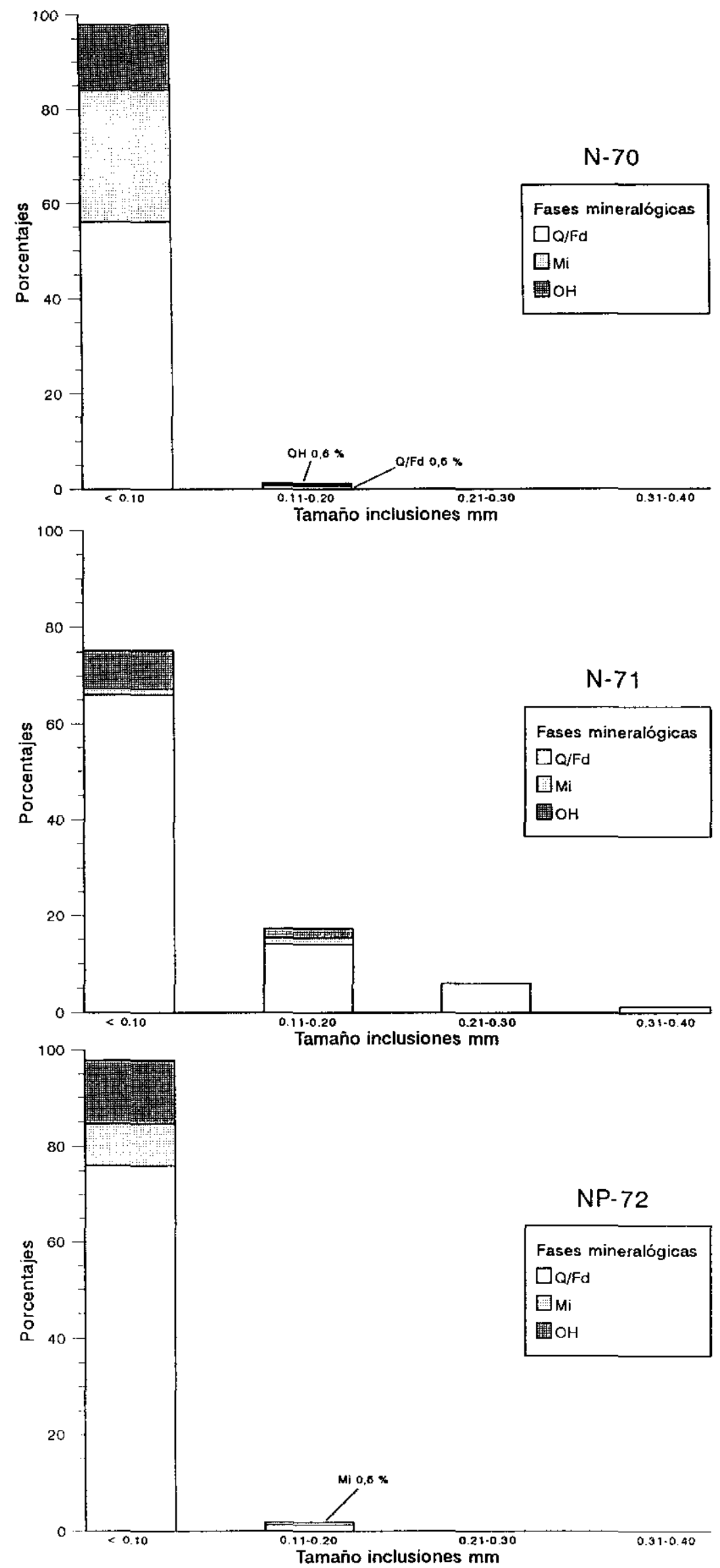

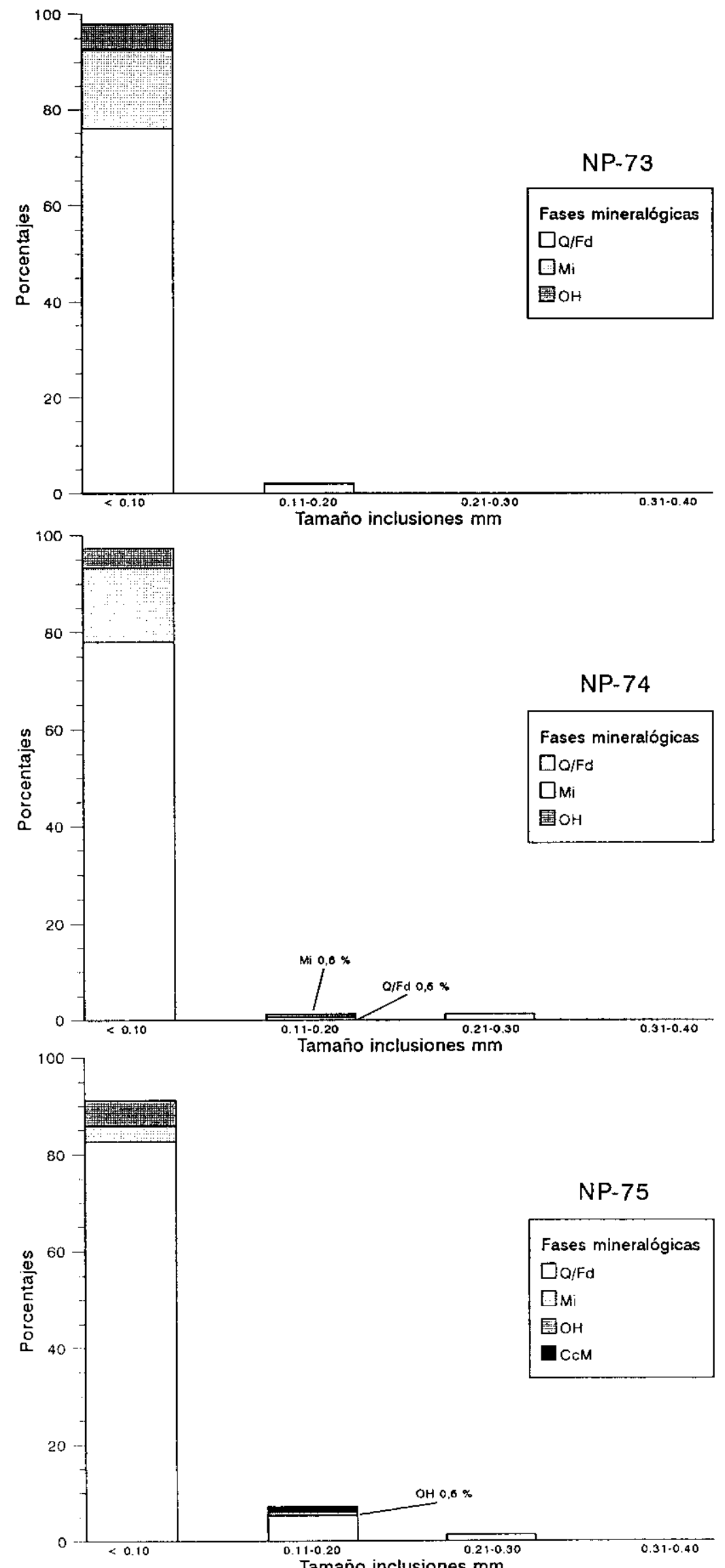

Tamaño inclusiones $\mathrm{mm}$ 

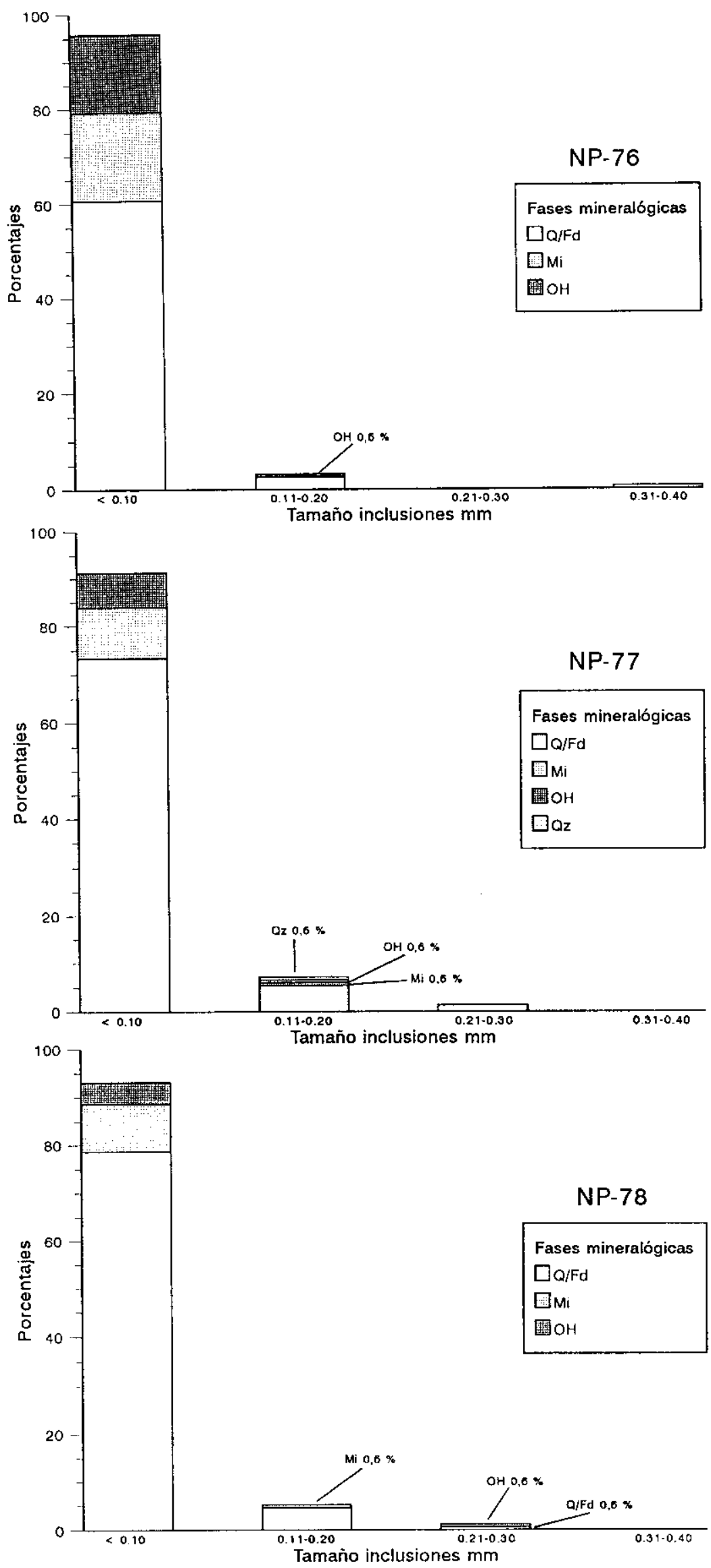

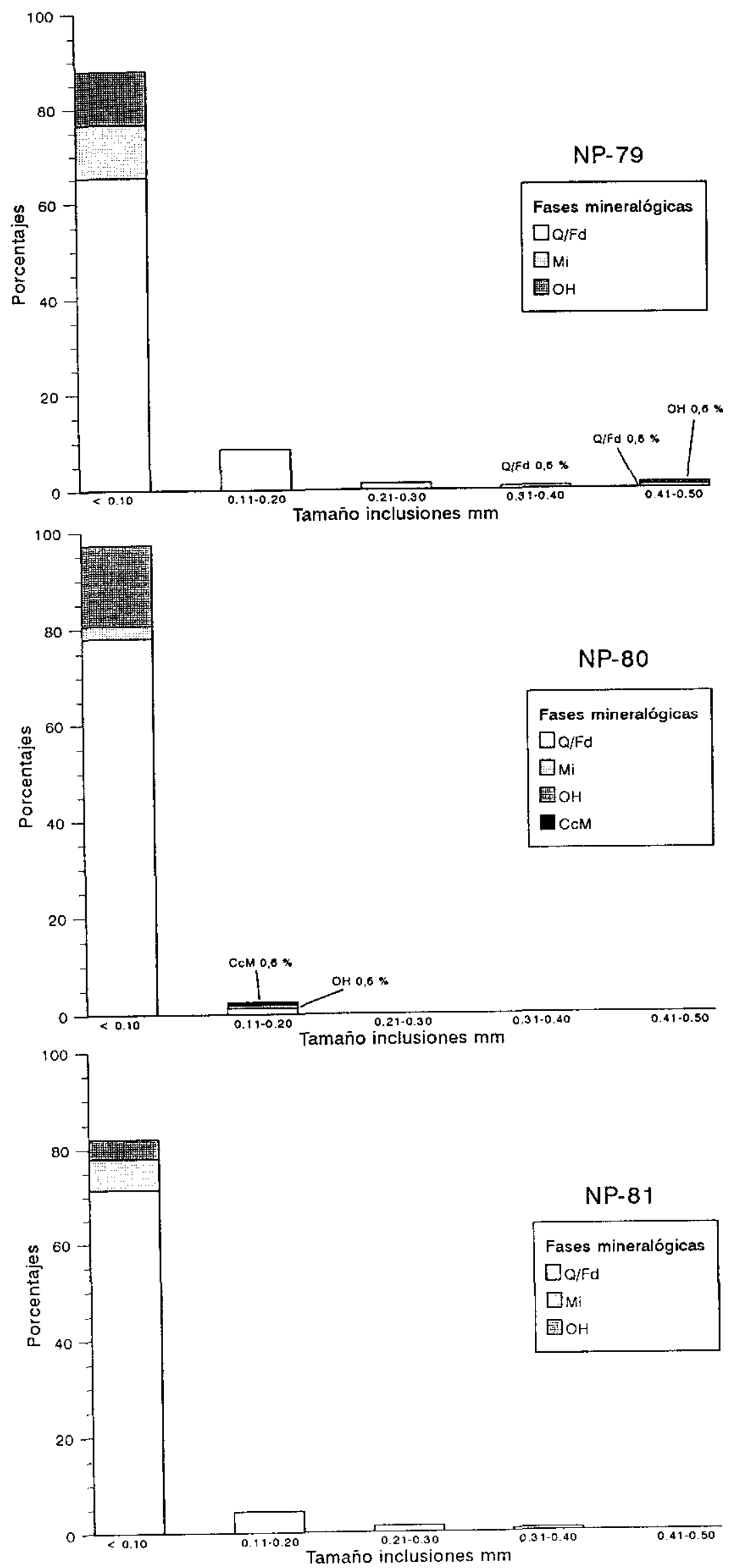

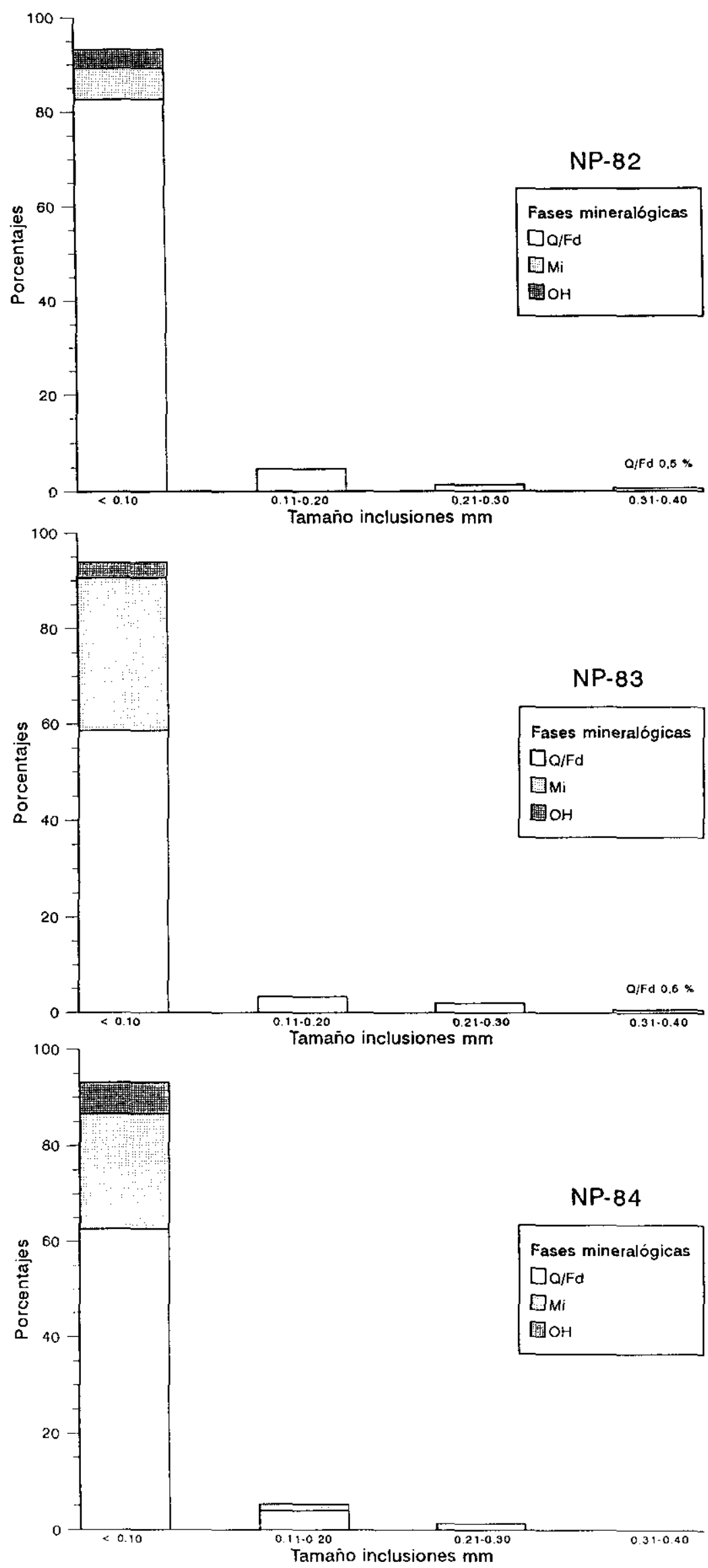

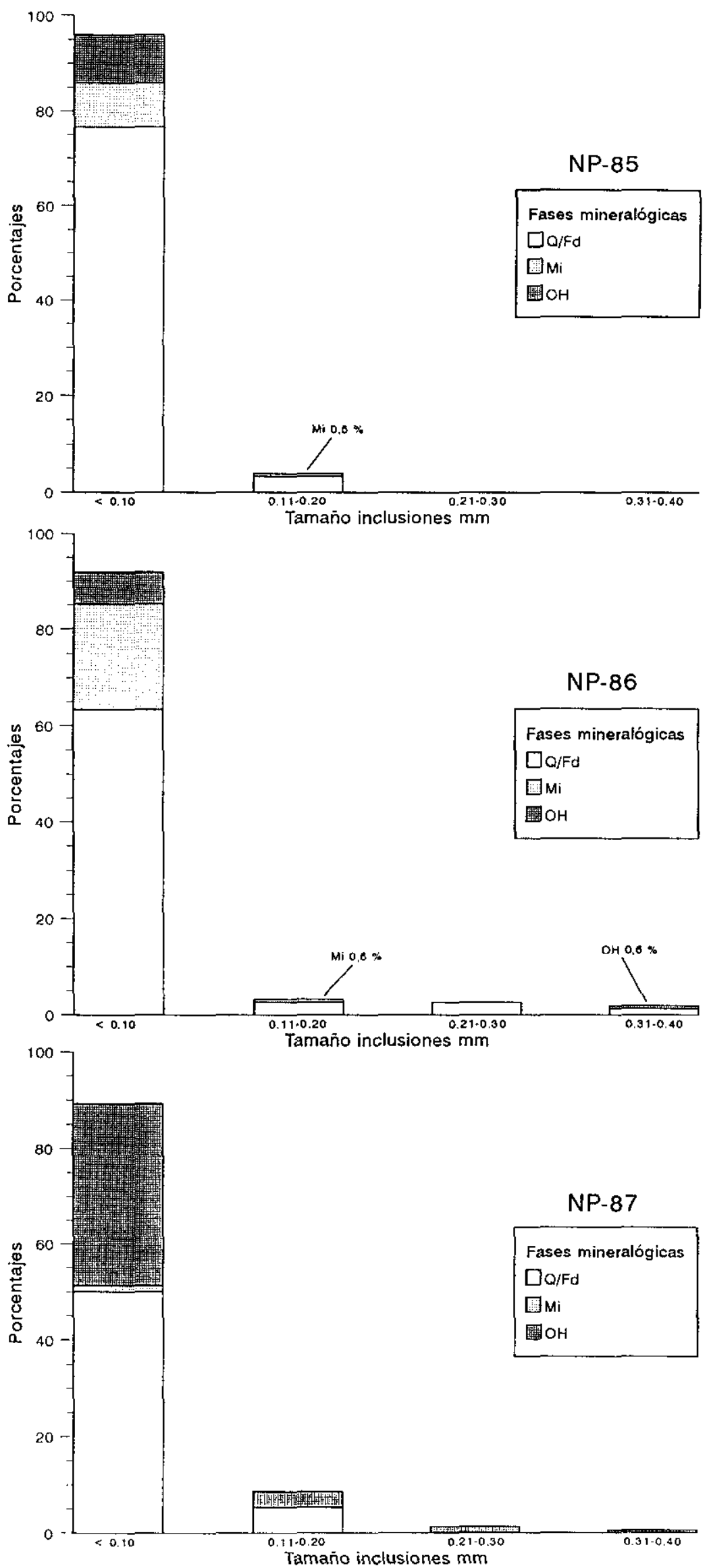

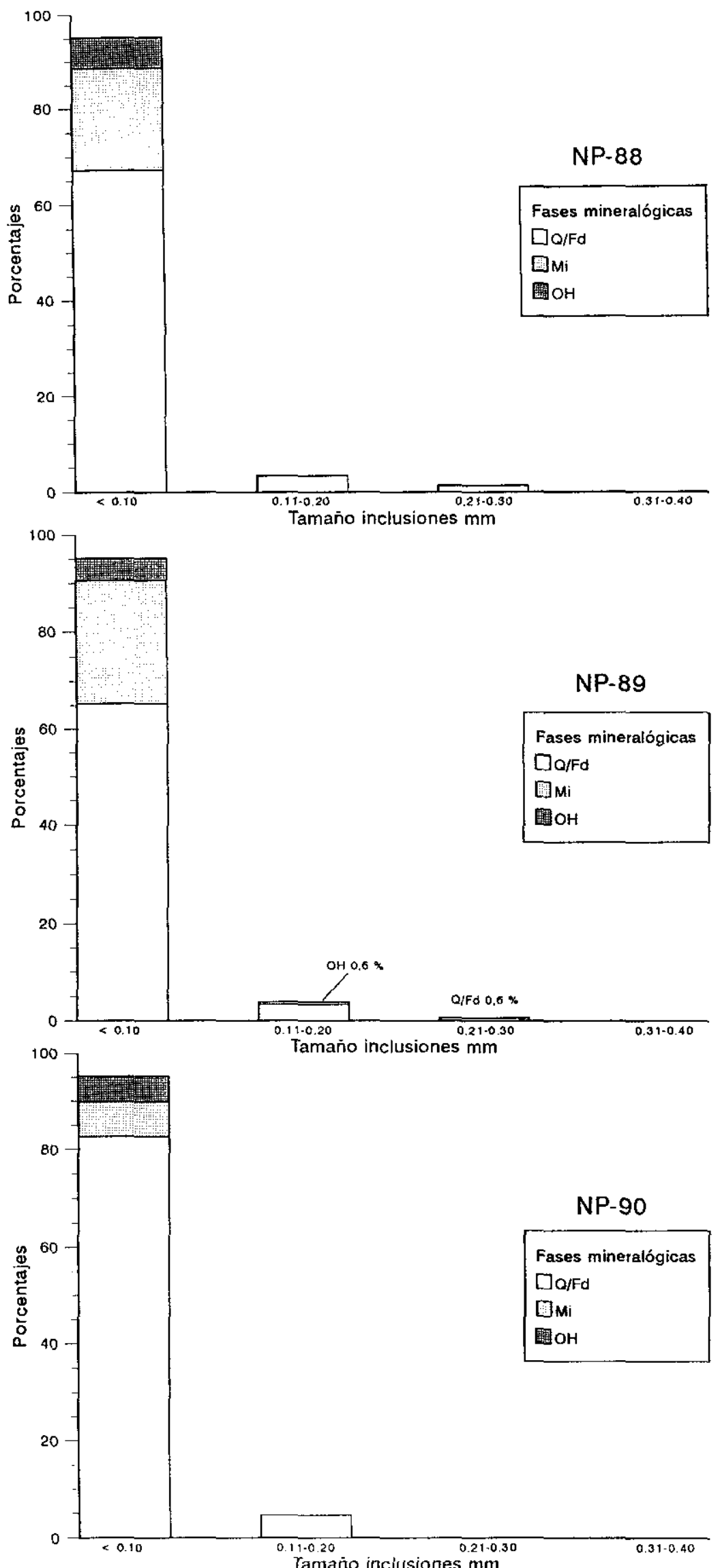

Tamaño inciusiones mm 

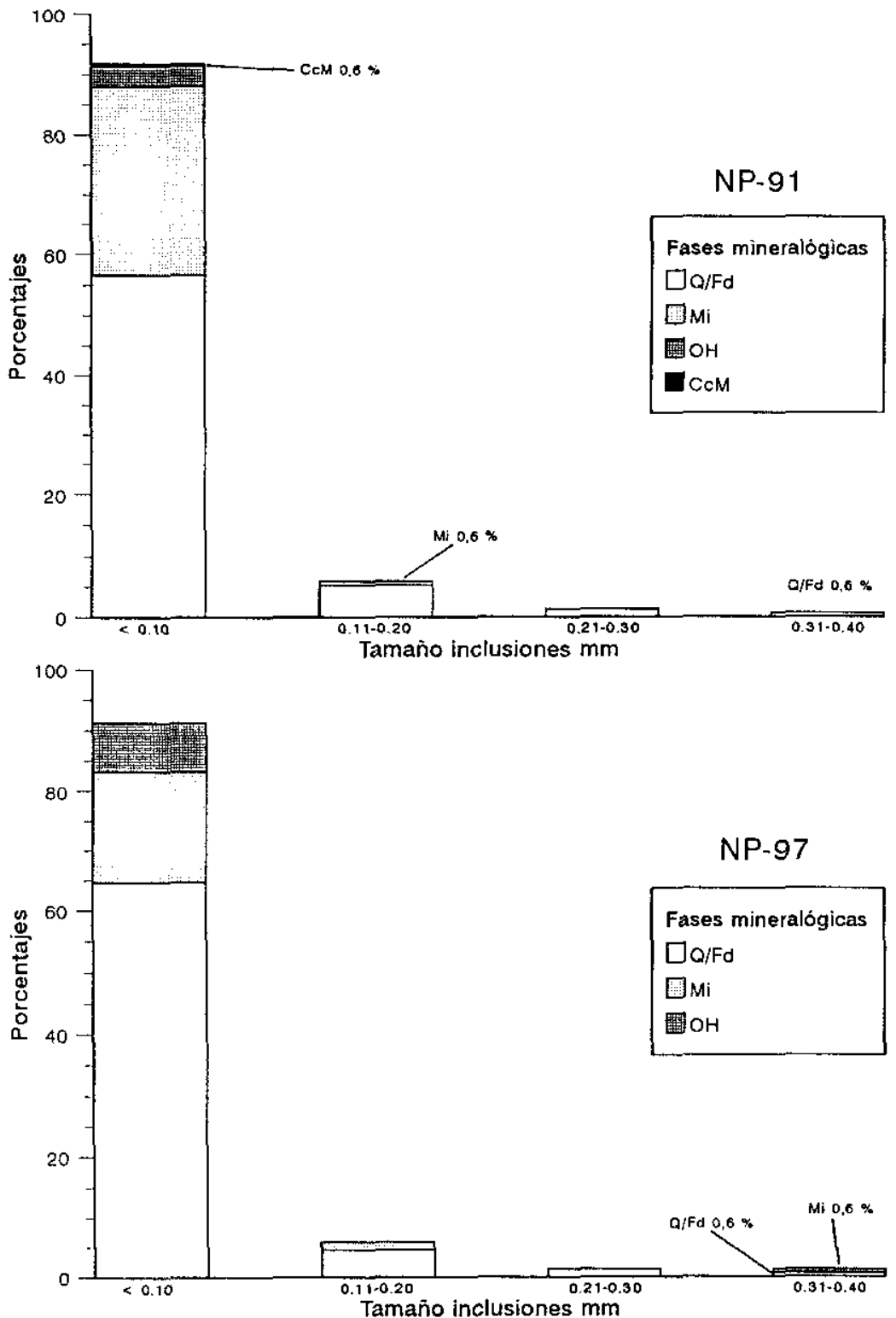

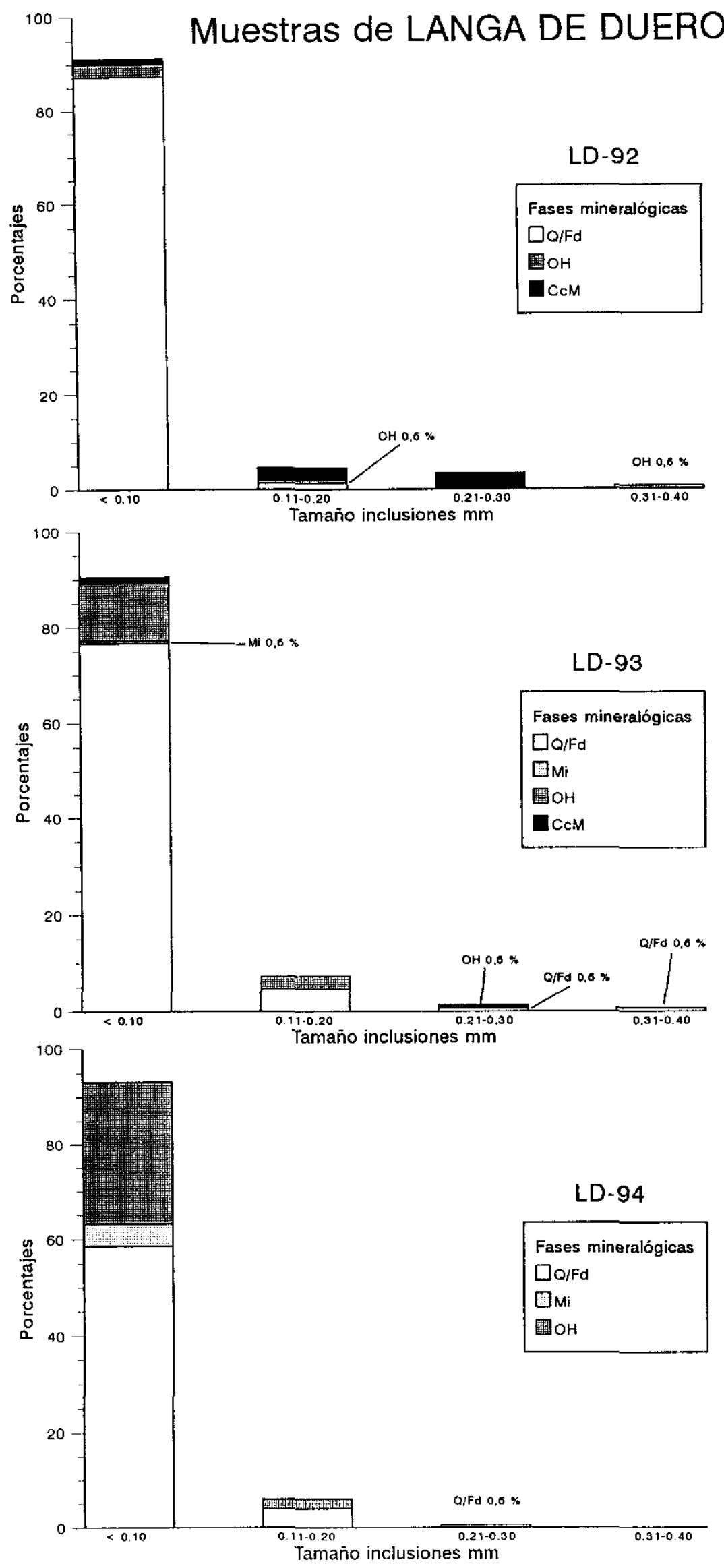


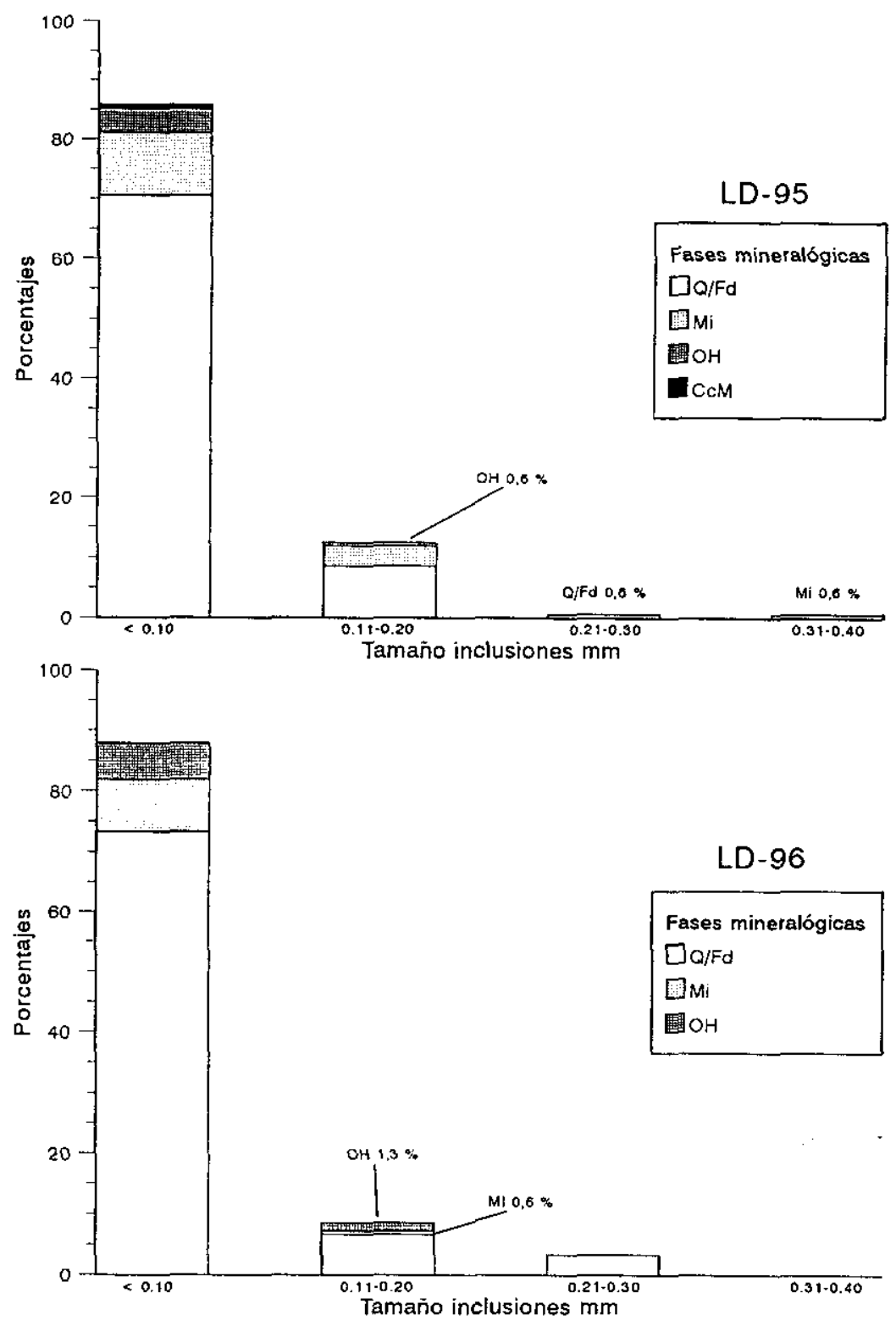



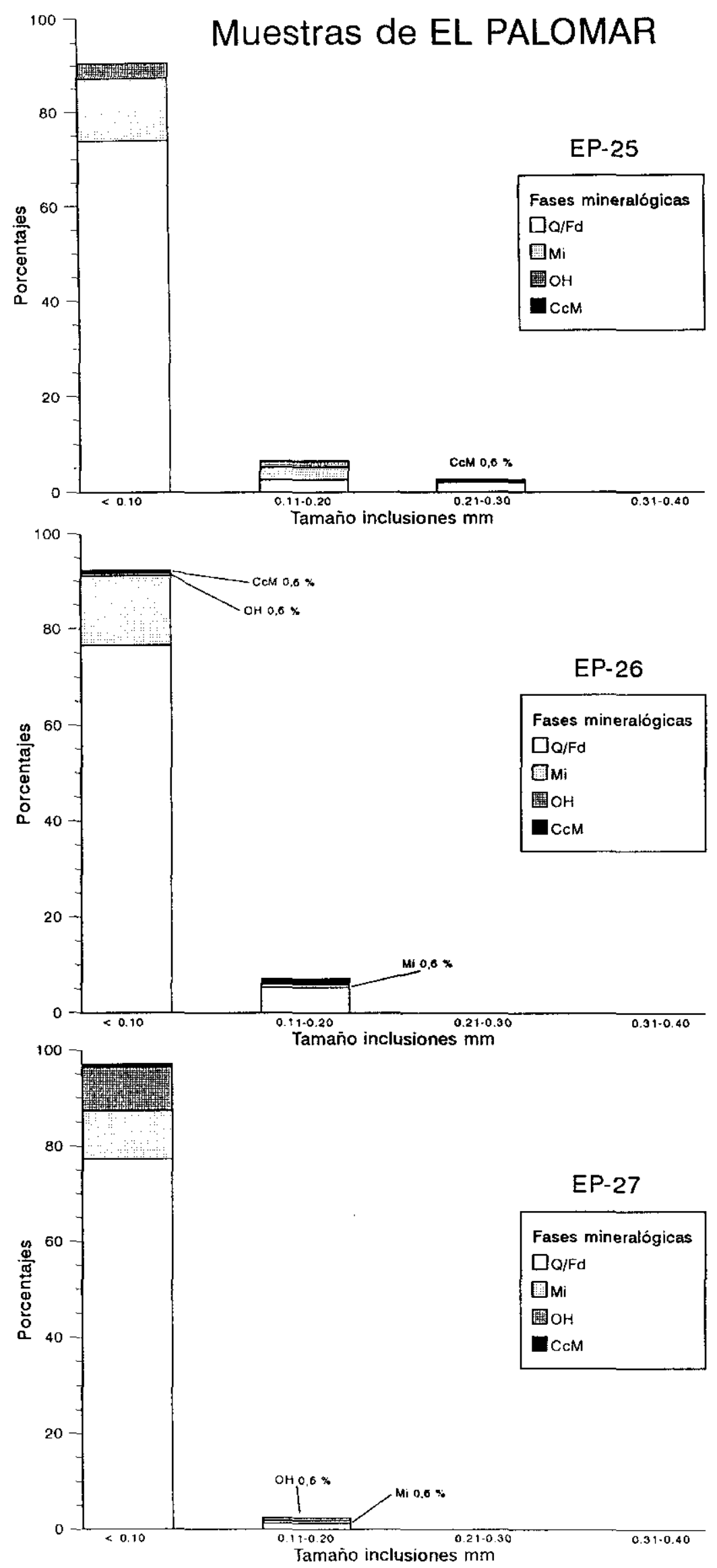

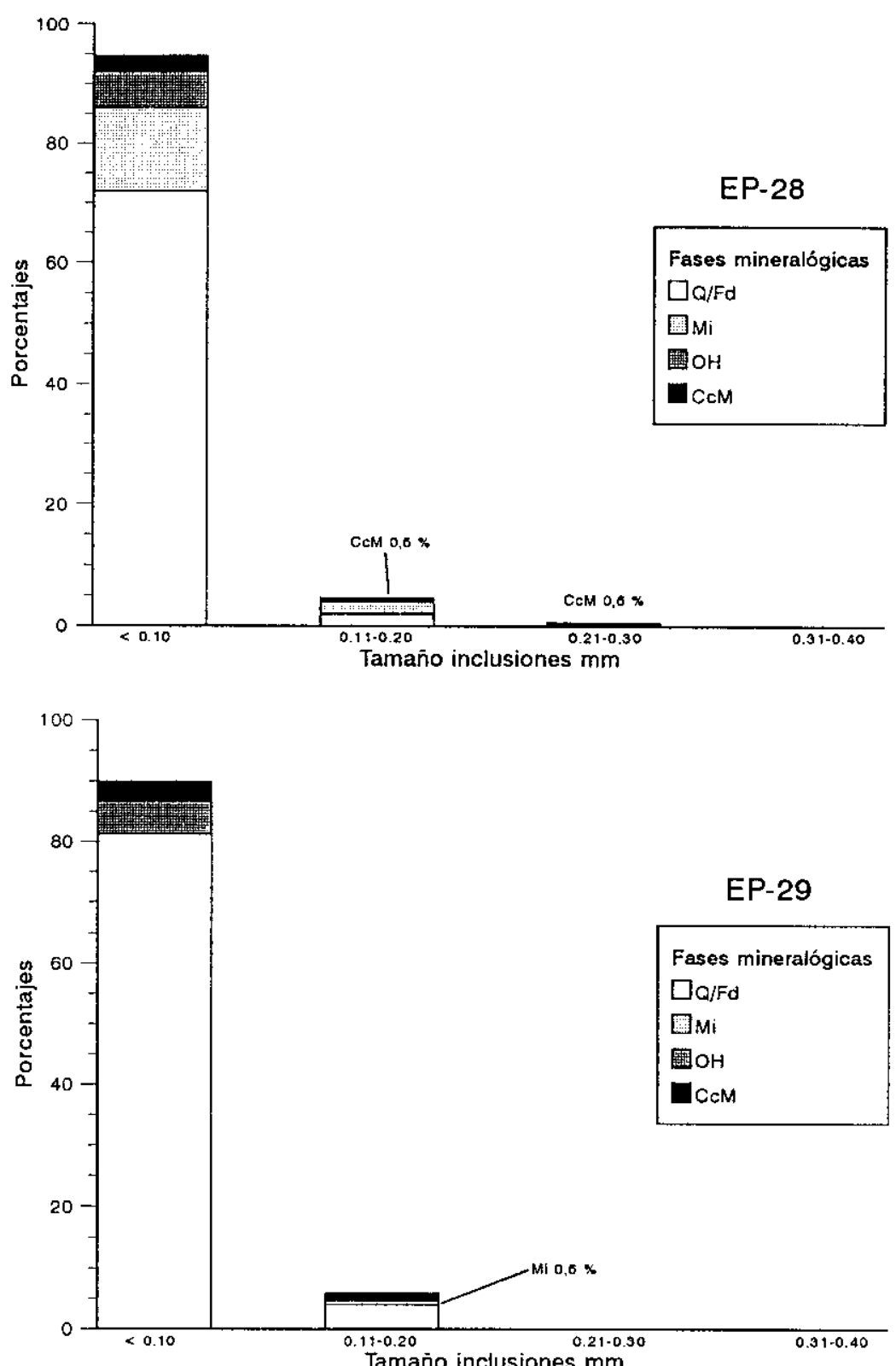

Tamaño inclusiones $\mathrm{mm}$ 

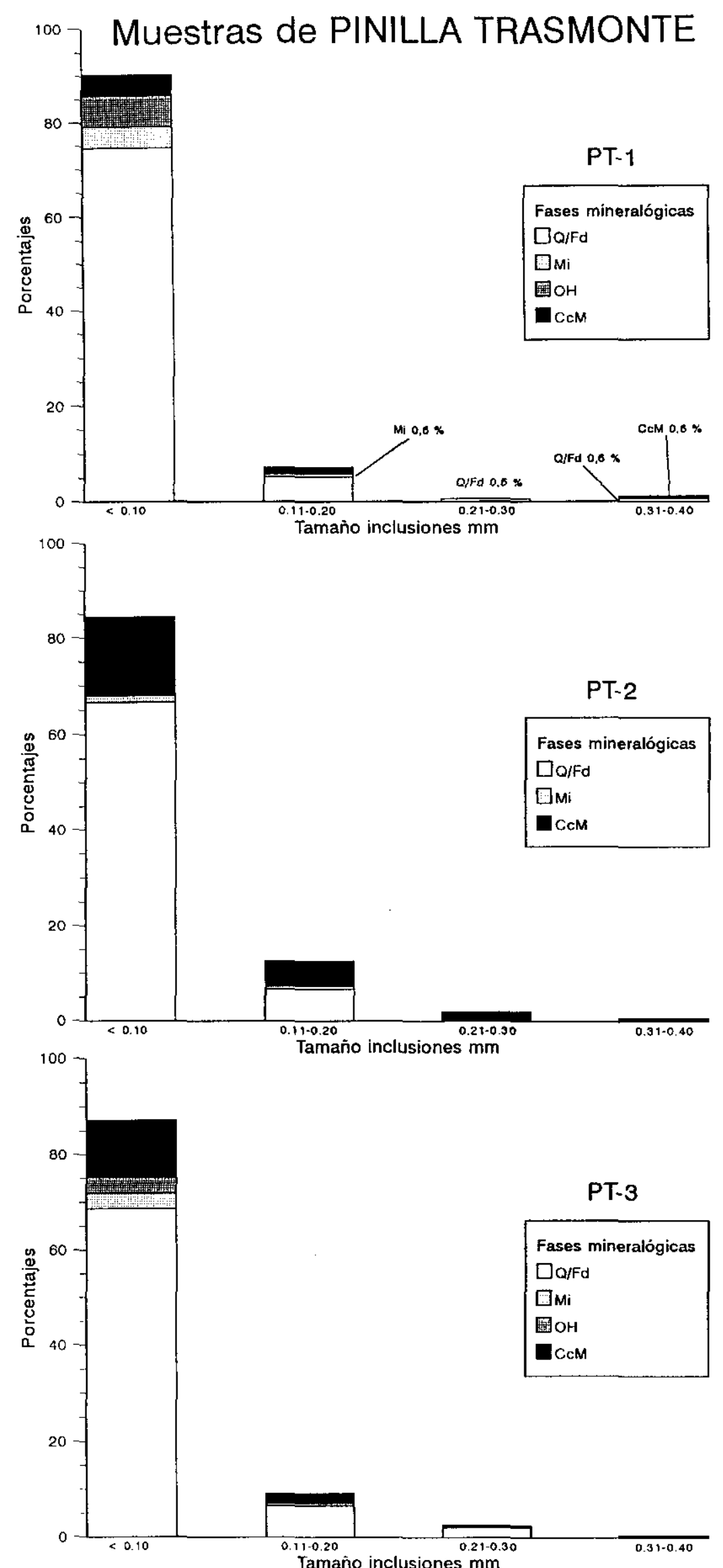

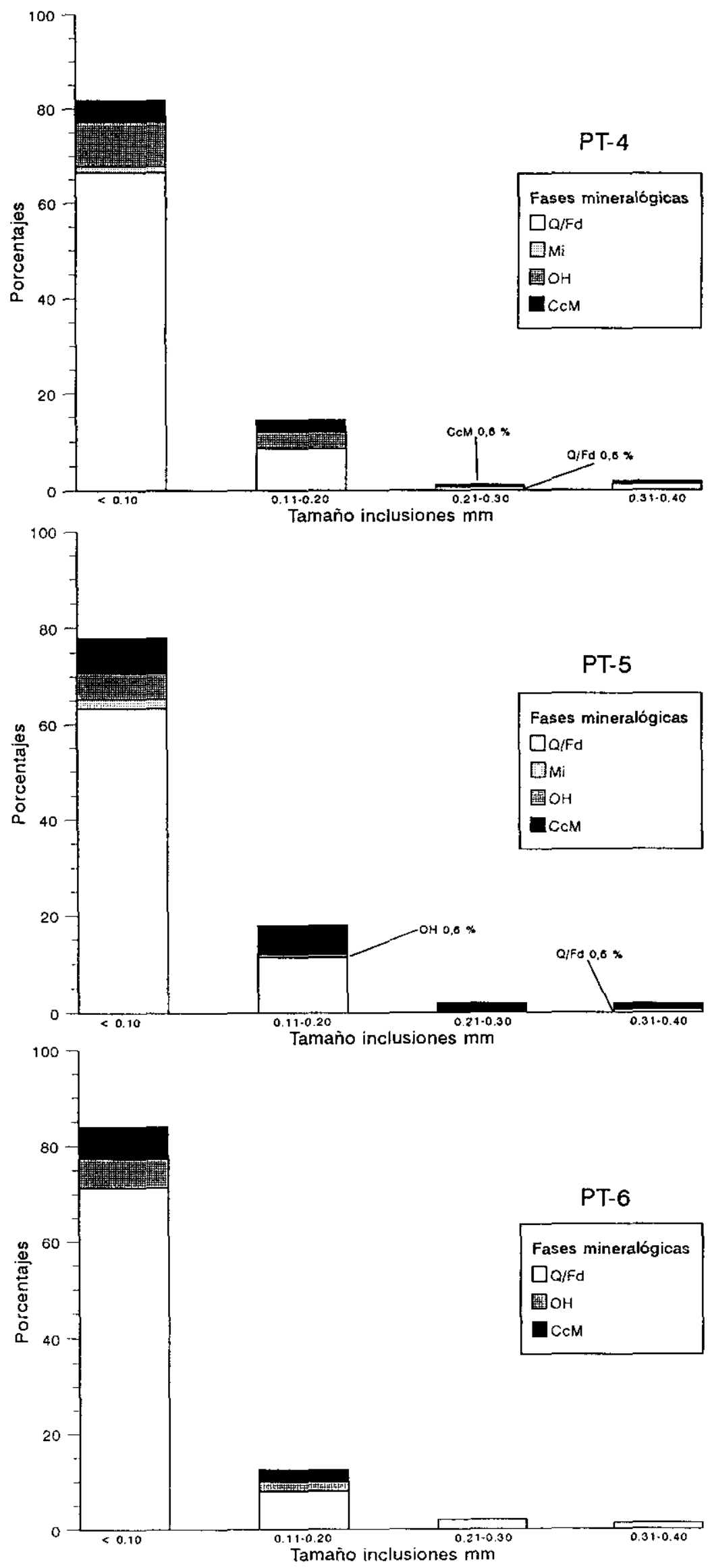

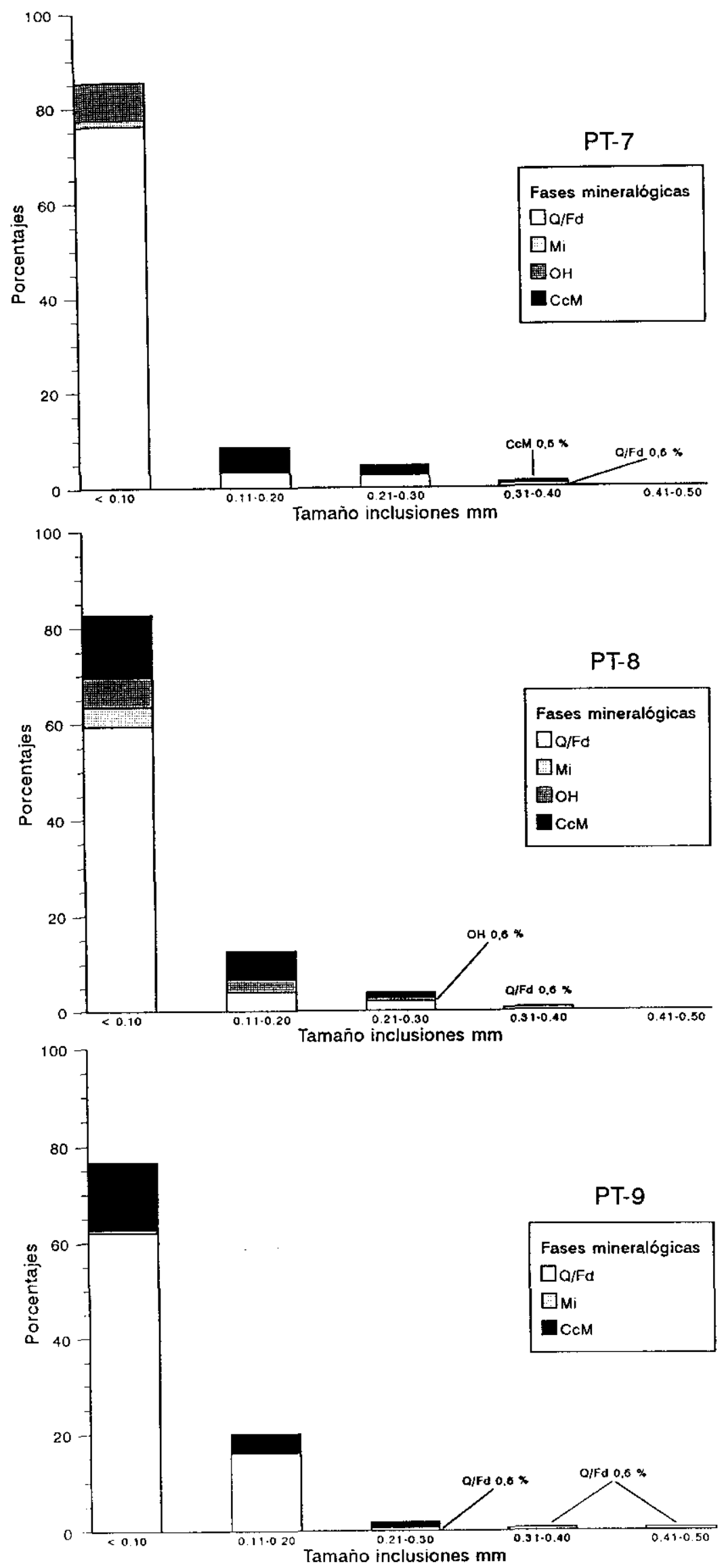


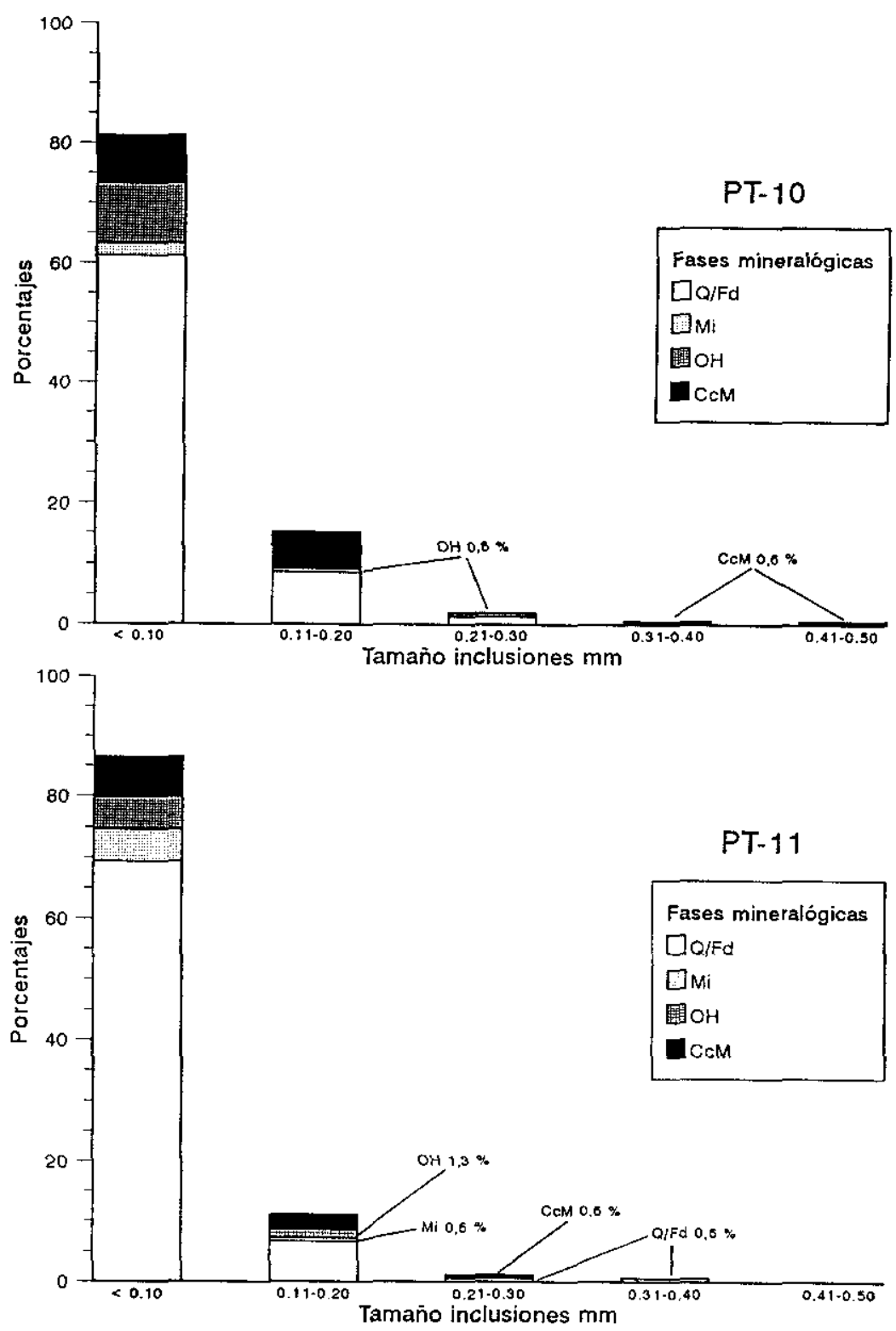



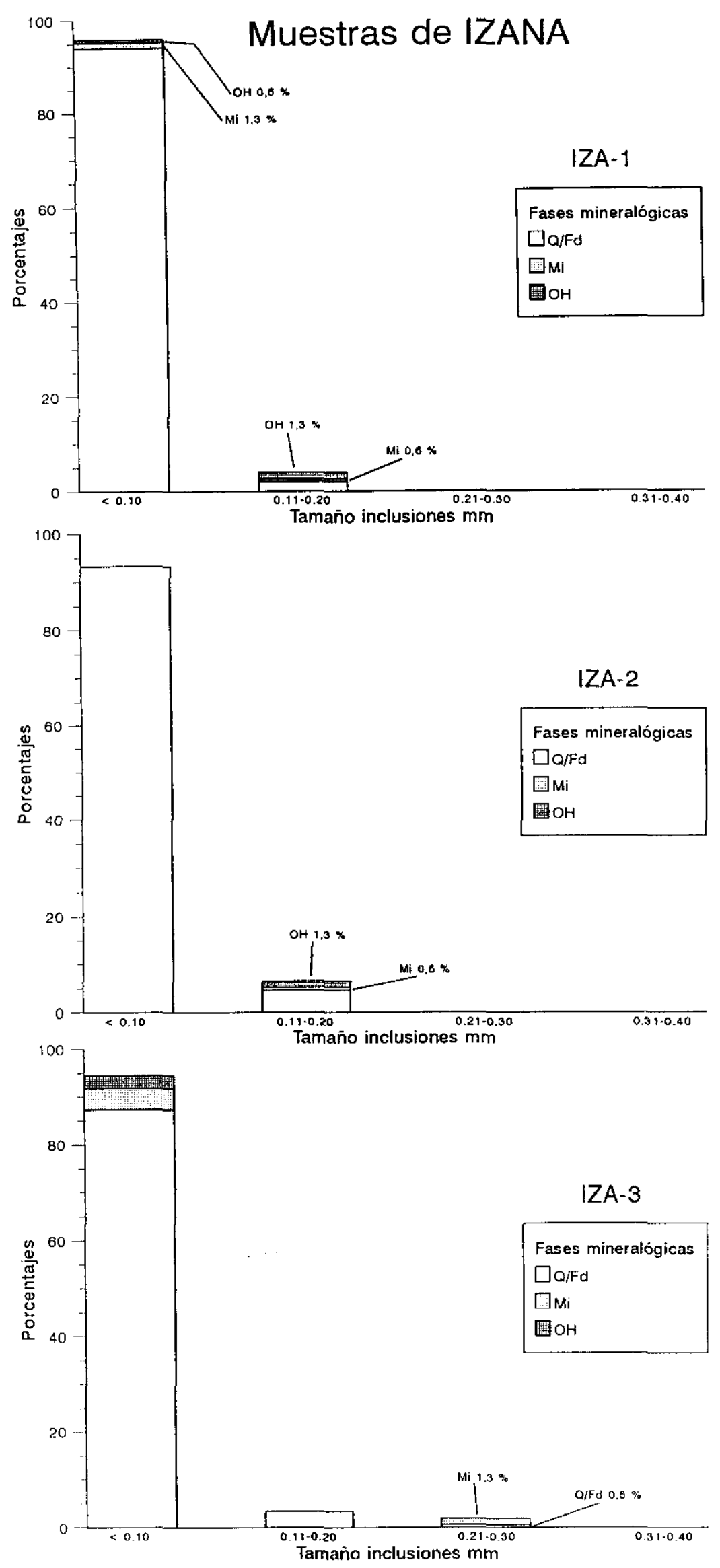

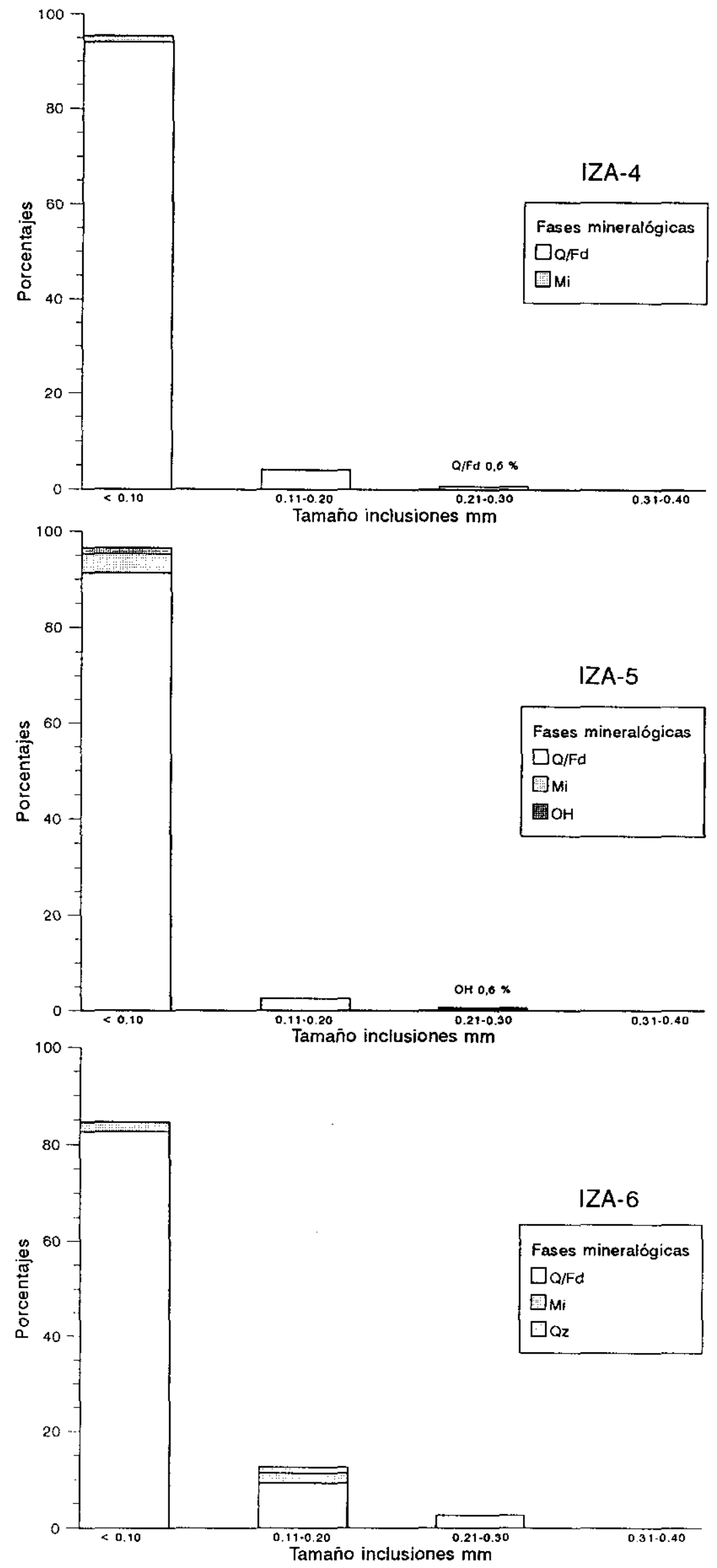

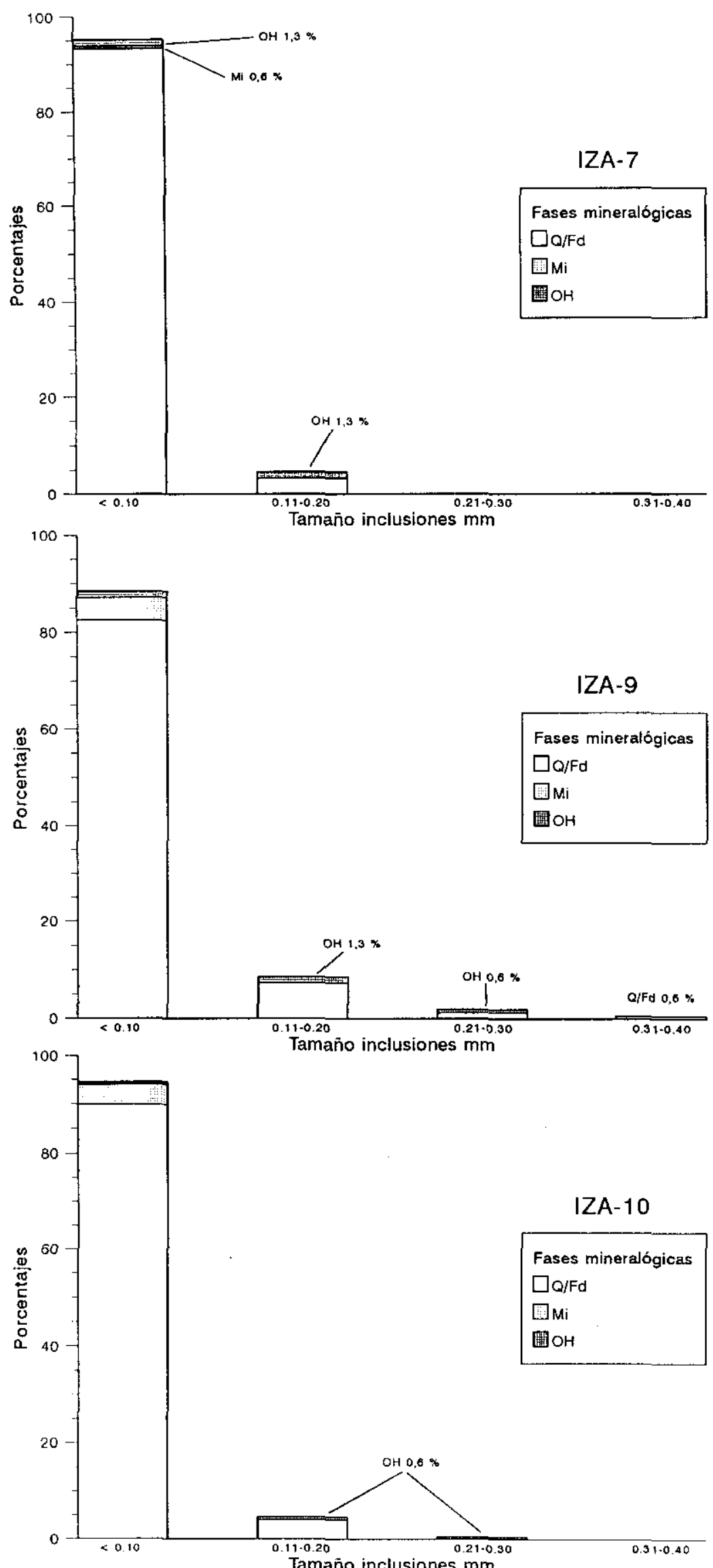

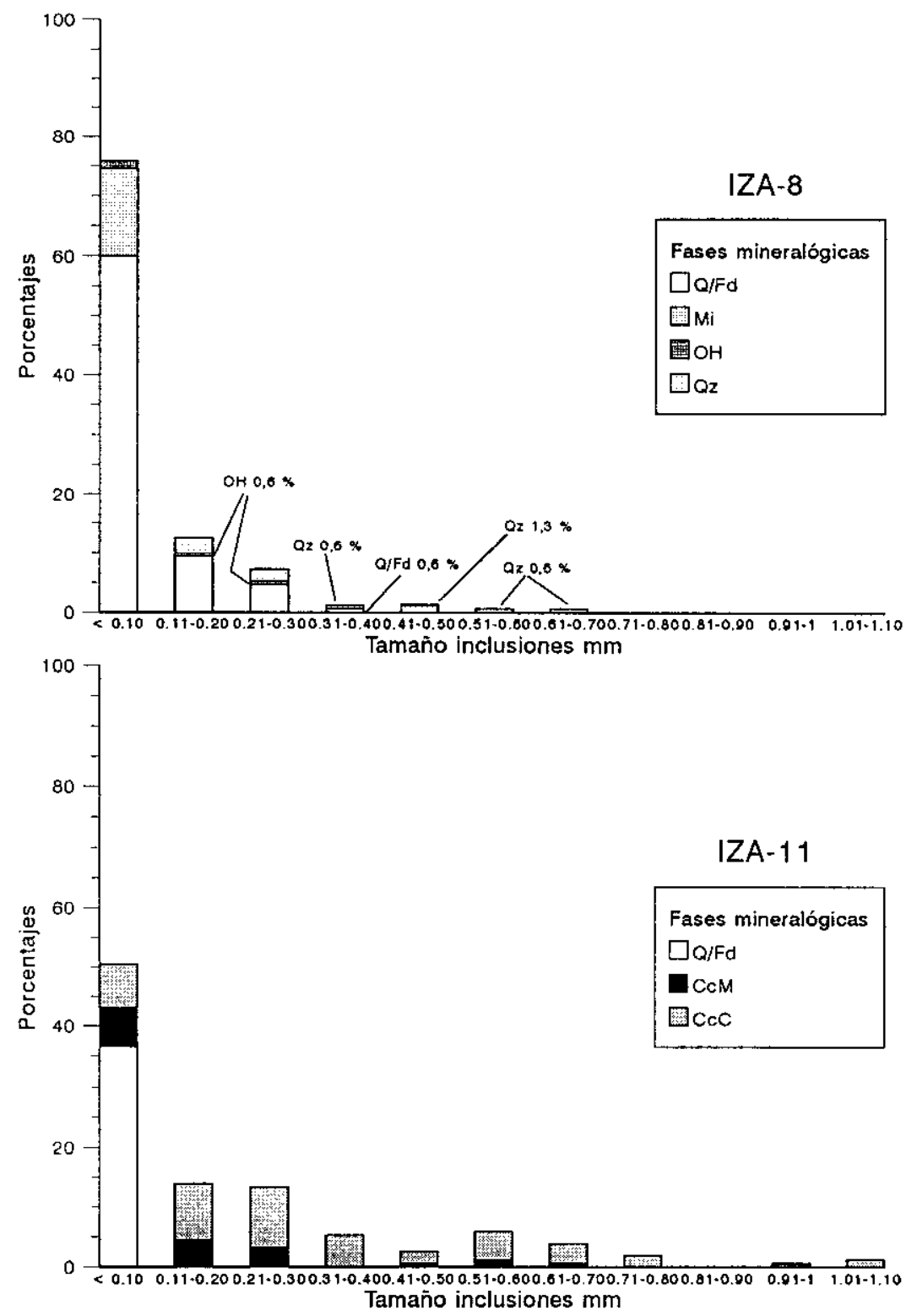

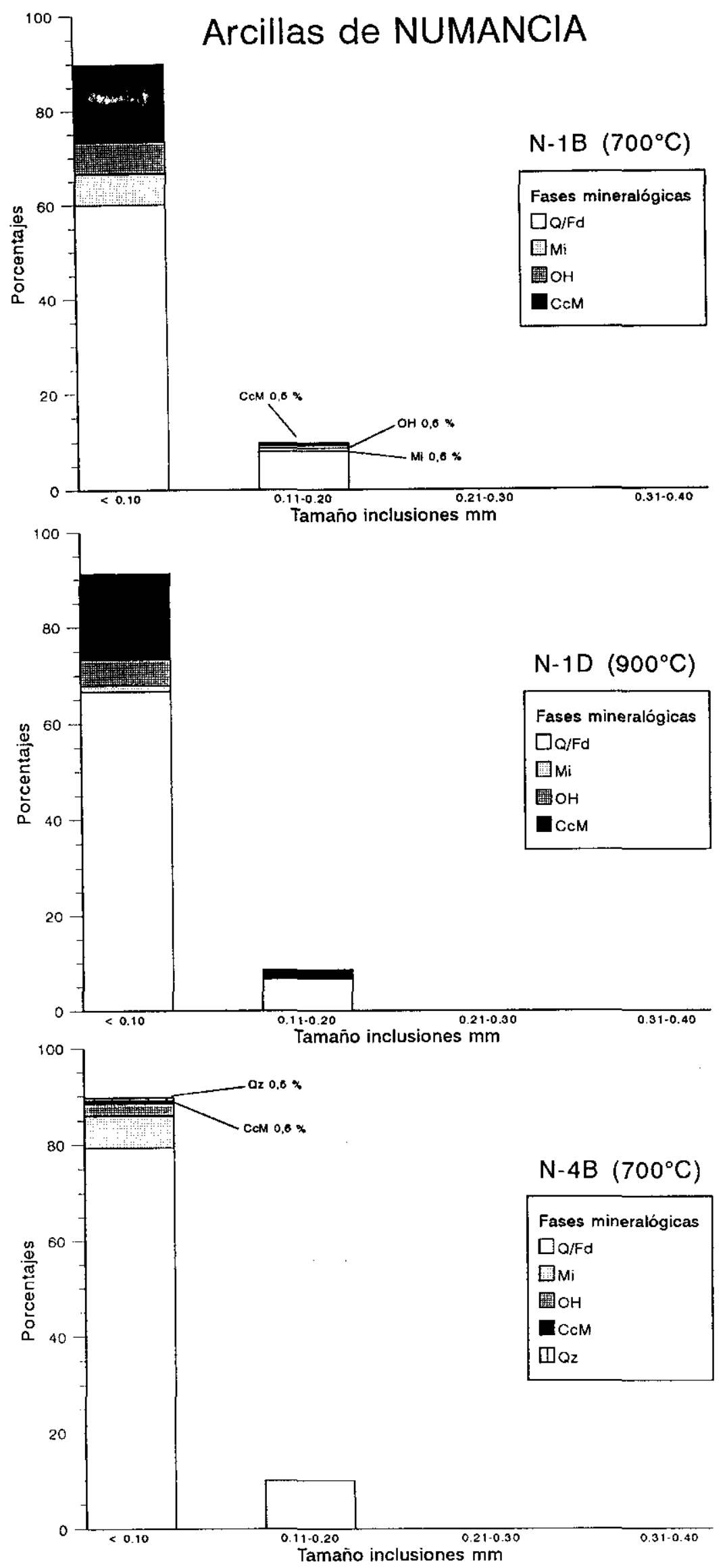


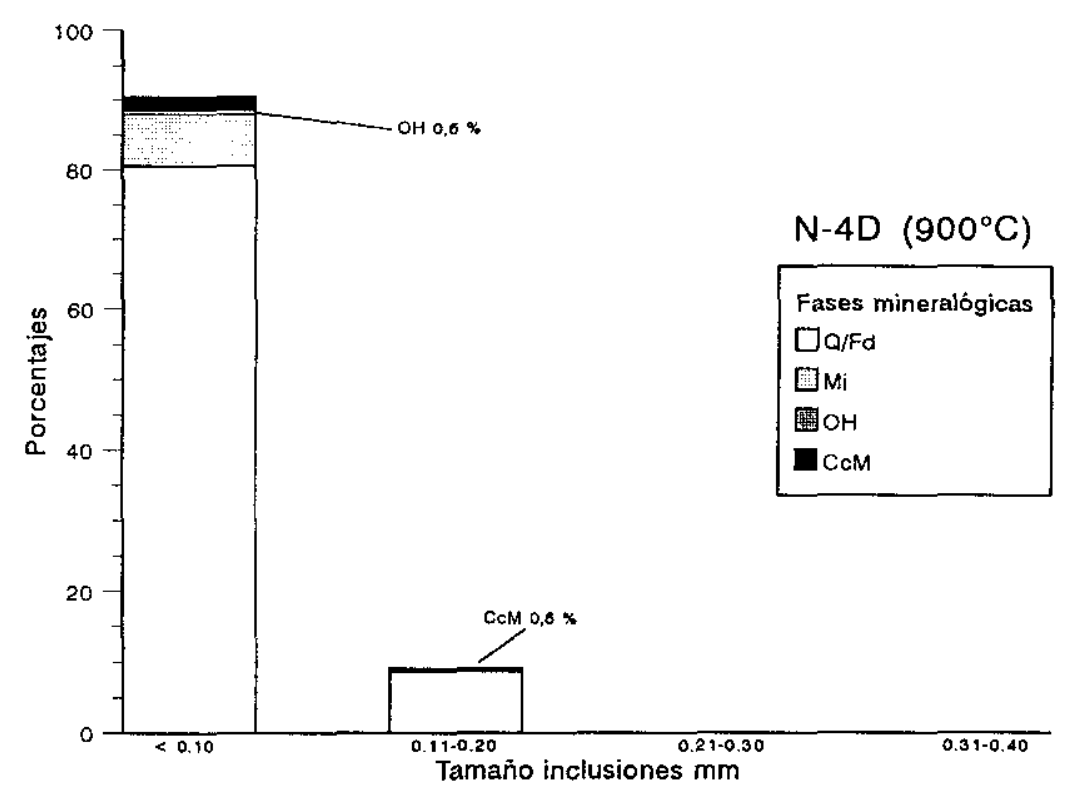



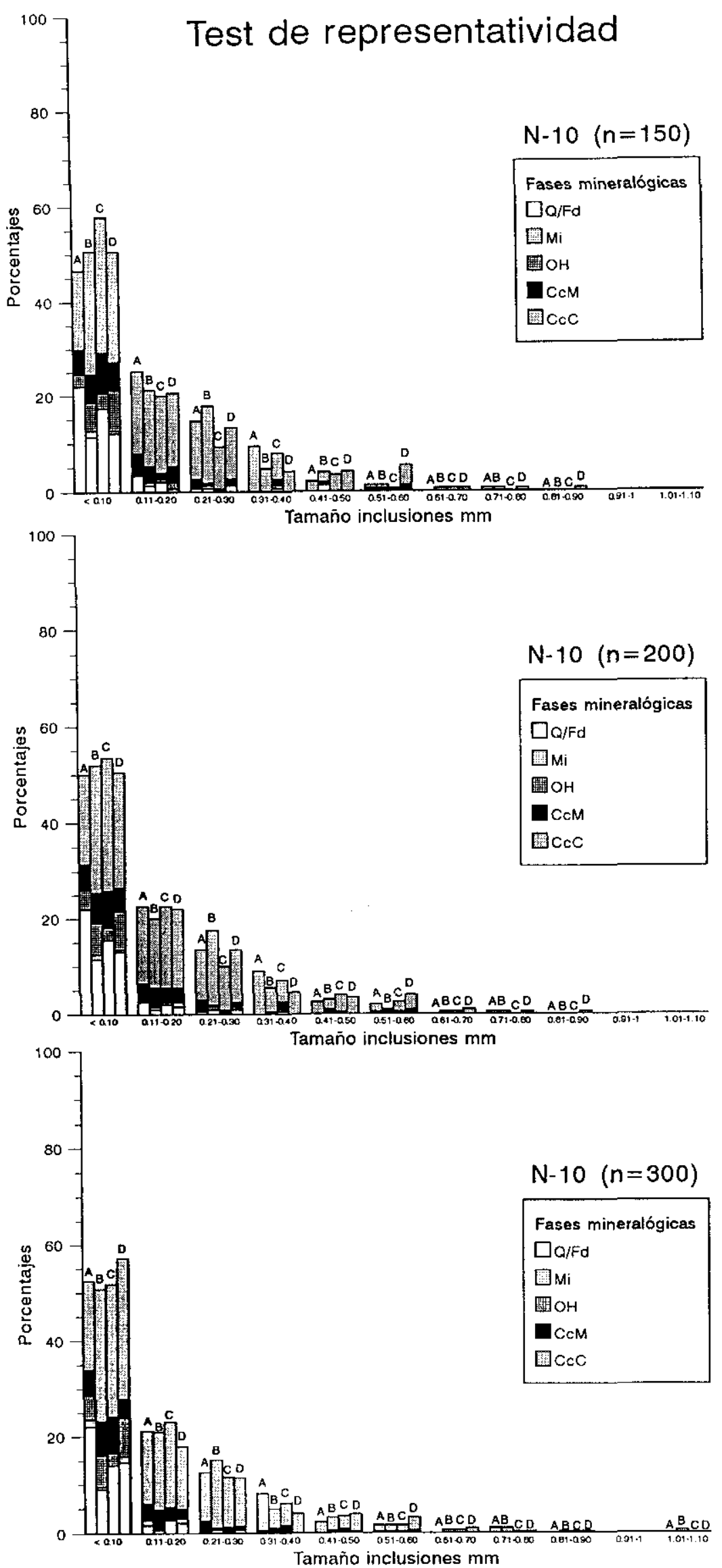

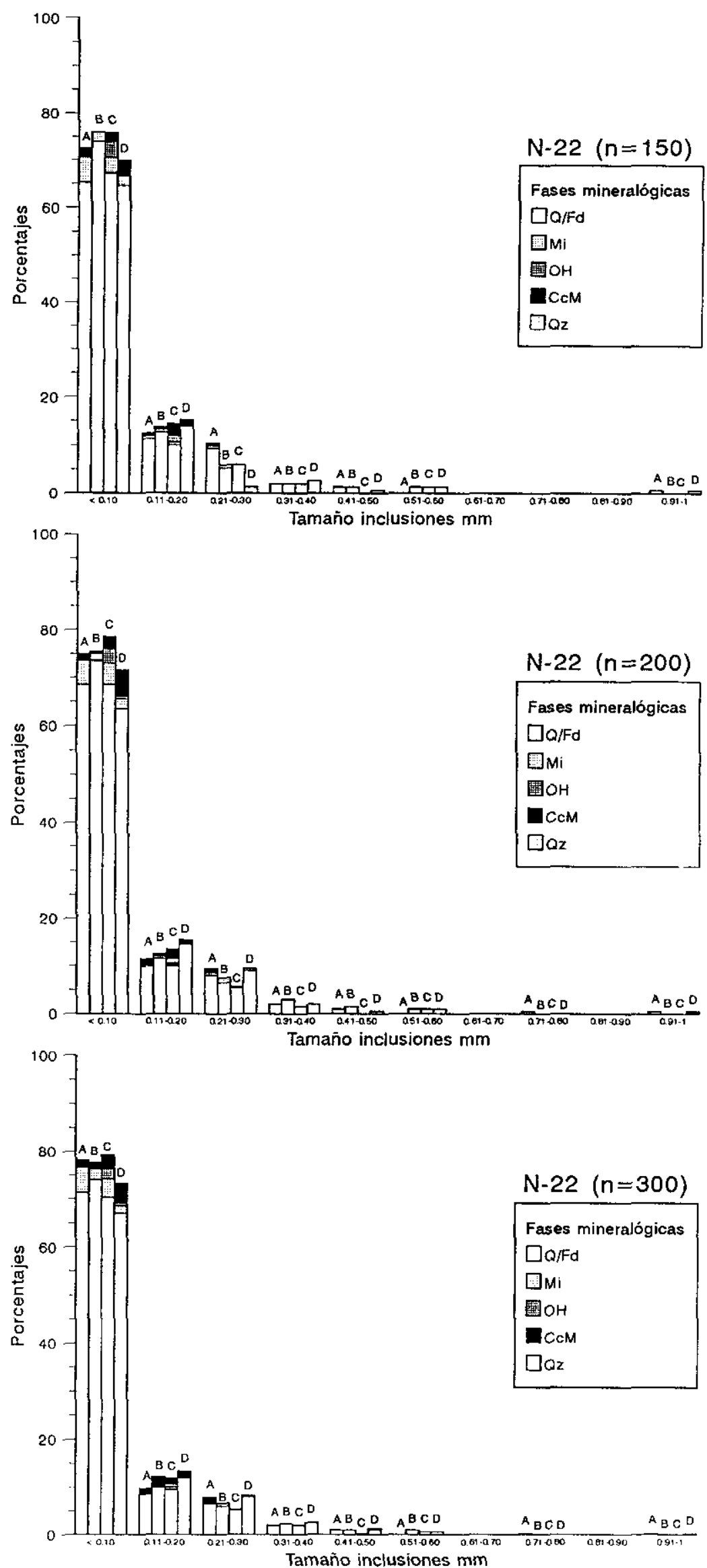

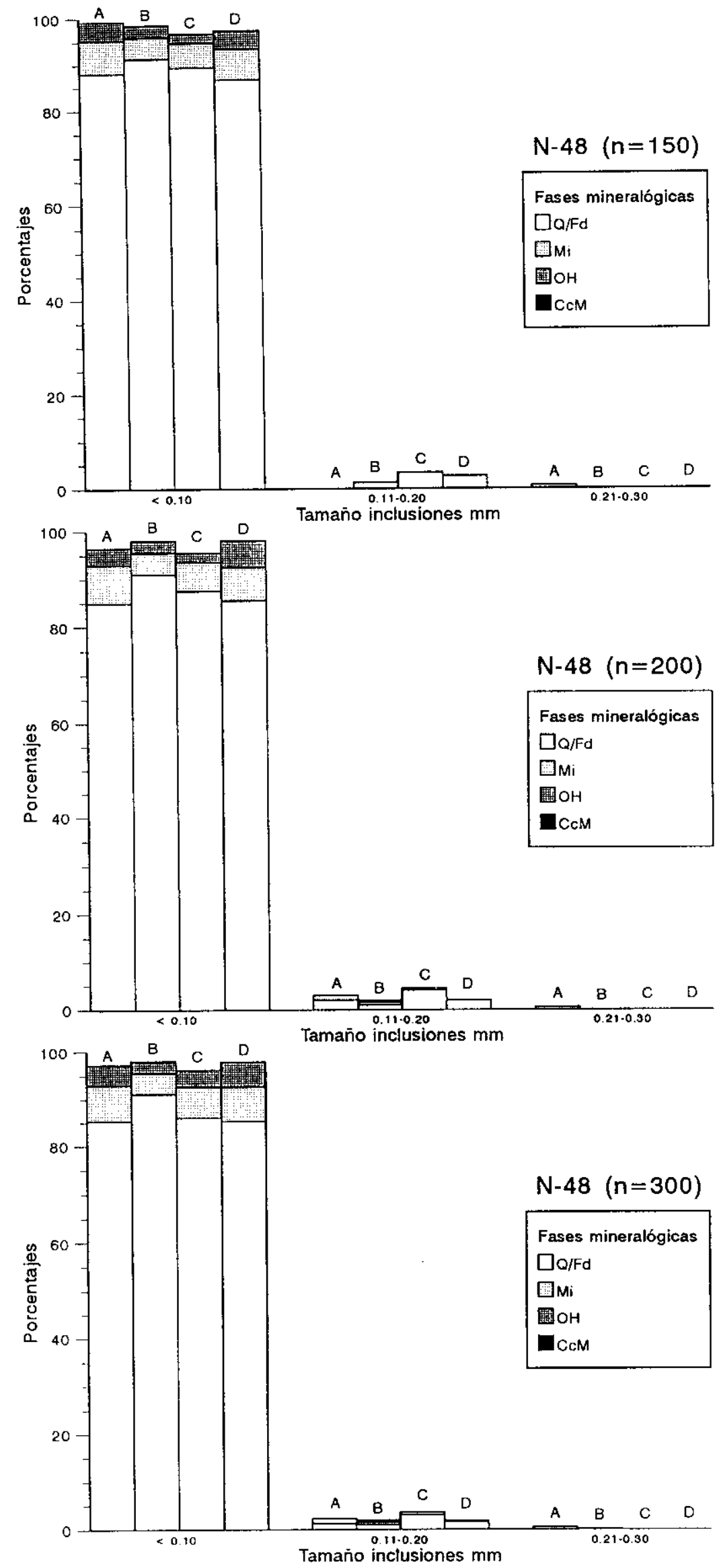

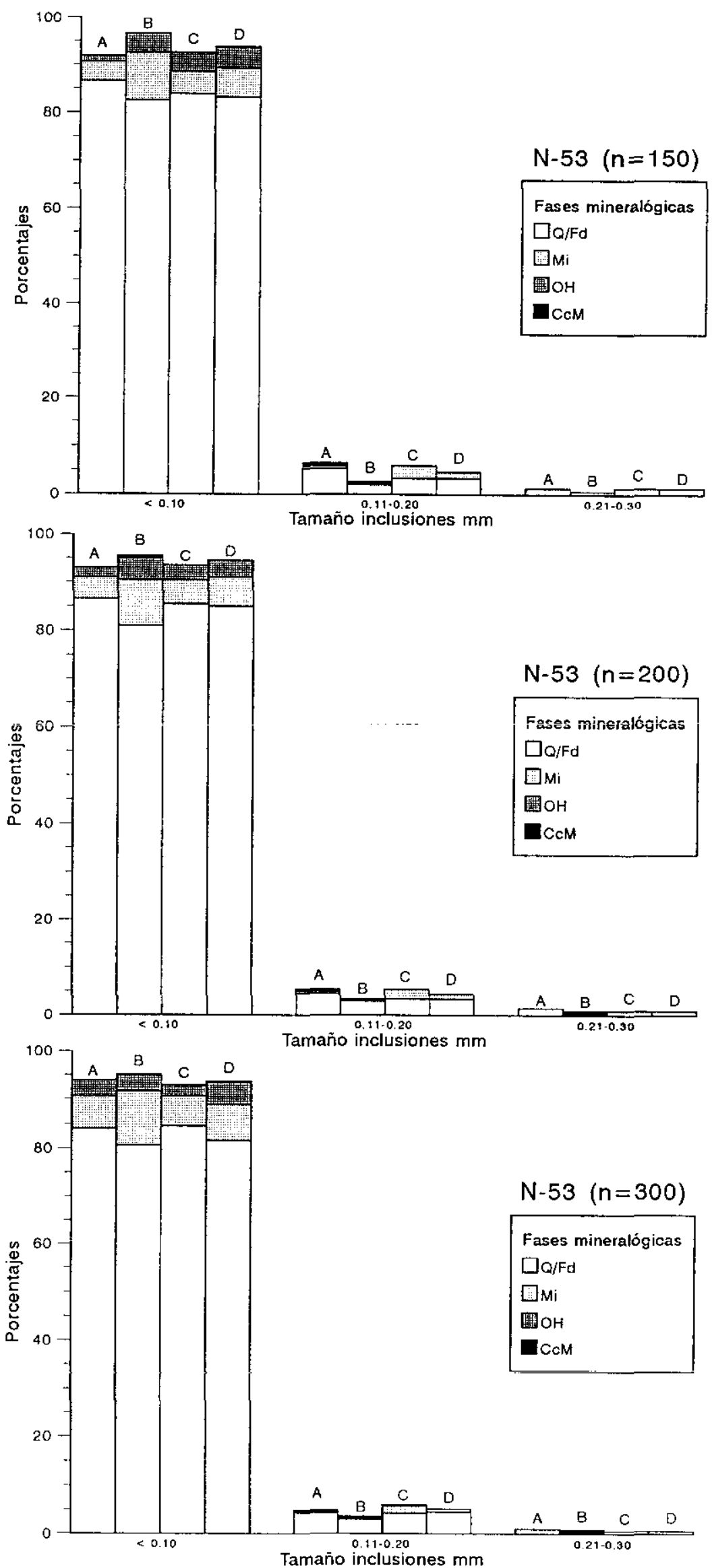

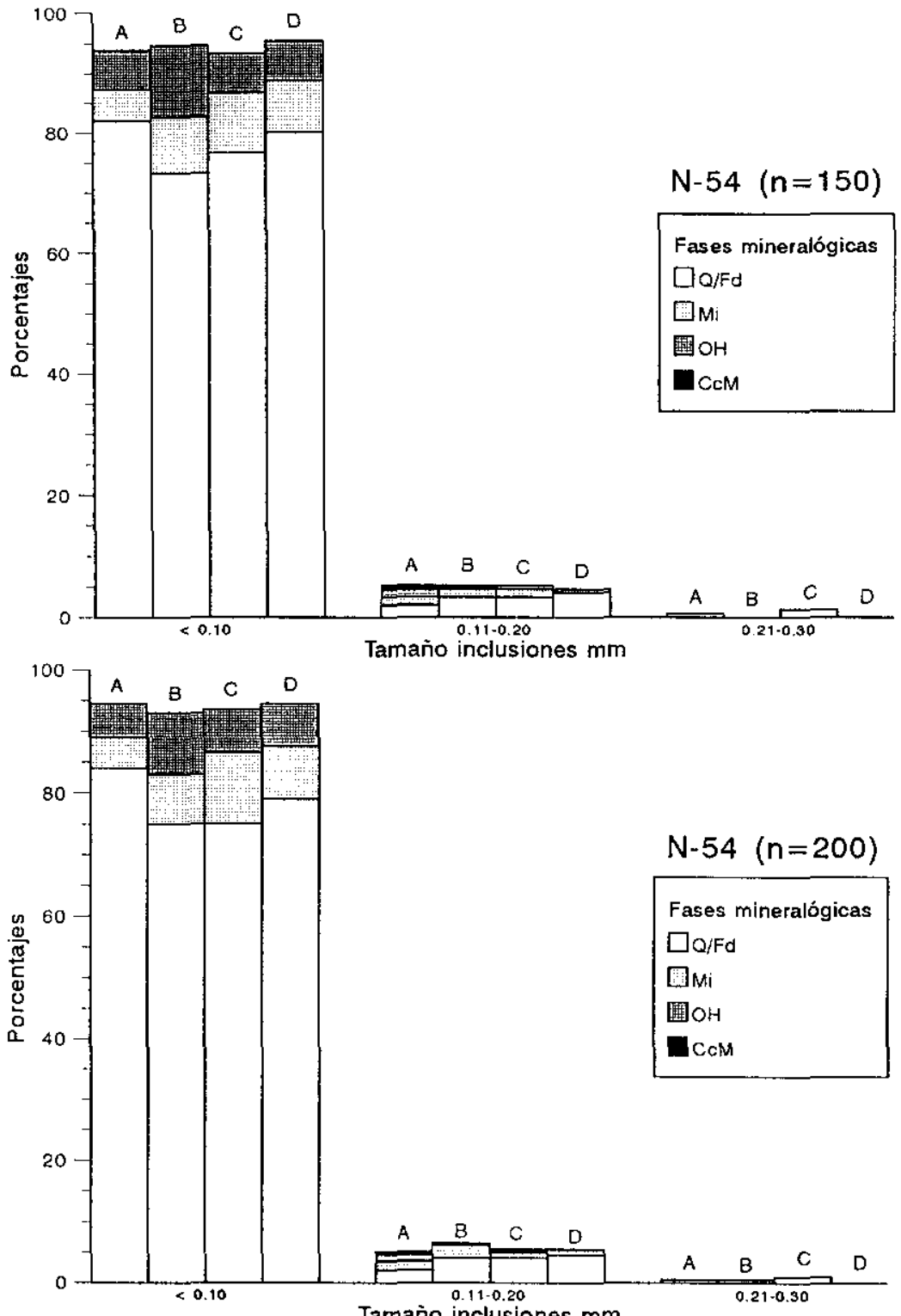

Tamaño inclusiones $\mathrm{mm}$

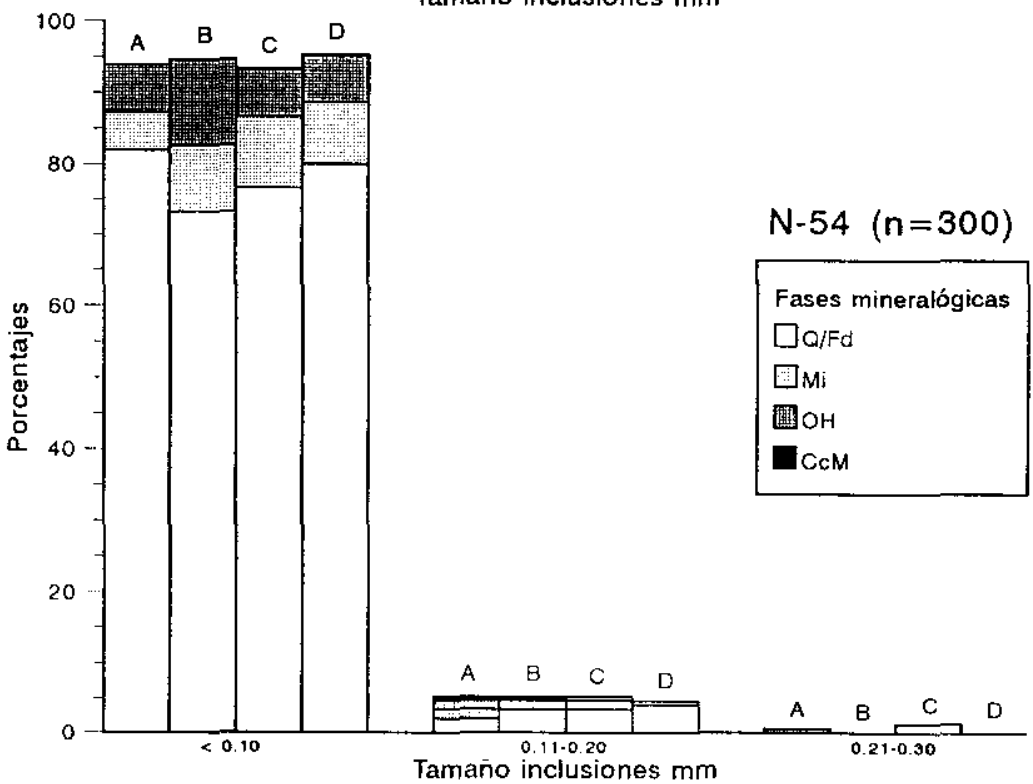



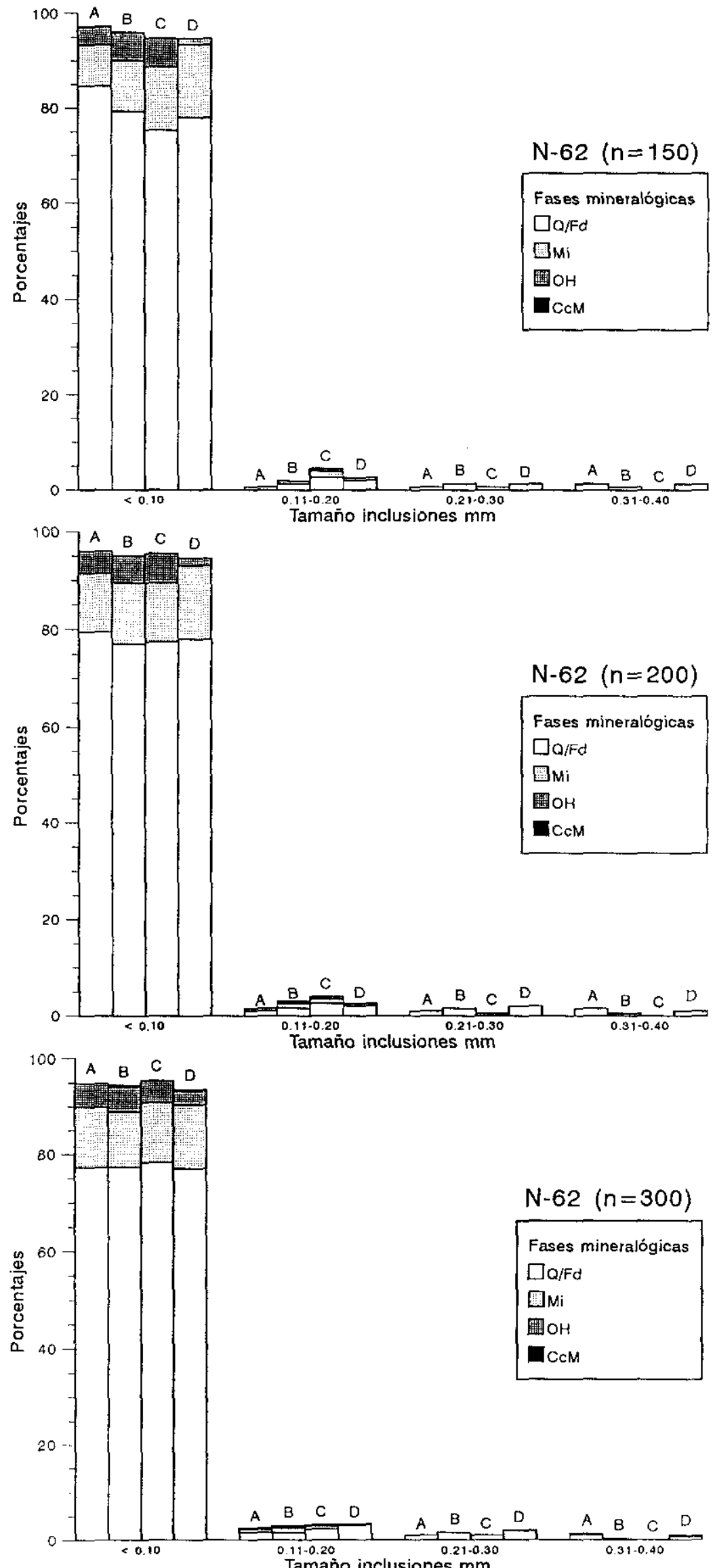

Tamaño inclusiones $\mathrm{mm}$ 


\section{APÉNDICE III}

En este apéndice se reproducen los diftactogramas obtenidos en el análisis mediante Difracción de rayos $\mathrm{x}(\mathrm{XRD})$ de 121 cerámicas (83 de Numancia, 5 de Langa de Duero, 5 de El Palomar, 11 de Pinilla Trasmonte y 17 de Izana); de 9 sedimentos arcillosos ( 8 de Numancia y 1 de Izana) a temperatura ambiente (A) y cocidos a $700^{\circ} \mathrm{C}(\mathrm{B}), 800^{\circ} \mathrm{C}(\mathrm{C}), 900^{\circ} \mathrm{C}$ (D) y $1.000^{\circ} \mathrm{C}$ (E); así como los obtenidos en la recocción de 4 cerámicas ( 3 de Numancia y 1 de Pinilla Trasmonte).

Los difractogramas de los sedimentos arcillosos, se ofrecen, en primer lugar, en columnas, con el propósito de mostrar la evolución de las fases mineralógicas en función de la temperatura de cocción. En segundo lugar, se ha optado, también, por ofrecer estos mismos difractogramas a mayor tamaño, para facilitar una observación más detallada. Asimismo, los difractogramas de la recocción de las 4 cerámicas, se ofrecen, igualmente, en columnas, en las que se ha añadido a la izquierda el difractograma de la muestra en el Estado como se reciben (ECSR), justo en el nivel de temperatura de cocción que más similaridades presenta con ella. Cuando esto no ha sido posible, el difractograma de la muestra correspondiente, se ha situado entre los dos niveles más similares. Por último, también se muestran a mayor tamaño, por los mismos motivos que en el caso de los sedimentos arcillosos. 
En general, los difractogramas se reproducen en el área comprendida entre $2^{\circ}$ y $44^{\circ} 2 \theta$ por ser ésta la que más interés ofrece para este tipo de muestras. No obstante, para las muestras $\mathrm{N}-8 \mathrm{~A}, \mathrm{~N}-8 \mathrm{~B}, \mathrm{~N}-8 \mathrm{C}, \mathrm{N}-8 \mathrm{D}$ y $\mathrm{N}-8 \mathrm{E}$ se ha ampliado hasta $49^{\circ} 2 \theta$ y para la $\mathrm{N}-20 / 1$ hasta $46^{\circ} 2 \theta$, con el fin de mostrar ciertas reflexiones de interés en cada caso. En el eje de las $x$ se representan $\operatorname{los}^{\circ} 2 \theta$ y en el eje de las $y$ las cuentas por segundo (cps).

\title{
CLAVES
}

\author{
A: Anortita
}

AL: Alfa-alúmina o Corindón

C. Calcita

D: Diópsido

DO: Dolomita

FK: Feldespato potásico

G: Gehlenita

H: Hematites

I: Ilita y Filosilicatos

K: Caolinita

M: Mullita

OC: Óxido de $\mathrm{Ca}$

P: Portlandita. Hidróxido de $\mathrm{Ca}$

Q: Cuarzo 
Arcillas de NUMANCLA
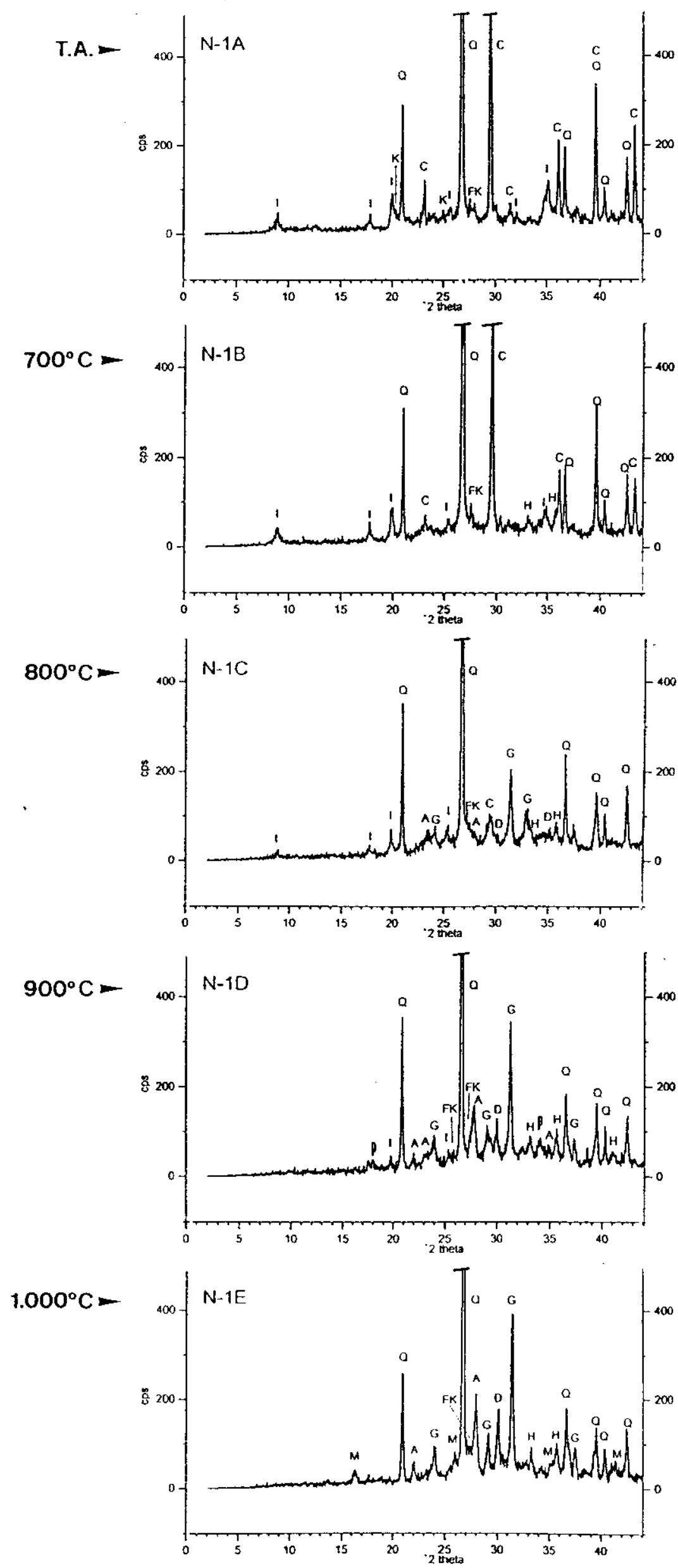


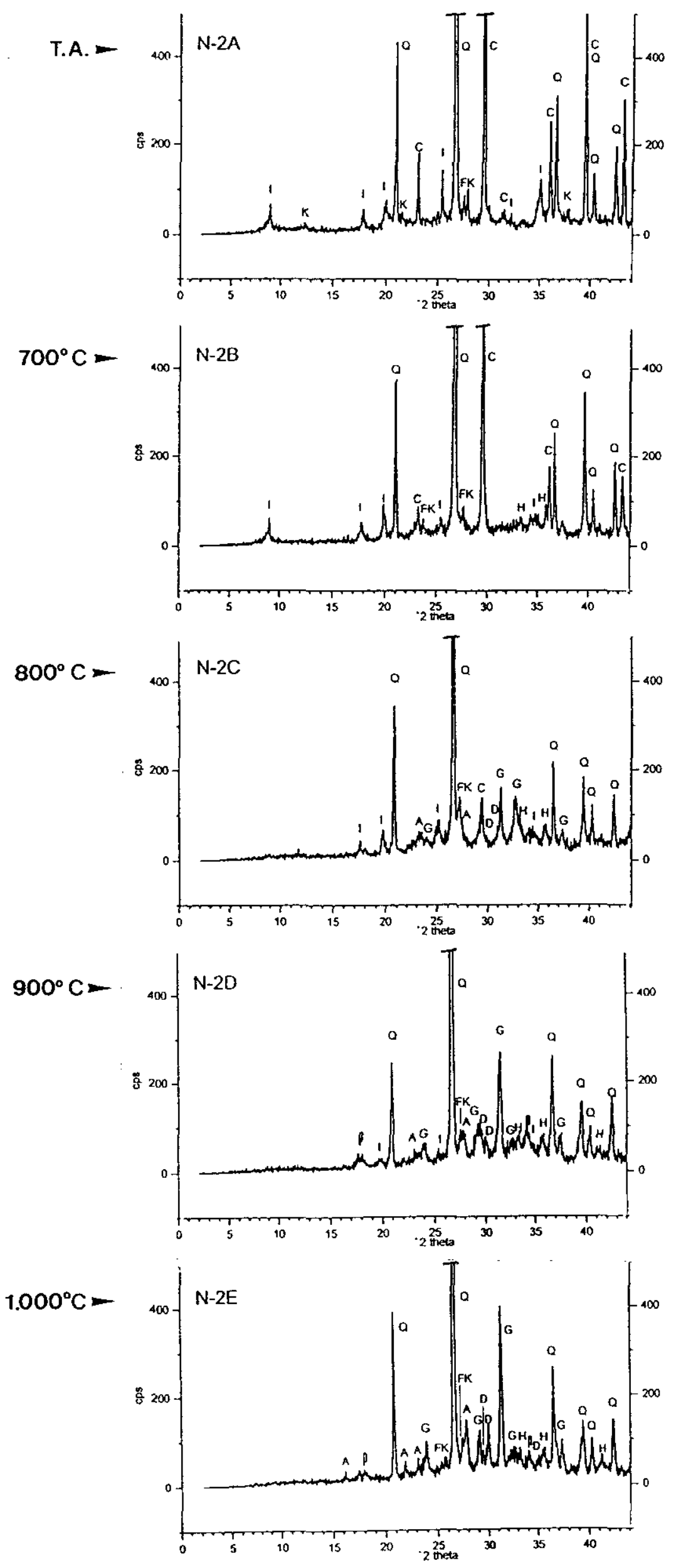




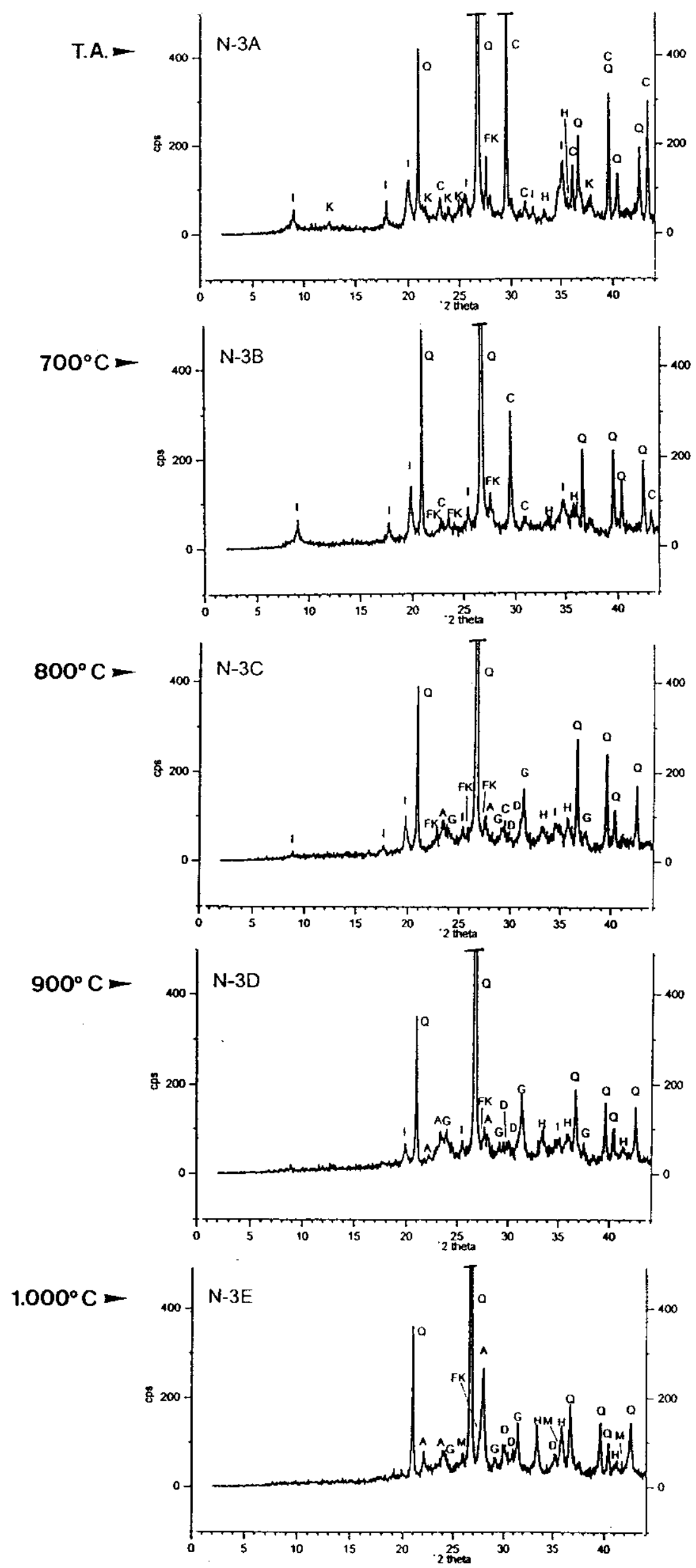




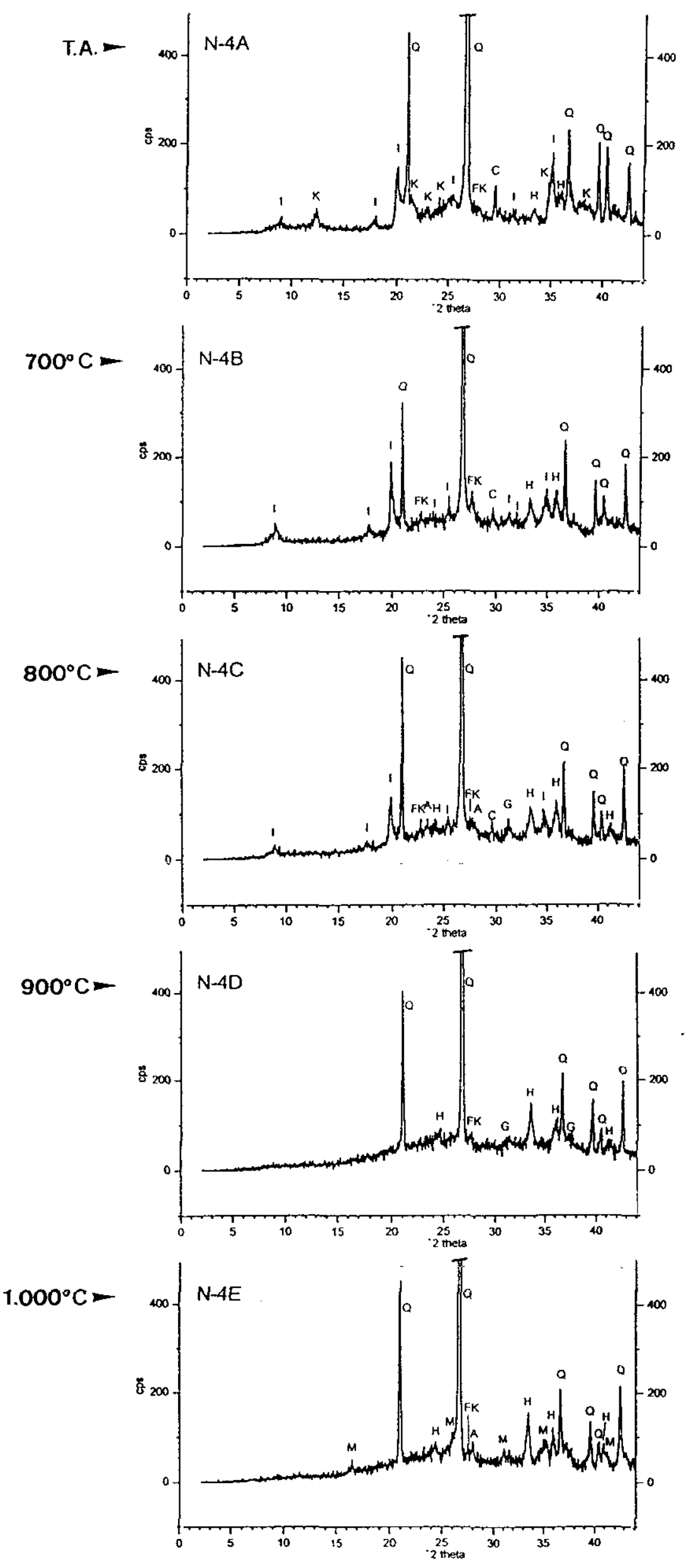




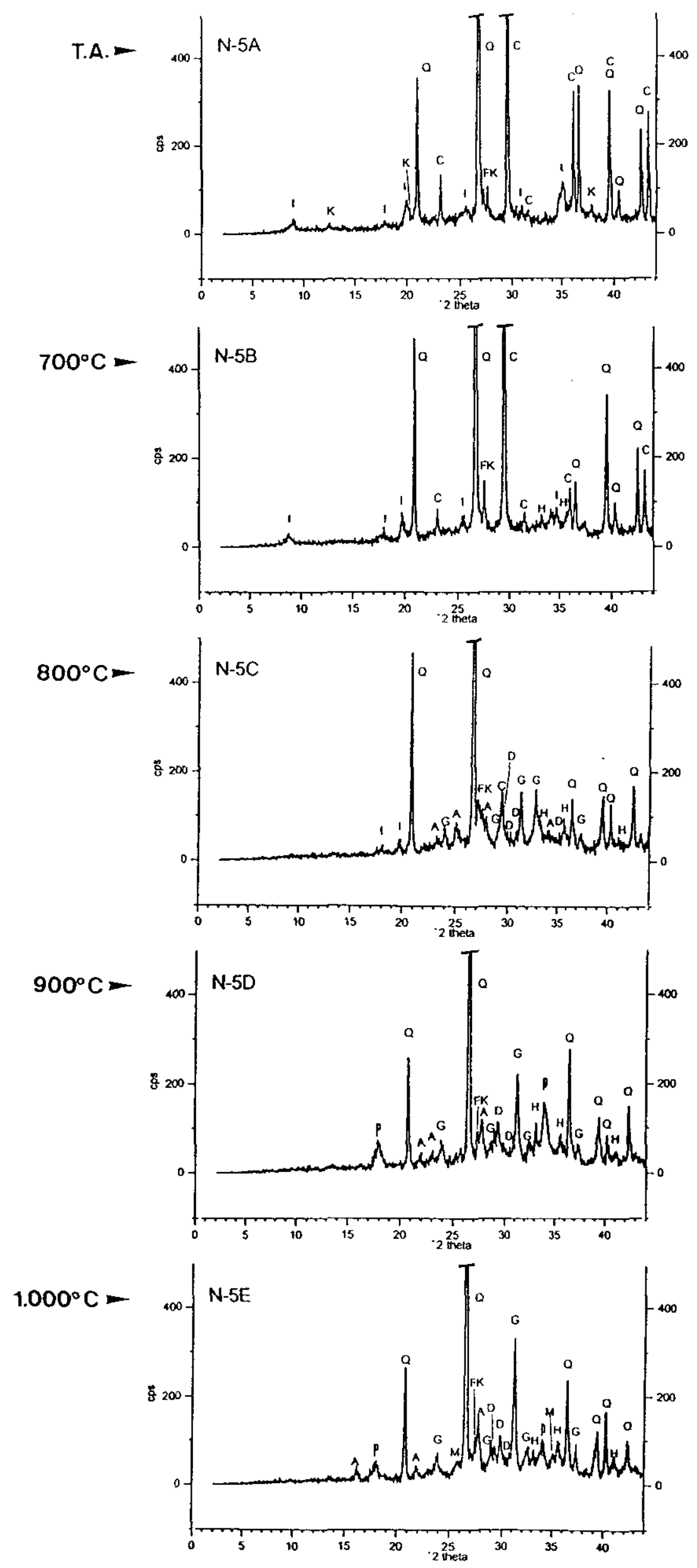




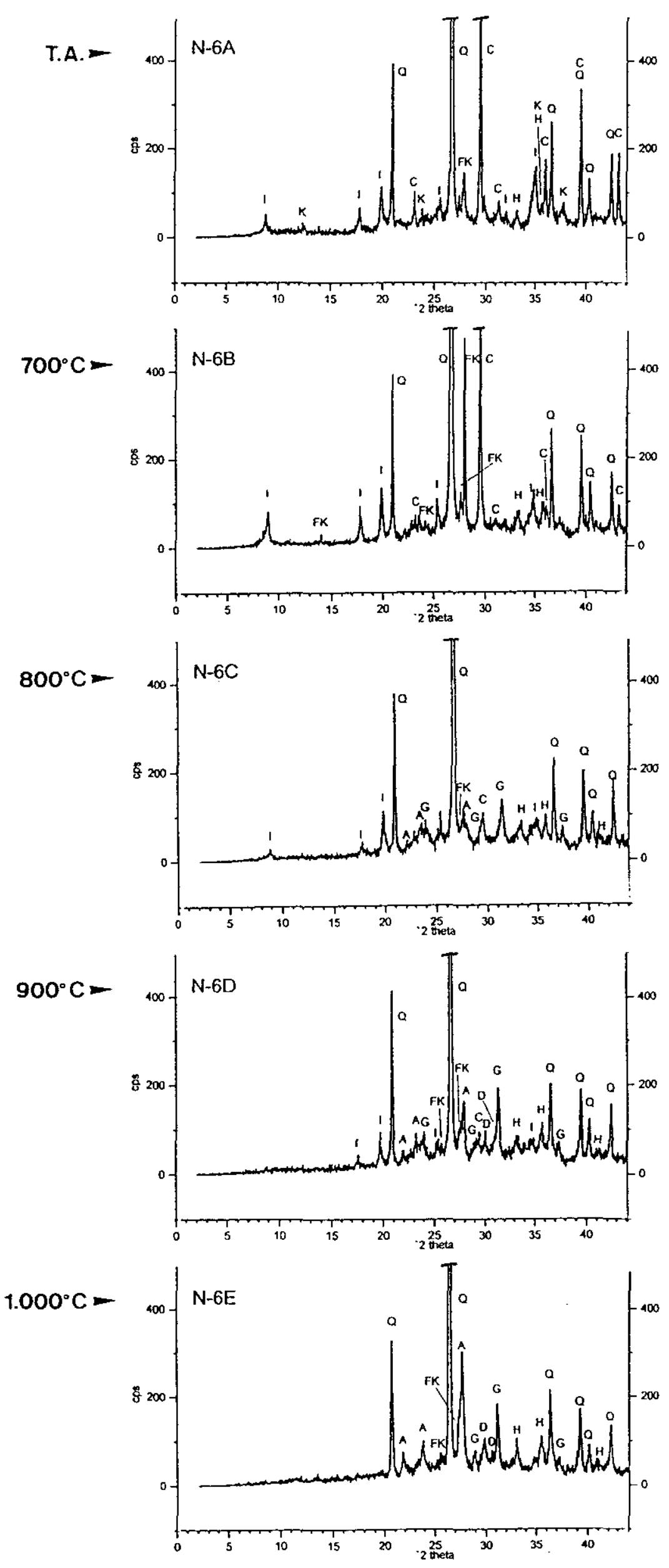




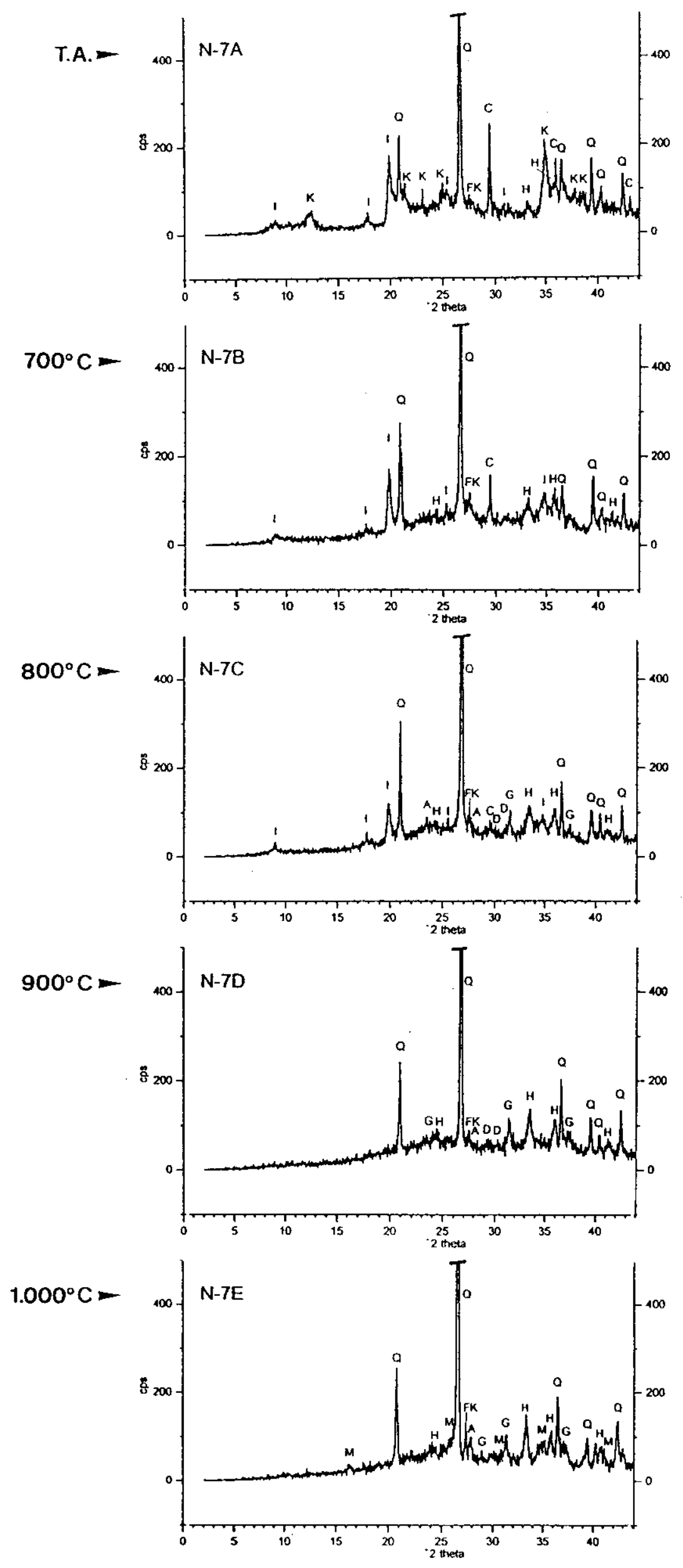




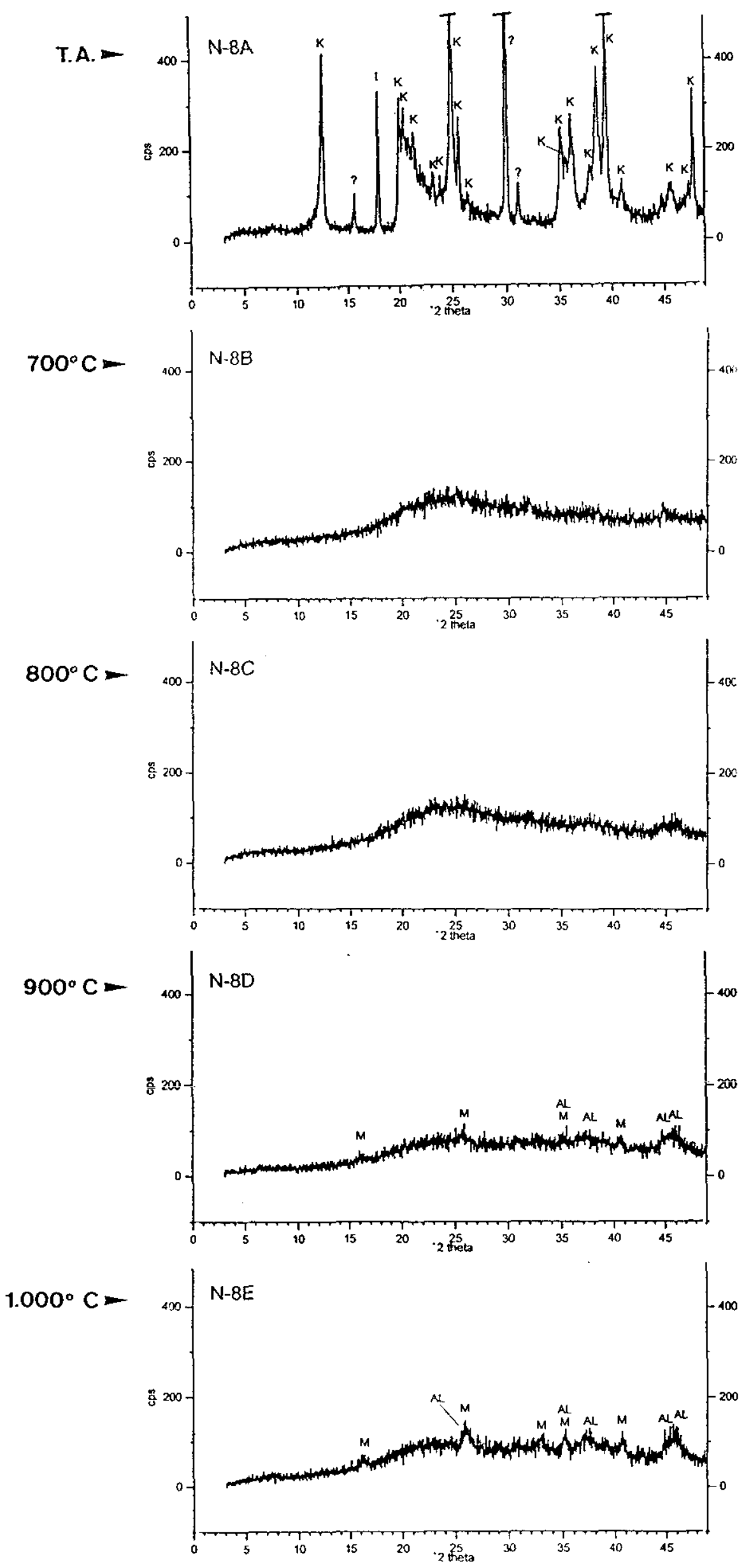




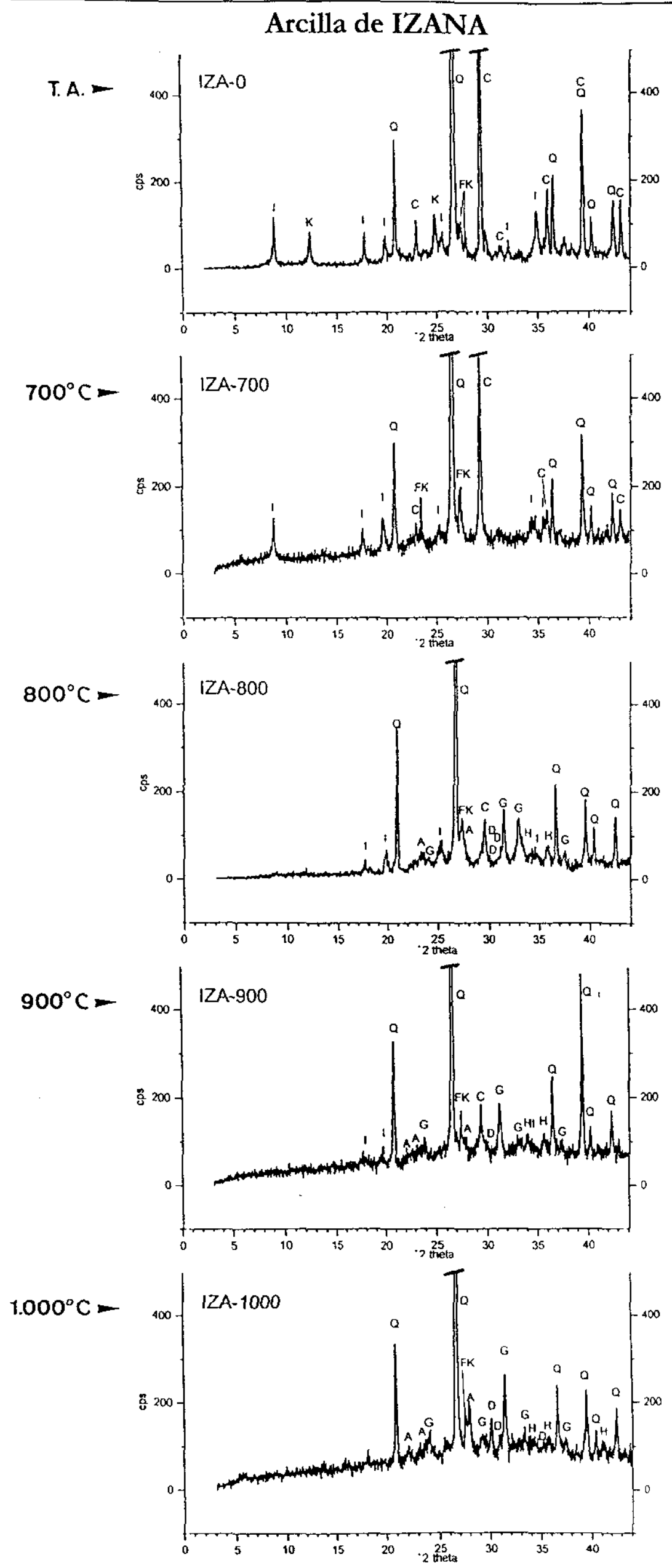




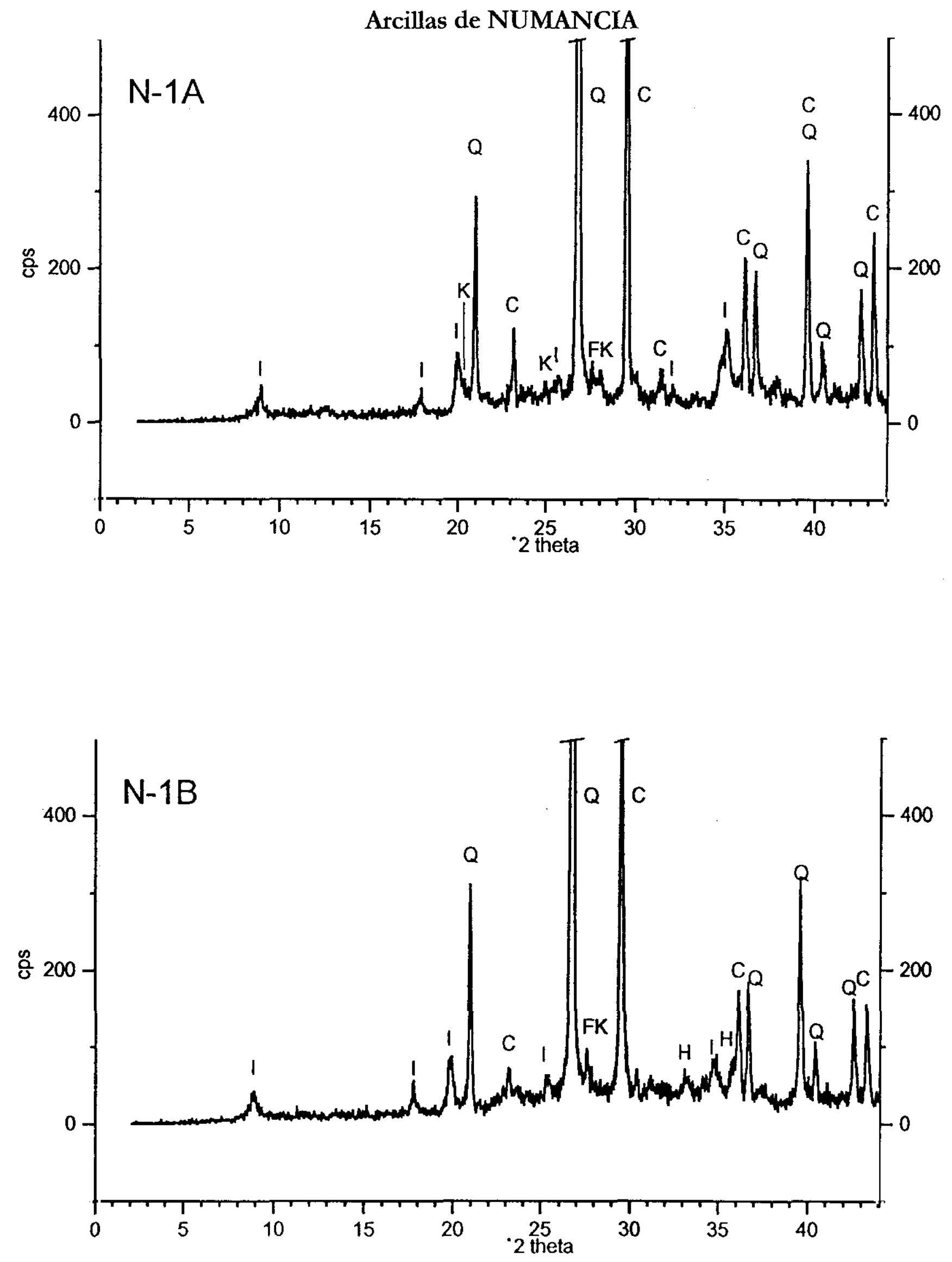

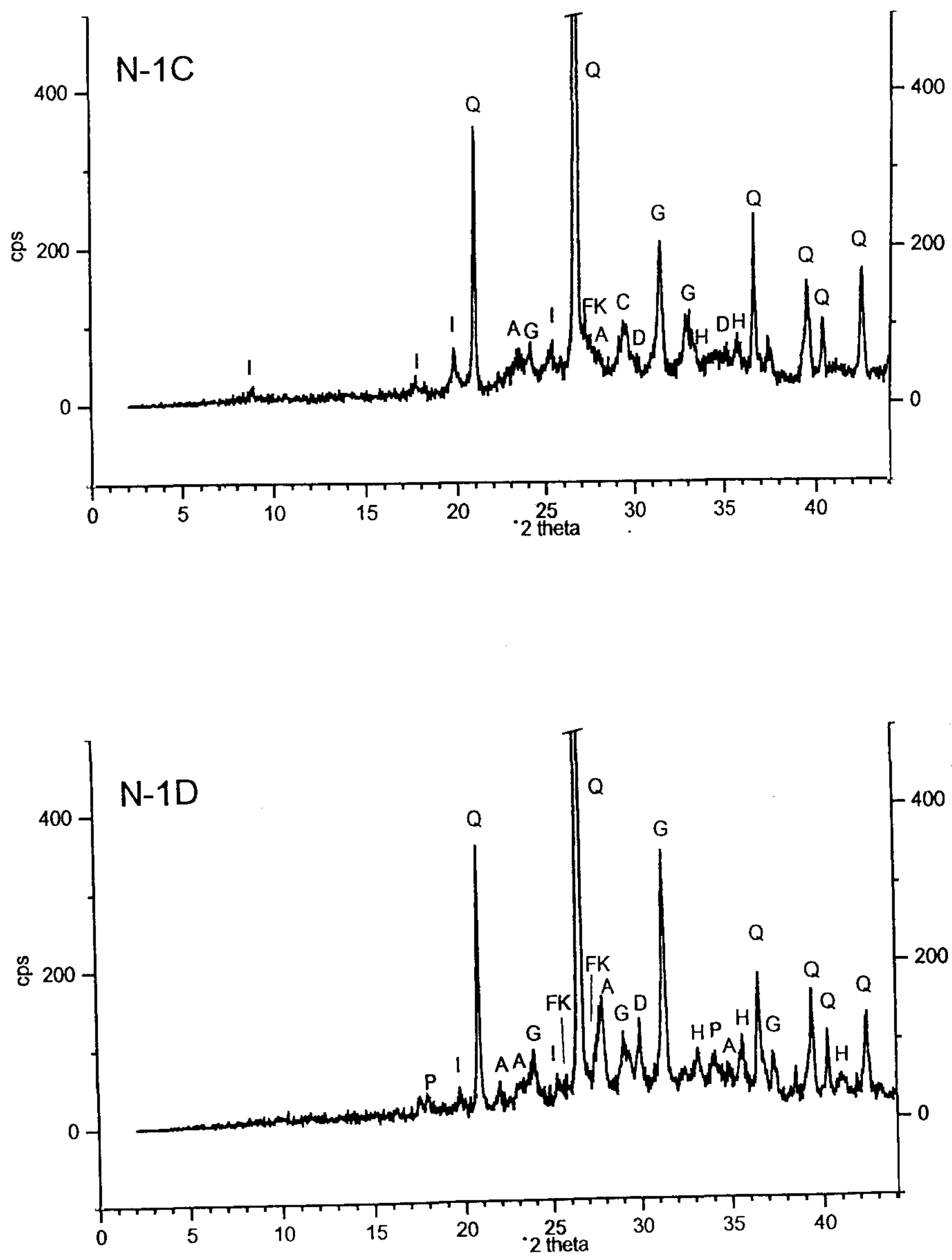

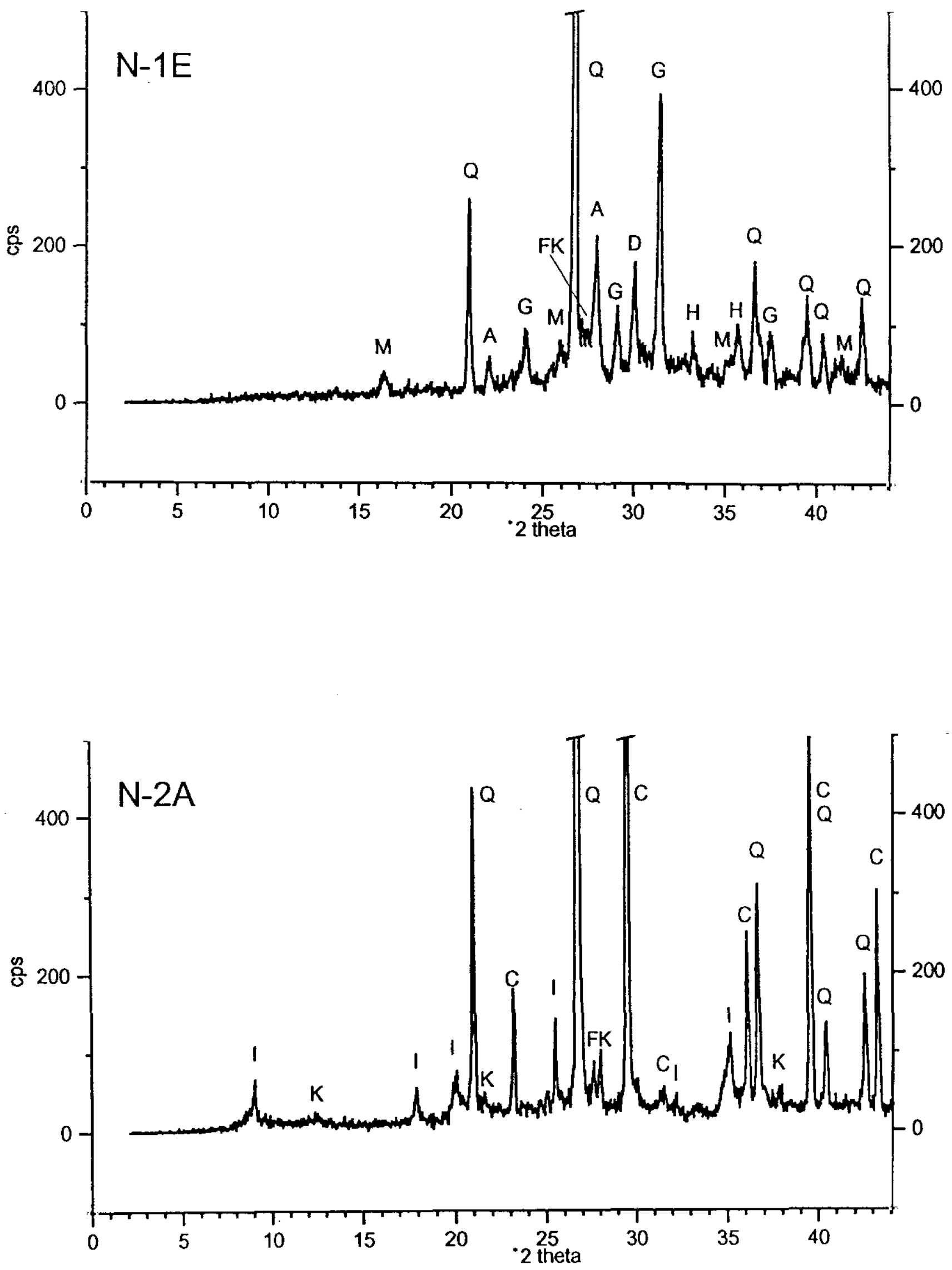

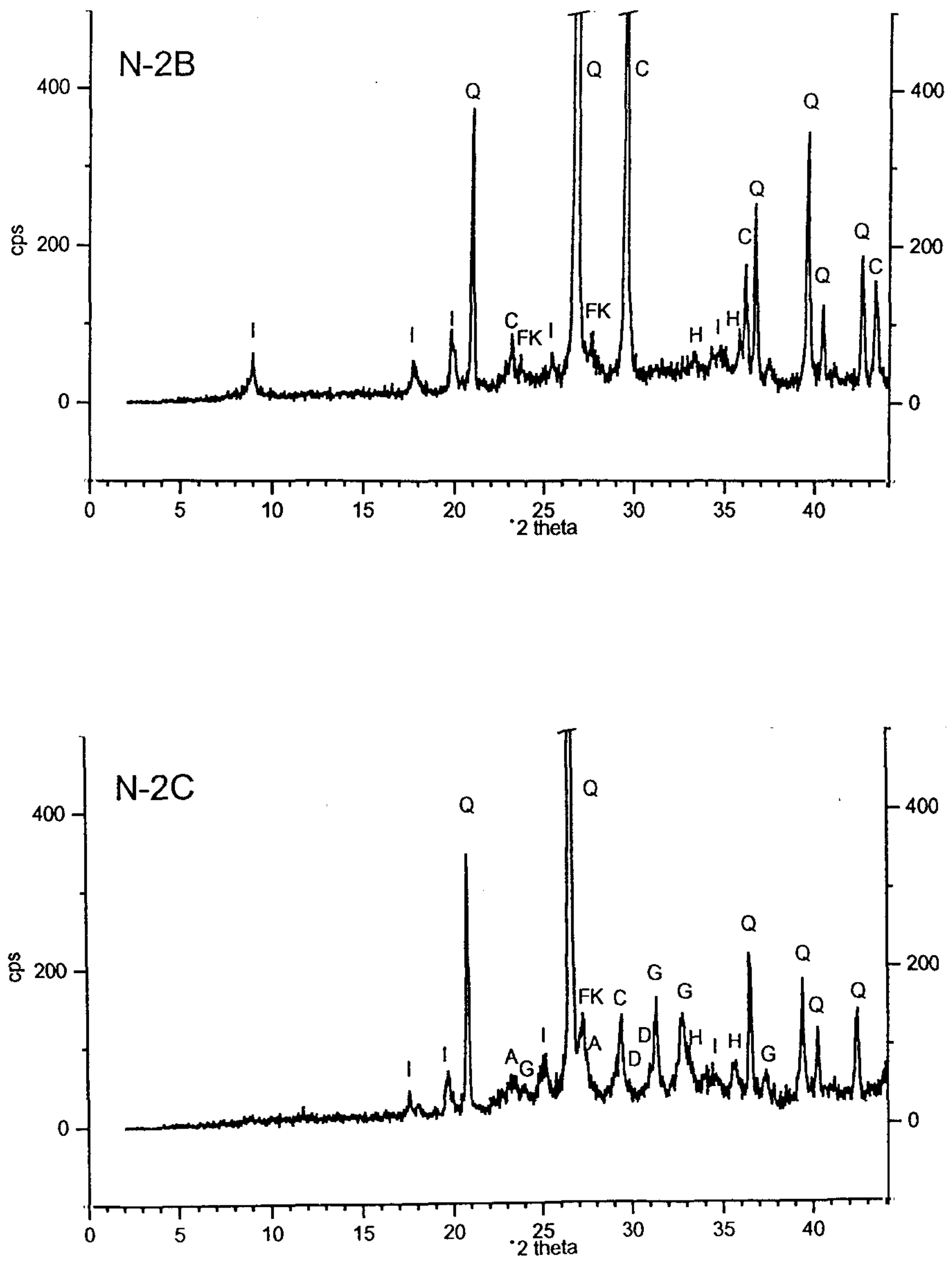

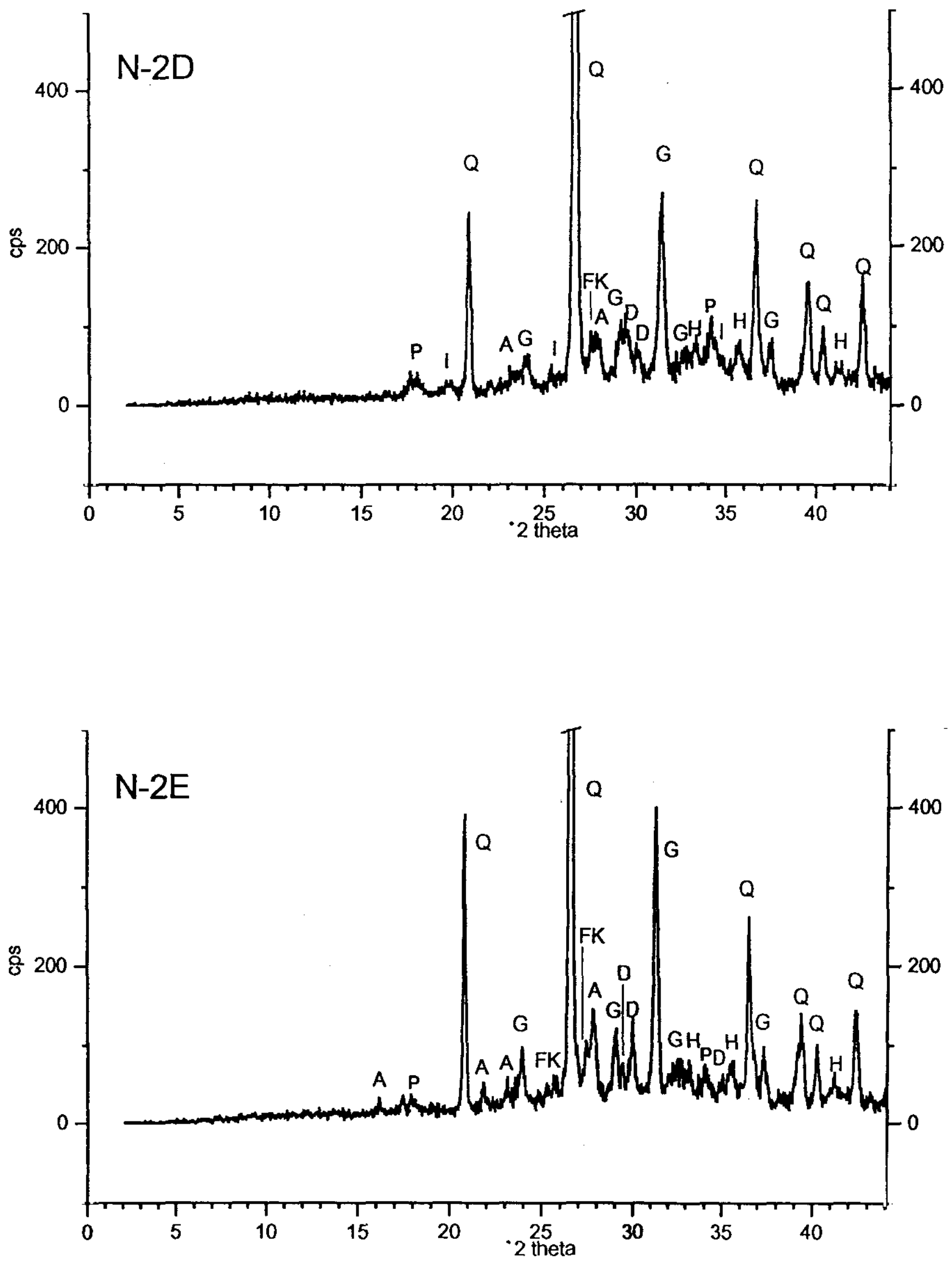

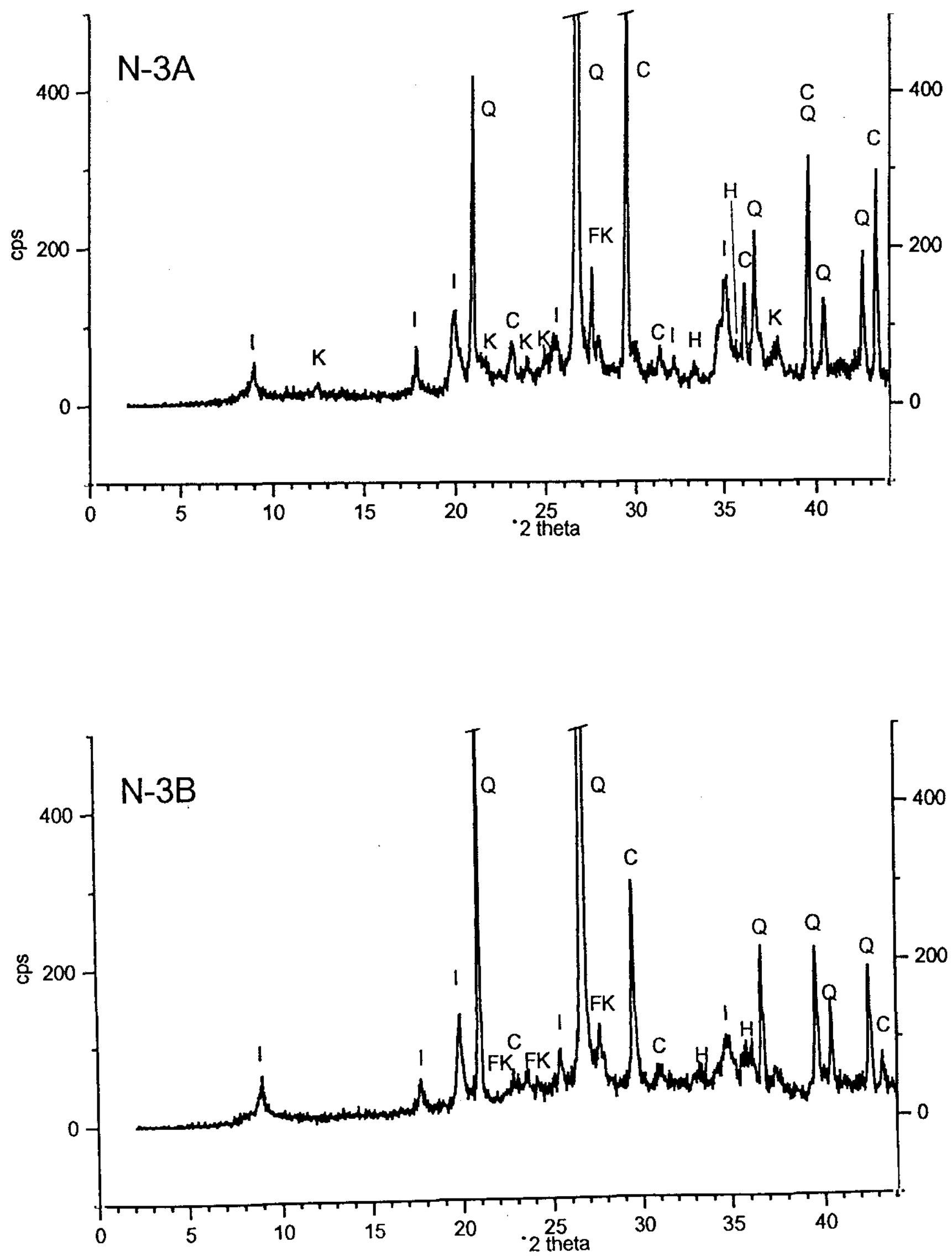

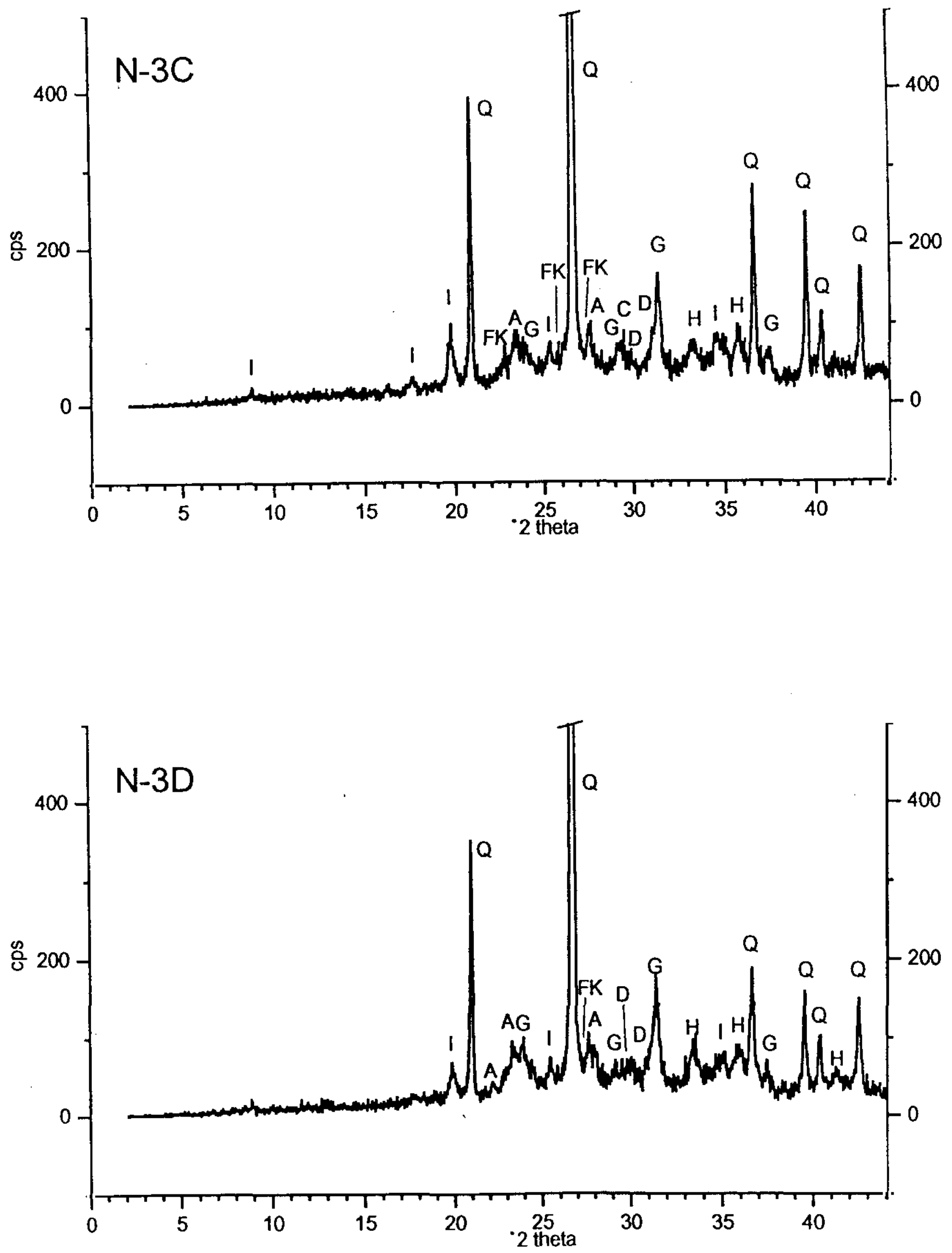

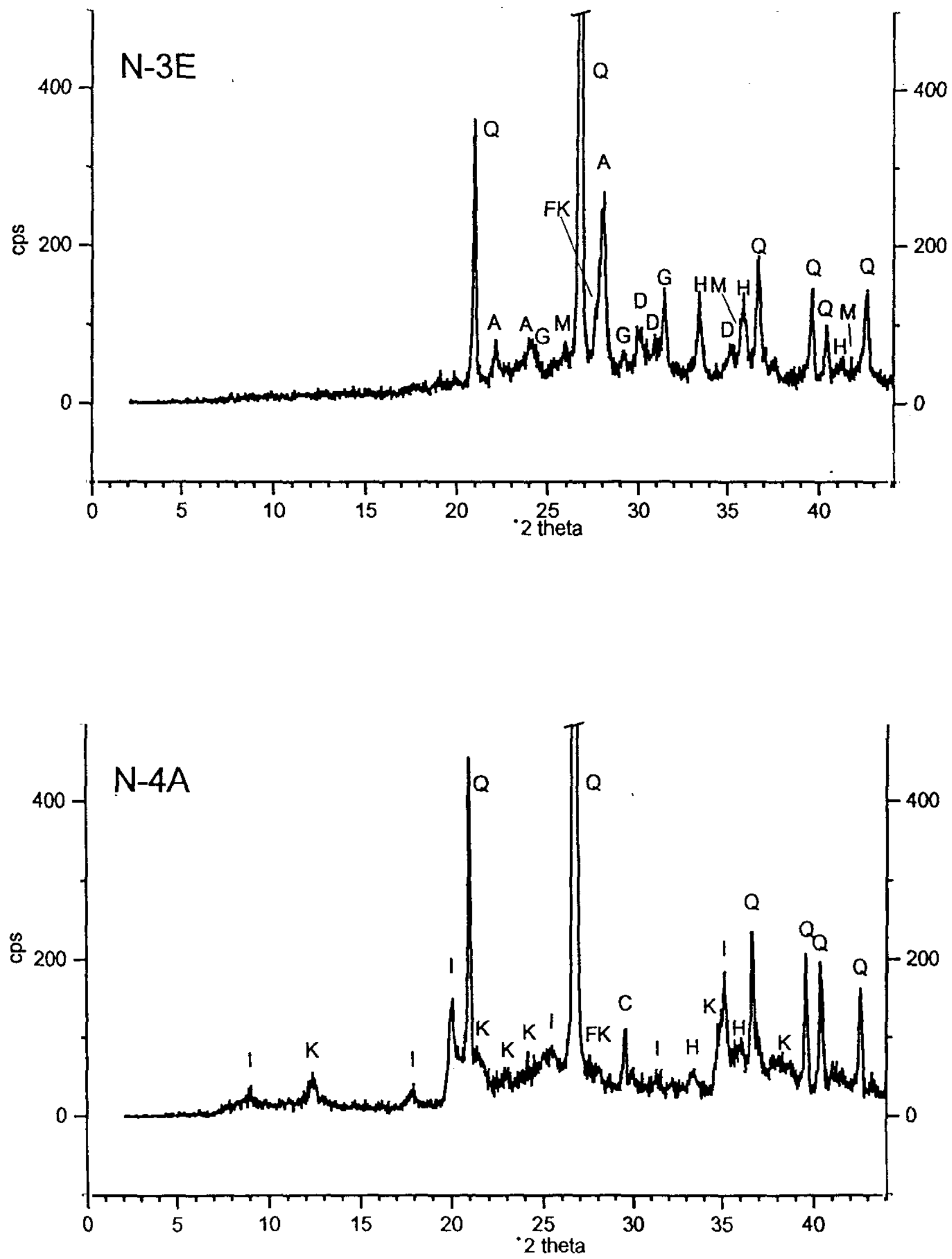

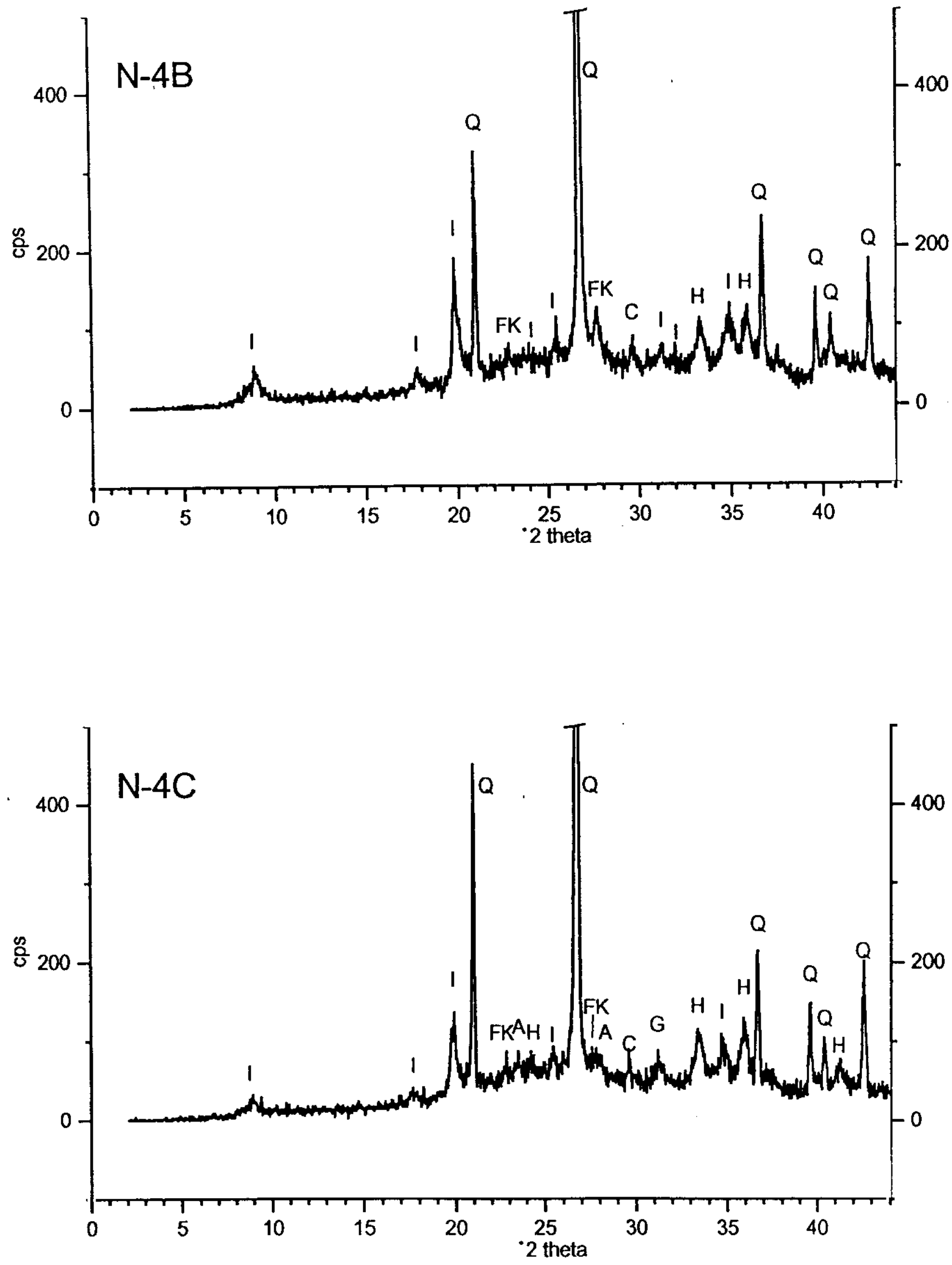

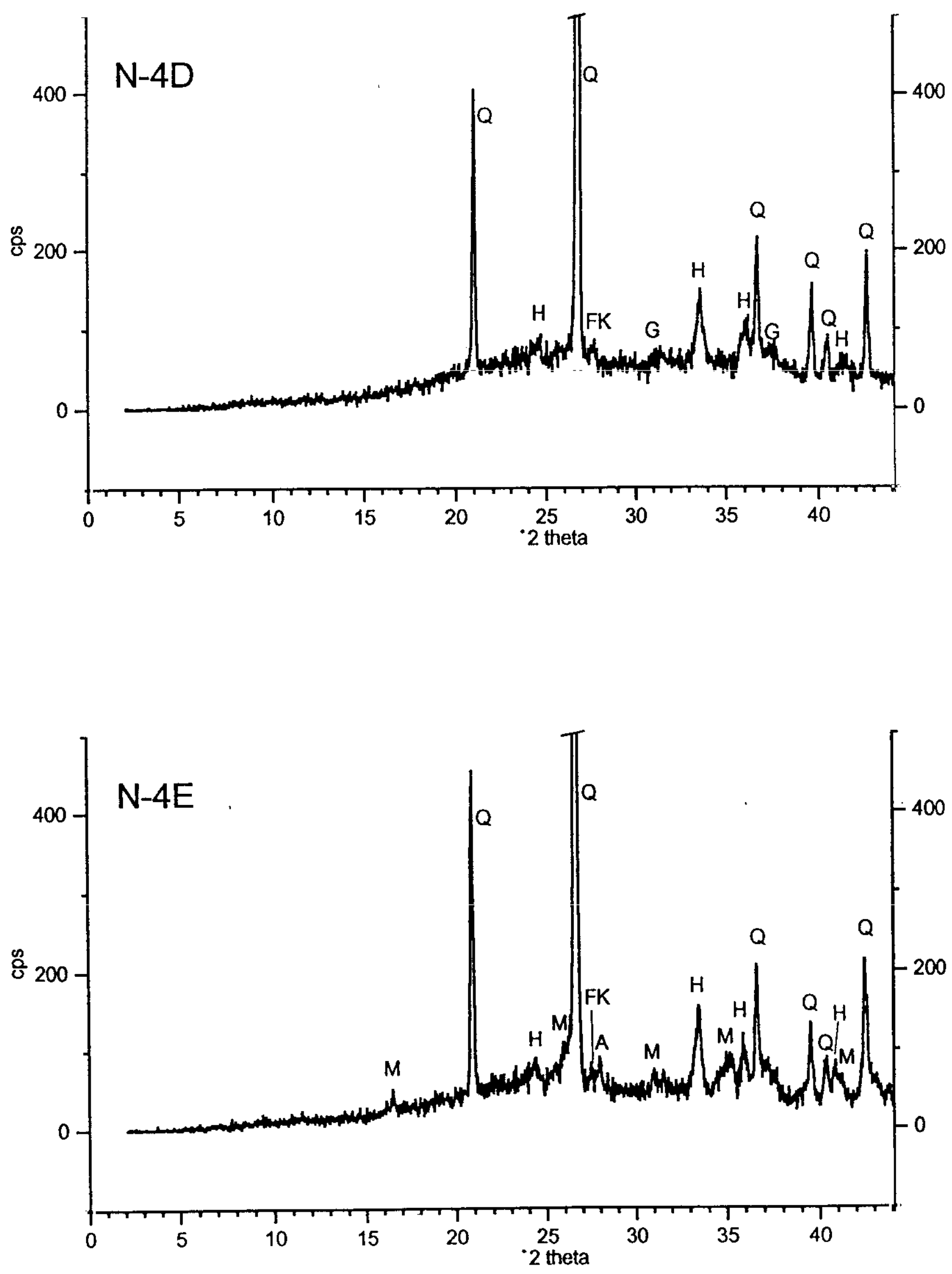

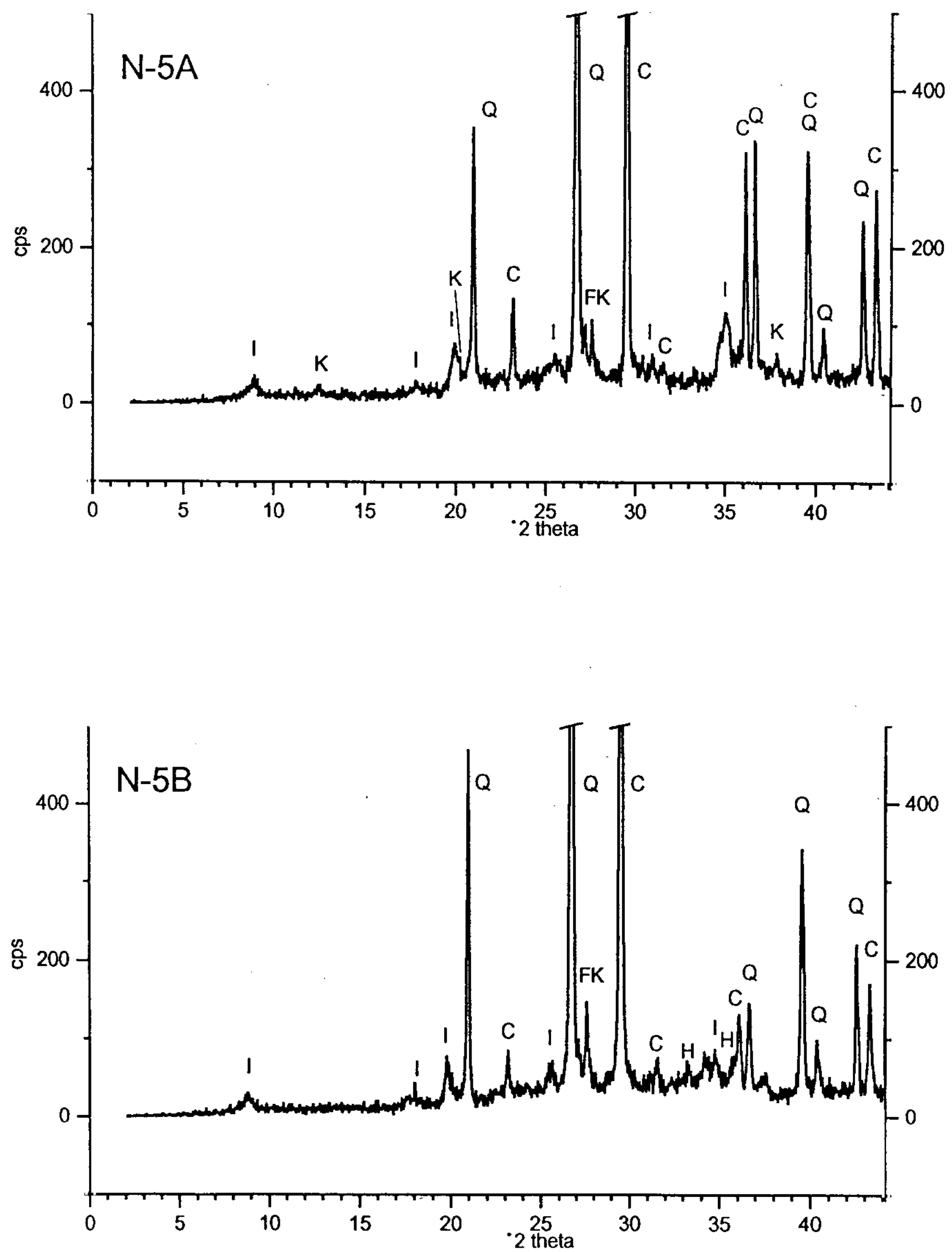

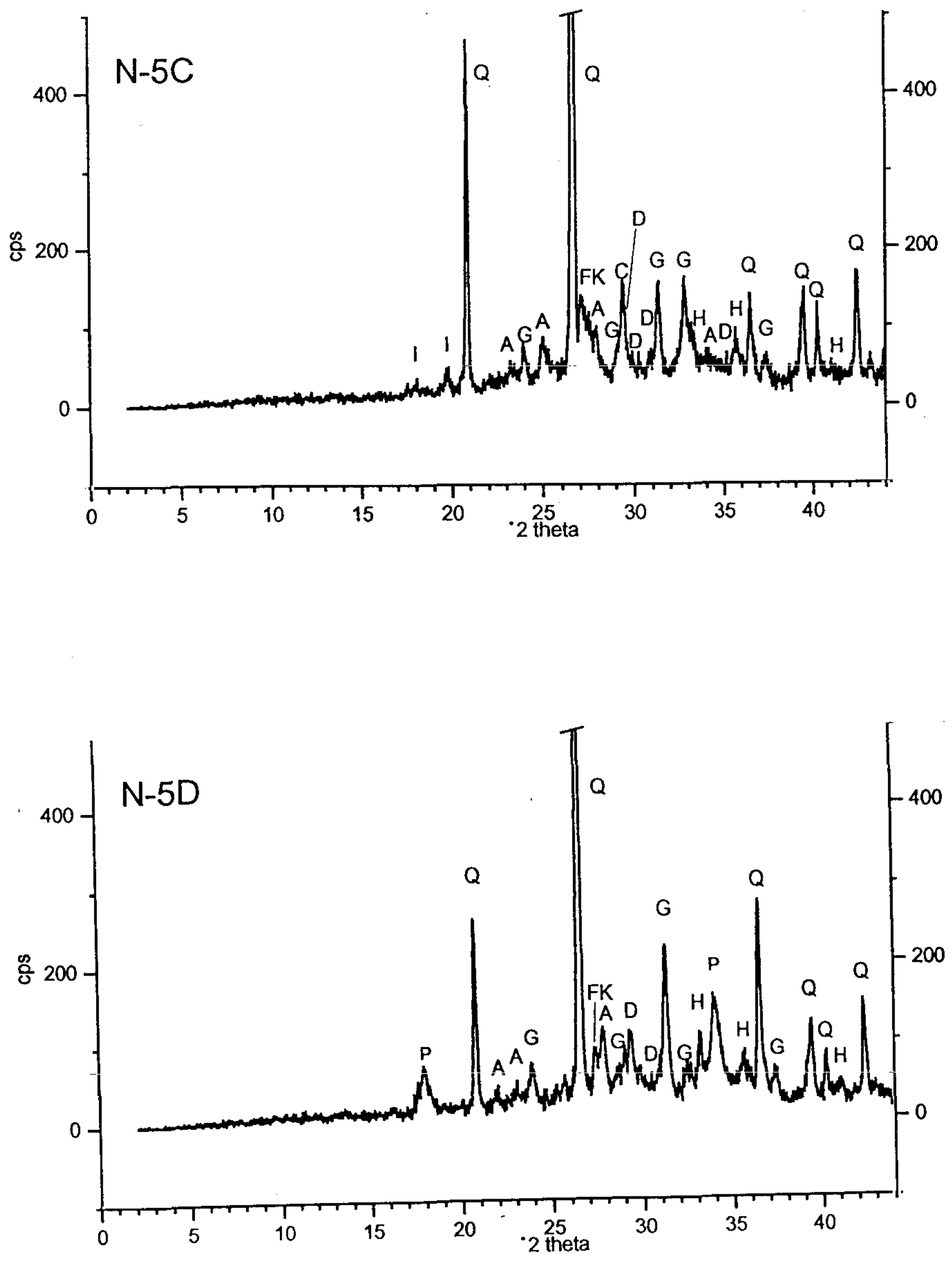

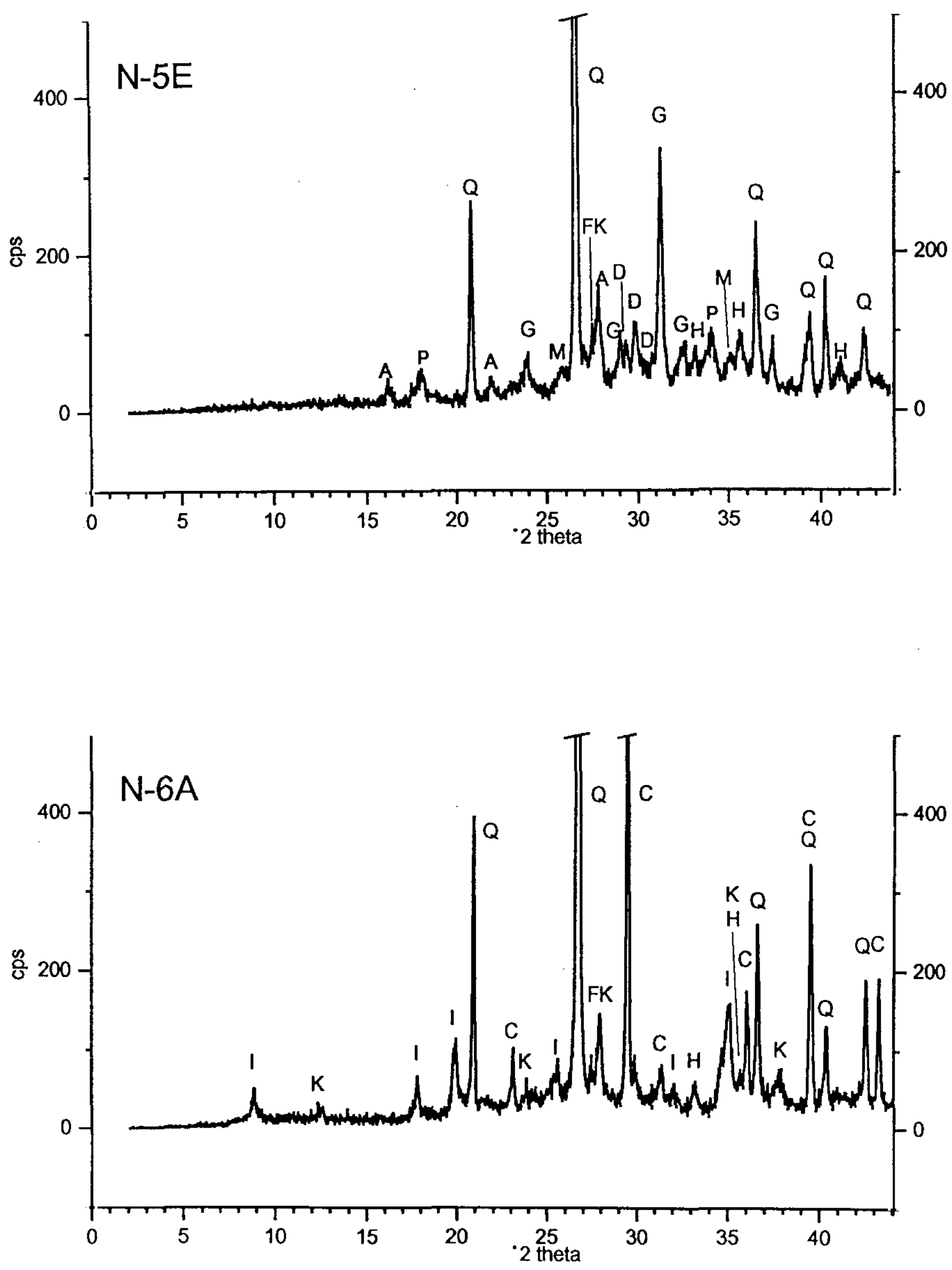

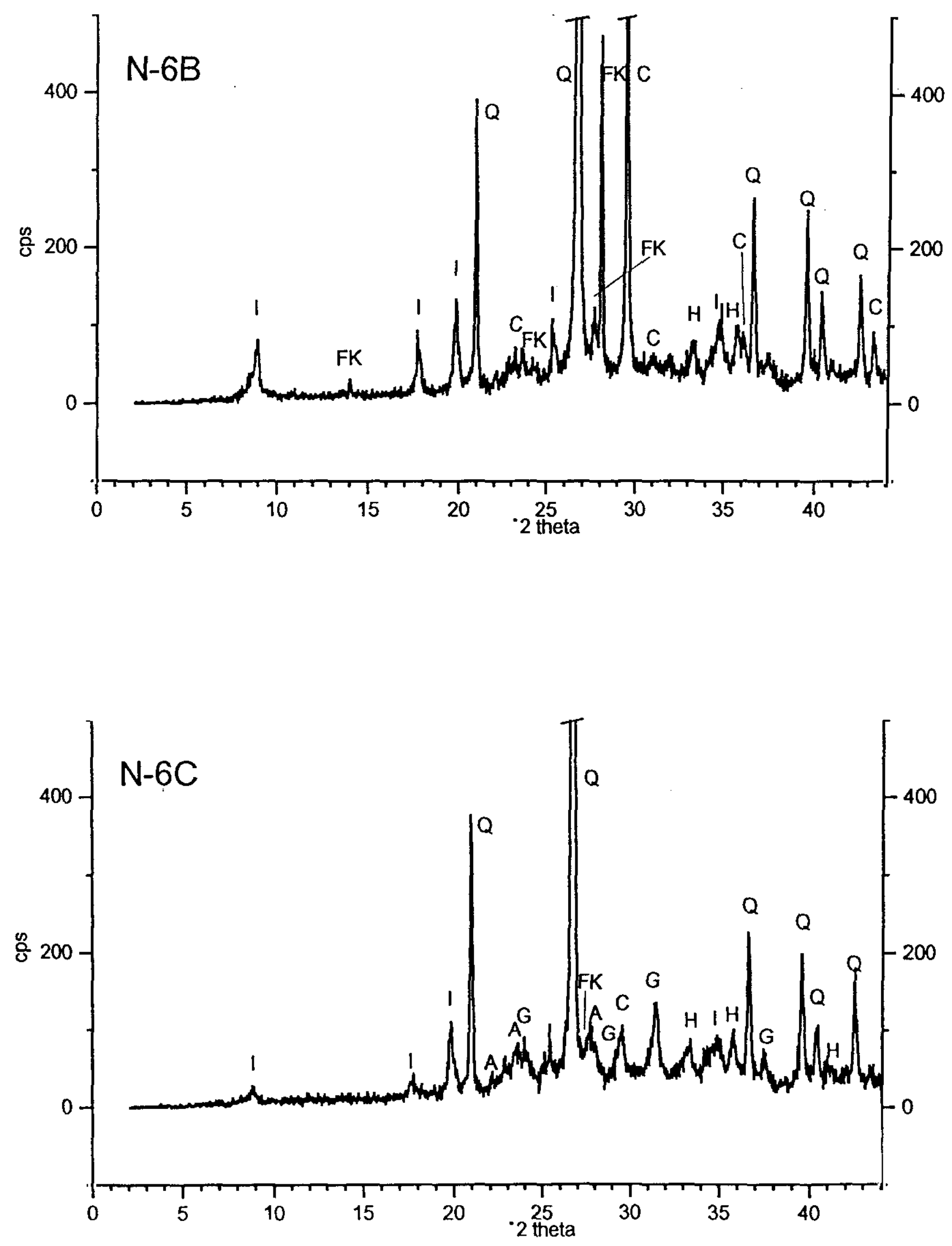

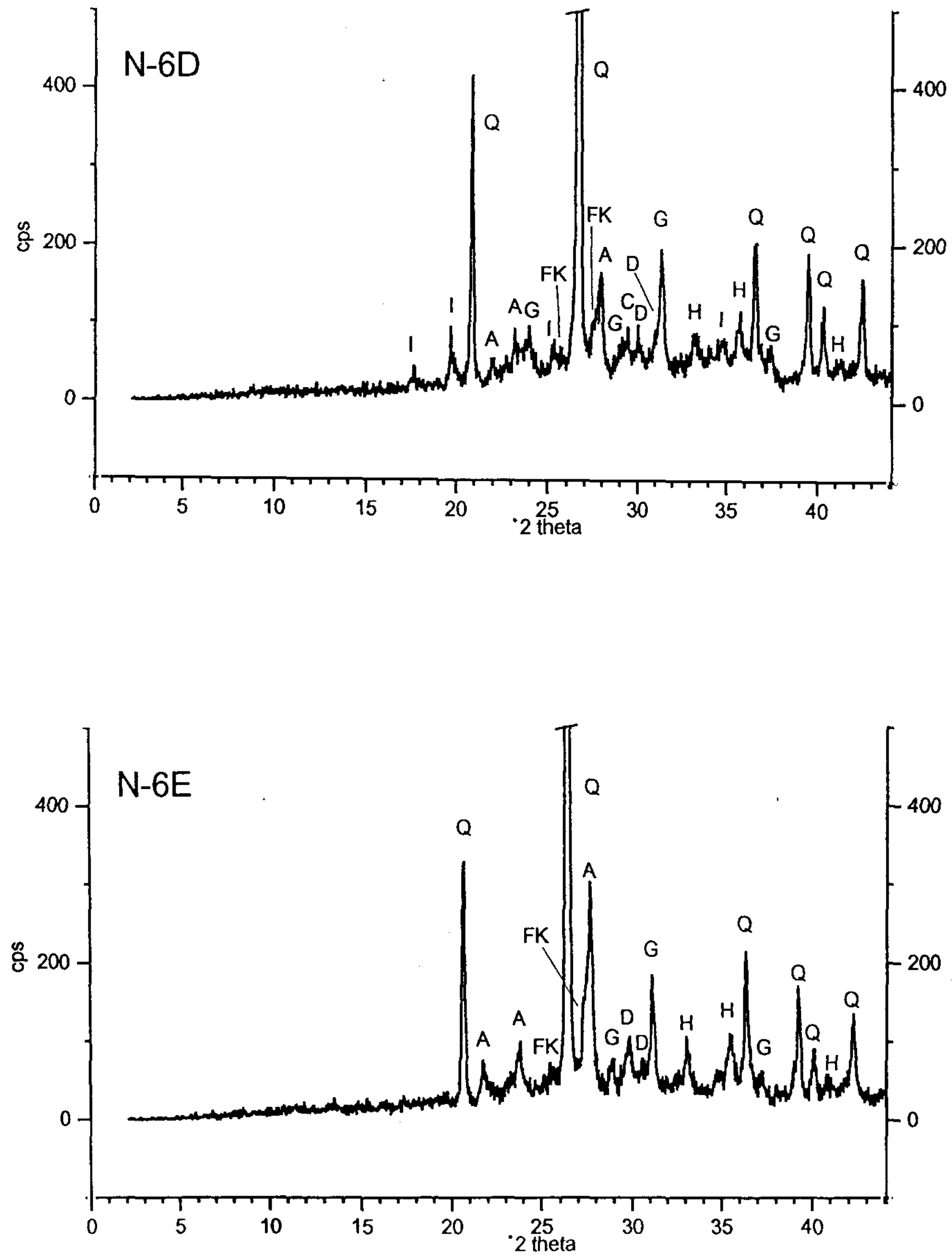

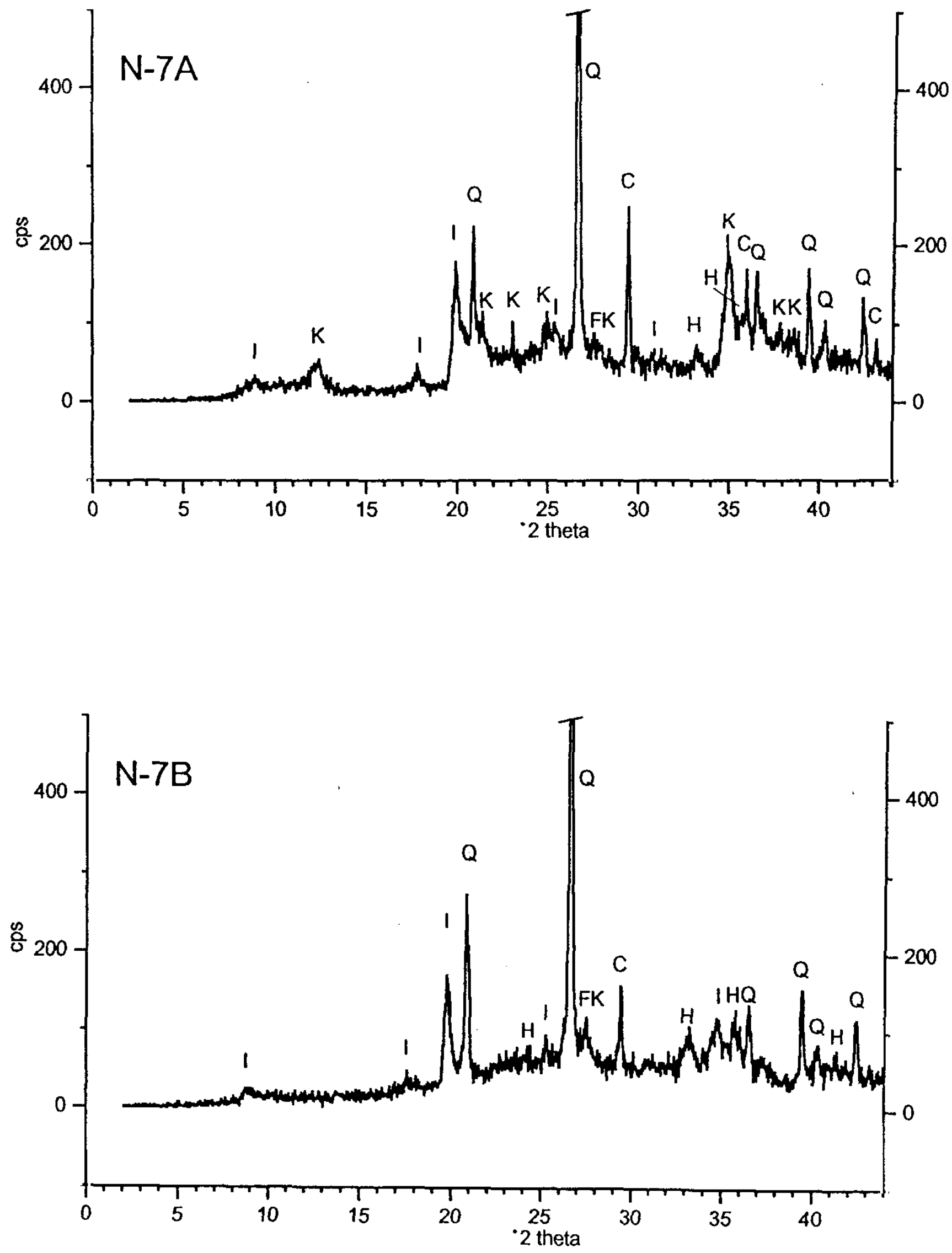

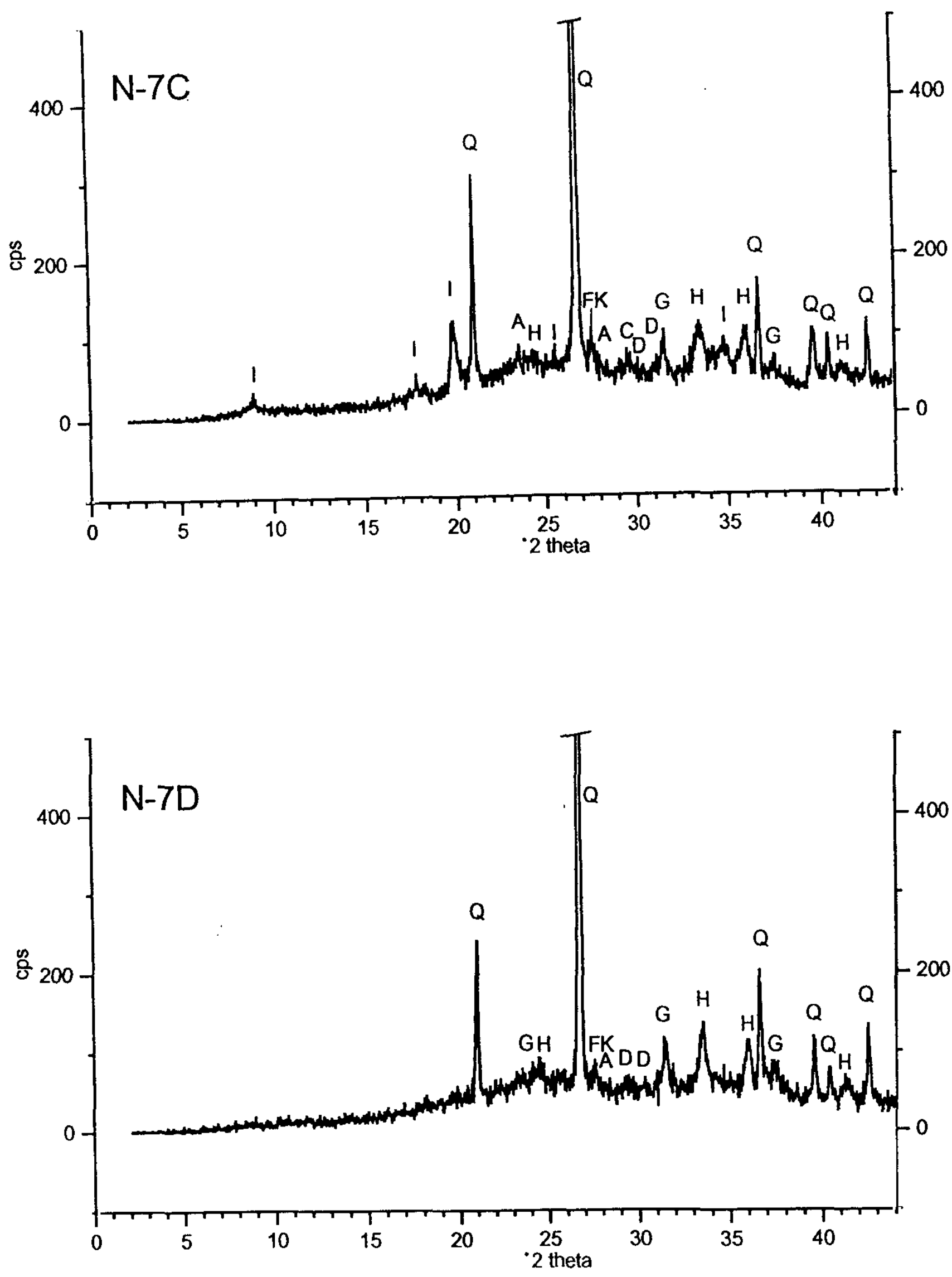

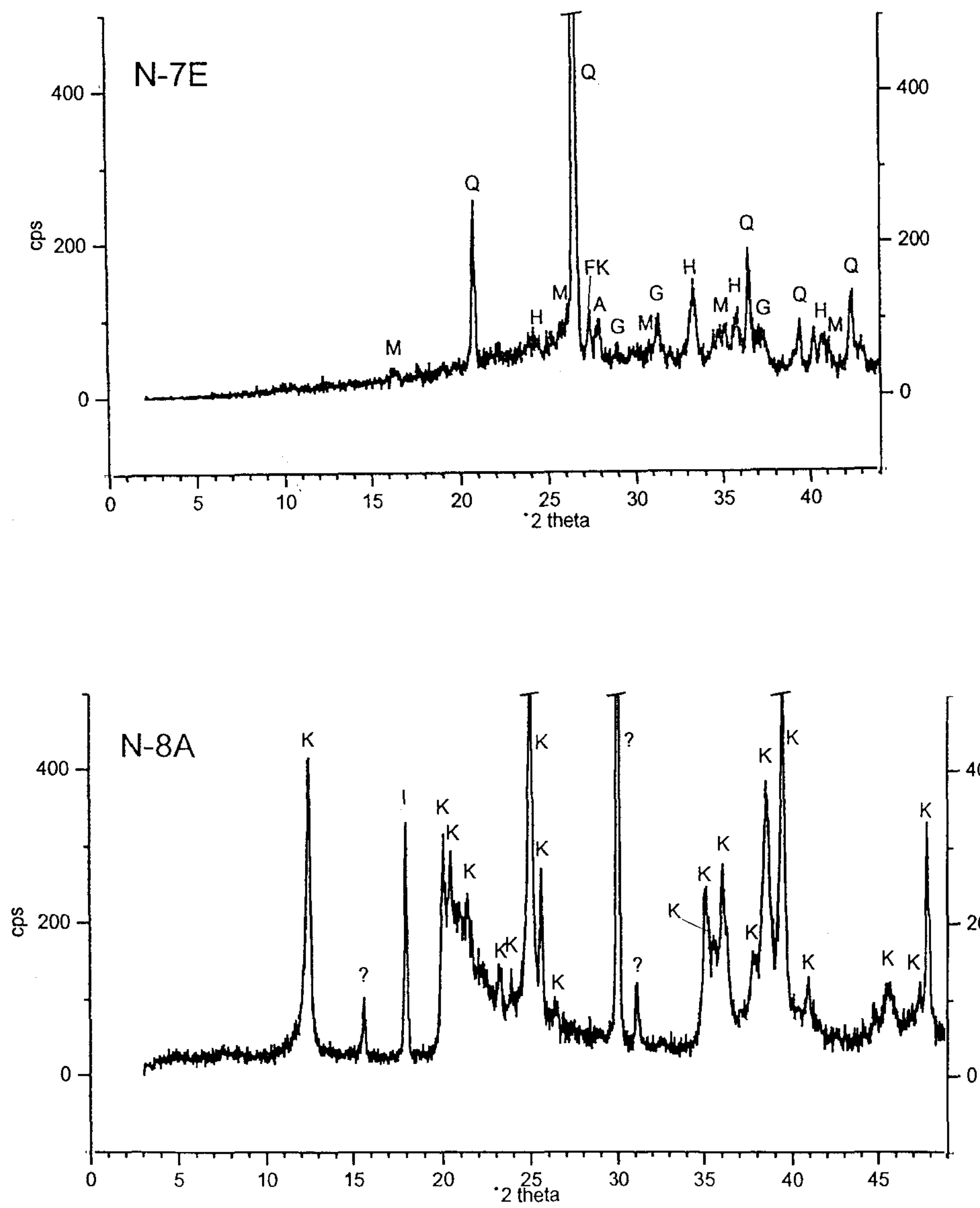

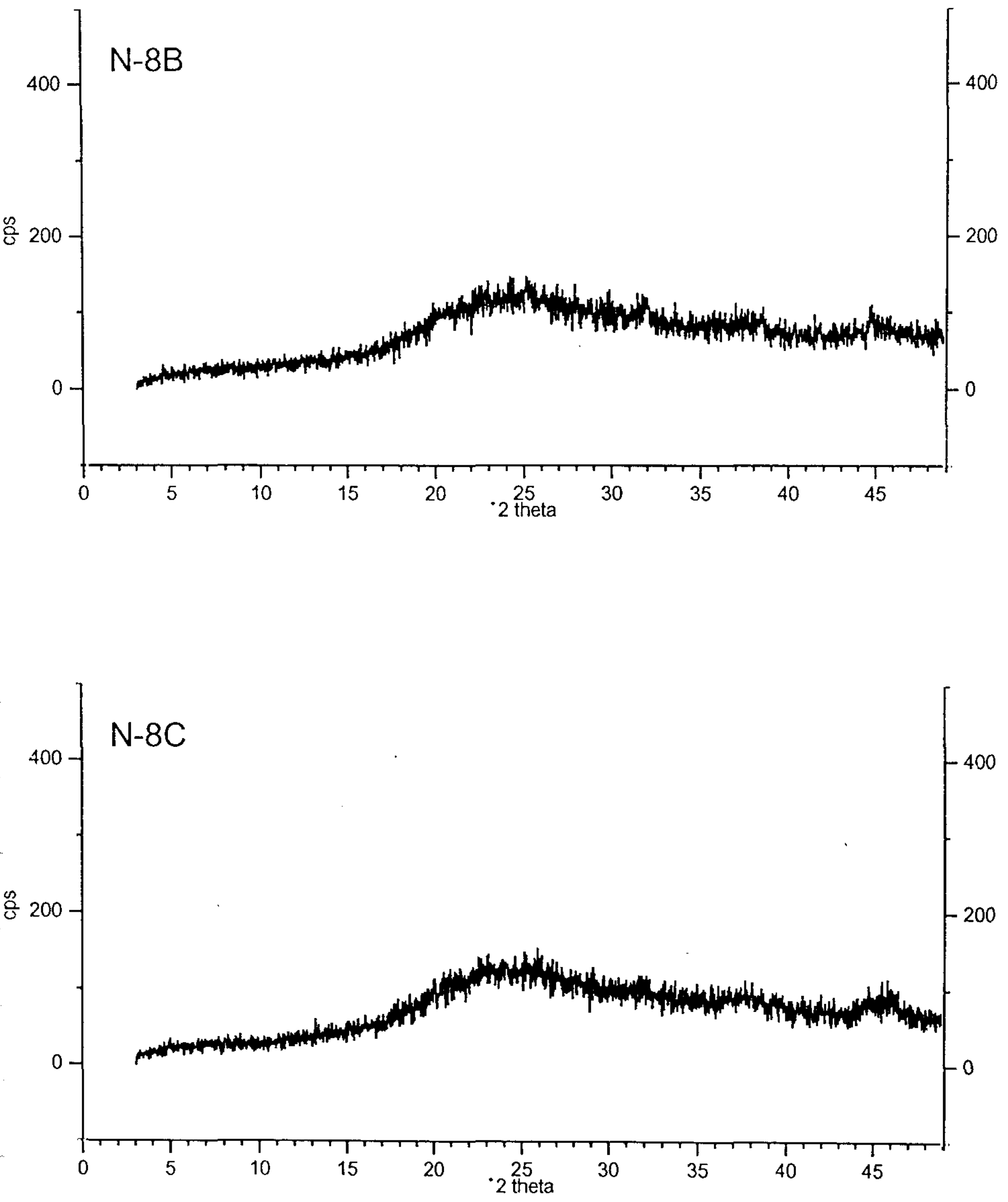

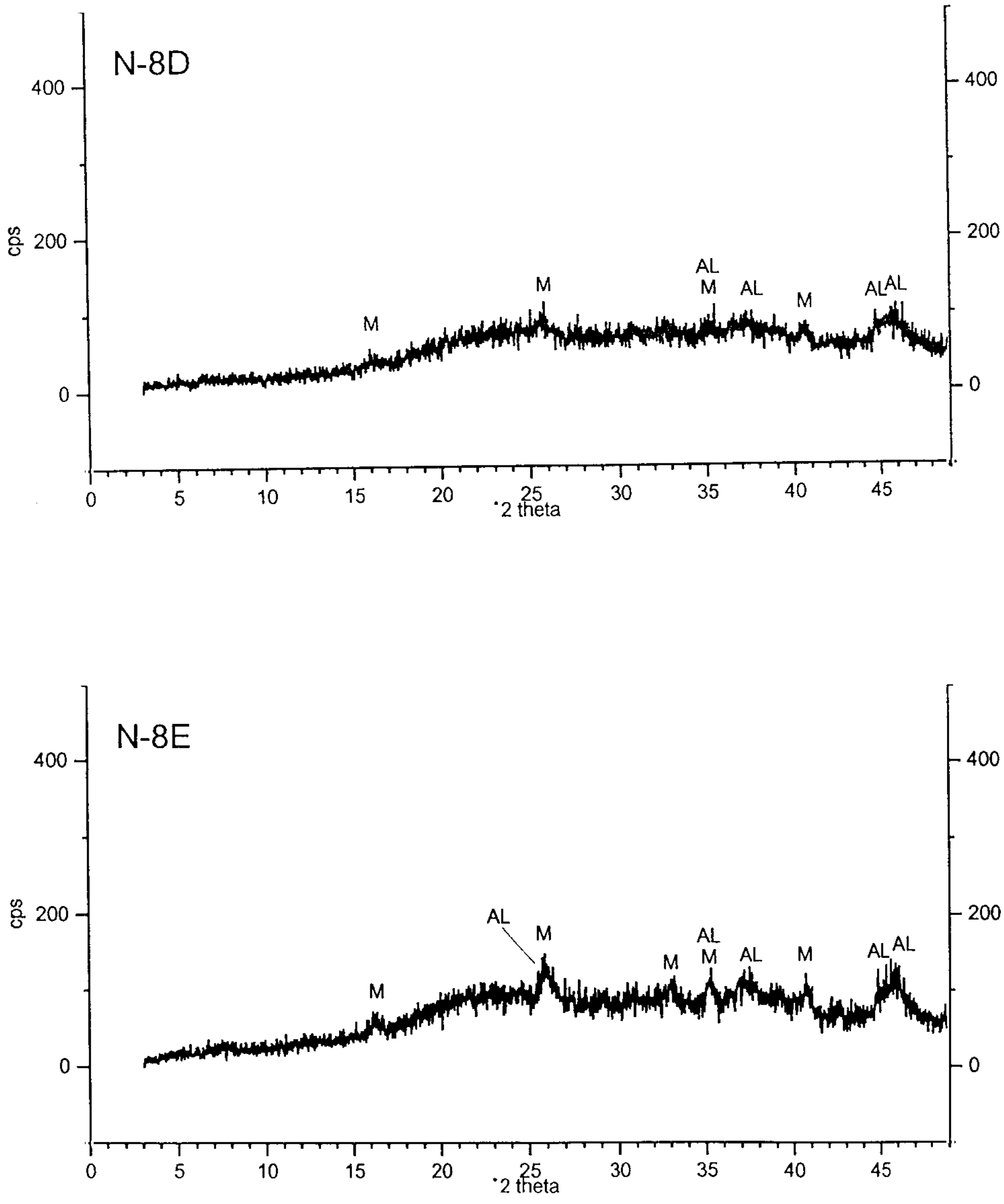

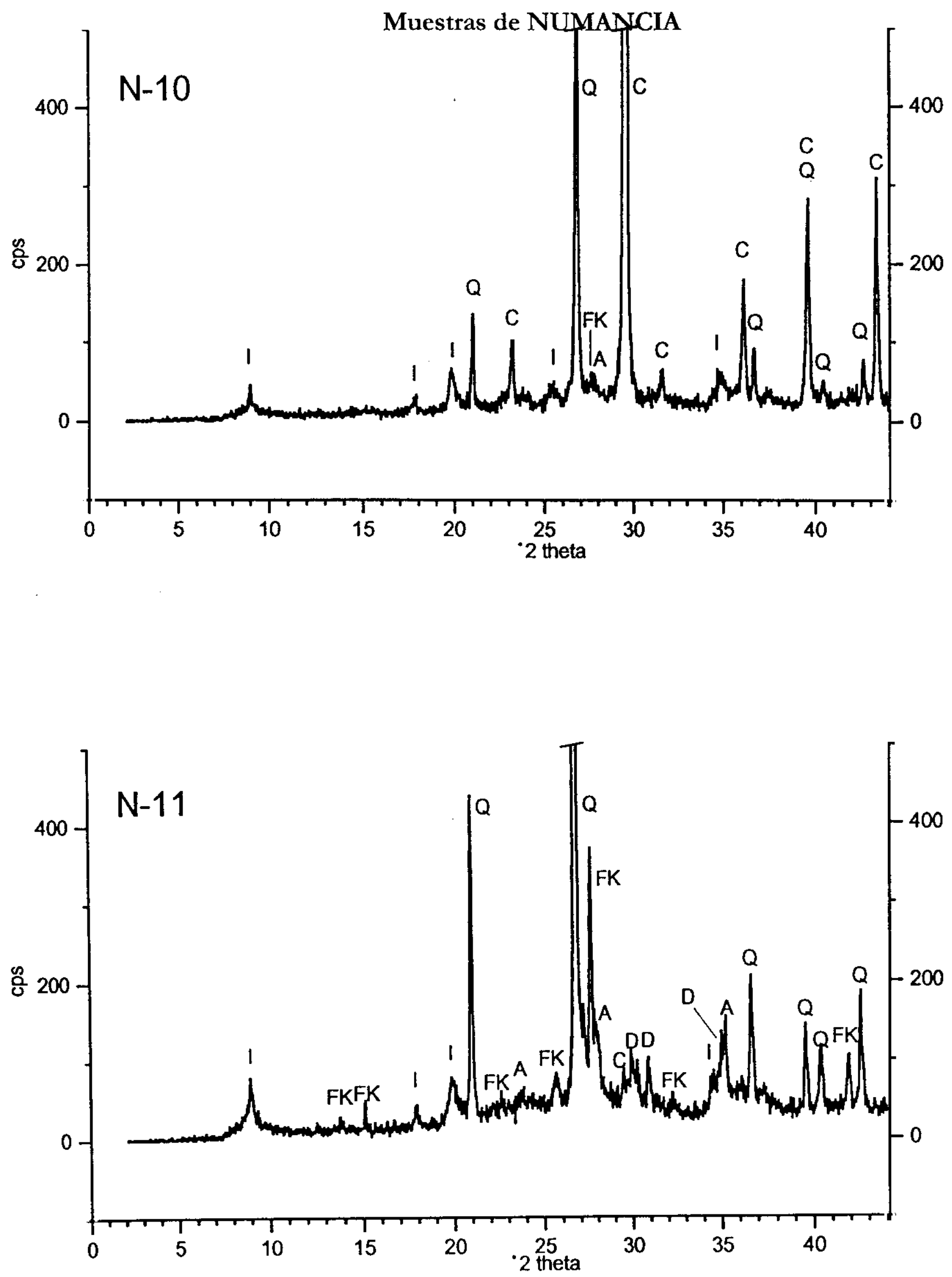

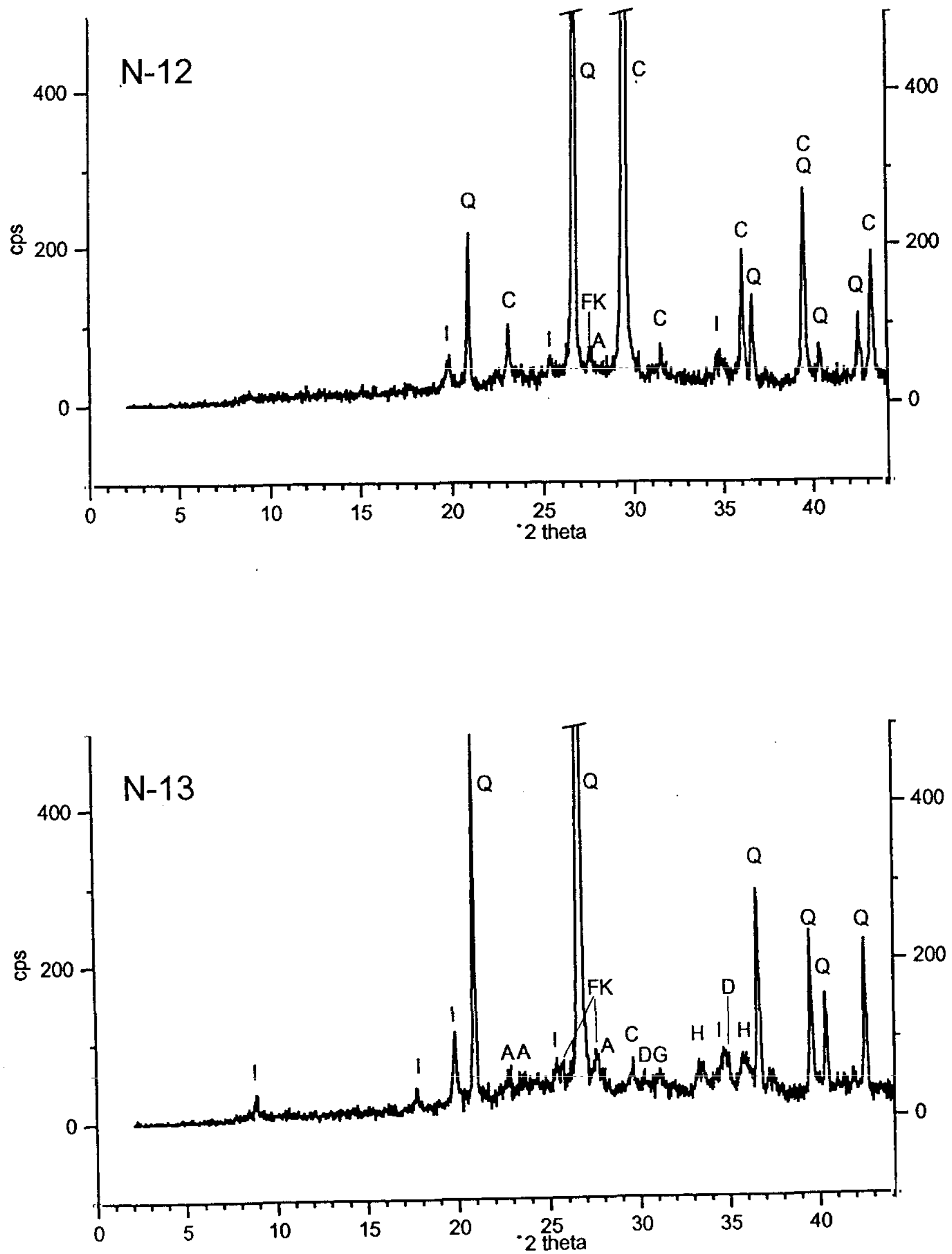

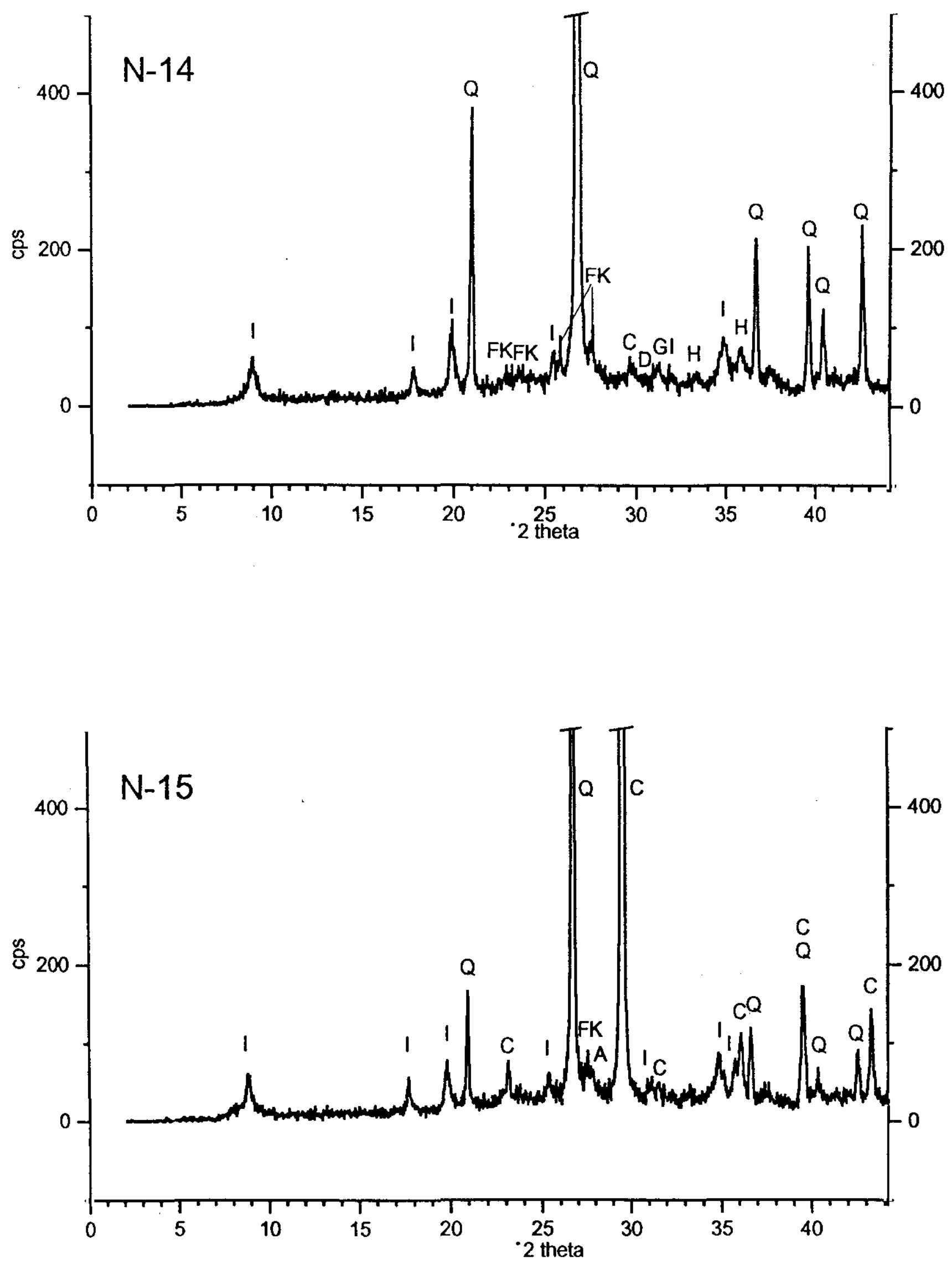

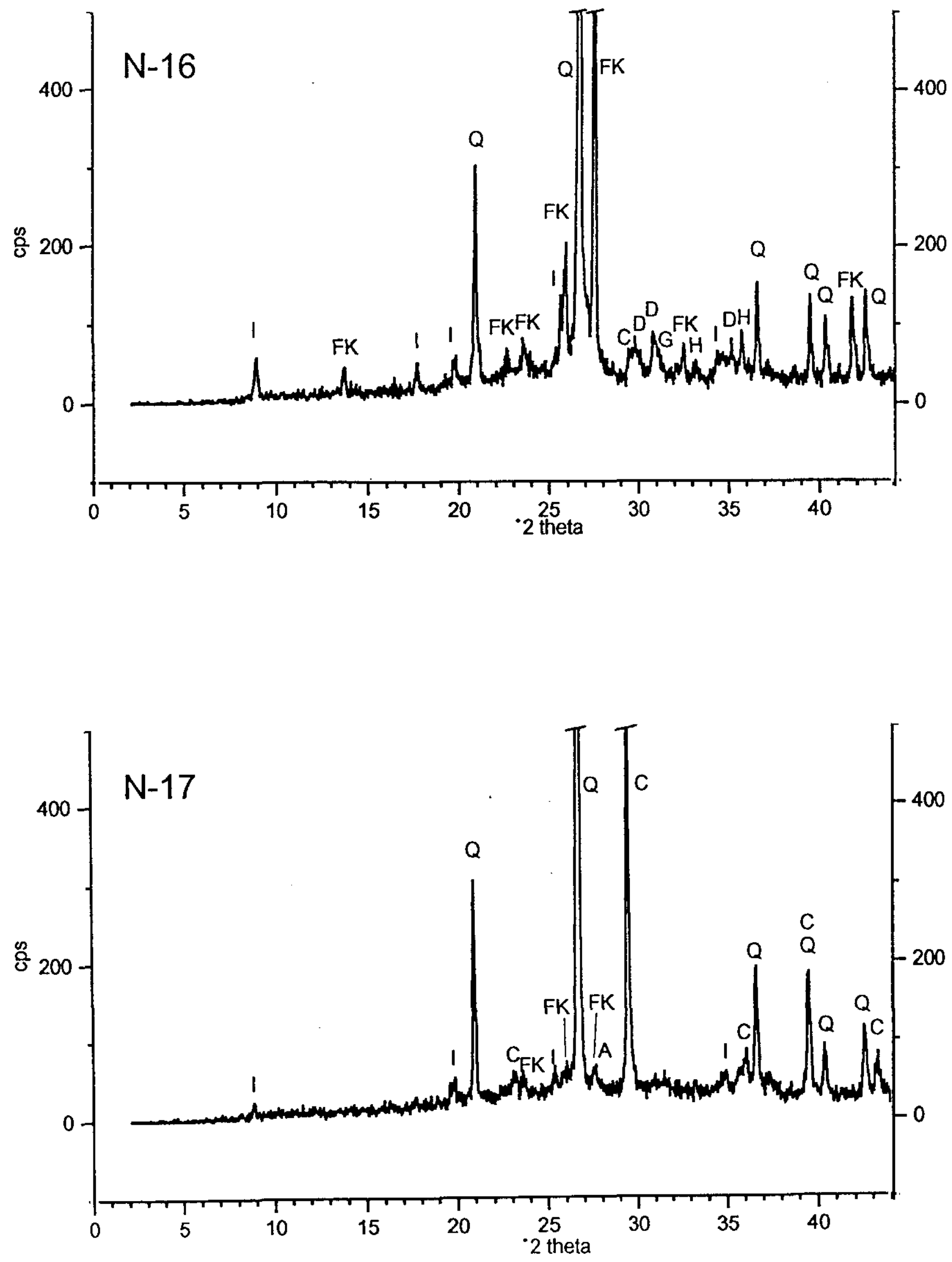

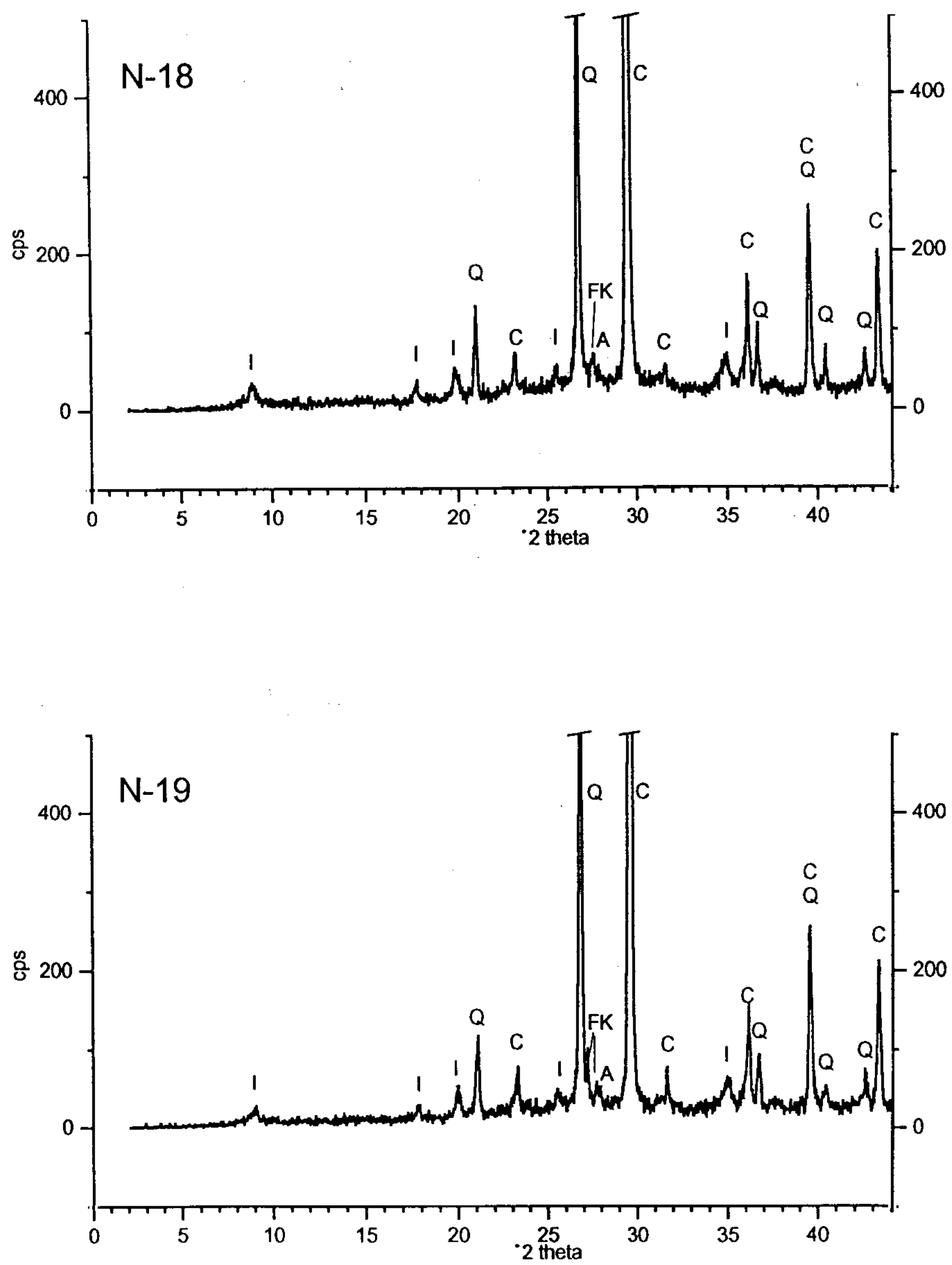

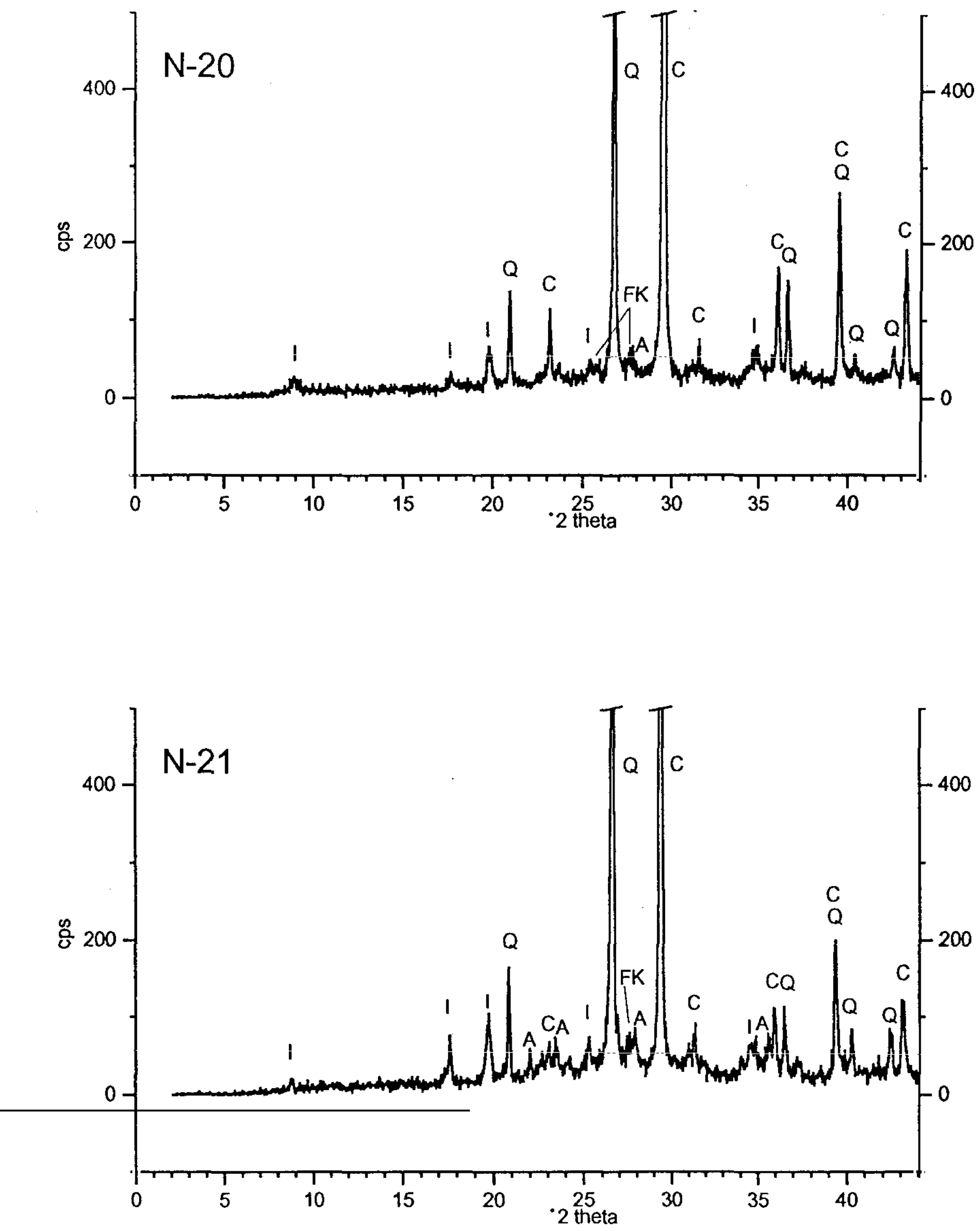

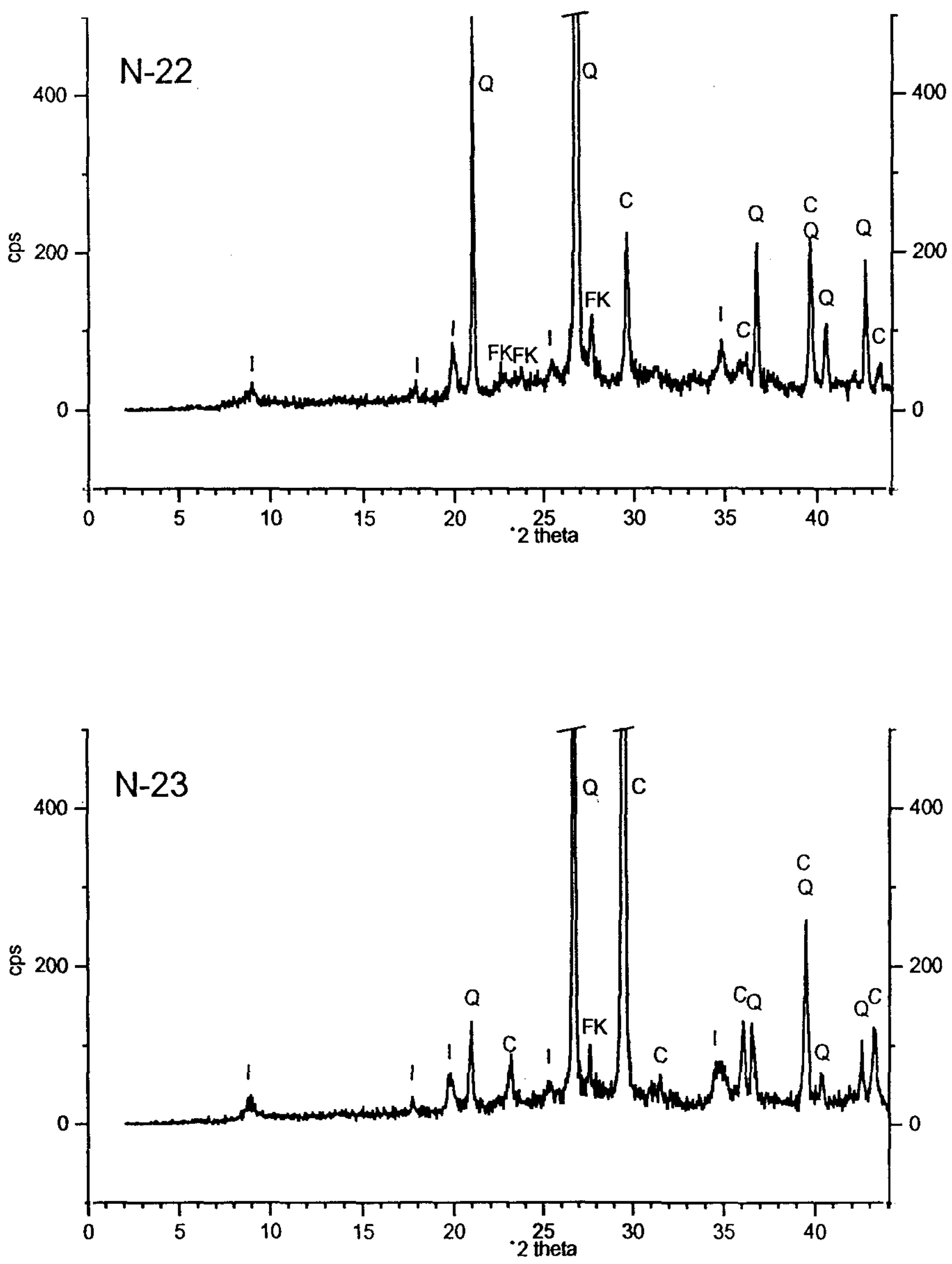

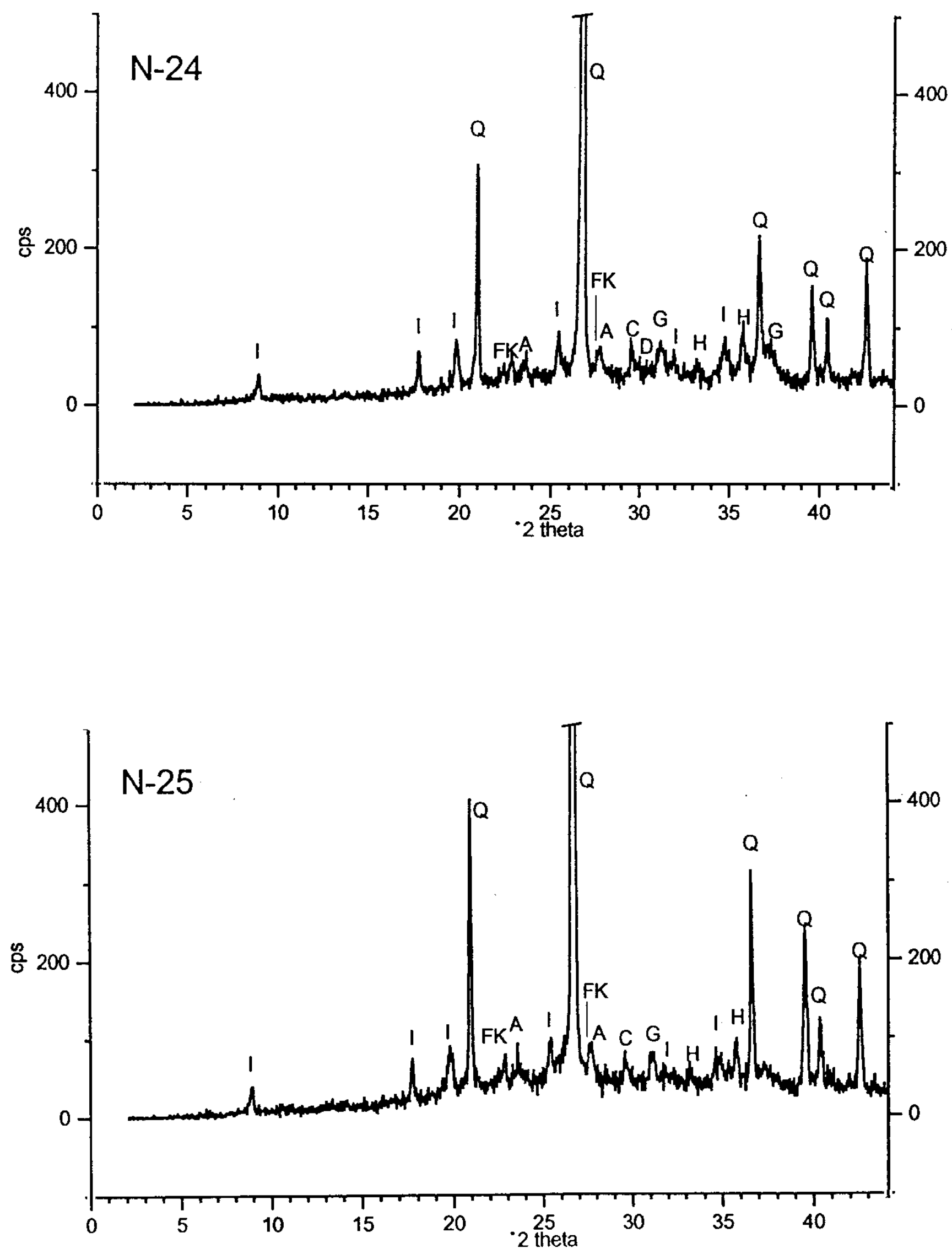

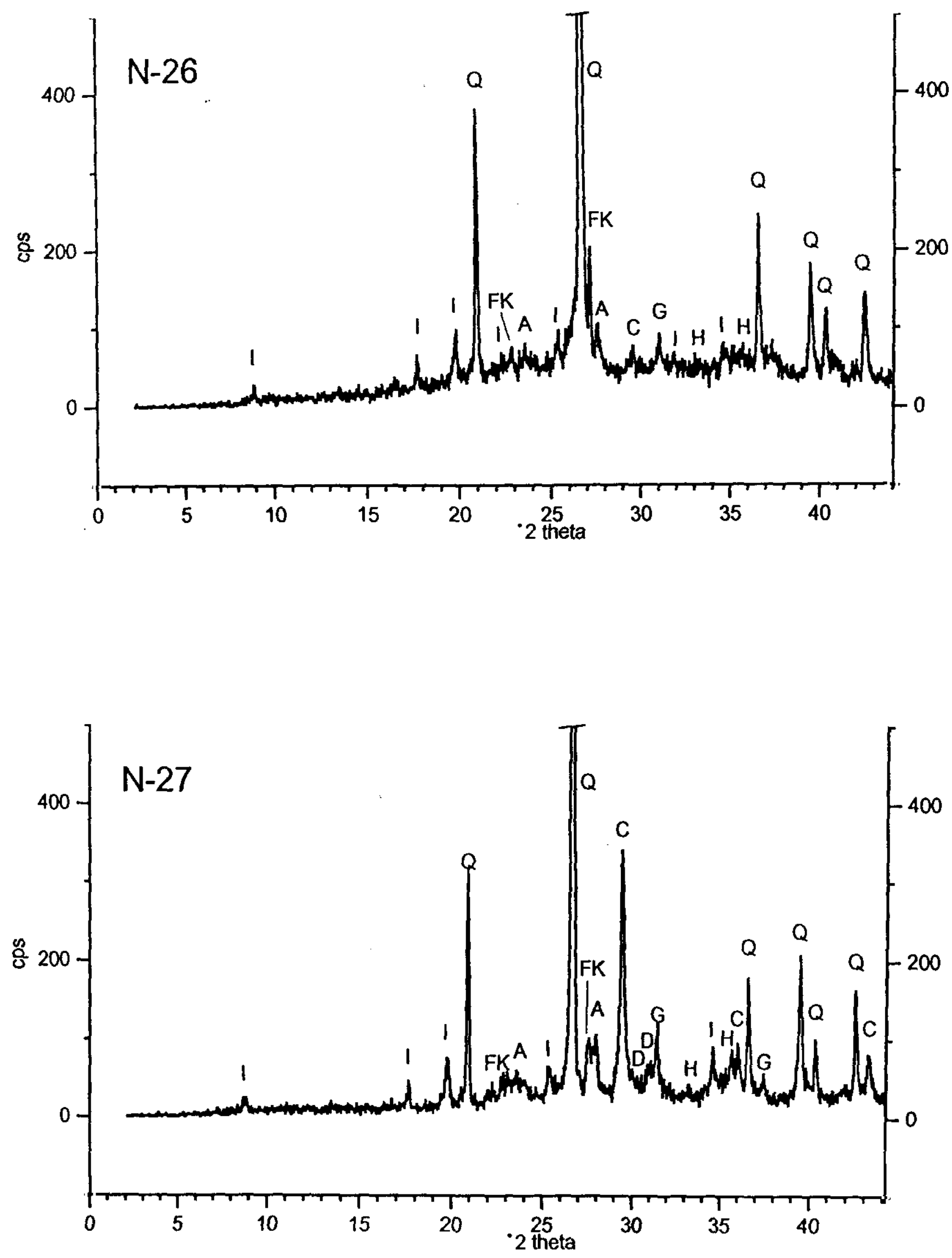

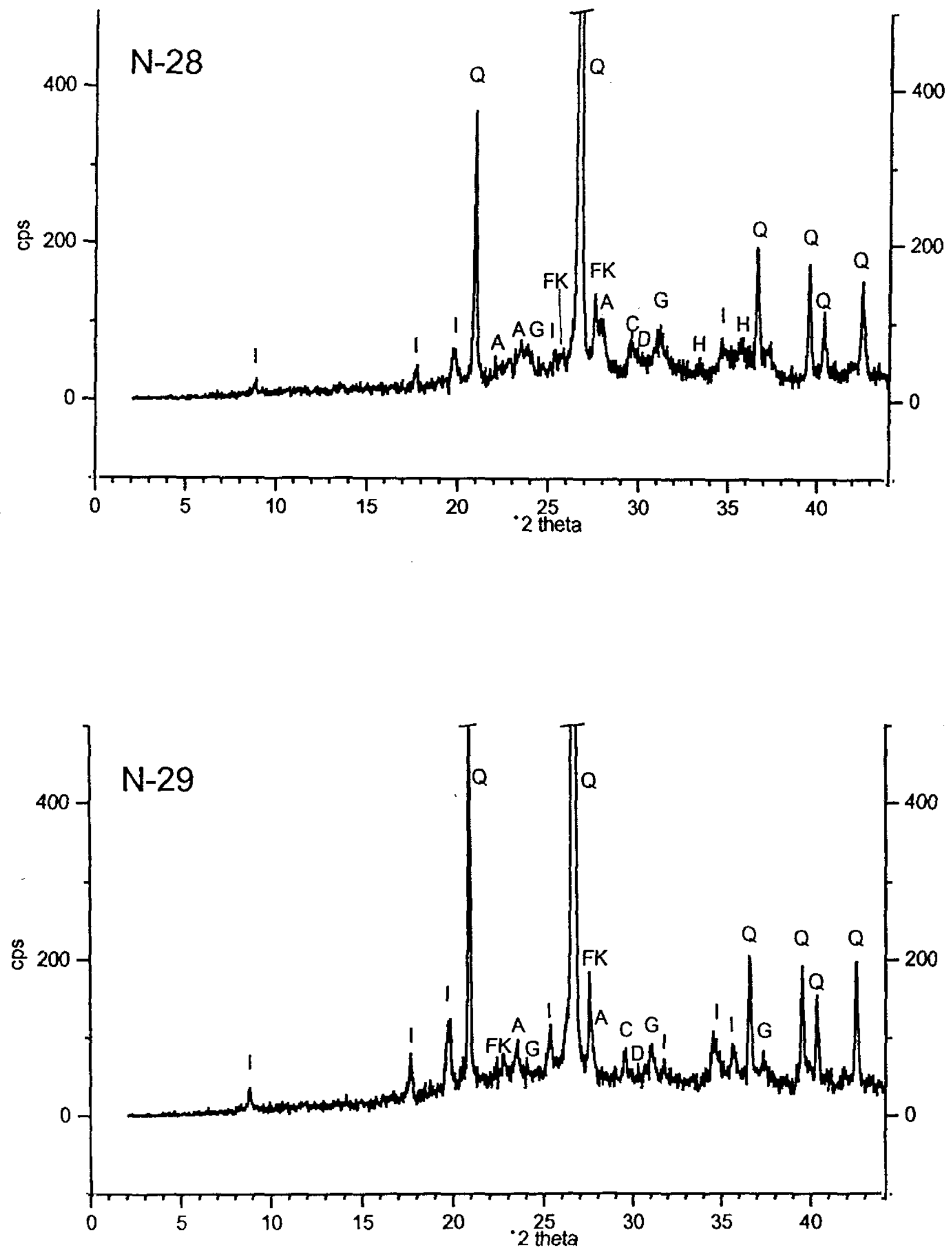

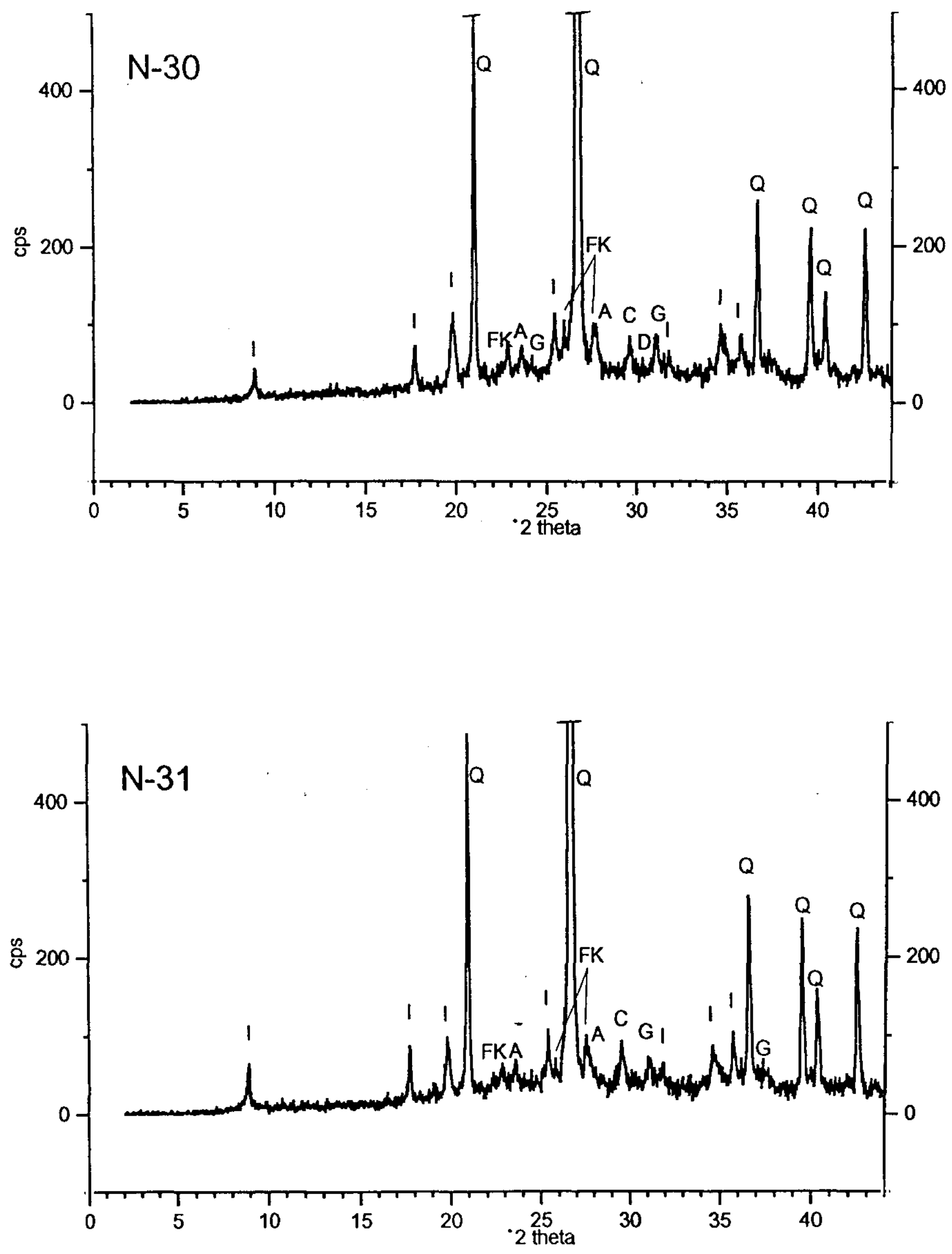

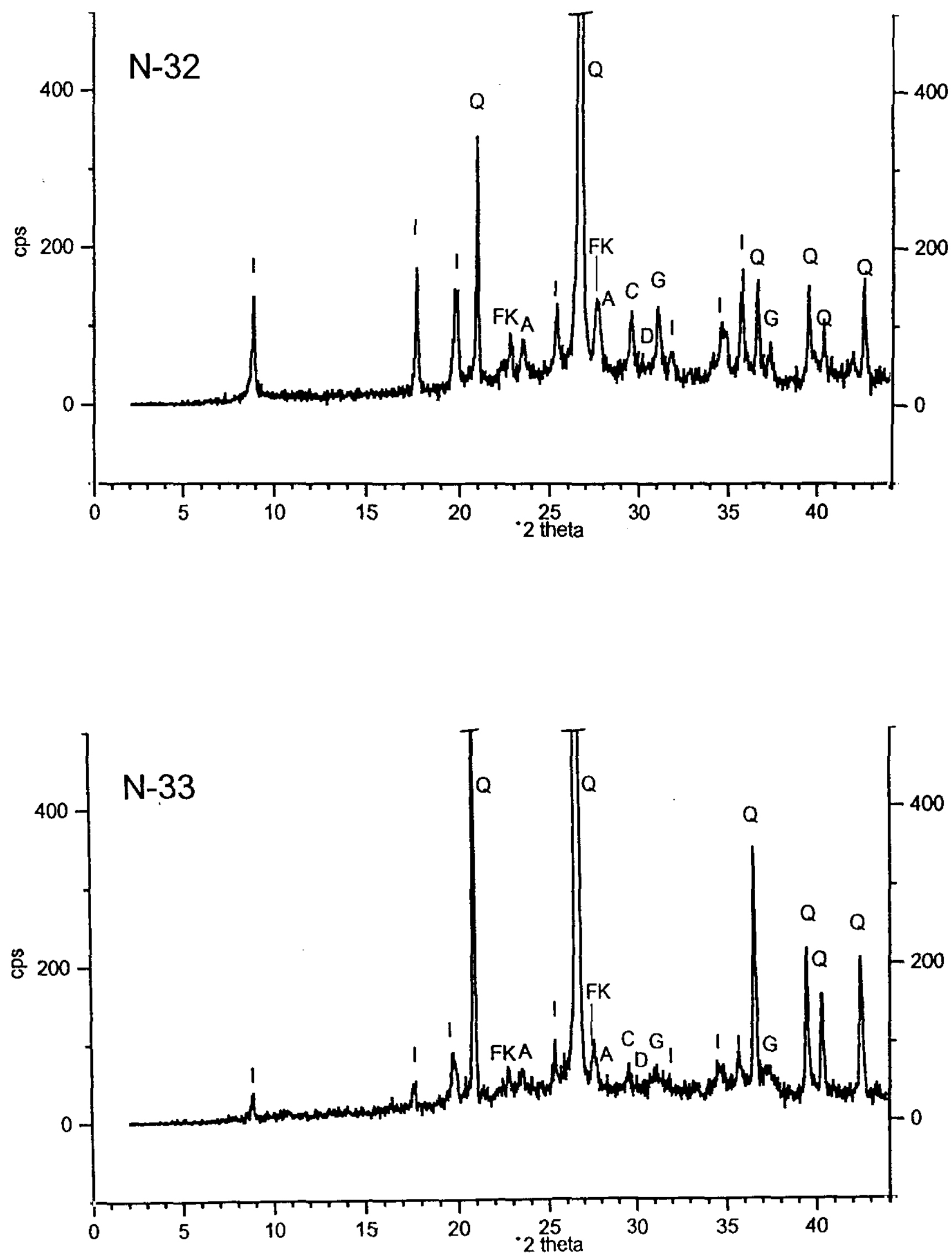

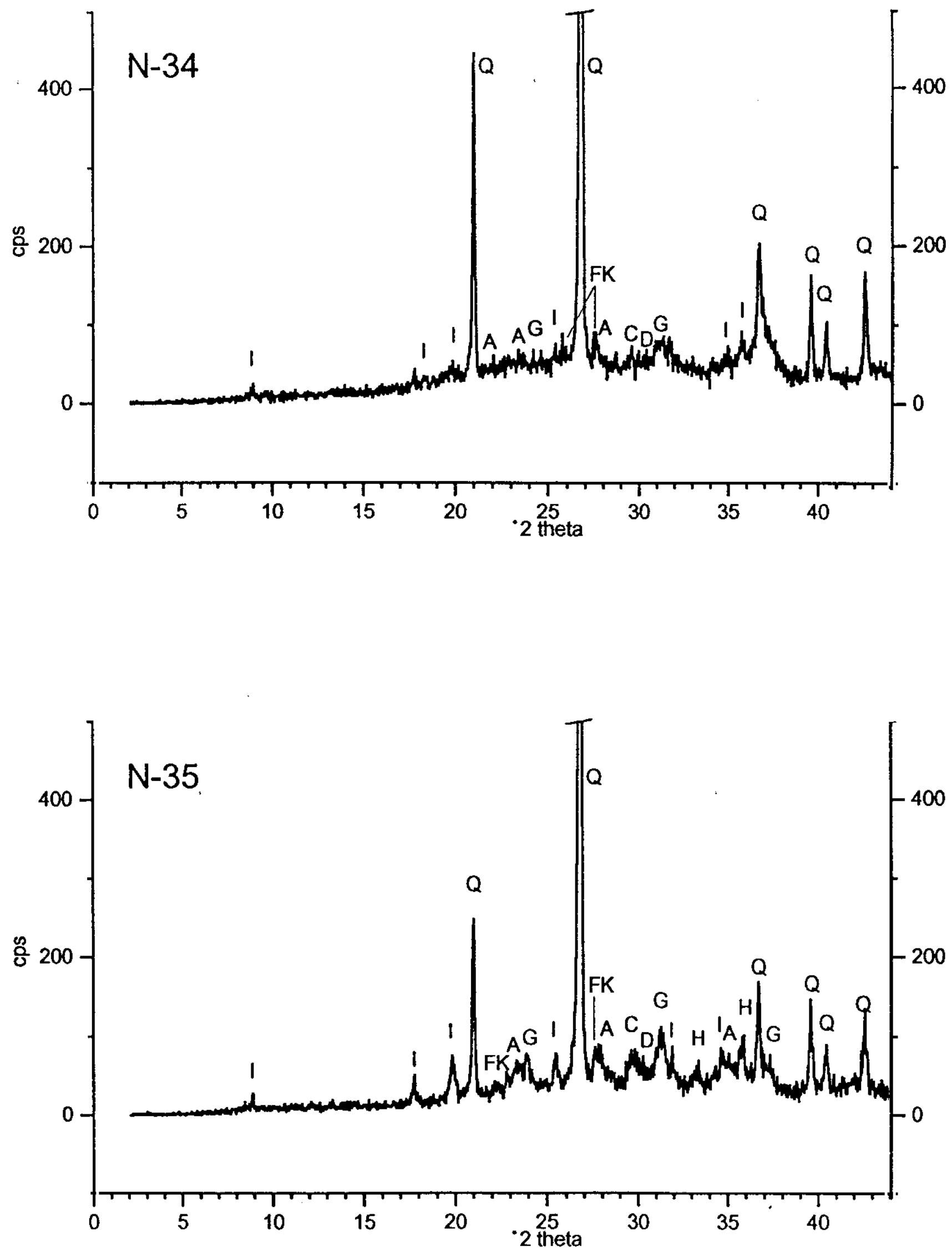

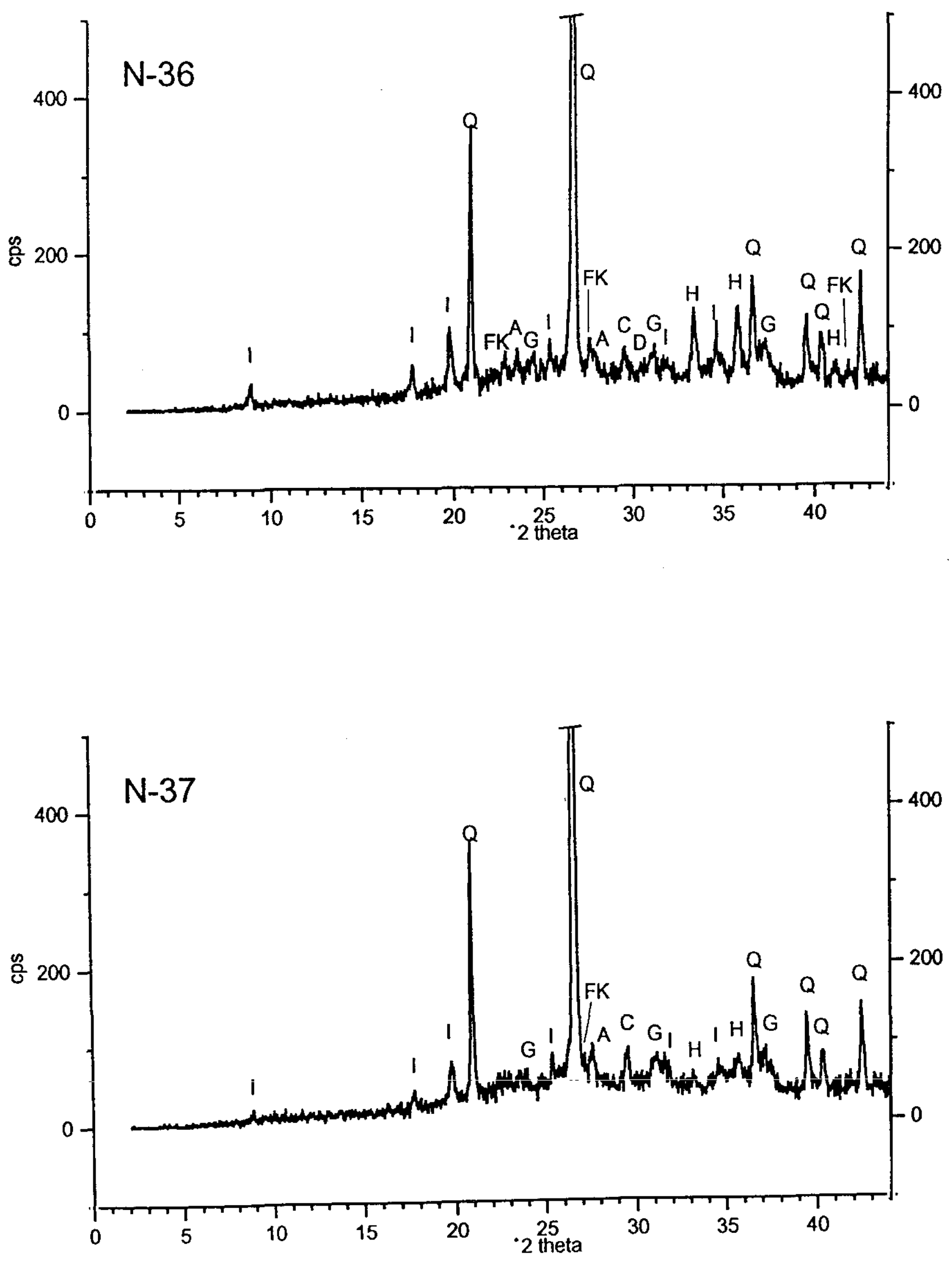

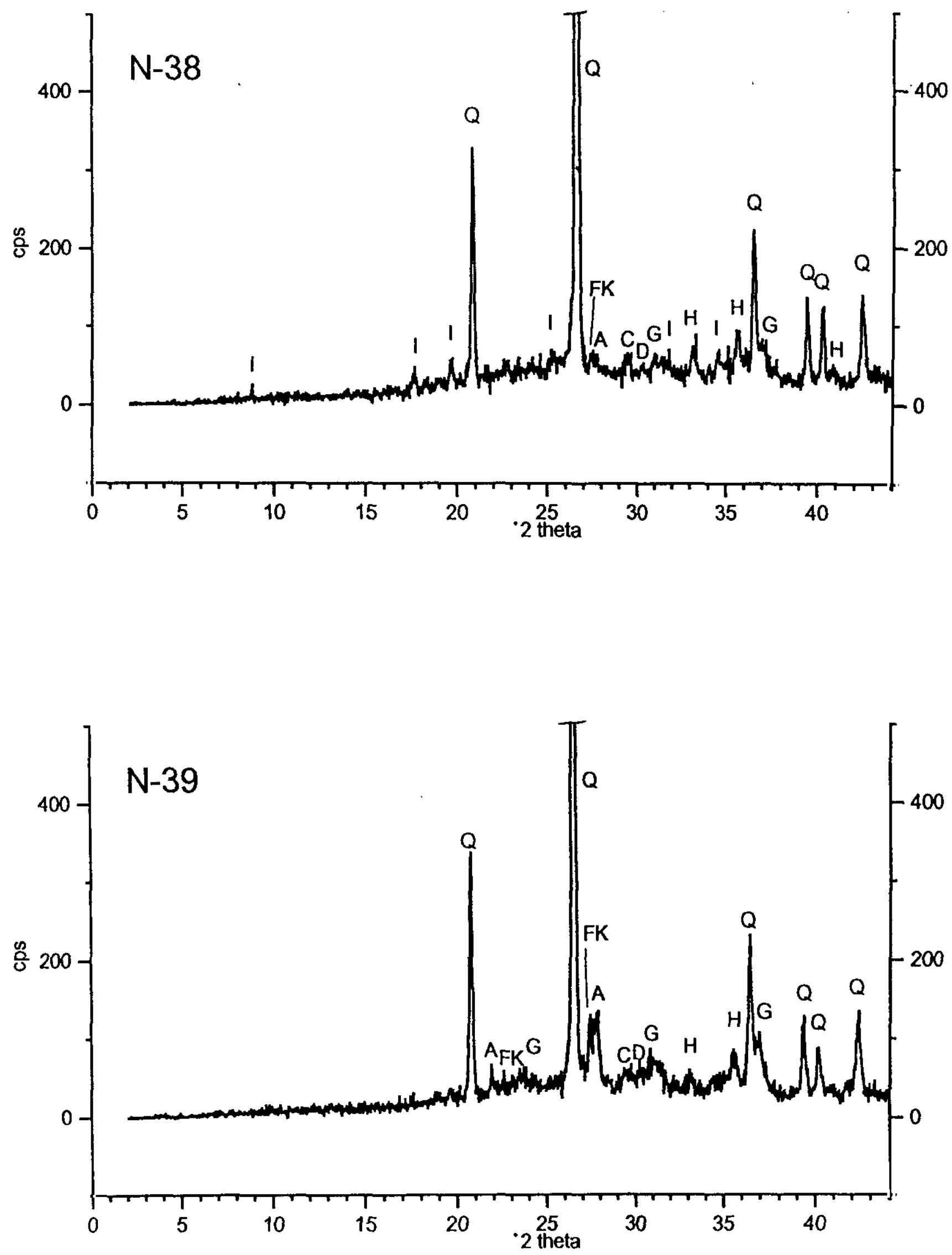

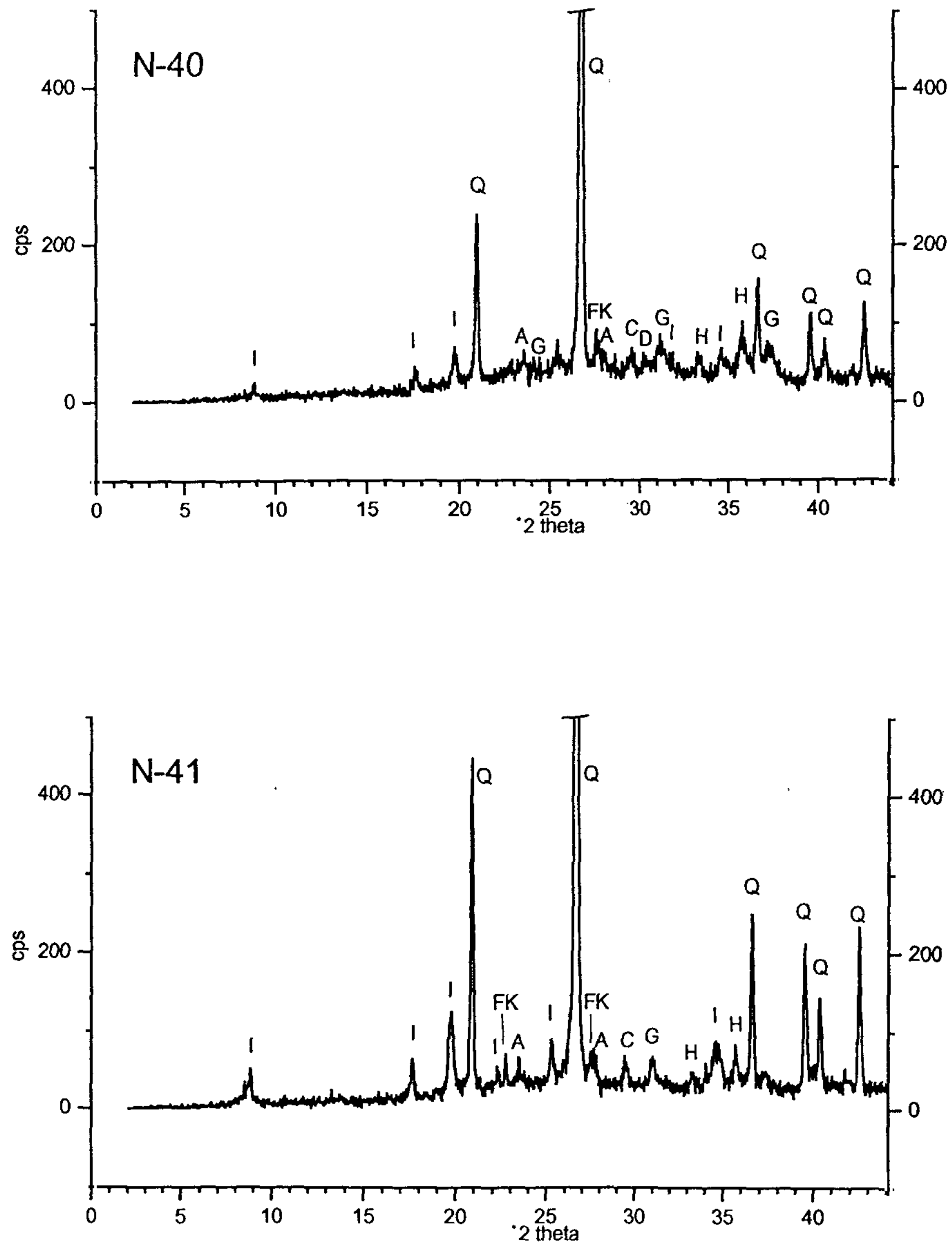

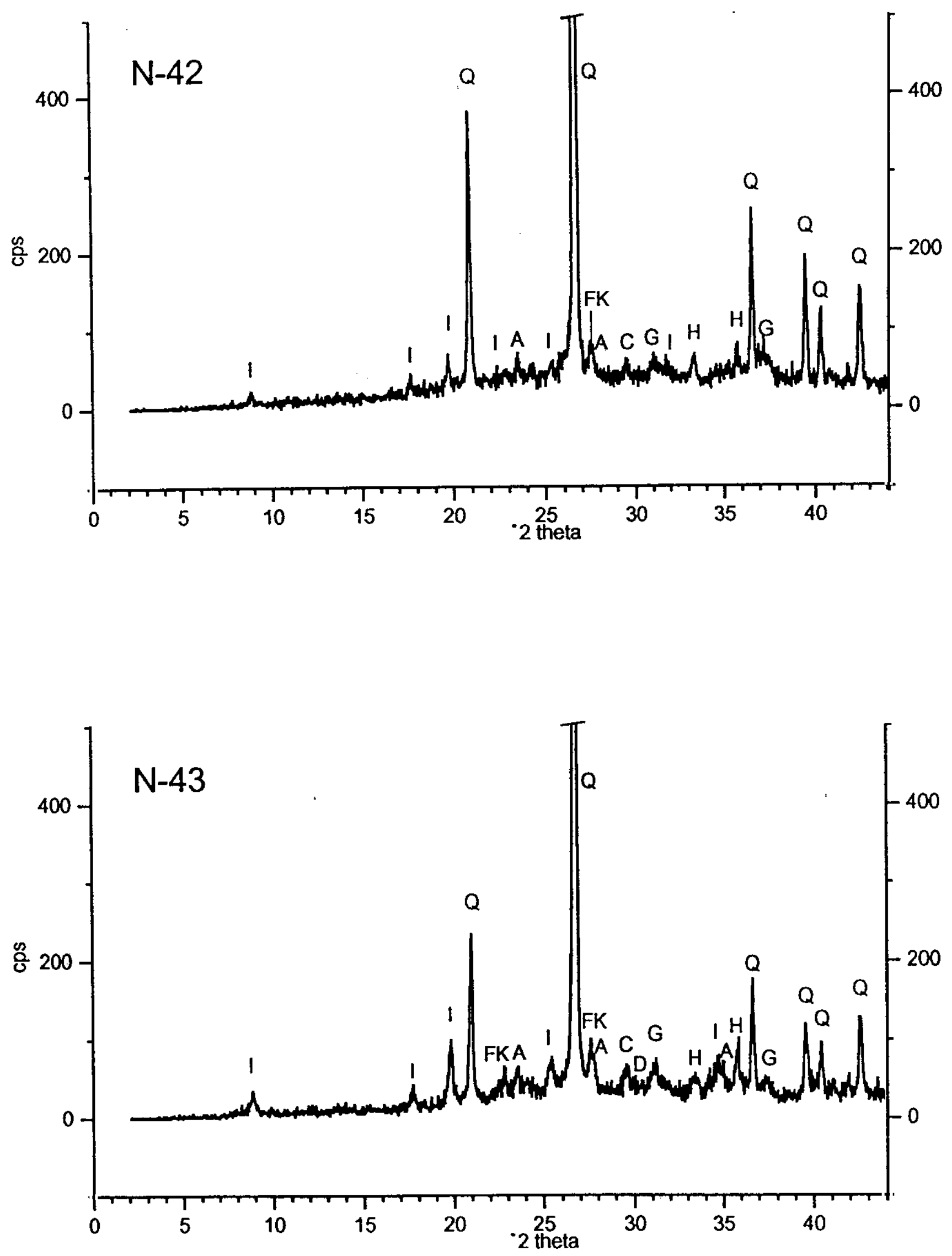

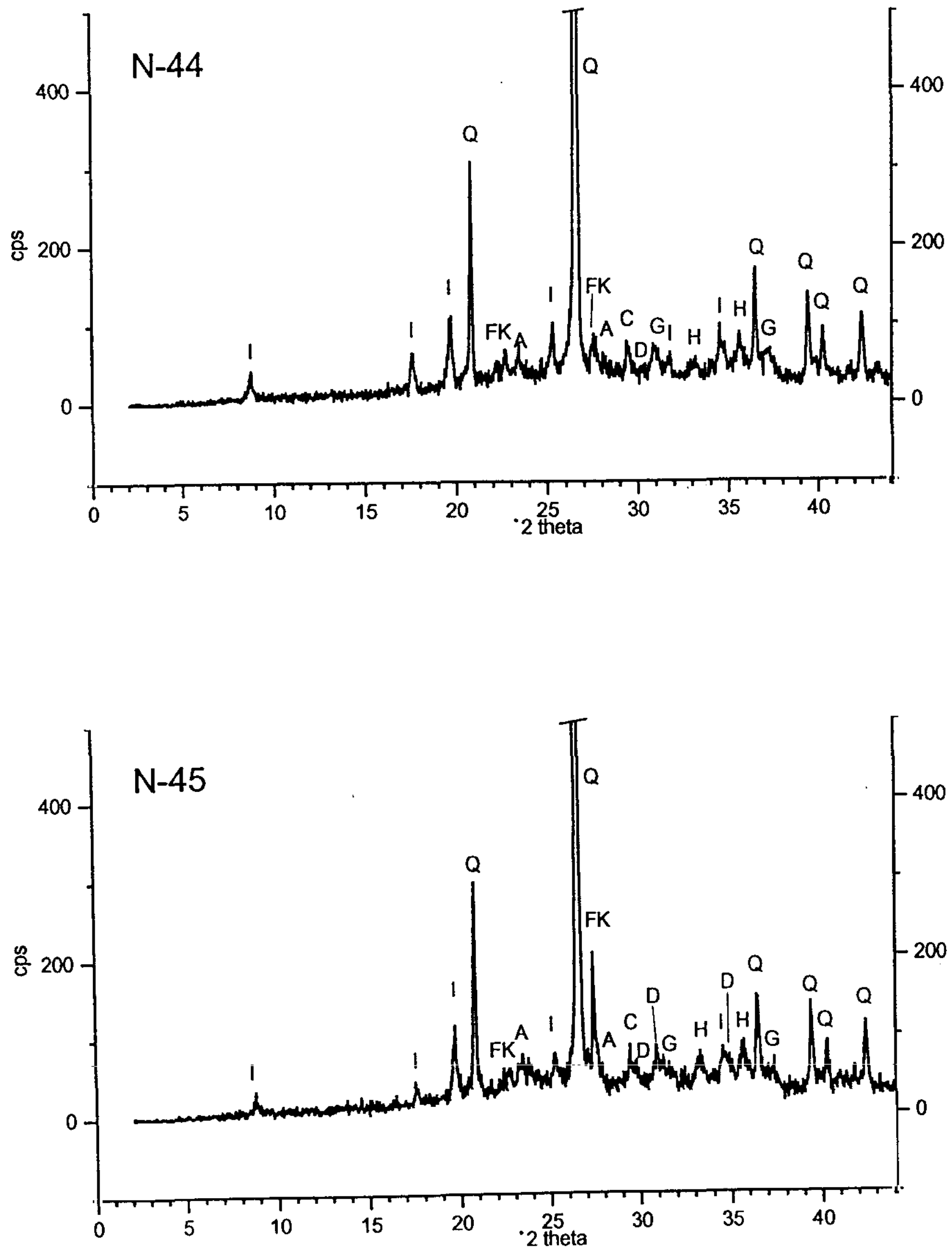

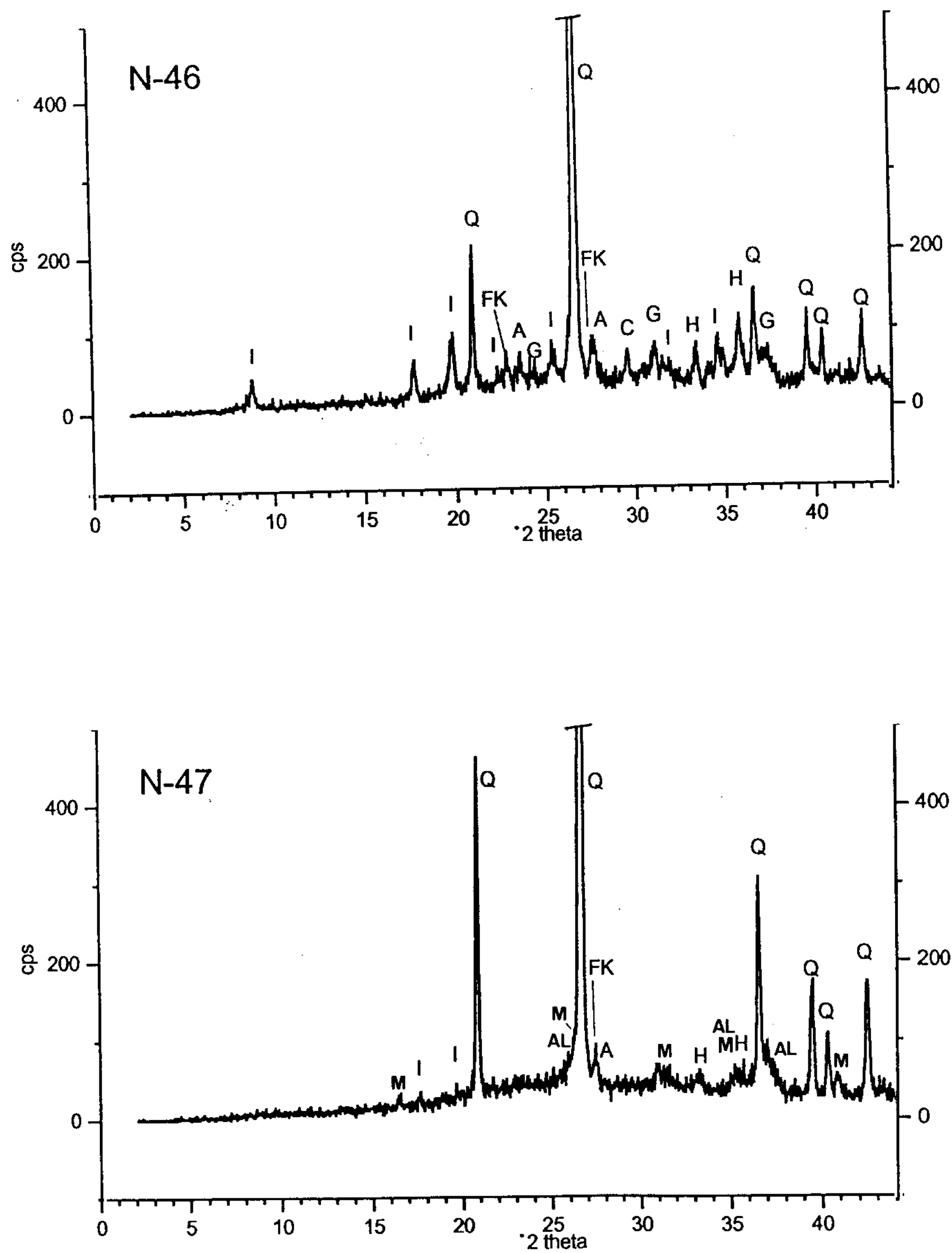

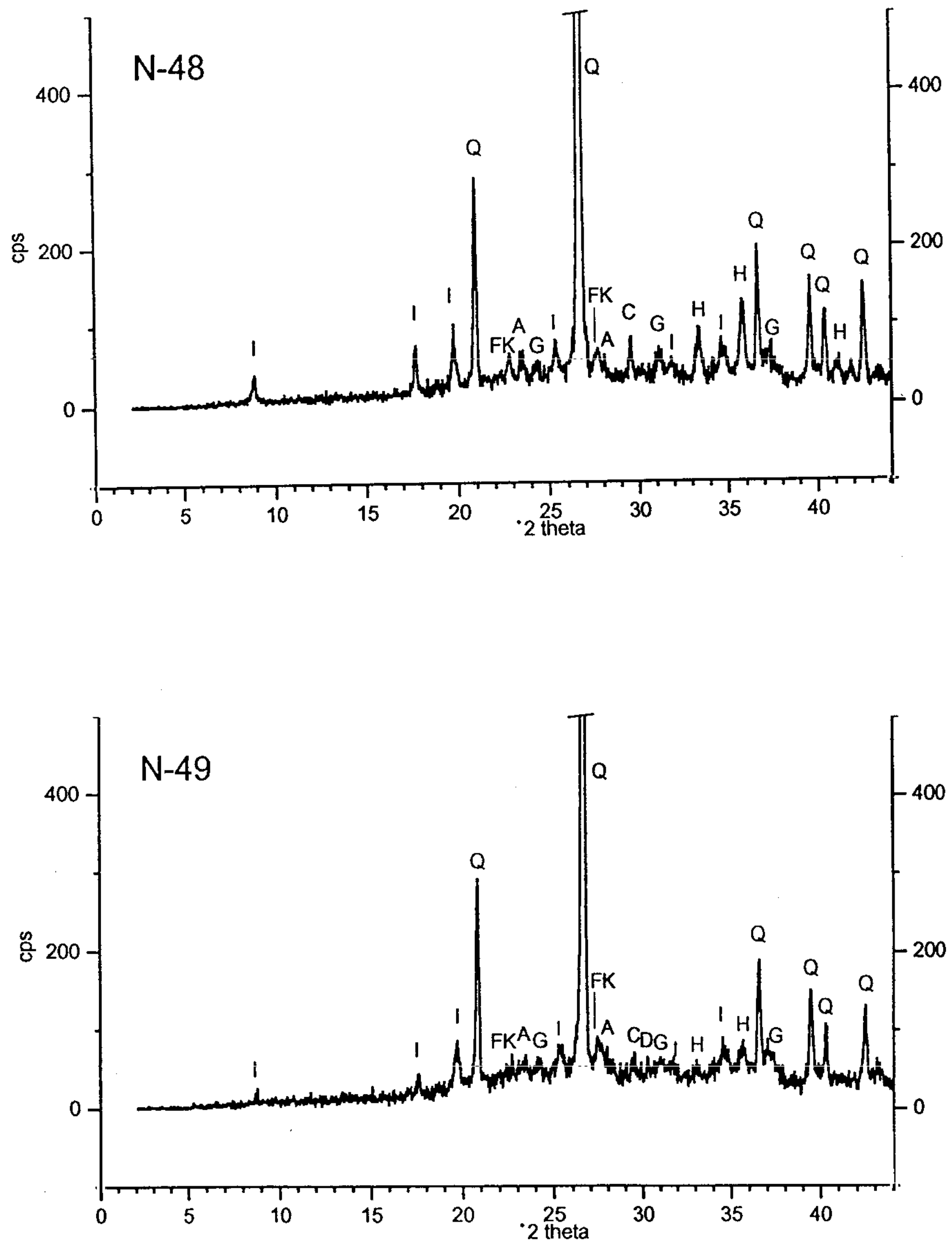

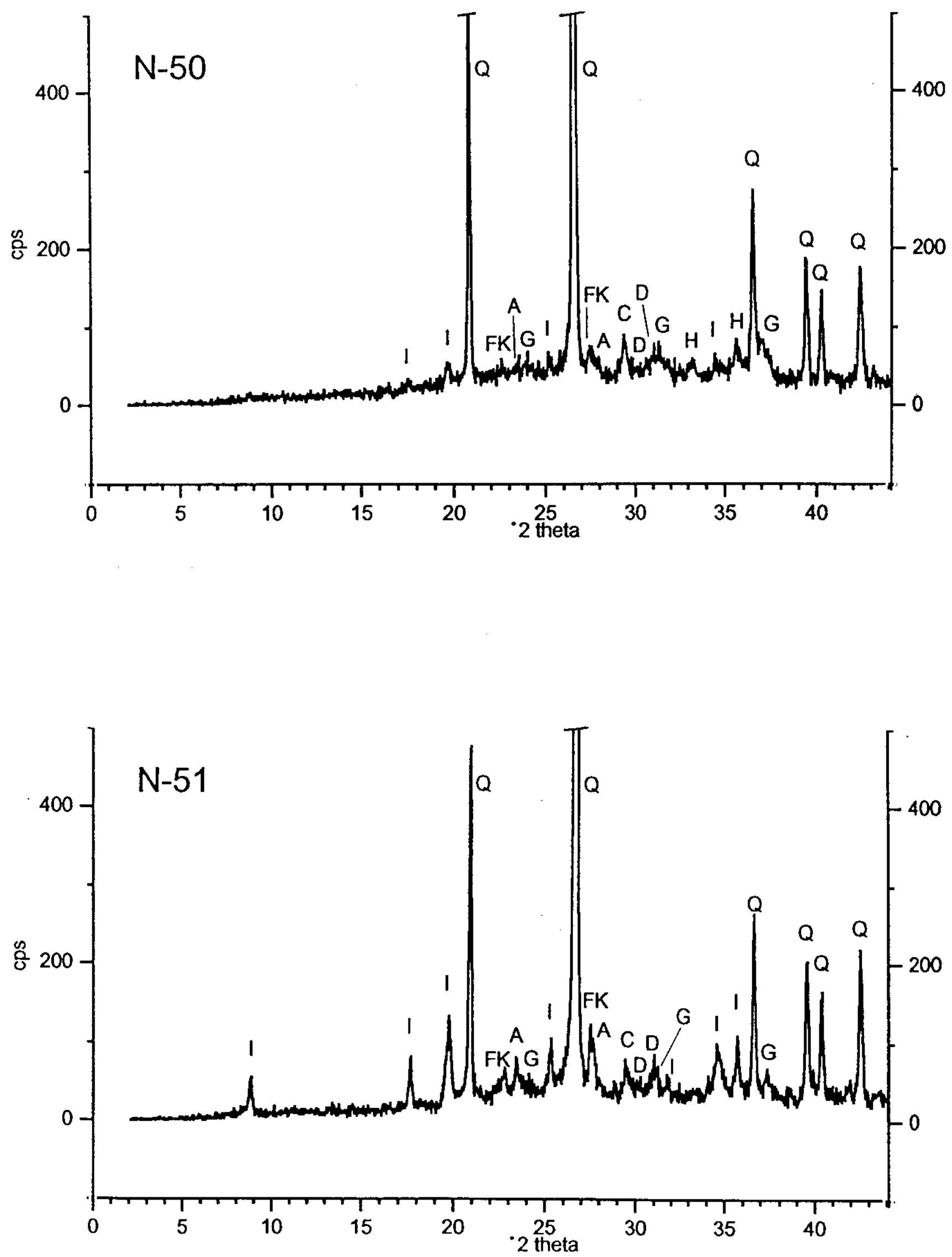

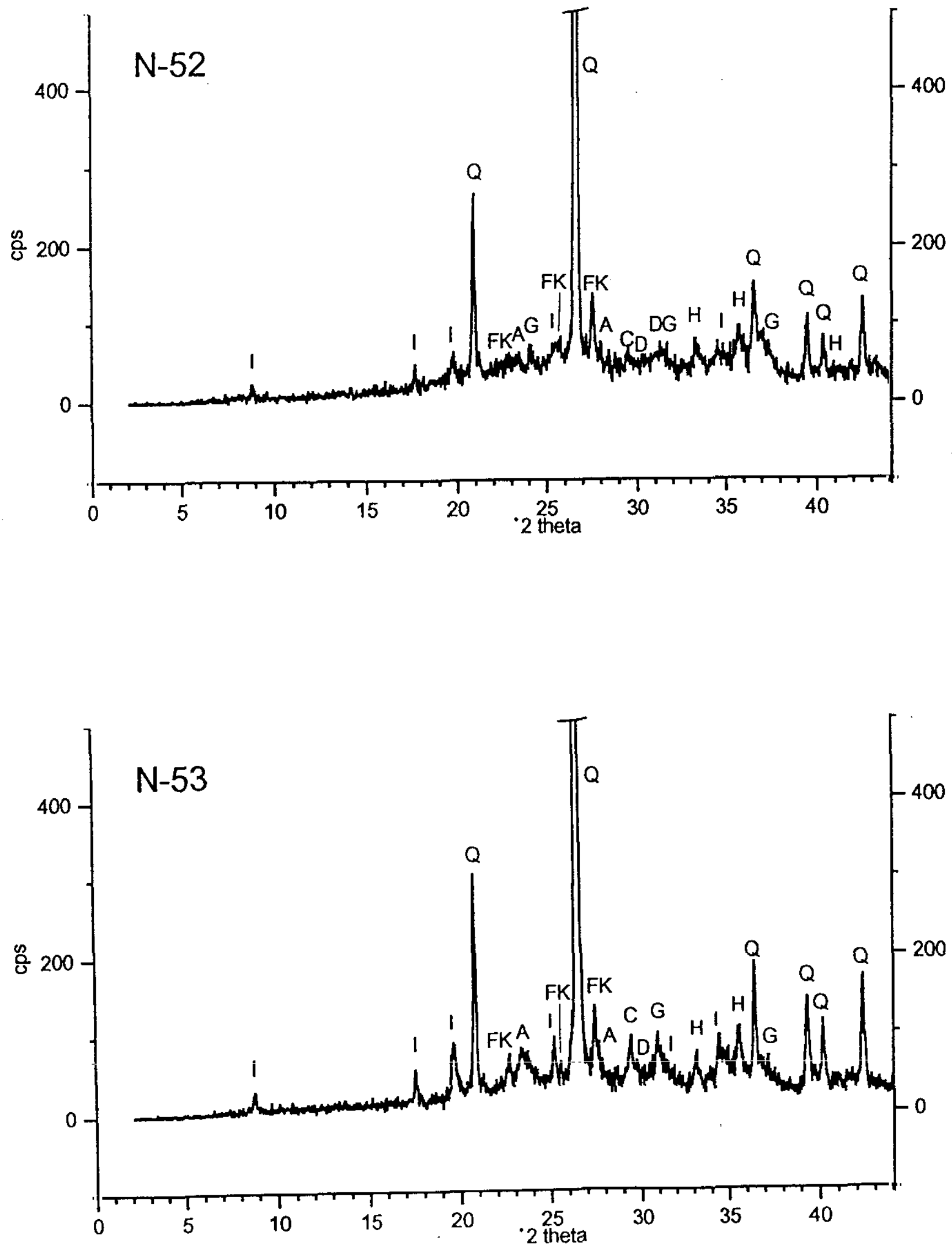

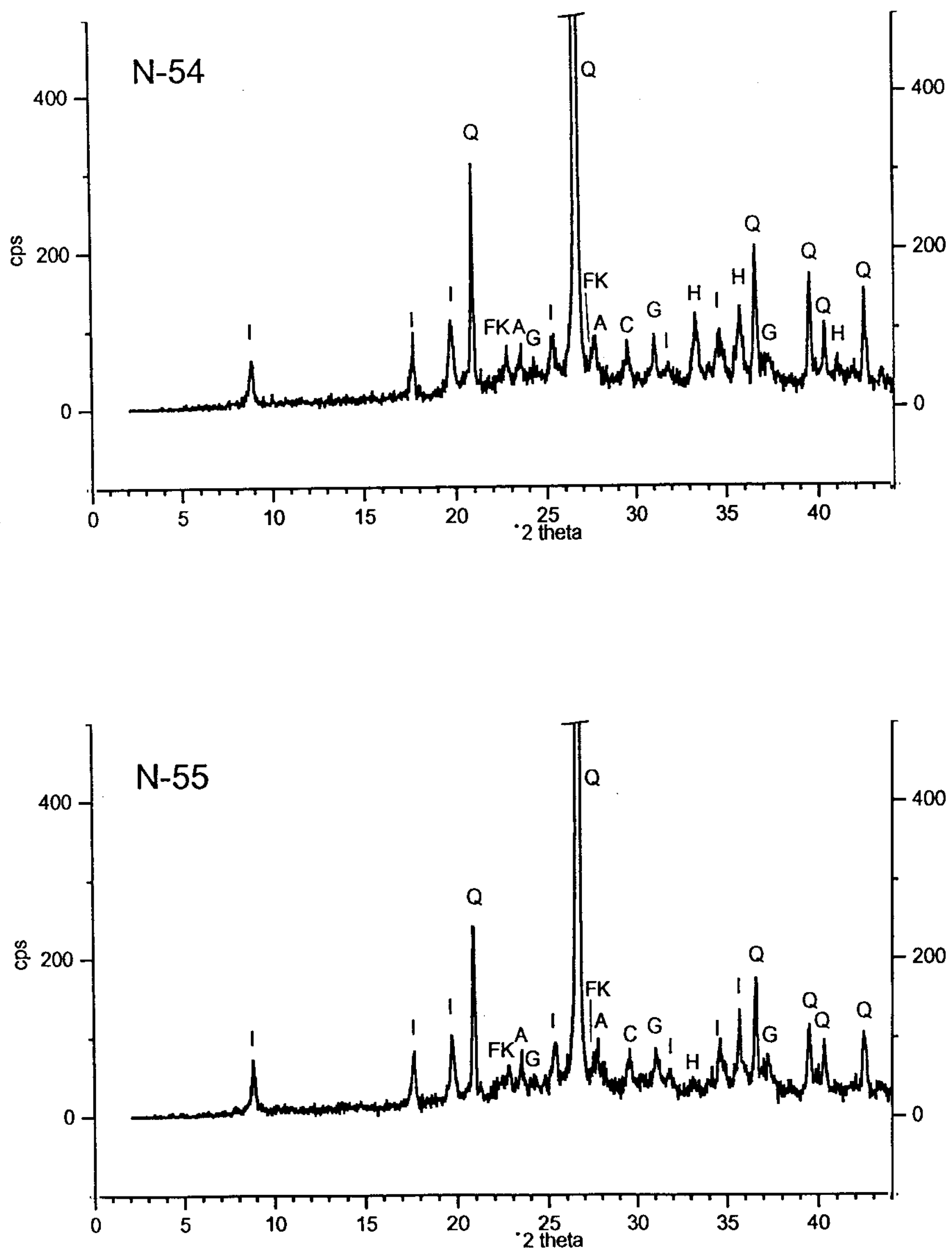

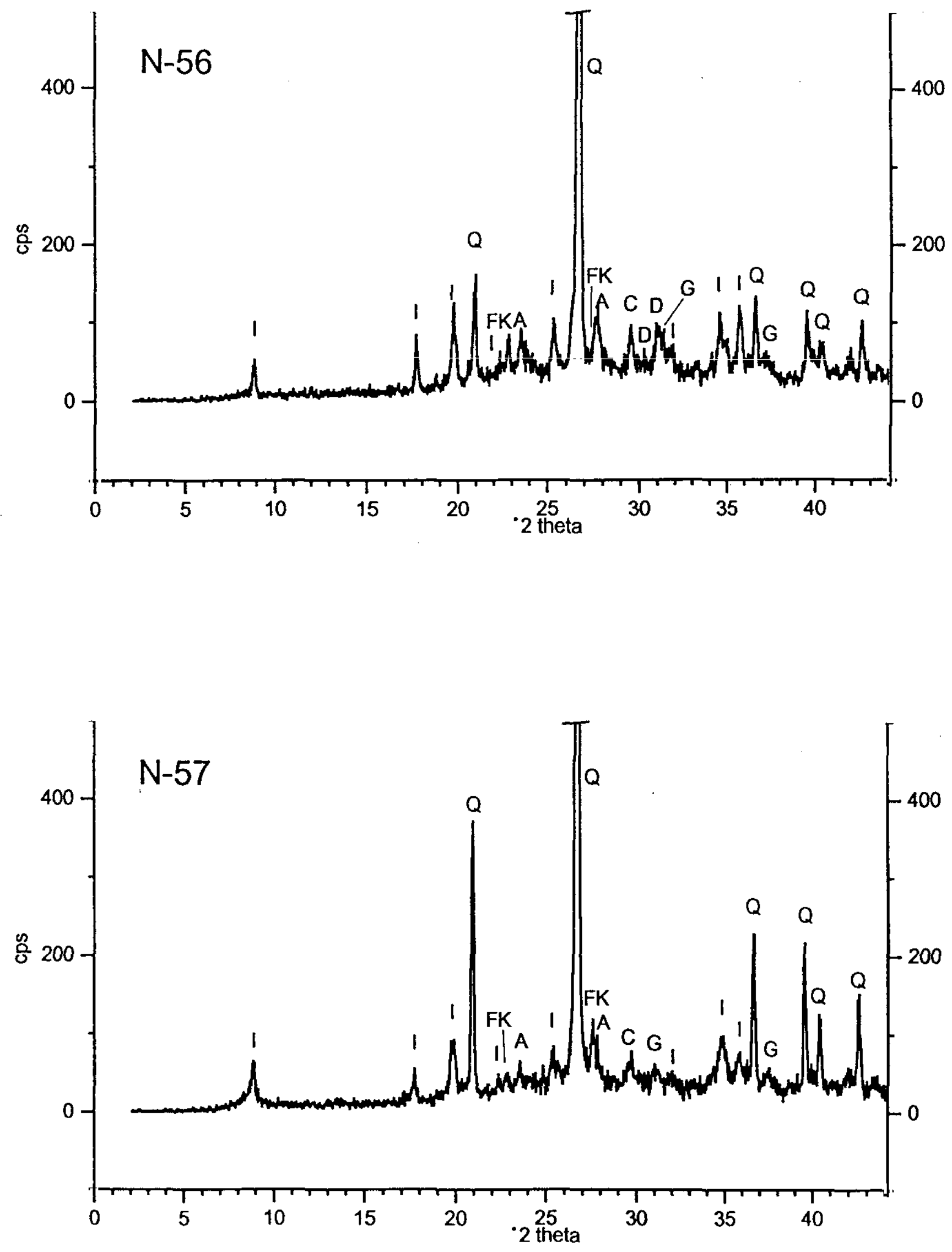

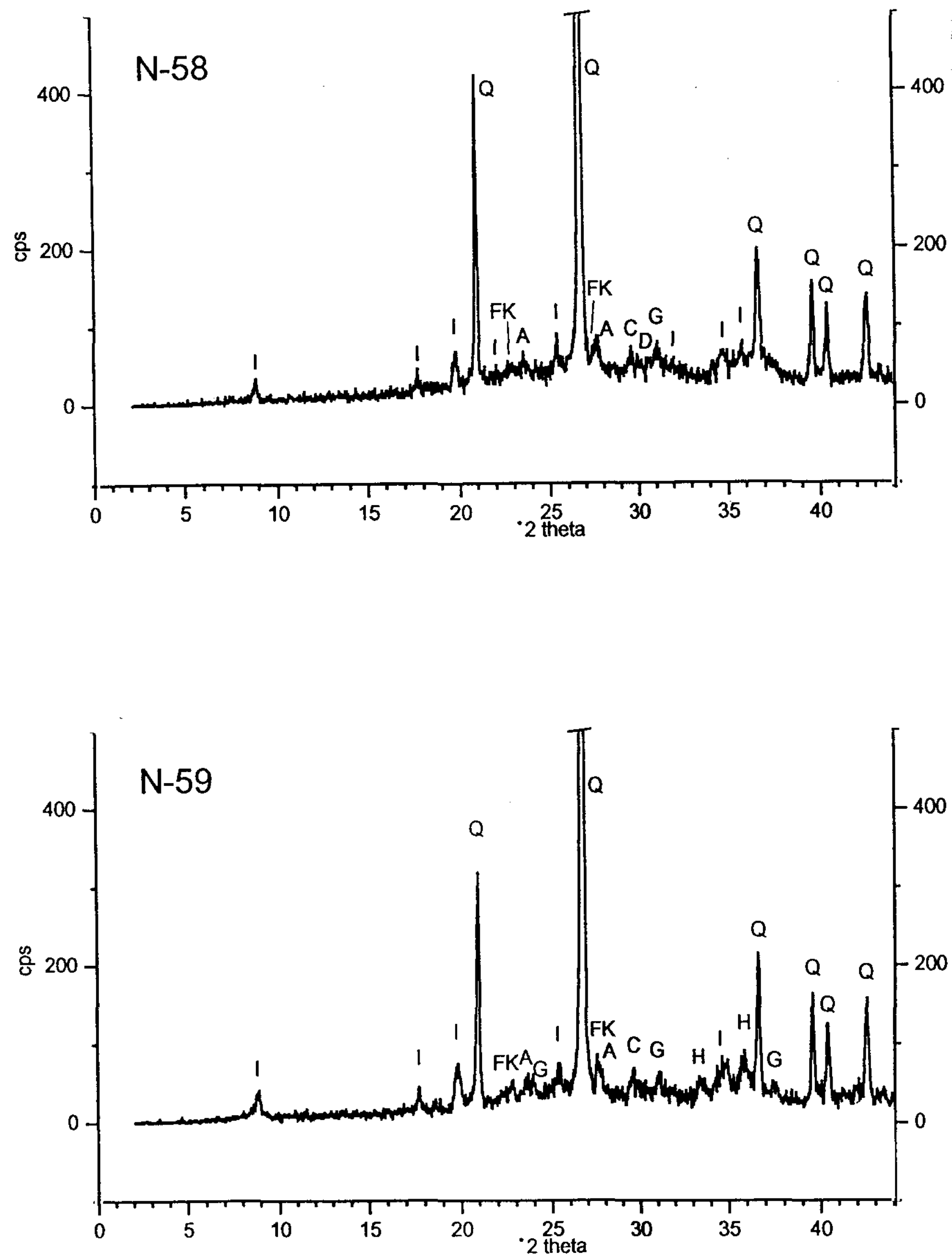

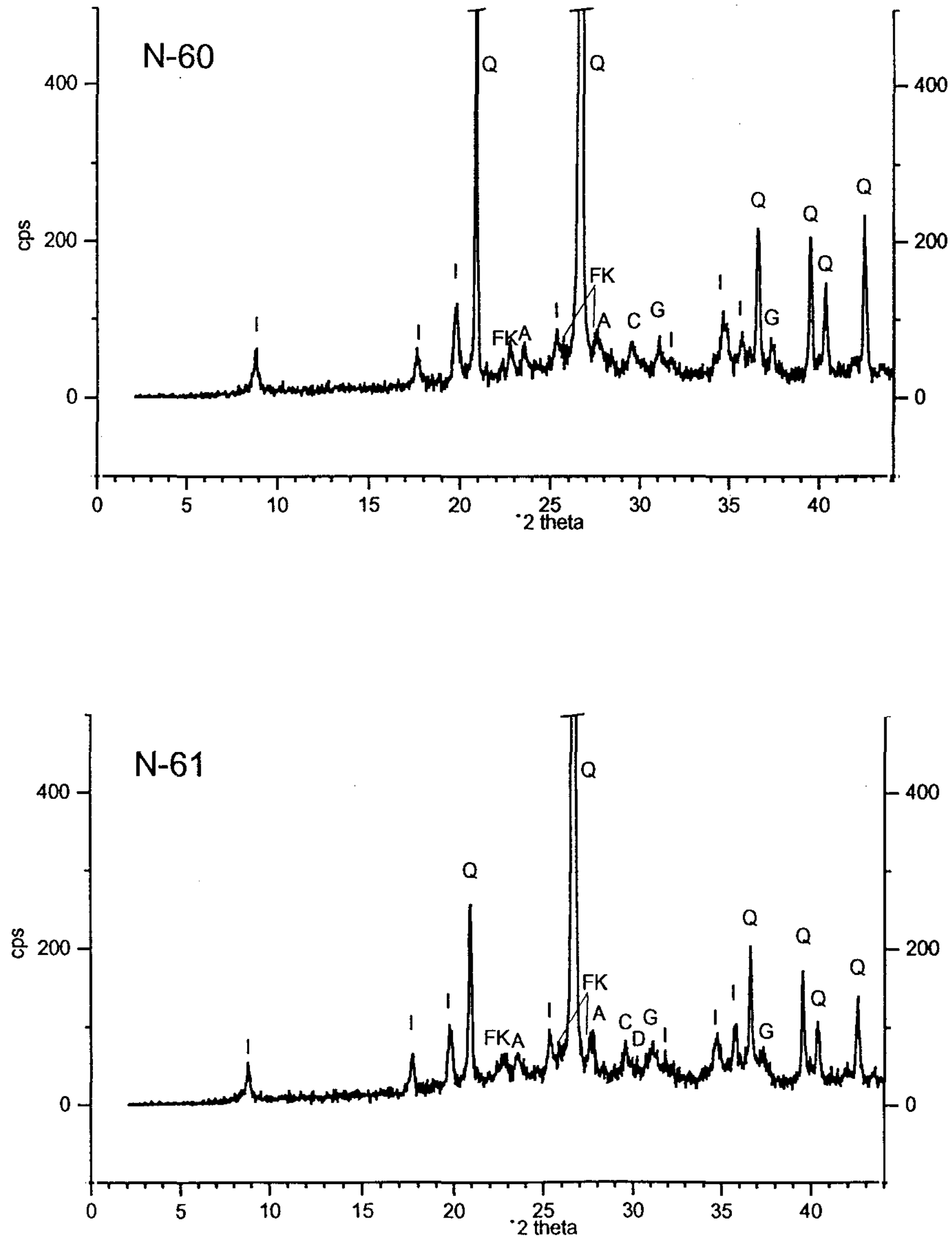

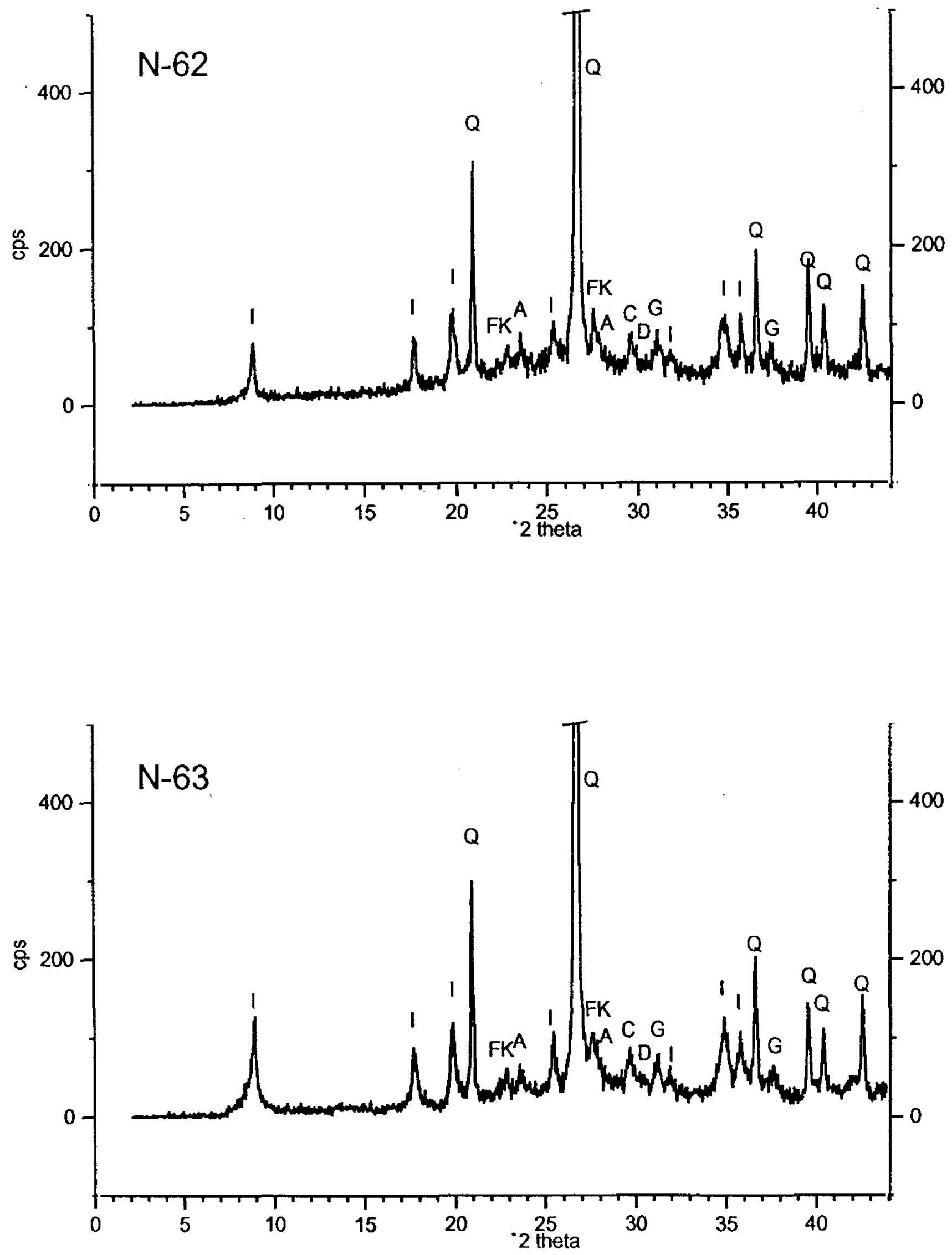

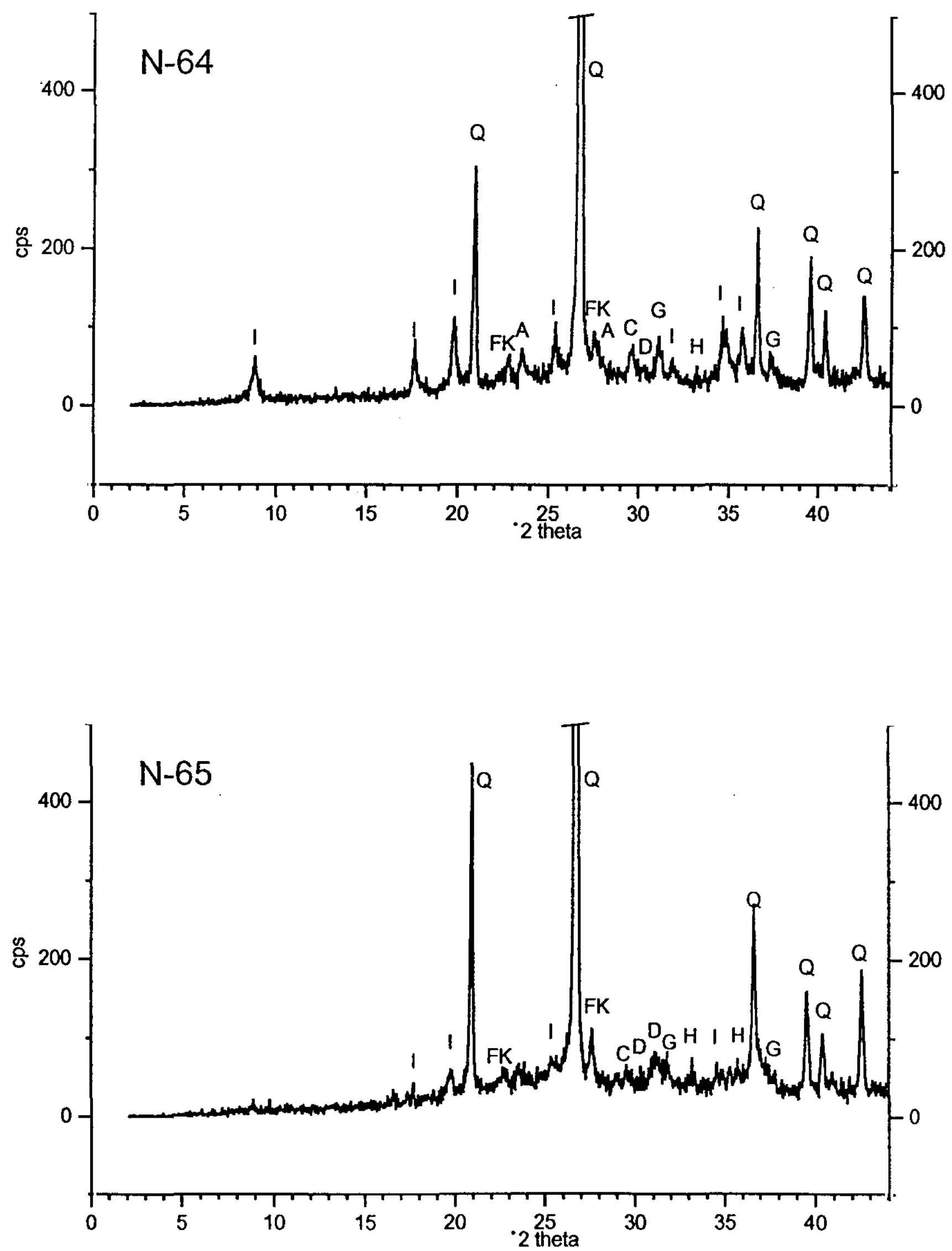

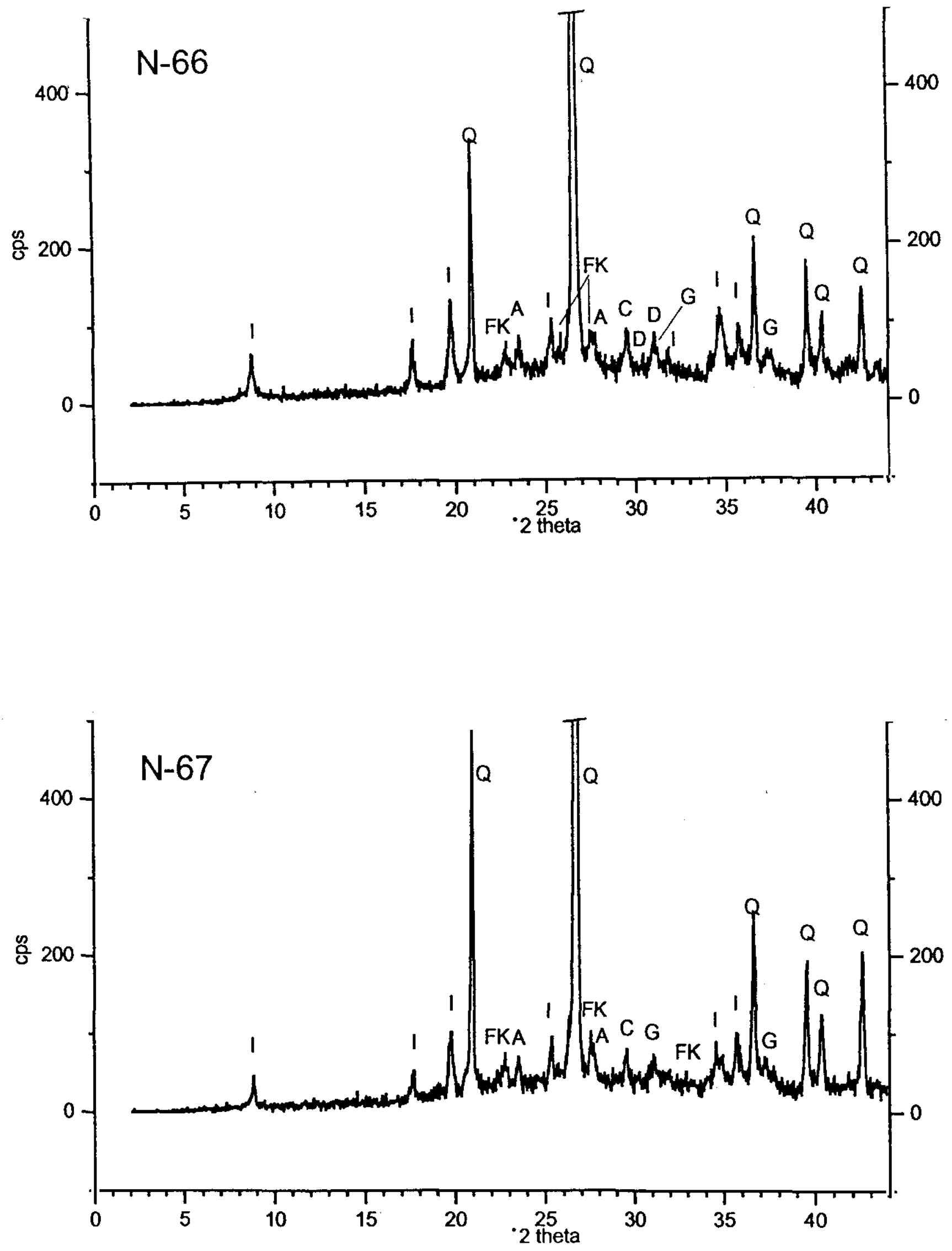

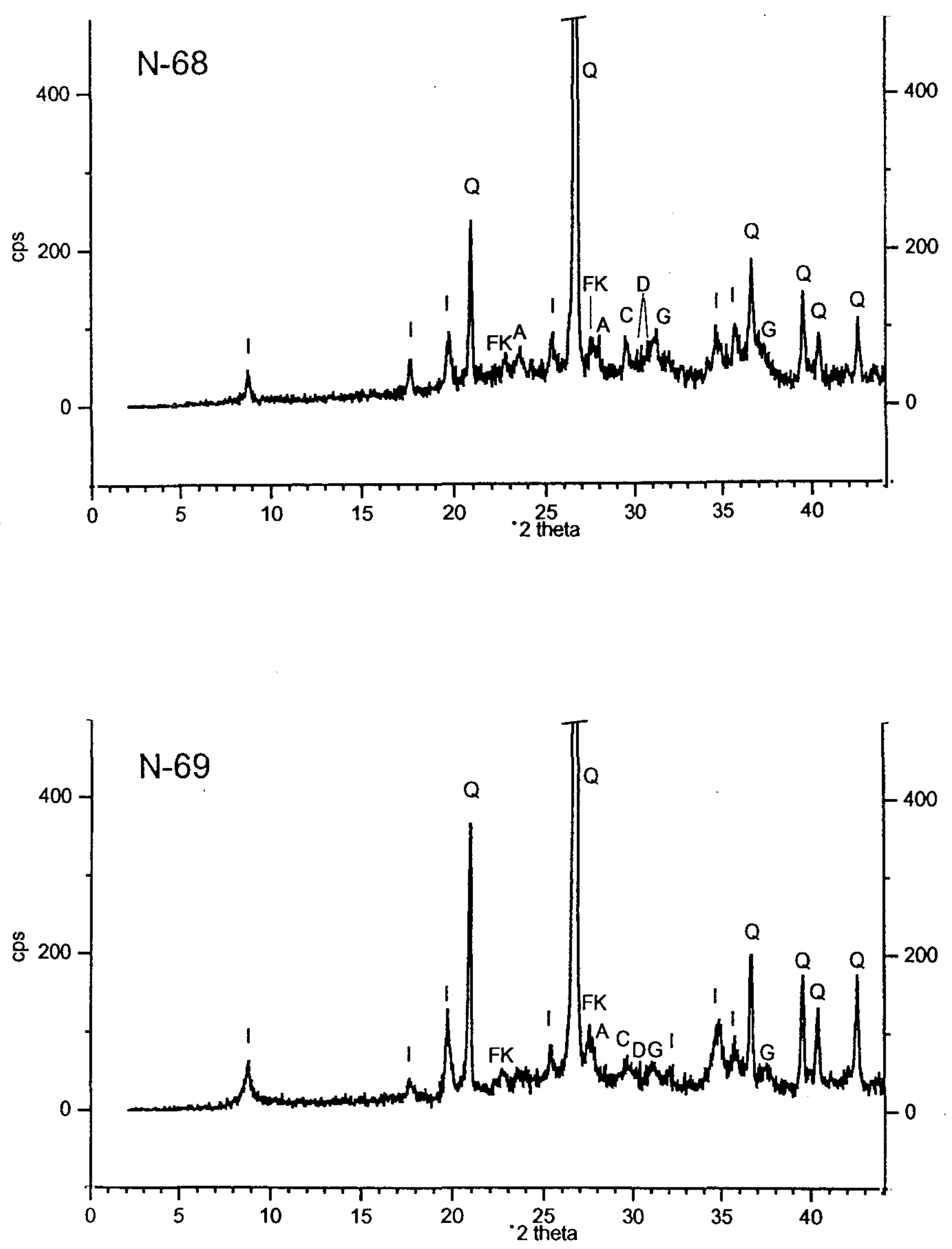

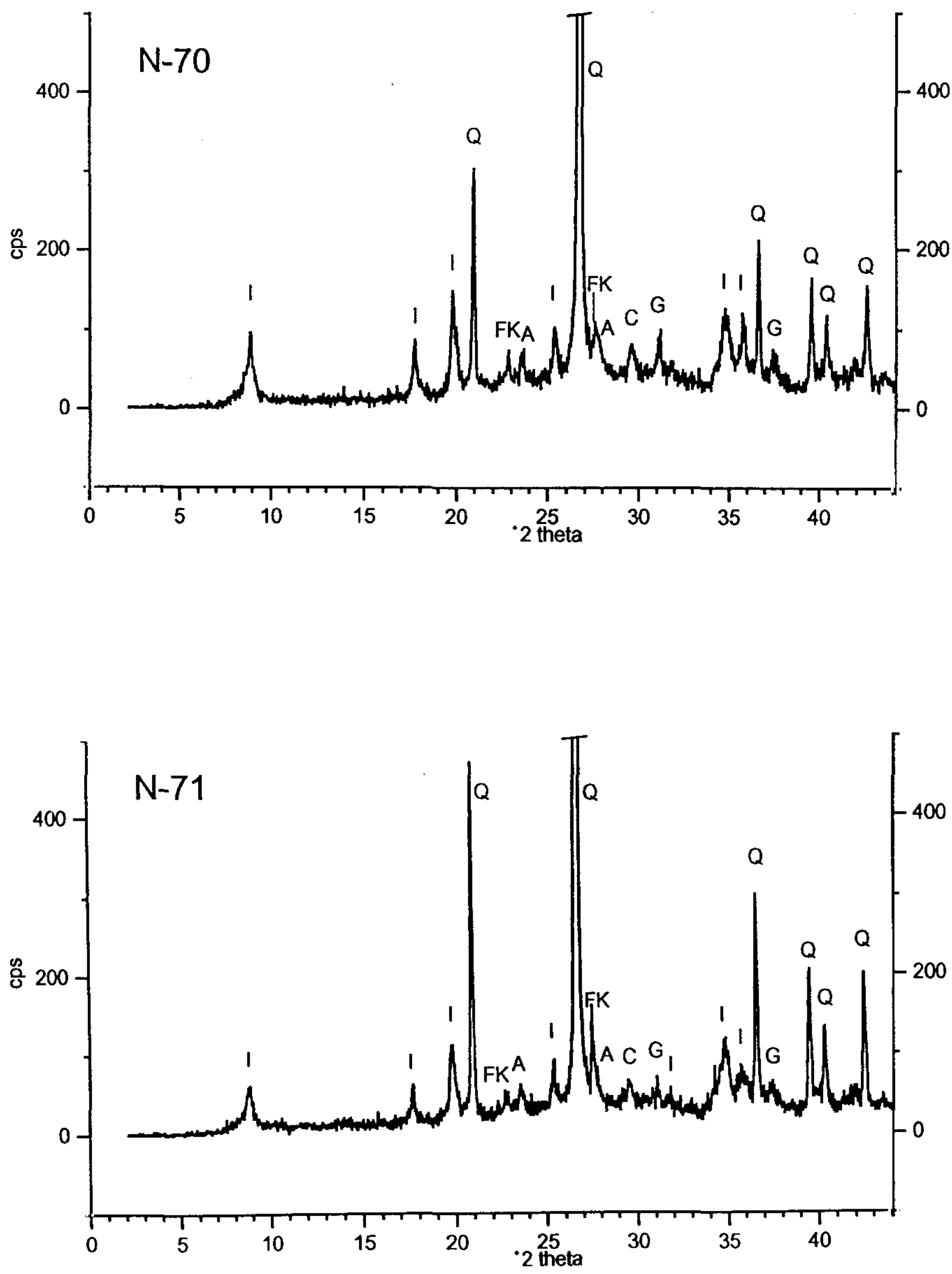

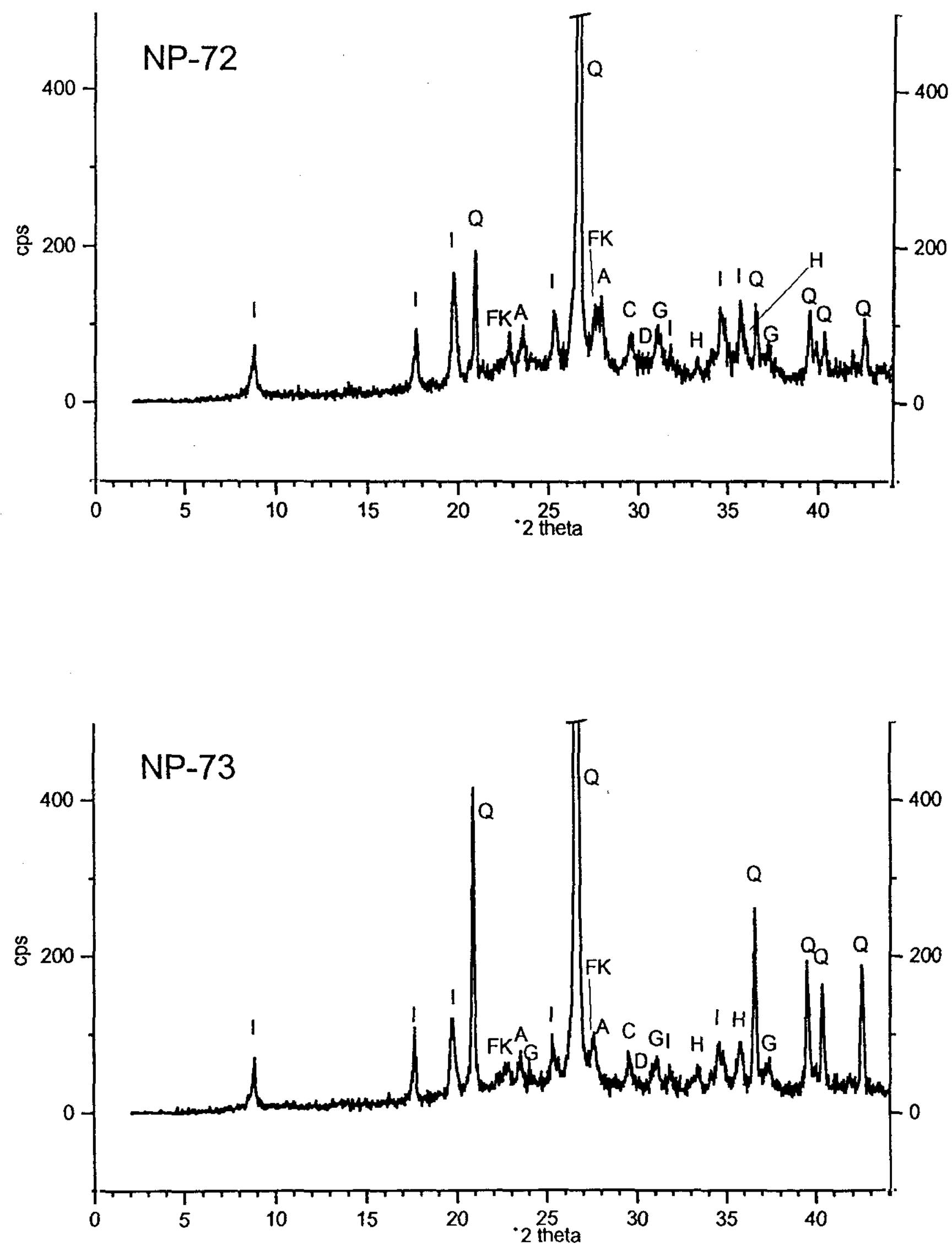

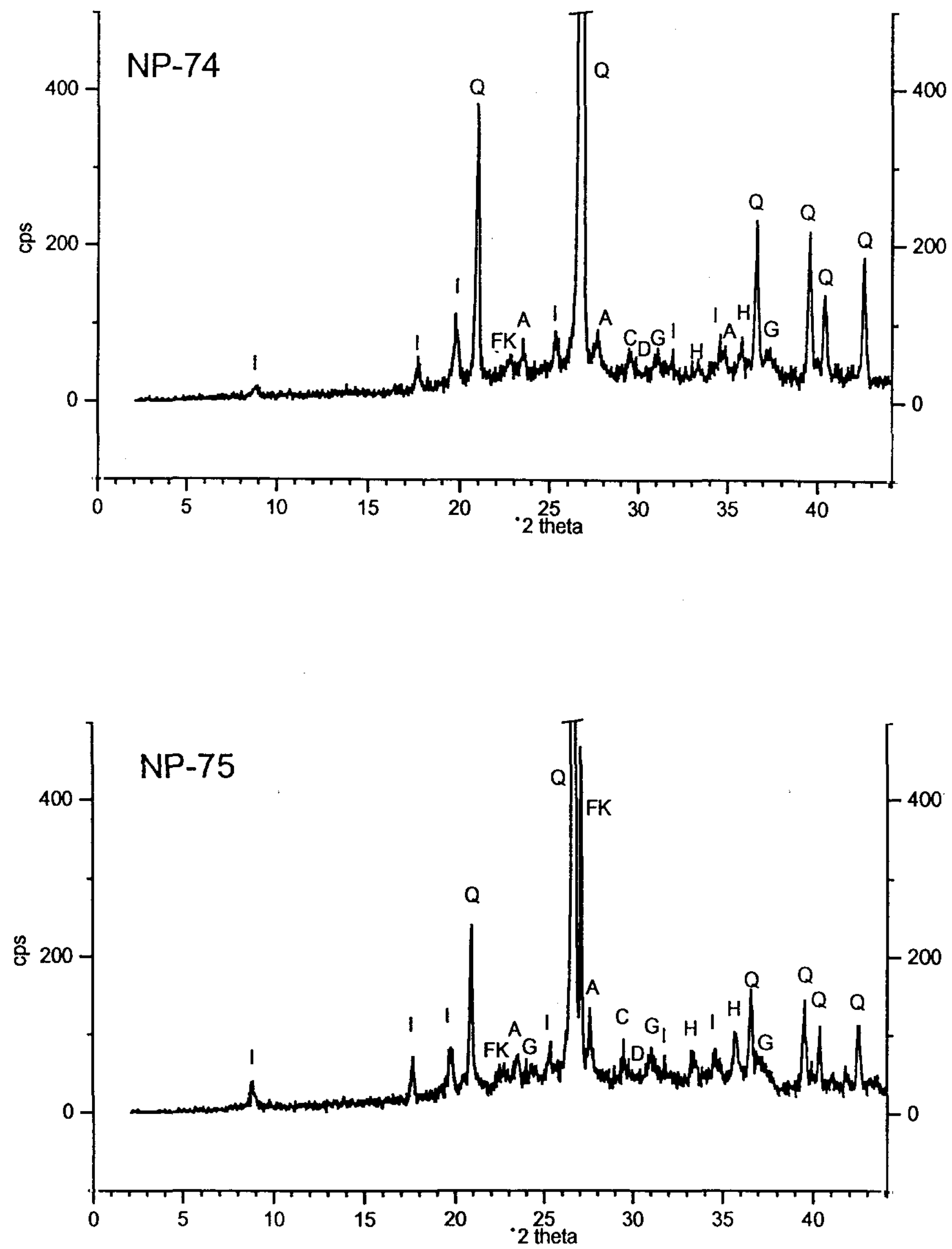

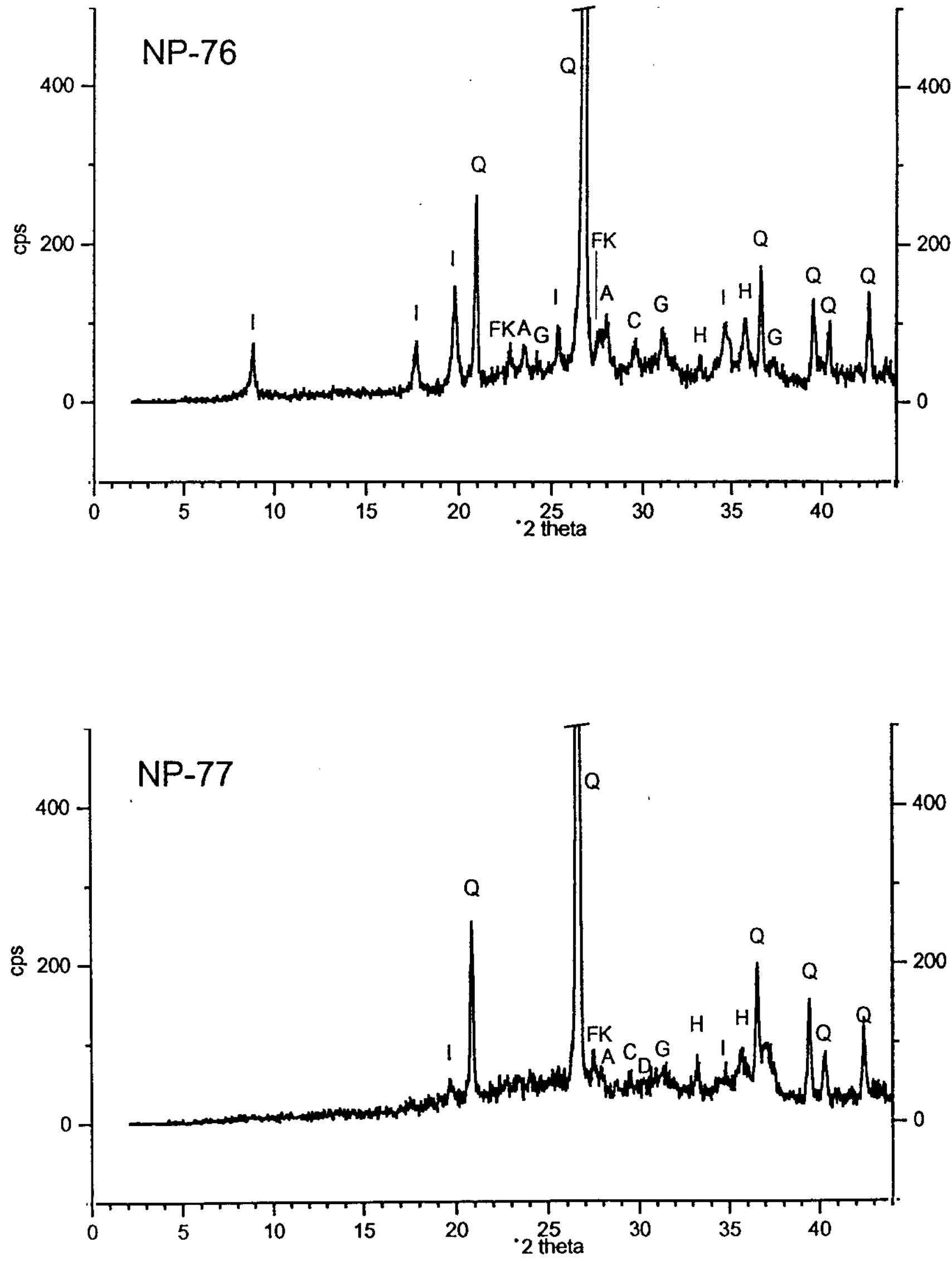

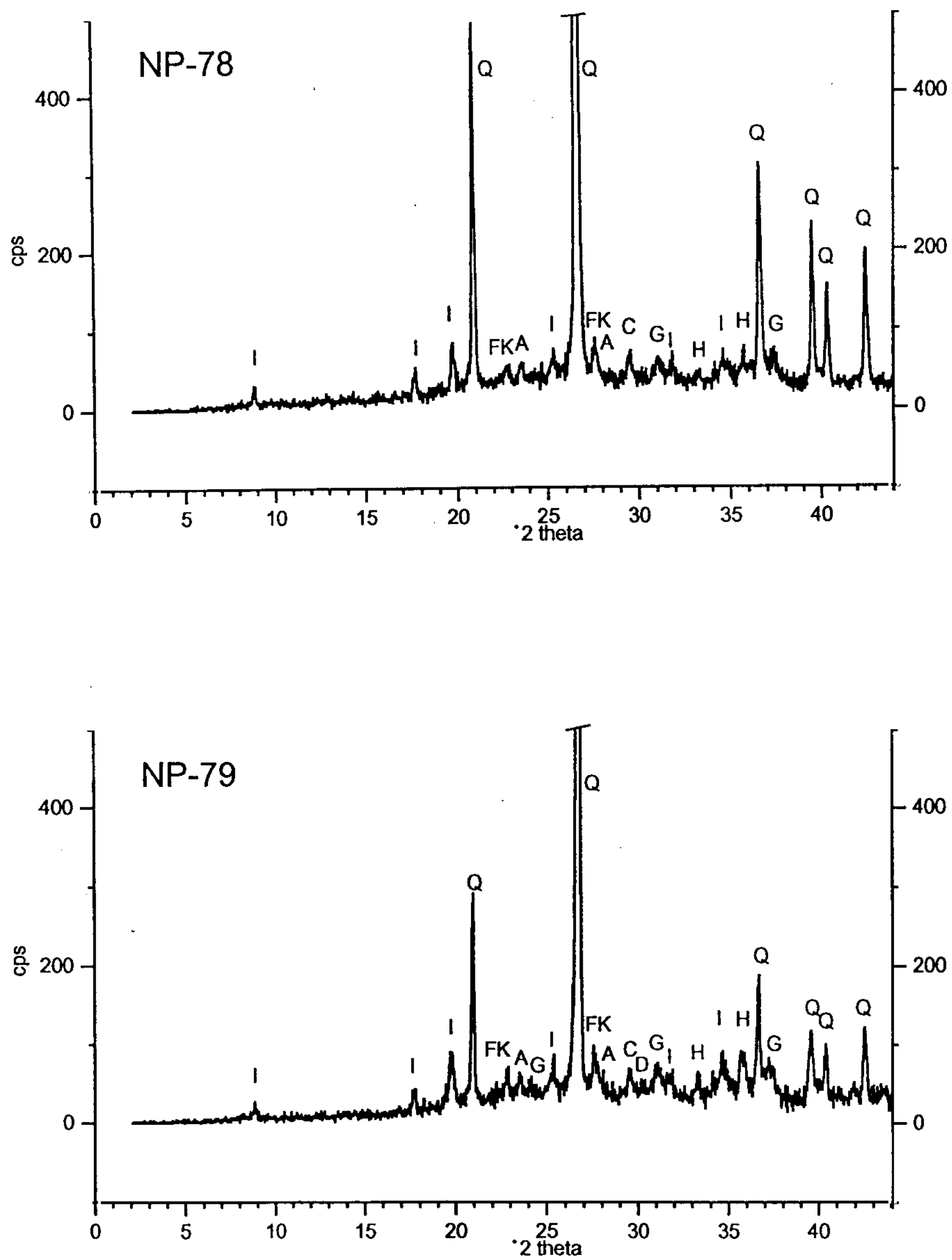

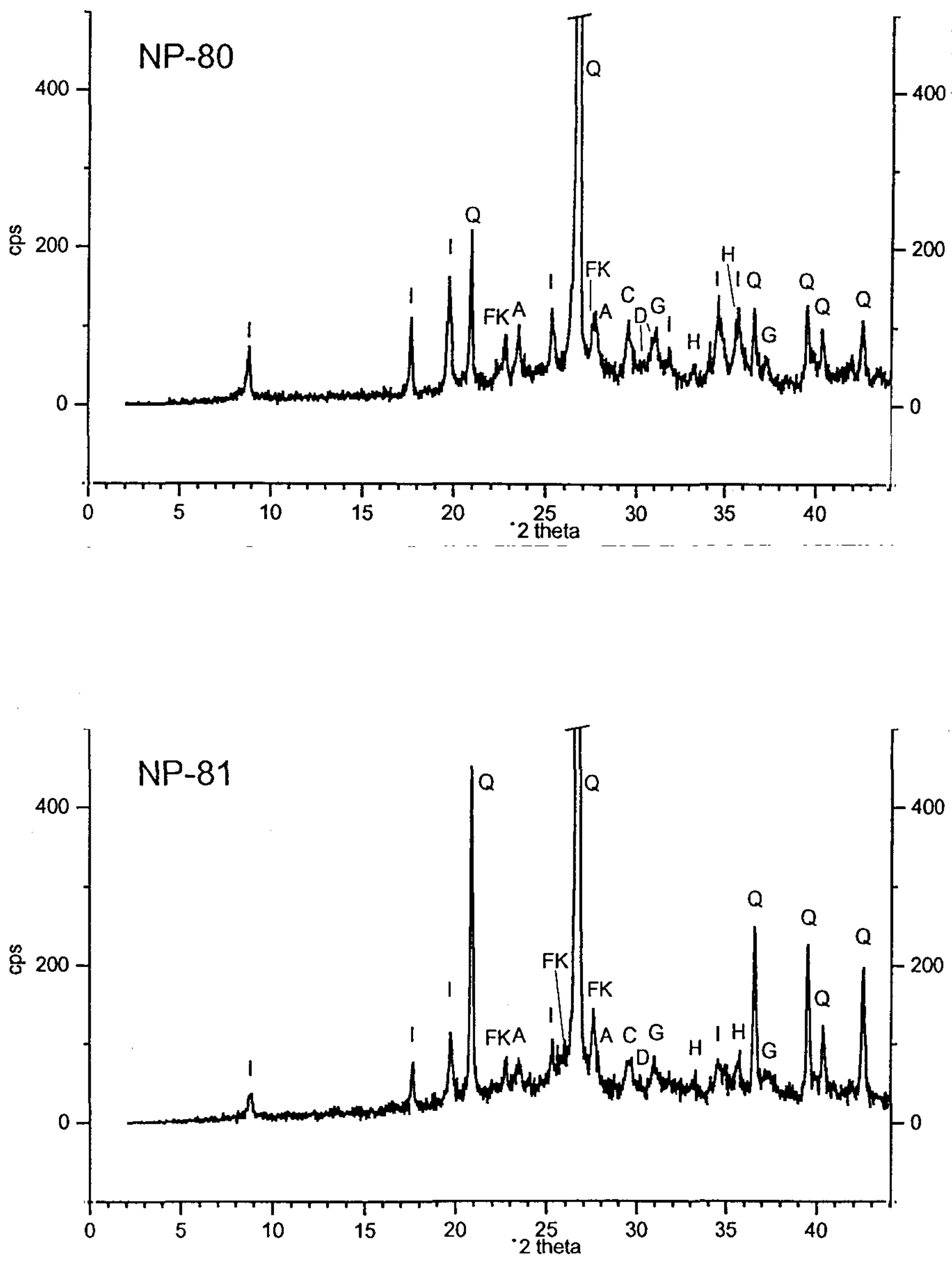

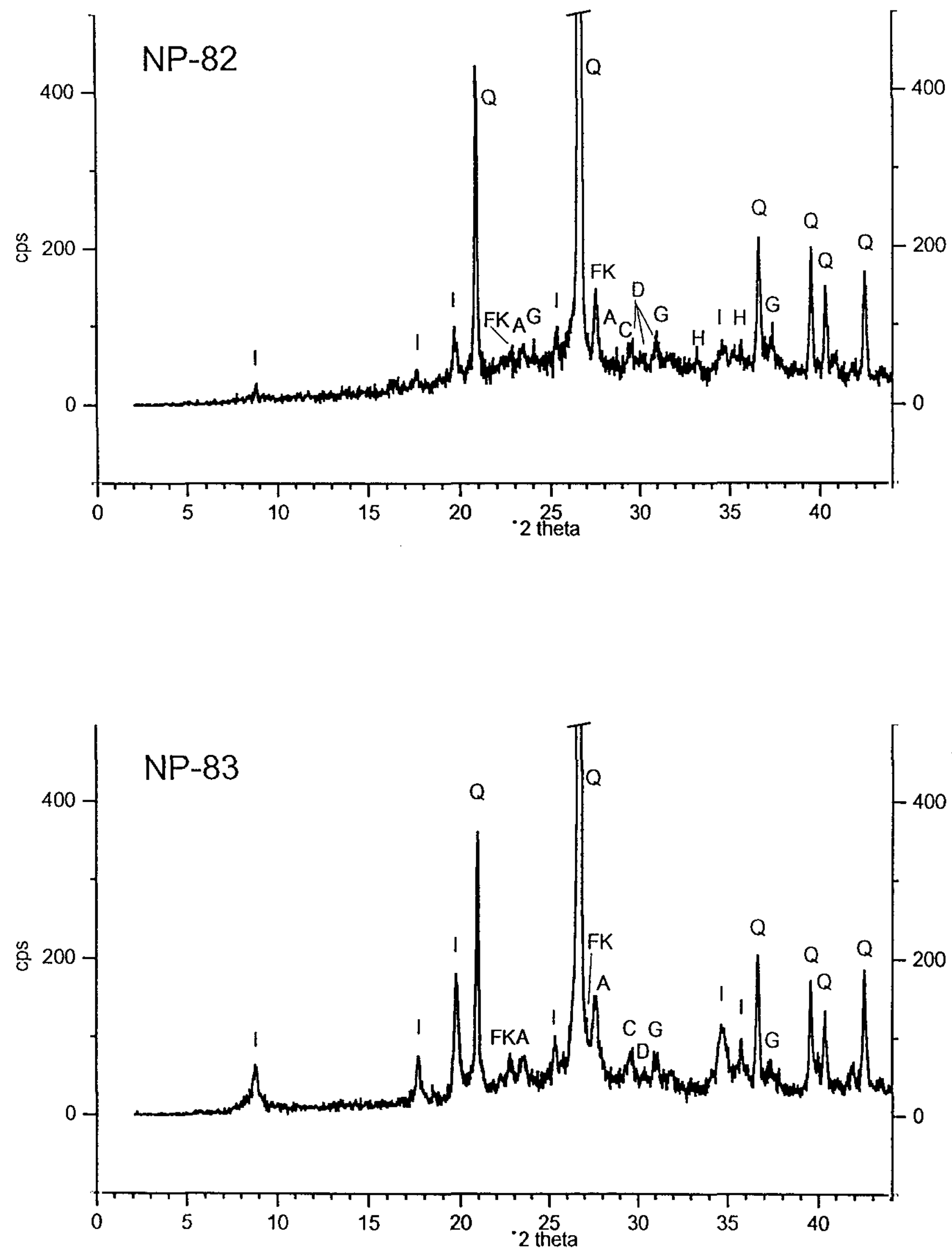

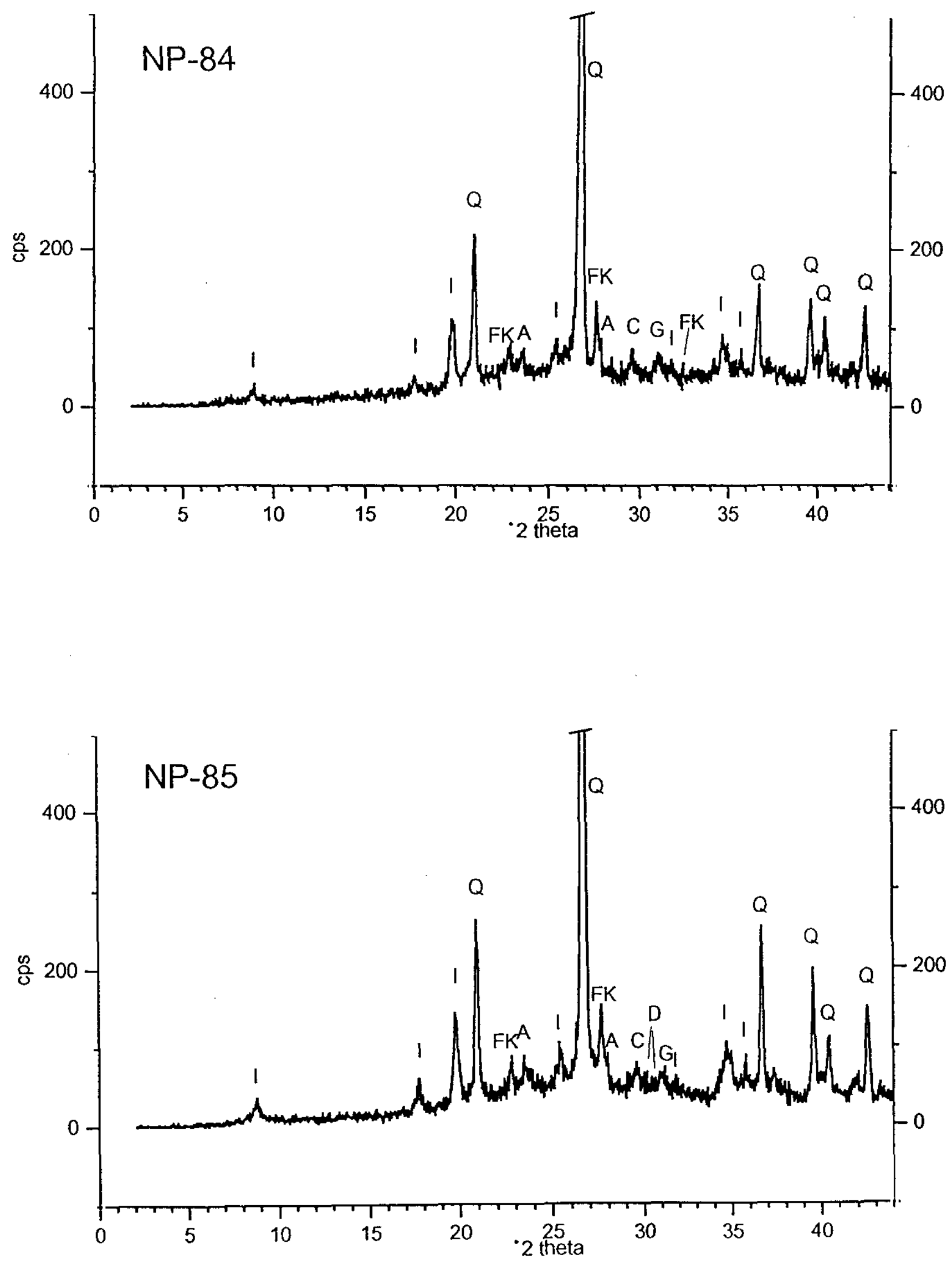

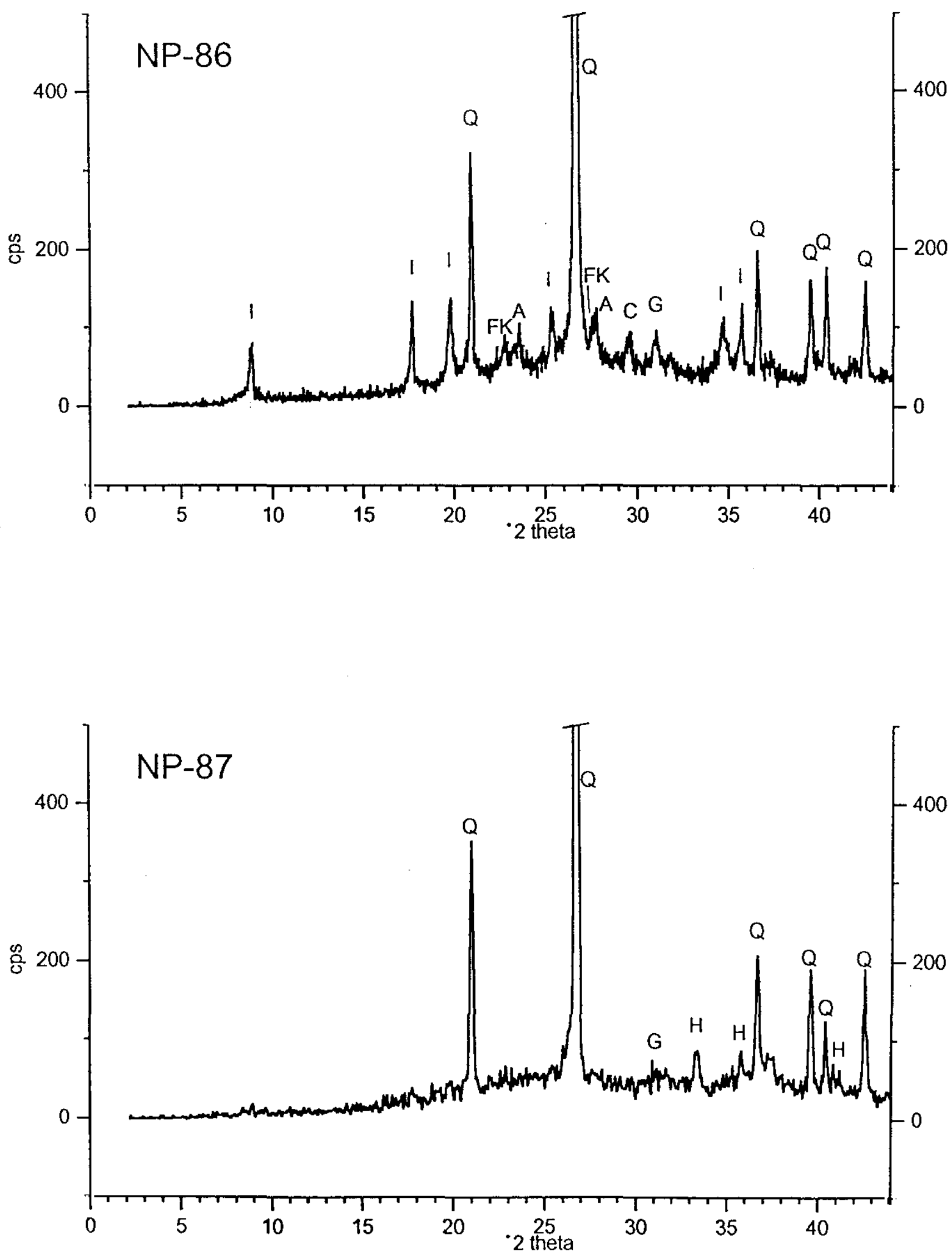

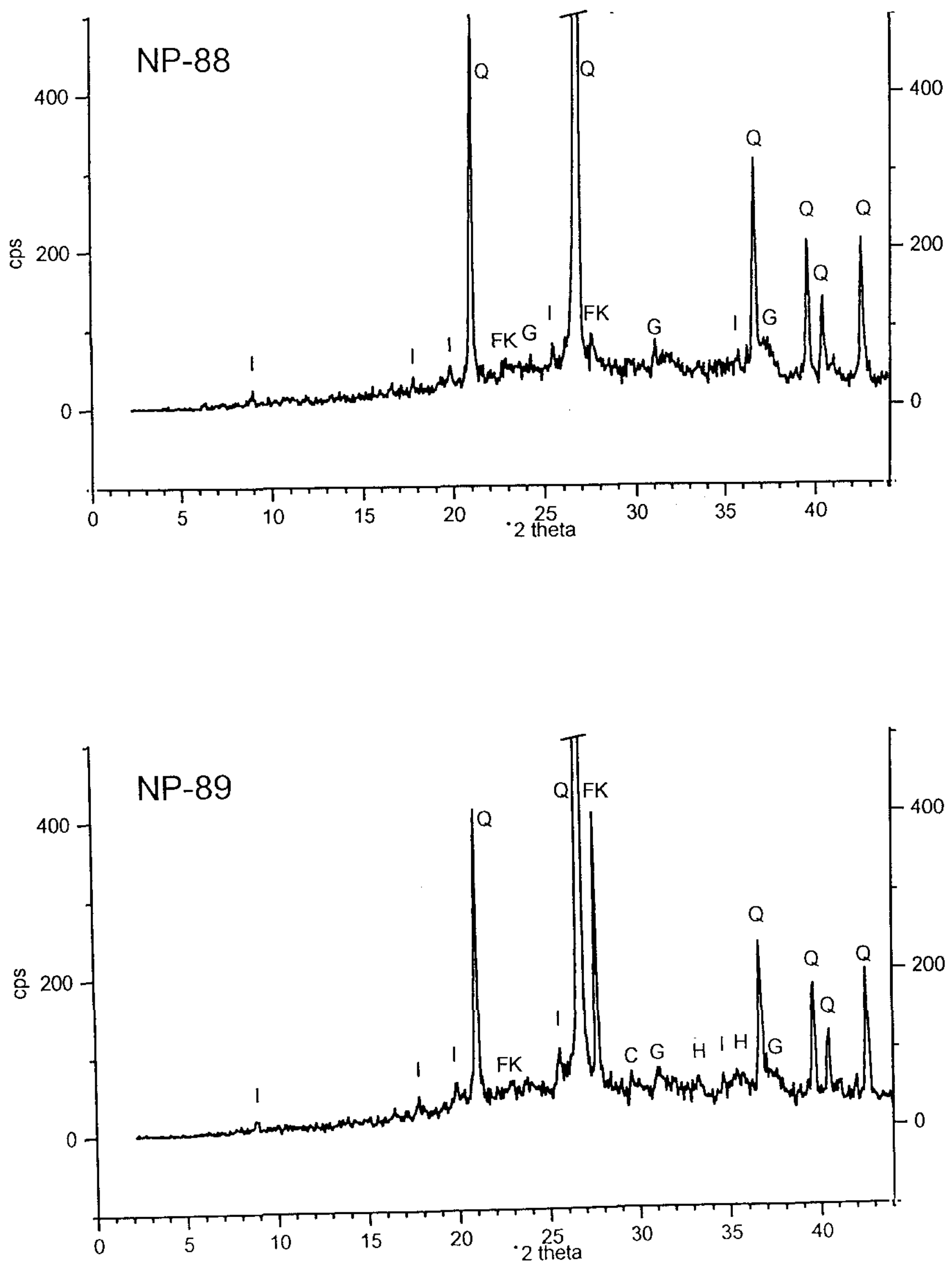

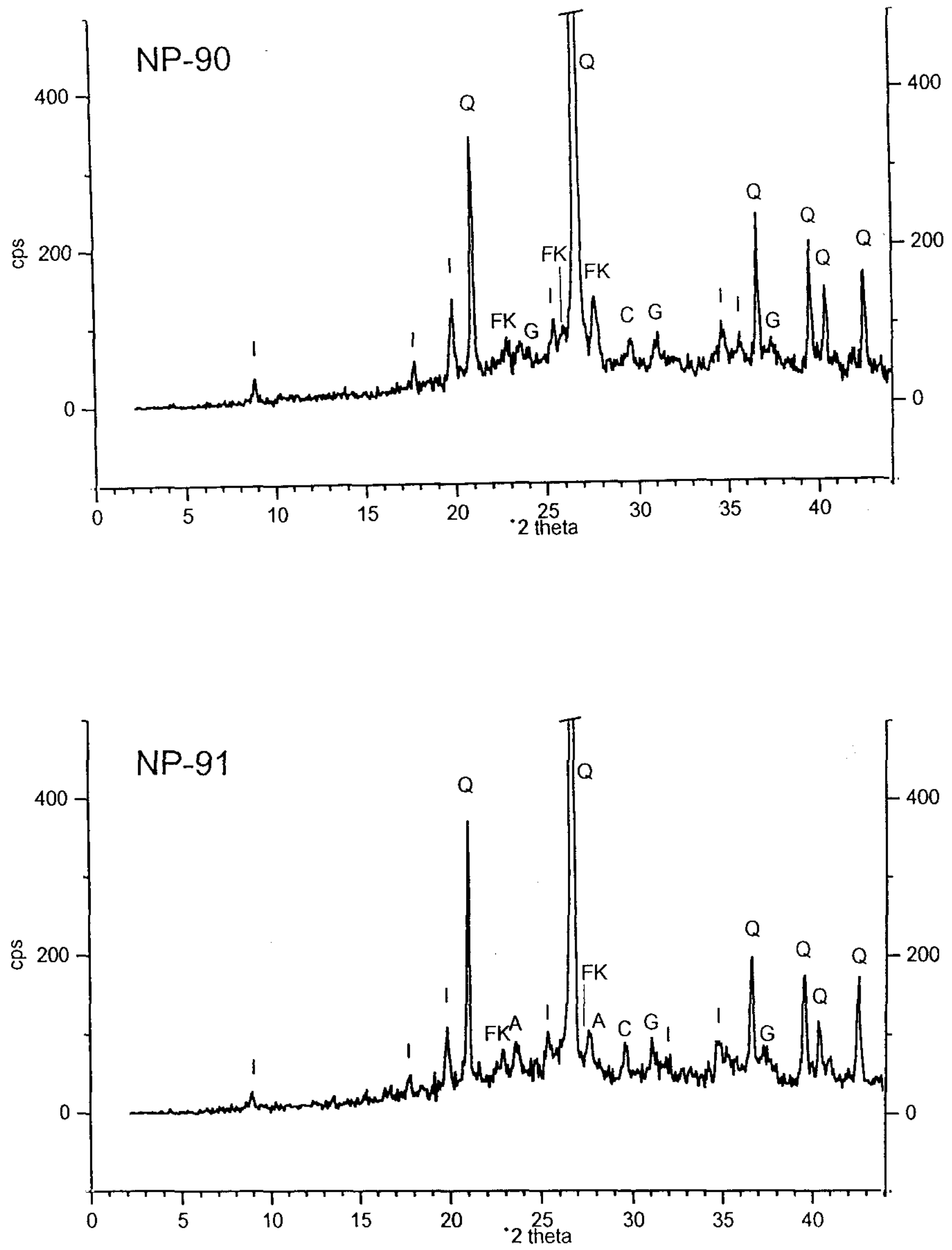


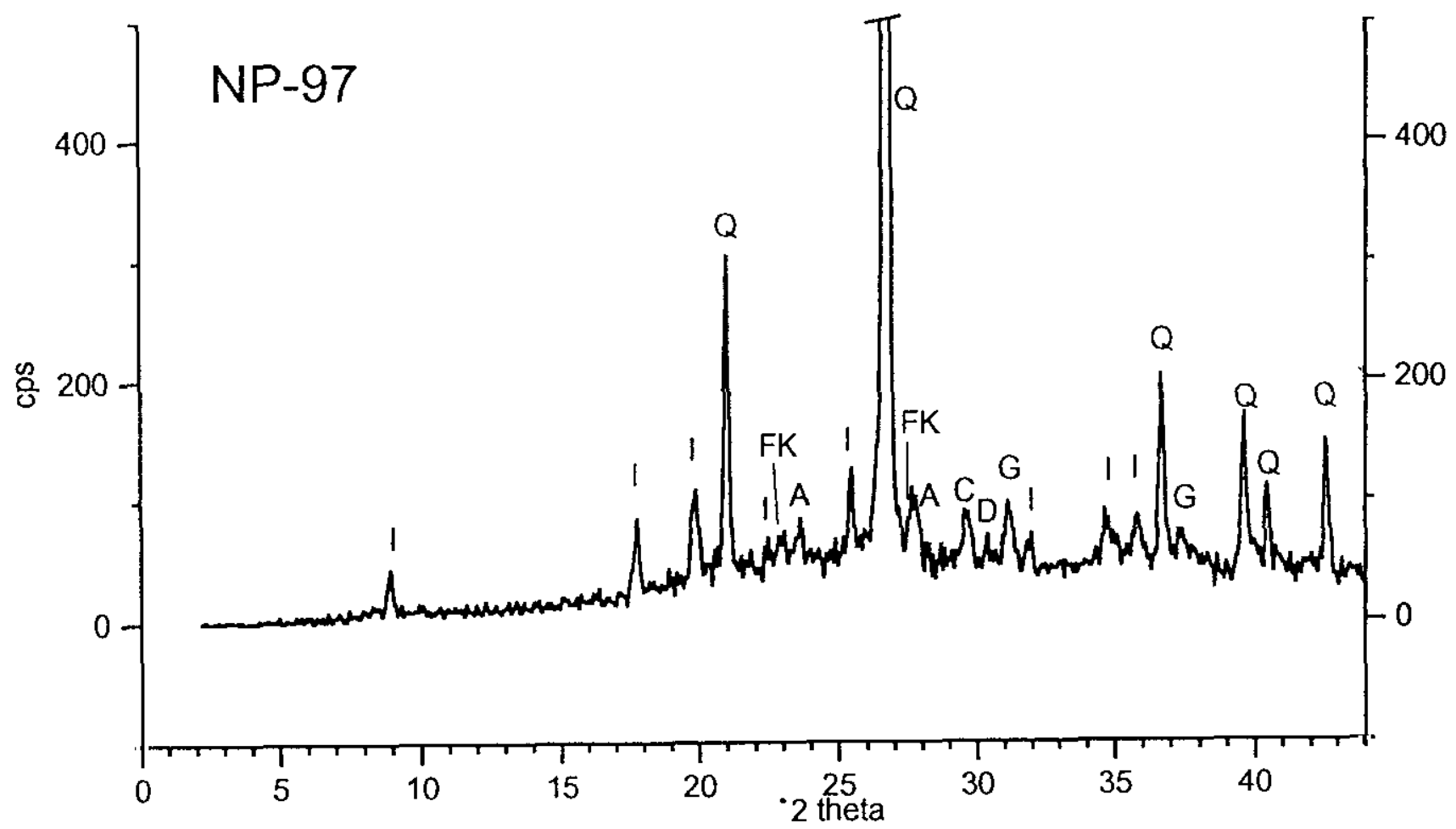



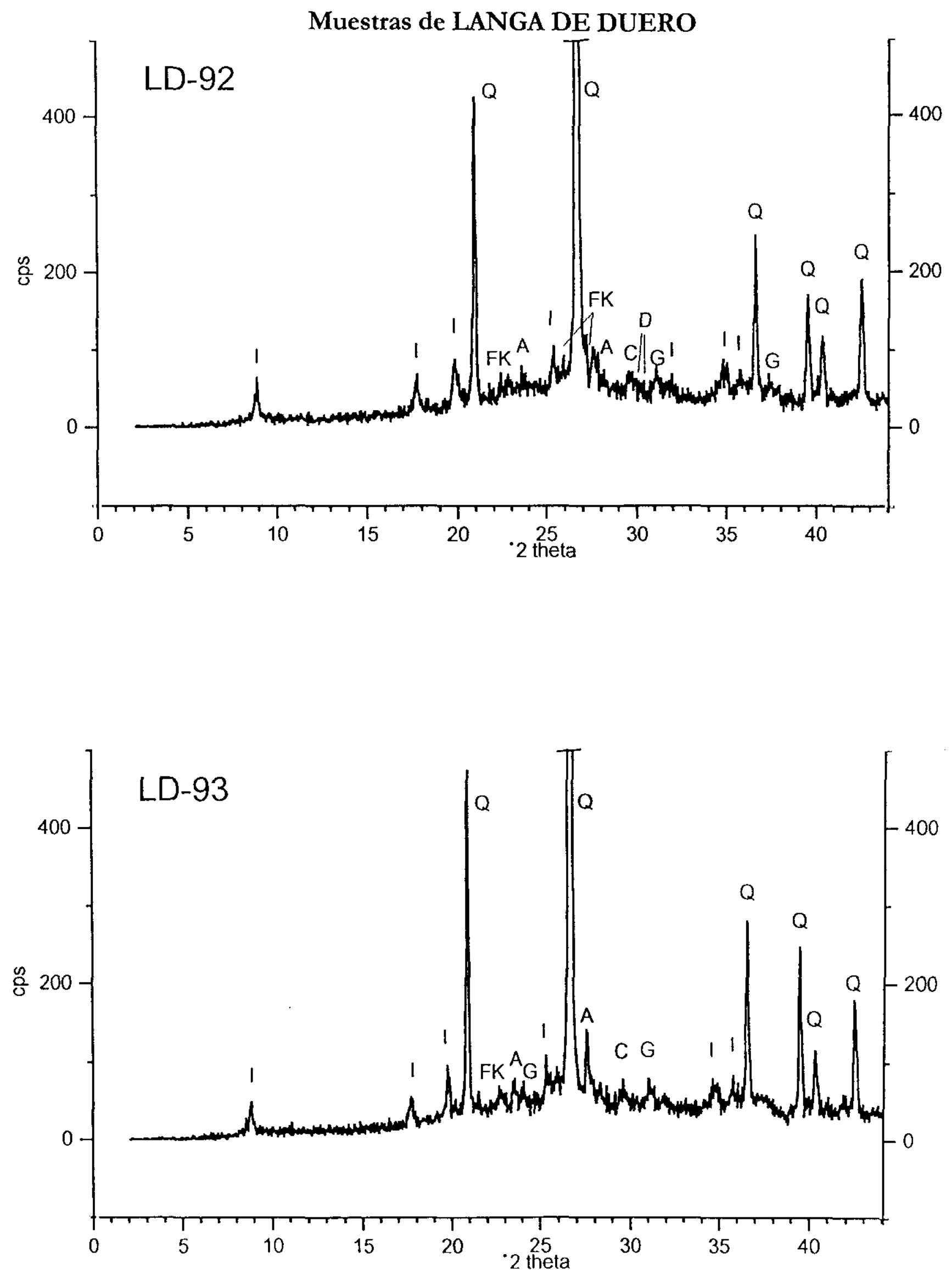

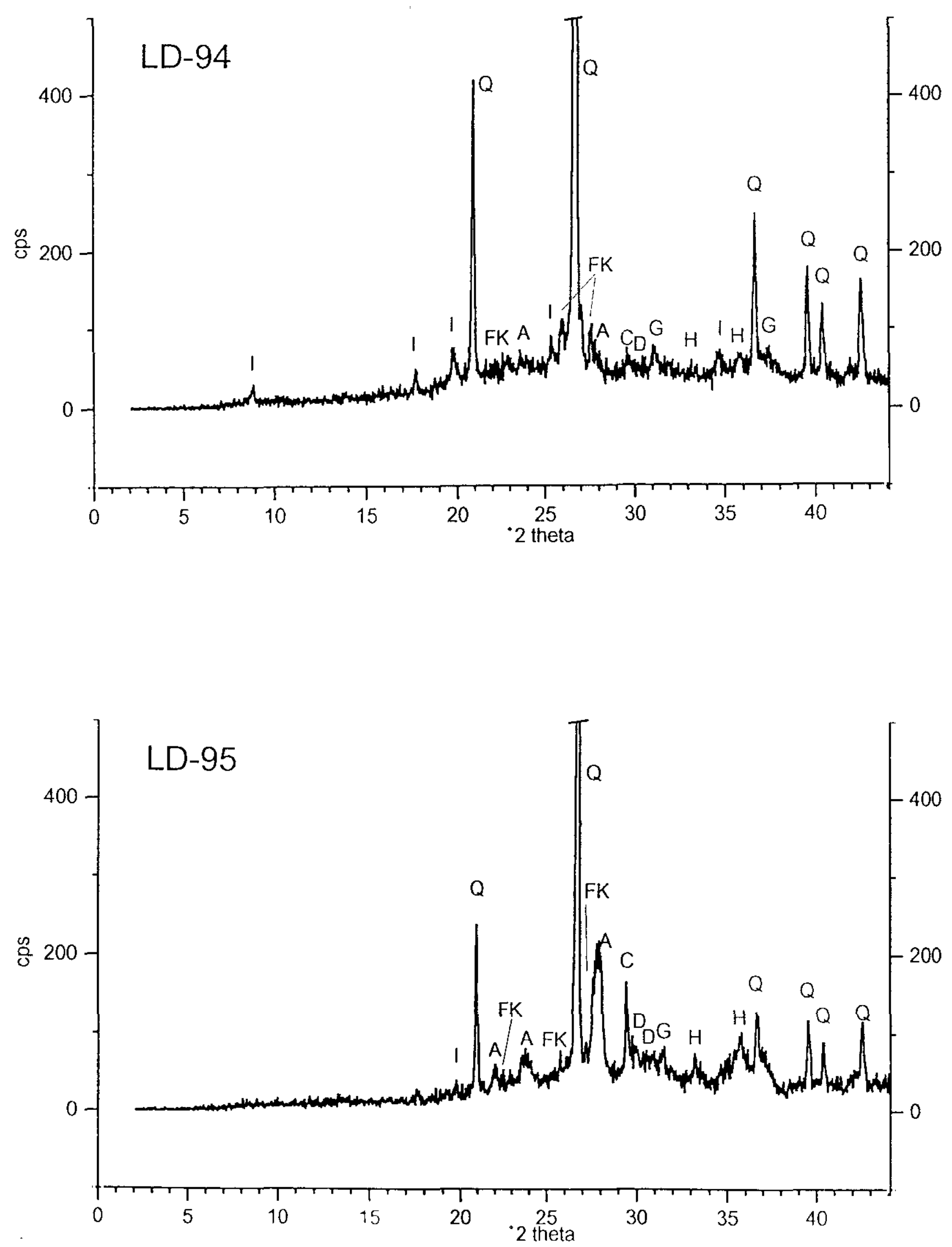


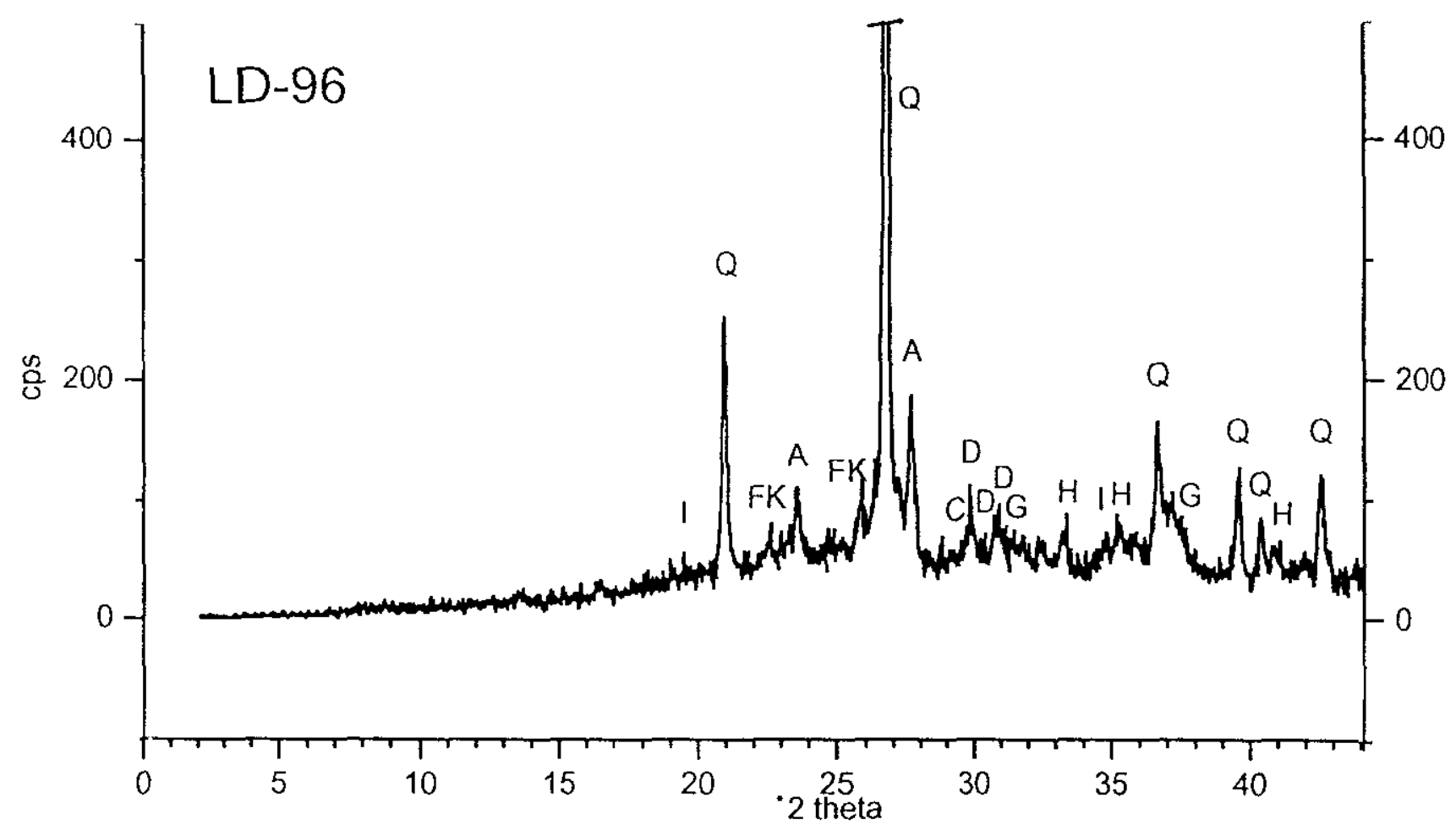



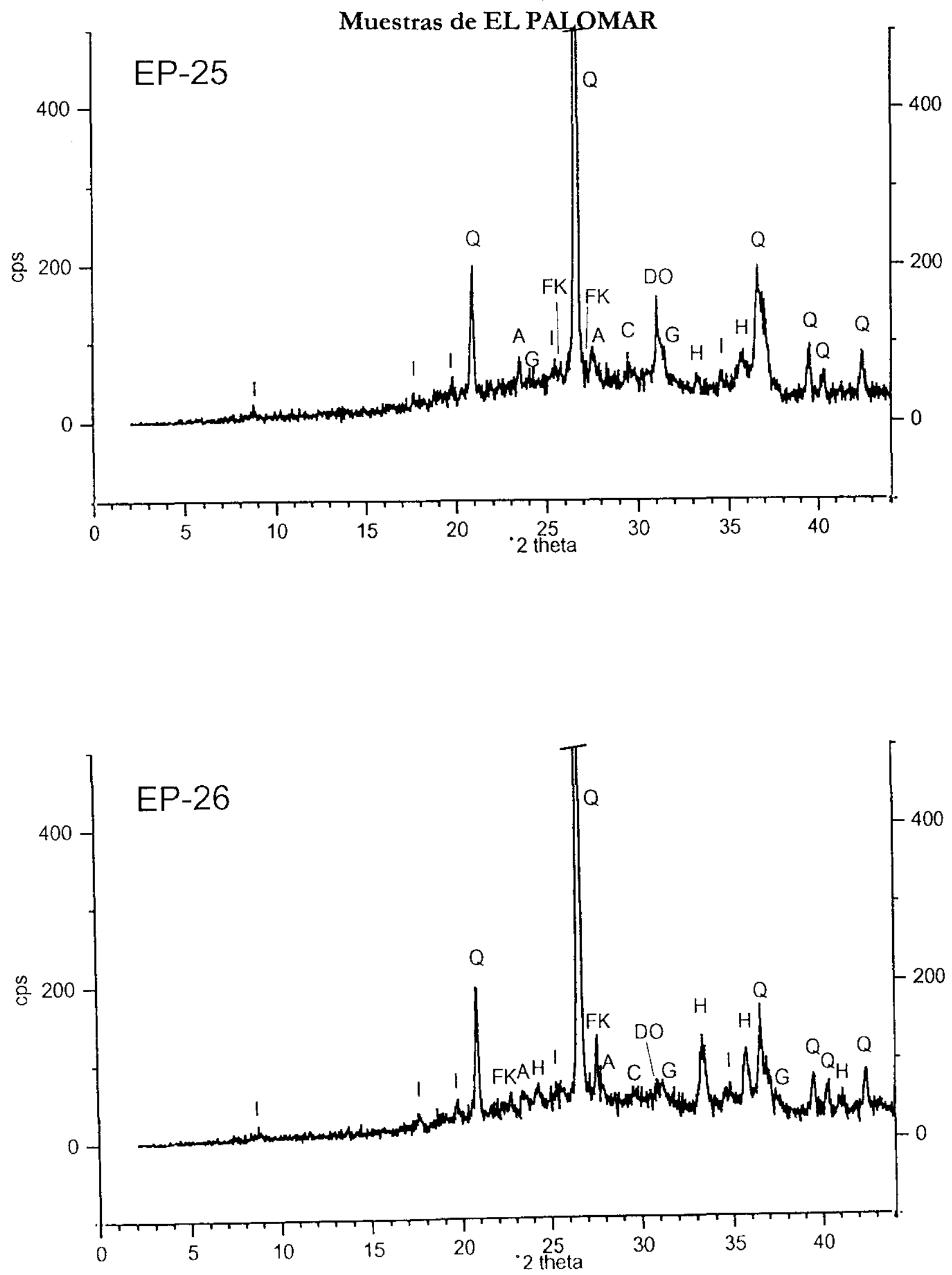

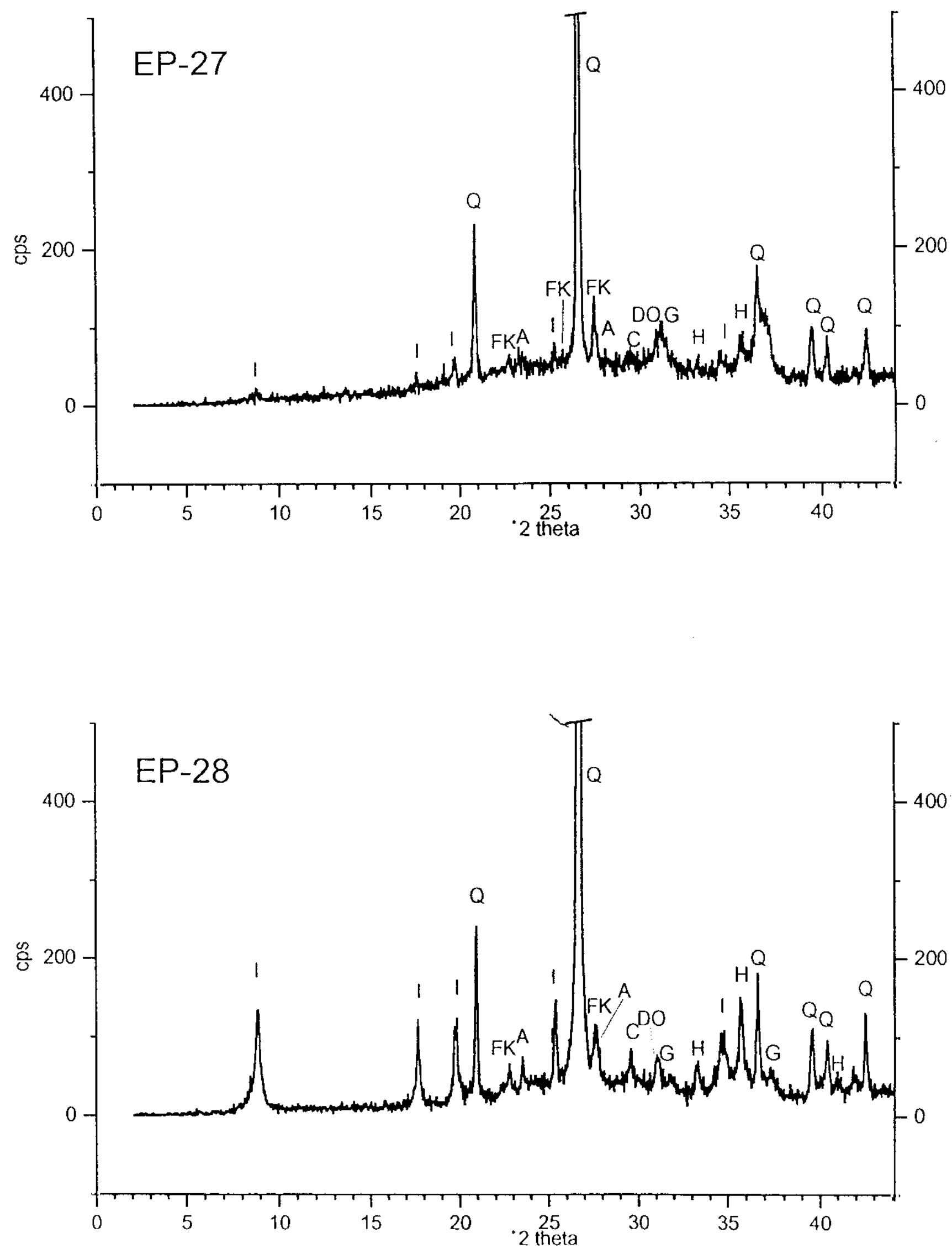


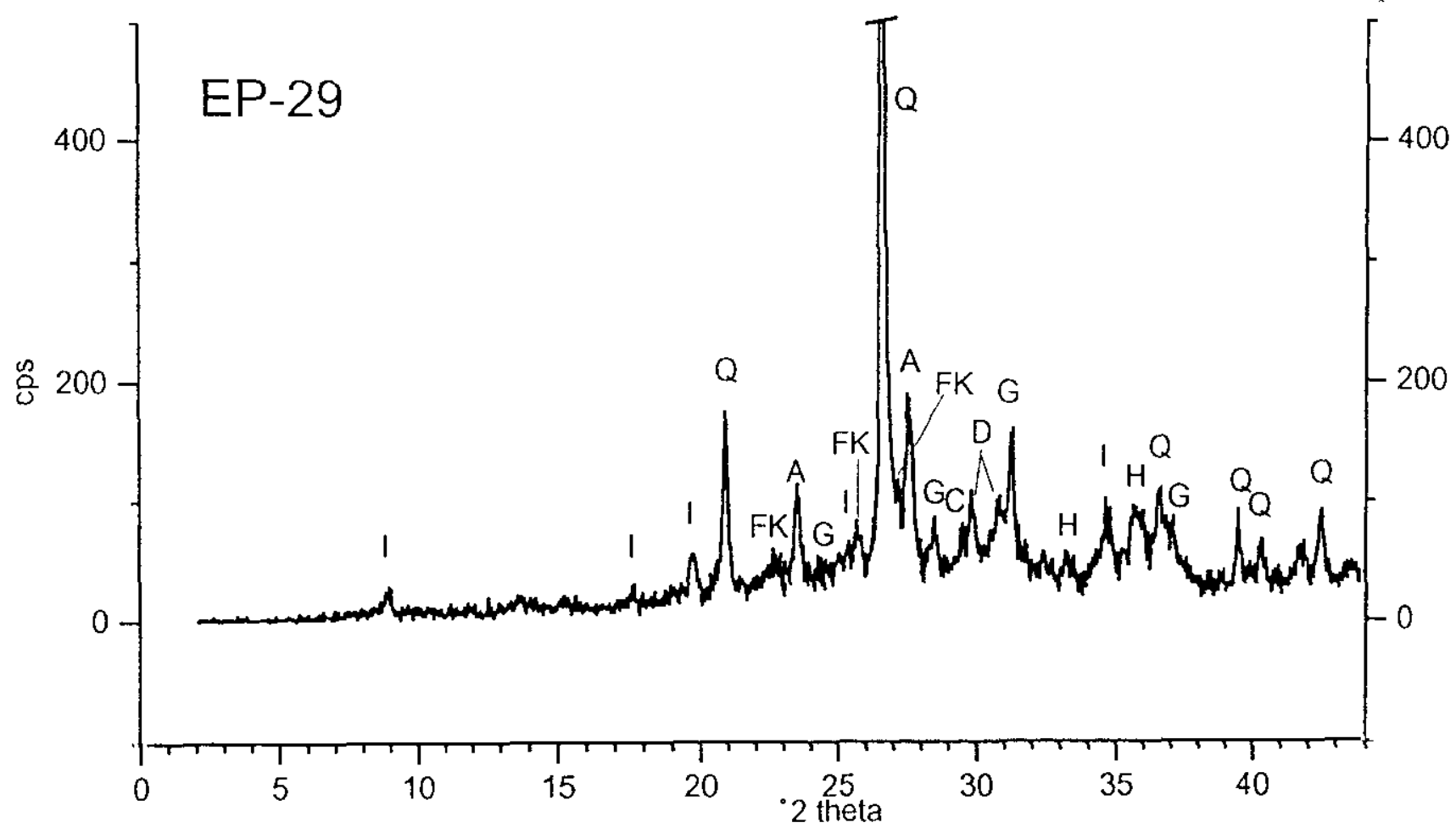



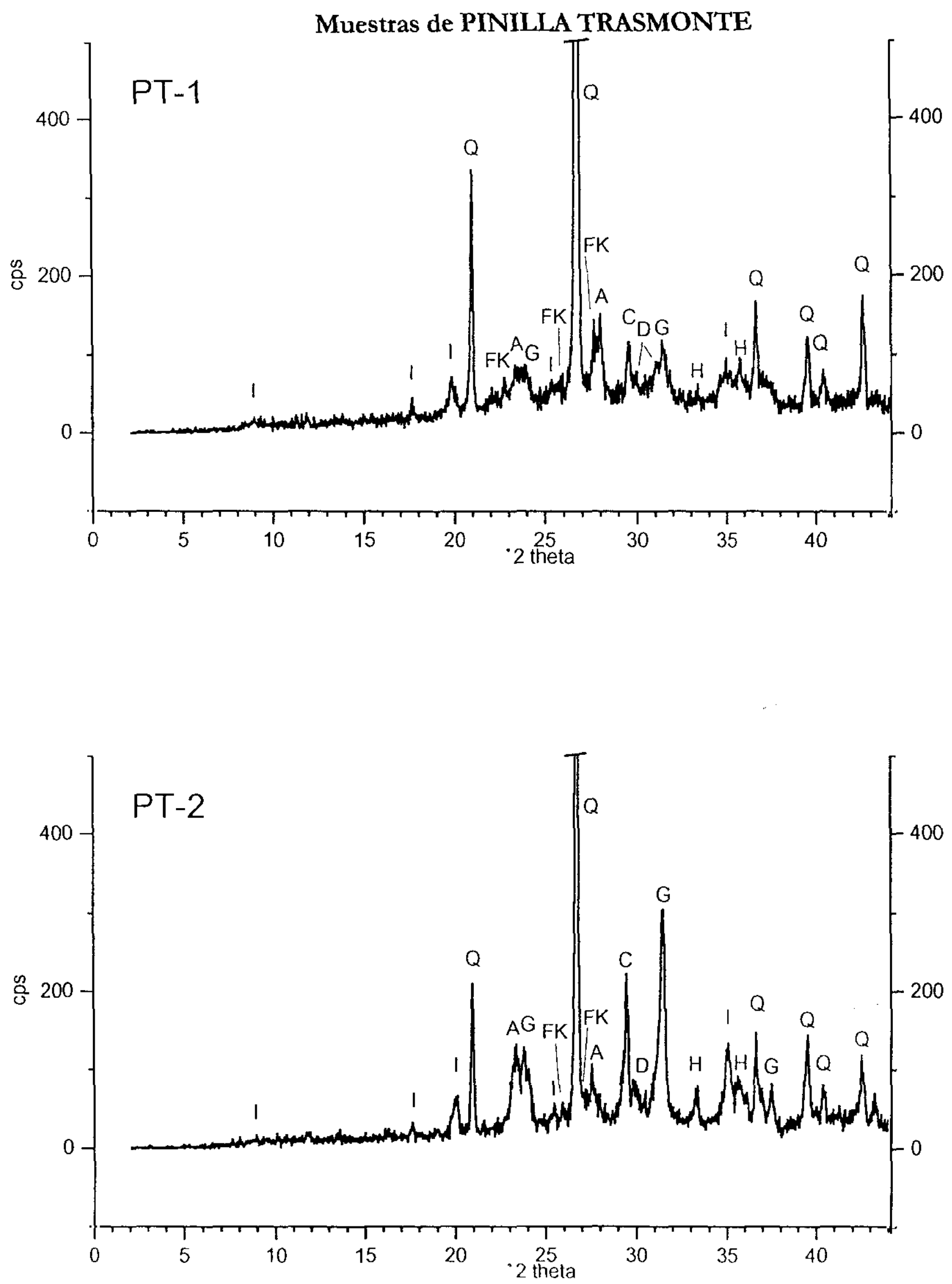

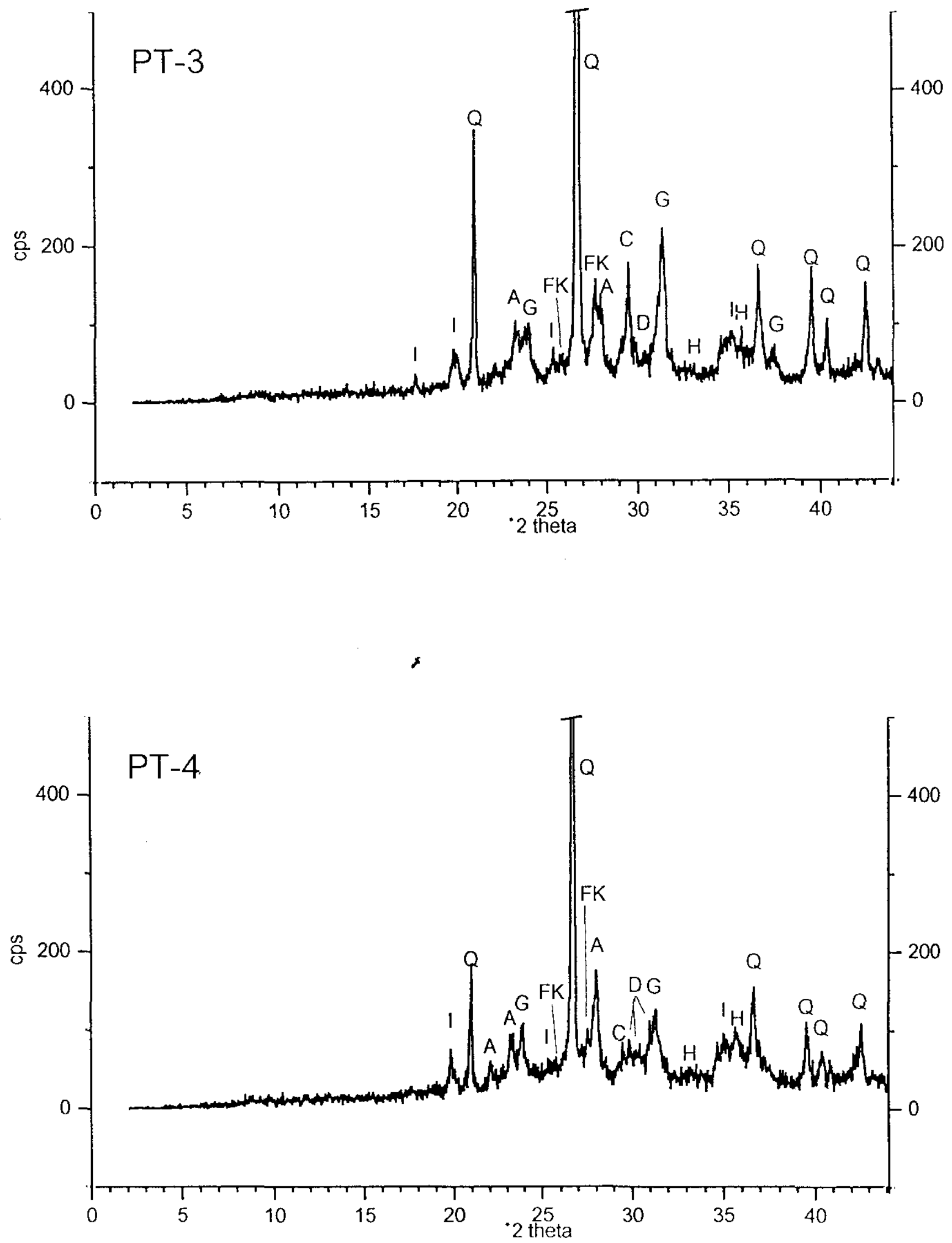

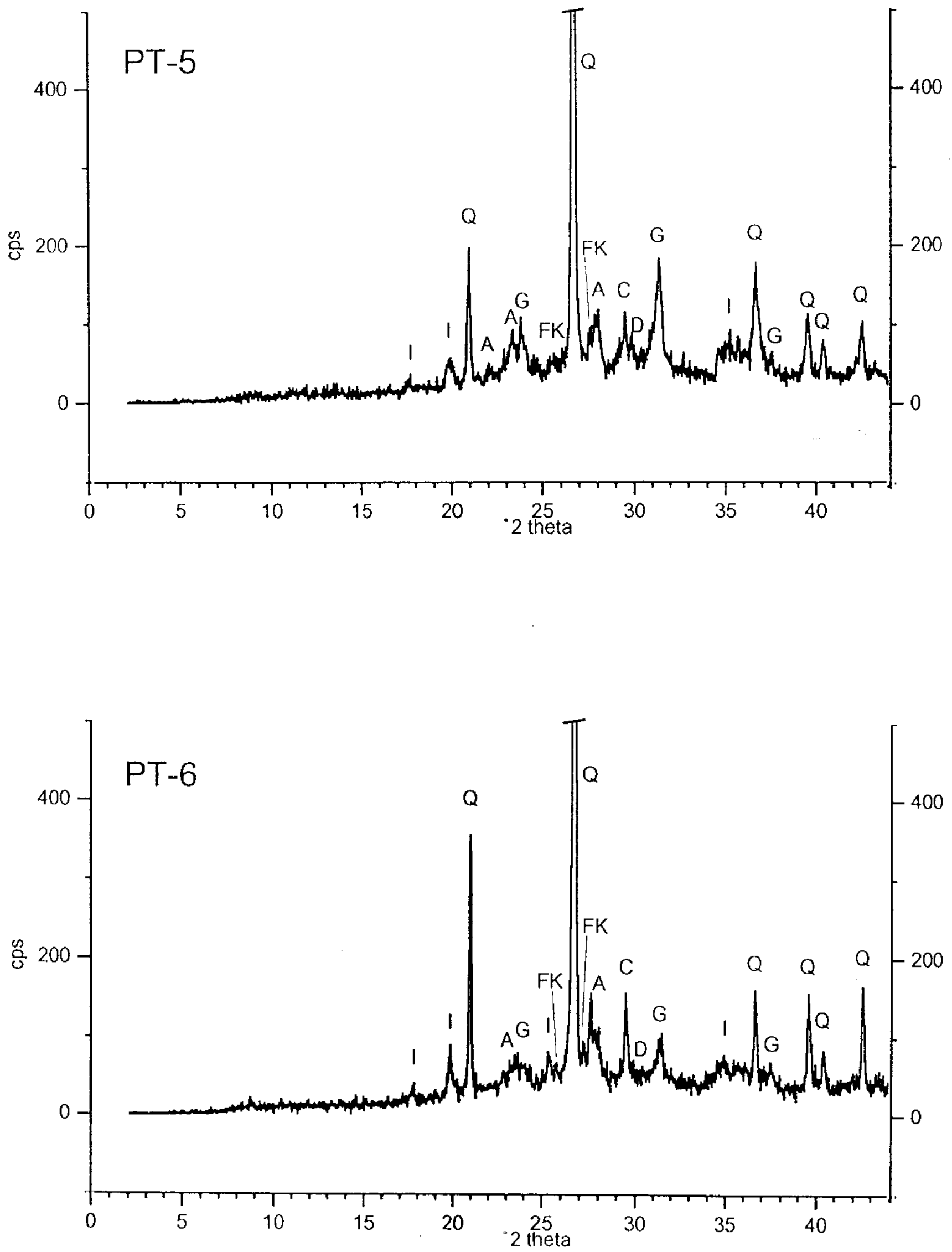

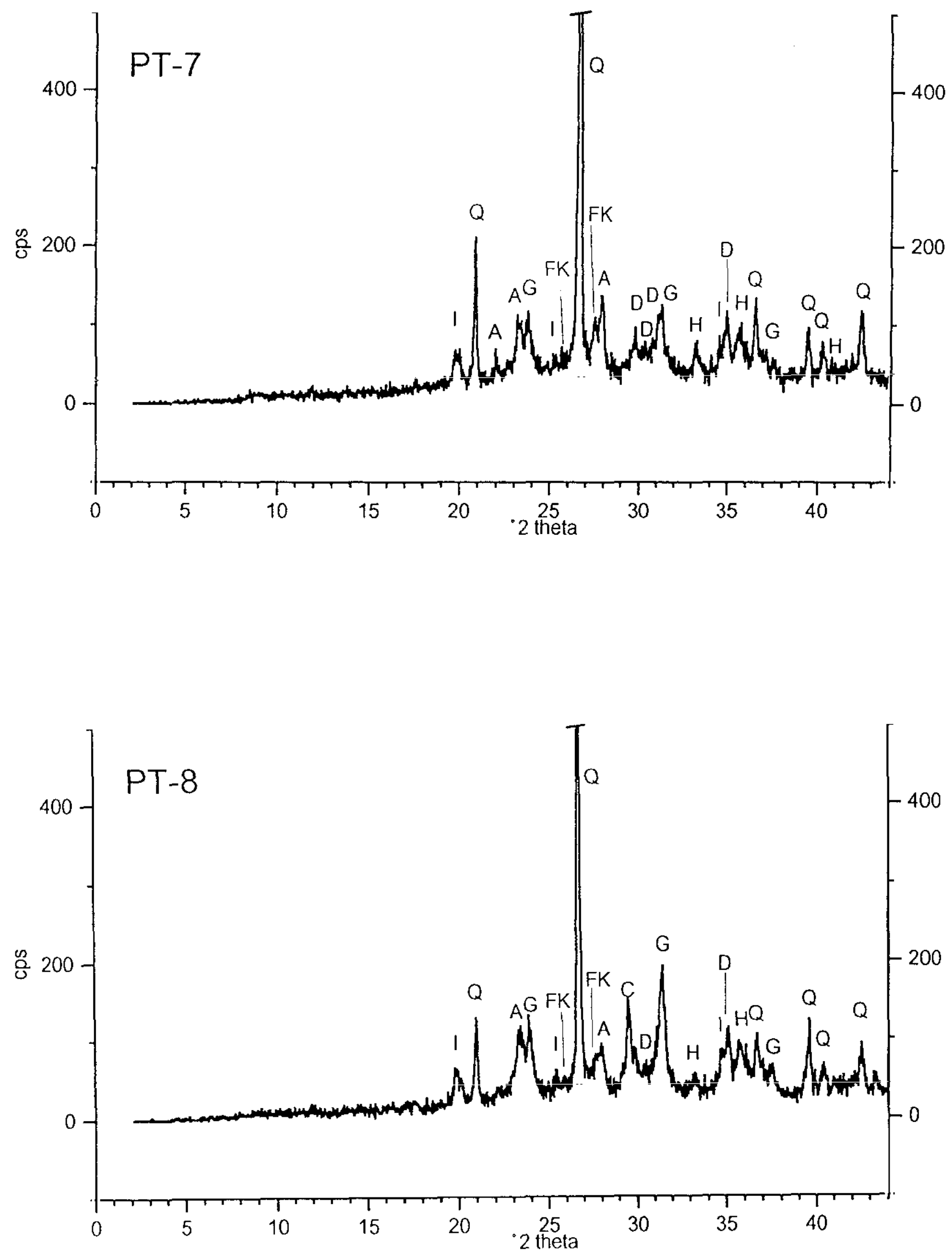

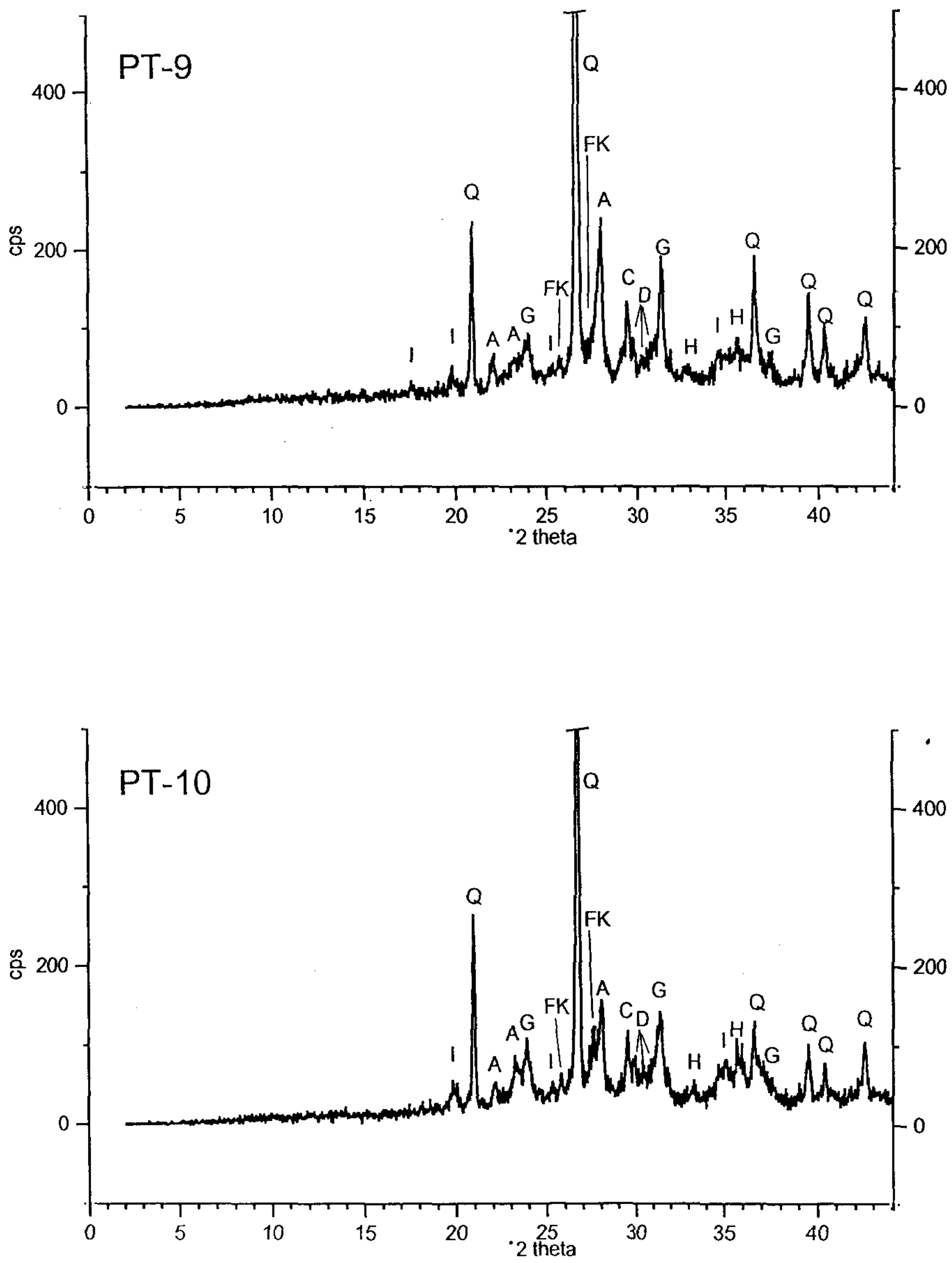


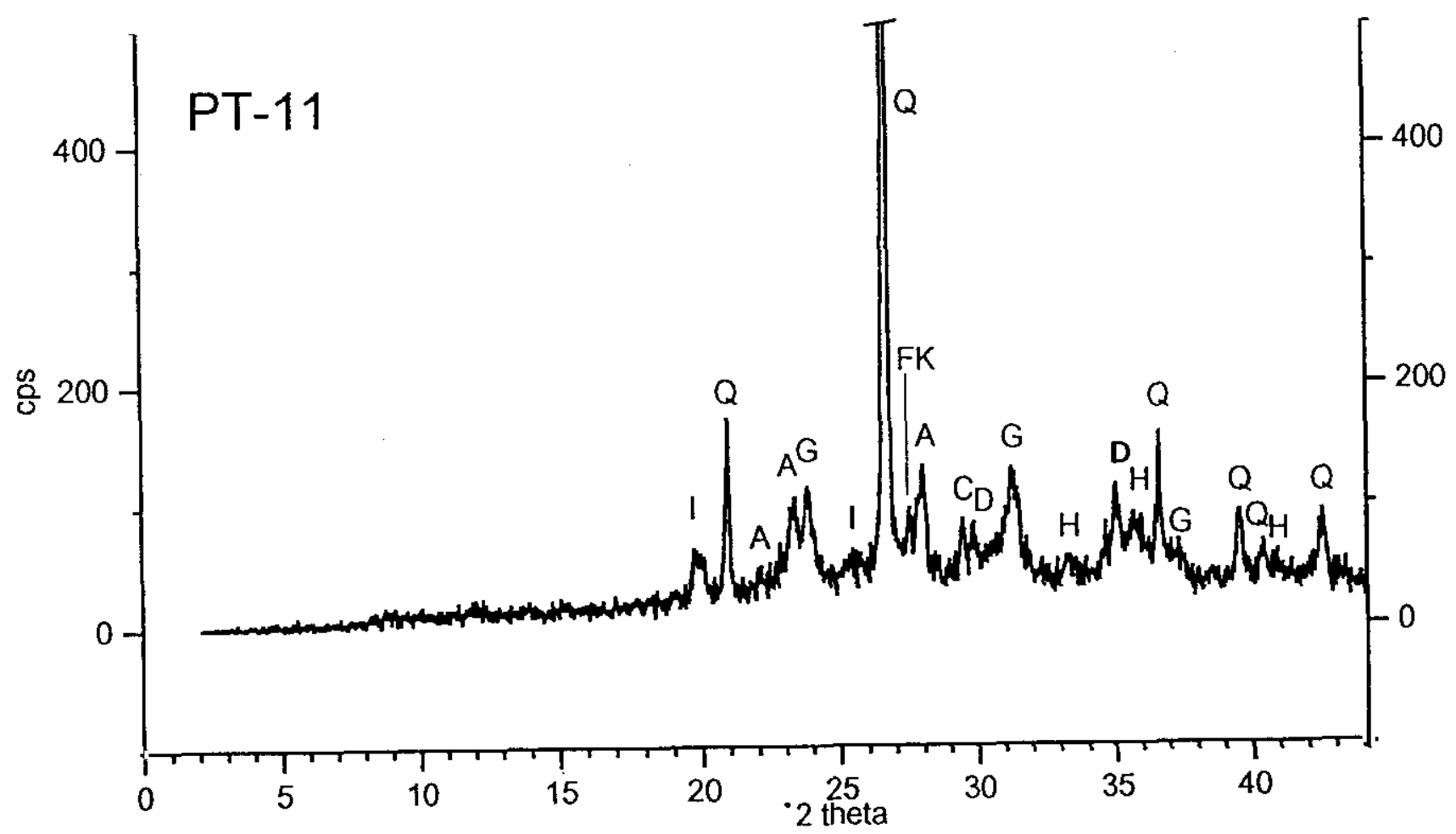



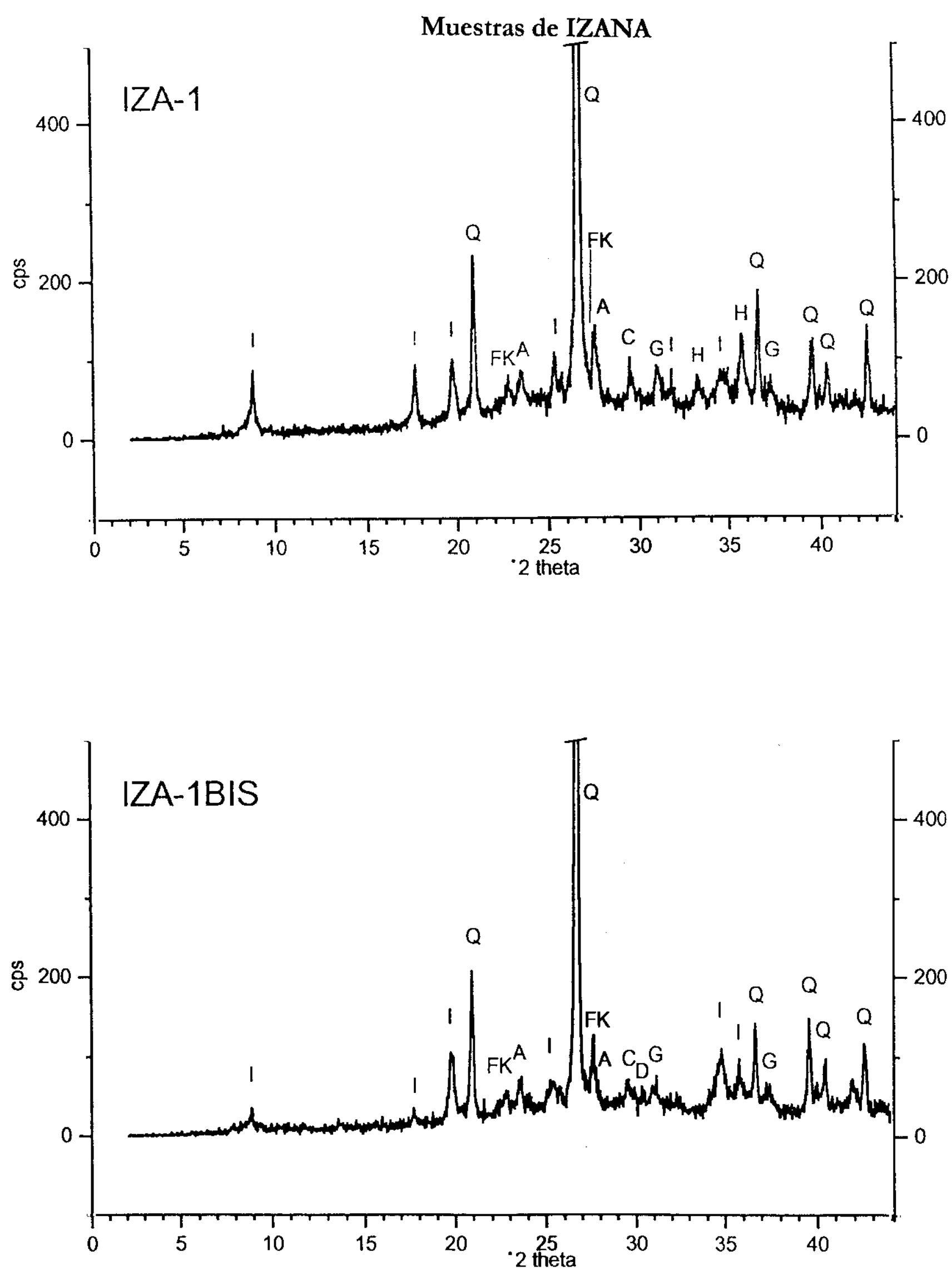

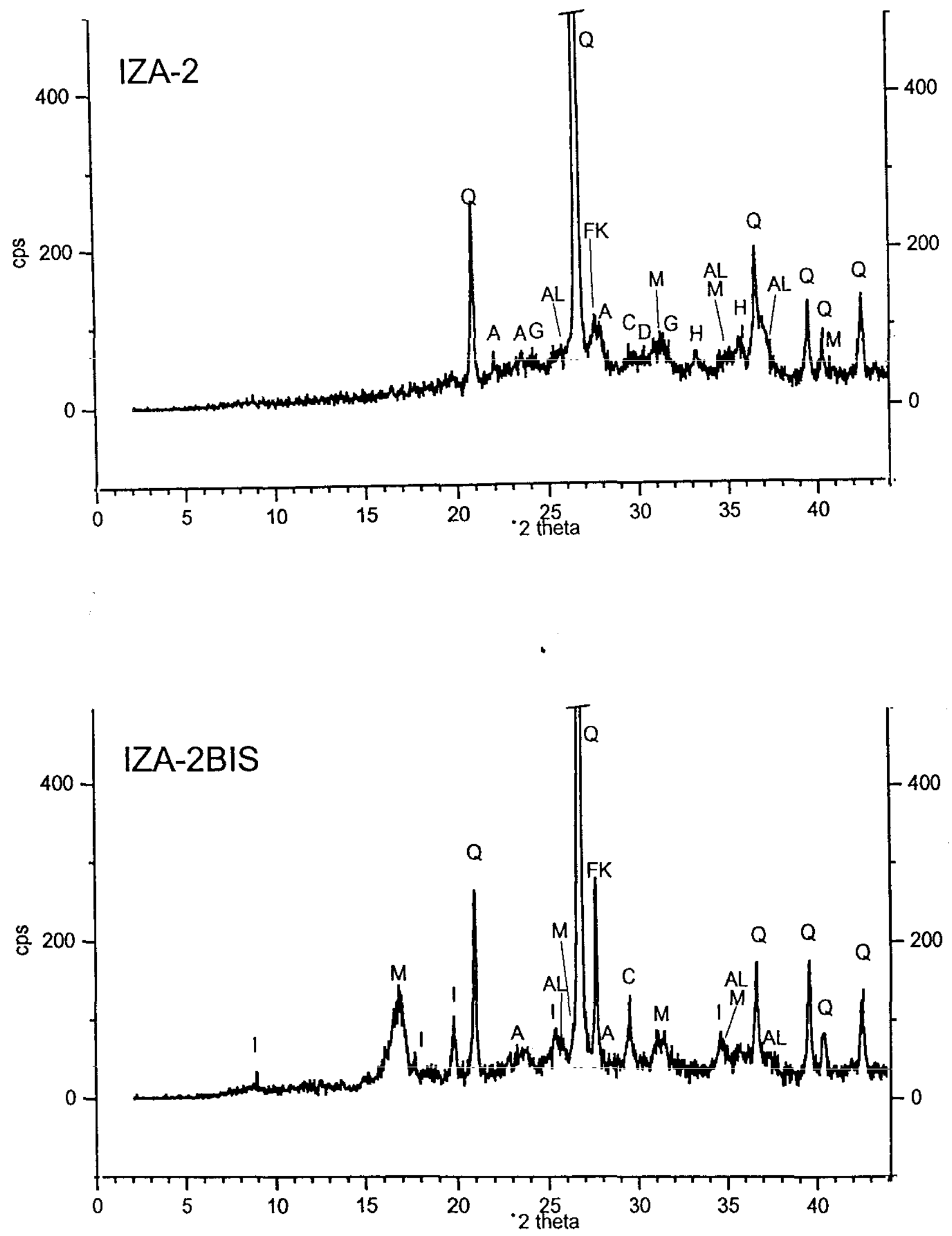

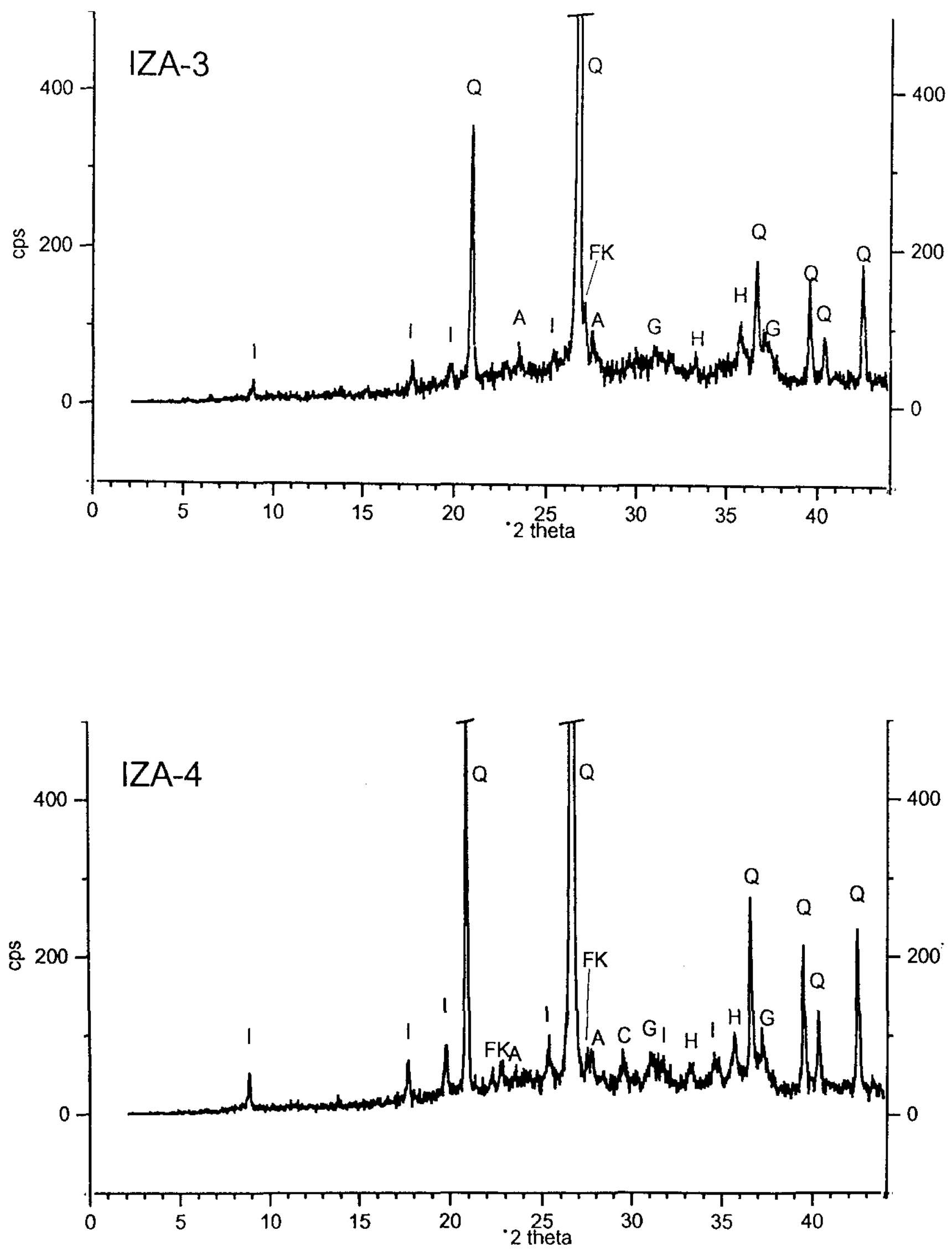

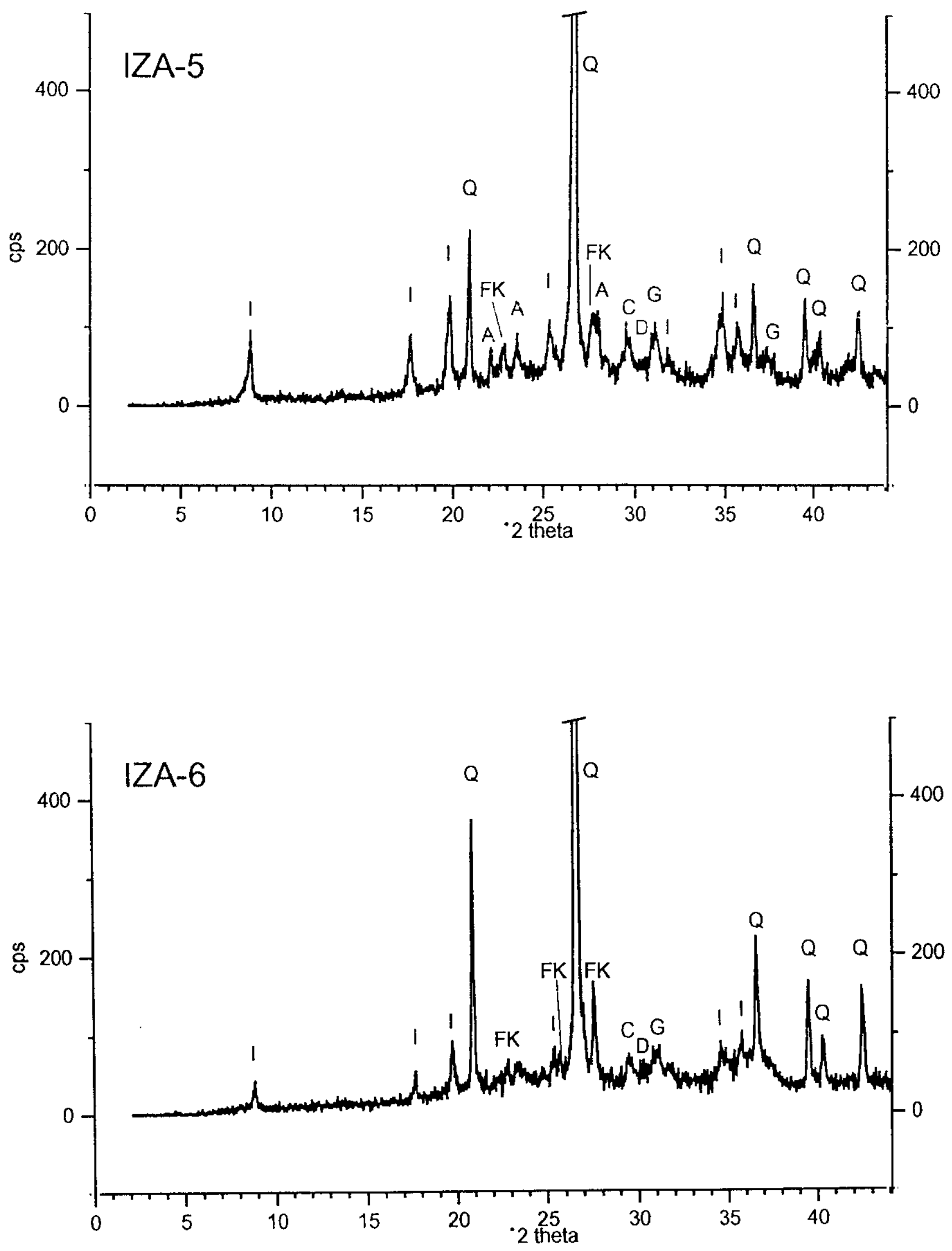

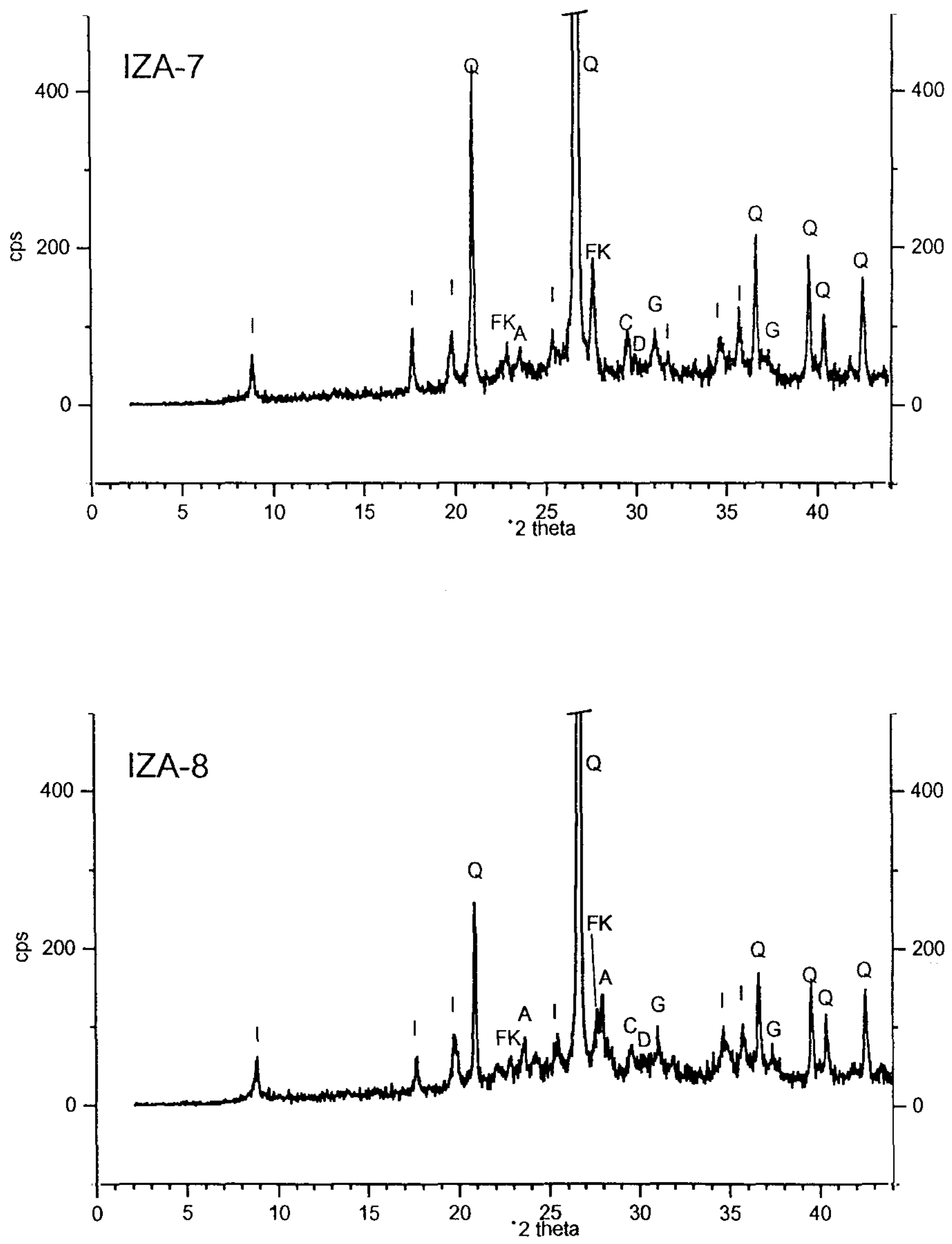

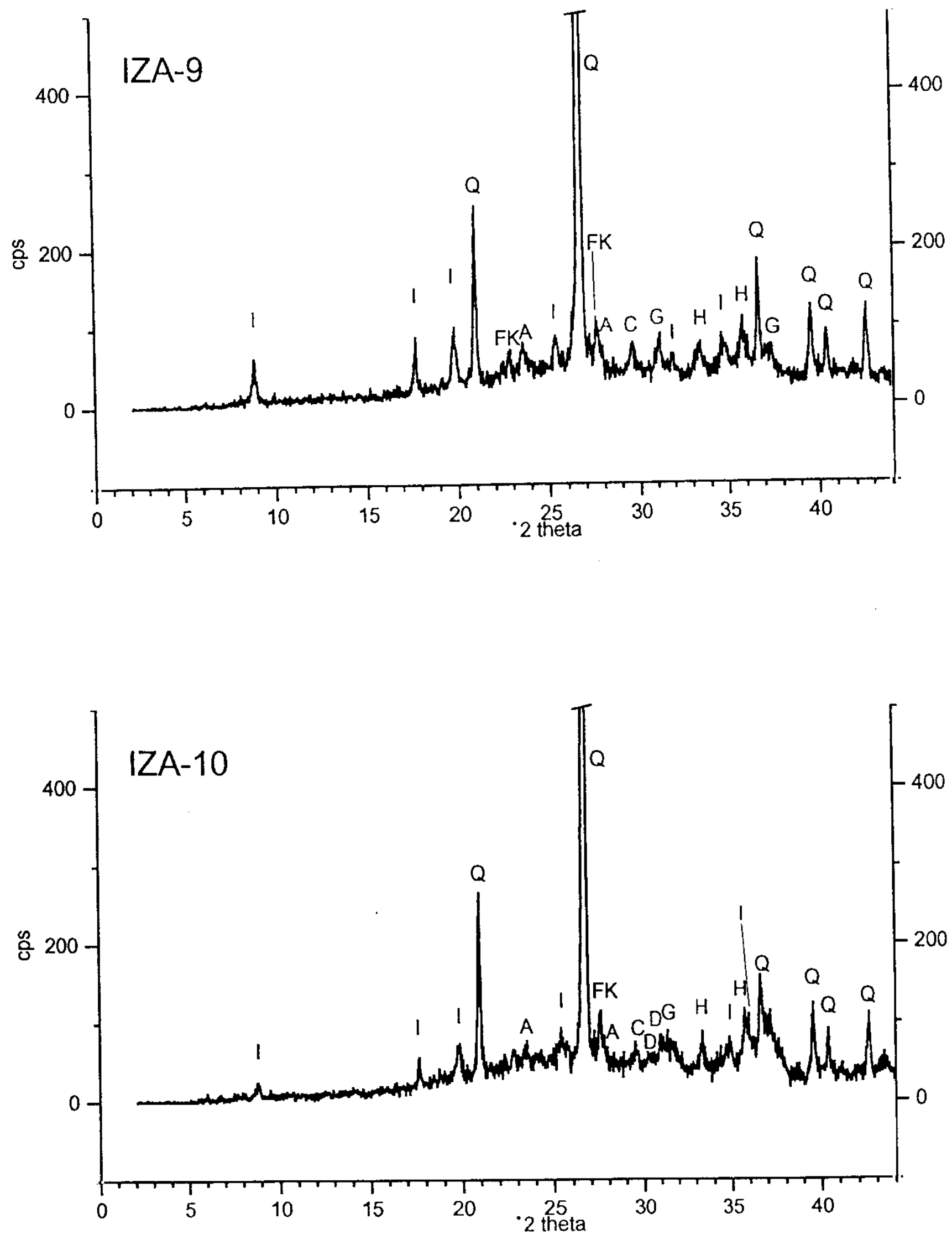

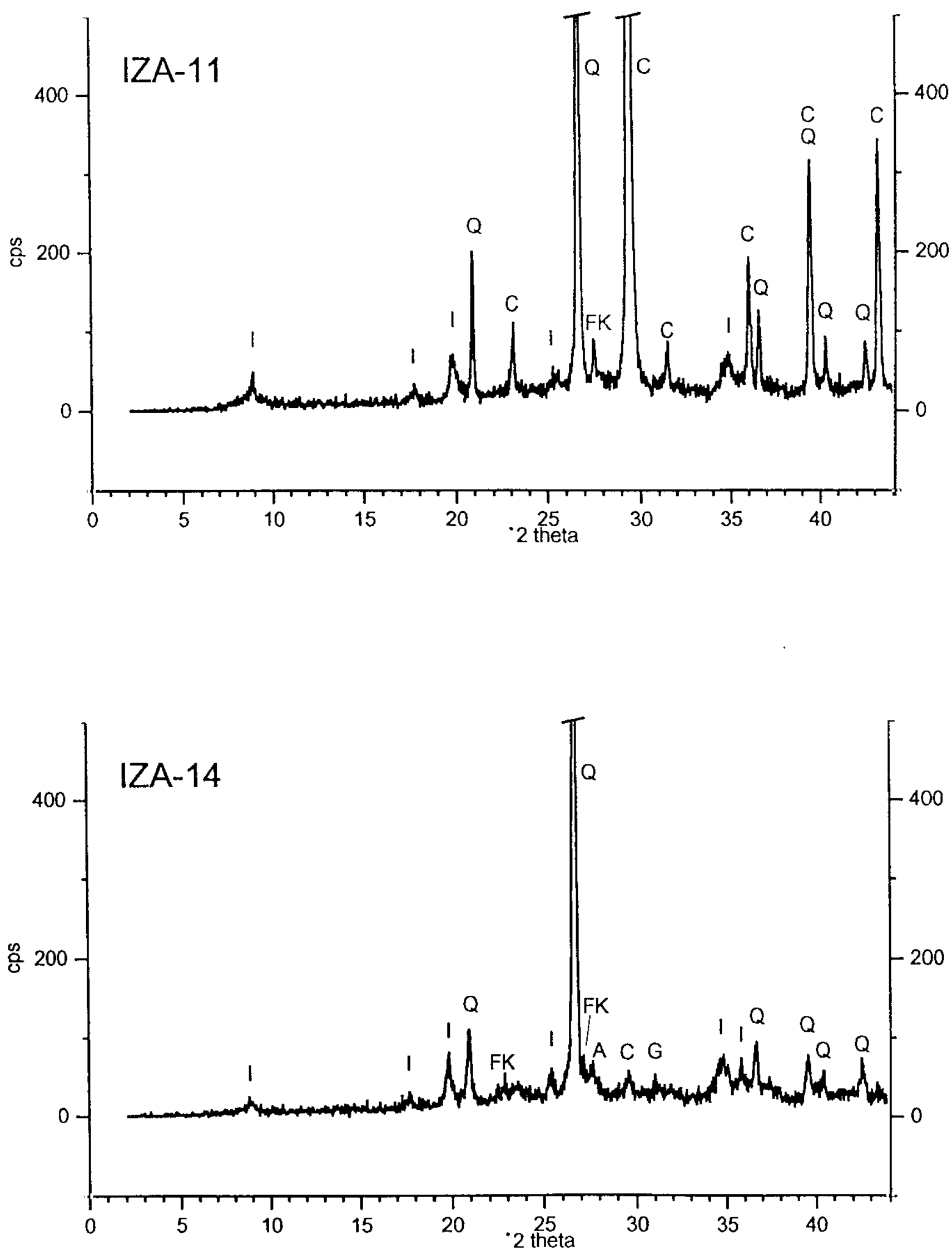

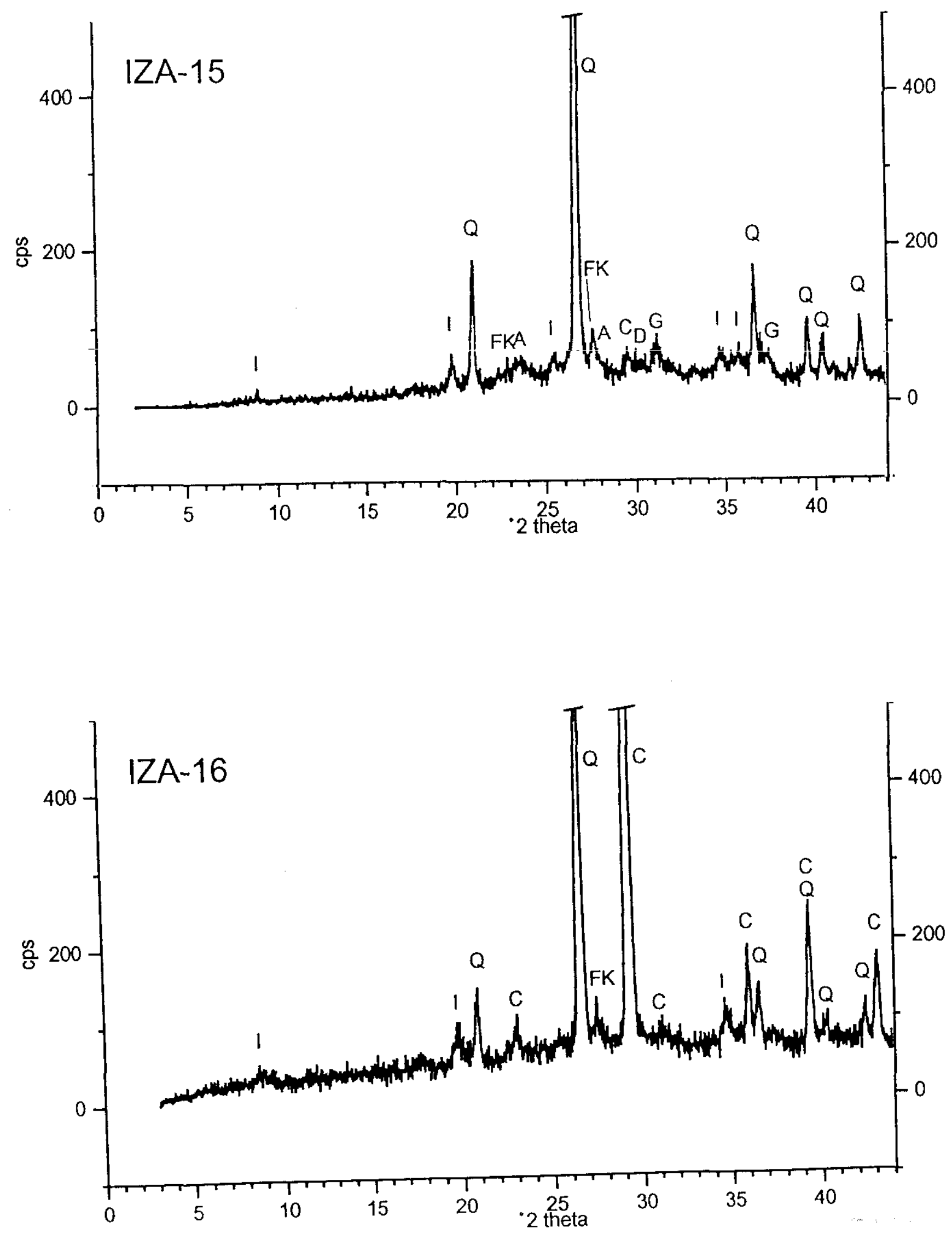


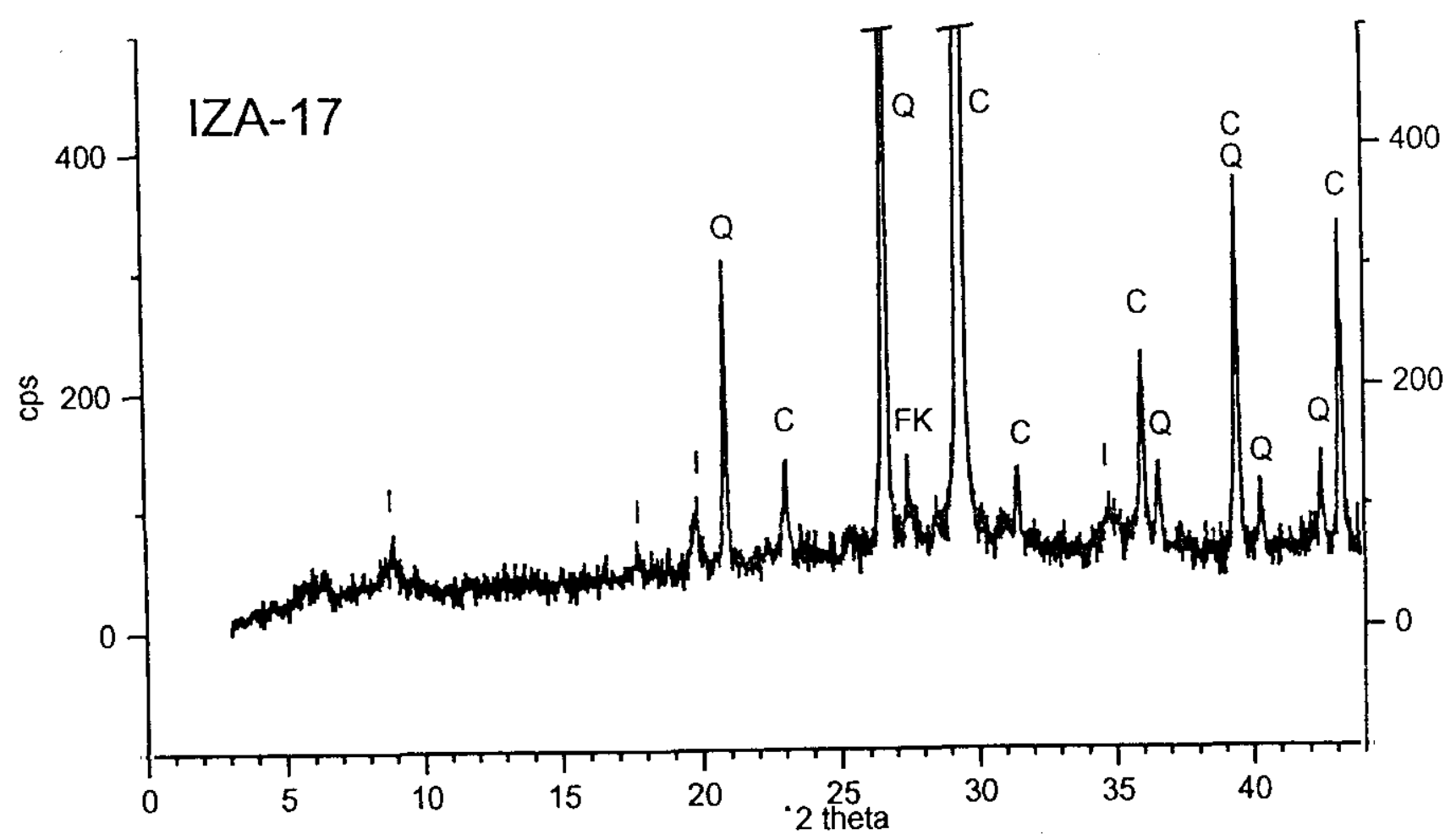



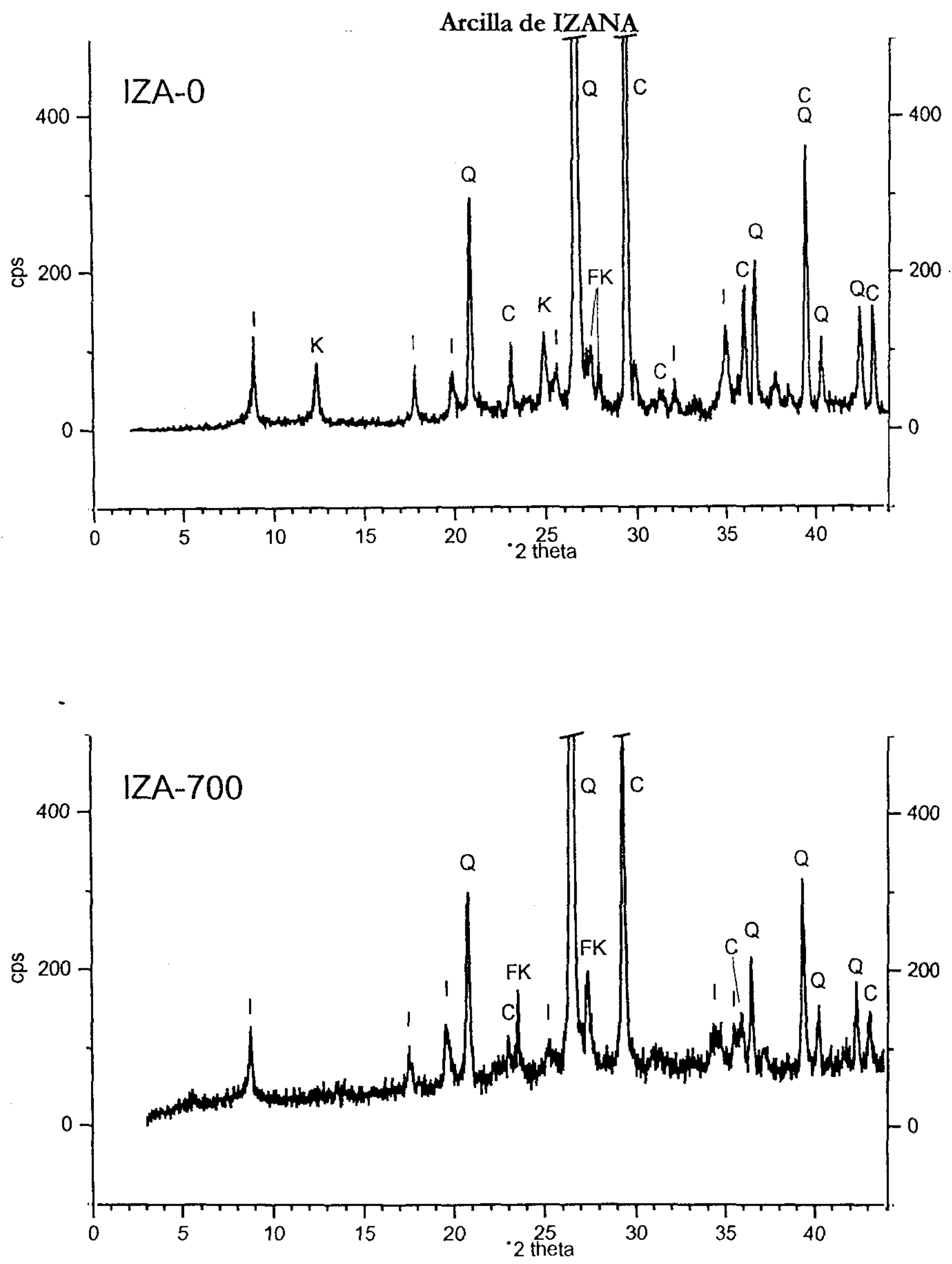

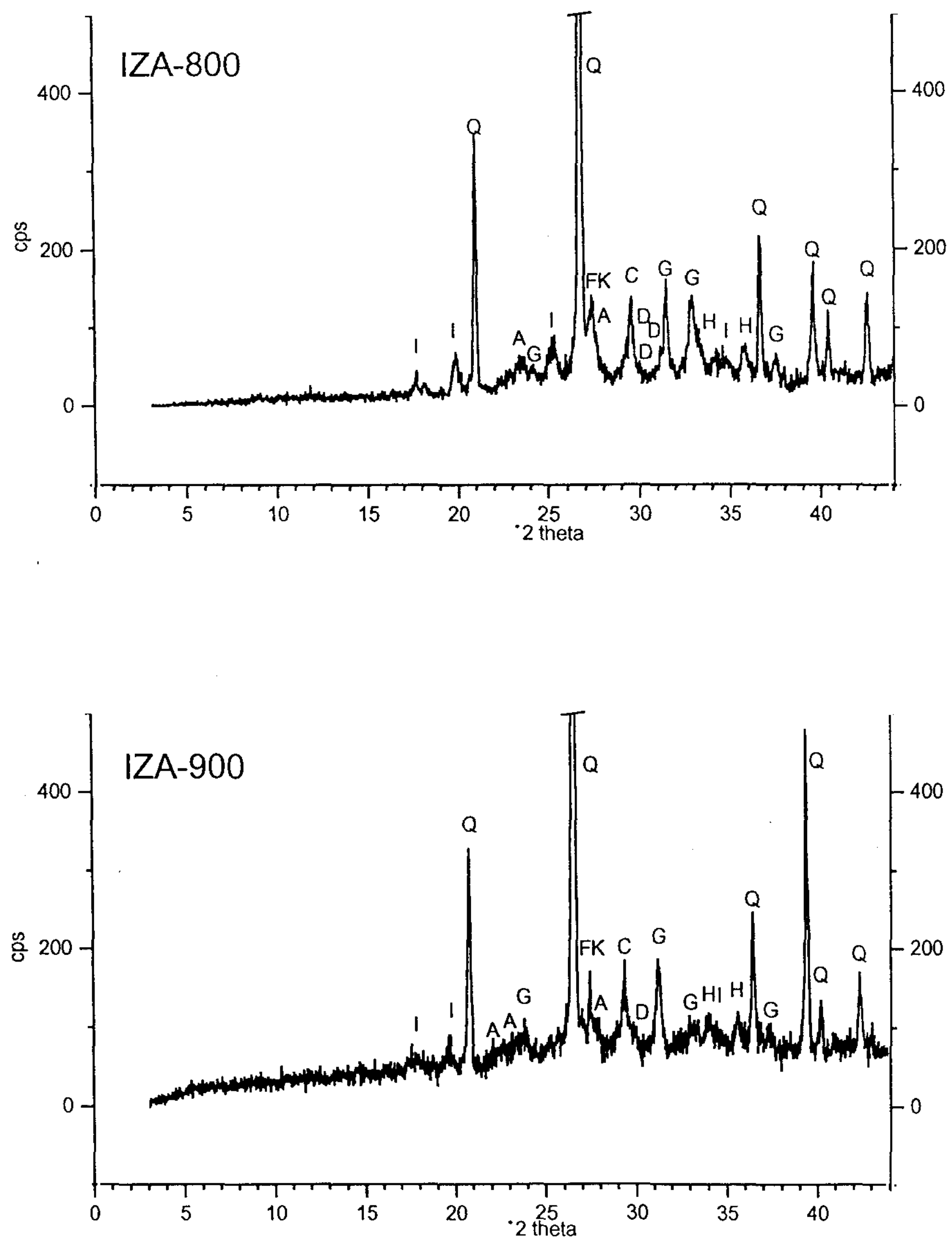


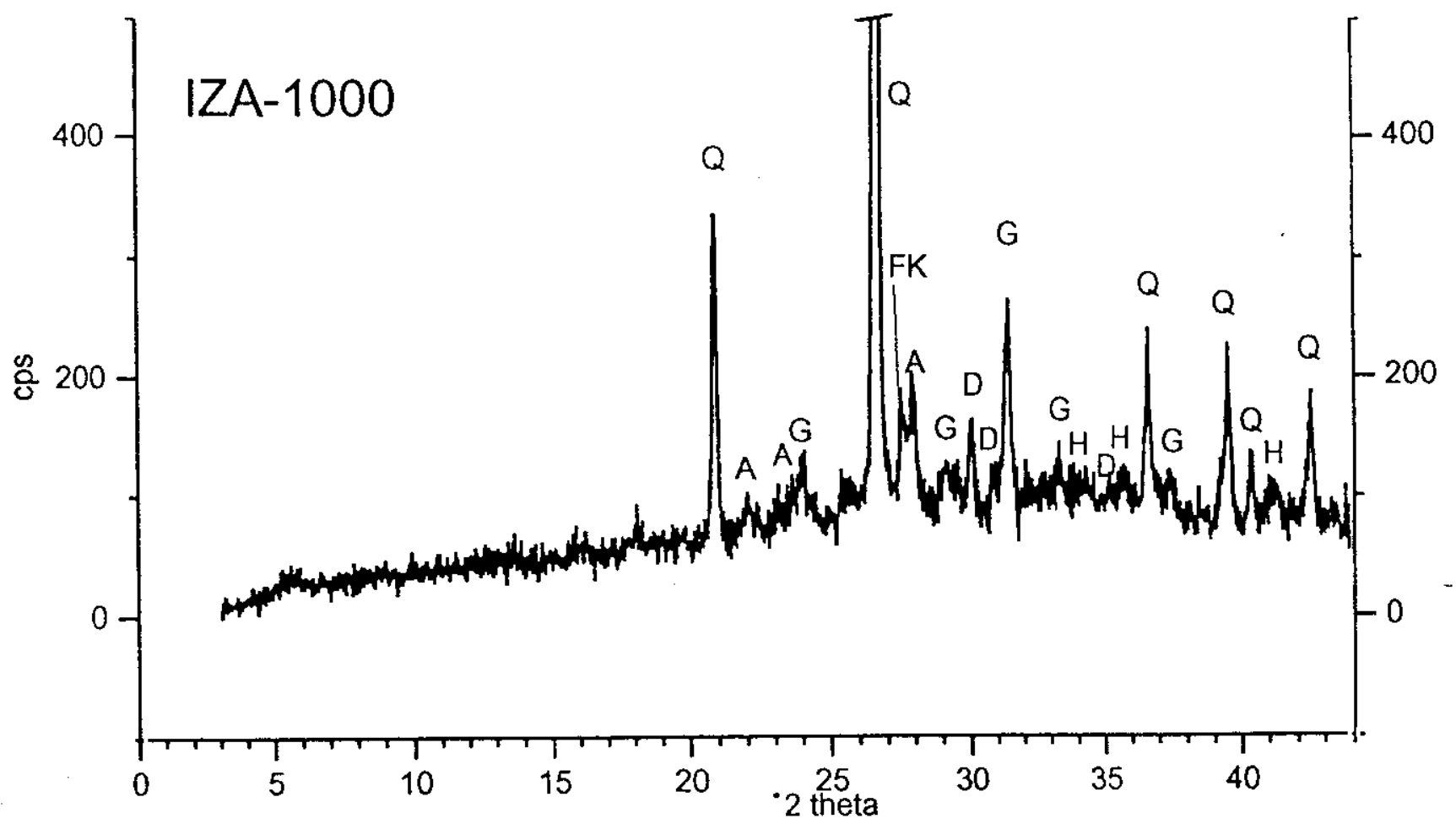




\section{RECOCCIONES}
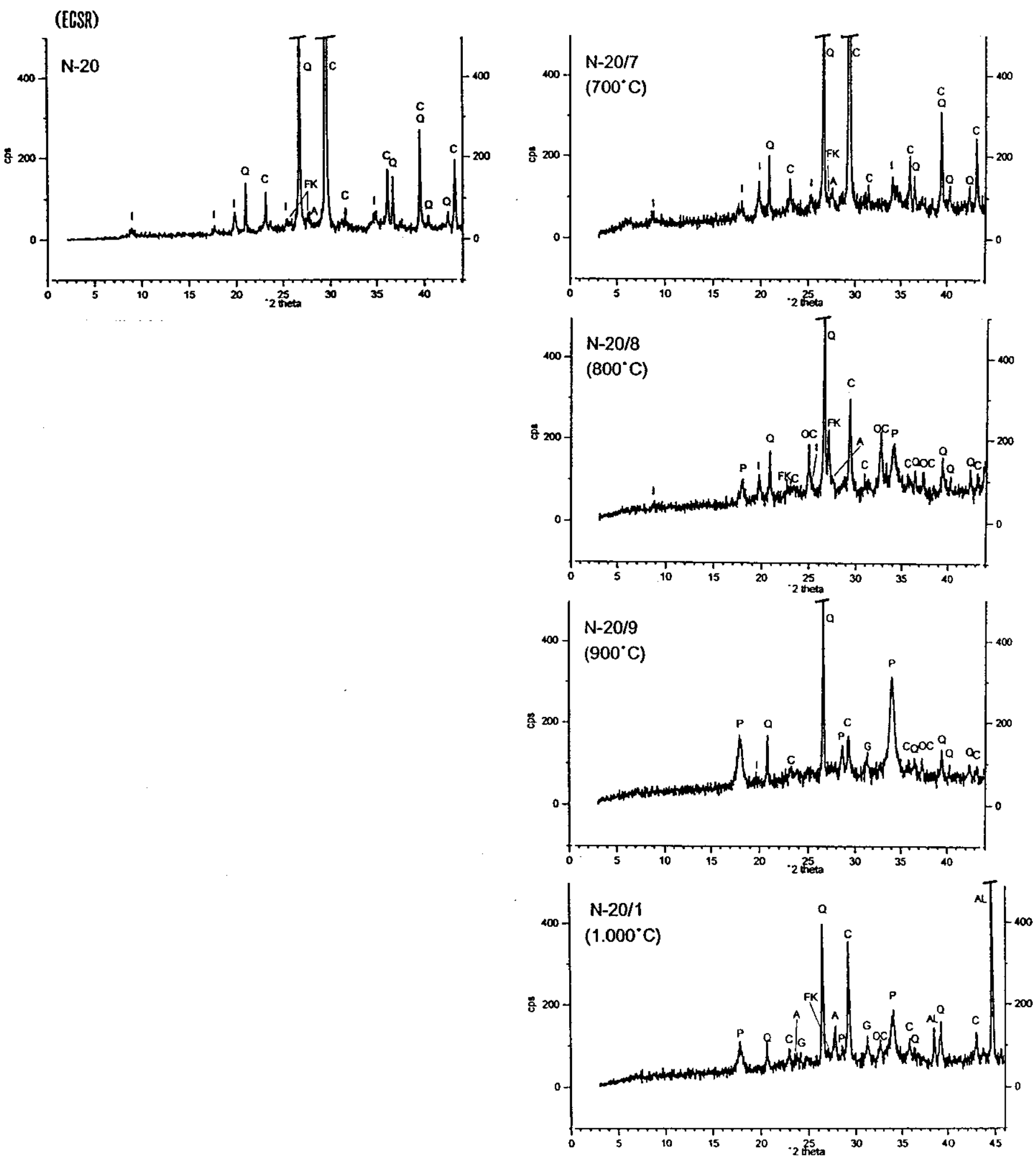

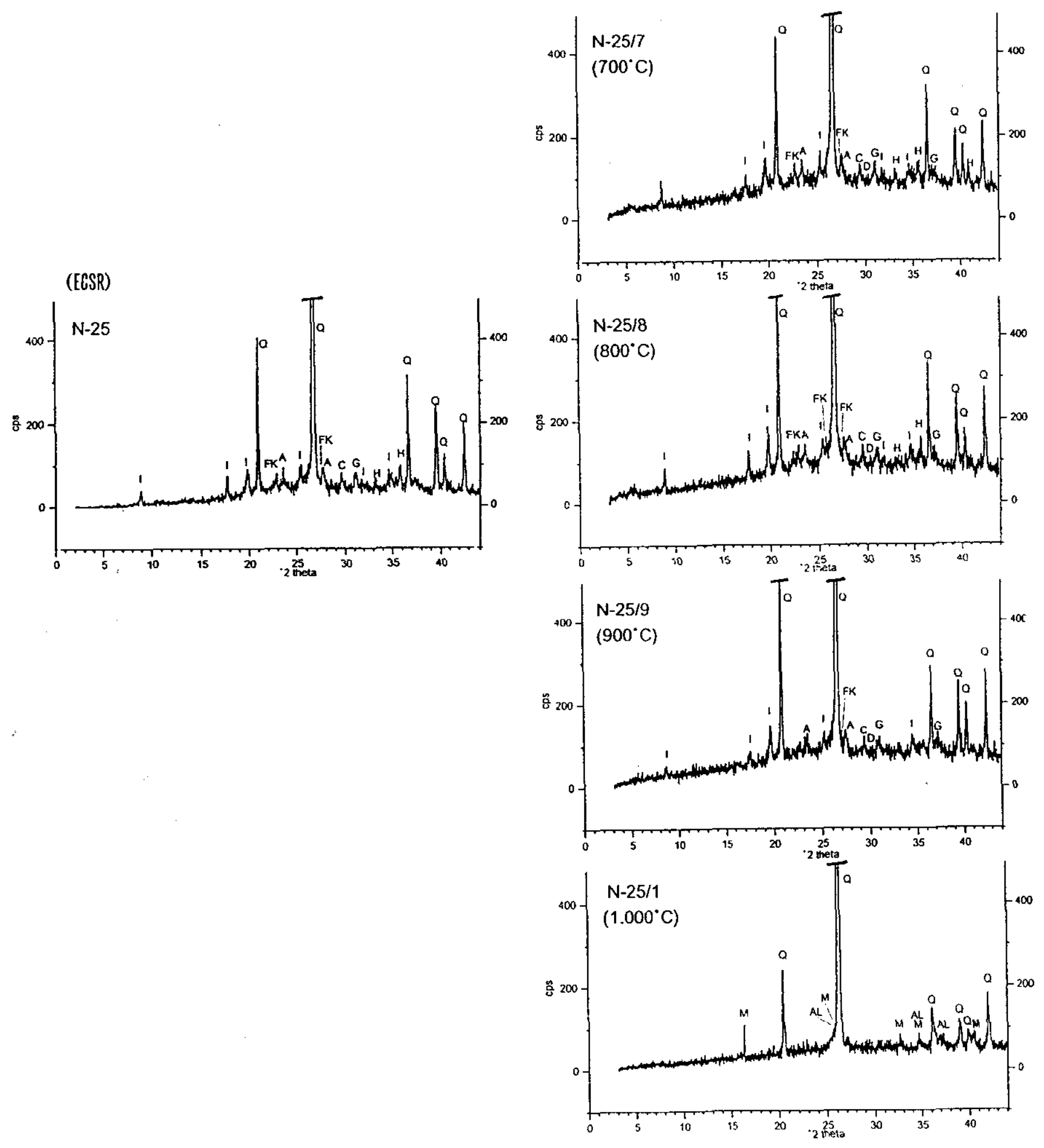

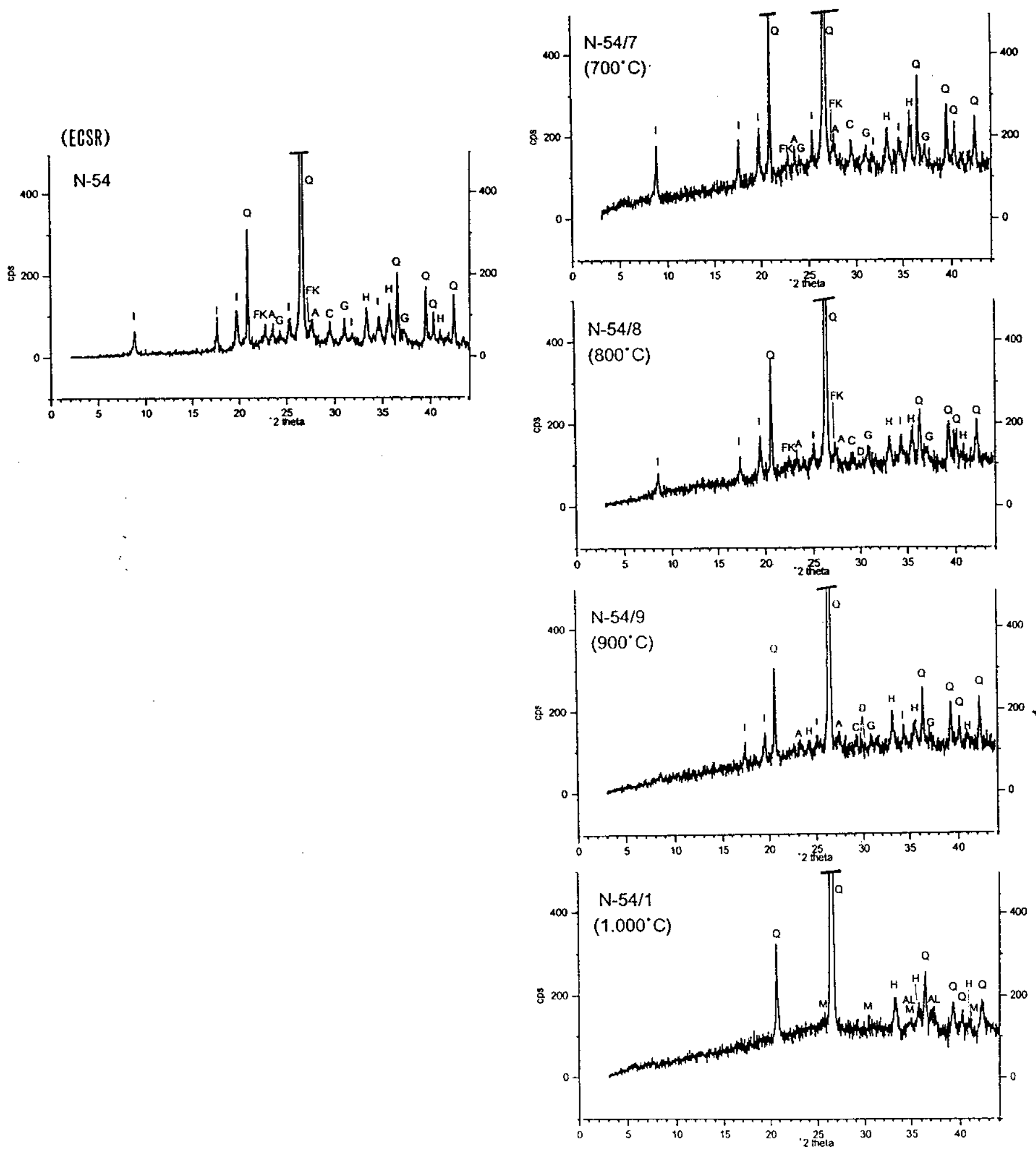

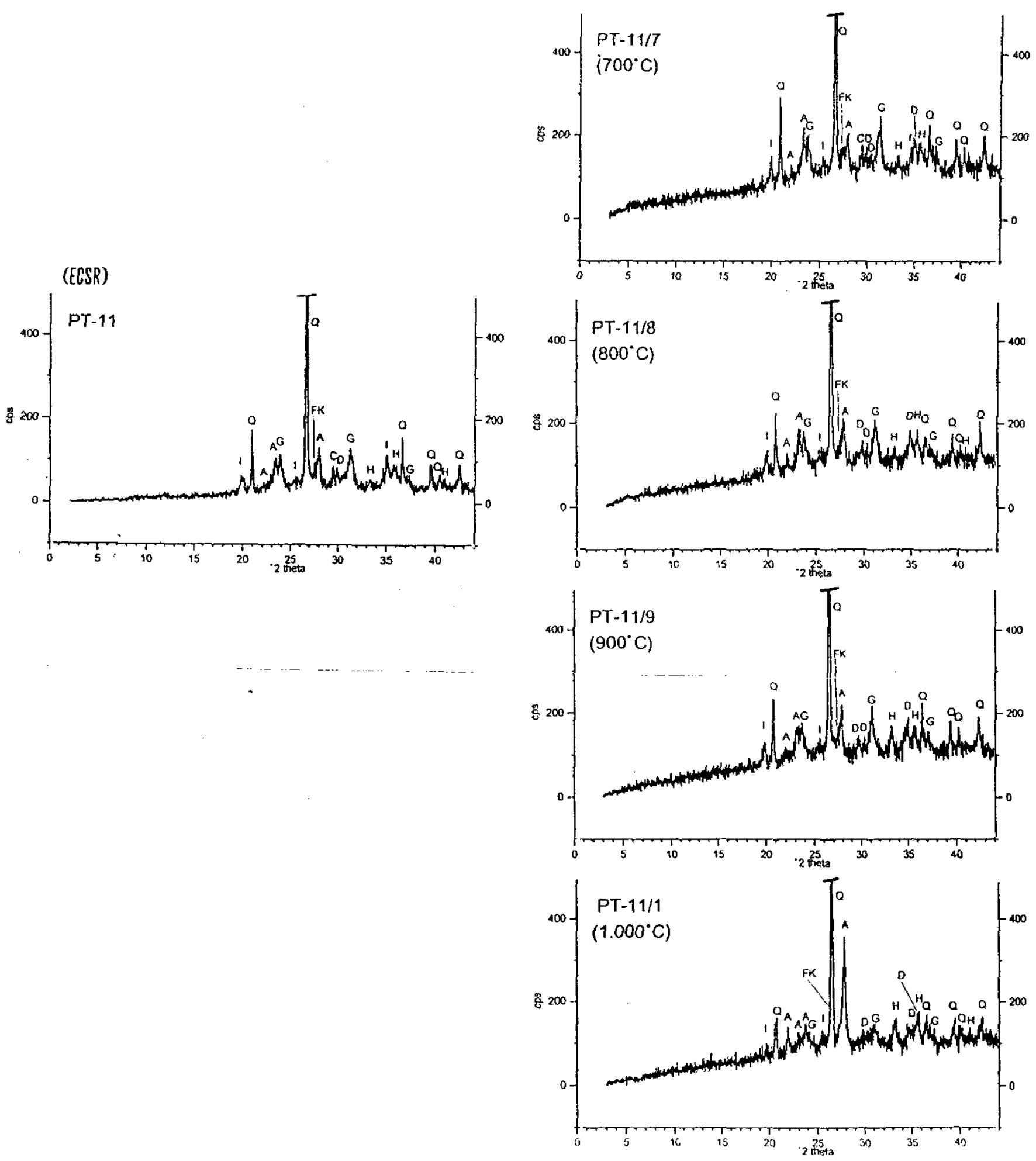

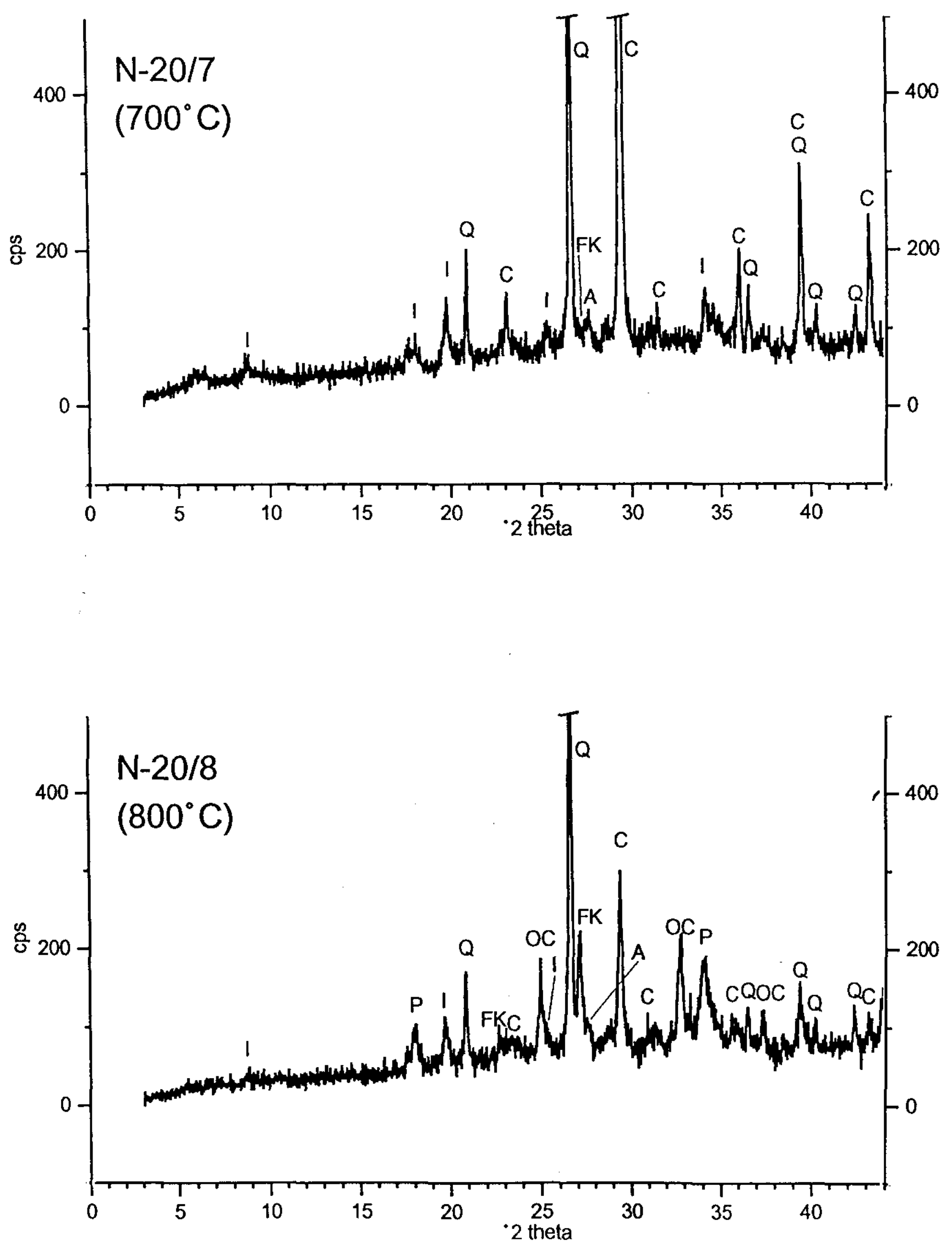

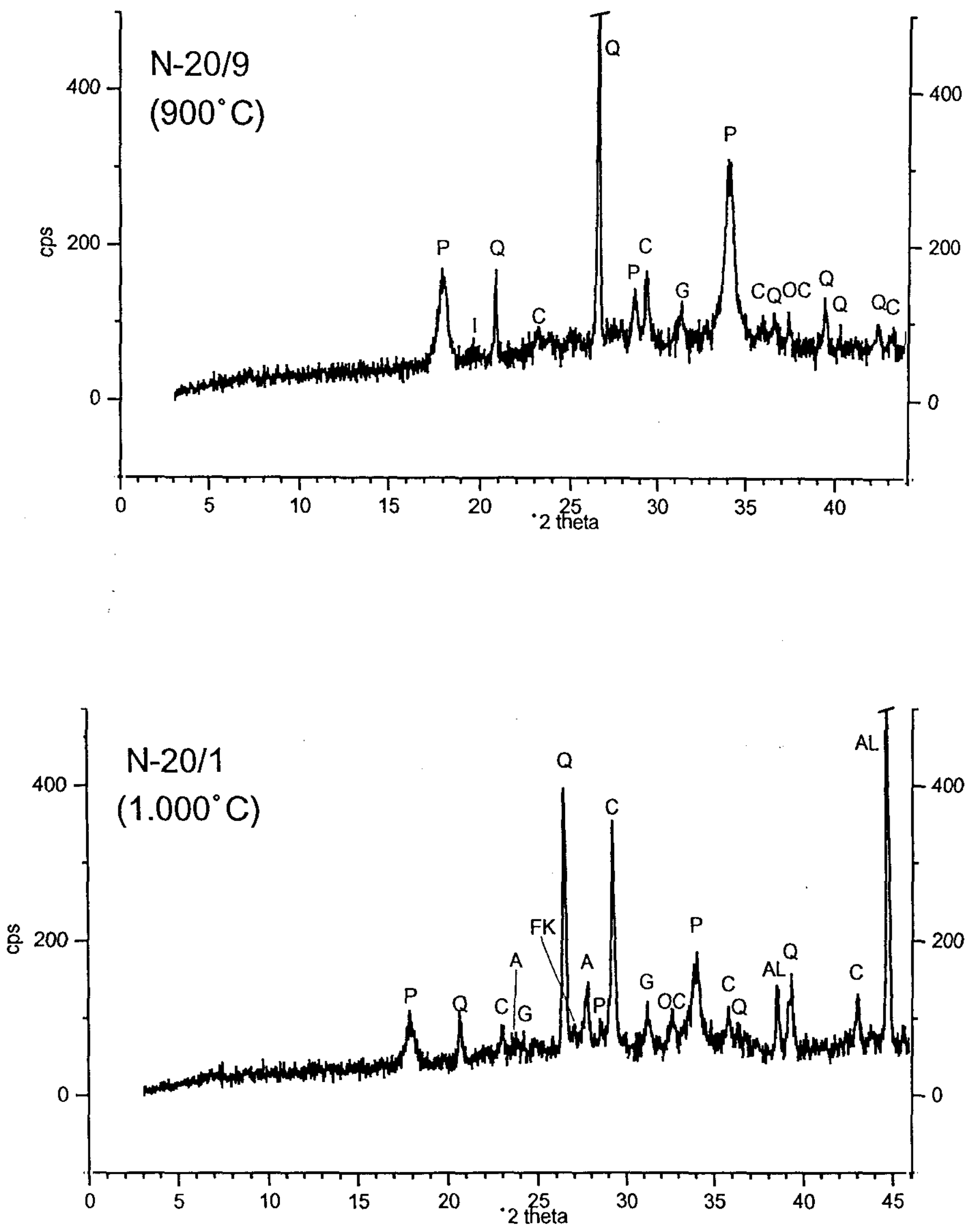

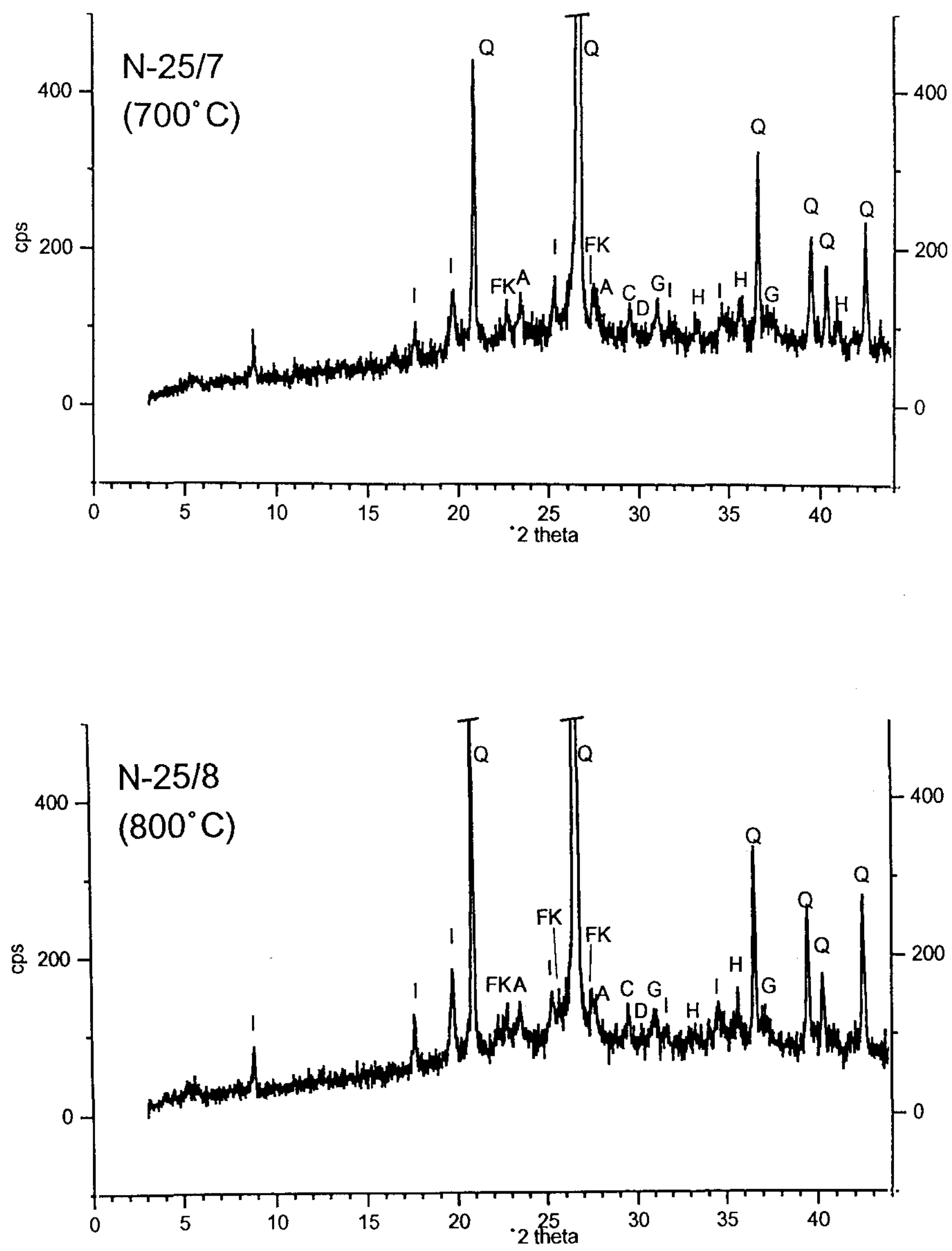

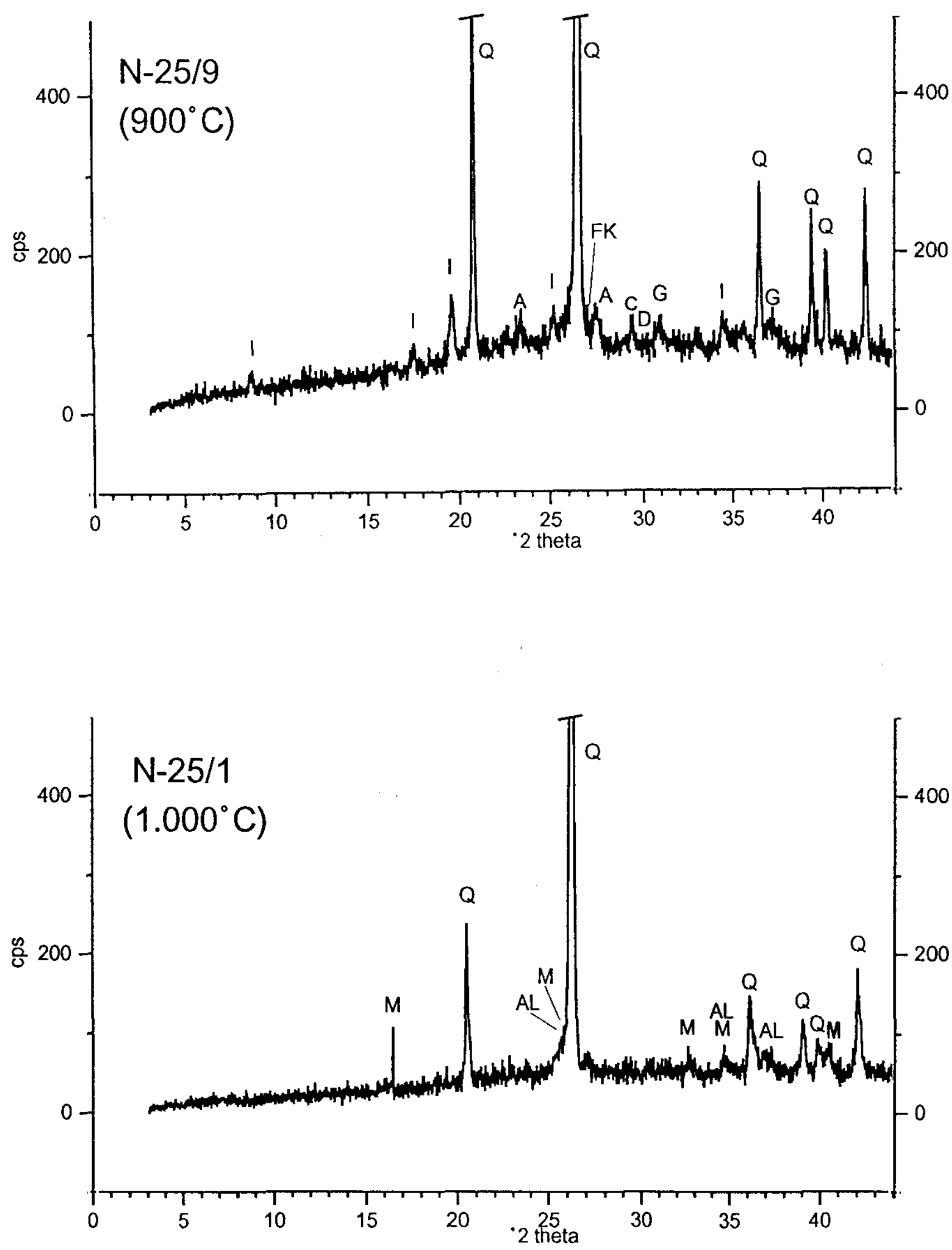

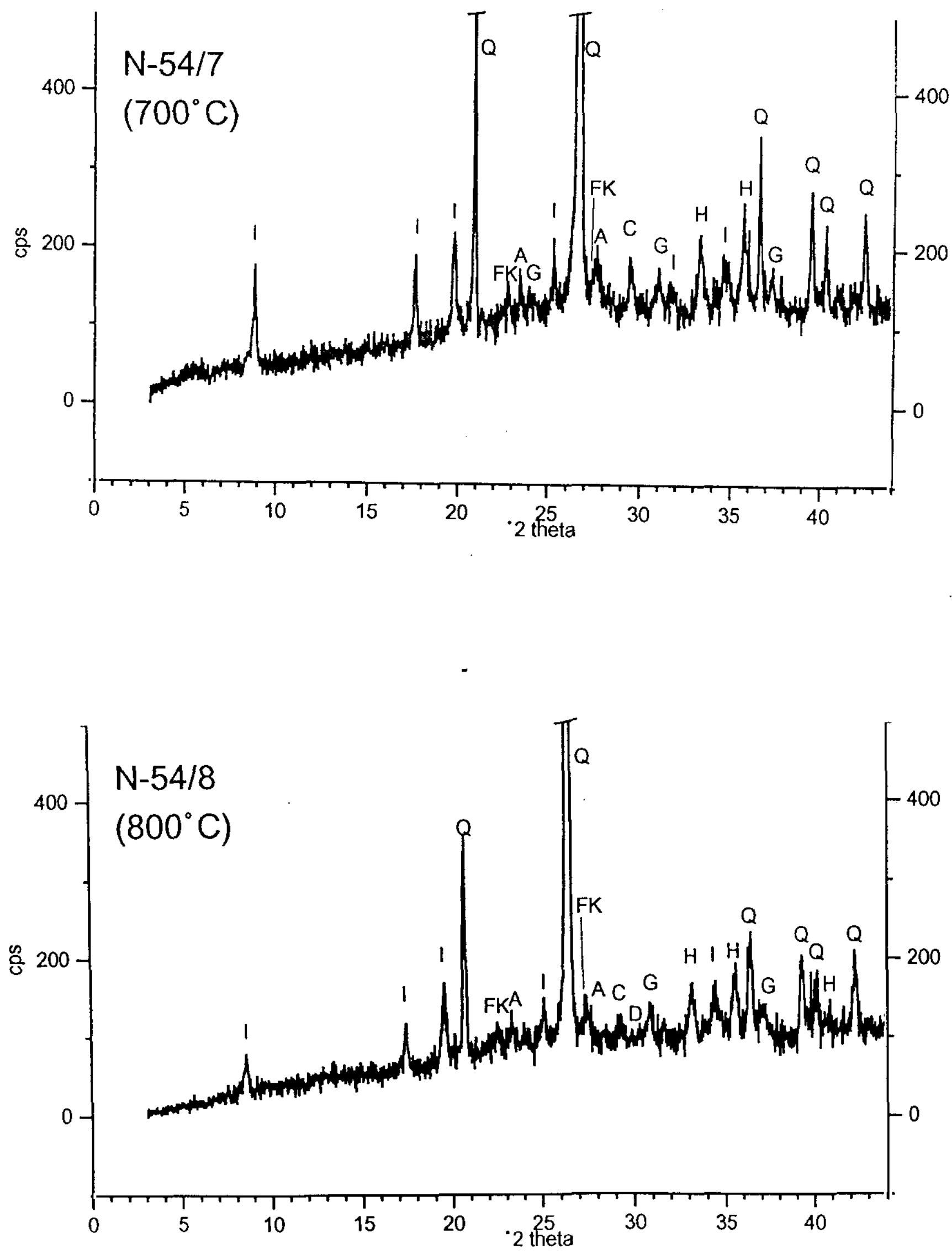

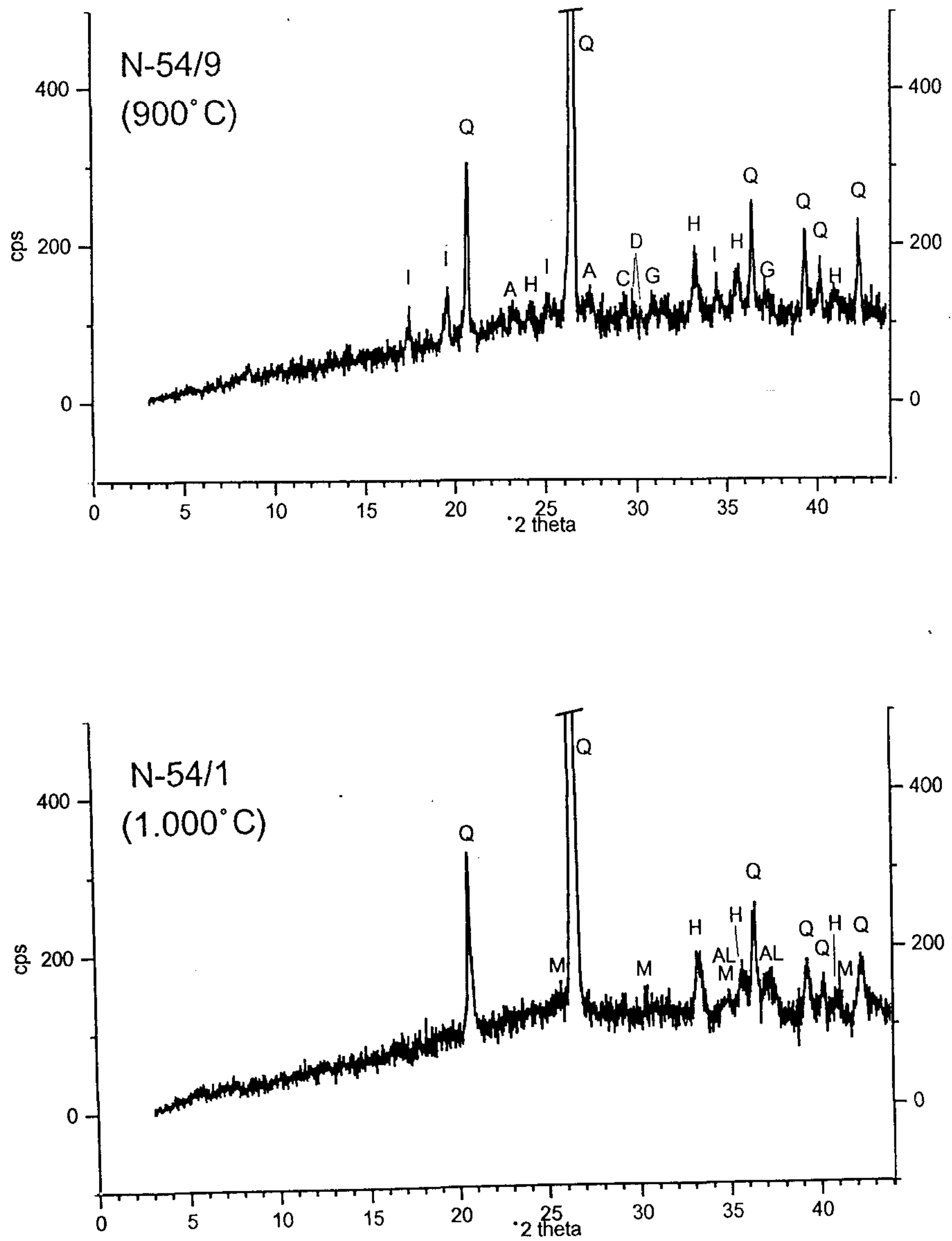

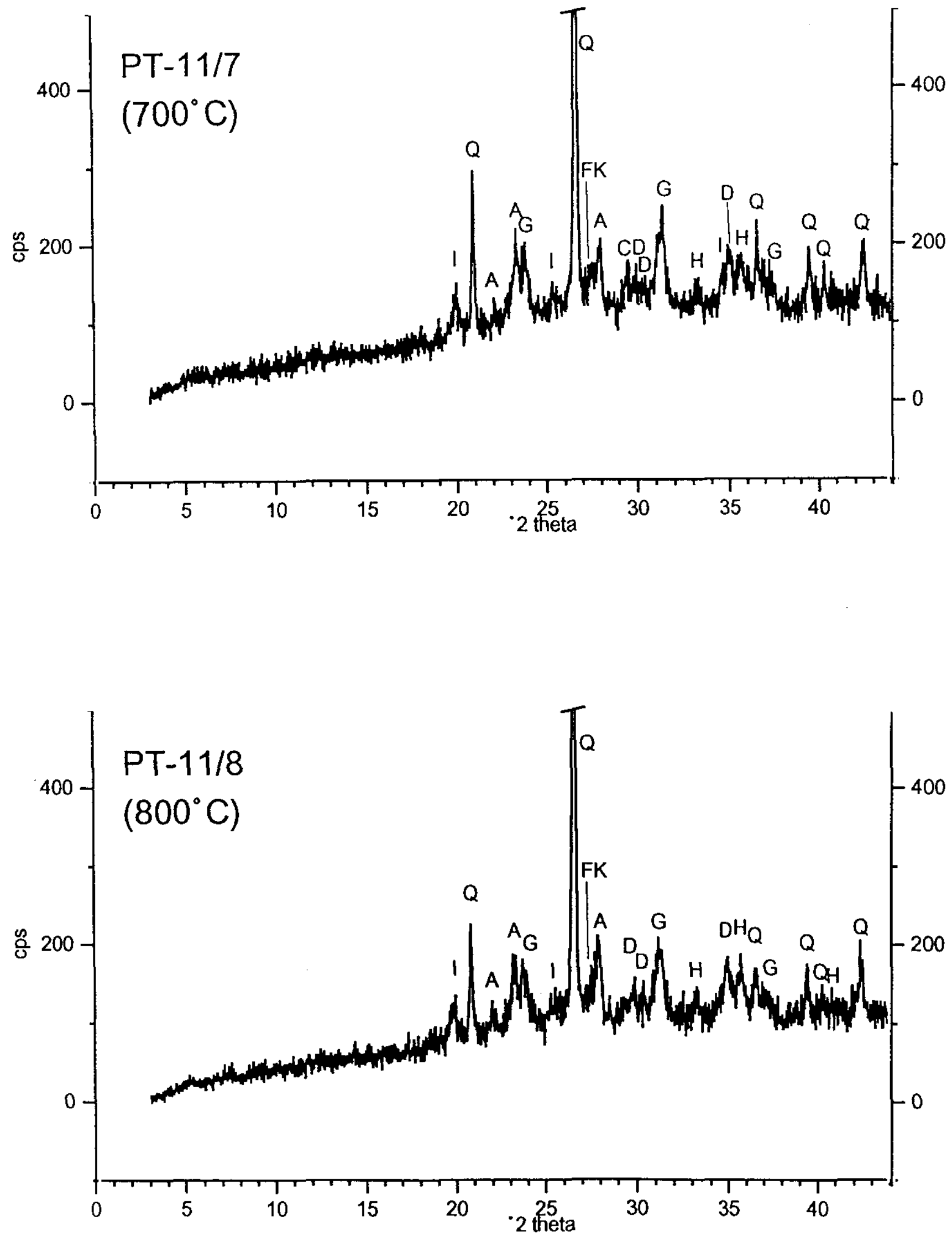

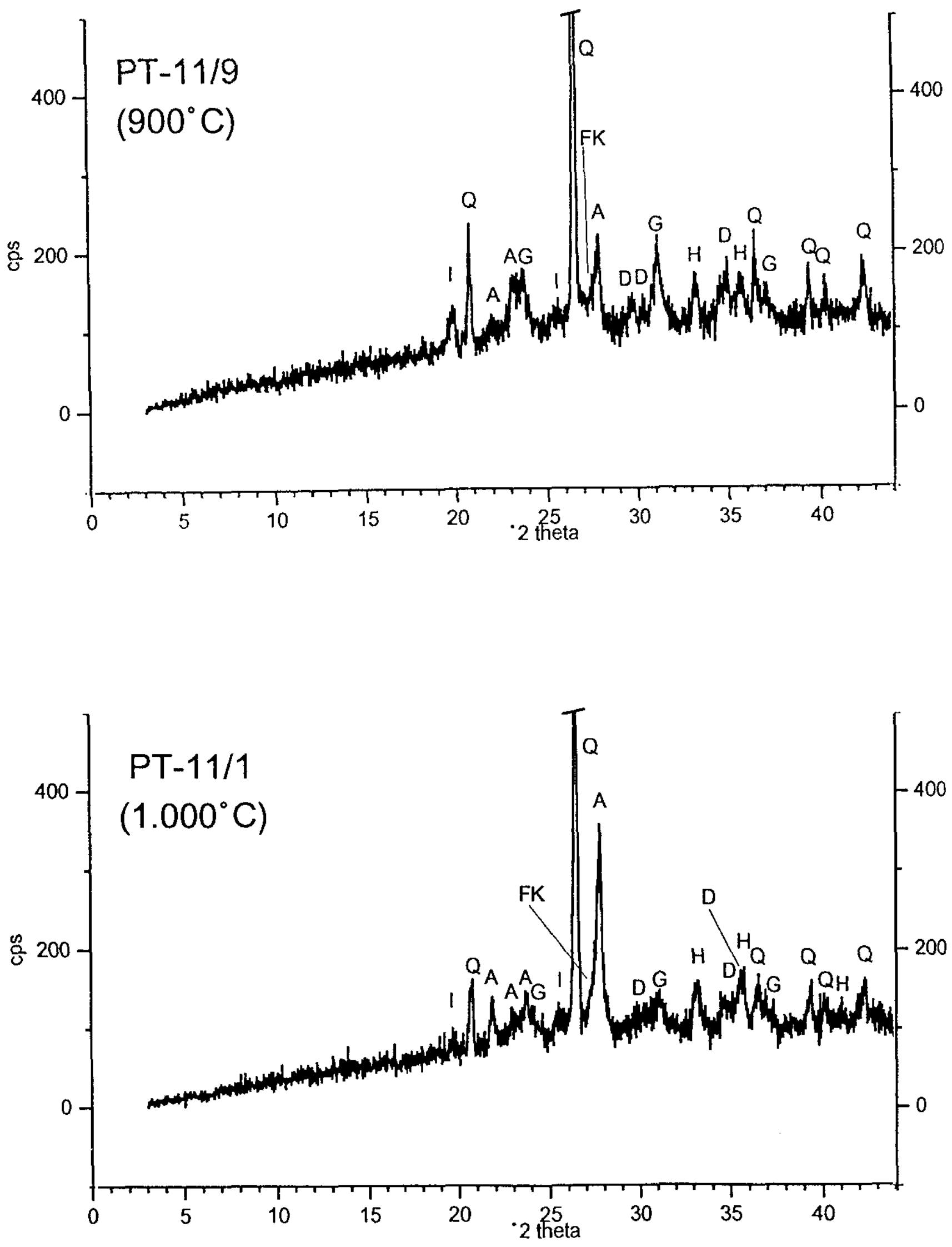